


$$
\text { a. }
$$



TRAITÉ PRATIQUE ET DIDACTIQUE

DE L'ART DES JARDINS

PARCS _ JARDINS _ PROMENADES 
Paris. - Typographie Charles UNSINGER, $S_{3}$, Rue du Bac. -2382. 


\section{L'ART' DES JARDINS}

\section{PARCS_JARIDINS_PROMETADTS}

ÉTUDE HISTORIQUE - PRINCIPES DE LA COMPOSITION

DES JARDINS - PLANTATIONS

DEGORATION PITTORESOUE ET ARTISTIQUE DES PARCS ET JARDINS PUBLICS

\section{TRAITE PRATIQUE ET DIDACTIQUE}

PAR

IE BARON ERNOUE

TROISIÉME ÉDITION, ENTIEREMENT REFONDUE, AVEC LE CONCOURS

DE

A. A L P H A N D

Diresteur des Trazanx de la rille de Par is, Inspecteur général des Ponts et Chaussées

Ouvrage orné de jio Illustrations

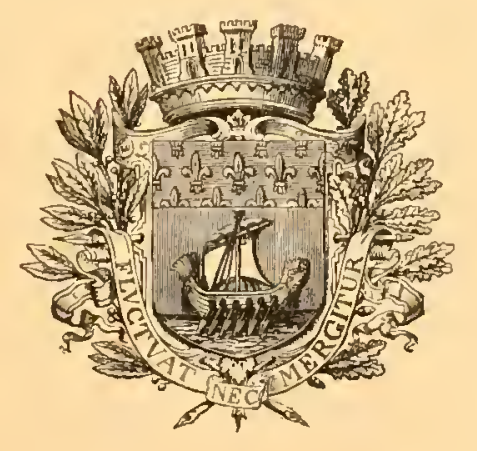

\section{PAR I S}

J. ROTHSCHILD, EDITEUR

13, RLE DES SAINTS-PERES, I3

Droits reservés 


$$
\begin{aligned}
& \text { SE } \\
& +53 \\
& i 7 !
\end{aligned}
$$

249536 


\section{A \\ L'É D I I TÉ PARISI EN NE \\ QUI A TANT CONTRIBUÉ}

A L'ASSAINISSEMENT ET A L'EMBELLISSEMENT DE LA MÉTROPOLE

ET AUX PROGRES DE L'HORTICULTURE 



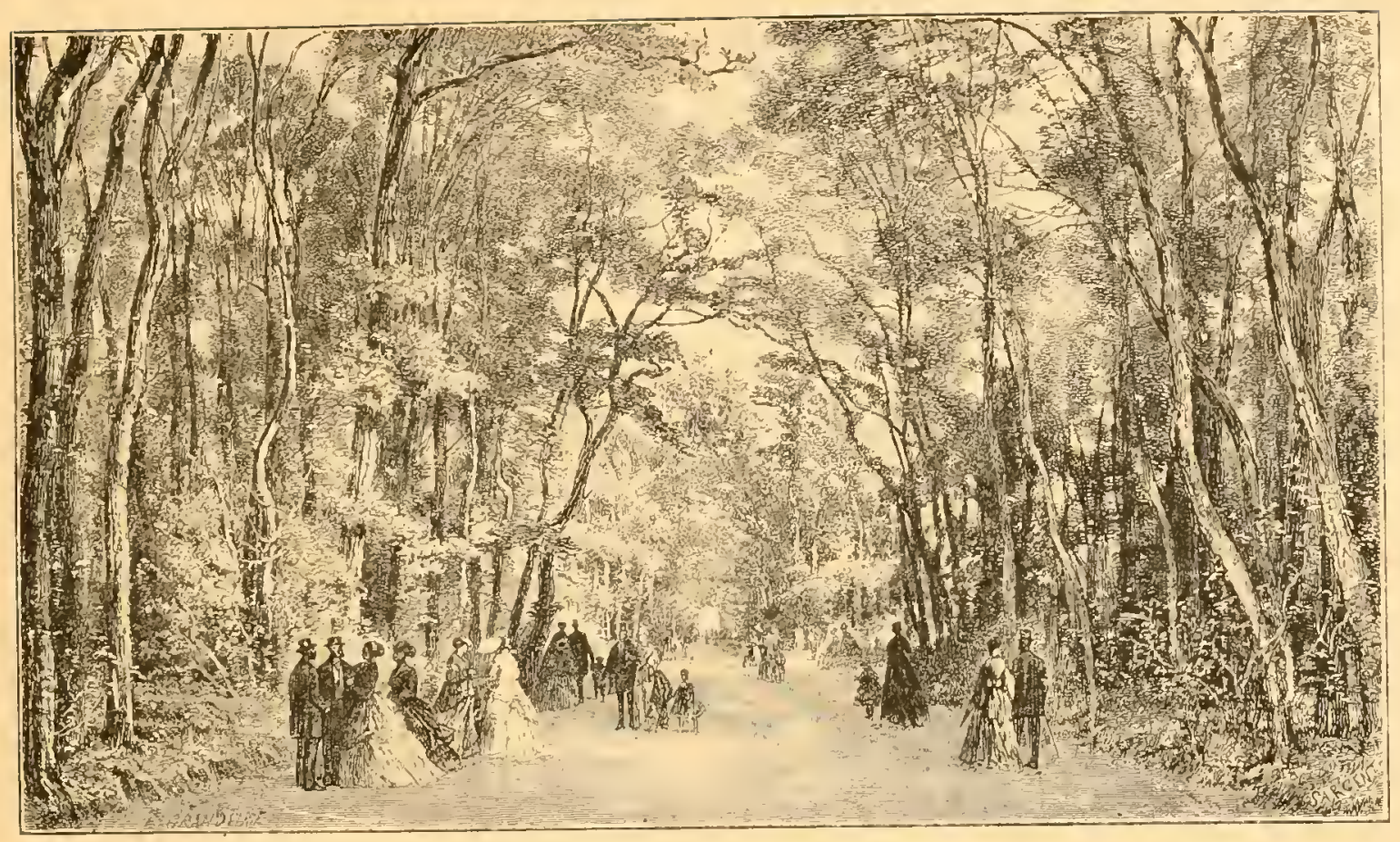

Bois de Vincennes. - Vue de la Route des Buttes.

\section{SOMMAIRES DES CHAPITRES}

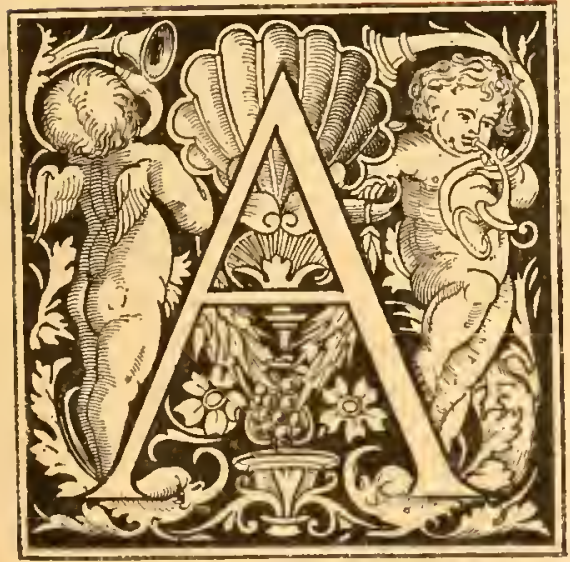

VANT-PROPOS DE L'ÉDITEUR

$I^{\text {re }}$ PARTIE. - HISTOIRE DE LART DES JAR-

DINS.

Les Jardins de la Grèce. . . . . . . . 3

Les Jardins de l'axicienne Égipte . . . . . . 6

Les Jardins Orientaux.

Les Jardins Chinois et Japonars. . . . . . 17

I.es Jardins Ronains. . . . . . . . . 25

Les Jardis du Moyen Age . . . . . . . 36

Les Jardins Italiens de la Renaissayce . . . . . . . . . . . . . . . 42

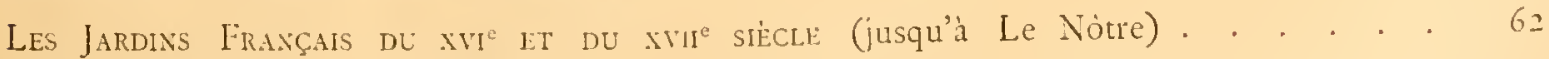

Les Jardins Françits du xili

LE PAYSAGE . . . . . . . . . . . . . . . . . . . . 95

Les Jardins Agrestes ol Irréguliers (Jardins Anglais) . . . . . . . . . . . 10 I 
Chap. Ier. - Tracé des Jardins Irréguliers ou Paysagers.

I. Définition, Principes généraux, p. I 24. - If. Étude et appropriation des alentours, p. I 26. - III. Double destination du Jardin paysager, p. I 30. - IV. Rejet des anciennes classifications, p. I3I. - V. Relicf du terrain, p. 132. - VI. Nécessité absolue d'un Plan d'ensemble, p. I34. - VIl. Premiers travaux de terrassement, p. I35. - VIII. Drainage, p. I36. - IX. Terrassements, p. I3 $8-$ X. Mouvements de terrain, p. I39. - XI. Plantations, p. I40. - XII. Rapport des plantations à l'labitation, p. I 42. - XIII. Combinaison des teuillages, p. I 48 . - XIV'. Étude des effets d'onbre et de lumière, p. ijo. - XV et XVI. Combinaisons diverses des plantations, p. I51. - XVII. Formes diverses des arbres, p. I59. - XVIII. Des Eaux, p. I64. - XIX et XX. Tracé des cours d'eau; Iles, p. I68. - XXI. Ponts, p. I7I. XXII. Fabriques, Temples, Édicules, p. I75. - XXIII. Loges d'entrées, Maisons de Garde, etc., p. I79. - XXIt. Rocailles, p. 185. - XXY. Gazons et Pelouses, p. I96. - XXVI à XXVIII. Emploi des Fleurs et des Plantes, p. 203. - XXIX. Tracé des Allées, p. 2I6. - XXX. Allées de ceinture, etc., p. 2:8. - XXXl. Confection, Dimension des Allées, p. 222. - XXXII. Entrées des Parcs, p. 224. - XXXIll. Clôtures, p. 228. - XXXIV. Potagers et Vergers, p. 229. - XXXV. Établissement et Décorations des Potagers, p. 23I. - XXXYI. Possibilité de fusionner le Verger avec le Jardin d'agrément, p. 232. - XXXVII. Des Serres, p. 238. - XXXVill. Volières, Ruches, etc., p. 244.

Chap. Il. - Tracé des Jardins Réguliers, dits liraxçais, et de ceux du gexre inixte.

I. - Possibilité des nouvelles applications totales ou partielles du Système régulier, p. 245. - II. Règles pour le choix du Style, p. 248. - IHI. Opérations préparatoires, Établissement des Perspectives, Direction des Allées, p. 251. - IV. Plantation, p. 256. - V. Méthodes de raciordement, p. 262. - VI. Places publiques, p. 266.

Chap. IIl. - Jardins de Ville et d'Institutelrs.

Chap. IV. - Créations Modernes.

I. Pares anglais, p. 274. - II. Pares allemands et autres Pares étrangers, p. 278 . III. Parcs français, P 293.

Ch.sp. T. - Promenades et Squares

I. Considérations préliminaires, p. 297. - II. Promenades modernes de Paris. Bois de Boulogne, p. 306. - III. Bois de Vincennes, Parcs des Buttes.Chaumont et Montsouris, p. 312. - IV. Squares parisiens, Fleuriste, etc., p. 324. - V. Promenades publiques, Turquie, Egypte, Inde, p. 331.

Les Services des Promexades de Paris

Prix des Principaux Travaux de Jardinage. 


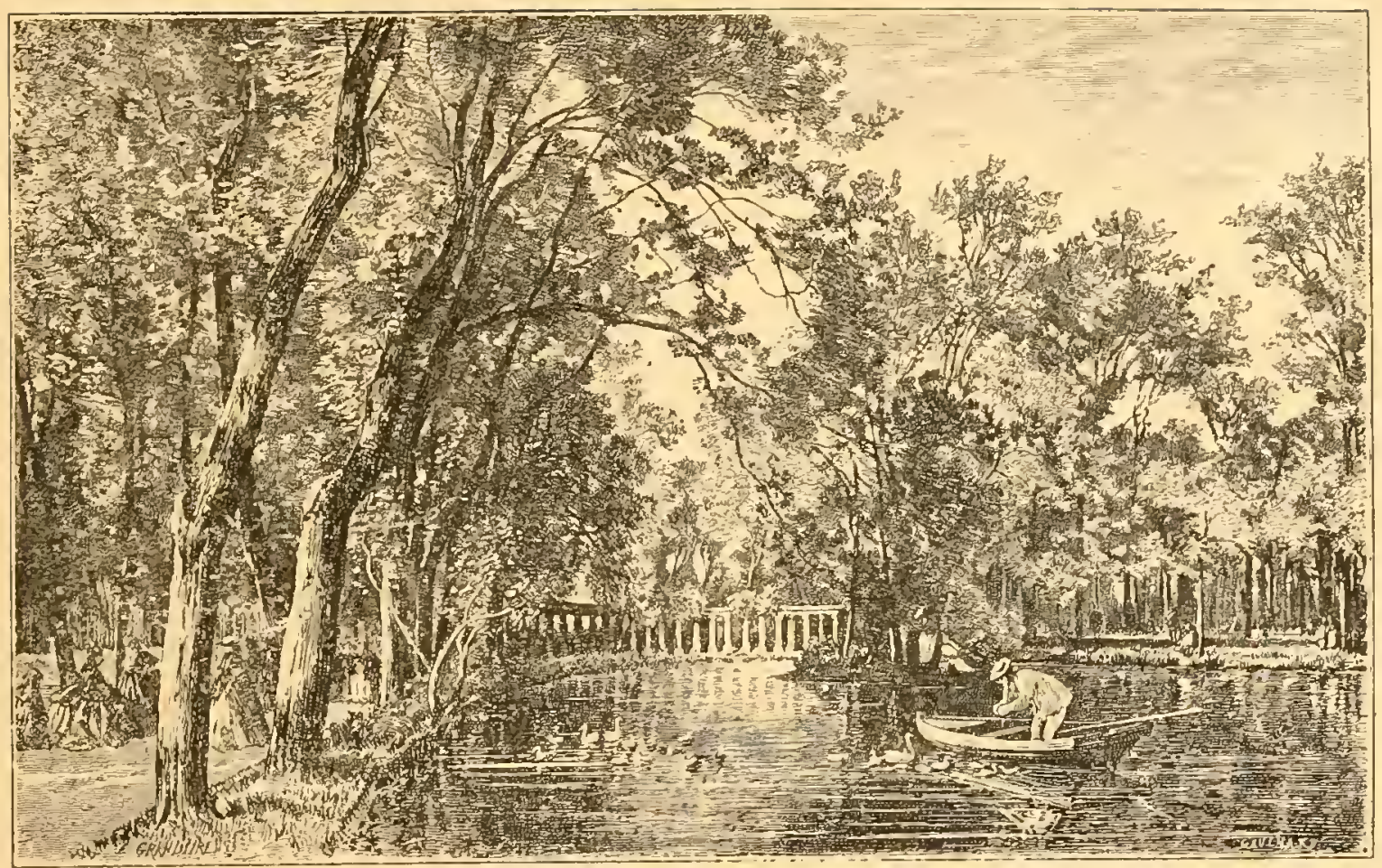

Pare de Monceatu. - Vue de la Numachie.

\author{
AVANT-PROPOS DE L'EDITEUR
}

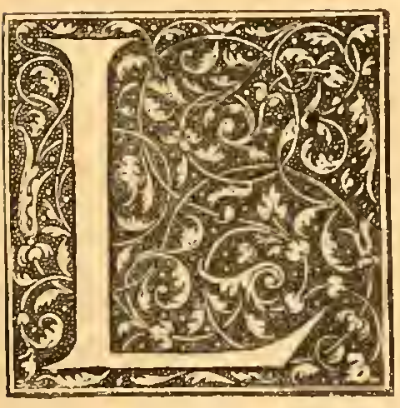

A premiere ibandse de ect onvrage, formant deux petits volumes, a parn cn 1868 .

Un denxième tirage, mis en vente quelques ammés apris, a été promptement épuisé, et ćest pour satisfaire anx.x nombrenses demandes qui nons sont adressées, que nous publions cette troisieme édtition, qui est en réalité une carvere nonvelle.

Poir a trazail, cutierement refondu, nonis arons obtem le pricicux concours de M. Alphand qui a bien vouln nons antoriser à reprodnire les préceptes formulés dans l'Introluction de son gramd onvrage sur les Promenades de Paris. 
Les ammales ale l'Art des Jardins en France offrent deux périodes mémorables. Le Nötre avelit inanguré la premiere, cu donmunt à ses créations un caractère essenticllement aristocratique; Paris a vu commencer la seconde it y a quelques ammées. Ses nouvelles Promenades ont obtenu, comme jadis les cencres de Le Nôtre, un succés cosmopolite, et cette impulsion s'est étendue jusqu'anx. jardins particuliers. C'est done la Ville de Paris qui a cu linitiative de cetle érolntion, conforme aux tendances de l'espril moderne et anx justes aspirations de la democratic; aussi arons-nous regardé connue ligitime de dédier la préscute publication à l'ÉDilité PARISIENNE.

La question d'art jone désormatis un róle considérable en toute close; des monnments, clle s'est ćtendue it la décoration intéricure, aux appartements. Claque fondation, chaque conception publique ou prive doit cu porter le cacbet et attester cette próocupution; alle se reflete partont, it tous les degrés de l'échelle sociale.

Les jurdins, soit an point de vne du pian général, soit à celni de leur améragement de ditail, de la conleur, de l'barmonic ot du dessin, devaicht anssi participir dans me large mesure à ce monzemant progressif. On pent dire, che effet, que tontes les branches de l'Art trouzent leur cmploi dans leur creation: - l'arbitecture, donl ils furcul, à l'origine, une derivution immediate; - la sculpture, qui conconrut de tont temps à leur decoration; - la pcinture, qui fournit surtout des enscignements indispensables pour les jardins du genre dit irrégulicr. Commucnl, en effet, composer des sciucs denls le style pay'sager, si l'on me sait pas d'abord ce que c'est qu'min paysage? Cette considiration si simple, nons a anssi determimé à ajonter lun cluapitre cntierentut nourean sur le paysage. Dans la partie bistorique, il forme me transition naturelle culre l'ire des compositions régulieres, des "architectures vertes », et l'avemuncut d'mu genre absolument opposé, quand lidice d'imiter la nature " dans ses beaux endroits », précent sur celle des combinaisons géomitriques.

Cette manifestation fut le témoignage non équiroque d'une irolution psycloologique, dont les grands paysagistes dn XVIT sićle onl été les pricurscurs.

L'onvrage est divisé en denx parlies principales; l'une historique, l'antre didactique.

Duns la preniere, qui est ann résumé des trazumx les plus mémorables accomplis jusqu'à nos jours, les autcurs ont tache de rassembler les indications les plus curienses, et surtont celles dont il pent ressortir des enscignements pratiques. Ils ont apprécie avec une grande impartialite la récrolution borticole din siécle demier.

Le premier chapitre de la partie didactique conticut les préceptes din gente irrégulier ou paysager, d'apris les maitres les plus autorisés: Replon, London, Mac Intosh, Licmp, Decaisue,

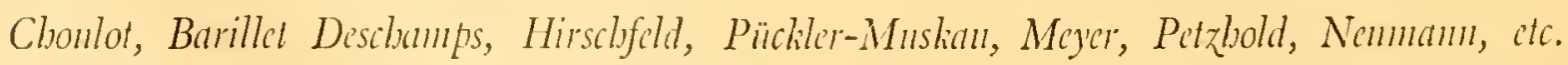
On tronuera dans ces pages l'exposé de la mithode et ales operations diverses, an nioyen desquelles 
it est possible d'arrizer ai la fusion, dans un cuscmble barmonicux, des formes les plus agréables de la mature et de l'art, fusion sans laquelle il vicxistera ianais de jardin.

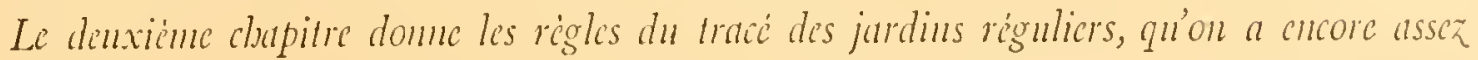

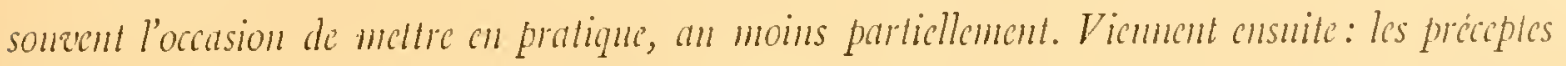
spécian.x pour l'itablissement des jurdins de villes; nue rezue sommaire des plais importanles créations modernes en France et à l'étranger. Un dernier cluapitre, consacré alux squares al promenades, conticut des renseignements teclmiques qui pourront âtre utiles aux administrations municipales disposées a suivre de loin l'cxemple de Patris, et anx propriétaires qui roudraicnt cxecuter, sur une écbelle moins vuste, des trazullx analogules, teis que la transformation l'mu bois ordinaire en pare ou jardin paysager.

L'illustration de ce volume a été l'objet de soins toul particuliers. On s'est efforcé de lui domer, dans toutes ses partics, un caructere at la fois attrayant ct ntile.

Aux nombrenx dessins, plans de pares et de jardins anciens et modernes, de plantes at d'arbres d'ornement, cmprumtés a nos publications borticoles et nolammicnt anx Promenades de Paris, nous avons ajoule un grand nombre d'exemples d'antres tirćs des linres les plus rares, représentent des cenveres importantes, dont plusicurs onl èté modifiés on n'cristent plus. Citons comme cxemple Clagny, le domaine quasi-royal de l'alticire Montespan, dont l'cumplacement est aujourd'bui occupé par la gare de Versuilles (rive droilc); les célibres parcs et jurdins du Quirinal, Ludovisi, Farnise, Frascali, Giusti à Vírone, et d'antres spécimun interessants des villas ituliemes de la Renaisance; les parcs anglais de Keve, Batlersea,

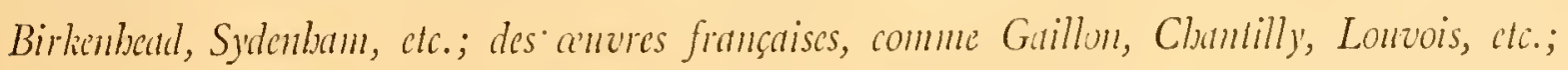
des créations allemandes, Schuwtzingen, Heidclberg, Sagan, Muskan, Potsdann, etc.; les partes espagnols de la Granja, d'Aranjuez; le Bois de la Cambre (Belgique), cte.

Nous víavous pas nígliyé non plus, à l'ocetsion, les effets de contraste résultant de l'aspect antéricur ou ultéricur des mêmes localités. Ainsi on tronvera en regard du pare actuel dis Bultes-Clatumont, un ancien plan qui donne whe jusle idée de la physionomie sinistre et reponssante qu'offraicut autrefois ces parages, si benrensement transformés.

Au clapitre du paysage, nous arons joint la reproduction de plusicurs des aurres les plus magistrales du Poussin, Clande Lorrain, Ostude, Pynalire, etc.

Comne un grand nombre de ces illustrations n'offrent pas senlement un attrait de pure curiosile, metis penvent fournir des renseignements pratiques, et quelles apparticunent par conséquent antant it la théoric qu'a l'bistoire, nous avons crn devoir les répartir ch proportion $\dot{a}$ pen pres ígale, dans les denx parties de ce volume, bistorique et didactique. L'barmonie de l'cusemble y a gagrić, sans que la logique ait en à cn souffrit.

L'onvrage se termine par un tablean sommaire des trantulx de la transformation de 
Paris, exicules d'apres un plan d'ensemble, et par l'indication des prix principanx des Iravinax de iardinage à Paris, docunents d'un séricuse interét pratique.

Nonis serions largentent récompensés de nos peines, si ce travuil ponvail contribuer at propager le goût de l'borticulture d'agrément; s'il pomenit domer anx jardiniers paysagistes une

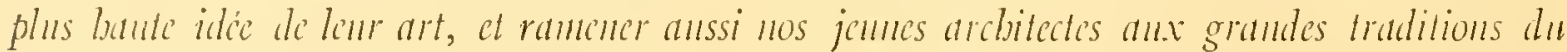
scizième siecle, époque oi les plus illustres arlistes, à la fois peintres, sculptenrs, ingénienrs, archi-

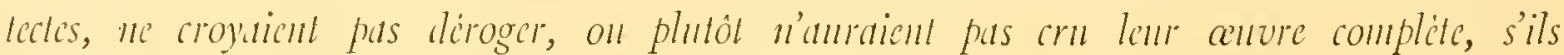
n'y araient pas compris l'étude des jardins, corollatre et complinuent des édifices.

Nons espérons anssi que ce rappel de l'auve à la fois artistique et plilantbrópique de la transformation de Paris, cuconragera les municipalitís at suivere cet exemple, et à établir duns de plus modestes proportions, des promenades, des squares, propices ankx joyen.x étuls de l'cufance, an delasseme'ul dis babitants laboricux, et dont la were repose a lat fois et lisprit at le's yeitx.

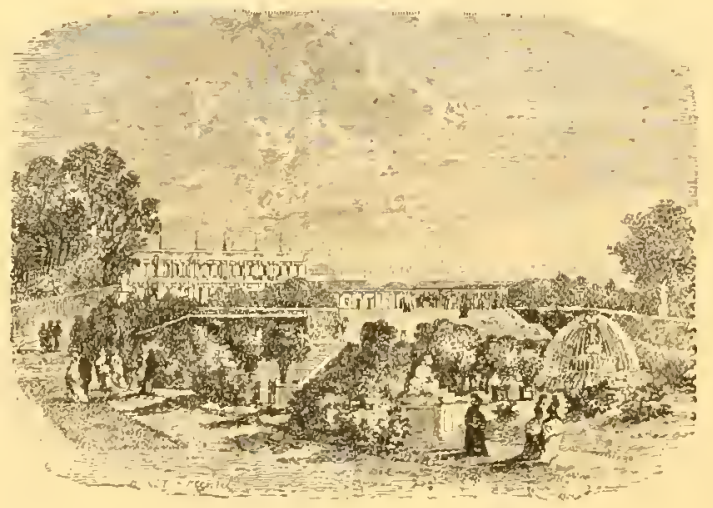




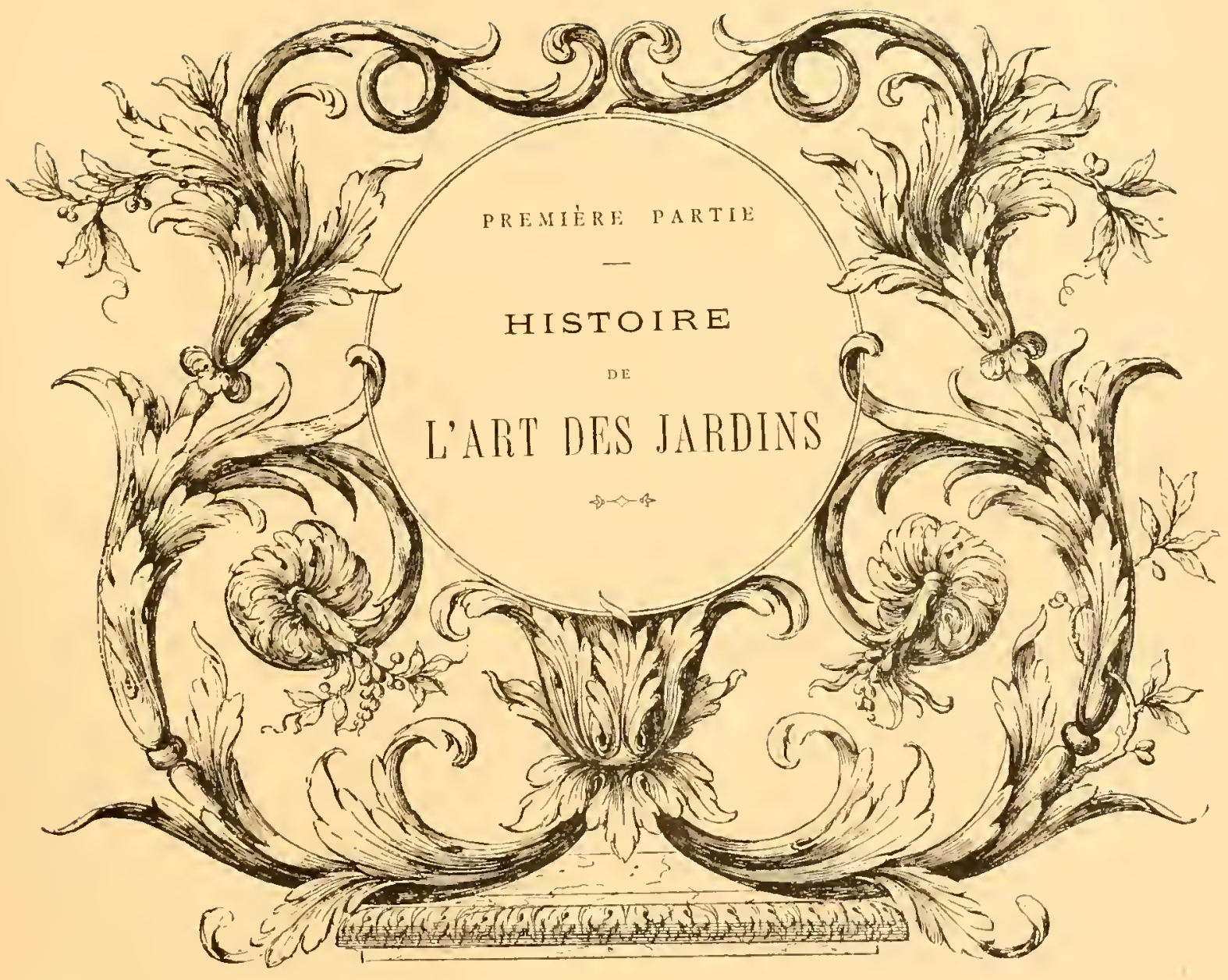





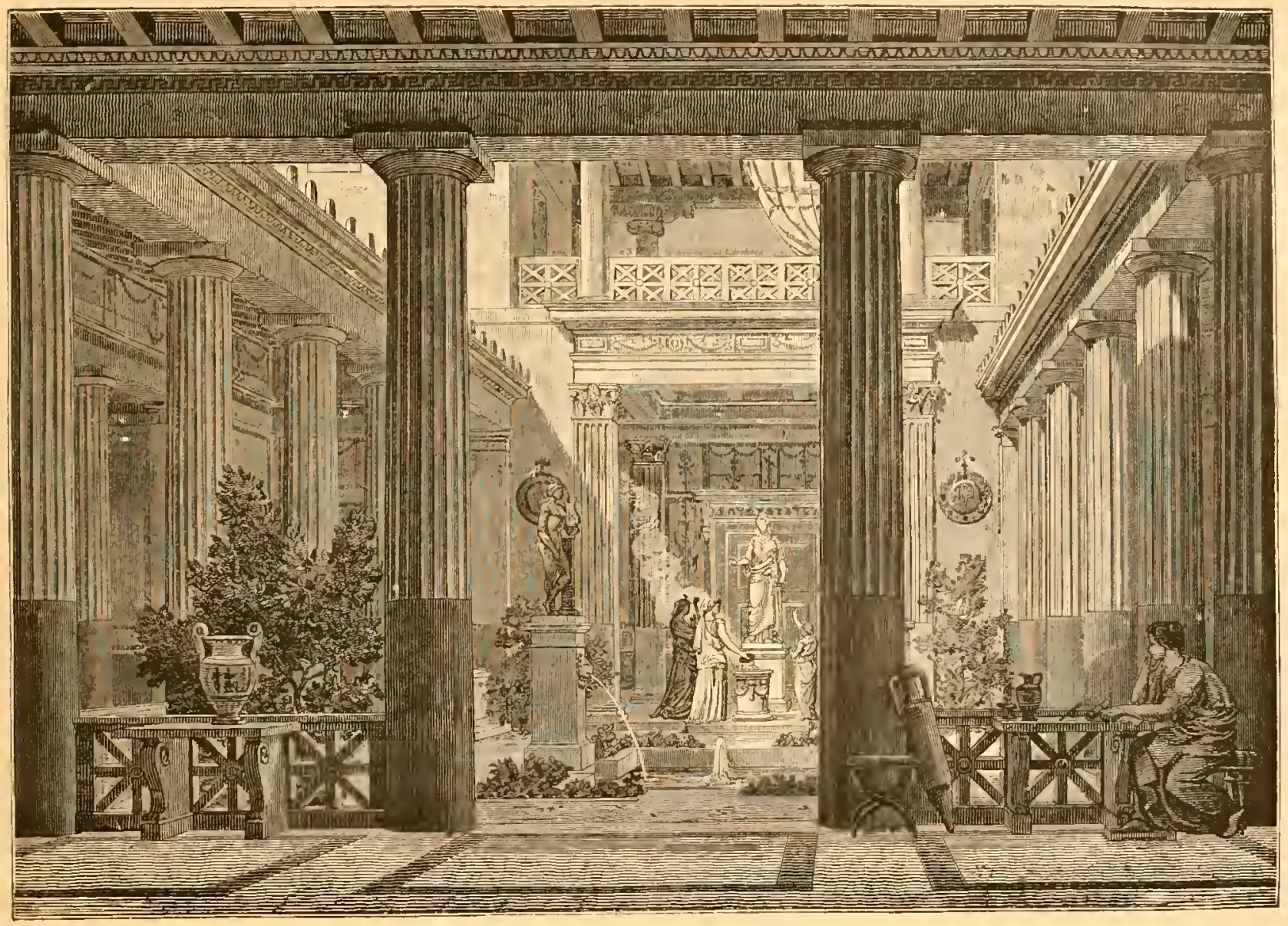

Fig. 2. - Restitution d'une Aula avec son Vestibule. - Au fond une Statue d'Hestia (Vesta).

\section{PARCS- JARDINS \\ ET PROMENADES PUBLIQUES}

LES JARDINS DE LA GRÈCE

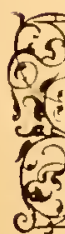

(25)

'ART des jardins, tant réguliers qu'irréguliers ou paysagers, se rattache intimement au progrès de la civilisation. Pendant bien des siècles, ce luxe de l'agriculture fut réservé pour les abords des grands édifices, temples, palais ou tombeaux. Aujourd'hui, les plus modestes habitations ont droit à cette parure. Un jardin d'une étendue médiocre peut, s'il est composé 
avec goût, avoir sur de vastes propriétés mal dessinées une supériorité analogue à celle d'un bon tableau de chevalet sur une grande toile médiocre, ou d'une simplicité élégante sur la richesse mal employée. Ce n'est pas un art à dédaigner, que celui qui met ce triomphe innocent à la portée des plus humbles fortunes, et touche, par tant de côtés, aux sciences les plus utiles, comme aux conceptions les plus poétiques.

La plus ancienne description d'un jardin gree est celle du jardin d'Alcinoüs dans l'Odyssée (vI, I I2-I32), faite évidemment d'aprés nature. Ce jardin, "que les immortels se plaisaient it embellir, ct qu'Ulysse contemplait avec admiration », comprenait un verger, une vigne et un potager; le tout copieusement arrosé par des rigoles d'eaux courantes, clos de haies vives, et d'une contenance de quatre gyes (i 4 à i 500 métres). Le verger était carré et planté régulièrement. Le mot orchatos, qu'emploie Homére pour le désigner, signifie littéralement "plantation alignée ». Les abords des temples ou des autres grands édifices furent de même plantés symétriquement. En Grèce comme partout, sauf chez les Chinois, l'jdée de dompter la nature a précédé celle de l'imiter. Pendant bien des siècles, l'homme n'a compris la possibilité d'embellir les alentours immédiats des habitations, qu'en les marquant profondément de son cmpreinte; les jardins n'étaient que des architectures végétales. Le goût des jardins irréguliers est une déduction moderne du sentiment intime des beautés de lil nature, sentiment qui n'existait dans l'antiquité et le moyen âge qu'à l'état d'impression religicuse ou de vague sensation.

Cette attraction existait chez les Grecs. On la trouve exprimée au cinquième livre de l'Odyssée, dans la description des abords de la grotte de Calypso, entourée d'arbres toujours verts et de gazons fleuris, sillonnés capricieusement par des ruisseaux. Homère reproduit ici, d'après nature, l'aspect d'une de ces Nymplices, mystérieuses retraites dont les Grecs, "ces éternels jeunes gens », ressentaient si vivement le charme, qu’ils l'attribuaient à la présence des divinités invisibles des bois et des eaux. Ils ne négligeaient pas non plus de se ménager la vue des beaux sites, au moyen de belvédères ou d'exèdres, à la limite des jardins. Mais ces jardins eux-mêmes ètaient toujours symétriques. Les plus magnifiques horizons étaient surtout, pour les artistes grecs, des cadres propres à faire ressortir leurs ouvres (I). A l'époque la plus floris-

(I) Il existe une harmonie intime d'aspect et de proportions entre les plus beaux monuments de la Gréce et leurs alentours. "Il est probable, suivant les hommes les plus compitents, que les artistes greis fixaient sur place les dimensions principales de leurs cuvres, en ạant égard aux reliefs naturels qui devaient leur servir de soubassement, aux parties 
sante de cette civilisation, les promenades publiques et les plus beaux jardins particuliers, comme ceux de Pisistrate et de Cimon, à Athénes, étaient toujours rẻgulièrement plantés comme le verger archaïque d'Alcinoüs, mais avec une grande variété d'arbres et quantité d'édicules, de bassins et de statues.

de verture qui devatient les encadrer. P'our obtenir des effets analogues, il faut, non pas calquer ces ocuvres servilement. mais travailler d'apres la mime méthode et en tenant compte de l'enscmble. " Ce précepte est applicable mème aux jardins irréguliers.

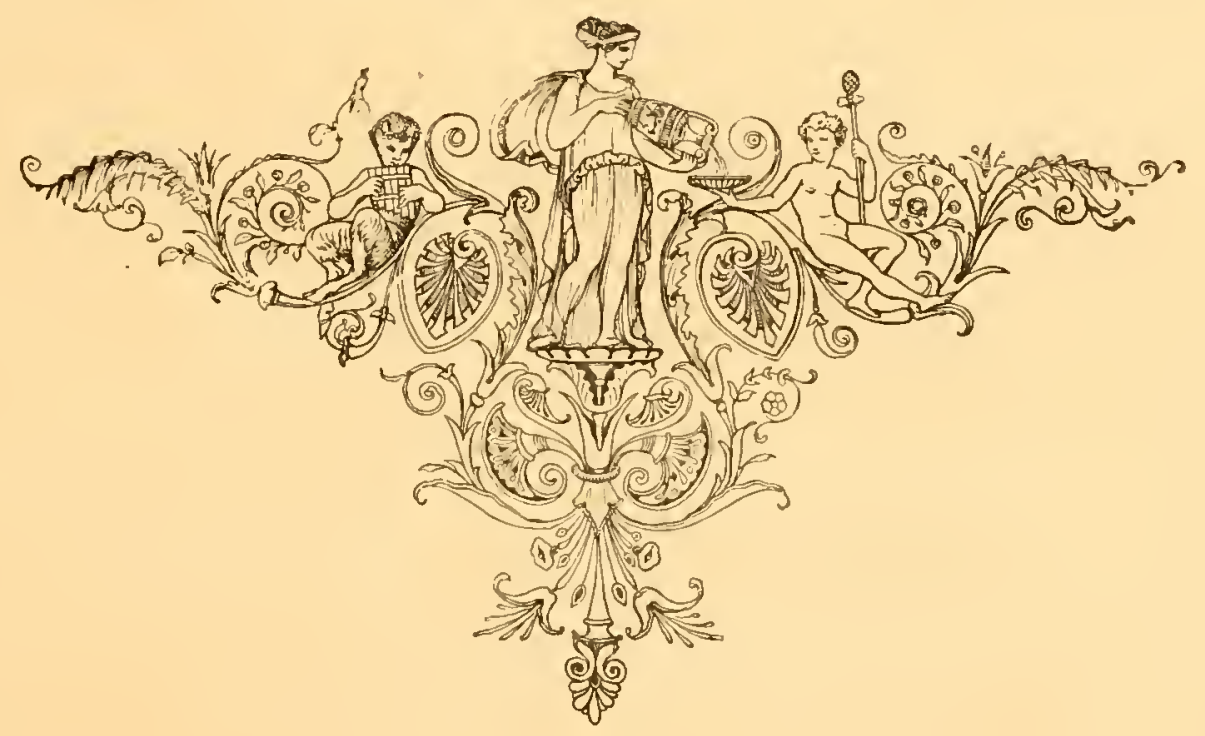




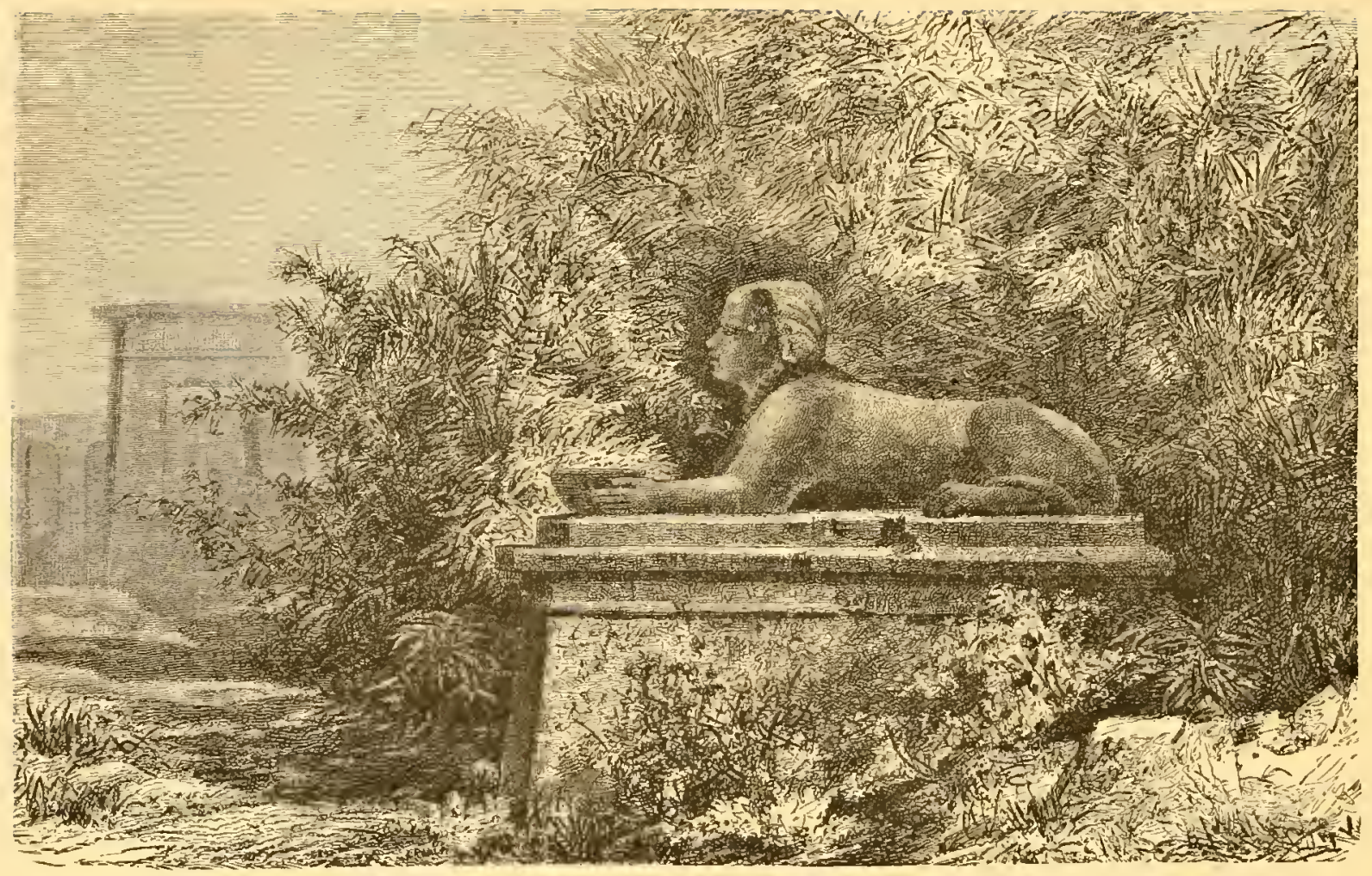

Fig. 5. - Sphinx de karnak.

\section{JARDINS DE L'ANCIENNE ÉGYP'TE}

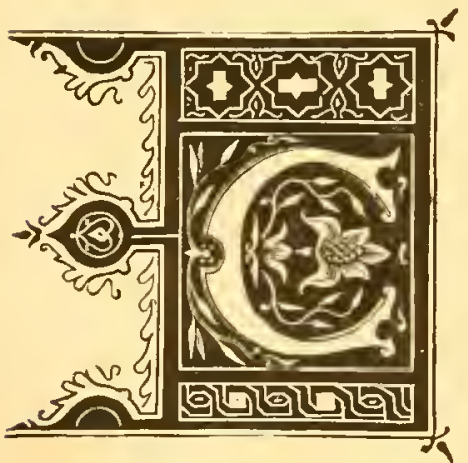

ES jardins étaient aussi du style le plus régulier, comme on le voit par la Figure 7. Des plantations de citronniers, de grenadiers, de palmiers, disposés en carré long sur trois rangs, encadrent une pièce d'eau de même forme, pouvant porter bateau ( $\mathrm{I}$ ). On plantait aussi les abords des temples et des tombeaux, les cours intéricures des maisons, mais non les rues, car celles-ci étaient généralement fort étroites.

Ces lignes inflexibles de plantations se raccordaient bien avec l'architecture invariablement rectangulaire des monuments, avec les figures colossales régulièrement alignées. Des canaux nombreux et bien entretenus donnaient une vigueur extraordinaire à la végétation. Cette verdure luxuriante remplissait un rôle essentiel dans les magnificences

(1) On employait sans doute aussi d'autres arbres de feuillage plus épais et de plus large envergure, comme le mimosa, et on se procurait un supplément d'ombrage dans les jardins particuliers au moyen de tonnelles de verdure. 
de la civilisation égyptienne. Aux teintes d'un éclat violent, elle en mêlait de plus douces; amortissait la lumiére trop intense, neutralisait l'action incommode, parfois meurtrićre de la chaleur.

Les ípoques les plus prospéres de l'ancienne monarchie (1v $, \mathrm{x}^{\mathrm{e}} \mathrm{1}^{\mathrm{e}}, \mathrm{xv} 11 \mathrm{1}^{\mathrm{e}}$ dynastics) furent aussi celles des plus beaux jardins. Sous les Ptolémíes et dans les premiers temps de la domination romaine, l'Égypte comptait encore parmi les régions les plus fertiles et les plus verdoyantes du monde. Alexandrie fut pendant plusieurs siécles la

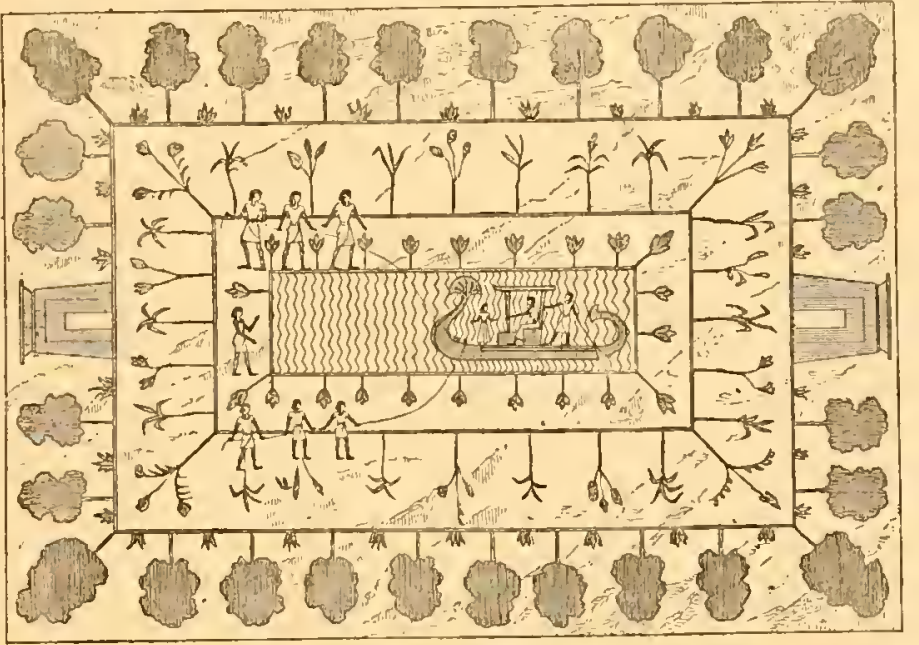

Fig. 7. - Bas-relief représentant un Jardin ėgyptien. (D'après Hlector Horeau.) seconde cité de l'empire; du temps d'Auguste et longtemps encore aprés, les jardins publics et les palais qui se succédaient sans interruption du côté du grand port formaient à eux sculs plus du quart de l'immense cité. La décadence avait commencé dès la fin du Iv siècle; elle fit de rapides progrès lorsque l'Égypte échappa aux empereurs d'Orient (640). Là comme partout, le fanatisme musulman accomplit son ouvre de destruction. Cependant, tandis que les monuments égyptiens sombraient dans les sables, et que l'effort si prodigieux de cette antique civilisation vers l'im-

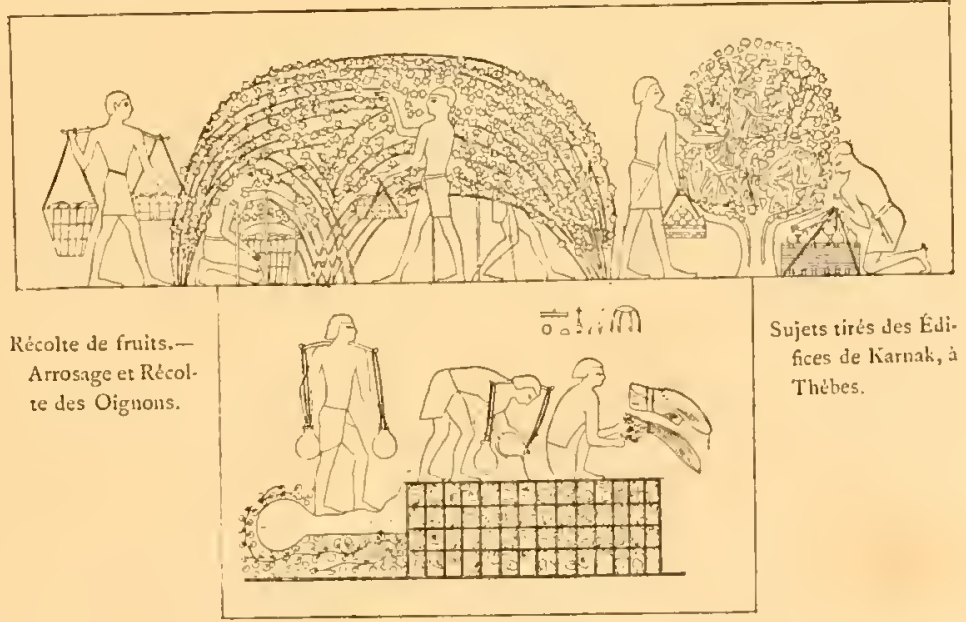

Fig. S et 9. - Monuments d’Égypte, par Champollion le Jeune, t. IV, Pl. 357, 358. (Didot.) mortalité n'aboutissait qu'à un engloutissement plus profond; les conquérants, installés sur d'autres points de la vallée du Nil, y refaisaient des jardins. Ceux de Khomarouyah, second prince de la dynastic toulonnide (fin du $\mathrm{x}^{\mathrm{e}}$ siècle) n'étaient, dit-on, nullement inférieurs aux Édens des Ramsés et de Cléopâtre. Les fleurs y étaient disposées en parterres de mosaïque 
figurant des versets du Coran; la base des grands arbres ètait enveloppée de tuyaux dorés (1) d'où l'eau retombait en pluie. On parle aussi d'immenses volières en forme de tours; d'un bassin de vif-argent, à l'usage spécial du khalife, qui s'y balançait à la surface, sur des coussins gonflís d'air, etc. Ces jardins, dont l'imagination des conteurs arabes a probablement exagéré les merveilles, occupaient une partie du vaste espace couvert aujourd'hui par les monticules de décombres qui s'étendent au sud du Caire actuel, entre le vieux Caire et le mont Moliattam (2).

Ce fut sous la domination des Turcs, à partir du xve siècle, que l'Égypte descendit au plus bas degré de barbarie et de stérilité. Sa renaissance date, comme on sait, de l'expédition française et du règne de Méhémet-Ali. Nous parlerons ailleurs des promenades publiques et des jardins de l'Égypte moderne.

(1) Ou plutôt de revẻtements de maçonnerie comme on en voit sur quelques anciens bas-reliefs. Plusieurs traits de cette description (les statues, par exemple), semblent se rapporter à l'ancienue civilisation égyptiemne.

(2) Voir le beau plan du Caire et de ses environs, dans le second volume de l'Itinivaire d'Orient d'Isambert.

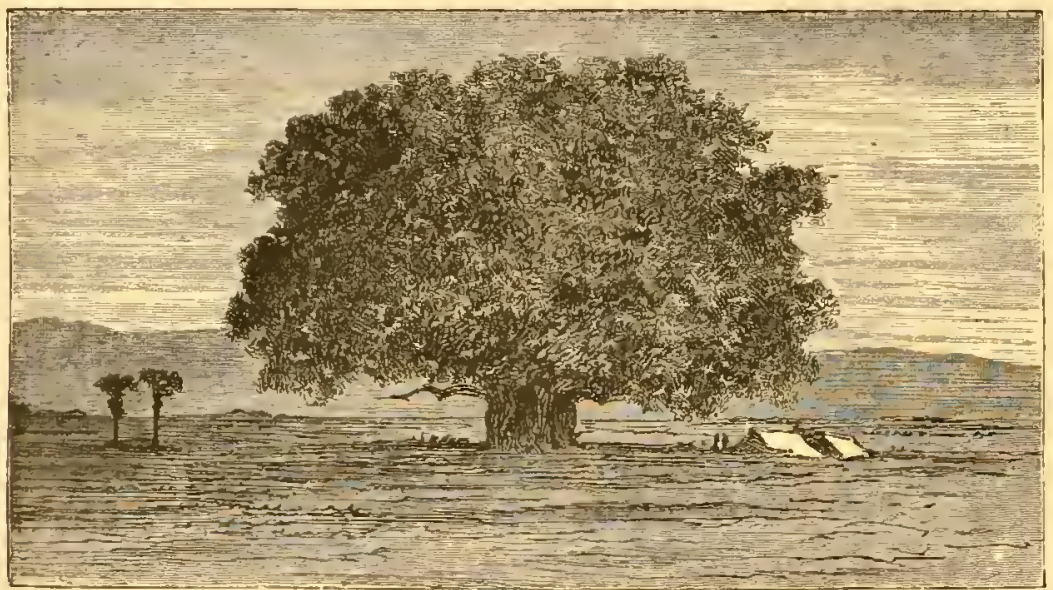

Fig. 10. - Sycomore. 


\section{JARDINS ORIENTAUX}

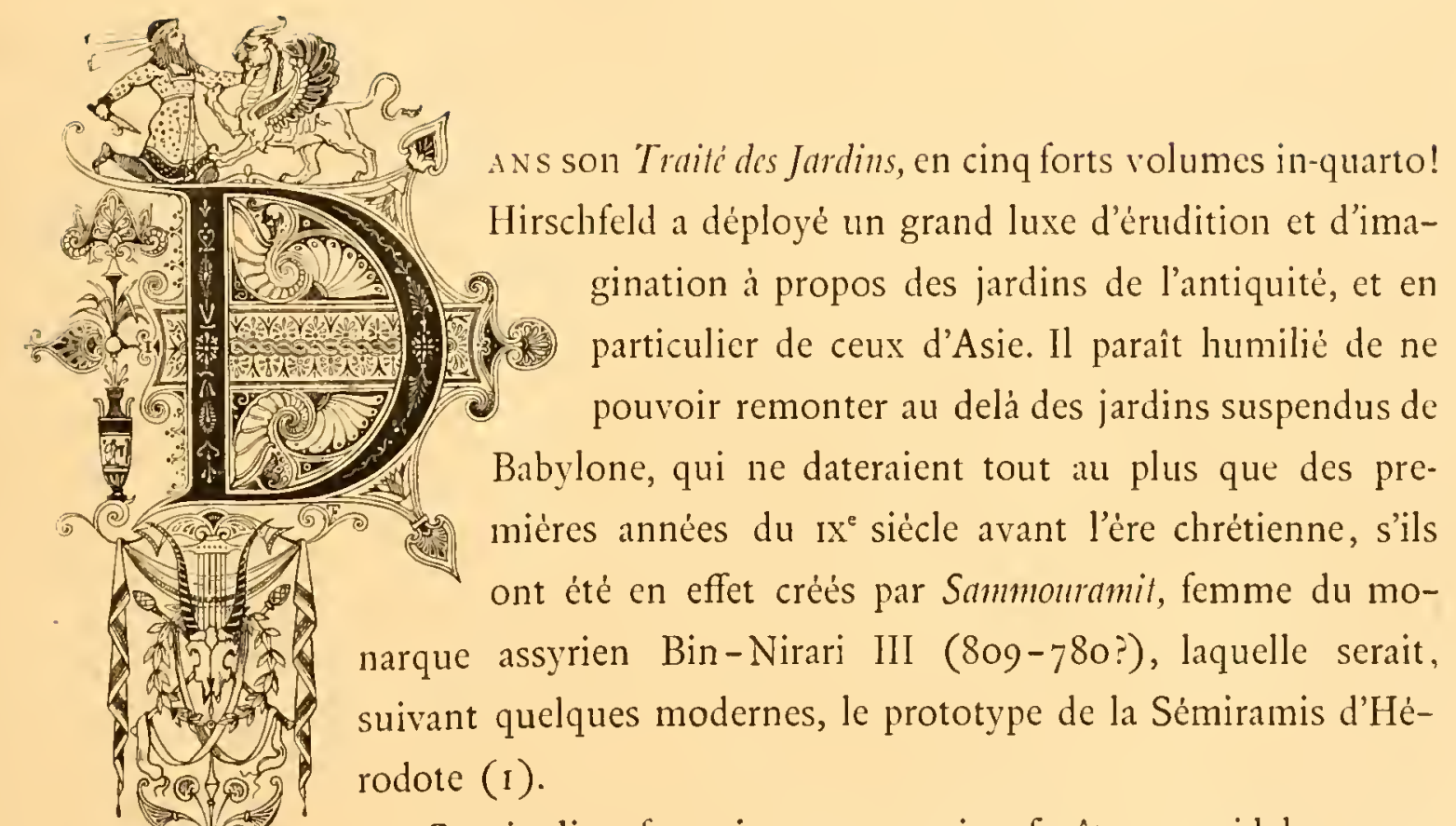

Ces jardins formaient une petite forêt pyramidale, composée de plusieurs étages de terrasses disposées en retrait et soutenues par des piliers. La base était un quadrilatere plein, régulier, dont chaque côté était long de quatre plethres (I 20 métres a peu prís). Les terrasses ainsi suspendues étaient faites de gros blocs de pierre recouverts d'une triple couche de roseaux imbibés d'asphalte, de briques et de plomb, pour empêcher les infiltrations; le tout supportant une épaisseur de terre suffisante pour faire vivre les plus grands arbres. On montait d'une terrasse a l'autre par des escaliers ou des rampes en glacis, disposés en spirale autour des piliers. Le nombre de ces piliers ou colonnes diminuait naturellement à chaque étage, et la dernière terrasse, suivant Diodore, reposait sur une seule colonne

(1) Voir Maspero, Histoire ancicnnc des bouples de l'Orienl, pp. 381 à 391. 
laute de cinquante coudées (près de 25 mètres). Ces jardins étaient arrosés par les eaux de l'Euphrate, que faisaient monter des appareils dissimulés dans l'épaisseur des supports.

On y avait rassemblé les plus belles flcurs, les plus beaux arbres et arbustes de toutes les parties de l'Empire assyrien; qui, dans ee temps-là, s'étendait de la mer Méditerranée à la Caspienne ct au golfe Persique. Si la description de Diodore est exacte, l'originalité de cette création consistait dans la disposition des terrasses qui les faisait cffectivement paraître suspendues, puisqu'elles reposaient sur des piliers et non sur des massifs pleins, comme dans les jardins pyramidaux ordinaires.

Il ne reste plus trace de végétation sur la colline Aurron-Ibn-Ali, emplacement présumé de ces jardins, l'une des sept merveilles du monde. Ce n'est pas là, mais parmi les débris du palais fortifié des rois de Chaldée (celui qui vit le festin de Balthazar et la mort d'Alexandre), qu'il faut chercher le seul arbre encore subsistant dans l'immense étendue des ruines de Babylone, le tamarix qui ne doit jamais mourir, suivant les musulmans Schiites, parce qu'il a servi à Ali pour attacher son cheval (I).

Les anciens rois de Perse avaient, dans les régions boisées et montueuses de leurs États, des châteaux et jardins de plaisance nommés Paradis, où ils émigraient pendant les grandes chaleurs avec leurs faroris et favorites. Il est fait clairement allusion à cette contume dans un passage des Acbarnicus d'Aristophane; le rapport burlesque des ambassadeurs athéniens qui reviennent de Perse sans avoir pu remplir leur mission, parce que le grand Roi venait précisément de partir pour plusieurs mois avec l'élite de ses gens, faire mue curre dans les montagnes (le texte grec est bien autrement énergique). Nous retrouverons la même habitude chez les grands Mogols.

L'Asie-Mineure était renommée pour ses Paradis. L'un des plus beaux, vers l'an $4 \mathrm{I} 2$ avant J.-C., était celui du satrape Tissapherne, à Sardes, auquel se rapporte une curieuse anecdote racontée par Plutarque dans la Vic d'Alcibiade: "Ce barbare "Tissapherne, qui aymoit les personnes fines et maulvaises, nomma Alcibiades le " plus doux séjour qu'il eust, pour les beaulx jardins, fontaines, bocages et prairies

(1) L'une des descriptions lús plus récentes et les plus completes des ruines de Babylone cst eelle qui se troure dans le voyage du Baron de Thielmanu, dont nous avons donné une transcription analytique (Le Cancase, la Pirse, etc.). 
« salubres et délectables qui y estoient, le tout accoustré royalement et magnificque" ment. » (Plutarque.)

Cyrus le jeune, non content de rechercher les arbres et les fleurs rares, se plaisait $\mathfrak{a}$ les planter et $\dot{a}$ les cultiver de ses propres mains; heureux s'il n'avait eu d'autre passion que celle de l'horticulture (I)!

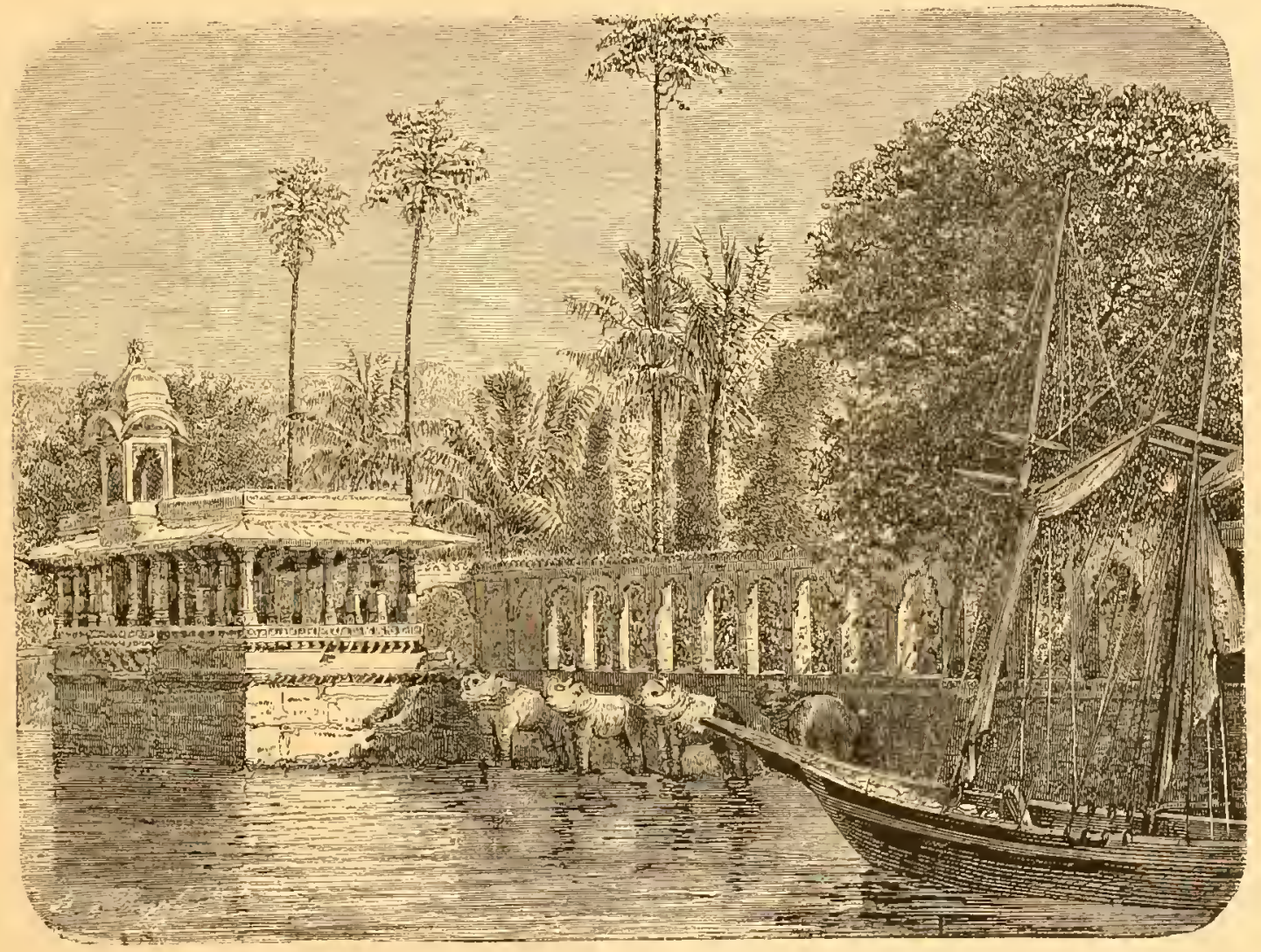

Fig. 12. - Partie du Jardin indien d'Ondeypoar. - (Voyez p. 12.)

Dans ces jardins, comme dans ceux d'Égypte, la ligne droite et la forme rectangulaire dominaient. Ils se composaient d'avenues pavées de larges dalles, bordées de canaux, et se coupant le plus souvent à angles droits. Les intervalles compris entre les avenues étaicnt plantés de quinconces, ou ornés de parterres, ou occupés soit par des piéces d'eau, soit par des vergers. Quelquefois ils servaient de parcs à des animaux domestiques ou sauvages. Ce type est encore celui des jardins persans et mogols relativement modernes. Au Xvil ${ }^{e}$ siècle, Chardin vit dans toute leur splendeur ceux

(1) Strabon parle avec admiration d'un autre Paradis, créé par les Séleucides en Syrie, et qui existait encore du temps d'Auguste, dans la vallée de l'Oronte. Il n'avait pas moins de neuf milles de circonférence. 
d'Ispahan formant douze étages de terrasses, coupées à intervalles réguliers par des canaux, parsemées de bassins avec jets d'eau, de pavillons, de volières dorées; ce shab aimait fort les oiseaux! Ces jardins étaient précédés d'une avenue de platanes, longue de trois kilomètres, ayant au centre un canal « dont les rebords étaient si larges que deux hommes à cheval pouvaient y cheminer de front, etc. » Toutes ces beautés sont aujourd'hui aussi délabrées que la monarchie persane ellemême.

Les empereurs Mogols ont laissé, dans toutes leurs provinces, des spécimens remarquables de ces «Paradis» (Fig. 12). Ceux de Delhi étaient, comme on sait, la dernière parcelle de territoire laissée par les Anglais au dernier des grands Mogols. Avant la catastrophe de i 857 , ils conservaient encore, malgré leur abandon, quelques vestiges de leur ancienne beauté. On cite aussi le pare impérial d'Agra (Rom-Bagh); les jardins qui entourent le tombeau d'Akbar et le monument funèbre érigé par Shah Jehan al sa favorite (Taj-Malıal); le "jardin des conquêtes », créé par Alibar, prés d'Ahmedabad, et dans lequel ce prince, aussi grand éducateur d'arbres que destructeur d'hommes, avait rassemblé toutes les espéces d'arbres fruitiers cultivés dans son empire.

Vers la fin du XriI é siècle, le dernier des vrais grands Mogols, Aureng-Zeb, créa à son tour, prés d'Alımehnagora, pour affirmer la conquête du Deccan, un palais et un parc qui existent encore, Farrah-Bagh.

Les touristes parlent avec admiration de ce parc que les révolutions ont épargné, où des orangers hauts comme nos chênes ombragent une piece d'eau trois fois grande comme le lac d'Enghien. Quant au palais, il est aujourd'hui occupé par une magnanerie, dont la cheminée ì vapeur s'éléve et lance insolemment sal fumce parmi les coupoles et les minarets.

Un autre parc, qu'a décrit le voyageur français Thévenot (xvil siècle), passait alors pour un des plus beaux de l'Inde : c'était celui qu'avait planté, prés de Surate, la belle Rauchen-Arâ, la sœur chérie d'Aureng-Zeb. Il formait un carré parfait, sillonné d'avenues, dont les quatre principales aboutissaient à un pavillon d'habitation à quatre faces, prècédées chacune d'un bassin en hémicycle.

Un domaine, encore plus curieux peut-être, était celui de Kajahmahal, sur le Gange, dont nous avons un plan détaillé daté de 1650 . Il appartenait à un autre membre de cette famille d'artistes mogols, Shah Soudjâh. Ce plan, reproduit dans l'Histoire 
sinérale des royages (t. IX, p. 575), nous offre la figure bizarre d'un palais de plaisance, avec ses jardins et ses dépendances, transformé en forteresse, ou plutôt en agrégation de réduits fortifiés pouvant chacun soutenir un siège. Malgré ces précautions, Shah Soudjâh fut vaincu (et tué, cela val sans dire) par son terrible frére Aureng Zeb, cn 1659 .

De tous ces jardins des grands Mogols, les plus dignes du nom de Paradis, par l'abondance et la pureté des eaux, la beauté de la végétation et des points de vue, sont ceux qu'ils avaient créés dans la fameuse vallée de Cachemire (Fig. I 3), sur les bords du lac Dal, et qui existent encore : Nasbint$B a g h$, le jardin des brises; Nisbât-Bagh, le jardin d'allégresse; Shotlamar-Bagh, le jardin du roi. Nous ne parlerons ici que du premier, qui est le plus ancien et aussi le plus grandiose. Il se com-

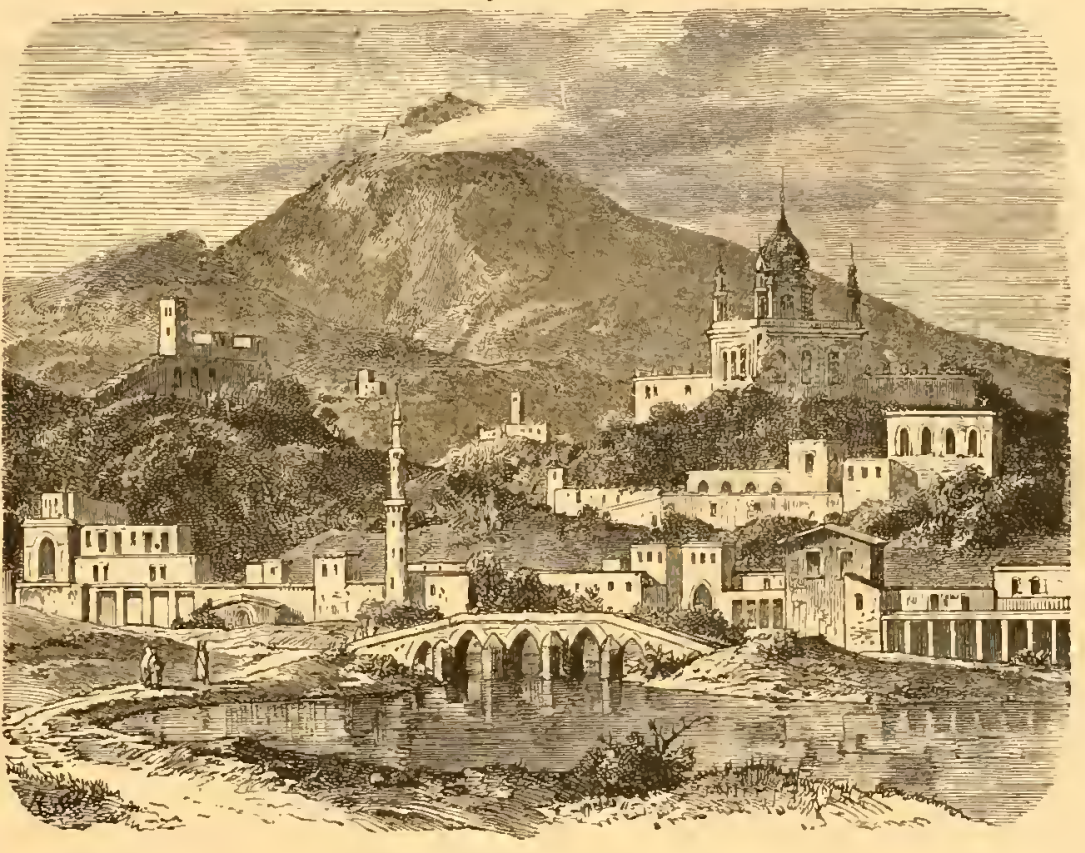

Fig. I3. - Vue de Cachemire. pose d'une série de terrasses plantées, relices par de majestueux escaliers, et dont la plus basse domine encore le lac d'une quarantaine de pieds. De ce point l'on jouit, au lever du soleil, d'un des effets de réfraction les plus heureux qui existent sur notre planète. On aperçoit, réfléchie avec une intensité extraordinaire dans ces eaux limpides, la plus belle partie de la vallée, avec son double encidrement de collines verdoyantes et de cimes neigeuses.

Ces despotes mogols avaient, comme Néron, des instincts artistiques; ce n'était pas, par malheur, la seule ressemblance!

Aujourd'hui, de profondes lézardes sillonnent les revêtements des terrasses, les dalles des allées; les marches sont disjointes ou brisćes. Mais le merveilleux paysage est toujours lá, réfléchi par ce miroir fluide; les arbres, contemporains des jours les 
plus brillants de cette dynastie, ont continué de prospérer depuis sa chute et ont atteint des dimensions colossales (1).

Nous reproduisons aussi un spécimen de jardin indo-chinois (Fig. I4); c'est un jardin de Siam, avec ses constructions en pilotis.

L'Yémen, ou Arabie dite burense (surnom contre lequel proteste son histoire)

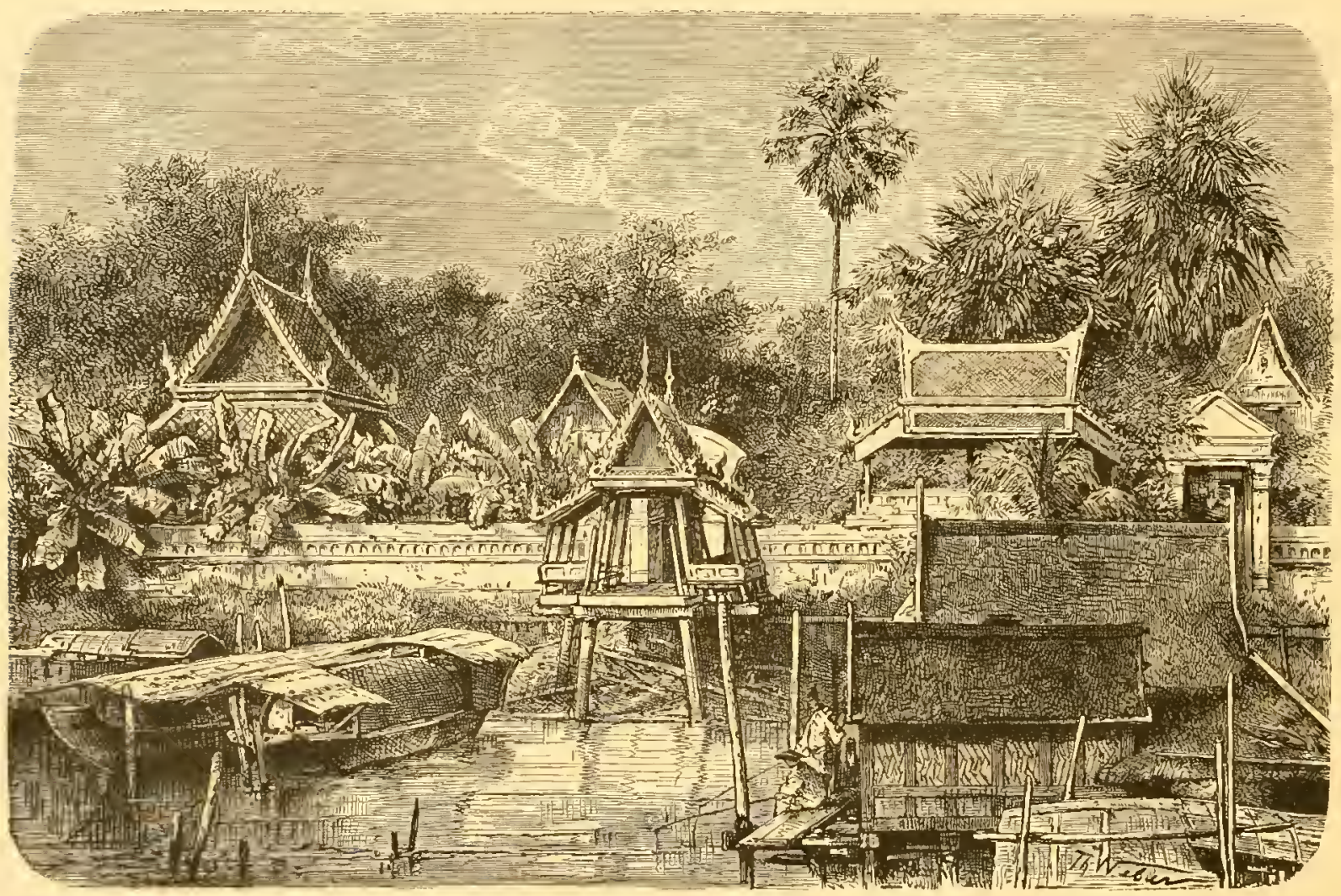

Fig. 14. - Vue d'un Jardı, à Sian.

était déjả célébre par ses jardins au commencement du xvil siécle. Le voyageur Van den Broek (16I4) parle d'un repas qui lui fut servi dans un vaste et magnifiqne jardin, planté d'arbres fruiticrs et de fleurs de toute espéce, «avec torce filets d'eau et cabinets bien ornès ».

Notre illustre compatriote Botta, l'un des rares Européens qui ont exploré l'Yémen, y trouva sur les bords de la mer, en ${ }_{1} 8_{37}$, " un jardin régulièrement planté, tenu avec une propreté presque anglaise, et décoré de cabanes de diverses formes, trés

(t) Nỏshim-Bagh est, dit-on, l'ocnvre du grand Akbar; les denx autres auraient été crés par son fils, Jelıan Guir, et son pelit-fils, Shah Jehan. On en trouvera la description dans l'excellent ouvrage de M. Drew, Jummoo and Kiashmir, dont nous avons publié une traduction libre sous le titre de Cacbenire et Petit-Thibet. 
simplement, mais trés joliment construites avec des trones et des branches de palmiers (1) \%.

Les anciens jardins mexicains ressemblent singulierement à ceux de l'Asie. Les plus remarquables, aujourd'hui détruits, étaient ceux de 'Tezcotzinco, créés au xve siècle par le grand empereur de Tezcuco, le Remerd comromé (Netzahualcoyotl). Ils étaient disposés en terrasses autour d'une montigne porphyrique en forme de cône. Un escalier de 520 marches taillées dans le porphyre et réfléchissant les objets comme des miroirs, reliait ces terrasses et aboutissait à un réservoir supéricur d'où, l'eau, amenée de trés loin par un aqueduc gigantesque, retombait en cascades et circulait alternativement cn canaux d'étage en étage (2).

Aprés ces jardins, comparables à ceux de Bibylone, on peut citer ceux de Chapoltepec, qui existent encore. Ils courrent les pentes de la colline de ce nom, et les bords du lac de Tezcuco, en face de Mexico, sur une étendue de quatre milles. On y admire surtout d'énormes cyprés, déjà séculaires à l'époque de la conquête, rivaux de ceux du Généralife et de Scutari. Leur sombre verdure s'harmonise bien avec les souvenirs qu'éroquent ces beaux licux, habités à trois siècles de distance par deux princes également infortunés et dignes d'un meilleur sort : Montezuma et Maximilien.

Nous reproduisons, ci-après (Fig. I5), un spécimen de jardin oriental, d'après Mayer; sa disposition est gracieuse et bien conforme aux descriptions anciennes et modernes. Il nous semble pourtant que l'cau y est trop ménagée. Nous voudrions des canaux pour accompagner les avenues et les parterres.

Les dessous des bois, les ombres tombant des voûtes élevées des grands arbres, les contrastes d'une lumière éblouissante éclatant brusquement à l'extrémité des parties ombrées, les rayons du soleil se jouant dans les branches, sur les marbres, dans les bassins, dans les gerbes d'eau jaillissantes, les profils des coupoles blanches ou peintes, les fléches dorées scintillant au-dessus de la verdure sombre, dans le bleu intense du ciel, tandis qu'en bas les murs en stuc ou en marbre sont noyés dans l'ombre que cette architecture fleurie semble éclairer, constituaient le décor principal des jardins

(1) Relation d'un royage dlans l'Yëmen, publiée pour la première fois à part en ISSO, par M. Ch. Levavasseur, p. 15.4. Botta, qui s'est illustré depuis par la déconverte des ruines de Ninive, explorait alors l'Yémen en qualité de royageur nduturaliste, pour le compte du Muséum.

(2) Voir, pour plus de détails, l'ouvrage de Prescott (Introl., ch. VI). 
orientaux... Seulement, ces méthodes ne peuvent être copiées dans nos contrées oủ le soleil n'a plus le même éclat, où les ombres sont molles, les teintes de verdure páles, les horizons grris et les habitudes plus expansives.

Xos d a 4 , nassifs de fleurs en pyramides; - $\rho$ a 6 , fontaines, liune devant l'habitation, lautre au fond du jardin, sous cies platanes; - - et 8 , grands parterres a compartiments, dont les côtés les plus longs sont plantés de grena. diers et d'orangers;

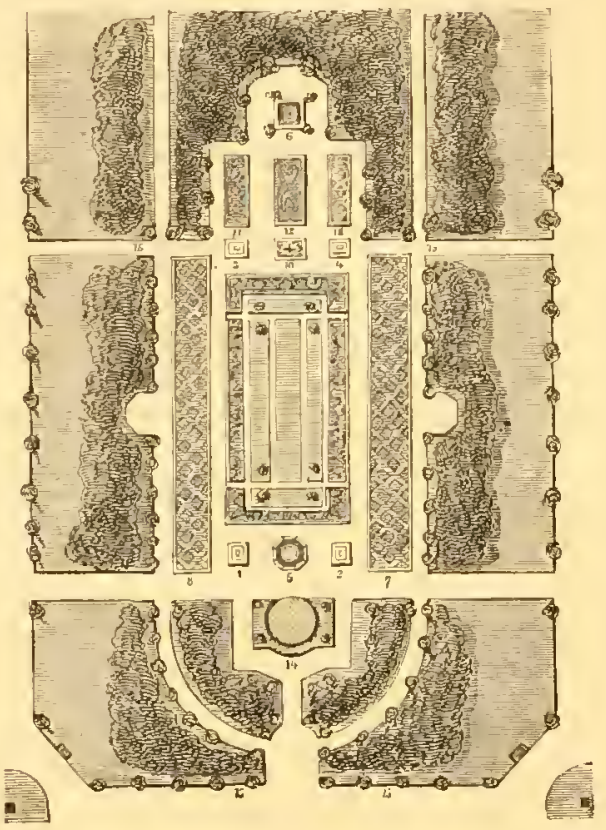

- 11,12, 13, trois petits parterres disposés devant la fon. taine $n^{\circ} 6 ;-14$, massif d'arbres ct. d'arbustes derrière l'habitation, traversé par l'allèe qui vieut de l'eutrée principale; - 15 , allice de ceinture planie de cyprés, ct bordee d'un fourré d'arbustes.

Fig. 15. - Jardin de Style oriental. - Voyez p. Is.) 

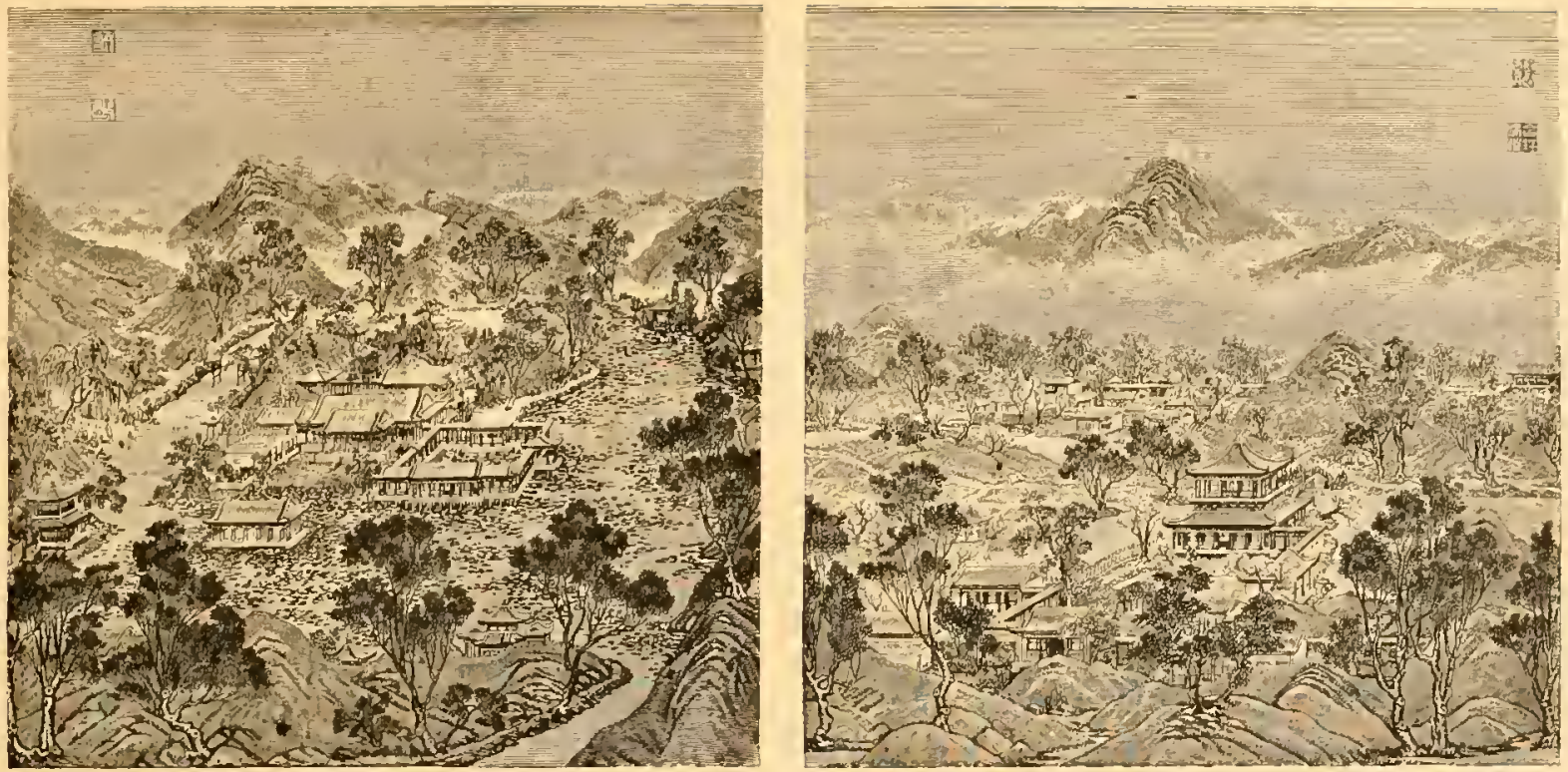

Fig. 16 et 17. - Jardin des Jardins (Yven-Ming-Yven).

\section{JARDINS CHINOIS ET JAPONAIS}

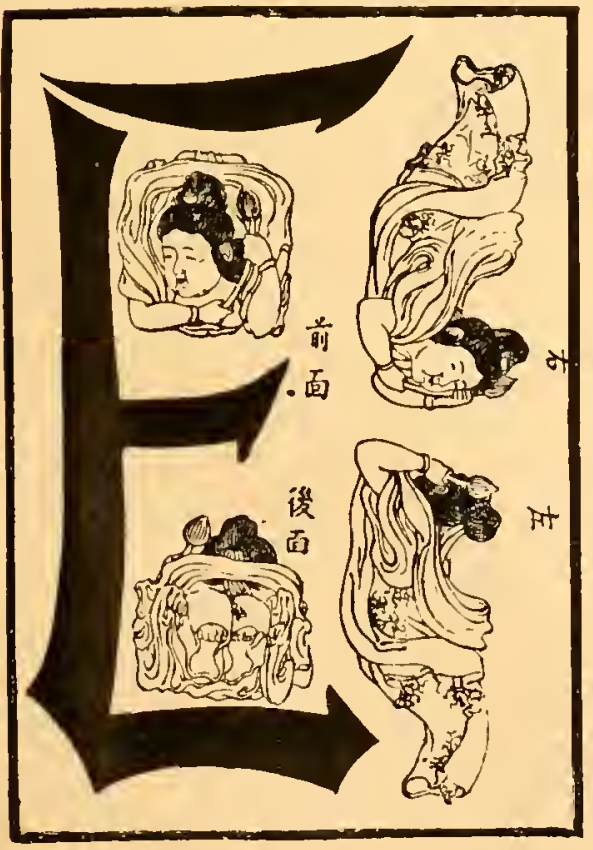

N passant des "paradis » de la Grèce, de la Perse, de l'Inde et de l'Égypte à celix des Chinois et des Japonais, nous entrons en quelque sorte dans un monde noureau. Nous y trourons un sentiment non moins vif des beautés de la nature, mais se manifestant tout d'abord d'une façon très différente, par l'imitation. Ces peuples de race jaune nous ont devancés de bien des siècles pour l'invention des parcs irréguliers, comme pour celles de la porcelaine, de la poudre, de la boussole, de l'imprimerie.

Comment leur était venu ce goût des jardics paysagers, c'est ce qu'il n'est pas facile de devincr. Des artistes trés compétents voient dans ces jardins une dérivation et comme une continuation végétale de l'architecture contournée et capricieuse des Chinois. Nous y verrions volontiers aussi une réminiscence tradi- 
tionnelle des régions montagneuses habitées par les ancêtres de ces peuples. Les inventeurs des arts et sciences qui apparaissent sous le premier empereur historique (Hoang-Ti, souverain jaune, 2698 av. J.-C.), venaient, suivant les écrivains chinois, de la région des monts Kouen-Loun, dont sortent les deux grands fleuves de la Chine, le Hoâng-Ho (fleuve jaune) et le Yang-Tse-Kiang (fleuve bleu). De plus, on voit que les princes des plus anciennes dynasties résidaient dans les provinces occidentales voisines de ces montagnes. La comme ailleurs, mais dans de plus vastes proportions, les émigrants durent descendre en suivant le cours des fleuves et de leurs afluents, et se répandre comme eux dans différentes directions, à mesure que les terrains inférieurs formés par les terrains d'alluvion devenaient habitables.

Cette coutume, si générale chez ces populations émigrées, de reproduire autour de leurs demeures une image réduite des montagnes dont leurs aïeux étaient venus, pourrait bien aussi avoir eu, à l'origine, un caractère religieux, et se rattacher au culte des ancêtres.

On a des renseignements fort anciens, mais fort hyperboliques aussi, sur la magnificence et l'étendue des parcs impériaux. Suivant le Livre sacré des Annales, un des principaux griefs allégués contre Cheou-Sin, espéce de Sardanapale chinois ( I 22 av. J.-C.), ćtait ses dépenses excessives en maisons de plaisance. On lui reprochait, il est vrai, bien d'autres peccadilles, comme de "faire mettre en broche et rôtir les gens de bien. » Nous n'entrerons pas — de peur de n'en jamais sortir — dans les pares légendaires des anciens empereurs chinois, parcs qui auraient eu trente et jusqu'à cinquante lieues de tour, et trente mille jardiniers!!! Mieux vaut arriver de suite à ceux des empereurs de la dynastie tartare actuellement régnante, sur lesquels nous avons des renseignements plus positifs.

Le " Jardin du printemps perpétuel » (Chun-Chang-Yen), créé dans les environs de Pélin, par Kang-Hi, le Louis XIV de cette dynastie, a été décrit de visn, en I690, par le P. Gerbillon, jésuite.

"Ce palais, dit-il, est situé entre deux grandes piéces d'eau, l'une et l'autre couronnées presque entièrement de petites hauteurs formies de la terre qu'on a tirée pour creuser les pièces d'eau. Toutes ces hauteurs sont plantées d'abricotiers, de pêchers, etc... Les Chinois, dit-il encore, font consister la beauté des maisons de plaisance et des jardins, dans une grande propreté, et dans certains morceaux de rocailles extraordinaires qui aient l'air tout à fait sauvage... Ils aiment surtout les petits 
cabinets (pavillons) et les petits parterres fermés par des haies de verdure qui forment de petites allées... (Les jardins sont) le goût général de la nation. Les riches y font une dépense considérable. Ils épargnent bien moins l'argent pour un morceau de vicille roche qui ait quelque chose de grotesque ou d'extraordinaire, comme d'avoir plusieurs cavités ou d'être percé à jour, que pour un bloc de jaspe ou une statue de marbre. ")

Le "Jardin des Jardins» (Yven-Ming-Yven), saccagé en I860, avait été commencé
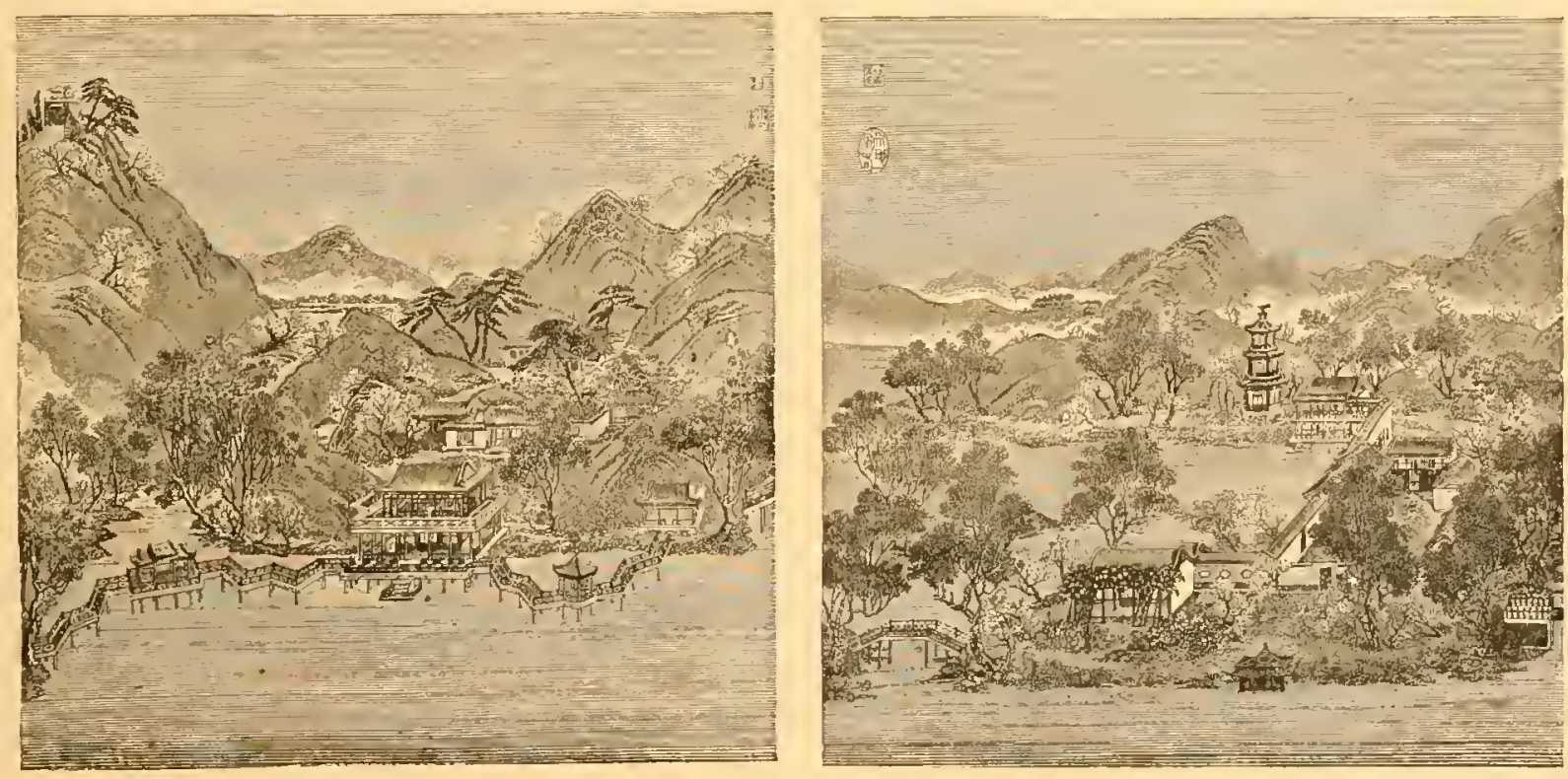

Fig. 19 et 20. - Jardin des Jardins.

en I 723 par l'empereur Yout-Ching, et terminé par son fils Kien-Long. Cette cuvre a une grande importance dans l'historique des pares et jardins. Aussi nous reproduisons en partie la fameuse description d'Attiret ( 1743 ), et plusieurs des principales scènes de ce parc (Fig. I6, I 7, I9, 20), d'après des peintures chinoises de la même époque qui se trouvent à la Bibliothéque nationale (aux Estampes).

Attiret, artiste de talent, était entrẻ dans l'ordre des Jésuites, comme frére convers, et ne voulut jamais sortir de cette humble situation. Il fut envoyé en Chine par ses supérieurs, et y resta jusqu'à sa mort ( 1770 ), attaché comme peintre au service de l'empereur, office qui n'était rien moins qu'une sinécure, comme on le voit par sa correspondance, et qu'il exerçait littéralement pour l'amour de Dieu. Il parle avec admiration du Jardin des Jardins, « où presque partout il règne, dit-il, un beau désordre, 
une anti-symétrie rustique et naturelle... Dans un vaste terrain, l'on a élevé à la main de petites montagnes, hautes de vingt à soixante pieds, et qui forment une infinité de vallons. Des canaux d'une cau claire arrosent le fond de ces vallons, et vont se joindre en plusieurs endroits pour former des bassins. On parcourt ces canaux et ces bassins sur de magnifiques barques. J'en ai vu une de treize toises de longuéur et quatre de largeur, sur laquelle était un superbe pavillon. Dans chacun de ces vallons, sur le bord des exux, sont des bâtiments parfaitement assortis de plusieurs corps de logis, de cours, de galeries ouvertes et fermées (comme dans la Fig. I6), de parterres, de cascades, ete., ce qui fait un assemblage dont le coup d'œil est admirable. On sort d'un vallon par des circuits ornés de petits pavillons, de petites grottes, à l'issue desquels on retrouve un second vallon tout différent du premier, soit pour la forme du terrain, soit pour la structure des bâtiments. Les collines sont couvertes darbres à fleurs; les canaux, bordés tout rustiquement avec des morceaux de roche dont les uns avancent, les autres reculent, et qui sont comme l'ouvrage de la nature. Les bords sont semés de fleurs qui sortent des rocailles; chaque saison a les siennes. Outre ces canaux, il y a partout des sentiers, pavés de tout petits cailloux, qui conduisent d'un vallon à l'autre.

"Arrivé dans un vallon, on aperçoit les bâtiments (Fig. 17). Toute la façade est en colonnes et en fenêtres; la charpente dorée, peinte, vernissée; les murailles de briques grises, bien taillées, bien polies. Les toits sont couverts de tuiles vernissées, rouges, jaunes, vertes, etc., qui, par leur mélange et leur arrangenent, font une agréable varićté de compartiments et de dessins. Ces bâtiments n'ont presque tous qu'un rezde-chaussće, quelques-uns un étage. On y monte par des rochèrs, qui semblent être des degrés naturels... Au-devant on a placé, sur des piédestaux de marbre, des figures en bronze et des umes pour brûler des parfums. Chaque vallon a sal maison de plaisance.

" Les canaux sont coupés, de distance en distance, par des ponts de briques, des pierres de taille ou de bois. Du reste, ils sont toujours différents pour la construction; il en est qui vont en tournant ou en serpentant. On en voit qui ont de petits pavillons de repos soutenus par des colonnes (Fig. I9); d'autres ont aux deux bouts des arcs de triomphe... »

"J'ai dit plus haut que les canaux vont se décharger dans des bassins. Il y a un de ces bassins qui a prés d'une demi-licue de diamètre en tous sens, auquel on a donné 
le nom de mer; c'est un des plus beaux endroits (Fig. i 9). Il y a sur les bords de grands corps de logis séparés par des canaux ou par des montagnes. Les bords de ce charmant bassin sont variés à l'infini; aucun endroit ne resscmble à l'autre. ” Attiret cite encore les enclos pour la chasse, les ménageries, les " cages et pavillons moitié dans l'cau et moitić sur terre » (comme les deux qu'on roit sur le devant dans la fig. 19); les réservoirs entourés d'un treillis de cuivre pour les poissons, etc. Il décrit aussi la petite ville située au centre du pare, "destinée à faire représenter par les cunuques, plusieurs fois l'année, pour l'amusement de l'Empereur, tout le commerce, le tracas, le mouvement et même les friponneries d'une grande ville. »

Au milieu de cette "mer intéricure ", comme l'appelaient pompeusement les Chinois, s'élevait une île rocheuse supportant un vaste pavillon ou plutôt un palais en miniature, d'oủ l'on dominait l'ensemble du pare (Fig. I7).

Cette description eut en Europe un retentissement que son modeste auteur ne préroyait guére. Flle y fit un grand nombre de conversions... au système des jardins irréguliers. Sa véracité, naguére contestée, a cessé de l'être depuis que nous connaissons la Chine. Attiret avait même omis quelques détails qui auraient paru incroyables, comme les toits à bords relevés et frangés de sonnettes, et les îles flottantes, dont les habitants de Cachemire et les anciens Mexicains connaissaient aussı l'usage. La seule chose qu'on puisse lui reprocher, c'est un peu trop d'enthousiasme; lu1-même convient qu'il subissait à la longuè l'influcnce du goût chinois. En réalité, ces imitations des sites pittoresques ne sont souvent que des réductions étriquées, tourmentécs. Les Chinois en agissent arec les rochers, les arbres, les ruisseaux, etc., comme avec les pieds de leurs femmes. Les scénes du " Jardin des Jardins » et autres trahissent une préoccupation constante de donner aux objets de toute nature une apparence baroque, exceptionnelle. On y trouve, par exemple, des ponts à arches carrées, et, par contre, des portails complètement ronds. Les arbres portent des traces visibles de mutilations, de déformations calculées pour modifier leur forme naturclle, et aussi pour obtenir des fleurs plus grandes et en plus grande quantité. Ces chinoiseries paysagères sont à la grande nature ce que les acrostiches sont à la poésie.

Avec cette esthétique singulière, les Chinois ne sauraient gonter le style régulier, ni pour les bâtiments, ni pour les jardins. "Lorsqu'ils voient, écrivait Attiret, des estampes de nos édifices, ces grands corps de logis les épouvantent. Nos étages surtout leur paraissent insupportables : Il faut, disait l'empercur Kang-Hi, que l'Europe soit 
bien petite, bien misérable, puisqu'il n'y a pas assez de terrain pour étendre les villes et qu'on est obligé d'y habiter en l'air. " Cependant son petit-fils, KienLong, eut, dans la dernière partie de son règne, la fantaisie de faire faire quelques essais d'imitation de ces palais, de ces jardins français si vantés. Les Jésuites plantèrent à Pékin même des avenues droites qui subsistent encore. Le palais dit de la Mer sercine, ses jardins, ses terrasses et ses jeux hydrauliques, exécutés sous leur direction, offraient un amalgame curieux et nullement déplaisant des styles français et chinois. On cite surtout une ingénieuse combinaison d'horloge hydraulique, composée de douze figures d'animaux fantastiques disposés autour d'un bassin:

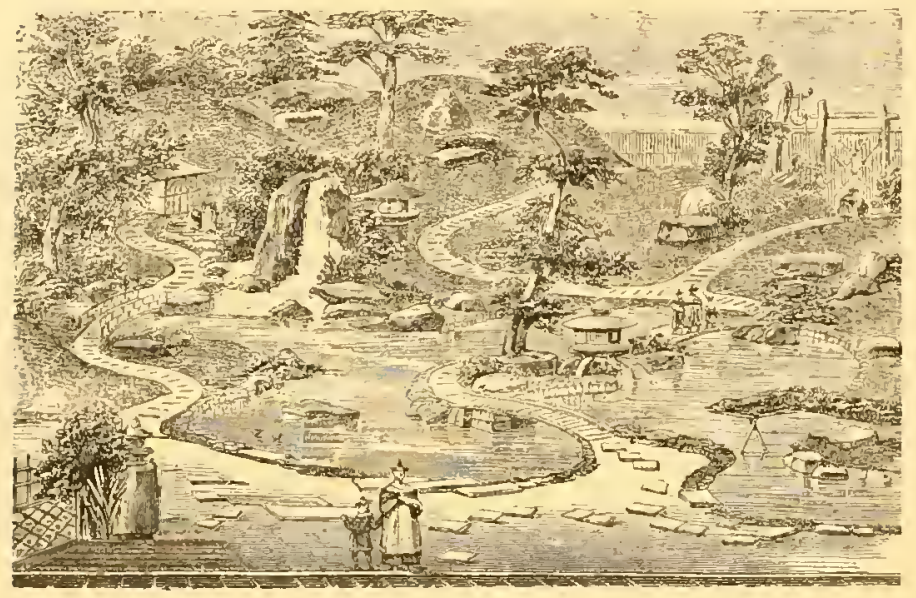

Fig. 2r, - Jardin japonais (d'apres un Dessin original).

le nombre des jets émis à la fois correspondait à celui des 'heures.

Les jardins japonais ressemblent fort à ceux de la Chine, comme on en peut juger par la reproduction du dessin d'un artiste indigène (Fig. 21).

La disposition de ce jardin est tout à fait conforme aux descriptions rapportées de ce pays, à deux siècles d'intervalle, par Kæmpfer et par $M$. de Hübner : "Une partie du jardin, écrivait Kimpfer en I69I, est pavée de pierres de diverses couleurs qu'on prend dans les rivières, ou sur le bord de la mer. Le reste est couvert de gravier, que l'on nettoie soigneusement. Dans toutes les autres parties, il régne une apparence de désordre, qui est d'un agrément infini. Les plus grandes pierres occupent le milieu, et forment une allée. Des fleurs, entre lesquelles il y en a toujours quelqu'une de rare, sont disposées d'espace en espace. A l'un des coins, un petit rocher, parfaitement imité, orné de figures d'oiseaux et d'insectes de métal, offre une cascade formée par un petit ruisseau. Il est accompagné d'un petit bois, composé d'arbres qui peuvent croître les uns près des autres. Les arbres sont d'autant plus estimés qu’ils sont plus vieux, plus tortus et plus difformes, etc. »

M. de Hübner a vu de même, en $187 \mathrm{I}$, " de petits jardins oú de petits filets d'eau forment de petites cascades, plantés de petits chênes, de petits sapins 
tourmentés, lacérés, tordus, selon le goût du pays. De petits ponts, consistant en une seule pierre, sont jetés sur des torrents artificiels. Le goût, certes, est contestable, et le dessin a je ne sais quoi d'enfantin. Il y a pourtant lí de l'imagination, et les proportions sont harmonieuses. Si de votre balcon vous plongez le regard dans un de ces jardins, il vous fait l'effet d'un parc. Mais voici une jeune fille qui passe, et elle est plus haute que ce vieux cèdre. Tout cela n'est qu'un joujou, mais un joujou charmant »(I). Toutefois, les Japonais paraissent savoir faire, mieux que les Chinois, du paysage grand comme nature, quand l'espace le permet. M. de Hübner cite avec éloge les jardins du château de plaisance des Shoguns, Homagaten ou Palais de la Plage, situé sur le bord de la mer, prés d'Yeddo. “ Le château a été gauchement enropéanisé; mais le parc est resté japonais. De magnifiques arbres, des terrasses, de petits lacs artificiels, de petits promontoires, des ponts jetés sur les criques, le terrain naturellement et artificiellement accidenté, et, entre les arbres, l'horizon de la mer; partout la solitude et le silence. » Il signale encore plusieurs parcs de Daïmios, d'un très beau caractére, et n'offrant rien, ou presque rien d'étriqué et de contourné. Bien que sujets aux mêmes aberrations de goût que les Chinois, les Japonais semblent doués de plus hautes aptitudes artistiques. Ils l'ont bien prouvé à l'Exposition française de $\mathrm{I} 878$.

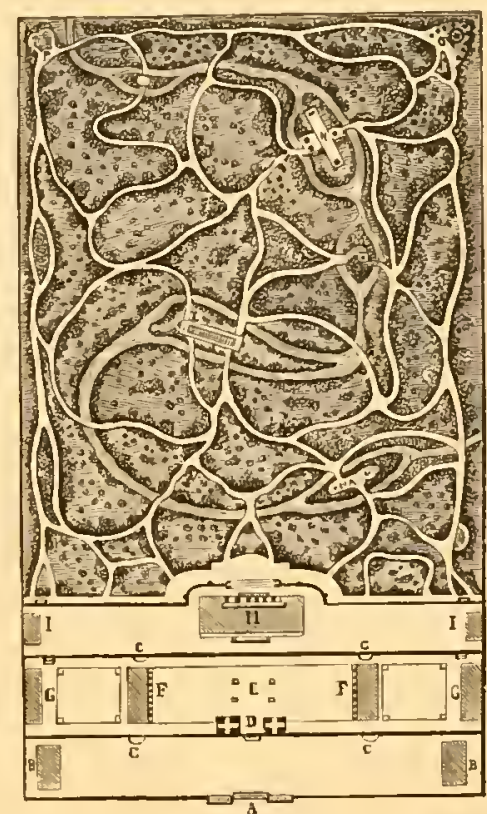

Fig. 22. - Plan d'un Domaine chinois.

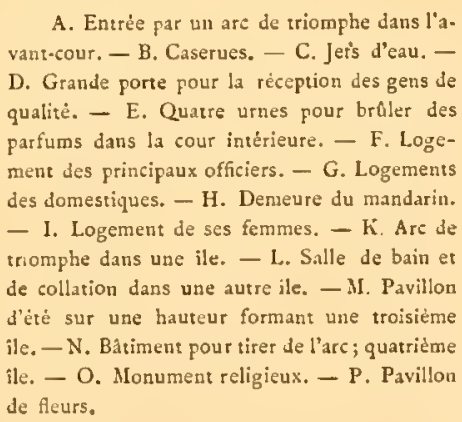

Nous croyons utile, au point de vue technique, de reproduire le plan d'un domaine chinois non impérial (Fig. 22), mais pourtant d'une certaine importance, situé dans les environs de Pékin. C'était, comme on va le voir, l'habitation d'un mandarin militaire, et qui ne s'épargnait pas les arcs de triomphe avant la guerre de 1860.

(i) Promenade autour du Monde, I, 429. Suivant les annales des empereurs du Japon, le goût pour les fleurs commença dans ce pays au printemps de l'an de J.-C. S12, époque où le Dairi alla au jardin de la Source des Génies (Sin-Y'eu-Sin), contempler des fleurs et faire des vers. 
Par le tracé des eaux et des allées, comme par la multitude de ponts, d'îles et de kiosques, ce parc ressemble encore d'une manière frappante aux premiers jardins irrèguliers d'Europe, dits anglo-clinnois.

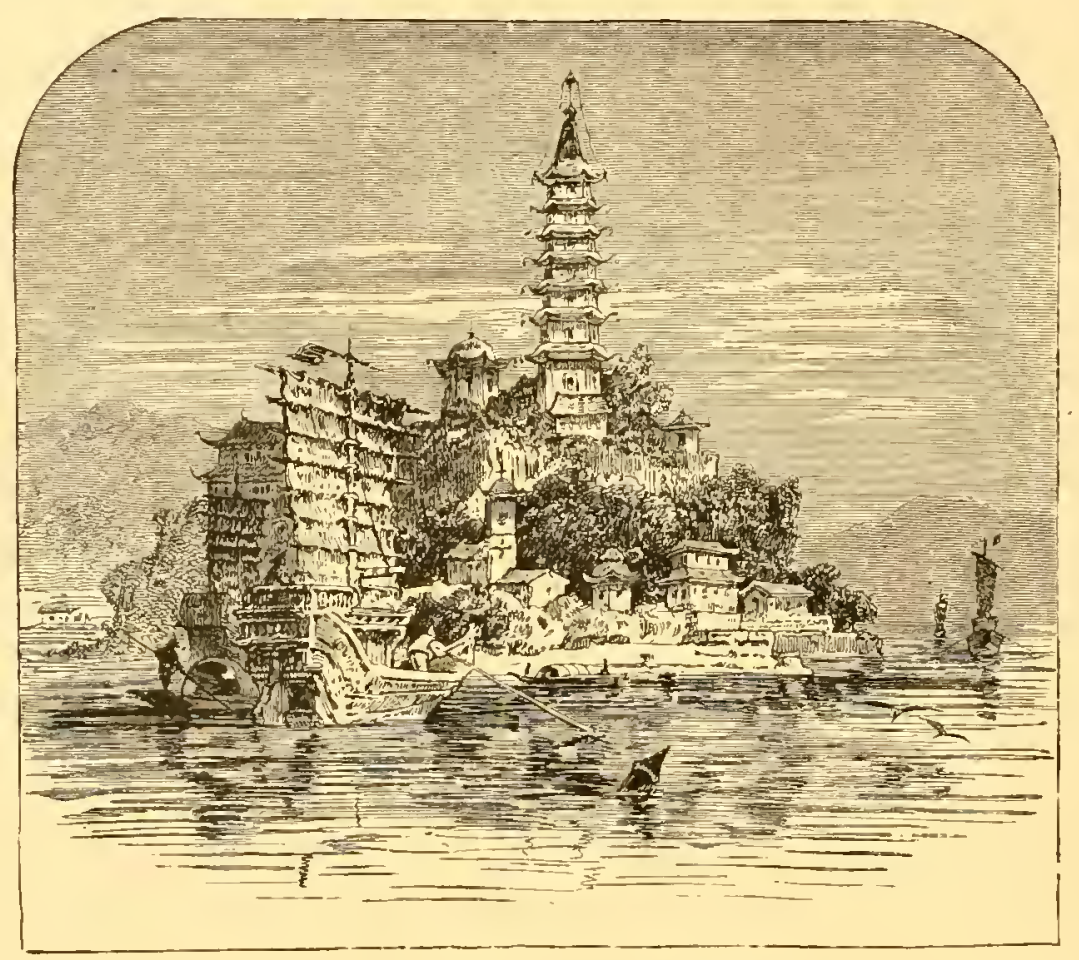

Fig. 23. - L'Ile d'Or, Yung-Tse-Kinang. 


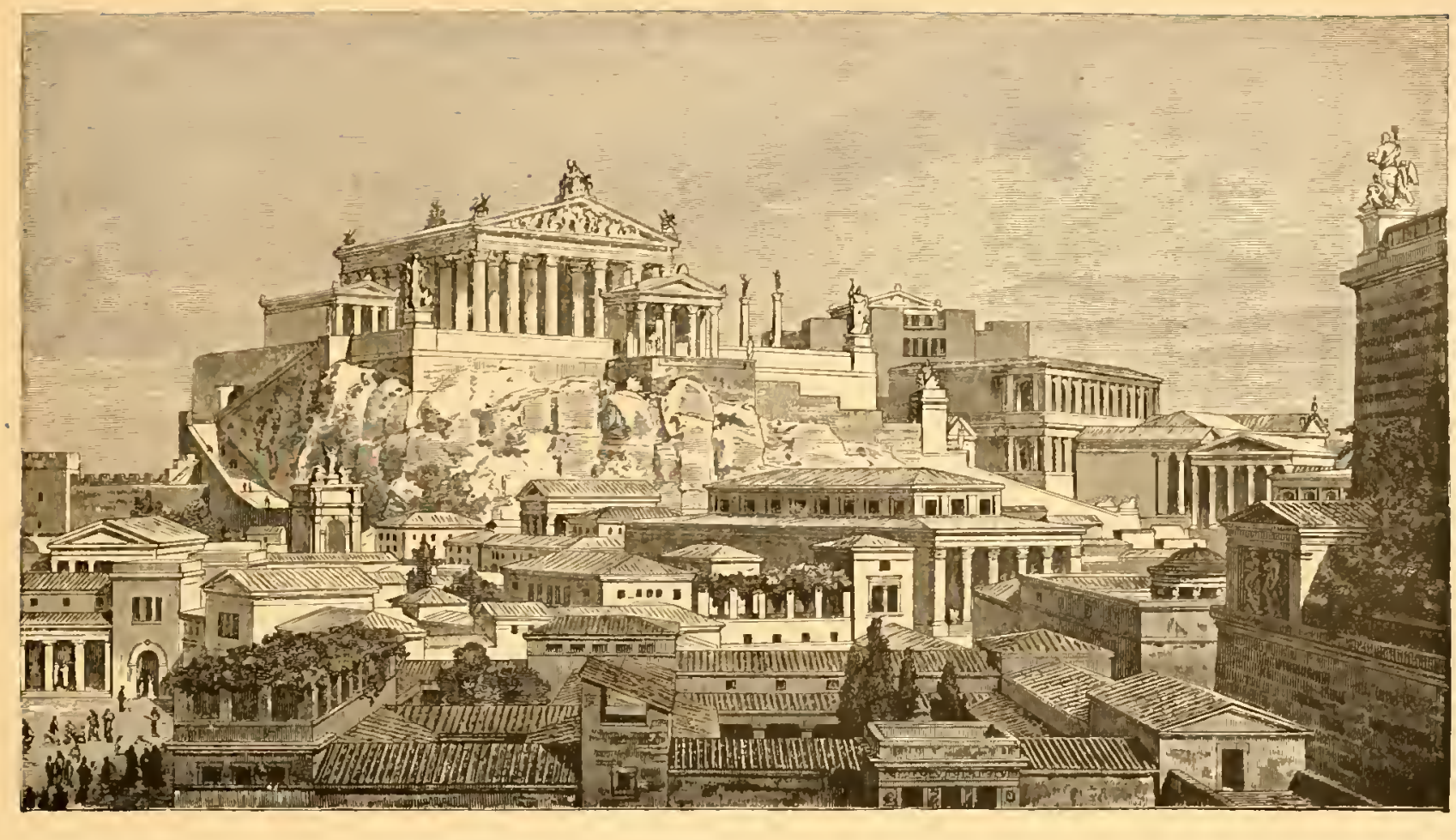

Forum Boarium.

Temple de Jupiter.

Basilique

Tabularium.

Temple frés du Forum romanum.

Fig. 24. - Restauration du Capitole, a Rome.

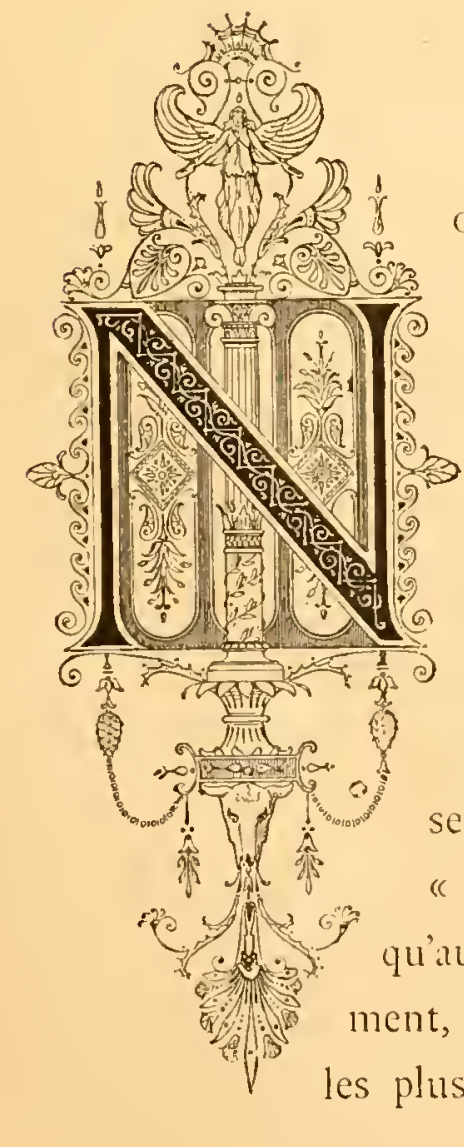

\section{JARDINS ROMAINS}

ous ne savons rien de l'horticulture romaine primitive: Cincinnatus et Caton l'Ancien avaient des fermes, des potagers, et non des parterres et des villas. Mais, aprés la ruine de Carthage, la conquête de la Grèce et de l'Asie, " tout homme riche eut des jardins ». C'était en quelque sorte le complément de son luxe; comme une seconde galerie, oú il réunissait les objets d'art achetes, conquis ou volés dans les provinces étrangéres. On vantait " les belles allées a se promener ” de Lucullus, autant que ses livres, ses tableaux, ses statues, et même que ses diners. "Tellement, dit Plutarque qui vivait dans le sicicle suivant, u'aujourd'hui que la superfluité a pris un si grand accroissement, encore compte-t-on les jardins que fit faire Lucullus entre es plus somptueux et les plus délicieux qu'aient les empereurs. ” 
Cet éloge s'appliquait surtout à ceux qui courraient la colline oú s'éléve aujourd'hui la villa Médicis (Monte Pincio), et à la villa du cap Misène, point " d'oú l'on jouit, dit M. Reclus, d'une des vues les plus vantées de la planète. „ Cette villa avait d'abord appartenu à Marius, mais Lucullus l'avait fort embellie. Réunie dans la suite au domaine impérial, elle fut le théâtre de la mort mystérieuse de Tibère. Parmi les autres.jardins déjà célèbres avant la fin de la République, il faut citer d'abord, à Rome même, ceux de Salluste, de Pompée, de César et d'Antoine;

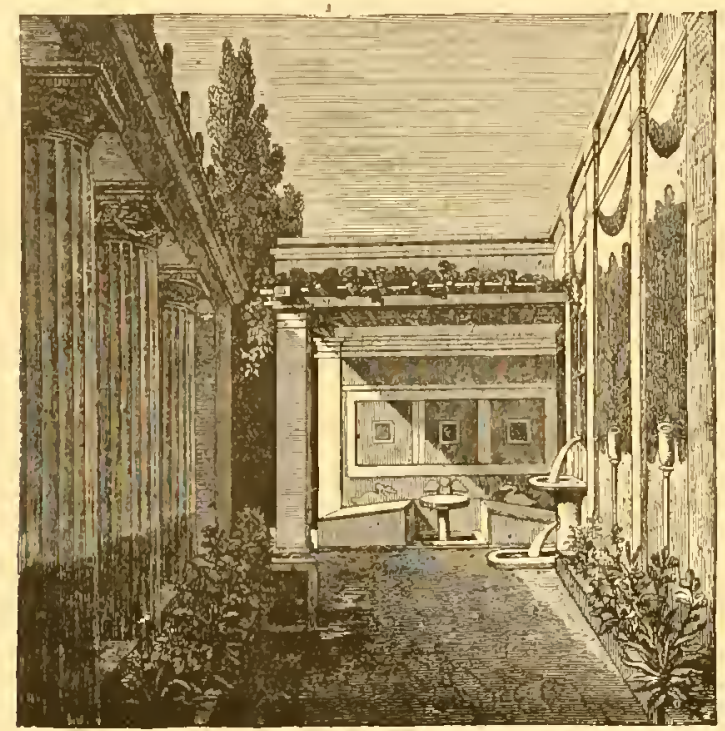

Fig. 26. - La Casa di Sallustio, à Pompéi. (Restauration.) puis ceux de Catulle à Tibur et à Sermione sur le lac de Garde; ceux de Cicéron à Tusculum et à Pouzzoles, etc.

Les plus importants de ces jardins, bien quayant depuis longtemps et souvent changé de maîtres, étaient cependant toujours désignés par les noms de ceux qui les avaient créés. "Il semblait que ce fût pour cux un titre de gloire qu'on craignait de leur ravir. ") Les jardins de Salluste, par exemple, portaient encore son nom trois siècles après sa mort. - Ces oasis de verdure, également propices aux plus graves entreticns et à des conversations d'un genre tout différent, étaient très recherchées. Ce n'était pas toujours la sagesse qui prévalait sous les voluptueux ombrages de Baïa (Fig. 29), oủ déjả, avant Auguste, on se disputait le terrain jusque dans la mer. Du cap Miséne au lac Averne, la contríe entière était le plus charmant des jardins.

Après la chute de la République, cette passion des jardins tourne à la monomanie. "Non contents d'aroir transporté la campagne à la ville, les Romains la mettent sur la ville même, en installant sur les terrasses non seulement des parterres et des arbustes à fleurs, mais de grands arbres et des bassins assez larges et assez profonds pour porter bateau. Dans tout le Latium, les villas avaient "écrasé les moissons sous leurs pieds de marbre (I) ), si bien que "plusicurs millions d'hommes 
avaient faim comme un seul », quand les vents retardaient l'arrivée des blès d'Égypte ou de Sicile. La résidence favorite de l'aristocratie romaine, pendant les grandes chaleurs, était toujours Baïa, "l'hôtellerie des vices » (vitiortun diversorium), suivant Sénéque. "Non-seulement, dit-il, on y fait le mal, mais on s'en vante (1). Aussi j'en suis reparti dés le lendemain, ne me souciant pas plus de demeurer dans un lieu de débauche, que dans un lieu de torture. » Baïa, au reste, était l'un et l'autre. Pompée, Lucullus, César, Tibère $\mathrm{y}$ avaient habité, puis Agrippine et Néron. Les ruines des thermes, des mystérieux réduits qu'on y entrevoit encore, à demi submergès, gardent avec les flots, leurs vieux complices, d'étranges secrets du passé! Néron, surtout, aima les jardins jusqu'à la

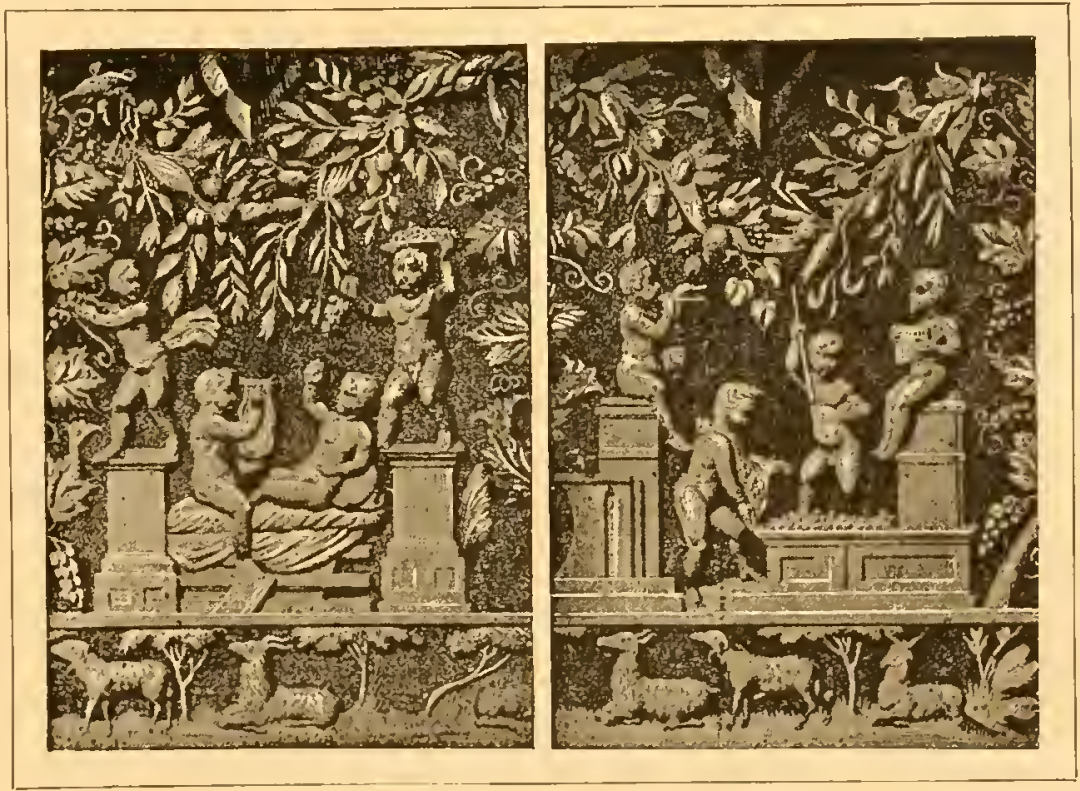

Fig. 27 et 28. - Viridaria, d'aprés des Peintures murales de Pompéi, formant des Retraites ornées de Statues, de Fontaines, etc. (D'après la Vie antique, page 287.)

rage. Il tenait cette passion (et bien d'autres) de sa mère, qui jadis avait fait périr l'opulent Statilius Taurus, sous prétexte de magie, mais en réalité pour s'emparer de ses jardins. Aprés l'incendie de Rome, Néron fit construire sur l'emplacement d'une partie des quartiers détruits un nouveau palais plus beau que l'ancien, et planter un parc encore pius extraordinaire que le palais, s'il faut en croire Tacite et Suétone. On y trouvait des vignobles, des moissons, des pâturages, des enclos contenant du gibier de toute espéce, des bains de mer et d'eau douce, et une vaste salle à manger en forme de rotonde, renfermant des tables servies nuit et jour. Il est probable que ces champs, ces enclos et le reste, étaient compris dans les intervalles des avenues.

En dépit des convulsions volcaniques du sol, des ravages et de l'abandon des hommes, les environs de Bä̈a, ces Champs-Élysées de l'ancienne Rome, conservent 
encore un attrait indéfinissable. "Hs sont, dit de Brosses, comme ces vieilles beautés qui, sur un visage tout ruiné, laissent encore deviner la trace de leurs anciens agréments. » Nulle part la nature ne s'entend mieux à parer, à enguirlander les ruines, que sur ce rivage, éternel enchantement des artistes et des poètes (Fig. 29).

A l'époque de Domitien, Stace nous donne dans les Silzes des détails curieux, et

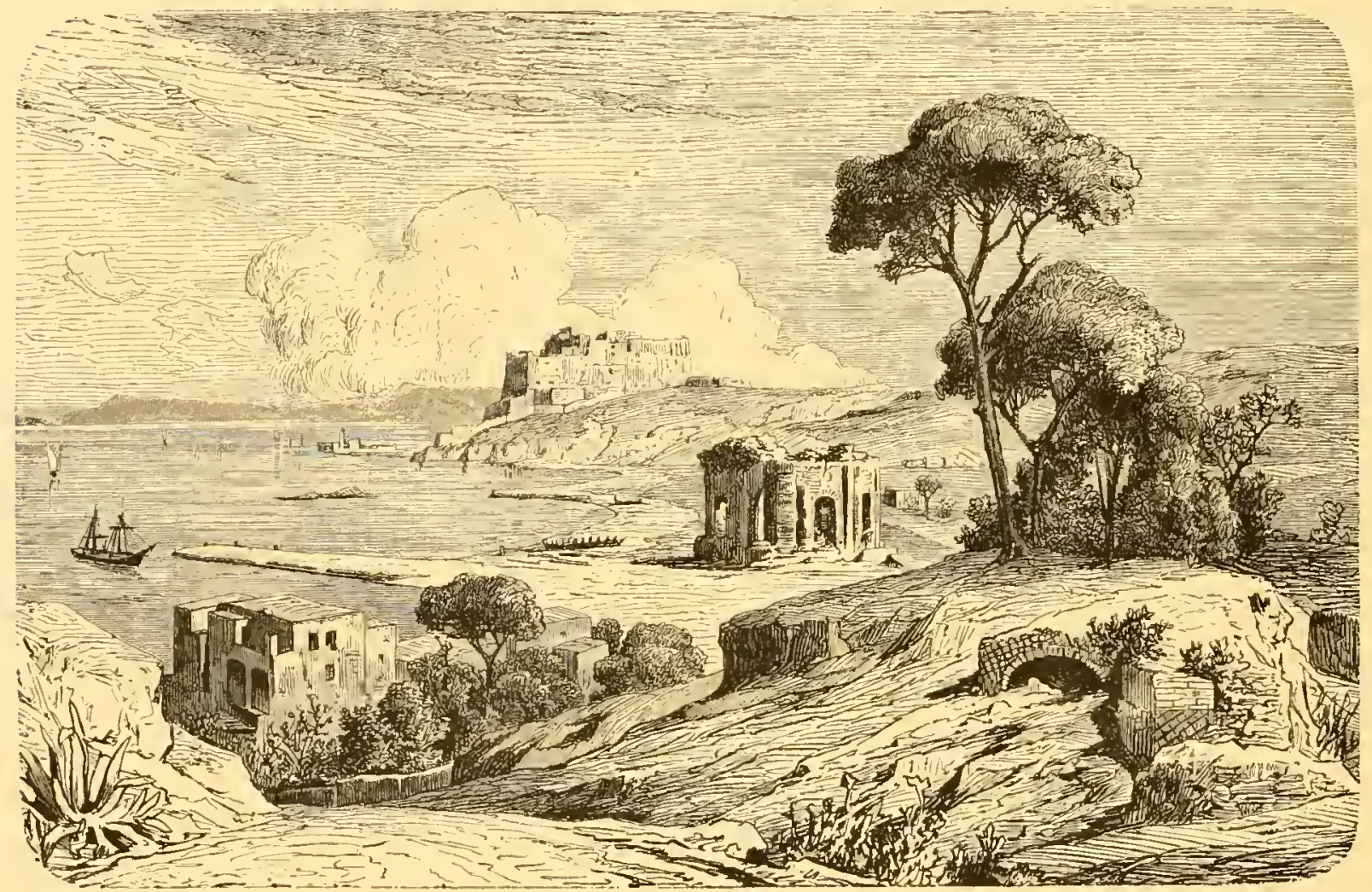

Fig. 29. - Vue actuelle du Golfe de Baïa.

rarement cités, sur les villas de deux de ses amis, Vopiscus et Pollius Félix, situées l'une a Tibur, l'autre ì Sorrente (Fig. 30). Celle de Vopiscus ćtait entre deux des cascades de l'Anio, dont le bruit n'arrivait à l'oreille que comme un doux murmure. «Dans toutes les chambres, dit le poète, on avait la compagnie des Nymphes »; ce qui veut dire chastement et simplement, que l'eau de l'Anio et de ses affluents y était amenée par des conduits. L'habitation avait vue d'un cêté sur la rivière, dont on pouvait, des yeux, suivre fort loin le cours, en amont et en aval; de l'autre, sur des massifs d'arbres séculaires. L'un de ces arbres, qui se trouvait à la place même où l'on bâtissait la maison, avait été religieusement conservé dans la cour intérieure, et projetait ses 
rameaux verdoyants au-dessus des toits et à travers les portiques. "Tout autre propriétaire, dit Stace, eût abattu sans pitié cet arbre magnifique. Aussi l'Hamadryade reconnaissante (I) réserve de longs jours à Vopiscus! »

Il n'est pas facile de ressaisir des détails techniques dans cette poésie ondoyante et ampoulée. On croit pourtant comprendre que les jardins s'étendaient en terrasses sur les deux rives de l'Anio, entre lesquelles la communication se faisait au moyen d'un bac. Ils étaient sillonnés de ruisseaux, dont l'un, arrêté au passage pour le service des thermes, allait ensuite « réchauffer les Nymphesdel'Anio». Vénus même avait

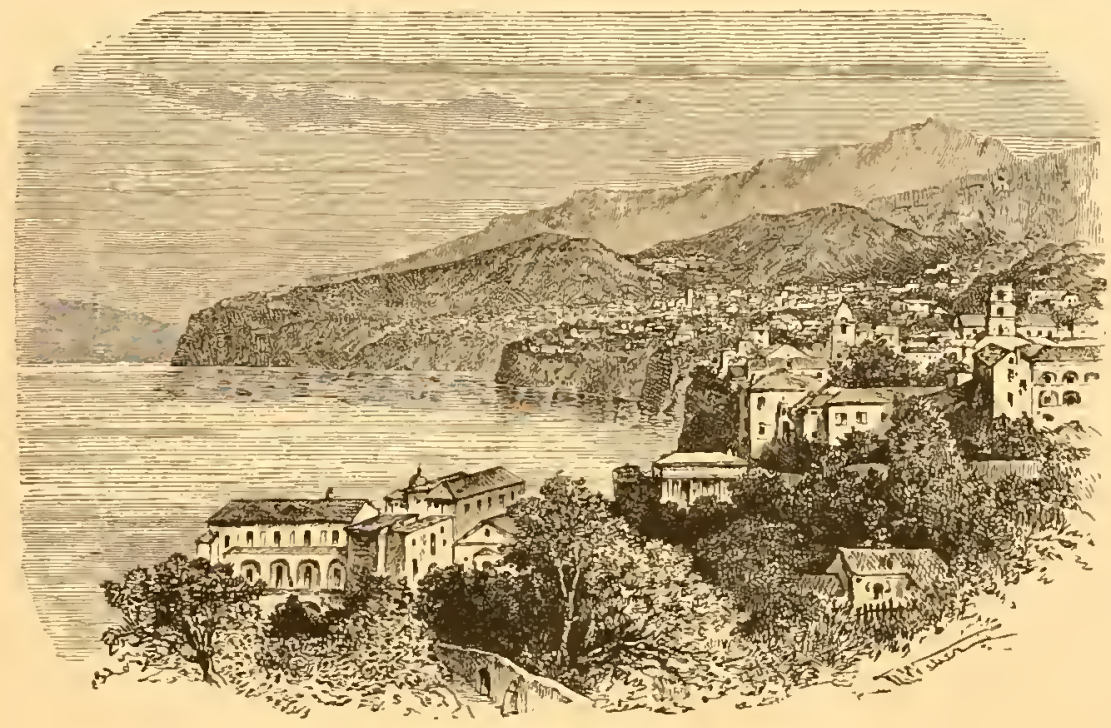

Fig. 30. - Vue de Sorrente. présidé à l'établissement de cette retraite; elle y avait laissé le parfum de sa chevelure et consigné quelques-uns de ses Amours :

El volucres vetuit discedere natos.

La villa de Sorrente (Fig. 30) avait exigé de plus grands travaux. C'était originairement un terrain aride, d'un accés difficile, sans autre attrait que la beauté de la vue sur le golfe. Il avait fallu tout créer, rapporter des terres, niveler le sol, etc. La description de l'établissement de ce jardin régulier ne manque pas d'élégance. " 11 y avait un rocher, là oú vous ne voyez plus qu'une surface plane; de maigres broussailles, à la place qu'occupe aujourd'hui l'habitation. Par contre, voici des futaies, lá oủ il n’y avait pas même de terre, etc.

Mons erut bic, ubi plana vides : bare lustra fucrmt,

Quae nunc lectu subis. Ubi munc nemora ardua cemis,

Hic nec terra fuit. Domuit possessor, et illum

Formantem rupes, exbugnantemque secuta

Gaudet bumus...

(Silv., II, 2, v. j+ et suir.)

(1) Celle dont l'existence était attachie à celle de l'arbre. 
Stace ajoute que l'horizon de ce golfe incomparable était habilement réparti entre toutes les chambres. Chacune avait sa vue particulière, encadrée de verdure. Les jardins descendaient en terrasses vers la mer, et aboutissaient il une crique profonde et toujours calme, abritée du côté du large par une ceinture de rochers. Cette agréable retraite était encore embellie « par la présence d'une nymphe d'eau douce accourant au-devant de l'onde amére », c'est-ì-dire par un ruisseau d'eau vive... Plusieurs traits de cette description semblent se rapporter à l'un des plus délicieux réduits qu'offre cette côte : le port en miniature dit Bain de Diane. Nous y retrouvons notamment la « Nymphe d'eau douce qui vient se réunir à la mer », et fait même maintenant un beau saut pour la rejoindre, car elle y tombe en cascade d'une assez grande hauteur.

Il est intéressant de comparer cette description avec celle d'une autre villa maritime à peu près de la même époque, la Laurentina, de Pline le Jeune, amateur insatiable de jardins, comme on sait. Celle-lì était dans une situation moins pittoresque, mais plus roisine de Rome, et d'un accès plus facile sur la plage. Aussi il avait fallu planter du romarin au lieu de buis, du côté de la Gestatio (allée de ceinture), exposé à recevoir l'écume des vagues, et le jardin était composé principalement de mûriers et de figuiers, arbres qui supportent bien le voisinage de la mer.

Pline possédait dans son pays natal, sur les bords du lac de Côme, deux autres villas auxquelles il a consacré une de ses plus jolies lettres. "Chacune a son caractère et son charme particuliers. L'une, que j'appelle ma Tragédie, est majestueusement campée sur un promontoire entre deux golfes, et domine tout le lac. L'autre, ma Comédie, est au contraire tout à fait sur le bord. De l'une je suis au loin les évolutions des pêcheurs; dans l'autre, je puis moi-même pêcher de ma chambre, et presque de mon lit. » (Ép. IX, 7.)

Mais sa villa favorite était celle qu'il possédait dans la région du haut Tibre (Fig. 3 I). L'habitation était sur une hauteur isolée, au milieu d'un vaste amphithéâtre de montagnes boisées, de vignes, de prairies et de cultures, dans lequel on n'apercevait pas le moindre rocher; détail sans doute essentiel pour constituer un paysage accompli dans les idées de Pline, qui ne sont plus les nôtres. La propriété était entourée de murs que dissimulaient des palissades de bois et de lauriers, le tout disposé en contre-bas, de manière à dégager de toutes parts la vue des alentours. Elle 
renfermait de nombreux spécimens de sculpture végétale. Ce genre de décoration, mis à la mode du temps d'Auguste par un amateur nommé Matius, avait singulièrement développé l'art ou l'industrie des jardiniers topiaires, tondeurs ou ciscleurs d'arbustes. Pline montrait avec orgueil à ses hôtes, des parterres à compartiments formant diverses figures de géométrie; des buis façonnés en boules, en lettres com-

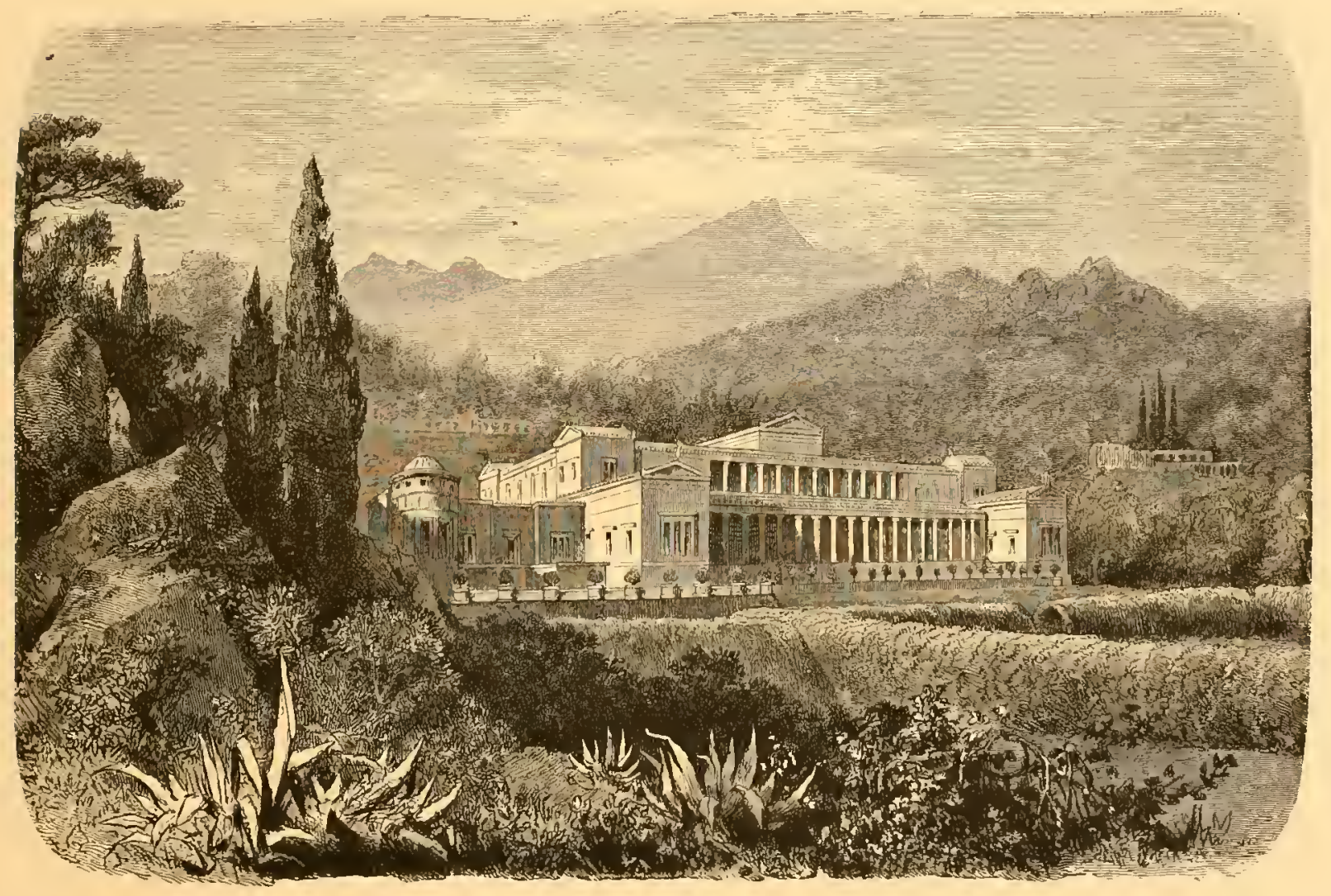

Fig. 31, - Villa de Pline, d'après une Restauration, par Schinkel (Iroyez p. 30).

posant des mots entiers, tantôt le nom du propriétaire, tantôt celui de l'ouvrier; en animaux de grandeur naturelle se faisant vis-it-vis. Ces tours de force puérils étaient déjà un signe de décadence. L'une des parties les plus intéressantes de ce pare était l'hippodrome, grand parallélogramme coupé d'un bout à angles droits, et aboutissant de l'autre à un labyrinthe en hémicycle terminé par une plantation de cyprès. Les deux grands côtés étaient bordés de platanes que reliaient entre eux des festons de lierre, genre de décoration fort heureusement imité de nos jours dans l'avenue de la fontaine de Médicis, au Luxembourg (I).

(1) Les labyriuthes plantés, déjả connus des Grees, étaient une dérivation des labyrinthes bailis d'Égypte et de Crète. 
Ces jardins étaient encore remarquables par l'abondance et la beauté des caux, et par la singularité de certains jeux hydrauliques. Pline était surtout fier d'une pièce de marbre sculpté figurant un de ces lits de jones tressés qui servaient pour les repas (stibadimm). L'au, jaillissant de la partie inférieure du stibadinm, comme sous la

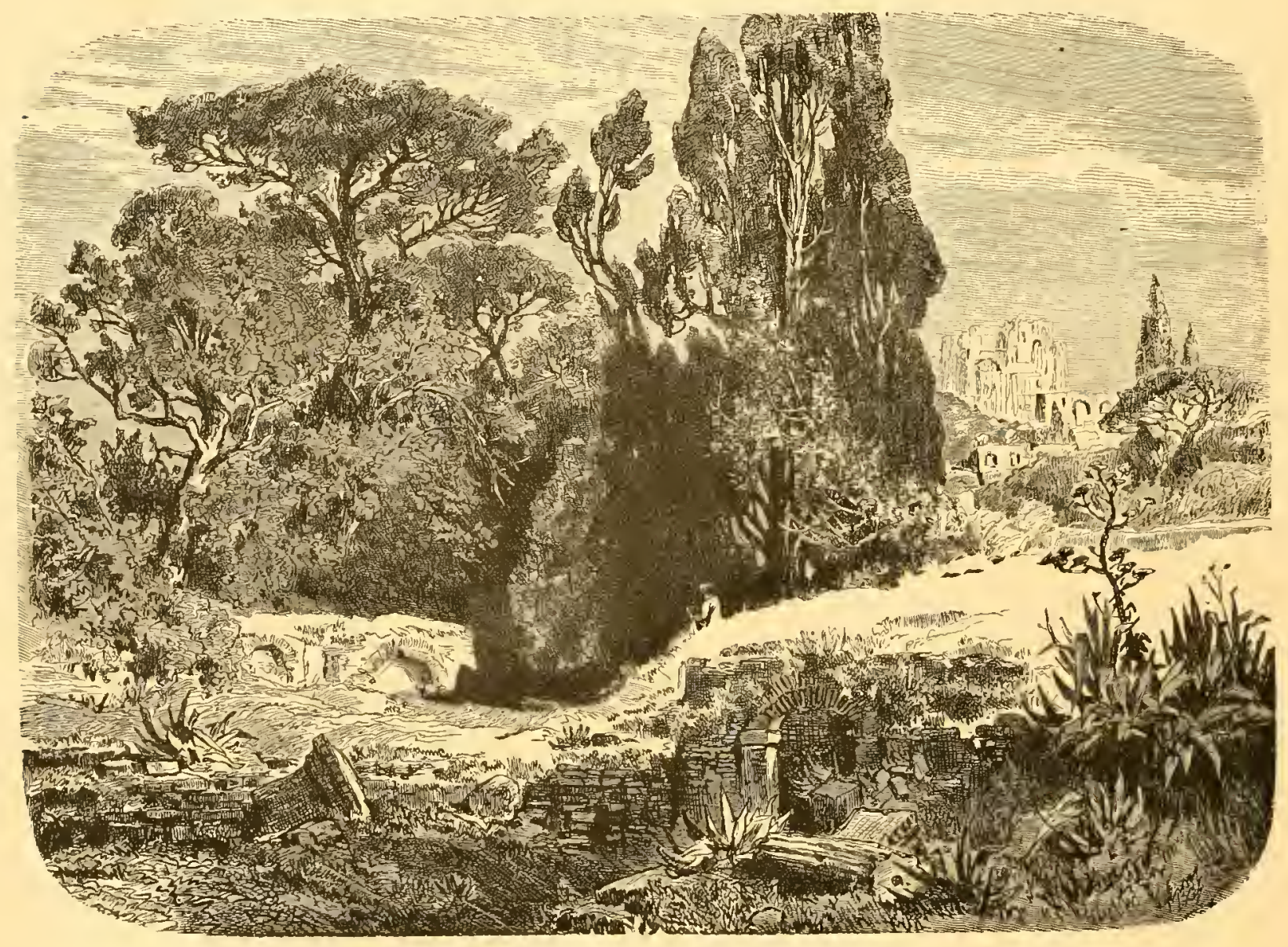

Fig. 32. - Vue actuelle de la Villa Adriana, prés Tivoli.

pression des convives, retombait dans un bassin. Ces artifices mécaniques et ceux de sculpture végétale n'ont été que trop souvent reproduits dans les temps modernes.

Ces descriptions des villas et jardins de Pline sont si détaillées, si précises, que Scamozzi, Fílibicn, et d'autres artistes habiles, ont pu en recomposer des plans assez vraisemblibles.

La colossale villa Adridna (Fig. 32), édifice quelques années aprés, était bien en effet une ville de plaisance, ou plutôt une ville-musée. Cet empereur-artiste y avait rassemblé des reproductions des sites et des monuments les plus fameux de l'empire. 
On y voyait un theître grec, un thèître latin, des imitations grandes comme nature du Poecile, du Lycée, de l'Académie, de la vallée de Tempé; une Naumachie, des temples de différents pays et le différentes formes; les Enfers même n'y étaient pas oubliés. C'était, dans un périmètre de dix milles, la concentration des merveilles du monde connu. Mais, en ce monde, "les plus belles choses ont le pire destin »;

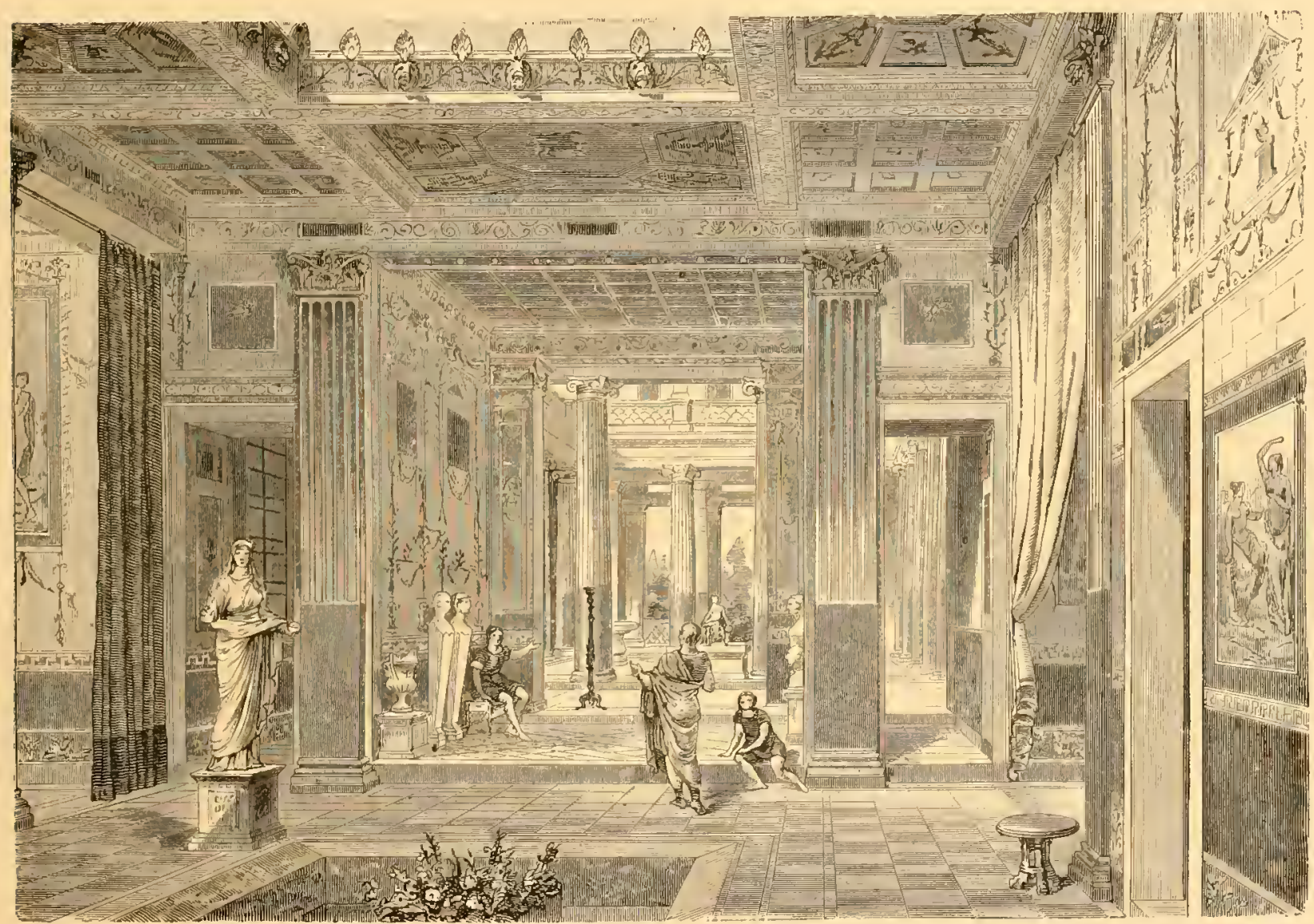

Fig. 32. - Restitution d'un Intérieur d'une Villa romaine; au fond le Jardin.

celle-là n'a pas échappé à cette loi inflexible. Pilléc par les Empereurs de la décadence, saccagéc par les rois harbares, ou, pour comble d'opprobre, habitée par cux; cnsanglantée pendant les guerres civiles du moyen âge, transformée en carrière pour la construction du moderne Tivoli, la villa d'Adrien a subi, sous toutes les formes, les caprices destructeurs de l'homme, plus redoutables que ceux du temps. Mais il y avait lá une telle accumulation de richesses artistiques, qu'on n'a pu ni tout enlever ni tout anéantir. Les fouilles pratiquécs sur cette colline nous ont restitué bien des restes précieux de l'art antique, à commencer par la Vénus de Médicis. Aujourd'hui 
cncore, l'emplacement si bien choisi par Adrien fournit de beaux sujets d'étude aux paysagistes, avec ses perspectives d'une mélancolie grandiose sur les montagnes et la campagne romaine; ses arbres séculaires, cyprès, yeuses, pins parasols, dont les racines s'enlacent peut-être $a \dot{a}$ des chefs-d'œuvre encore inconnus.

Dans sa correspondance, Sidoine Apollinaire parle de plusieurs villas galloromaines considérables qui, par conséquent, existaient encore dans la seconde moitié $\mathrm{du} \mathrm{v}^{\mathrm{e}}$ siècle; il était temps de les décrire (Fig. 32)! Ce qu'il en dit prouve l'incurable frivolité de cette aristocratie dont les jours étaient comptés. Dans son œurre poétique, plusicurs pièces sont des dithyrambes en l'honneur des villas de ses amis. On y trouve çí et là, parmi bien des traits emphatiques et de mauvais goût, un sentiment délicat et profond des beautés de la nature.

On voit, par ces diverses descriptions, que les Romains n'employaient qu'un nombre assez restreint d'espéces d'arbres, d'arbustes et de fleurs. Ils n'avaient guére dans leurs jardins, en fait d'arbres, que des platanes, des peupliers, des mûriers, des figuiers, des cyprés, des pins parasols. Leur fleur favorite était la rose, mais ils ne connaissaient que celles qui fleurissent une fois l'an, sauf une seule variété remontante, celle de Poestum.

Néanmoins les grands amateurs trouvaient moyen d'avoir des roses toute l'année, en collectionnant les variétés de l'Asie, de la Grice et de l'Italie, depuis les plus hâtives jusqu'aux plus tardires. L'une des plus estimées était la rose à cent feuilles, aujourd'hui trop dédaignée. Les jardinıers romains dissimulaient les tiges épineuses des rosiers en les mêlant aux lauriers, dont les roses semblaient un produit nouveau.

Les Romains affectionnaient aussi les violettes, les pervenches, les parots, les lis. Pline l'Ancien donne une recette pour obtenir des lis d'un rouge pourpre aree de la lie de vin. On roit aussi dans cet écrivain (xix, 5) que ses contemporains connaissaient l'usage des serres vitrées en talc. Sénéque dit également (Ép. I 22) qu'on faisait violence il la nature en faisant éclore des fleurs en plein hiver, fomento aquarmm calentimn; ce qui signifie au moyen d'eau chaude circulant dans des conduits, et non pas en arrosant les plantes arec cette eau, comme l'ont cru quelques latinistes peu pratiques.

On faisait aussi, dans les jardins, un grand usige de l'acanthe, notamment au pied des lits ou bancs de gazon, oú ces feuilles molles, épaisses et rampantes, for- 
maient une sorte de tapis naturel. Cette plante était évidemment une de celles que les sculpteurs et les architectes avaient constamment sous les yeux.

Tous les documents prouvent que chez les Romains l'œurre du jardinage était subordonnéc à la partie monumentale. Les architectures et sculptures régétales des topiaires étaient conçues dans un systéme régulier, mais non rigoureusement symétrique, de même que les constructions qu'elles encadraient et continuaient, pour ainsi dire, en plein air. On voit notamment, par les descriptions de Pline, que les formes extéricures des édifices étaient souvent subordonnées il leur destination aux dépens de la symétrie, et que « cette ćlasticité dans l'ordonnance des bâtiments se retrouvait dans les lignes du jardin. »

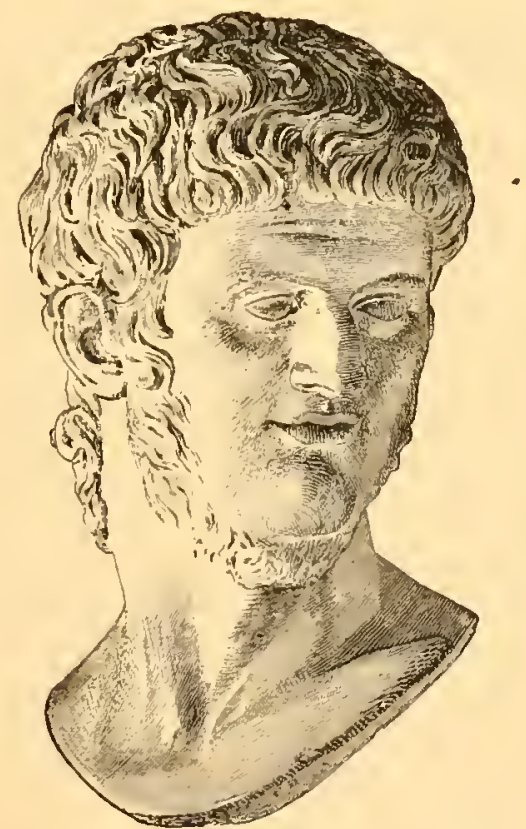

Fig. 33. - Buste de Nèron étant jeune. 


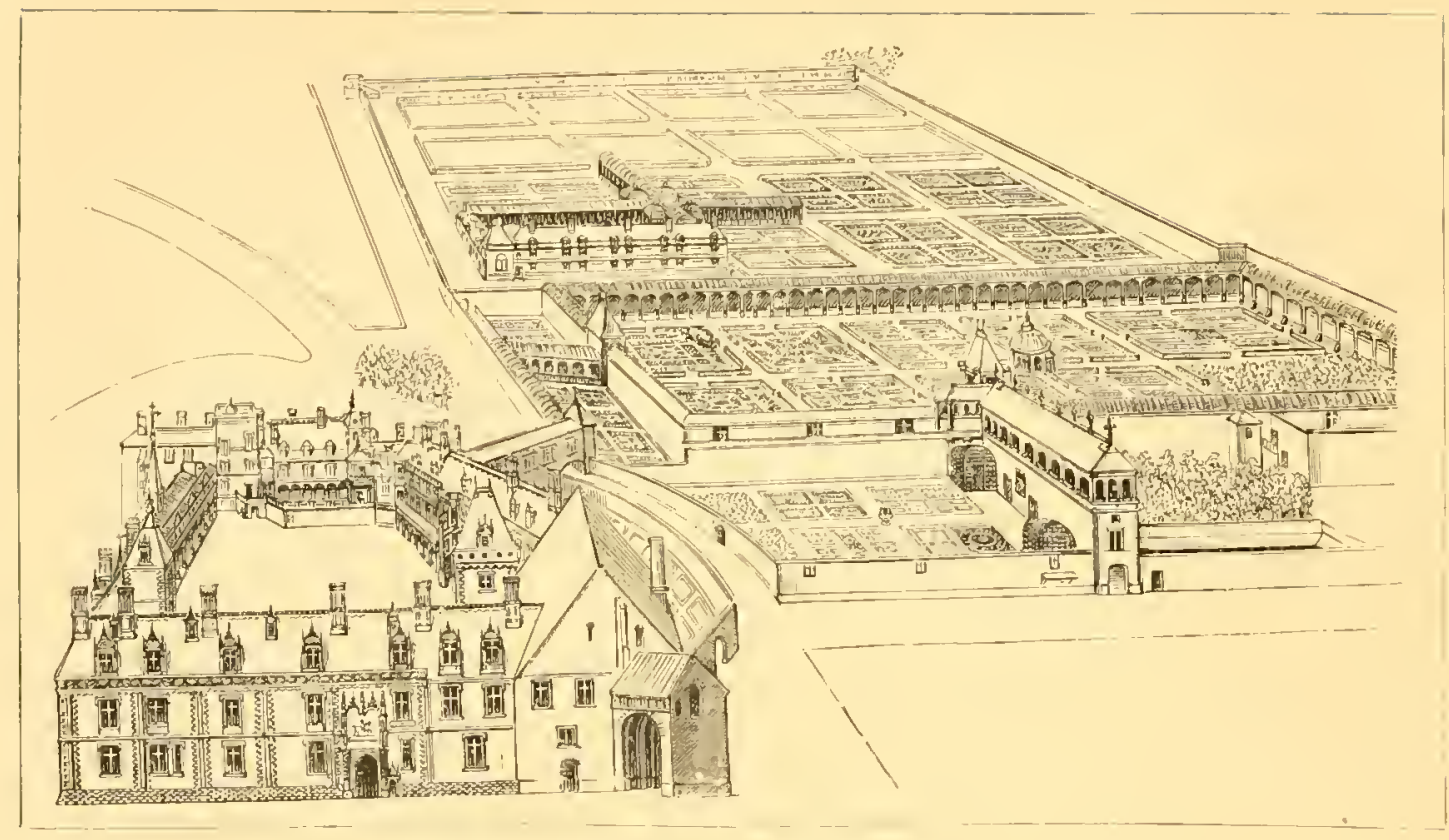

Fig. 34. - Chàteau et Jardins de Blois, d'apres Du Cerceau. (Voye; p. 62.)

\section{IARDINS DU MOYEN AGE}

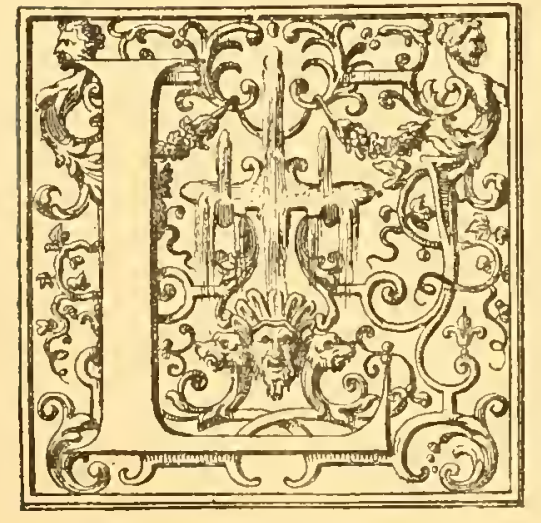

Es jardins de l'aristocratic romaine avaient disparu arec elle sous les pas des barbares. Toutefois, la tritdition n'en fut jamais completement interrompue. On en retrouvait la trace autour de certaines villas mérovingiennes, et surtout dans les préaux des cloitres (Fig. 36). L'horticulture utile fut conservie et même pousséc à un haut degré de perfection dans les grandes abbayes d'Italie, d'Allemagne, des Gaules, refuge des lettres et des arts. Parmi les jardins mérovingiens, le plus célébre est le verger de Childebert, situé sur la rive gauche de la Scine, en aval du palais des Thermes. Fortunat a célébré ses allées couvertes de treilles, ses rosiers, ses pommiers, qui donnaient, comme de raison, les meilleurs fruits du monde, ayant eu l'honneur d'être greffés de la propre main du roi.

D’aprés toutes les descriptions des jardins de cette époque, on aperçoit facilement que les idées de beauté et d'agrément en 'ee genre étaient, dans l'esprit du temps, 
inséparables de la symétrie. Ainsi l'ordonnance du "jardin tout rert », oú siégent Dídnicl et sa cour dans le roman de la Rose, est absolument régulicre en tout ce qui concerne la plantation et la distribution des calux,

\section{Sans barlololles et sans raines.}

On y entend, il est vrai, « les oisillons, faisant dans les buissons bien sentans

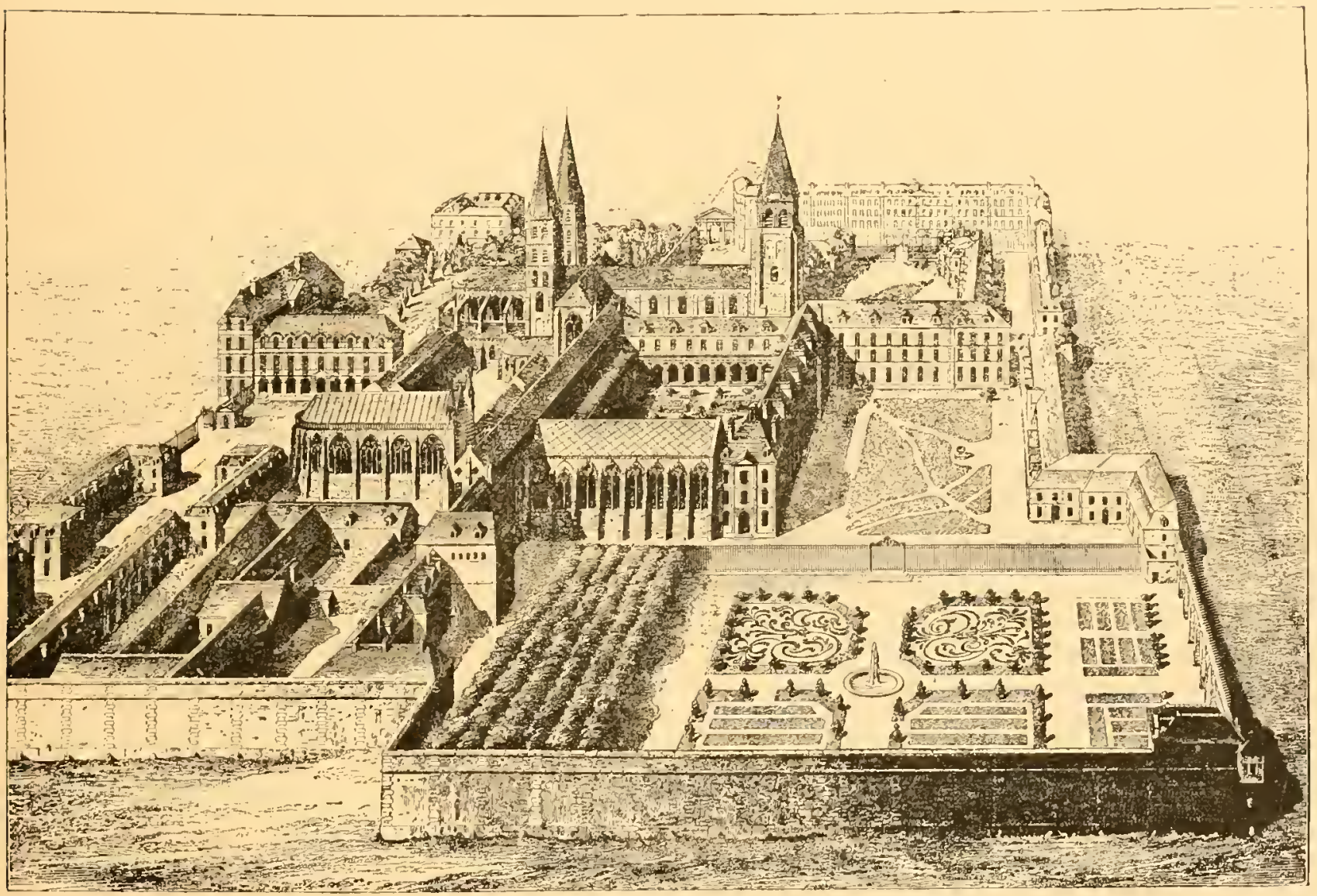

Fig. 36. - Vue de l'Abbiye de Saint-Germain-des-Prés, avee ses Jardins, - (D'après Albert tenoir.)

une musique qui pouvoit oster tout deuil. »On voit les daims et les chevreuils folâtrer sous les grands arbres; les lapins, hôtes assez compromettants d'un parc régulier,

\footnotetext{
. . . yssir de leurs tanieres

En monlt de diverses manicies.
}

Mais la tenue des jardins oú ces ébats ont lieu n’en est pas moins correcte. Les flcurs «odorantes et de haut prix » sont réparties en compartiments; on a choisi de préférence les blanches et les rouges, comme " plus franches sur toutes autres », et 
plus propres à dessiner nettement les contours. Les arbustes sont taillés en murailles de verdure, les arbres de toute espéce régulièrement plantés et alignés. La régularité domine pareillement dans l'Éden du Dicaméron, calqué, dit-on, sur le jardin d'une. villa italienne du temps. Des ailées droites, couvertes de tonnelles, y rayonnaient d'un point central, occupé par une fontaine monumentale, d'où l'eau s'épanchait en "branches admirablement tracées », etc.

Sauval a recueilli des détails curieux sur les jardins royaux du xive siècle en France, et specialement Paul, évidemment fort troubles qui suivirent le fluence de l'adminisCharles V s'étendit aux royaux. Il fit faire, entre Saint-Paul (Fig. 38 ) une qui lui coûtérent " cinq doute sur l'emplacement rue de la Corisaic. Chargnes qui garnissaient les promenade, et les tondelisées dont la rue Bcallle souvenir. Mélant l'a-

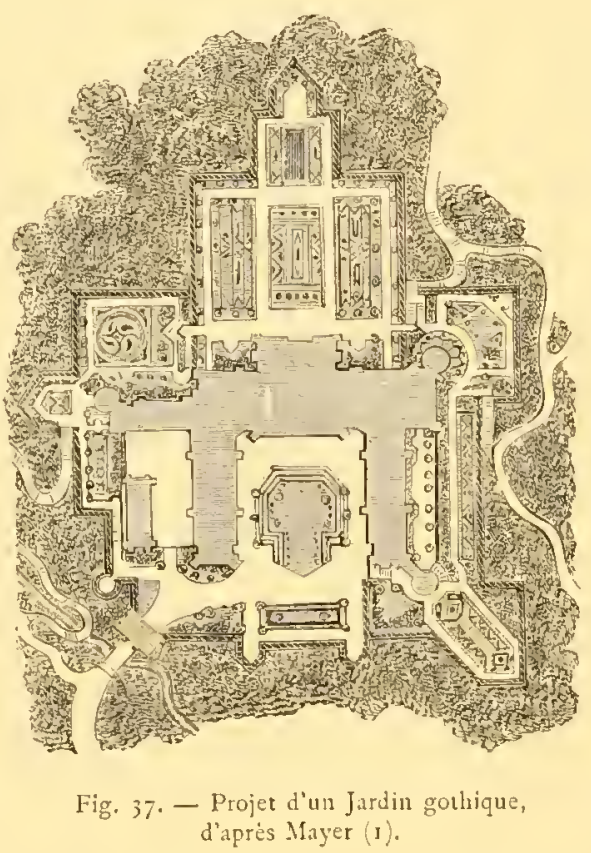
sur ceux de l'hôtel Saintnégligés pendant les désastre de Poitiers. L'intration réparatrice de potagers et vergers autres, dans celui de plantation de cerisiers sous le cent », sans qu'occupe aujourd'hui la les VI renouvela les vitreillages des allées de nelles crénelées et fleurtreillis conserve encore gréable à l'utile, il planta non-seulement des arbres a fruits, mais force roses et lis, et " huit lauriers verts achetés sur le Pont-au-Change ». C'était évidemment, à l'époque de ces travaux (I39\$), une importation toute nouvelle et de grand luxe à Paris. Bien des souvenirs historiques se rattachent à ces jardins de l'hôtel Saint-Paul. Ce fut sous ses treillis que Charles VI, le lendemain de l'entrée solennelle de sa femme dans Paris, reçut une députation de notables, costumés en ours et en licornes. Ces aimables bîtes faures apportanent au jeune couple le don de joyeuse entrée, des plats et hanaps d'or et d'argent, que le roi daigna trouver « biaux et bien ouvrez ». Isabeau de Bavière était

(1) Il ne faudrait pas prendre pour des spécimens vraiment historiques les modèles de style gothiąue donnés far Mayer, liemp et autres, dans lesquels on s'est amusé à figurer des compartinents en forme de trifles, feuilles de cliardon, etc. Nous croyons cependant devoit donner, comme échantillon de ce genre de travail, un fragment du projet de grand jardin soi-disant gothique (Fig. 37), qui fait partie de louvrage de Mayer : Die schane Galtenlimst. 
alors en pleine fleur de beauté, et les Parisiens charmés se demandaient « si elle n'était pas venue du Paradis s! On vit bien, plus tard, qu'elle n'avait rien d'angélique.

Au printemps de I $4 j \mathrm{I}$, précisément à l'époque du procés et de l'exécution de Jeanne d'Arc, le régent anglais Bedford eut la fantaisie de bouleverser de fond en comble le jardin royal de l'hôtel des Tournelles (Fig. 38). Il y replanta une grande quantite d'arbres fruitiers variés, et, comme arbustes d'agrément, des épines et trente et un bonx; c'était évidemment aussi une haute nouveauté. De plus, « il fit ouvrir neuf cents toises de tranchées, pour y planter 5,9I 3 ormes qu'on amena par eau au port de l'École et qui coûtaient quatre livres parisis le cent; si bien que pour le nouveau plant il fallut arracher les haies d'un labyrinthe appelé la Maison de Dedalus, dont on fit joI quarterons de cotrets; 》) ce qui semble bien indiquer que l'antique tradition des labyrinthes dans les

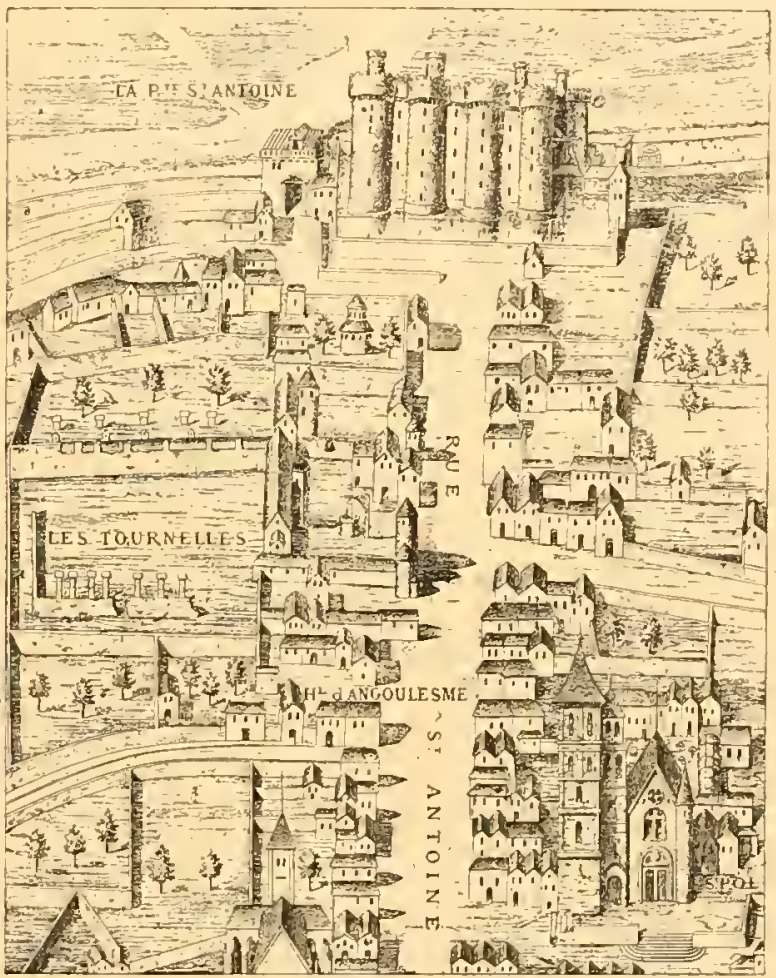

Fig. 38. - Hótel des Tournelles et partie du Quartier Saint-Paul, vers I540, - D’aprés le Plan de la Tapisserie. jardins ou promenoirs n'avait jamais été interrompue. Tous ces traviux avaient évidemment pour but d'affirmer la prise de possession de Paris et du royaume. C'était du jardinage politique, comme celui des Grands-Mogols. La fortune des Anglais n'en

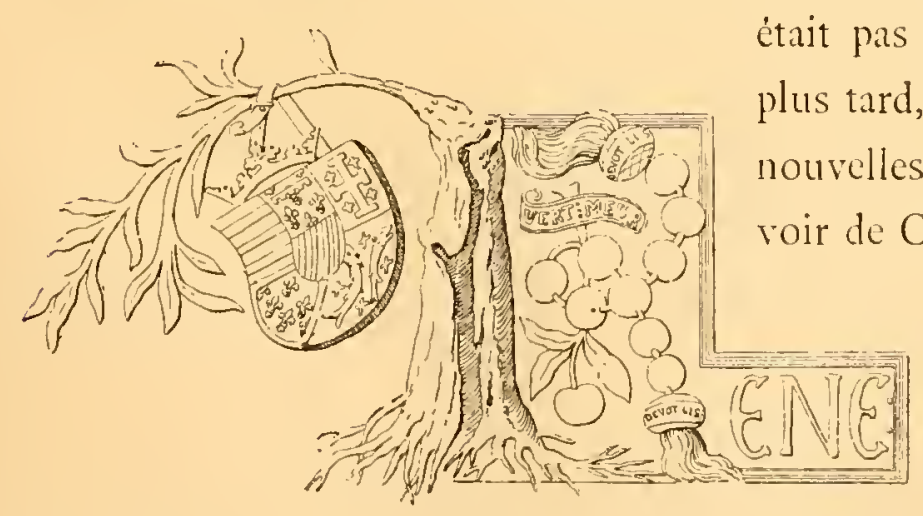

ENÉ d'Anjou a enfin créé les derniers jardins du moyen âge, qu'il serait bien injuste d'oublier.

Dans l'intéressante monographie qu'il a consacréc à ce prince artiste, M. Lecoy de la 
Marche cite plusieurs documents qui attestent sa sollicitude pour ses « jardinaiges. » Il y avait au château d'Angers un grand et un petit jardin, que René orna tous deux de treilles " en charpenteric hien ouvrées, belles et bien faites ». Suivant M. Lecoy, " le grand jardin offrait quelque peu l'aspect naturel et pittoresque des jardins anglais modernes (I). " Cependant, les pịceces qu'il cite semblent plutôt donner l'idée d'un jardin régulier, comme on l'entendait alors. "On y voyait de petits prénux de gazon, des allées soigneusement ratissées et des roucs, e'est-i-dire des corbeilles ou parterres ronds, bordés de clisses de bois. "Dans le mémoire de Desbans, concierge du château, retrouvé aux Archives nationales, on remarque les articles suivants: " $\mathrm{X}$ sols pour mote et ouvriers à faire le petit préau du grant jardin. - Item, II sols 6 deniers pour achat d'une clisse de boys jardin. - Item, pour six homaudit grant jardin ung jour enmote, pour lier lis vigne et que grimpantes?), necticr (netpetit jardin, pour paye et desencore parmi les ceuvres d'horimitation de la Sainte-Baume toresque, aux environs d'Ansurtout ceux d'Aix, son séjour

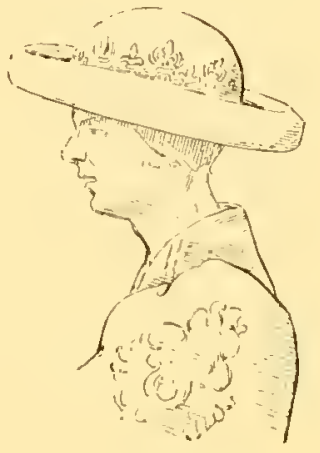

Fig. 40. - Portrait du Roi René, d'aprics un Manusirit d'Albi.

pour habiller la roe du grant mes jardrincurs qui ont esté ticr pour couvrir ladite roe de falloit i lier (d'autres plantes toyer) les allées du grant et pens XX sols (2) ). Il fiut citer ticulture de René, La Bammelle, de Provence, dans un site pitgers, et ses jardins de Provence, favori dans sa vicillesse. La « se mit a planter, enter arbres, édificr tonnelles, purillons, vergiers, galeries, jardins... Entre ces louables passe-temps usant le rieux prince ses jours, entroublioit et mettoit arriere les causes de sa mélancolic, et dist plusicurs fois aux princes et ambassadeurs qui le venoyent visiter, qu'il aymoit la rie rurale sur toutes les autres, parce que c'estoit la plus seure façon et manière de vivre, et lia plus lointaine de toute terrière ambition. » (Bourdigné.)

A dire vrai, les jardins de René se ressentaient fort de son séjour à Naples. La Baumette, les bastides d'Aix et de Marseille ne ressemblaient déjal plus guére aux maussades promenoirs de nos châteaux encore militaires, qui, dans leur morgue

(i) Le Roi René, t. 1I, P. 9.

(2) L'entretien des jardins d'Angers était primitivement confié à un jardinicr spécial payé quarante livres par an. Le concierge Desbans fut chargé de ce soin quand René se retira définitivement en Provence. Il y avait aussi au chảteau de Baugé des jardins soigneusement entretenus, avec un Dedalıs. 
féodale, "semblaient dédaigner, éloigner la campagne et le travail des champs, la terre des serfs!! »

On retrouve au contraire, dans ces créations de René, sinon un sentiment défini des beautés du paysage, du moins cette admission familière des jardinages s'étendant librement en cultures variées autour des promenoirs royaux; - ce mélange d'art et de nature, de ménage clampétre, dont il avait pu voir les premiers modèles en Italie.

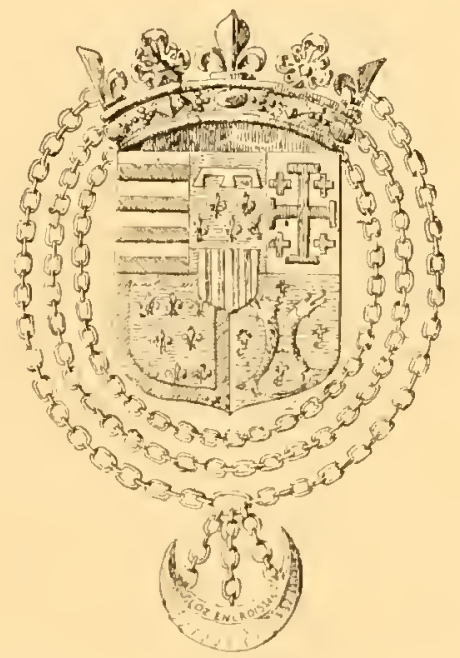

Fig. 4t, - Armoiries du Roi René. 


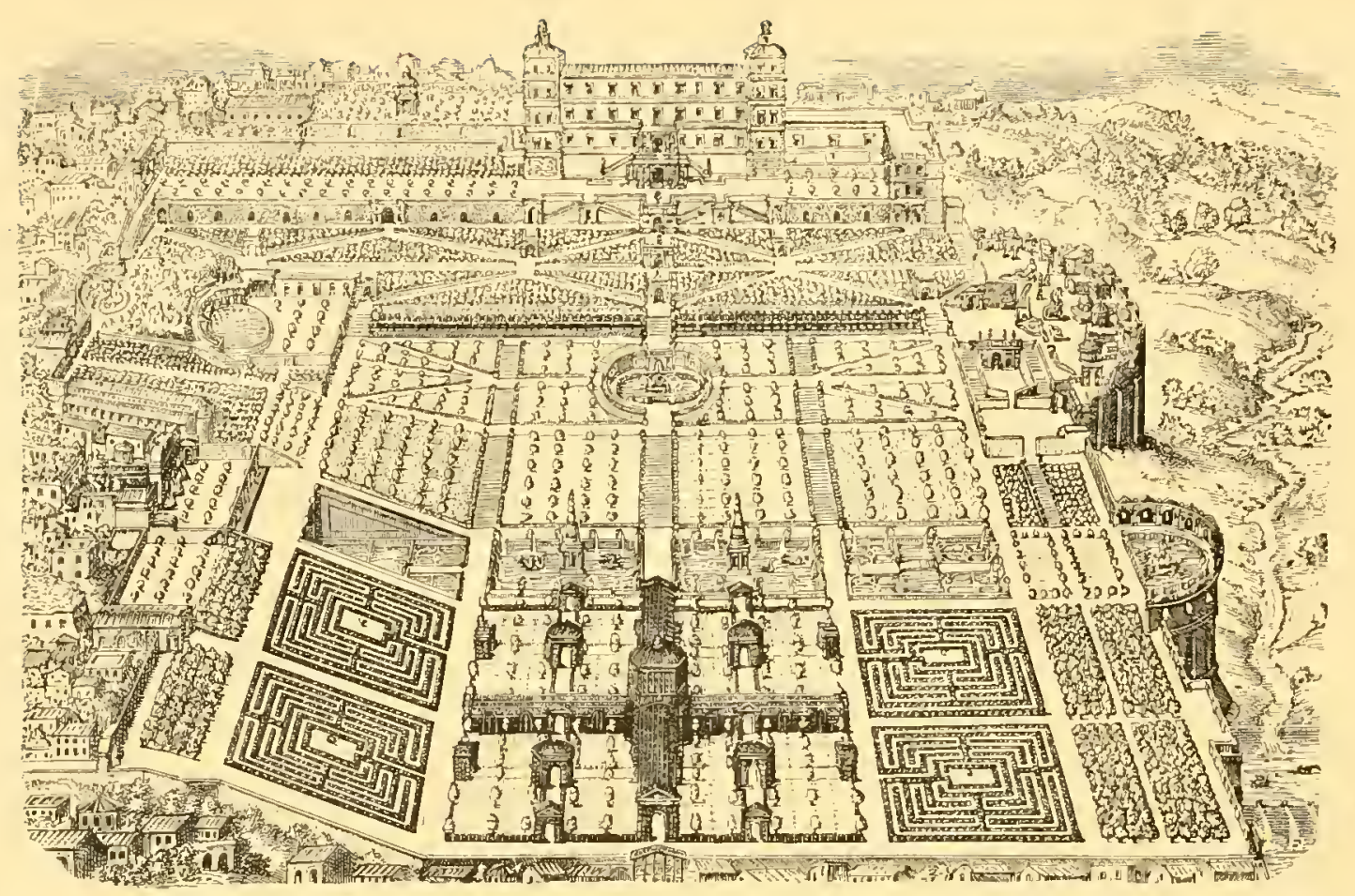

Fig. 42. - Vuc générale de la Villa d'Este. (Ioycr Vues de Détail, pages 57 et 58, et le Texte, page 55.)

\section{JARDINS ITALIENS DE LA RENAISSANCE}

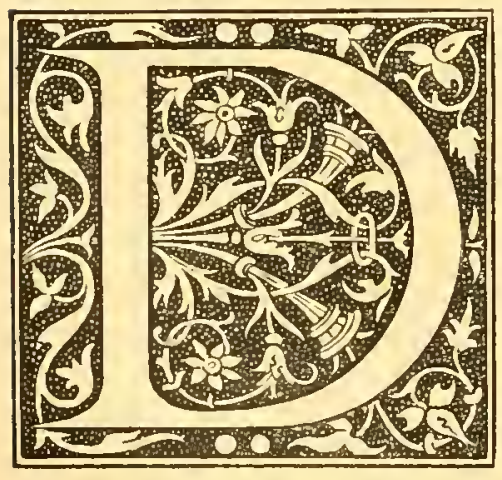

ES terrasses áriennes, des jardins suspendus, les vues les plus varices. Tout prés, l'idylle du ménage des champs. Aux jaillissantes caux des fontaines de marbre, le cerf arce la vache, venant le soir sans défiance; de grands troupeaux au loin en liberté; la fenaison ou les vendanges, une vie virgilienne de doux travaux. Tout cela encadré du sérieux lointain des Apennins de marbre, ou des Alpes aux neiges iternelles.

"L'hiver n’ôte rien à ces paysages. L'abandon même et les ruines y ajoutent un charme nouveau. Dans les jardins oú cesse la culture, les grandes vignes laissces en liberté semblent se plaire en l'absence de l'homme. Elles sont maîtresses du logis, s'emparent des colonnades, se prennent aux marbres mutilés et caressent les statues reures. Tout cela trés saurage et très doux. »

C'est ainsi que Michelet a exprimé d'une manière à la fois juste et poétique 
l'impression que produisent encore aujourd'hui, malgré leur état d'abandon, ou plutôt á cause de cet abandon, les palais de plaisance et les jardins italiens de la Renaissance. Les grands architectes de ectte époque, en imitant le style des édifices de l'antiquité, reproduisaient d'instinct, en quelque sorte, comme complément d'ornementation, les parterres, les terrasses ornées de vases et de statues, les portiques et arceaux de verdure, les piéces d'caux machinécs. Ce qui a péri ou vicilli dans ces créations, c'est précisément ce qui fut le plus vanté d'abord, les concesssions aux caprices de la mode (comme les fantaisies et les surprises hydrauliques). Ce qui reste aujourd'hui le grand et puissant attrait de ces jardins, c'est qu'ils ont été, ìl'époque moderne, la révélation de l'art du paysage. Ce ne sont plus de simples promenoirs circonscrits, isolés. "On a réalisé un majestueux décor autour de l'habitation, et

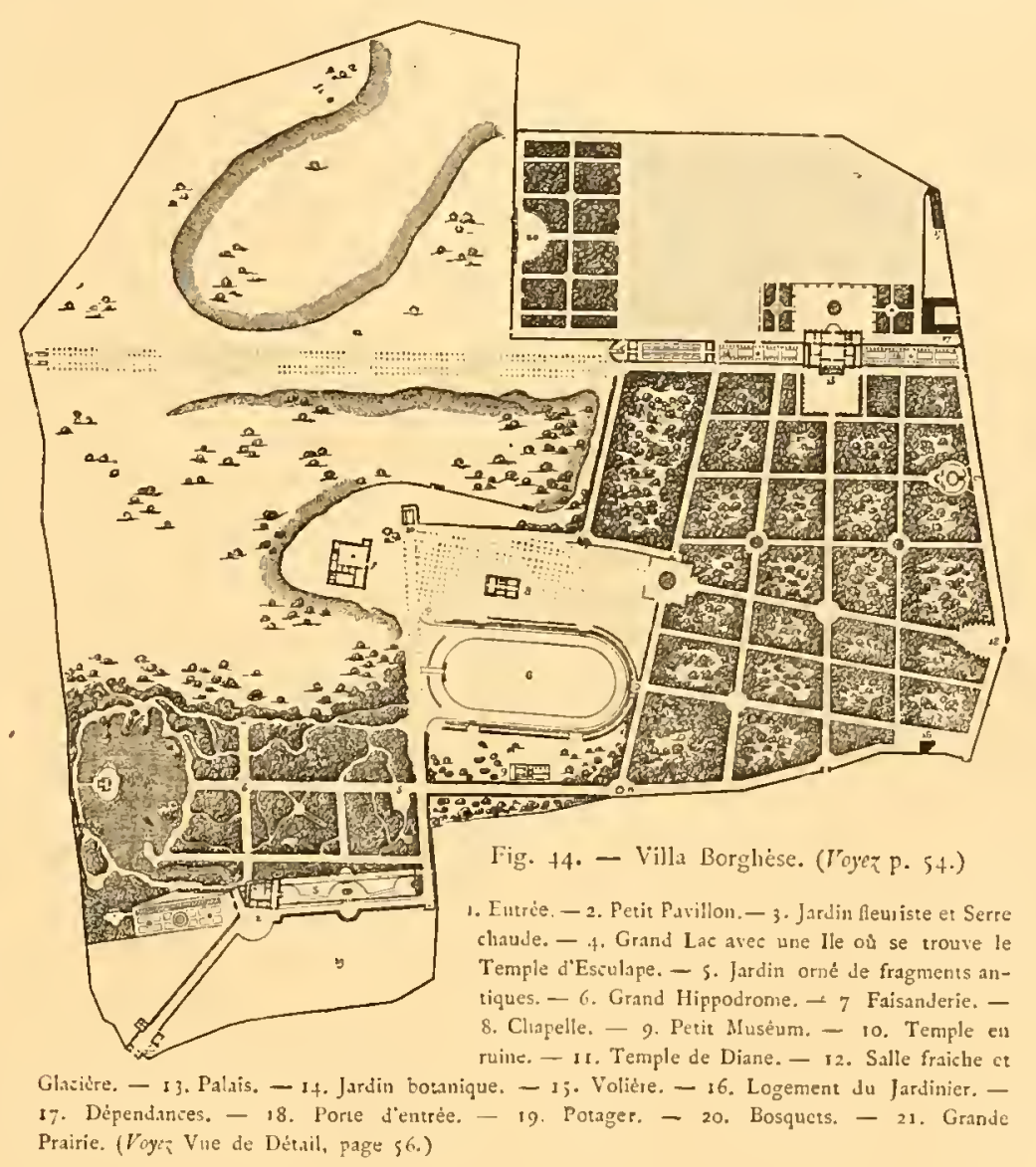
ouvert de larges accés pour

la vue aux perspectives du dehors. On a fait fête à la nature; on l'a comprise et aimée. On a étudić ses effets gracieux ou grandioses; on est arrivé enfin au vrai sentiment de l'art. " Les grands seigneurs de la Renaissance prenaient quelque plaisir à contempler l'œurre humble et féconde du serf, que dédaignaient leurs farouches prédécesseurs. Il est vrai qu'ils n'en étaient pas bcatucoup plus tendres pour le serf lui-même.

Ces jardins sont génćralement disposés en amphithéâtres sur des pentes. Soit qu'ils s'élévent au-dessus de l'habitation, soit qu'au contraire celle-ci en forme le couronnement, ils offrent toujours des terrasses, de vastes escaliers, des chutes d'eau; 
souvent aussi le relief du sol nécessite des allées obliques ou tournantes, qui rompent

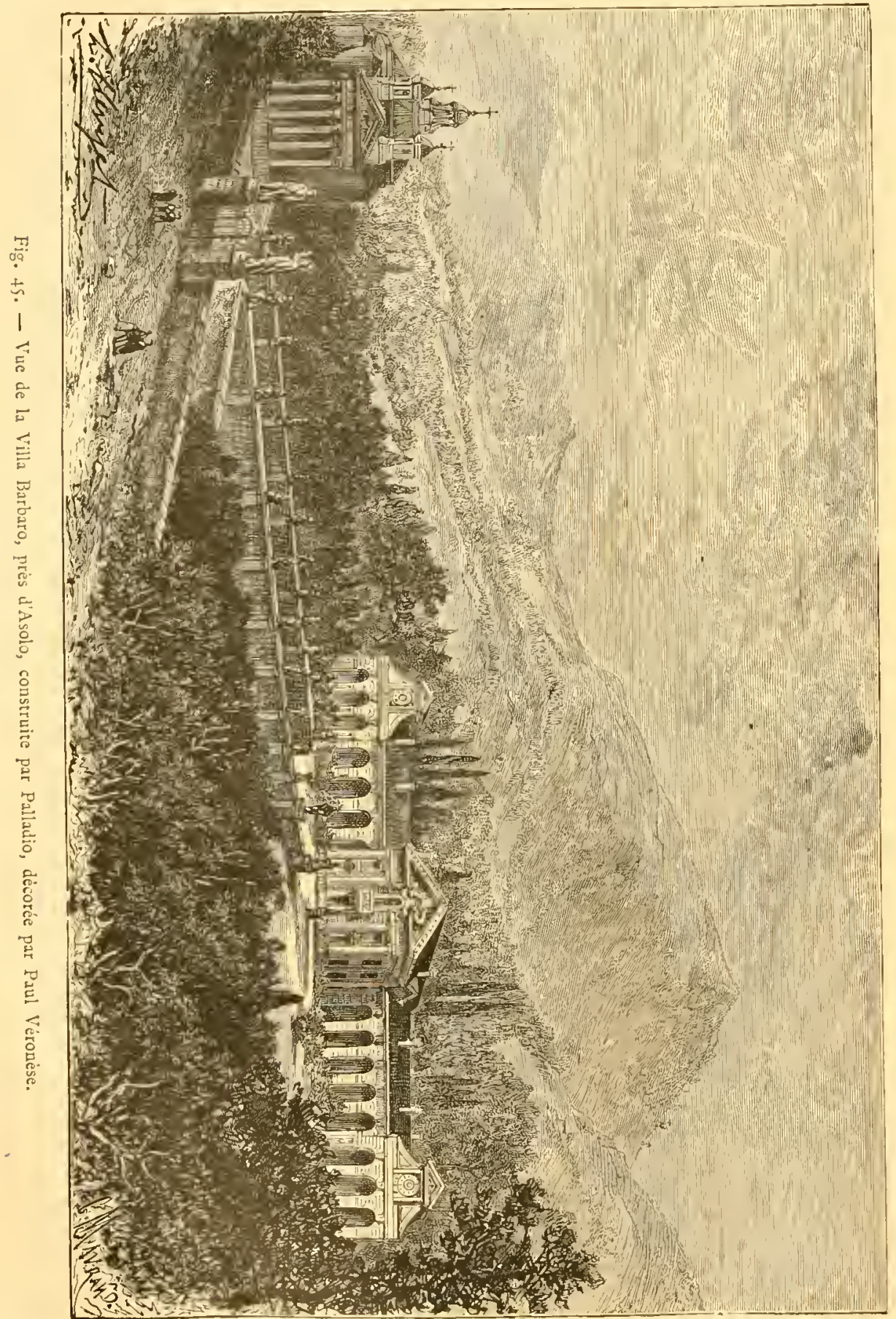
la monotonic. On peut dire que, saut l'intérêt spécial des objets d'art de valcur trés diverse (1), amassés souvent avec profusion dans ces pares de la Renaissance et de l'âge suivant, qui en a ru cinq ou six les a vus tous. Nous nous bornerons done à mentionner ici les plus intéressants par la beauté des sites et des caux, comme par les souvenirs qui s'y rattachent. Parmi ccux de l'Italie du Nord, la première place appartient à celui du palais Giusti (Veronetta), "que la nature a assez bien servi (Fig. 46), dit de Brosses, pour lui donner dans son jardin même des

(1) Beaucoup de ces débris ćtaient, clez les anciens, des cuvres de pacotille; " ce quui subsisterait chez nous si, après un long enfouissement, on retrouvait des stattes d'escaliers et des bustes d'hótel de ville. " C'est l'observation fort juste de M. Taine (Vovage en Italie, 1, 298.) 
rochers, au moyen desquels on a des grottes et des torrents sans fin, surmontés par de petites rotondes ouvertes de tous còtés sur la ville et sur tout le pays coupé par le cours de l'Adige. A gauche, la vue ne se termine pas, et id droite les montagnes du Tyrol l'arrêtent. Outre cela, la quantité de cyprés prodigieusement hauts et pointus lui donnent l'air d'undecesendroits où les magiciens tiennent le sabbat. Il y a un labyrinthe. J'y fus plus d'unc heure au grand solcil à tempêter, sans

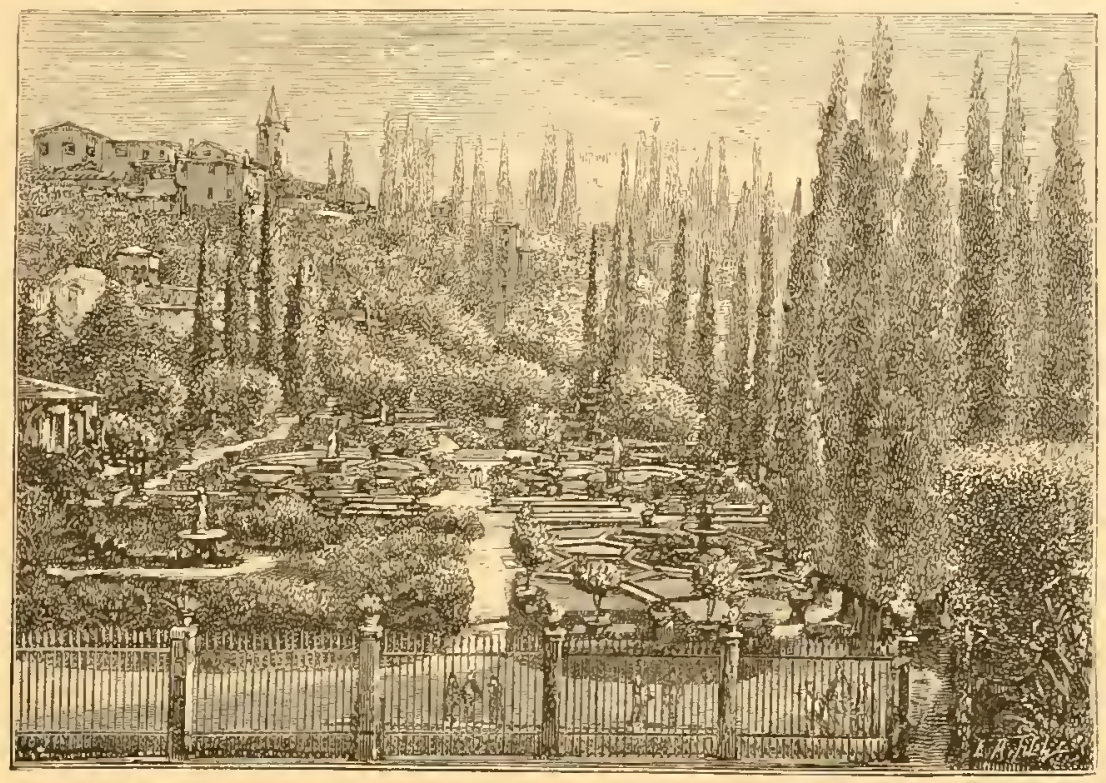

Fig. 46. - Vue des Jardins du Palais Giusti, à Vèrone. - Etat actuel d'apres une Photographie.

pouvoir me retrouver. » Ces jardins n'ont guère été entretenus depuis lal visite du spirituel magistrat dijonnais, mais ils y ont plutôt gagné que perdu. "La végé-

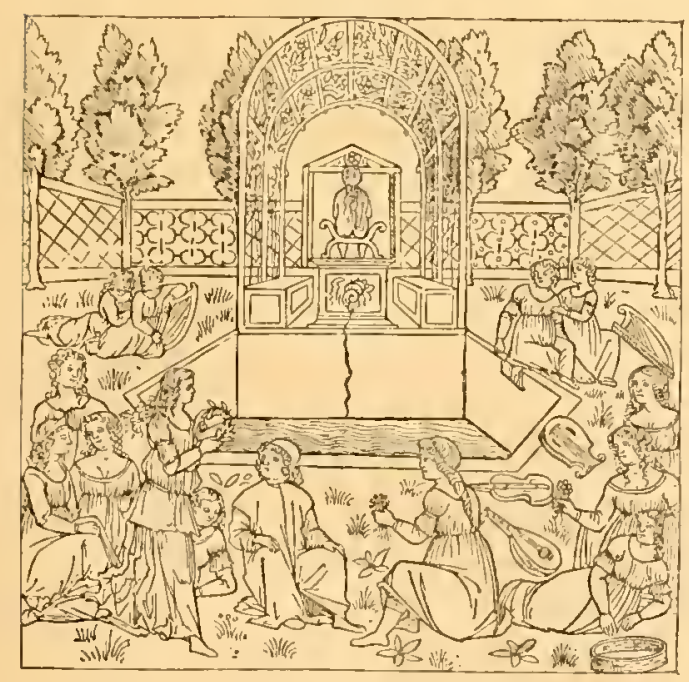

Fig. 47. - Discours du Songe de Poliphile. (Paris, MDLXII) tation y est superbe, dit un touriste de 1878 . De beaux arbres, laturiers, citronnicrs, oliviers, au milicu desquels percent les noirs eyprés, escaladent la colline. On monte pur un lacis de sentiers se perdant sous les arbres, toumant les pelouses et longeant des terrasses oú des statues quelque peu écornées disparaissent à demi sous les plantes grimpantes. Plus haut, le sentice s'escarpe davantage, de petits escaliers aux marches tremblantes montent a la terrasse supéricure. Dans le massif, encadréce par un fouillis de branches et de lianes, s'ouvre une grotte oú murmure un filct d'eau, lé scul bruit qu'on entende arec le frétillement des lizards. De là toute la surface du jardin s'aperçoit sous le grand soleil, les énomes eyprés 
donnent de larges masses d'ombre; et, par dessus le palais, les rouges tours de Vérone se profilent sur un cicl superbe. (Les vicilles villes d'Italie, p. 289.) (I). 》 Non loin de là, les bords de la Brenta offraient naguère une suite d'élégantes villas

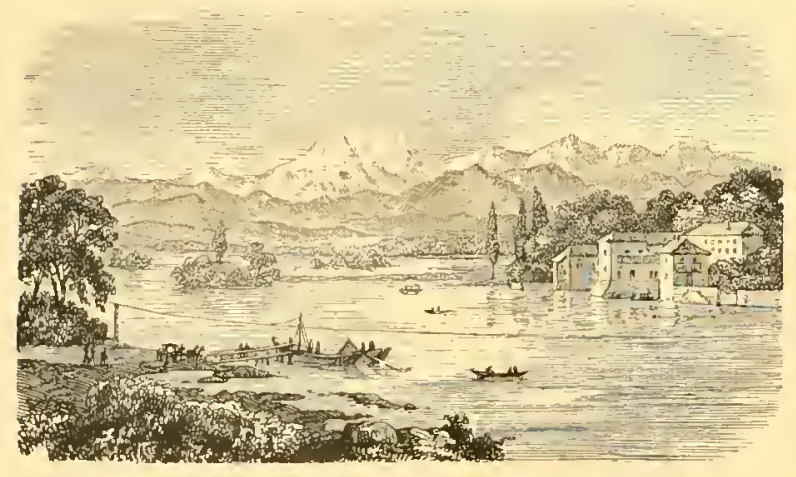

Fig. $4^{8}$. - Lago Maggiore. Sesto Callende. appartenant à des sénateurs de Venise (Fig. 45). Avant de quitter les bords de l'Adriatique, nous reproduisons une Scène dans un jardin empruntée au cèlébre Songe de Polipbile (I 499), et qui donne une idee exacte de ces jardins de l'aristocratic vénitienne dans le temps de sa plus grande splendeur. (Fig. 47, éd. de 1561, gravure par Jean Cousin.)

La plus curicuse était, dans la seconde moitic du siécle dernier, celle de Quirini; Altichicro, qu'a longuement decrite la spirituelle contesse de Rosenberg, anic trés intime du proprictaire. Le pare d'Altichicro se composait également de salles et de cabinets de verdure reliés par des allées treillagées, et dont chacun ètait le sanctuaire d'une divinité de l'Olympe (2).

Parmi les nombreuses villas du lac de Côme, charmantes pour la plupart, nous citcrons seulement les villas Sommariva et Serbelloni, remarquables, la premicre, par les objets d'art qui la décorent; l'autre, par son heureuse situa-

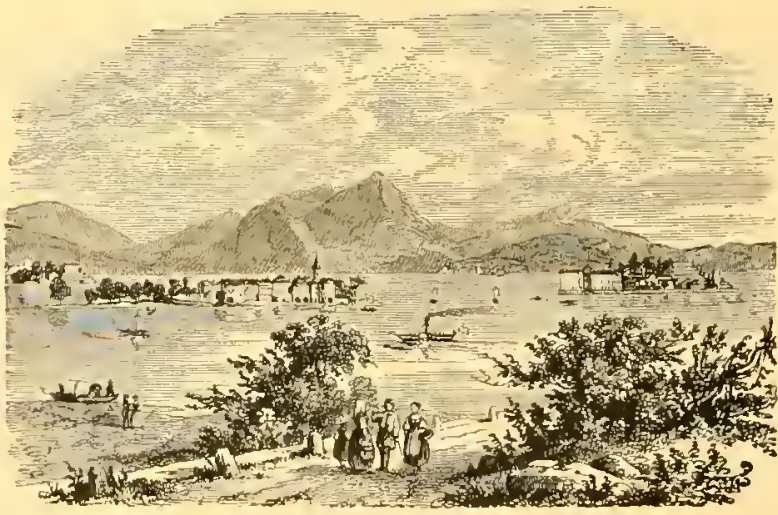

Fig. 49. - Iles Borromeses, - Vue de Baveno. tion sur un promontoire d'oú l'on jouit d'admirables points de vue sur les trois branches du lac. Cette situation ressemble si fort a celle de la villa Tragídie, de Pline, qu'on la croirait volontiers identique. 11 y a lia aussi un effet de contraste saisissant, entre cette villa si riante et la ruine d'aspect farouche qui la domine, débris

(1) De cette terrasse supérieure, on montre aux voyageurs le clamp de bataille de Custoza; on pourrait leur en faire voir bien d'autres! Il est peu d'endroits au monde oi l'on se soit plus exterminé que dans ces plaines de l'Adige.

(2) La description d'Altichicro forme un volume in- $4^{\circ}$, rare et recherché conme tous les ouvrages du même auteur. Parmi les édicules du pare, on remarque un autel lédié aux Furies, sous un berceu de vignes, a pour conjurer les rixes qu'engendre trop souvent l'ivresse $)$. 
d'un manoir féodal devenu ensuite franchement un repaire de brigands, et détruit au quatorziéme siécle par Galéaz Visconti, un de leurs collégues plus chanceux.

Sur le lac Majeur, nous citerons Sesto Callende (Fig. 48), et l'Isola Bella (Firg 49), dont la création ne remonte quà l'an I670; ct qui vit, ou plutôt végéte sur son ancienne réputation. C'est un essai d'imitation des jardins suspendus de Babylone, comme on les comprenait ì cette époque; une montagne pyramidale carrée,

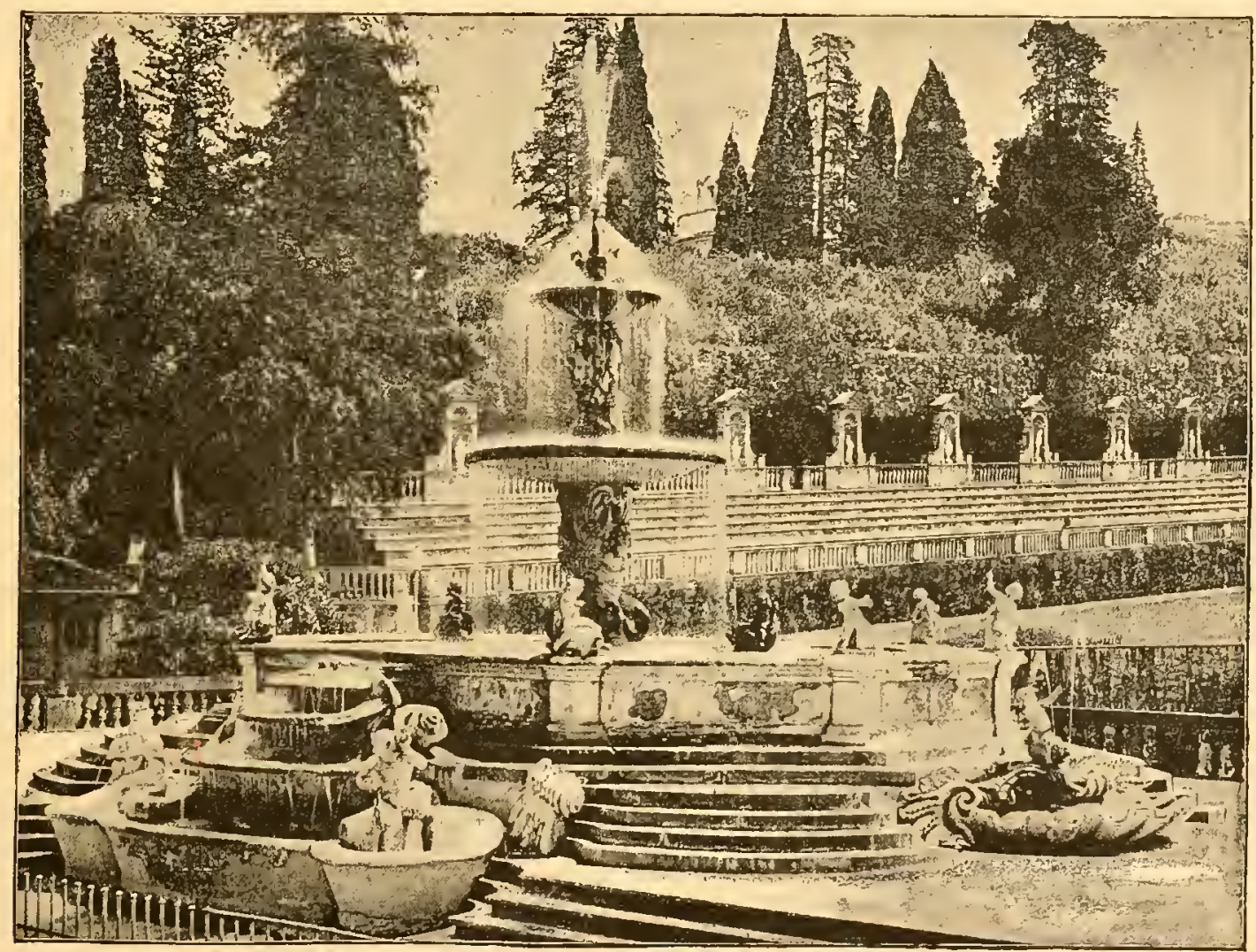

Pig. so. - Fontaine et Vue du Jardin de Boboli, a Florence.

soutenue par des arcades et découpée en terrasses. Cette piéce d'architecture végétale était encore trés admirice an xvin siécle; de Brosses y trouvait des " endroits exquis » que, pour notre part, nous y avons vainement cherchés.

Le plus célébre des pares toscans est le real Giardino di Boboli (Florence), attenant au palais Pitti (Fig. 50 et $5 \mathrm{r}$ ). Ce jardin, dessiné vers I 50 , n’a guére conservé de son tracé primitif que la terrasse qui borde la façade méridionale du palais et la longue avenue à la suite, terminée par un bassin oú s'éléve, au milieu d'un îlot, la fontaine monumentale de Jean de Bologne, représentant Neptune et deux Tri- 


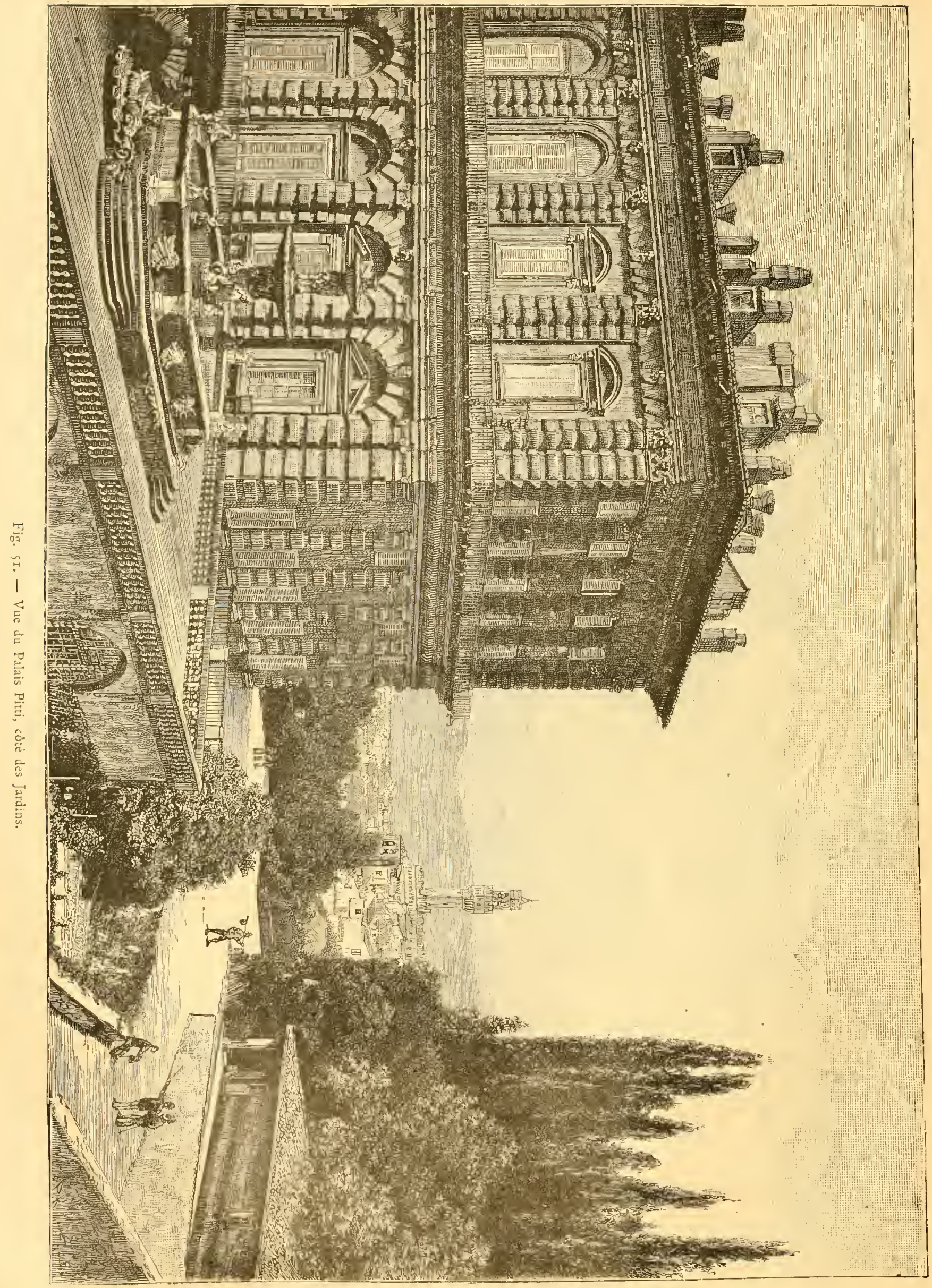


tons (Fig. jo). Cet ensemble, d'un effet assez grandiose, a donné, dit-on, lidèe de la scène principale du pare de Versailles, celle qui se déploie en face du palais et

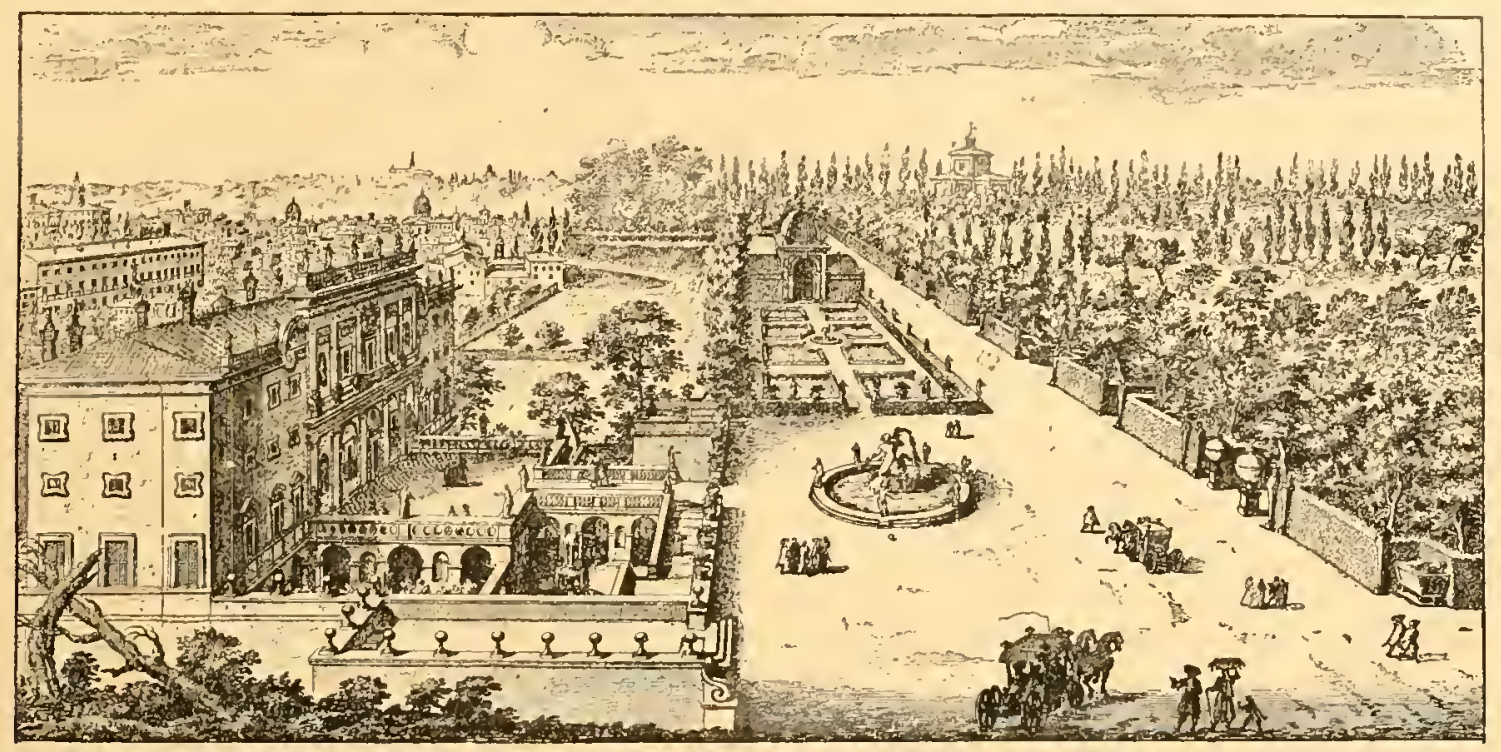

Fig. 52. - Vue du Jardiu Ludovisi. - D'aprés Giov. Battista Falda. (Foyer p. 5r.)

aboutit au grand canal. Les jardins Boboli sont resserrés à l'ouest et au sud par

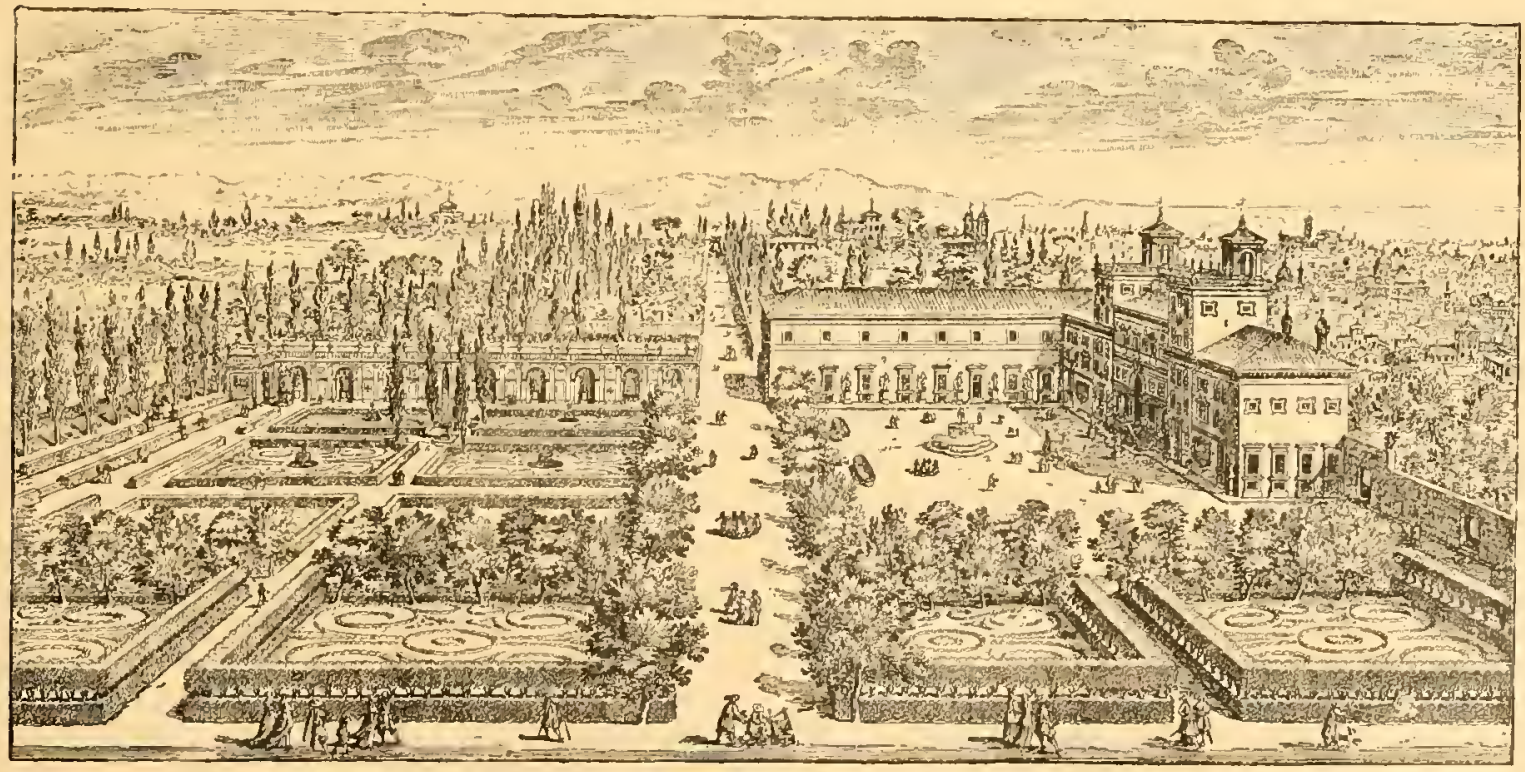

Fig. 53. - Vue des Jardins de la Villi Médicis. - Daprés Faluds. (Voyea p. 52.)

la forteresse du Belvédére et les remparts. Leur plus grande étendue est du côté de l'est, dans la direction de la Porta Romana. Cette irrégularité de forme, les acci- 
dents du sol et les variétés de cultures leur donnaient, dés le xrme siécle, une physionomie exceptionnelle. "Ces jardins n'ont pas le sens commun, écrivait de Brosses, et par cette raison me plaisent infiniment. Ce ne sont que montagnes, vallées, bois, buttes, parterres et forêts, le tout sans ordre, dessin, ni suite, ce qui leur donne une physionomic fort agréable. y 11 y a dans ces quelques lignes une sorte de pressentiment de la réaction imminente contre le style régulier.

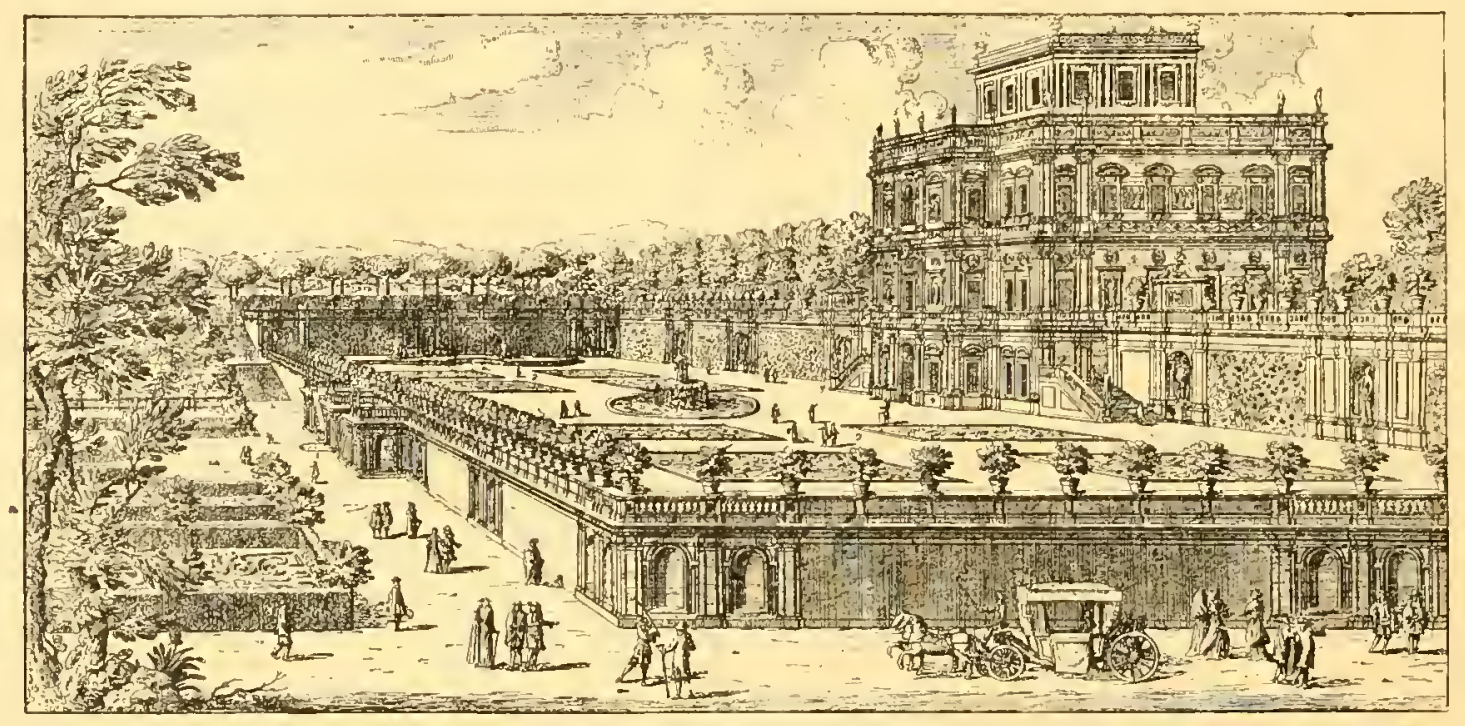

Fig. 54. - Vue de la Villa Pamphili, d'apres Falda. (Toyez p. 52.)

Pratolino ( I kil. de Florence), qui n'existe plus pour ainsi dire, mérite pourtant une place dans l'histoire des jardins. Ce domaine arait été créé et arrangé pour Bianca Capello, la courtisane rénitienne aux cheveux d'or, devenue grande-duchesse. Les jardins étaient surtout célébres par leurs jeux hydrauliques. On y voyait, de grandeur naturelle, un Jupiter lançant un tonnerre aquatique; le siége d'une forteresse, avec canons et arquebuses à eau; la Samaritaine de l'Érangile, venant remplir et remportant son amphore, et la flute hydraulique d'un dieu Pan accompagnant cette érolution, etc. » Toutes ces machines coûteuses plaisaient singulièrement ì Biancia, ct son mari, "qu'elle tenait à sa dévotion », comme dit Montaigne, n’épargnait rien pour la satisfaire. Ce fut elle qui mit à la mode les surprises hydrauliques, dont l'usage persista longtemps non-seulement en Italie, mais dans des régions oú ces douches étaient encore plus désagréables. Dans une des grottes de Pratolino, les visiteurs étaient aspergés (rien que d'eau claire, il est vrai) par des figures de Harpies... Toutes 
ces gentillesses furent reproduites, aree des variantes, dans les villas romaines. Aujourd'hui, le palais de Pratolino a disparu; le parc, abandonné, n'est plus qu'un massif de broussailles, au milieu desquelles la statue colossale de l'Apennin, seul débris de ces magnificences évanouies, épanche mélancoliquement son urne dans un marceage.

On peut citer encore, aux enrirons de Florence, le Poggio a Catano, ou mourut

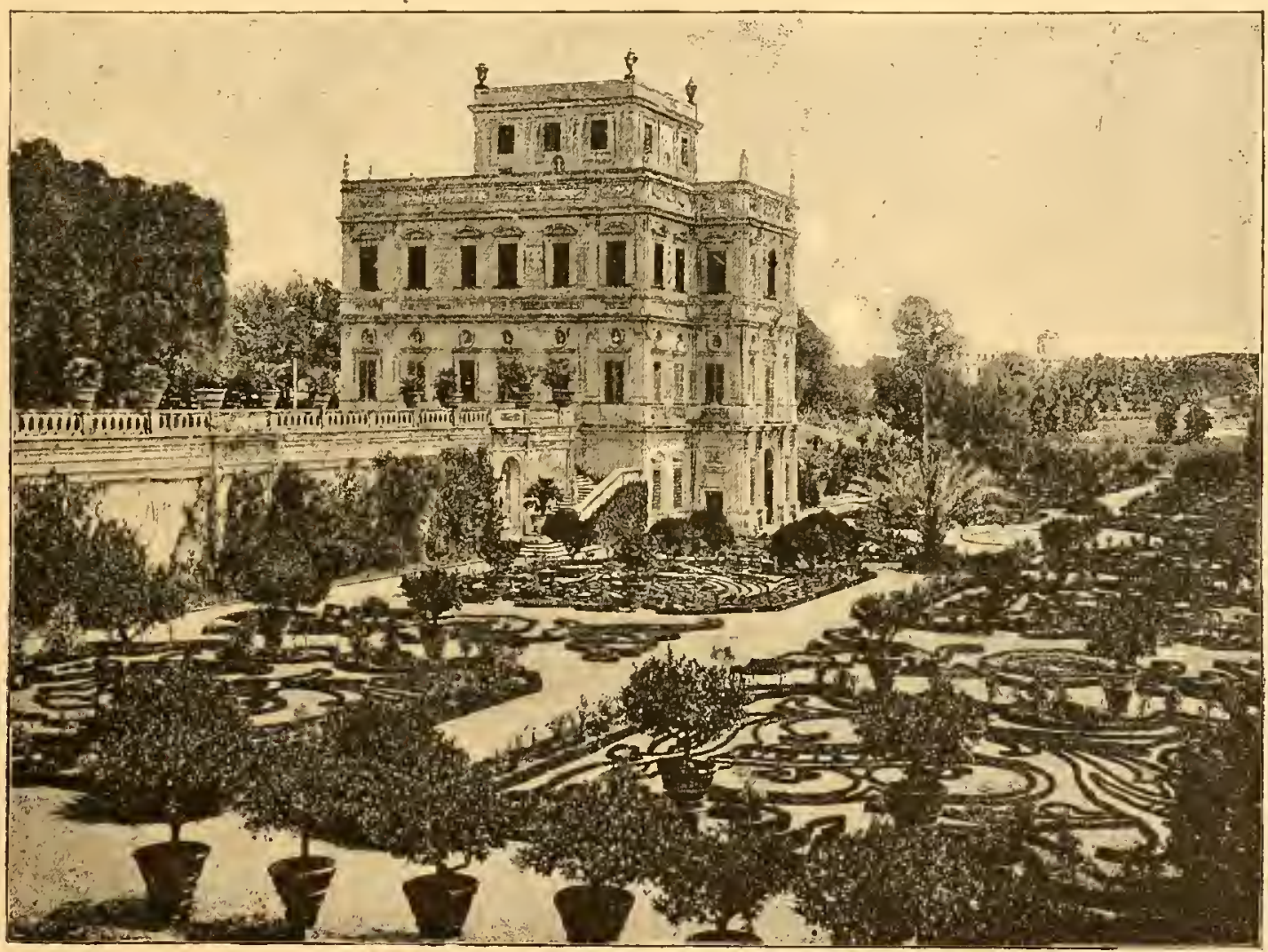

Fig. 55. - Vue de la Villa Doris Pamphili avec ses Parterres, - Etat actuel. (Voyez p. 52.)

subitement arec son mari (en 1587) cette même Bianca Capcllo, l'une de ces créatures décerantes et fatales, “ astres qu'un démon conduit»; - la villa Palmicri, qui a remplacé celle oú Boccace avait placé son Dícaméron; ielle del Giojello, qui fut la trés douce prison de Galilée.

Les villas romaines du Xrré au xvine siecle n'offrent pas moins d'intérêt. Plusieurs occupent l'emplacement de célébres villas antiques. A Rome même, les jardins de Salluste sont remplacés par le pare Ludovisi (Fig. 52), auquel servent d'enceinte les vicilles murailles de Rome; - ceux de Lucullus, de Néron et de Galba, par les 
villas Médicis (Fig. 53), Pamphili (Fig. 54 à 56), B.rbarini. Aussi les travaux de fondation, de terrassement et de plantation ont mis i jour assez d'objets d'art

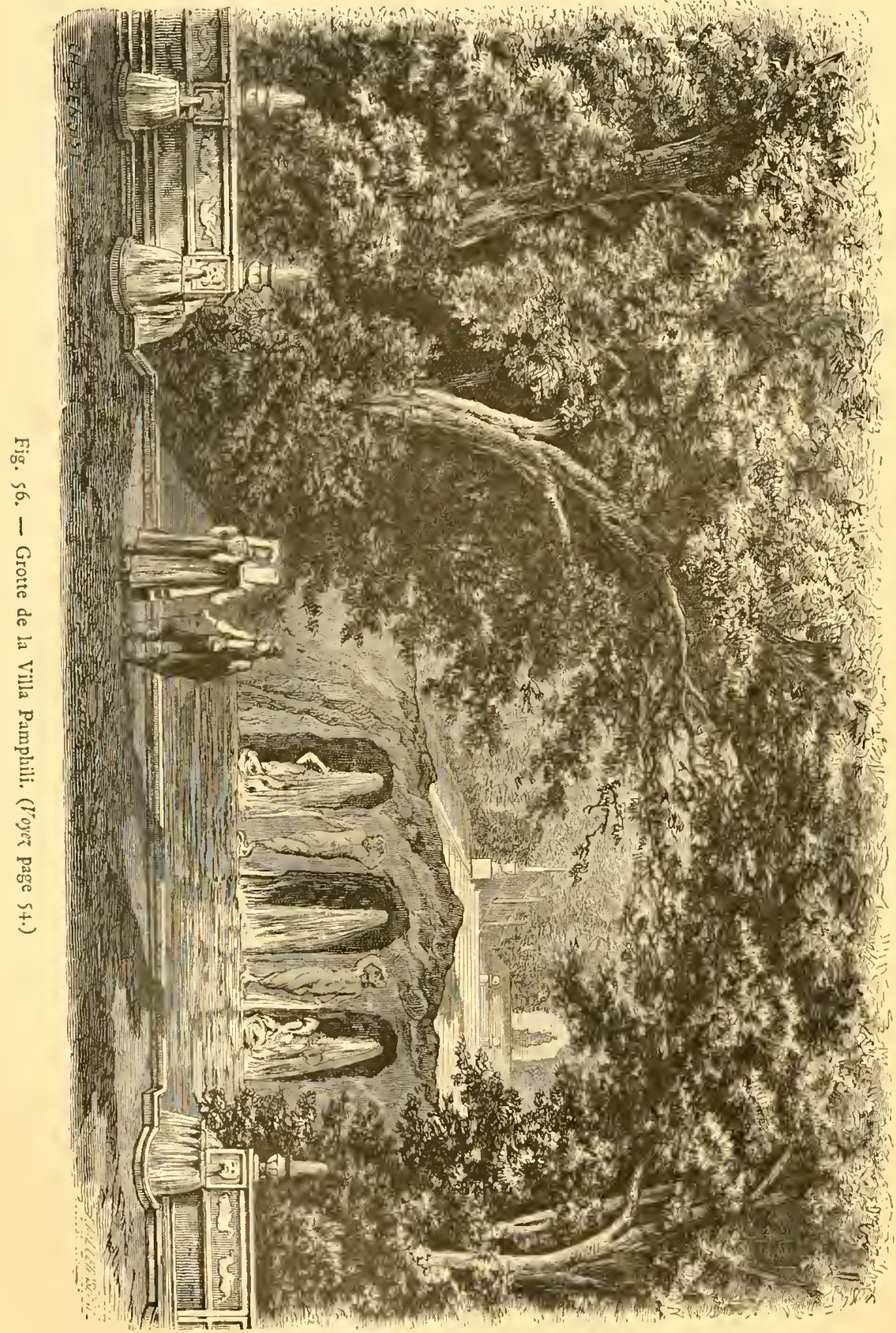

pour décorer, jusqu'à l'ncombrement, les nouvelles crúations (1).

Parmi celles situées dans les environs immidiats de Rome, les villas Mattei, Pamphili, Borghise, Albani, méritent une mention spéciale.

La villa Mattei (1581-1586) a gardé, par une rare et heureuse exception, le nom de l'artiste qui l'a créée. Son emplacement offrait plusieurs irrégularités dont il a su tirer habilement parti (Fig. 57). Ainsi, contrairement is l'usage ordinaire dans ce temps-là, la grande entrée est

latérale. Du côté où les jardins prennent leur principal développement, s'étend une

(1) M1. Taine a décrit admirablement les villas Ludovisi, Albani et Borghẻse, dans leur état actuel. (Voyage en Italie, I, 295 et suiv.) 
longue pelouse bordée de cyprès et aboutissant à un hémicycle (4) cn gradins que couronne un buste colossal d'Alexandre. Tout le long de cette pelouse, du côté droit de l'habitation, règne une terrasse ayant rue par-dessus des bosquets sur le mont Aventin. Du côté opposé, une façade latérale plus étroite est encadrée dans un large perron conduisant à une terrasse garnie de plantations il gauche, tandis qu'en face s'ouvre bientôt la perspective inattendue d'un raste espace en contre-bas, encadré de verdure ( $\zeta$ ) et orné d'antiquitès. Il $\mathrm{y}$ a là un exemple très remarquable d'alliance de la fantaisie au style régulier.

La villa Pamphili est une auvre en partie française (Fig. 54 à 56). Le Nôtre y mit la main, lors de

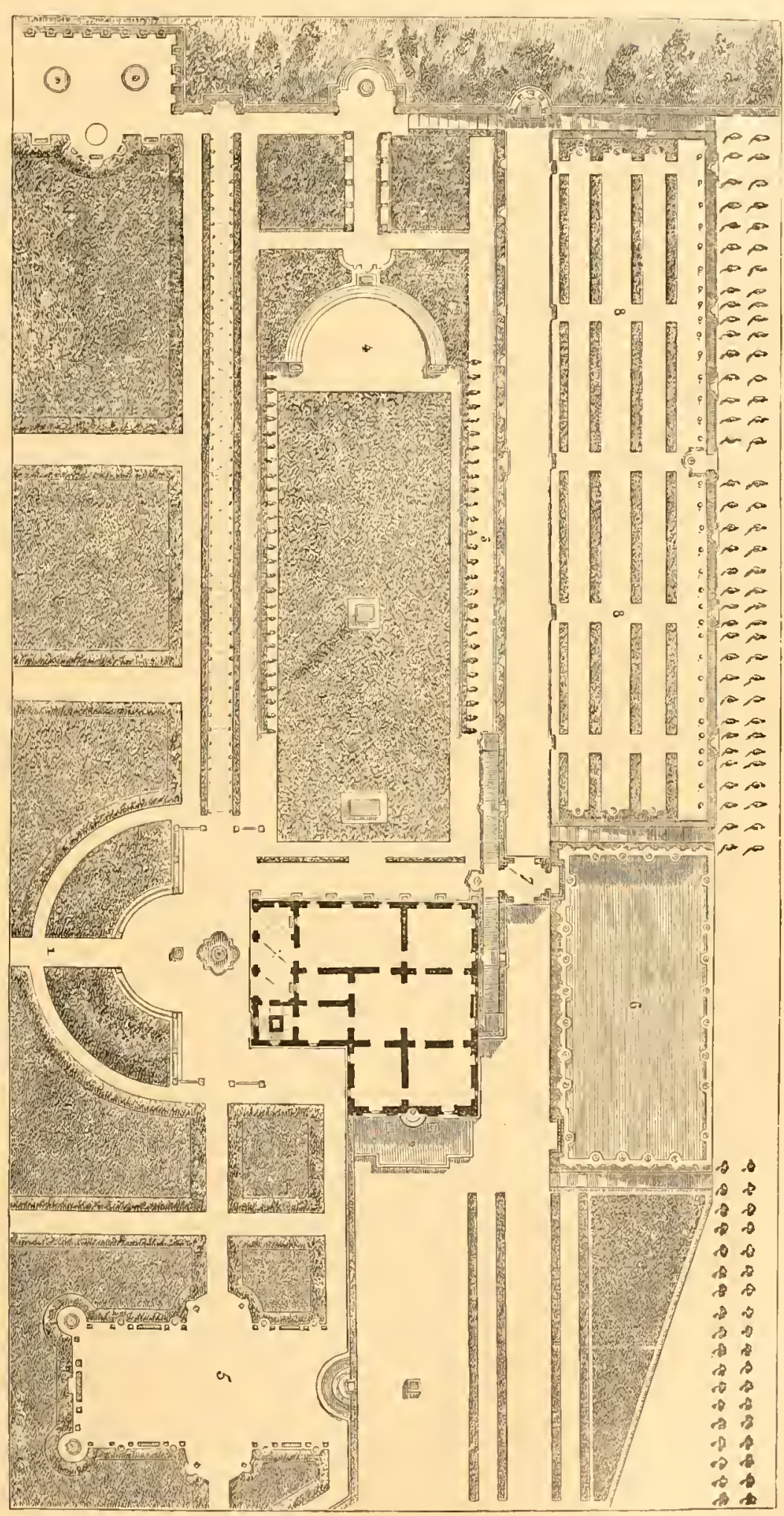

Fig. 57. - Plan de la Villa Mattei.

1. Entrée. - 2. Bassin. - 3. Grande Terrasse. - 4. Hémícycle. - 5. Salle de Verdure. 6. Grande Pièze d"eau, - 7. Loge, - 8. Bosquets couverts. 


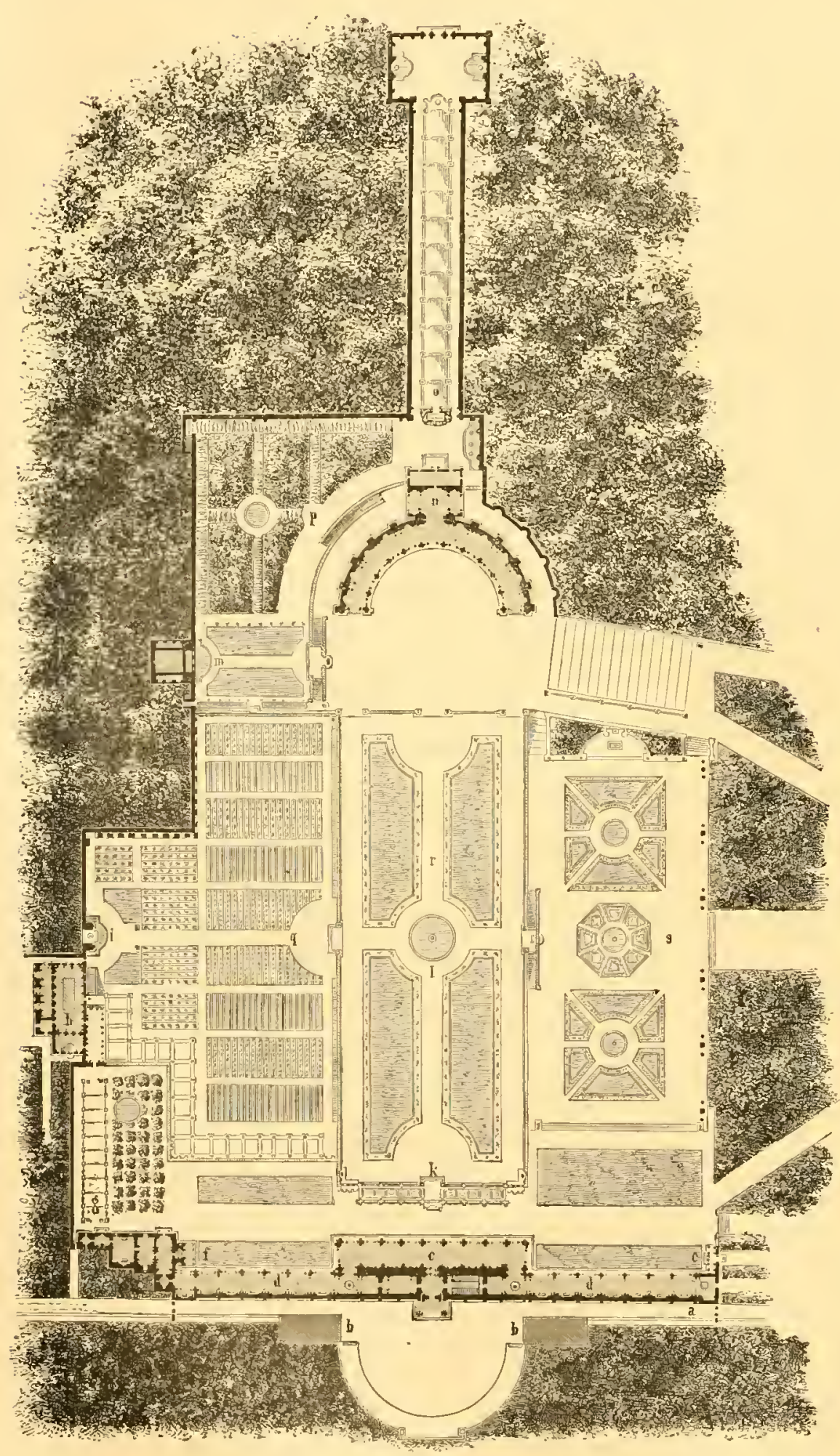

Fig. $58,-$ Plan de la Villa Albani. ce royage a Rome, pendant lequel il surprit et charma le pape Clément $\mathrm{X}$, par sa familiarite affectueuse et naive. (V. Saint-Simon.) A l'aspect de cette grotte à trois compartiments (Fig. 56) par lesquels l'eau se déverse en cascades au-dessous d'un escalier monumental, on devine que le créateur de Versailles a passé par lá.

La villa Borghése est un raste pare de quatre milles de tour, semé de bâtiments de tout genre et surtout célébre par ses pelouses ondulées, pleines d'anémones et de pâquerettes, et par ses magnifiques ombrages (Fig. 44 et 60).

La villa Albani ne date que de 1774. C'est bien une auve franco-italienne, 
majestueuse et pompeuse à l'excés, réminiscence visible de nos grands jardins français du siécle précédent (Fig. 58 et 59). L'un des détails les plus caractéristiques est l'avenue par trop triomphale conduisant ì la salle, ou plutôt au temple du billard.

Dans les environs de Rome, la villa d'Este (Figures 42, 6I, 62), commencée en I 540 et terminée seulementen 573 , reste une des plus intéressantes par la composition générale, la beauté du site et des eaux. De Brosses se moquait avec raison des nombreux colifichets, des charivaris hydrauliques qui existaient encore de son temps à la villa d'Este et à celle de Frascati, et dont le temps a fait justice. Mais il

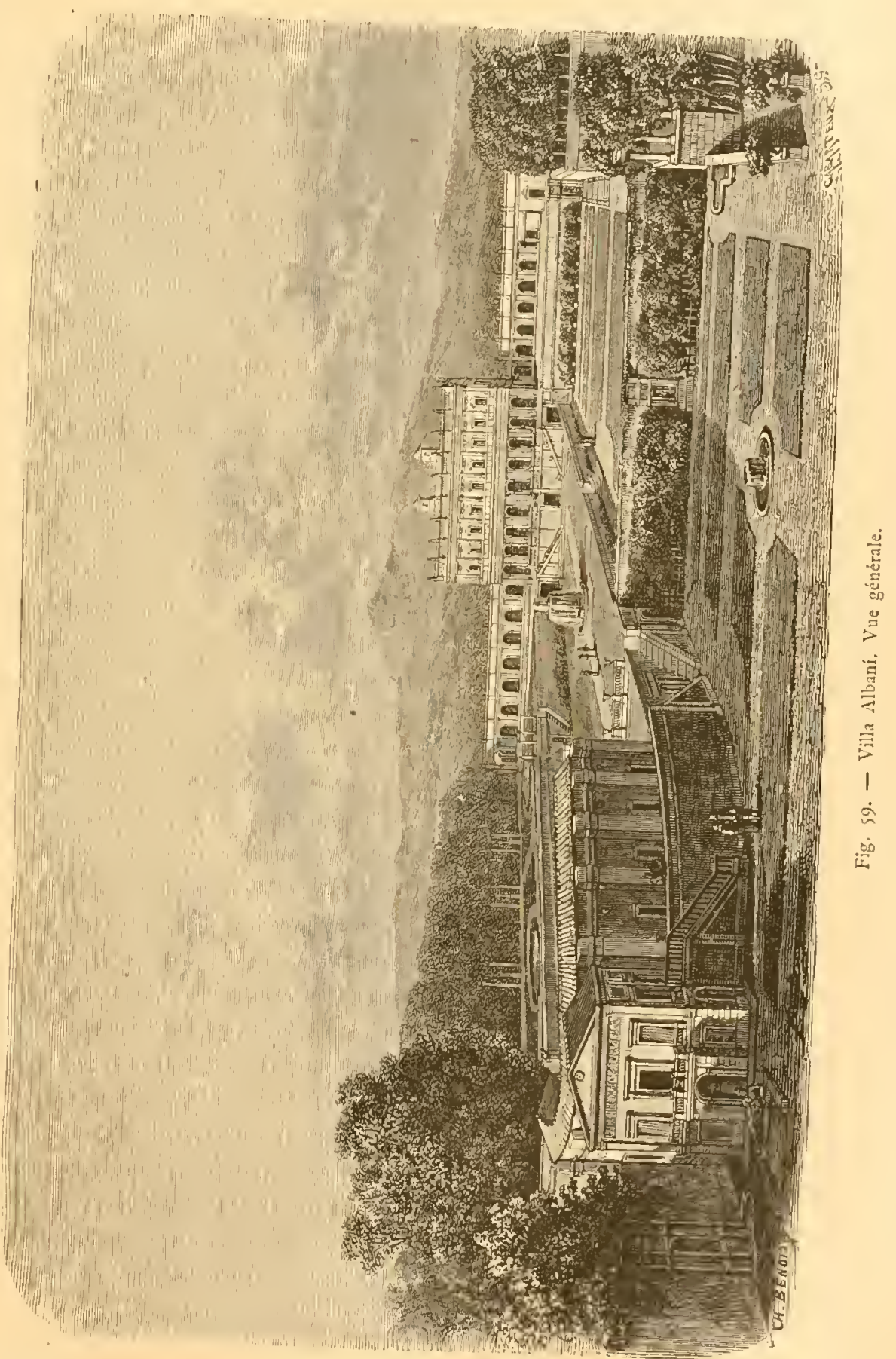
admirait fort les «grandes piéces»; notamment, à la villa d'Este, le "portique orné de colosses, par lequel les eaux du Teverone entrent dins le jardin ", le canal, la terrasse des jets d'eau formant avenue (Fig. 6I), les Fontaines de Pégase et d'Arétluse 
(Fig. 62). Tout en donnant encore la préférence, en bon Français, aux magnificences hydrauliques de Versailles, où " tout est dans le grand », il reconnaissait que les

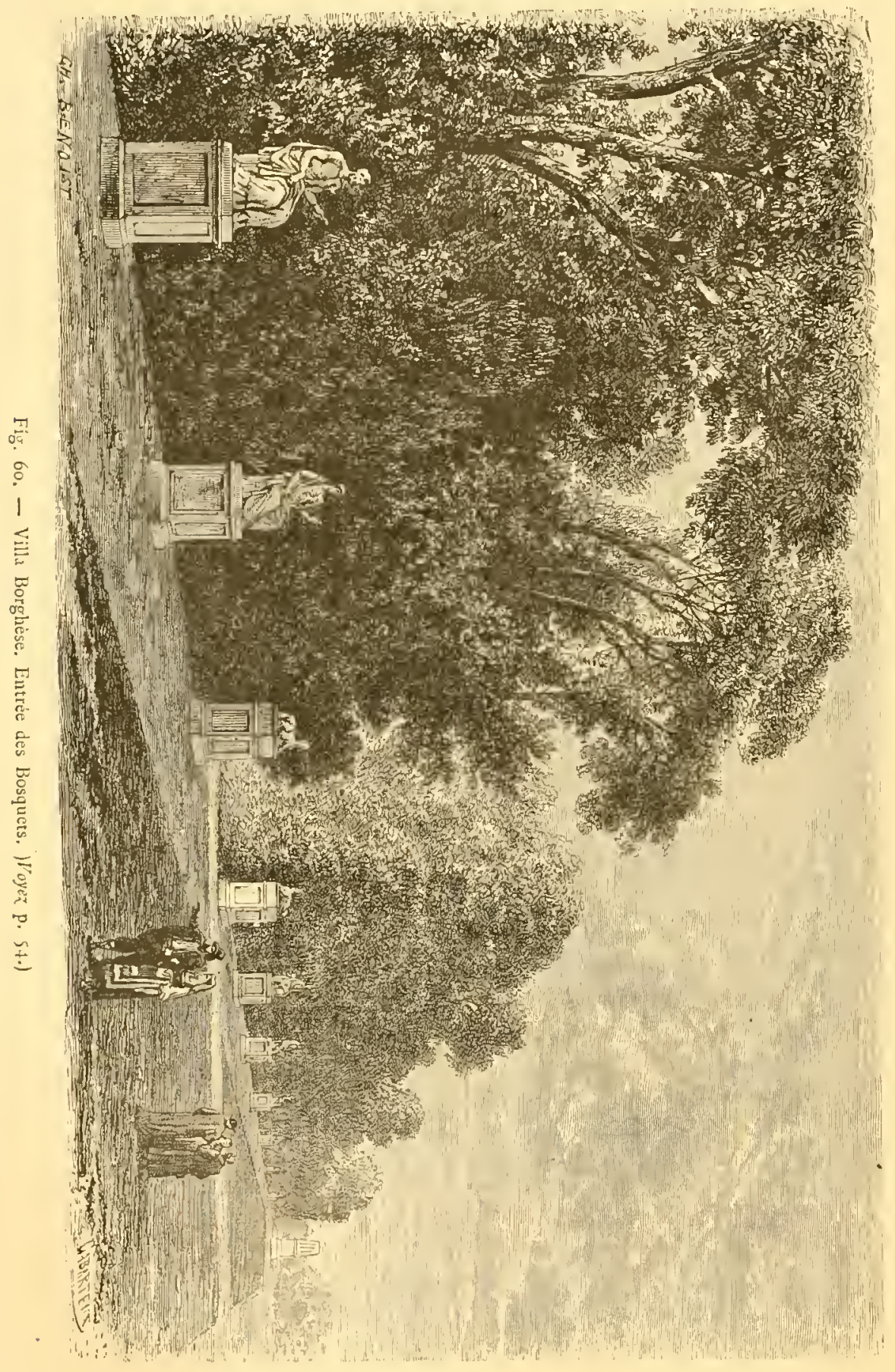
caux de Tibur et de Frascati l'emportaient fort par la clarté et la limpidité (Lettre 48 ).

Il faut citer encore les jardins de Farnèse (Fig. 63), ct celui des Papes, sur le Quirinal (Figure 64), dont l'architecture est"d'Ottavio Masiarini.

Un des plus grands écrivains de notre temps a magistralement décrit l'impression poétique que produisent les grandes villas de Frascati, en dépit ou plutôt à cause de leur état de délabrement et d'abandon. " De Frascati à leur point le plus élevé (Tusculum), les collines tusculanes ne sont qu’un immense jardin partigé entre quatre ou cinq familles princières. Les villas Falconieri, Aldobrandini, Conti, plus haut, la Ruffinclla, et, en revenant vers l'est, la Taverna et Mondragone, tout cela sc tient et se communique... Le caractère 
général est de deux sortes : celui de l'ancien goût italien, et celui de la nature locale qui a pris le dessus, grâce à l'indifférence ou à la décadence pécuniaire des maîtres de ces folles et magnifiques résidences. Si rous voulez une exacte description de ces résidences, telles qu'elles étaient encore il $y$ a cent (cinquante) ans, vous les trouverez. dans les lettres du président de Brosses.Il s'en est beaucoup moqué....., mais s'il revenait ici, i] trouverait un grand et heureux changement (I)... Les eaux ne soufflent plus dans des tuyaux d'orgue; elles bondissent encore dans des

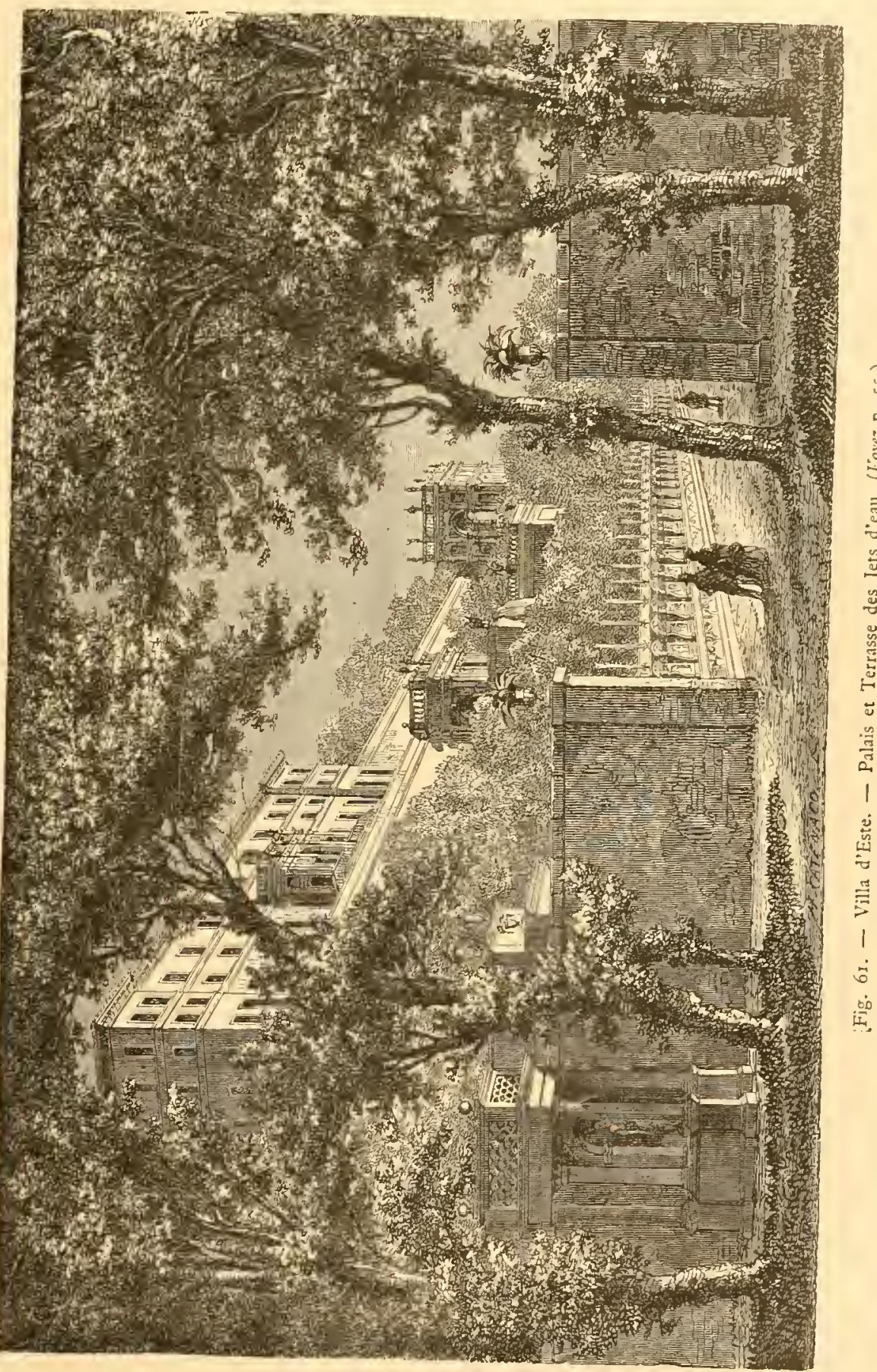
conques de marbre et le long des grandes girondes; mais elles y chantent de leur voix naturelle. Les rocailles se sont tapissées de vertes chevelures qui les rendent à la vérité.

(I) Changement dont il serait peut-être encore plus effarouché que charmé. Comme bien d'autres réformateurs utopistes du siècle dernier, de Brosses était loin de prévoir ni de souhaiter, dans aucun genre, une révolution aussi complète. 
Les arbres ont repris leur essor puissant sous un climat énergique, et sont devenus des colosses encore jeunes et pleins de santé. Ceux qui sont morts ont dérangé la symétrie des allées; les parterres se sont remplis de folles herbes; les fraises et les violettes ont tracé des arabesques aux contours des tapis verts; la mousse a mis du velours sur les mosaïques criardes... Et maintenant, ces grands pares jetés aux flancs des montagnes forment, dans leurs plis verdoyants, des rallées de Tempé, oủ les ruines

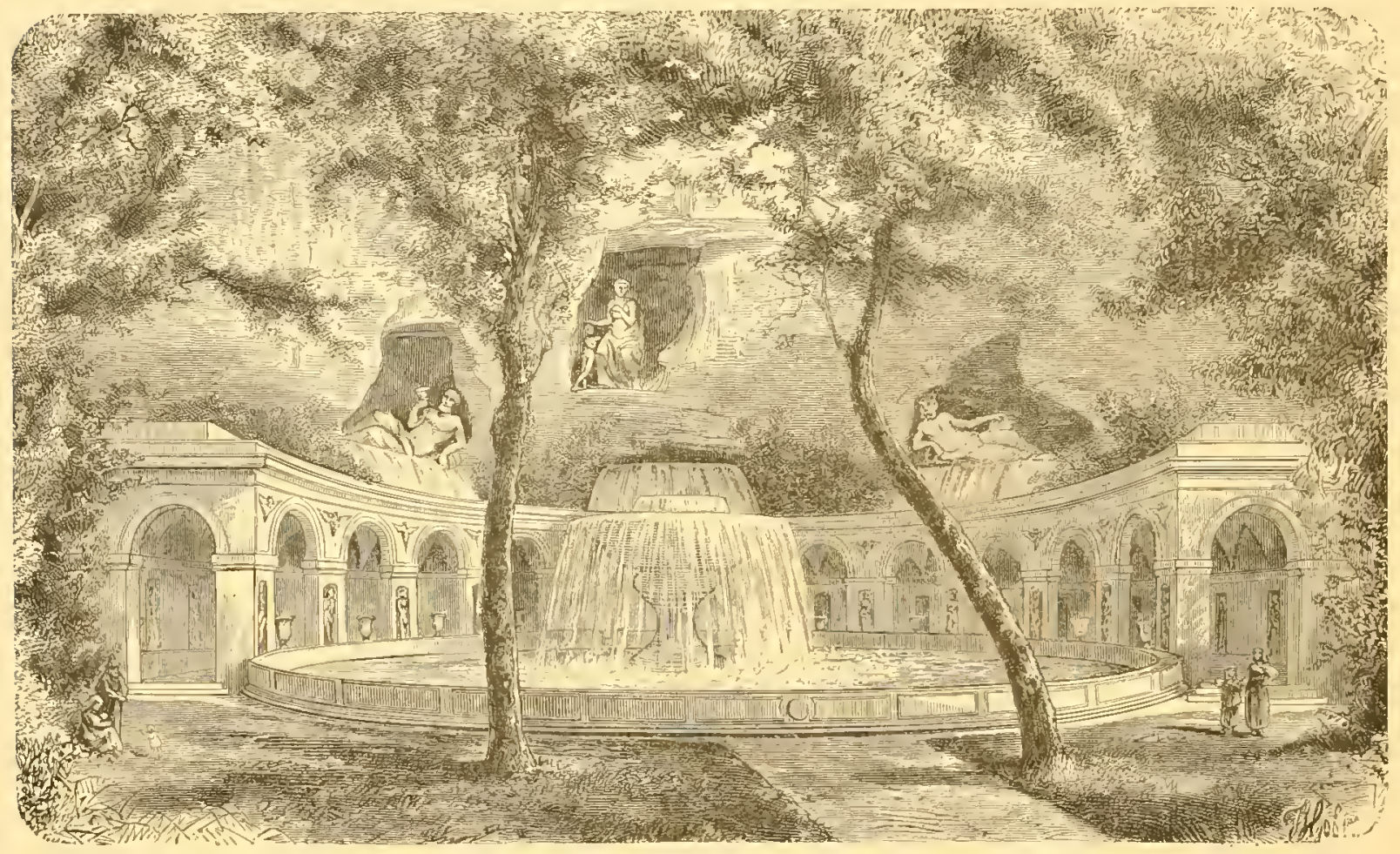

Fig. 62. - Villa d'Este, - Grand Bassin de la Fontaine d’Arèthuse, (Iogez p.'ss.)

rococo et les ruines antiques décorées par la même végétation parasite, donnent à la victoire de la nature un air de gravité extraordinaire. Comme, en somme, les palais sont d'une coquetterie princière ou d'un goût charmant; que ces jardins avaient été dessinés avec beaucoup d'intelligence sur les ondulations gracieuses du sol, et plantés aree un rrai sentiment de la beauté des sites; enfin, comme les sources abondantes y ont été habilement dirigées pour assainir et vivifier cette région bocagère, il ne serait pas rigoureusement rai de dire que la nature y a été mutilée et insultée. Les brimborions fragiles y tombent en poussière, mais les longues terrasses d'où l'on dominait l'immense tableau de la plaine, des montagnes 
et de la mer; les perrons de marbre et de lave qui soutiennent les ressauts du terrain; les allées couvertes; enfin, tout ce qui, travail élégant, solide ou utile, a

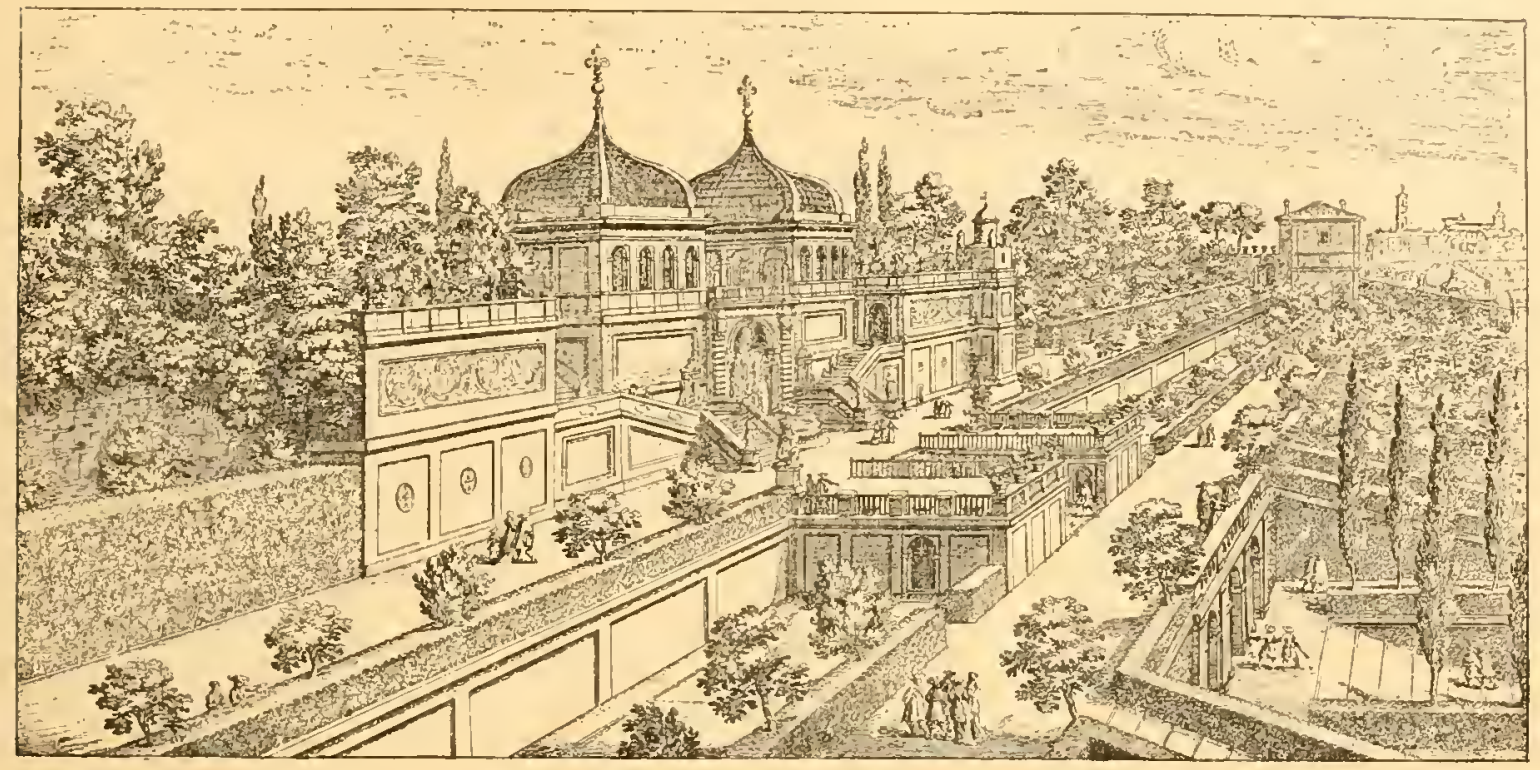

[Fig. 6;. - Vue des Terrasses du Jardin Farnése sur le Mont Palatin. - D'après Falda. (Ioycz p. 56.)

survécu aux caprices de la mode, ajoute au charme de ces solitudes, et sert à

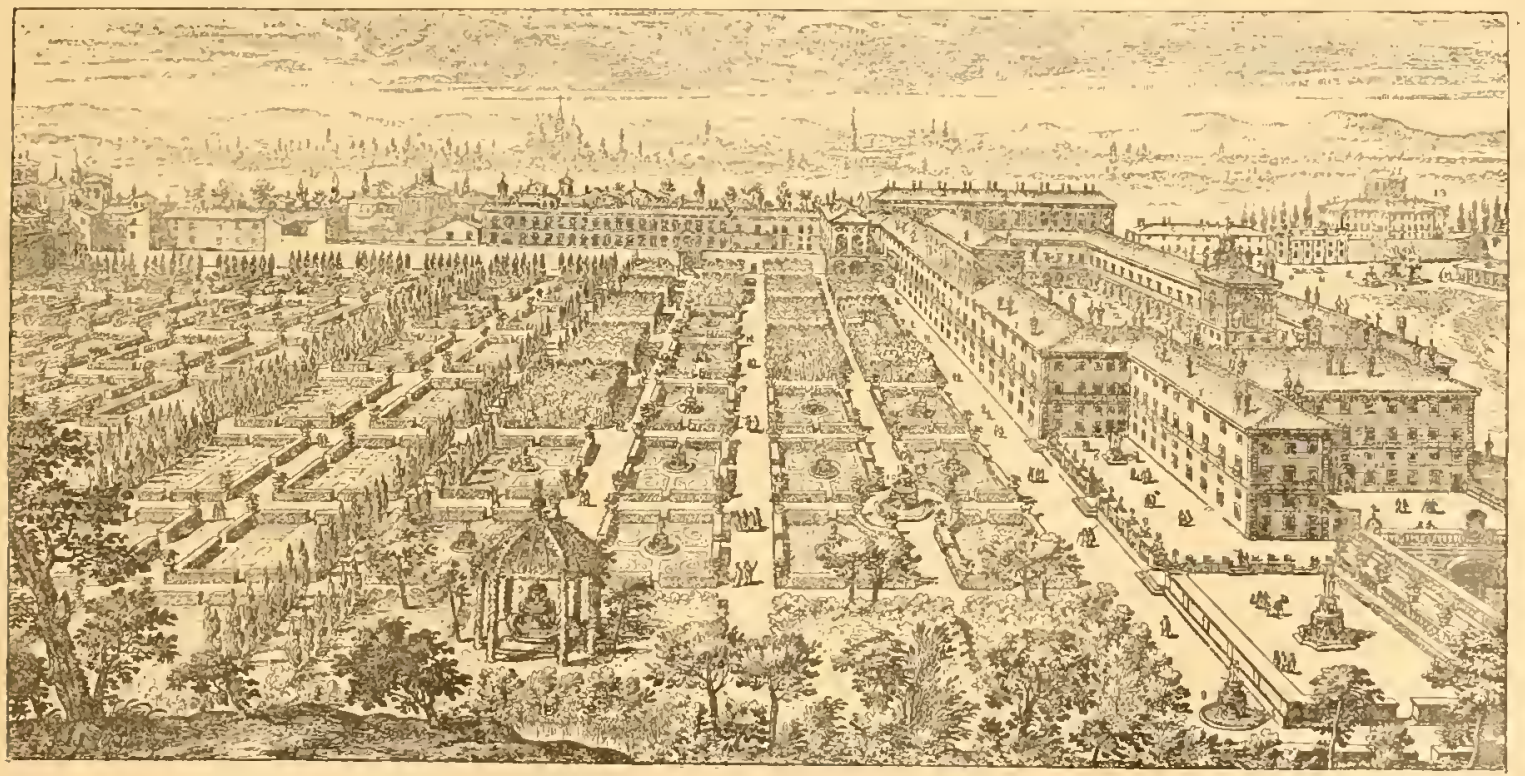

Fig. 6f. - V'ue des Jardins du Qnirinal (x:me siecle). - D'aprés Falda. (loyea p. 56.)

conserver, comme des sanctuaires, les heureuses combinaisons de la nature, et la monumentale beauté des ombrages. ») (George Sand, Daniclla.) 
Reste à savoir si ces sanctuaires pittoresques auxquels nul attrait ne manque, pas même, dit-on, la chance de rencontrer des brigands, seront encore long-

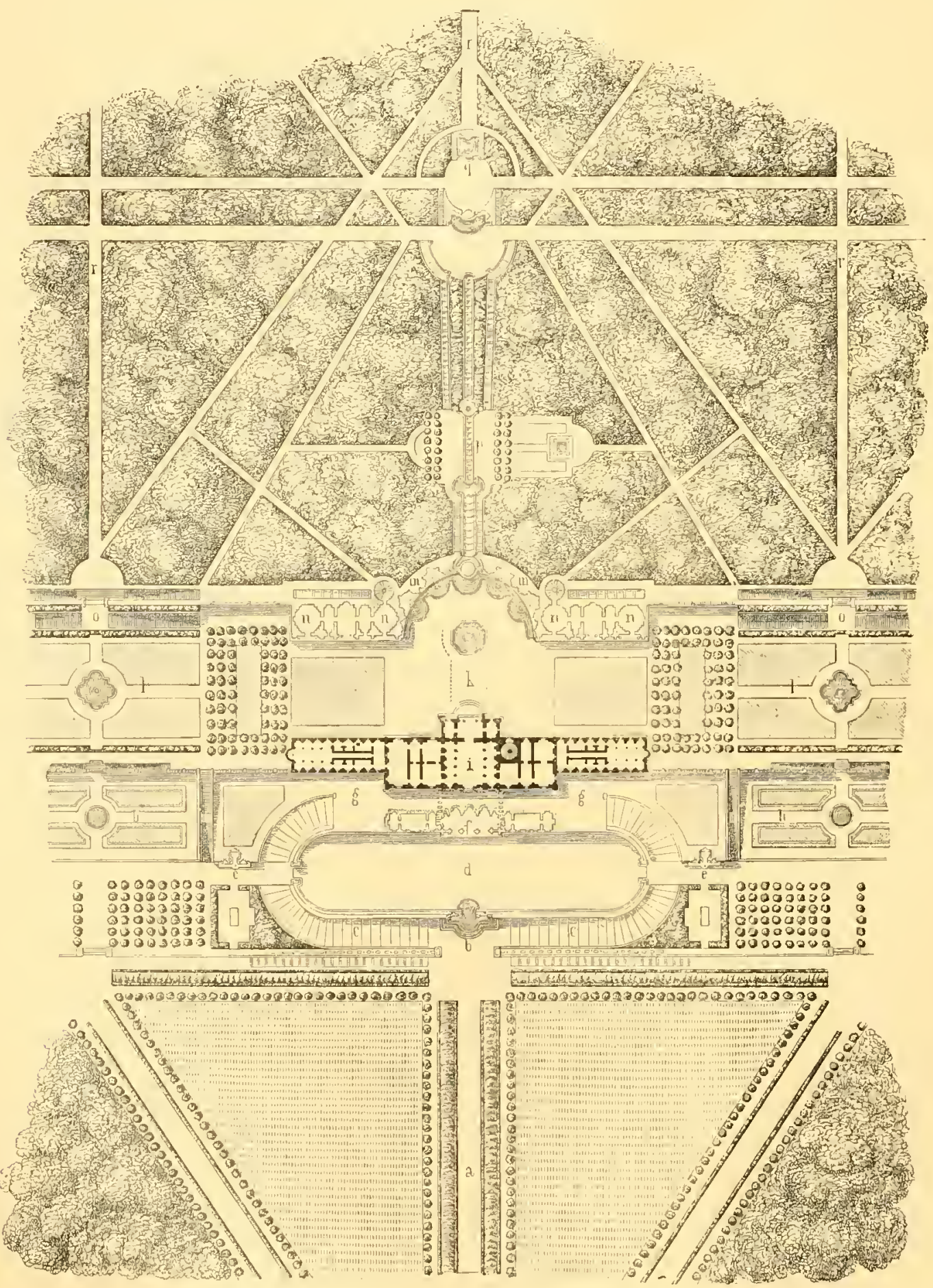

Fig. 6j. - Plan de la Villa Aldobrandini. (loyez p. 6r.)

$a$. Entrce priucipale, $-b$. Fontaine $-c$. Escalier. $-d$. Terrassc. $-c$. Fontaine, - f. Grotte. $-g$. Terrasse. $-b$, Parterre. - Vestibulc $-k$. Terrasse. -1 . Pelouse, $-m$. Terrasse, $-n$. Salles recouvertes et Terrasse. $-o$. Grand escalier. -1. Cascade. q. Fontaine. $-r$. Avenue. 
temps respectés. L'endroit oú la nature a eu le plus à faire, ou plutôt à défaire, pour mettre un beau désordre, est la villa Aldobrandini. Comme on le voit par la figure ci-jointe (Fig. 65), la symétrie la plus inflexible avait présidé à la création de cette œuvre. A Mondragone (Fig. 66) la "victoire de la nature » est bien plus complète, et la gucre y a puissamment contribué. C'est une superbe position militaire, et ce genre de beauté porte malheur. Tout le monde connaît la description qu'a faite George Sand de cette énorme ruine panachée d'herbes flottantes et d'arbustes, vrai labyrinthe auquel les effondrements causés par les boulets autrichiens ont ajouté de nouvelles complications ( 1 ).

(s) Dans une autre villa de Frascati, la Ruffinella, on remarque une fontaine végétale curieuse, et une allée bordée de cent noms d'écrivains illıstres, inscrits en buis façonné. Le tout est disposé sur une pente très raide, pour montrer sans doute combien la carrière d'homme de letircs est pénible. On attribue cette conception bizarre, mais non vulgaire, à Lucien Bonaparte, qui a été longtemps propriétaire de la Ruffinella.

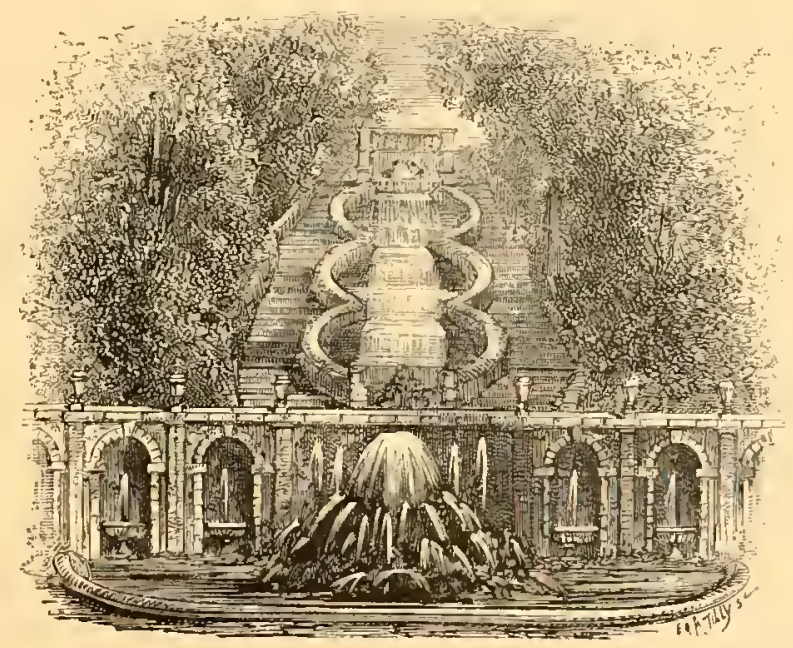

Fig. 66. - Cascades de la Villa Mondragone, exécutées par Giov. Fontana (1576). 


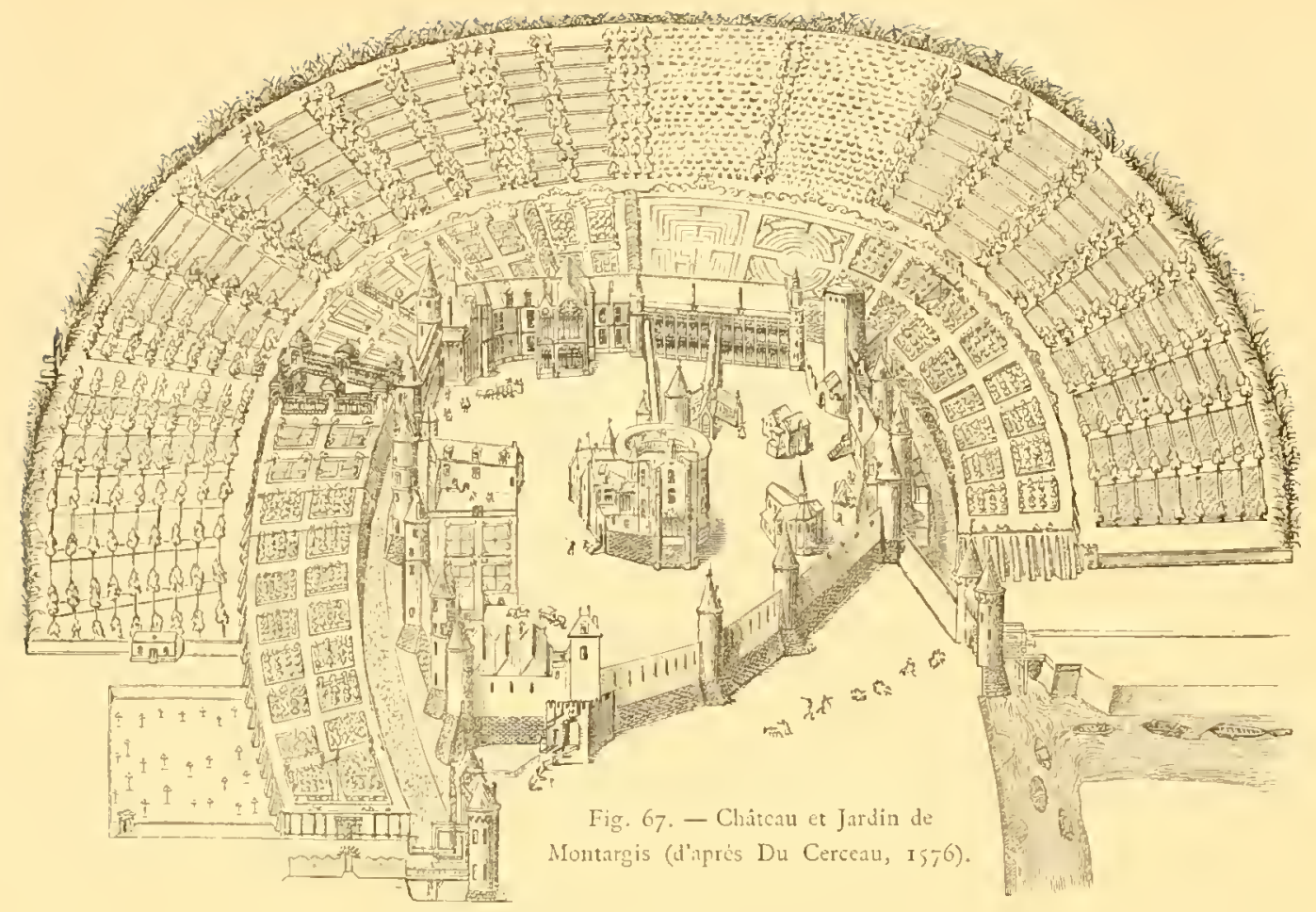

JARDINS FRANCAIS DU XVI ET DU XVII SIECLE (jusqu'a Le Nôtre)

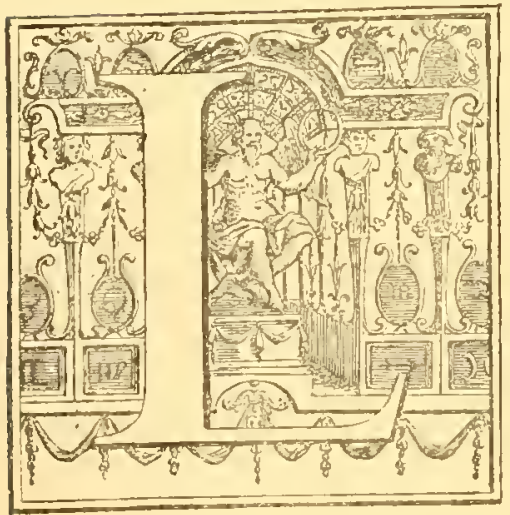

E mourement artistique de la Renaissance, farorisé par François Ier et ses successeurs, exerça une influence aussi considérable sur l'Art des jardins que sur tous les autres. Dés la seconde moitié du Xvie siècle, les abords des principaux châteaux royaux et princiers étaient aussi élégamment décorés qu'en Italie, comme en font foi les descriptions d'Androuet Du Cerceau et les plans levés par lui. Tels étaient les jardins de Montargis (Fig. 67), dont les carrés d'arbustes et les parterres étaient agréablement disposés en demi-cercle autour de la vieille résidence féodale; ceux de Fontainebleau (Fig. 78), de Gaillon (Fig. 69, 71, 72), de Blois (Fig. 34), de Saint-Germain en Laye (Fig. 70), d'Anet, de Verneuil. A Saint-Germain, où Henri II venait de faire construire le château actuel, les jardins descendaient vers la Seine par une séric de terrasses, dans l'épaisscur desquelles avaient été ménagées des grottes garnies de coquillages et de figures qui semblaient 
se jouer au milieu des eaux; ćétait une des merveilles du temps (Fig. 7o).

Ces jardins pouvaient aussi soutenir la comparaison avec ceux d'Italie pour la beauté des sites, « du regard », comme on disait alors. Il en était de mêne de Gaillon (Fig. 69, 70, 72). "Ce lieu, dit Du Cerceau, est accommodé de deux jardins, l'un desquels est au niveau d'icelui, et entre deux une place en maniere de terrasse. Or, cst ce jardin accompli d'une galerie belle et plaisante ayant sa veue d'un côté sur le jardin, et de l'autre sur ledit val vers la rivière. Quant a l'autre jardin, il est compris en ce val, sur lequel la galerie a son regard merveilleusement grand. » Du Cerceau parle ensuite du lieu de Clatrtrense "abondante en tout plaisir », que le cardinal avait fait ériger « au même val, tirant vers la rivière », et d'un parc supérieur, disposé en rampes alternativement ombragées et à ciel ouvert, et couronné par un ermitage factice. Ce n'était plus le temps des vrais crmitages, pas plus que des vraies chartreuses! Ce pare avait remplacé l'ancienne torteresse féodale du temps de Philippe-Auguste (I).

On sait que Gaillon, l'un des types les plus achevés des villas françaises de la Renaissance, est aujourd'hui une maison de détention. Quand on parcourt ses galeries et ses salles transformćes en dortoirs et en ateliers, ses cours devenues des préaux, rien ne rappellerait a l'esprit ses magnificences disparues, si l'on ne retrouvait enfin l'un des portails (l'autre (Fig. 7I), est à l'École des Beaux-Arts), et la « terrasse au regard merveilleusement grand. »

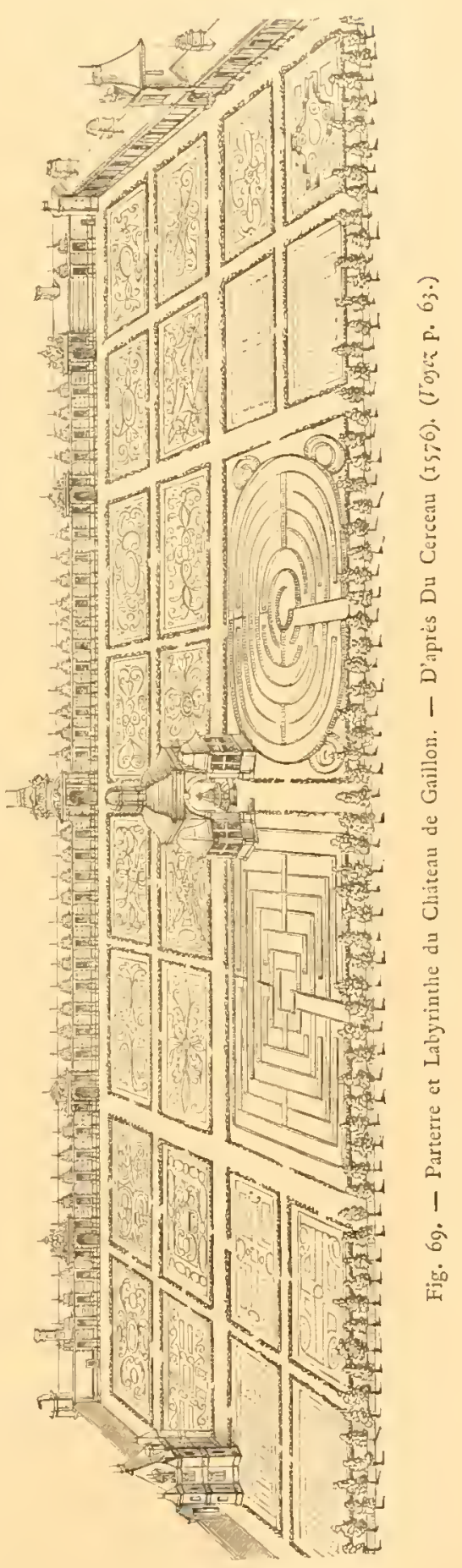

L'art des jardins, négligé pendant les guerres de religion, participa à l'énergique et intelligente impulsion donnée par Henri IV it tous les arts de la paix. Au com-

(1) Des plus excellents bastiments de France, par J. Androuet Du Cerceau. 
mencement du xvil e siècle, Olivier de Serres proclame, avec une fierté patriotique, " qu'il ne faut voyager en Italie ni ailleurs pour voir les belles ordonnances des jardinargs, puisque notre France emportc le prix sur toutes nations. » On voit aussi, par

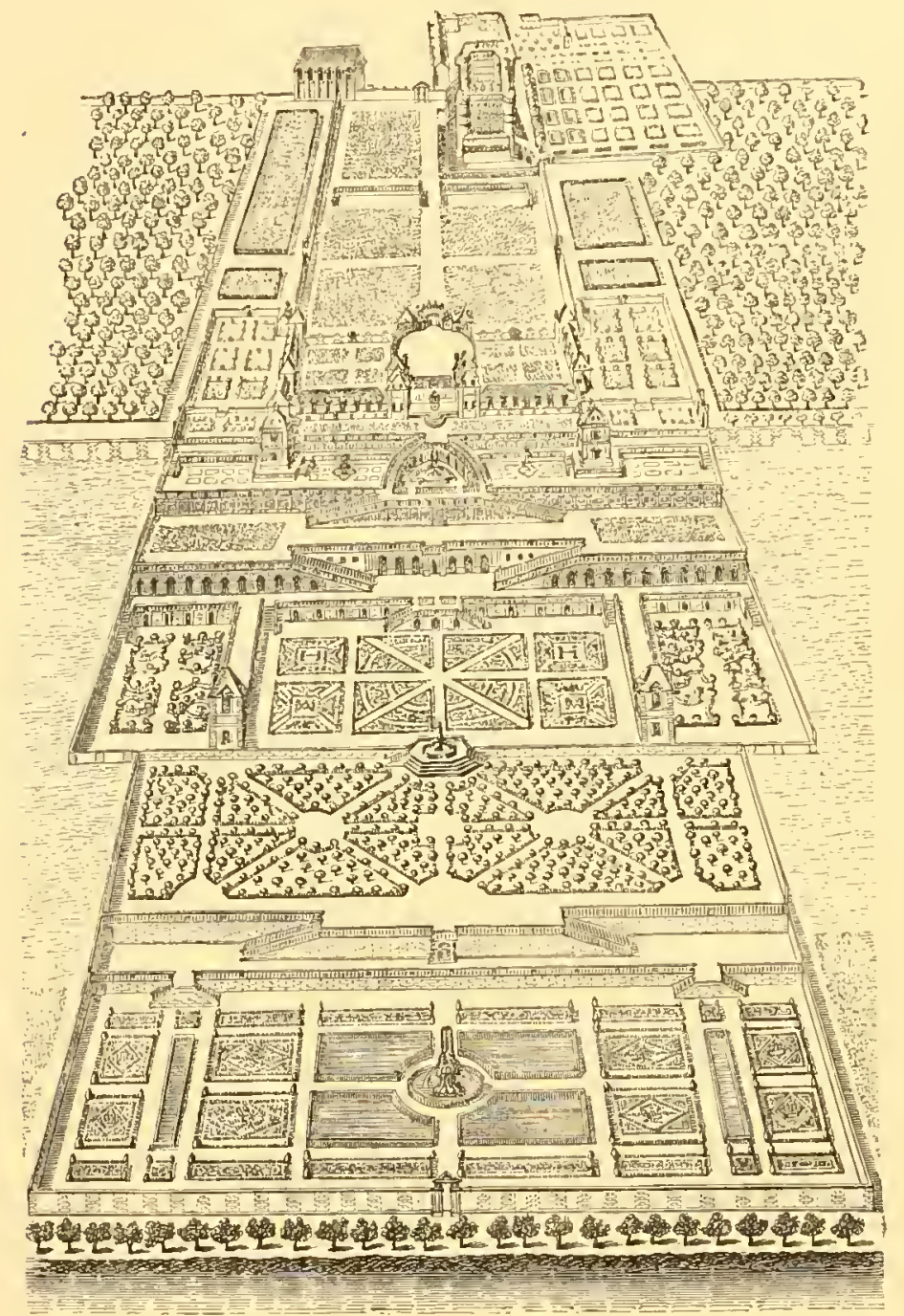

Fig. 70. - Chåteau et Jardins de Saint-Germain-en-Layee, (Voyé- p 6;) ses descriptions et les figures du temps, que les jardiniers français égalaient et même surpassaient ccux d'Italie pour l'exécution des parterres de broderie et à compartiments (Fig. 73). « Ici, dit-il, sera montré comme l'on doit se servir des herbes et les employer, ayant égard à leurs facultés pour l'ornement des parterres. » Parmi les " excellents jardins de plaisir disposés en ce royaume ", il cite ceux que le roi faisait alors dresser en ses royales maisons de Fontainebleau, de Saint-Germain, les Tuilerics, Monceaux, Blois, etc. (I). On y voit avec admiration « les herbes parlant lettres, devises, chiffres, armoiries, cadrans (Figures 74 à 77); les gestes des hommes et des bêtes; la disposition des navires, batenux et autres choses contrefaites on herbes et arbustes, avec merveilleuses industrie et patience. Les myrtes, la larande, le romarin, la trufemande (?), le bouis (buis), sont les plus propres plantes pour bordures, et qui durent plus longuement. Et aux compartiments simples, doubles, entrecoupés et rompus, la marjolaine, le thym, le serpolet, l'hyssope, le pouliot (menthe pouliot, Pngelinm), la sauge, la camomille, la

(1) Il s'agit ici du Monceaux de Gabrielle d'Estrées, aujourd'hui détruit, et auquel avait travaillé J. de Brosses. Nonobstant l'opinion commune, ce grand artiste avait été connu et employé par Henri IV avant que Marie de Médicis vînt en France. 
menthe, la violette, la marguerite, le basilic et autres herbes demeurant toujours vertes et basses. "Il y joint deux modestes plantes potagéres qu'on est surpris de voir figurer dans ces raffinements, l'oseille et le persil! Mais rien n'est comparable au buis, pour la faquelle il se prête taisies du ciseau: l'horticulture. Il que la « bonse vrai qu'elle lui coup.

Serres vante « quelques-uns ments que le roi Saint-Germain, veaux jardinsdes Fontainebleau

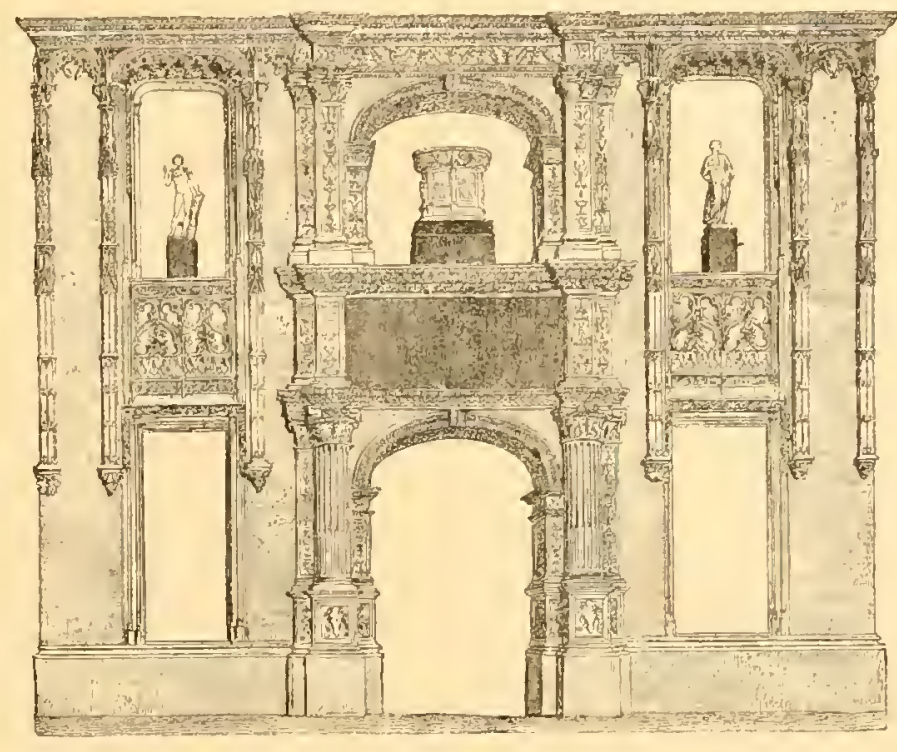

Fig. 7r. - Portail de Gaillon. (Ecole des Benux-Arts a Paris. (V. p.63.) cilití avec lita toutes les fanc'est le serf de ne lui manque senteur »; il est manque beau-

Olivier de particulièrement des compartia fait faire $\dot{a}$ et en ses nouTuileries et de (Fig. 79), au dresser desquels M. Claude Molet, jardinier de Sa Majesté, a fait preuve de sa dextérité ». On voit, en effet, dans un plan qui est de ce temps-là, que, sauf un Dedalus en charmilles et un bosquet du côté du quai, tout le reste était en parterres à compartiments marque aussi le plus ancien Tuileries, qu'à le château a ujourd'hui, terres par une A l'époque des le plus caracić-

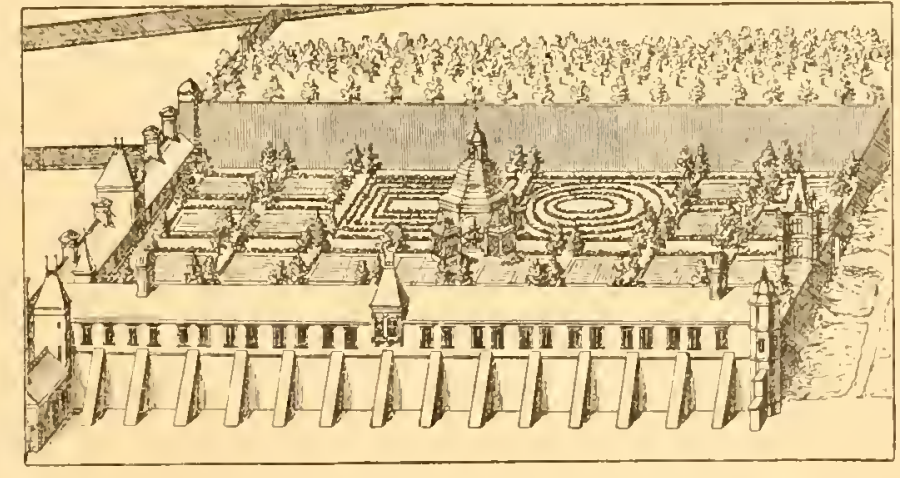

Fig. 72 - Parterre et Labyrinthe du Jardin de Gaillon. (Voyei p. 63.) variés. On redans ce plan, qu'on ait des cette époque était, comme séparé des parvoie publique. Valois, le trait ristique de Fonle grand étang, tainebleau était avec sa quadruple allée d'ormes, création très heureuse de François Ier. L'irrégularité des constructions n'avait pas permis d'établir un plan d'ensemble pour les abords: c'était comme une réunion de jardins. Il y arait celui des Pins (aujourd'hui jardin anglais), ou se trouvait la fontaine Blean, dont il n'existe plus de trace; le jardin des buis 
(de Diane), établi dans les fossés en partie remblayés de l'ancien châtcau; un jeu de paume, une palestre, des ifs taillés le long des fossés d'eau courante allant vers le grand étang; des statues, des édicules, des tonnelles et des allées couvertes en treillage, des parterres bordés de buis, des ouvrages hydrauliques dans le genre de ceux de Saint-Germain, des charmilles taillées à pic, etc. Ces jardins, irréguliers dans l'ensemble, symétriques dans le détail, avaient été comme le Décaméron de la régente Catherine et de son escadron volant de beautes, milice des plus irrégulières. Henri IV

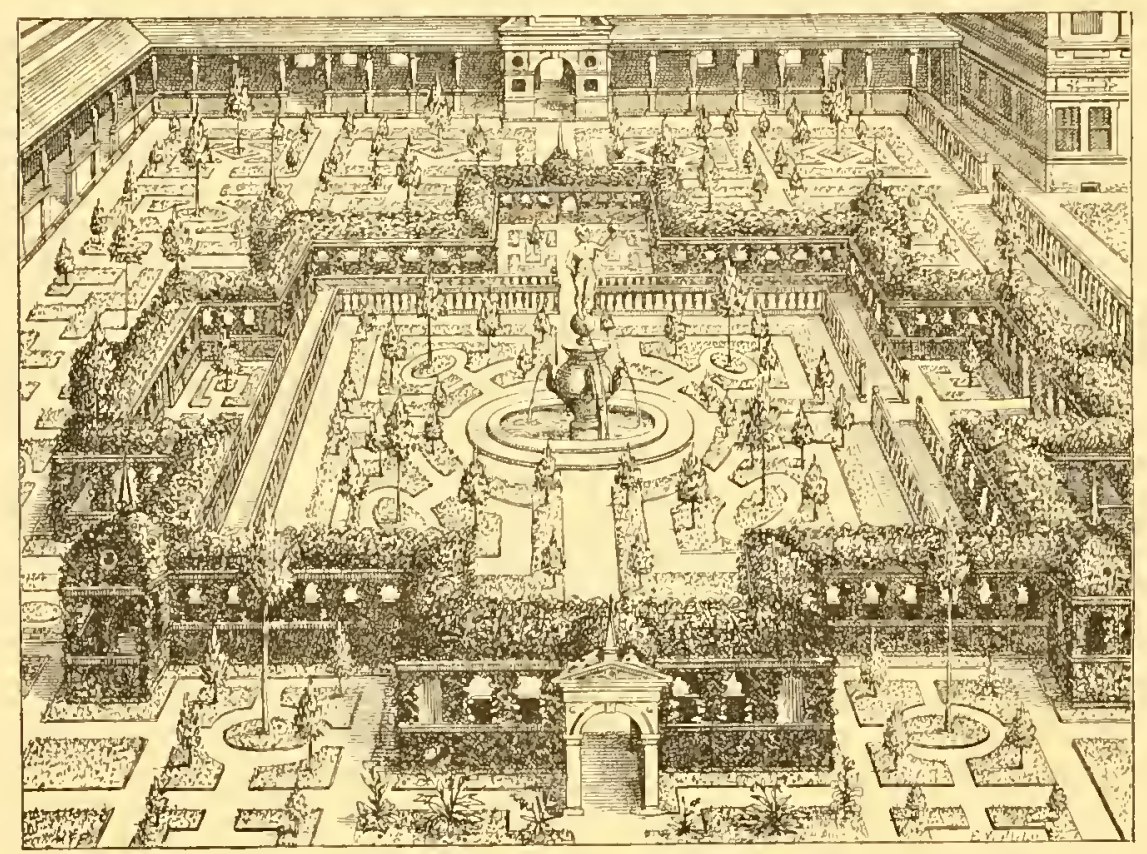

Fig. 73. - Parterres, d'aprés Jean de Vriès. (Voyci p. 64.)

fit travailler pendant toute la durce de son règne tant au château qu'aux jardins, qu'il augmenta du double. Fontaincbleau lui doit le grand canal; le parc, qui, comme on l'a dit avec raison, semble faire entrer les jardins dans la forêt; le grand mur tapissé du fameux espalier

dit la troille du Roi; et d'autres ornements qu'ont fait disparaitre des remaniements ultírieurs.

André Molet, fils de Claude, lui succéda dans l'office d'intendant des jardins du roi. Non moins habile ouvrier que son pere pour les parterres (Fig. 79), il prétendit de plus donner des préceptes généraux. Dinns un ouvrage intitulé : Des Ornements des jardins de plaisir, il prescrit, comme premier embellissement, " une grande avenue d'ormes à double ou triple rang, perpendiculaire a la façade, avee un grand demicercle ou carré au commencement... Puis, en la face de derrière, les parterres de broderie d'icelle, afin d'être regardés et considérés facilement par les fenêtres sans aucun obstacke d'arbre, palissade ou autre chose haute qui puisse empêcher l'wil d'avoir son étendue. » Ce travail de broderie ou de mosaïque était ce que Molet entendait 
le mieux. Aussi il a bien soin d'en faire la piece principale. Viennent ensuite " les parterres à compartiments de gazon, comme aussi bosquets, allées, palissades hautes et basses, faisant en sorte que la plupart des allées aboutissent et se terminent toujours
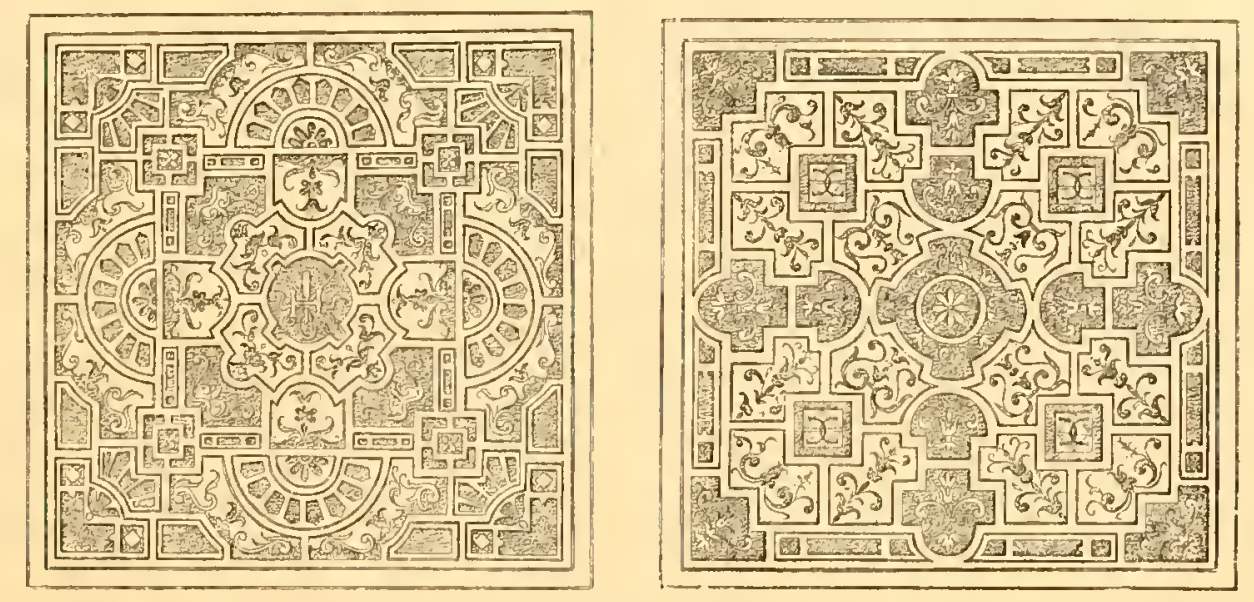

lFig. $7+$ et 75 . - Parterres da Jardin des Tuileries sous Henri IV. (Toyei p. 64.)

a quelque statue ou centre de fontaine, et aux extrémités d'icclles allées y poser de lelles perspectives peintes sur toile, afin de les pouvoir ôter des injures du temps. ”
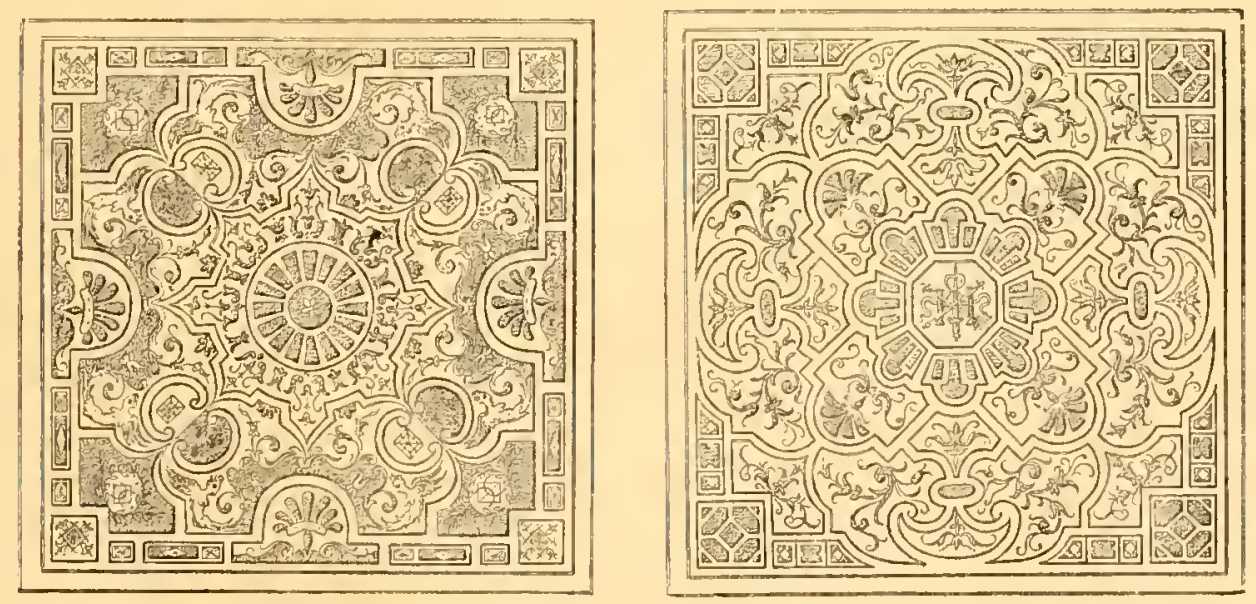

Fig. 76 et $7 \%$ - Parterres du Jardin des Tuileries sous Henri IV. (Ioyz p. 64.)

Puis, pour perfectionner l'œuvre, "placer des statues, bâtir les grottes ès lieux convenables, sans oublier les volières, jets d'eau, canaux et autres ornements, pour former le jardin de plaisir parfait. "

On s'est moqué avec raison de ce programme, qui semble le «numérotage 
des pièces d'une machine. "Toutefois, il y a des circonstances atténuantes à faire

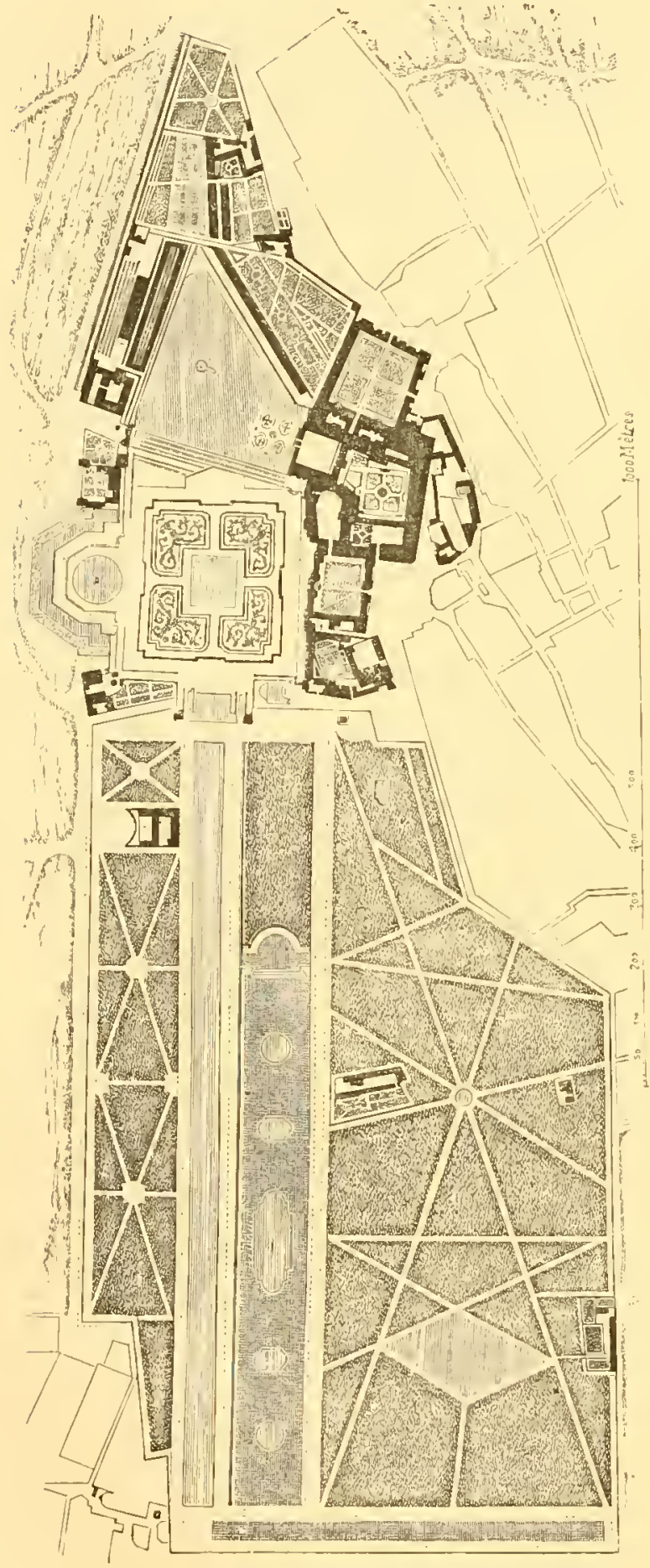

Fig. 78. - Chateau et Jardins de Fontainebleau. (Ioyez p. 65.) valoir en faveur de Molet, moins habitué à tenir la plume que la bêche ou le ciseau. Il ne conseillait sans doute l'emploi de perspectives factices que pour masquer des clôtures ou des vues disgracicuses, ce qui se pratiquait aussi en Italic (I). Quant aux parterres ciselés, aux palissades de buis (Fig. $S_{I}$ ) ou de chamilles, taillées à pic, en colonnes, cn arcades, en boules, aux grottes pseudo-rustiques, etc., c'etait également de cette manière que Bernard Palissy, un véritable et grand artiste, comprenait le jardin dílectable (Fig. So). Ce goût persista jusqu’a L.e Nôtre. Dans " les Amours du Roy et de lat Royne m, œuvre de l'une des futures victimes de Boilcau, Puget de la Serre (1625), le dieu Pan célébre les noces de Louis Xill par une fête pastorale dans un pré tapissé de fleurs où les arbustes et les plantes affectent toutes sortes de formes géométriques, "droites lignes, cercles, carrés, triangles, ovales, ce qui ćtait grandement délicicnx à voir. » La Serre, alors l'un des domestiques de la Reine-mère, décrit ici ce qu'il voyait dans tous les jardins royaux. Pour quiconque appartenait de prés ou de loin à la cour, ou se piquait de bel esprit, il n'existait pas alors d'iutre manière de comprendre l'art des jardins. On nous saura sans doute gré de reproduire ici l'élé(1) Un siècle plus tard, de Brosses cn citc un curieux exemple à Milan. 
gante description d'un jardin du plus pur style Louis XIII, par Théophile Gautier. " Une allće sabléc conduisait au château, traversant un jardin ou parterre planté selon la derniére mode. Des bordures de buis, rigoureusement taillées, y dessinaient des arbres oú se déployaient, comme sur une piéce de damas, des ramages de verdure d'une symétrie parfaite. Les ciseaux du jardinier ne permettaient pas à une feuille de dépasser l'autre.... Des sables de diverses couleurs servaient de fonds à ces dessins végétaux qu'on n'eût pas plus régulićrement tracés sur le papier. A moitic du jardin, une alléc de même largeur se croisait avec la premiére, non pas a angles droits, mais en aboutissant à une sorte de rondpoint dont le centre était occupé par une pièce d'eau, ornée d'une rocaille scrvant de piédestal à un Triton, enfant qui souflait une fusée de cristal liquide avec sa conque. Sur les côtés du parterre, régnaient des charmilles palissadées, tondues à vif. Une industrie savante avait fait de ces arbres,

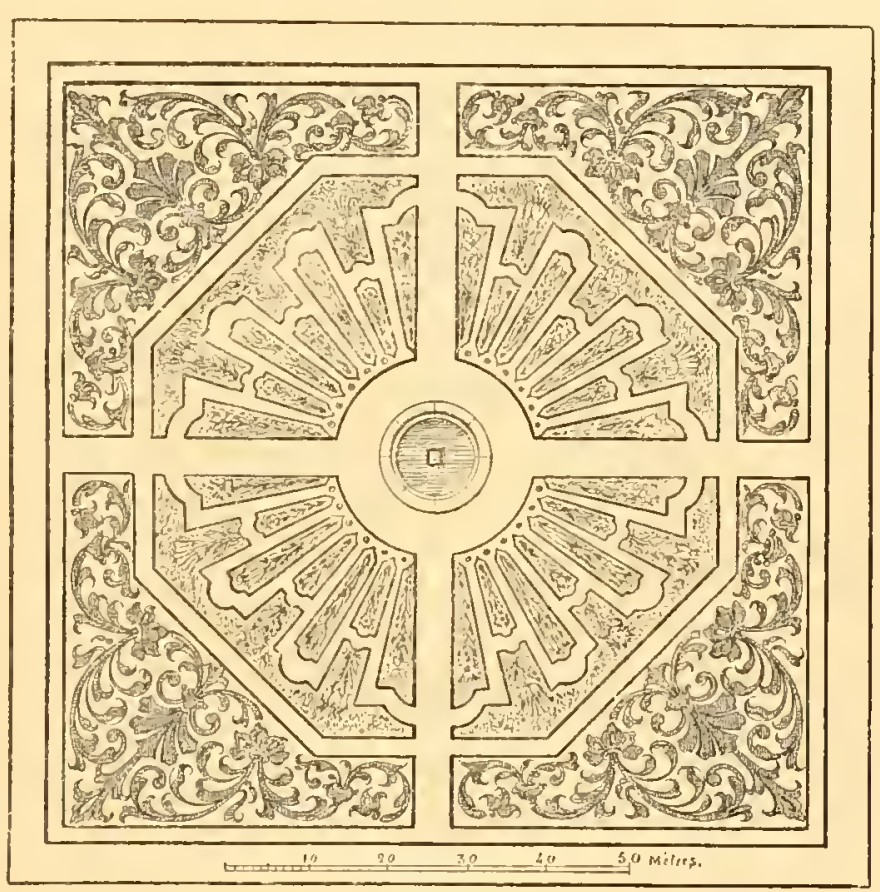

Fig. 79. - Parterre en Broderie, par André Molet (I6,I). (V. p. 65. qu'il eût été difficile de reconnaitre pour tels, un portique à arcadés, qui laissaient par leurs baies apercevoir des perspectives et des fuites ménagées à souhait, pour le plaisir des yeux, sur les campagnes environnantes (Fig. 8o). - Le long de l'allée principale, des ifs taillés en pyramides, en boules, en pots à feu, alternés de distance en distance, découpaient leur feuillage toujours vert. » (Th. Gautier, Le Capitaine Fracasse.)

On trouve aussi des renseignements curicux sur les jardins français de cette époque (premiére moitié dn Xrile siecle) dans les récits du voyageur anglais Evelyn, qui visita la France en 16.4. 11 parle avec admiration du jardin des Tuileries, déjả trés différent de ce qu'il était un demi-siècle auparavant, comme on le voit par le plan de Gomboust, qui est à peu près de cette époque 
(Fig. 82) (1). C'était, dit-il, " un véritable paradis ». Il donne aussi de grands détails sur Rueil, dont les magnificences surpassaicnt alors celles des châteaux royaux. Aussi bien "Rueil avait été créé pour le véritable roi, Richelieu ». C'est à Rucil, dit-on, que Le Nôtre emprunta la première idèc de Versailles; mais on a dit la même chose du parc florentin de Boboli. On royait à Rueil une foule de curiosités végétales d'importation nouvelle, notamment les premiers marronniers qui aient été plantés

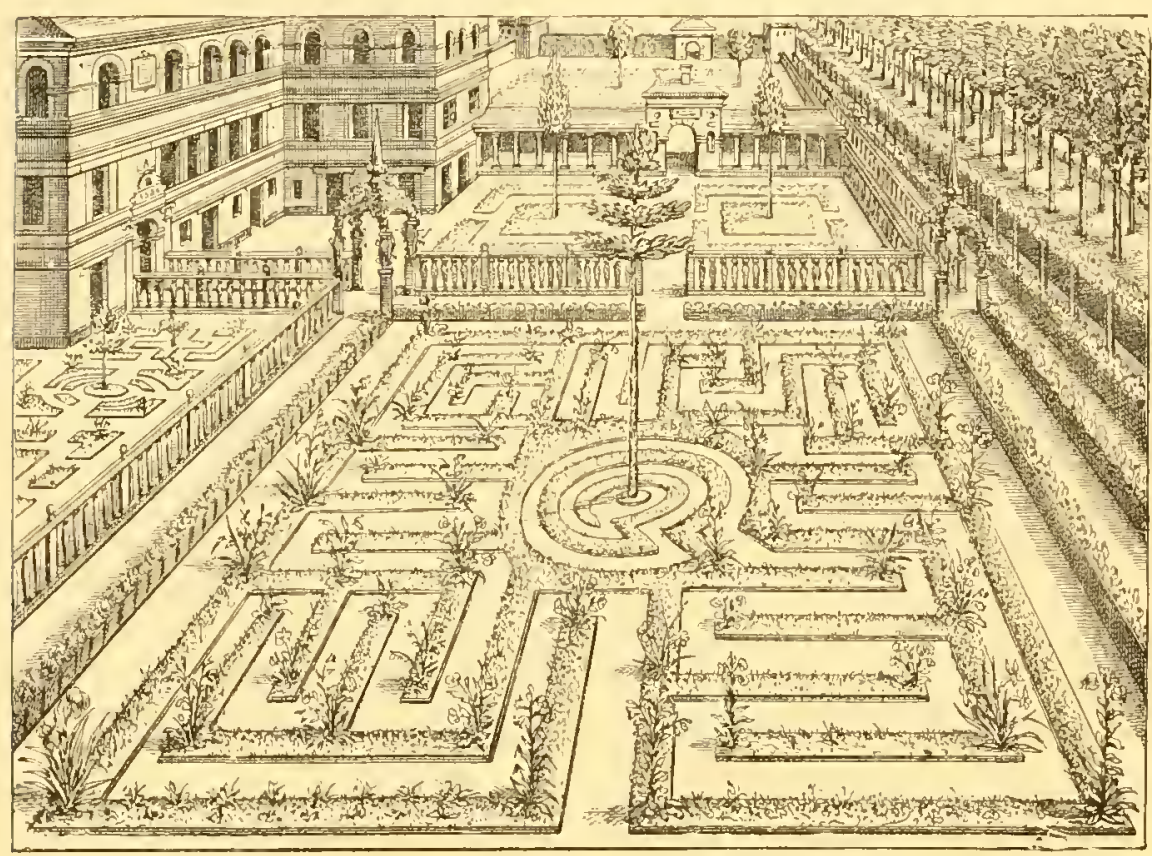

Fig. 80. - Parterre ciselé, d'aprés Jean de Vriés, (Voyz p. 68.) en France. Cet arbre très rustique, et pouvant se prêter à tous les caprices du ciseau, était une conquête précicuse pour les jardins réguliers. Les jeux hydrauliques étaient les plus beaux qu'on eût encore vus en France. Evelyn parle entre autres d'une rangée de mousquctaires qui faisilient feu ou plutôt faisaient cau sur les visiteurs (2). Ce domaine quasi-royal, depuis longtemps nègligé, a été finalement détruit en 1793 .

(1) On voit qu'il s'était opéré de grands clıangements depuis Henri IV. Le palais était alors affecté au logentent de Mademoiselle (de Montpensier) (Fig. 82). On renarque, à la hauteur du passage voùté qui existe actuellement en face du pont de Solférino, l'Oisellerie que Louis Xlll avait fait construire. Le bâtiment communiquait avec le palais par un passage souterrain qui servait au roi pour venir voir ses oiseaux; il servit depuis pour des communications moins innocentes, si l'on en croit çtte mauvaisc langue de Tallemant. De l'autre cỏté de la a rue Neuve-Saint-Honoré », on aperçoit les Jacobins. Qui cùt dit alors que cent quarante ans plus tard ceci tuerait cela!

(2) Ces pièges hydrauliques importés d'Italie étaient alors à la mode. Nlte de Montpensier raconte qu'vn 1656 elle alla avec plusieurs seigneurs et dames faire collation chez Esselin, maitıe de la chambre aux deniers de chez le roi, qui avait à Essonnes une bclle maison et des jardins, auxquels les " deniers de cliez le roi " n'avaitnt sûrenent pas nui. Il y avait là une grotte machince qu'on lui haissa traverser impunément, comme princesse. Mais aussitôt après, " on làcha des fontaines sortant du pavé " sous les jupes des autres dames. Tout le monde s'cnfuit ou tomba; une princesse allemande, plus vigoureusement aspergée que les autres, fut relevée « ay'ant son masque croté, son visage de mėme, son mouclıoir, ses manchettes et ses habits déchirćs en la plus plaisante manière du monde. "Wademoiselle avait conservé un excellent sourenir de celte partie de campagne. 
Du temps de Louis XIII, le pare de Rambouillet était déjà l'un des plus vastes de France, mais la célébre marquise, qui s'était fort gênée pour l'arrangement de son hôtel, n'était plus en état de faire de grandes dépenses à Rambouillet. Aussi la majeure partie du pare restait à l'état naturel de forêt, et n'en était que plus agréable, suivant nos idées modernes. Le seul souvenir qui se rattache à cette époque est celui des roches oú, suivant une tradition attestée par Tallemant, Rabelais était venu souvent se reposer dans le grotte qui porte encore son nom. C'était parmi ces roches,

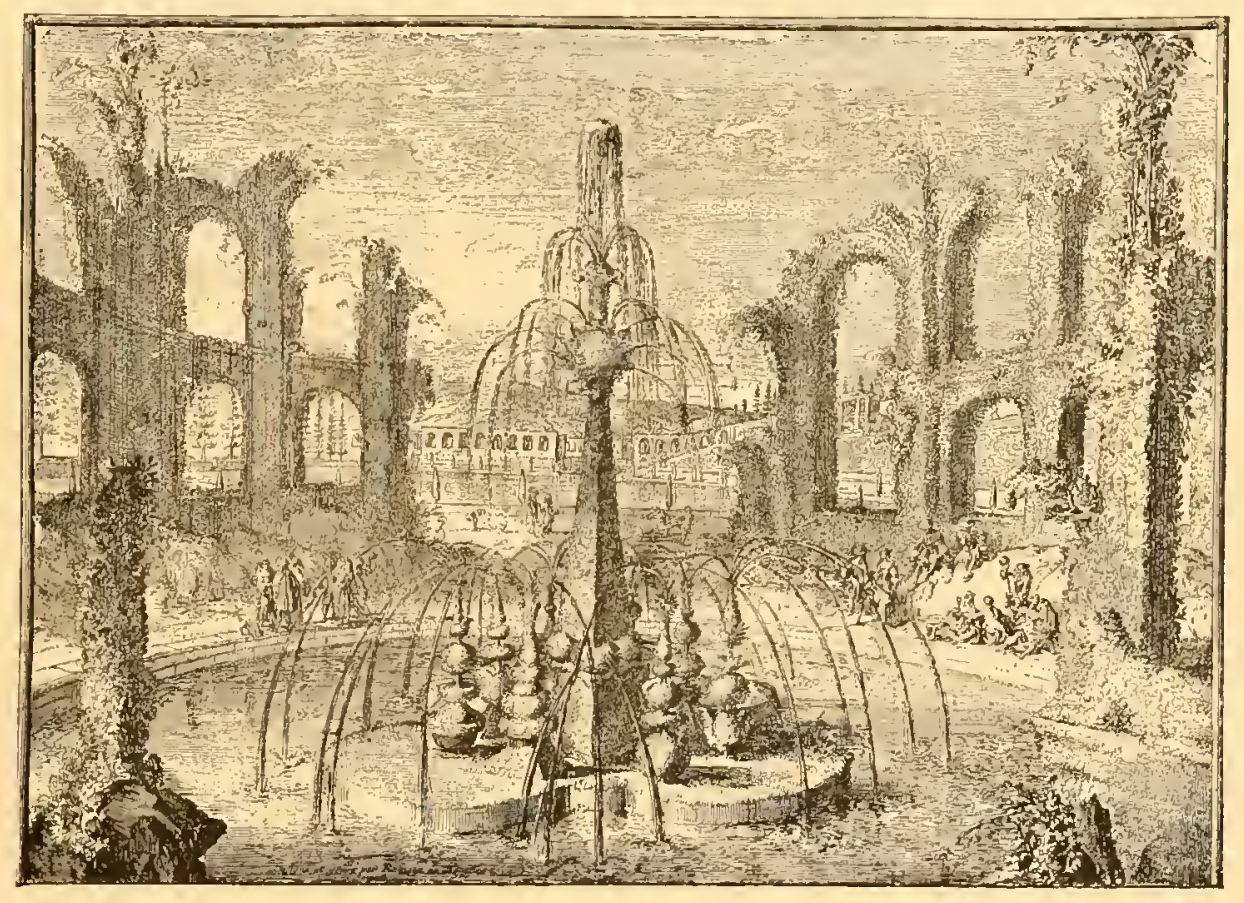

Fig. 81, - Architecture découpée en Verdure, Palissades en Buis, Fontaine, etc. (Toyer p. 68.)

qui se trouvaient alors dans une prairie dont on a fait depuis une île, que la marquise donnait ses fameuses fêtes mythologiques. (V. son article dans Tallemant.)

Il y avait aussi dés lors des jardins bourgeois de médiocre étendue, mais bien entretenus et que la meilleure compagnie allait voir par curiosité. De ce nombre était à Paris même celui de Nicolas des Yvetaux (I), qu'on appelait le dermier des bonmes, parce qu'il demeurait rue des Marais-Saint-Germain (où Racine demeura aussi dans la suite, aujourd'hui rue Visconti); et que sa maison était la dernićre de Paris de ce côté-lá. Elle communiquait par une voûte souterraine avec le jardin, qui 


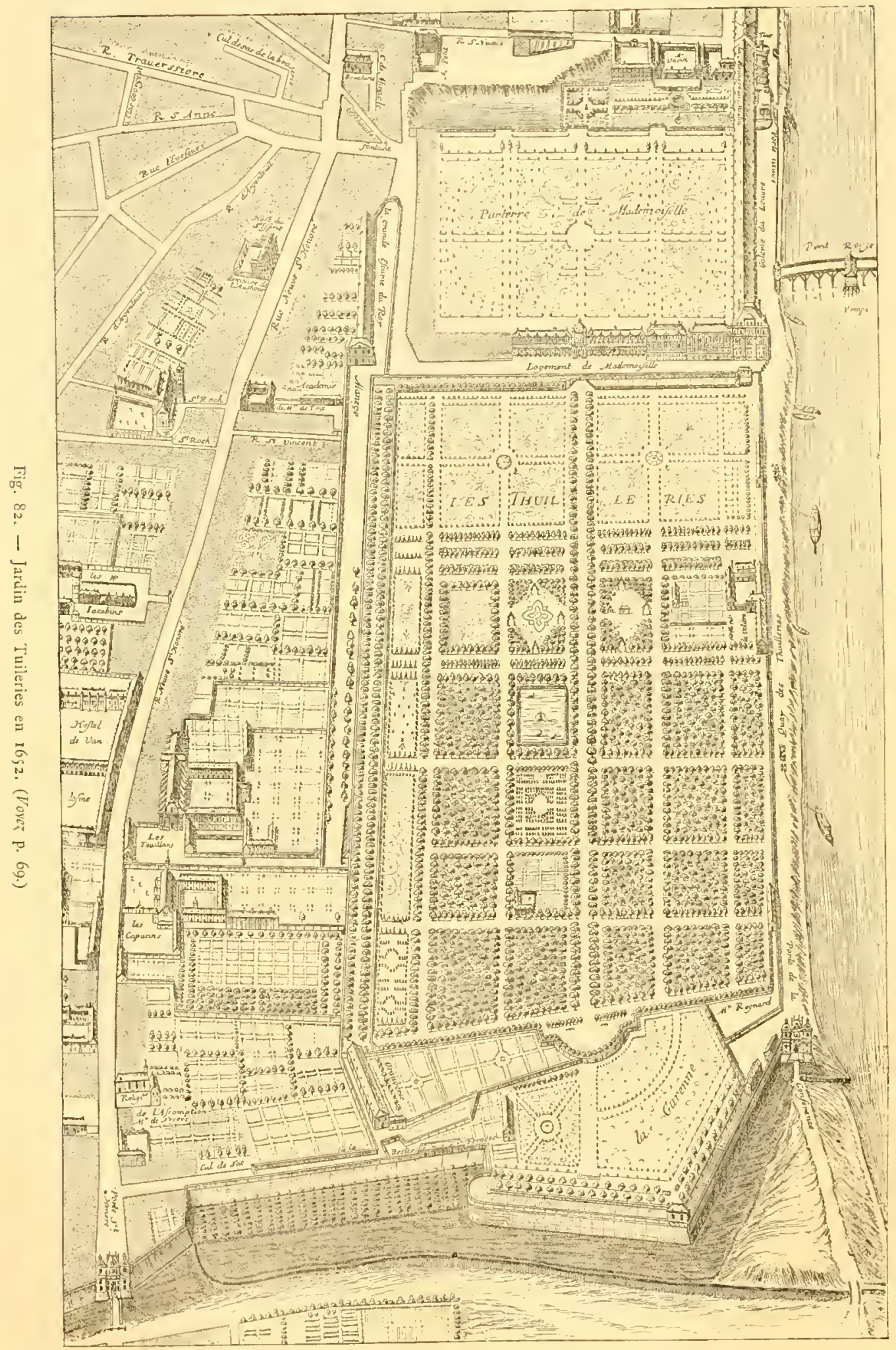

arait une sortic sur la rue du Pré-aux-Clerés. Suivant Tallemant, "la maison était 
disposéc aussi extravagamment que maison de France, ainsi que le jarlin et le bonhomme costumé à l'avenant. " Par malheur, Tallemant ne nous dit pas en quoi consistait la disposition extralvagante de ce jardin, mais nous possédons celle du jardin de Conrart, le premier secrétaire perpétuel de l'Académie française. Elle se trouve dans la Clélie de Mle de Scudéry, où Conrart est désigné sous le nom de Cléodamas, et sa propriété sous celui de Carisatis.

"Imaginez-vous qu'on trouve en arrivant à Carisatis une cour proportionnée à celle du bâtiment qu'on roit à ganche ch chtrant... Pour la face qu'on a en aspect, c'est une balustrade, au delá de laquelle est une espéce de vestibule rustique bordé par un rang de grands arbres, qui semblent n'être lá qu'afin qu'on ne trouve pas d'abord cette admirable vue qui fait les délices de ce lieu-lá. Derricre cette haute allée oú

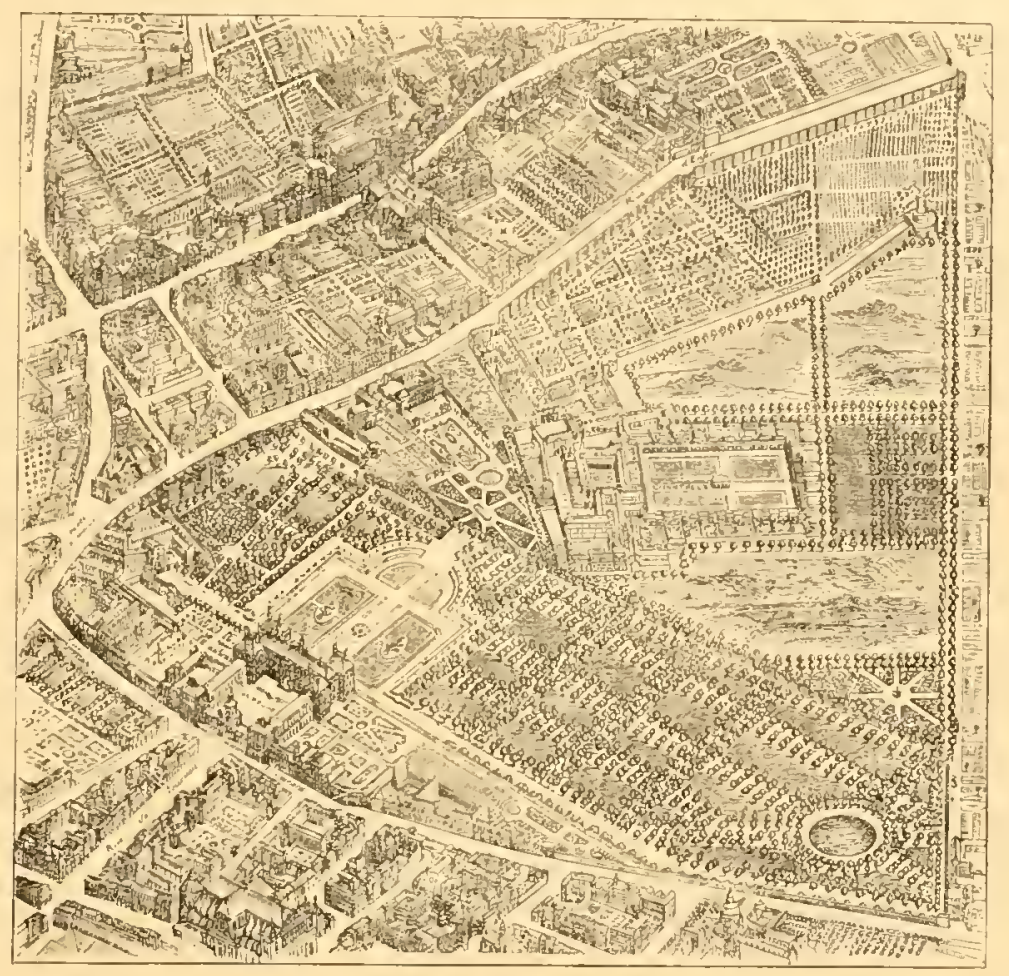

Fig. 83. - Vue à vol d'oiseau du Palais et des Jardins du Luxembourg at xv1 Siècle. (Toyez p. 74.)

l'on découvre tant de choses, est un beau verger et un bois si agréable, qu'on ne le sçauroit trop louer. Il n'est toutefois pas de grande étendue, car il n'a que huit allées principales, au milieu desquelles est une grande figure de Vénus. Mais il a tant de petits sentiers et de petites routes solitaires, et elles se croisent tant de fois, qu'on peut s'y perdre et s'y lasser. Il y a aussi sept cabinets (de verdure) de diverse grandeur, et les plus jolis du monde. Les arbres en sont si beaux, le vert si trais et l'ombrage si charmant, qu'il n'est pas possible d'être en ce lieu-lá sans plaisir et sans esprit. Il semble qu'on n'ose y estre malade ni malheureux. "

C'est aussi de cette époque que date une création plus importante, celle du Luxembourg. (Fig. \$3.) Le dernier jardinier habile dont le nom ait été conservé 
avant Le Nôtre, est Boyceau, qui travaillait pendant la minorité de Louis XIV. Nous reproduisons (Fig. $S_{4}$ ) le plan d'un parterre de broderies, exécuté à SaintGermain par ce Boyceau, en 1653. Le dessin ne manque pas d'élégance, mais semble aujourd'hui plus propre ì servir de modéle d'orfévrerie ou de tapisserie, qu’ì être exécuté en verdure et en fleurs. Ce fut Le Nôtre qui fit passer la mode de ces parterres, dont il disait " qu’ils n'étoient bons que pour les nourrices qui, ne pouvant quitter leurs enfants, s'y promenoient des yeux et les admiroicnt du deuxiéme étage. Il y excelloit néanmoins, comme dans toutes les parties des jardins (1). Mais il n'en faisoit aucune estime, et il avoit raison, car c'est ou on ne se proméne jamais. »(Saint-Simon.) Cette critique est parfaitement justifiéc par les spécimens de ces parterres qu'on voit encore dans quelques villas italiennes, par exemple ceux de l'Isola Bella et de la villa Pamphili. Vu des fenêtres du palais, celui-ci produit l'effet d'un vaste tapis de couleurs voyantes, représentant des armoiries ornées de guirlandes et autres ormements. Il existe encore en France, dans le jardin de l'Hôtel-dc-Ville de Castres, un curieux parterre de ce genre.

(1) Il l'avait bien montré dans l'exécution du Parterre des Fleurs, sur les dessins de Lebrun, au Chiteau de Vaux.

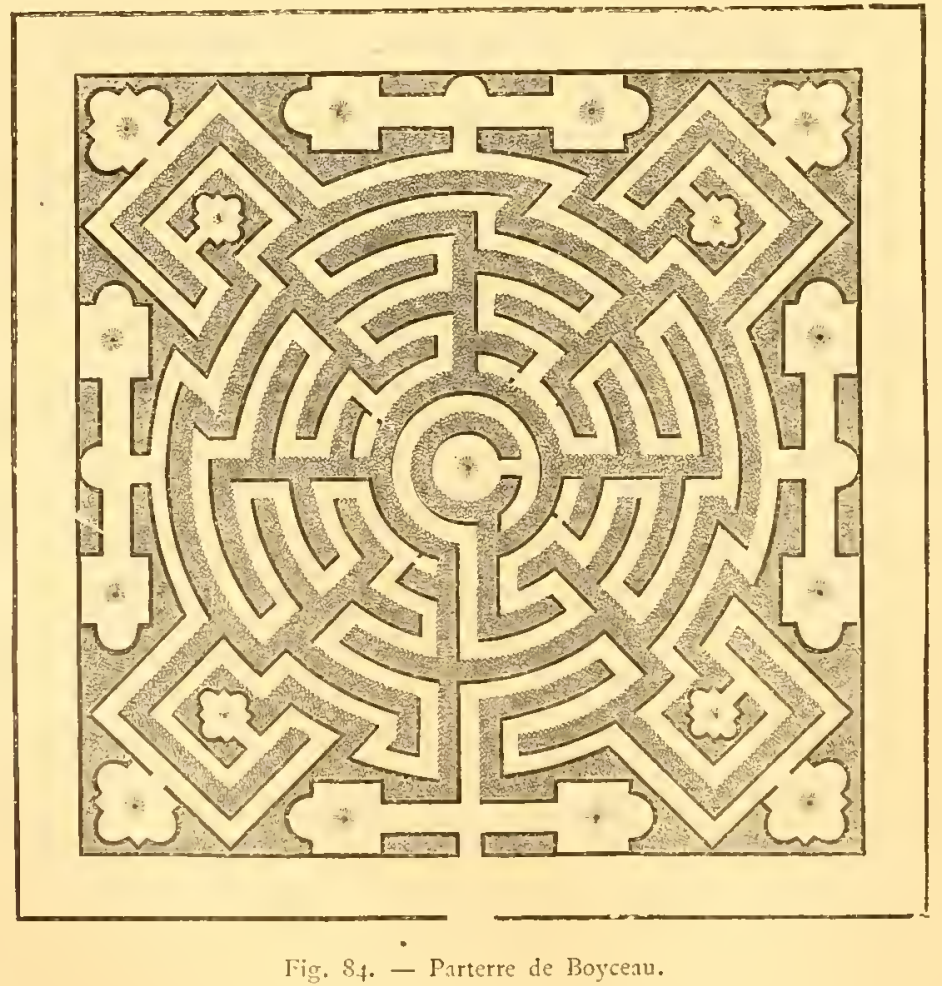




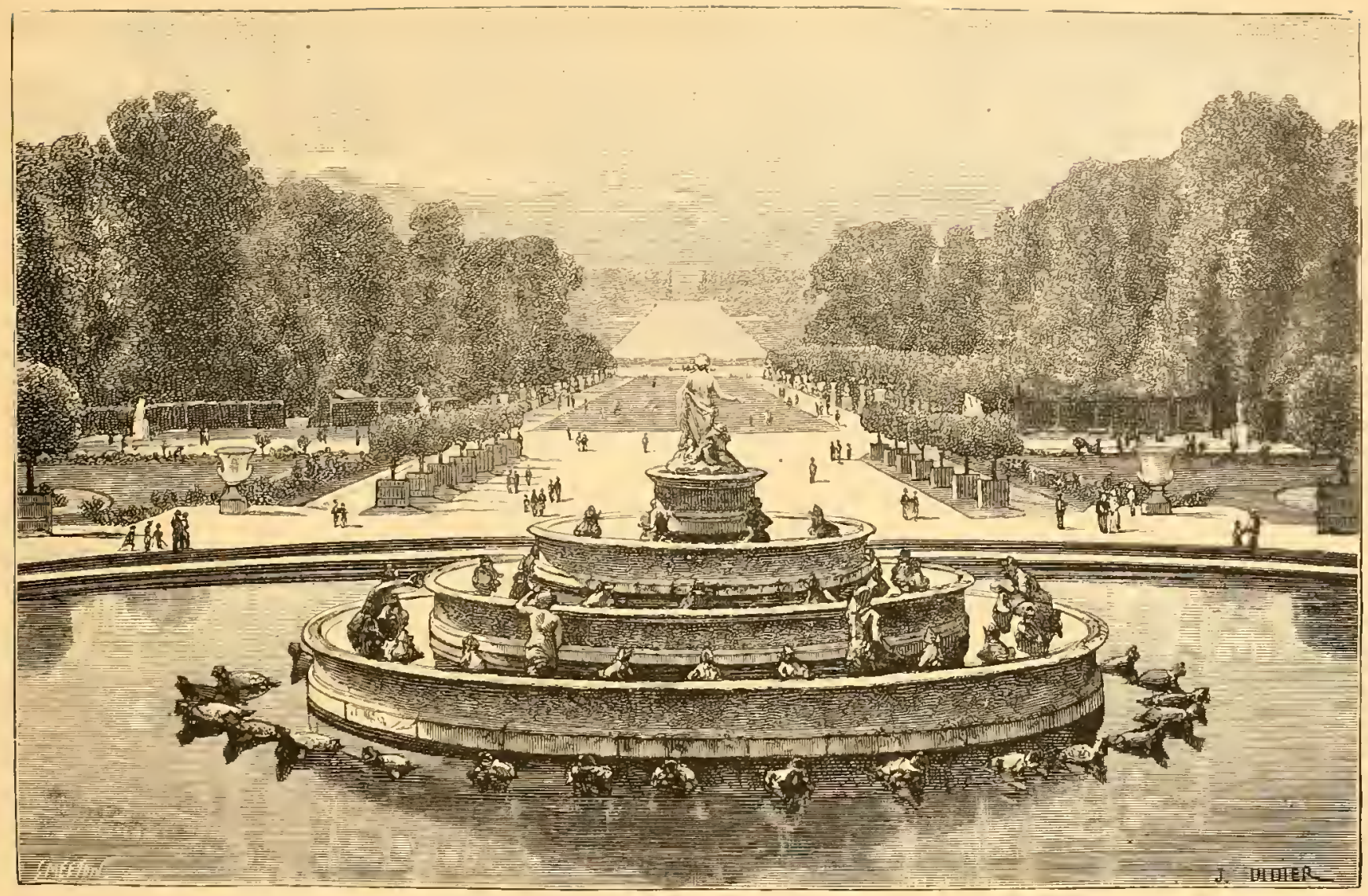

Fir. $S_{j}$. - Pare de Versailles. Vue de la Fontaine de Latone et du Tapis-Vert.

\section{JARDINS FRANÇAIS DU DIX-SEPTIĖME SIÉCLE (Le Nôtre)}

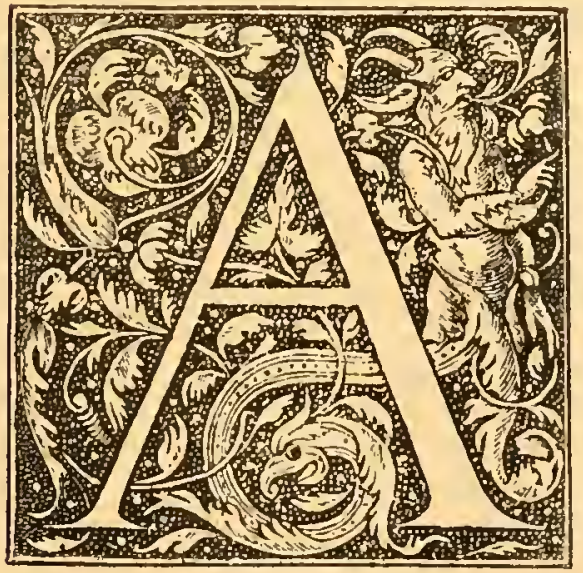

PRÈS avoir vécu quatre-vingt-huit ans dans une santé parfaite, Le Nôtre (Fiğg. 9I), dit Saint-Simon, mourut (en i 700) avec sa tête et toute la justesse et le bon goût de sa capacité, illustre pour avoir le premier donné le dessin de ces beaux jardins qui décorent la France.

“ Le Nôtre avait une probité, une exactitude et une droiture qui le faisaient estimer et aimer de tout le monde. Il travaillait pour les particuliers comme pour le Roi, et avec la même application; ne cherchait qu'à aider la nature et à rédure le vrai bean an moins de frais qu'il ponvait. Tout ce qu'il a fait est encore fort 


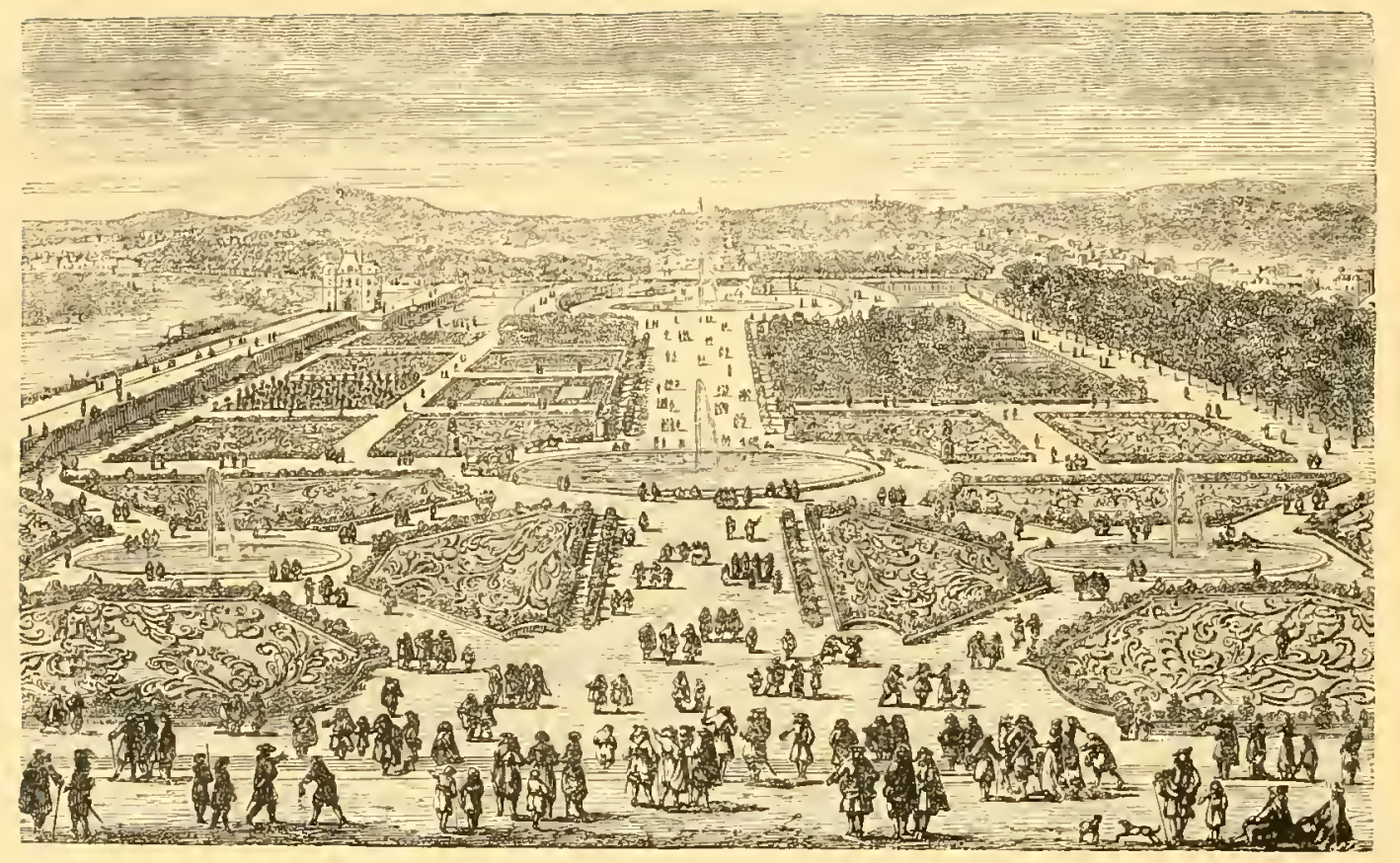

Fig. 87. - Jardin des Tuileries, dapres Le Nötre (1680). (Voyci r. 79)

8. Porte de ha Confèrence. - 2. Cours la Reine. - 3. Mculon, - 4. Le fer à Chevat. - j. Nouveau Chemin

de Virsailles

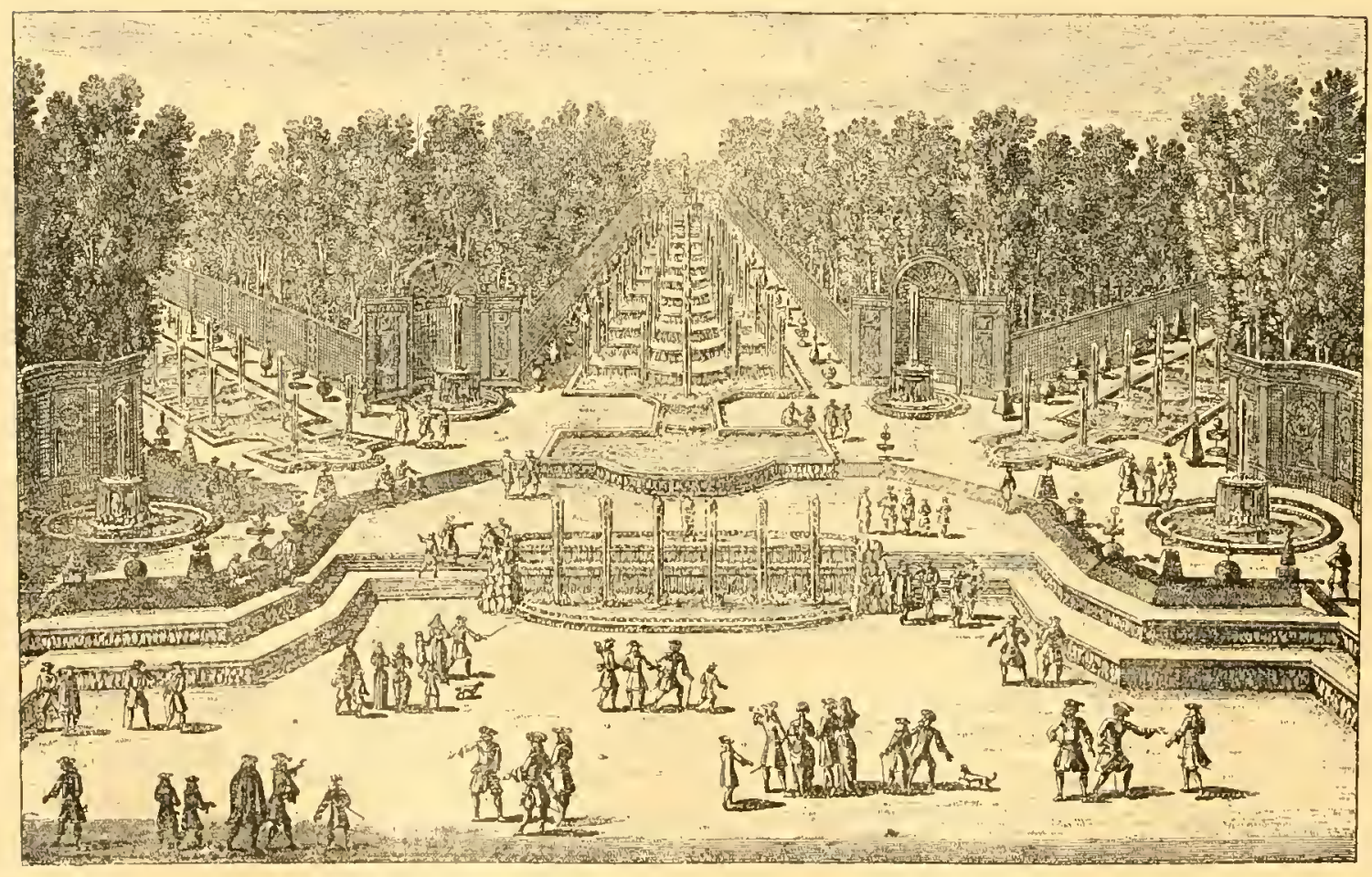



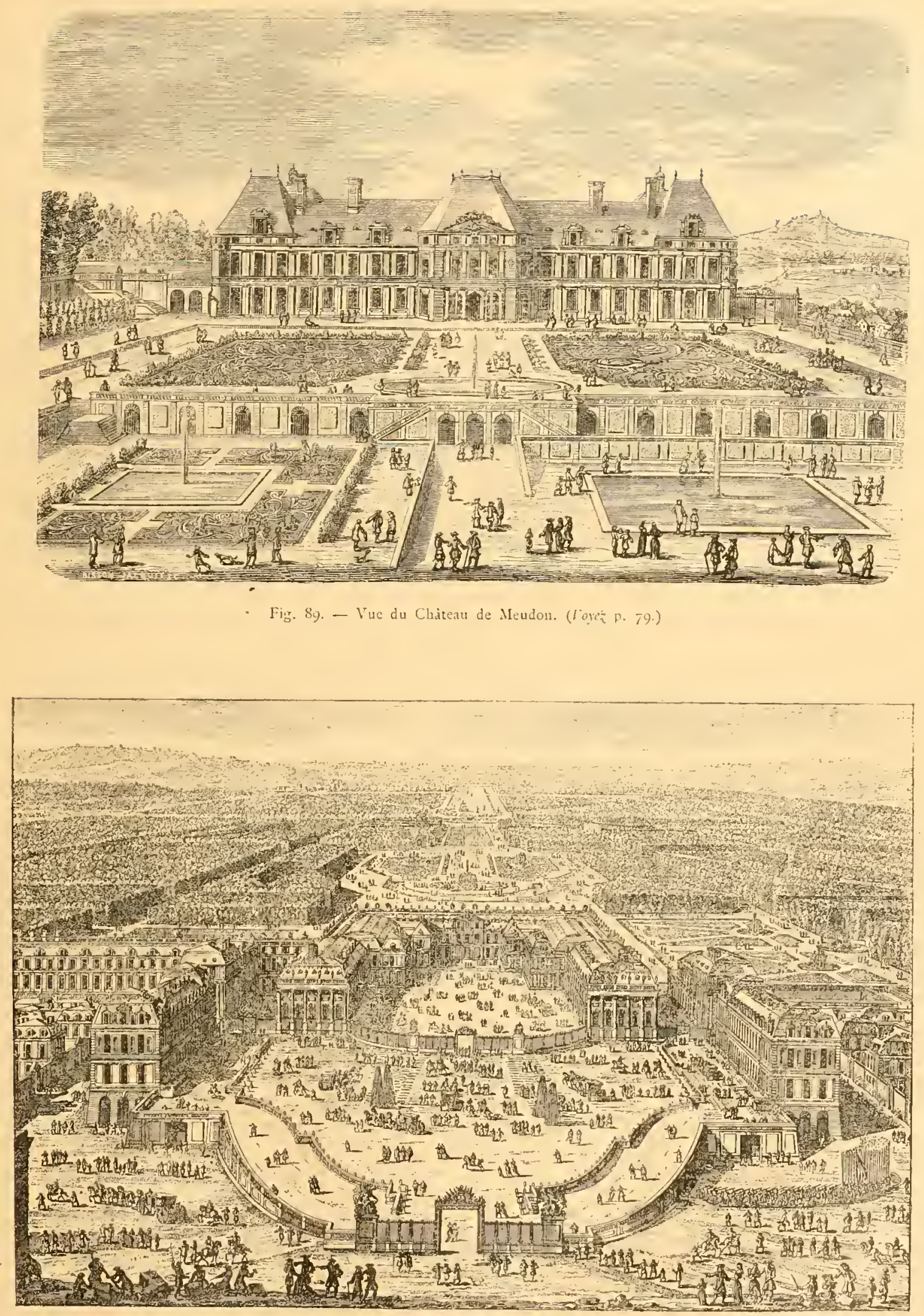

Fig. 9o. - Vue du Clateau de Versailles a vol d'oiseau (1688). (Voyez p. 78.) 
au-dessus de tout ee qui a èté fait depuis, quelque soin qu'on ait pris pour l'imiter. »

Ce fut, comme on sait, le pare de Vaux qui commença la réputation de ce grand artiste; Louis XIV jugea que Le Nôtre ne pouvait être surpassé que par Le Nôtre luimême. Le pare de Versailles (Fig. 85, 88 ì 90, 92), son chef-d'ouvre, a heureusement survécu à toutes les révolutions. C'est le plus prodigieux effort qui ait été jamais tenté, pour metabords d'une réharmonie avec rain.

mémorable poura bien des obsernous bornons à pales. D'abord, décorateurs des de la Renaissance que tous pour beauté des sites, sur ce terrain inse suffire à luipar l'harmonie et nance des lignes lité du paysage,

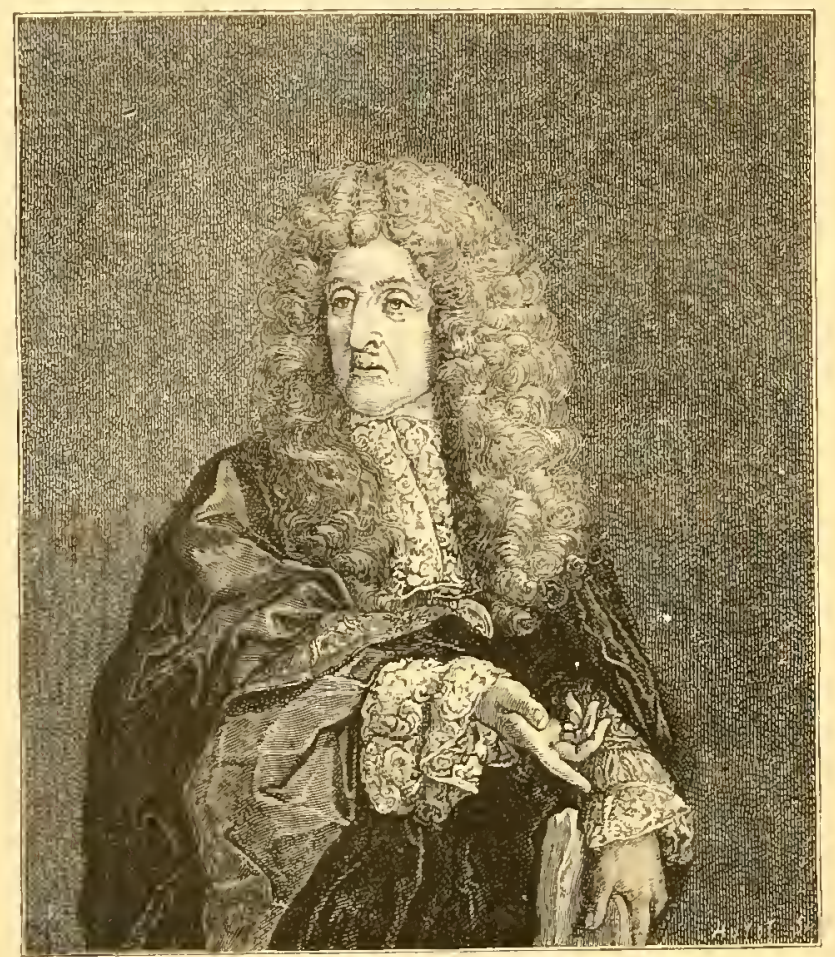

Fig. ǵr. - Portrait d'Andrẻ Le Nỏtre, peint par Carlo Maratti, grave jar Masson. tre la majesté des sidence royale en celle du souveCette ouvre rait donner lieu vations. Nous deux des princitandis que les villas italiennes avaient eu presauxiliaires la Le Nôtre a dû, grat de Versailles, même; suppléer, la belle ordonfactices, à la nulet il était difficile d'y mieux réussir. Ensuite, au milieu de ce colossal triomphe du genre régulier, on déméle tacilement une certaine recherche de la variété. Ce n'est plus lia l'inflexible régularité de la villa Aldrobandini, par exemple. En examinant le détail des bosquets, et même l'ornementation des parterres nord et sud, dans le voisinage immédiat du château, on reconnaît que Le Nôtre s'est écarté de la symétrie par goût et sans nécessité.

Le Nôtre travaillait en même temps ì Versailles pour Louis XIV, et à Chantilly pour le grand Condé. Mais à Chantilly (Fig. 93, 94), son ceurre a subi des retouches qui en ont sensiblement altéré le caractére. En revanche, c'est lui qui a donné aux jardins de Fontainebleau (Fig. 78) leur physionomie actuelle, par la construction de 
la terrasse qui encadre et domine les quatre carrés du parterre et le bassin central. 1] refit presque entièrement le jardin des Tuileries, comme on le voit en comparant le plan de 1680 à celui de Gomboust (Fig. 87). Dans cette conception largement ébauchée, déjà l'on reconnaît les principaux linéaments de l'œuvre définitive; à droite, la nouvelle plantation de la terrasse des Feuillants; puis la majestueuse alléc centrale avec ses deux bassins, prolongée au delà du pont tournant par « le nouveau chemin de Versailles» $\left(n^{\circ} 4\right)$, la future grande allée des Champs-Élysées. Celle-ci, à peine tracée, escalade fièrement l'horizon, et semble déjà réclamer pour point termimus un are de triomphe. A gauche, on voit la terrasse du bord de l'eau, dégagée, mais non encore plantée. La vue, dans cet état ancien, n'en était peut-être que plus belle. Le regard se portait librement sur la porte monumentale de la Conférence, les massifs du Cours-la-Reine et l'amphithéâtre boisé des hauteurs de Meudon.

A Meudon (Fig. 89), à SaintCloud (Fig. 95 et 96), Le Nôtre avait su tirer un excellent parti des accidents de terrain. Bien des détails de la

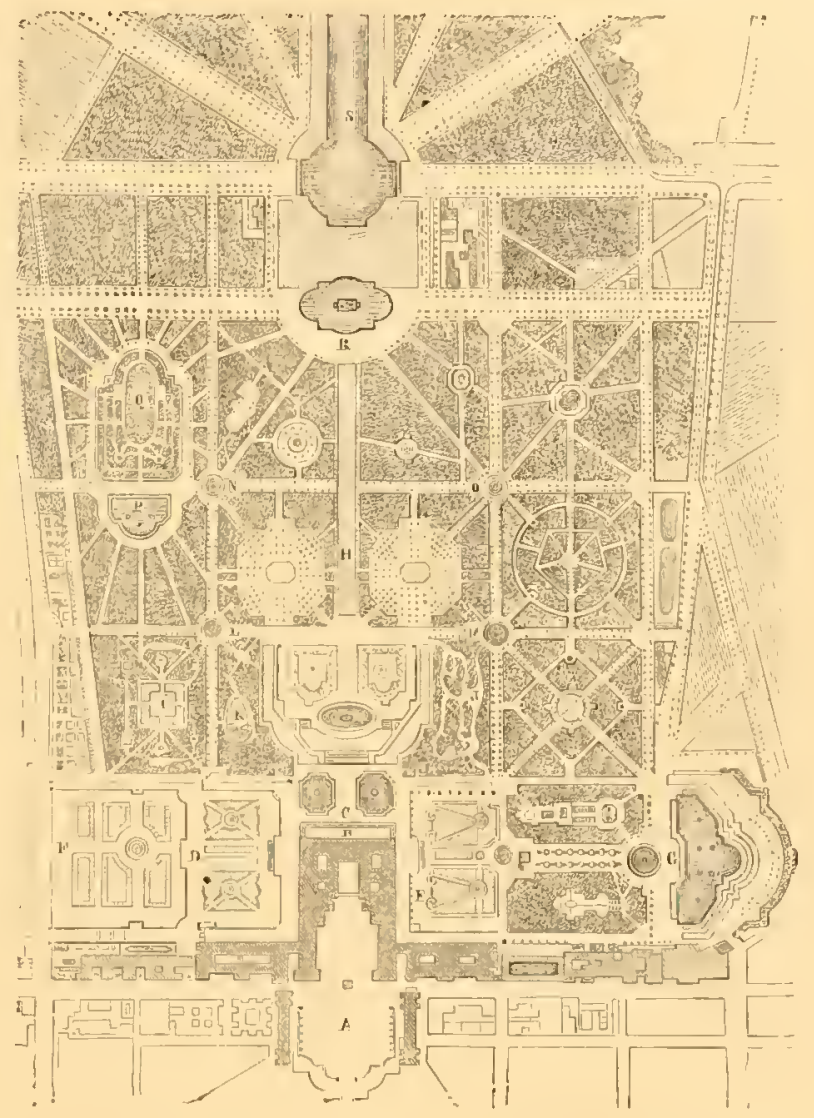

Fig. 92. - Vue du Parc de Versailles. (I'oyer p. 78.)

A. Cour du Chàteau. - B. Galerie de Tableaux. - C. Parterre d'Eau. - D. Par terre de Fleurs, - E. Parterre de Fleurs, - F. Orangerie. - G. Bassin de Neptune. - H. Allée du Tapis-Vert. - I. Labyrinthe, - J. Bains d'Apollon. - Ii. Salle de Bal. - L. Fontaine de Saturne. - MI. Fontaine de Cérés. N. Fontaine de Bacchus. - O, Fontaine de Flore. - P. Fontaine, - Q. lle Royale. - R. Bassin d'Apollon. - S. Caral.

décoration primitive avaient été remaniés ou supprimés dès le siècle suivant, comme la grotte de verdure qui ombrageait naguére la cascade. Mais combien d'autres choses ont péri ì Saint-Cloud!

Aprés avoir travaillé pour Fouquet, Le Nôtre travailla pour Colbert, et le parc de Sceaux comptait aussi parmi ses plus belles créations (Fig. 97). On connait la triste destinée de ce domaine quasi-royal, détruit à la Révolution, sauf une parcelle transformée en guinguette! Mieux vaudrait avoir disparu entiẻrement, comme 


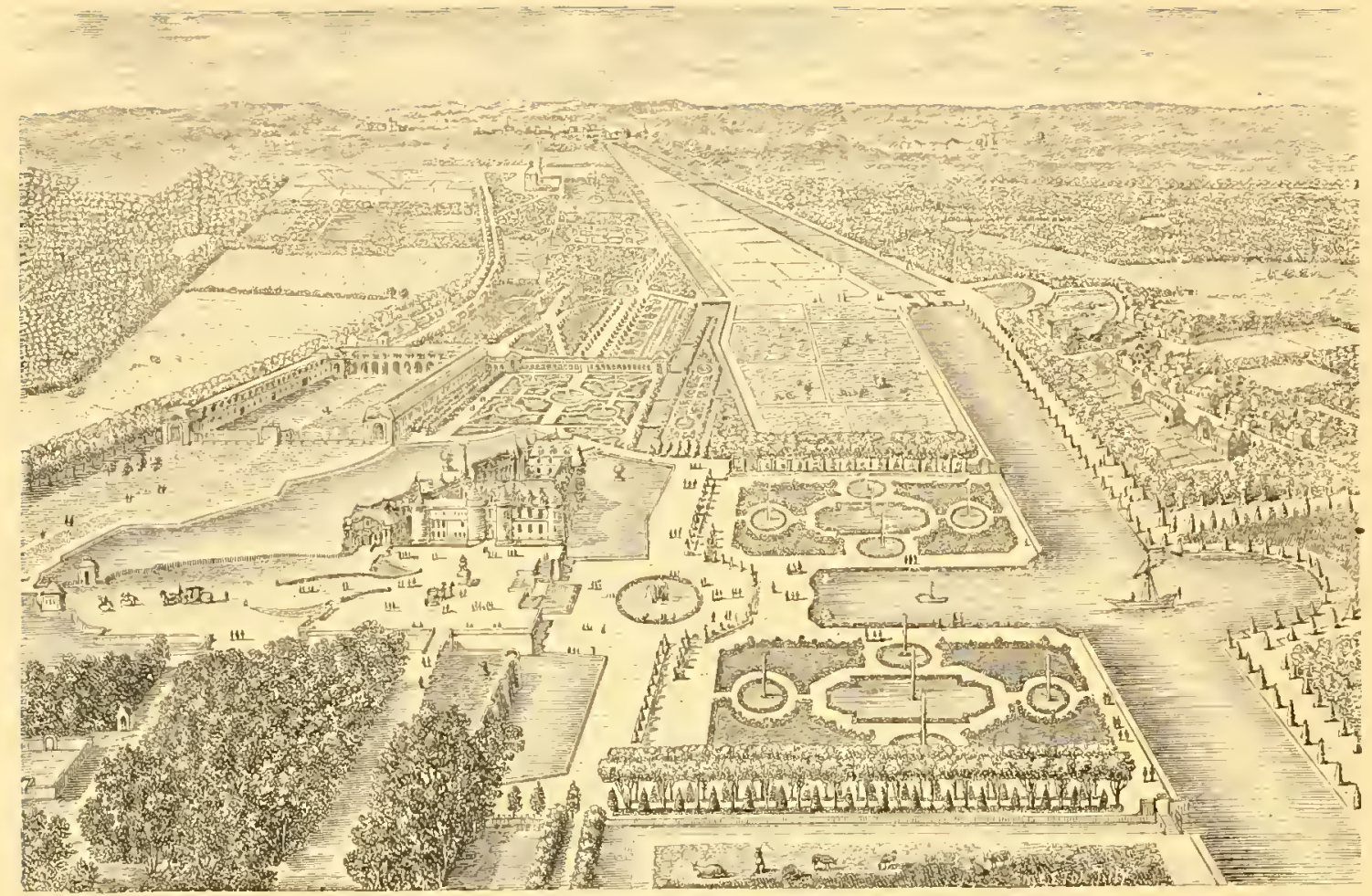

Fig. 9;. - Chiteau et Jardin de Chantilly. (Iogez p. 78.)

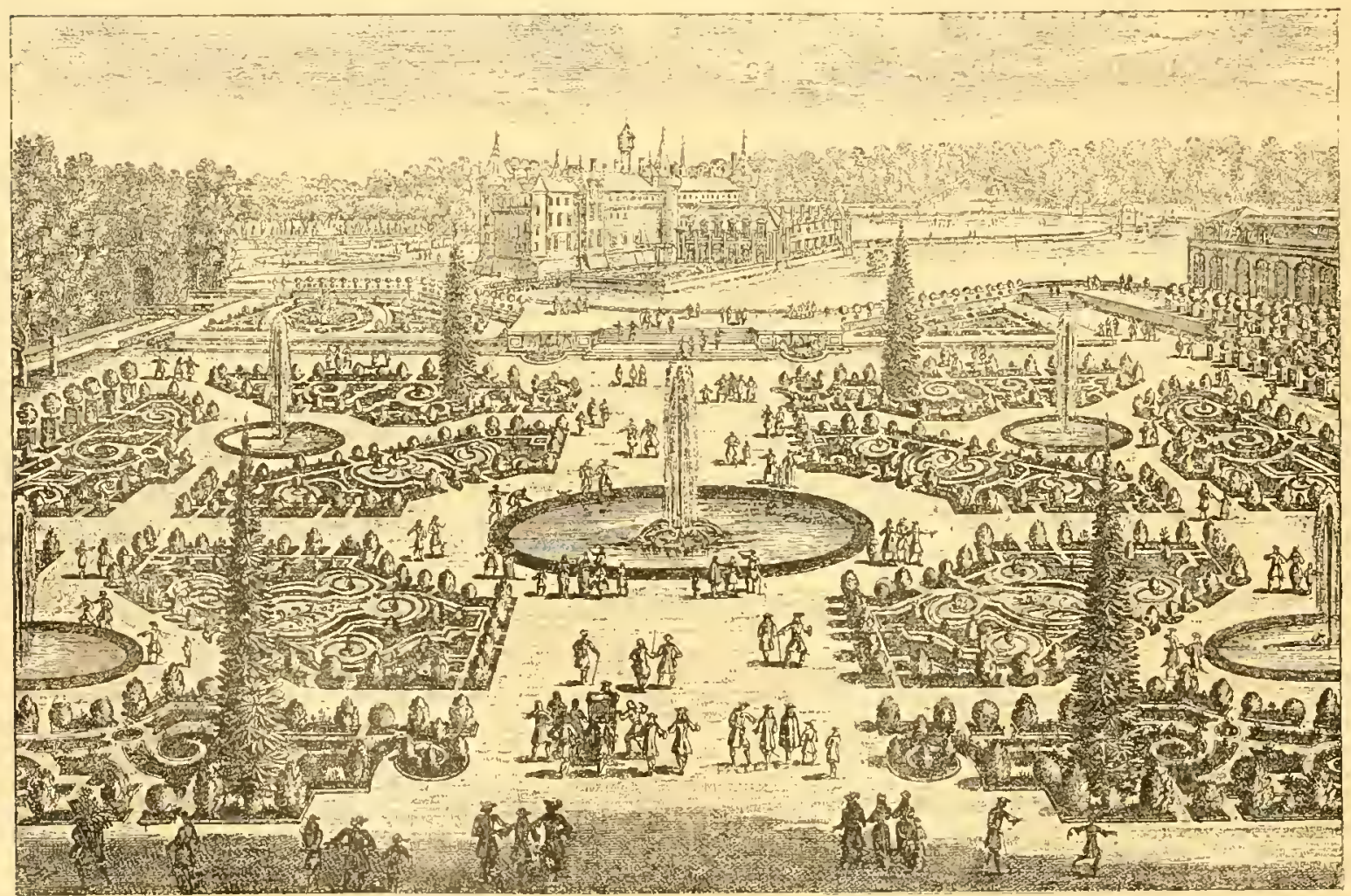

Fig. 94. Chateau de Chantilly avec ses Parterres, (Tove p. 78.) 


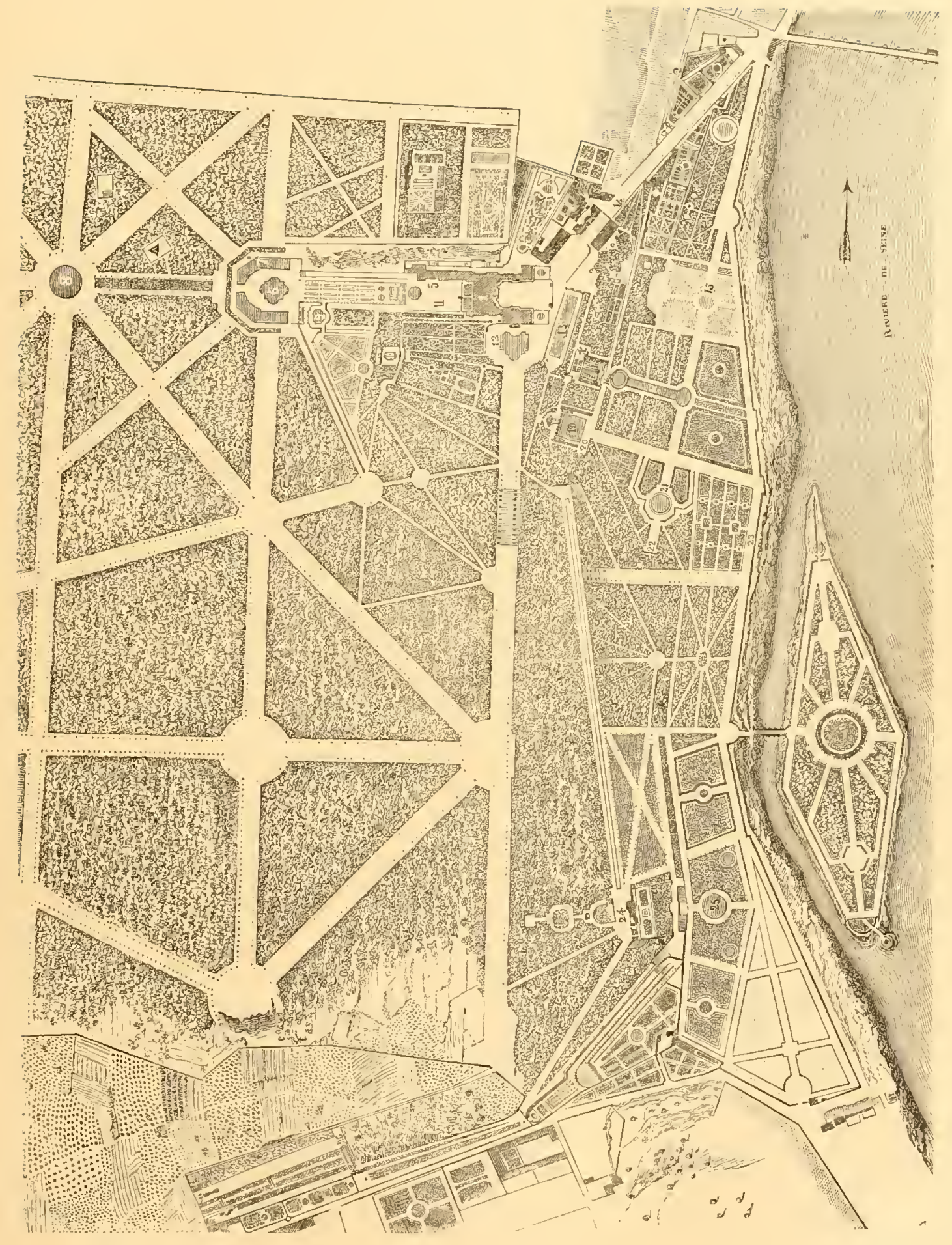

Fig. 95. - Jardins et Parc de Saint-Cloud, créés par Le Nỏtre. (Vogei p. 79.)

I. Chătean. - 2. Jardin de M. le due de Chartres, - j. Jardin d"Apoilon. - 4. Labyrinthe, - 5. Oranceric. - 6. La Gerbe, - 7 Canal des 24 Jets, - 8. La grande Gerbe. - 9. Les Trois Bouillons, - to, La Table de Marbre, - ir. Les Goulottes, - 12. Bassin du Fer a Cleval. - 13. Bassin des Carpes, - 14. Jardin particulier de Son Altesse royale, - 15. Le Tiller, - 16. Les Cascades. 37. Les grandes Nappes, - I3. Le Champignon. - 19. Le grand Jet, - 20. Grotte de Rocailles, - 21. Bassin de la Gerbe, 22. Portíque de Treillage. - 23. Les Bassins. - 24. Trianon, -.. 25. Bassin de Vénus. - 26. Perie Cuscade. 
Clagny, le "palais d'Armide » de Montespan. Il n'en reste que trois rares gravures du temps, dont une rue d'ensemble (Fig. 98), et quelques lignes de

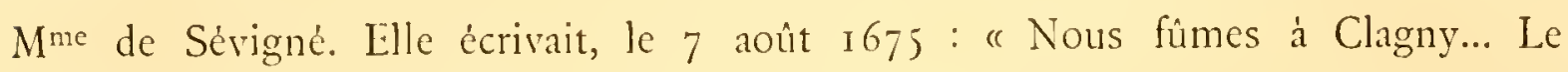
bâtiment s'éléve à rue d'œil, les jardins sont faits. Vous connaissez la manière de Le Nôtre; il a laissé un petit bois sombre qui fait fort bien. Il y a un

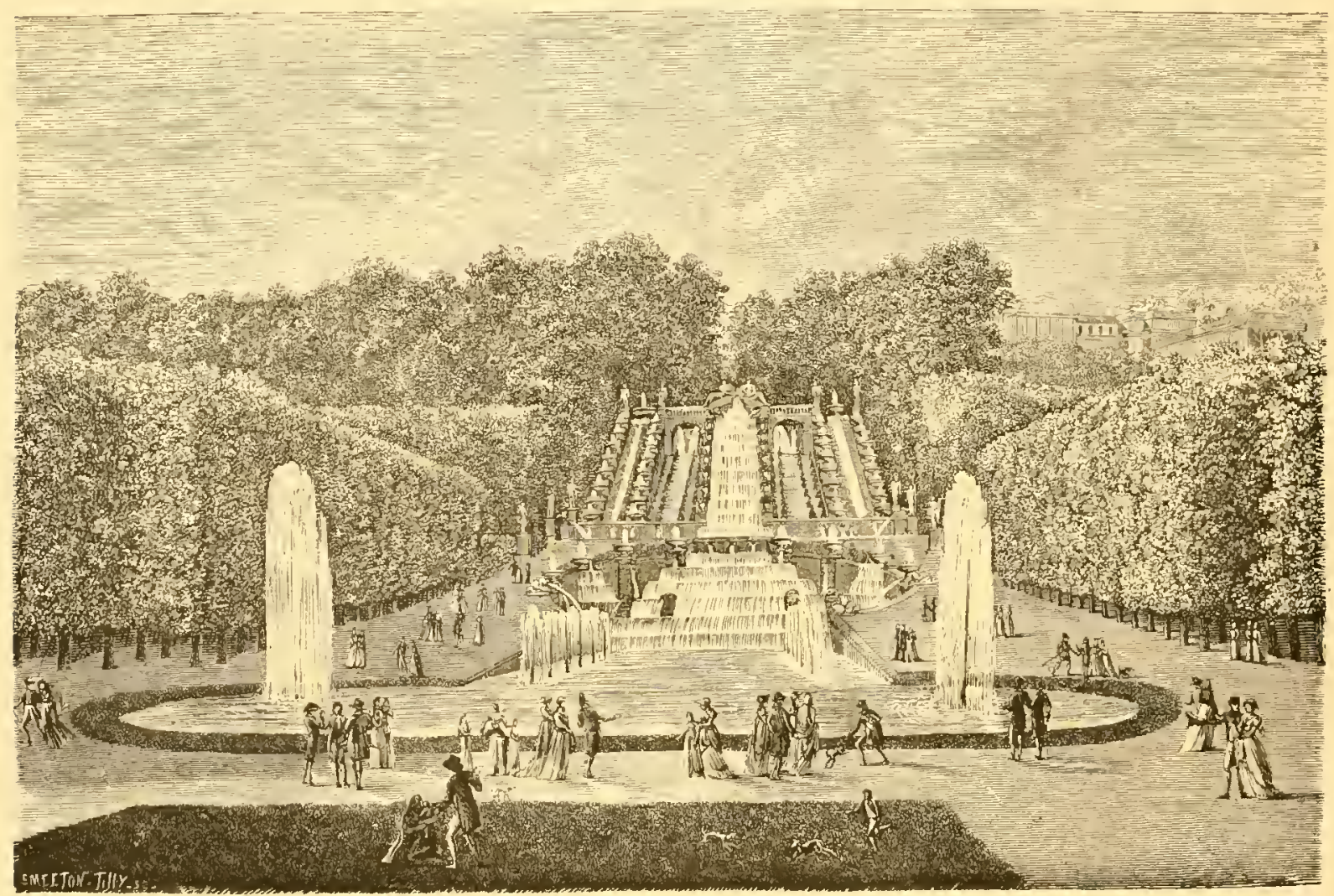

Fig. 96. - Cascade du Parc de Sxint-Cloud, d'après Baltar (Calcographie du Louvre). (I'ogea p. 79.)

bois d'orangers dans de grandes caisses: on s'y proméne; ce sont des allées où l'on est á l'ombre; ct, pour cacher les caisses, il y a des deux côtés des palissades à hauteur d'appui, toutes fleuries de tubéreuses, de roses, de jasmins, d'œillets. C'est assurèment la plus belle, la plus surprenante et la plus enchantée nouveauté qui se puisse imaginer. „ Elle ajoute qu'on aimait fort ce bois, pour lequel on faisait acheter " les tourterelles les plus passionnées. » Onl, c’était l'ami solide de la grande marquise (le Roi), et la marquise elle-même, qu'un peu auparavant $M^{\text {me }}$ de Sévigné représentait au milieu de ses ouvriers, pareille à Didon faisant bâtir Carthage. Cette charmante description atteste la souplesse du talent de Le Nôtre, qui savait 


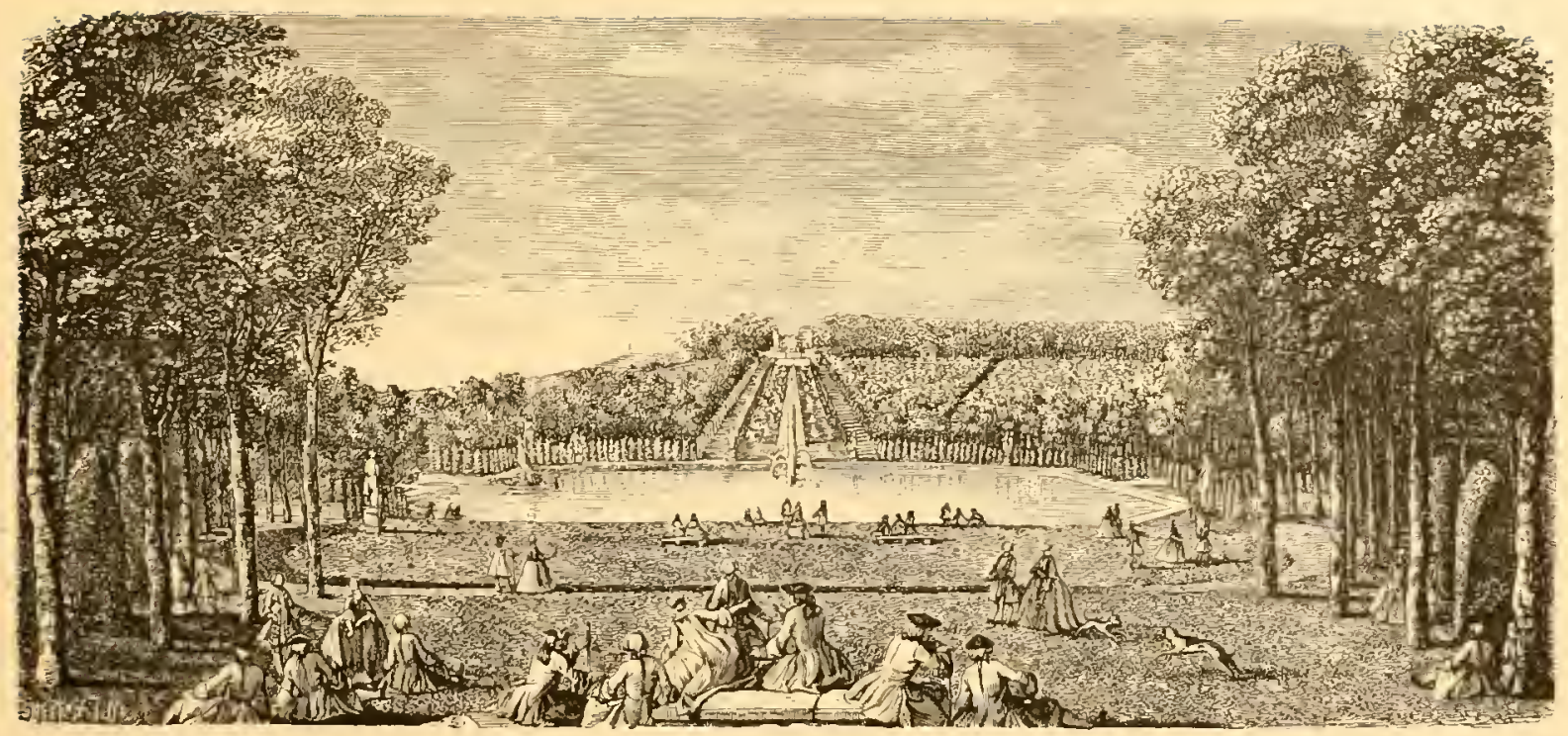

Fig. 97. - Cascade du Pare de Seaux, d'aprés Rigaud. Voyez p. 79.)

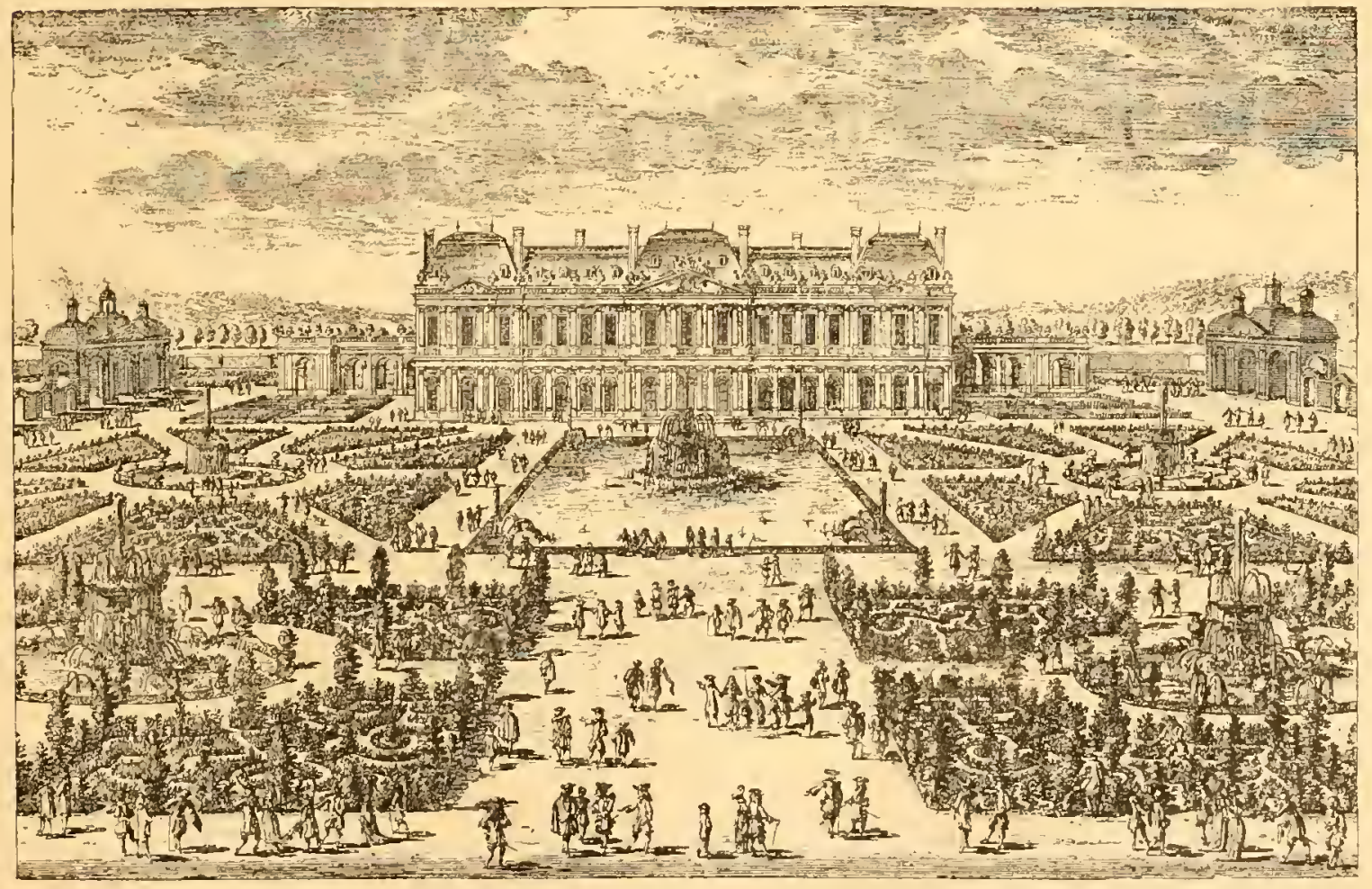




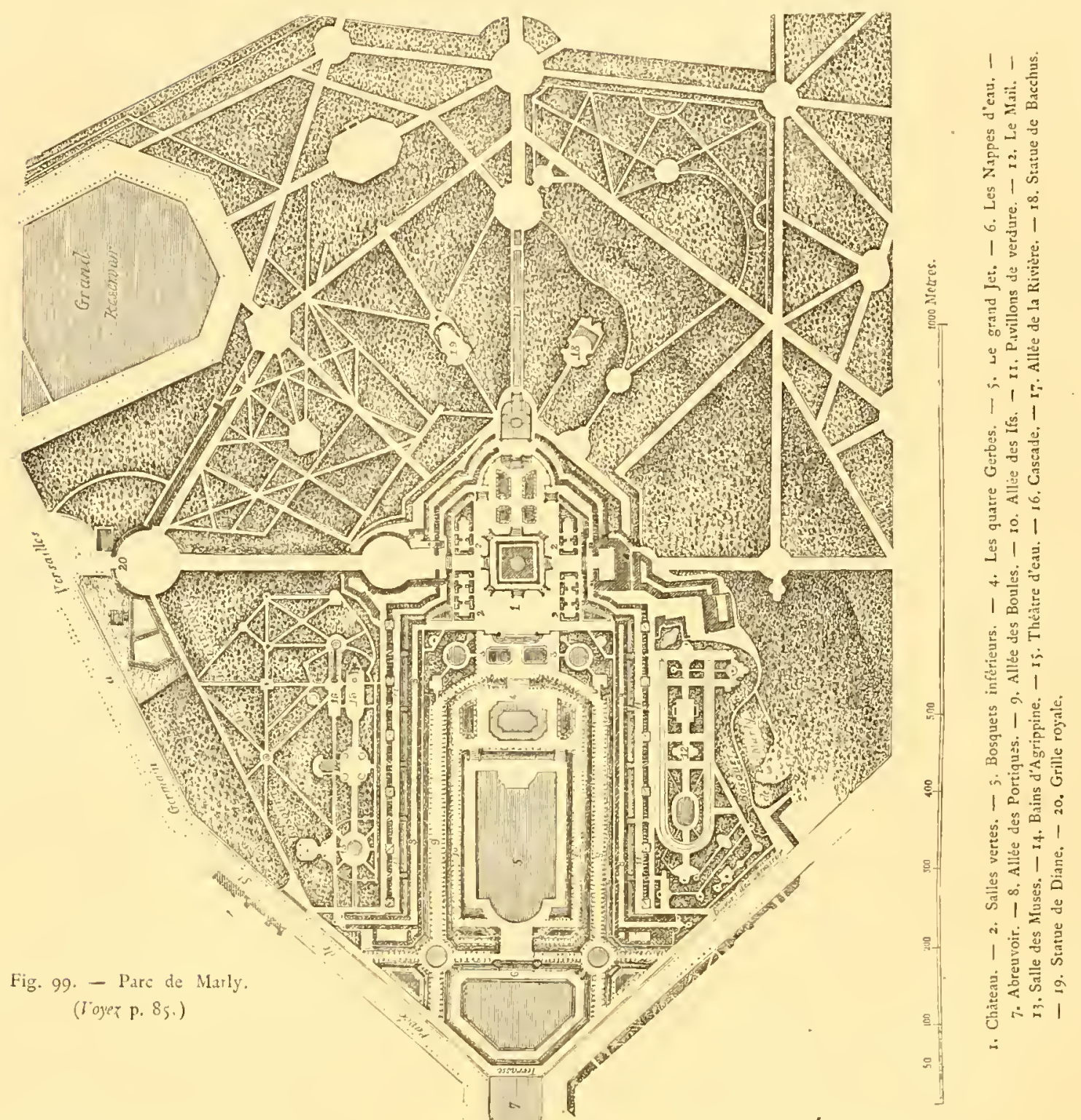

allicr au besoin la grâce à la occupait dans son curre une

A Saint-Germain (Fig. 70), le travail de Le Nôtre (I674), reconnaissable, mais la terl'une des plus magnifiques rope, pour la vue et l'étendue

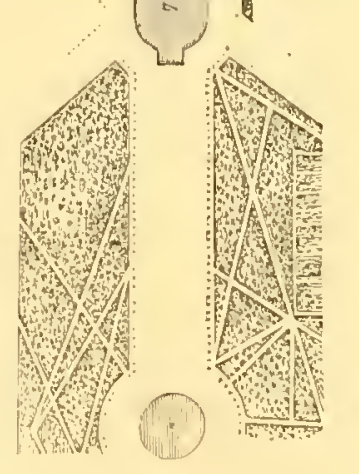

majesté. Évidemment Clagny place spéciale (I).

il faut citer, non le parterre, ou plusicurs fois remanié, n'est plus rasse, établie par lui en 1672 , promenades qui existent en Eudu parcours. I.c Nôtre, bien qu'octogénaire, conçut et cxécuta lui-même en partie une autre création non moins

(1) On sait que Clagny coûta ذ̇ la France, tout conpris, la somme de 2,861,728 livres 7 sous 8 deniers. Quand ce fut fini, le rìgne de la marquise ćtait sur son déclin. Aussi le Roi, qui avai si souvent prescrit de ue rien épargner, tronva la dépense excessive. 
remarquable et d'un genre tout différent, l'Ermitage de Marly (Fig. 99) (I), dont les plantations furent terminées par Duruzé, l'un de ses éléres. On doit aussi à Le Nôtre la promenade publique de Dijon, l'une des plus belles de France, qui a heureusement survécu aux révolutions et échappé à peu prés aux remaniements; celle d'Amiens (la Hotoie), qu'a chantée Gresset; - le jardin royal de

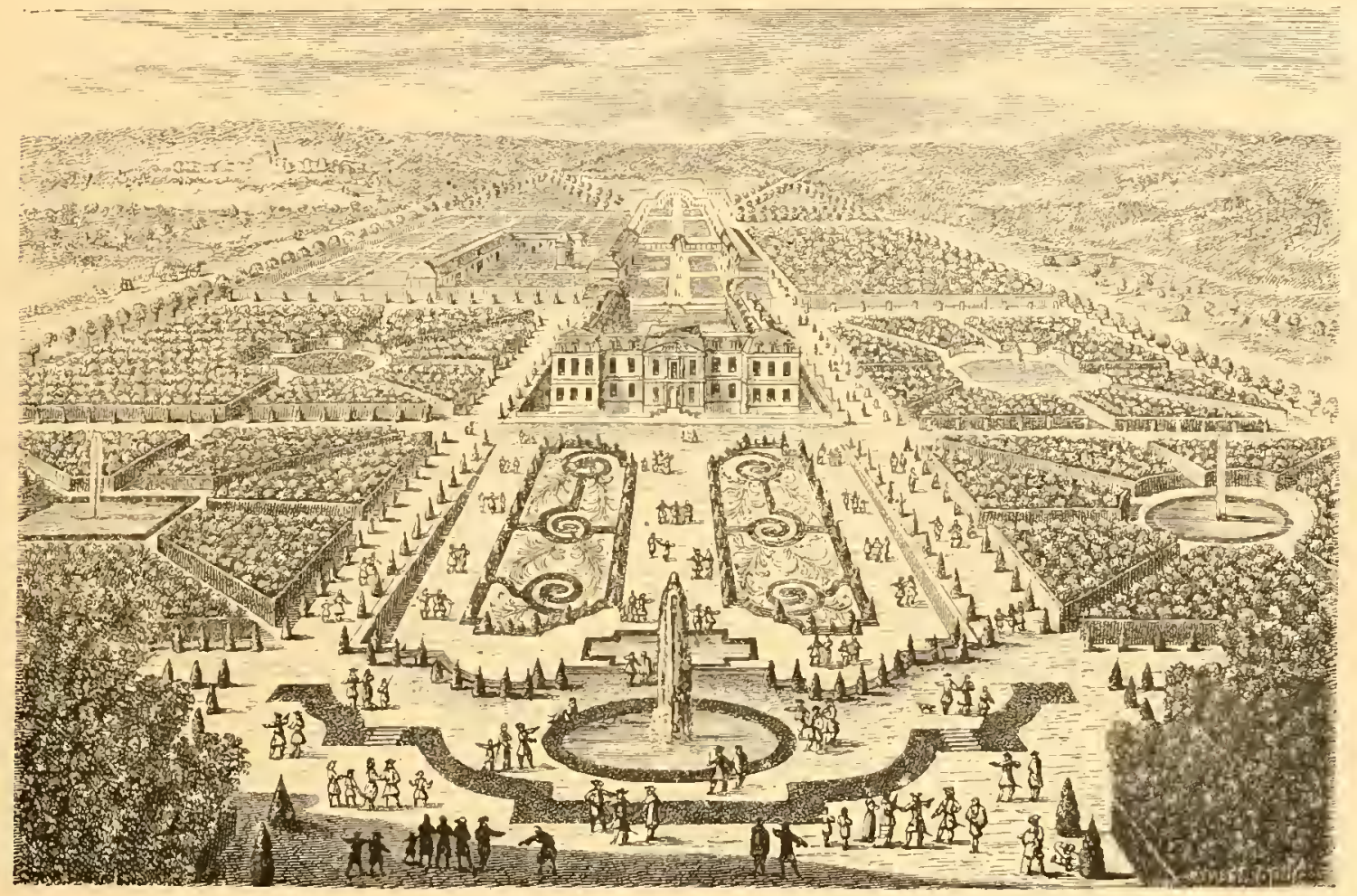

Fig. Ioo. - Chiteau de Lauvois, prés de Reims.

Turin, auquel il avait su fort habilement donner un air de grandeur, malgré sa petitesse réclle, etc. Micux cncore que les palais, les parcs de Le Nôtre mettent en relief la grandeur de l'ancienne société française, et celle des catastrophes qui l'ont frappée.

On retrouve l'imitation de Le Nôtre dans tous les parcs français ou remaniés en France jusqu'i l'avénement du style irrégulier, dont on a conservé d'anciens plans, comme ceux de Louvois, prés de Reims (Fig. Ioo) et de Liancourt (Fig. ror) (2).

(1) Mimotres du marquis de Sourches, IV, 194. Ce serait i Marly que Lnuis NIV aurait fait pronener Le Nôtre en chaise à cỏté de lui, un mois avant la mort du célébre jardinier.

(2) Dans ce dernier plan, le grand bocage d'alles convertes et accolées, qu'on remarque sur la droite, doit remonter à une époque antérieure. 


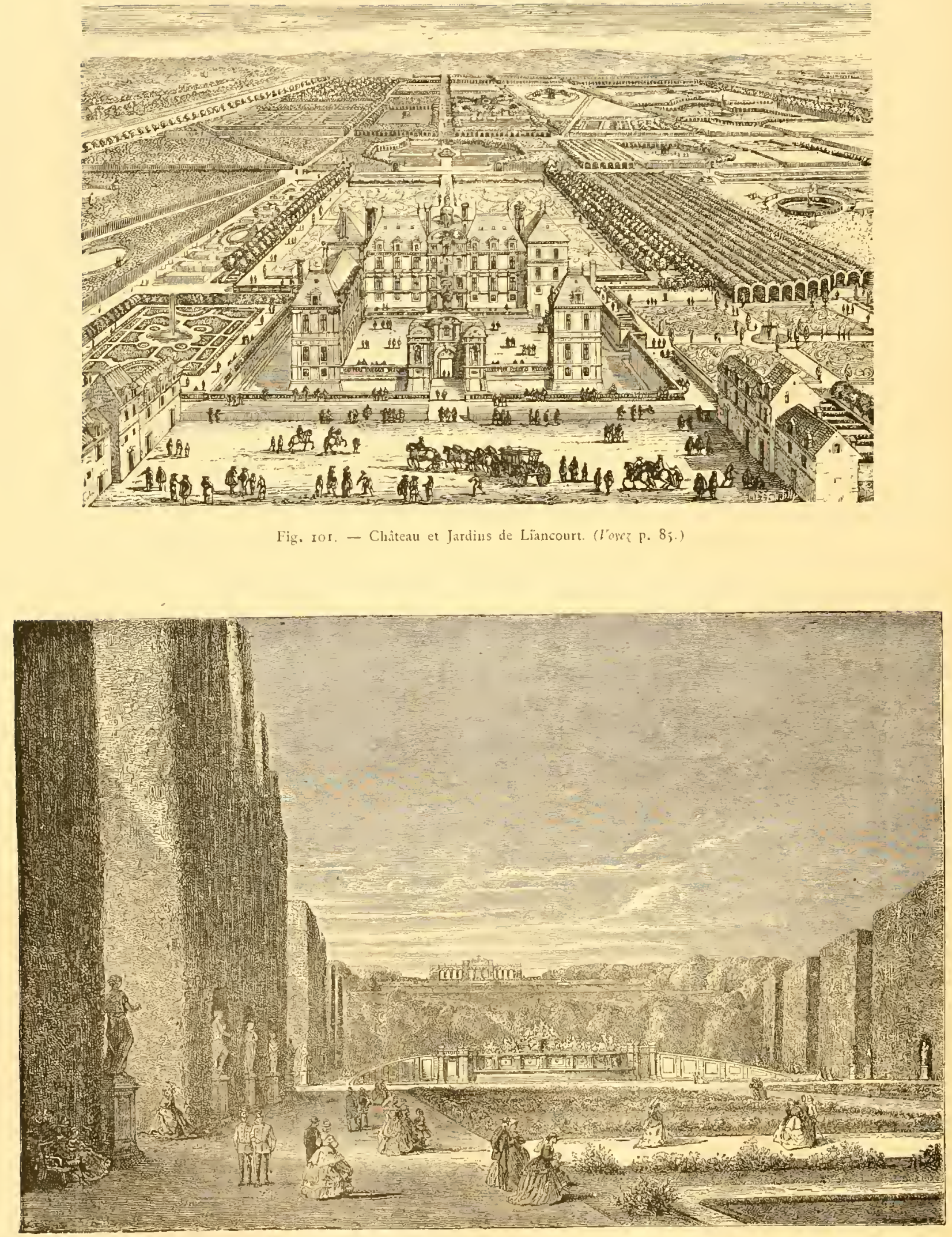




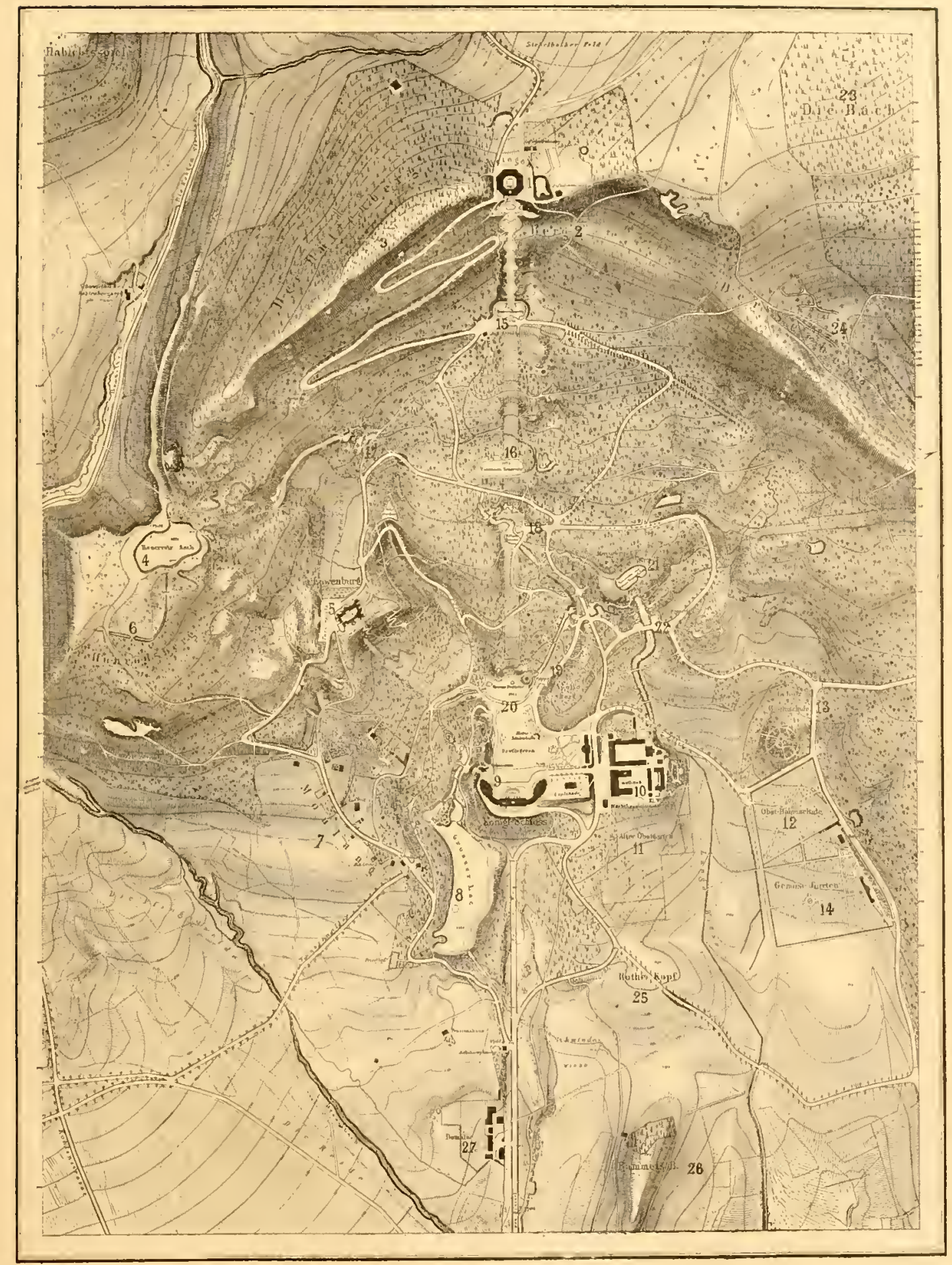

Fig. 103. - Pare de Wilhemshulse, piés Cassel. (Dessiné par Kaupert. Phan publié par la librairie Schropp, de Berlin) (Voyci p. go.)

1. Hauteur d'Hercule. - 2. Montagne de Clarles. - 3. Hinteur de la Chaumière. - 4, Réservoir Asch. - 5. Ruines de Lion. - 6 Alohtagne du Hunrod. - 7. Moulang. - 8. Gtand Lac. - 9. Grand Lac, - 10. Ho̊tel et Kestaurant. - 31. Aneien Jardin d'arboriculture, - 12, Ecole d'Arboriculture, - 13. Ecole d'Arburiculture forestière. - 14. Jardin fotager, - 1j. Bassin de Nepiune. - 16. Réservoir pour les Fontaines, 17. Cascades, - 18. Bassin de l'Eufer. - \$9. Teuple d'Apollon, - 20. Grande Fontaine. - 21. Tenuple de Mercure et Réserrour des Noutelles Cascades, - 22, Nouvelles Cascados, - 2j. La Bach (Forèts). - 24. Lo Seeberg, - 25. La Tète Rouge, - 26. Le Rammelsberg. - 27. Dumane et Eicuries. - 28. Kivierc la Druscl. 
3.

W

W.

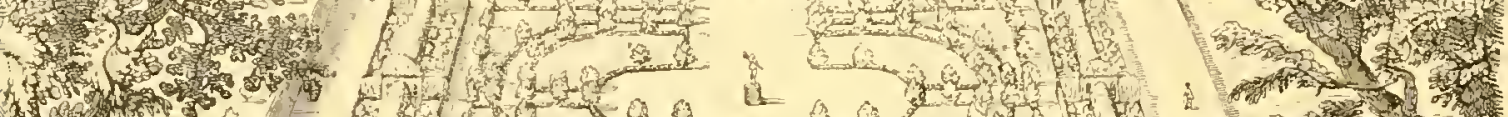

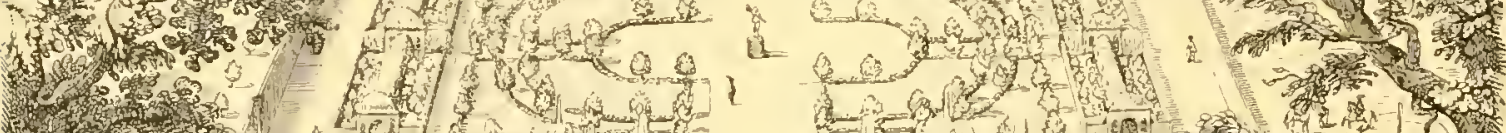
W. 1)

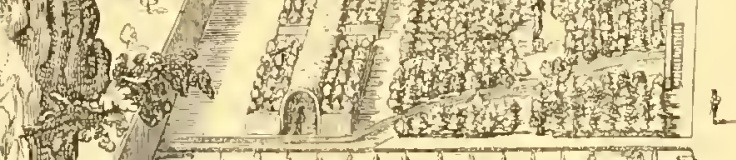
1)

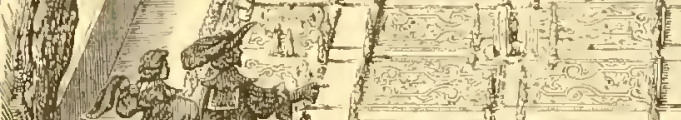

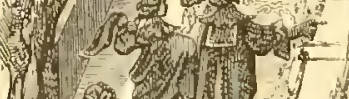
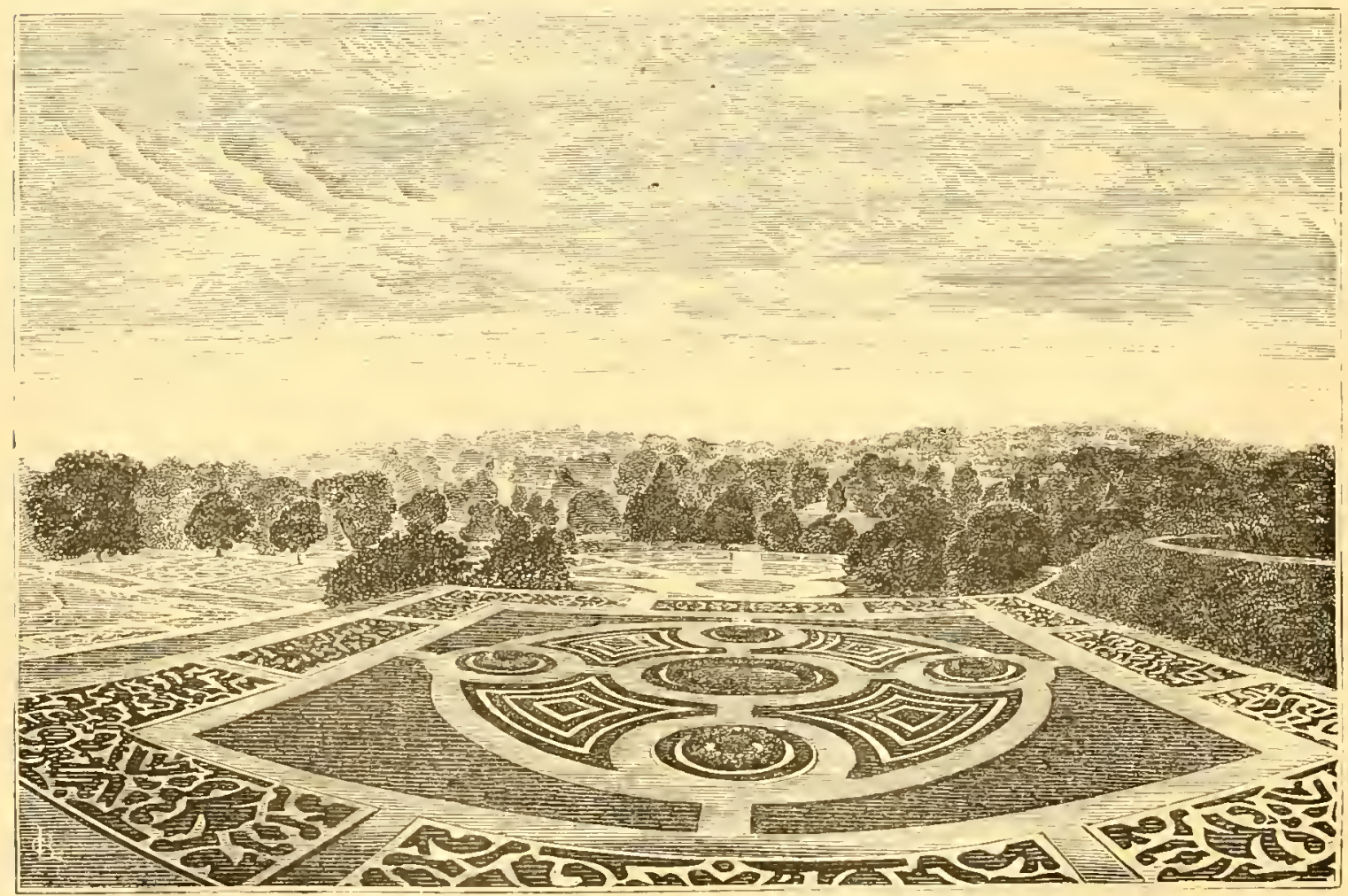

Fig. ro5. - Parc de Drumlanrig, au Due de Buccleuch. (Ioyez p. 22 ) 


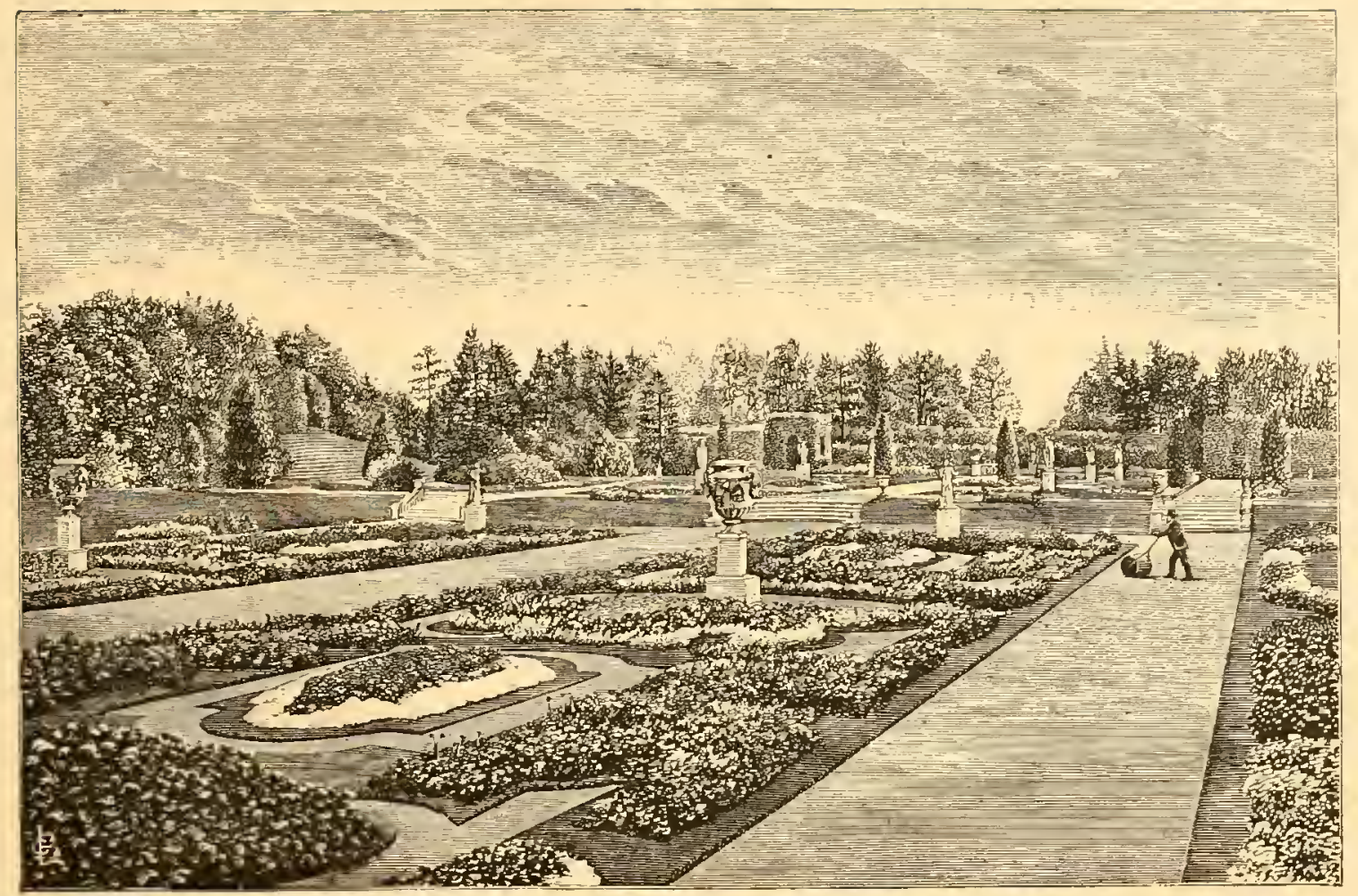

Fig. Io6. - Vue du Parc du Chàtean de Knebworth. (Toyez f. 92.)

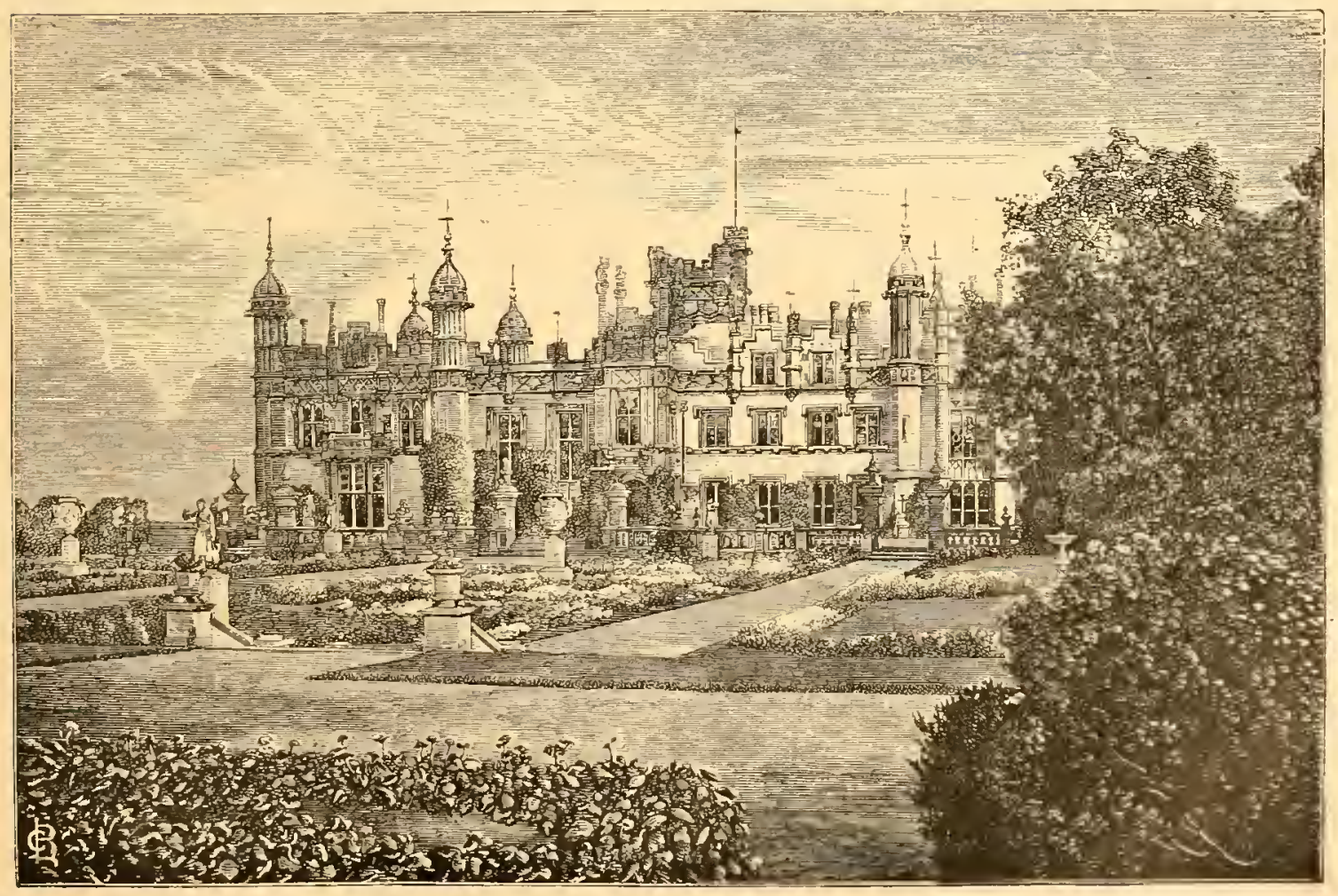

l丷ig. 107. - Chåtcau de Knebwortl, appartenant a Lord Lytton. (Ioyez p. 92.) 
Cette influence s'étendit dans toute l'Europe civilisée. L'empereur d'Autriche voulut avoir son Versailles à Schœenbrunn (Fig. IO2); le roi de Naples, le sien à Caserte; la Russie eut plus tard le sien à Peterhof. Le landgrave de Hesse avait eu la même ambition pour son château de Wilhelmshœhe (Fig. IO3). Il prit pour auxiliaire un réfugié français qui a chérement payé sa gloire future, Denis Papin. Les rois d'Espagne avaient, dès le xv1 siècle, le parc d'Aranjuez, avec des avenues déjá fort

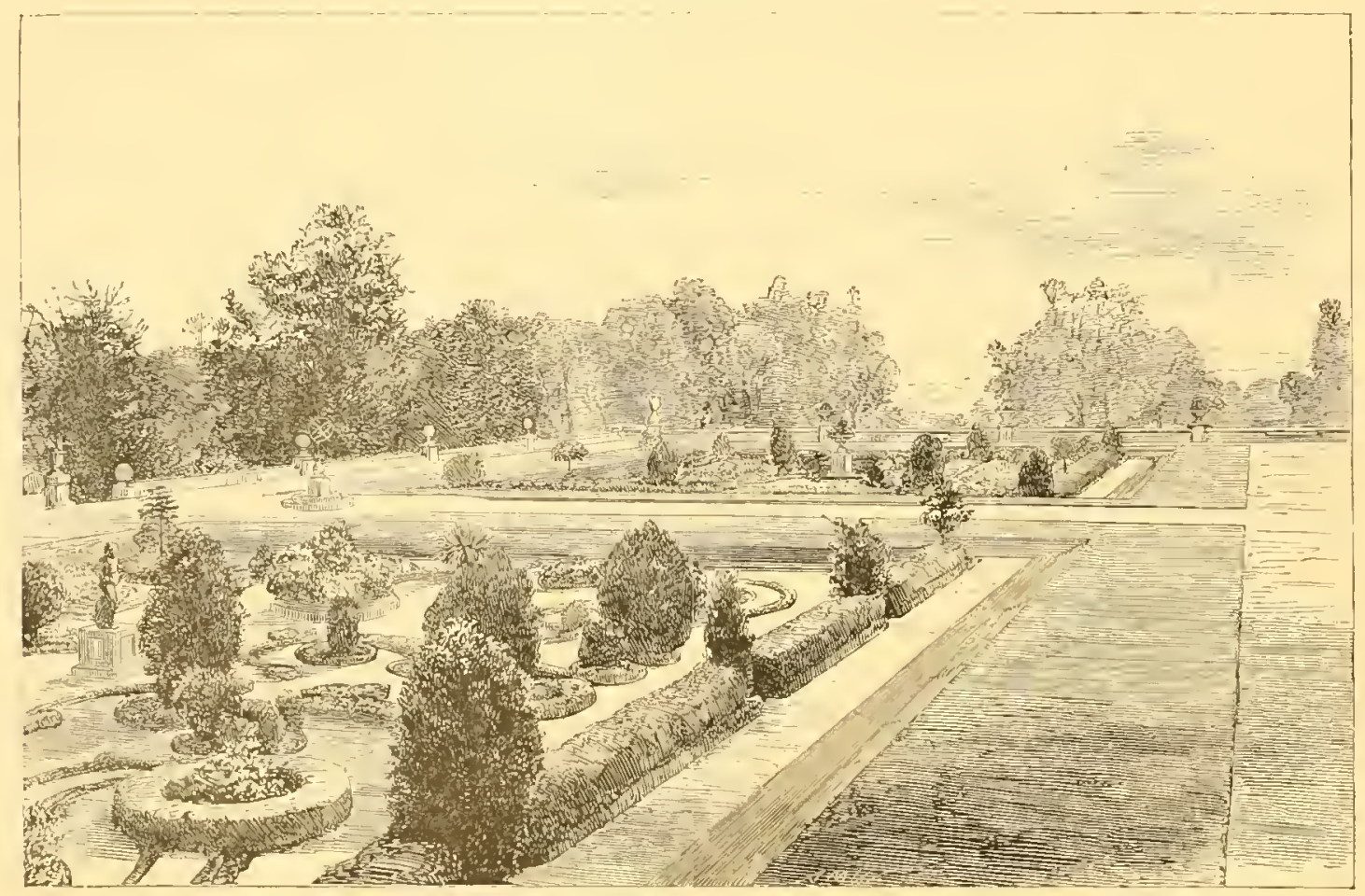

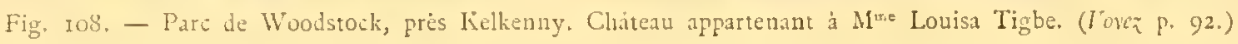

belles ău temps de l'ambassade de Saint-Simon (1722), et le reste, arrangé et toujours entretenu depuis l'origine par la rolonté expresse de Charles-Quint, dans ce que le noble duc appelait le goût flamand, c'est-à-dire du temps de la Renaissance; " coupé de bosquets, de berceaux bas et étroits, et pleins de fontaines de belle cau, d'oiseaux, d'animaux et de statues mécaniques inondant les curieux. » Accoutumé aux jardins de Le Nốre, Saint-Simon trouva « bien du petit et du colifichet » a Aranjuez, "mais le tout faisait quelque chose de charmant et de surprenant en Castille, par l'épaisseur de l'ombre et la fraicheur des eaux. » Aujourd'hui, le «colifichet » a disparu, mais les avenues restent, et comptent parmi les plus belles du monde. Dans les autres parcs royaux, l'ambassadeur reconnaît 
l'application du nouveau style français. Le parterre du Retiro ressemblait de tout point au Luxembourg. Le château de La Granja était alors en construction, et les jardins à peine ébauchés s'étendaient jusqu'au pied des montagnes, dont la bidense beunté faisait tout l'aspect du château, mais qui avaient l'avantigge de " fourmiller des plus grosses sources », et d'approvisionner des bassins et des jets d'eau sans nombre,

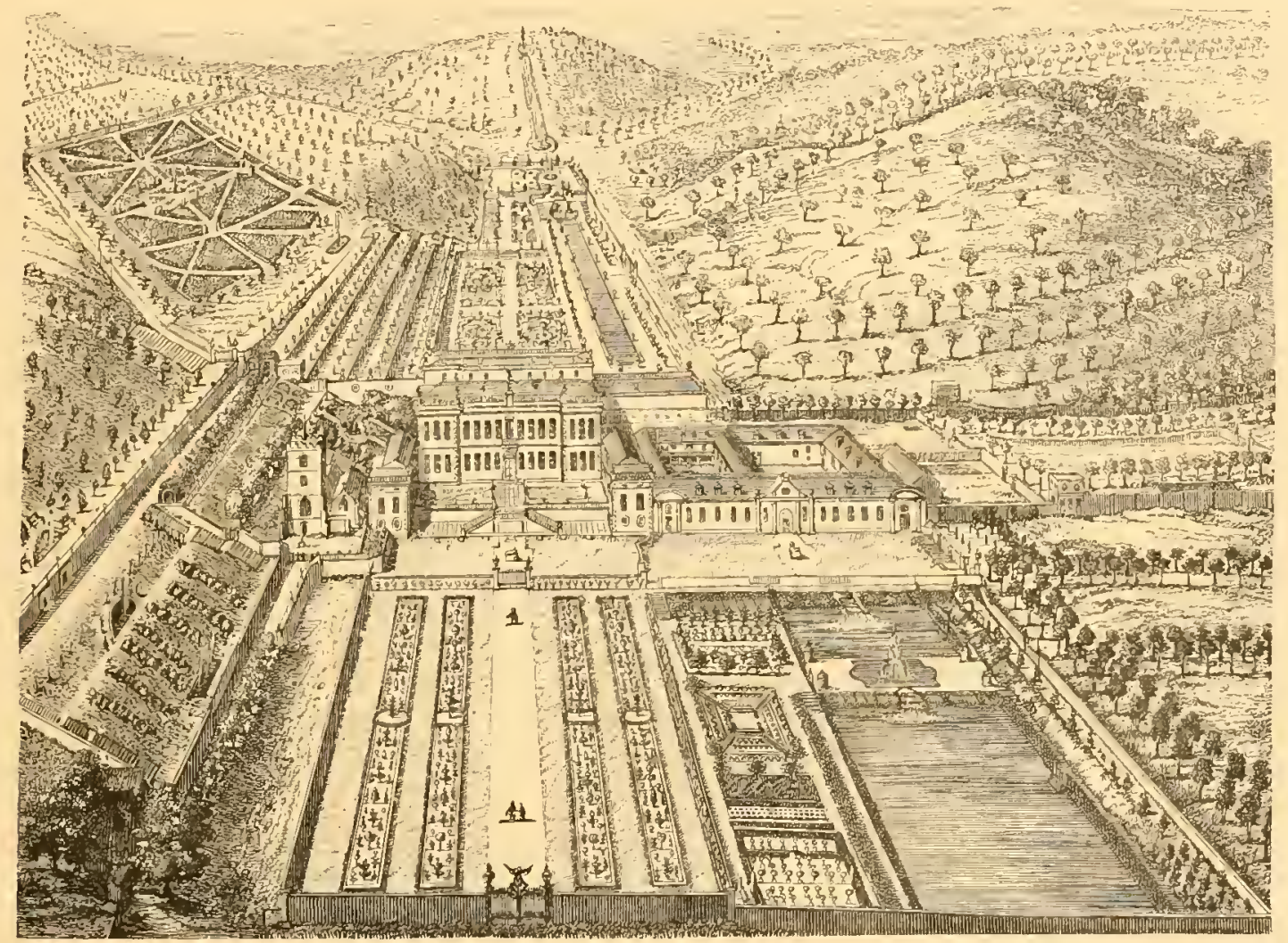

Fig. 109. - Chàteau de Durham, d'après Ǩip (Britania illustruhtu). (Voyez p. 92.)

" dont plusieurs jetoient gros comme la cuisse, le double de la hauteur de ce beau jet d'eau de Saint-Cloud, qui faisoit la jalousie du feu roi (Louis XIV). »

Le jardin du comte de Pembroke (Fig. I04), qui paraît être de la fin du xvı siècle ou du commencement du $\mathrm{xvIl}^{\mathrm{e}}$, est un type curieux des plus anciens jardins réguliers anglais. Nous y retrouvons les parterres en broderies et les tourelles, les ifs régulièrement taillés, les carrefours ornés de statues. Aprés le rétablissement des Stuarts, la prépondérance française s'étendit jusque sur les jardins. Ceux de Greenwich et de Saint-James, dessinés par Le Nôtre lui-même, furent imités dans toute l'Angleterre, et continuérent de l'être, même après la révolution de 1688 . 
Nous citcrons encore, parmi ces anciens parcs anglais, ceux de Chatsworth (Fig. II I), de Knebworth (Fig. 106 et 107), Drumlanrig (Fig. 105), et Woodskock (Fig. ro8). Tout en guerroyant contre la France, l'Angleterre continuait à subịr l'influence du goût français. Ce pays, oủ des principes tout opposés devaient bientôt prévaloir, est peut-être celui oủ les plus grands efforts avaient été faits pour appliquer le

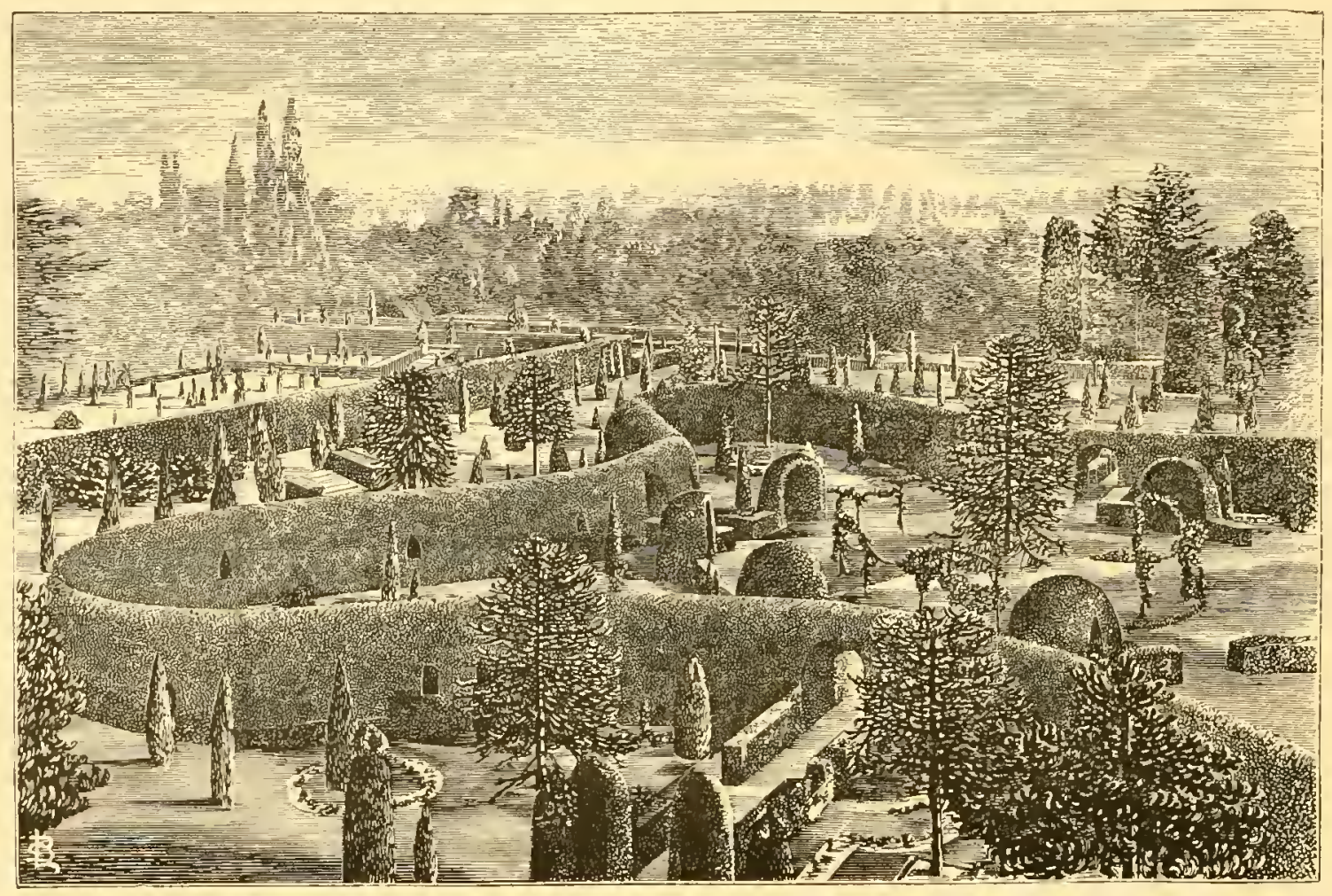

Fig. 110. - Parc du Château d'Elvaston (dans le Derbyshire), appartenant au Comte d'Harrington. (Ioyez p. 93.)

système régulier, même dans des localités d'où semblaient l'exclure la description capricieuse des bâtiments de diverses époques et les accidents du sol, comme à Durham (Fig. 109).

On trouvait aussi dans ces jardins réguliers anglais de curieux spécimens de sculptures végétales. Tandis que ce systéme d'ornementation était à peu prés réduit ailleurs, notamment en France, à un rôle tout à fait secondaire, il restait plus que jamais à la mode dans les Pays-Bas et en Flandre. Cette fantaisie persistante s'explique, chez ces peuples, par la monotonie de l'horizon, le morcellement des domaines, la manie de la curiosité, de tout ce qui exige un entretien constant, méticuleux. Un dessinateur de ardins, presque contemporain de Le Nôtre, reproduisait en buis, charmille ou épine- 
vinette des scénes de chasse, par exemple un groupe composé d'un homme enfonçant un épieu dans la gueule d'un ours et secondé dans ce combat par son chien (I). On a aussi conservé le souvenir d'un jardin, près de Harlem, oú toute une chasse au cerf était représentée en charmille; d'une caricature d'abbé, à Saint-Omer, entouré d'un chapitre d'oies, de dindons et de grues, en ifs et romarins; d'un autre, gardé par des gendarmes en buis, etc. Ces tours de force furent répétés en Angleterre sur une grande

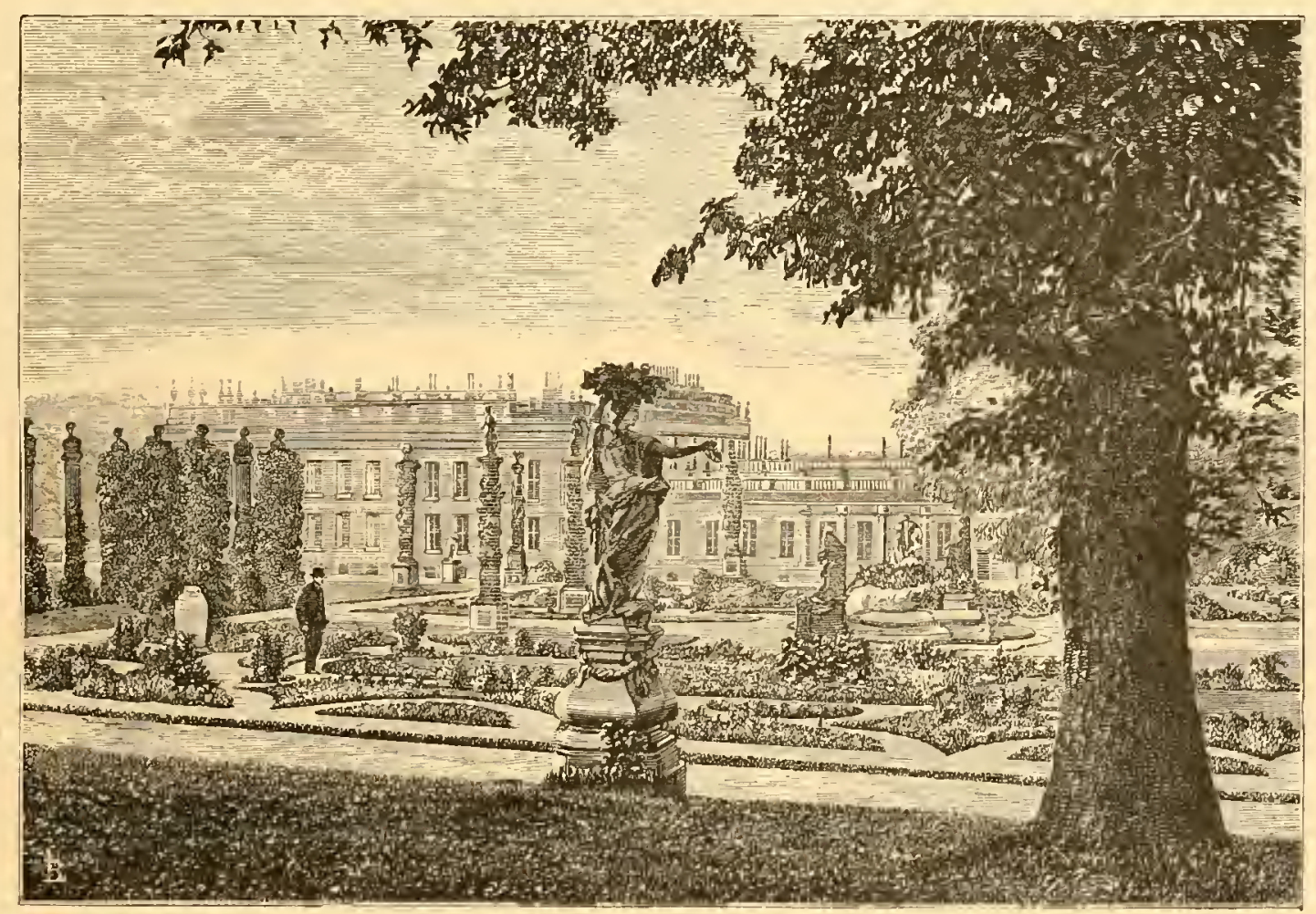

Fig. Int. - Chatsworth, an Duc de Devonshire.

échelle, après l'avénement de Guillaume d'Orange. Un dessinateur nommé Wyse, homme d'imagination, aprés tout, transforma des pares en ménageries d'animaux dans diverses attitudes, gardés par des géants, le tout en ifs et en buis.

L'ancien pleasure-ground d'Elvaston-Castle (Fig. I Io) offrait, dans une enceinte de palissades de verdure faisant office de rempart, quantité d'arbres et d'arbustes taillés

(1) On trouve une gravure représentant cette sculpture dans un livre fort rare, l'Horticullura, de Lauremberg de Rostok. - Francfort, 1654. Aujourd'hui encore, les jardins du fameux village de Bruck sont remplis de sculptures semblables, représentant des colonnes, des statues, des arcades, des animaux réels ou de fantaisie. Quelques tours de force du mème genre ont été longtemps conservés en France. On entretenait encore, en 1808, daus un parc voisin de Clartres, des instruments de musique gigantesques, groupés en labyrinthe. 
de manière à figurer les ruines éparses d'un temple. Dans un passage de Pope, qui raille ces fantaisies grotesques, il est question d'un groupe en buis représentant le combat légendaire du patron de la Grande-Bretagne contre le monstre infernal. "Le bras du saint n'est pas encore assez long, mais au printemps prochain il aura suffisamment poussé pour atteindre le dragon. »

Ces efforts, souvent malencontreux, pour concilier deux choses absolument contraires, pour introduire la variété, l'imprévu dans l'ordre régulier, indiquaient assez l'approche d'une rérolution. Le temps des architectures végétales finissait, celui du paysage allait commencer (I).

(1) Parmi ies spúcimens les plus remarquables de pares français de cette époque, nous aurions pu citer encore ceux de Le 'Tellier à Chaville, de Richelieu en Poitou, et plusieurs autres dont il ne reste que les belles gravures de de Pérelle. Une curiosité de ce temps, dont aucun écrivain n’a parlé, c'est, ou plutôt c'élait le parc du comte de La Forest, à Fl ỉ̉sine dans le Vendômois, offrant, dans un espace de moins de quatre hectares, une réluction exacte de Versailles. Il a subsistédans cet état jusque vers i 850 .

Les parterres du jardin de Choisy, dont nous reproduisons le labyrinthe (Fig. I12), étaient l'une des ouvres de Le Nôtre les plus réussies.

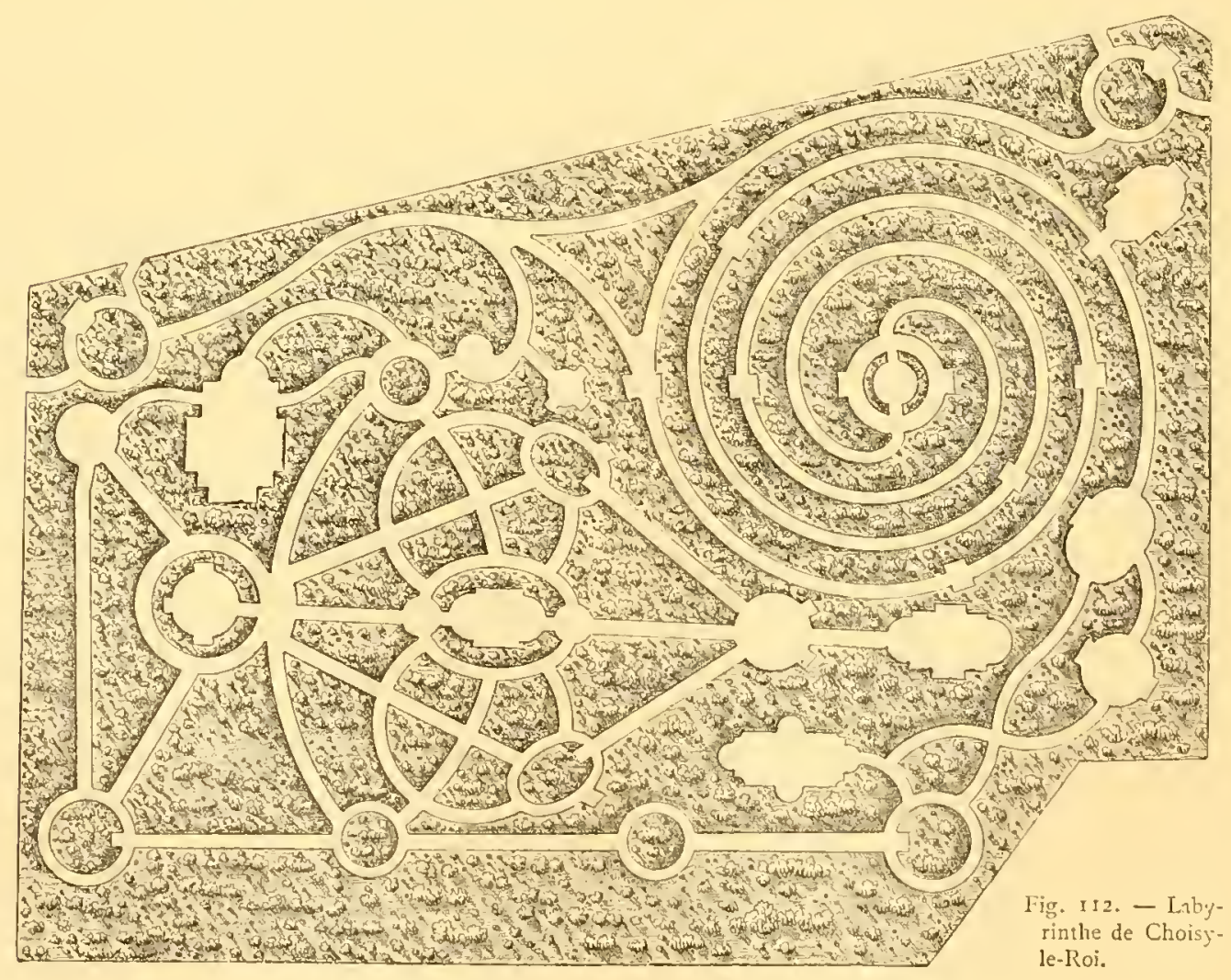




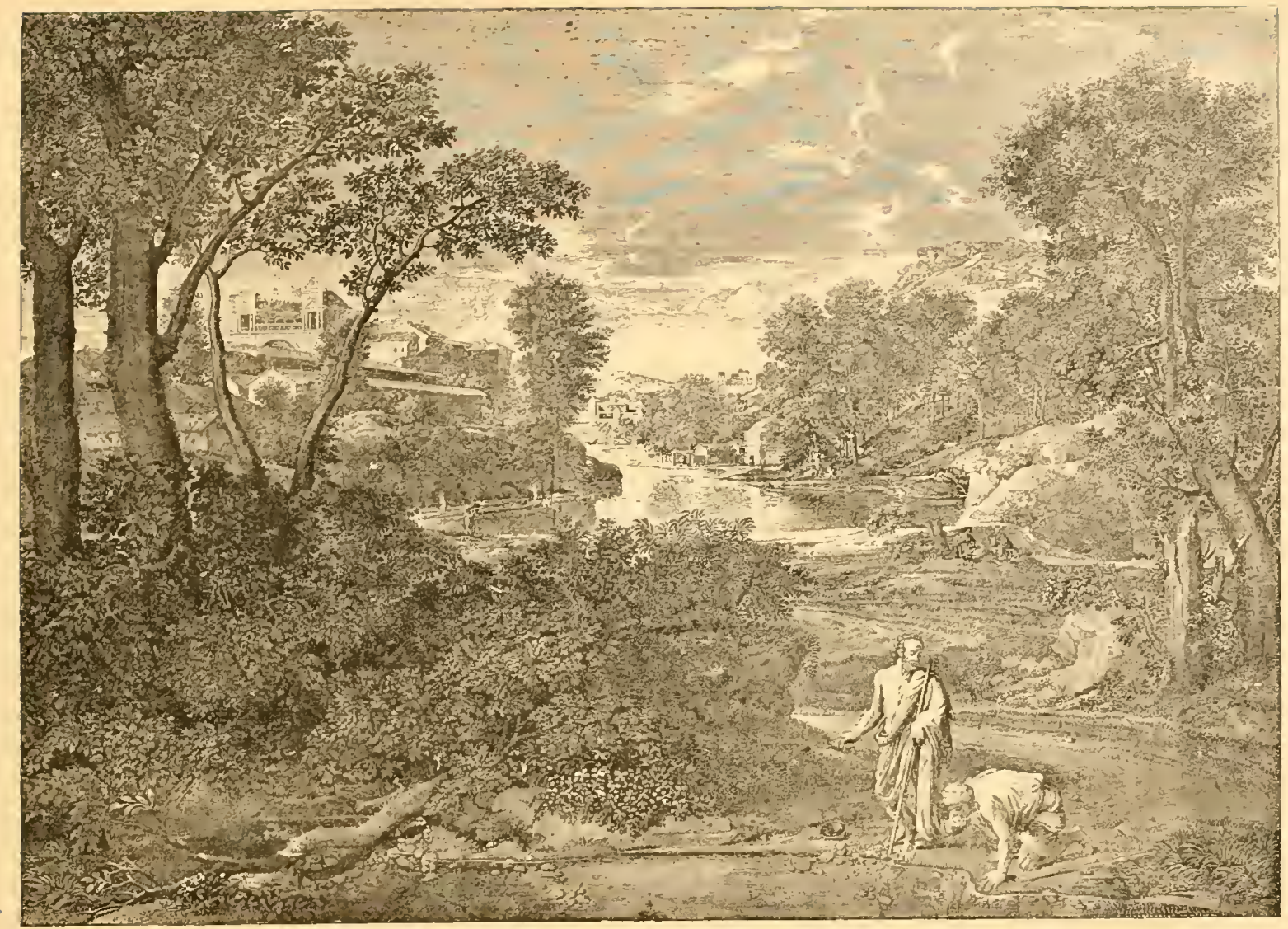

Fig. I I3. - Diogène. Paysage de N. Poussin, gravé par Boudet, I68 f. (Calcographie du I.ourre.)

\section{LE PAYSAGE}

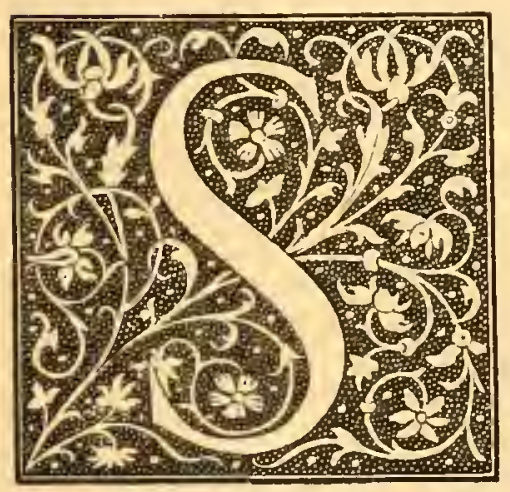

UIVANT un de nos contemporains, à la fois penseur profond et grand écrivain, "les jardins anglais (agrestes ou irréguliers) indiquent l'avènement d'une autre race, la domination d'un autre goût, le régne d'une autre littérature, l'ascendant d'un autre esprit, plus compréhensif, plus solitaire, plus aisément fatigué, plus tourné vers les choses du dedans. ") (Taine, Voydge en Italie, I, 297) (1). Une des conséquences de cette évolution psychologique, et non l'une des moindres, a été ce qu'on peut appeler

(I) Ceci n'est pas absolnment exact, on plutôt est incomplet. On ne saurait nier que le style des jardins chinois, prototype du genre irrégulier, n'ait une corrélation intime avec celui des constructions. Mais l'observation de M. Taine n'en est pas moins vraie, en ce qui concerne l. disposition morale qui a déterminé et favorisé l'adoption de ce genre en Occident. 
l'étude analytique des beautés de la nature, des sites de différents caractéres. On a recherché à quoi tiennent les impressions si varićes qu’ils produisent, à quelles combinaisons d'eaux, de feuillages, de lumiẻre, d'horizons tourmentés ou paisibles, correspondent ces impressions tristes ou gaies, douces ou violentes; ce qui fait la

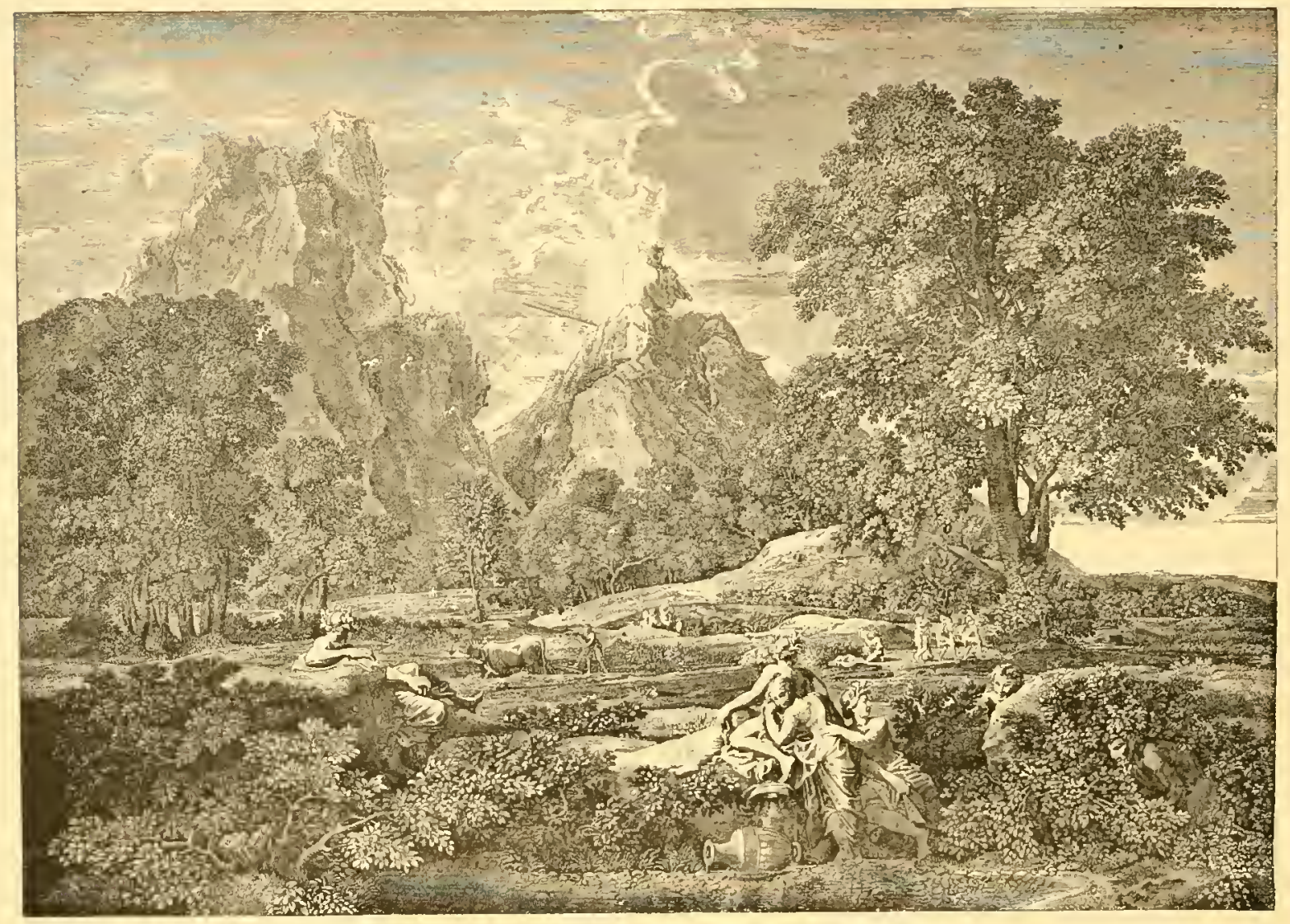

Fig. :15. - Polyphème, par N. Poussin, grave par Boudet. (Calcographie du Louvre.)

gráce de certains aspects naturels; et, pour parler comme Saint-Simon, la bidcuse beanté de certains autres; - hideuse, et pourtant triomphante!

Quelques grands peintres, et notamment le plus grand de l'école française, Poussin, ont été les initiateurs du monde moderne dans cette voie nouvelle. La peinture de paysage n'était, à l'origine, qu'un accessoire de la peinture historique. Les événements reproduits par les artistes se passant souvent en plein air, ils se trouvèrent entrânés insensiblement à étudier tous les aspects sous lesquels peut être reproduite la nature. Plus tard, les figures prirent souvent moins d'importance dans les tableaux, tandis que le site en obtenait davantage. Les représentations des 
Mystires, en Italie et ailleurs, exigèrent des décorations, et cette imitation en grand des paysages et des perspectives fit naitre l'idée de peindre des sujets analogues dans des dimensions réduites, en les animant de quelques figures. Avant que des artistes se vouassent cxclusivement à ce genre, des maîtres de premier ordre, à commencer par Raphaël, avaicnt donné plus d'impor-

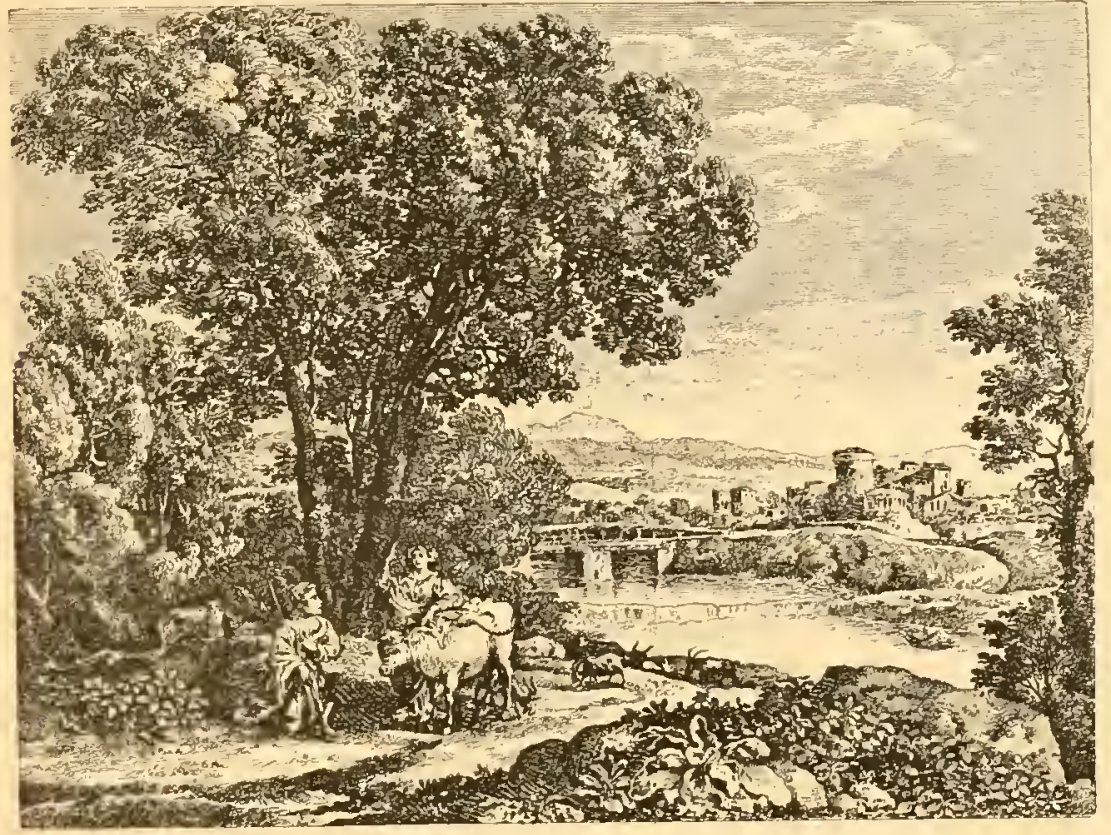

Fig. 116. -- Claude Lorrain. - Paysage avec la Vache. (I'oyez p. 99.) tance au paysage dans leurs compositions. A Venise, Titien lui avait imprimé un accent de mâle grandeur

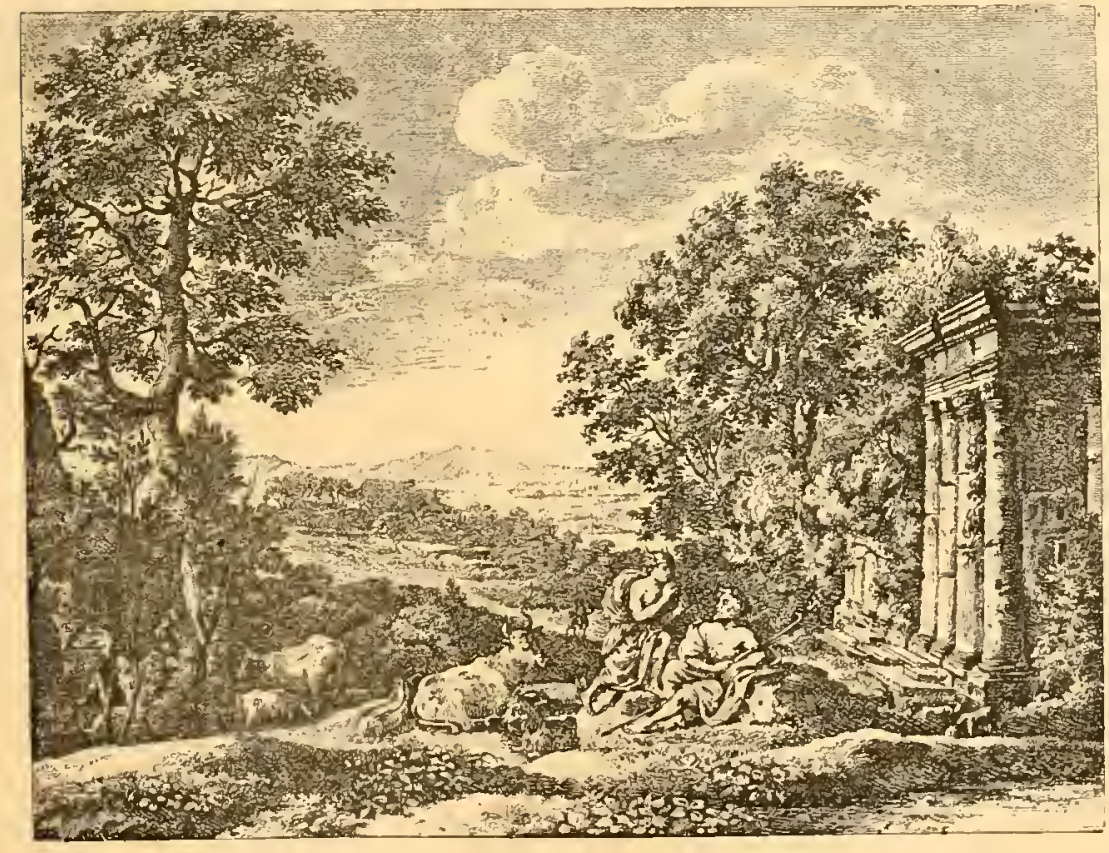

Fig. II7. - Claude Lorrajn, - Paysage; Mercure endort Argus. (I'oyez p. 99.) et de vérité saisissante. Dans l'un de ses chefsd'œuvre, le Martyre de Saint Pierre le Dominicain (qui malheureusement n'existe plus), il avait placé cette scéne terrible dans un paysage admirablement assorti au sujet, et dont les premiers plans étaient grands comme nature. A Rome, le Dominiquin s'exerça dans cette branche de l'art, en traitant parfois des sujets mythologiques en figures de petite 
dimension dans des tableaux où le rôle principal appartient au paysage (I). Dans ce

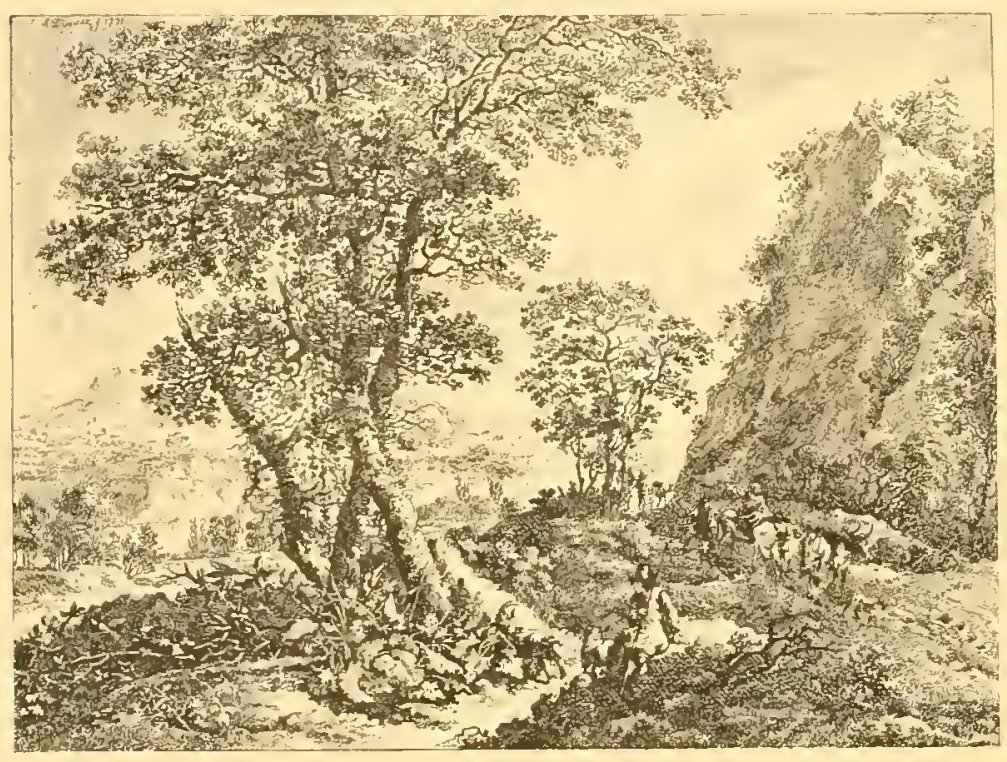

Fig. ris. - Paysage far Berghem. (Iroyez p. 99.)

genre, il fut imité et surpassé par le Poussin. Cet artiste, grand entre les plus grands, avait été souvent amené à composer des sites en harmonie avec les sujets d'histoire sacrée ou profane qu'il avait à traiter. Il l'avait toujours fait avec le plus heureux discernement, non pas arec une fidélité littérale et absolue dont les éléments n'étaient pas à sa portée, mais en tirant de ce qu'il connassait le parti le meilleur et le plus judicieux. Ce goút si sûr, ce sentiment si développé du beau ne lui firent pas défaut, quand, dans quelques moments d'enthousiasme pour le spectacle de la nature, il choisit le paysage comme but principal et presque unique de ses compositions. Ses tableaux dans ce genre ne sont pas nombreux, mais tous portent le cachet de son génie. Tous offrent. le double mérite d'une com-

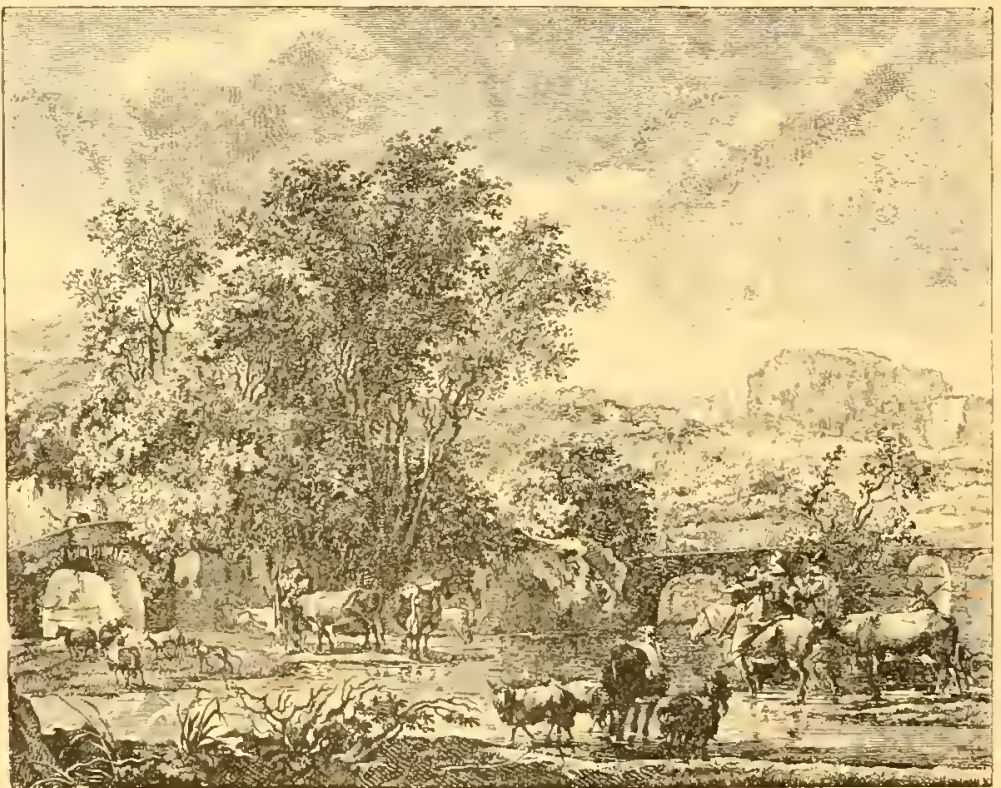

Fig. 119. - Nicolas Berghem. - Paysage. (T oyez P. 99.) position grande et simple, malgré la richesse des détails et de l'heureuse combinaison

(1) Voir notamment au musée du Louvre les $n^{0 s} 495,496$, 300. On trouve des exemples semblables dans les cuvres de Carrache, de l'Albane, de Mola, etc. 
des lignes pour l'unité de l'effet (I). L'étude de ces ourres n'est pas moins nécessaire aux dessinateurs des jardins paysagers qu'aux peintres. Ils y trouveront, pour la composition des scènes de diffèrents caractères, des modèles dont il convient de s'inspirer, sans les copier servilement (2).

On comprend qu'il n'est pas question ici de l'imitation parfaite de la nature. Sous ce rapport, Poussin est inférieur, non seulement à son contemporain Claude Lorrain (Fig. 116 et 117 ), mais à plusieurs autres maîtres anciens et modernes. En reranche, il n'a pas d'égal pour la composition des paysages, bien que quelques-uns de ses successeurs, Gaspard, Dughet, par exemple, aient 'mar-

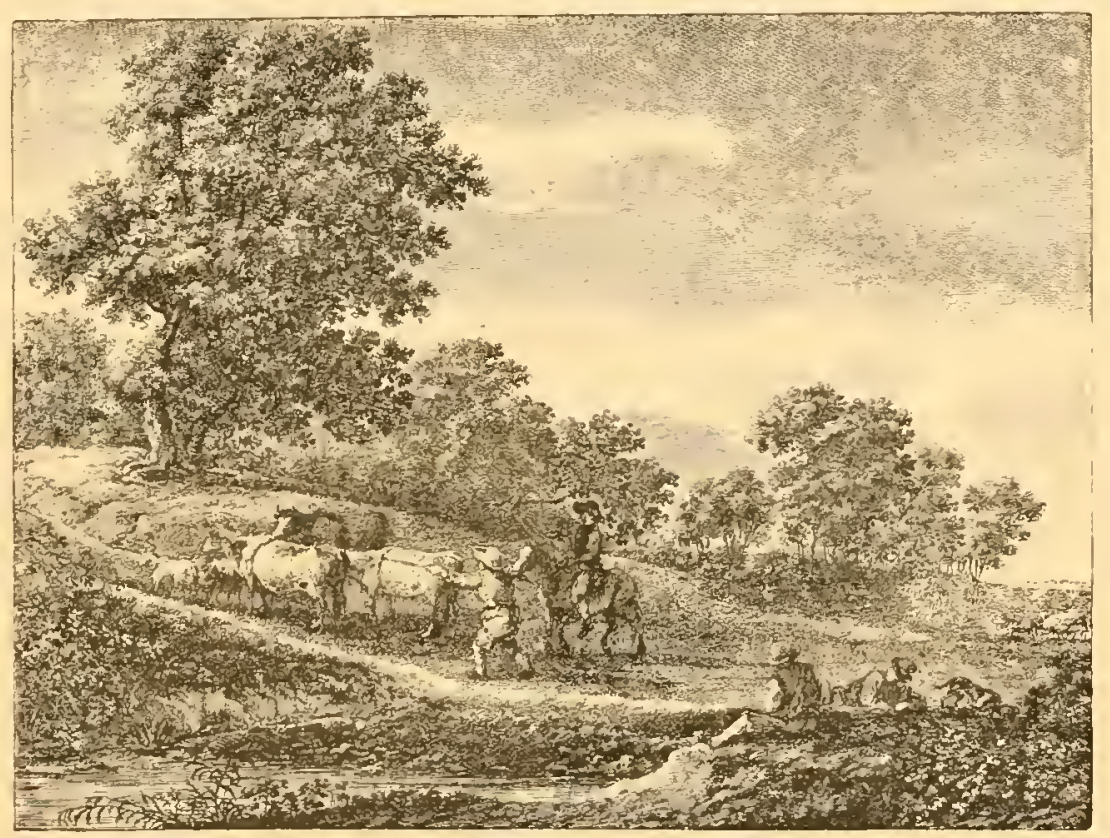

Fig. I 20. - Isasc Ostade. - Paysage.

ché avec succés sur ses traces, et laissé des cuvres dignes d'être étudiées (3).

Parmi les grands paysagistes, il faut citer également Salvator Rosa, Watteau, dans l'école hollandaise, Berghem (Fig. i Is et I I9), Ostade (Fig. I20), Pynaker (Fig. I2I), Ruysdaël, Hobbema; dans l'école française moderne, Rousseau, Cabat, Corot, Millet, etc.

On a voulu attribuer au Tasse une part d'initiative dans les commencements

(1) Il ne faut pas oublier, pour bien juger son ceuvre, "qu“il y a maintenant deux siècles passés qưil est mort et qu'il n'y a guère plus de cent ans que l'Afrique du Nord et la côte occidentale de l'Asie sont bien contues au point de vue de l'art et de la nature ". (Bouchitté, Le Poussin, p. 395.)

(2) Notamment les Funérailles de Phocion, où le paysage s'harmonise si bien avec le sujet; l'Ouragan, lat Peur, le Diogène (Fig. IIj), le Polyphime (Fig. I İ) oú un artifice de perspective produit un si grand effet, et où Poussin a si heureusement fait intervenir, au second plan, l'idylle du ménage champêtre.

(3) J'ai un paysage de lui, dont le sujet principal est un cours d'eau qui forme successivement plusicurs petits lacs ou bassins naturels bordés de plantations. On pourrait y trouver des indications utiles pour la disposition d'caux abondantes dans un jardin paysager. 
des jardins paysagers, à cause de la description des bocages enchantés d'Armide, au Chant XVI de la Jérusalem délivrée :

"L'art qui créa ces beautés, les accroît encore en se dissimulant...; et la nature, en retour, se plait à imiter son propre imitateur.) ) Ces gracieux concelli auraient, dit-on, été inspirés au Tasse par le souvenir d'un jardin irrégulier qui existait de son temps prés de Turin. L'existence de ce jardin ne nous est connue que par une lettre du Tasse écrite au temps de ses pires accès de folie (1580), ct doit, par conséquent, être tenue pour suspecte. C'était d'ailleurs l'époque de la plus grande splendeur des villas italiennes de la Renaissance, notamment de celles d'Este et Aldobrandini, bien plus conformes à la tradition antique, et par conséquent au génie italien (I). Aujourd'hui encore, pour la même raison, les jardins irréguliers sont assez rares en Italie. Ils produisent, en général, moins d'effet dins les contrées du Midi, baignćes d'une clarté égale, que dans l'atmosphère brumeuse du Nord. Aussi, suivant des hommes trés compétents, ce nouveau style devait rúussir d'abord dans le pays brumeux par excellence, l'Angleterre, ou les paysages sont moins admirables par la richesse de lia végétation, que par les contrastes que produit le jeu de la lumière.

(1) Ceste description des jardins d'Armide ne serait-elle pas tout simplement une réminiscence des abords de la grotte de Calypso dans l'Odyssée?

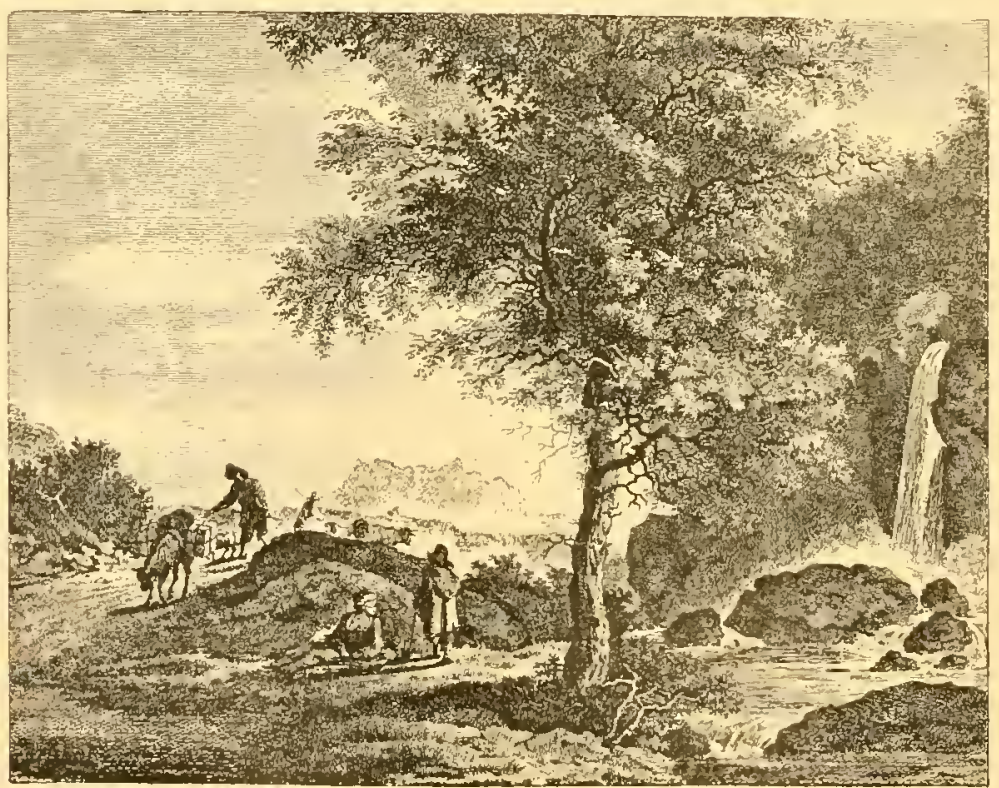

Fig. 121. - Adam Pynaker. - Paysage. (Toyez p. 99.) 


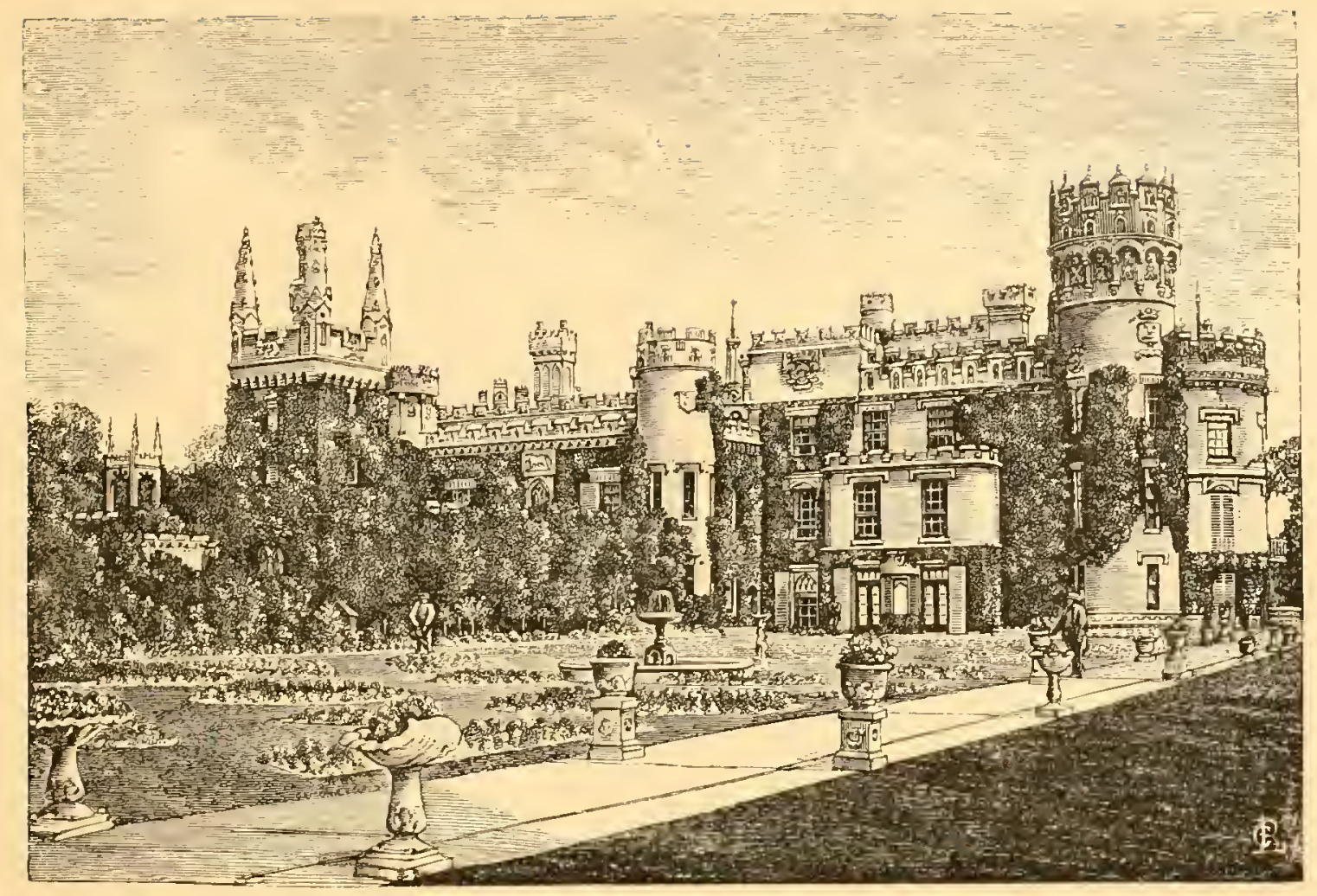

Fig. 122. - Eridge Castle (Sussex), un des plus anciens Parcs d'Angleterre, appartenant au Marquis d'Abergavenny:

\section{JARDins AGRESTES OU IRRÉGULiERS (Jardins Anglais)}

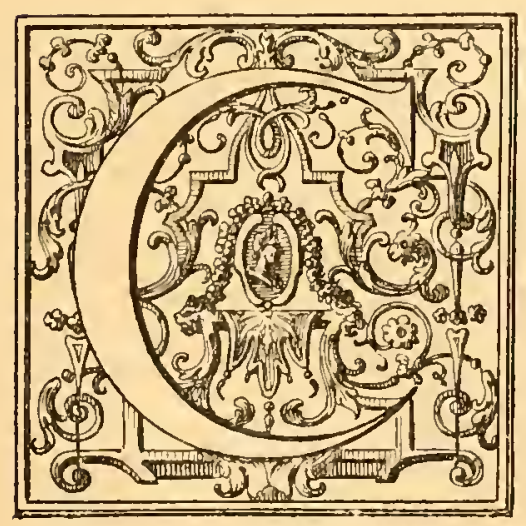

ETTE révolution dans l'art des jardins, dont l'Angleterre fut le premier théâtre, n'y commença que vers 1720 , mais elle avait été pressentie et même formulée dans la première moitié du siècle précédent. Les principes d'une théorie des jardins, fondée, au rebours de l'ancienne, sur le sentiment et la reproduction des beautés de la nature, avaient été nettement posés par l'universel Bacon, dans un passage important de ses Sermones, imprimés dès 1644 . Suivant sa théorie, un parc doit se composer de trois sections ou fractions principales, reliées entre elles par un systéme d'allées embrassant la totalité du domaine. Il commence par une pelouse ouverte et se termine par des 
bosquets. Entre la pelouse d'entrée et le bocage final, s'étend le jardin proprement dit, enveloppant de tous côtés l'habitation. Bacon recommandait que les allées de liaison et de ceinture fussent plantées de manière à donner de l'ombre à toute heure, mais il difendait de rechercher cet arantage an moyn d'ancune disposition symétrique d'arbres on d'arbustes. Il proscrivait, jusque sous les fenêtres des châteaux, les sculptures végétales et les parterres de mosaïque " dont il filut, dit-il, laisser le

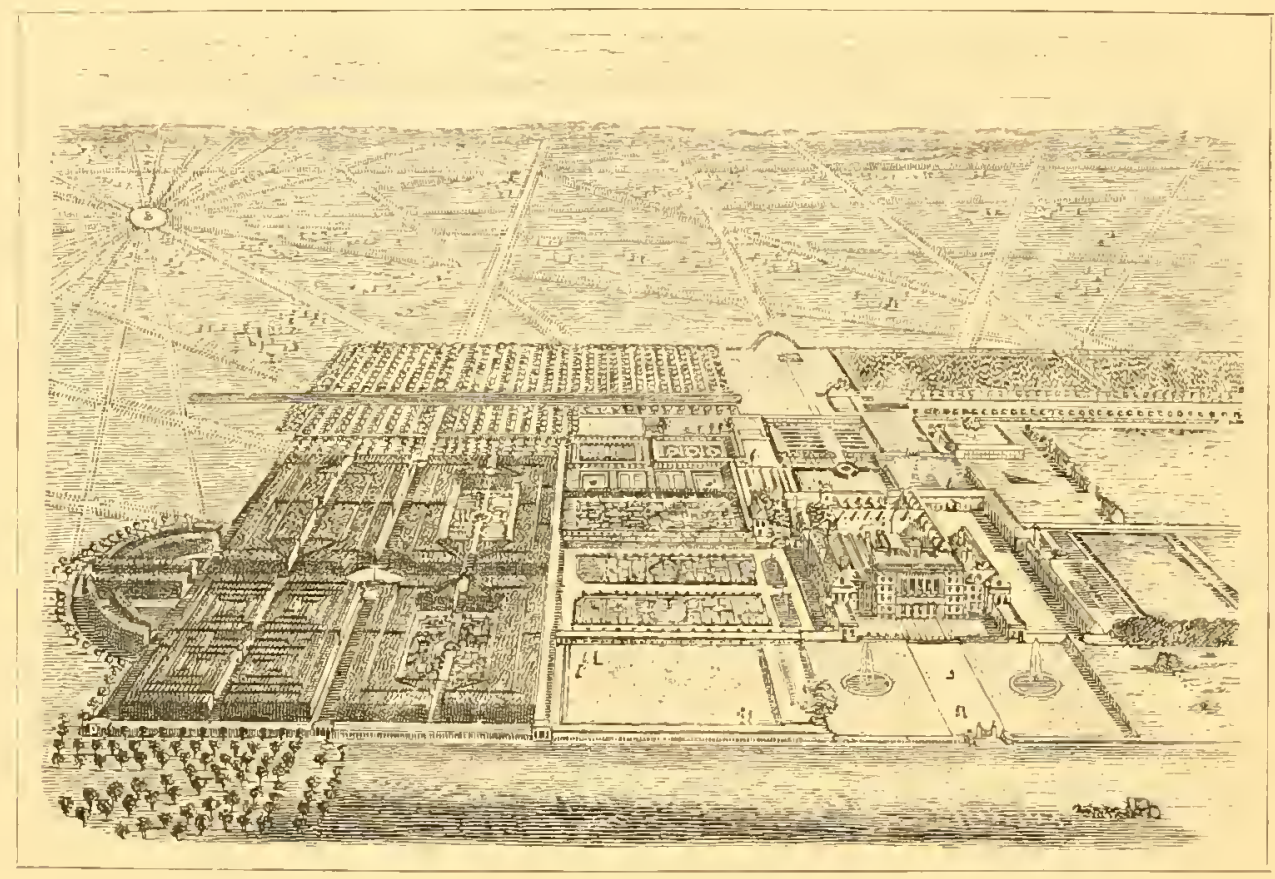

Fig. I24. - Château de Badminton, appartenant au Due de Beaufort. (Toogè p. Ioz.)

monopole aux confiseurs. "Il condamne aussi, comme désagréables et insalubres, les réservoirs, les bassins où l'eau reste immobile. Un pare doit présenter des ondulations, et, s'il est possible, un point culminant arec belvédére. Il serait bon aussi de ménager sur la lisiére quelques élévations, d'où l'on jonirait des plus beaux points de vue des environs et de l'ensemble de la propriété. Il recommande de réserver un emplacement bien exposé, destiné à former un arborctum ou pépiniẻre d'essai pour les arbres fruitiers et d'ornement susceptibles d'être acclimatés. Ces préceptes, aujourd'hui d'usage commun, étaient, du temps de Bacon, d'une hardiesse singulière. Lui-même, un peu plus loin, semblait s'effrayer de sa propre audace, et admettait, dans le pleasure-gronnd ou jardin réservé, des ornements réguliers et des édicules conformes au goût du temps. 
La fameuse description du Paradis de Milton, composée quelques années après, est visiblement conçue dans le même ordre d'idées. Ce jardin, dont Dieu même a été l'ordonnateur, ne conticnt rien de symétrique; les ruisseaux y tracent de capricieux sillons sous les ombrages; " les fleurs n'y sont pas curieusement disposées en compartiments ou en rosaces, mais répandues en profusion par la nature parmi les vallons, les plaines et les collines boisées... »

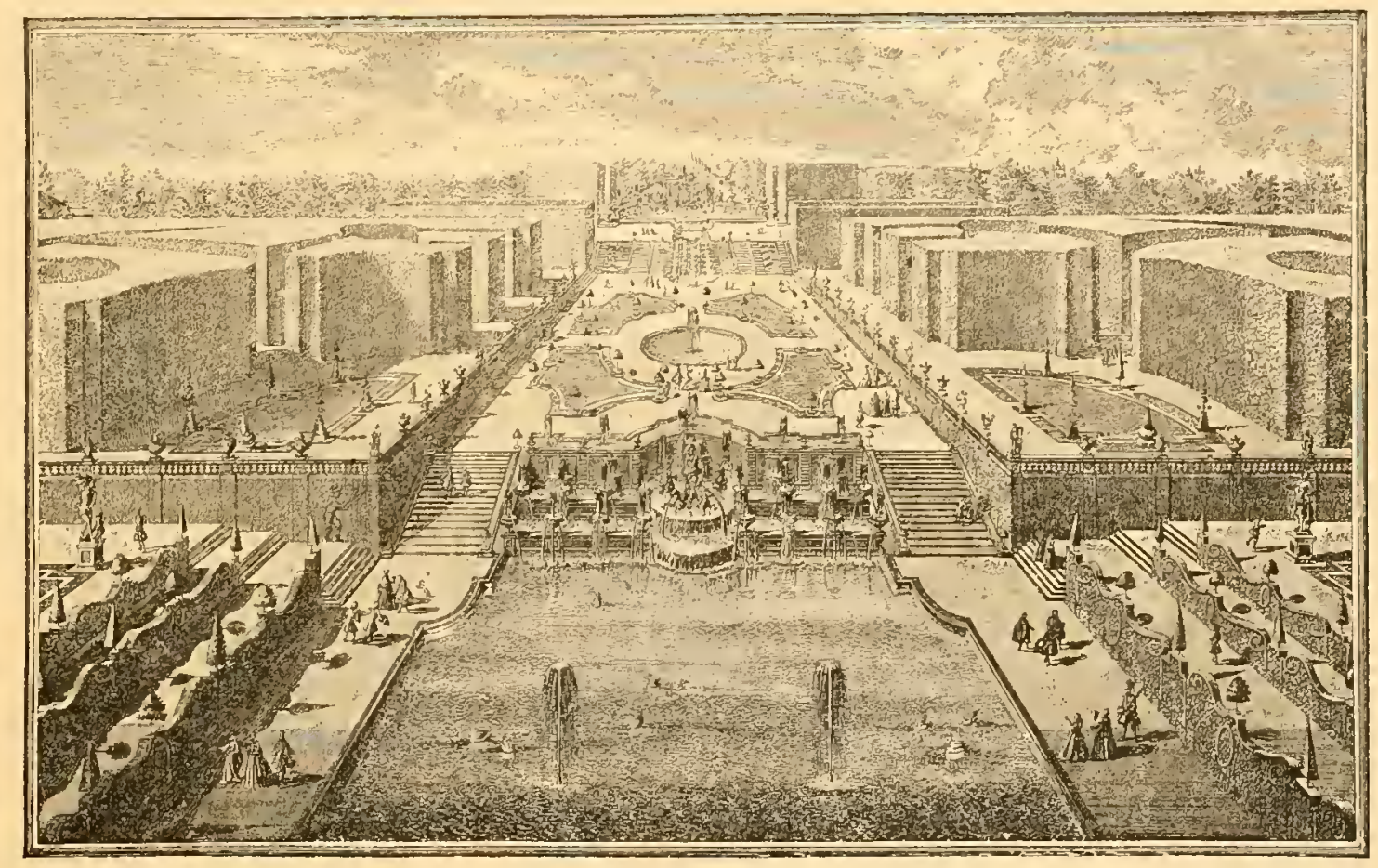

Fig. I25. - La Favorite, ancien Parc près Mayence.

Ces aspirations étaient prématurécs. Tous les plans de pares anglais du temps des Stuarts, de Guillaume III et de la reine Anne, appartiennent encore au style régulier (Fig. I22 et 124). Il en était de même en Allemagne, où la lutte se prolongea longtemps entre les deux genres opposés, comme en font foi les curieux plans des jardins de la Favorite, près Mayence (Fig. I25 et 126), de Heidelberg (Fig. I 27), et le jardin épiscopal de Würtzbourg, encore remanié d’après le système régulier, dans la seconde moitié du xvinte siècle (Fig. I28). On y remarque, dans le voisinage du palais épiscopal et de l'église (I et 22), un libyrinthe (I $\$$ ) renfermant deux édicules singulièrement placés en si édifiante compagnie; des temples de Flore (20) et de Bacchus (19). Ce jardin est encore conservé dans le même état. 
Pourtant le systéme contraire avait eu en France, et auprés de Louis XIV luimême, un zélé partisan dans le poète Dufresny, homme fort irrégulier de toute manière, et qui improvisait avec la même facilité des jardins et des comédies. Il est au moins vraisemblable que les premières indications des Jésuites sur les jardins chinois (vers 169o) avaient rivement frappé l'imagination ardente et paradoxale de Dufresny. Il avait, dit un de ses biographes (qui écrivait en 1733 et l'avait connu),

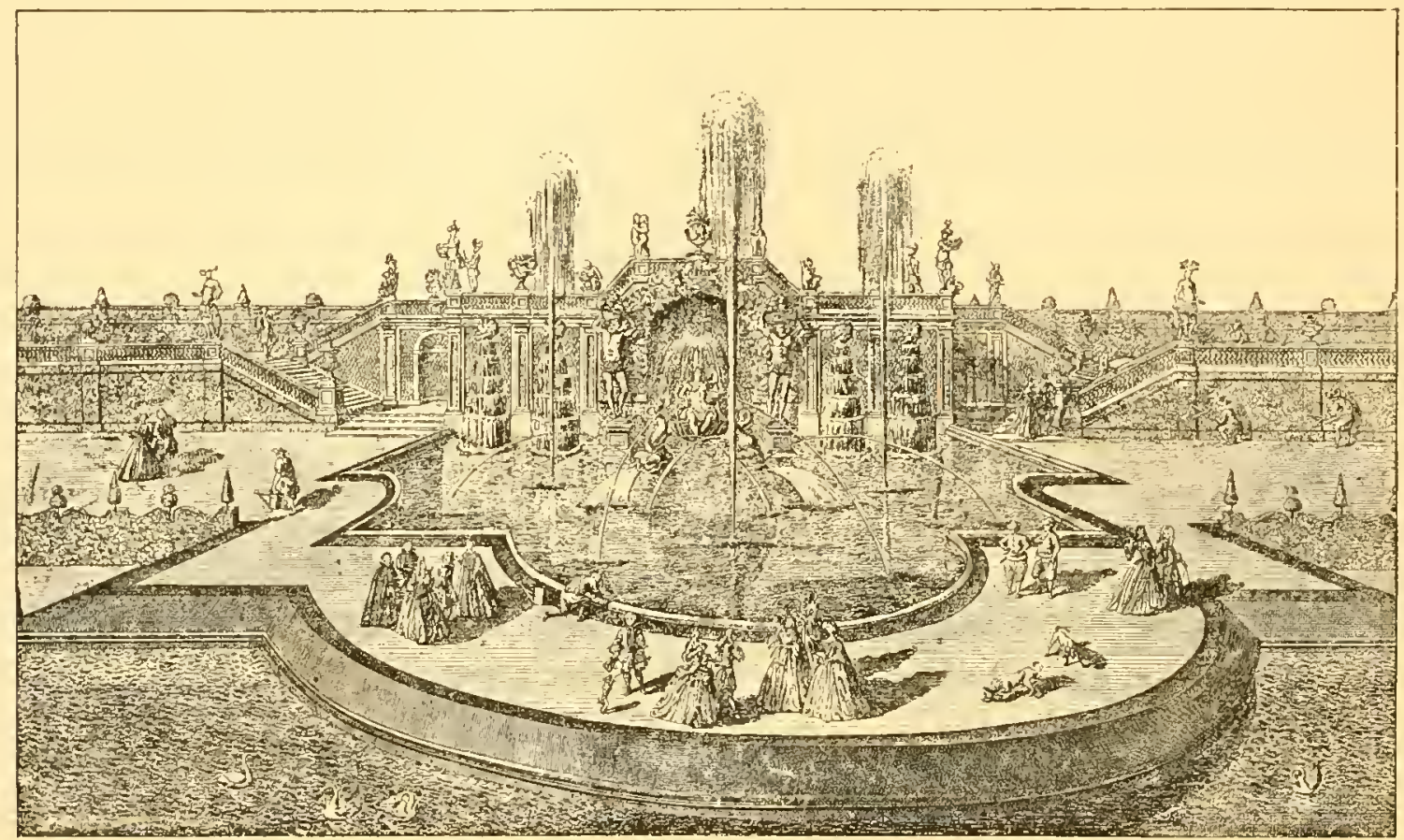

Fig. 126. - Fontaine du Pare de la Favorite, d'aprés Salomon Kileiner. (Tovez p. 103.)

un goût dominant pour l'art des jardins. Mais les idées qu'il s'était faites à ce sujet n'avaient rien de commun avec celles des grands hommes que nous arons eus et que nous avons encore en ce genre. Il ne travaillait avec plaisir, et pour ainsi dire à l'aise, que sur un terrain inégal et irrégulier. Il lui fallait des obstacles à vaincre, et quand la nature ne lui en offrait pas, il s'en donnait à lui-même: c'est-à-dire que d'un emplacenent régulier et d'un terrain plat, il en faisait un montueux, afin, disait-il, de varier les objets en les multipliant. Pour se garantir des vues voisines (I), il leur opposait des élévations de terre, qui formaient en même temps des belvédéres. Il

(1) C'est-à-dire pour empêcher les voisins de voir. 
disposa dans ce goût les jardins de Mignaux, aux environs de Poissy, ceux de l'abbé Pajot, prés de Vincennes, etc. Louis XIV, dont Dufresny était, dit-on, arrière-cousin de la main gauche, s'intéressait à lui et voulut à diverses reprises faire sa fortune, mais le grand Roi lui-même n'était pas assez puissant pour cela! On a prètendu aussi, tantôt qu'il avait hésité ì l'origine entre les plans de Le Nôtre et ceux de Dufresny pour les

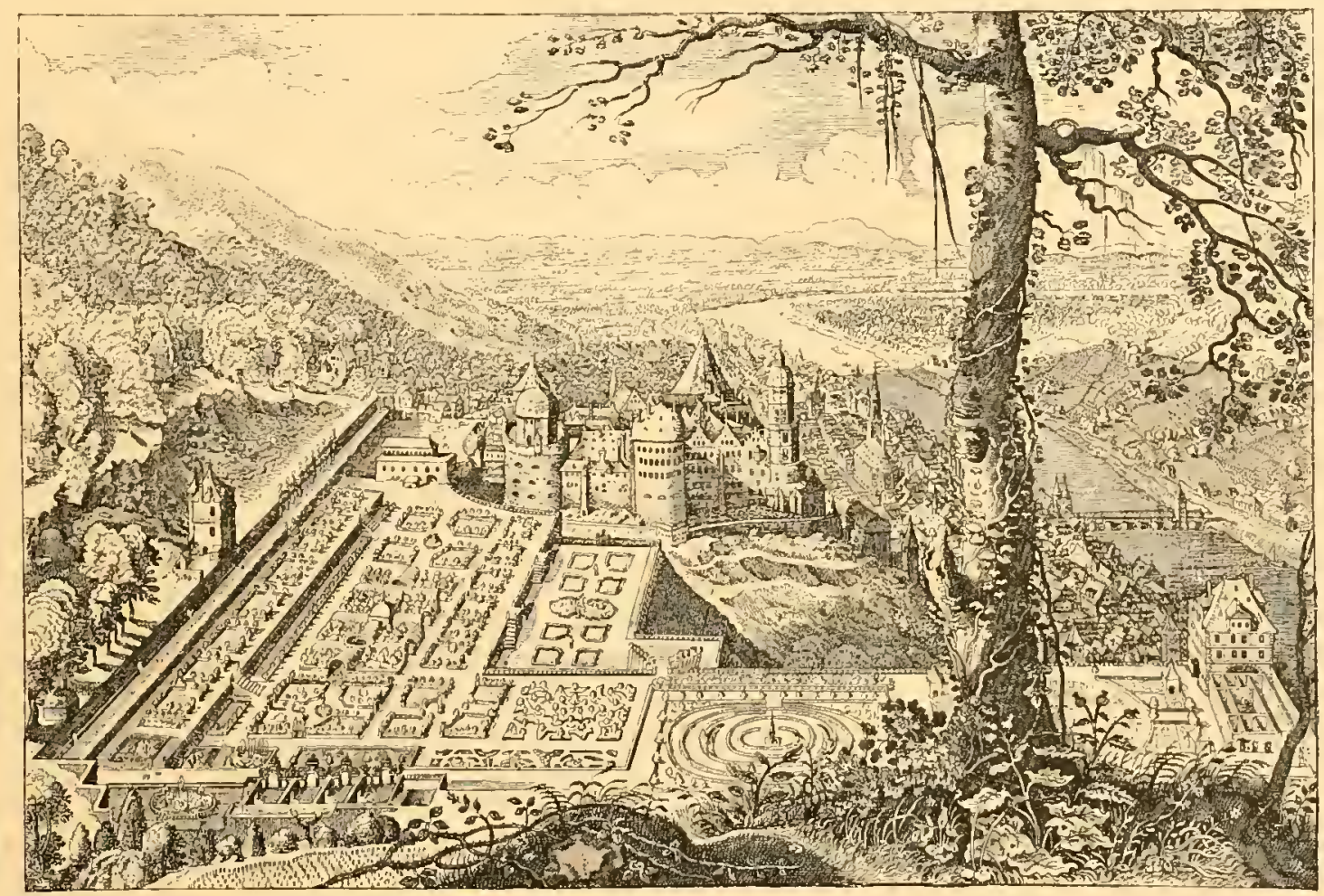

Fig. 127. - Cháteau et Jardins de Heidelberg. (Toyci p. 103.)

jardins de Versailles, tantôt que dans sa vieillesse il avait failli se décider à les refaire complétement d'aprés les idées de ce dernier. Ces assertions viennent, dit-on, de Dufresny lui-même, ce qui ne prouve pas qu'elles soient vraies, au contraire (I)!

Cette première tentative n'eut qu'un succés éphémére, et la vogue du système opposé, considéré plus que jamais comme national, se prolongea en France jusqu’à la

(I) Dufresny descendait, dit-on, d'un fils naturel d'Henri IV et de la femme d'un jardinier, ce qui expliquerait bien, au gré des partisans de la théorie des affections hérédiaires, le caractẻre hảbleur ct spirituel du poète et ses goủts de jardinage. Né en 1648, Dufresny était beaucoup trop jeune pour présenter des plans en concurrence avec ceux de Le Nòtre pour Versailles, à l'époque où ceux-ci furent adoptés. D'autre part, dans ses dernières annéss, Louis XIV n'était préoccupé, en fait de jardins, que de ceux de Marly. Enfin, ce fut surtout dans les dernières années de sa vie (17/4-24), et par conséquent après la mort de Louis XIV, que Dufresny s'occupa de jardins. 
fin du règne de Louis XV. Tous les auteurs français qui ont écrit jusque-lá sur les

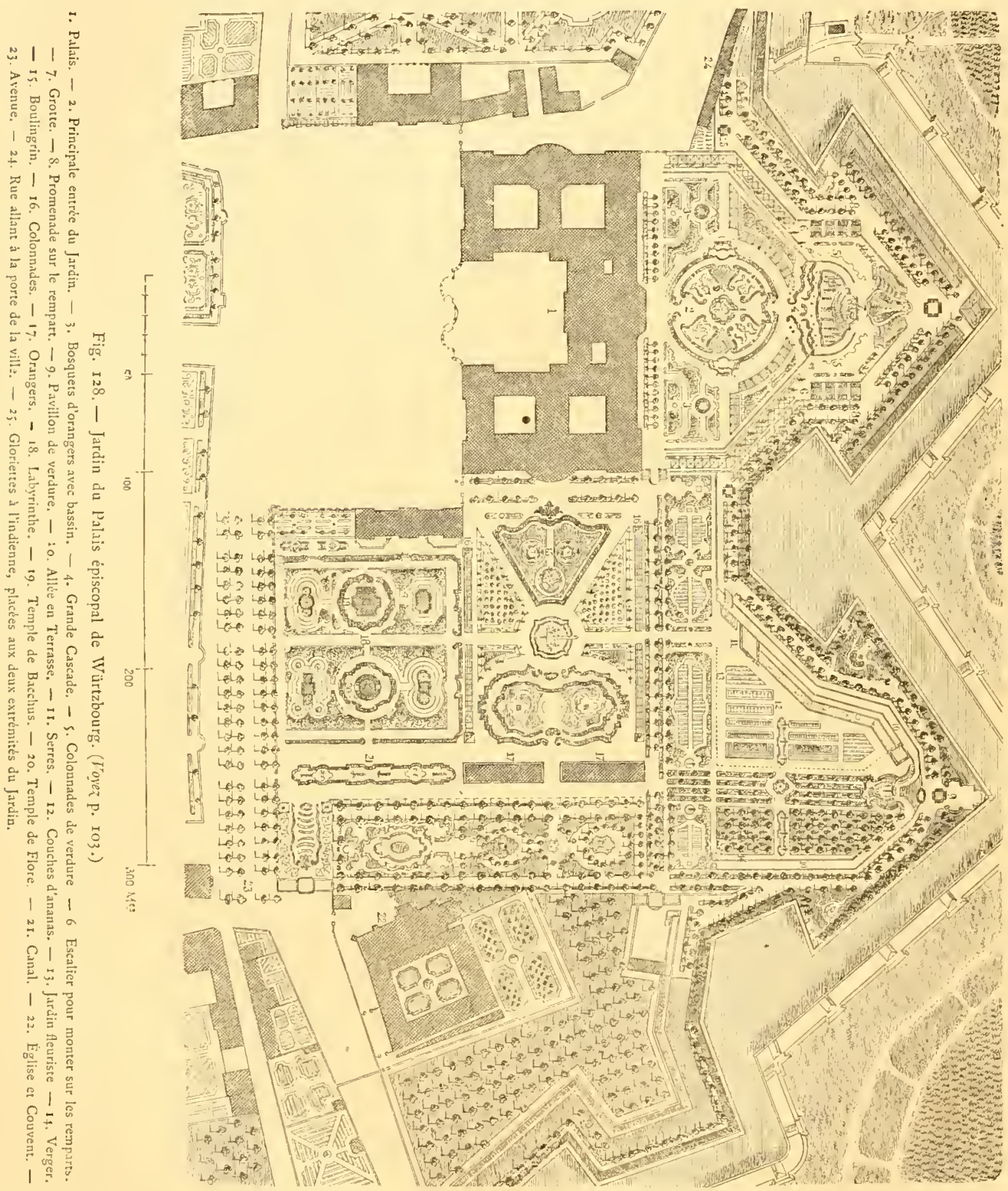

jardins, ne font mention que de ceux du genre régulier, et ne paraissent pas en soupçonner d'autres.

Il n'en était pas de même en Angleterre. Le nouveau système indiqué par Bacon 
et esquissé à grands traits dans le Paradise lost, fut nettement formulé par Addisson. Par une anomalie curieuse, l'auteur froid et compassé de Caton proscrivait en horticulture la régularité classique qu'll introduisait dans la tragédie anglaise. On a souvent cité un passage de son poéme intitulé: La Campagne, qui contient le programme de la "ferme ornée », telle qu'on la comprend aujourd'hui. "Pourquoi, disait-il, un propriétaire ne ferait-il pas de son domaine entier une sorte de jardin?...

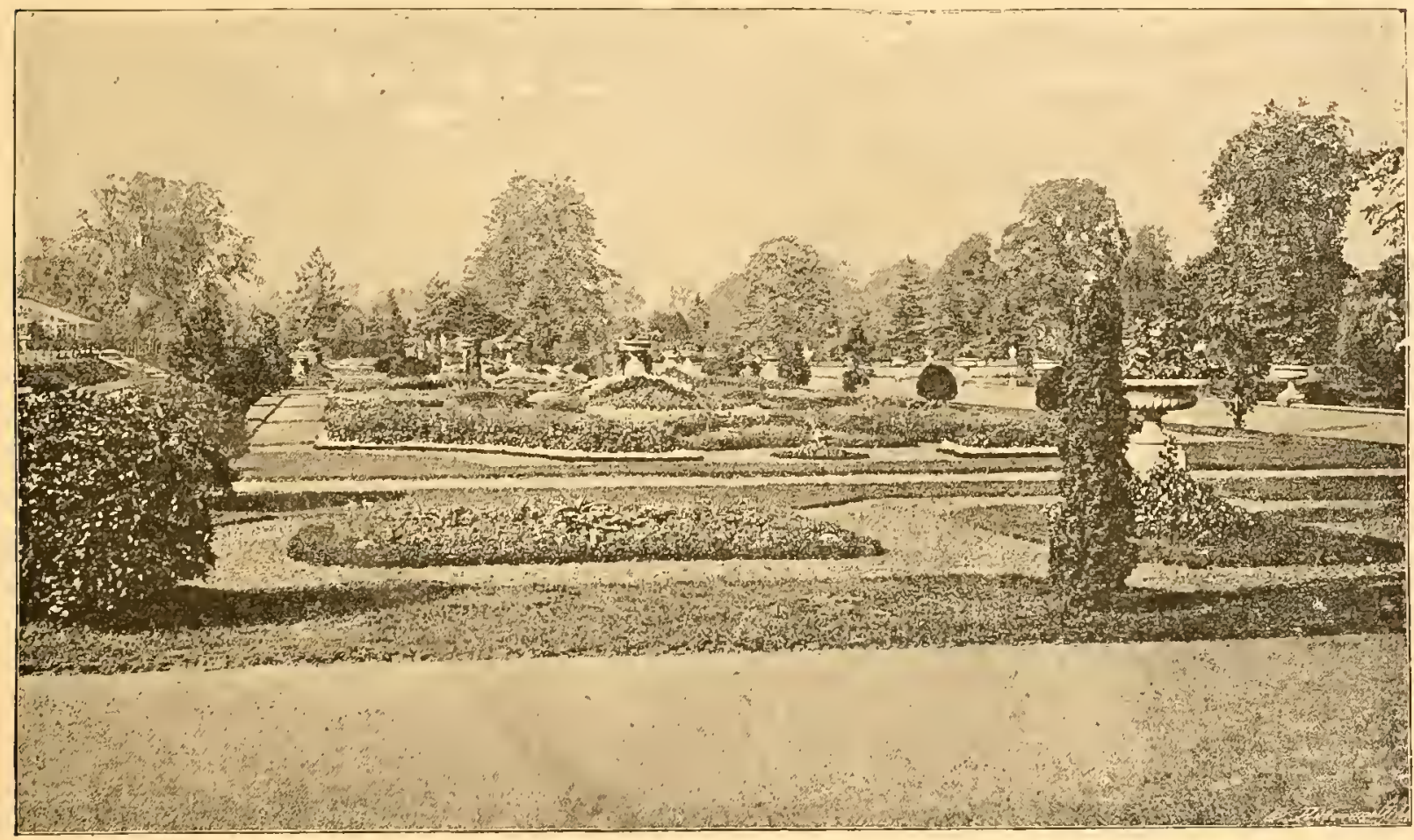

Fig. 129 - Vue du Jardin de Kert. (Troyez p. 108.)

Si les prairies recevaient de l'art du fleuriste quelques embellissements, il composerait un délicieux paysage, rien qu'avec son petit domaine. »

Ces idées furent virement reprises par un autre écrivain, qui a joui de son vivant d'une réputation aujourd'hui bien amoindrie. Pope attaqua énergiquement les jardins classiques: il se moqua des arbres taillés, "semblables à des coffres verts posés sur des perches, » et des autres architectures végétales. Il joignit l'exemple au précepte, en disposant dans le goût nouveau son petit domaine de Twickenham prés de Londres. Cette plantation fait époque dans les annales de l'horticulture anglaise. Ce fut là que le célèbre dessinateur Kent trouva, dit-on, ses meilleures inspirations le parc d'Esher, maison de campagne du premier ministre Pelham, et le parc histo- 
rique de Claremont. En rapprochant la date de ces premiers travaux (1720) de celle des essais de Dufresny ( $1714_{-24}$ ), on est amené à penser que la France, en ceci comme en bien d'autres choses, pourrait réclamer le mérite de la priorité. Mais, en Angleterre, cette réaction contre le genre régulier, spécialement réputé français, devint une affaire d'amour-propre national.

Alors, au rebours de la prophétie d'Isaie, les espaces unis se soulevérent en collines, les chemins droits se recourbérent. Les eaux jadis captives dans des bassins ou des réservoirs, asservies à des fantaisies grandioses ou puériles, furcnt rendues à leur pente naturelle, encore factices de terrain; les avedans des massifs aux conplus tard, les paritsans de la Chine un puissant ren" magots », jadis repoussés déjà signalé la lettre du jédes jardins. Chambers, archide Kent dans la création du (Fig. 1 29), publia à son tour nois, qui faisait plus d'honsa mémoire, car il était resté n'avait pas même vu les

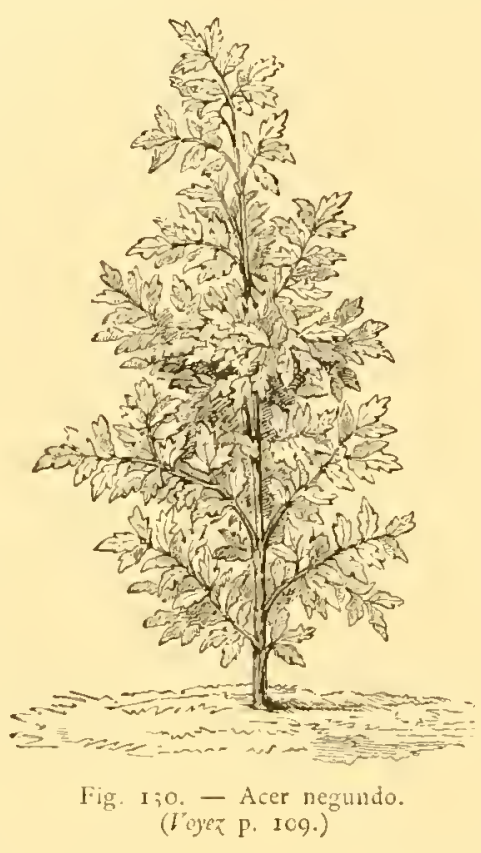
accélérée par des accidents nues détruites ou absorbées tours capricieux. Un peu cette révolution reçurent de fort. Ce fut la revanche des par Louis XIV! Nous avons suite Attiret, sur le jardin tecte anglais, collaborateur parc important de Kew un livre sur les jardins chineur à son imagination qu’à peu de temps en Chine, et parcs impériaux. Mais, comme il prêchait au nom des Chinois le retour absolu à la nature; ses descriptions, conformes à l'esprit du temps, obtinrent un grand succès, non seulement dans son pays, mais en France et en Allemagne. Ses préceptes furent bientôt développés et commentés dans un grand nombre d'autres ouvrages. L'un des meilleurs est encore celui de Whately, publié en i 770 sous le nom modeste d'Obserations (1).

"Plusieurs de ces observations sur la forme des bosquets, la direction des allées, des ruisseaux, le rapprochement des diverses teintes de verdure, peuvent encore être consultées utilement. Plus sage que la plupart des dessinateurs et propriétaires anglais contemporains, il blâme la prétention de contrefaire, dans des jardins d'agrément, les scénes naturelles les plus violentes.

(1) Whately (Sir Thomas) était, à cette époque, membre du Ministère. 
Il avoue, malgré son antipathie pour le style français, " que les avenues formant d'épaisses voûtes de verdure ont un charme particulier, ct qu'il vaut micux conserver cette disposition que de sacrifier des arbres importants, qui ne peuvent plus être déplacés. »

C'est aussi a cette époque de révolution horticole qu'appartient la Théorie des Jardins, du professeur danois Hirschfeld. Celui-lì, plus radical que Whately,

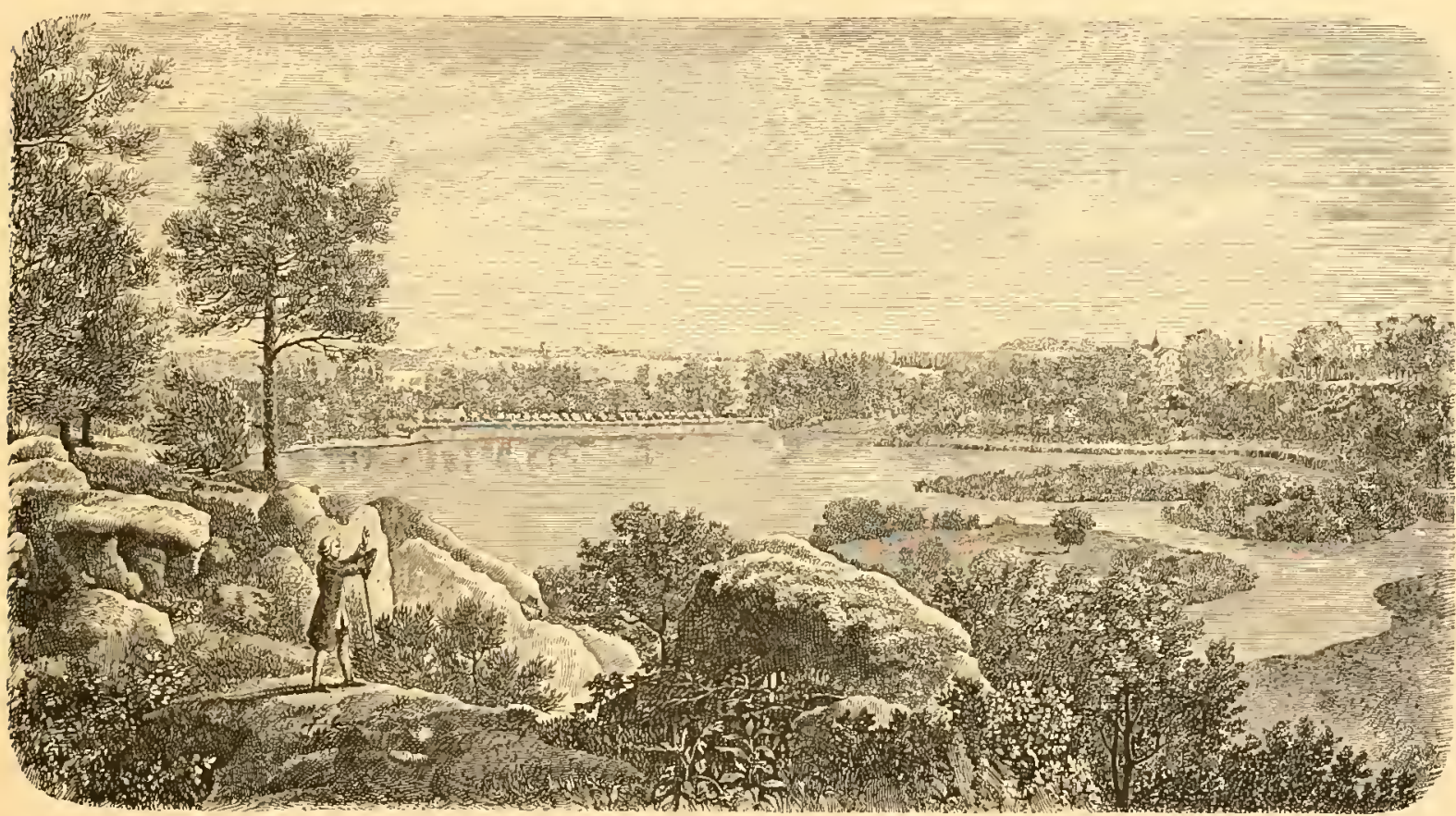

Fig. 1;1. - Étang da Désert, à Ermenonville. (Voyci p. 110.)

repousse toute symétrie. Il parait avoir voulu reproduire dans son livre le désordre pittoresque qu'il vante, et nianque absolument de goût, bien qu'il répéte ce mot à chaque instant. Ses extravagances sont quelquefois curieuses. Il donne, par exemple, un plan de répartition des parcs en quatre compartiments distincts, suivant les saisons; ou bien des préceptes pour appliquer la métaphysique à l'art des jardins, en assortissant leur physionomic à la profession, au caractère et même à la figure du propriétaire, ou aux sentiments dont il veut favoriser l'expansion chez ses visiteurs. Ces impressions morales peurent être obtenues infailliblement au moyen de certaines combinaisons d'arbres et d'arbustes, indiquées par le jardiniste philosophe. L'Acer negundo (Fig. Ijo) en considération de son feuillage d'un vert tendre, est particulièrement recommandé pour les scènes d'amour! Hirschfeld traite de fabuleuses 
les descriptions de Chambers et même celle d'Attiret, et bannit en conséquence la chinoiserie de ses parcs. En revanche, il les encombre de temples grecs. Malgré

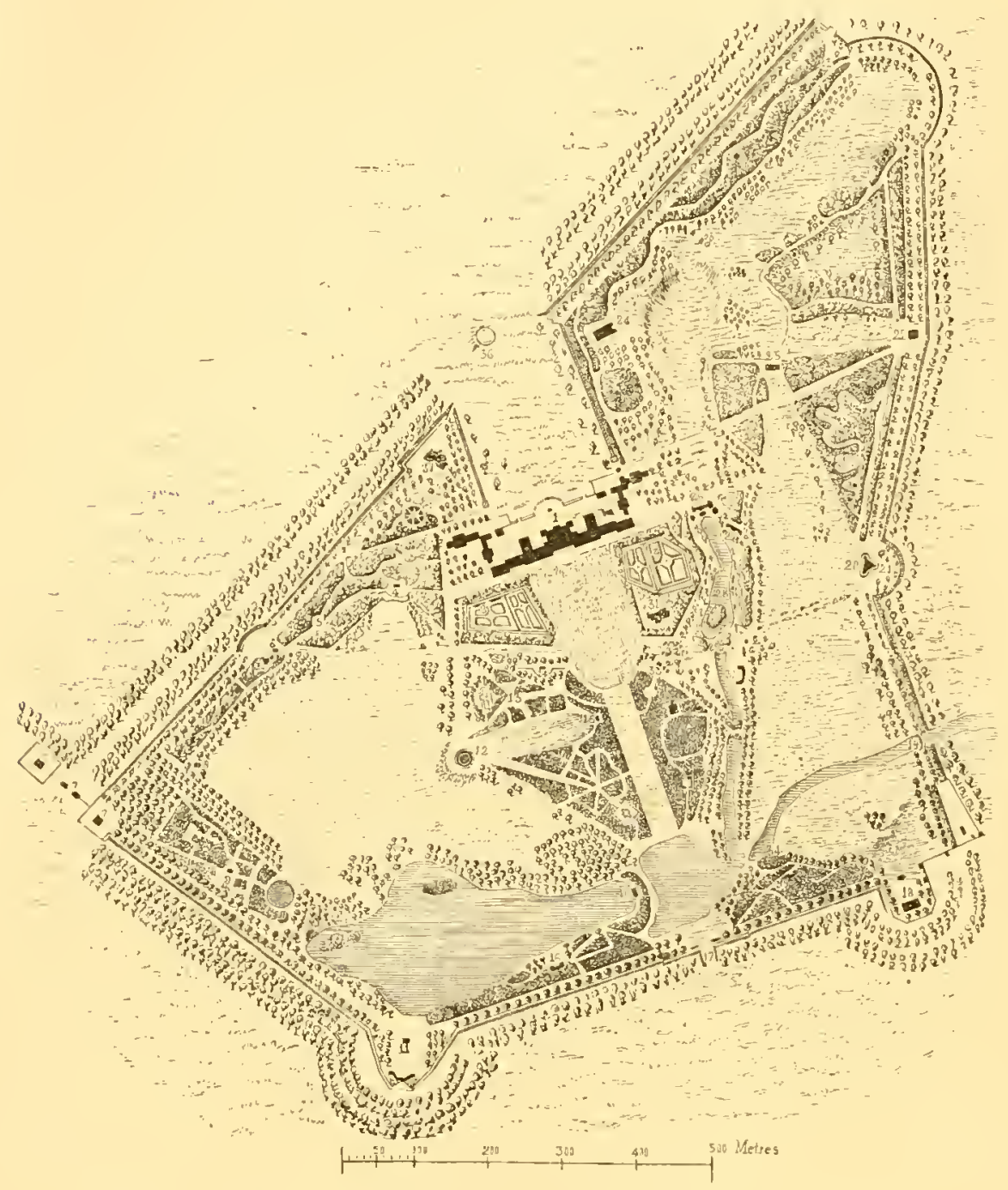

Fig. 132. - Parc de Stowe en Buckinghamshire, amélioré par Kient, en 1738. (Ioyez p. II2.)

1. Maison d'labitation, - 2. Deux Jaruins potagers, - 3. Orangerie, - 4. Tenaple de Bacihus, - s. Ermitage SaintAugustin. - 6. Statue de Dryade. - 7. Pavillon et Grille. - 8. Pyramide. - 9. Monuments de la reine Caroline. - 10. Cascade, - Ir. Temple de Vẻnus. - 12. Rotonde, - 13. Catene de Didon. - I 4. Colonne et Statue du roi George. - 15. Théätre de la Reine. - I6. Grotte du Berger. - I7. Entréc des Jardins. — 18. Temple de l'A mitié, - 19 Pont de Pembroike, - 20. Temple gothique. - 21. Himicycle des sept Divinites saxonnes. 22. Statue de lord Cobham, - 23. Temple de la Poésie pastorale, - 24. Temple Grec - 25. Teniple des Dames. - 26. Grotte et silex, porcelaine et coquillages, décorée de glaces et d'une statue de Vénus. - 27. Bains frojds. 28. Rivière des Aulnes, - 29. Pon de rocailles et Cascades, - 30. Temple des illustres Breions, - 3x. Eglise paroissiale. - 32. Temple de l'ancienne Vertu, - 33. Temple à la moderne Vertu et Arcade d'Armide. - 34. Monuments de Congrève. - 35. Grotte en cailloux. - 36. Statue de George I๕r. - 37. Salon de Nelson. ces puérilités, cet ouvrage est recherché à cause des nombreuses figures qu'il conticnt, notamment des jardins paysagers composés par Brandt, l'un des introducteurs du genre irrégulier en Allemagne.

En France, JeanJacques Rousseau (Fig. I 3 I) fut l'un des plus énergiques promoteurs du nouveau systéme. " Il faisait voir l'aurore à des gens qui ne s'ètaient jamais levés qu'à midi, le paysage à des yeux qui ne s'étaient encore arrêtés que sur des salons et des palais, le jar-

din naturel à des hommes qui ne s'étaient jamais promenés qu'entre des charmilles tondues et des plates-bandes rectilignes. ») (Taine, l'ancicn Rigime, p. 357.)

L'emploi des jardins irréguliers commenęa à prévaloir en France vers i77o. Il 


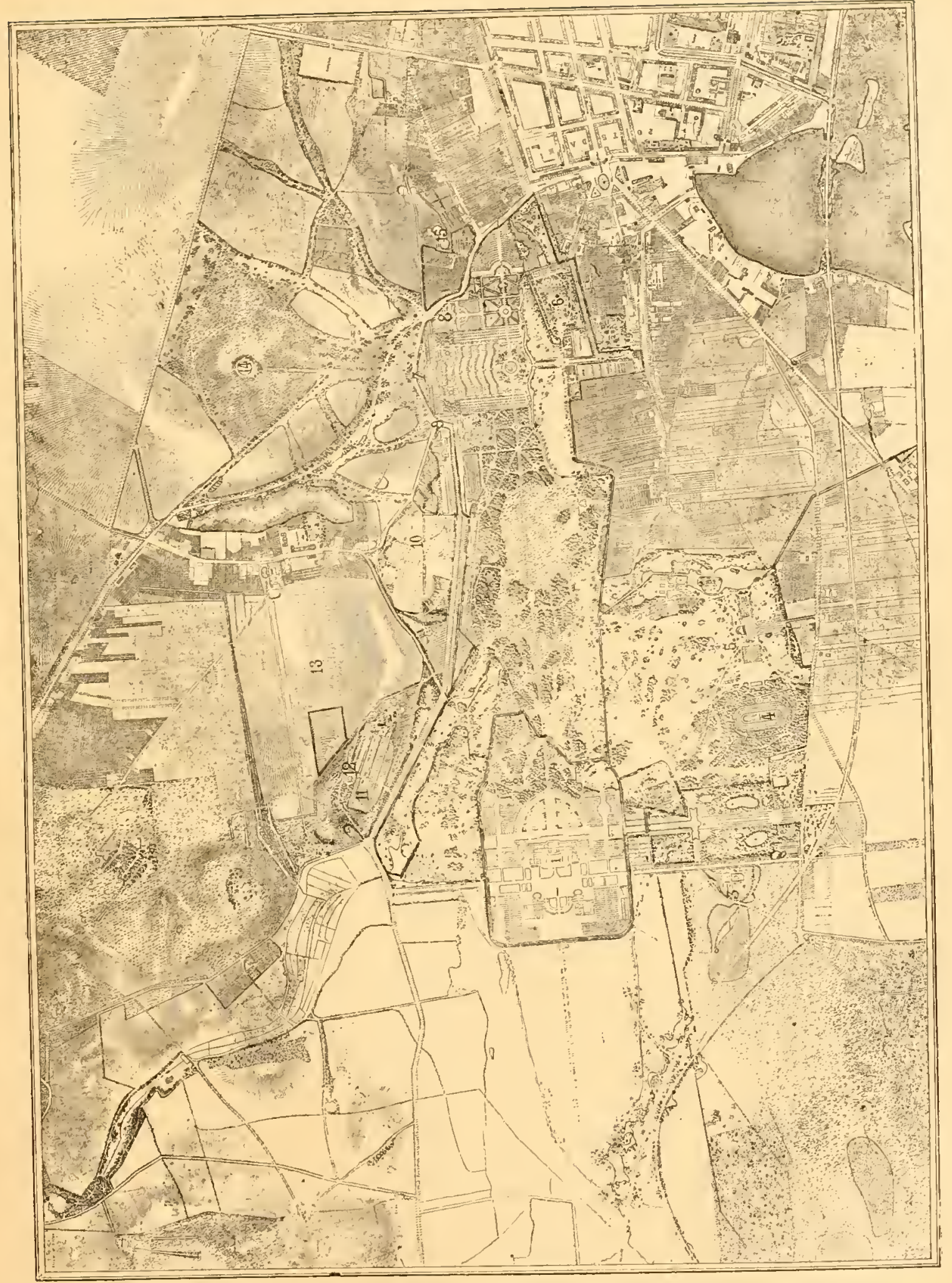

- Reproduction d'après un Plan gravé en I853

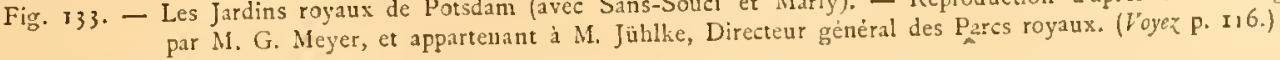

1. Paluis nouveau, - 2. Temple antique. - 2. Pépinière. - 4. Hippodrome. - j. Petit Château appelẻ Charlottenhof, -6 Marly. -7 . Le

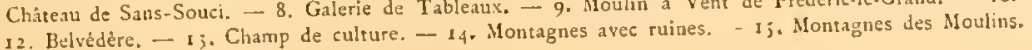


donna lieu à la publication d'un grand nombre de dissertations et de traités, parmi lesquels on remarque ceux de Watelet, de Valenciennes, de Morel, de Girardin, l'ani et le dernicr hôte de Rousseau. Les anciens jardins avaient été spécialement célébrés par le P. Rapin; les nouveaux le furent par Dallicres, Delille et Fontanes. Comme on l'a dit avec raison, les formes délicates de l'architecture de cette époque s'encadraient mieux dans les jardins irréguliers, que les constructions pompeuses et emphatiques

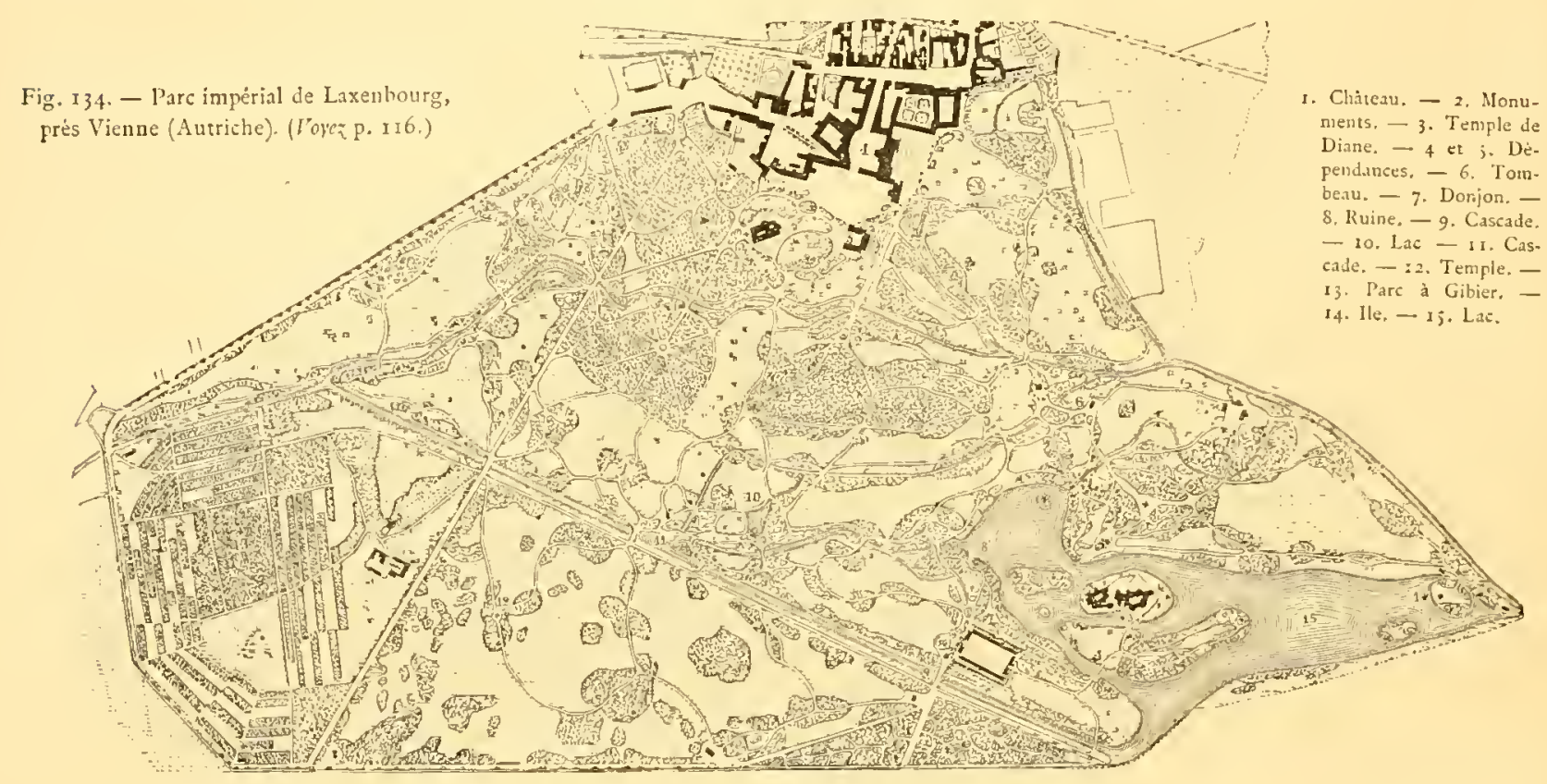

de l'époque antérieure. C'est un nouveau témoignage en faveur du systéme de corrélation intime entre le caractére des constructions et celui des jardins.

- Il y eut au début de cette révolution, comme de toutes les autres, des tâtonnements et des erreurs regrettables. On s'écarta fort de celte harmonieuse unité dont les compositions paysagères du Poussin offraient pourtant de si beaux modéles. «Les jardins furent des essais de poèmes divisés en différents chapitres », dont les sujets, tantôt religieux, tantôt sérieux ou des plus profanes, formaient des contrastes souvent choquants ou grotesques. Le type le plus curieux de ce genre d'ornementation fut longtemps le fameux parc de lord Granville, Stowe (Fig. I32). Ce parc, dessiné régulièrement à l'origine, avait été remanié de fond en comble par Kent et Brown, vers 1738. On pouvait, en quelques heures, y visiter, dans une étendue de 350 arpents, plus de vingt édifices de premicr ordre, sans compter les autres. C'était le plus étrange 
chaos de souvenirs grecs, latins, anglo-saxons, religieux, pliilosophiques, mythologiques et folàtres. A moins de cinquante mètres du "Temple de Bacchus », se trourait "l'ermitage de saint Augustin », au sortir duquel on accostait une statue de Dryade. Prés du "Temple des illustres Bretons », on voyait la sépulture d’un lérrier favori, avec une épitaphe interminable. La "caverne de Didon », ornée du groupe des deux amants, s'ouvrait non loin du « Temple de la Vertu féminine antique », et de la véri-

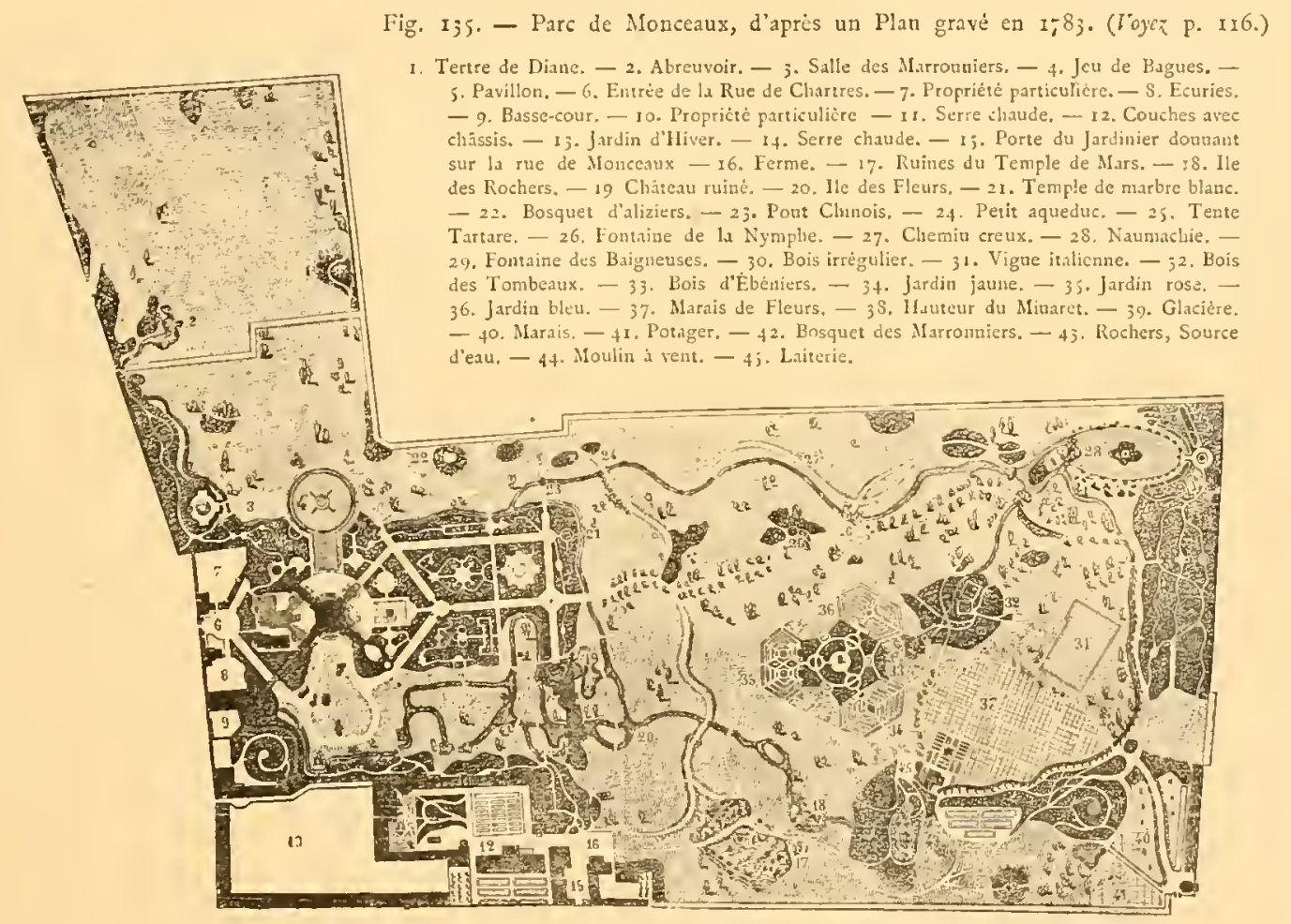

table église paroissiale, comprise dans le parc. Il y avait aussi, fort près de cette église, un temple de la Vertu féminine modeme. C’était un édifice en ruines, presque entièrement caché sous des plantes pariétaires, allégorie peu flatteuse pour le beau sexe contemporain... Le parc de Kew (Fig. I 29), non moins célébre, offrait un nouvel élément de variété, ou plutôt de confusion. Plusieurs fabriques de style chinois, notamment "la maison de Confucius », toute voisine d'un "Temple du Dieu des Vents", attestaient que Chambers avait passé par là. Ce même Chambers donnait des recettes soi-disant chinoises, plutôt iroquoises, pour forger des sites terribles. Il fallait :

Choisir des rochers de forme hideuse et fantastique, arrangés de façon qu'ils semblent prêts à tomber sur les promeneurs; 
Rechercher aussi les arbres les plus contournés, les planter de maniére qu'ils semblent ployés sous l'effort incessant des tempêtes (il sera bon d'en casser et d'en enfumer quelques-uns, pour simuler les traces de la foudre);

Précjpiter les eaux sur des pentes abruptes, à travers des obstacles de toute espéce (quartiers de rocs, trones d'arbres, etc.), qui les maintiennent à

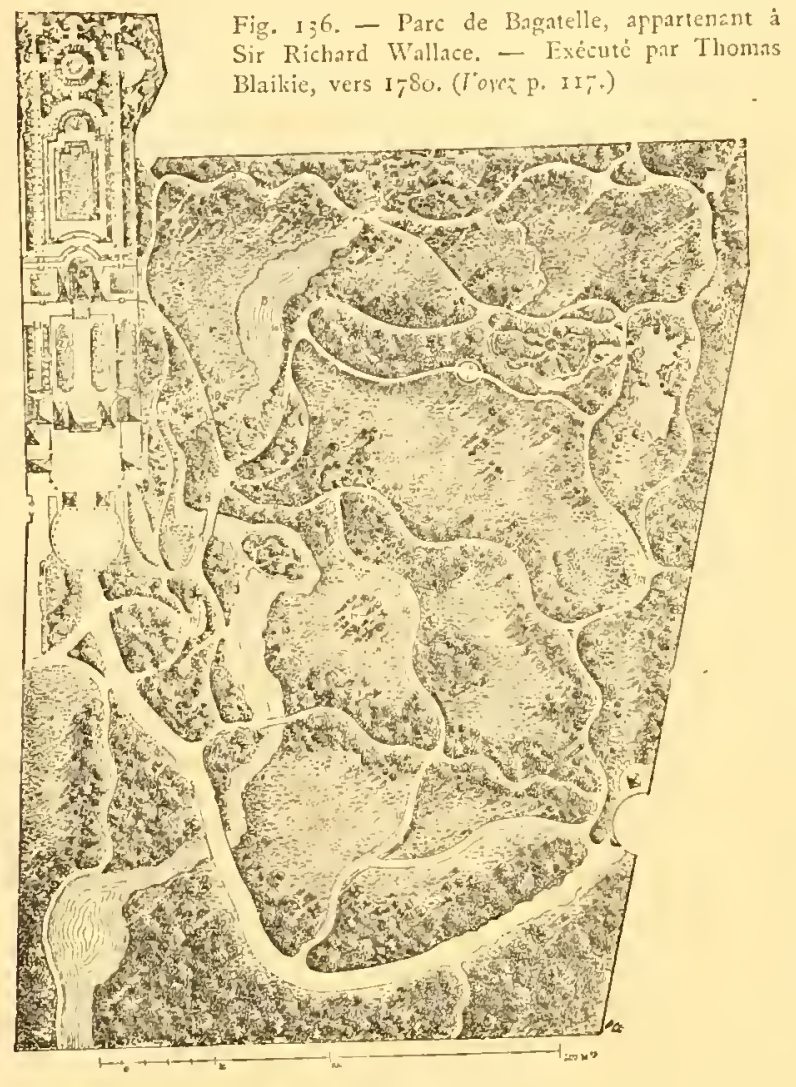

l'état de cataractes mugissantes;

Disposer çà et là quelques sơmbres cavernes, qu'on puisse supposer habitées par des bêtes ou des hommes de proie. Çà et lâa, aussi, des croix ou des obélisques avee des inscriptions rappelant la cruauté et la fin tragique des bandits. La fumce de fours à chaux ou de verreries masqués par les bois, ajoutera it la terreur en simulint des volcans. Quelques petits gibets, dressés de distance en distance, seront aussi du meillcur effet;

Enfin, pour couronner le tout, dans un ravin ou sur une hauteur de l'aspect le plus farouche, un temple de la Vengeance ou de la Mort, auquel conduira un sentier escarpé, " couvert d'herbes sinistres ». Bien que novateur zélé et convaincu, le dessinateur français Morel, auteur de la Théorie des Jurdins, reste ébahi de cette fantasmagorie, à propos de jardins d'agrément. Ces excentricités n'en avaient pas moins passé dans la pratique; on exagérait le pittoresque en dépit de la nature elle-même. Kent planta à Kensington des arbres rachitiques, d'autres tout à fait morts. Son collegue Brown, surnommé le Shakespeare du jardinage, proscrivait toute trace apparente de culture, et conduisait jusque sous les fenêtres principales de l'habitation des bosquets de la plus sauvage apparence (1).

(1) On trouve de curieux exemples, avec figures, de pares anglais créés ou remantés à sctte époque, dans un volume intitulé : Observalions sur les jardins anglais, publié à Londres en $180 \mathrm{I}$. 
Bientôt les pares du continent rivalisèrent avec ceux d'Angleterre, pour la bizarrerie et le mauvais goût des décors artificiels. Celui des Radziwill, auquel Delille a consacré quelques vers, était un des chefs-d'œuvre du genre. Pour franchir un cours d'eau large d'une vingtaine de pieds, on montait dans un bac amarré d'un côté à un Sphinx, emblème des périls de la navigation, de l'autre à un autel de l'Espérance. On débarquait dans un bois sacré, encombré d'autres autels. Un sentier ombragé conduisait à un édicule gothique, asile de la Mćlancolic, d'où l'on passait au temple grec, où un goût exquis avait réuni des figures de Vestales autour des statues de l'Amour et du Silence!!! On rencontrait ensuite la tente d'un paladin, un salon oriental avec des portes en acajou, un Musée d'antiquités, la plupart factices; enfin, le mo-

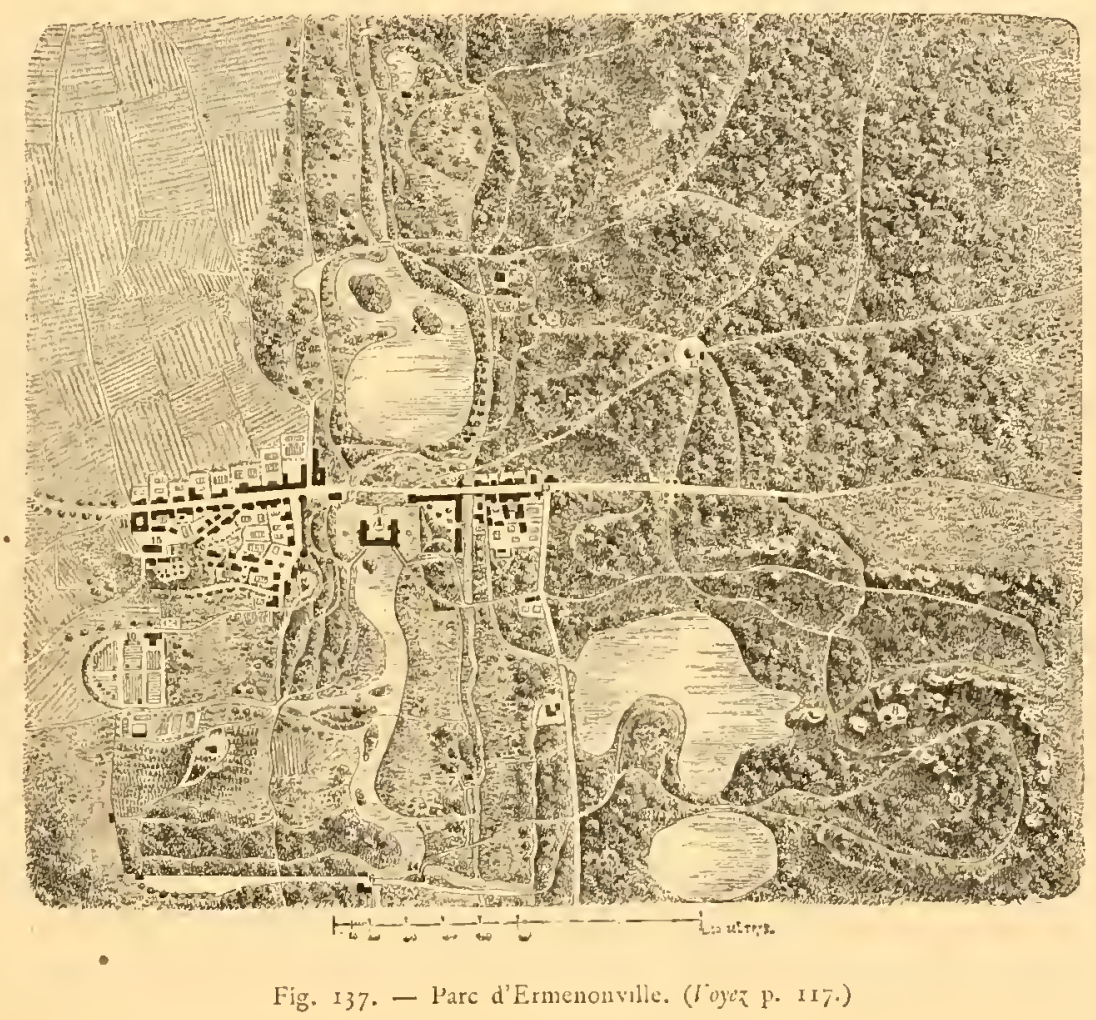
nument funèbre que la princesse Radziwill s'était fait faire d'avance, pour l'agrément des visiteurs.

Dans la plupart des grands parcs allemands, le style régulier est maintenu aux alentours immédiats des habitations; le reste est du style pittoresque. Dans ce genre mixte, c'est surtout le travail de raccordement qui fait ressortir le mérite du dessinateur. Parmi ces pares, on remarque Nymphenbourg (Bavière), Worlich (AnhaltDessau), Wilhelmshœhe (Fig. 10j) près Cassel, déjà nommé; puis, en Prusse, Postdam et Sans-Souci (Fig. I 33); en Autriche, Laxenbourg (Fig. I34) et Lundenbourg, le plus vaste et le plus beau. Il faut citer encore, dans de plus lointains parages, l'ancienne résidence favorite de Catherine II, Tzarskoë-Selo. Il y a là aussi une collection d'édicules cosmopolites, des ruines gothiques, un pavillon chinois, un bain 
ture et un obélisque égyptien qui est le monument funéraire des chiens favoris de la grande Impératrice.

Ce parc, comme bien d'autres cuvres du même genre, offre cncore de l'intérêt, non pour ces ornements factices auxquels on attachait jadis l'importance la plus grande, mais à cause des souvenirs historiques qui s'y rattachent et de la beauté des plantations.

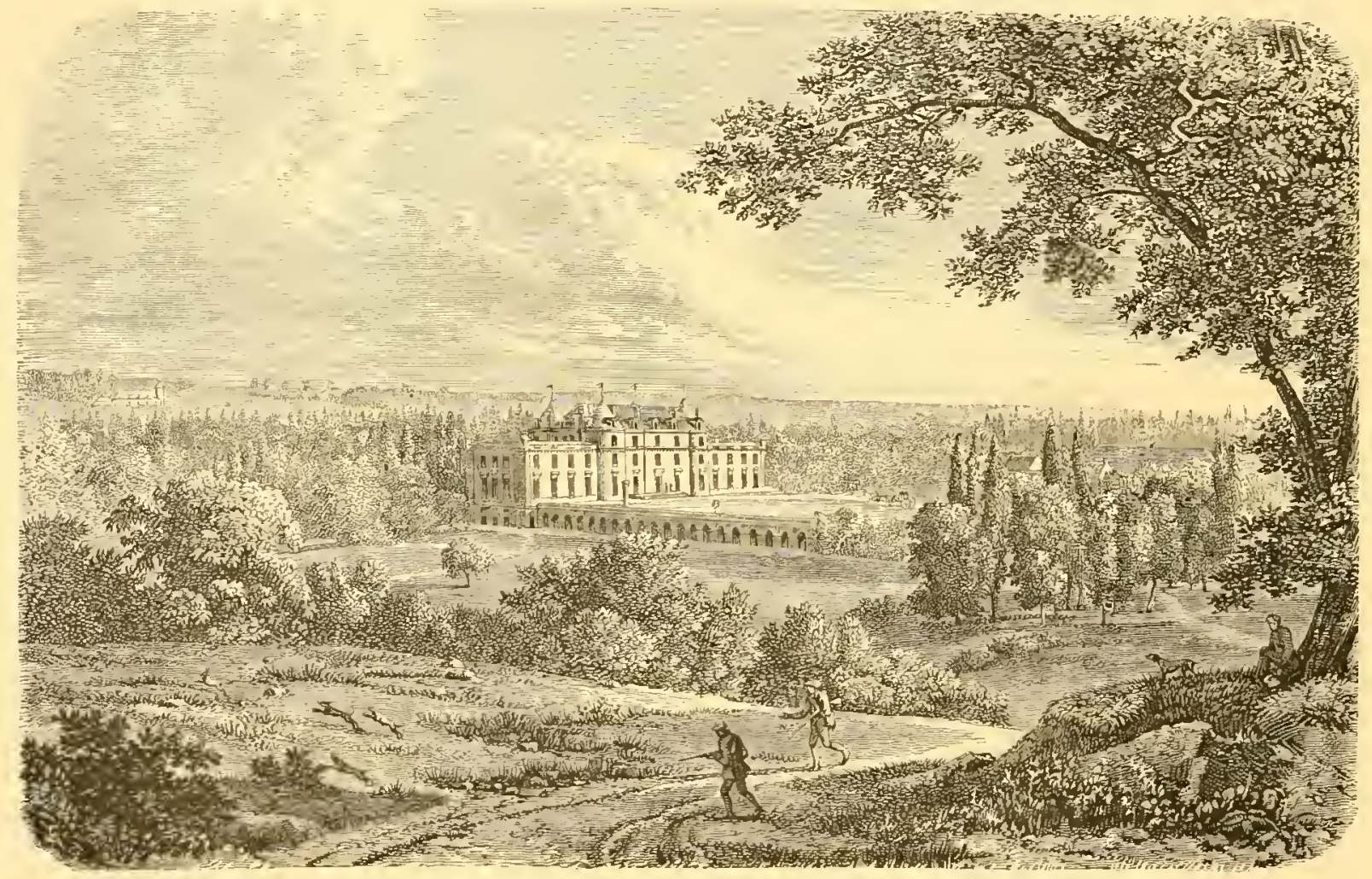

Fig. I38. - Vue du Chiteau de Méréville. (I'oyez p. I17.)

L'un des plus remarquables jardins irréguliers français créés avant la Révolution, fut celui de Monceaux, dessiné en 1778 par Carmontelle, pour le duc d'Orléans. (Fig. I35).

Le plan primitif offre un des plus anciens exemples de compromis entre les deux genres opposés. Le style régulier était maintenu aux abords de l'habitation; et l'on retrouvait même, dans l'intérieur du parc, une réminiscence des plus anciens parterres; les « jardins rose, jaune et bleu. »

Tout le reste était franchement irrégulier, et le dessinateur avait fait de louables efforts pour intéresser par des moyens purement naturels. Néanmoins, il 
s'était conformé au goût du jour, par l'installation d'un pont chinois, d'une tente tartare et autres fabriques dont les plus intéressantes ont été conservées dans le Square actuel.

Les pares de Bagatelle (Fig. I;6), d'Ermenonville (Fig. 137), de Méréville (Fig. IjS et I 43 ), de Morfontaine (Fig. I42), justifient encore leur vieille célébrité.

Ermenonville, chef-äœuvre de Morel, reste l'un des plus beaux types du genre

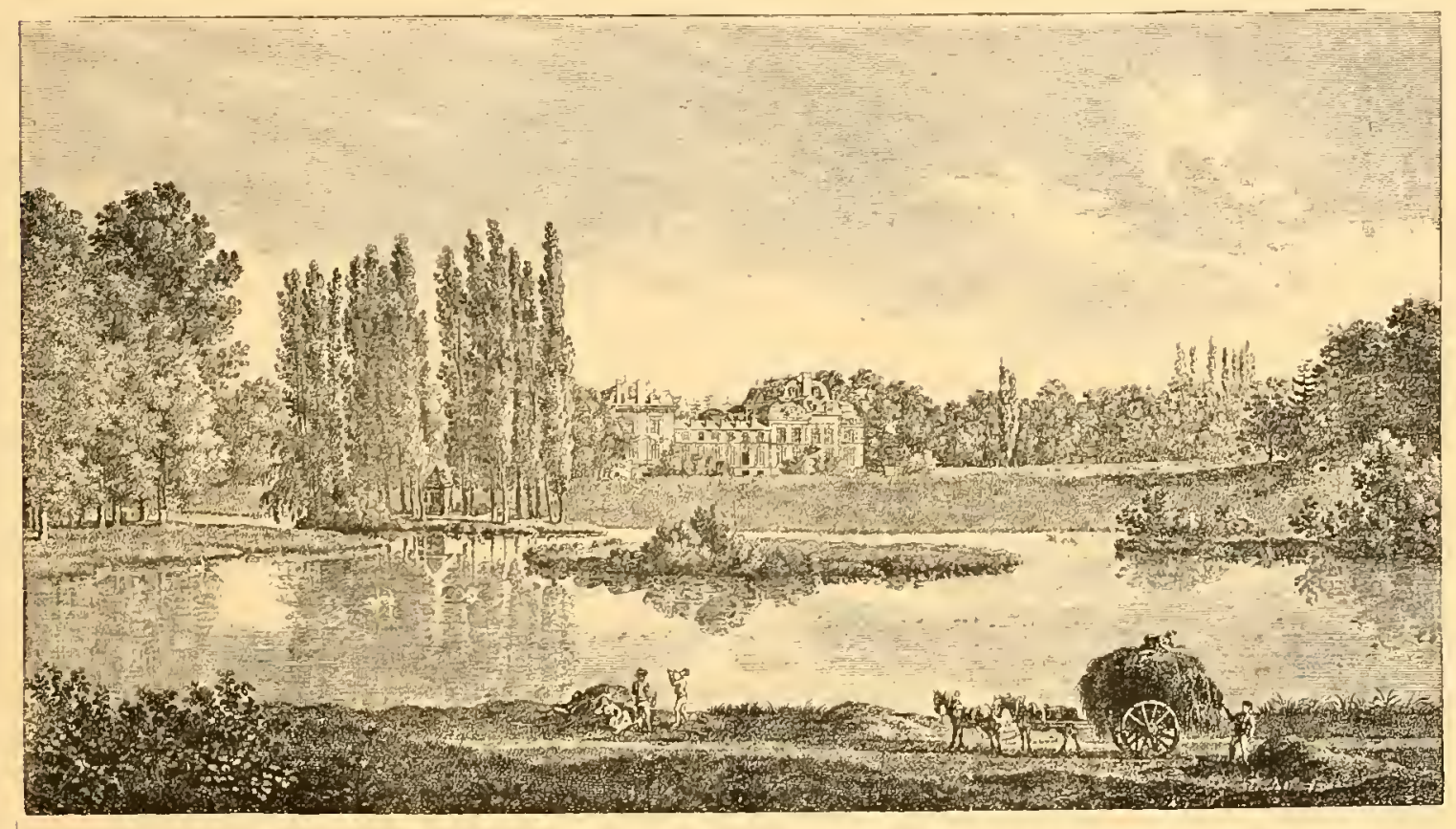

Fig. I39. - Chateau de Guiscard. (Dessin de Constant Bourgeois.)

irrégulier primitif. Il y a encore trop de fabriques, plus que n'eût voulu le dessinateur, qui n'était pas tout à fait le maitre. Mais tout n'est pas factice dans les ornements de ce parc; on y trouve, habilcment encadrés, la dernière habitation de Rousseau et son monument funébre. Inspiré par le souvenir de l'homme célébre auquel la France devait dejjá, en attendant mieux, la Révolution dans les jardins, Morel s'est surpassé lui-même, en cherchant surtout ses effets dans la disposition des points de vue, le caractère varié des eaux et des plantations. Le contraste du Désert avec le reste du parc est à lui seul presque un trait de génie; malheureusement il fut reproduit à satiété. Chaque propriétaire voulait avoir son désert, comme autrefois son labyrinthe. 
On citait encore de confiance, il y a très peu d'années, une autre œuvre trés

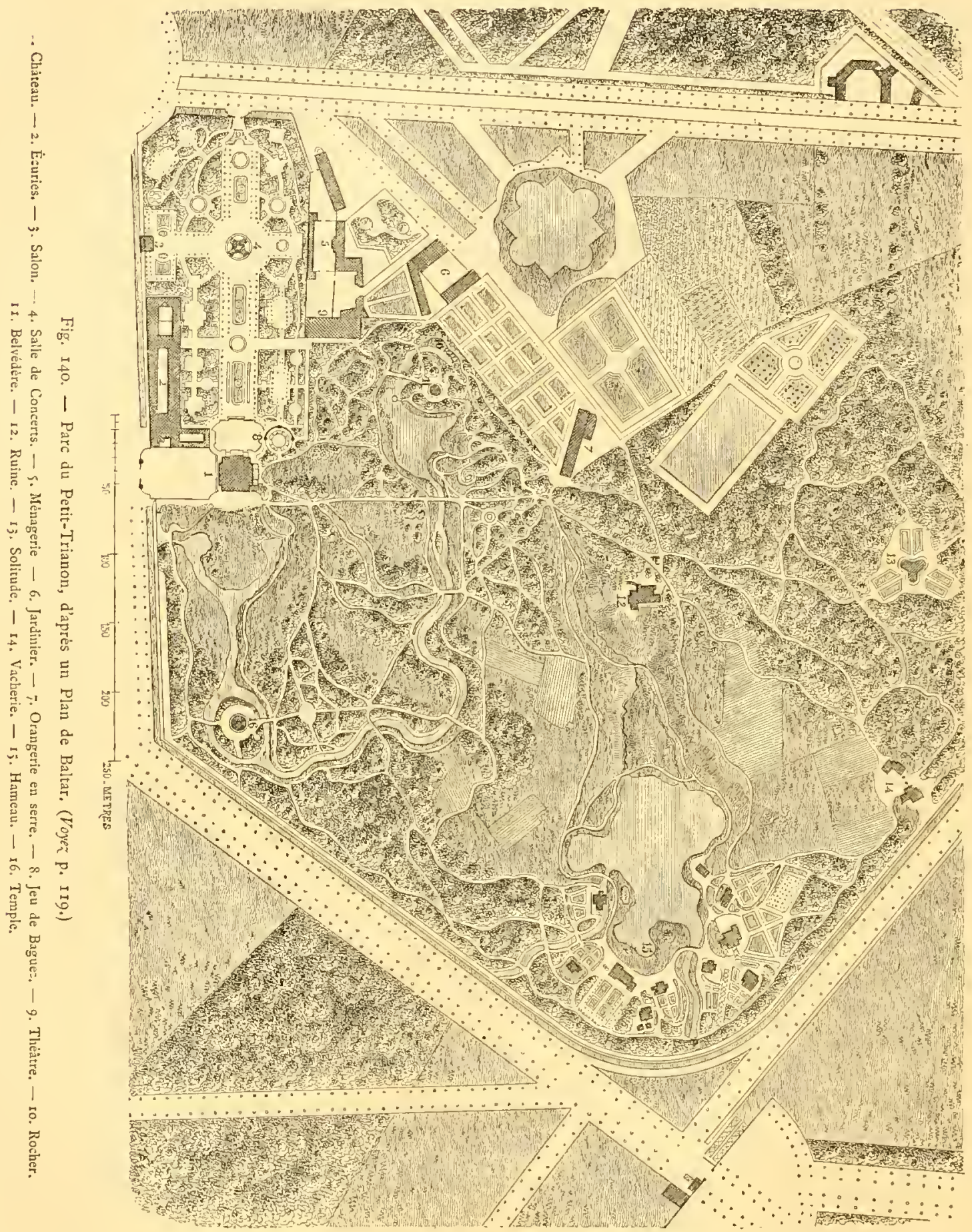

remarquable de Morel, le parc de Guiscard (Fig. 139). Malheureusement celui-là était comme la jument d'Arlequin, qui joignait à ses perfections le léger défaut d'être 
morte. Il n'existe plus depuis I $8_{3}$ I (1). Enfin, parmi les anciens pares irréguliers qui existent encore, il ne faut pas oublier celui du Petit-Trianon (Fig. I 40), qui emprunte un charme particulier au souvenir de Masrie-Antoinette.

Cette évocation nous améne naturellement à la Révolution, qui fit, comme on le sait, une terrible exécution des grandes propriétés. Depuis ce cataclysme, la vogue est plus que jamais au style irrégulier, mieux approprié aux domaines de médiocre étendue (2). Mais il y eut encore, dans son application, bien des aberrations de goût.

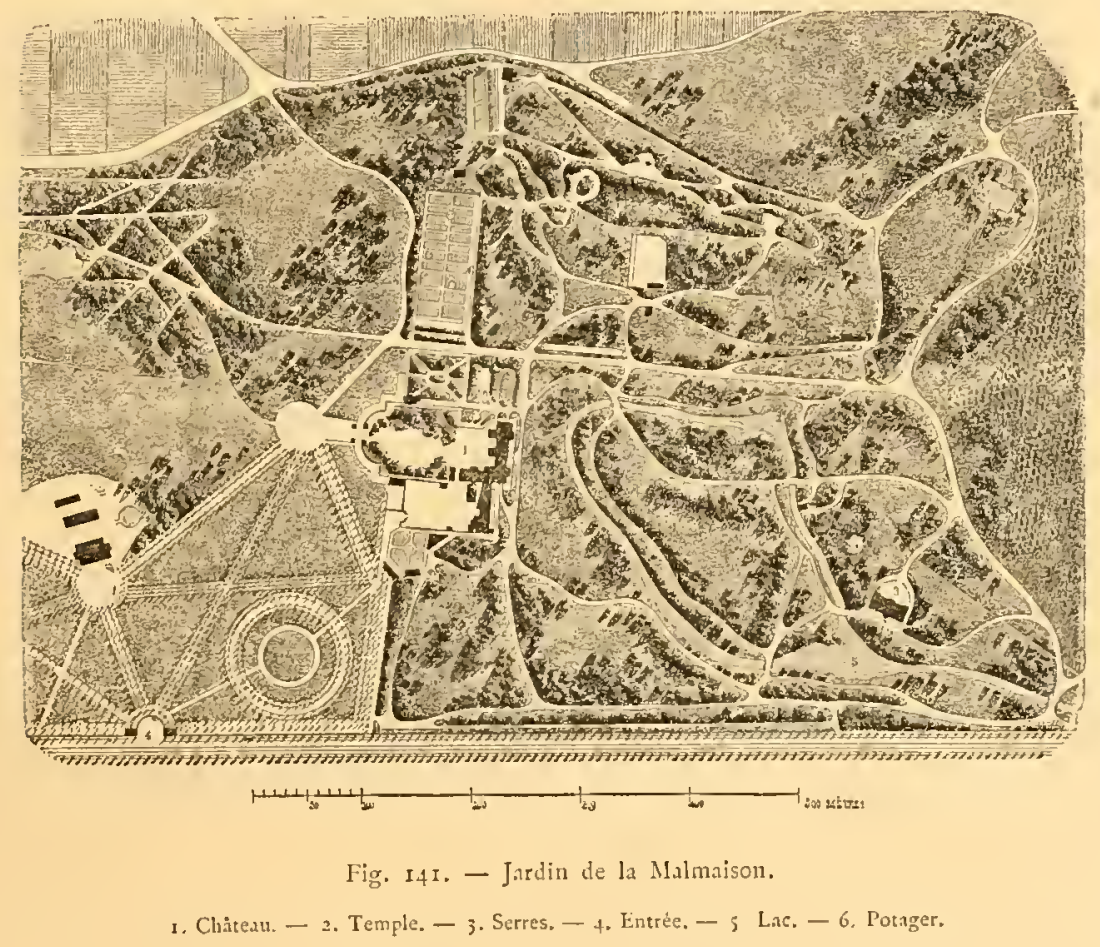

Cependant, depuis i 850 , on remarque un progrés incontestable. Les artistes et les amateurs éclairés ont compris que le véritable charme de ce style réside non sculement dans la disposition et les teintes habilement varices des plantations, mais dans l'unité de plan ou le rapport des diverses parties du domaine à l'habitation principale.

Les plus anciens jardins paysagers, échappés aux dévastations, fournissent aux dessinateurs modernes des renseignements précicux. Par un heurcux et rare privilège, en vieillissant ils embellissent! La nature, en reprenant ses droits, a opéré dans ces jardins d'heureuses transformations. Elle a fait disparaitre bien des ornements puérils, et le développement des plantations autour des pavillons, des grottes, des ruines

(1) Bien d'autres parcs, depuis longtemps détruits, méritent au moins un souvenir; celui de Boutin, par esemple, dessiné avant Monceaux dans le genre agreste, et fameux depuis comme jardin public sous le non de Tivoli. Paris renfermait déjai, à l'époque de la Révolution, un grand nombre de jardins irréguliers, quelques-uns publics ou quasi-publics; nous en citerons quelques-uns, dans le shapitre des jardins de ville anciens ou modernes.

(2) Deux parcs des plus remarquables, celui de la Malmaison (Fig. 141) (détruit) et celui de Morfontaine (Fig. If2) (dans son ćtat actuel), datent des premières annces du xixe siecle. 
factices, leur donne souvent bien plus de caractère et d'agrément qu'elles n'en araient à l'origine."On peut aussi se rendre compte, dans ces parcs, de l'effet définitif d'un grand nombre d'arbres et d'arbustes relativement nouveaux.

En résumé, après des changements qui correspondent aux évolutions psychologiques et sociales des différents pcuples, l'Art des jardins, exercé par d'habiles artistes disposant de ressources plus étendues que jamais, est cntré, depuis la seconde moitié du présent siècle, dans une voie plus rationnelle, dans un ordre d'idées plus en harmonie avec l'esprit moderne et le mode actuel de division et d'exploitation des propriétés. Nous allons essayer, dans les pages suivantes, de formuler les principes admis par les hommes les plus autorisés pour l'établissement des parcs et jardins, et particulicrement celles du genre ou style paysager, le plus fréquemment appliqué aujourd'hui.
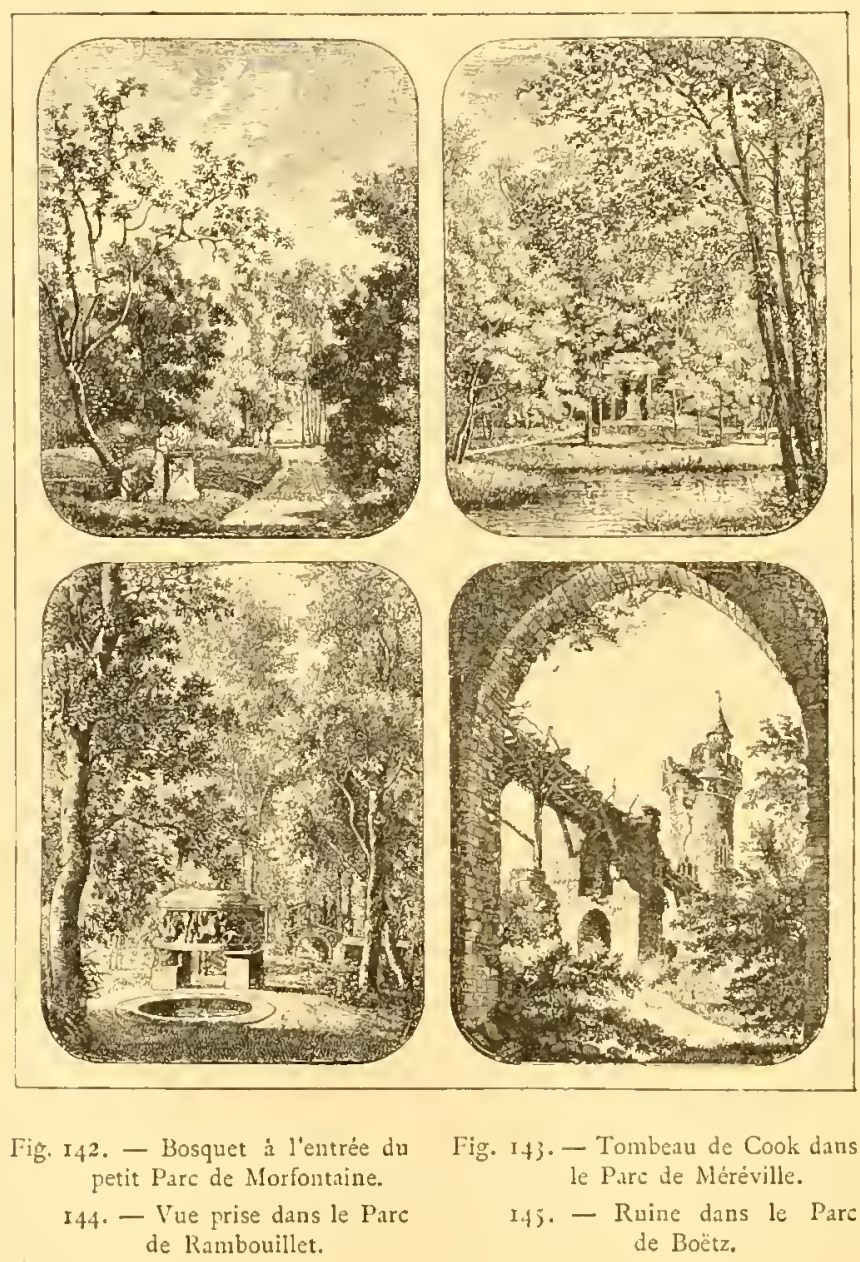


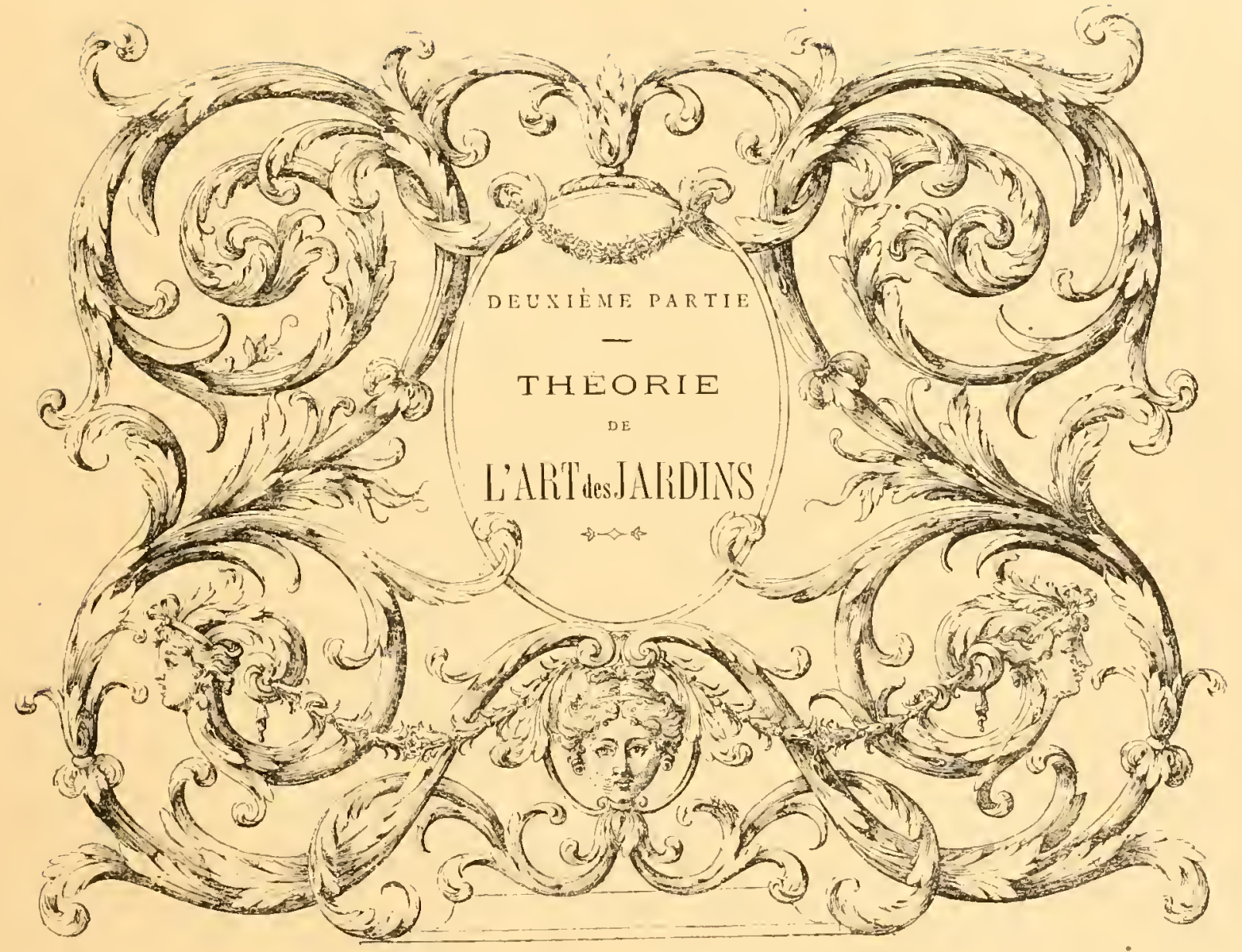





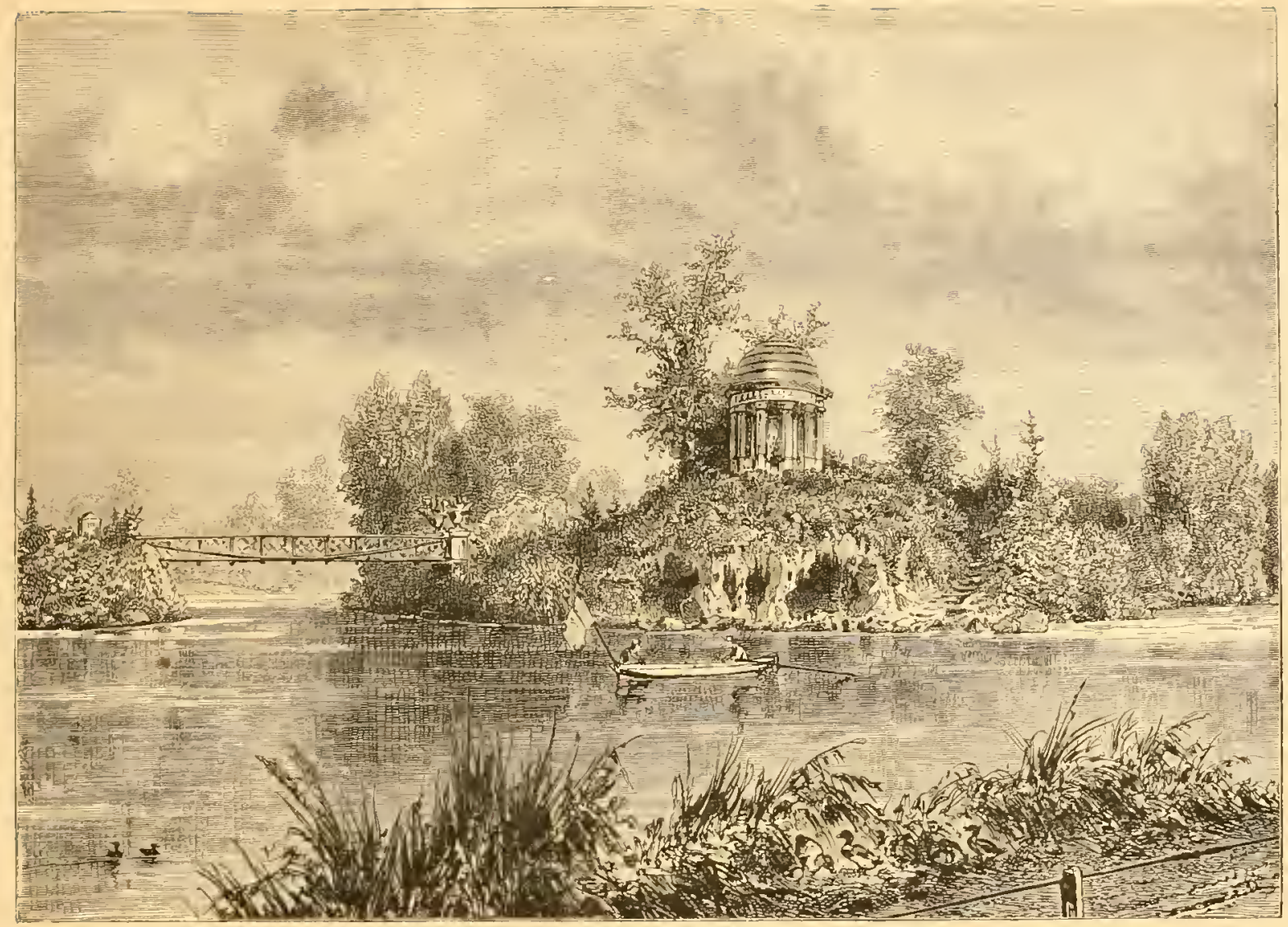

Fig. 147. - Rotonde et Grotte de l'lle de Reuilly, au Bois de Vincennes.

\section{CHAPITRE PREMIER}

TRACÉ DES JARDINS IRRÉGULIERS OU PAYSAGERS

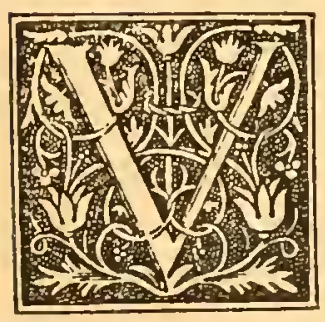

OULANT donner à notre travail un caractère marqué d'utilité pratique, nous allons exposer avec plus de détail les préceptes qu'on a le plus fréquemment occasion d'appliquer, ceux qui concernent les jardins et pares irréguliers. Cependant nous consacrerons un chapitre spécial au style régulier, à cause de l'usage partiel qu'on en fait encore assez souvent aux abords des habitations, dans les ceuvres du genre mixte, ou symitriques-paysagires. 
I. - Définition. - Principes généraux. - Suivant un des classiques de l'art des jardins paysagers, ect art consiste dans " la concentration d'un enscmble de paysages naturels, idéalisés et poétisés (1). ”Nous reproduisons ici (Fig. I 49) le

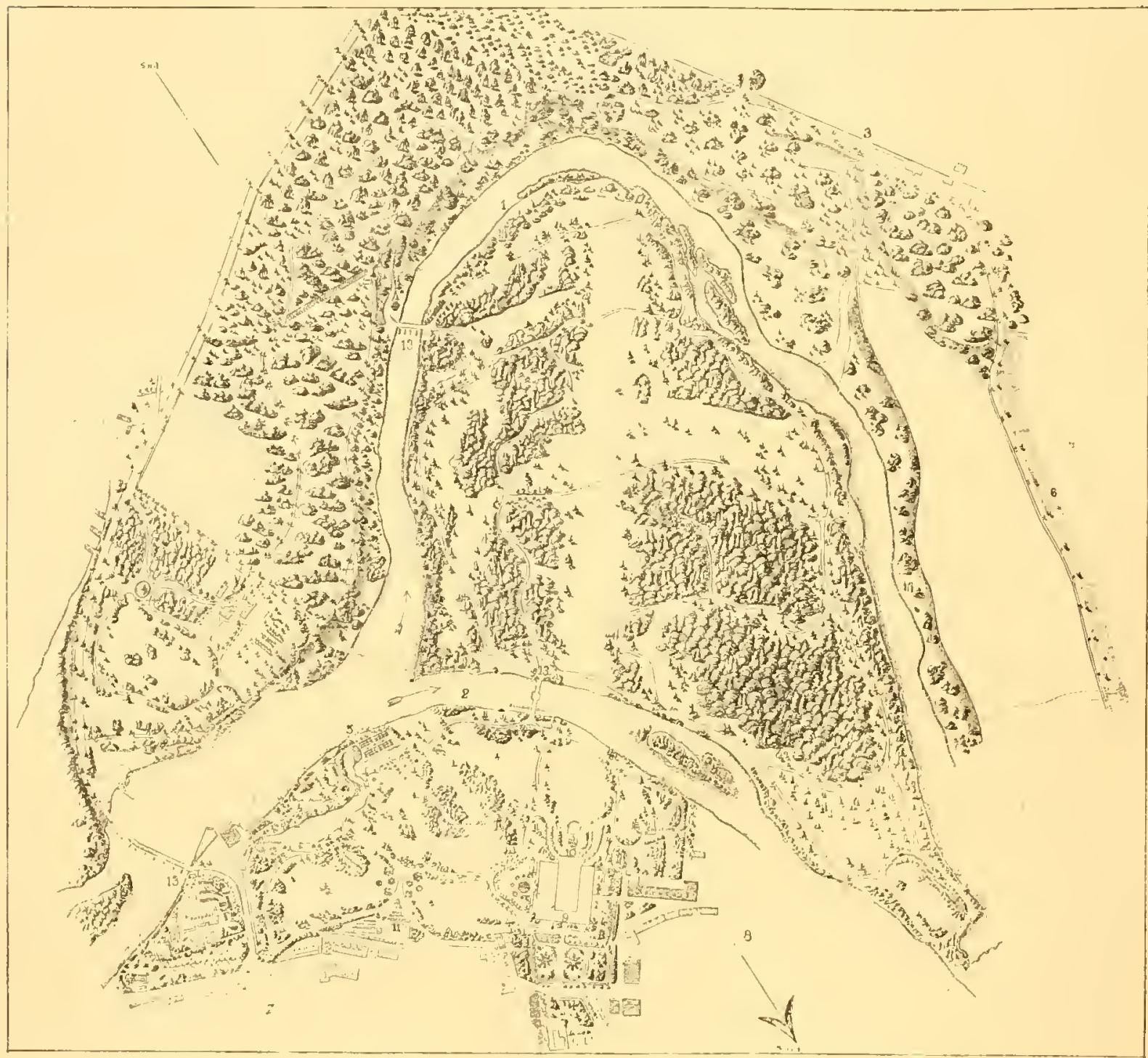

Fig. 149. - Parc de la Duchesse de Sagan, d'après le Plan de Teíchert,

I. Rivière le Bober. - 2. Branche de la Rivière du Bober. - 3. Chemin de fer de Sagan a Glogau, - 5. Jardin hollandais et Orangerie. 7. VMle de Sagan. - 8. Ville de Sagan. - 9. Clẫteau - 10. Orangerie derrière le Château. - Ix. Serre. - I2. Ponts sut le Bober.

fameux pare de Sagan, strictement conforme à ce système, dont les adeptes les plus habiles ont été en Allemagne, L. de Sckell et le prince Pückler. Cette définition ingénieuse paraitra peut-être trop complexe, trop aristocratique, pour un art qu'on

(i) Prince Päckler-Muskau, Elude sur la Planlation des Parcs (IS.17). 
peut aujourd'bui pratiquer arec sucećs, même arec des ressources pécuniaires très limitées. Il se peut, en effet, que les conditions restreintes de l'emplacencnt ne permettent qu'une scéne, qu'un tableau; et ce tableau unique offrira de l'intérêt, s'il est bien composé et bien exćcuti. De plus, il importe de tenir compte de l'effet que produisent, considérís isolíment, les mourements de terrain et les effets de plantation qui concourent à l'ensemble. Ils doivent satisfaire au besoin de variété, fournir des incidents ou épisodes agréables. Mais l'unité doit, partout et toujours, être une condition prédominante et comme la clef de voute de la composition du parc le plus vaste, comme du plus modeste jardin piysager.

Cette unití, qui paraît facile it obtenir, est trop

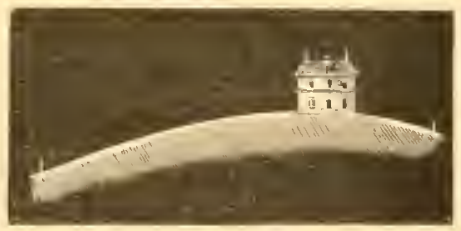

Fig. r 5̧o, - Maison sur une I Jauteur. fréquenment mal comprise ou violée. Aujourd'hui encore, on rencontre souvent, dans des propriétés arrangées d'une façon prétentieuse, un pitoyable amalgame d'ornements artificicls, un mélange incohérent de tous les genres; une profusion d'édicules inutiles et de mauvais goût, d'allées mal dessinées et faisant double ou triple emploi; d'arbres et d'arbustes mal assortis, ete. Dans les jardins comme pirtout, l'harmonie est la base de tout ce qui est beau, de ce qui donne à l'esprit une satisfaction durable, et mérite par lí de fixer l'attention.

Cette hamonic sera toujours plus aisciment réalisćc, si l'habitation est

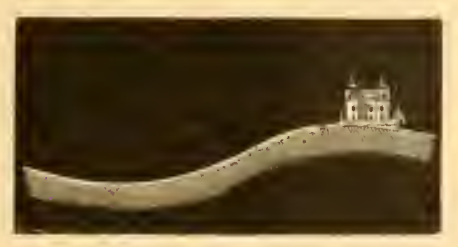

Fig. I5r: - Maison sur une Hauteur dominant un Terrain ondulé. situće sur une éminence. Alors le jardin, disposé en pente douce, paraît plis grand et donne à l'habitation plus d'apparence. Ceci sera micux compris par l'examcn de la figure ci-jointe (Fig. I 50), qui représente un terrain convere avec une maison a son sommet. Si le terrain est ondulé, comme dans la figure suivante (Fig. I I), l'aspect sera cncore plus agréable.

Ajoutons que des objets qui souven seraicnt à peine remarqués en rase campagne, gagnent infiniment s’ils se présentent habilement encadrís dans tes perspectives d'un jardin paysager. Dans ees conditions, la plus modeste église, une tour, une ruine même peu importante, une chaumiére, un moulin, peuvent ajouter quelque chose ì l'intérêt d'une propriété (Fig. 152).

Il ne faut pas négliger, si la disposition des licux le permet, d'augmenter l'effet d'un paysage, de lui donner l'attrait de l'impréve, en le faisant apparaitre 
tout à coup comme dans un cadre, au débouché d'une allée sous bois, ou d'un passage souterrain, comme Petzhold l'a fait, en dégageant dans le pare de Muskau, une perspective soudaine sur la Neisse (Fig. I53 et I54). Sans aller si loin, on peut trouver un exemple trís remarquable et peu connu de ce dernier effet dans un parc de la vallée d'Auge, aux environs d'Orbec. A. l'issue d'un court tunnel pratiqué à travers les hauteurs faisant point de partage, on se trouve tout à coup en présence

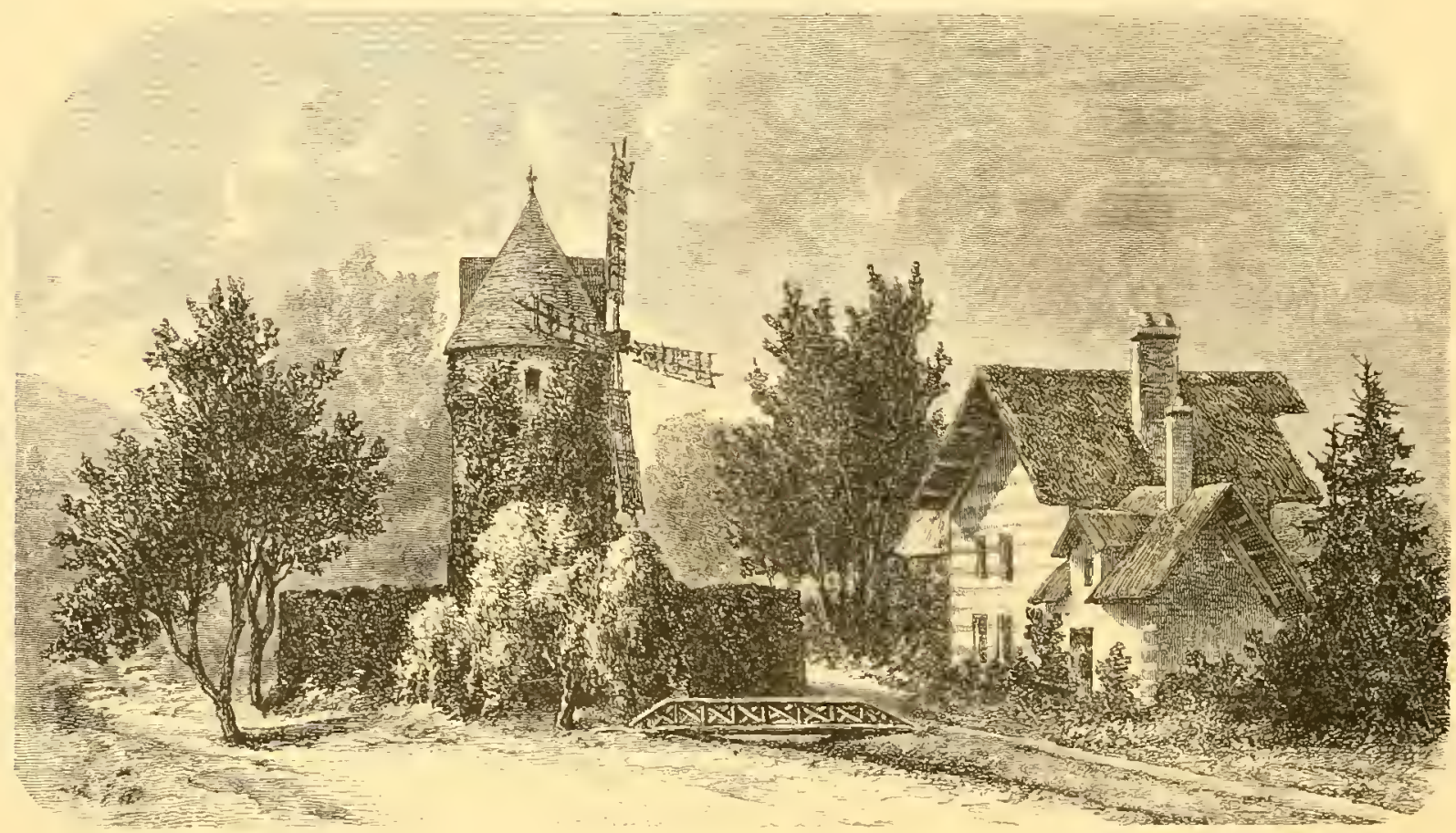

Fig. 152. - Moulin de Longchamps, au Bois de Boulogne. (Ioyri p. 125.)

d'une nouvelle vallée non moins gracieuse, celle de Livarot. Nous reproduisons une autre de ces surprises, ménagée dans la transformation du bois de Vincennes avec la perspective lointaine et imprévue du donjon (Fig. I55).

II. - Étude et Appropriation des Alentours. - L'étude et l'appropriation des alentours est un des préceptes les plus essentiels pour les plus grandes créations, comme pour les moindres. "Tous les objets éloignés qui offriront un intérêt quelconque, dit le prince Pückler-Muskau, devront être, pour ainsi dire, attirés dans notre domaine, de manière à dissimuler les limites. „ - Par contre, les aspects disgracieux seront soigneusement cachés par les plantations. En thése générale, un jardin paysager doit d'autant moins s'isoler, qu'il peut davantage 
emprunter au dehors. Il est rare que la campagne la plus unie n'offre pas quelque scéne intéressante; par exemple, quand le printemps déroule d’immenses pelouses de blés verdoyants; ou bien encore à l'époque des travaux de la moisson, ou même plus tard, quand les bestiaux sont parqués dans les champs. C'est lí lidylle, le " ménage champêtre », dont l'attrait est si puissant, que des personnages fort peu idylliques, Néron, par cxemple, ou les Borgial, aimaient à le contempler, soit en perspective, soit même en detail et de près, dans les intervalles des arenues de leurs jardins réguliers. (Voir les Jardins romains, ${ }^{\text {re }}$ partie.)

On augmentera l'intérêt de

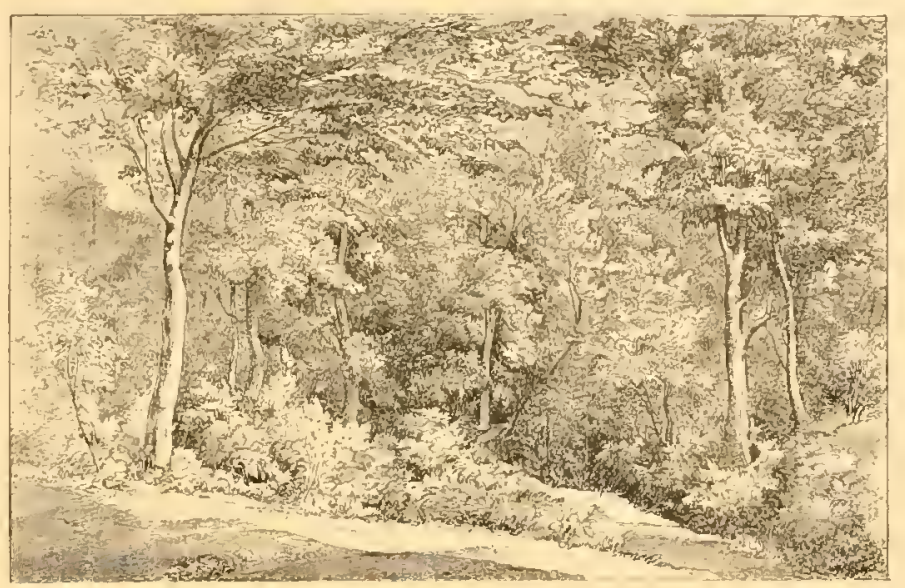

Fig. Ij3. - Bords plantés de la Rivière Neisse, dans le Pare du Prince Pückler. - Irue arant lis Trazanx, -- (Voyez p. 126.)

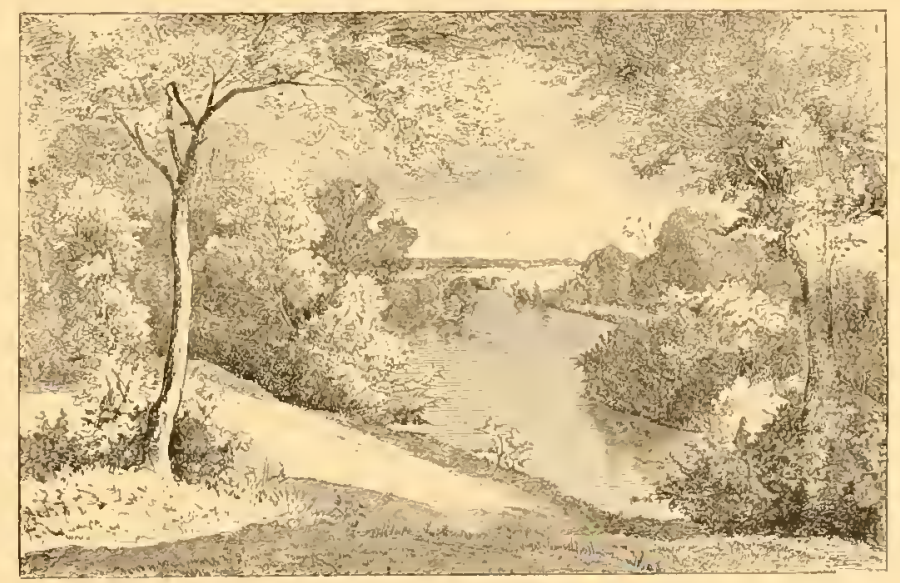

Fig. I54. - Percée pratiquée par Petzhold, dans le Parc de Muskau. D’après ses Dessins, - Vwe' actuelle domant sur la Neisse. - (Voyez p. I 26.) trains, les voitures, les piétons, qui sembleñt circuler dans l'enceinte du parc, lui donnent de l'animation, et le talent du dessinateur transforme en un ornement nouveau ce qui semblait un défaut sans remède (I).

(I) On peut voir un bel exemple de ce genre de travail dans le pare de Franqueville, près Rouen, coupé en deux par la route de Paris. C'est une des ceuvres les plus réussies d'un habile dessinateur normand, Duclos, mort misérablement en 1858 . 
Il est pourtant des circonstances où le jardin paysager, cerné impitoyablement par des constructions ou d'autres obstacles d'aspect disgracicux, doit tirer tout son agré-

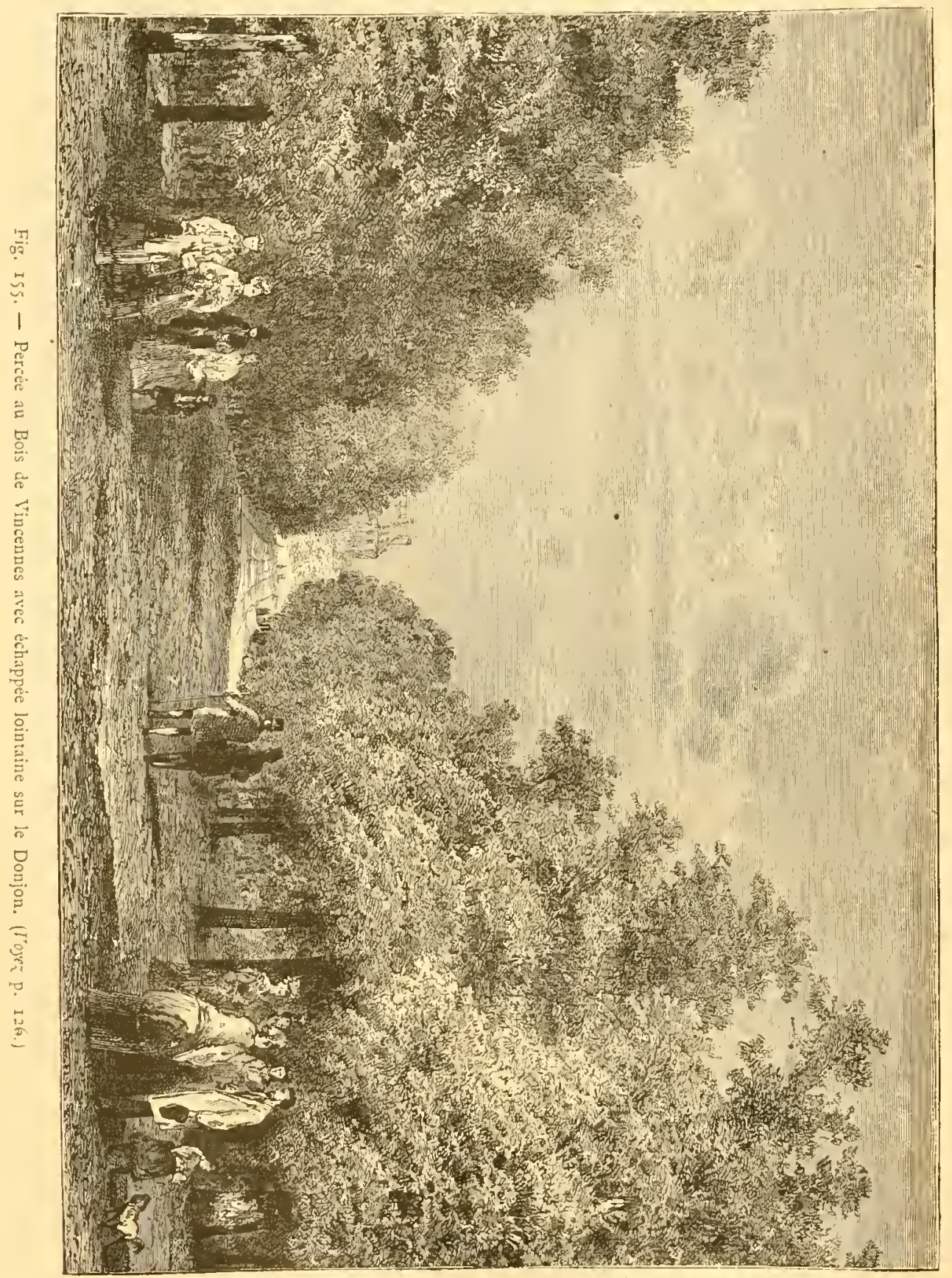

ment de luimême. Une cuvre de ce genre, bien réussie, est un des plus beaux triomphes de l'art du dessinateur paysager. L'un des mcilleurs spécimens de ce genre est le Square des Batignolles (Figure 157). 11 offre l'aspect de certains vallons solitaires des V'osges et du Jura, et un contrastedes plus henreux avec les abords plus que prosaïques quil a hallu cicher complitement. Mais, dans tous les cas, qu'il faille masquer les alentours ou les démasquer, les clòtures doivent être soigneusement dissimulées; éest une des lois inflexibles du genre. Cette dissimulation est toujours facile a rúaliscr; dans les espaces ouverts par des artifices de terrassements, 
des levées qui dérobent à la vue le fossé, le mur ou la haie établis en contrc-bas; et, dans les intervalles fermés, par des rideaux de plantations dont les arbres à verdure persistante doivent toujours former pour ainsi dire la trame.

Dans les plus anciens parcs de style irrégulier, le tracé des allées de ceinture trahissait une préoccupation constante d'obtenir le circuit le plus long possible, pour

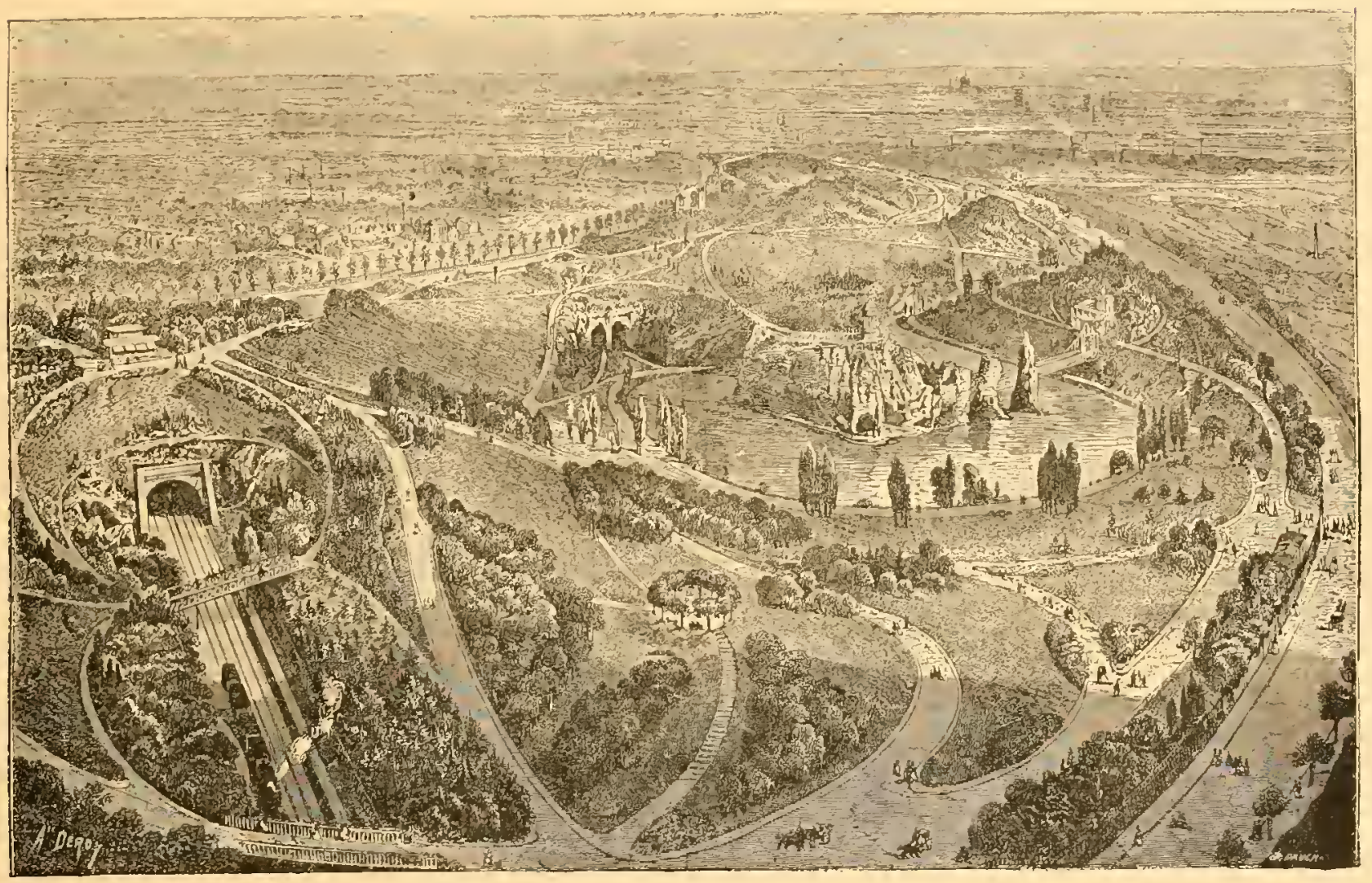

Fig. 156. - Vue à vol d'oiseau du Purz des Buttes-Claamont. Itoyci P. I27.)

faire paraitre le domaine plus grand. En conséquence, Kent, Brown et leurs premiers imitateurs effleuraient presque les murs, cachés seulement par une mince lisière de broussailles. L'expérience a condamné ce systéme. Au bout d'un certain nombre d'annćes, les grands arbres prennent leur essor, détruisent les broussailles et découvrent les clôtures, dont l'aspect incessant fait au contraire paraître la propriété moins grande qu'elle ne l'est. Pour produire et entretenir l'illusion, il faut done ne pas serrer de trop près les limites, et les dissimuler le mieux possible en couvrant les murs ou les palissades de plantes grimpantes, si on ne peut pas établir un sautde-loup. 
Nous reproduisons ici, d'aprés Repton, un modile de ce genre de travail

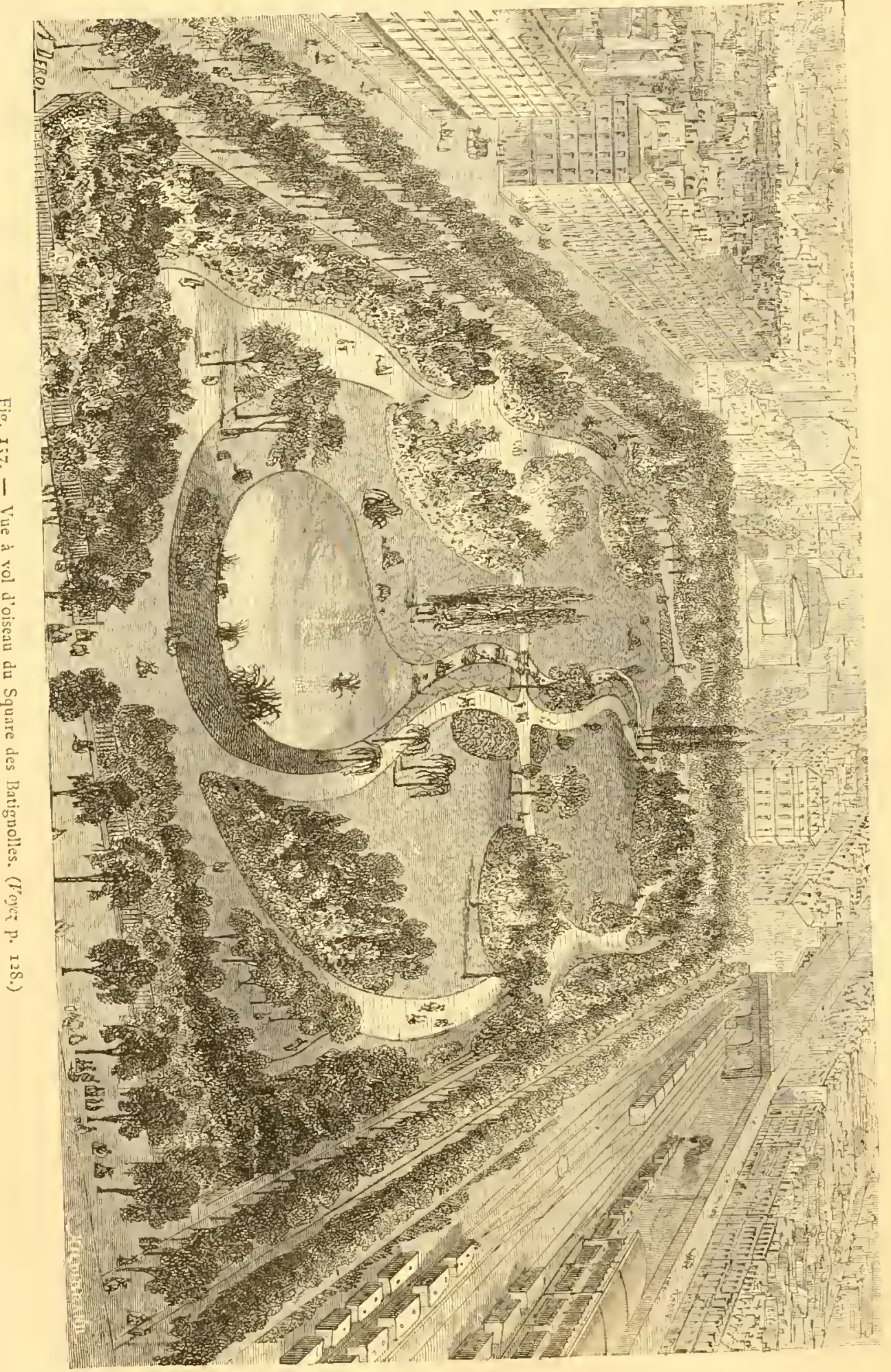

sur la limite d'une propriciti (Figures 158 et 159).

III. Double Destination du Jardin paysager. - La tendance à la retraite, i la possibilité de s"isoler, n'est pas moins conforme is la nature que l'amour du paysage. Bien des gens, même, sacrifient le plaisir de voir à cclui de ne pas être vus. L'un des mérites de l'art des jardins consiste pricisinnent à combiner ces deux avantages, qui au premier abord semblent 
s'exclure; à s'emparer en quelque sorte de l'extérieur par des percées intelligentes, mais sans se laisser envahir, de manière à être chez soi, tout en jouissant á volonté de rues agréables sur le dehors. Ce précepte est d'une application générale. Tous les jardins irréguliers, grands et petits, doivent être disposés de manière à satisfaire ce double besoin de retraite ou d'expansion.

Il faut dire encore que des tableaux d'un aspect vulgaire prennent une élégance imprévue quand ils sont ajustés habilement dans un paysage bien composé. Dans cette condition, l'aspect d'un village des plus ordinaires, de constructions isolées, comme un petit pont, un moulin ou même une simple chaumière, produira un excellent effet. On peut aussi tirer parti de la vue d'une gare, d'un bâtiment industricl ou de toute autre construction, pourvu qu'elle soit convenablement encadréc dans le paysage. (Fig. I60).

IV. - Rejet des anciennes Classifications. - Division des études. - Nous croyons devoir rejeter absolument les classifications de jardins ima-

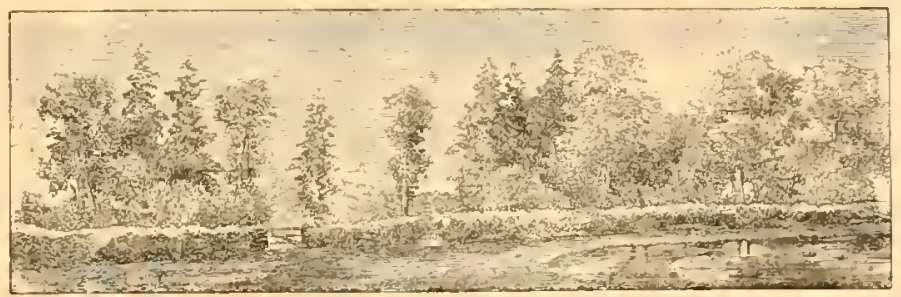

Fig. Igs. - Vue d'une Plantation de Limite, avant la Transformation. D'après Repton. (Ioyez P. I jo.)

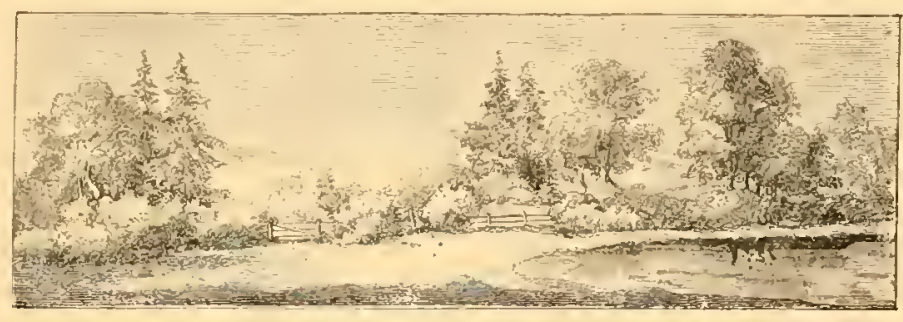

Fig. I 59. - Mẻme Emplacenent, après la Transformation. Ces deux dessins sont emptuntés a louvrage de Petzhold. (Toyez p. 1;0.)

ginées par les novateurs du dernier siècle. Ainsi, outre les jardins maraîchers, fruitiers, botaniques et d’agrément symétriques, G. Thouin distinguait huit genres de jardins de plaisance irréguliers : chinois, anglais, fantastique, champêtre, sylvestre, pastoral, romantique, plus le parc proprement dit ou carricre. D'autres se contentaient de quatre genres : le pays, le pare, la ferme, le jardin. Il serait facile de montrer, par de nombreux exemples, que ccux-lí même qui ont imaginé ces divisions n'en ont tenu aucun compte dans la pratique.

Parmi les jardins irréguliers primitifs, les plus agréables présentaient un caractére complexe; des ornements chinois, mythologiques, cosmopolites. Ils auraient dû par conséquent être considérés comme appartenant à la fois à ces diverses catégories, dont la délimitation rigoureuse n'a jamais existé que dans les livres. 
Les études pour le tracè d’un jardin irrégulier ou aģreste peurent être décomposées en trois partics principales:

Le Reliel: du Terrain;

Les Plantations;

Les Altées.

V. - Relief du Terrain. - L'étude du relief d'un projet de jardin agreste

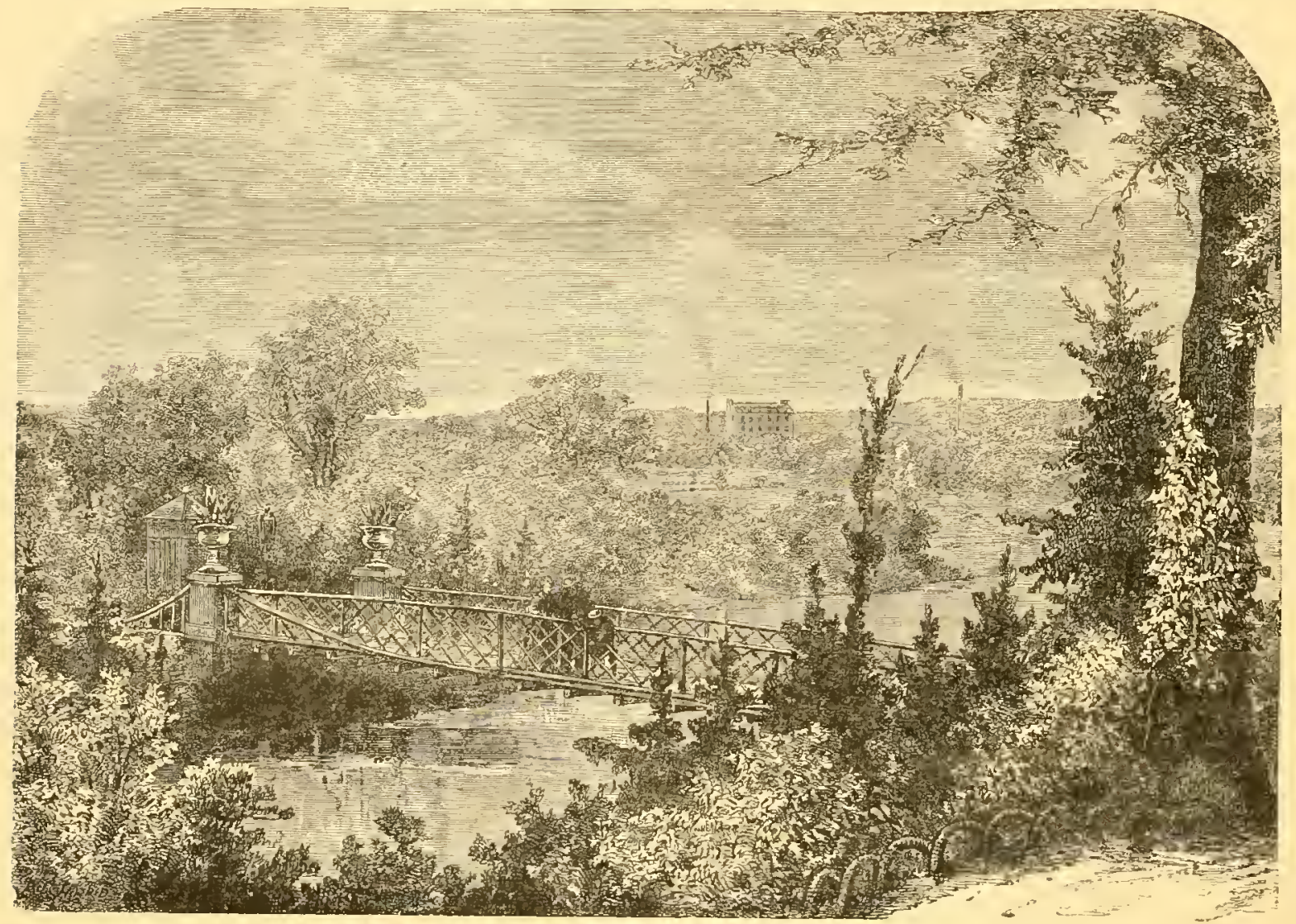

Fig. I60. - Vue prise dans le Bois de Vincennes, (Ioyci p. IzL.)

doit comprendre : $1^{\circ}$; la torme et la direction des vallées ou vallonnements; $2^{\circ}$, l'emplacement des plateaux, belvédéres et stations de promenade, tant dans l'intérieur que sur les limites de la propriété; $3^{\circ}$, tout ce qui se rapporte à la direction et à l'aménagement des caux; $4^{\circ}$, le choix et l'encadrement des points de vue.

Il est évident que ces diverses parties du travail ont entre elles une corrélation intime. Le tracé des cours d'eau, par exemple, est déterminé par le relief naturel ou factice du terrain, par sa pente plus ou moins rapide. Réciproquement, l'abondance 
plus ou moins grande des caux doit être prise en sérieuse considération dans la formation ou l'accentuation des mouvements de terrain.

Les travaux préparatoires d'un jardin paysager sont justement linverse de ceux des jardins réguliers, où l'on ne craint pas au besoin, suivant l'expression heureuse de Stace, de dompter la nature (domuit possessor), d'asservir le terrain à la fantaisie de son maître. Tout au contraire, dans le jardin paysager, l'art n'est jamais le dompteur, le tyran de la nature, il s'en fait en quelque sorte le courtisan. Il lil consulte sur le choix de sa parure, sur tout ce qui peut l'orner et l'embellir.

Cette étude préliminaire du terrain fournit à l'artiste intelligent toutes les données principales de

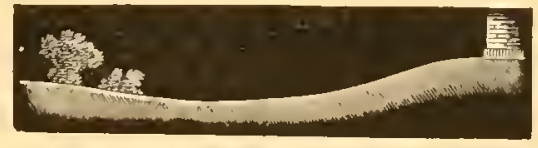

Fig. I6r. - Exlraussement d'un Massif. son plan d'ensemble; la direction des perspectives principales, celle des ruisseaux, l'emplacement des rapides, des cascades, des pièces d'eau, l'emploi le plus judicieux a faire des déblais. Remuer la terre pour composer un relief de fantaisie, est un mauvais système qui aboutit presque toujours à une déception, aprés d'énormes dépenses. On peut et souvent l'on doit retoucher le sol, mais sans modifier trop sensiblement le relief primitif. Ainsi, essayer, dans une plaine, un vallonmement trop tourmenté et trop accusé, c'est s'épuiser it faire de petites buttes, dont l'effet

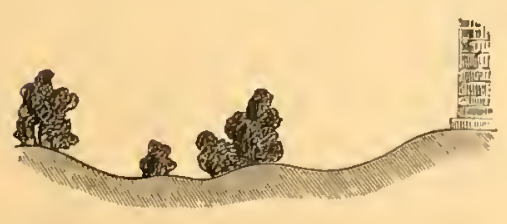

Fig. 162. - Creux pour les Allèes. est toujours mesquin... C'est l'opération fondamentale, dont tout le reste dépend. Dans un terrain accidenté, cette tâche est souvent facile. Il suffit d'adoucir les pentes, de donner aux courbes une forme agréable, d'effacer les bosses et de combler les vides disgracieux. Mais dans une plaine, les ondulations du sol ne peuvent être obtenues qu'au moyen et en proportion des déblais. L'une de ces éminences sera réservée pour l'habitation, s'il n'y a ni hauteur, ni versant naturel où l'on puisse l'établir. Cette disposition est importante au point de vue de la salubrité, comme de l'agrément. Le parc ou jardin, vu de la maison, doit s'élever en pente douce à mesure qu'il s'en rapproche. Il paraîtra ainsi plus grand, et donnera aussi meilleure apparence à l'habitation, tout en dégageant le paysage. Le rez-de-chaussée doit être toujours exhaussé de quelques marches. On devra pareillement, s'il se peut, exhausser les massifs, les plates-bandes, afin de les grandir, d'en dissimuler les limites (Fig. I6I). Entre ces levées, il y aura une sorte de creux oủ l'allée trouvera sa place (Fig. I62). 
Nous recommandons aussi de ménager ou de créer au besoin un ou deux plateaux, d'oúl l'on puisse cmbrasser non seulement l'intérieur du jardin, mais des vues extéricures. Ce précepte a été appliqué avec sucè́s dans les embellissements de Paris, notamment au bois de Boulogne, par la création de la butte Mortemart (Fig. I63).

VI. - Nécessité absolue d'un Plan d'ensemble. - Travail préparatoire. - Dans tous les cas, en plaine ou sur un terrain accidenté, il importe, avant tout et par-dessus tout, de ne commencer les travaux qu'avec un plan

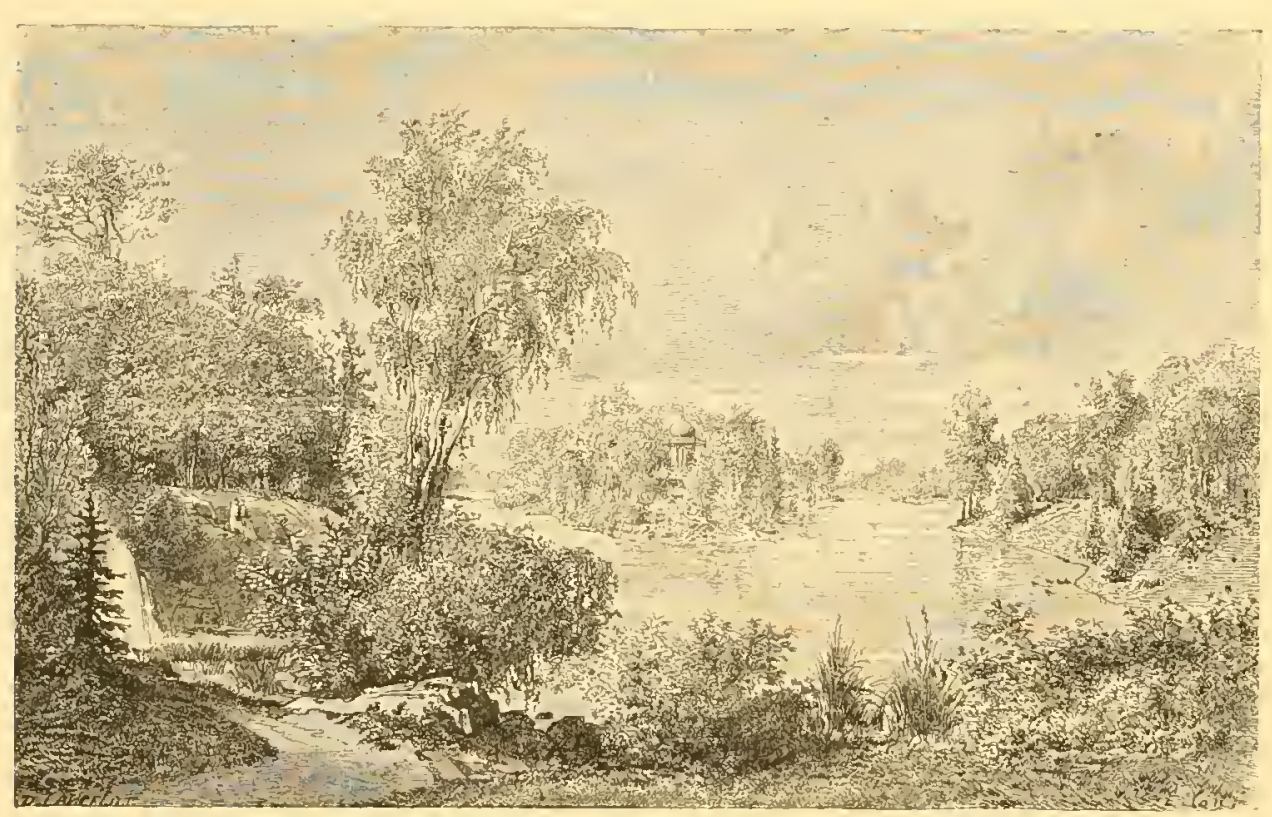

Fig. 163. - Tue du Lac du Bois de Boulogne, prise de h Butte-Mortemart.

d'ensemble bien arrêté, sous peine de tâtonnements ruincux, ou même d'échec complet. Après avoir terminé l:avant-projet, on le contrôle et on le rectifie par une nouvelle série de recherches et d'épreuves préparatoires sur le terrain, en plaçant des jalons dans les directions principales, et s'efforçant de se rendre compte des effets qu'on reut obtenir. Les lignes tracées dans l'avant-projet suivant les axes de vision, doivent être reportées sur le terrain au moyen des jalons, reliant le centre de chaque tableau à créer aux stations principales, d'où il sera visible en tout ou en partie. D'autres lignes de jalons relient entre elles ces stations principales, ct aussi les points sccondaires. Les résultats de ces épreuves préparatoires, qu'on ne saurait trop réitérer, sont reportés sur l'arant-projet, qu'ils transforment en projet difinitif. C'est d'après cette reconnaissance du champ d'opérations que se réglent : I $^{\circ}$ les modifications a apporter au relief du sol, qui sont comme des jours ouverts sur les perspectives et les paysages; $2^{\circ}$ les plantations qui encadrent ces perspectives, 
$3^{\circ}$ la distribution des caux. Nous phaçons ici, comme spécimen de ce genre de travail, l'avant-projet du pare de Montsouris (Fig. 164).

VII. - Époque des premiers Travaux de Terrassement. - L'époque de la créntion du jardin est un détail de l. plus haute importance. Dans les climats tempérés, l'été et l'automne sont les meillcures saisons pour les terrassements. Les terres qui ont été disposées pendant l'été ont le temps de se tasser avant que l'on ne plante, et tous les travaux s'y font dans des conditions meilleures. Le moment le plus favorible est la fin de l'été ct le commence-

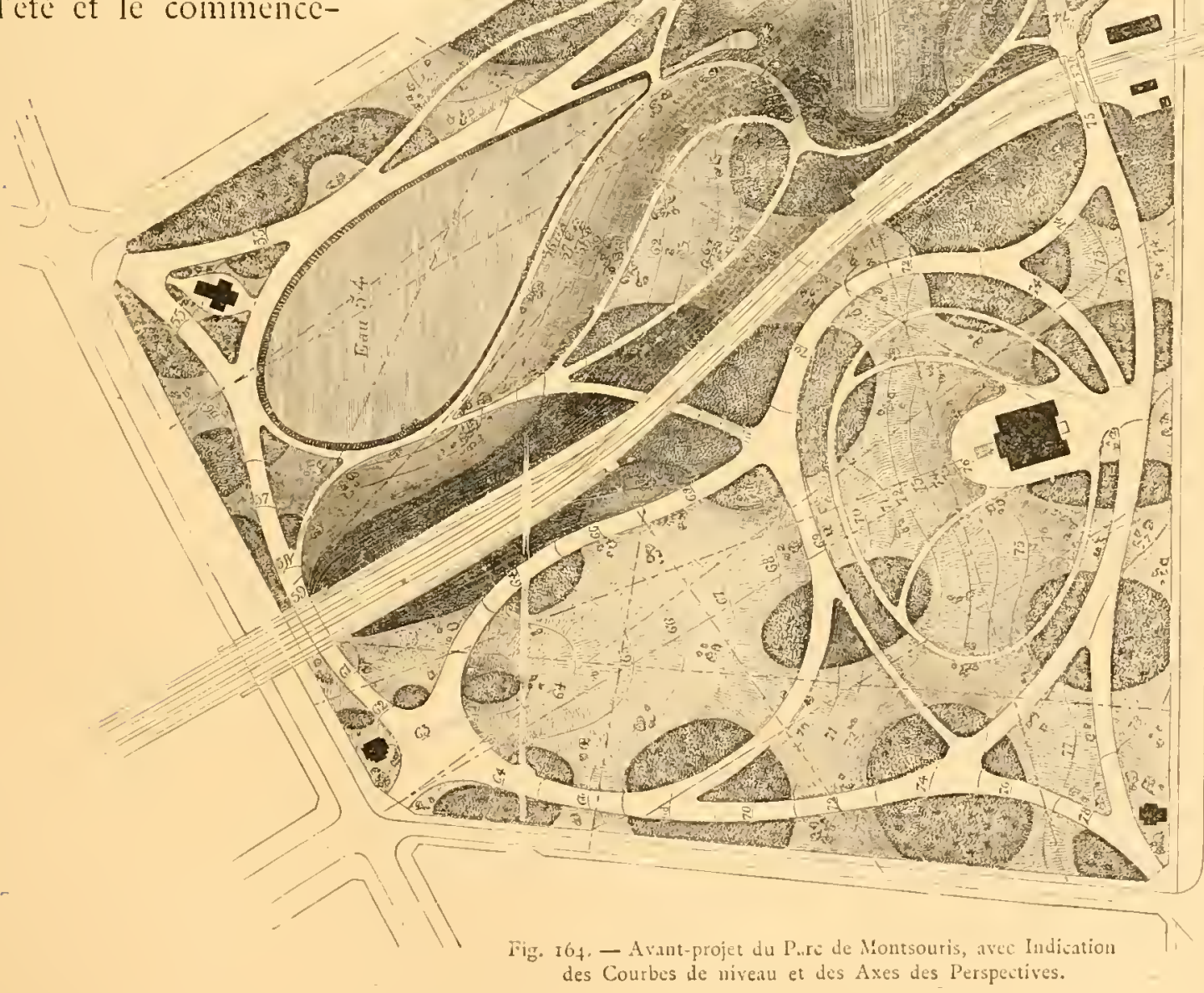

ment de lautonne (fin noût-septembre), parce que dans cette période le sol commence a être ramolli par les pluies, et qu'aussitôt aprés, les gazons et les arbres peuvent être changés de place sans trop souffrir. (Régle variable, bien entendu, suivant 
les latitudes.) La terre réclame des soins différents, suivant qu'elle est destinée à recevoir des plantations ou des gazons. Il y a des plantes, comme par exemple le Gyncrium (Fig. 165), des arbres, comme l'Eucalyptus (Fig. I 66), qui exigent une terre

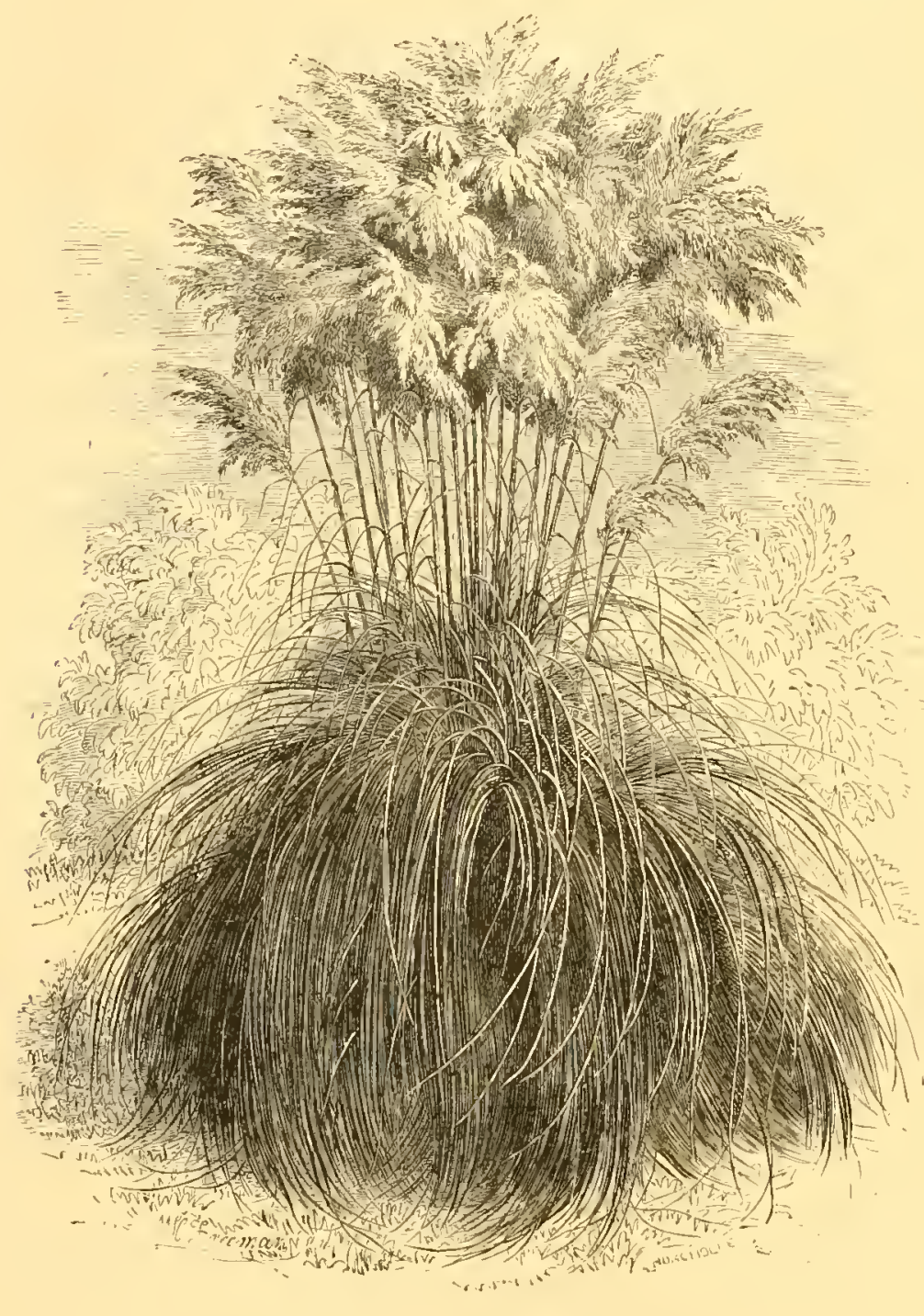

Fig. I65. - Gynerium argenteum. fertile et légère. D'autres arbres, notamment le mélize, I'Aylanthe (vernis du Japon), préférent les sols les plus médiocres; d'autres, comme l'Abies piusapo (Fig. 167), se plaisent d:ans tous les terrains, mêmecrayeux; ou, comme le Pinns cercelsa (Figure I68), exigent une terre lègère substanticlle. Une forte proportion de terre végétale neutralise dans une certaine mesure, pour les plantations d'arbres et d'arbustes, le désavantage d'un climat ingrat et d'une mauvaise cxposition. Pour les pelouses, au contraire, micux vaut un sol léger, même pauvre, s'il a été bien nettoyé et préparé.

Les herbes fines y réussiront plus facilement, et les mauvaises herbes ne s'y plairont pas.

VIII, - Drainage. - L'opération préliminaire du drainage dans les terrains humides n'est pas moins nécessaire pour la création d'un jardin ou d'un parc que pour toute autre culture. Un sol marécageux à l'excés ne convient pas plus aux végétaux qu'aux animaux et aux hommes. 
Lc drainage est non seulement nécessaire pour débarrasser le sol de l'eau stagnante préjudiciable aux plantes, mais aussi pour permettre à l'air d'y pénétrer plus librement. Il peut, de plus, fournir au parc futur un supplément précicux d'cau courante.

Plus le sous-sol est dur et serrí, plus il faut que les drains soient enfoncís profondément. La profondeur requise pour les drains ordinaires est de $I^{m}$ a $I^{m}, 25$, et de quelques centimétres de plus pour les drains plus forts. Un métre suffit, en général, quand la couche inféricure est sablonneuse.

La distance entre les drains varie suivant la profondeur des tranchées et la nature du sol; la pente se règle d'après l'inclinaison du terrain à assainir. Les tuyaux de tuile ou d'argile, qu'on emploie d'ordinaire, ne valent rien dans les terrains boisés. Ils y sont promptement effondrés et obstrués par les racines.

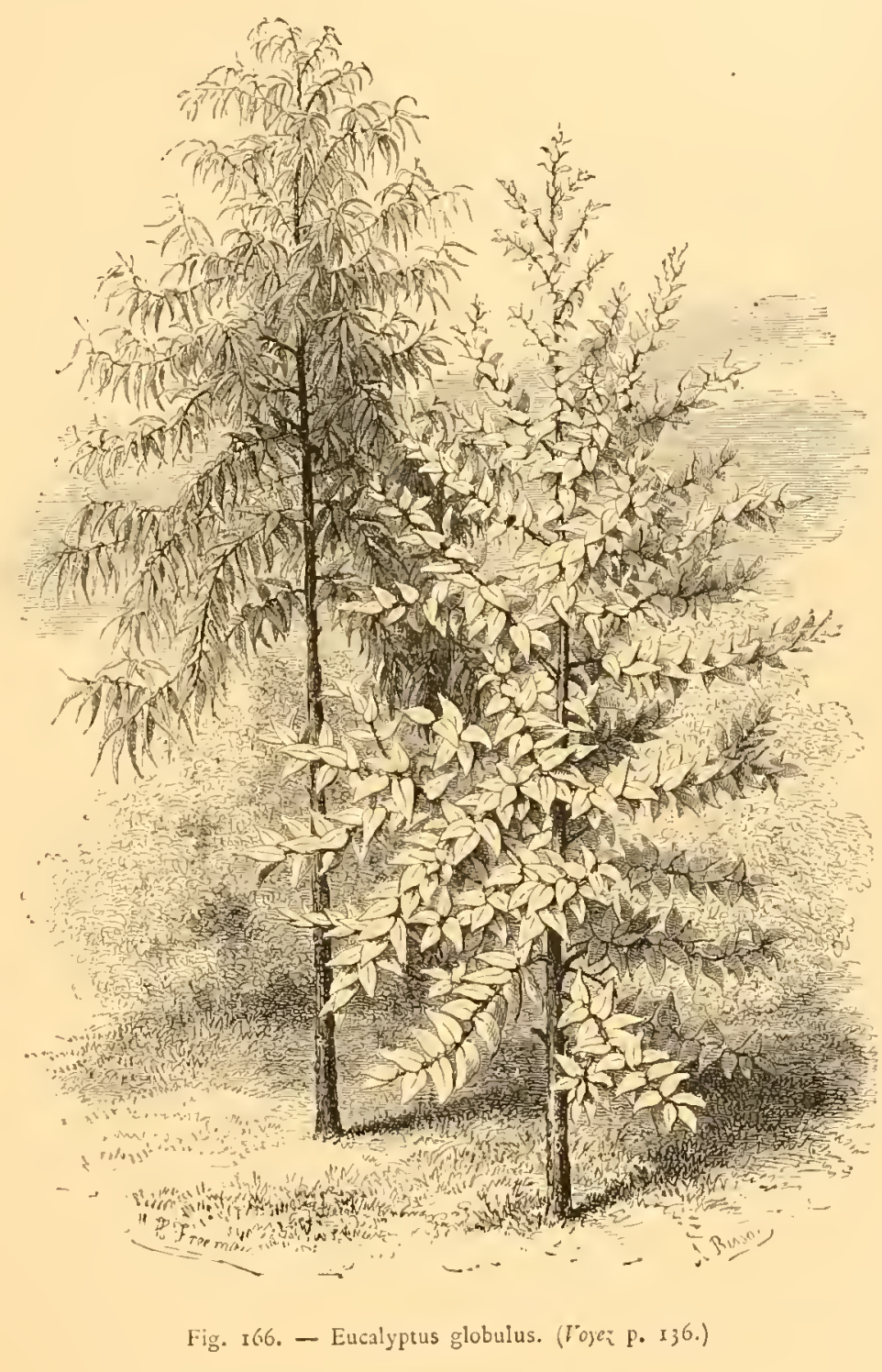

En pareil cas, et presque toujours, les drains en moellons ou en cailloux sont bien préférables. Ceux-lá doivent avoir quinze à seize centimètres de largeur dans le haut. Les grands drains recevront une inclinaison plus prononcée (I).

(1) Le drainage, qu'on croit d'invention moderne, était déjal pratiqué de temps immémorial dans les grandes cultures monastiques. Nous avons vu, dans le vaste enclos d'une chartreuse détruite ì la Révolntion, de ces drains de cailloux admirablenent installés, qui fonctionnaient encore solxante ans plus taṛd, sans avoir eu besoin d’être réparés. Les drains cn fascincs ou cu branchages disposés en croix sont absolument condamnés par l'usage. 
Après le drainage, la terre doit être bien remuée à un métre de profondeur, pour faire bénéficier de l'opération une plus grande quantité de terre végétale. Il faut que le produit des drains déversé dans le collecteur ait une issue d'accès facile, pour qu'on

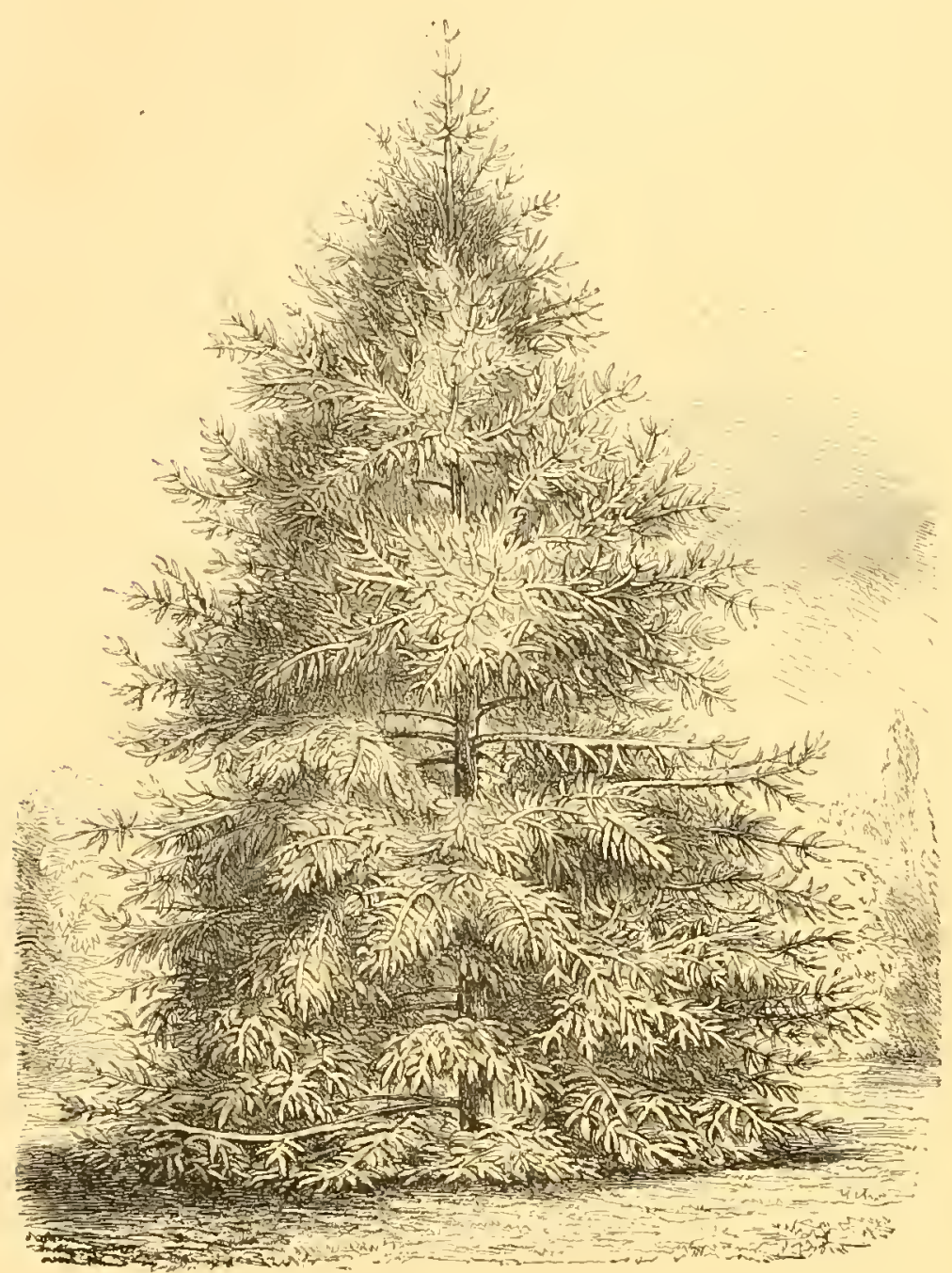

Fig. 167. - Abies pinsapo. (Iogez p. 1;6.)

puisse en tout temps s'assurer qu'ils fonctionnent bien. L'observation de cette régle est particulièrement importante dans les jardins et pares où ce produit peut être employé d'une façon agréable et utile, pour alimenter un bassin, simuler un ruisseau d'eau courante, pour l'irrigation, etc.

Il faut bien se rendre compte de la nature du sol, avant d'entreprendre cette opération, qui, même dans un espace restreint, peut être bonne à certaines places et inutile ou nuisible dans d'autres; par exemple, si le sol est naturellement sec, léger, disposé en pente, ou si l'on trouve un fond sablonneux ou pierreux.

Les deux figures 169 et 170 représentent, l'une un petit drain fait avec des pierres cassées et couvertes de mottes, l'autre un grand drain plus enfoncé en terre, avec un tuyau au fond.

IX. - Terrassements. - Les terres lourdes, épaisses ou nouvellement drainées devront être retournées à fond, soit pour être mises en herbes, soit pour recevoir des plantations. Si le sous-sol est argileux, il faut éviter de le ramener en dessus. L'argile ne fait jamais bon effet à la surface d'un jardin d'agrément. Il en est 
autrement dans les potagers : lá, elle peut servir à des mélanges, et sa présence n'est point un empêchement à l'application du systéme de culture qui consiste à intervertir alternativement le sol ct le sous-sol. Toute la terre végétale enlevẹe sụr l'emplacement des allées, des constructions, doit être utilisée pour les plantations, le potager et les parterres. On peut aussi en reprendre, pour la même destination, dans les endroits destinés aux pelouses, où il suffit amplement d'une couche de vingt-cing à trente centimètres de bonne terre.

En général, les engrais, la chaux, les phosphates, les cendres, ne sont pas nécessaires dans la partie ornementale, sauf pour les rosiers, qui réclament un sol riche. Toutefois, quand la superficic est dure ou argileuse, les engrais deviennent indispensables partout. Si les

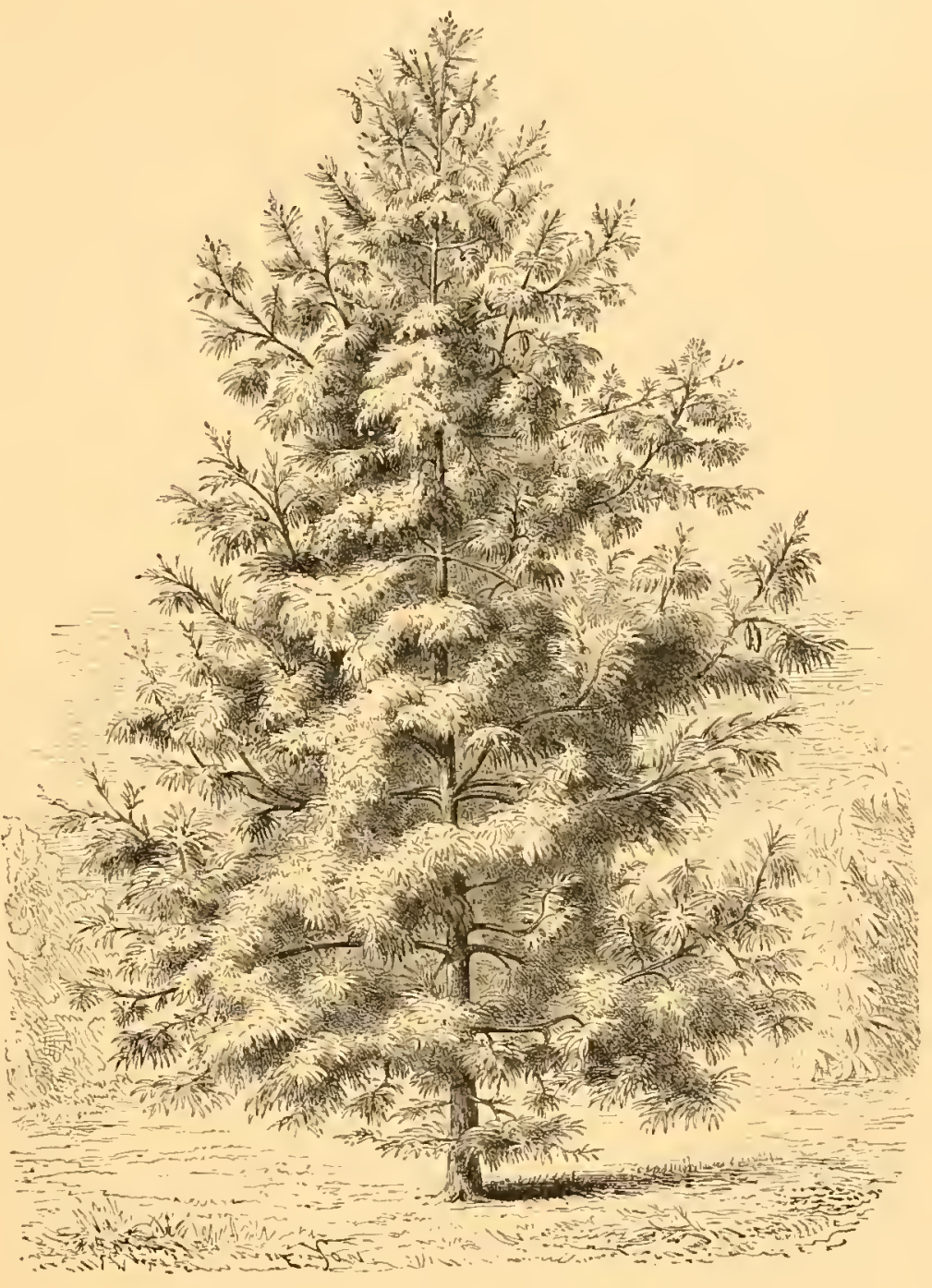

Fig. 168. - Pinus excelsa. (I'oyer p. $\left.{ }_{13} 6.\right)$ circonstances le permettent, le sol du futur jardin devra être préparé une annće d'avance. On pourra alors détruire les mauvaises herbes et améliorer la terre, en y cultivant des pommes de terre, navets et autres plantes sarclées. Une annce ainsi employée n'est pas perdue.

X. - Mouvements de Terrain. - Les retouches des accidents naturels du sol, et la création d'éminences et d'ondulations artificielles, constituent l'une des parties les plus intéressantes et les plus difficiles du travail. 
La régle fondamentale en ce qui concerne les mouvements de terrain dans les jardins et parcs irréguliers, c'est que tous ces changements doivent avoir un air naturel. C'est en quelque sorte d'aprés elle-même que la nature doit être corrigée et embellic.

En général, il ne faut user des mouvements de terrain artificiel qu'avee sobriété, en tenant compte de la physionomie générale du pays, ou de l'importance du parc ou

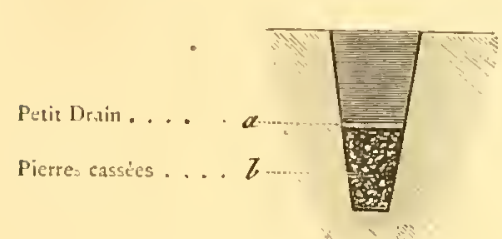

Eichelle de sc. pour $1^{m} 20$.

Fig. I69. - (Ioger p. I 38.$)$ jardin à créer. Des accidents de terrain trop multipliés dans un pays naturellement uni, et dans une propriété peu étendue, rappellent la fable de la Grenouille voulant se faire aussi grosse que le Bouf.

Toute éminence factice doit s'harmoniser avec les alentours, se raccorder en pente douce avec la plaine, comme la plupart des rraies collines, et présenter de même, sur sa surface entière, des ondulations plus ou moins caractérisées. D'autre part, l'importance de ces ondulations doit être proportionnée à celle de la hauteur elle-même. Une éminence lilliputienne trop accidentée, est aussi ridicule dans un grand pare que dans une petite proprićté.

Disons encore que les points culminants de collines artificielles devront être, en régle générale, les plus larges, les plus arrondis, suivant la forme la plus harmonieuse des collines naturelles.

La figure 17 I nous donne les contours d'une éminence, avec des lignes désignant les points auxquels se rapportent les sections. De plus, comme on le verra tout à l'heure, l'importance des accidents de terrain

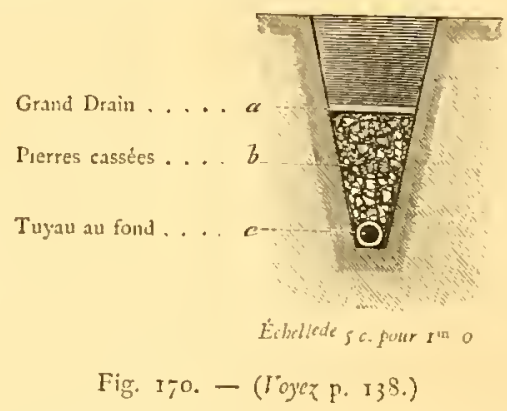
naturels ou factices, pourra être singulièrement accrue par les artifices de la plantation.

Le système d'adoucissement général des pentes, d'exclusion des lignes abruptes, comporte de nombreuses exceptions dans les grands parcs, où l'on dispose d'assez vastes espaces pour rechercher les effets pittoresques. Mais cette recherche serait presque toujours de mauvais goût dans les petits jardins paysagers, auxquels convient essentiellement le style tempéré.

XI. - Plantations. - Aprés l'étude du sol, vient naturellement celle des 
plantations (I). Les effets du développement des arbres, qui se rapproche et associe les feuillages, justifient les prévisions du véritable artistc, révélent tout le mérite de ses combinaisons, souvent incomprises à l'origine. Le dessinateur habile esquisse des tableaux dont il confie l'achévement à la lente mais infaillible collaboration de la nature. Il lui prépare, lui impose en quelque sorte sa tâche, et travaille ainsi plutôt pour l'avenir; - comme le fameux luthier de Crémone, Stradivarius, qui eut le courage de fabriquer des instruments dont le mérite ne pouvait être pleinement apprécié qu'un siécle plus tard.

On a beaucoup écrit, beaucoup divagué sur la manière d'assortir le caractére des plantations avec celui des édifices. Par cxcmple, un célébre artiste anghais, Repton, prétend que les arbres de forme pointue s'harmonisent mieux avec l'architecture gothique, et ceux à têtes rondes avec le style grec. Cette distinction nous paraît au moins subtile, à propos de jardins irréguliers. Si l'habitation a un caractére architectural tellement important et accentué, qu'on éprouve le besoin de lui raccorder le décor du jardin d'une façon tout à fait marquée, micux vaudrait revenir franchement à « l'architecture verte », et aux préceptes des Molct ct

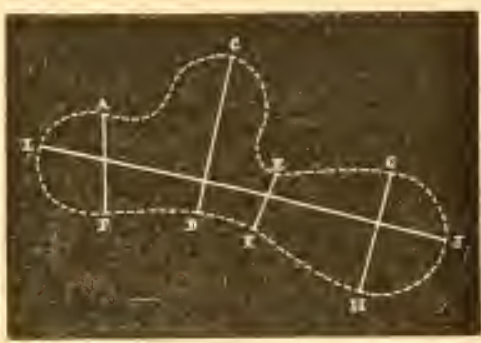

Fig. 171.-Contours d'une Èminence. (l'oye; P. I.fo.) des I.c Nôtre. Mais, si la régularité en est bannie, on aura bien de la peine à démontrer que le roisinage d'un sapin colossal, d'un if plusicurs fois centenaire, puisse ctre plus convenable dans le voisinage d'un édifice gothique ou pscudo-gothique, que celui d'un chêne ou d'un orme; et que la préscnce d'un cédre du Liban ait quelque chose de sholing à proximité d'un portique corinthien.

En un mot, il nous paraît chimérique ct anormal de rechercher a maintenir,

(i) Arboretumet Fleuriste de la Ville de Paris. Description, culture et usage des arbrcs, arbrisseaux, et des plantes herbacées et frutescentes de plein air et de serre, employées dans l'ornementation des pares et jardins, par A. Alphind. - Un volume in-folio. Prix : so fr. - Paris, J. Rothschila, éditeur.

"Cct ouvrage intéresse au plus haut degré les Horticulturrs. Pépinitivistes et Propriétaires de parcs et jardins. 11 contient les noms français et latins de tontes les plantes ornementales, l'origine, l'indication du sol, l'exposition, l'emploi, les caractéres principaux des feuilles, fleurs, fruits, l'époque de la floraison et la haliteur des vígétaux. Il est divisé en deux parties:

"I. - Arboretum. - I. Arbres et grands arbrisseaux d'ornements it feuilles caduques. - 2. Coniferes. 3. Arbrisseaux et arbustes à feuilles caduques. - 4. Arbrisscaux et arbustes à feuilles persistantes. -5 . Arbrisseaux et arbustcs de terre de bruyére. décoratif. »

" II. - Fleuriste. - Plantes herbacies et frutescentes, de plein air et de serres, flcurissantes et it feuillage 
dans le genre irrégulier, une harmonie entre la forme naturelle des arbres et la structure des édifices. Un bel arbre de n'importe quelle essence sera toujours le bienvenu prés d'une habitation de n'importe quel style.

Si pourtant l'on veut it toute force que les contours de certains arbres s'accordent mieux avec certaines architectures, nous ajouterons qu'il importe encore plus de tenir compte des teintes de la verdure, et aussi de la densité et de la forme du feuillage. Ainsi, la verdure sombre sied bien aux abords des édifices antiques ou qui simulent l'antiquité, tandis que les teintes moins foncées s'harmonisent mieux avec ceux d'un caractère plus moderne et moins grave. Suivant Kemp, les feuilles légéres, découpées, conviendraient aux abords des constructions de style grec ou oriental, tandis que les feuillages épais feraient mieux ressortir les détails délicats des sculptures gothiques et de la Renaissance. Pourtant tous les amateurs qui connaissent l'Orient ont pu apprécier le puissant effet que produit le rapprochement de la verdure opaque des cyprès pyramidaux, tranchant sur les blancheurs ensoleillées et les découpures de l'architecture orientale, et sur le bleu du ciel (Fig. I 72 ).

XII. - Rapport des Plantations à l'Habitation. - En général, " les grandes plantations ne doivent commencer autour d'un édifice qu’à une distance double de sa hauteur. Aucun détail intéressant de construction ou de sculpture ne doit être dissimulé, de tons les côtés, par ces plantations. Pour lia même raison, il ne faut pas, en principe, mettre de grands arbres trop près d'une construction monumentale. " Tels sont les préceptes fort sages de Lothar Abel, l'auteur de l'Estlotik der Gartenkinnst. Mais des buissons, ou quelques arbustes, peuvent être employés avantageusement pour dissimuler les inégalités de niveau qui se présentent fríquemment aux abords des constructions vraiment anciennes.

Dans une propriété du genre irrégulier, l'habitation ne doit jamais paraitre isolée; il importe qu'elle se relie au paysage. Si les lignes ne peuvent se raccorder d'une maniére harmonieuse, on y pourroit au moyen d'arbres isolés ou en groupes. L'observation de ce précepte est encore plus nécessaire quand la maison est sur une hauteur. Mais, à moins de circonstances exceptionnelles, les arbres ne doivent jamais toucher aux constructions.

La plantation est une des parties les plus difficiles de l'art. L'harmonie entre les formes diverses des arbres comme entre les nuances des feuillages est une étude inépuisable, mais dans laquelle les plus habiles peurent se tromper. Lá aussi, toute- 
fois, l'observation de certains principes généraux peut préserver de graves erreurs, et mettre au moins sur la route du succès. Le premier de tous est un respect scrupuleux pour les beaux et vieux arbres (Fig. 173 , Chêne vert du bois de Vincennes).«La main de l'homme est prompte et forte pour détruire, lente et débile pour recrécr. Ni les Crésus, ni les Alexandre ne sauraient rétablir dans sa majesté le chêne que dix siecles avaicnt respecté. ) Sans doute, dans les rares contrées encore riches en grands arbres, il est parfoisindispensable d'en sacrifier quelques-

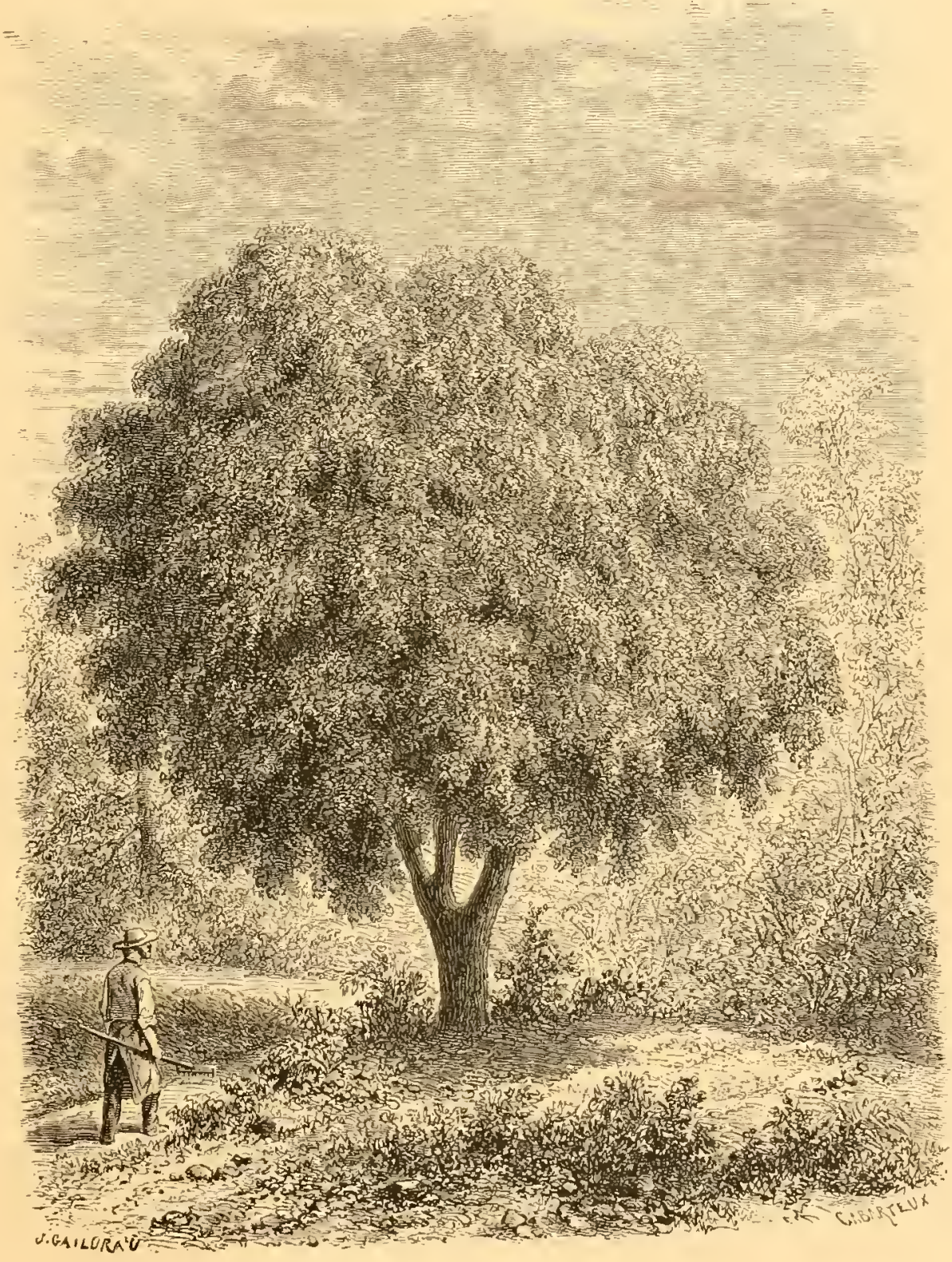

Fig. 172 - Chène vert au Bois de Vinzennes.

uns pour mettre en évidence d'autres plus beaux, démasquer un point de vue remarquable, etc. Mais une absolue nécessité peut seule justifier ces sacrifices, et c'est faire acte de bon goût que de pousser jusqu'aux dernières limites l'audace de la transplantation, pour des arbres très forts qu'il faut absolument déplacer.

Ce sujet (la transplantation) est d'un intérêt majeur. Nous y reviendrons, 


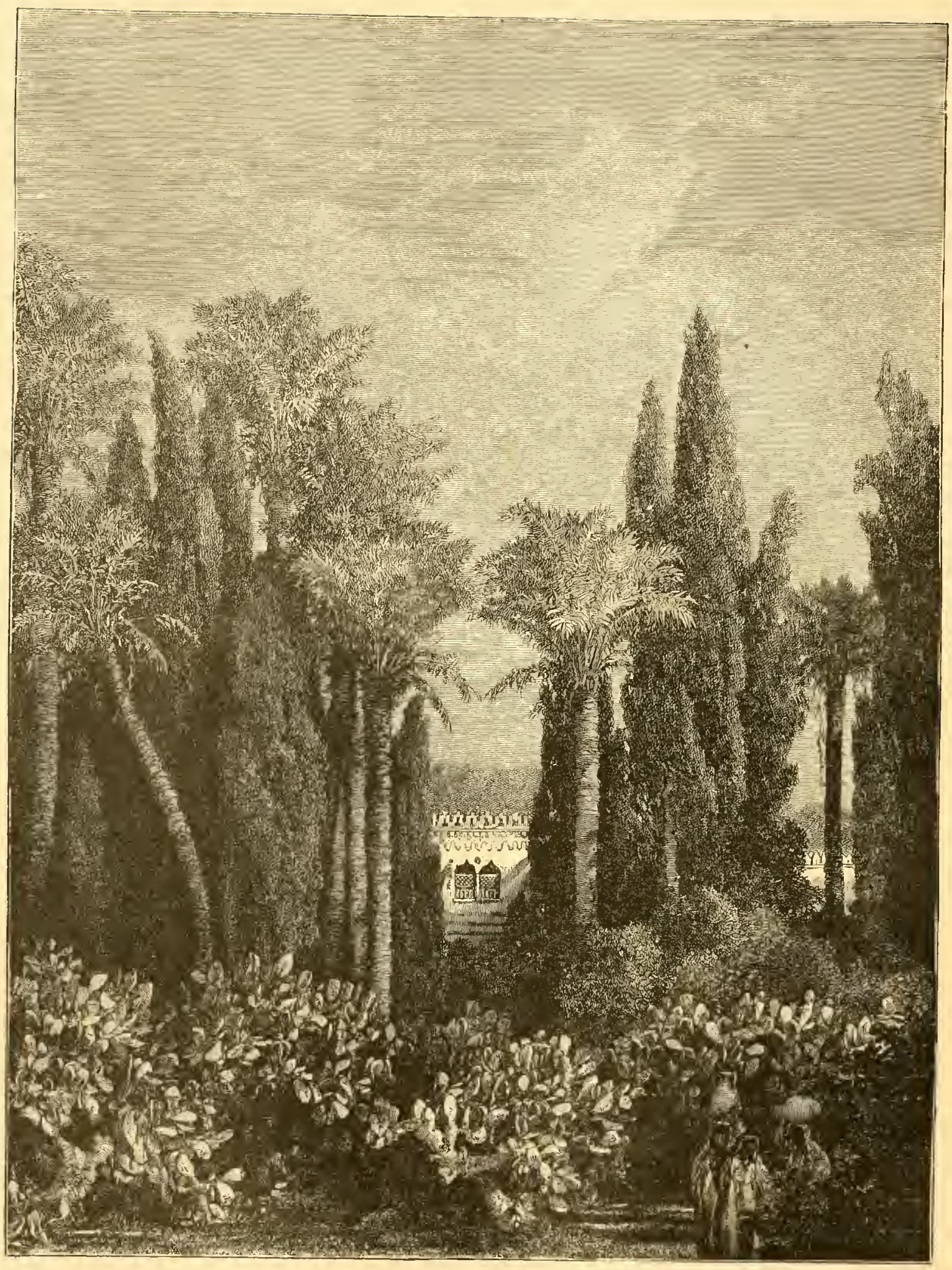

Fig. 173. - Jardiu princier au Caire. (Iover P. I+2.) 
au point de vue pratique, dans un autre chapitre de ce volume, celui des Promenades publiques.

Nous rappellerons encore, comme susceptible d'une application au moins fréquente, le précepte d'un dessinateur anglais : "Ne plantez jamais un arbre isolé, sans lui donner un buisson pour compagnon et pour protectcur! » On est sûr, par exemple, d'obtenir des effets agréables en associant au feuillage d'arbres verts de teintes sombres, des touffes de chèvrefeuilles ordinaires ou à réseaux d'or, de rosiers grimpants, de vignes vierges, de sureaux, qui égaient tour à tour ces compagnons sévéres; de lcurs grappes de fleurs ou des teintes variées de leurs feuillages.

C'cst aussi une régle généralement admise de composer la plus grande partic des plantations, surtout dans le fond des parcs, d'arbres et d'arbustes indigènes, et de réserver les productions exotiques, même de pleine terre, pour les groupes isolés au premier plan (Fig. I 74), et surtout pour les places les plus rapprochées de l'habitation et des serres. C'est d'ailleurs le meilleur moyen

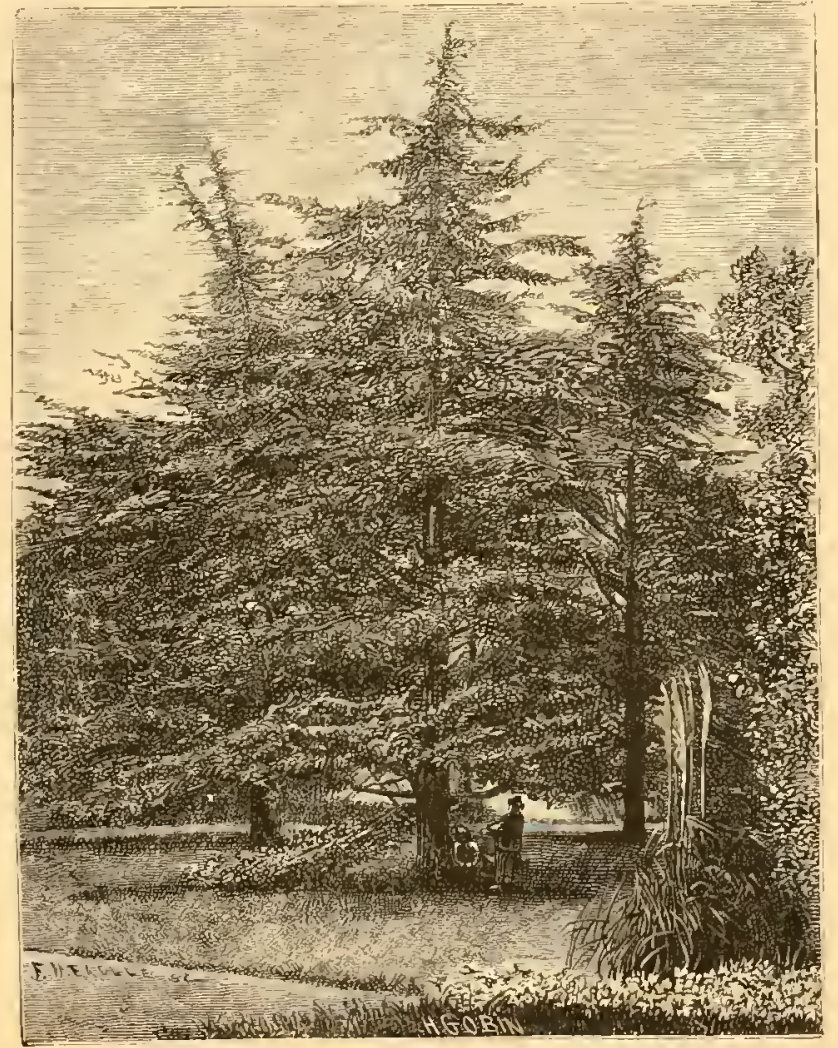

Fig. 174. - Groupe de Ceddres du Liban. de faire l'essai des variétés nouvelles, de connaître leurs qualités ct leur tempérament. D'habiles horticulteurs ont conçu, pour ces végètaux exotiques, une aversion qui semblerait justifiée par d'insignes déceptions, et aussi par l'abus qu'on a fait quelquefois de certaines variétés à feuilles panachées. Il est certain que ces produits de caprices maladifs de la nature (et quelquefois d'artifices mercantiles), n'offrent souvent qu'un médiocre intérêt; l'amateur, qui les a payés fort cher, est exposé à les voir demeurer malingres et rachitiques, ou se confondre, en grandissant dans un terrain plus riche, avec les especes ordinaircs. Toutefois, une exclusion absolue des nouveautés susceptibles d'acelimatation scrait par trop rigoureuse. Si l'on avait 
toujours procédé ainsi, nous ne compterions parmi nos arbres fruitiers ni le cerisier, ni le pécher, d'origine persane. Nous aurions repoussé des arbres comme l'acacia-robinia, le gnolia, et même Lombardie, qui filit isolément ou dans bien qu'on en criles. avenues où il célébredessinateur, grenadicrs au port saurions non plus duction récente de conifires rusti-

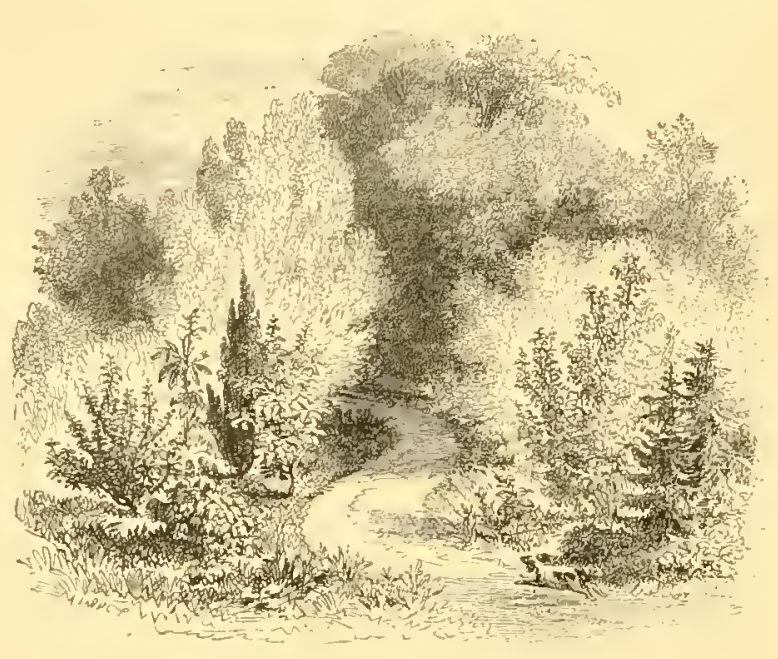

Fig. 175. - Tue d'une Plantation variee. sophora, le male peuplier de trís bonne figure certains massifs, tique l'emploi pour produit, suivant un l'effet d'une file de d'armes. Nous ne regretter l'introd'un grand nombre ques, quoique exotiques, dont les teintes variées tranchent agréablement (Fig. I75) sur celles en général plus sombres de nos arbres verts d'Europe (I). Des arbres symétriquement alignés

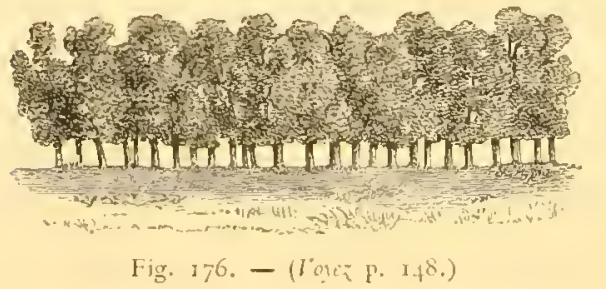

y éviter aussi les plantations trop denses. Un jardinet ainsi obstrué a l'air d'une prison dont l'intérieur ne peut être vu de personne, mais d'où l'on ne peut

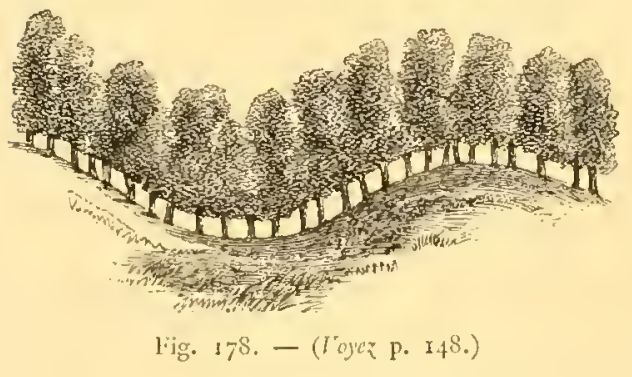
rien voir non plus.

Rien de plus
monotone en-
core, qu'une
plantationdont

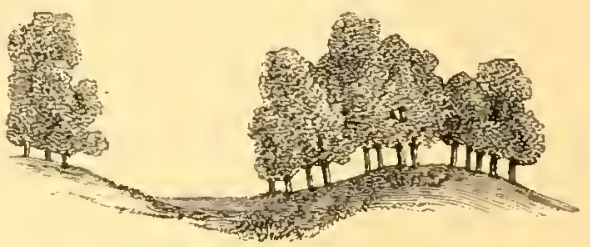

Fig. $179 .-($ Iogex p. 148.$)$

les arbres sont tous de même hauteur, de même variété, de même forme.

(I) L'hiver de I\$\&o a été, il est vrai, une terrible épreuve pour plusieurs de ces coniferes, notamment pour le I'ellingtonia, l'Abies pirsapo des sierras espagnoles, le cèdre Diolara, le Pimus excolsa. Comme les animaux malades de ia peste,

Ils ne mouraient pas tous, mais tous étaient frappès.

En revanclue, plusieurs autres, et des plus beaux (par exemple les A. Nordmamiana, Canadensis, Pindrour, le Cupressus Lausoniana, ont victorieusement résists. 


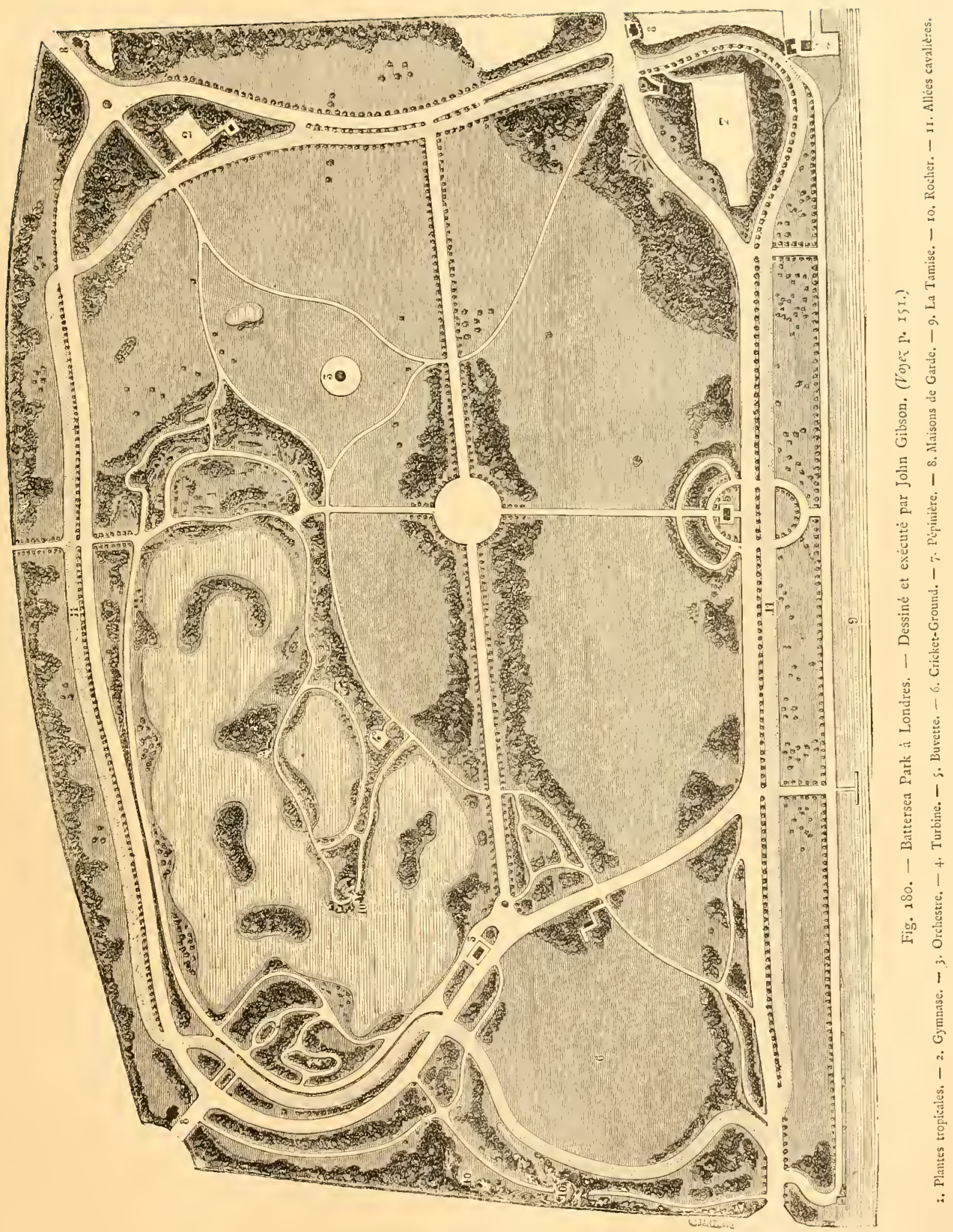


La Figure 176 nous montre une de ces lignes symétriques sur un terrain plat. La Figure i 77 nous apprend la maniére de rompre cette uniformité, en employant quelques arbustes, tels que des épines, des houx, etc... Le même défaut

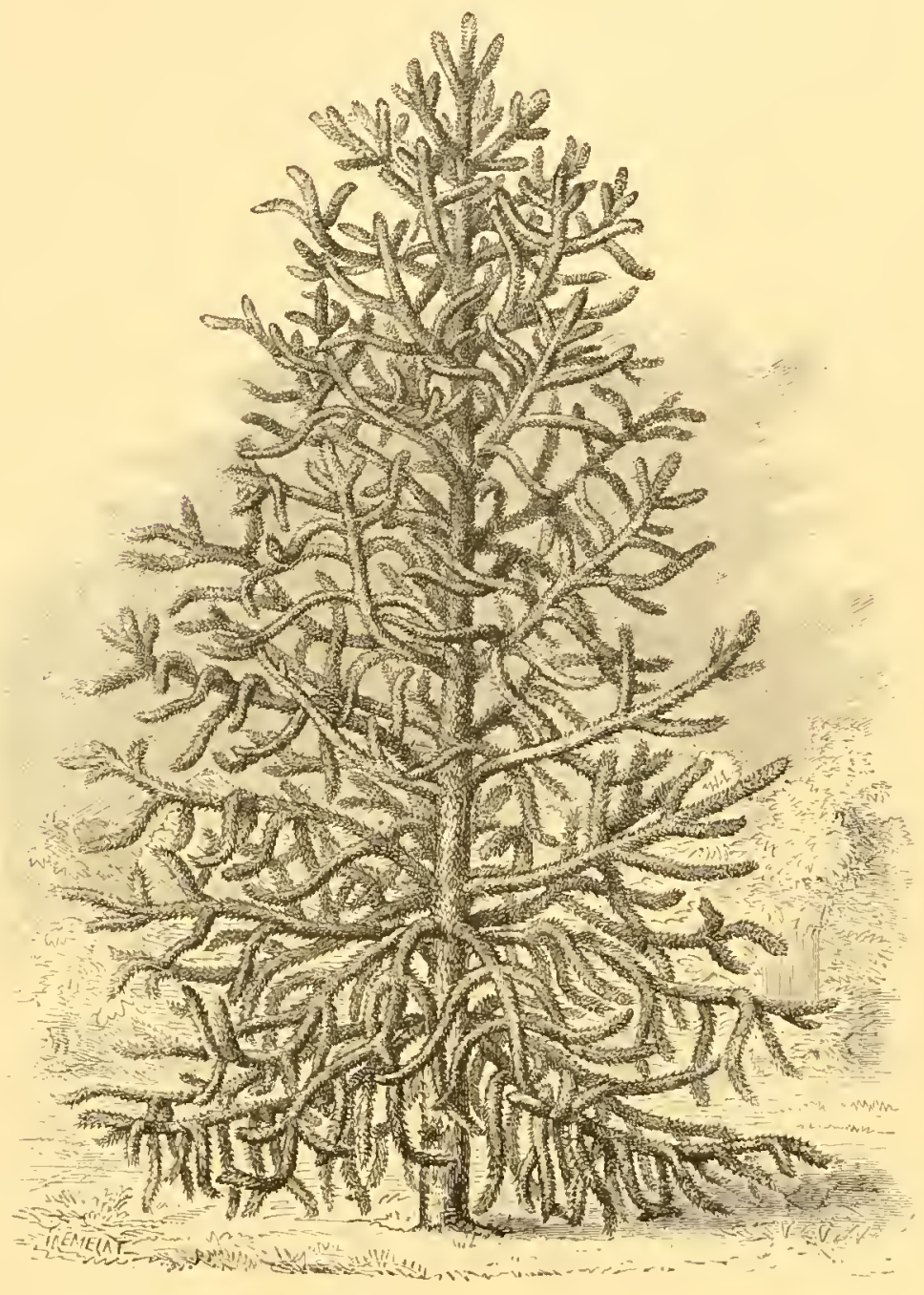

Fig. 8 s. - Araucaria imbricata. (Toyez p. 15I) apparaît, moins disgracieux toutefois, sur un terrain ondulé (Fig. I 78 ), et la manière de le corriger est indiquée dans la Figure I79, où les arbres sont disposćs en massifs, suivant le relief du ter rain.

\section{XIII. - Combinai-} son des Feuillages. La combinaison des feuillages est un des sujets sur lesquels il est le plus dificile de donner des régles fixes, ct qui font le désespoir des artistes. Plusieurs des plus habiles (notamment le prince Pücliler), ont loyalement aroue que les dispositions sur lesquelles ils comptaient avaient trés souvent échoué, et qu'en retour ils avaient reçu force compliments à propos d'effets qu'ils n’avaient ni cherchés ni prévus lors de la plantation. Nous roilá bien loin de la confrance naïve de Hirschfeld, qui donne imperturbablement des recettes infaillibles pour fahriquer à volonté des scénes des quatre saisons, mélancoliques, amoureuses ou terribles.

lei, comme presque loujours, la vérité est entre les extrêmes. Il est difficile, wais non impossible de produire, par la combinaison de divers feuillages, des 
effets originaux et gracicux. On peut, par exemple, tirer un heureux parti des reflets du solcil sur des arbres d'une couleur exceptionnelle, comme le hêtre pourpre; sur des tiges élancées d'une nuance particulière, comme celles des boulenux, des platanes, apparaissant dans la pénombre d'une futaic. On peut également combiner d'avance un effet vraiment féerique, qui se produira infailliblement au bout d'un certain nombre d'annces, en plaçant sur la lisière des massits, aux endroits

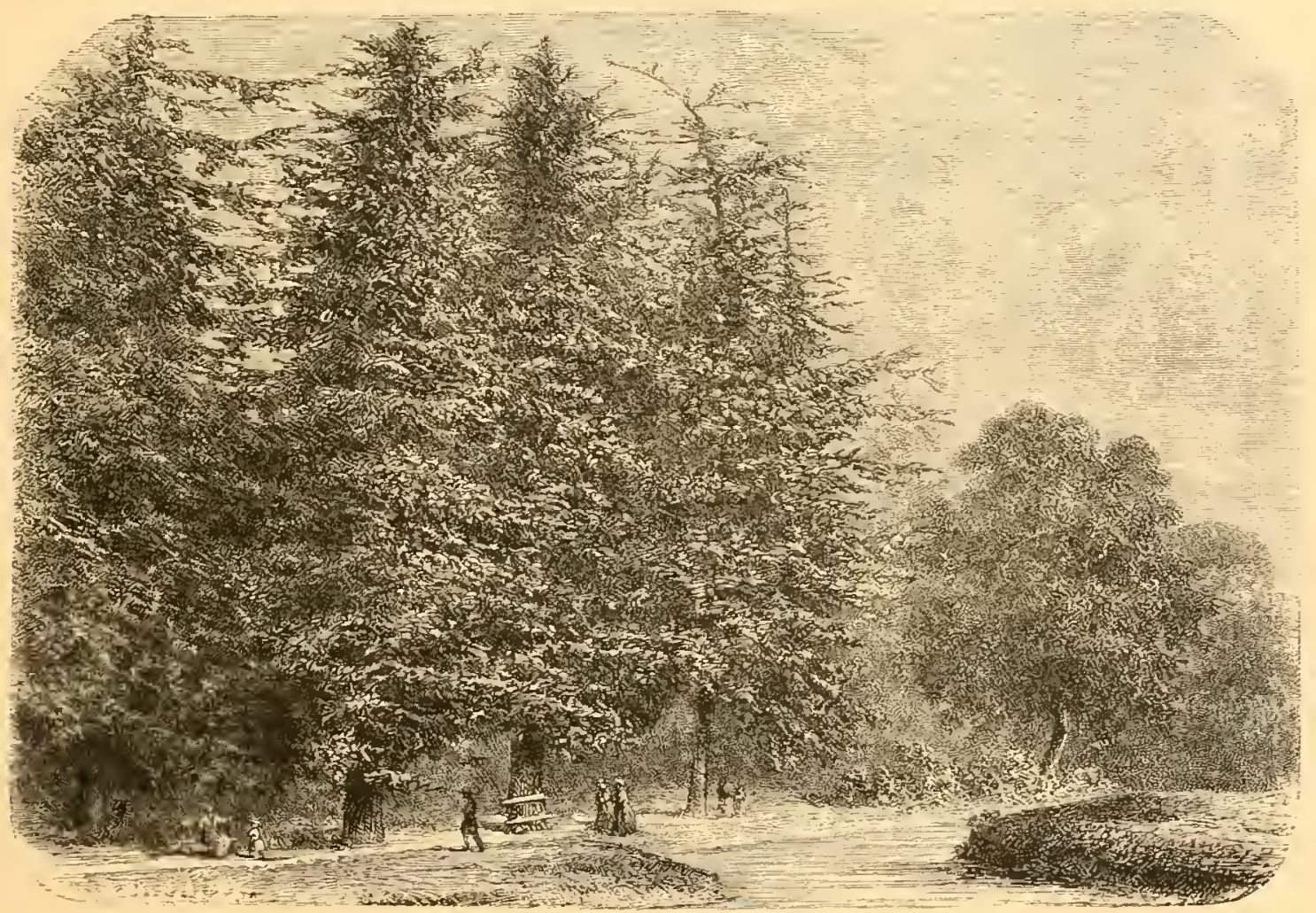

Fig. 182, - He des Cidres. (Voyci p. 1;2.)

les plus exposés aux vents, des arbres it feuilles bicolores, comme le tilleul argenté, le taxodium, le genévrier-cédre (Oxycedrus), qui donnent de charmants reflets en ondulant au gré de la brise. Nous avons vu aussi les dispositions fortuites ou préparées d'arbres à feuillages d'un vert tendre; - trembles, peupliers suisses, ¿́rables negundo, mélézes, etc., - apparaissant à la suite de masses d'un vert sombre, simuler à s'y méprendre des prolongations de perspective, surtout quand ces cimes s'éclairaient des rayons du soleil levant, ou se coloraient des demiers feux du soir. Mais, pour obtenir de ces résultats exceptionnels, il faut saufranchir des riggles banales du poncif paysager; tenir compte de l'orientation des arbres, des variantes 
d'allure des diverses essences juxtaposées, des changements de teintes suivant les saisons. Il faut, pour donner ces touches magistrales, non seulement un grand fonds d'expérience, de connaissances spéciales, mais un instinct divinatoire fort semblable au génic.

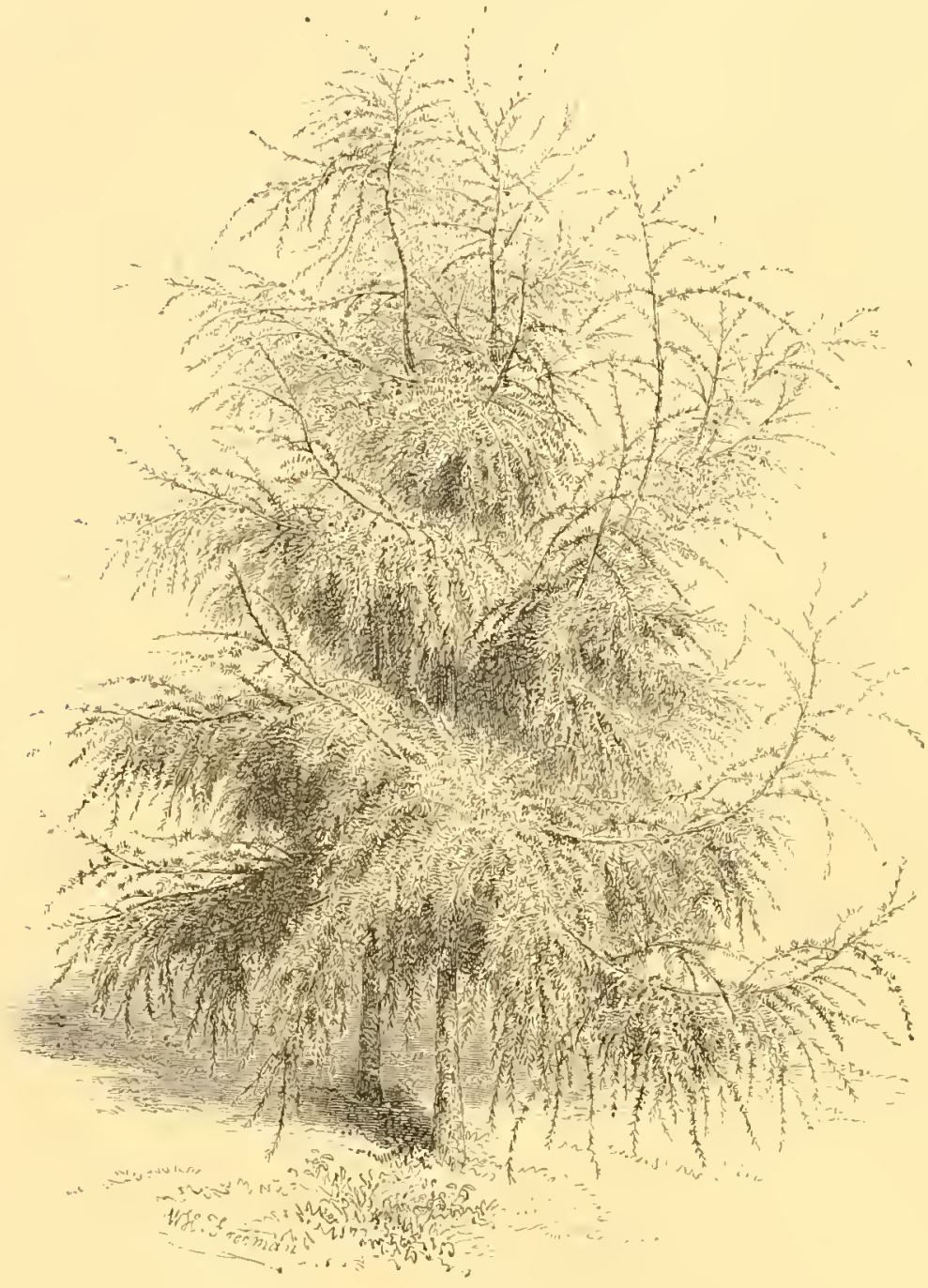

Fig. 183. - Larix europa pendula. loyer p. 153.)
XIV. - Étude des Effets d'Ombre et de Lumière. - On voit, par ce qui précéde, que la recherche et l'étude des effets d'ombre et de lumière conviennent aux dessinateurs de jardins, aussi bien qu'aux peintres et aux architectes.

Parmi les ondulations d'un jardin paysager, comme i travers les lignes majestueuses des avenues classiques, le soleil a son rôle ainsi que l'ombre. Ces jeux alternatifs sont d'un attrait singulier par les temps brumeux, si fréquents dans les régions du Nord, alors que le soleil ne brille que par intermittences, et que l'ombre des nuages interposés

proméne ça et lí parmi les pelouses, les massits, les cimes des grands arbres, ses trainées capricieuses.

Le dessinateur doit s'appliquer à faire valoir ces gracieuses oscillations, ces fuites et ces retours de lumière. Aussi il importe de disposer spécialement les plantations ì l'ouest et au sud-ouest, en vue de ces effets alternatifs. C'est en effet la direction dans laquelle ils se produisent arec le plus d'avantage, á cause de f'allongement des ombres. 
Parmi ces effets, l'un des plus heureux est celui d'un rayon de soleil couchant, arrivant par une couléc habilement ménagée entre deux massifs, en traçant un long sillon d'or sur la verdure des pelouses. Les autres expositions, bien que moins importantes à ce point de vue spécial, ne sont pas í négliger. A l'est, on ne doit planter qu'avec précaution, car trop d'ombre de ce côté scrait nuisible. Dans toute l'étendue de la propricté, la position des massifs doit être calculée de manière à donner des ombres commodément variées suivant les heures, et à diversifier agréablement l'aspect des allées.

XV. - Combinaisons diverses des Plantations. - Les plantations d'un grand pare doivent naturellement être plus denses que celles d'une petite propricté, à moins toutefois

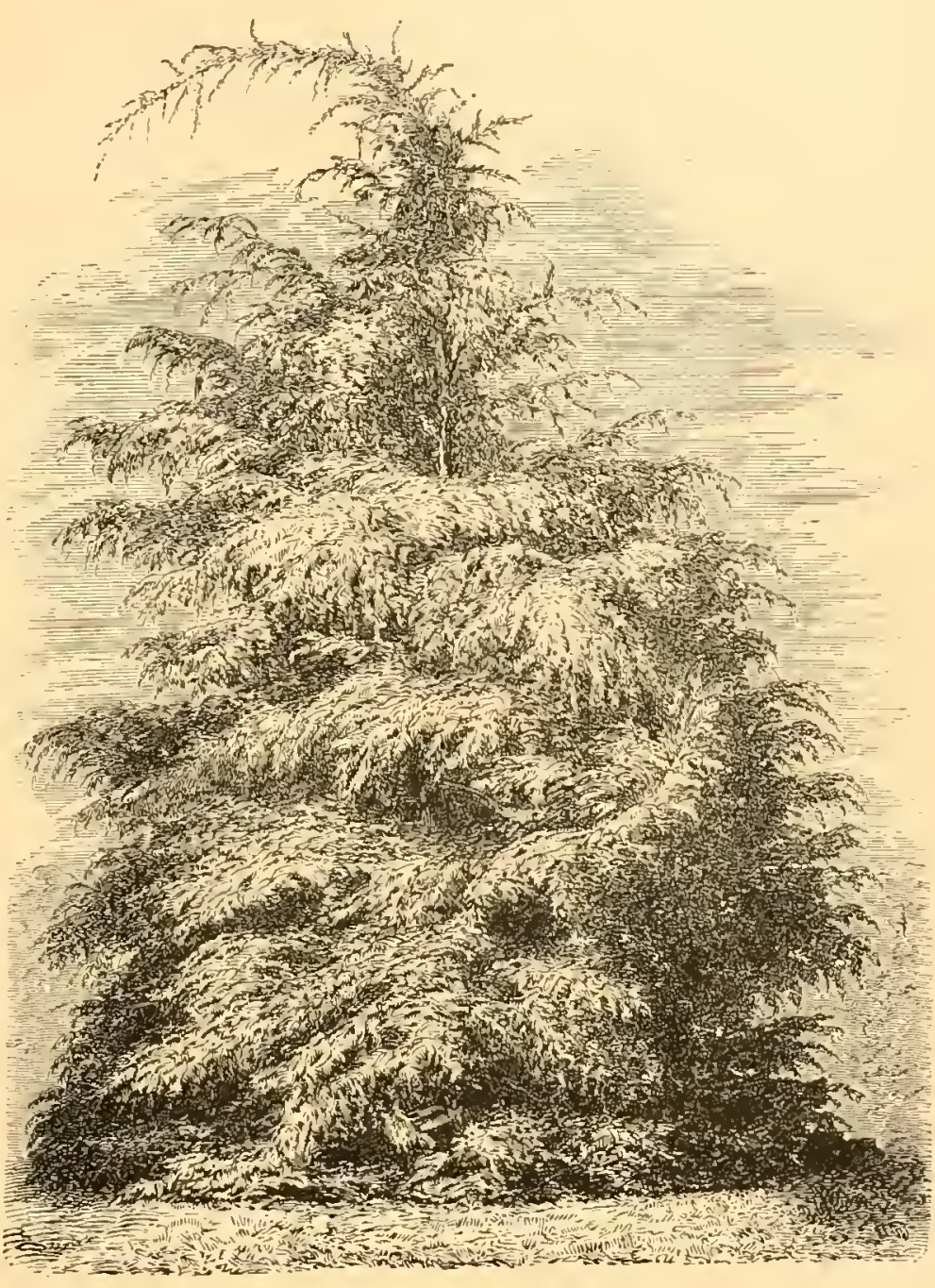

Fig. $18_{4} \cdot-$ Cedrus D.odara. (Ioyez p. 153.) que le climat ne soit particulièrement froid. Ainsi, la plantation de Battersea Park, à Londres (Fig. I So, p. I47), habilement disposée pour accompagner les eaux et les pelouses, mais sans profondeur, est bien appropriée au climat de Londres.

Il importe que l'aspect d'un grand pare tende insensiblement à se confondre avec celui des alentours. Pour cette raison, les arbres et les arbustes, même de pleine terre, dont le port et le feuillage trahissent l'origine exotique, comme l'Arancaria imbricata (Fig. I 8 I, p. I48), seraient déplacés dans les parties lointaines du pare. On 
emploiera avantageusement les épines, les diverses varictés de houx, sur la lisiére des massifs, ainsi que les rhododendrons et azaléces ordinaires, réservant les plus belles variétés pour le voisinage de l'habitation. Quand on défriche un bois pour l'arranger

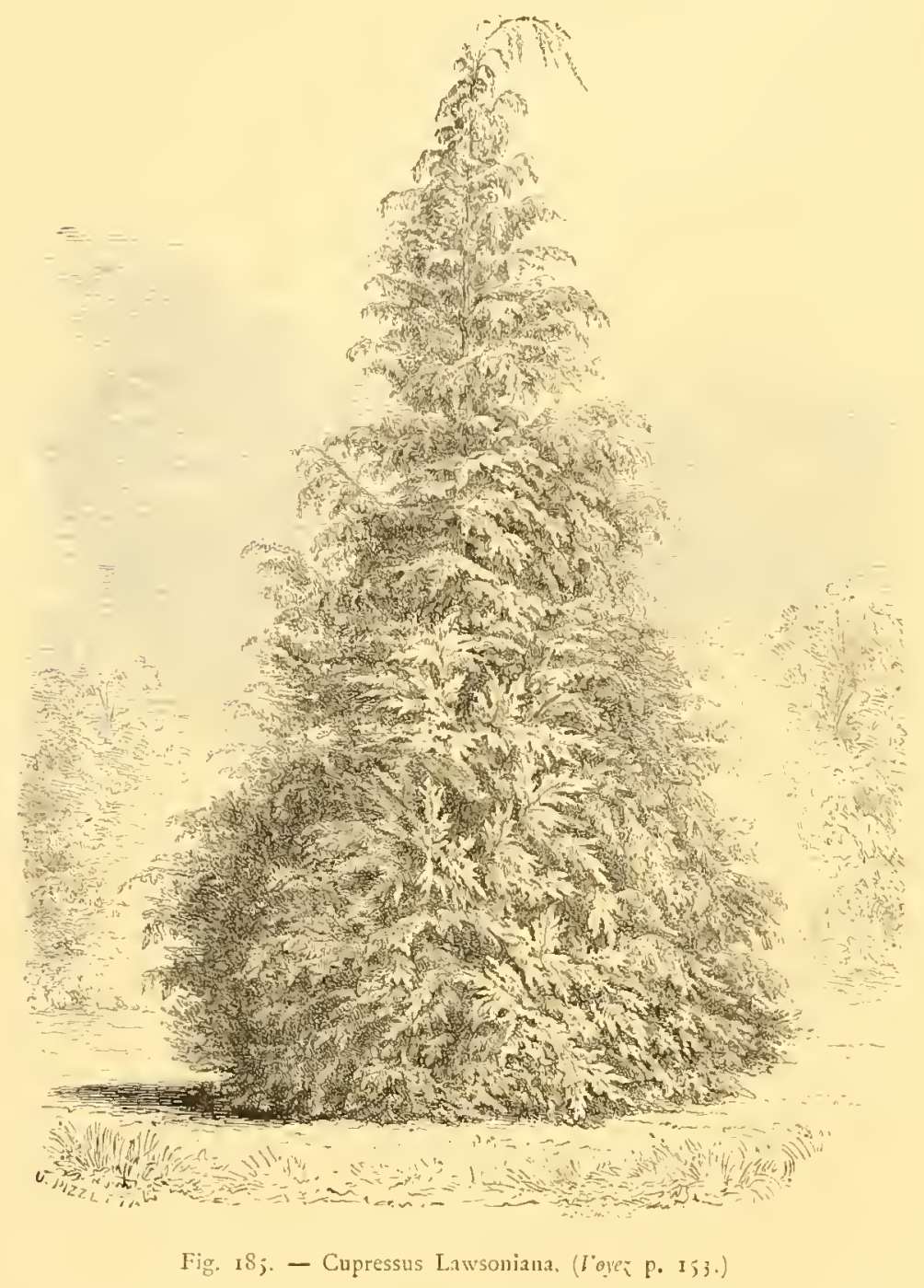

cn parc, il filut avoir soin de réserver çà ct là, surtout dins les endroits les plus retirís, des touffes de bruyères et de fougères, pour retenir quelque chose du caractere foresticr.

Les essences d'arbres à teuilles caduques les plus propres à composer, dans nos climats, les masses principales d'un pare, sont le chêne, le chitaignier, le charme, l'orme, le bouleau, les diverses variétés de tilleuls, de peuplicrs, l'érable, le frêne, le hêtre ordinaire et pourpre; les acicias (pscudo), le catalpa, le tulipier et autres arbres d'Amérique dont le feuillage prend de si belles teintes en automne; le marronnier, l'aune ordinaire et à fouilles en cour, les magnolias, le vernis du Japon, etc.

Parmi les grands conifères, il faut citcr d'abord les espéces indigènes; épicéa et sapincte, puis le méleze et le pin d'Autriche, qui ont le précicux avantage de réussir dans les plus mauvais terrains. Le cédre du Liban soutient fièrement sa vieille réputation. C'est encore un des arbres verts qui produisent le plus d'effet; planté isolément ou par petits groupes (Fig. I 82 , p. I49). Mais sa verdure est trop sombre, son aspect trop sévère pour qu'on puisse en composer exclusivement de très grandes 
masses, comme on a fait en Angleterre dans le pare de Chiswick, qui présentement a l'air d'un cimetiére de grands hommes. Ce roi des coniféres produit au contraire un excellent effet, mélangé à d'autres essences d'unc teinte plus gaie et à branches plus flexibles, comme le Larix pendula (Fig. I $8_{3}$ ) ou le cedre diodara. Ce dernier (Fig. I 84) est d'un aspect des plus sćduisants, surtout dans sa jeunesse, mais résiste difficilement a nos grands hivers, quand il n'est pas trés abrité. On peut en dire autant d'un autre arbre également d'origine himalayenne, ot plus remarquable encore par son encolure et les teintes variables de son feuillage, le Pinus cxcelsa ou du Népaul.

Nous recommandons particuliérement les espéces suivantes d'arbres verts, trés rustiques, avec lesquelles on peut arriver

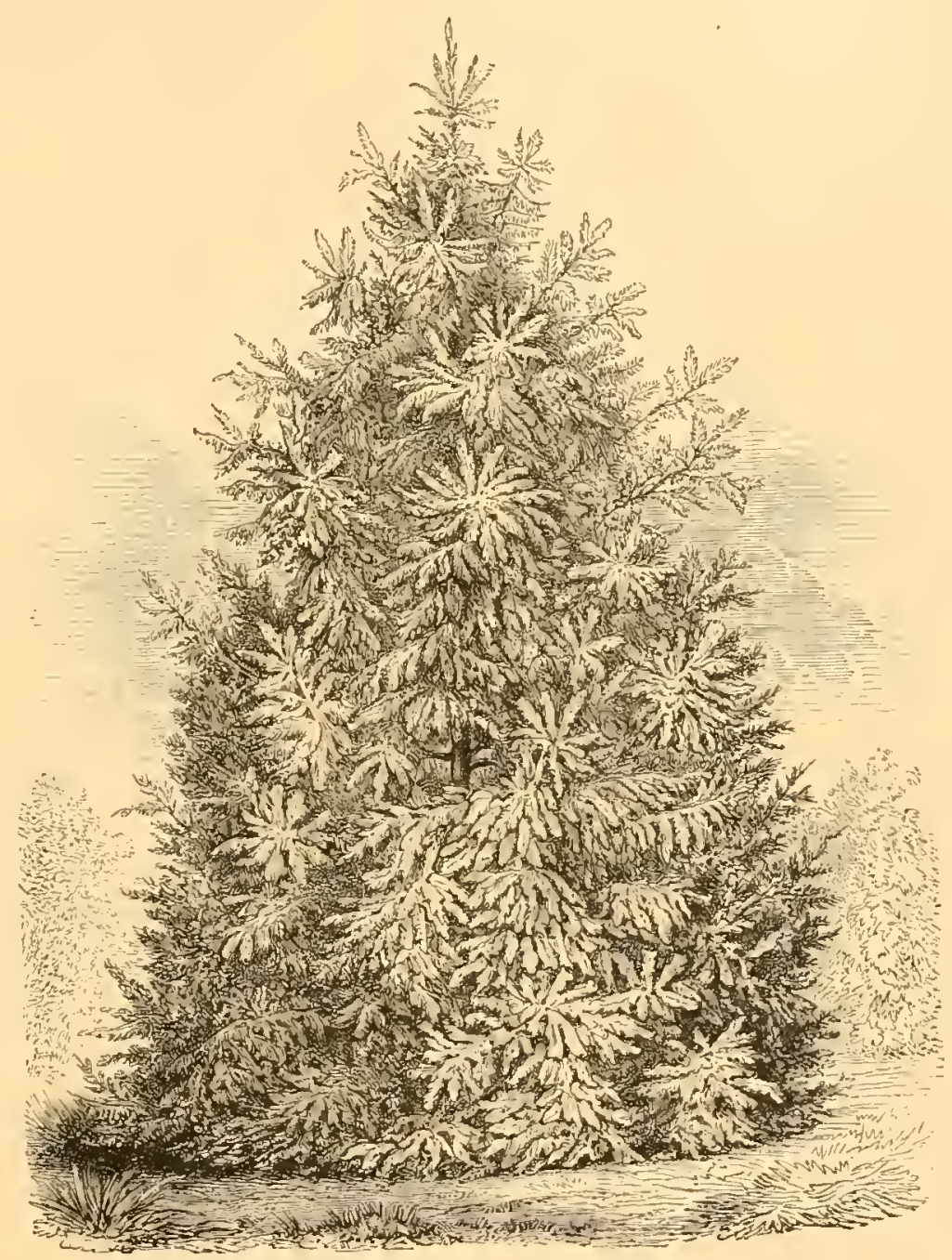

Fig. 186. - Picea Morinda. à des combinaisons de verdure très heureuses : cèdre de l'Atlas ou argenté; - Cupressus Lazusoniana (Fig. IS5), l'un des plus élégants, et trop peu employé jusqu'ici; - Picea Morinda (Figr. I 86); - Tsuga Canadensis (Hemlok), très attrayant à cause de ses branches allongćes et flexibles; - A. Nordmamiana, l'un de ceux qui forment le micux la pyramide; beau feuillage bicolore; - Thuya gigantea (Fig. I $S_{7}$ ), arbre magnifique, d'une verdure sombre, mais brillante; - Abies Pindroze, très rustique; - A. Pinsapo, qui nous vient des sierras d'Espagne, et semble en effet l'bidalgo des conifíres par sa 
fiére tournure; - Thmyopsis borealis, à plusieurs tiges se reliant en faisceau de forme sphérique, l'un de ceux qui produisent le plus d'effet, plantés isolément. Son surnom indique à quel point il est rustique; celui-là ne se contente pas de braver

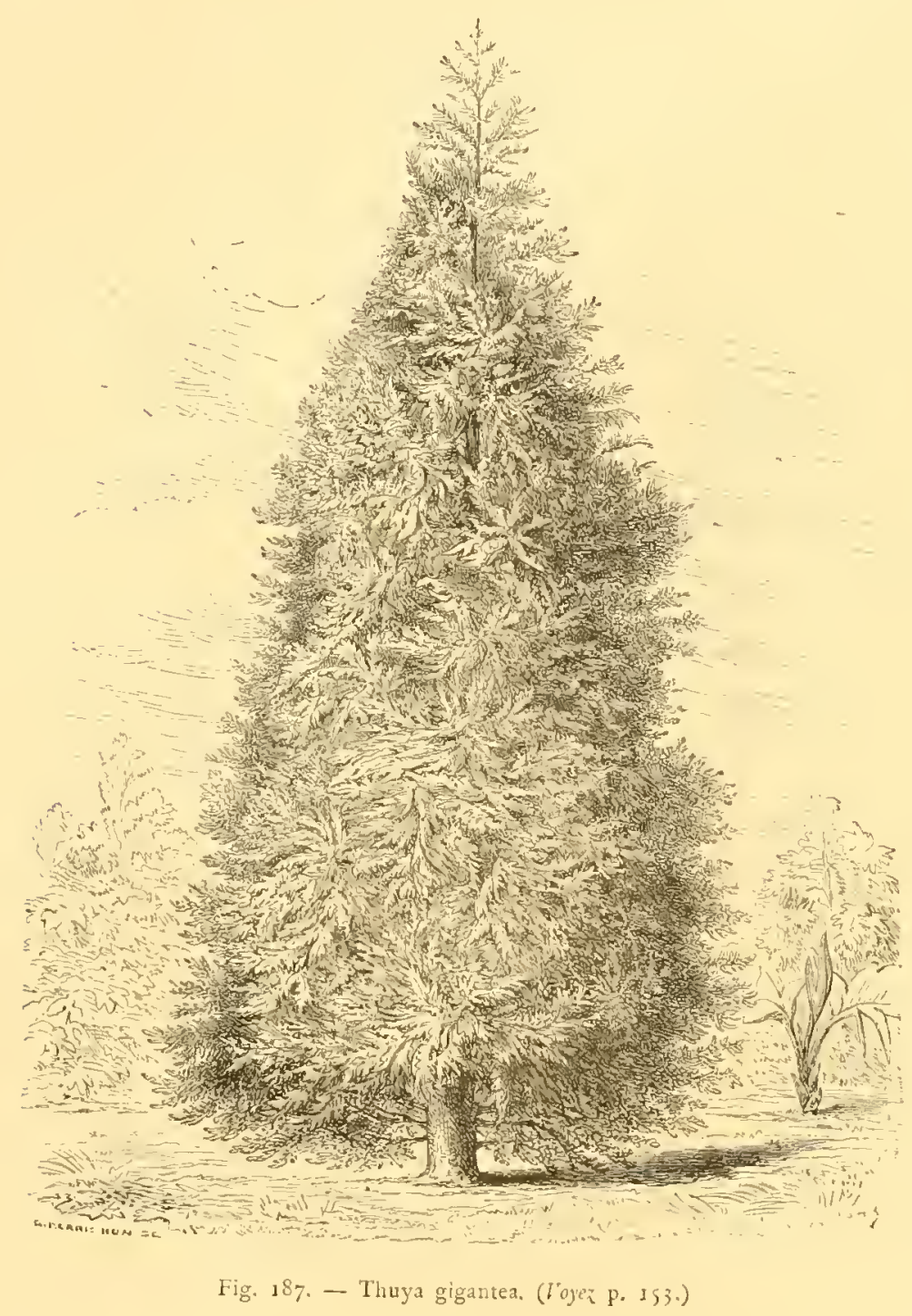

les grands froids, il les aime!

Le géant des coniféres, Sequoia IVellingtonia (Figure ISS), paraît définitivement acclimaté, ainsi que l'autre Sequoia qui croît également très vite; celui à feuilles d'if, dont les bourgcons, toutefois, sont frèquemment atteints par la gelée. On sait que ce dernier offre une exception remarquable à l'une des principales lois de la végétation des coniféres. Il drageonne et donne sur le vieux bois, sur la souche, même sur les racines, des cépées d'une beauté remarquable. Conme cn même temps il supporte bien l'ombrage et le couvert, on entrevoit la possi-

bilité d'obtenir, au moyen de cet arbre, un effet tout à fait original; des taillis résineux sous futaie d'arbres verts ou même à feuilles caduques.

En premier plan, on emploiera avantageusement les coniféres de seconde et troisième grandeur, comme les diverses variétés de Thuyas, de Genévriers, l'Abics nigra nana, le Taxns bibernica (Fig. I89), le Cèdre de Virginie. On peut aussi, à l'occasion, y joindre des arbustes à feuilles persistantes: houx, lauriers, alaternes, etc. Au rebours de nos essences indigènes, plusieurs de ces coniféres étrangers, 
notamment le Wollingtonia, le Pinus excelsa, le P. Cimbro (Fig. I9o), le C. Larusonima, l'A. Nordmanimana, préférent les terres fraíches aux sablonncuses.

L'un des massifs du bois de Boulogne nous offre un hẹreux essai de réunion . du cèdre du Liban avec le Laryx pendula (Fig. I $8_{j}$ ).

Ce rapprochement rappelle le beau vers de Victor Hugo :

C'est la grâce tremblante it la force appuyée.

Nous avons obtenu un effet du même genre en mêlant le vert presque noir de l'A. Pindroru au feuillage plus gai de l'A. Nordmamiana (Fig. 191) et du Larusoniana, et en y joignant deux arbres encore peu employés en France, l'A. Ceplalonica et le Clacmaropsis Fortunei.

Nous recommandons aussi cettc autre combinaison expérimentée par nous avec succès : $P$. Morinda,

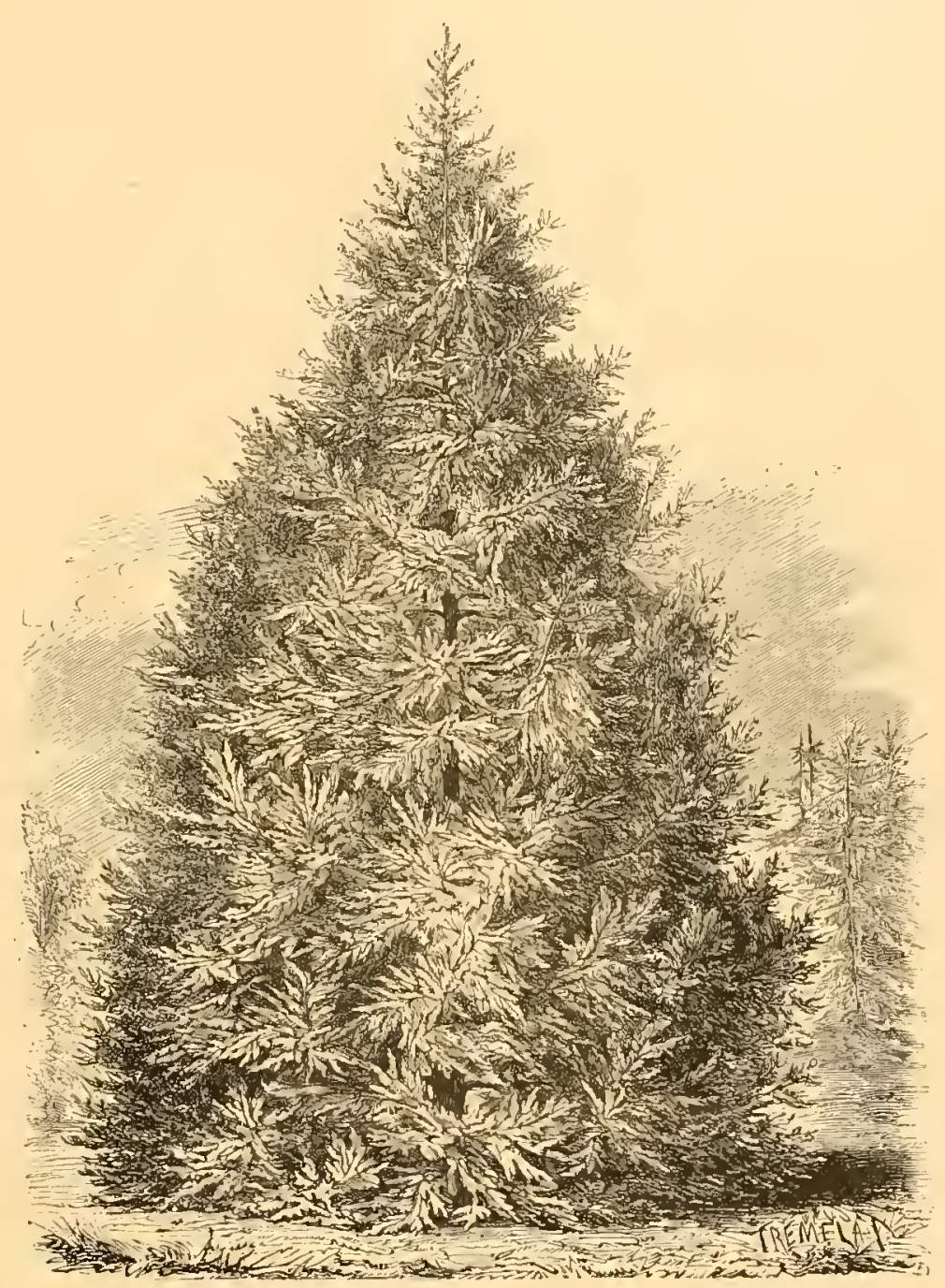

Fig. I88. - Wellingtonia gigantea. (I'oyez T. I54.) A. Canadensis, Thuya fastigiata, Pimus excelsa, Cammingbania sinensis (Fig. 192), Abics Douglasii (Fig. 193). XVI. - Autres Conseils sur le même Sujet. - Si les grandes perspectives se présentent obliquement, on atténuera ce défaut en traçant des lignes partant des fenêtres, et arrivant dans cette direction (Fig. I94, p. I6I). On réglera les plantations d'aprés ces lignes, en laissant des intervalles irréguliers entre les projections. Ces intervalles sont indiqués dans la figure par les fléches.

Généralement, d'ailleurs, la plantation doit être ordonnée d'aprés les points de 
vue pris des principaux appartements. En conséquence, quand on crée un jardin, il faut tracer une série de lignes partant en faisceau de la partie la plus importante de l'habitation et se dirigeant vers différents points de l'horizon, de manière à

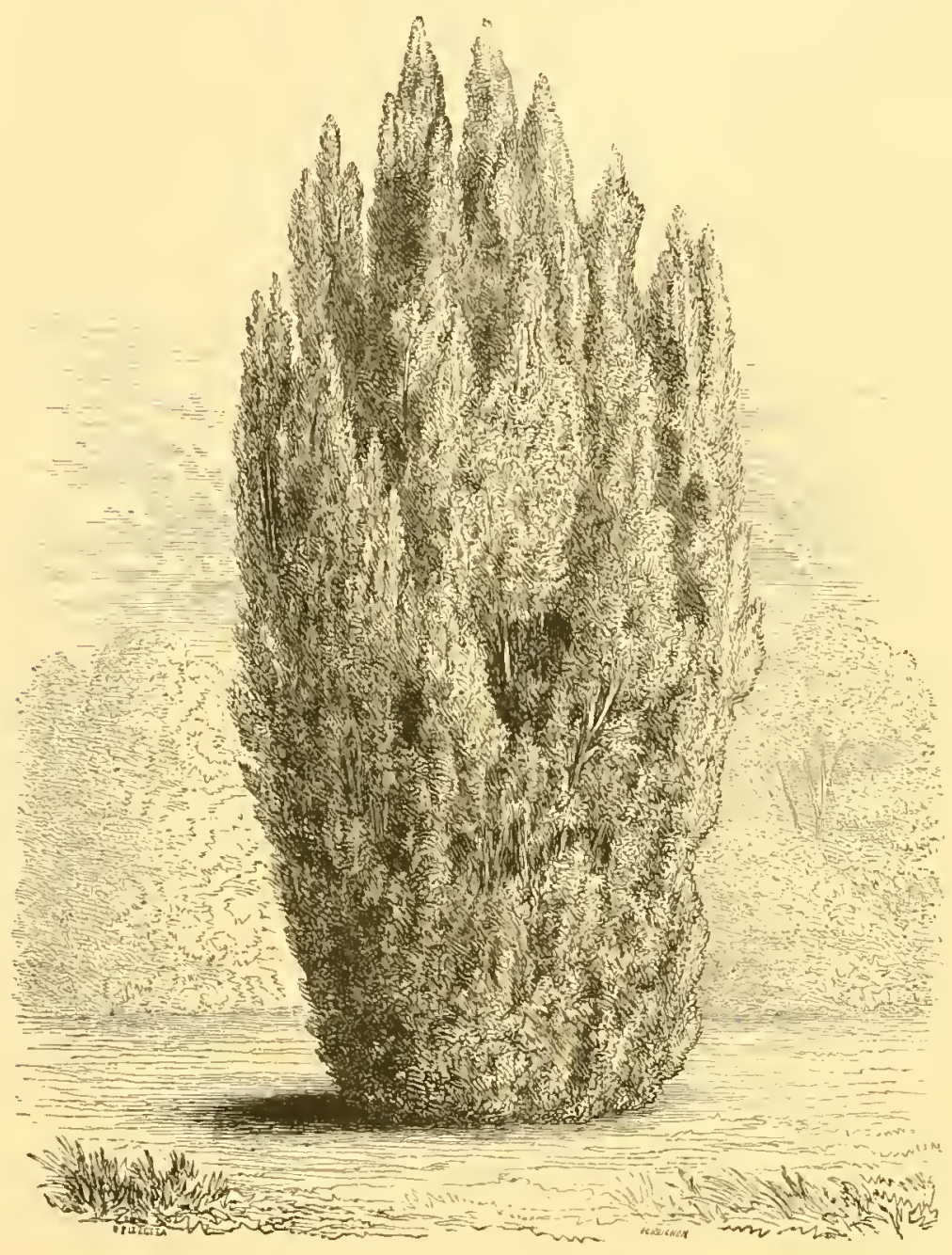

Fig. I89. - Taxus baccata Hibernica, (I0yez p. I5..) s'entre-croiser avec les perspectives latérales et à former ainsi une sorte de damier irrégulier sur le terrain d'opérations. La figure 195 (page 161), donnera une idée suffisante de l'importance de ce travail préliminaire, pour la fixation des éléments essentiels de la plantation.

Voici encore, sur ce sujet, quelques observations essentielles:

Les lignes de vision (Fig. 196, P. I6I) ayant ćté établies dans toutes les directions choisies, il faut éviter de créer, trop près de ces lignes, des masses de verdure trop compactes, qui resserreraient ou obstrue-

raient les perspectives. Les abords de l'habitation doivent rester libres, ou trés peu couverts, et être disposés en pelouses. Les plantations des pelouses se composent de quelques arbres isolés, ou de groupes de trois à quatre sujets (Fig. 197), ou de quelques bouquets d'arbustes. C'est là que doivent figurer les espéces les plus rares... En plantant les massifs ou les arbres isolés, on doit tenir compte de la forme des silhouettes, du feuillage, de la grandeur des feuilles, de manière à obtenir un grand nombre d'oppositions et de plans dont la succession augmente, en apparence, les profondeurs de la perspective et produise d'agréables contrastes de coloris... 
Les massifs rapprochés de l'habitation sont le plus souvent composés, partic d'arbres de haute taille et partie d'arbustes à fleurs ou à feuilles décoratives. Les arbustes à fleurs doirent être mélangés de maniére à obtenir dẹs floraisons successives (I). Il en est de même de la couleur changeante des feuilles... Il faut donc préroir le rôle que jouera un arbre ou un arbuste dans un massif, surtout quand il occupe une place bien en vue... Il faut encore tenir compte de la hauteur des végétaux employés, éviter que ceux qui atteignent un trés grand développement soient placés dans le voisinage d'autres sujets qu'ils ćcrasent par comparaison; ou bien qu'ils n'occupent un espace trop considérable. Cette précaution est utile surtout dans les jardins peu étendus; il faut en bannir les arbres et les arbustes de

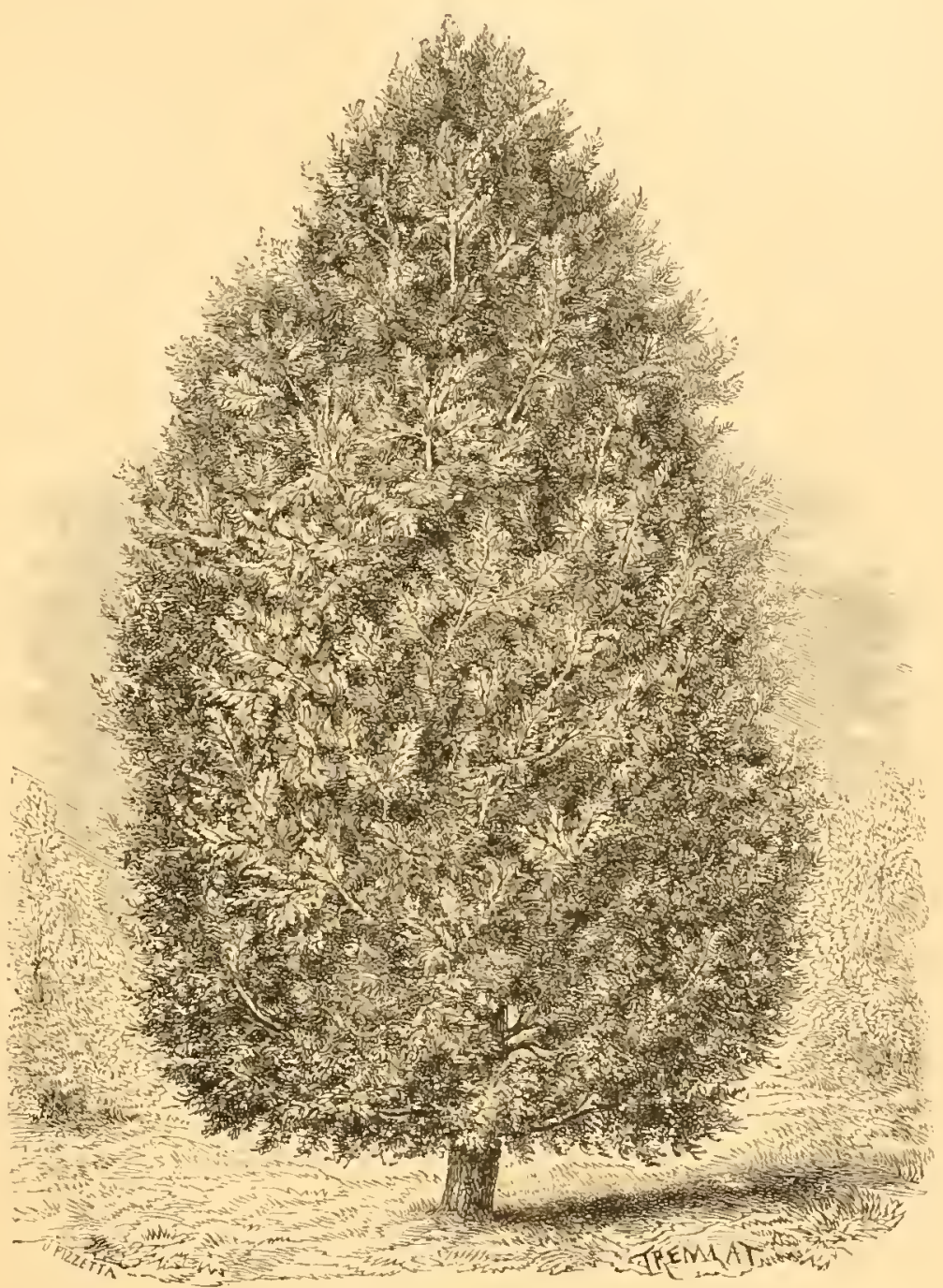

Fig. 190. - Pinus Cembro. (Voyer p. I55.) trop large envergure. On trouvera plus loin un curieux spécimen de plantations transformées par Petzhold dans le pare de Tieffurt. La figure igs nous montre ces plantations dans l'état antérieur. Elles cachaient la vue de l'eau, que l'habile paysigiste a restituée en leur domnant la forme que nous royons dans la figure 199, page r62. Enfin, on doit disposer, dans les parties découvertes, quelques arbres auprés

(1) Par exemple, arbres de Judée, lit.ıs, syringas, l'irrilitit luted; les diverses variétés de spirées, les magnoli.ıs grandifolia et grandifora. 
des allées. Il est indispensable de placer sur les hauteurs les espéces qui y croissent naturellement, et, dans les parties basses, celles qui aiment l'humidité ou qui ont besoin d'être abritées. Cctte répartition conserve au paysage un air de réalité

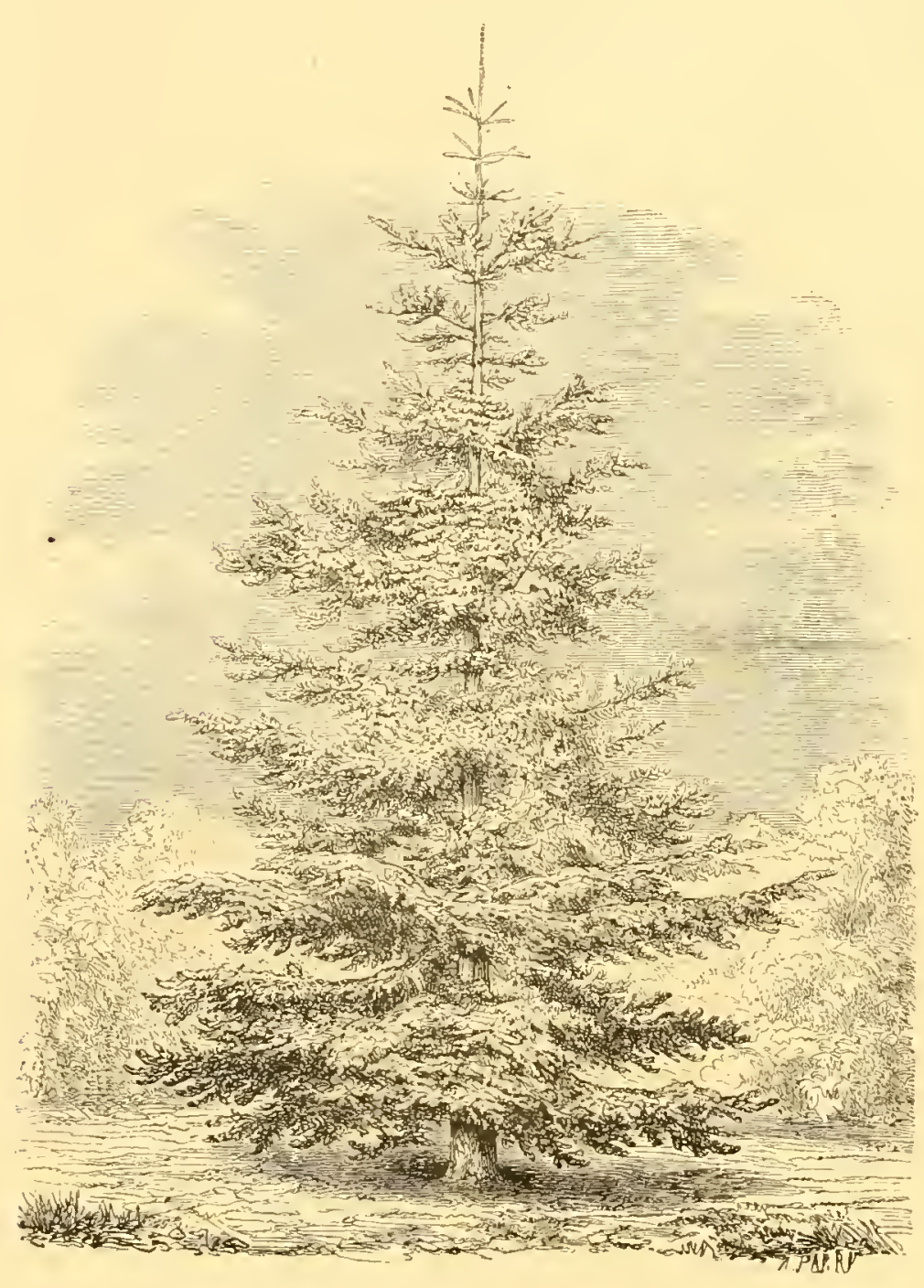

Fig. 19т. - Abies Nordnanniana. (Voyez p. I55.) (Fig. 200). Par exemple, les trembles, les platanes, les diverses variètés d'arbres pleureurs, se plaisent au bord de l'eau. Il faut y joindre l'aune, qui contraste heureusement arec la verdure argentée des saules; et le cypres chauve ou de la Louisiane, dont le feuillage, d'un beau vert, prend une si belle teinte rouge dans les derniers jours d'automne. Le tulipier, qui devient à la même époque d'un jaune orangé magnifique, demande aussi un terrain humide; il produit beaucoup d'effet, planté isolément dans un îlot, surtout en automne, quand il se détache sur la verdure sombre des rives de la piéce d'eau. C'est un des arbres qui, pendant quelques semaines, donnent à nos pares du Nord quelques-unes des teintes éclatantes de la végétation tropicale. Les cimes des peupliers d'Italie, s'élançant au-dessus des masses, produisent un excellent effet. Cette espéce est du très petit nombre d'arbres à feuilles caduques qui peuvent être mélangés aux arbres verts.

Les hauteurs doivent être plantécs, suivant la physionomic générale du pays, tantôt de sapins, tantôt de charmes, d'ormes, de châtaigniers et de chênes. Cc 
dernier arbre sera toujours un des plus beaux ornements des grands pares, comme des forêts. Son seul défaut est la trop grande lenteur de croissance, mais les sujets remarquables qui se trouveraient sur le terrain confié au dessinateur, devront être soigneusement réservés et mis en évidence (Fig. 20I, p. 164 , chêne du pare des Minimes). Cette régle est d'ailleurs applicable aux beaux arbres de toute espéce; aucun ne doit être sacrifié qu'en cas de nécessité absolue.

XVII. - Formes diverses des Arbres. Pour un paysagiste, les arbres peuvent être classés d'après leur taille, leur forme, la couleur ou la dimension de leurs feuilles. Certains arbres affectent nettement une forme fusclic (peupliers d'Italie), pyramidale (sapins), de parasols (pins du Midi) (Figure 202), sphérique (marronniers, tilleuls), retombante (arbres pleureurs)

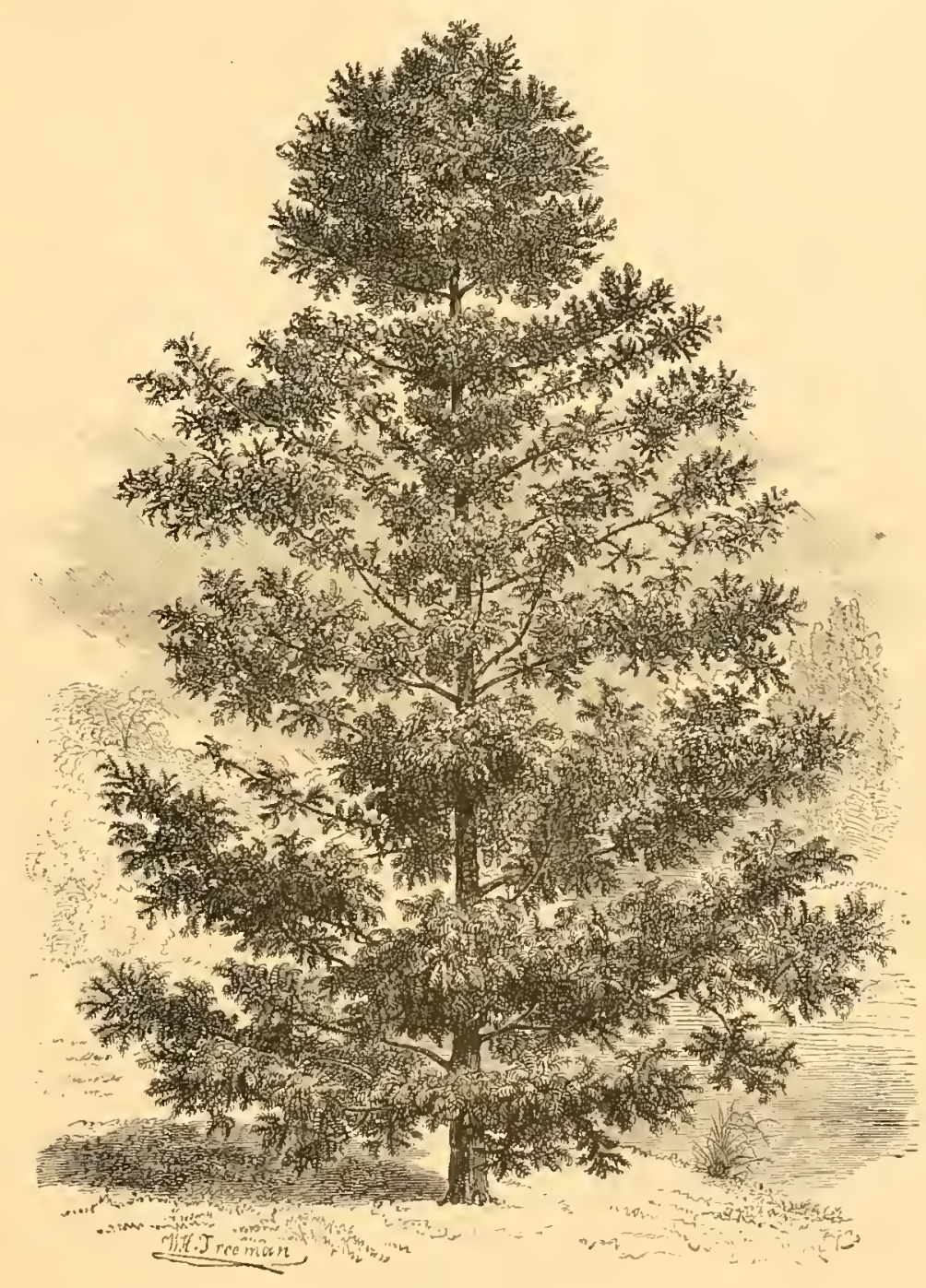

F̈̈g. 192. - Cunninghamia sinensis. (Foyer P. I55.

(Fig. 203, p. 165), ou franchement irrégulière, comme le chêne, le frêne, l'orme, cte. Chaque arbre a une attitude particulière, qui se rapproche plus ou moins d'une de ces formes simples.

Dans les parcs iréguliers, les plantations doivent être généralcment composées de plusieurs espéces d'arbres, mais assortis avec goút et discernement au point de vue de la taille, de l'attitude, des formes et des teintes de feuillage. Dans toute plantation, deux écueils sont à éviter : la monotonie et la confusion. Si le jardin 
paysager est, comme on l'a dit, " une symphonie de formes et de couleurs », une plantation composée d'une scule espéce d'arbres produit la même impression de fatigue qu'un seul et même son prolongé, tandis qu'une plantation trop mélangée et

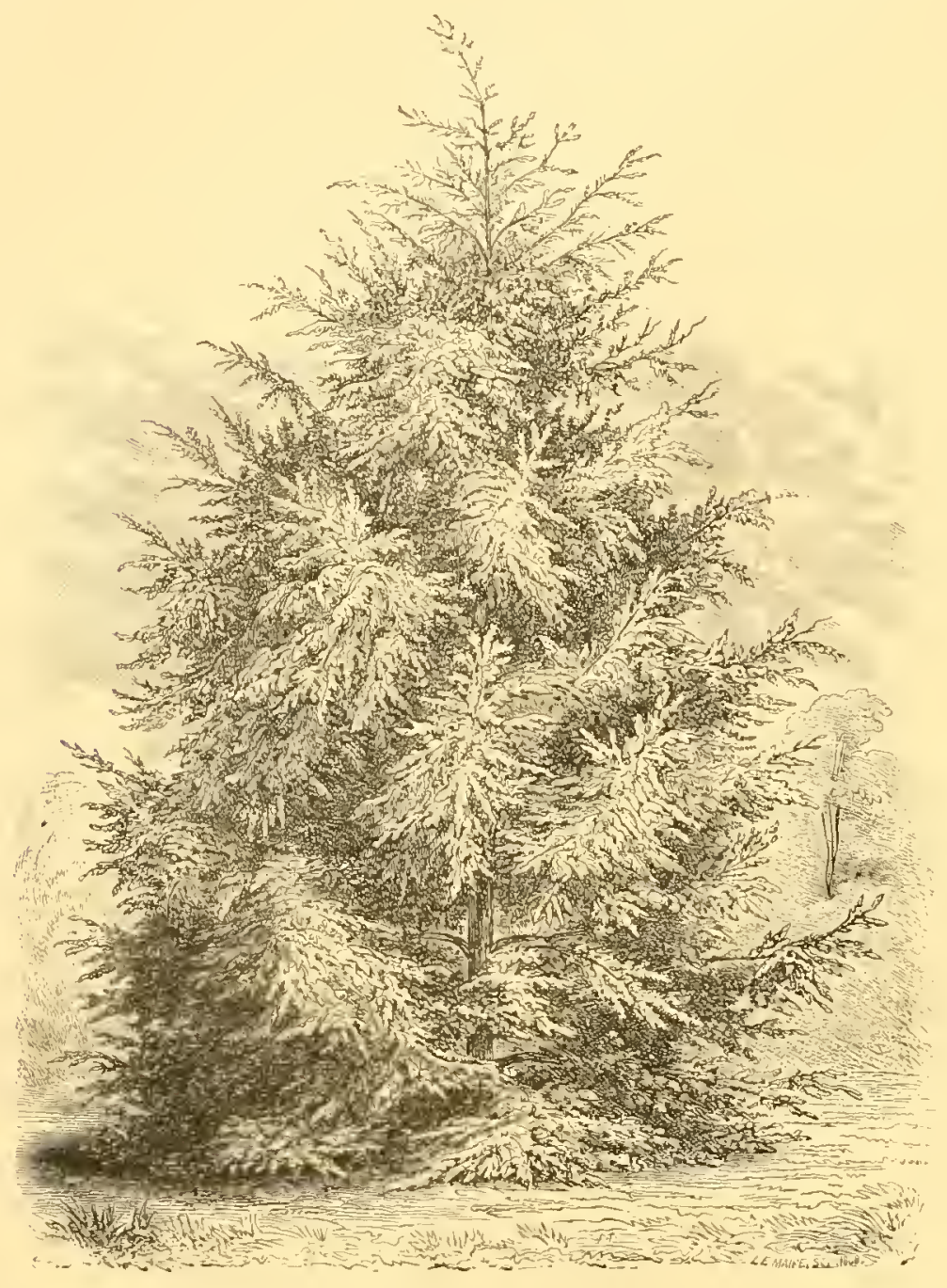

Fig. 193. - Abies Douglasii. (Toyei P. 155.) faite au hasard est un charivari " de formes et de couleurs ».

Il importe de faire prédominer, dans le jardin paysager à créer, les espéces d'arbres les plus communes dans le pays; parce que ce sont clles qui fournissent les plus beaux sujets. On y ajoute d'autres essences, en les répartissant de telle sorte que les masses forment des lignes onduleuses, dont émergent çà et là des cimes plus élevées, peupliers d'Italie, trembles, etc. La composition des silhouettes doit être prévue quand on plante de jeunes arbres; il faut les disposer d'après la taille moyenne

qu'ils atteindront, arrivés à leur entier développement. Il importe aussi de varier les essences, non seulement sur les rebords, mais jusque dans l'intérieur des massifs, même les plus profonds, afin de ne pas avoir un couvert d'un aspect trop monotone, comme dans les futaies ordinaires. Pour les dessous de bois, que l'on peut appeler les paysages intéricurs, on doit mélanger les essences, afin d'obtenir de la variété dans l'éclairage des massifs de verdure. Ainsi, il est bon d'avoir tantôt des groupes d’arbres à feuilliages trés épais, et tantôt des feuillages légers, laissant 
pénétrer la lumiére. Pour ces effets d’iradiation dans les bois, l'artiste consultera utilement l'ouvre de Diaz; comme celle de Poussin pour la composition générale

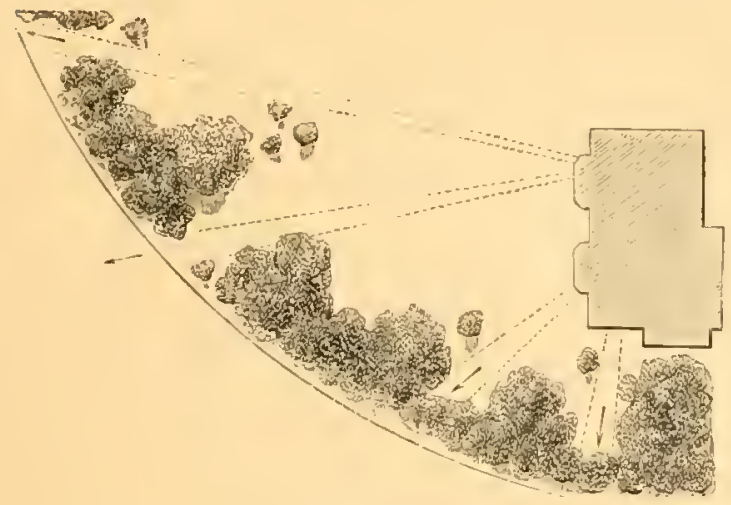

Fig. 194. - (Iover p. I5;.)

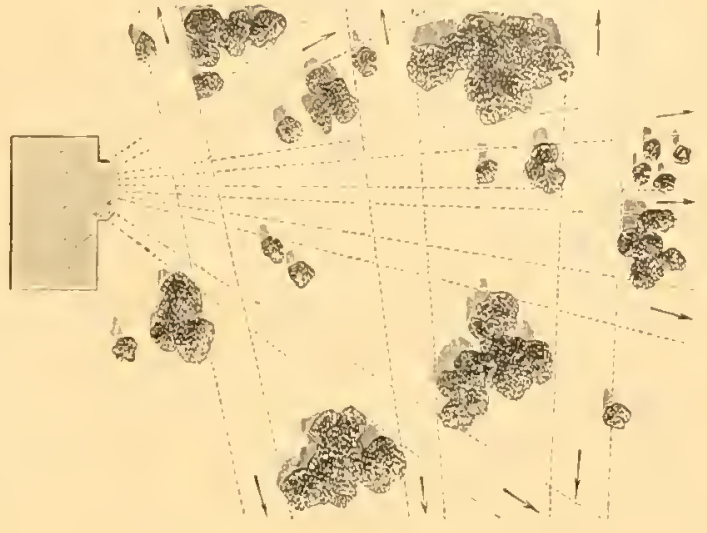

Fig. 19j. - (loyci p. 1,6)

du paysage. Afin de faciliter ces jeux de lumiere au fort des massifs, il faut y ménager des elairiéres qui permettent aux rayons du soleil de descendre çà et lí

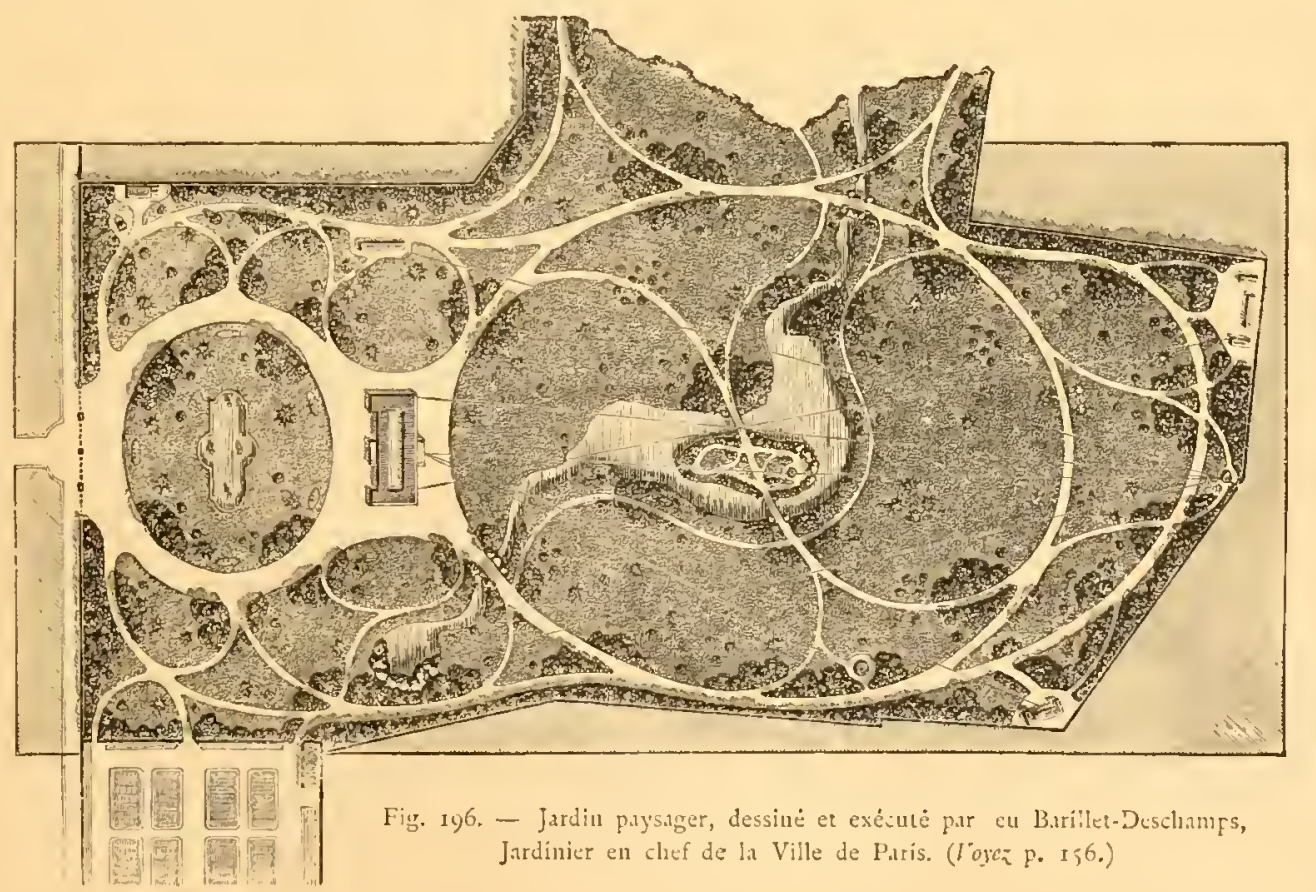

jusqu'au sol. Il faut tenir compte aussi, à l'interieur comme à l'extérieur, des péripéties de la coloration des feuillages: du bel effet, par cxemple, que ne manquera pas de produire en automne le contraste de la riche coloration des hêtres aree le vert persistant des chênes. 
Nous recommandons encore d'éviter, dans la composition des massifs, le rap-

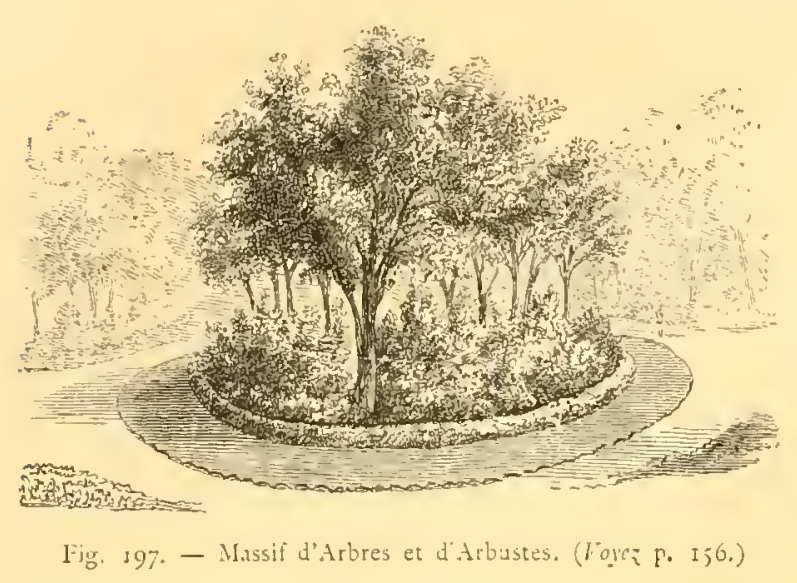
prochement continu d'un trop grand nombre d'arbres absolument de la même teinte, ce qui donnerait des plaques disgracicuses de couleurs trop sombres ou trop pâles. Sur le fond doucement nuancé de la masse, on peut détacher çì et lí des groupes ayant des tons plus clairs ou plus sombres. Il faut encore observer la grandeur du feuillage; ce dernier détail permettra d’isoler davantige certains groupes et d'approfondir les perspectives. Une autre précaution indispensable, et trop souvent nègligée, est de ne mettre aux prises que des essences de force à peu prés égale; sans quoi les plus vigoureuses étoufferaient les plus faibles, au grand détriment de l'harmonie générale. Le hêtre, par exemple, et l'épicéa, parmi les conifères, passent avec raisor pour des voisins dangereux.

Chaque massif doit avoir son rôle dans la scéne entière, et être disposé de manière à former partie du tout. Il faut donc, quand on dispose des groupes, ne jamais perdre de vue le plan général. Un massif double qu'une allée divise, doit, par l'arrangement des contours, sembler de loin n'en former qu'un. Les bords de ces

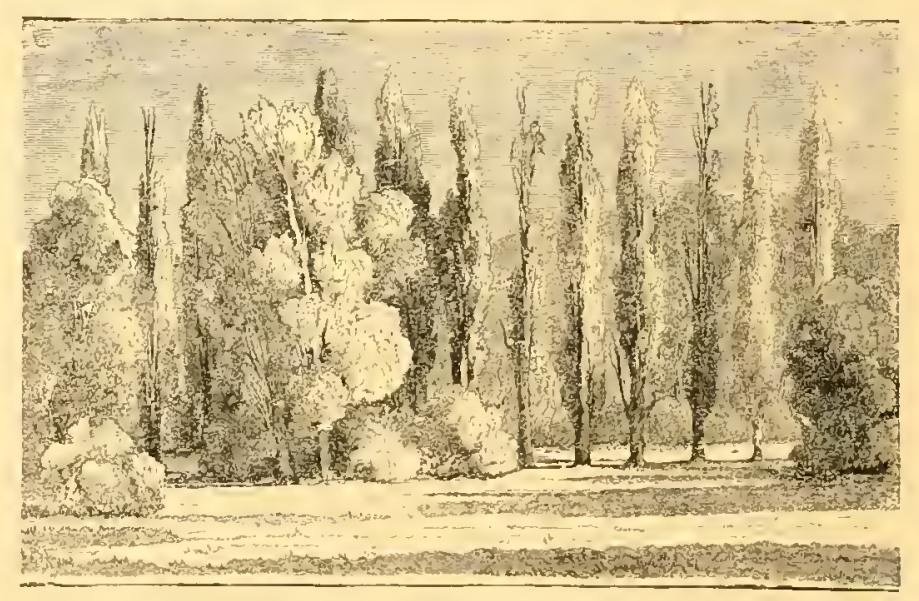

lig. jos. - Tue du Pare de Tieffurt. (Toper p. 157.)

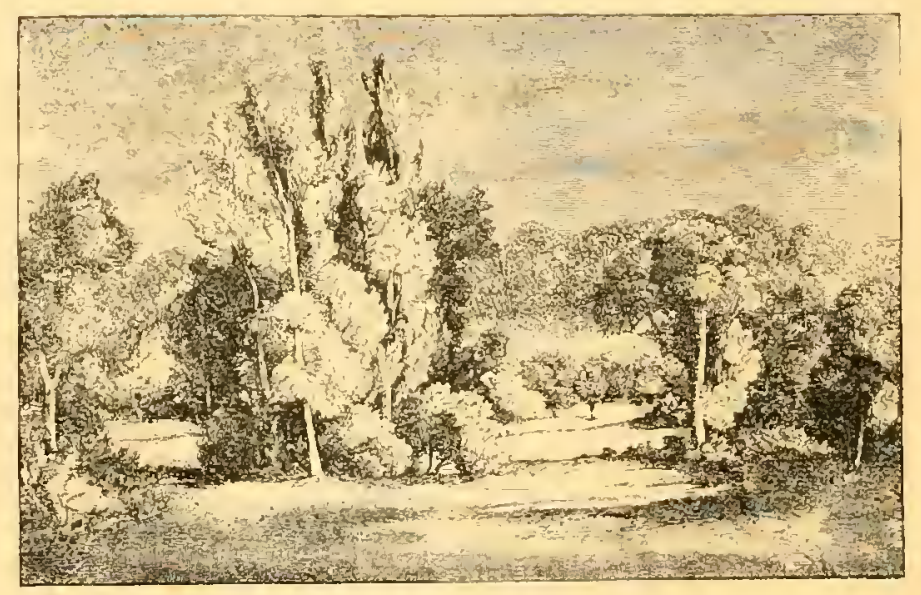

lïgr. I99. - Vue du Parc de Tieflurt aprés la Transformaticn, faite par Petzhold. (Ioysi p. 1;7.) groupes doubles, du côté de l'allée, doivent affecter un profil plutôt irrégulier, quand 
les masses ont une certaine ampleur (Fig. 204); plutôt uniforme, si elles sont étroites et petites (Fig. 20j). Dans une grande propriété, si le sol est acecidenté, on obtiendra un effet heureux en plantant çá et là des arbres sur le versant et le sommet d'une hauteur, pour simuler les abords d'une torêt (Fig. 206).

On ne saurait trop le répéter, la disposition des groupes sera toujours défectueuse, si on ne tient pas compte de l'effet à venir des lignes supérieures. La

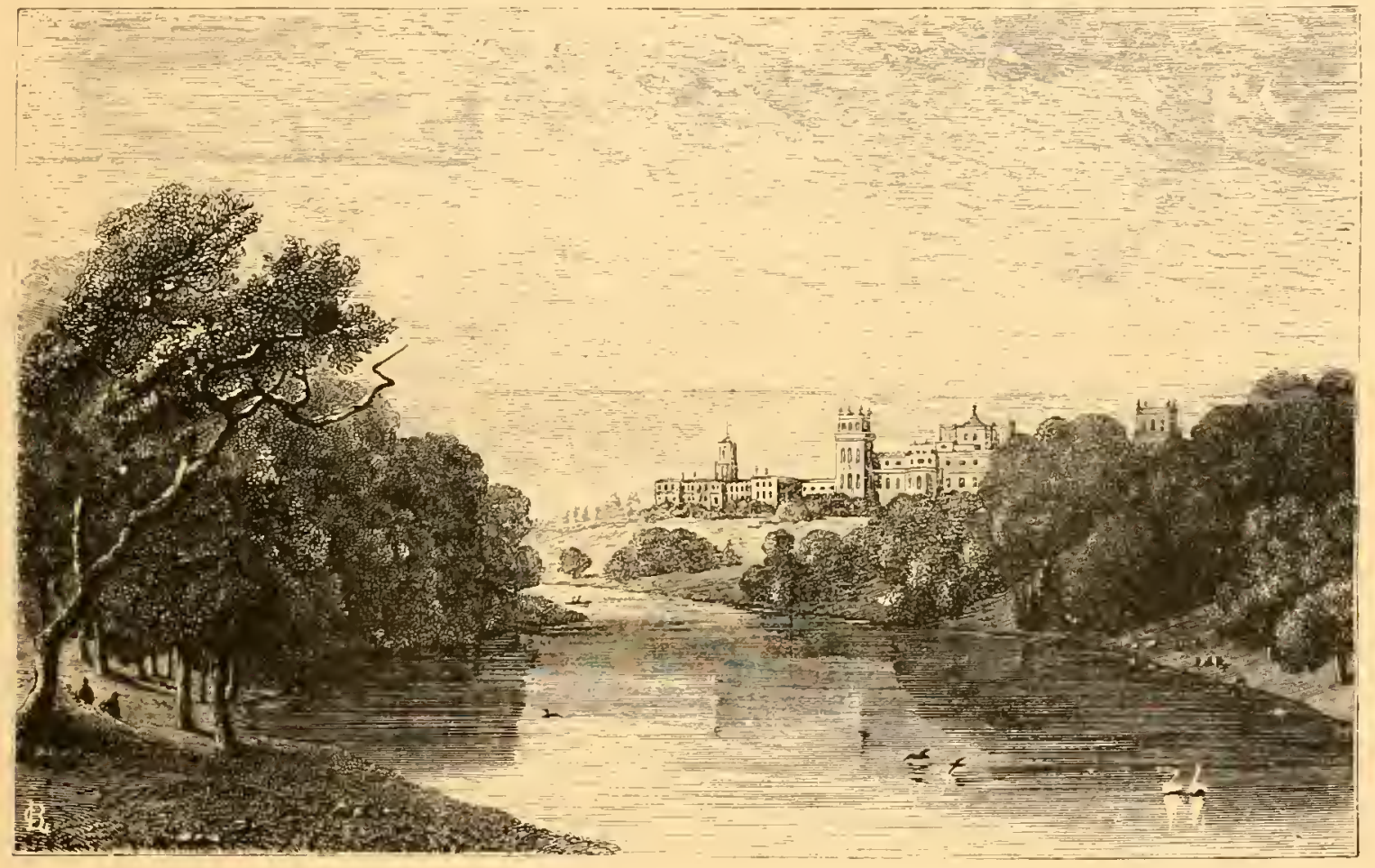

Fig. 200. - Vue du Chateau de Bleenheim, terminé en 17rg. - Appartenant au Duc de Marlboroígh. (Voyez F. Ig 8.)

meilleure partie de l'art du dessinateur consiste à tout combiner en vue de la collaboration de la nature, de manière à l'avoir pour auxiliaire, et non pour ennemie.

Dans les grands parcs irréguliers, largement conçus, notamment dans ceux d'Angleterre, le "ménage champêtre » a son rôle comme dans ceux des grandes villes de l'Empire romain et de la Renaissance. Les plantations s'y confondent pour ainsi dire avec les cultures : "les larges allées sinueuses 》 servent à la fois à la promenade et aux transports agricoles. Par contre, on passe des champs cultivés, des grands bois et des taillis au parc, et du parc au jardin (Pleasure Ground). C'est pour celui-ci qu'il faut réserver les arbres, arbustes et plantes exotiques qui réclament des soins particuliers, ou qui, par leur rareté et leur beauté, méritent d'être le plus en 
vue; les bordures et les corbeilles de fleurs et de plantes à feuillage ornemental; les plant s de serre installées sur les pelouses pendant la belle saison, etc. La mature

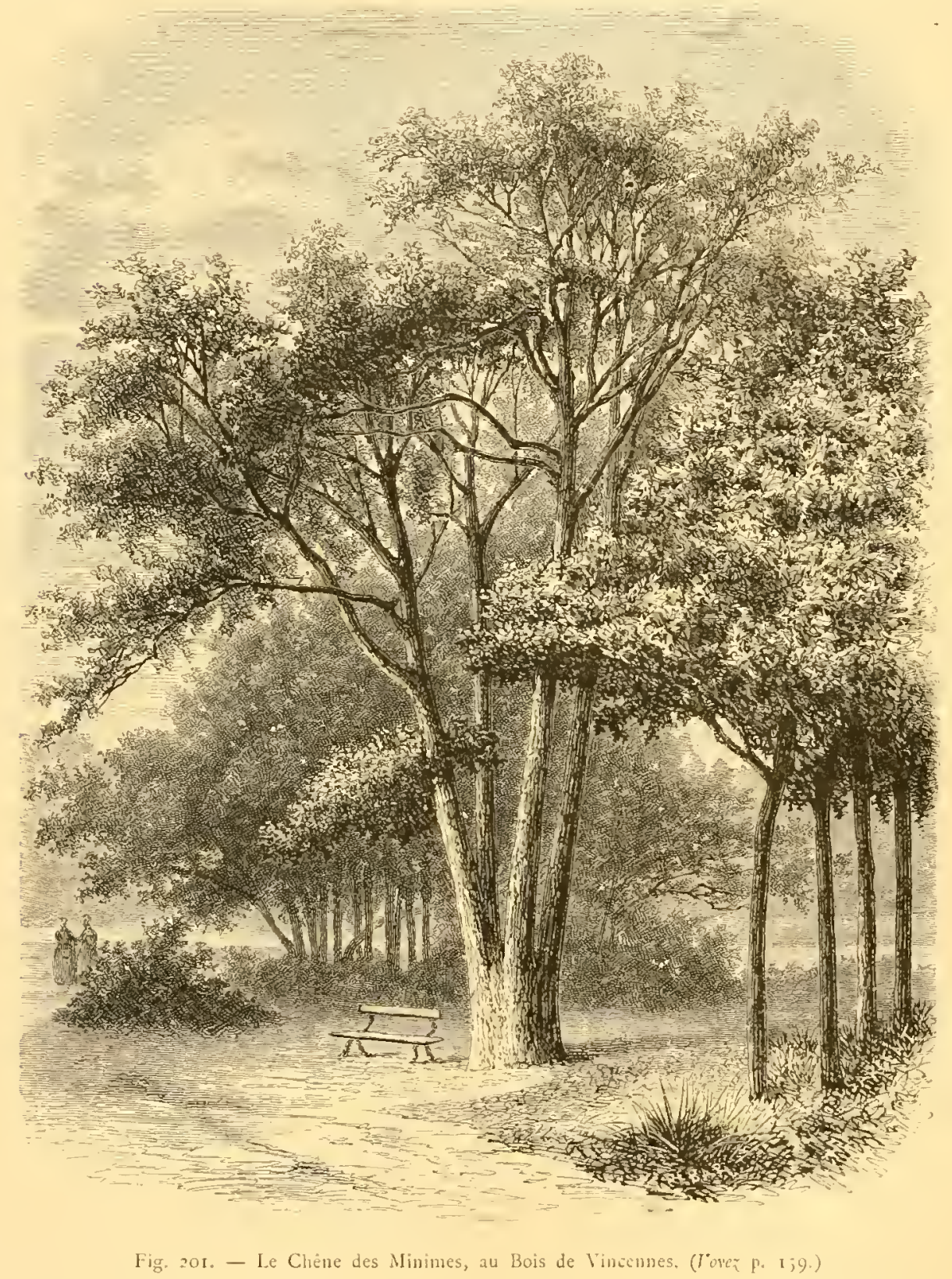

n'y est ni annulée niesclave, comme dans les « architectures vertes » d'autrefois, mais au contraire cultivée avec une recherche spéciale, et comme recellue d'art.

XVIII. -
Des Eaux. -
Formeàleur
donner. -
Plantations
surles Bords - Un ruisseau d'eau courante dirigé avec intelligence, une piéce d'eau bien dessinée, bien entretenue, contribuent beaucoup à l'agrément d'un jardin ou d'un parc. Mais, si les eaux ne sont pas. l'objet de soins bien entendus et suivis, elles cessent d'être un agrément pour derenir un fléau; - celles surtout qui ne peurent se renouveler d'une façon constante.

Suivant la judicieuse maxime d'un célébre dessinateur anglais, l'artiste doit surtout se préoccuper de la marche (progress) en ce qui concerne l'eau courante, et 
des détails du pourtour (circuity) pour les eaux plus ou moins dormantes (I). Les premieres pourront cheminer sans inconvénient sous bois, tandis que les autres devront être exposées, au moins d'un côté, à l'action de l'air et de la lumière. On sait en effet par expérience, que les étangs entic่rement enveloppés d'arbres sont généralement tristes et malsains. Quant aux formes du pourtour, les plus simples sont toujours les meilleures, surtout si la pièce d'eau est petite. Dans ce cas, la recherche de bords contournés à l'excès serait absolument ridicule.

Dans les jardins irréguliers, la forme la plus convenable est celle d'une ellipse allongée. Le principal avantage de cette configuration est d'cmpêcher qu'on n'embrasse entièrement la piéce d'eau d'un seul coup d'œil. Quelques courbes, quelques creux garnis de plantations hautes ou basses, suivant les circonstances, pourront faire paraitre une

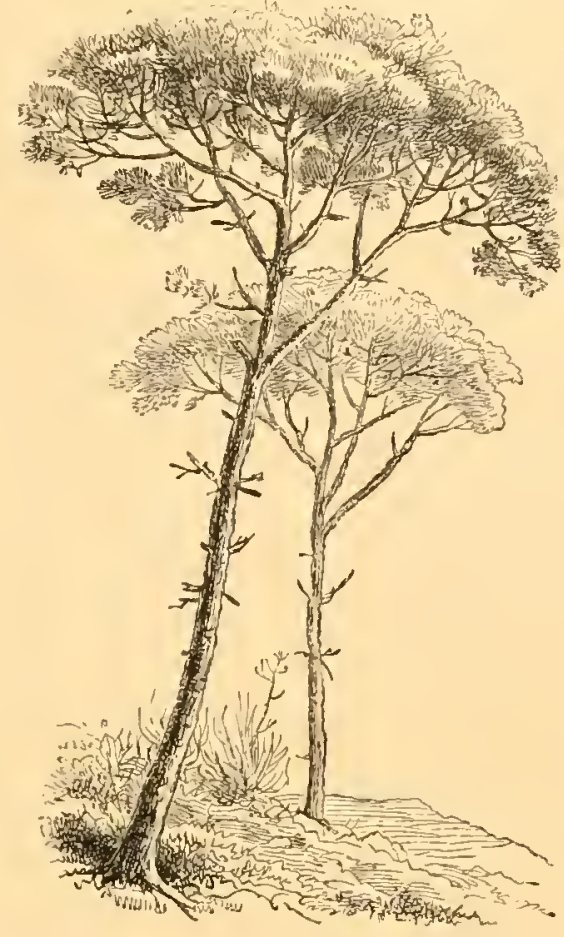

Fig. 202, - 1'in Farasol, (Togez p. 1;y.) pièce d'cau plus grande qu'elle n'est en réalité. Les îles et les îlots contribuent aussi

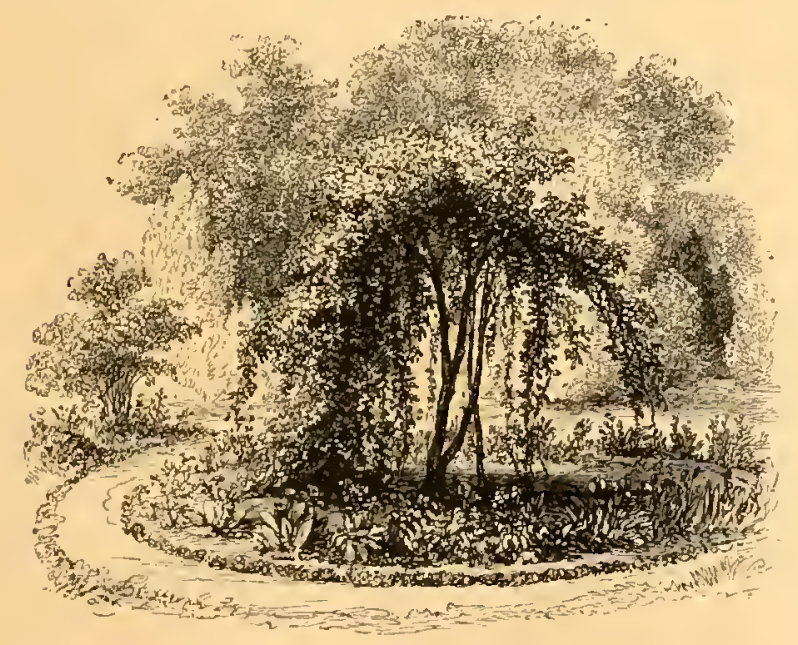

Fig. 203. - Massif avec Arbres retombants. (Toyez P. I 59.) beaucoup à la beauté des pièces d'eau, pourru qu'elles soient suffisamment grandes. On peut en voir des exemples remarquables : à Ermenonville (la fameuse île des Peupliers) (Fig. 207), plusieurs au bois de Boulogne, et à Vincennes (Fig. 208), l'île de SaintMandé. (Foyez P. 167.)

Les bords doivent toujours être plus ou moins exhaussés, et plantés en partie d'arbres dont les branches fassent saillie ou s'inclinent sur l'eau. Les diverses variétés d'arbres à branches retombantes, saules, soplıoras, frênes, hêtres pleu(1) Repton, Obserzations on modern gardening (1Sor). 
reurs, seront toujours d'un excellent effet dans cette situation. On obtiendra aussi un résultat trés heureux et peu commun, en mettant un platane sur un rebord escarpé,

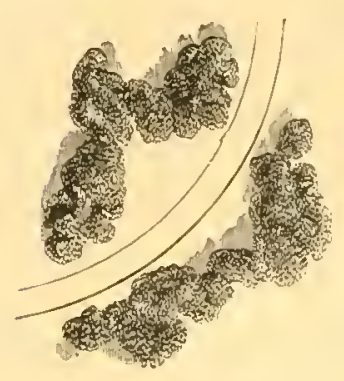

Fig. 204. $-\left(t^{*}\right.$, p. 163$)$.

de maniére à ce que la tige incline fortement sur l'eau. Pour les plantations isolées sur le bord des lacs ou étangs artificiels, nous recommandons aussi le cyprès de la Louisiane, qui se plaît dans les terrains humides, et dont le feuillage se colore magnifiquement en automne; les Aruudo dourax, Bambusa anrea

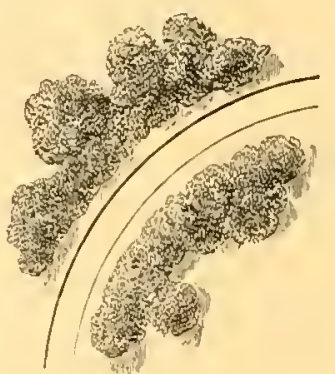

Fig. 205. $-(r$. p. :63.)

(Fig. 209), Thalia dealbata (Fig. 210), etc. On peut aussi l'employer avec avantage dans les îlots. Toutes ce plantations, dans le roisinage immediat de l'eau, doivent être faites avec la plus grande circonspection,

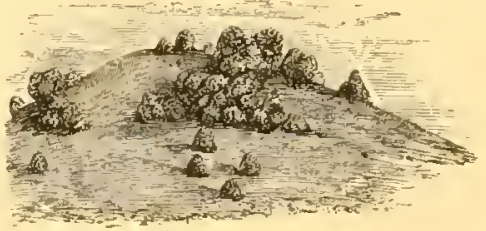

Fig. 206. - (Voere page 163.) en ménageant les points de vue et réservant des espaces libres pour l'air, la lumière et le jeu des reflets (Fig. 2 I I, p. I 70.)

Petzhold cite, dans son remarquable ourrage sur l'Art des Jardins, la Transfor-

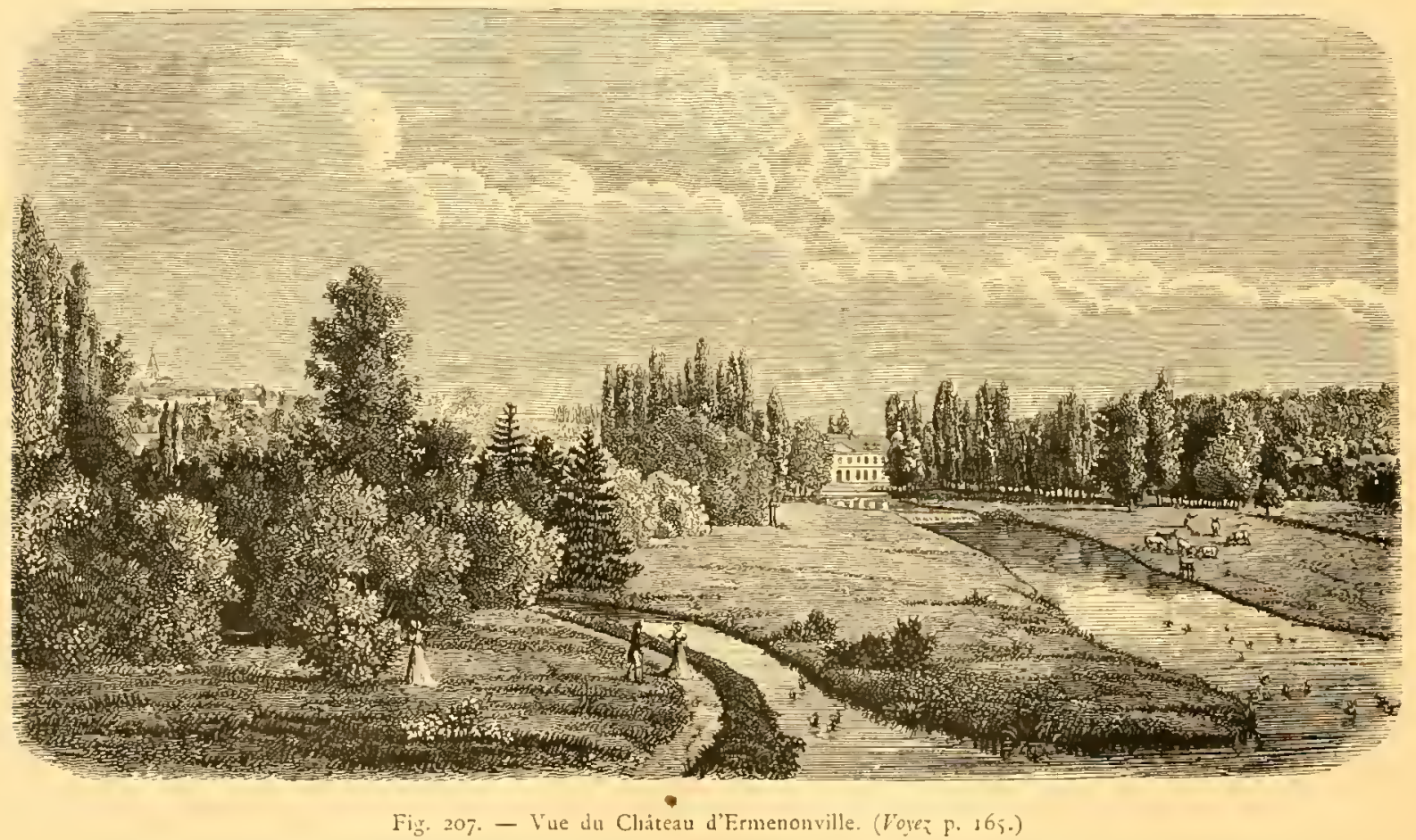

mation de Fromhouse; nous le reproduisons (Voirp. I 7 I), avant et après les modifications faites par Repton. L'eau est traversée aux extrémités par deux ponts produisant 
ainsi l'illusion d'une grande étendue, grâce aux arbres qui masquent li perspective (Fig. 210 et 2 I 1 ).

Dans les ondulations des rives, il faut s'efforcer de reproduire les caprices gracieux de la nature. On peut, pour varier les effets, disposer ça et là sur les berges quelques rocailles ornées, principalement à l'approche d'une cascade ou d'un gué. Mais il faut user sobrement de ce genre de décor, ainsi que des plantes aquatiques, roseaux, nénuphars, etc., surtout dans les jardins et les pièces d'eau d'étendue médiocre.

Il est facile de tirer parti du moindre filet d'eau courante, mais on peut aussi rendre les eaux dormantes agréables, en ayant soin d'en combattre les inconvénients.

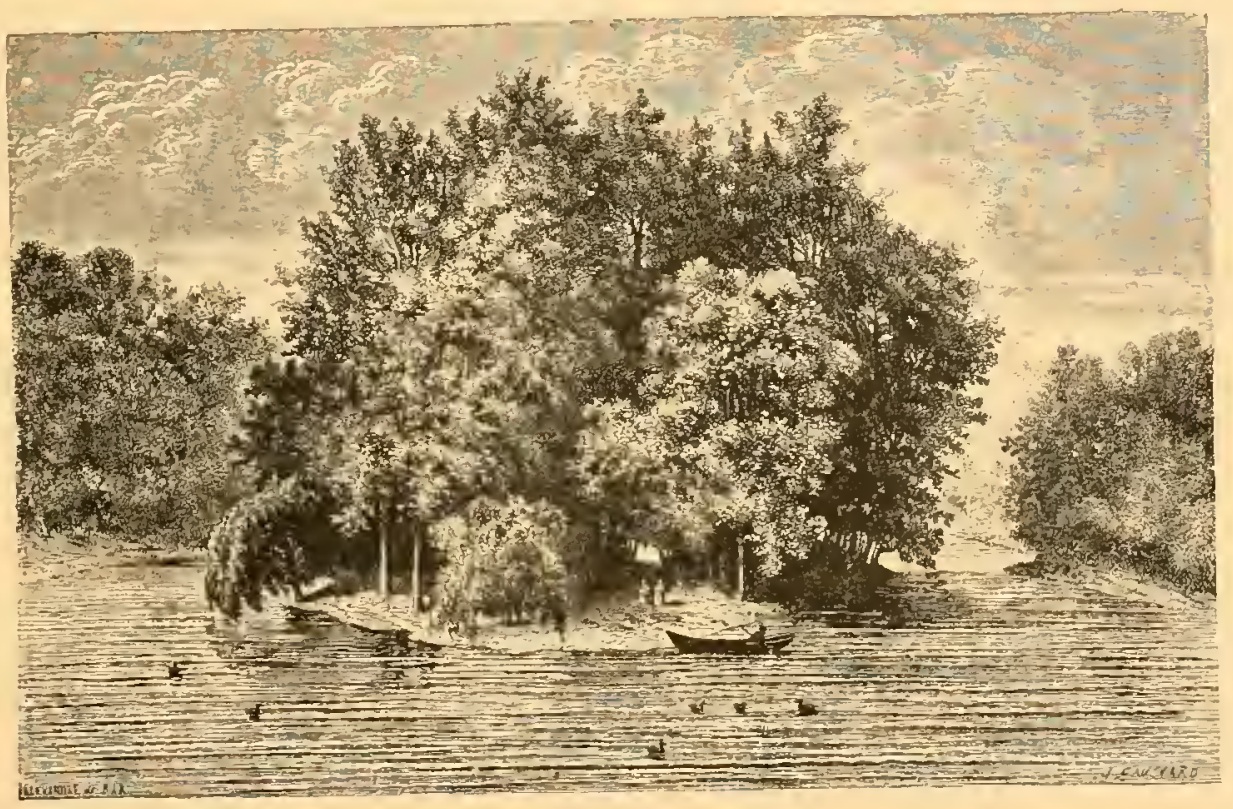

Fig. 208. - Lac de Saint-Maude au Bois de Vincennes. (Foger p. 165.)

En thése générale, plus l'eau d'un étang ou lac artificiel se renouvelle difficilement, plus il importe que les bords soient en partie découverts, surtout du côté le plus exposé aux grands vents. Ils emportent la mauvaise odeur, et donnent it l'eau une agitation factice, capable de faire illusion, si la pièce d'eau est bien dessinée. On ne doit pas négliger non plus d'augmenter l'approvisionnement d'cau, au moyen du drainage. Si la forme et la nature du terriin s'y prêtent, des drains dont l'orifice est dissimulé par quelques pierres ou quelques plantes, déversant leurs eaux sur une pente rapide, produiront, pendant une grande partie de l'année, l'effet de sources d'eau vive.

Les cygnes, canards, sarcelles, etc. (Fig. 2 I4, p. I 72), animent singuliérement une pièce d'eau, mais ils ont l'inconvénient d'en dégrader les bords, de détruire les plantations aquatiques et le frai des poissons. 
XIX. - Conduite des Cours d'Eau; Iles. - Les caux sont une des parties les plus difficiles des jardins irréguliers. - La création d'une cascade, d'un ćtang ou d'une rivière demande a la fois des connaissances pratiques trés appro-

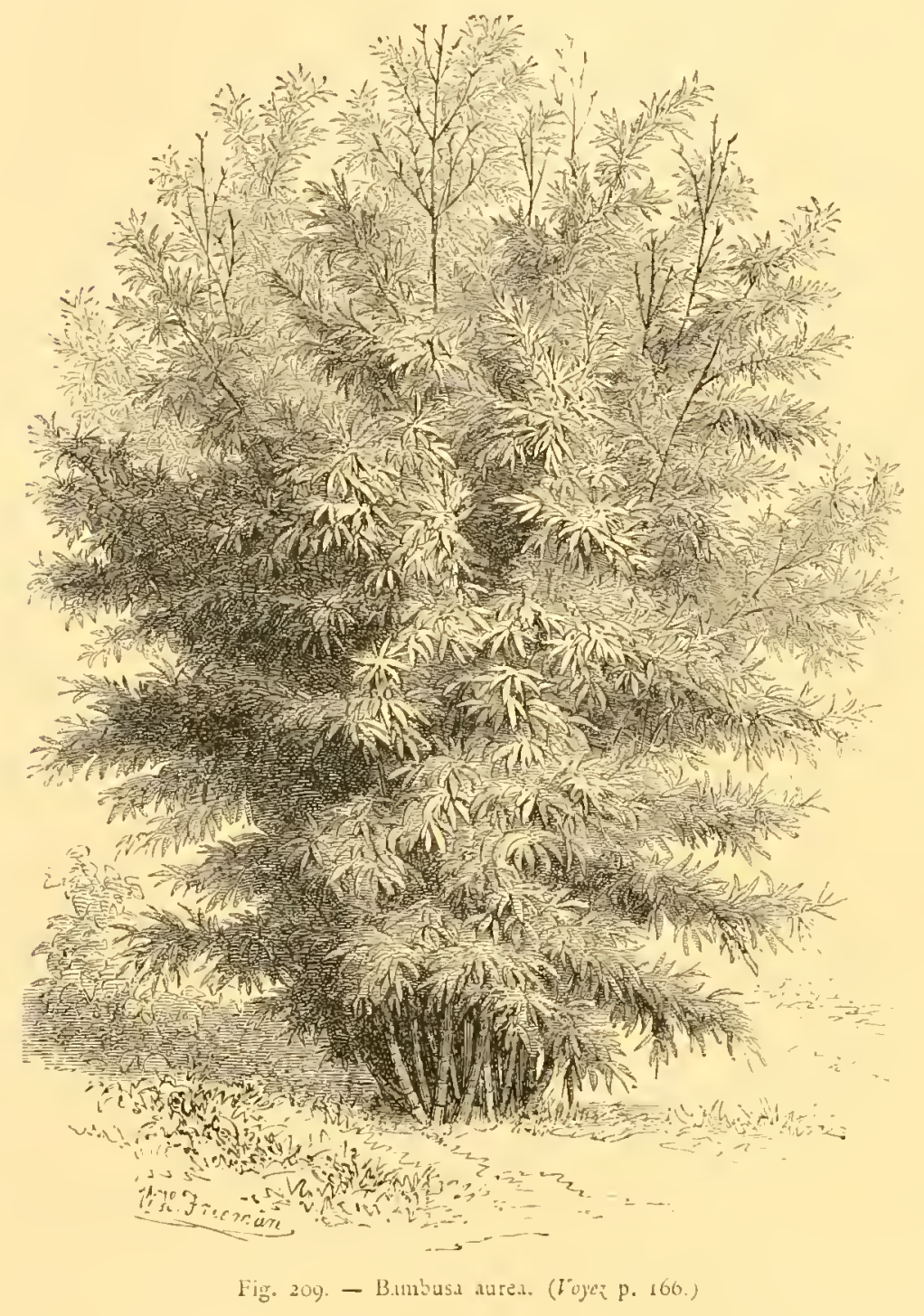
fondies, beaucoup de goût et d’imagination, pour ćviter tout effet banal ou affecté. Nous donnons, comme spécimens de cascades, la cascade des ButtesChaumont (Fig. 2 I j), celles des bois de Boulogne (Figure 216) et de Vincennes (Fig. 217), la très curieuse cascade Aldobrandini (Figure 218), exemple rarissime et dont nous ne conseillons pas l'imitation, d'emploi du style régulier dans la disposition des rocailles; enfin, les cascades pittoresques de Mérérille (Figure 219) et du pare Monceaux (Fig. 220).

Meyer est un des meilleurs auteurs à consulter pour la conduite des cours d'eau (Fig. 22 I). Il donne de judicieux conseils sur les plantations les plus convenables aux abords des rivières et ruisseaux; sur la manière de motiver, par des exhaussements factices auxquels les plantations donneront, en grandissant, un air de plus en plus grand de vérité (Fig. 222); des courbes brusques, des replis qui, tout en ménageant l'espace, doment au cours de l'eau l'attrait de la surprise. Dans les courbes, les rives doivent en général être plus écartées (Fig. 223, p. I 76).

Kemp, auquel nous empruntons un projet bien conçu de lac artificiel arec 
îlot (Fig. 224), recommande de ne pas encaisser les cours d'eau trop profondément. Cette disposition peut néanmoins avoir son utilité pour l'effet pittoresque, dans certains passages accidentés. Mais, employée d'une façon continue, clle aurait le double inconvénient de trop cacher l'eau et de lui retirer son plus grand charme, la transparence. Aussi, quand on ne peut éviter cet encaissement, il faut dégager les rives par des talus trés ouverts.

La forme des îles, l'escarpement et la composition de leurs bords, doivent se régler d'après lia rapidité plus ou moins grande du courant. En les rapprochant ou les écartant plus ou moins des rives de la piéce d'eau, on peut simuler, suivant les circonstances, tantôt le confluent de deux rivières, tantôt une seule embouchure. Dans l'un et l'autre cals, les promontoires it $l_{a}$

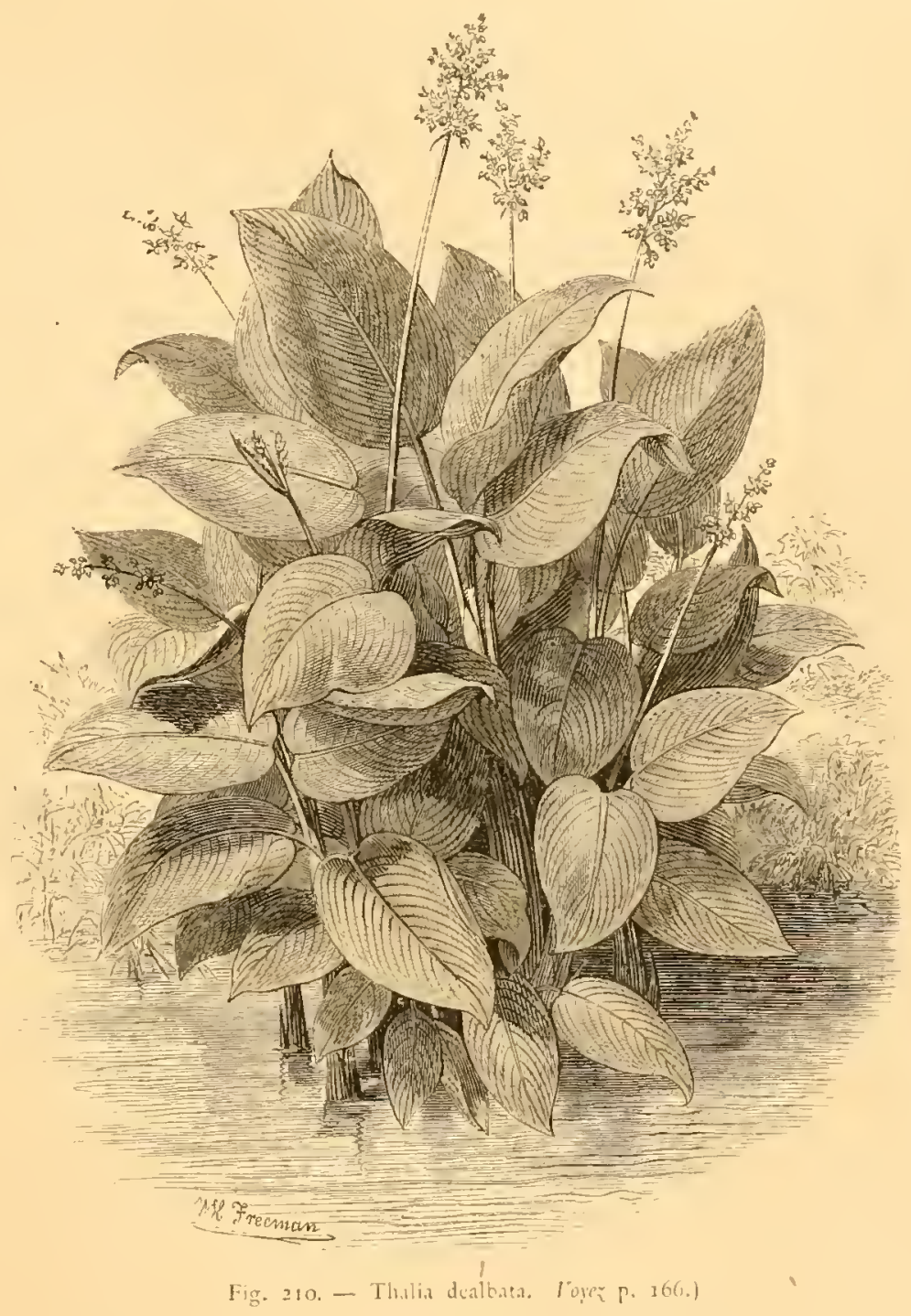
pointe des îles ou à l'extrémité des courbes les plus prononcées, sont un emplacement des plus favorables pour l'installation d'édicules ou de stations de repos. (Fig. 225.) Le prince Pückler-Muskau a donné des indications pratiques fort utiles à ce sujet. 11 conseille notamment de multiplier les plantations, tant de grands arbres, que d'arbustes et de roseaux (Fig. 226, Saccharmm egyplicuse, Firg. 227, Andropogon forimosum) dans les îles, et généralement sur le bord des ruisscaux, des pićces d'eau, car « c'est surtout dans les lignes séches que la nature est difficile à imiter. » 
XX. - Voici encore, sur ce sujet délicat, quelques indications dont on pourra tirer parti.

Quand il est nécessaire d'aroir recours à des chutes, il faut éviter de les faire

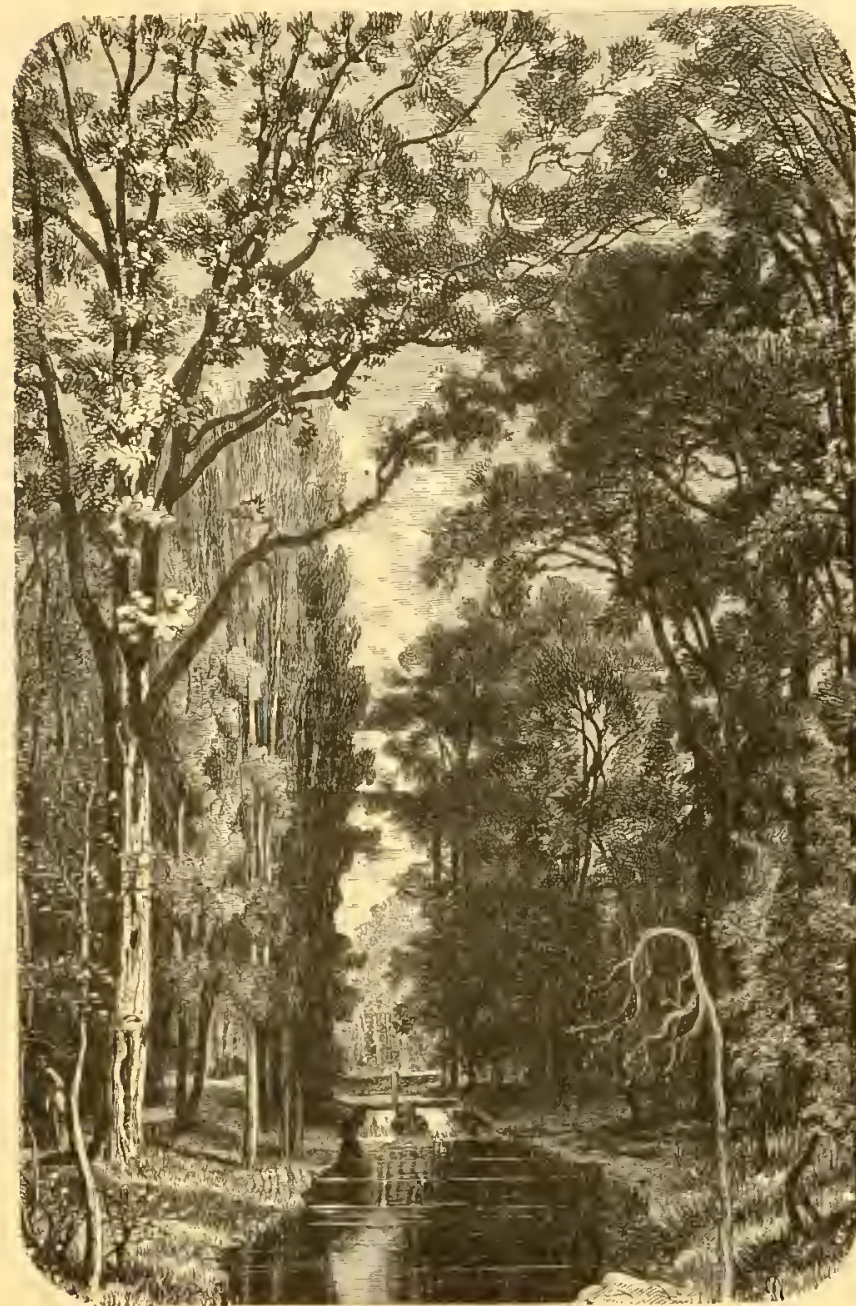

Fig. 2I - Vue de la Riviere de Charenton. (Ioyezp. I66.) trop rapprochées ou équidistantes. Pour rendre moins apparent cet inconvénient, quelquefois difficile á éviter, on dissimule les chutes dans la verdure... Les pièces d'eau, dans des endroits découverts, doivent avoir le plus d'étendue possible. Dans les parties boisées, au contraire, elles peuvent n'avoir qu'une étendue restreintc... Les contours de leurs rives, toujours justifiés par les mouvements du bassin qui les contient, sont d'autant plus agréables que leurs lignes sont d'un dessin plus simple. En général, il faut bien se garder d'établir le niveau des eaux au-dessus des pelouses et des allées voisines. Toutefois, cette règle comporte quelques exceptions. Nous arons obtenu un effet assez original, en faisant passer une allée dans un isthme entre deux piéces d'eau situées í des niveaux très différents, et dont l'une est alimentie par le trop plein de l'autre, que raméne un ruisseau artificiel. Cette allée passe en corniche au-dessus de l'étang de décharge inférieur, et en même temps en contre-bas de la piéce d'eau supérieure, qui paraît comme suspendue au-dessus d'elle avec son cadre de verdure.

Enfin, il importe de disposer les plantations, aux abords d'une pièce d'eau, de telle sorte que le spectateur n'en puisse embrasser d'un coup d'œil toute l'étendue. Au moyen d'iles boisées et de massifs sur les bords, l'on peut toujours donner à 
une nappe d'eau une apparence de grandeur indéterminéc. Ajoutons que la forme donnée au contour des rives peut et doit aider puissamment á l'illusion. Nous en trouvons un exemple remarquable dans la disposition de la pićce d'ealu irrégulière du jardin Flora, à Cologne, l'une des œuvres du célèbre jardinier paysagiste Lenné. (Figure 228) (I).

XXI. - Ponts. - Dans les grands parcs, comme dans les petits, les ponts rustiques sont presque toujours d'un aspect plus agréable que ceux en bois ouvragé et que les ponts métalliques. Si toutefois on préférc ces derniers, à cause de leur solidité, il faut du moins que leurs lignes maigres et anguleuses soient dissimulées par des plantes grimpantes.

Les Promenades de Paris fournissent des spécimens de ponts rustiques, ponceaux, passerelles, etc., etc., entre lesquels on n'a que l'embarras du choix. Nous recommandons spéciale-

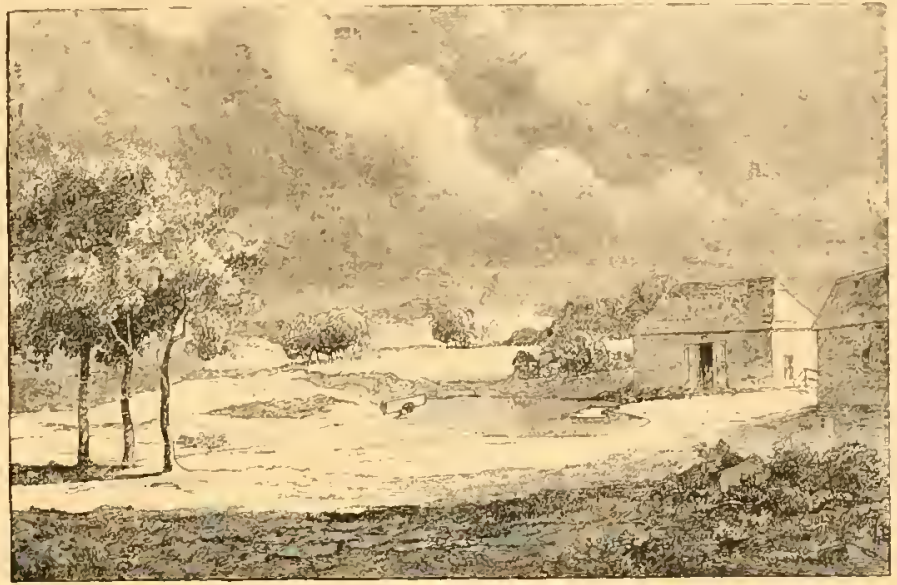

lig. 252. - Vue de Fromliouse avane la Transformation. (fojea p. Ic 7 )

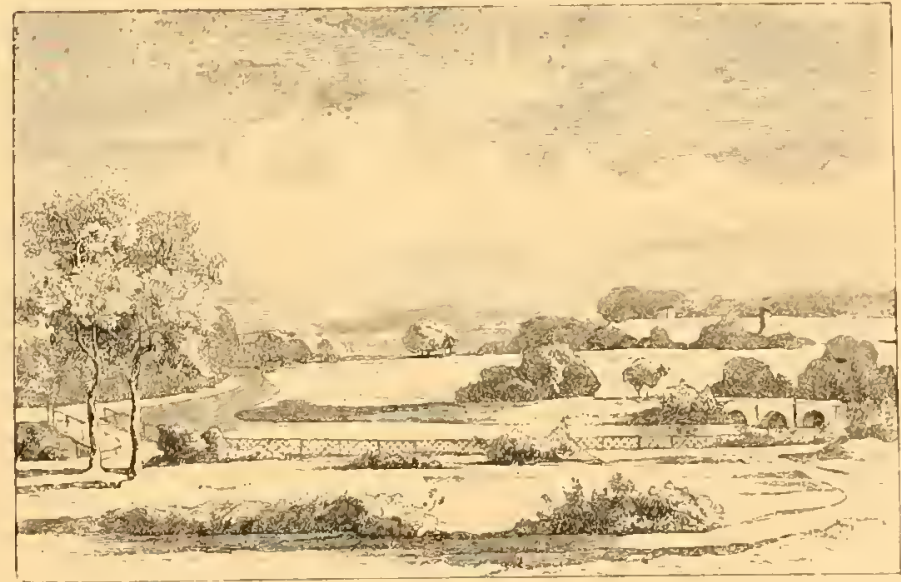

Fig. 213. - Vue de Fromhouse aprés la Transtormation. (Iojcip. 167.)

ment le pont rustique sur le ruisseau de Longchamps (Fig. 229), la passerelle sur le lac de Charenton, qui toutefois ne convient que pour un trés grand parc; le pont rustique sur la riviére de Joinville, et celui du restaurant de la Porte-Jaune (Fig. 231) au bois de Vincennes.

(1) Quelques dessinateurs de jardins recommandent ce qu'ils appellent les cascales pur diricalion, c'est-ì-dire lemploi, sous certe forme décorative, du trop plein des retenues d'eau affectées il des usages industriels ou ì l'arrosement des prairies. Cette combinaison de l'effet utile avec l'effet pittoresque ne saurait ètre bonne, que si hal retenue est asse forte pour que la cascade ne reste jamais completennent í ses. 
Nous y joignons un modéle de ponceau plus modeste qui peut convenir dans une petite propriéte (Fig. 235, p. 183). Nous reproduisons aussi deux types de ponts rustiques assez originaux, empruntes ì l'ouvrage d'Hirschfeld (Figures 233,234, P. I 83 ). Celui on forme d'escalicr pourrait être d'un heureux effet dins un emplacement accidenté, ou l'une des rives scrait fort en contre-bas de l'autre.

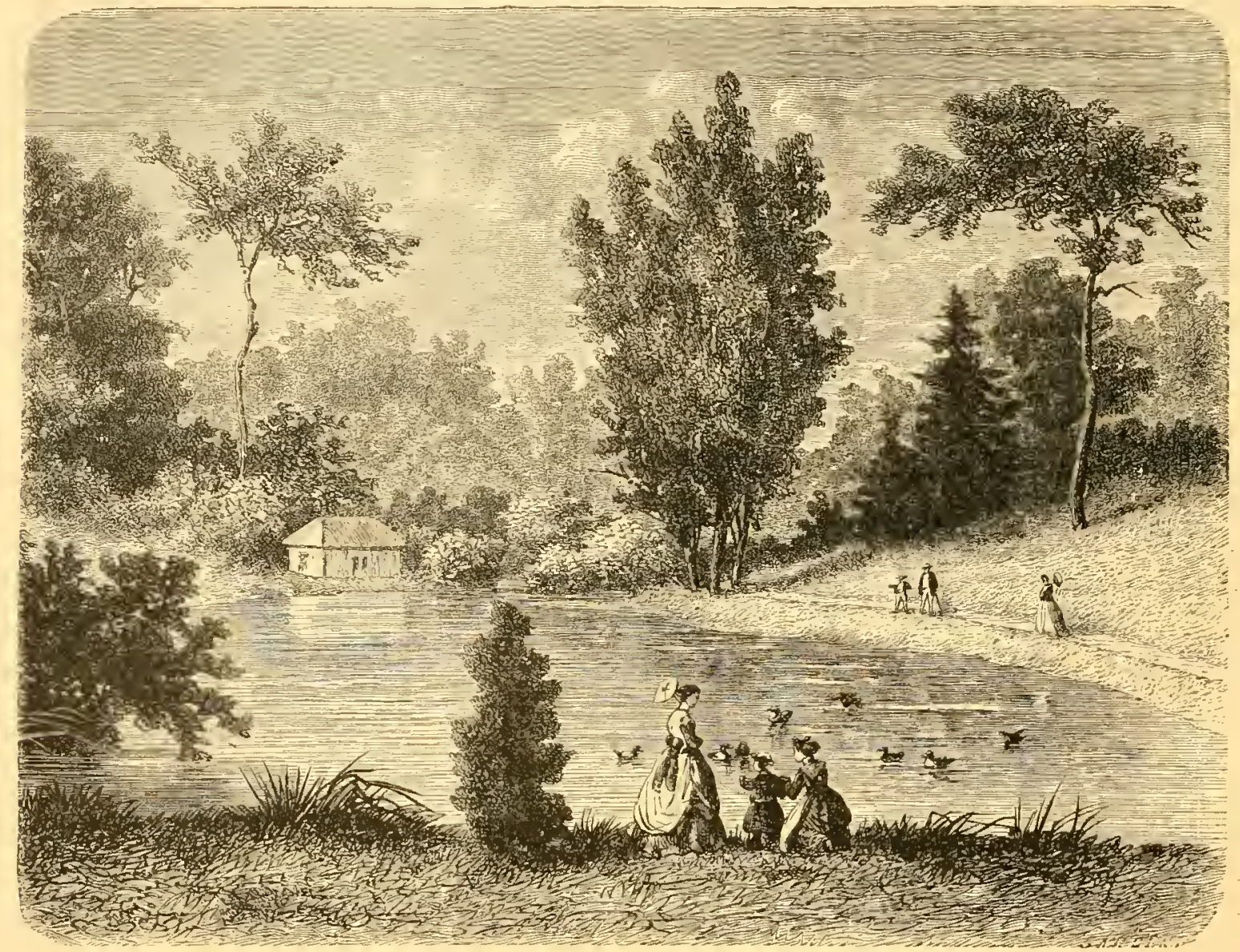

Fig. 214. - Lac du Jardin d'Acclinatation, au Bois de Boulogne. (royez p. 167.)

Nous avons v'u un essai, probablement unique, de poniean regital. Les balustrades étaient faites avee de jeunes plants d'osier recourbés, dont on avait piqué en terre les extrémités qui avaient repris de boutures, tandis que des tiges ainsi ployées cn ares repoussaient des jets verticaux. Cette combinaison neuve et diun effet gracieux, avait été imaginée par Duclos, le dessinateur normand dont nous avons déjà parlé.

Nous figurons également un pont en osier d'un paysage de Java (Fig. 2j2, p. IS2), dont on peut se servir comme modèle. 
Les ponts rustiques en pierre sont d'un usage moins fréquent (Fig. 230, p. I 8 I) que ceux en bois. On peut les employer avee avantage dans les pays où la picre est commune, et surtout aux abords des agrégations de roches ou de rocailles. Certains passages, dits gués, ne demandent ni ponts ni ponceaux; il y suffit de quelques pierres disposies d'une façon commode, mais dont le rapprochement doit toujours paraitre naturel (Figure $2 j 0, \mathrm{P} . \mathrm{I} \mathrm{I}_{\mathrm{I}}$ ).

Disons enfin que tout pont ou ponceau, si modeste qu'il soit, doit être suffisallnnent motizis; cette règle ne comporte pas d'exception. Ainsi, un pont jeté sur une picice d'eau trop exiguë, et dont une extrémité au moins n'est

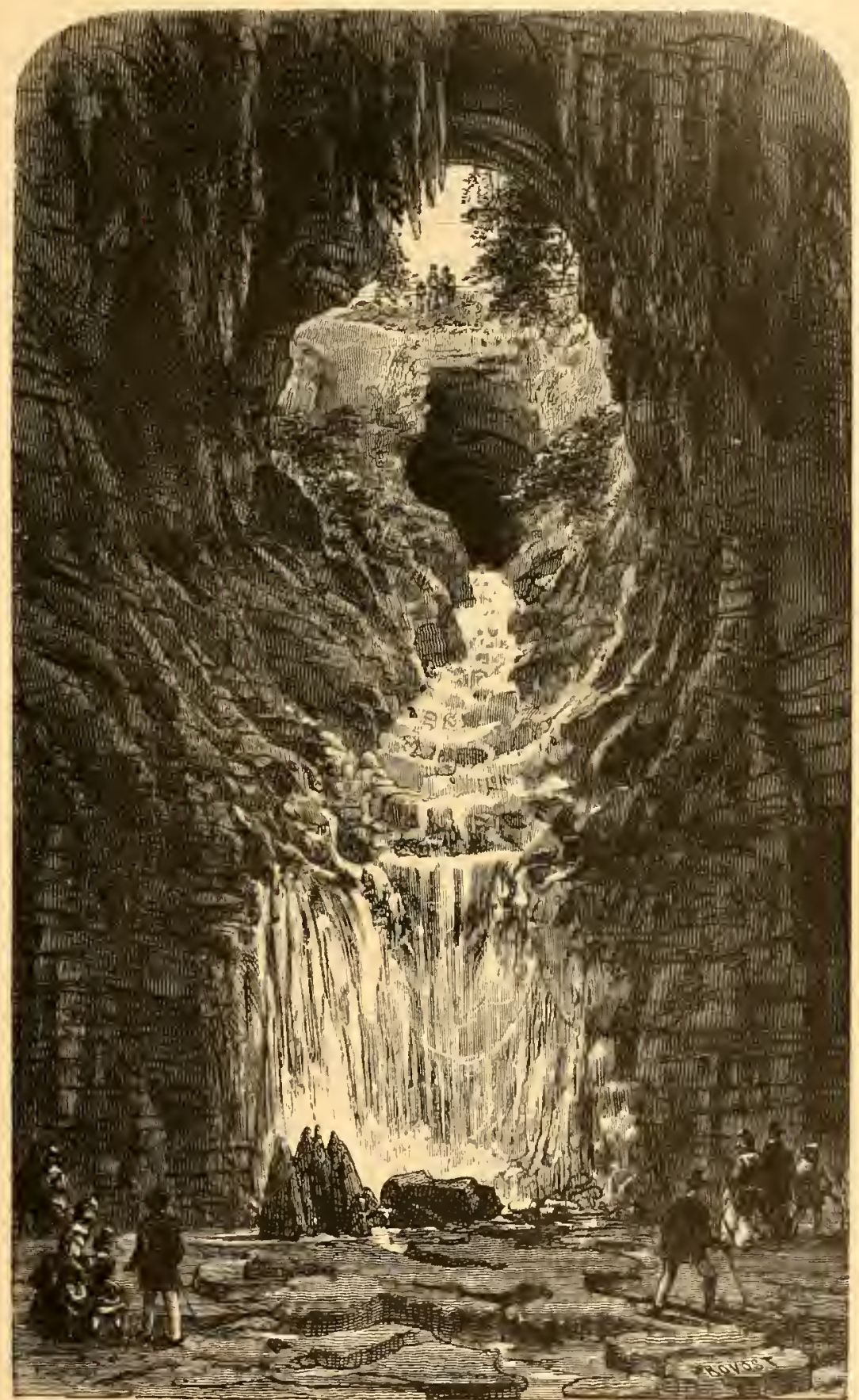

Fig. 21j. - Casiale des Buttes-Chaumont. (Tiyzi p. I6S.) pas dissimule par des plantations, sera toujours d'un effet mesquin, sinon ridicule. Il faut que l'établissement d'un pont soit justifié par la direction de l'allée, par l'importance du cours d'cau ou du ruvin a franchir, ou par celle au moins apparente 


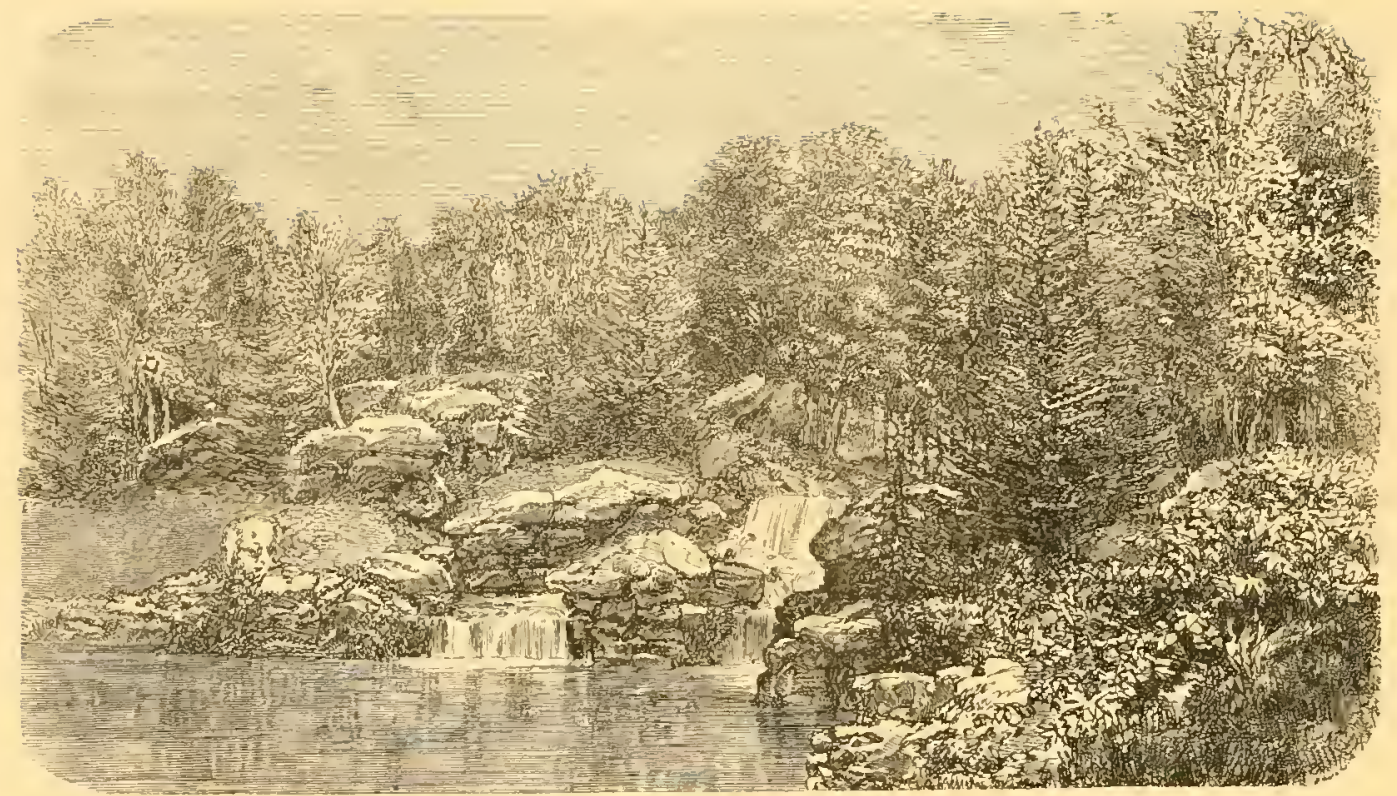

Fig. 216. - Cascade du Lac supérieur, au Bois de Boulogne. (Tojex p. I68.)

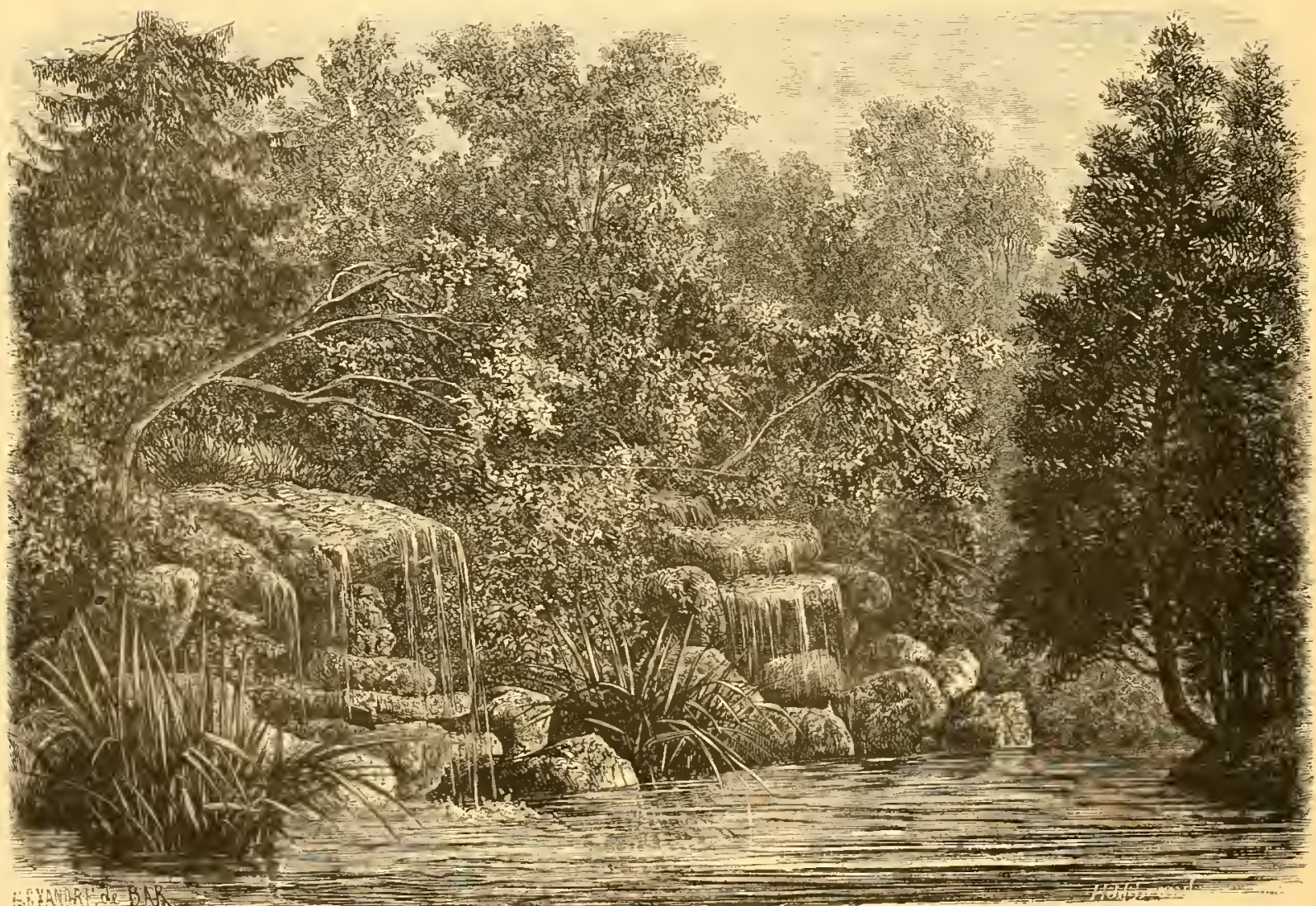

Fy 217. - Cascade du Lac des Mlinimes, au Bois de Vincennes. (Voyez p. 165.) 
de la pièce d'eau. Nous insistons sur ce précepte, parce qu'il est souvent oublié, même par d'habiles dessinateurs. Combien ne voit-on pas de passerelles et même d'ouvrages plus importants, jetés sur des flaques d'eau auxquelles on dirait volontiers, comme Saint-Amant au Tibre, dans sa Rome rilicule:

C'est bien ì rous d'aroir un pont!

\section{XXII. - Fabriques;}

\section{- Temples, Édicules}

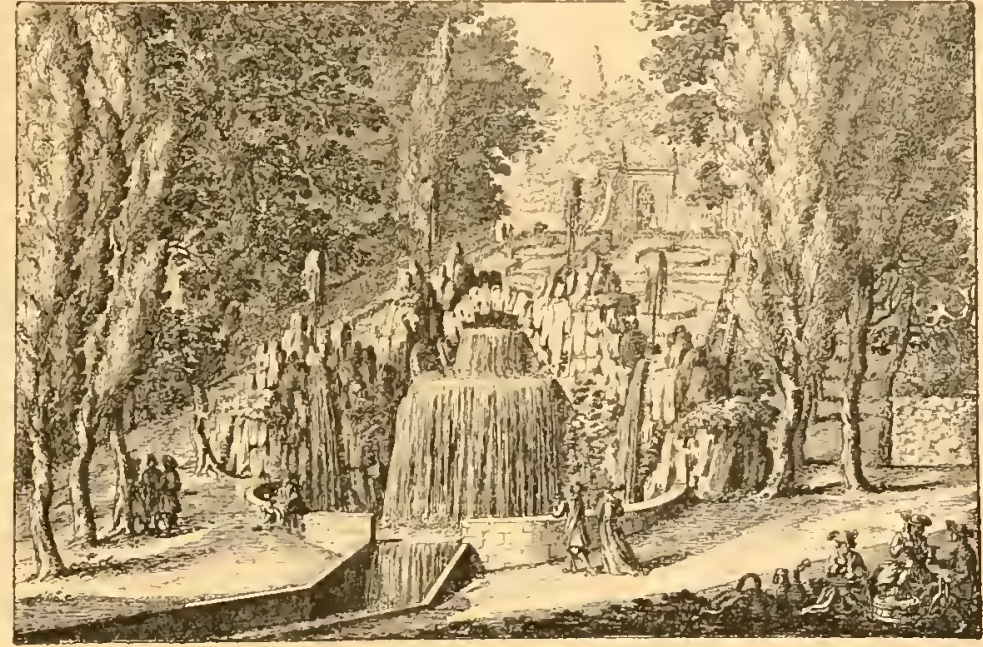

Fig. 218. - Cascade dans la Villa Aldobrandini. (Voyer p. I68.)

mythologiques, allégoriques ou historiques. - C'est surtout dans le choix

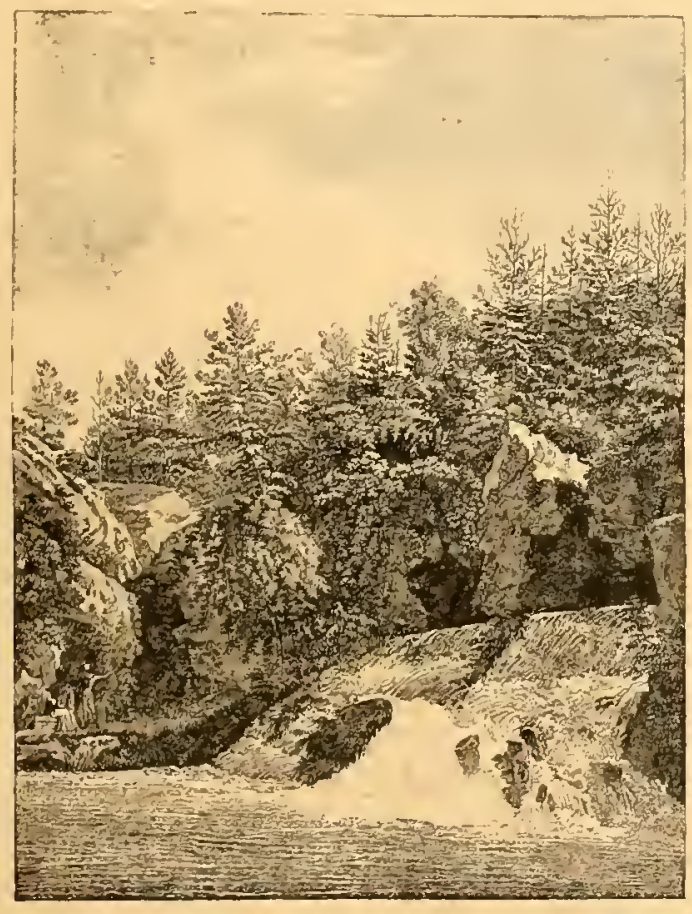

Fig. 219. - Cascade naturelle du Pare de Mérérille. D'aprés de Laborde. (Voyer P. I68.)

et la disposition des ornements de ce genre, que le vrai style paysager, dont nous cherchons à formuler les principes, s'écarte des errements primitifs du genre irrégulier. L'art tend aujourd'hui à réunir, autant que possible, l'agréable à l'utile; il rejette les monuments, ermitages, ruines tactices, les pieces à surprises, les inscriptions, dont on abusait si fort autrefois. “ Les pensées des plus célébres auteurs ne sont mulle part mieux placées que dans leurs ouvrages. »

Cependant ce genre de décoration a encore ses partisans. Il n'y a pas bien des années qu'on a vu s'élever, dans le parc d'un prince germanique, un pavillon crénclé de notes figurant l'air populaire : Freut cucls des Lebens! Non loin de la, on rencontre un banc dédié à l'Amitié, avec un dossier dont les courbures en bois rustique forment les noms d'Oreste et de Pylade. Dans un parc près de Vienne, nous avons 
vu, il n'y a pas longtemps, un édicule en forme de tonneau, dans laquelle e'st assıs

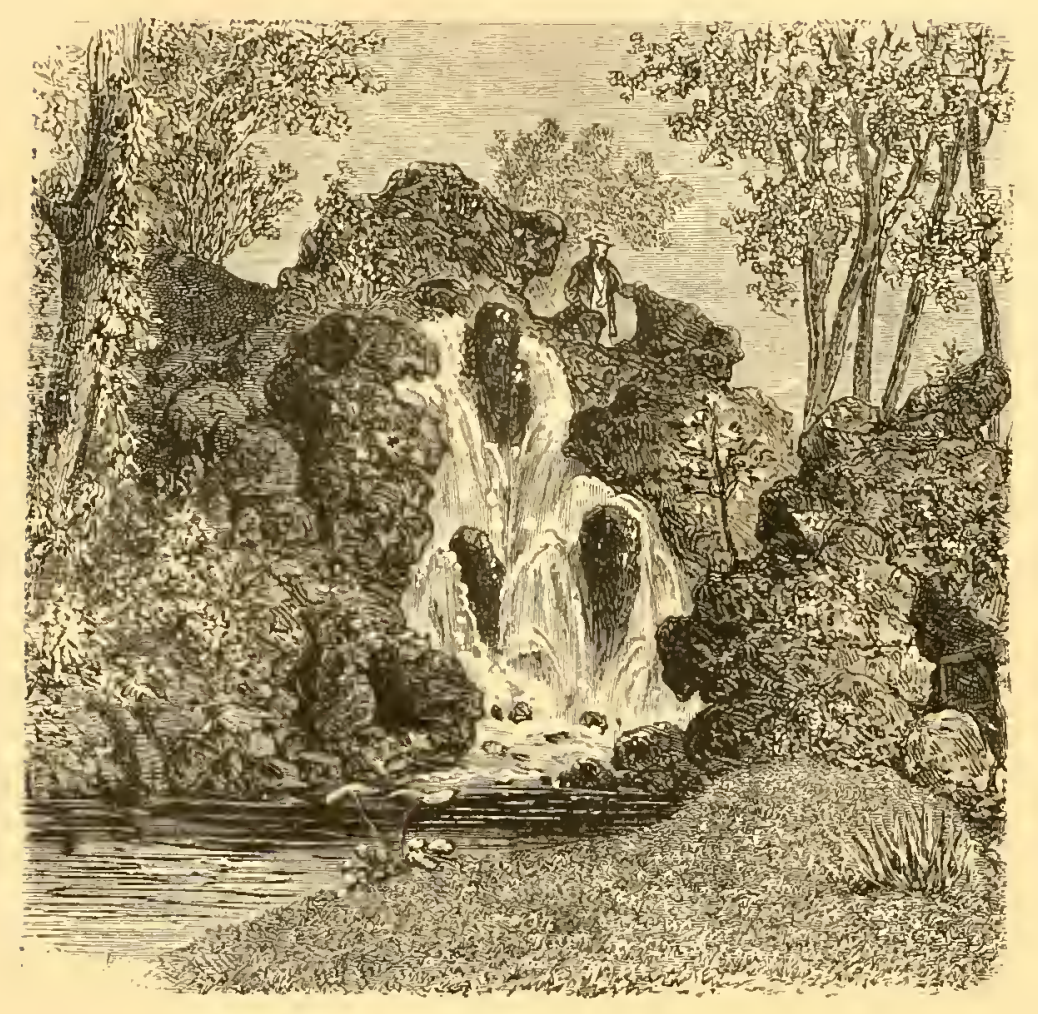

Fig. 220. - Cascade et Lintrèe de l.ı Grotte, au Par Monceaux. (Ioyez p. 268.)

un Diogène tenant sa lanterne allumée. En arrivant sur le seuil, le visiteur marche nécessairement sur un ressort qui fait éteindre la lanterne, comme si le philosophe apercevait enfin l'homme longtemps cherchć. Tous les colifichets, toutes les puérilités cosmopolites des ancicns jardins réguliers et irréguliers se retrouvent accumulés dans un pare moderne italien, admirablement situé, celui de la villa Palavicini (Fig. 237, P. I 84 ), près de Gênes, encombré de monuments et d'üdicules égrptiens (un obélisque sur-

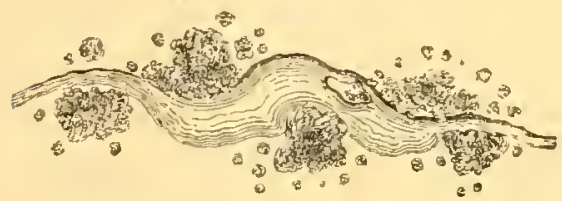

Fig. $221-\left(\right.$ Hillo $16^{\circ}$.

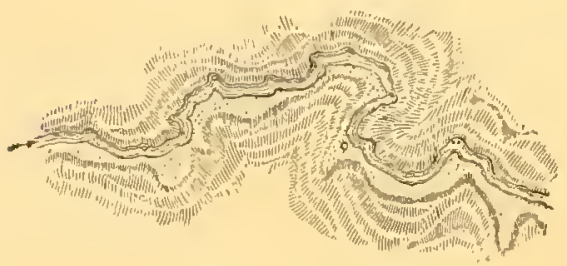

Fig. 222, - (Toyer. p. 168.)

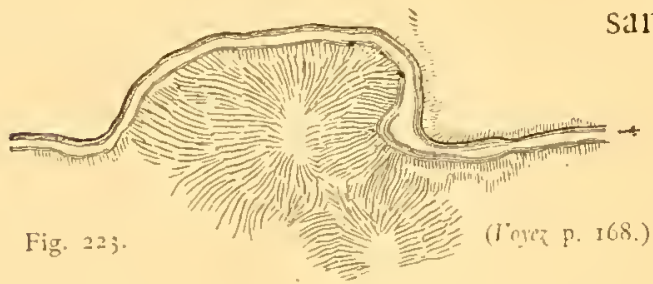
voir dans ces enfantillages, mais certaines réminiscences allégoriques ont encore de nos jours

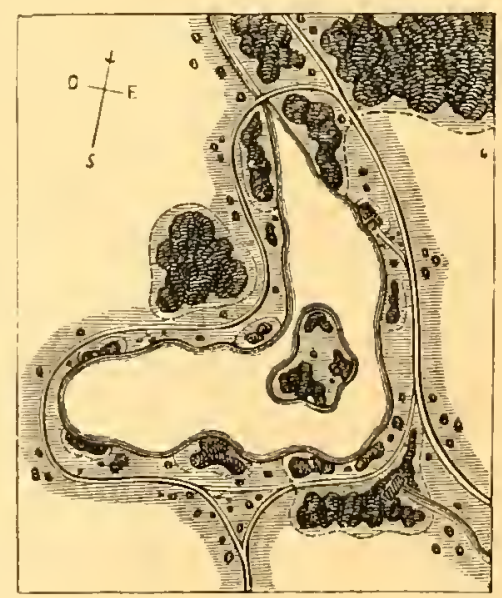

Pig. 224. - (Ioyez p. 169.) gissant brusquement au beau milieu d'un lac), tures, grees, temples païens, chapelle gothique, etc.

On y a même repro. duit, pour l'agrément des touristes qui aiment le frais, quclques-unes des surprises aquatiques des pares de la Renaissance. L'art n'a rien a 
ardeur pendant de longues années, le prince Pückler-Muskau ait élevé dans son célébre parc un temple à la Persicírance. Nous croyons qu'on peut aussi considérer comme bien motivéc une autre construction plus moderne du même genre, le « Temple de la Sibylle », érigé dans le pare des Buttes-Chaumont (Fig. 239), sur un promontoire qui domine cet océan parisien si plein de mystéres. Mais ces édicules symboliques ne doivent être admis dans un jardin paysager (Fig. 23\&), que dans les circonstances, fort rares, oil ils ont le mérite de l'apropos. Nous en dirons autant des évocations de l'Égypte, de la

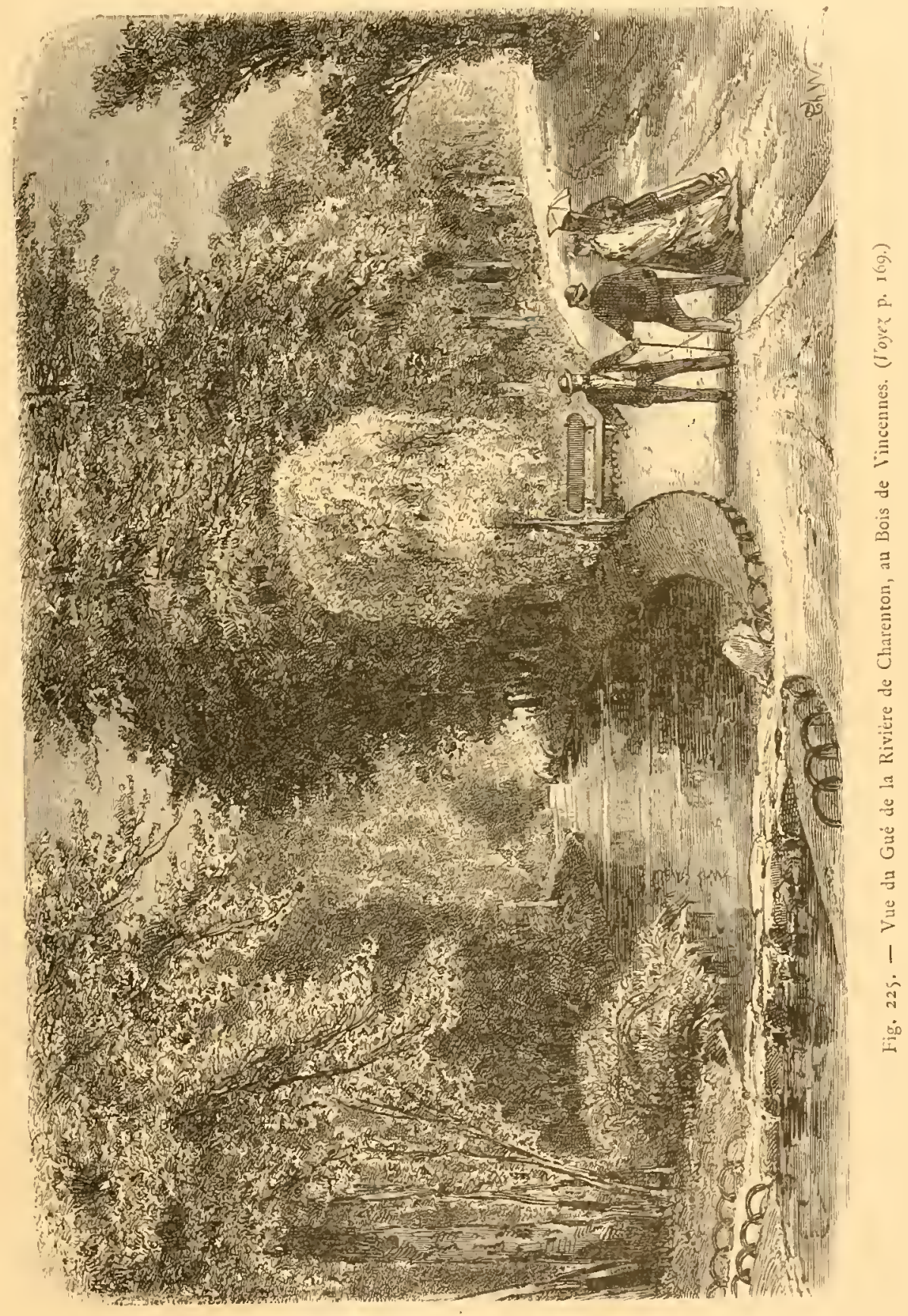

Grèce et de Rome, et des imitations du style chinois. Cette exclusion ne saurait s'étendre avec la même rigueur au rappel de souvenirs lociux, quand la mémoire d'un ancien édifice, d'une ruine, d'un événement mémorable ou d'un personnage. célébre se rattache à l'emplacement ou au proche roisinage du jardin paysager. C'est 
ainsi qu'un des plus beaux ornements du parc de Méréville est la colonne rostrale érigée à la mémoire des deux frères de Laborde, compagnons de Lapeyrouse, héroïques jeunes gens qui se dévouèrent pour sauver leur camarade d'Escures, et

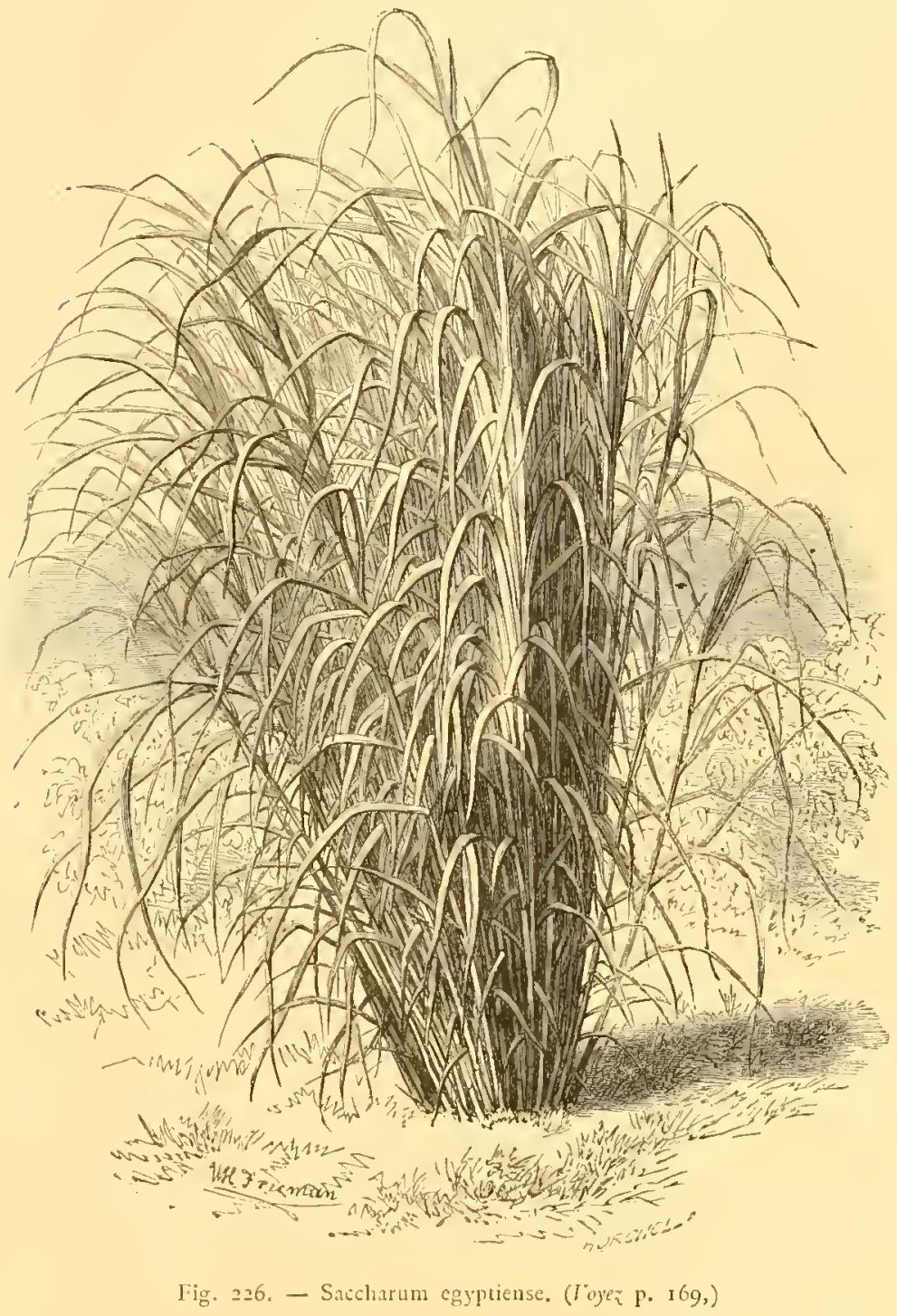
périrent avec lui. Le parc de Rambouillet se recommande surtout par la chaumière (entierrement construite en coquillages) et la laiterie de Marie-Antoinette; par l'île des Roches, où suivant une ancienne tradition, Rabelais serait venu souvent, quand il était de la suite de François Irr; et par le kiosque octogone, bâti au bord de cette île. C'était la place favorite de Nipoléon. "On sait par lui-même, dit Gozlan, que ses plus hardies entreprises furent conçues au murmure des eaux de Rambouillet, et tracées au crayon dans le petit lisosque qui porte son nom. » De même, en dépit de la profusion des sentences anciennes ou modernes, de "l'autel de la Rêverie », de la pyramide dédiée aux poètes, de la pierre moussue, sous laquelle sont censés ensevelis les infortunés tués dans les temps de superstition, du temple de la «nouvelle Philosophie », etc., les restes du pare d'Ermenonville empruntent un. charme réel à l'aspect du donjon authentique de Mont-Épiloy, superbe ruine féodale heureusement dégagée par Morel, .et au souvenir de J.-J. Rousseau, "J'homme de la Nature et de la Vérité (?) ». Plusieurs des plus beaux pares modernes de l'Europe offrent, de même, des souvenirs 
locaux du plus vif intérêt (Fig. 244). A Twiclienham, par exemple, le tombeau véritable de la mére de Pope; et à Sans-Souci, le fameux moulin qui rappelle un des plus beaux traits de la vie du grand Frédéric, font bien plus d'impression que tous les monuments et ruines factices. A Prague, le pare Kinsky, magnifiquement planté, occupe l'emplacement de l'ancienne forteresse, théâtre de plusicurs des scènes les plus émouvantes de l'histoire d'Allemagne, de l'héroïque défense du marechal de BelleIsle. Ces souvenirs ajoutent encore à l'effet que produisent, parmi les massits de verdure, les restes authentiques de cette citadelle. Nous citerons encore dans ce genre, en France, le parc de Radepont (Eure), qui jouit du rare avantage de réunir dans l'espace d'une centaine d'hectares: un ravin d'aspect farouche, ou s'accomplit jadis plus d'un

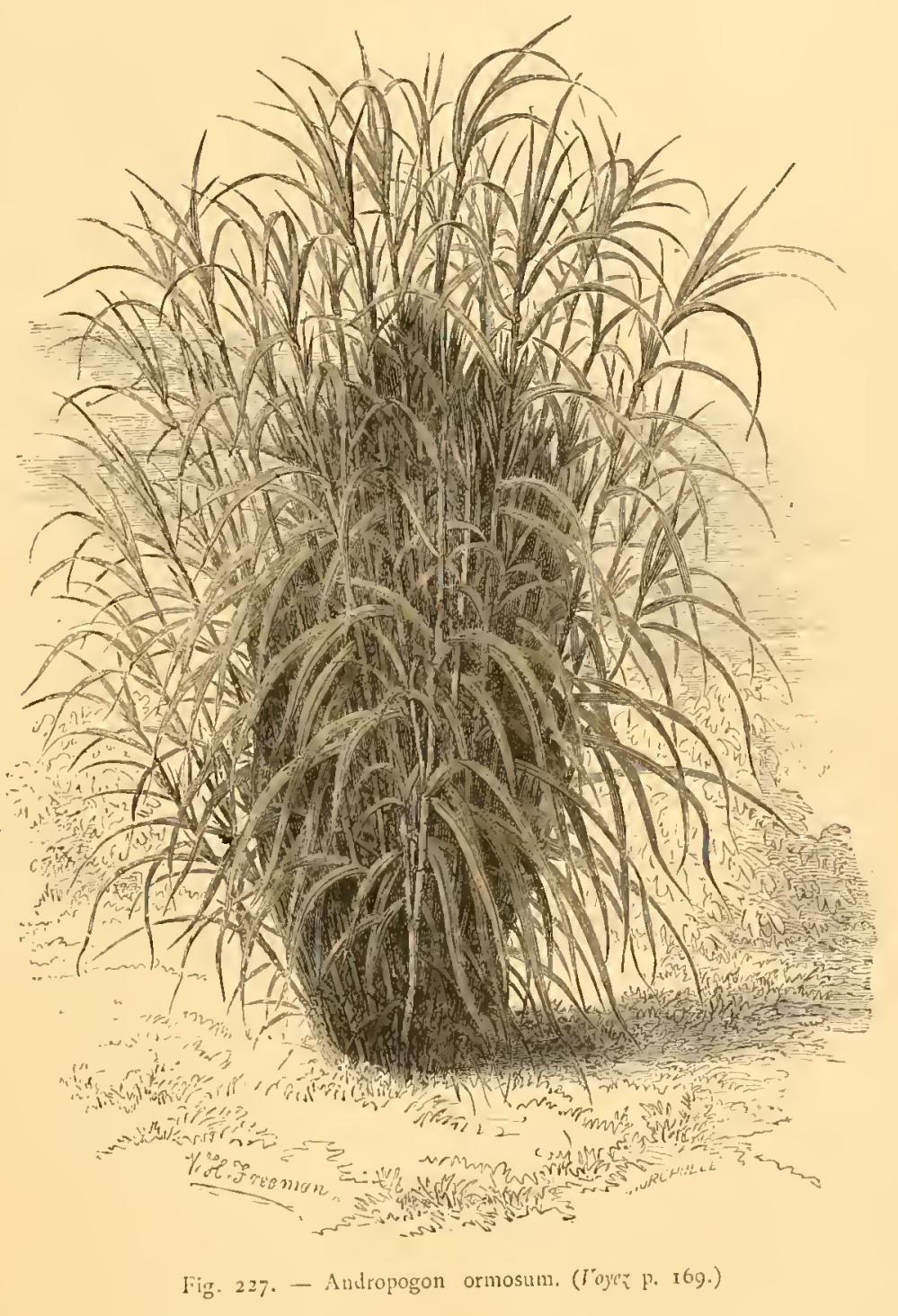

sacrifice humain; les substructions d'un château-fort pris et ruiné par PhilippeAuguste, et de beaux débris gothiques d'une abbaye de temmes dont la fondation remonte au $\mathrm{xI}^{\mathrm{e}}$ siècle. Avec de pareilles ressources, pas n'est besoin de ruines artificielles.

La récente transformation des grandes promenades parisiennes offre aussi plusicurs exemples du respect et de l'évocation des souvenirs historiques; au bois de Boulogne, la Croix-Catelan (Fig. 245); à Vincennes, la pyramide de I 73 I (Fig. 243), etc. XXIII. - Loges d'Entrée, Maisons de Garde, etc. - Toutefois, 
en dehors de ces bonnes fortunes exceptionnelles, les meilleures fabriques dans les jardins paysigers sont celles qui joignent il l'attrait d'une forme gracieuse et pittoresque, le mérite d'une destination utile : belićderes, salles de repos, abris pour les calvaliers, voliéres, embarcadéres, maisons de garde, de jardinier, loges d'entrée, etc.

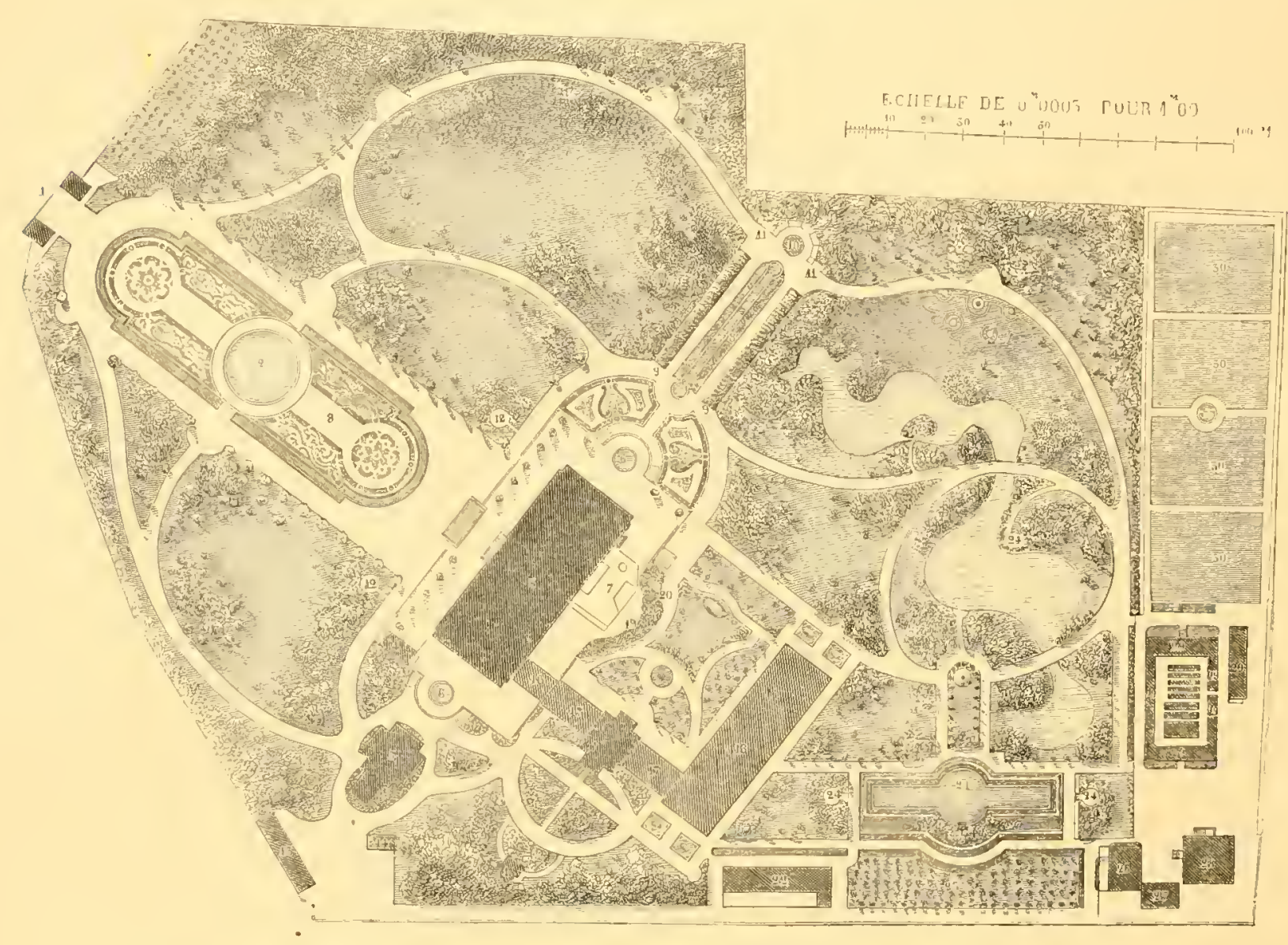

Fig. 228. - Jurdin La Flora, à Cologne, dessiné par Lenné, exécuté et modifié par J. Niepraschk ell 1863. (I0yez p. 171.)

x. Entrèe principale. - 2. Jet d'eau, - 3. Jardin d'hiver, - 4. Kiosque à musique. - 3. Machine il vapeur, - 6. Bassin, - 7, Aquariun d'eau douce et de mer. - 8. Cascades. - 9 Caseades. - 10. Temple de Lysierate. - 11. Viranda. - 12. Tente. - 13. Dependances. - 14. Mtagasin de charbon, - 15. Water-slose $15,-16$. Galerie de communieation, - 1\%. Sertes, - 18 . Orangerie, - 19. Roche, - 20. Entrèe de l'aquariam en ité, - 21, Bassin de Neptune, - 22. Serre chaude, - 23. Culture de Coniféres, - 24. Gloriette, - 23. Kiosque, - 26. Habitation du Directeur. - 27. Habitation du Jardinier. - 28. Ėcole d'Horticulture, - 29. Serres. - jo. Jardin fruitier.

Dans une propriété un peu étendue, l'un des buts de promenade les plus agréables quion puisse créer, sera toujours une loge d'entrie en forme d'habitation rustique avec une petite piéce d'eau soigneusement entretenue; un potager et un verger touchant immédiatement à la campagne, et d'une dimension assez restreinte pour qu'on comprenne de suite qu'ils sont à l'usige d'une seule famille. Plus l'aspect de cette maisonnette scra champêtre, plus heureusement il contrastera avec l'élégance croissante de la décoration végétale jusqu'aux abords de la grande habitation, " tout 


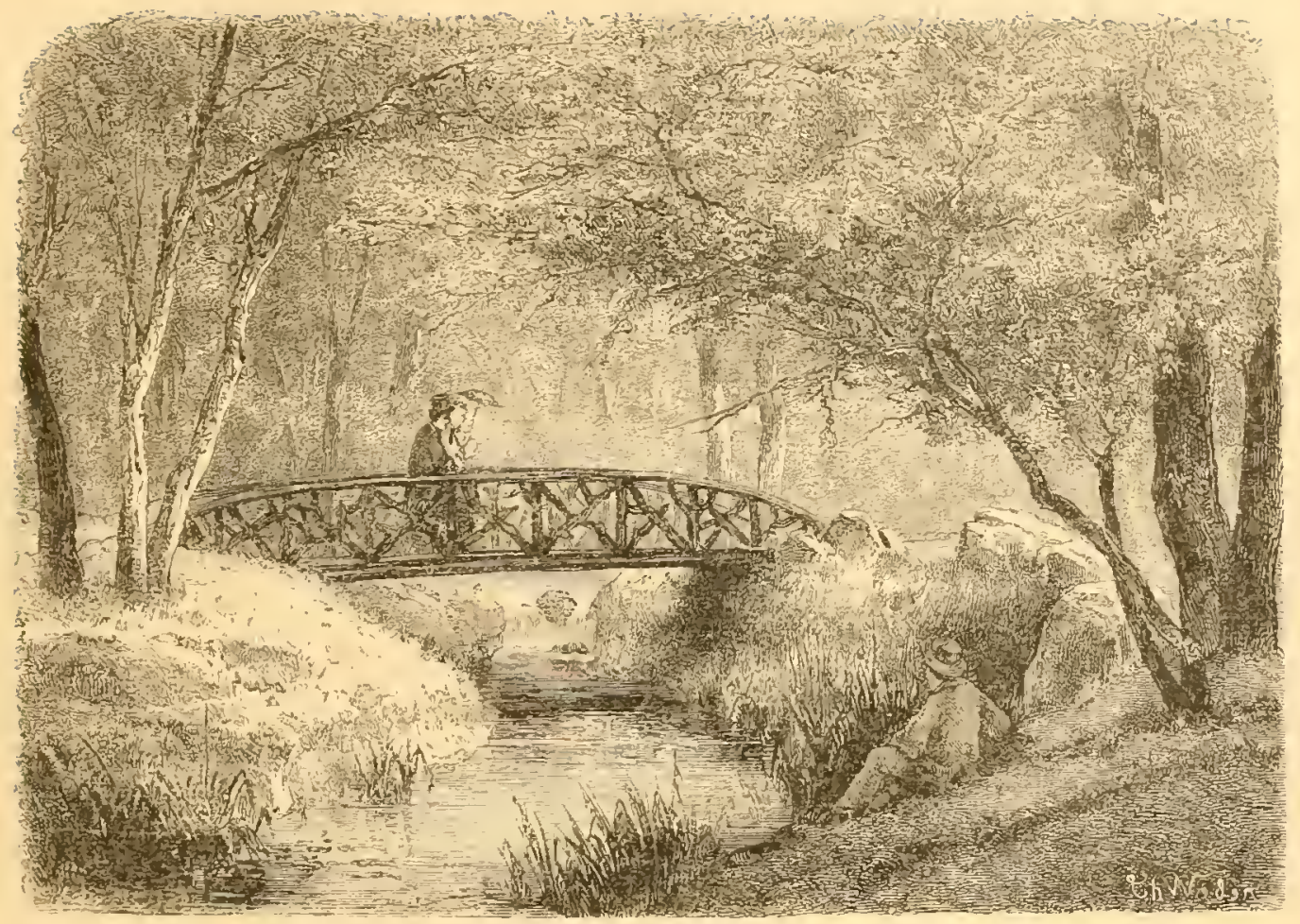

Fig. 229. - Pont rustique sur le Ruisseau de Longchamps, au Bo:s de Boulogne. (Voyce p. i7r.)

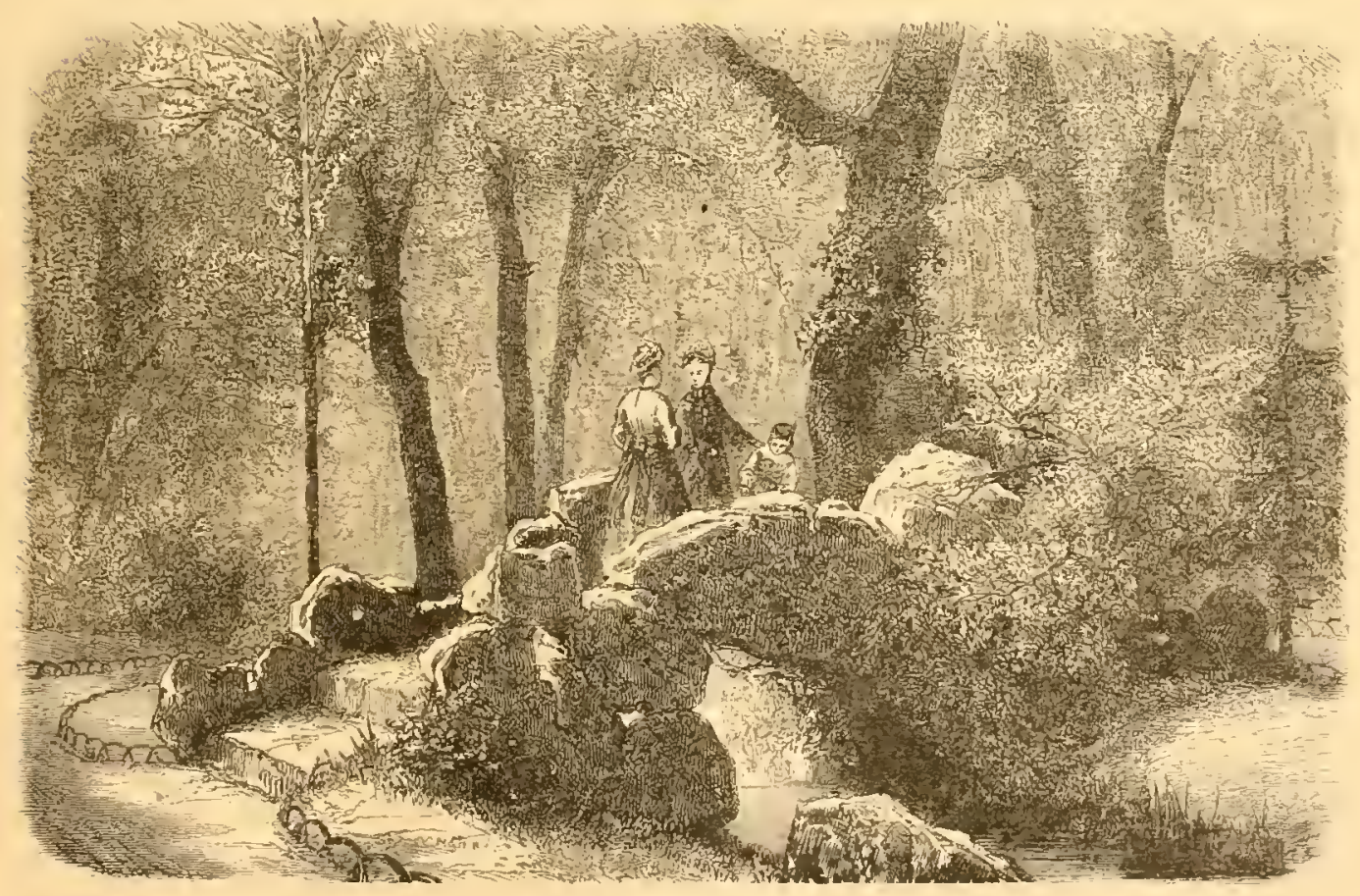

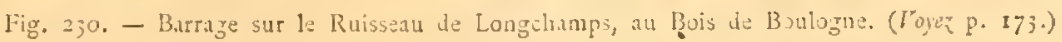


en projetant à une grande distance l'idie de cette habitation. » C'est à Whately que revient le mérite de cette remarque, dont nous avons plus d'une fois constaté la

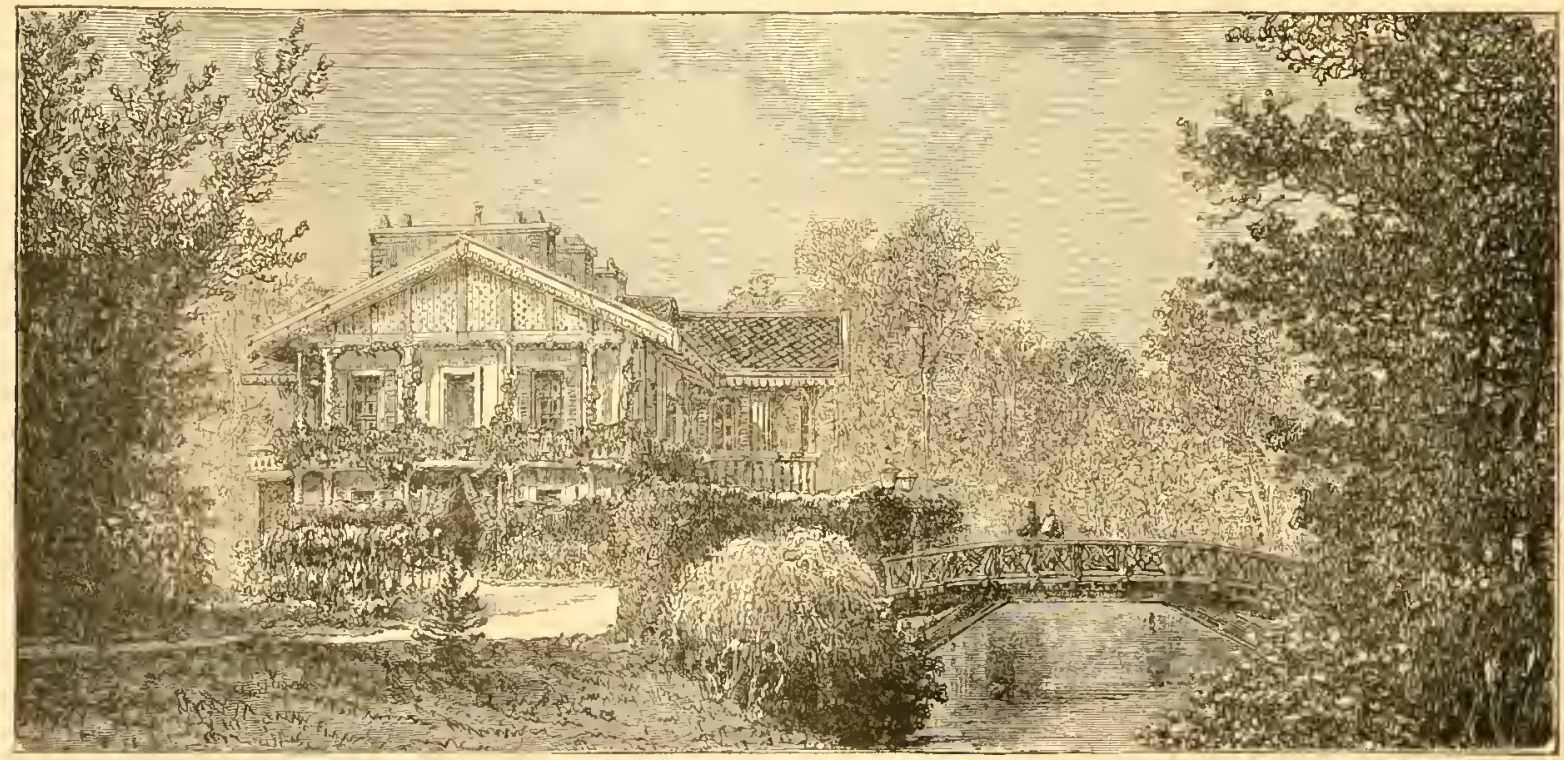

Fig. 23I. - Pont du Restaurant de L. Porte jaune, au Bois de Vincenues. (Tover p. I7r.

justesse. Par contre, on doit proscrire absolument ces constructions bâtardes improprement nommées chalets, amalgame choquant des styles les plus opposés, moitié helvétiques, par tié gothiques. édifices hybrides dès le temps des irréguliers (I), sement persisté qu'à nos jours. rions trop engateurs et les protenir de telles

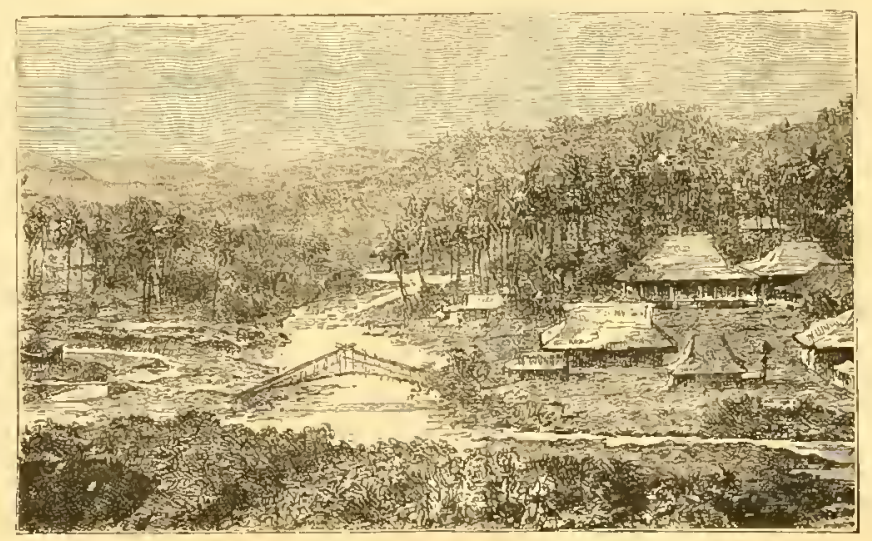

Fig. 232, - Pont dans un Paysage de Java. (Toye p. r72.) excmple, et moiL'usage de ces avait conmencé premiers jardins et a malheureusans cesse jusNous ne sauger les dessinapriétaires às'absaberrations, et nous mettons sous leurs yeux plusicurs modéles de loges, d'abris, stations de repos, ctc., d'un goût plus pur, parmi lesquels ils n'auront que l'embarras du choix.

(1) Voir, par exemple, dans la collection Le Rouge, le clalet d'entrée de Bagatelle, avec son toit en saillie à la façon des chalets du Jura, surplombant une terrasse gothique! Nous avons eu le regret de trouver, dans certains ouvrages très modernes, de ces constructions hybrides, proposées comme modules. Les deux maisons de garde du Bois de Boulogne et des Buttes que nous reproduisons ici, sont gothiques; mais l'unité de style y a été scrupuleusement observée. 
Le style et l'importance de ces loges doivent être en harmonic non seulement avec l'habitation principale, mais avec les alentours immédiats de la loge. La forme de la grille, celle de l'entrée, doivent aussi être prises en considération. Ces constructions doivent généralement être

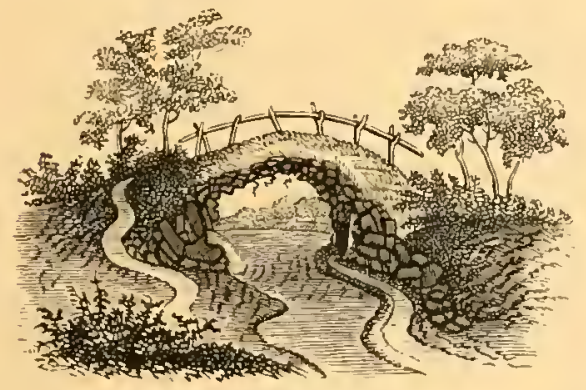

Fig. 233. (Voyer P. I72.)

simples, garnies de plantes grim-

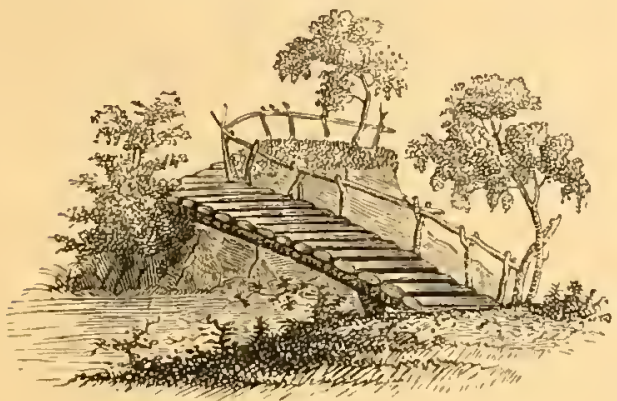

Fig. 234 . (Voyei p. 172.)

pantes. Voici d'abord deux spé-

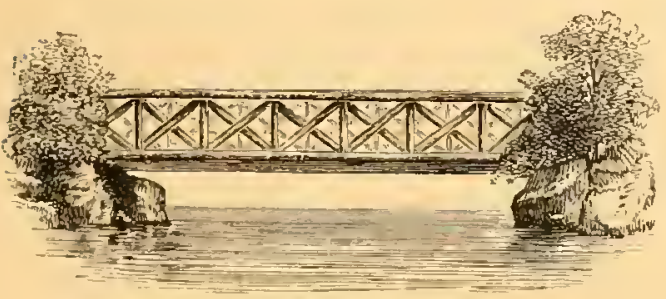

Fig. 235. (Toyci p. I/2.)

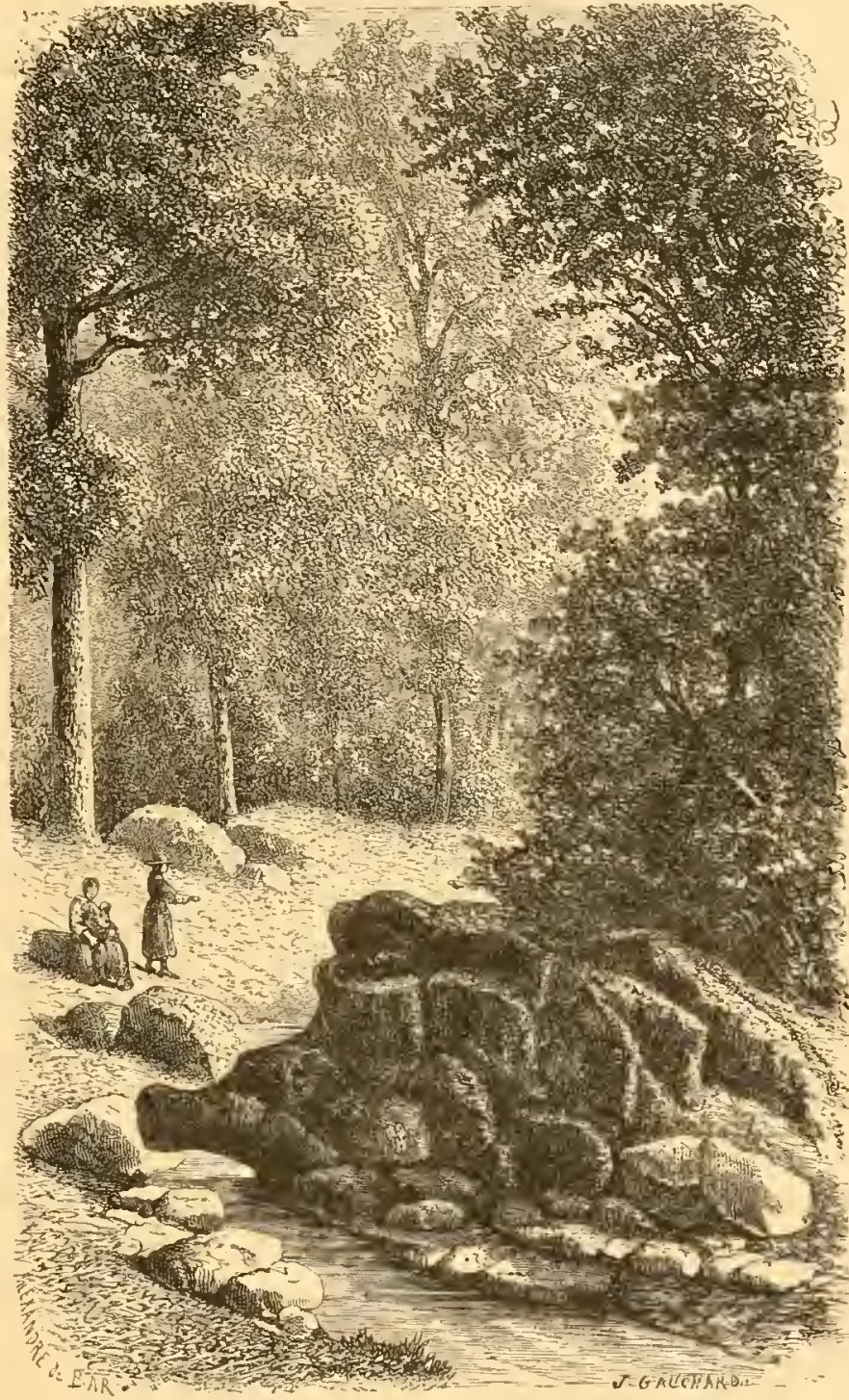

Fig. 236. - Rapide du petit Ravin de Saint-Mandé. (Ioyez p. I73.)

cimens empruntés à Kemp. Le premier (Fig. 2fI) convient pour une propricté de moyenne étendue; l'autre (Fig. 242) se rapporte évidemment à un domaine plus considérable.

Nous indiquons ensuite les maisons de garde et pavillons du bois de Boulogne (Fig. 246, p. I 89), l'Exèdre à la pointe nord de l'île du grand lac (Fig. 248), le modéle d'abris (Fig. 249); les maisons de garde du pare des Buttes-Chau- 


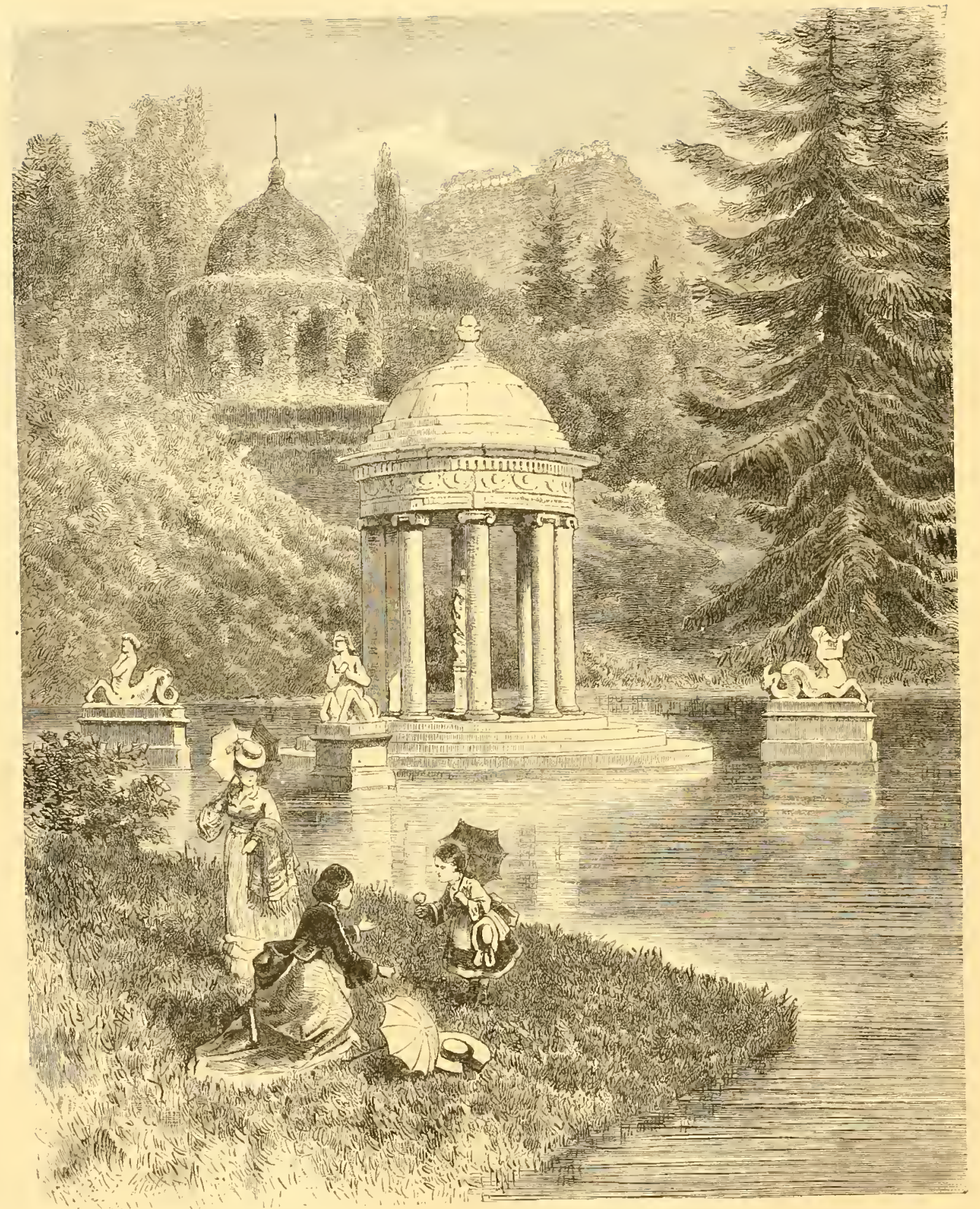

Fig. 237. - Temples du Parc de la Villa Tallavicini, pris de Génes. (Iovir p. 1;6.) 
mont, dans la décoration desquelles on a tait un essai d'emploi de la faïence, inité du châtean de Madrid et de quelques autres constructions du rve siècle (Fig. 2f6). Sans doute on ne doit pas s'en tenir, pour l'ornementation d'un grand parc (mênxe irrégulier), à l'emploi des arbres et des fleurs. Les ourres de l'architecture et de la sculpture sont charmantes dans un paysage, lorsqu'clles sont bien cmployées et qu'elles ont une destination sérieuse. Que tous ces édicules soient done décoratifs, mais justifiés par une certaine nécessité; que les ponts soient proportionnés à l'importance des cours d'eau; que les salles de repos soient aménagées et visiblement construites pour l'usage auquel on les destine; qu'on ne leur donne. pas, par exemple, un faux air de temple an-

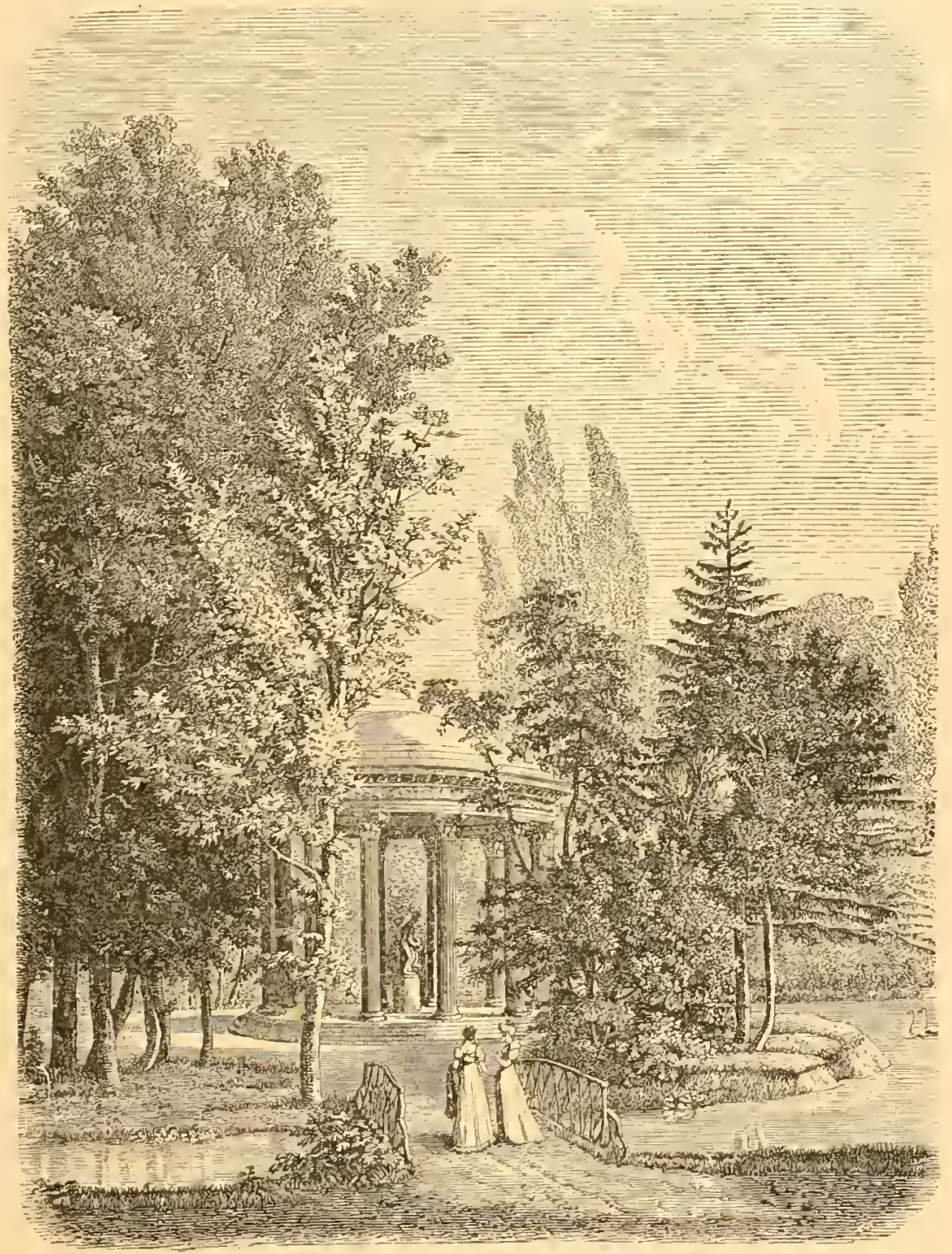

Fig. 238. - Temple de Vénus, à Trianon. (D'après la Calcographie du Louvre. (I. p. J77.) tique; qu'un banc soit un banc, et non un rocher, un fragment de colonne, et ainsi du reste. - Ces petites constructions ne doirent pas être placées trop en évidence, mais se montrer discrètement, et ne se laisser voir tout à fait que d'un ou deux points de vue (I).

XXIV. - Rocailles. - Même dans un parc d'étendue médiocre, il serait

(1) Un lavoir rustique, bien encadré de verdure, est un des ornements les plus aaturels et gracieux d'une pièę d'eau. 
regrettable de se priver des plantes dites rocuillc; notamment des plantes alpines et

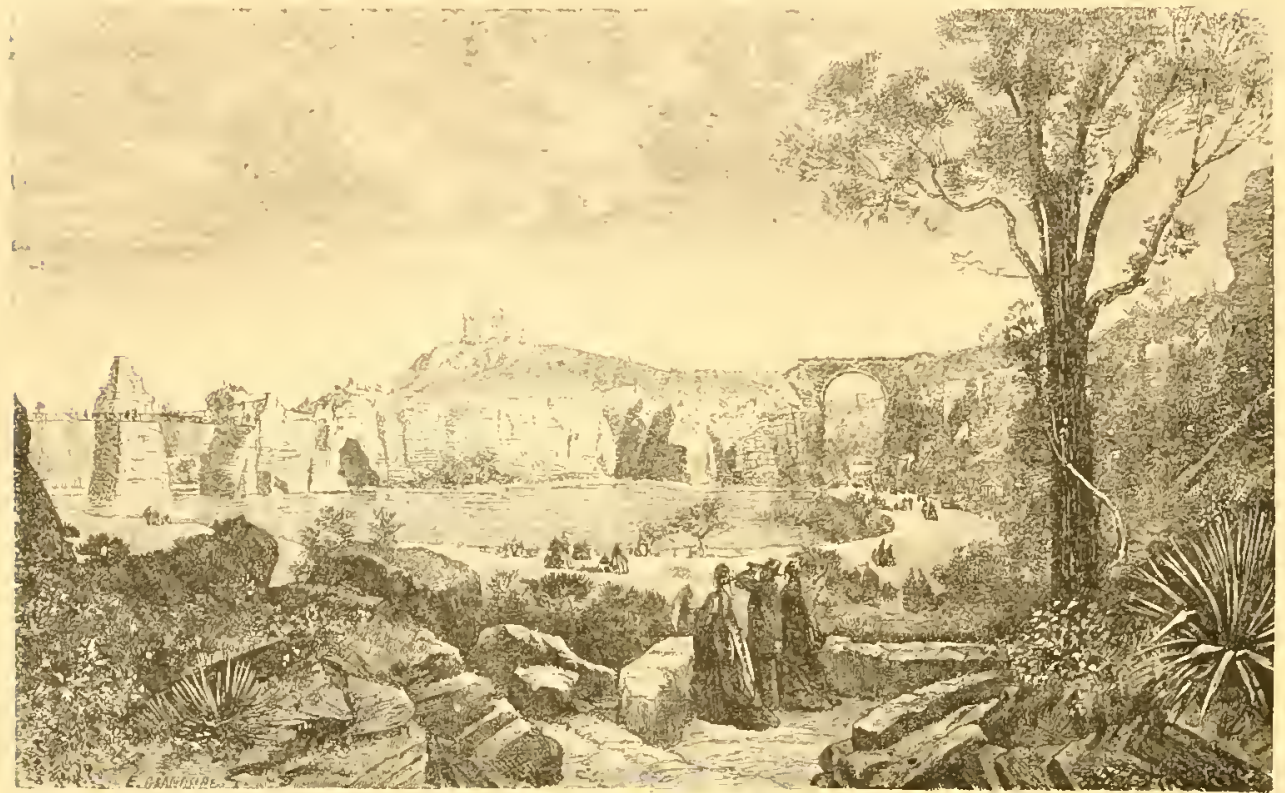

Fig. 239. - Temple des Buttes-Chumont. (Tojez p. I\%, des fougères.

Nous empruntons à l'ouvrage de M.Verlotsur les plantes alpines les conseils judicieux qu'il donne pour leur emploi dans les rocailles, et générale-

ment dans les jardins paysigers. "Plus on séloigne des lieux où croissent spontanément les plantes exigences de culet partant plus leur difficile. Aussi n'y especes essenticlqu'un très petit être cultivées en les jardins situés très éloignée de turelles. Si, en lons établir le bisont répandues nous ne trouvedehors des rustiet Scduml et de

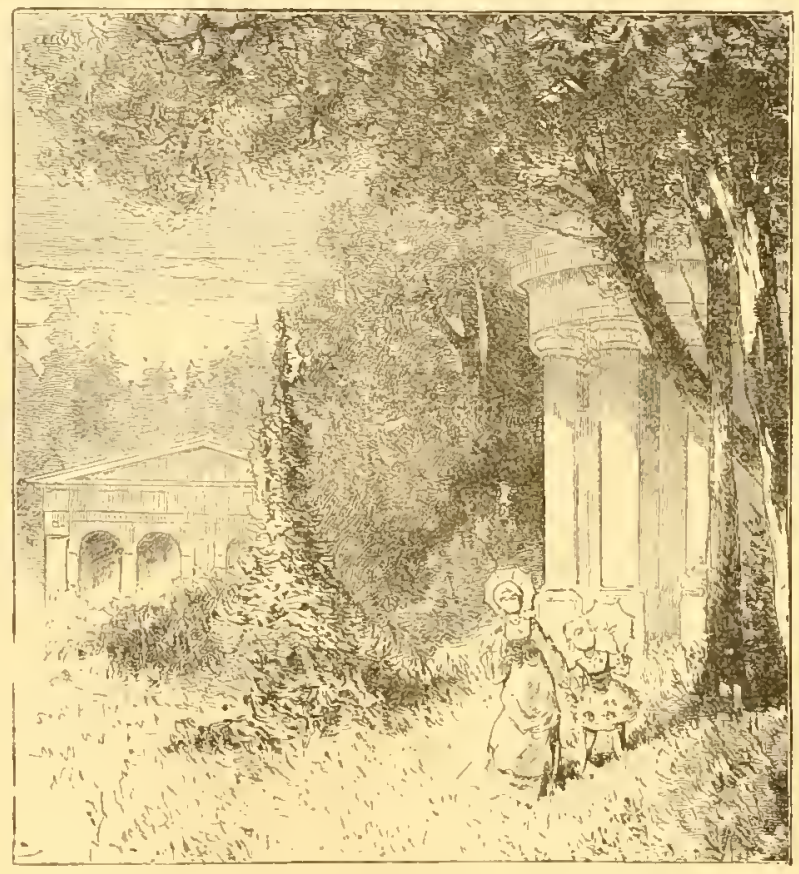

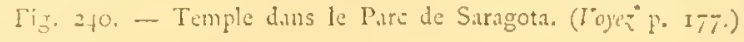
alpines, plus les ture augmentent, emploi est rendu a-t-il, parmi les lement alpines, nombre pouvint pleine terre dans a une distance leurs stations naeffet, nous voulan de celles qui dans nos parterres, rons à citer, en ques Scmperviznm quelques Saxifrages à feuilles cartilagineuses, que quatre espéces : les Gentiuna acanlis, Aralis alpina, Valeriana montana et Myosolis alpeshris, employées it la formation de belles et durables 
bordures; et encore arons-nous vu que la premiere avait besoin, pour produire tout son effet, d'habiter un lieu quelque peu éloigné des grands contres, et que lí seulement elle pouvait montrer en nombre ses admirables fleurs. Cependant, si on modifie un peu la nature du sol naturel du jardin et qu'on

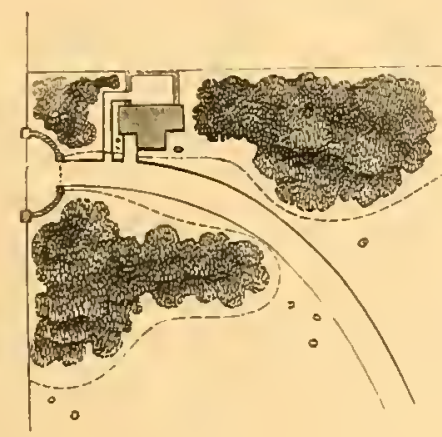

Fig. 2q. (Toyei p. r8r.)

lui substitue une terre légère, fraîche et plus perméable, on

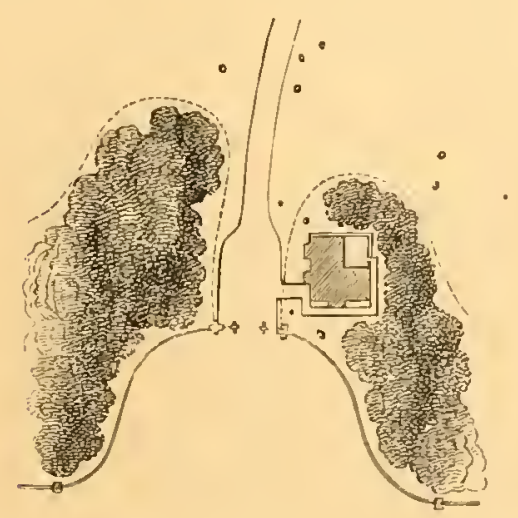

Fig. 242. (I0iciz P. IS3.)

aura un petit nombre d'especes á ajouter aux précédentes. Nous les trouverons surtout dans le genre Saxifraga, ce seront les: S. Iyphoides, geranioides, furcata, Geum, birsuta et umbrosa, etc. Si enfin à un terrain plus léger et plus poreux, nais un peu élevé au-dessus du niveau du sol, s'ajoute une exposition demi-ombragéc, ce nombre s'accroîtra encore, et nous verrons, sur les talus ou les glacis qui présenteront ces conditions, prospérer un nombre plus grand d'espéces empruntées aux altitudes 


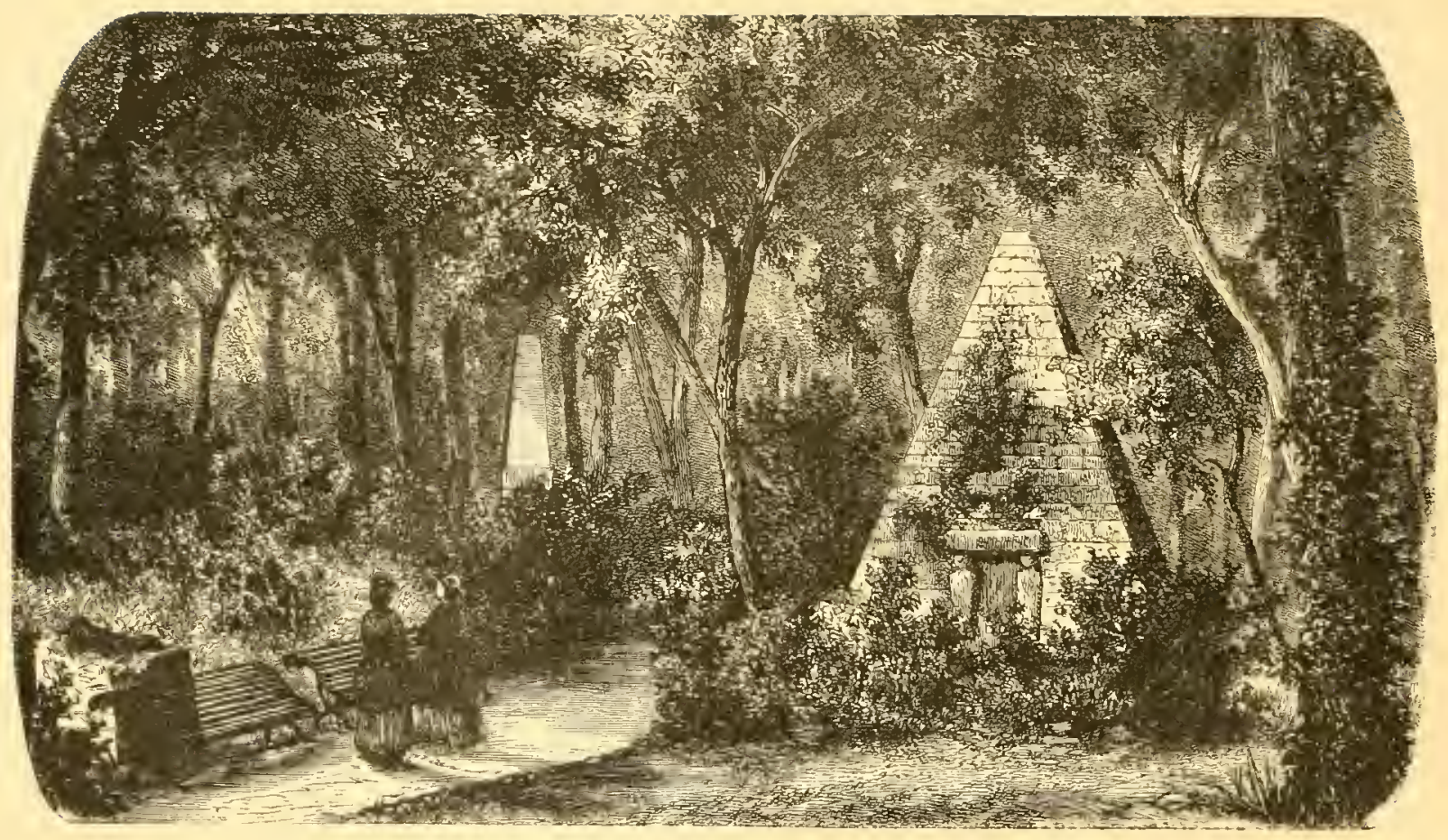

Fig, 24, - Pyramide et Obélisque du Parc Monceau. (T'over p. r79.)

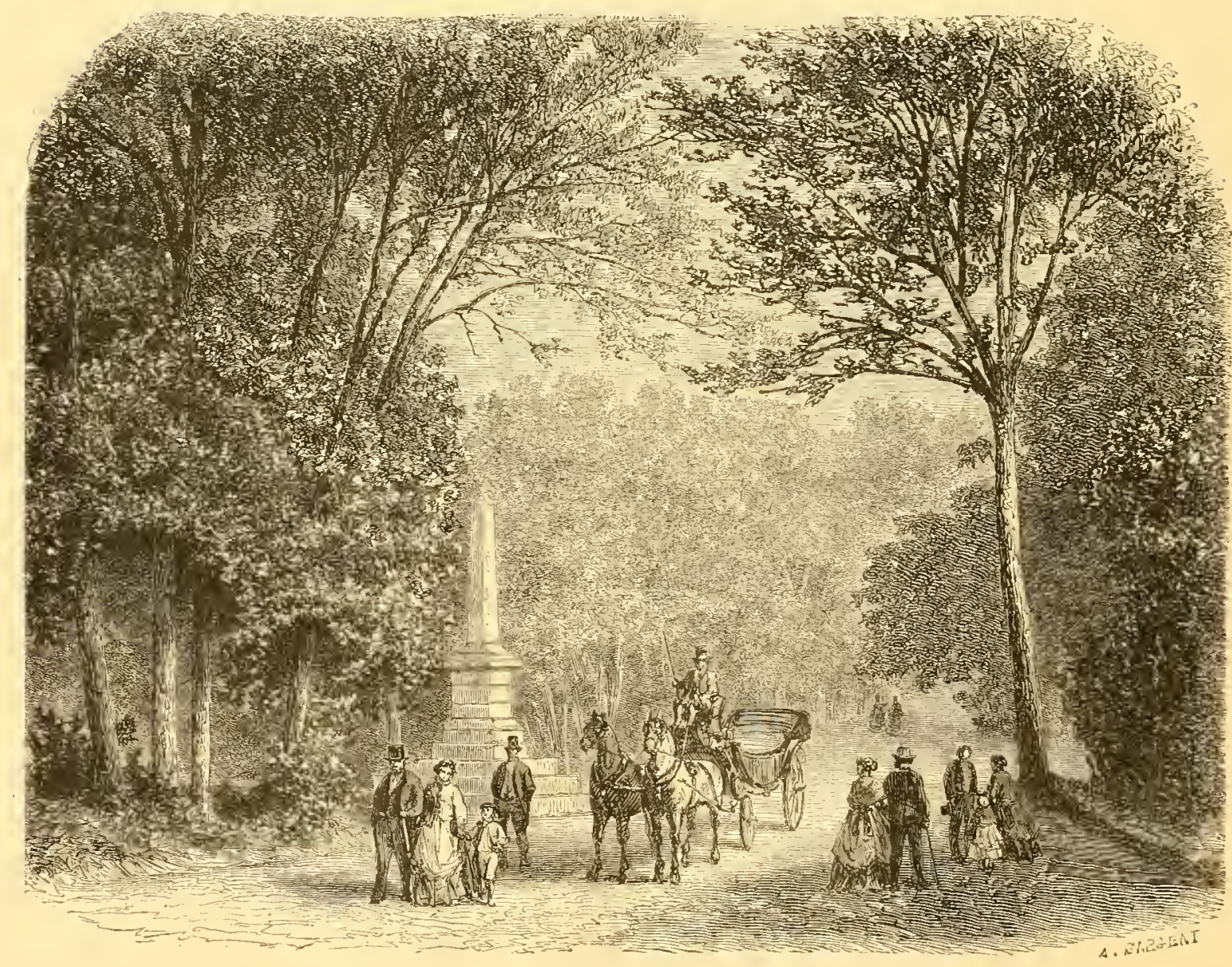

Fig. 245. - La Croix Catelan, an Bois de Boulogne. (Toyez p. 179.) 


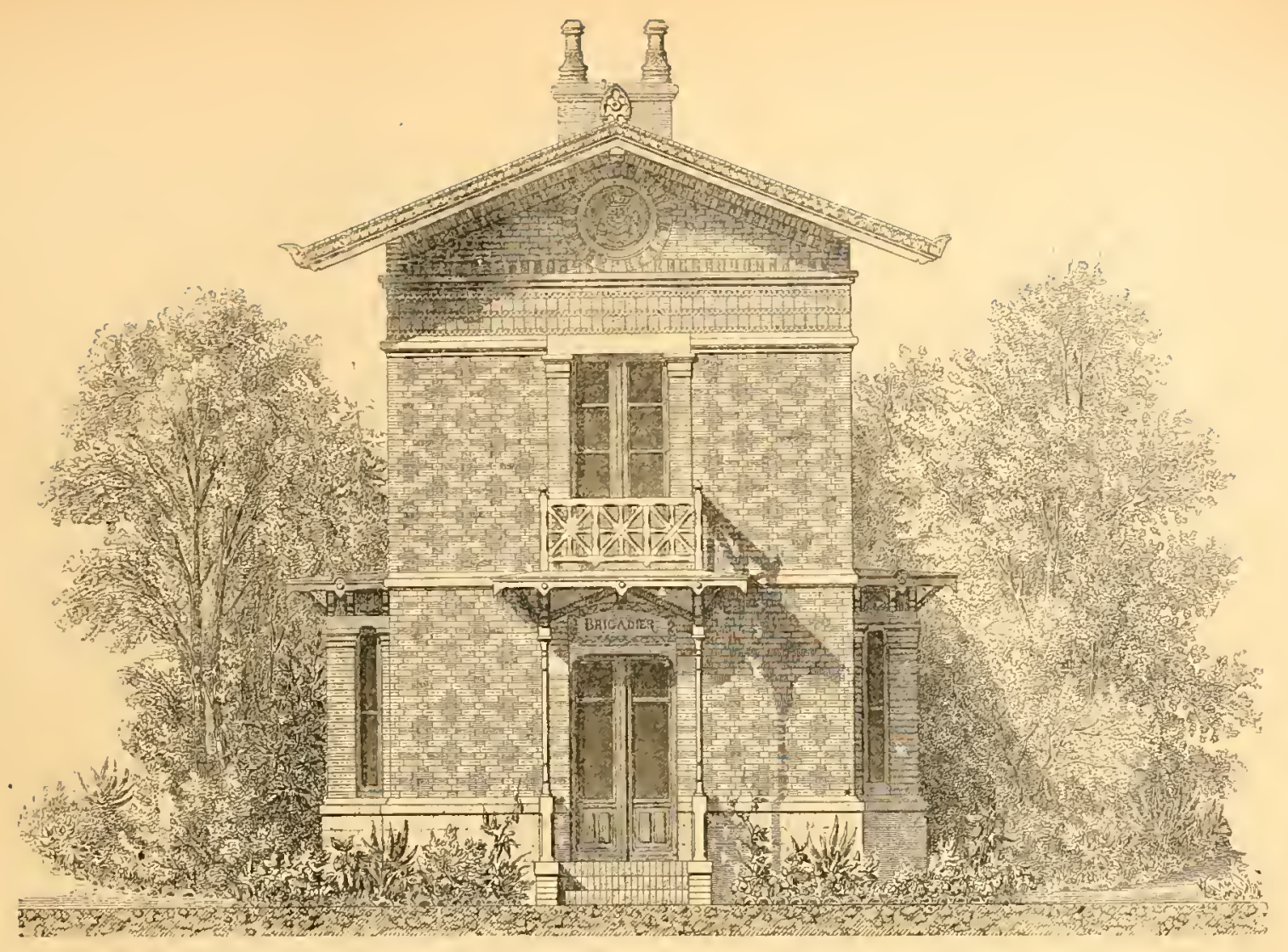

Fig. 246. - Façade princip̧ale d'un Pavillon de Garde, aux Buttes-Chaumont. (Iover P. is j)

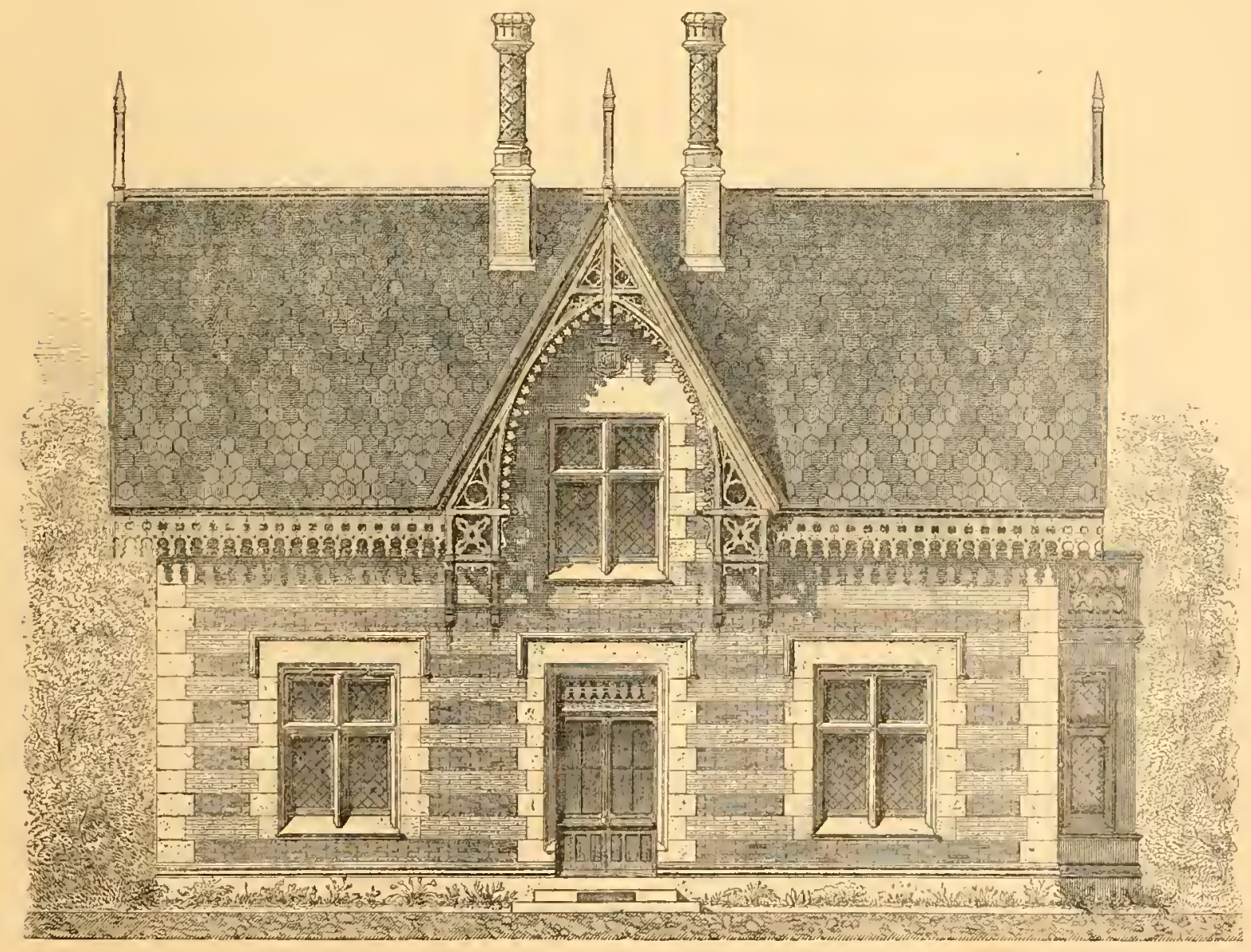

Fig. 2.7. - Maison de Garde a la Porte des Princes, au Bois de Boulogne. (Tojez p. 18;.) 
élevées. Là pousseront, outre plusieurs Saxifriges délicats, tels que S. muscoides, oppsitifolia, tenclla, cumeifolia, etc., la plus grande partic des primevéres à souches caulescentes, notamment les Primmla marginata et viscosa, puis l'Adonis vormalis, le Genliana asclepiadea, le Savertia pereninis, les Campamula caspitosa, muralis et garganica.

Les plantes alpestres qui caractérisent la végétation d'une zone moins élevée et qui se rapprochent par conséquent davantage des lieux oì nous pouvons les placer,

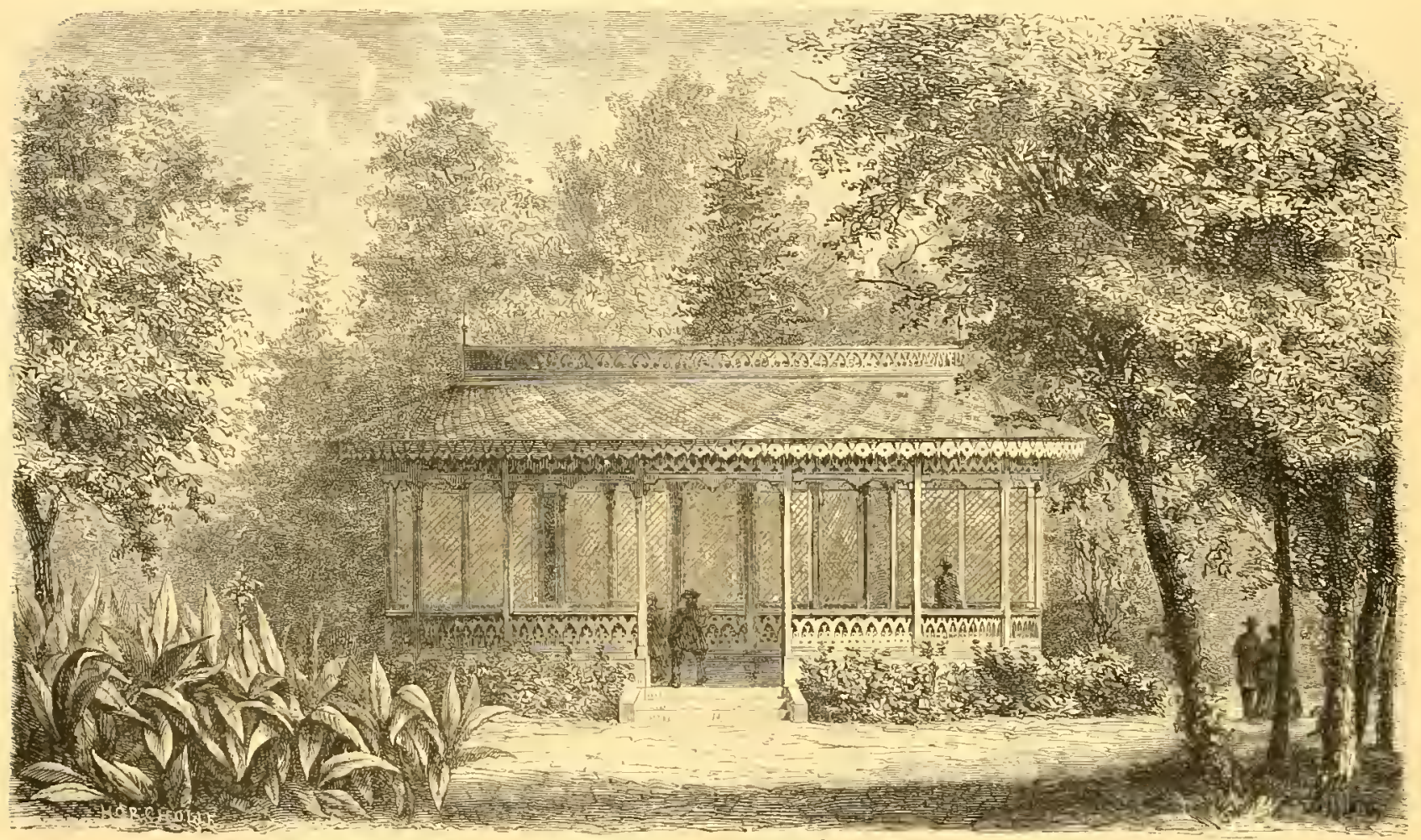

Fig. 248 . - Elèvation de l'Exedre au Bois de Boulogne. (Tove p. I 83. )

offrent par cela même moins de difficultés. Aussi, la plupart des espéces cultivées généralement sous l'épithète d'alpines n'appartiennent, il faut le reconnaitre, qu'à cette seconde division.

Mais il ne faudrait pas croire cependant que celles-ci n'ont pas besoin de soins particuliers. Ces soins ne seront pas différents de ceux que nous venons d'indiquer pour les plantes de nos hautes montagnes. Les plus rustiques de la série : Potentilla alba, Alchimilla alpina, etc., pourront servir à former des bordures; d'autres, un peu plus délicates, exigeront une terre spéciale comme aussi un lieu incliné; d’autres enfin se refuseront ì croitre en pleine terre, si le sol n'offre pas les qualités de légé- 
reté nécessaire, ainsi qu'une exposition convenable. Ajoutons qu'il ne faut pas donner une importance absolue à l'altitude peu considérable ì laquelle une plante aura été trouvée, car il n'est pas rare de voir les plantes des hauts sommets descendre dans des régions plus basses oú clles ne seront en réalité que des transfuges. Tel est le cas des Silcuc vallesia, Saponaria ocimoides, Gypsoplilia repens, etc. (I).

Il est done indispensable, pour cultiver dans nos plaines les plantes alpines ou alpestres, de les réunir dans un licu qui remplira au plus haut degré les conditions suivantes: sol léger,

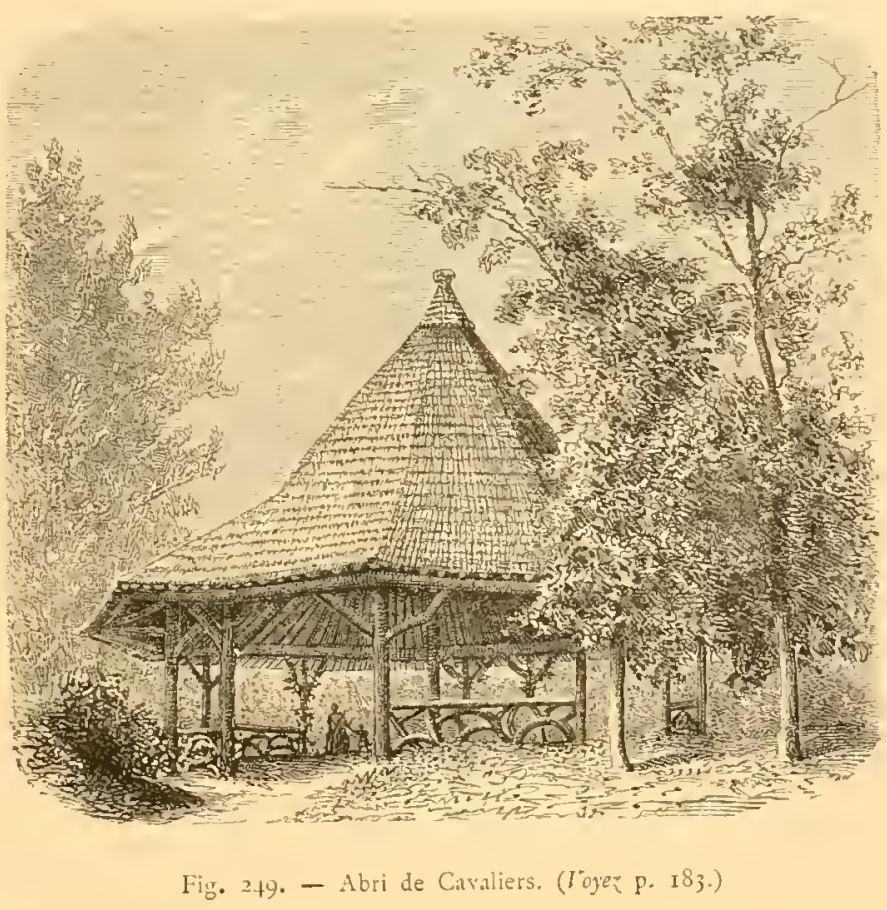
frais, incliné, reposant sur un épais drainage et situé à une exposition à demi ombragée. Cutte exigence, qu'explique

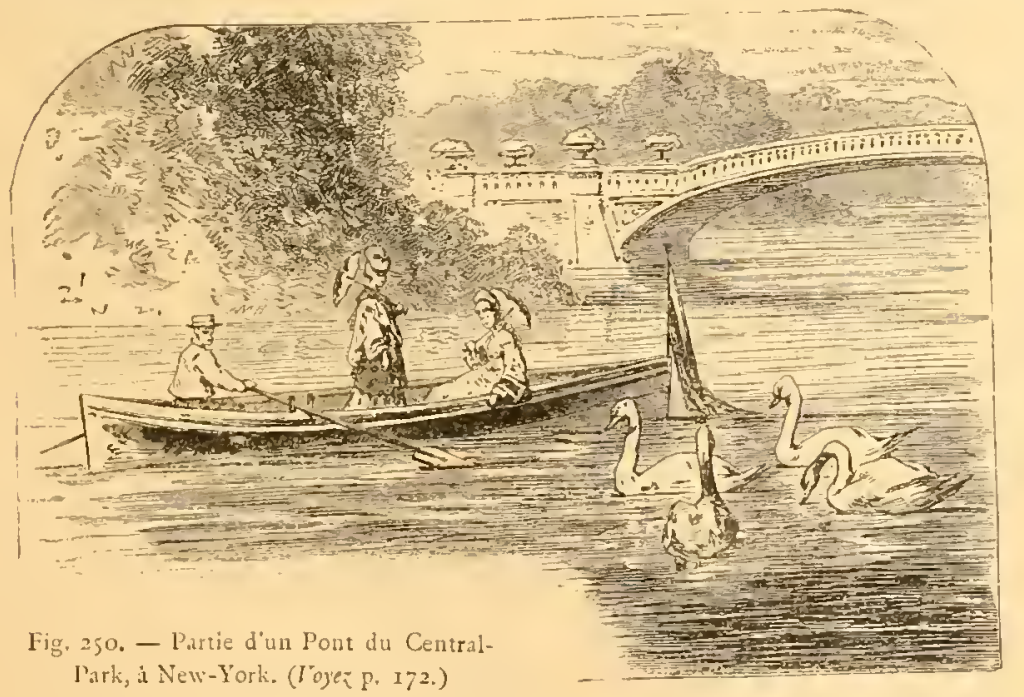
du reste le milieu dans lequel clles vivent spontanément, est facile à satisfaire jusqu'à un certain point, car, dans un jardin de quelque étendue, il est bien rare de ne point rencontrer un endroit sinon montueux au moins incliné (talus ou tertres) qui pourrait en recevoir (V.Fig. 256). Nous avons dit que les conditions essentielles pour ces plantes étaient, dans le milieu que nous habitons, un sol léger, poreux et frais, et un endroit abrité autant que possible contre les

(1) Voir pour plus de détails l'ourrage de M. Verlot : Les Plantes AlpiNes; lcur Cullure, Botanique, Emploi, etc. Avee so chromotypies, - J. Rotlischild, Ėdieur. 
rayons du soleil. Dans les jardins paysagers, il n'est pas rare de rencontrer

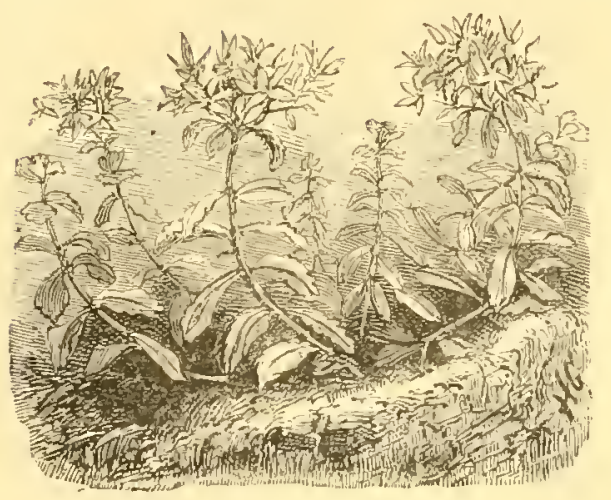

Fig. 25r. - Sedum oppositifolium. ces conditions réunies.

Nous reproduisons ici le Scllum oppositifolium (Figure 251), le Limum fluvim (Figure 252), le

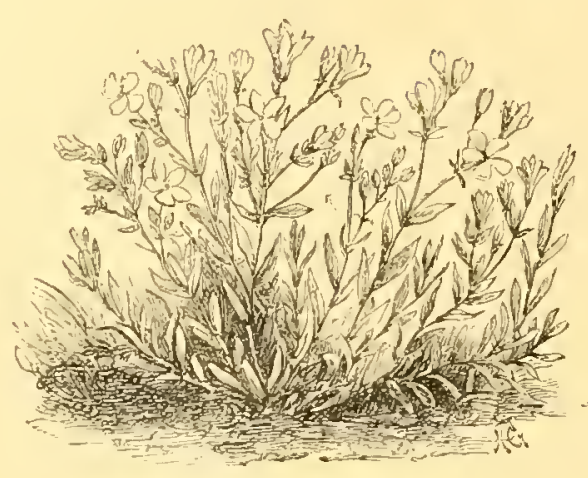

Fig. 252. - Linum flavum.

Limum suffinticosum (Fig. 253), le Cypripedium spectabile (Fig. 254), le Savifraga longifolia (Fig. 255), l'Aster Dianlbus monspessulamus

Il faut aussi faire, avec géres, ces végitiulu non rieux, et dont lis vogue

La Fongertic, comme vra être organisće d'une tant néanmoins toute exa-

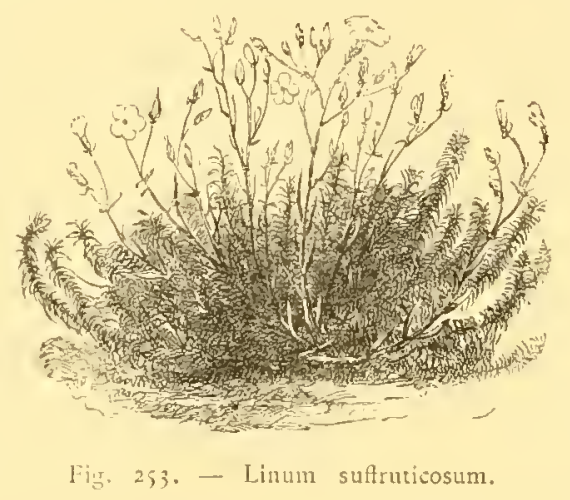
alpimus (Fig, 257), et le (Fig. 258, P. 193). discrétion, usage des foumoins gracieux que cus'accroît tous les jours (1). l'appelle M. Naudin, defaçon pittoresque, en évigération dans ce sens, en désaceord aree la nature générale du terrain et l'importance du parc. Les arbres et

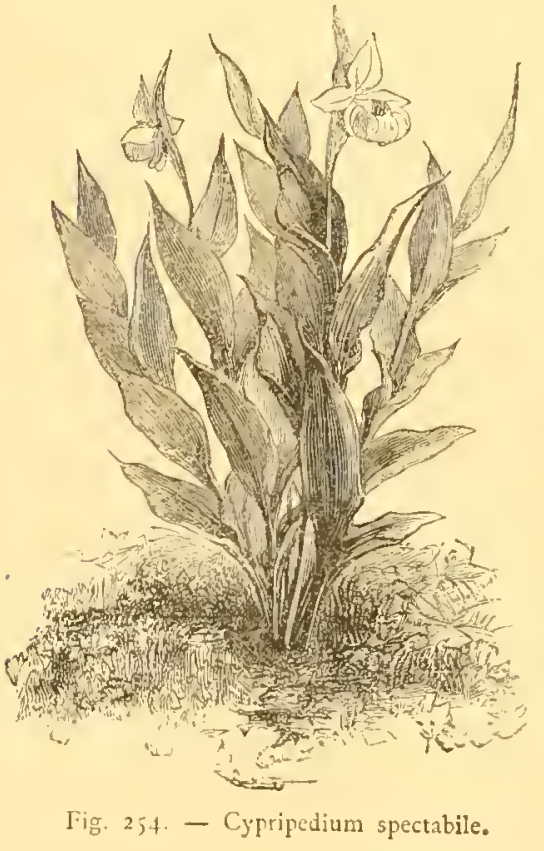
arbustes à feuilles persistantes conviennent particulièrement aux abords de ces retraites. Ces plantations doivent être faites avec un soin particulicr. On doit réserver des parties couvertes pour les fougères et autres plantes qui ont besoin d'ombre, et aussi des parties découvertes

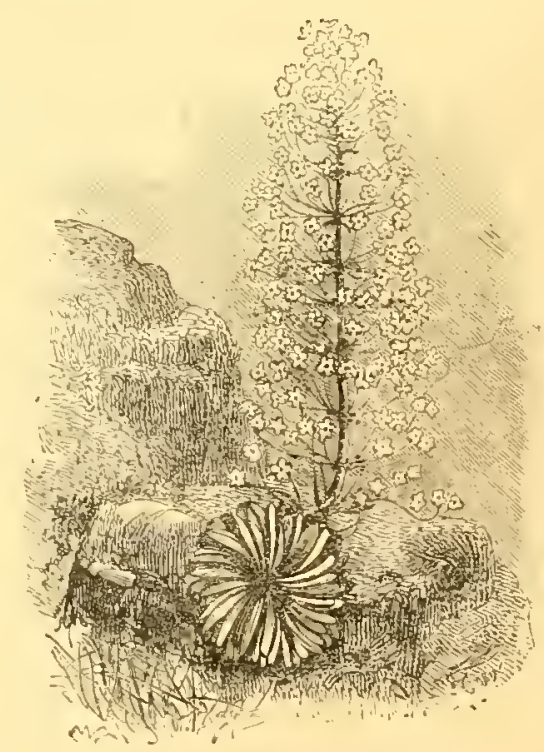

Fig. 2j;. - S.xilraga longifoli..

(1) Consulter Les Fotgères, par MM. Rivière et Roze; 2 volumes in-8o. - Paris, J. Rothschild, Éditeur. 
pour celles qui réclament du soleil. L'humidité est trés nécessaire à plusicurs de ces plantes. Il taut done tâcher d'amener de l'eau courante dans les rocailles, et d'y organiser une petite cascade. Le choix de l'emplacement de la future fougeraie

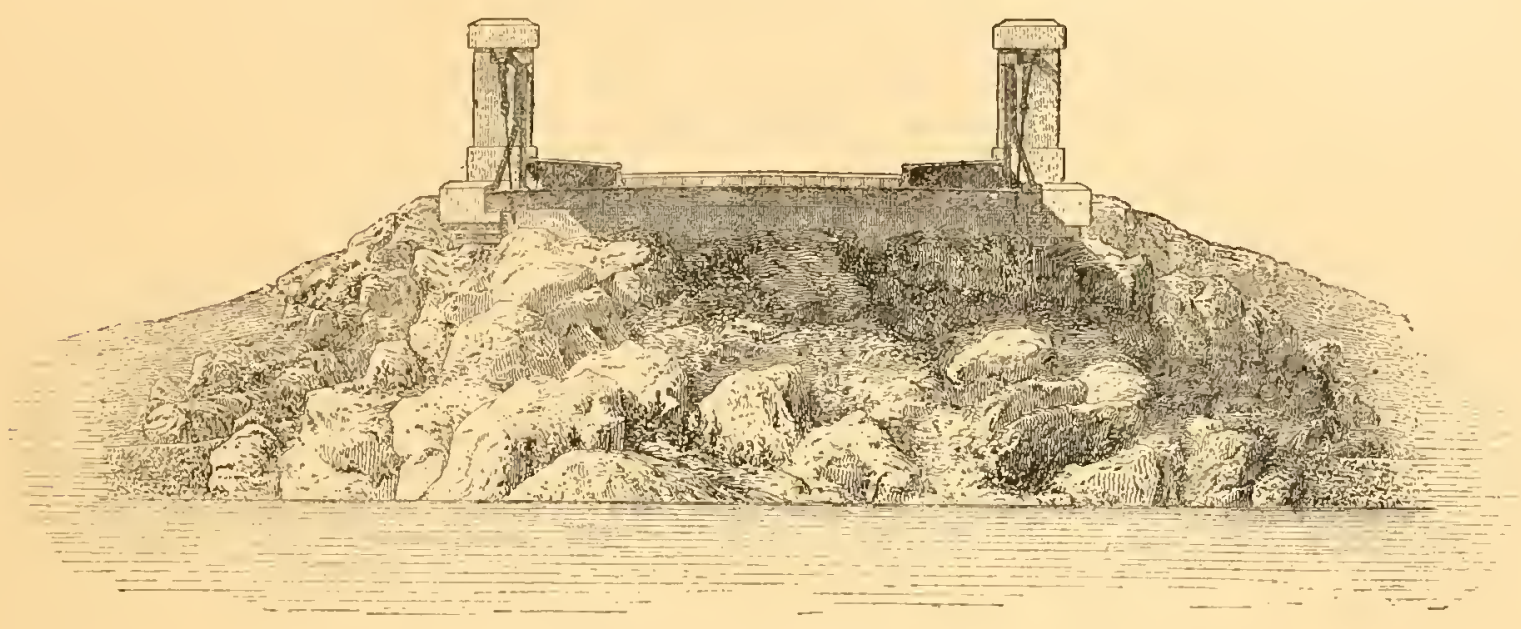

Fig. 256. - Rocailles au Pied d'un Pont du Bois de Vincennes. (Toyez P. I9r.)

a son importance, dit M. Riviére. La partie d'un pare ou d'un jardin abritie par de hauts murs, ou par des arbres de baute futaie, devra particuliérement attirer l'attention. Quoiqu'un grand nombre de fougères ne puissent supporter les rayons du soleil, le terrain qu'on

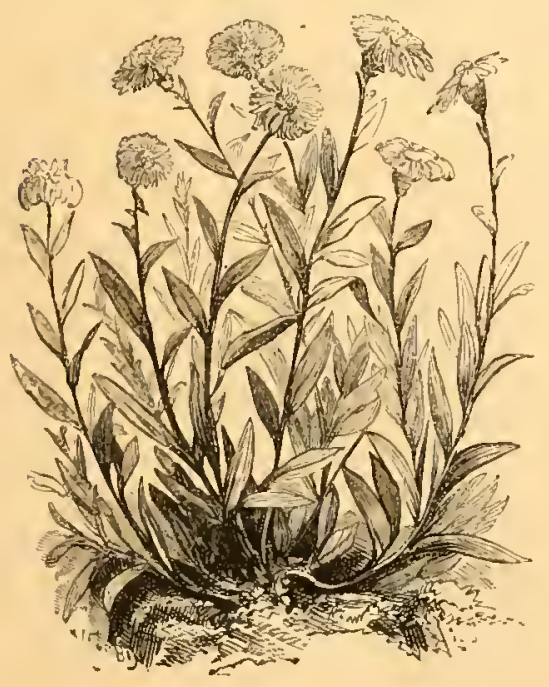

Fig. 257. - Aster alpints. (Voyer P. 192.) choisira ne sera pas tellement dépourvudes rayons bienfaisants de cet astre, qu'on n'y puisse trouverune place convenable pour les plantes qu aiment cette exposition.

" L'emplace-

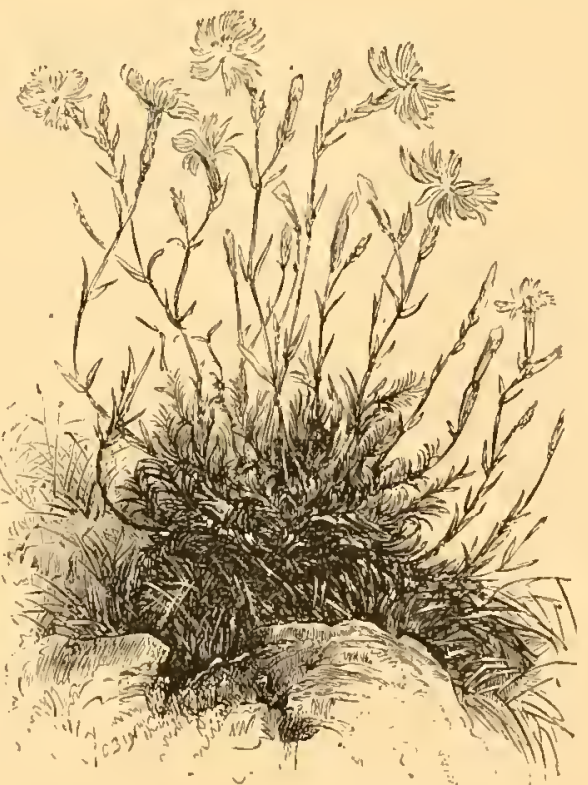

ment étant trouvé,

il faudra préparer le terrain destiné à recevoir la plantation. Nous agissons ici comme nous le faisons dans toutes les serres: drainage au fond, recouvert d'un compost convenable pour asseoir les fougères; l'ornementation, suivant le goût du propriétaire, sera 
également en rapport avec l'ètendue dont on disposera; ainsi : massifs entourés d'allées, ruisseaux et rochers, cascatelles, etc., s'uniront pour apporter leur contingent d'élégance et de fraîcheur. 11 importe, on le comprendra, que la fougeraie soit

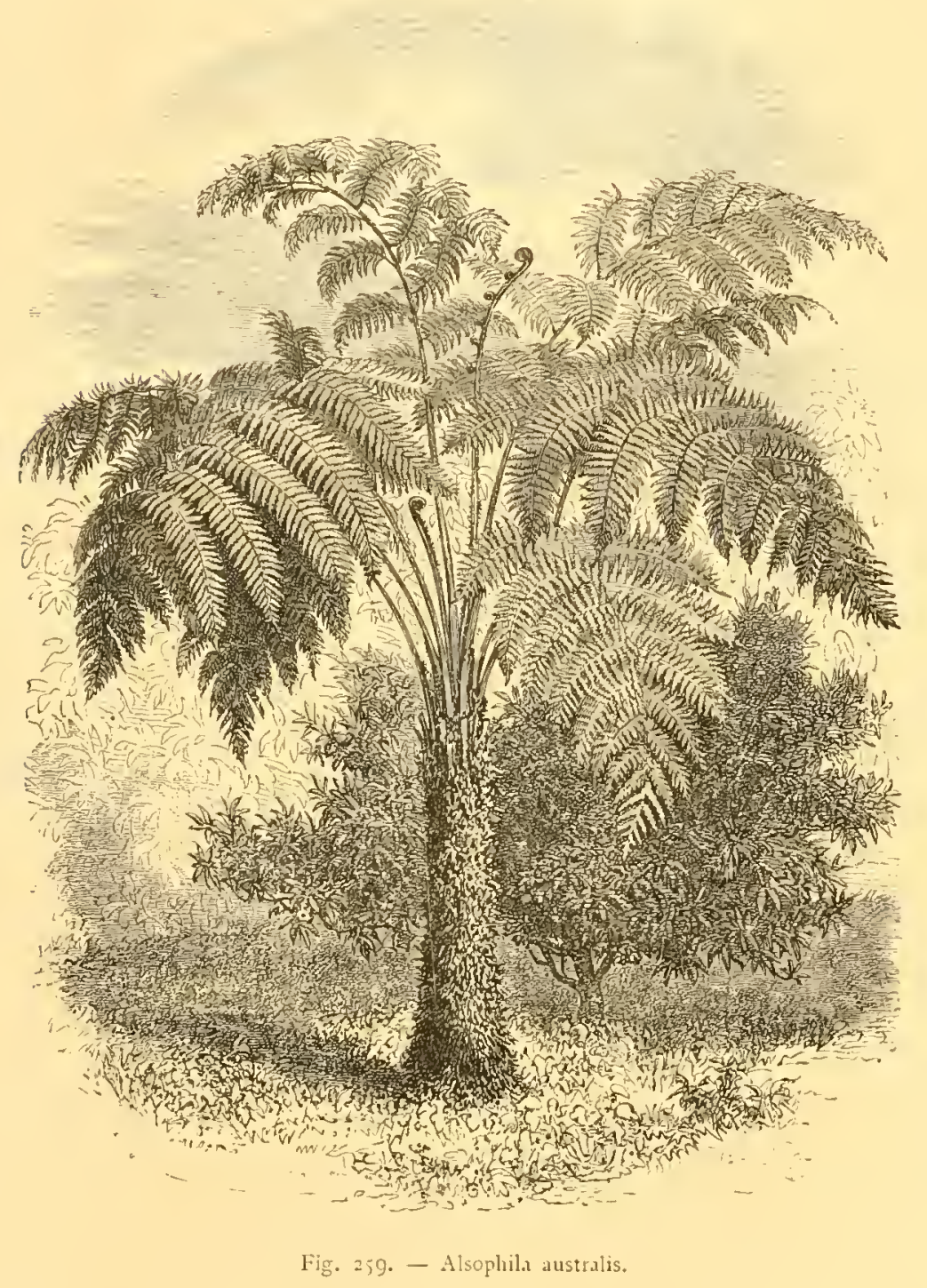

légèrement en pente, mais de telle sorte, cependant, que chaque petite partic supportant une plante reste horizontale et un peu en cuvette entre les fragments de roche, afin que les caux d'arrosement y soient retenues et remplissent leur office. Les plus grandes espéces devront occuper l'arrière-plan, les moins blevées le premier; de cette façon toutes les plantes seront en vue.

« Les especes cultivées ilnsi sur des rochers demandent l'ombre constante et une grande humidité, particulièrement de onze heures it trois heures.

«Les fougerres cultivables en plein air peurent, par leur contexture, supporter, sous notre climat, les hivers les plus rigoureux, if en existe un assez grand nombre d'espéces ou de variétés, toutes plus jolies les unes que les autres. Disposées avec art par groupes isolés sur les pelouses, elles contribuent singulièrement à orner nos jardins. Quelques-unes, en raison de leur beau développement, pourront être plantées isolément. Quoique, en général, ces fougères vivent à l'état spontané dans les parties de bois abritées des rayons d!̣ soleil, elles préférent, étant cultivées, une exposition peu ombragée. » 
Nous reproduisons ici quelques-unes des fougères les plus ornementales: l'Asoplita anstralis (Fig. 259), l'Osmunda Claytoniana (Fig. 260), l'Osmunda cimnamomea (Fig. 261), le Pteris tricolor (Fig, 262), le Diclisonia squarrosa (Fig. 263). Les rocailles doivent être formées, autant que possible, de pierres du pays; jamais de produits artificiels, tels que briques, scories, etc. Dans ce détail des jardins paysagers, comme dans tous les autres, il faut s'écarter le moins qu'on peut de la nature. Lcur silhouette ne doit être ni trop simple ni trop tourmentée. Nous

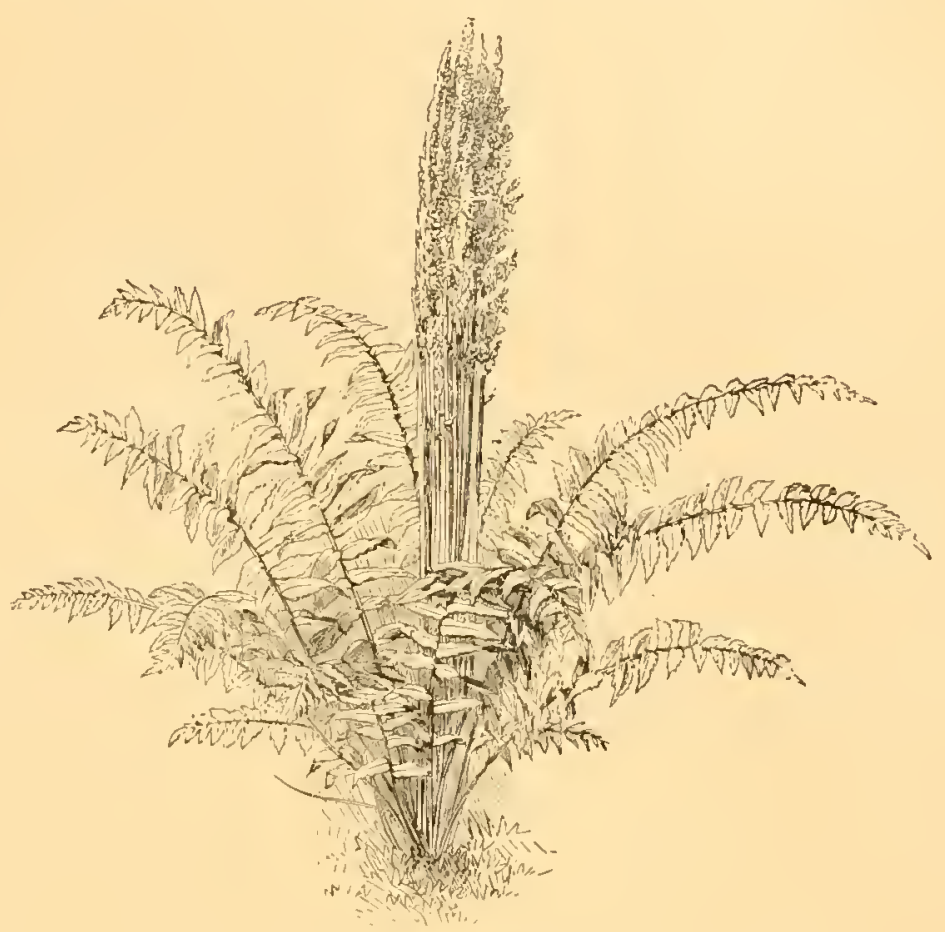

Fig. 260. - Osmunda Claytoniana. donnons un joli spécimen de rocailles, empruntéa au pare de Sydnope Hall (Fig. 257).

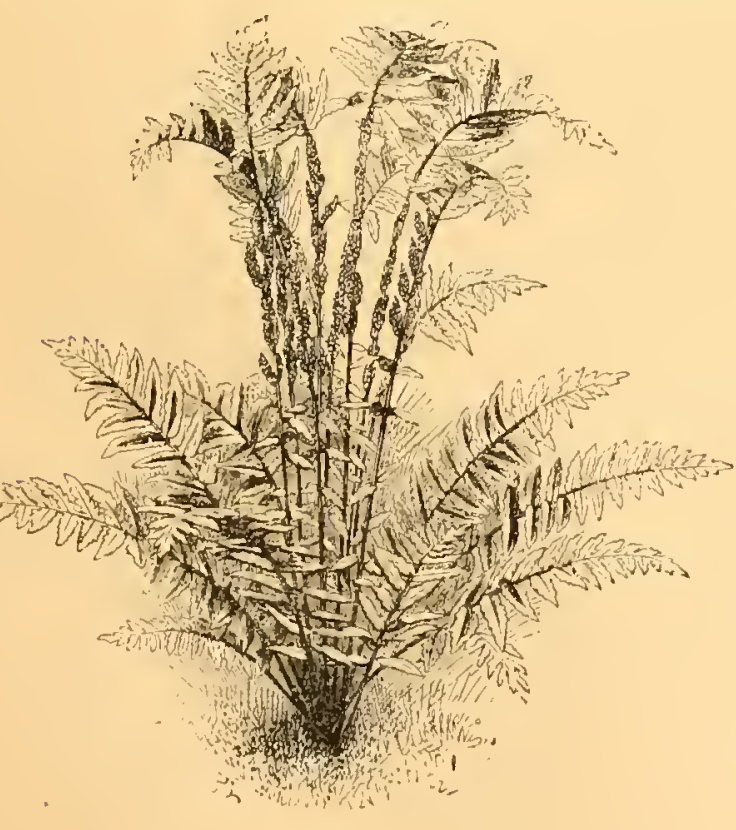

Fig. 26r. - Osmunda cinnamomea.

Les agrégations rocheuses ne doivent jamais commencer ni finir brusquement, mais être préparées par des affleurements disposés comme au hasard.

Les buissons traînants, le Coloneaster et autres arbustes du même genre; toutes les plantes d'un aspect pittoresque et sauvage, trouvent leur place dans le voisinage ou dans les interstices des rochers. Quelques-unes même, par la bizarreric de leur attitude, ne conviennent que là le Jmniperns recurva, par cxcmple.

L'importance des grottes et rochers artificiels doit être proportionnée à celle du 
parc. Quand une grotte un peu considérable s'ourre suffisamment en contre-bas, le

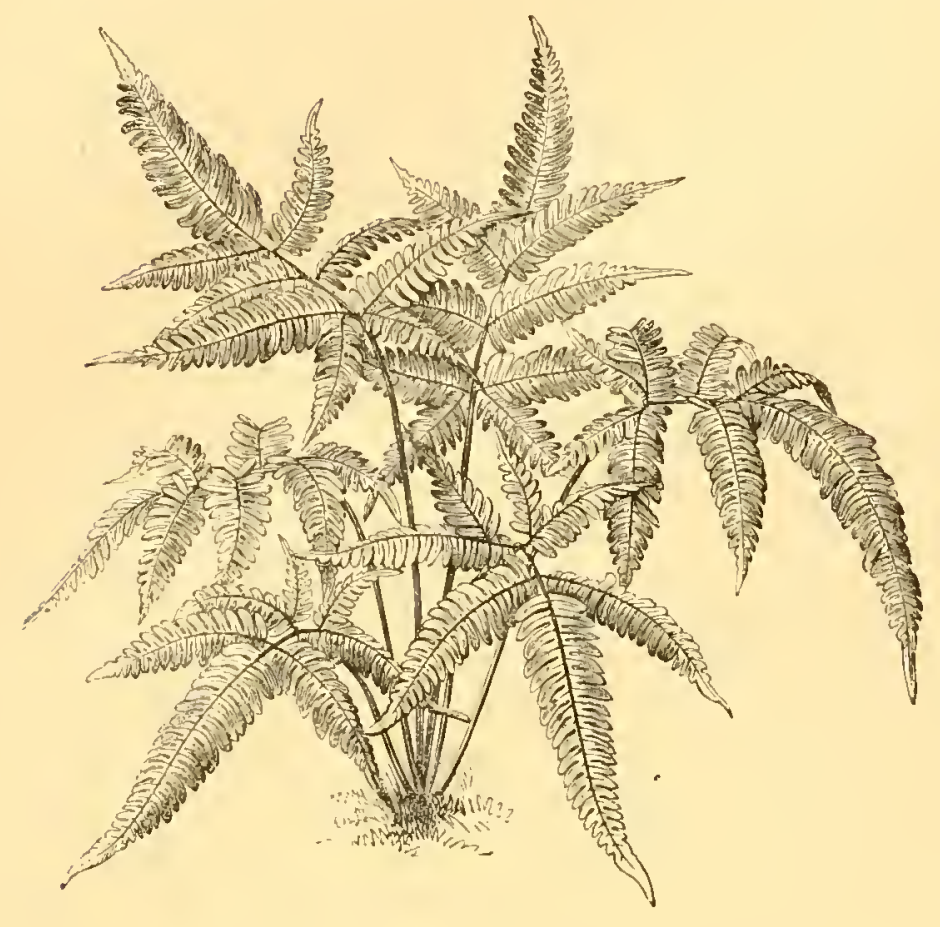

Fig. 262. - Pteris tricolor. (logez p. I95.) dessus doit être réservé pour les espéces de conifères du vert le plus sombre : épicéas, ifs, pins noirs d'Autriche, etc. (Fig. 264, p. I 97). Pour peu que le terrain favorise leur croissance, ils donneront bientôt une tournure véridique et imposante aux rochers factices.

Mais gardons-nous de rouloir ajouter à l'illusion par des moyens artificiels, comme l'exhibition d'un mannequin d'ermite, ou míme d'un ermite figurant, loué pour la circonstance, comme on faisait au siècle dernier! Il faut aussi qu'une grotte ait une assez grande étendue, pour quon puisse y risquer convenablement des imitations de stalagmites et de stalactites, comme au pare Monceaux (Fig. 27I), et, sur une plus grande échelle, à la grotte du Bois de Boulogne (Fig. 268).

XXV. - Gazons et Pelouses. - Suivant dcux des maitres de l'horticulture, Decaisne et Naudin, "les pelouses diffèrent des gazons proprement dits, en ce que l'herbe, moins choisie, y devient plus haute,

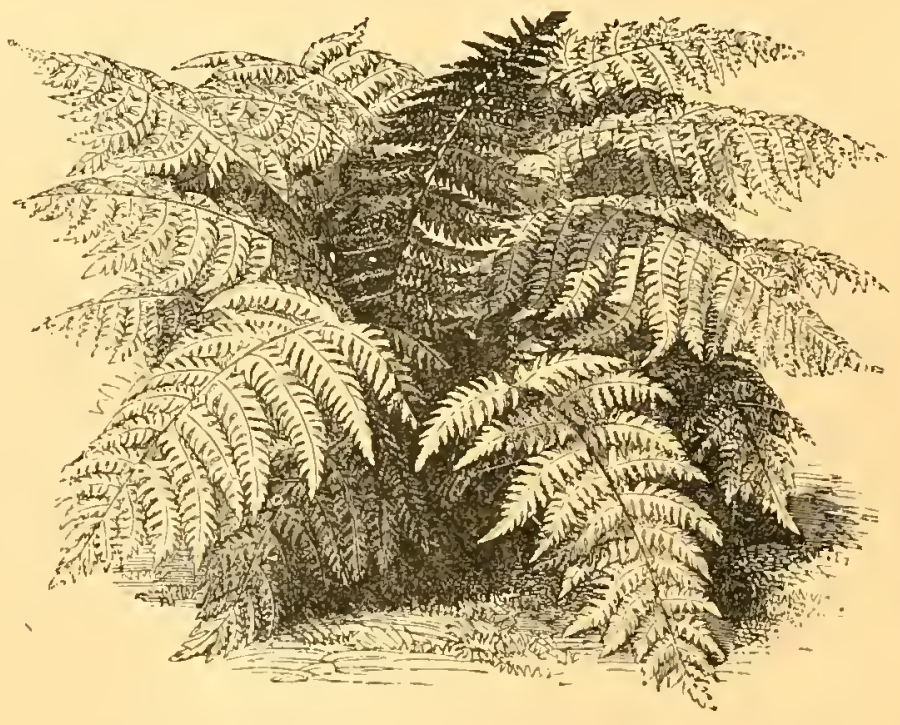

Fig. 263. - Diclisomia squarrosa. (Toyez p. 195. et qu'on leur donne des soins moins assidus. Le gazon, plus fin et mieux entretenu, est fait pour être regardé de prés; la pelouse gagne à être rue d'une certaine distance, 


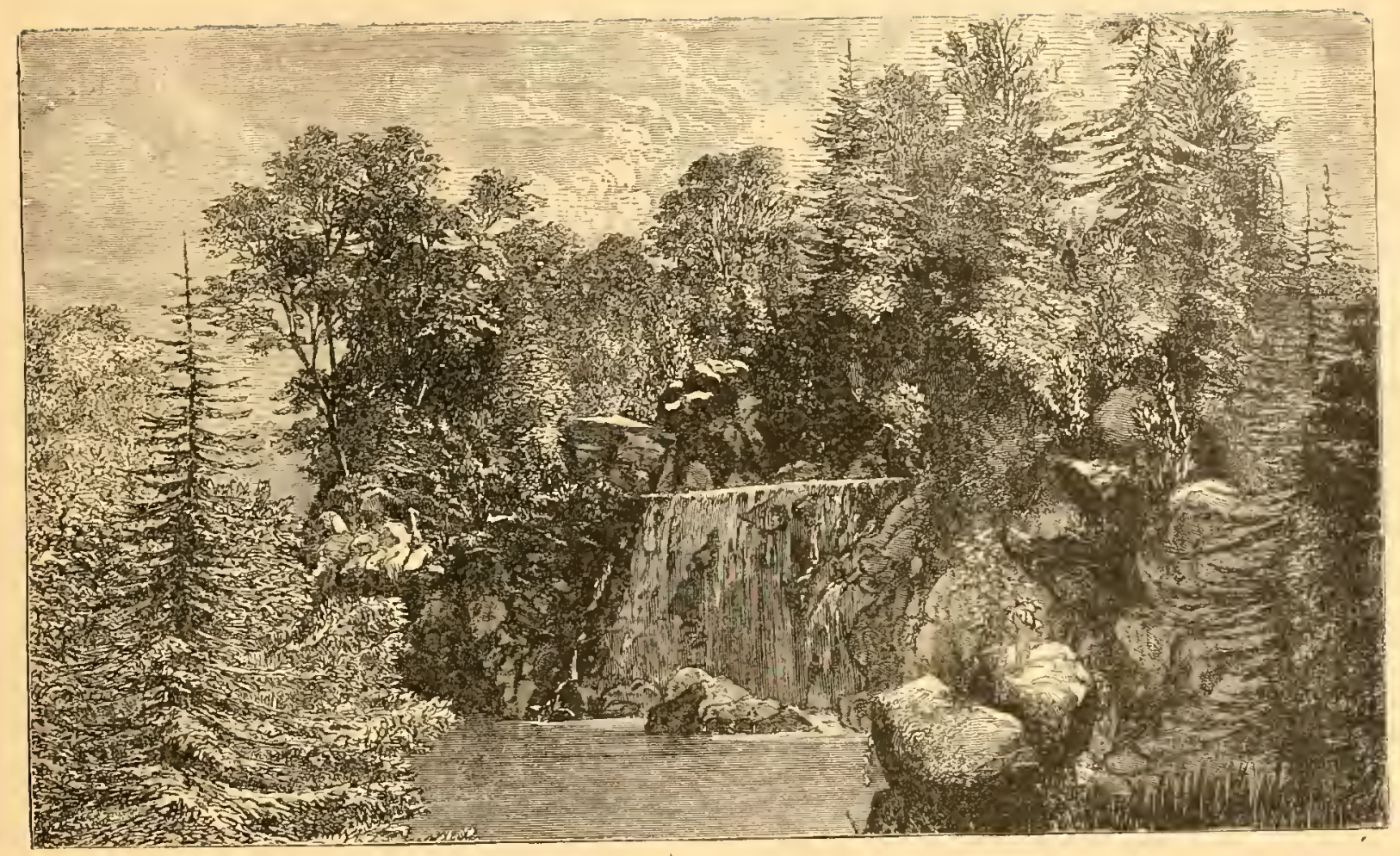

Fig. 264. - Les Cascades du Bois de Boulogne, en tace Longchamps. (Toyci p. 196.)

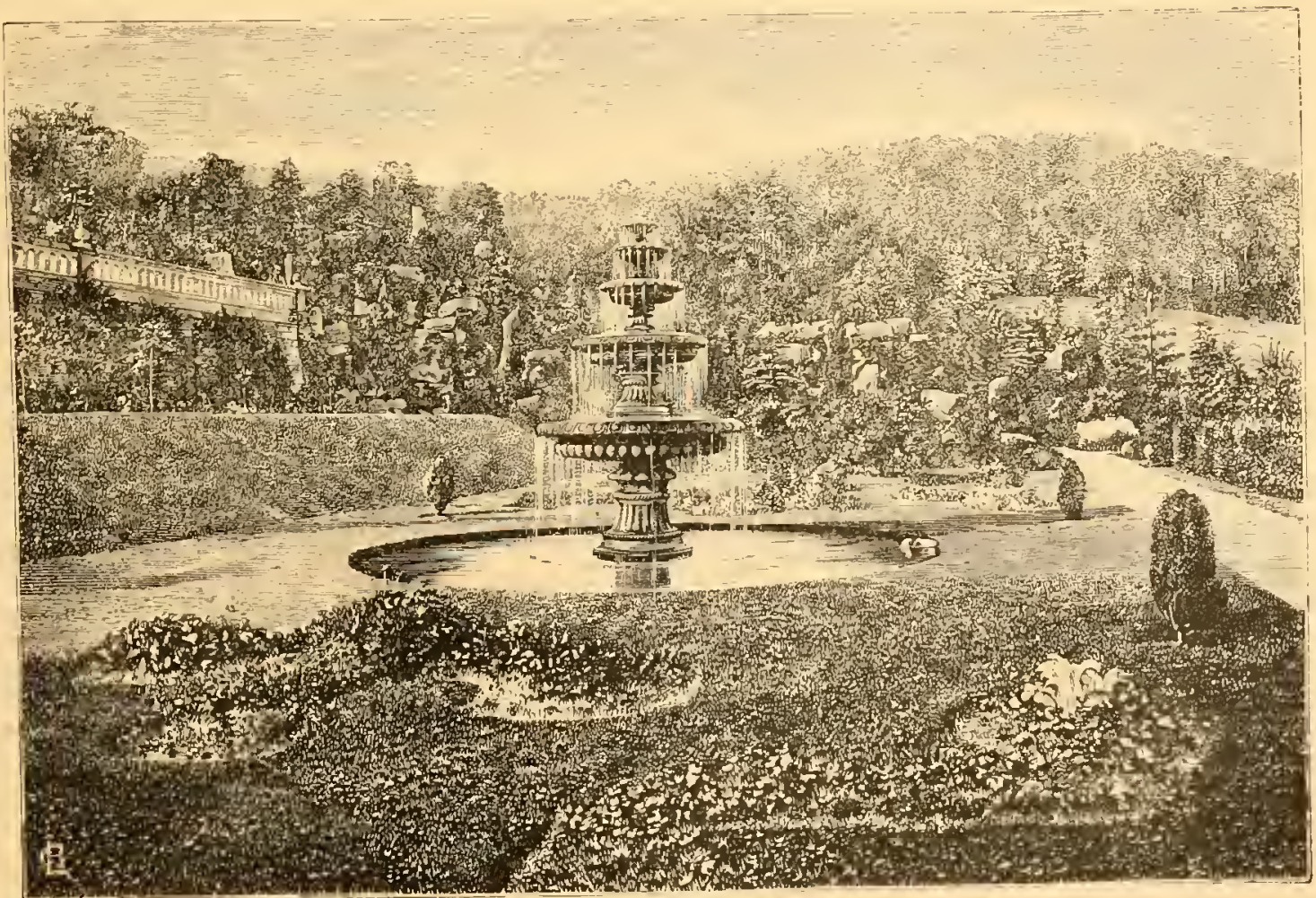

Fig. 26;. - Fougeraie et Jardin floral du Paic de Sydnope Hall (Derbyshire;, appartenant id M. Barrow. (Vovez p. 195.) 
ce qui suppose toujours une certaine étendue. » Lherbage, pelouse naturelle, forme

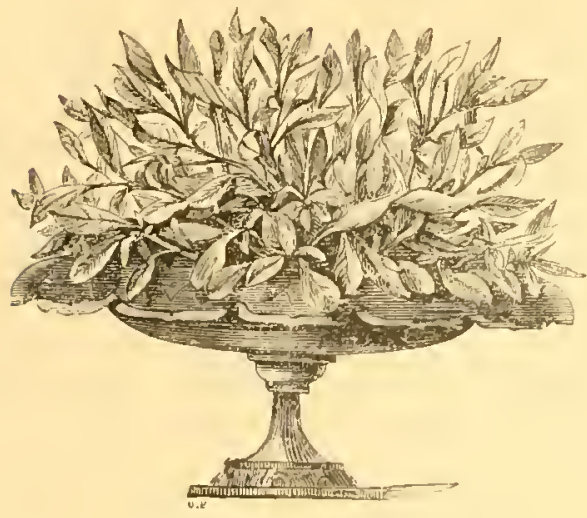

Fig. 266. - Altermathera sessilis, Var, amoun. (loyei p, 20,1) le dernier

terme de

cette pro-

gression.

On peut

résumer

en quel-

ques mots

ce triple

caractire,

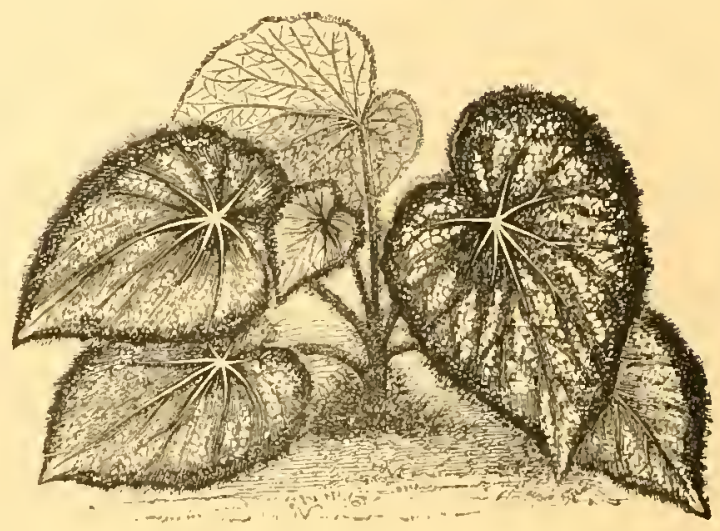

Fig. 267. - Begonia Rex (Bégonie royale de Marshall). (Toyer P. 20.4.)

en disant que les gazons doivent être tondus, les pelouses tauchées, les herbages pâtufois, la prébétail est effet sur les même assez bitation, toutes les soient priprotiger les et les corLe choix portion des les plus problissement pelouses et varient sensuivant le nature des caisne siférence la moutons

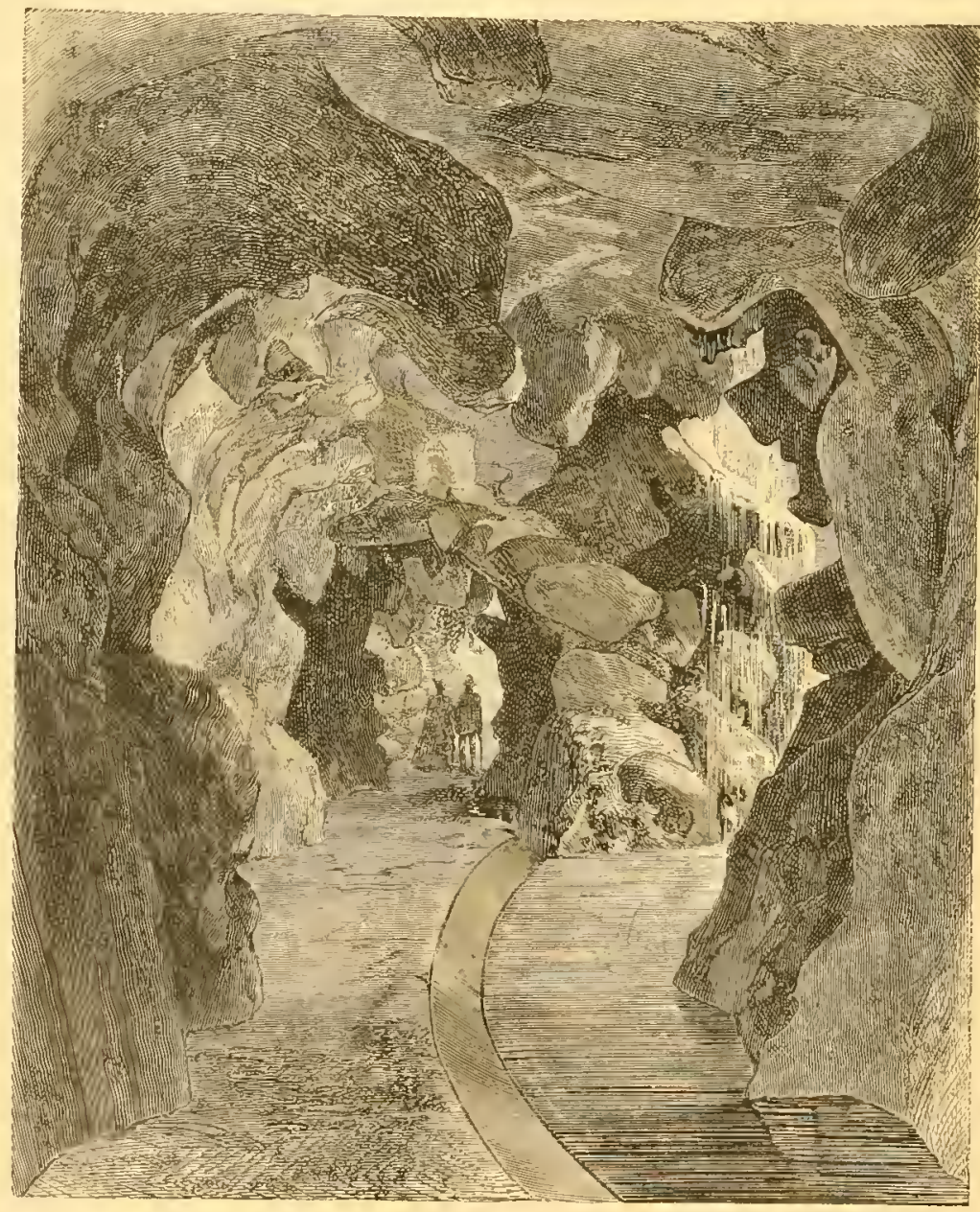

Fig. 269. - Intérieur des Cascades du Bois de Boulogne. (Toyez r. I96.) rés. Toutesence du d'un bon pelouses, prés de l'hapoursu que précautions ses pour plantations beilles.

et lis programinées pres à l'ètades gazons, herbages, siblement climalt et lal terrains. Degnalede préfétuque des f Festuca orina) et les espéces voisines (Feshuca rubra, duriuscula), puis le paturin des prés (Poa 
pratensis), la fléole (Plblemm pratense), le cynosure (Cymosmrus crislatus), Ia flouve

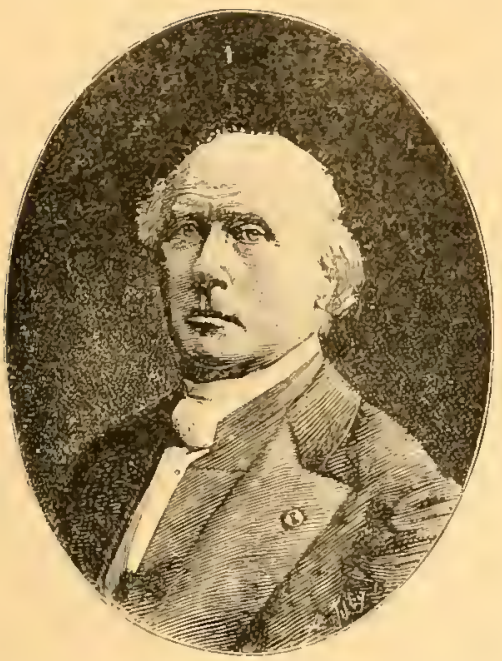

Tiv. 269. - Portrait de ]. Decaisne, Membre de I'Institut, Professeur de Culture au Muséum. odorante, l'i-

vrile vivace

oul ray-grass,

les agrost $\mathrm{i}$ -

des. Il écarte

les brômes et

autres grami-

nces trop for-

tes, qui cau-

sent presque

toujours des

vides disgra-

cieux. Lil

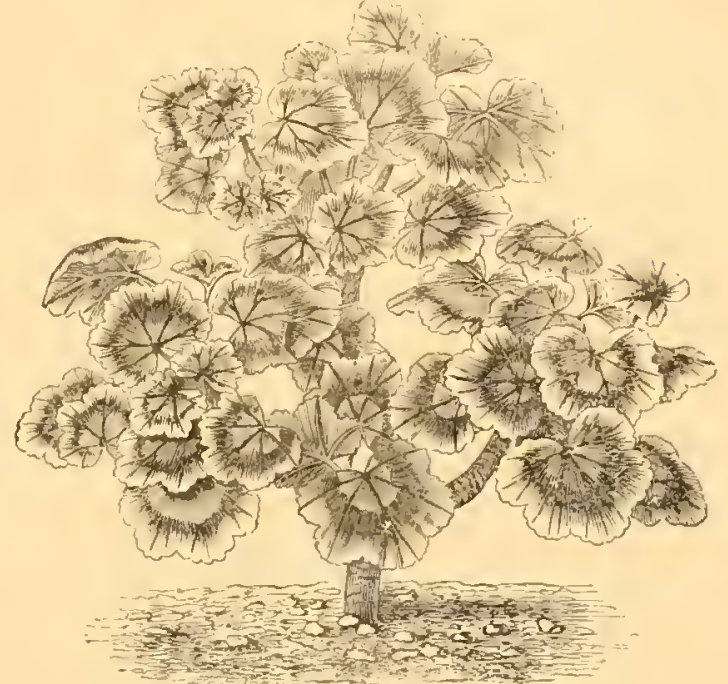

Fig. 2;0, - Pelargonium zonale, var, quadricolor. (Ioyez p. 204.)

même considíration d'unitormité d'aspect doit faire bannir des gåons proprement

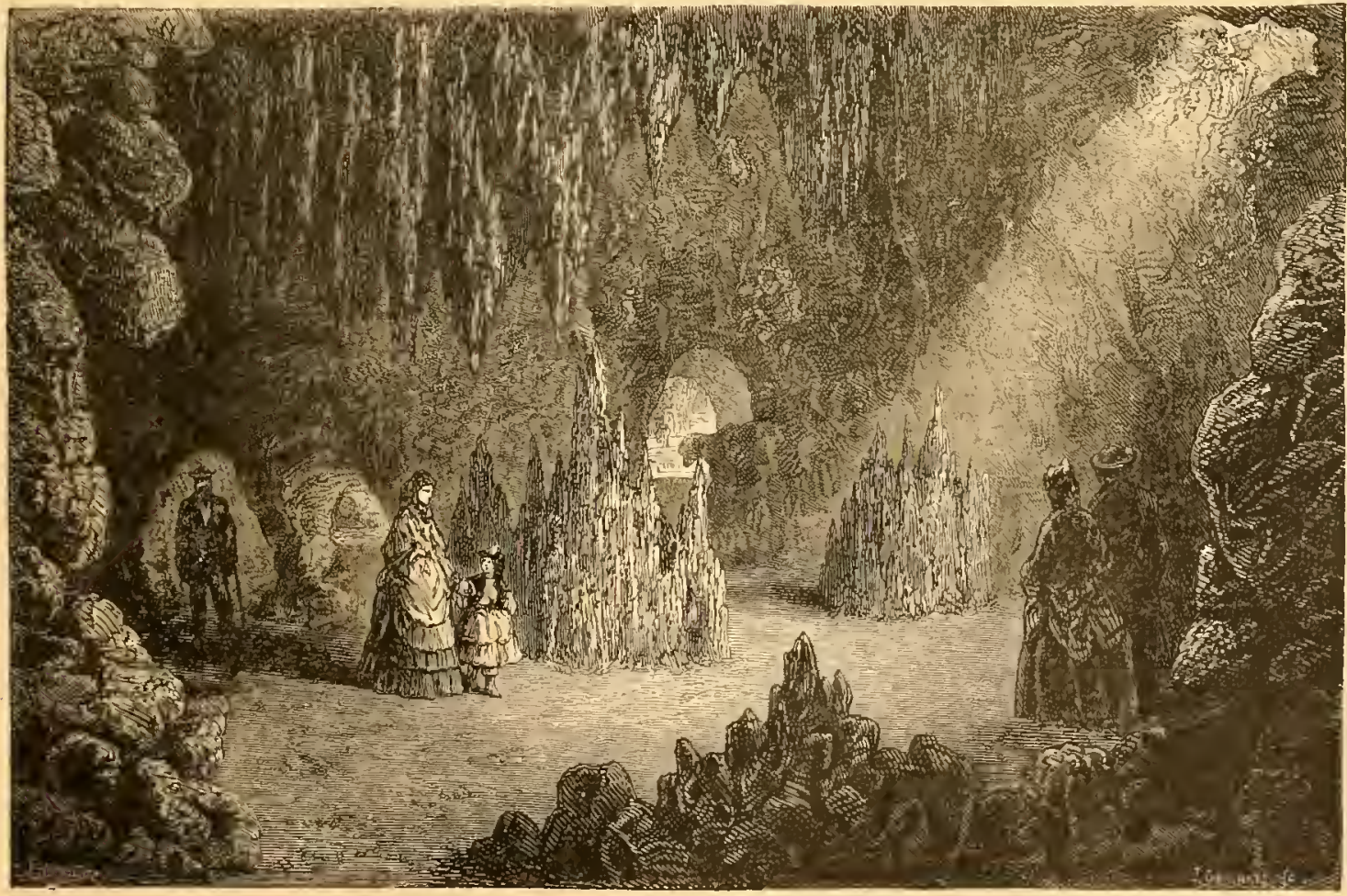

Fig. 27I. - Intérieur des Cascades du Parc Monceaux. Ioye z. I96.)

dits le tréfle et autres herbes à fleurs trop voyantes. Mais cette régle n'est pas 
applicable aux pelouses d'une certaine étendue. Le tréfle blanc, surtout, y est d'un bon usage et d'un effet agréable.

Lors de la création des pelouses du Bois de Boulogne, on a semé, par hectare,

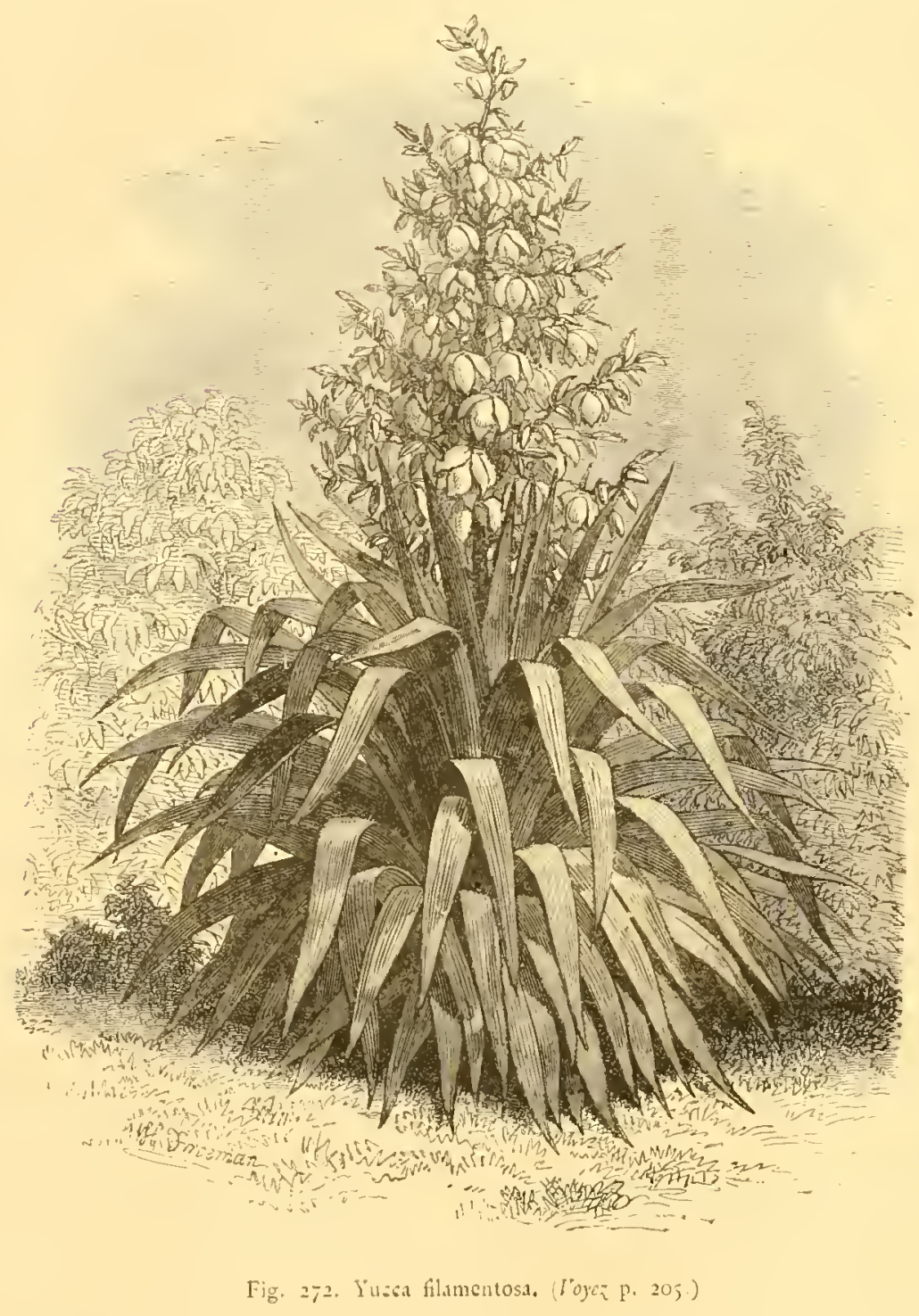
environ 250 kilog. du mélange suivant: ray-grass, 40 kilog.; brôme des prés, to kilog.; fétuque traçante, so liloğ.; ill., ovine, I s lilog.; cretelle des prés, 5 lilog.; flouve odorante, 2 kilog. Les terrains siliceux du bois étaient singulierement défavorables a cette transformation; ils ont été amendés à l'aide de détritus de l'ancien bois ct de terres argileuses. Pour les endroits les plus arides, on a employé ave succés une autre composition, le lawn-grass. Dans les parties les plus difficiles, le prix du métre de ces pelouses n'a pas dépassé 75 centimes, ce qui prouve bien quavec de l'habileté et de la persévérance, on peut imposer la verdure aux sols les plus réfractaires.

Voici encore une recette que donne Mayer pour obtenir un gazon épais, court et d'une finesse cxceptionnelle. C'est un mélange de graines composé comme il suit:

Lolinm perenne, 3; Poa pratensis, I; Poa compressa, I; Poa trivialis, I; Agrostis stoloniferu, I; Agrostis rmlgaris (alba), I; Cynosurus cristatus, I; Antboxanthum odoratum, I. (En tout, io partics.) 
Ces proportions doivent subir des variantes, suivant que le terrain est plutôt sec ou humide. Dans le premier cas, il faut renforeer d'une demi-part la proportion des deux Agrostis; dans le cas contraire, c'est sur Poa pralcnsis et $P$. trivialis, que l'augmentation doit porter. Pour obtenir une herbe passable dans les endroits ombragés, Mayer conseille les deux Agrostis et le Poa nemoralis( (I).Ces indications évidemment ne sont pas absolues, mais un jardinier habile trouvera bien vite la proportion convenable pour son terrain. Si les herbes d'especes fortes sont en moindre quantité, le gazon est plus fin, plus doux, et a moins souvent besoin d'être tondu. Quand on peut se procurer de belles mottes de gazon, il est plus avantageux de les employer pour créer une pelouse que de la semer. Même si l'on procède par voie de se-

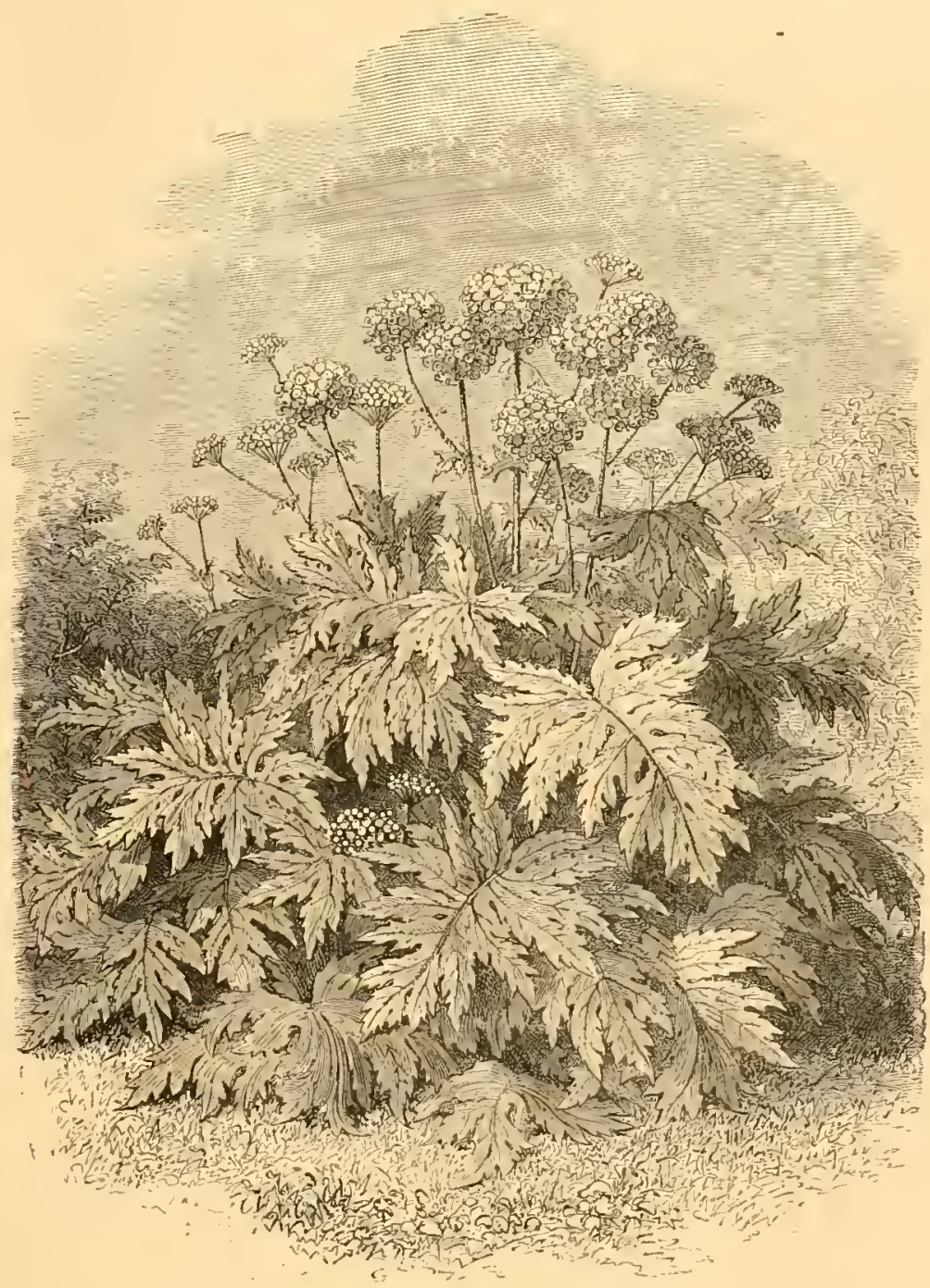

Fig. 273. - Heracleum giganteum.

mailles, il faut toujours que les bords soient gazonnés; cet encadrement profite ì la solidité du travail. L'automne est la saison la plus favorable pour ce mode de formation de pelouses avec des mottes. La terre s'enléve alors plus facilement sans se séparer; elle se divise d'une manière plus nette; l'humidité assure et accélère la

(1) Cependant, lorsque les grands massifs sont trop épais, leur ombrage finit par empẻcher absolument le gazon de pousser jusqu'à une certaine distance, et favorise la croissance des mauvaiscs herbes. Pour y remédier, il faut couvrir ces terrains de plantes qui croissent volontiers à l'ombre, comne la pervenche, le lierre, l'Hypericum calycimm. 
reprise. Quand le plaquage du gazon est fait, il faut jeter de la graine dans les inters-

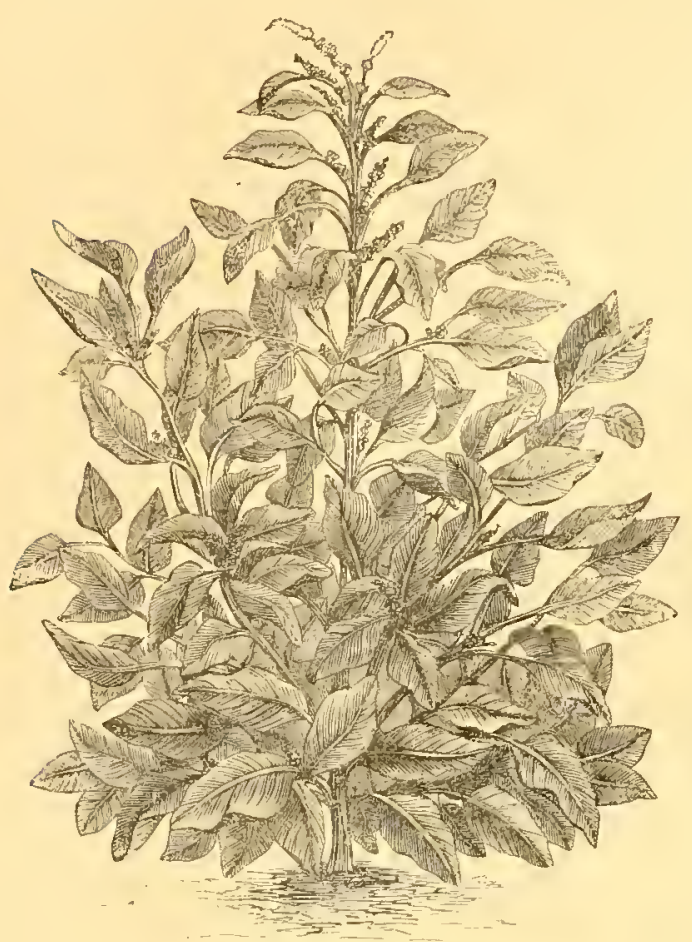

Fig. 27t. - Amarantus melanciolicus. tices pour les effacer. Lorsquion scime une pelouse, il importe que la terre ait été bien labourée fin mars ou fin août : et une semaine a-

prés on

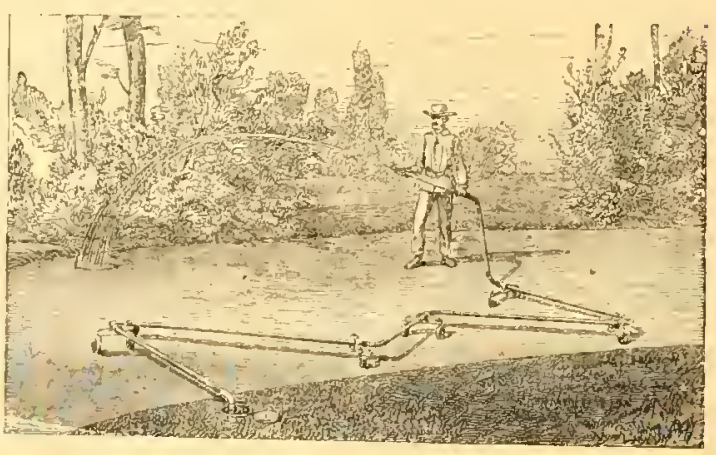

Fig. 275. - Lance pour arroser. (Toyer 1). 203.)

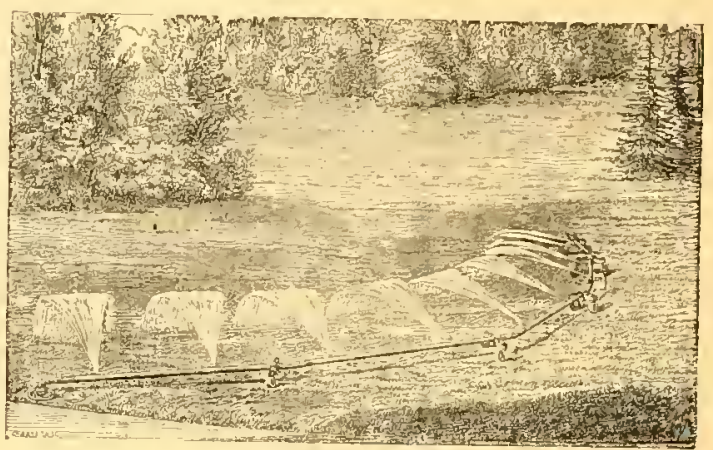

Fig. $2 ; 6 .-$ Conduites pour anoser les Pelouses. (T. . . 203.)

peut commencer le travail. Il faut semer épais, puis fouler, ratisser, et finalement

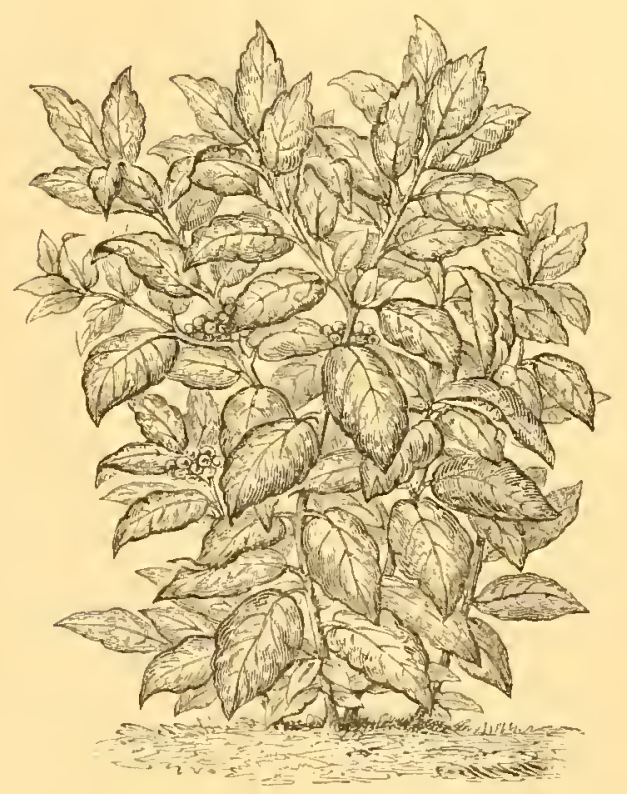

Fig. $27 \%$. - Aucuba japonica. passer le

roulean. $U_{n}$ jour relativement sec, dans une saison pluvieuse, est celui qui convient le mieux pour semer les graines de gazon com-

me toutes

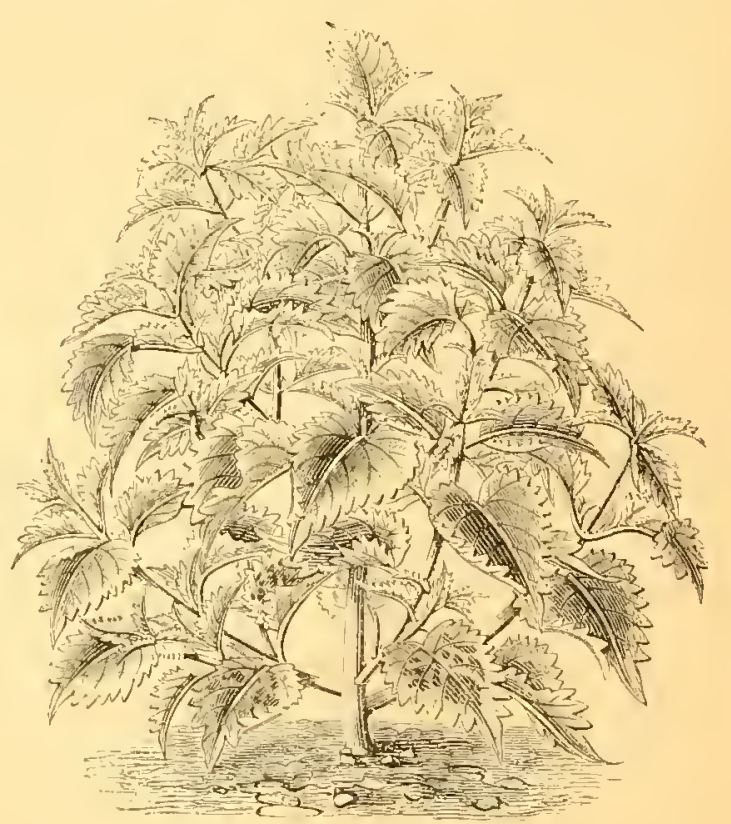

Fig. 278. - Coleus Verschaffelti. (Toyez p. 204.)

les autres. Des soins apportés à ces premiẻres préparations dépend toute la beauté 
à venir de la pelouse. Pour l'arrosage des pelouses dans les urandes proprićtés, il y a avantage sous tous les rapports, même celui de l'économic, à employer le systéme de la lanee (Ficelui des conduiroulettes (Fi-

XXVI.EmFleurs et Feuillage en Corbeilles, de border de les massifs d'artes, devenu fort d'hui, n'en est

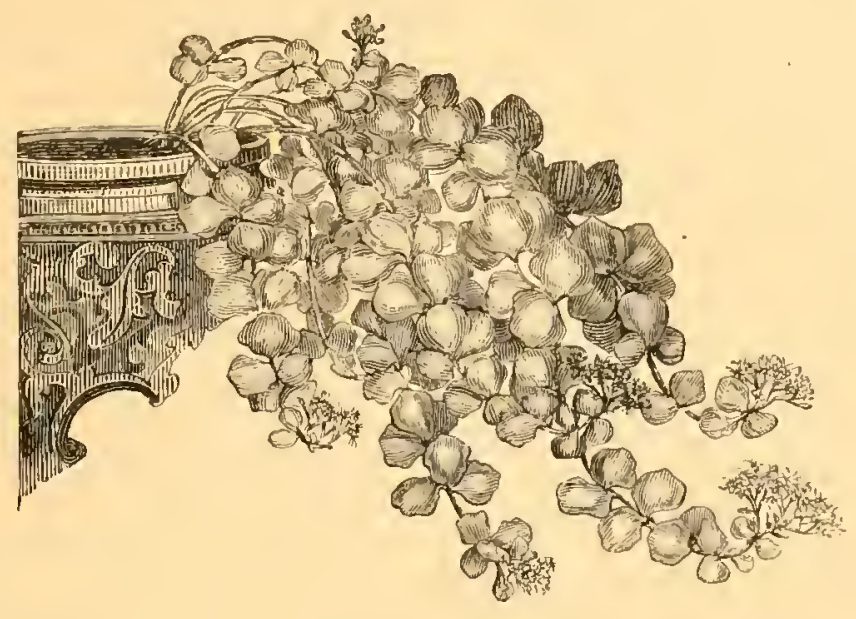

Pig. 279. - Sedum Sieboldii. (I0vez P. 204.) gure 275), ou tes articulécs sur gurc 276). ploi des Plantes à Bordures, etc. - L'usage fleurs cultivées bres et d'arbuscommun aujourpas moins vivement critiqué par des horticulteurs émérites. Dans tous les cas, cette ornementation ne doit être employce, dans les jardins particuliers, qu'aux abords de l'habitation.

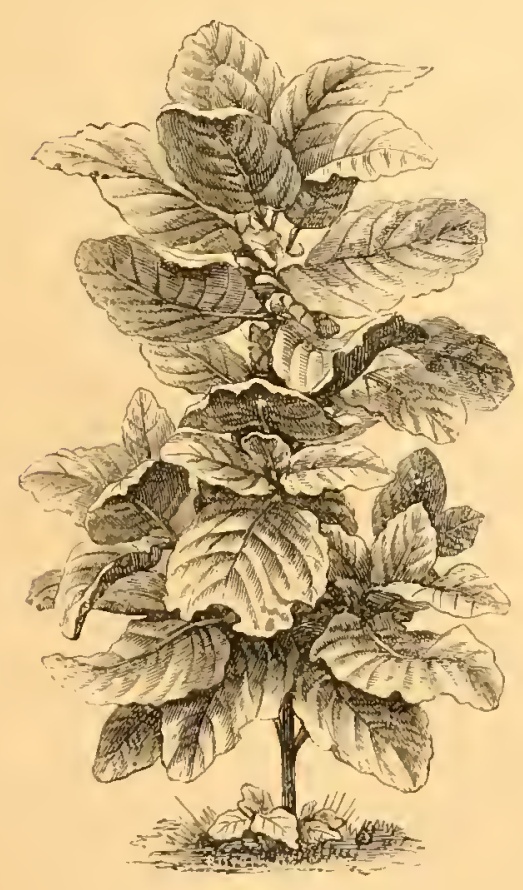

Fig. 2So. - Wigandia macropluylla.

Depuisquelques années, la mode il prévalu des corbeilles rondes ou elliptiquesdefleurs ou de plantes à feuillage, soit toutes de même espéce, soit parzones parallèles alternies (comme deux de Colcus, séparées par une bande de Pelargonimm), soit encore en une

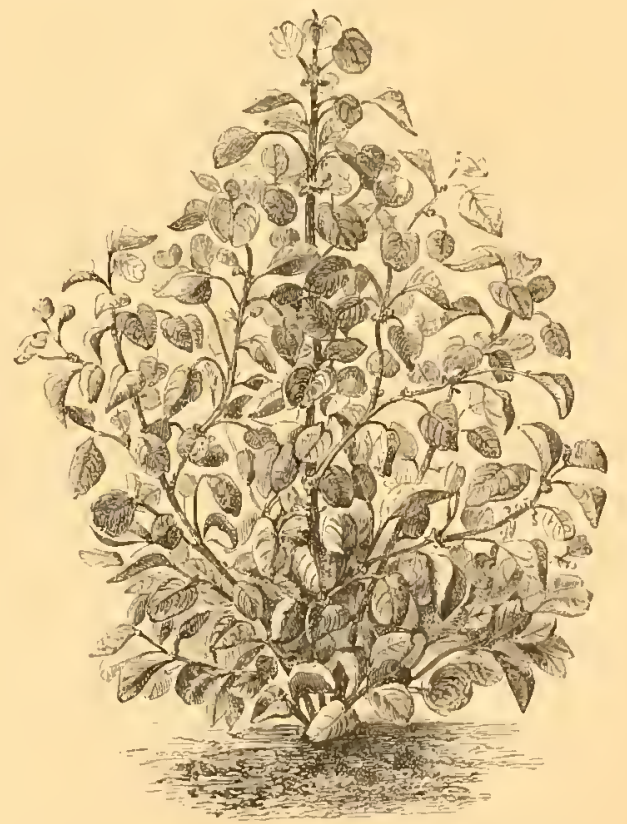

Fig. 281. - Achyranthes Vursinafteltii. ( $l^{*}$. p. 204.)

seule masse avec bordure de plantes plus basses, aussi de couleur tranchée. On a même cssayé, depuis quelques années, des compartiments en croix, des bordures en festons, etc. Mais il serait prudent de s'arrêter dans cette voie; clle nous raménerait aux anciens 
parterres en mosaique, dont l'entretien serait d'un prix exorbitant et hors de proportion avec l'effet obtenu. Le grand avantage du systeme des corbeilles, c'est que chaque groupe de plantes à fleurs ou à feuillage ornemental peut être soigné d'ensemble. Parmi celles qui font le meilleur effet, ainsi disposces en corbeilles ou en bordures, nous

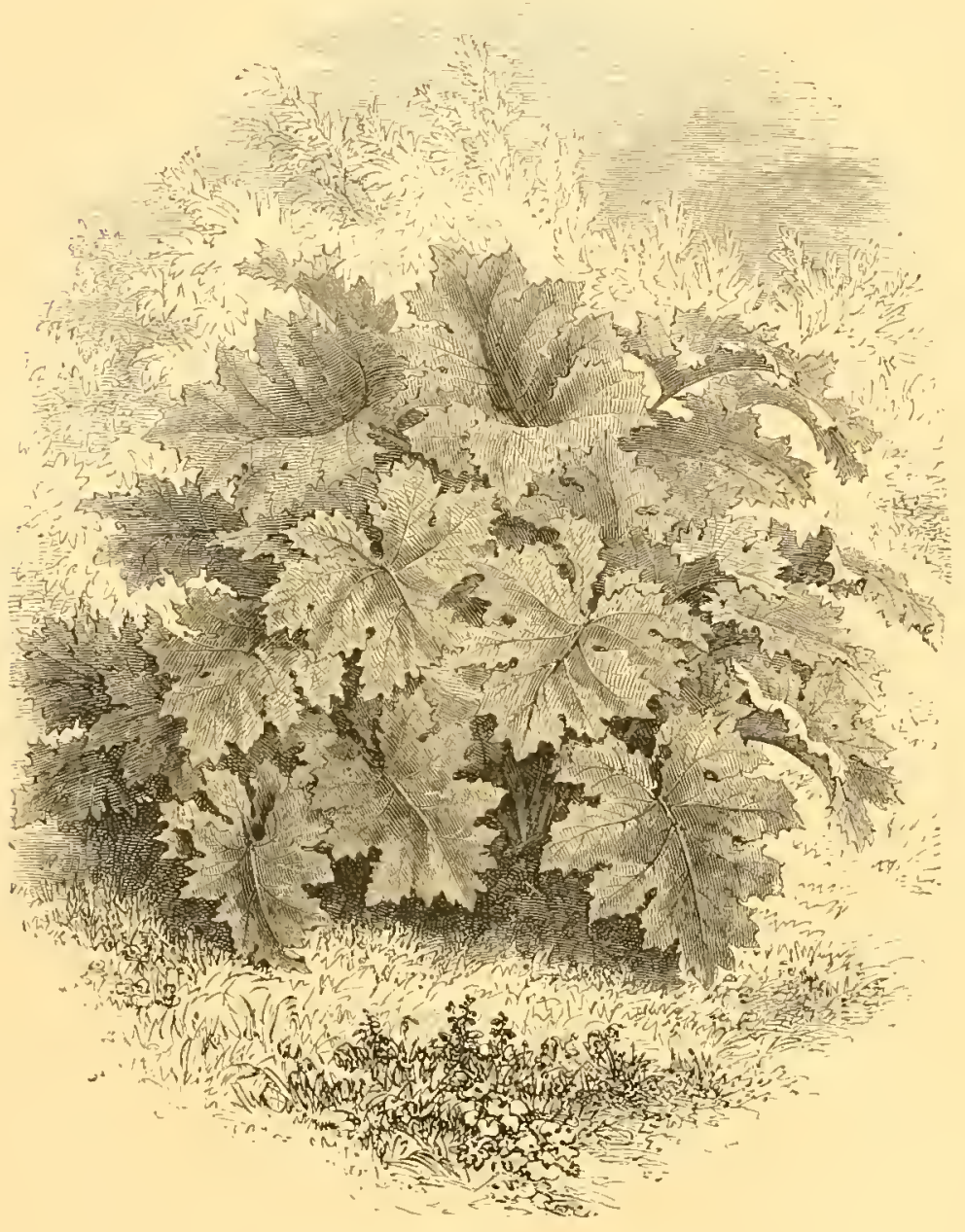

Fig. 282, - Ferdinanda eminens. citerons les diverses variétés de Pelargonimu (notamment le zonale) (Fig. 270), de Bégonias (Fig. 267), de Colens (Fig. 278), de Sedmm (Figure 279), de Solanmm (surtout l'Amazonicum, le plus rustique et le plus florifère); les Pétminias, les Autlownis, les Cannas (Fig. 289), Acbyranthes, Alternanthera sessilis (Fig. 266); puis encore les Verbenas (verveines), les Lantanas, d'une coloration trés riche, mais d'une odeur désagréable, etc. L'emploi de la plupart de ces plantes est aujourd'hui général; on trouve même dans d'humbles jardins de majestueux cannas entourés de Colcns, des corbeilles d'anthemis

bordées d'achyranthes, des Bégonias bulbeux à fleurs rouges ou roses, avec un entourage de Salvias aux larges feuilles d'un blane d'argent, etc. Mais chaque année voit paraître quelques variétés de plantes, et aussi quelques dispositions nouvelles. L'une des plus belles et des plus originales est un semis d'Acbyrantbes sur un fond de Lobílias à fleurs bleues. Cette combinaison produit un effet gracieux et fantastique, digne d'un jardin de fées.

XXVII. - En principe, les plantes les plus curieuses, les plus délicates, doivent être placées sur les gazons et au bord des massifs les plus voisins 
de l'habitation, pour composer une sorte de Musíe ritgítal. Les yuccas (Fig. 272), les fuchsias, les dahlias et autres plantes rustiques scront distribués dans des parties du parc plus éloignées. Mais les traces de culture des fleurs doivent graduellement devenir moins apparentes, et finir par disparaître aux endroits où, grâce ì l'habile dissimulation des limites, le domaine se confond avec les alentours. Ce principe est également applicable aux arbustes.

Les amateurs dépourvus de serre chaude, et même de serre tempérée, peuvent y suppléer au moyen de certaines plantes très rustiques, dont les robustes attraits ne doivent d'ailleurs être dédaignés nulle part. Ainsi, on peut se consoler de l'absence des Colcus avec le Perilla, plante annuelle qui produit un effet analogue, soit en bordures, soit en massifs, grâce à son feuillage élégamment découpé, d'un

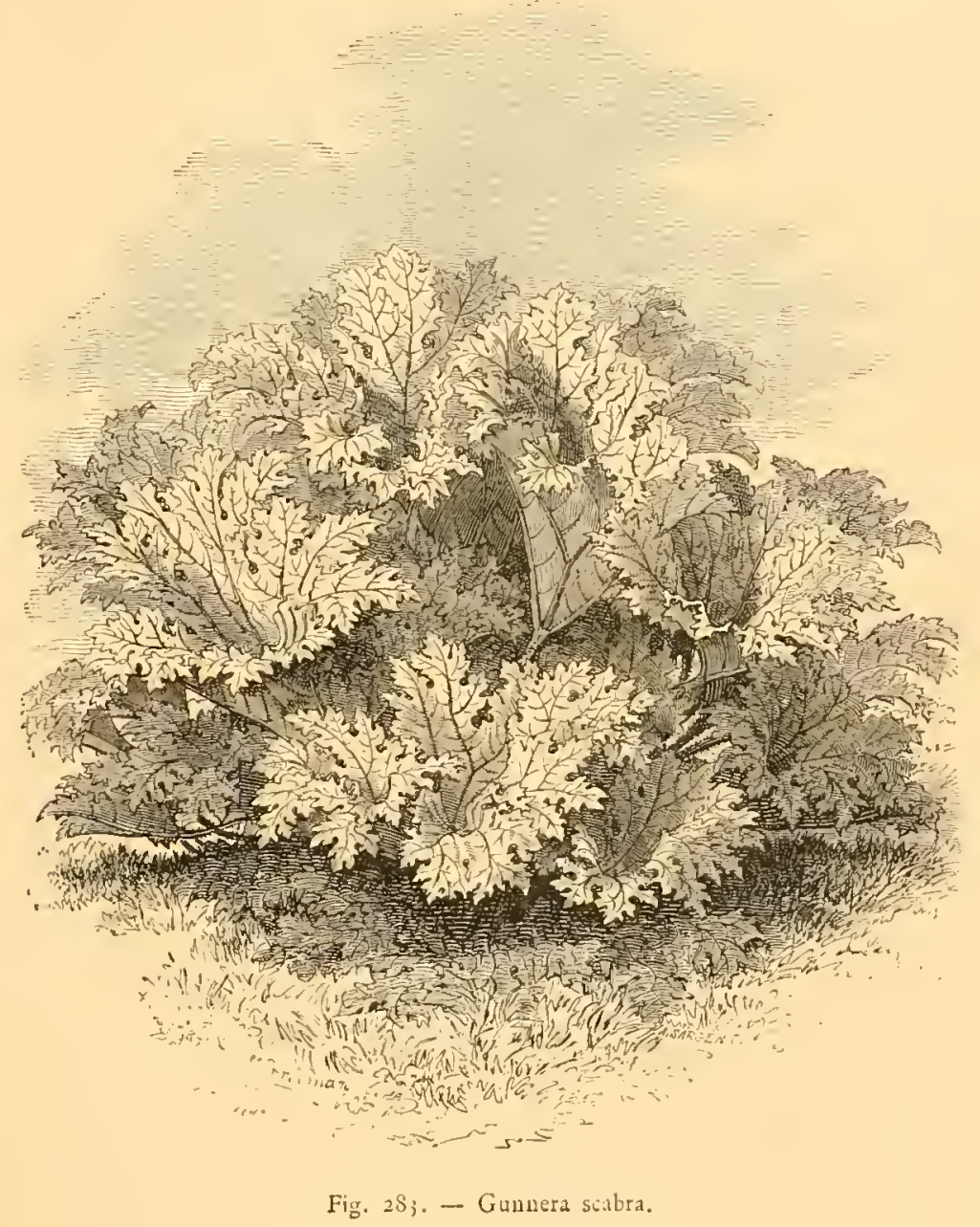
violet presque noir. Ils ont aussi a leur disposition bien d'autres régétaux recommandables par leur feuillage ornemental ou leurs fleurs; comme le Ricinus sanguincus (Fig. 286) qui peut figurer honorablement partout, soit isolé, soit en massits; l'Hortensia, trop dédaigné aujourd'hui, et qui, bien abrité, forme d'almirables massifs roses, toujours fleuris depuis le commencement de l'été jusqu'aux gelées : puis encore les diverses varictés de Brassica (Fig. 288) ou choux violet et panaché, qui rivalisent avec les plus belles plantes ornementales pour la découpure élégante et la belle coloration du feuillage, et, de plus, résistent aux froids les plus rigoureux. 
La rose, qui, en dépit de toutes ces nouveautés envahissantes, mérite et garde toujours son titre de reine des fleurs; - une royauté à l'abri des révolutions! — joint aussi a la rite de la rusplus opulencomme dans bles, elle fait cipaux orneterres et des peut aussi forgazons, de très

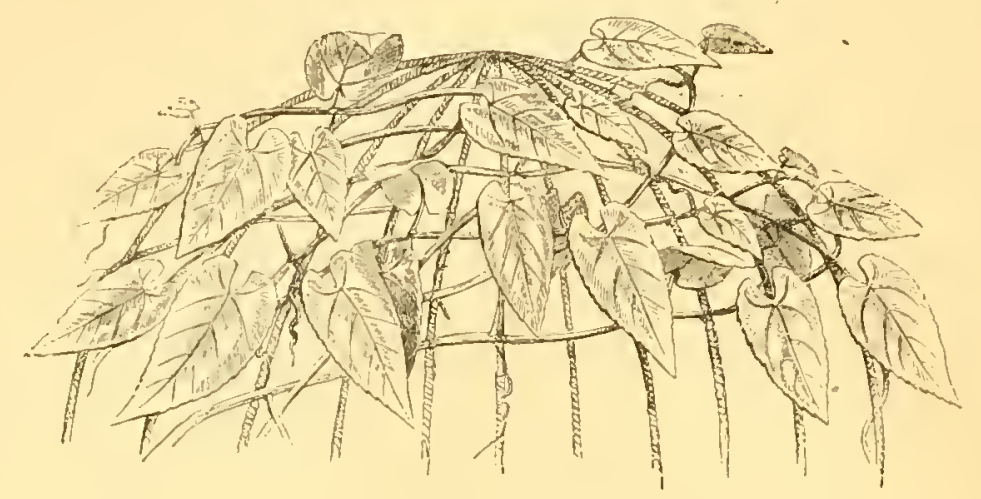

Fig. 284. - Cissus discolor. beauté le méticité. Dans les tes propriétés les plus huml'un des prinments des parpotagers. On mer, sur les belles corbeilles avec des rosiers à hautes et basses tiges dissimulées sous d'autres plantes. Les rosiers francs de pied, principalement ceux du Bengale, de Bourbon, noisette, font

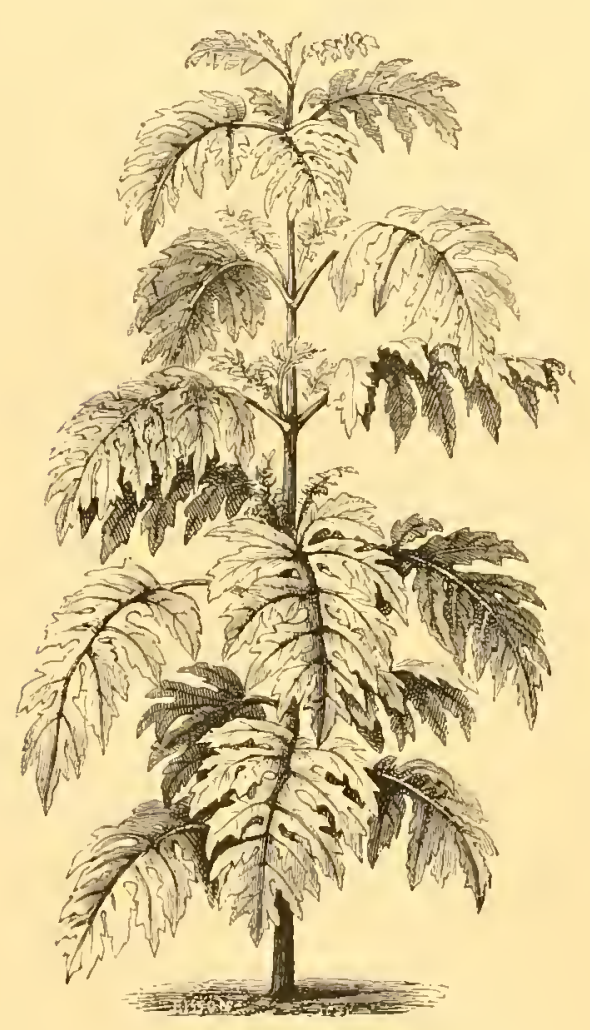

Fig. 285. - Montagnata heraileifolia. très bonne figure sur la lisiére des massifs. On peut aussi les mêler, ainsi que les vitriétés salmenteuses; non seulement aux buissons de lauriers, comme faisaient dejal les Romains (Voir Jardins romatilus, $I^{\text {re }}$ partic), mais aux autres arbustes à teuilles persistantes, notamment aux rhodo-

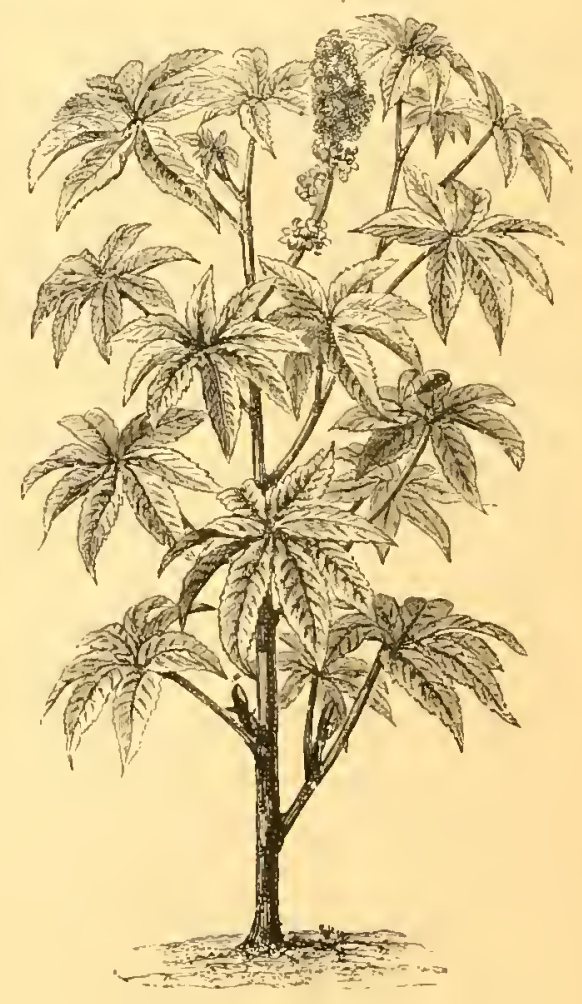
Fig. 286. - Ricinus sanguineus. (

dendrons qui se parent ainsi, en été et en automne, d'une floraison nouvelle. Nous recommandons d'une façon toute spiciale cette combinaison, dont nous arons fait l'expérience arec succès. 


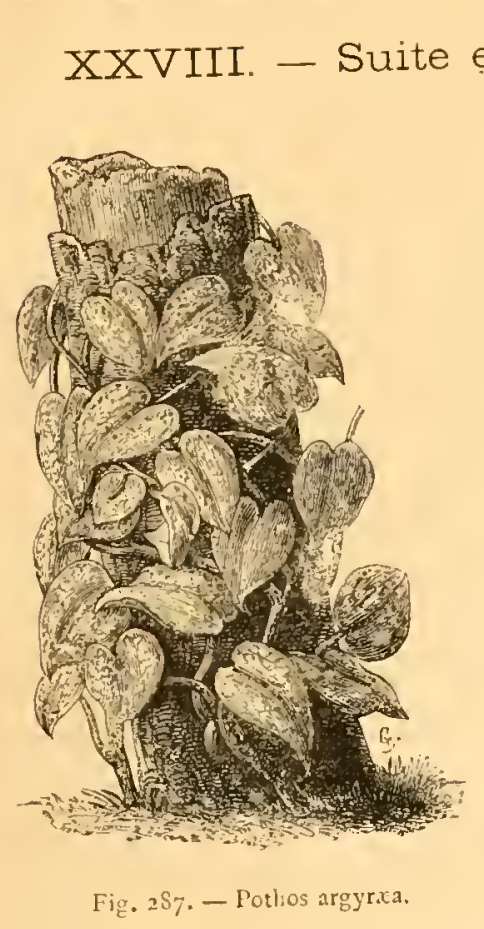

et Fin. - Comme nous l'avons dit précédemment, ces bordures de fleurs ou collerettes fleurics autour des plantations, employées pour la premiere fois dans les promenades parisiennes, ct aujourd'hui un peu partout,

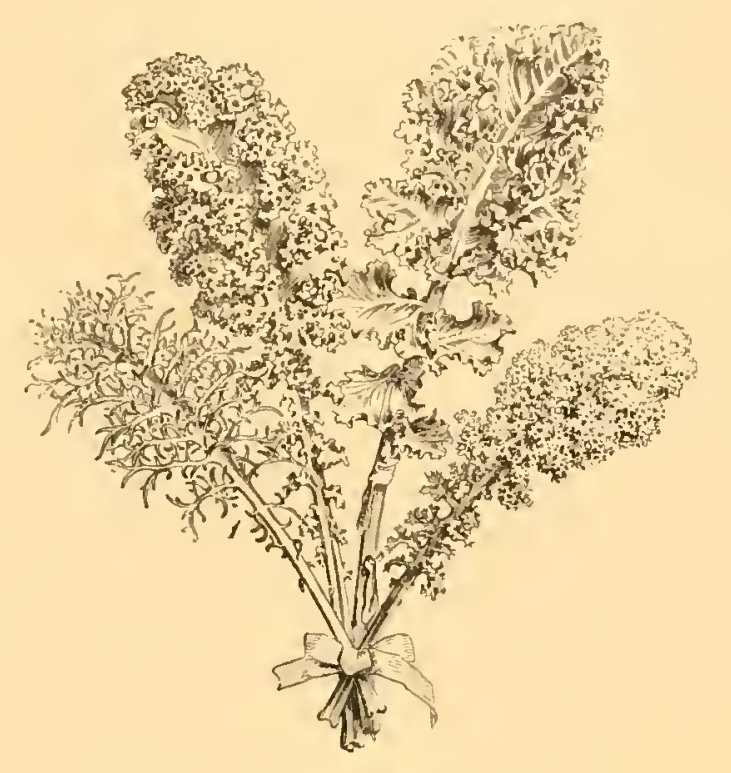

Fig. 288. - Brassica sinensis, Var. (Voyez p, 205.)

sont quelquefois composées de plusieurs sortes de plantes à fleurs ou à feuillage, disposíes en zones b.undes trop étroites un bon effet : cha3o à 40 centimetres donc mieux, si la très large, n'emespèce de plantes. beilles, on ne peut sion au-dessous de métre d'une corle petit diamétre tique. Dans quelpriétés, on s'est deécarté il tort de cette de tout petits masplantes rares en unc innovation malmes circulaire et

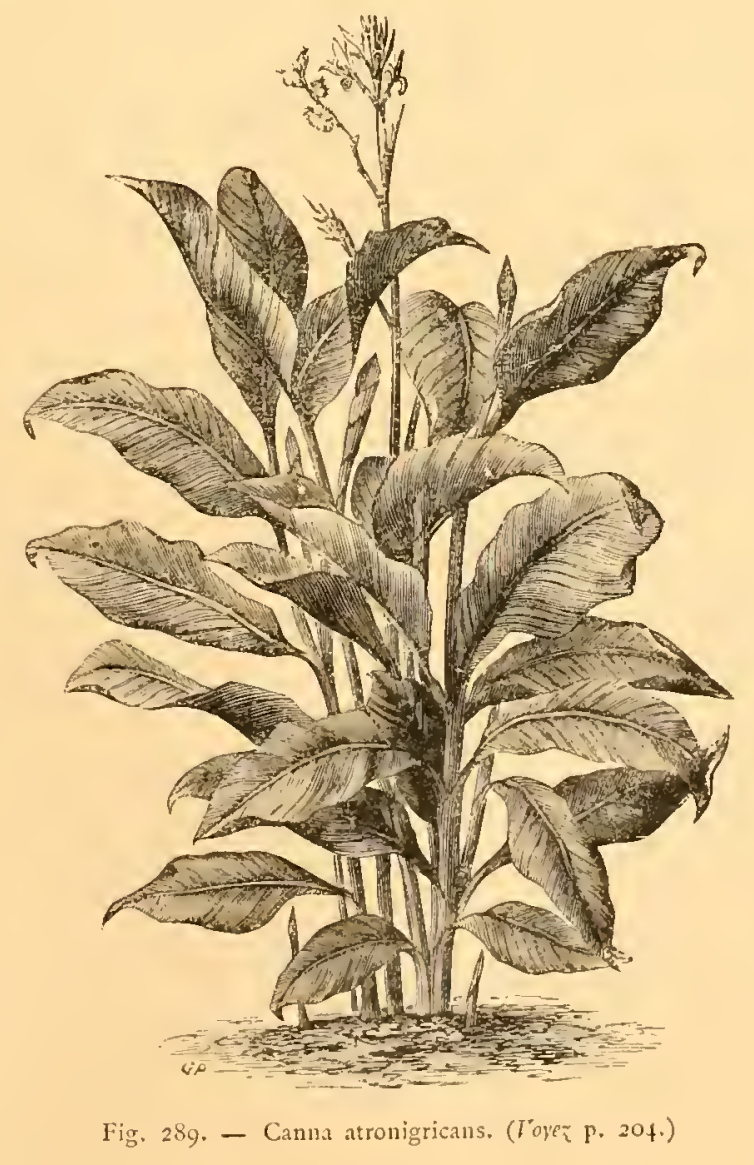
paralléles. Mais des ne produiraient pas cune doit avoir de de largeur. Il vaut bordure n'est pas ployer qu'une seule Quant aux coren réduire la dimen2 métres pour le diabeille circulaire, ou d'une corbeille ellipques grandes propuis quelque temps règle pour former sifs circulaires de forme de pités; c'est heureuse. Les forelliptique sont préférables à toutes les autres, et surtout la forme clliptique : d'abord parce qu'elles 
s'adaptent bien au renflement du sol qui supporte les corbeilles, et au mouvement circulaire des allées; en sccond lieu, parce que le groupement des fleurs se fait plus naturellement dans un périmitre arrondi (1) ». Un autre gracieux ornement des

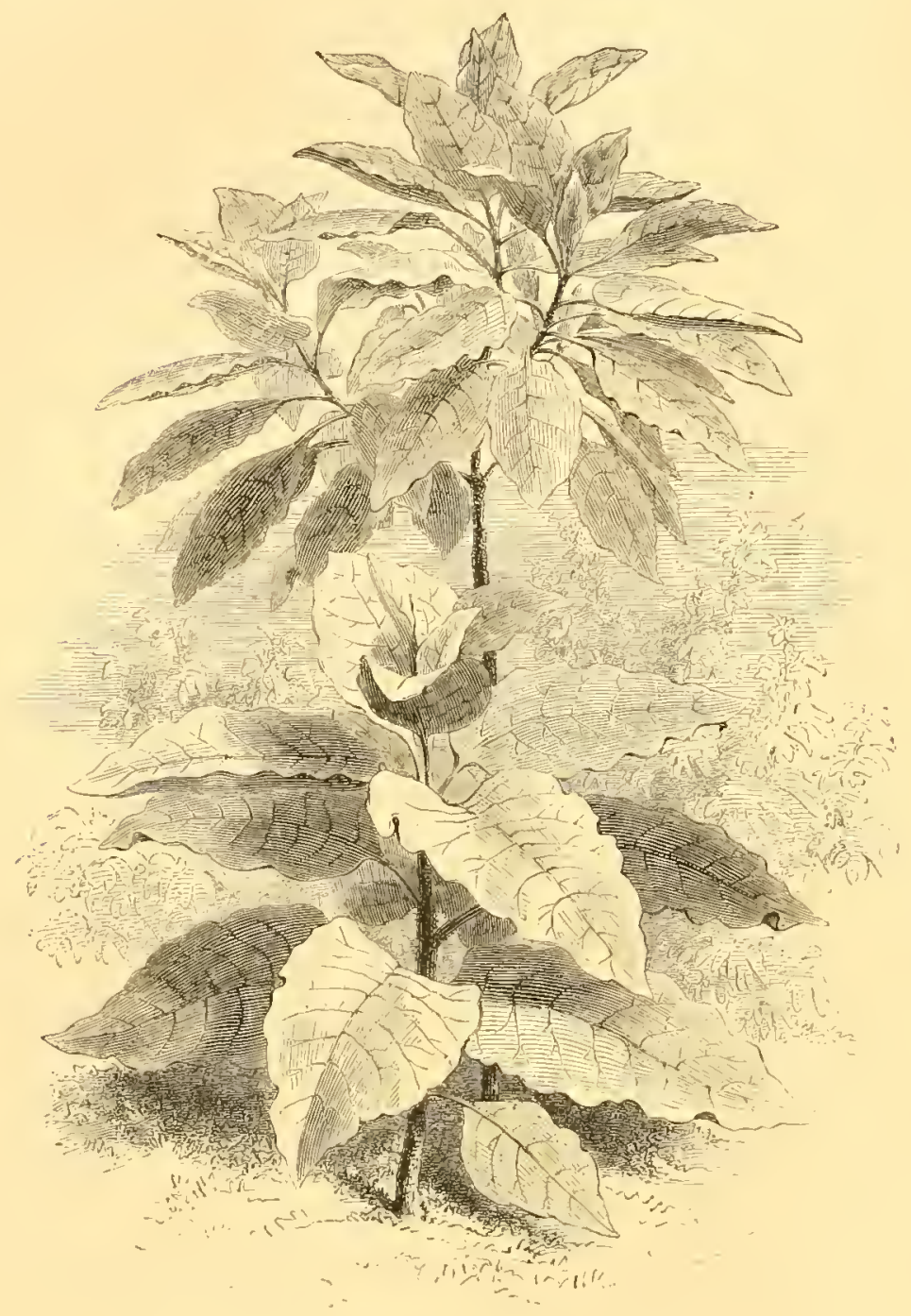

Fig. 2jo, -n Nicotiuna Wigaudioides. pelouses consiste à y placer, pendant la belle saison, des plantes exotiques d'un port remarquable, que l'on y distribue isolément. Il faut toutefois varier les espéces, les grouper, les mettre à distance, et les entretenir arec tous les soins qu'elles méritent. Ce mode de décoration a été employé arec succés dans les Promenades de Paris, aree des plantes empruntées au Flcuriste de la Muette.

Pour remédier à l'inconrénient d'avoir de grandes places vides sur les pelouses dans les derniers beaux jours d'automne; quand on a enlèvé les plantes annuelles et les plantes de serre, on peut les remplacer par les espéces

les plus basses d'arbustes à feuilles persistantes, réservées én pots pour cette destination, comme : Erica carnea, Cotoneaster microplyylla, Mabonia Aquifolinm, Menziczia

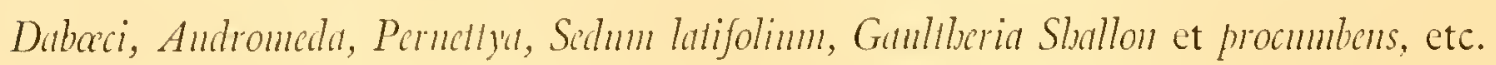

Quelle que soit leur torme, les massifs de fleurs doivent être bombés au milicu,

(I) On dispose assez fréquemment aujourd'hui des corbeilles circulaires, autour des grands arbres placés en saillie sur les pelouses et n'ayant de feuillage qu'i la cime. Cette décoration est d'un effet assez gracieux, mais on n'y peut guére employer que des plantes en pots, à cause du voisinge des racines. 
d'une hauteur moyenne de 20 à 2 j centimétres au-dessus du gazon. Cette méthode, aujourd'hui universellement admise, a l'avantage d'assainir le sol, de donner plus d'air aux racines, et de micux faire valoir la beauté des feuillages ou des fleurs

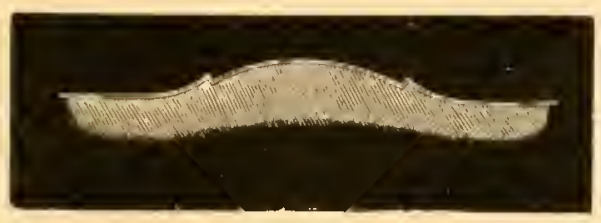

Fig. 291, - Allée bombée.
(Fig. 29I). Cet exhaussement de la surface des massits a aussi l'utilité d'en faire réssortir les contours;

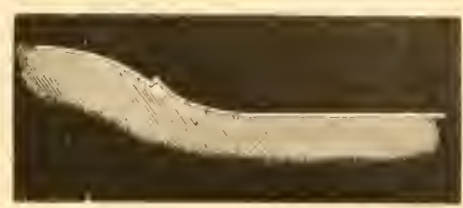

Fig. 292, - Pente graúuée.

mais il faut que les pentes soient bien graduées (Fig. 292). Le gazon doit s'́lever de même en pente douce sur les bords; et une bande de terrain, large de quelques centimétres, doit être ménagée entre l'extrémité supérieure du gazon, et le rebord inférieur du massit.

Nous donnons comme spécimen des distributions de plantes en massifs et en corbeilles, quelques-unes des dispositions qui

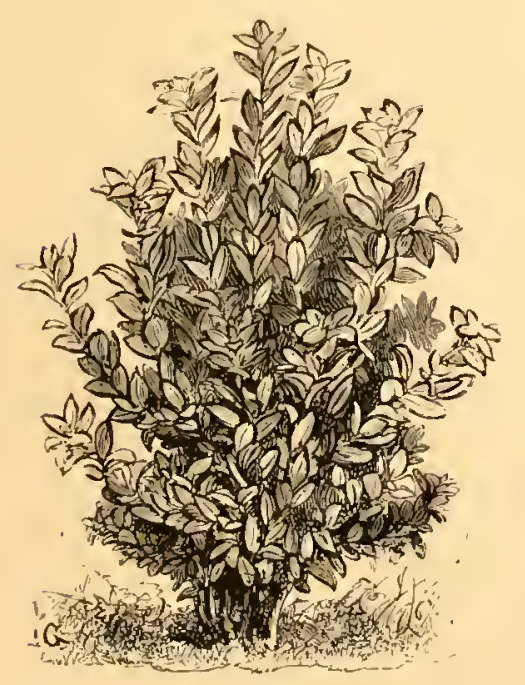

lig. 293. - Fusain du Japon.

ont été adoptées pourl'embellissement de la Ville de Paris :

Avenue du BOIS DE BOULOGNE. MASSIFS. - I. KSculus rubicunda (Marronnier rouge); Aralia spinosa (Aralie

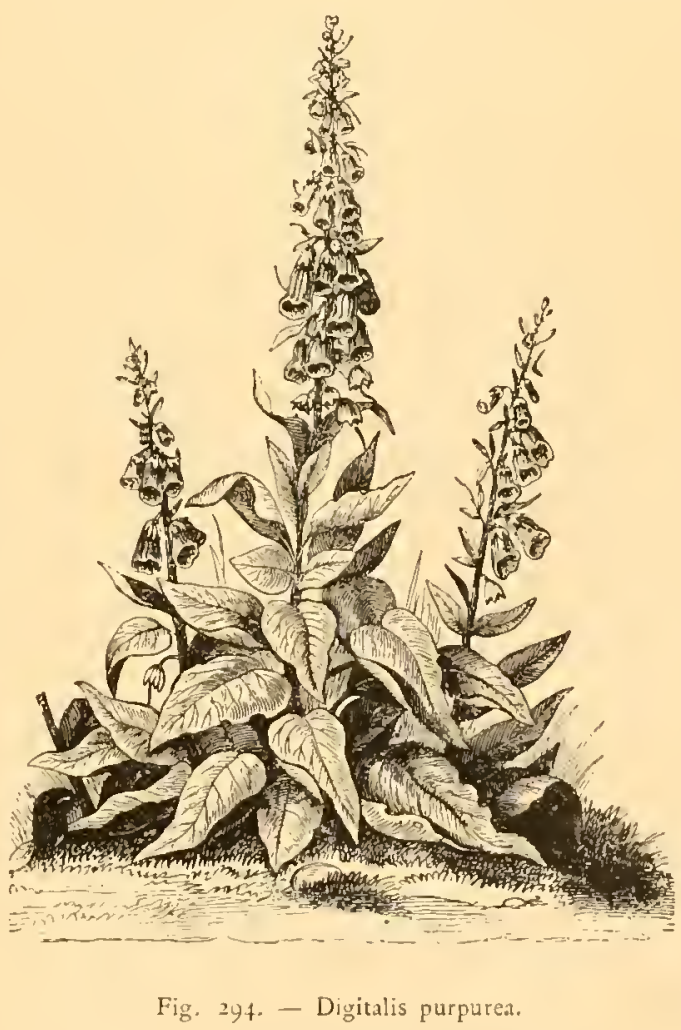

épineuse); Pelargoninm Lutccice glorice (Pelargonium gloire de Paris). - 2. Abelia triflora (Abélie à trois fleurs); Aralia spinosa (Aralie épineuse); Colens marmoratus (Coléus marbré). - 3. Symploricarpos (Symphorine); Tropcolmm lncifermm (Capucine de Lucifer). - 4. Pavia (Pavier); Gazania splendens (Gazanie éclatante). - 5. Quercus (Chêne); Saponaria ocimoides (Saponaire faux basilique). - 6. Sambncus (Sureau); 
Corysanthenum pimalifidm (Chrysanthème pinnatifide). - 7. Berberis (Épine-vinette); Cupbea plalycentra (Cuphéa à larges éperons). - 8. Corylus (Noisetier); Ganra Lindlscimeri (Gaura de Lindheimer). - 9. Lonicera (Chèvrefeuille); Penstemon gentianoides

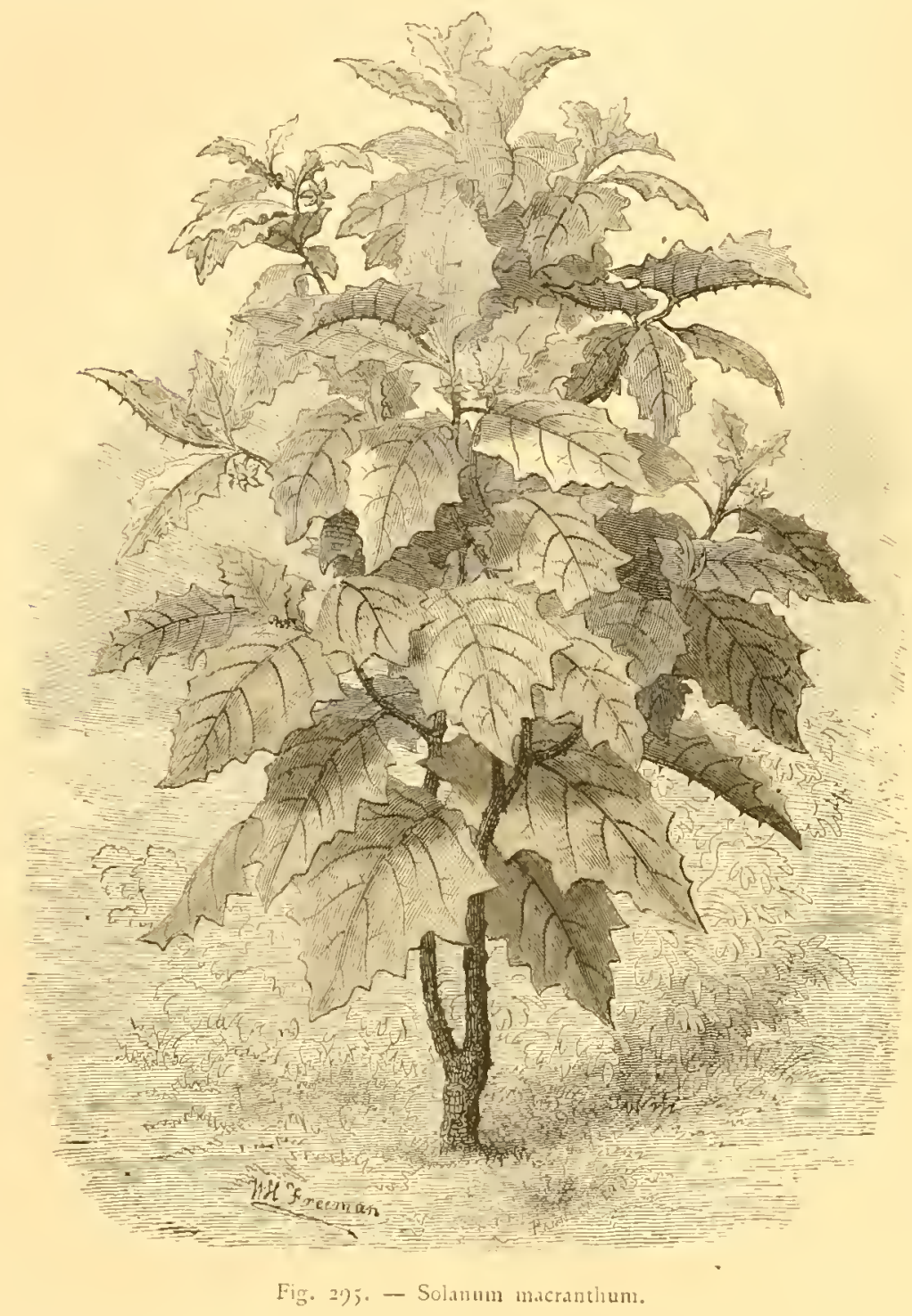
(Penstemongentianoüde). - Io. Clentatis (Clématite); Scaliosa nana (Scabieuse naine). - I I. Platanus (Platane); Fucbsia (Fuchsic). - 12. Catalpa (Catalpa); Amygdalus (Amandier); Petunia (Pétunie).-13.RobiniapsendoAcacia (Robinicr faux Acacia); leronica meddensis (Véronique de Meaus). I4. Cbionanthus (Chionanthe); Pelargonimm zonale (Géranium zoné). Ij. Hippoplate riannoides (Argousier rhamnoide); Pbillyrea (Filaria); Pllox Drmmmondi (Phlox de Drummond). - I6. Cy'donia japonica (Cognassier du Japon); Verbena rubra (Verveine rouge). 17. Fraximus (Frêne); Petmuia (Pétunie). - I8. Tilia (Tilleul); Campamula pyramidalis (Campanule pyramidale). - 19. Buxus (Buis); Pelargonimin zonale (Géranium zoné). - 20. Acer (Érable); Chrysanthemum frulcscens (Chrysanthème frutescent). - 21. Hibiscus syriacus (Althéa, Mauve en arbre); Pelargonimm grandiflormm (Géranium à grandes fleurs). - 22. Carpinus (Charme); Diantlus barbatus (CEillet barbu ou de poétc). - 23. Ilex (Houx); Agcratum carnlcum (Eupatoire bleue). - 24. Ilex (Houx); Chrogsanthomum frulescens (Chrysanthème frutescent). - 25. Fağus (Hêtre); Fuchsia 
fulgens (Fuchsie brillante). - 26. Cratcegus Pyracantha (Buisson ardent); Verbena Rosamunda (Verveine de Rosamonde). - 27. Ribes (Groseillier; Guma Lindbimeri (Gaura de Lindheimer). - 28. Qucrus (Chêne); Phlox Drmmmonli (Phlox de Drummond). - 29. Populus (Peuplier); Erysimum Petrozuskianuın (Vélar de Pétrowslii). - 30. Hydrangea (Hydrangée); Ribes (Groseillier); Verbena (Verveine). 3 I. Betula (Bouleau); Mirabilis jalapa (Belle-de-nuit, faux Jalap). -- 32. Jasminmm (Jasmin); Lantana rosea nana (Camara rose nain). 33. Cormus (Cornouiller); Amarantus melancbolicus (Amarante triste).-34. 07 mus (Orme); Tagetes erecta (Rose d'Inde dressée). 3). Cytisus (Cytise); Lantanc (Camara). - 36. Pcenia arborea (Piroine en arbre); .Pblox Drummondi (Phlox de Drummond). 37. Salix (Saule); Calcndula officinalis (Souci des jar-

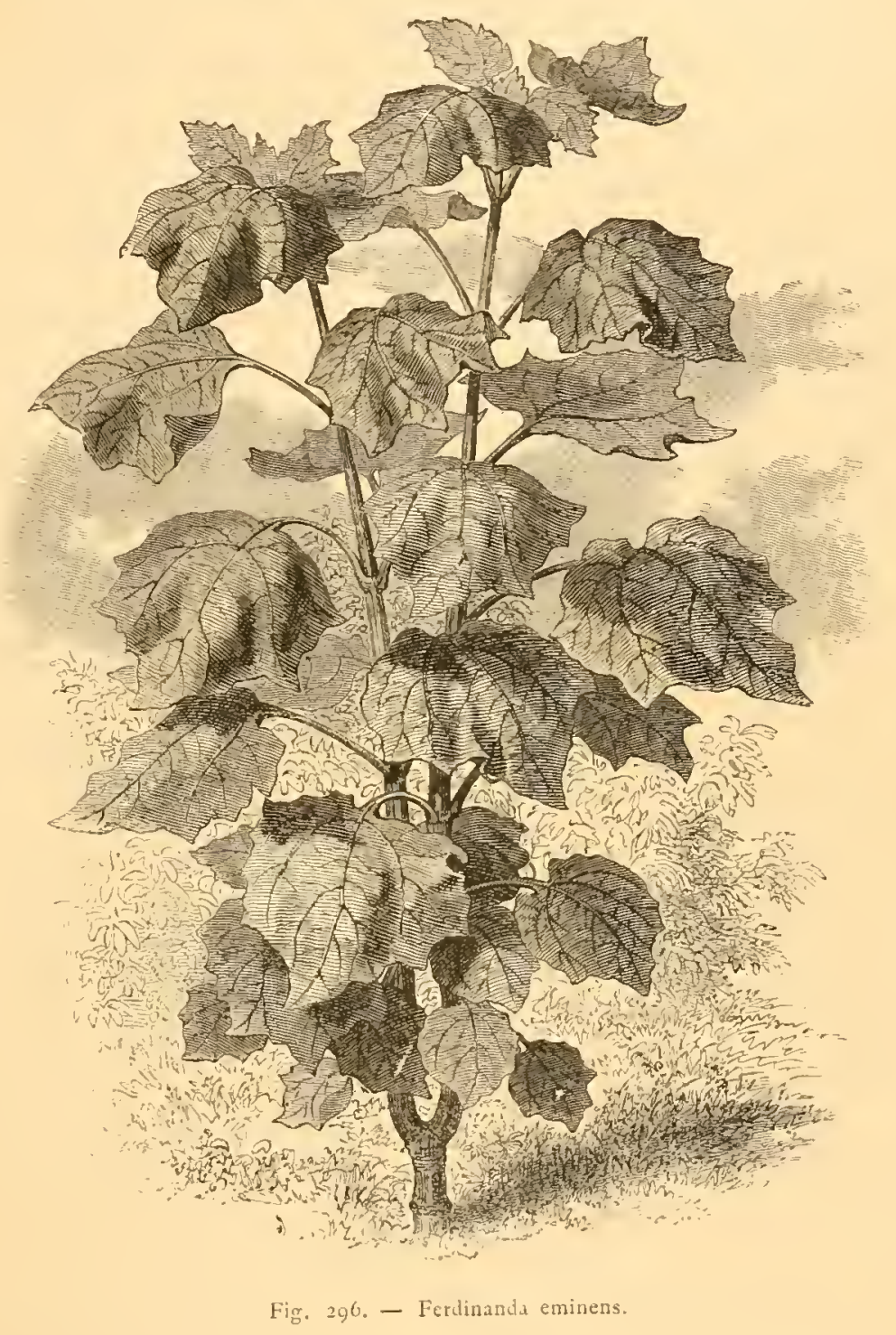
dins). - 38. Sorbus (Sorbier); Ancmone japonica (Anémone du Japon). - 39. Morus (Múrier); Amarantus speciosus (Amarante gigantesque). - 40. Ccanotbus (Céanothe); Verbena (Verveine). - 4r. Acer (Érable); Amarantus caudatus (Amarante queue-derenard). - 42. Corylus (Noisetier); Ancmone japonica (Anémone du Japon). - 43. Vilurnum Tinus (Laurier-tin); Pblox Drummondi (Phlox de Drummond). -- 44. Esculus (Marronnier); Lantana (Camara). - 45. Gleditscbia triadantbos (Févier à trois épines); Lycium (Lyciet); Amarantus melancbolicus (Amarante triste). - 46. Juglans (Noyer); 
Campanula pyramidalis (Campanule pyramidale). - 47. Fraximus (Frêne); Campamula carpatica (Campanule a fleurs en cœur). - 48. Syringa (Lilas); Limmm pereme (Lin vivace). - 49. Panlownia imperialis (Paulonie impérial); Rlms copallina (Sumac co-

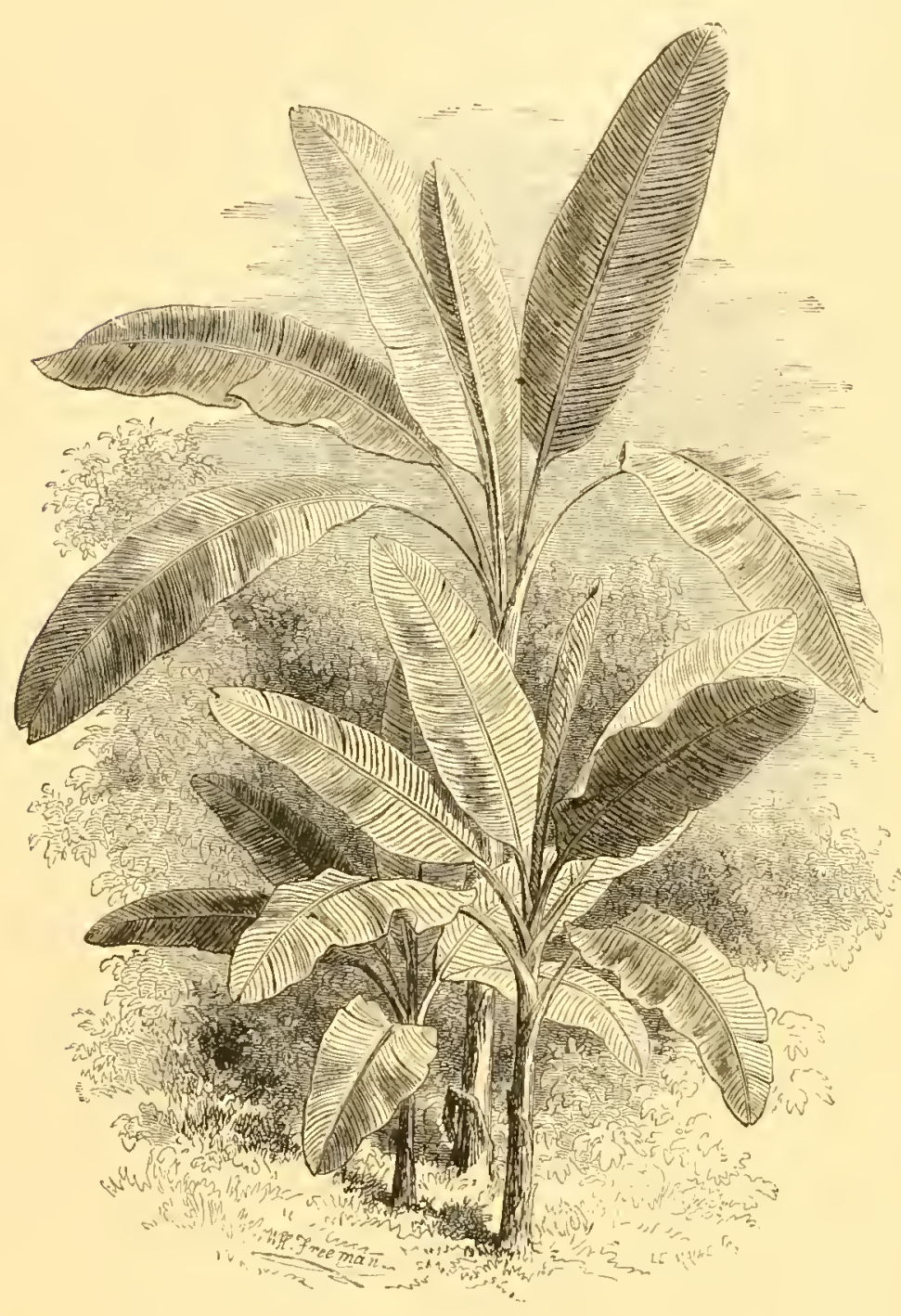

Fig. 297. - Musa rosacea.

pal); Dianthus semperflorens (Cillet toujours fleuri). 50. Magnolia grandiflora (Magnolier à grandes fleurs); Pelargoninm zonale (Géraniumzoné).-51. Esculus mbicunda (Marronnier rouge); Aralia spinosa (Aralie épineuse); Diantlus barbatus (CEillet barbu ou de poète).

Avente du Bols De Boulogne. - Corbeilles. - I. Centanrea candidissima (Centaurée cincraire, trés blanche); Lobclia Erinus (Lobélie Érine). - 2. Senecio platanifolius (Seneçon à feuilles de Platane); Solanmm amaronicum (Morelle des Amazones). - 3. Hibiscus simcnsis (Ketmie, Rose de la Chine).

Iles du Bols De Boulogne. - Corbeilles. - 1. Nicotiana wigandioides (Tabac à feuilles de Wigandie). - 2. Solanmm amazonicum (Morelle des Amazones). - 3. Musa rosacca (Bananier à spathes roses). — + Solanum amazonicum (Morelle des Amazones); Lobelia Erimus (Lobélie Érine. - 5. Ficus clastica (Figuier élastique). - 6. Colocasia esculcnta (Aroüdée comestible). - 7. Colocasia batavicusis (Aroüdée de Batavia; Lobelia Erimus (Lobélie Érine). - 8. Hydranged bortcnsis (Hortensia); Plox decussata (Phlox acuminé). -- 9. Hydrangea foliis variegatis (Hydrangée à feuilles 
panachées); Plolox decussuta (Phlox acuminé). - Io. Conoclinimn jantlinum (Hébécline violette); Plylox decussata (Phlox acumine). - I s. Hibiscus Cooperi (Ketmie de Cooper, à trois couleurs); Diantlus Hedcuigi (CEillet de IJedewig). - 12. Furfuginun grande (Ligulaire grande).

- I3. Duranta Plumicri

(Durante de Plumier); LCbelia Paxtoni (Lobélie de Paxton). - i 4. Aclyrantes Verscloaffelli (Irésine de Verschaffelt); Pclargonimm bederacum (Géranium lierre). - I5. Dracena Draco (Cordyline sang-dragon); $\mathrm{Ver}$ bena Maboncti (Verreine de Mahonet). - 16. Araliu pupyrifera (Aralic a papier); Portulaca grandiflora (Pourpier à grandes fleurs). I 7. Sulvia splendens (Sauge éclatante); Lieniga maritima (Alysse maritime). I8. Begonia tomcutosa (Bégonic tomenteuse). 19. Plumbago carula (Dentelaire bleue). - 20, $\mathrm{Be}-$ gonia fuclosioides (Bégonie à

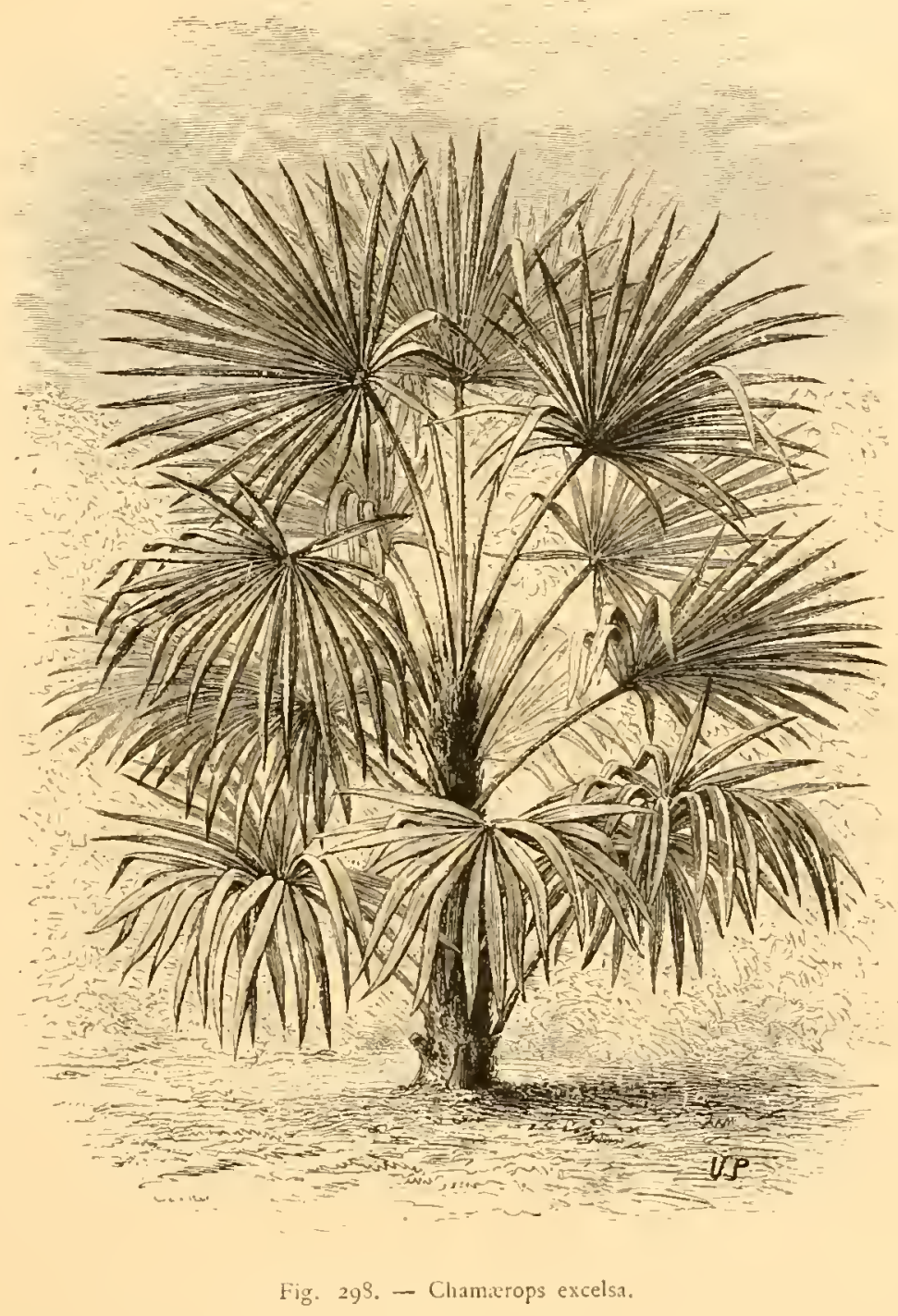
fleurs de Fuchsie). - 2I. Chrysanthemum frutescens (Chrysanthème frutescent); Agcrutum colestinum (Eupatoire bleue); Pelargonium zonde (Géranium zoné). 22. Phorminu tenax (Lin de la Nouvelle-Zélande). - 23. Begonia lucida (Bégonic luisante). - 24. Canma (Balisier). - 25. Scnecio platanifolins (Seneçon à feuilles de Platane). - 26. Eurybiu rosmarinifolia (Astère à feuilles de Romarin). - 27. Centamrea candidissima (Centaurée cinéraire, très blanche); Lobelia Erinus (Lobélie Érine). 28. Canna (Basilier); Fuchsia conqueror (Fuchsie conquéror). - 29. Erytbrima crista 
galli (Érythrine crête-de-coq). - 30. Colocusia odora (Aroïdée odorante); Plblox Drummondi (Phlox de Drummond). - jI. Cassia floribunda (Casse à fleurs nombreuses); Scabiosa nanu (Scabieuse naine). - 32. Conoclinium macroplyyllnm (Hébécline

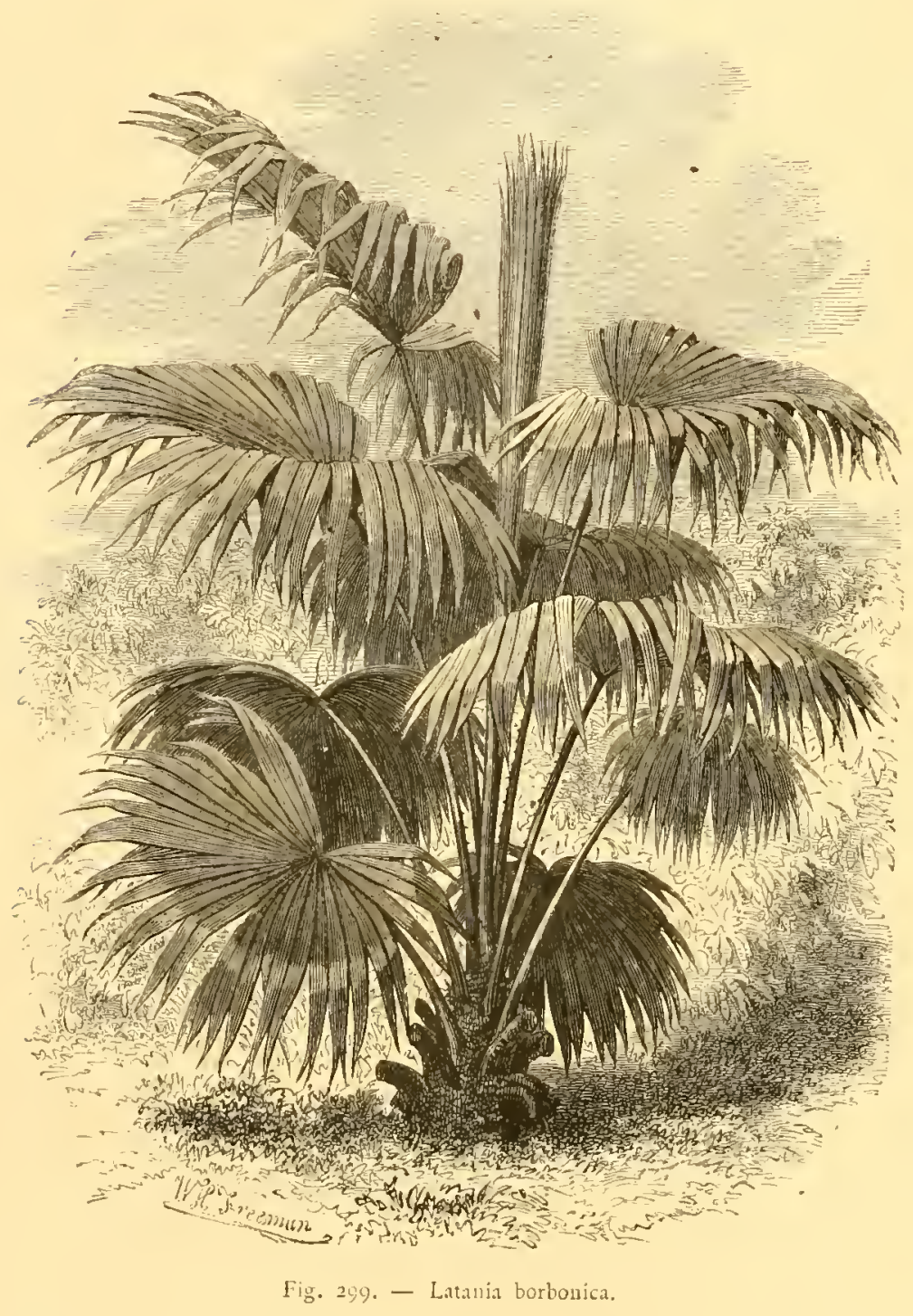

a grandes fleurs); Kaniga maritima fol. var. (Alysse maritime à feuilles panachées). - 33. Spármamia africana (Sparmannie d'Afrique); Sanvitalia proambens (Sanvitalie rampante). 34. Solanmm robustum (Morelle robuste); Aclyyrantbis l'orschaffelti (Irésine de Verschaffelt). - 35. Musa paradisiaca (Bananier à gros fruits); Gazania splendens (Gazanie éclatante). 36. Dracenul congresta (Cordyline entassée). - 37. Begonia grandis (Bégonie grande). - 38. Urtica macroplyylla (Ortie à grandes teuilles). - 39. Begonia Prestoniensis (Bégonie de Preston). - 40. Eucalyptus Globulus (Eucalypte it fleurs globuleuses); Graplualimm lanatum (Immortelle laineuse). - 4 I. Pconia arborca (Pivoine en arbre); Delpbinimm pulchrum (Pied d'alonette remarquable). - 42. Pelargonium (Géranium). - 43. Escallonia macrantba (Escallonie à grandes fleurs); Sanvitalia procumbens (Sanvitalic rampante). - 4. Funkiu subcordata (Hémérocalle à feuilles en cour). Pré Catelan au Bols de Boulogne. - Massifs. - i. Picea excelsa (Pesse, Sapin Epicia); Cerasns Insitanicu (Laurier de Portugal); Ageratmm calestimm (Eupatoire bleue). - 2. Biota oriantulis (Thuia de la Chine); Taxus baccata (If commun); 
Pelargonium Nosegay (Géranium Nosegay). - 3. Acer Neşundo foliis rariegalis (Érable à feuilles de Frêne panachées); Perilla nankincnsis (Périlla de Nankin). - 4. Asculus (Marronnier); Ezonymus latifolins (Fusain ì larges feuilles); Tageles patula (CEillet d'Inde étalé). - 5. Acer pscudoPlatamus (Érable Sycomore); Cerasus Lauro-Cerasus (Laurieramande); Tagetes crecta (Rose d'Inde dressće). - 6. Pimus Laricio (Pin Laricio); Cednot7ns americanıs (Céanothe d'Amérique); Pelargoninm Rubcus (Gíranium à fleurs rouges). - 7. Thuid occidenlalis (Thuia du Canada); Evonymus (Fusain); Clorysanliowmum frutcscens (Chrysanthéme frutescent). - 8. Pavia lnted (Pavier jaune); Ligustrum japonicum (Troëne du Japon); Callistepluns sincusis (ReineMarguerite). - 9. Panlownit (Paulonie); Buxus arborescens (Buis en arbre); Fuclosia Vonus de Medicis (Fuchsie Vénus de Médicis).- I o.Rhododcndrum ponticum (Rhododendron à

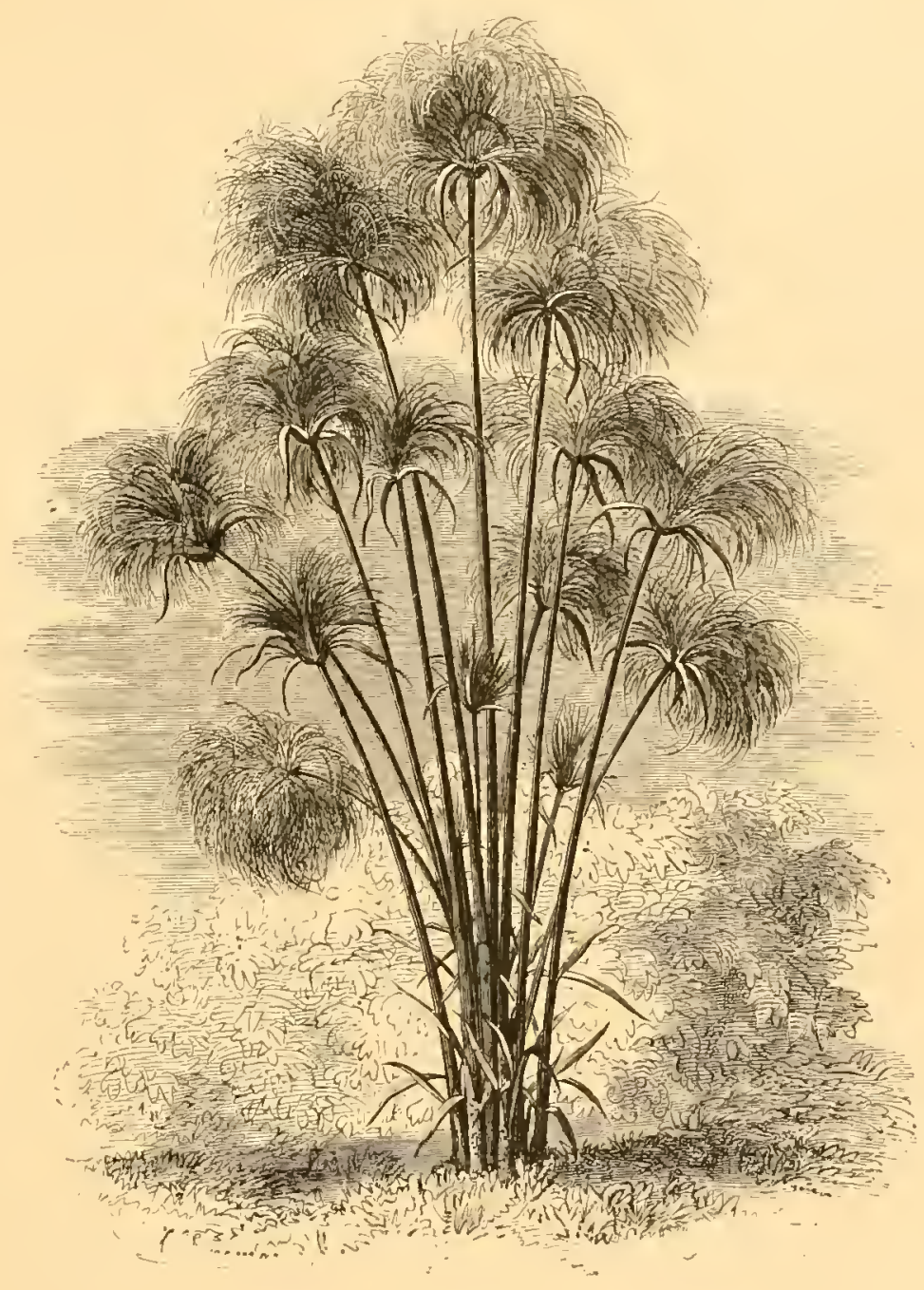

Fig. 300. - Cyperus papyrus.

fleurs violettes); Pelargoninm cibristimus (Géranium christinus). -- I r. Pimus Strobns (Pin de lord Weymouth); Rhammus Alatermus (Alaterne ordinaire); Plumbago carnla (Dentelaire bleue). - 12. Picca cxcelsa (Pesse, Sapin épicea); Pclargoninm Rubens (Géranium à fleurs rouges). - I 3. Pica cxcelsa (Pesse, Sapin épicéa); Mabonia (Mahonie); Veronica meldensis (Véronique de Meaux). - I 4. Magnolia grandiflora (Magnolier à grandes fleurs); Veronica Andersoni (Véronique d'Anderson). - I5. Magnolia conspicua (Magnolier Yulan); Azalea pontica (Azalée pontique); Hydrangea bortcnsis 
(Hortensia). - i6. Magnolia grandiflora (Magnolier à grandes fleurs); Amarantus camulatus (Amarante queue-de-renard). - 17. Magnolia (Magnolier); Callistcplnus sincnsis (Reine-Marguerite). - I S. Pica cxcelsa (Pesse, Sapin épicéa); Ligustrum oz'alifolimm (Troëne a feuilles ovales); Amarantus candatus (Amarante queue-de-renard). - I 9. Magnoliu Sonlumgeana (Magnolier de Soulange). - - 20. Rhododendmun ponlicum (Rhododendron à fleurs violettes); Panicum pliculum (Panie plie). - 2 I. Roliniu psendoAcuciu (Robinicr fulux Acacia); Liysustrmm japonicum (Troëne du Japon); Amarantus bicolor (Amarante de deux couleurs). - 22. Pimus sylerstris (Pin sylvestre); Ceanollous amcricuna (Céanothe d'Amérique). - 23. Querans (Chêne); Ilex (Houx). - 24. Quercus (Chêne); Rbododcudrum ponticum (Rhododendron à fleurs violettes). - 25. Qucrus (Chêne); Kalmia latifolia (Kalmie à feuilles larges).

XXIX. - Tracé des Allées. - Le tracé des allées est, pour les dessinatcurs habiles, lit dernière opération au point de vue de l'étude. C'est, en effet, un accessoire tout à fait subordonné au reste de la composition, et dont il convient de ne s'occuper qu'aprés que l'ensemble de cette composition est arrêté, le terrain nivelé, les plantations distribuées. L'allée n'est, ne doit être qu'un itinéraire. Elle permet de se transporter d'un point à un autre, en suivant la direction la plus commode et la plus agréable. Elle n'ajoute aucun charme au tableau, et lui nuit souvent; aussi dont-elle être complètement effacée dans les perspectives. Pour restreindre ces surfaces arides, on fait leur jonction dans des massifs de verdure, qui masquent les parties latérales. Étant donné un certain nombre de points de vue déterminés á l'avance, le tracé des allées doit être exécuté de manière à diriger le promeneur vers ces points, en suivant des lignes légérement circulaires. Il est bon que ces lignes présentent un mouvement continu, sans brisures ni retours multipliés. On n'emploie guère la ligne droite dans les jardins irréguliers, parce qu'elle ne s'harmonise pas avec les ondulations des vallées. La ligne droite est agréable sur une surface plane horizontale on inclinée. Mais elle est d'un mauvais effet sur les surfaces ondulées, qui la font paraître brisée, parce qu'elle accuse trop les inègalités. Pour suivre les mouvements des rampes et pour contourner les obstacles, la courbe a toute la souplesse désirable. Elle se prête mieux à surmonter les difficultés, et elle permet de dérober plus aisément à l'œil les surfaces arides (sections d'allées), que sal direction sinueuse fait disparaitre derriére çes rideaux de verdure. 
Il faut éviter les lignes serpentantes, et ne les admettre qu'autant qu'elles sont

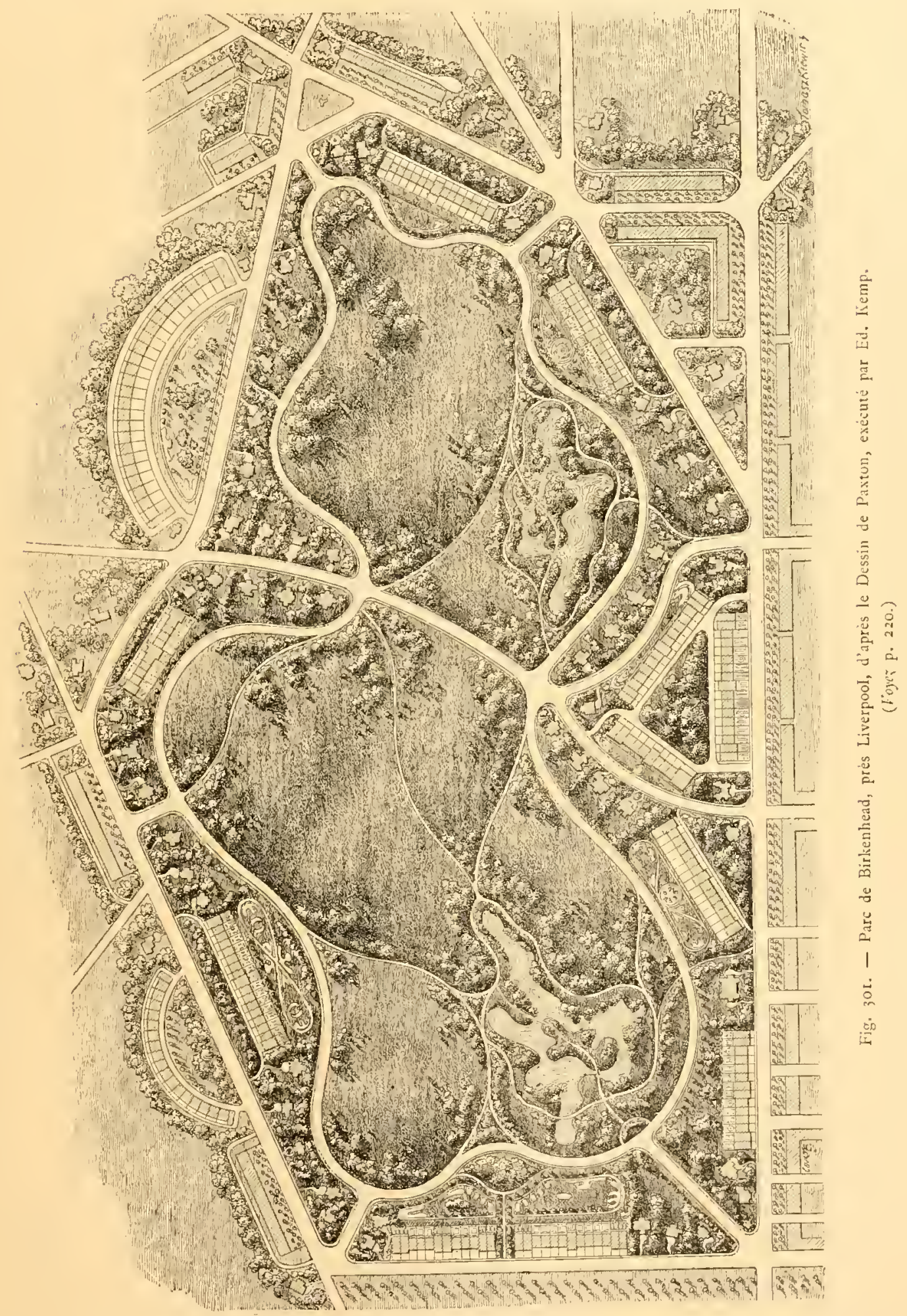

justifiées par la nécessité : par exemple, si elles suivent les sinuosités d'une rivière, 
d'une piéce d'eau; si elles servent à franchir des déclivités un peu fortes, ou à contourner un obstacle inévitable.

Dans les pelouses, il est indispensable de tenir les allées un peu enfoncées, ou (plutôt) de relever légèrement le gazon sur leurs bords, de manière qu'à une certaine distance la zone sablée disparaisse sous la verdure, et que les promeneurs semblent marcher sur l'herbe. Le tracé des allées exige beaucoup de soin. L.curs contours, formant des lignes trés pures, doivent se détacher nettement sur le gazon. Il faut éviter les contre-courbes, qui prolongent la vue des parties sablées et font réapparaître l'allée dans une direction inverse; - ou du moins tâcher de masquer ce retour.

XXX. - Allées de Ceinture, creuses, etc. - Le style régulier, désormais et à bon droit dénommé français, despote plus universel et plus obẻi que Louis XIV lui-même, tenait encore tous les jardins des palys civilisés soumis à ses lois, quand le peintre Hogarth, précurseur révolutionnaire, proclama que la ligne serpentine était la véritable ligne de beauté. Sans doute les allées ne sont qu'ur: accessoire, ou plutôt un corollaire dans la composition d'un jardin paysager; mais un corollaire indispensable. Leur contour ondulé est un des principaux ćl'iments de charme et de variètí; dans des allées de ce style bien tracées, on reconnaît l'imitation des plus gracieuses fantaisies de la nature. C'est par le caprice et le mystère de leurs allures, que les ruisseaux et les sentiers naturels plaisent aux yeux et parlent à l'imagination. Aussi une allée dont toutes les courbes se voient en même temps, perd tout son intérêt. Il importe donc que ces courbes offrent autant de variété que le permettent leur longueur et leur étendue (Fig. 302).

Pour les relier et les dissimuler en même temps, soit d'une section de l'allée à l'autre, soit de l'extérieur, on a recours à des groupes de plantations, composés surtout d'arbres à feuilles persistantes, et accompagnant des sièges ou des abris rustiques; épisodes dont l'importance doit être en rapport avec celle du domaine. Un léger terrassement en contre-bas suffit souvent pour dissimuler la courbe d'une allée.

Pour faire naître et entretenir l'illusion de la grandeur, il importe que les allées ne soient pas trop aperçues de l'habitation, que leur sol soit continuellement dissimulé par des massifs de plantes et d'arbres, et des combinaisons de 
terrassenients. La figure 303 nous montre une section d'allée venant de la maison,

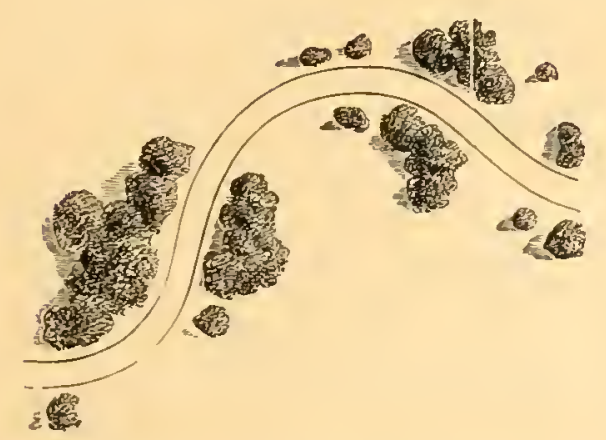

Fig. 302.

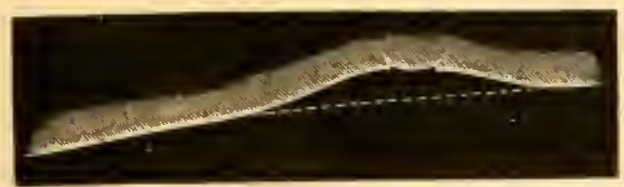

Fir. 30 ;

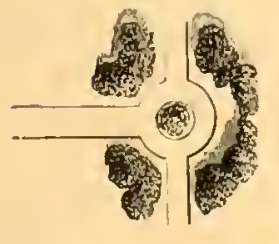

Fig. 304.

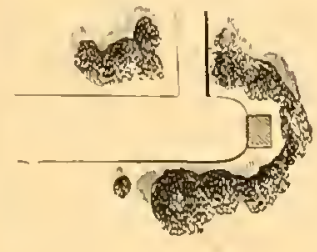

Fig. 305. traversée par une autre allée, qui ne doit pas être vue de loin.

Dans les jardins tant réguliers qu'irréguliers, on peut marquer, par des

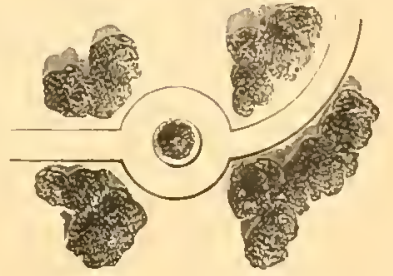

Fig. 306. combinaisons diverses, la terminaison, la rencontre ou la bifurcation des allées : placer, par exemple, soit un siège semi-circulaire, soit une statue ou un vase à l'extrémité de l'allée (Figure 304); un buisson ou tout autre objet ì l'endroit où une grande allée se bifurque en deux plus étroites (Fig. 305), ou change de direction (Fig. 306). La figure 307 indique une allée

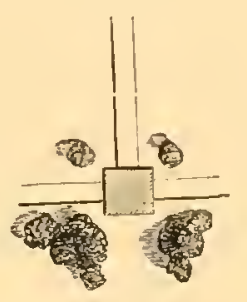

Fig. 307 .

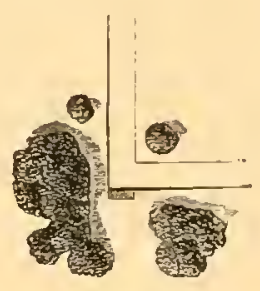

Fig. 308.

droite avec double bifurcation, et une volière ou autre édicule au point d'intersection. La figure jo8 indique une allée avec ouverture sur la campagne.

L'allée doit se diriger vers le but à atteindre, non directement, mais par un mouvement continu; car incliner à droite sans cause apparente, aprẻs s'être dirigé vers la gauche, indique un certain désordre d'esprit, comme si le but était indéterminé. Dans les propriétés d'une étendue médiocre, les plus nombreuses de beaucoup, le dessinateur doit savoir faire naitre et multiplier « ces causes apparentes », pour allonger le parcours sans monotonie, faire naitre et entretenir l'illusion. De brusques déviations (quand elles ne sont pas motivées) semblent inspirées par une réflexion subite, qui raméne le promeneur dans une direction imprévue ou oubliée... Il faut que le paysage change d'aspect à mesure que l'on se déplace; c'est encore une des raisons qui doivent faire proscrire la ligne droite dans les jardins pittoresques... La ligne courbe force le promeneur à se déplacer latéralement, et la ligne de vue est toujours tangentielle à la courbe de l'allée; par conséquent, le tableau change constamment d'aspect durant 
la promenade. Le tracé d'une allée ne doit done jamais être paralléle á l'axe d'une ligne perspective, a moins qu'on ne veuille prolonger la durie de la vision dans une même direction. Dans un jardin particulier, le résélu des allées est en quelque sorte

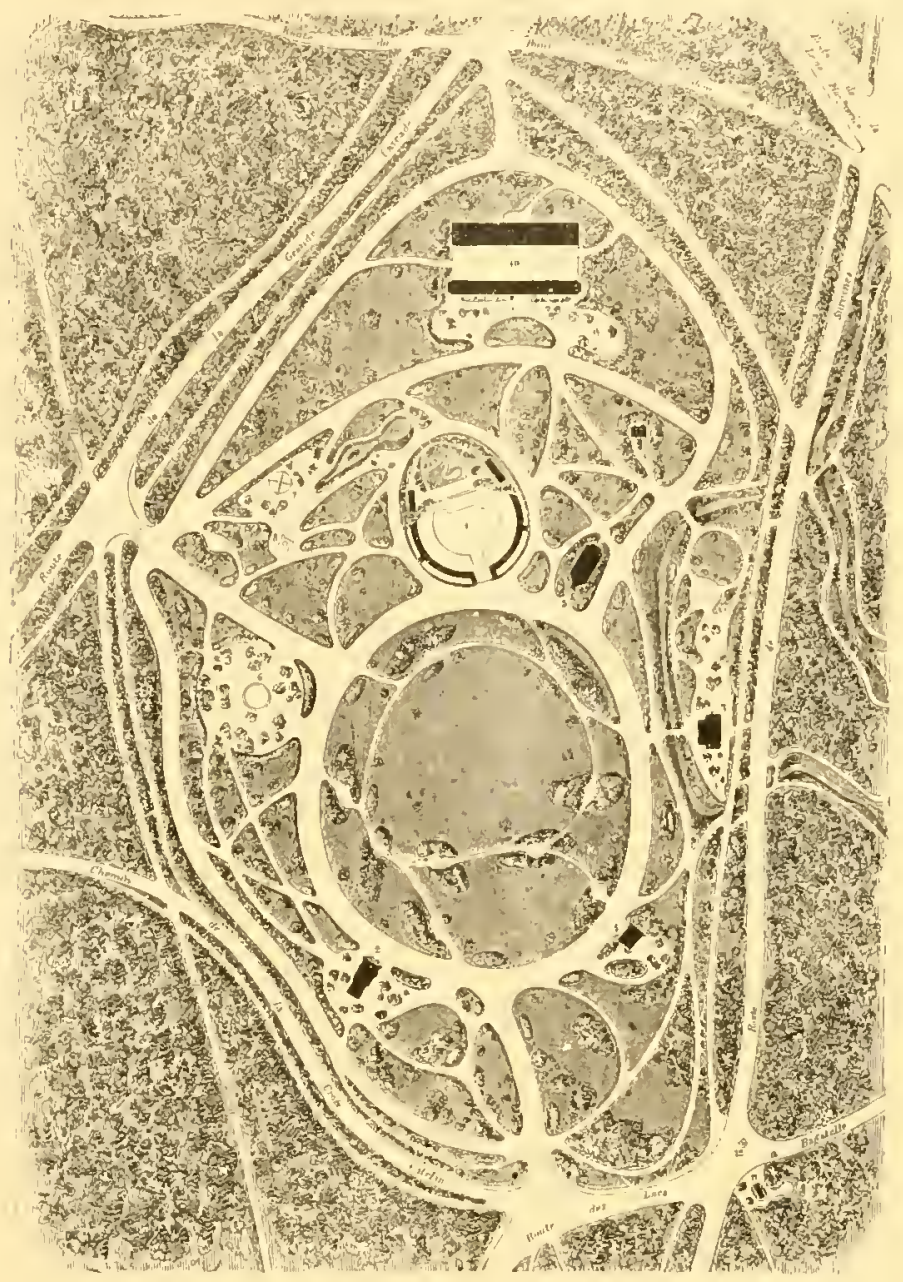

Fig. 303. - Plan du Pré Carclan, au Bois de Boulogne.

I. Thcàte des Fleurs. - 2. Buffer. - ; Brisserie - 4. Photographie - 5. Thciure de Magie. - 6. Orehestre. - 7. Jeux divers - 8 Aquarium. - 9. Cabinets. 10. Vacherte, - I1. Bureau de Tabic. - 12. Croix Catehan. concentrique; les voies qui sont situées sur les points éloignés, doirent toujours ramener le promeneur vers les parties centrales ou vers l'habitation.

Ordinairement on étabiit une voie ou allée qui côtoie de plus ou moins près les limites toujours soigneusement dissimulées du domaine, et à laquelle se rattachent les roies secondaires. C'est l'allée de ccinture, qui, dans les parcs et jardins irréguliers, peut être utilisée en tout ou en partic pour l'arrivée principale, quoi qu'en aient dit $M$. Kemp et quelques autres horticulteurs anglais. Nous figurons ici deux excellents tracés d'allées, l'un Fig.jor, par Paxton, etl'autre Fig. 309, par Barillet-Dechamps.

Voici encore, à propos des allées, quelques préceptes complémentaires qui ont leur importance. 11 fiut que leur niveau varie incessamment. Les différents points de vue de la maison, du jardin, du pays enviromnant, doivent être pris, généralement, des endroits oú le terrain est plus élevé. En principe, et à moins d'une configuration du sol exceptionnelle; comme par exemple si l'habitation est située à mi-côte d'une colline faisant partie du jardin; - clle ne doit pas être vue d'une plus grande hauteur que celle oủ elle est placée elle-même. - Cette régle souffre encore une exception, quand l'endroit élevé, d'oú l'on a vue sur la maison, 


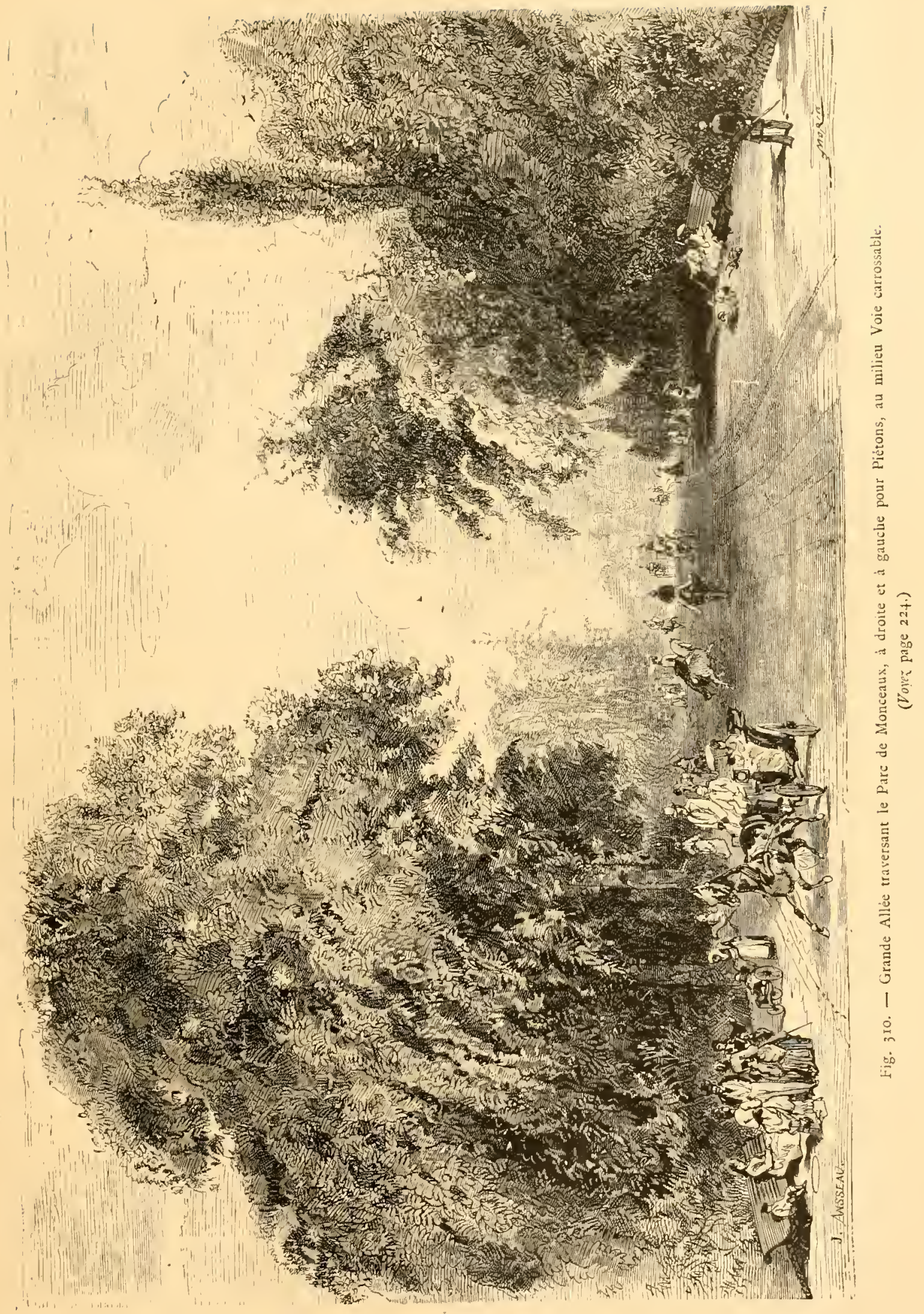


en est séparé par une forte dépression de terrain. Quand deux allées suivent forcément une direction à peu près parallèle, ce parallélisme sera dissinuulé soigneusement par des mouvements de terrain ou des plantations.

Si l'allée se bifurque, les embranchements doivent prendre une direction si

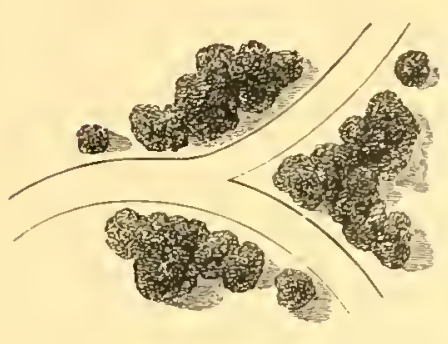

Fig. ;11. nettement divergente, qu'ils semblent bien ne plus devoir jamais se réunir (Fig. 3 I I ).

Les arbustes ou plantations qui garnissent par intervalles les côtés des allées ne doivent jamais former une ligne régulière, ni les ombrager de façon à les rendre impraticables par l'humidité. Aussi, dans les climats pluvieux, il importe de réserver les ombrages les plus épais pour les endroits disposés en pentes rapides. Une allée creuse, si elle est tracée avec intelligence, ajoutera toujours quelque chose à l'intérêt d'un jardin régulier, même peu étendu. Elle concourt à l'agrandissement factice, en donnant une promenade de plus, dont on peut facilement prolonger le parcours au moyen de courbes bien ménagées. D’autre part, ce ravin sinueux, ombragé par places, pourra produire un effet pittoresque, vu de la partie supérieure du jardin. Celui de l'hôtel d'Espagnac (Paris, faubourg Saint-Honoré), dont le plan figure dans la collection Le Rouge, était un spécimen remarquable de ce genre de travail. Il était traversé obliquement par une allée creuse, dont les diverses sections étaient dominées par les ponts qui reliaient de distance en distance les allées supérieures.

En résumé, il faut, dans une propriété irrégulière bien dessinée, que toutes les allées emmènent ou raménent, sans répétition des mêmes objets, ou en les montrant dans un axe différent, et, par conséquent, avec une autre physionomie. Ce principe s'applique aussi bien aux petites qu'aux grandes voies. Chacune doit avoir sa raison d'être spéciale, vraie ou apparente, et concourir à l'effet de l'ensemble. Le tracé de deux allées voisines sera donc.calculé de telle sorte, que les mouvements de terrain et les plantations les maintiennent distinctes dans tout leur parcours. On doit éviter soigneusement la trop grande multiplicité des allées, le parallélisme, les inflexions brusques sans raison suffisante, les chemins trop sinueux trop près de l'habitation.

XXXI. - Confection, Dimensions des Allées. - Voici quelques indications techniques, empruntées aux meilleurs auteurs, pour la confection des allées. Elles doivent être bombées au milieu; de 20 à 25 centimètres selon la largeur et 
même davantage dans les lieux très humides, afin de donner à l'eau un écoulement facile.

Ce précepte n'est applicable qu'aux jardins irréguliers; dans ceux dits à la française, les allées doivent être plates, pour conserver le caractère du genre.

Une allée ordinaire doit reposer sur un empierrement d'environ 30 centimétres; mais une voie carrossable réclame une plus grande épaisseur. Un tiers environ de ce ballast doit être composé de gravier fin, le reste de tuileaux, cailloux, pierres concassées. La natura du gravier varje beaucoup suivant les pays. Il réclame quelque mélange, s'il contient de l'argile ou de la chaux, ear alors il devient fangeux quand il est mouillé. Il faut, dans ce cas, y joindre du sable d'une nature plus sèche. Au contraire, le sable de mer (á moins qu'il ne contienne les matières que dépose une rivière à son embouchure) sera toujours trop friable; il faudra y joindre de la chaux ou de l'argile dans la proportion d'un sixiéme environ. Un tel mélange est excellent, très réfractaire à l'humidité (Kemp). Pour former la surface, le sable de rivière sera toujours préférable, si l'on peut s'en procurer.

La figure ci-jointe (Fig. 3 I 2) représente la coupe d'une allée large de $1^{\mathrm{m}}, 5 \mathrm{O}$. Ses bords doivent être

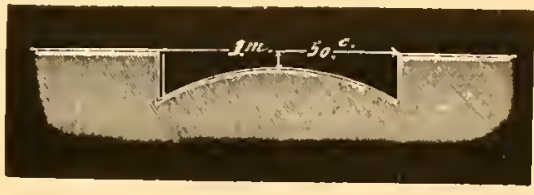

Figg. 312. formés de matériaux ménageant une sorte de drainage naturel qui, d'espace en espace, communique avec un drainage véritable. Dans les terrains accidentés, on creuse souvent, soit dans les pentes, soit aux endroits les plus bas oú les eaux se réunissent et séjournent, des rigoles latérales, afin d'empêcher la dégradation des allées. Ce détournement n'a guére d'inconvénients dans les parties boisées; il en a au contraire beaucoup dans les pelouses, oú ces rigoles portent souvent autant de sable que d'eau. Ce qu'il y a

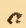

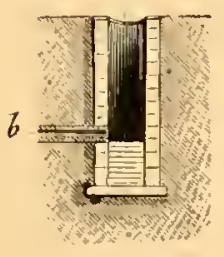

Fig. 313. de mieux à faire en pareil cas, c'est d'installer dans ces mauvais endroits de petits réservoirs construits en cailloux ou en tuiles, et recouverts d'une grille. La figure 3 I 3 représente un de ces déservoirs: $a$ est le couvercle grillé au niveau de l'allée; $b$ le drain qui forme déversoir.

Les bordures des allées doivent être particulièrement soignées, car elles jouent un grand rôle dans l'aspect général. Elles doivent être unies, juste au même niveau des deux côtés (sauf, bien entendu, dans les allées en corniche), et dessinces d'une manière précise. Pour que les bordures remplissent ces conditions, 
il faut que les mottes de gazon soient compactes, empruntées à une prairie de bonne nature. Leur largeur doit être d'environ is centimétres, l'épaisseur de io à i 5 . Il importe

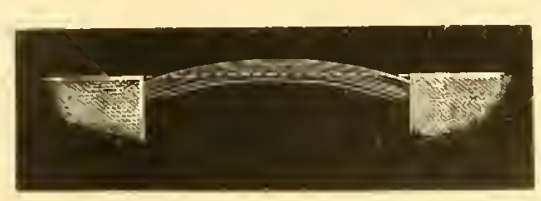

Fig. 314 . qu'clles soient, en moyenne, légèrement bombies au milicu, et un peu plus basses sur les côtés que la pelouse adjacente (Fig. 314). Les allées courbes, qu'on dissimule ordinairement le plus possible, doivent en conséquence être tenues à un niveau un peu inférieur aux pelouses (Fig. 315). Il faut

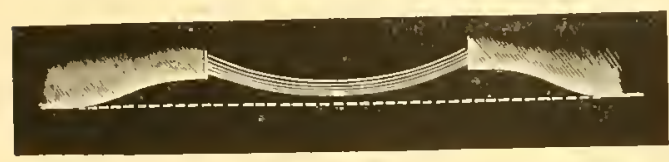

Fig. 315 . aussi leur donner une surface plus convexe que celle des allées droites (Fig. 316). Les dimensions des allées varient assez sensiblement, suivant leur destination (voir Fig. 3 ro, Allée du Parc Monceaux). Les allées carrossables doivent aroir au moins 4 métres; les ordi-

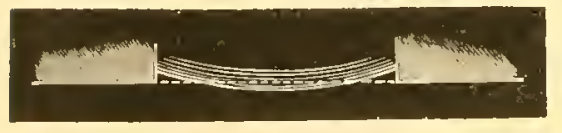

Fig. 316. naires, permettant it 4 personnes de circuler de front, de $2^{m}, 50$ à 3 métres; les petites allées $\mathrm{I}^{\mathrm{m}}, 50$. Kemp réduit a 3 mètres la largeur des allées carrossables; cette dimension n'est suffisante que dans les petites propriétés.

XXXII. - Entrées des Parcs. - Suivant quelques auteurs, l'entrée d'un pare franchement irrégulier ne doit être aperçue ni de l'habitation, ni des principaux endroits de promenade. Ce précepte est une déduction logique du principe de la dissimulation des clôtures, mais son application n'est pas toujours possible. La perspective plus ou moins lointaine d'une loge d'entrée, construite avec goût et bien accompagnée, peut produire un excellent effet, et il serait souvent fâcheux de s'en priver (I).

Kemp dit aussi " qu'une route d'arrivée ne doit pas s'engager dans le domaine à une trop grande distance des bâtiments, ni suivre les clôtures ». Nous croyons, au contraire, qu'une propricté ne peut que gagner à cette prolongation d'arrivée, si tout est convenablement disposé sur le passage. Par la même raison nous pensons aussi (et nous en avons fait l'expérience), que l'on peut faire avec succès, pour l'arrivéc principale, l'emprunt d'une section plus ou moins considérable

(1) Nous n’avons pas à revenir sur ce qui a été dit ci-dessus de ces loges d'entrée, dont nous avons donné d'execllents modèles. Nous répéterons seulement que si l'entrée se trouve suffisamnent doignée de l'habitation, on obtiendra sûrement un effet des plus heureux, en donnant au logement du concierge et it ses dépendances l'aspect d'un colfage ou petite demeure à part, accompagnée par les preniers massifs qui se présentent à l'entrée du parc. 


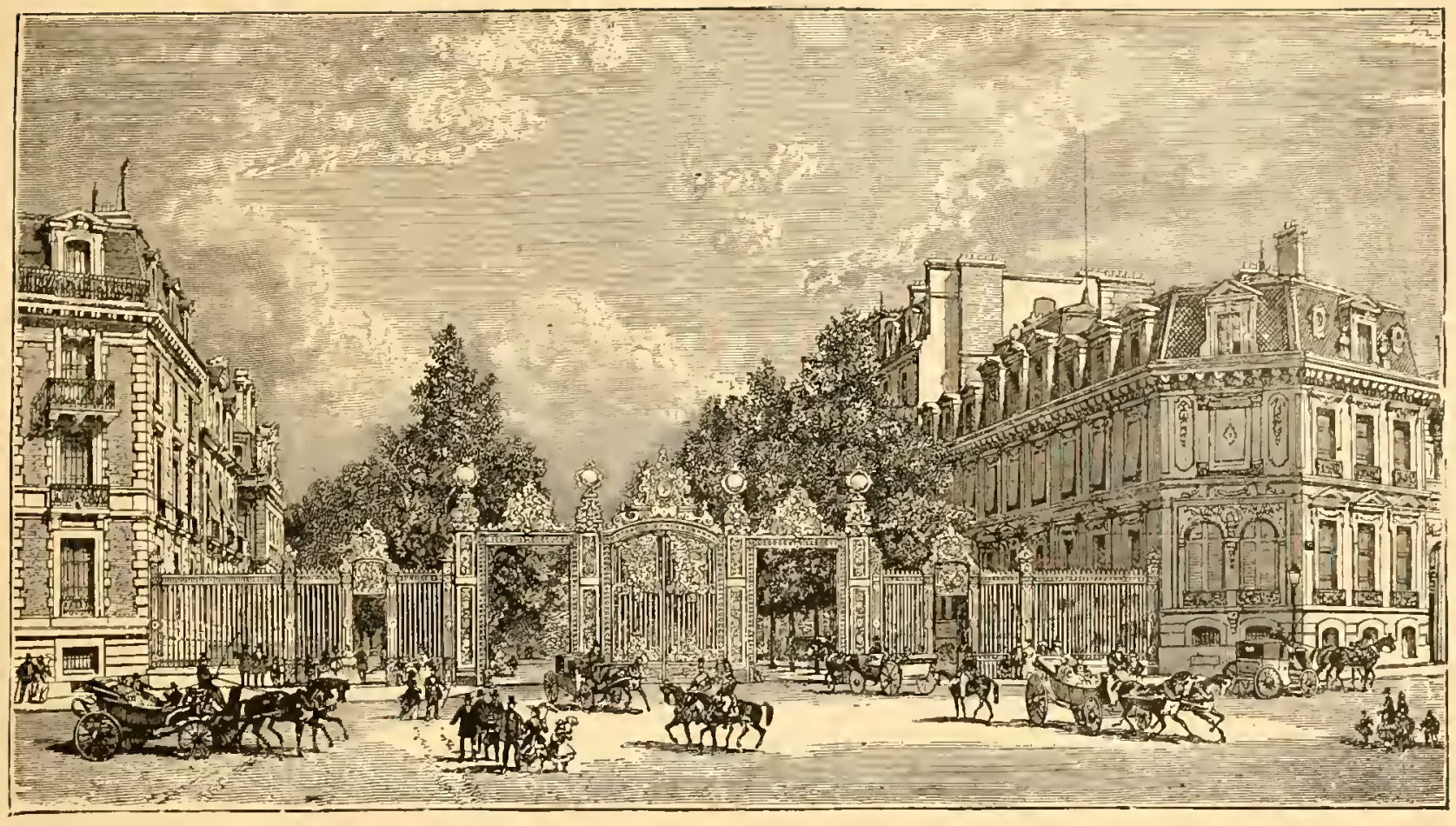

Fig. $317 .-$ Entrée du Pirc Monceau.

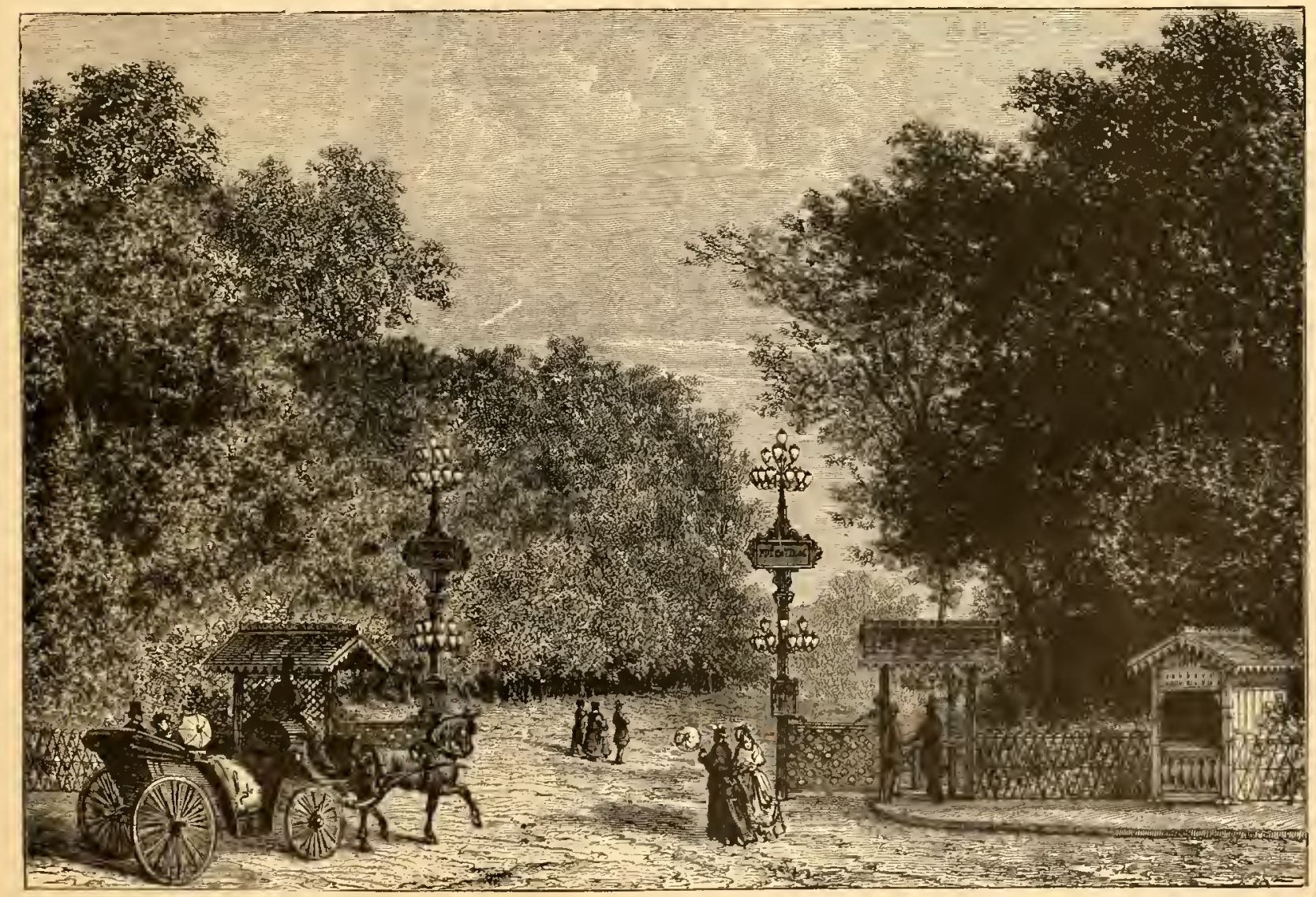


de l'allée de ceinture; et, par conséquent, côtoyer souvent d'assez près les clôtures pendant ce parcours; pourvu, bien entendu, qu'elles soient habilement dissimulées.

Le même auteur se contredit et revient implicitement à notre opinion, quand il ajoute, un peu plus loin : "qu’il importe de s'élever vers l'habitation par lạ

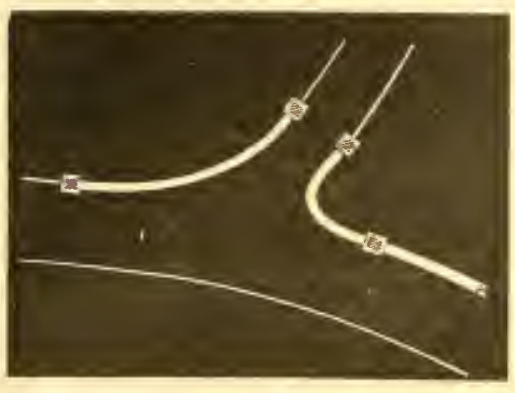

Fig. 319. - Entrèe de Parc.

tefois, si l'on veut donner à l'entrée un caractère plus imposant, il faudra faire les

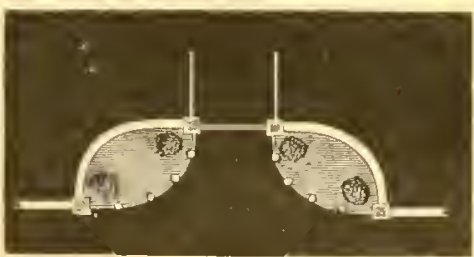

Fig. 320. - Entrée de Parc. longée. »

En principe, l'entrée doit être perpendiculaire au grand chemin; cependant il peut être quelquefois nécessaire de la placer dans un angle ou dans une courbe.Généralement, les murailles ou autres clôtures de chaque côté de l'entrée, doivent affecter une forme convexe en abordant la grande route (Fig. 319). Toumurs concares, et disposer de chaque côté des bornes reliées de chaines, formant la courbe convexe. Lintervalle compris entre ces deux courbes sera gazonné, et orné d'arbustes ou de buissons à fleurs, si l'espice est suffisant (Fig. 320). pente lia plus douce, et conséquemment la plus pro-

Quelquefois deux entrées sont indispensables, quand la propriété est importante et roisine de deux villes ou bourgs situés dans des

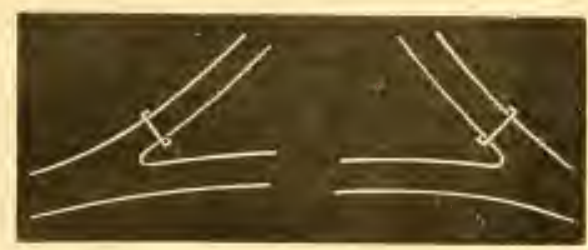

Fig. 321. - Entree doublc. directions différentes. La figure 32 I donne le modéle d'une de ces entrées doubles, régulièrement disposées. Cet arrangement suppose que les deux villes ou bourgades voisines sont à l'opposite l'une de l'autre, et relièes par une route sur laquelle s'embranchent les deux entrées. Cette disposition d'embranchement pourrait, sans inconvénient, être moins régulière, ct n'en ferait même que meilleur effet, dans une propriété du style paysager.

Quand le relief du sol est fortement accidenté entre la route et l'habitation, il faut dissimuler les remblais de l'allée d'arrivée avec tout le soin possible, en les reliant par des plantations à l'ensemble.

Si, au contraire, le terrain est uni, le style de la maison régulier, et l'intervalle 
entre elle et la route assez grand, si enfin la route est déjà reliée à l'habitation par une belle avenue, ce serait une faute de la sacrifier. Mais, pour que cette combinaison, empruntée au style régulier, produise tout son effet, il est essentiel que l'avenue s'ouvre en ligne droite, sur un terrain plat, ou au moins sur une pente doucement et régulićrement inclince. A l'arrivée devant l'habitation, on est toujours disposé

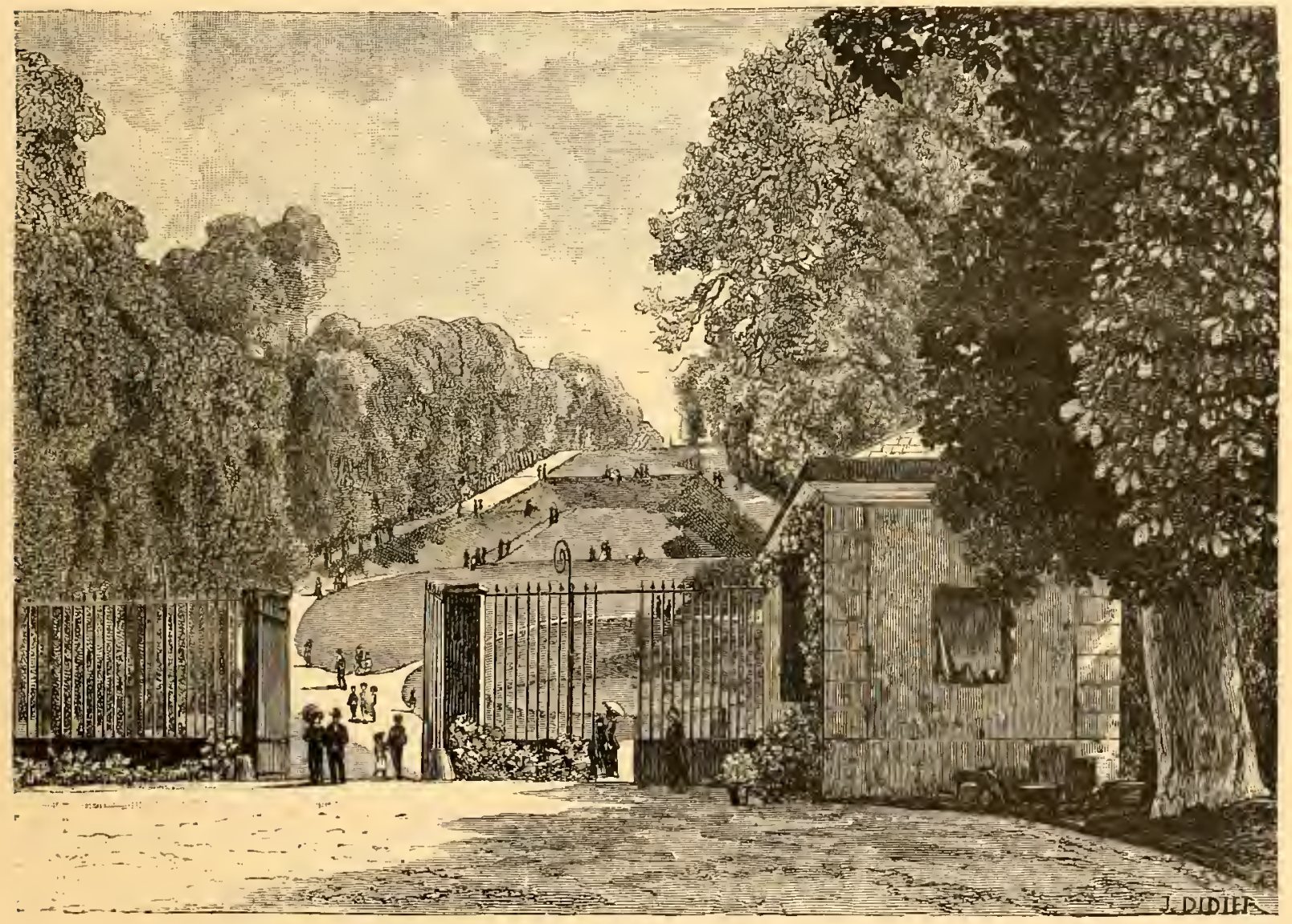

Fig. 322. - Entrée du Parc réservé de Saint-Cloud.

à exagérer la largeur de l'allée, au détriment de l'étendue en pelouse et de l'effet général, pour donner aux voitures une plus grande facilité de tourner. Pour déterminer cette largeur, il faut naturellement prendre en considération l'importance de l'habitation et d'autres circonstances; mais, en moyenne, ro à 12 mètres doivent suffire. Nous figurons ici quelques entrées de grands Pares des Promenades de Paris et des environs (Fig. 3 1 7,3 I 8,322 ).

Quand l'entrée n'est séparée de l'habitation que par un eśpace étroit et borné de tous côtés, il faut bien, même dans un jardin du style paysager, recourir à la 
combinaison d'une petite pelouse ovale ou circulaire, ornée de fleurs et d'arbustes à feuilles persistantes (Fig. 323). Mais, pour peu qu'on

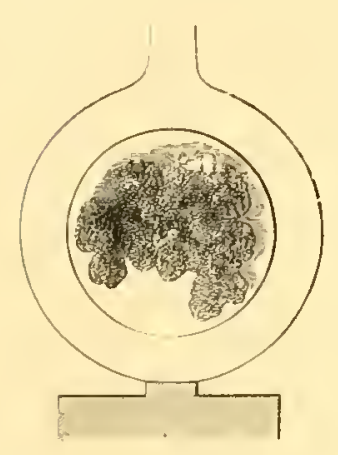

Fig. 323 . puisse s'étendre à droite et à gauche, i] vaut beaucoup micux prolonger cette devanture en ellipse, en la reliant aux plantations de clôture, de manière à éviter toute apparence de régularité (Fig. 32.4). Les routes angulaires (Figure 325), ou octogones (Fig. 326), sont d'un effet satisfaisant quand on

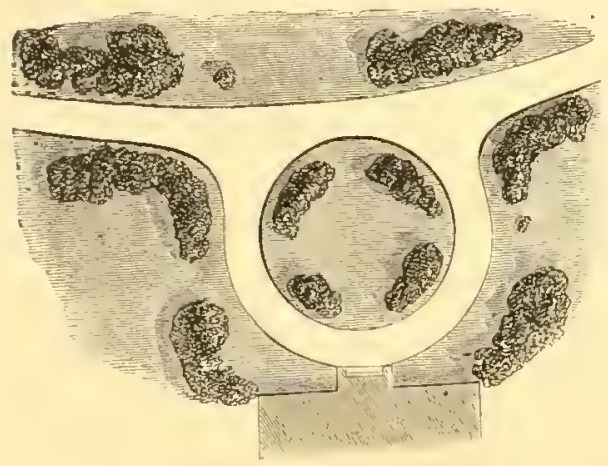

Fig. $32 \%$,

veut se conformer au style classique, bien que l'habitation ne soit accessible que latéralement.

Sil n'est pas possible d'organiser une entrée de service particulière, on tournera la

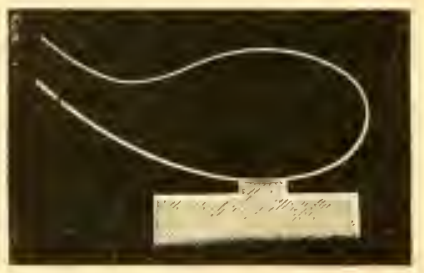

Fig. 324 .

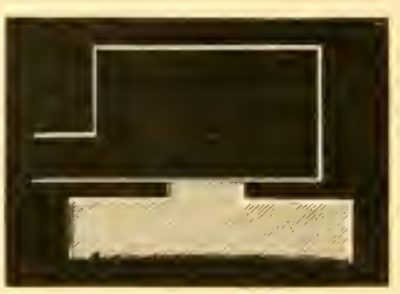

Fig. 325 .

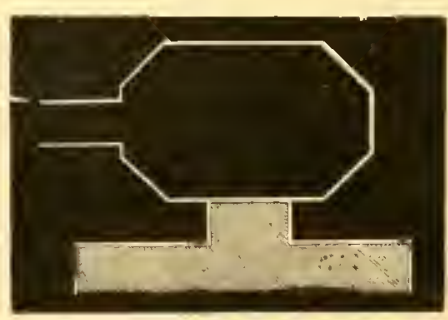

Fig. 326 .

difficulté en établissant, sur le chemin qui se dirige vers les communs, un embranchement circulaire, affecté à l'habitation (Fig. 327).

XXXIII. - Des divers Systèmes de Clôtures. - On ne saurait trop le redire; il importe toujours de dissimuler les clôtures, d'empêcher même qu'on les soupçonne ou qu'on y pense. Les fossés, faciles à rendre invisibles au moyen de légers mourements de terrain, sont donc, quand la nature des limites le permet, le meilleur mode de clôture.

Il ne faut user qu'avec discrètion des fossés partiels, dits sauts-de-loup, et seule-

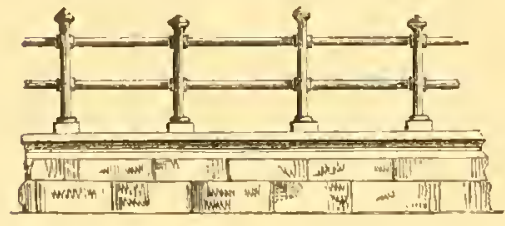

Fig. 328 . ment quand e'est le seul moyen de faire brèche sur une perspective intéressante, placée dans cet axe. Les abords de cette brèche doivent être habilement raccordés avec les premiers plans, au moyen des plantations.

Nous donnons (Fig. 328) un modèle de clôture assez élégant. Le mur a 80 centimètres de hauteur; les barres des balustrades 25 milli- 
métres de diamétre. On peut y substituer, soit des treillages mécaniques, soit des

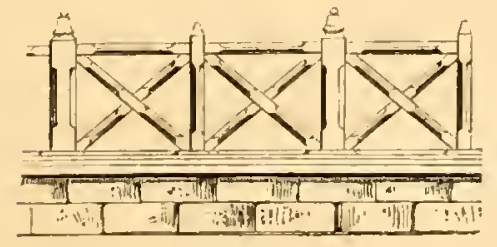

Fig. 329 . balustrades en bois de chêne ou de châtaignier, dans le genre de celle-ci (Fig. 329). Nous citerons aussi, comme clôture extérieure solide et facile à dissimuler, les palis-

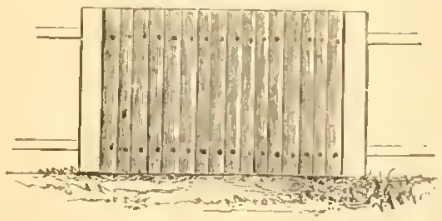

Fig. $3 ; 0$.

sades en bois, dont voici le modèle le plus simple (Fig. 330). Pour les clòtures intérieures, qui n'exigent

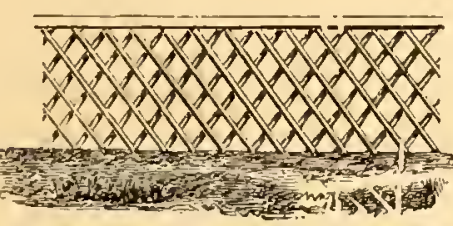

Fig. $33 \mathbf{1}$.

pas la même solidité, on emploiera soit celles en fil de fer galvanisé, soit, dans les pays où le bois est commun, des clôtures

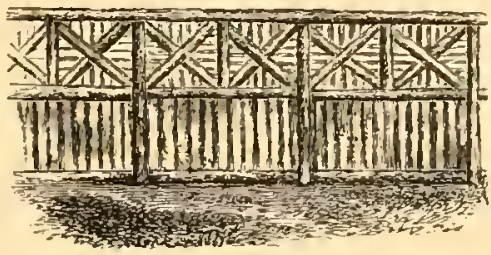

Fig. 332 .

de bois rustique (Fig. 331). Enfin, pour dissimuler, soit au dehors, soit dans l'intérieur, une vue désagrẻable, on peut recourir au système de palissade ci-joint (Fig. 332), haute de $\mathrm{I}^{\mathrm{m}}, 5 \mathrm{O}$ à 2 mètres, couverte de lierre et autres plantes grimpantes.

Malgré leurs nombreux inconvénients, dont les plus graves sont la cherté d'entretien et le peu de sûreté, les haies sont encore le système de clôture extérieure le plus usité. Il faut les soustraire aux regards en les plantant en contre-bas. Si cela est absolument impossible, le prince Pückler-Muskau conseille de les masquer, dans les parties couvertes, par un rideau serré d'ifs, de thuyas ou autres arbres verts de seconde grandeur, en avant duquel on dispose les autres plantations. Dans les parties découvertes, on peut atténuer la raideur des lignes de la haie au moyen de quelques buissons d'épines ou de houx irrégulièrement disposés.

Beaucoup d'arbres à feuilles caduques peuvent servir à faire des haies; celles d'épines sont les plus solides. On en fait aussi, dans certains pays, arec différentes espéces d'arbres verts. Celles de houx sont peut-être les plus belles de toutes, mais bien lentes à croître.

Tout ce qui vient d'être dit sur la nécessité de dissimuler les haies, soit en les disposant en contre-bas, soit par la plantation, s'applique également à tout autre système de clôture, murailles, treillages, grilles ou palissades.

XXXIV. - Potagers et Vergers. - L'adjonction d'un potager et d'un 
verger à une petite propriété d'agrément ne doit se faire quaprès mûre réflexion; non seulement sur le choix de la meilleure place, mais sur une question préalable qu'on néglige souvent ì tort.

Le domaine peut être assez restreint, les circonstances locales se présenter de

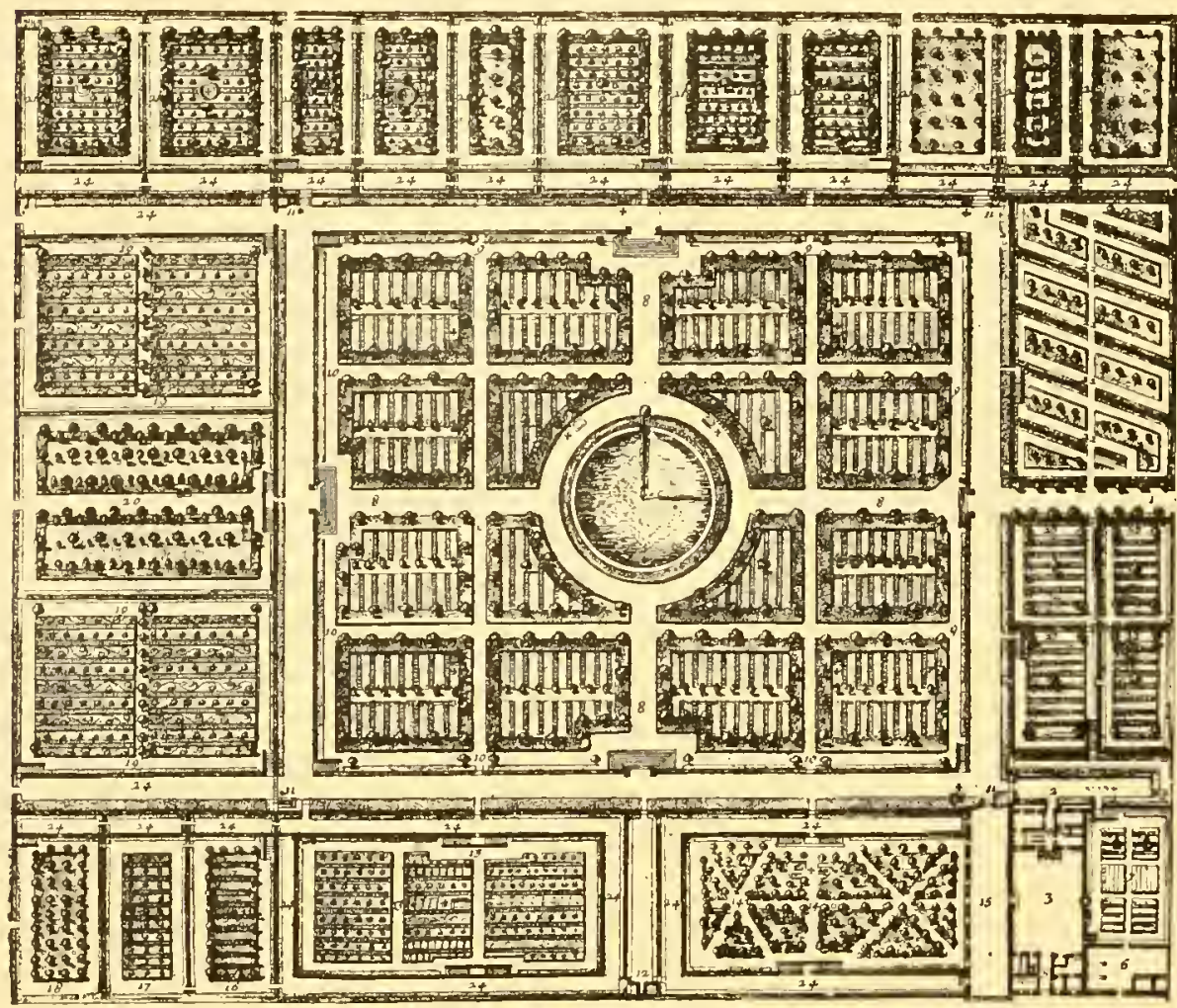

Fig. 333. - Potager de Versailles, dessinè et planté par de La Quintinie, gravé par Pèrelle.

1. Entrẻe pour le Roi. - 2. Entrée du commun. - 3. Cour du jardinet. - 4. Maison du jardinet. - s. Logement des garçons du jardinet. - 6. Basse-cour du jardinet. - 7. Petir jardin de fleurs. - 8. Grand quarré oú jardin des gros légumes. - 9. Espaliers de Pesches admirables et Nivettes. - ro. Espaliers de Poires. - II. Turrasse du grand quarrè avee muscats. - 12. Pavillon oú l'on distribue les herbes et salades. - 13. Melonnière avec conches de quelques fruits reptiles. - 14. Figuerie de Figuiers en caisses et en Espaliers. - 15. Galerie des Modelles au-dessous de laquelle est la serre pour Figuiers. - 16. Couches de petits Concombres et Pesches en Espalier. - 17, Couches d'lerbes à Salade avec Espaliers de Pavies et Burgnons. - 18. Figuiers en Buisson et en Espalier. - 19. Couches d'Asperges avec Espaliers de Pesches, - 20. Prune laye de pruniers en Buisson et en Espalier. - 21. Petits jardius des différents ligumes avec peschers, poiriers et pommiers en Buisson et en Espalier. - 22. Jardins biais avec Espaliers de lesches. - 23. Jardins pour les fraises avce cerises précoces. 24. Terrasses avec serres au dessous. - 24. Réservoirs pour l'arroser. telle façon, qu'il soit préférable de s'épargner l'établissement d'ul potager, d'un verger, ou même de tous les deux. Comme l'a dit un judicieux horticulteur anglais, pour cette installation, « un coin du jardin ne peut sulfire. Un potager, un verger n'ont de raison d'être que si l'on disposed'un espace assez vaste pour suffire à l'approvisionnement domestique de fruits et de légumes : sans quoi le profit et l'agrément ne compenseraient pas les dépenses d'établissement et d'entretien. „) Il en est autrement dans les propriétés d'une certaine importance; la l'horticulture utile joue un grand rôle. Elle peut même, comme nous le dirons tout à l'heure, concourir plus qu'on ne pense à l'ornementation du domaine.

Toutefois, bien des gens estiment que les potagers des particuliers coûtent 
toujours plus qu'ils ne rapportent. Telle était l'opinion bien arrêtée d'un souverain français qui passait pour entendre fort bien toutes les questions d'économie domestique. Il disait souvent " qu'il n'y avait pas de potagers ni de vergers plus économiques que la halle de Paris. » Nous croyons toutefois que, dans une propriété un peu étendue et située loin d'une grande ville, le potager et le verger sont indispensables. Bien placés et cultivés, ils ne tarderont pas à rendre plus qu'on ne leur a donné. Nous donnons ici, à titre de curiosité, le potager planté à Versailles par le célébre La Quintinie (Fig. 333 ).

XXXV. - Établissement et Décoration des Potagers. - En général, on donne aux potagers, installés sur une surface plane ou disposés en terrasses, une forme régulière. Tout le monde sait qu'un potager doit être bien protégé du côté du nord; la meilleure garantie d'abri est un bois épais, placé, par exemple, derrićre la serre ou autres dépendances, dans tous les cas à une distance et avec des précautions suffisantes pour le défendre des racines des grands arbres.

Les murs doivent être hauts de deux métres au moins, avec des chaperons en saillie. Nous conseillons de les construire plutôt en briques, si l'on peut se procurer facilement ce genre de matériaux. Ces murs sont les plus commodes pour établir les espaliers. A défaut de briques, on peut employer toute espéce de pierres, soigneusement jointes pour se préserver autant que possible des insectes. Dans une grande partie du nord de la France, on construit encore fréquemment des murs dont la base est en cailloux ou en moellons et le reste en argile. Ces murs, quand ils sont établis avec soin, sont excellents pour les espaliers dans les pays froids, à cause de la réverbération intense du soleil sur l'argile. Pour les treillages, il faut employer le fil de fer galvanisé ou le bois de châtaignier.

On installe aussi d'ordinaire, dans les parties les mieux exposées, des treillages ou espaliers supplémentaires, pour les diverses variétés d'arbres à fruit qui ont le plus besoin d'être abritées. Quand un potager est en forme de parallélogramme, les côtés les plus longs doivent être dans le sens de l'est à l'ouest, afin de ménager un plus grand espace à l'exposition du sud. On ne doit pas oublier que le côté de l'est est le moins sujet aux gelées perfides du printemps.

L'opération du drainage est rigoureusement indispensable dans un potager oú le sol est très humide. Une position en pente légèrement inclinée vers le midi, est la plus avantageuse pour toutes les cultures. Les arbres fruitiers ne réclament pas une 
trés grande profondeur de terre végétale. Si elle excède deux pieds, on peut disposer une couche de petites pierres, de tuileaux ou autres décombres, pour empêcher les

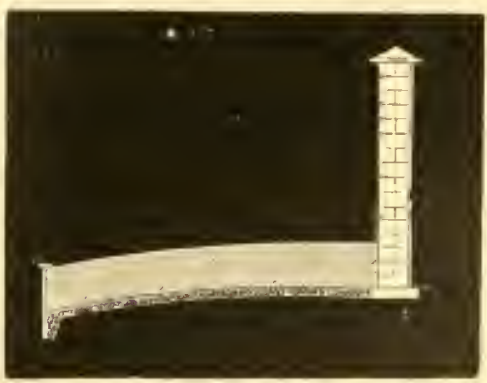

Fig. 334 . racines de trop descendre. Ce sous-sol sera conduit en pente douce vers des drains s'embranchant dans le système général (Fig. 334).

Un potager prend vite un aspect agréable, quand il est décoré de fleurs avec soin et avec goût. C'est là qu'on peut taire l'essai des nouveautés; donner asile aux plantes qui attendent le moment de figurer dans les massits, ou qui ne sauraient y figurer à cause de leur attitude, et aussi à ces fleurs si recherchées autrefois, aujourd'hui trop dédaignées, diesses en exil; comme les tulipes et les oillets.

XXXVI. - Possibilitél: de Fusion du Verger avec le Jardin

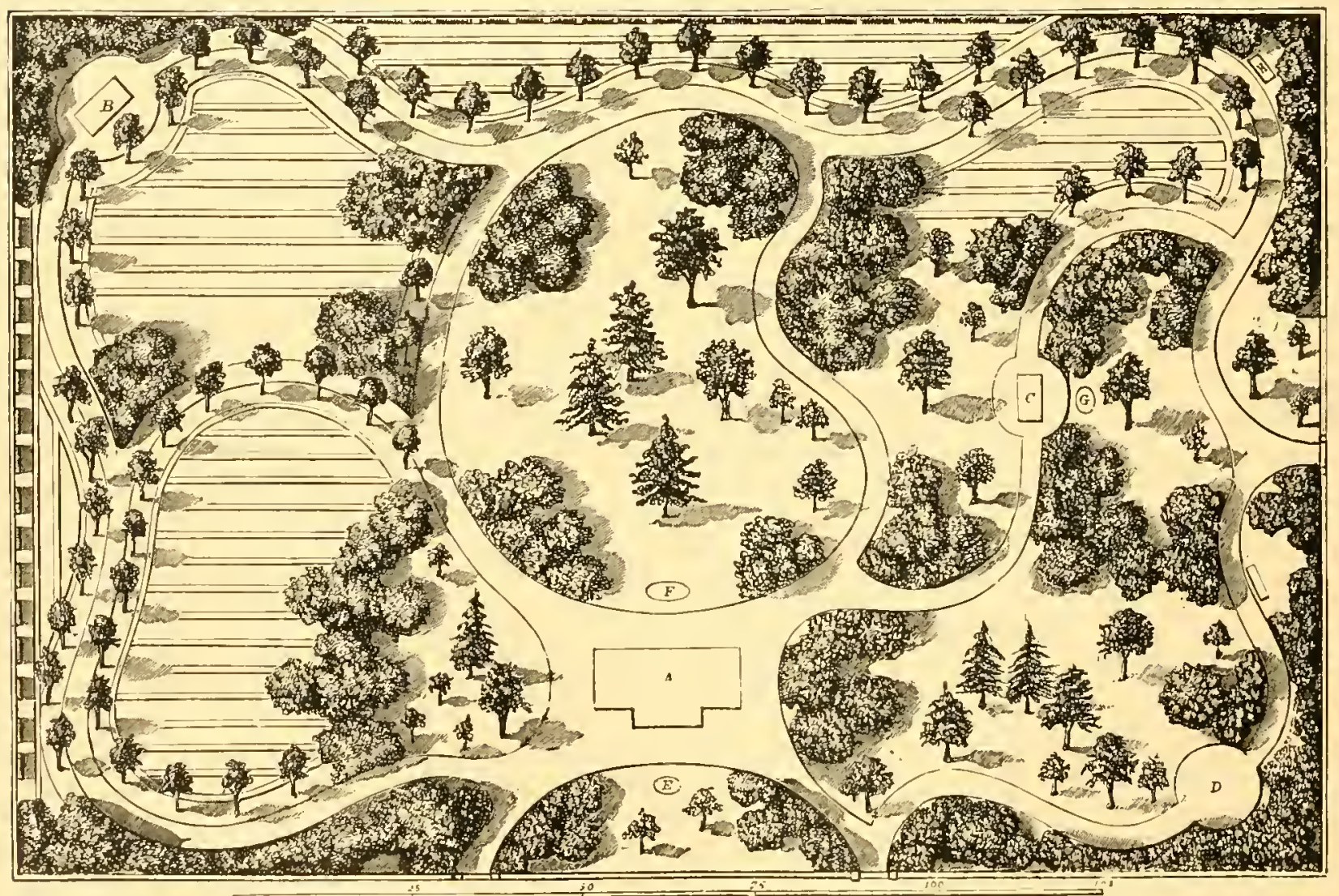

Fig. 335. - Jardin potager et paysager réunis.

d'Agrément. - L'idée dé l'incorporation du verger et même, suivant quelques 
auteurs, du potager au jardin d'agrément est unc conséquence naturelle de cette tendance si prononcée de nos jours, ì joindre l'utile au pittoresque (Fig. 335). Sous ce rapport, nous sommes bien en arriére de nos voisins d'Outre-Manche. On ne s'entend nulle part aussi bien qu'en Angleterre, à orner et à disposer des vergers pour la promenade. Un grand nombre d'arbres à fruit joignent l'agrément de la forme

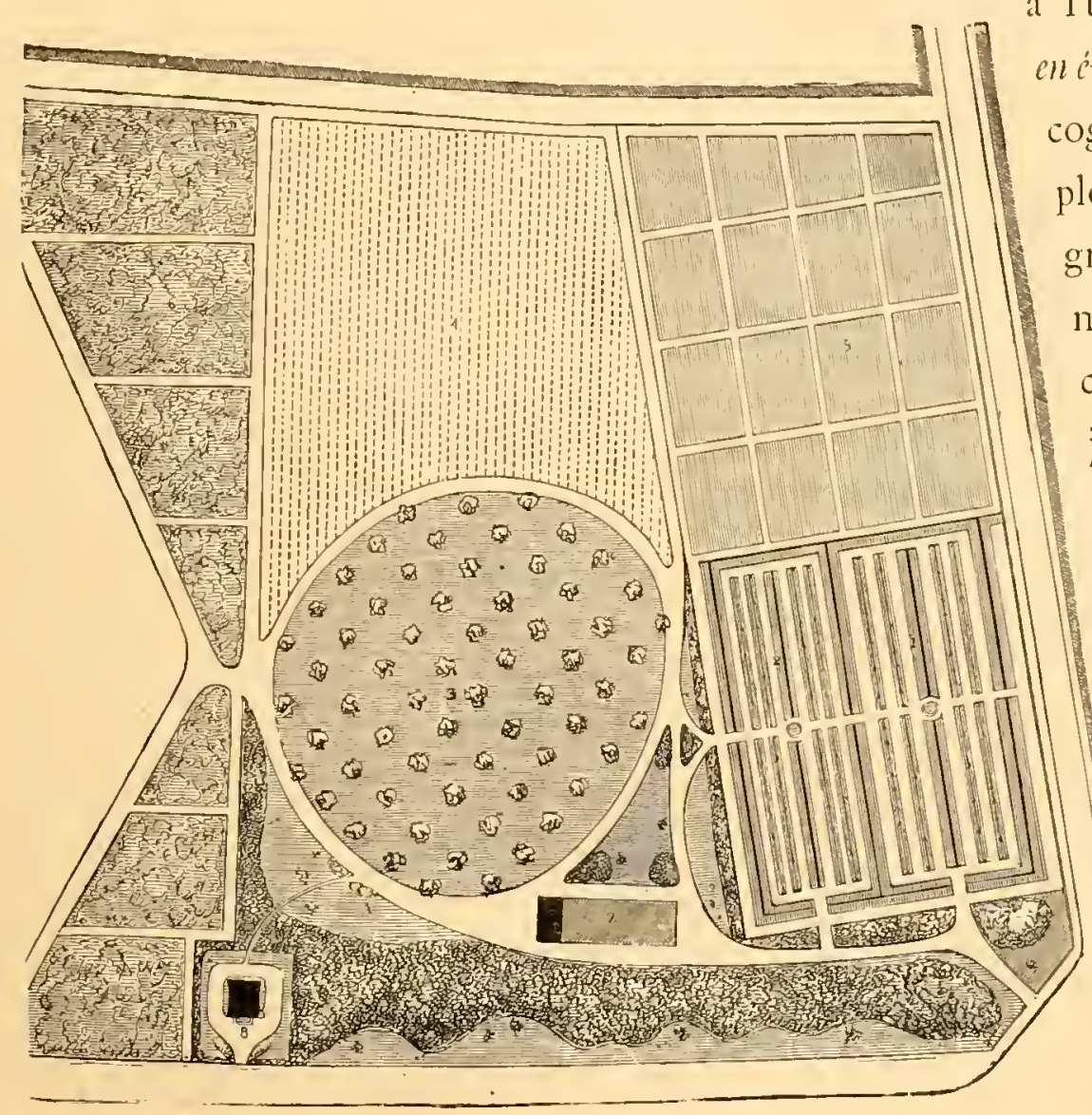

Fig. 330. - rlan general des jardins truitiers de Démonstration et ae Production, au Bois de Vincennes.

1. Jardin fruitier de demonstration. - 2. Jardin fruitier de production pour le clinat de Paris - 3. Verger. 4. Vignoble. - 5. Jardin potager. - 6. Pépinicre, - 7. Llangar. -8 Maison de Garde.

à l'utilité; tels sont ceux en éventail, les néfliers, les cognassiers, la vigne employce comme plante grimpante. L'agencement pittoresque de ces arbres, leur adjonction, dans des expositions favorables, aux plantations d'agrément, constituent un détail particulier de décor paysager, qui peut (E) donner lieu à d'intéressantes applications, même dans de petites propriétés. Nous donnons, comme spécimen, le plan des jardins fruitiers de démonstration et de production du bois de Vincennes (Fig. 336).

Plusieurs des artistes modernes, notamment Kemp et Mayer, se sont préoccupés sérieusement de cette fusion de l'utile avec l'agréable. Mais ces étrangers avaient eu pour prédécesseur dans cette voie, un Français, le fameux Morel (d'Ermenonville). Ennemi juré de la symétrie, l'auteur de la Théorie des Jardins la poursuivait jusque dans les potagers et les vergers. Il soutenait que bien souvent un arrangement irrégulier des arbres à fruit et même des légumes, serait non 
seulement plus agréable à voir, mais plus avantageux sous le rapport économique. "Le légumier, dont l'aspect est si froid, la distribution ordinaire si peu favorable a ses productions, - pourquoi n'attirerait-il pas mon attention sous le rapport de

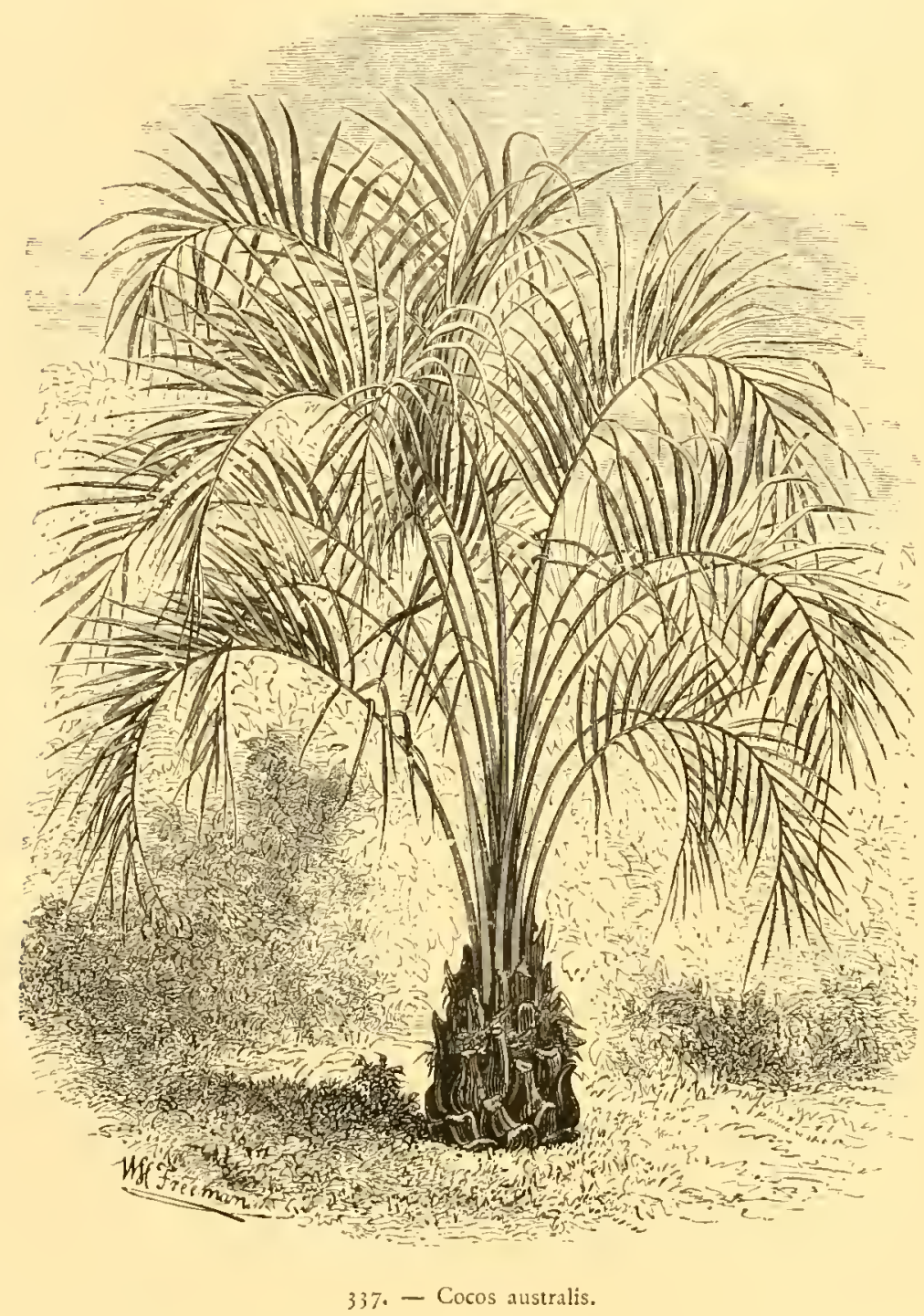

l'agrément? - Ce qui dépare cette culture, ce sont les allées larges et inutiles qui la découpent en petits carrés; ce sont les arbres fruitiers et les plates-bandes qui l'entourent et lui portent préjudice. Ce sont surtout les murs dont on l'environne de toutes parts; c'est le cadre qui l'attriste et en fait une partie isolée, sans liaison avec le site. Cette opposition entre le potager et les sites des environs ne saurait provenir du tableau même de cette culture, qui réunit une verdure soutenue et une grande diversité de production, à une grande végétation sans cesse en activité, fruit d'un travail journalier. L.e goût et la facilité de la culture décideront de la forme de mon légumier. La qualité du sol et l'exposition convenable lui assigneront sa place. Le buissonnier d'arbres á fruits, que j’appelle le verger cultivé, ne sera pas confondu avec les légumes, mais séparé et placé à l'abri des vents. Ces arbres étant ainsi groupés par espèces, le jardinier, pour les soigner, ne sera pas obligé de perdre ses pas et son temps à parcourir tous les points d'un grand espace, sur lequel on a coutume de les éparpiller. Les espéces étant ainsi rassemblées, au temps de leurs fruits, la récolte se fera à propos 
et sans embarras. Enfin, jaurai de grands arbres, là où les murs seront inutiles, parce qu'ils feront un meilleur abri. » Cette sage observation, faite pour la première fois par Morel, est entrée dans l'usage général. "Si je veux avoir des arbres en espaliers, dit-il encore, je construirai des murs dans la position la plus favorable. Mais je n'aurai pas des espaliers parce que j'ai des murs de clôture; rarement ces murs d'enceinte sont exposés de manière à remplir ce but. Les gros légumes, qui ont moins besoin d'arrosement, auront leur place dans la partie la plus élevée du terrain; les plantes les plus délicates seront dans le bas, ordinairement plus frais, plus à portée des eaux dont elles ont journellement besoin. Les sentiers n'auront de largeur que celle que réclame la facilité de la culture. Mon potager (étant) ainsi distribué, tout le terrain sera

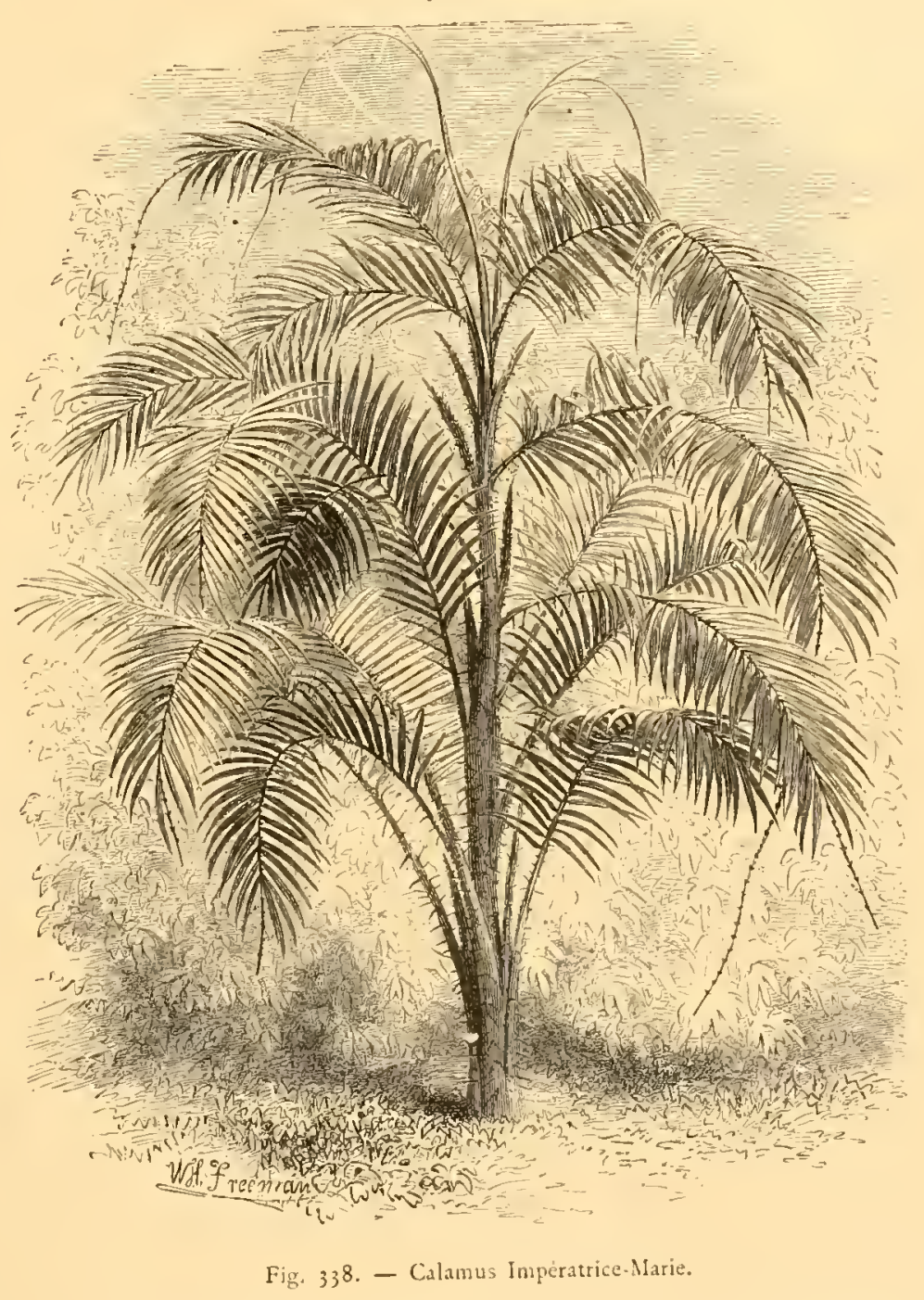
mis à profit, je n'en perdrai pas par de fastidieux compartiments et d'inutiles allées. Cet ensemble de verdure, dont la forme ne sera pas un carré entre des murs, mais oủ scront donnés le mouvement naturel du terrain et les facilités de la culture, flattera l'œil par le spectacle d'une riche et vigoureuse végétation non interrompuc. Ces dispositions, différentes de celles que suit l'aveugle routine, plus agréables comme effet, seront aussi mieux entendues sous le rapport de l'utilité. Elles ménageront le terrain, épargneront les bras et feront gagner du temps. ”

Dans la seconde édition de son ouvrage, publice en 1802 , Morel revenait et 
insistait énergiquement sur ces avantages de l'application du style irrégulier à l'horticulture utile.

"I.es arbres fruitiers destinés à former des vergers; plantés, suivant l'usage ordi-

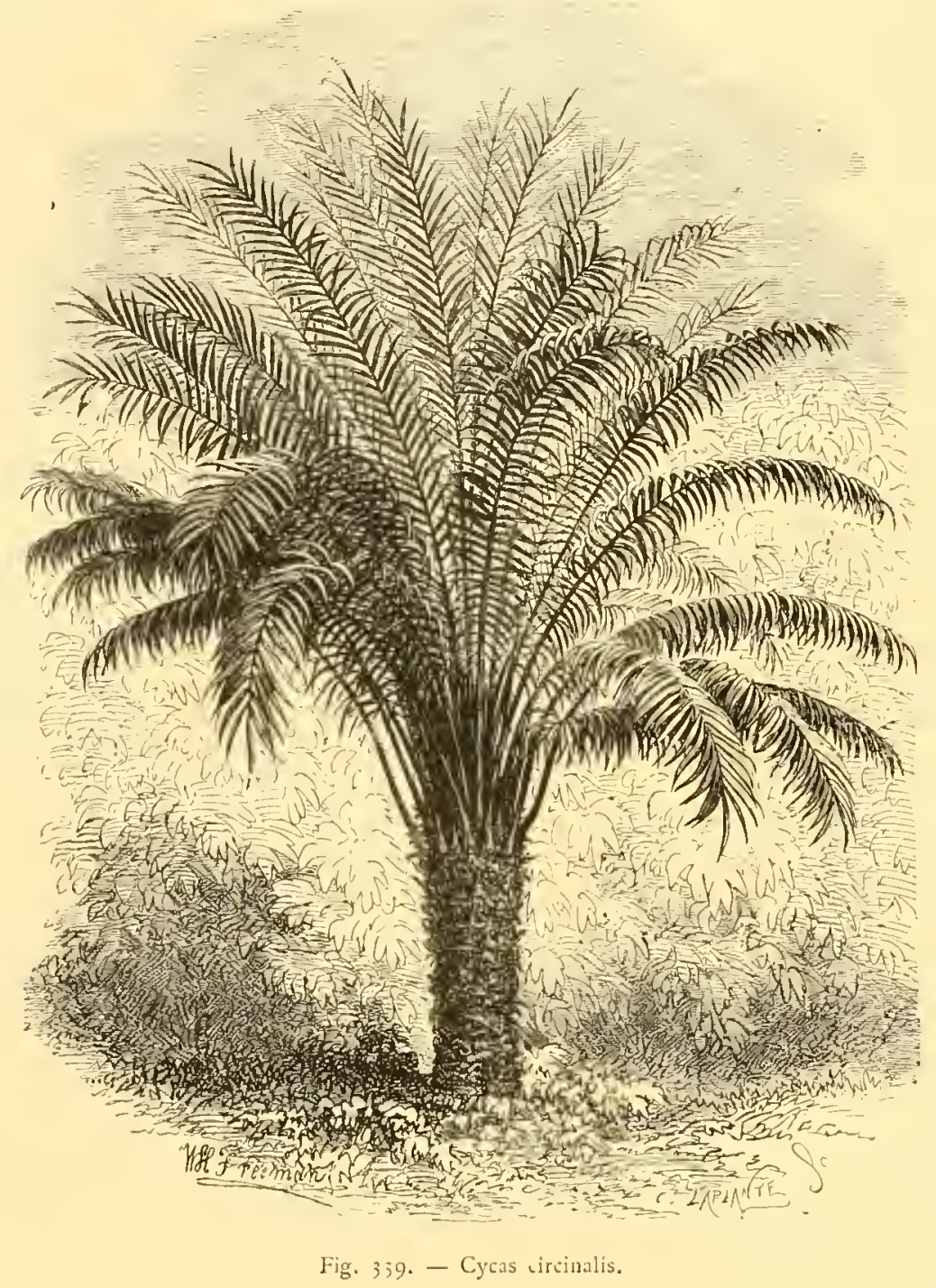
naire, en quinconces sur une prairie naturelle, $y$ sont distribués de la façon la plus désavantageuse pour eux et pour la prairic. Ces arbres ainsi espacés, s'élèvent moins qu'ils ne s'ètendent; leurs branches finissent par se rapprocher, par ombrager la totalité du terrain... L'herbe, sous leur ombre perpétuelle, est rare et ne saurait mûrir. Mais que les arbres soient groupés, que les groupes plus ou moins forts soient espacés de manière à laisser entre eux de grandes clairières! Dans cette disposition; les arbres donneront du fruit en plus grande abondance, et l'herbe gagnera en quantité et en qualité. En effet, l'ombre que projettent les groupes itant passagère, l'herbe ne subit la fraîcheur et l'humidité que par intervalles, et non d'une façon continue, comme il arrive quand les arbres couvrent toute la surface. Cette impression momentanée d'humidité est favorable a la densité de l'herbe; l'action alternative du soleil vient ensuite échauffer le sol, mûrit les plantes et n'a pas le temps de les sécher. Voilà ce que cette, méthode a d'avantageux pour la prairie; - voici ce que les arbres y gagnent. La disposition en groupes est le meilleur moyen: de les préserver des 
froids tardifs du printemps, des brouillards malfaisants qui altérent les fleurs à peine écloses des sujets les plus hâtifs... Il ne s'agit que de mettre les plus tardifs en opposition à ces vents destructeurs... Ces arbres ainsi assemblés se défendent mieux aussi contre les vents violents de l'automme. Enfin, ainsi groupés, et néanmoins espacés convenablement entre eux, ils s'arrangent ensemble sans se nuire. Ceux qui sont à la circonférence étendent librement leurs branches à l'air et à la lumière; et ceux du centre s'élévent pour aller chercher les mêmes secours. »

C'est peut-être aller bien loin que de poursuivre l'application du style irrégulier et paysager jusque dans le domaine des légumes, bien que les feuilles de plusieurs d'entre eux aient incontesta-

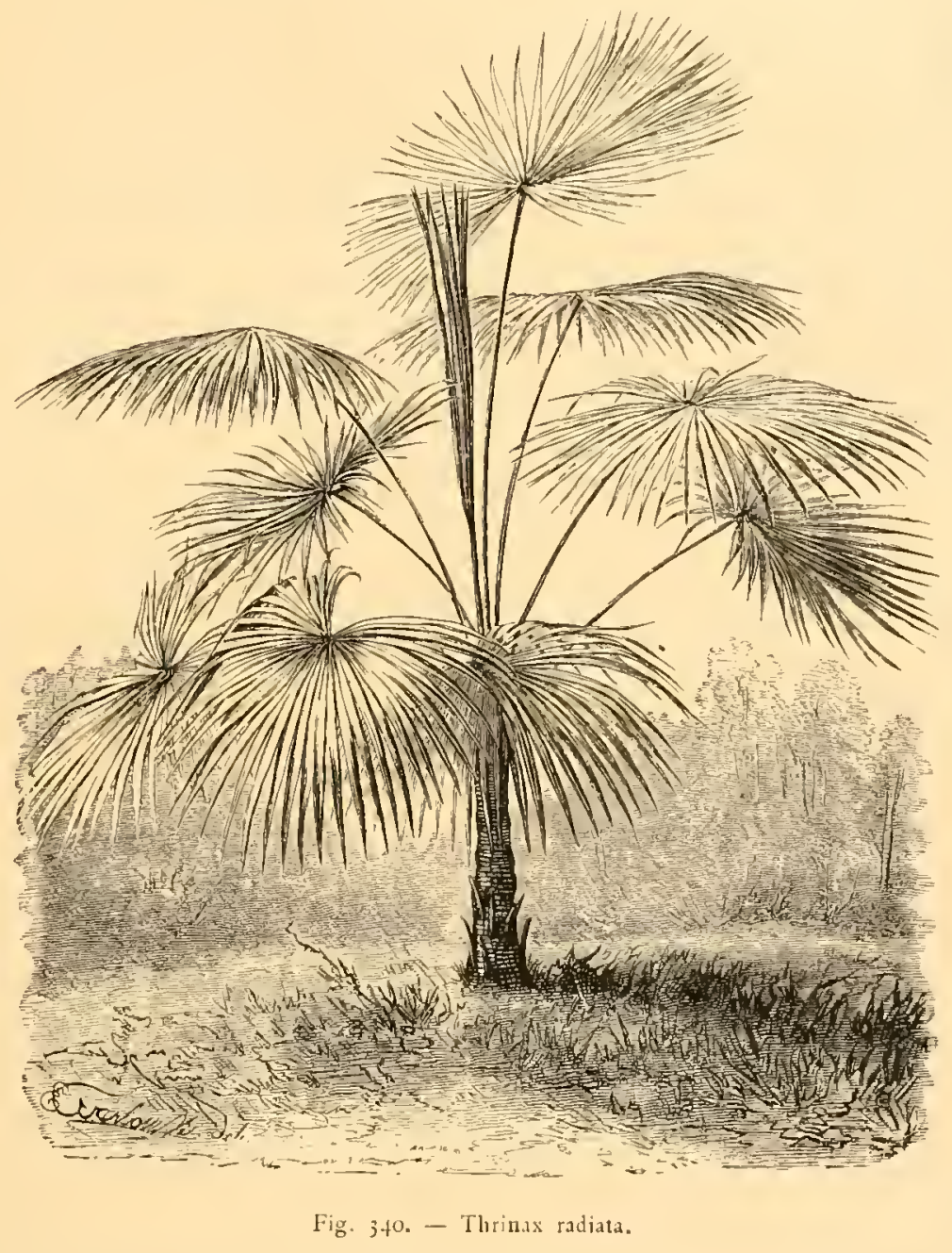

blement un caractére ornemental; l'asperge, par exemple. Mais nous avons peine it croire qu'une pelouse de carottes, par exemple, arec un massif d'artichauts; des oignons disposés en corbeilles, puissent jamais produire une impression bien pośtique, nonobstant l'opposition des formes et des couleurs.

Il n'en est pas de même de l'autre idée de Morel; ce qu'il appelle « le buissonnier d'arbres à fruits ou verger cultivé », disposé dans un coin retiré ct bien abrité du jardin. Nous avons vu quelques applications partielles trés heureuses de ce système; c'est un nouveau genre de surprise, mais agréable et d'un excellent goût. 
XXXVII. - Des Serres. - Une serre est aujourd'hui une annexe indis-

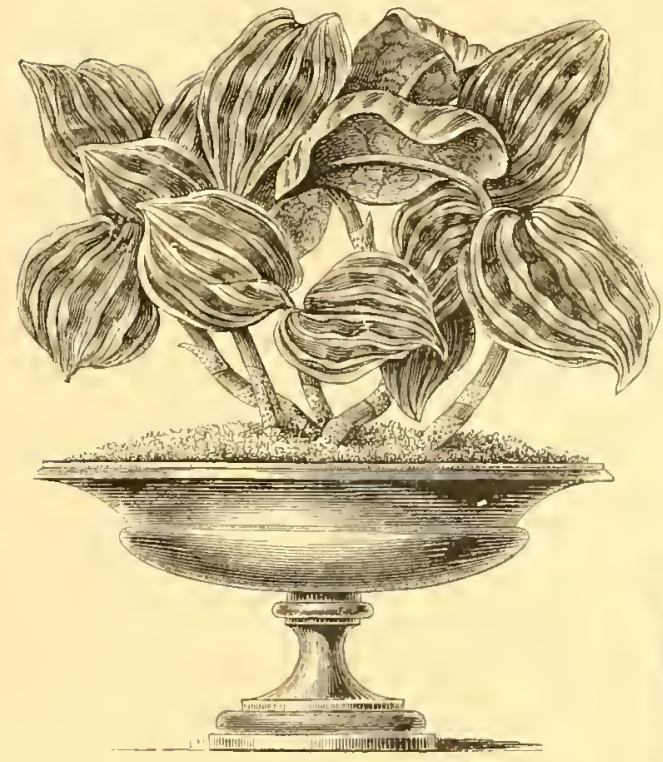

Fig. 343. - Dichorisandra undata.

rarement gracieux; soit qu'elle

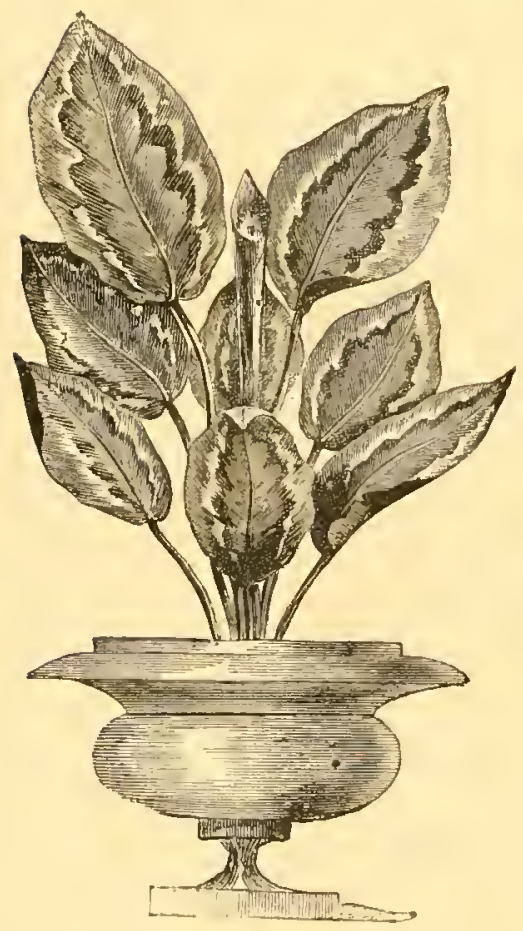

Jig. 345. - Calathea Veitchiana. pensable à tout jardin un peu important. Il estagréabled'enavoir une attenant à l'habitation; c'est une promenade accessible en tout temps. Mais, du dehors, l'aspect d'une serre de ce genre est

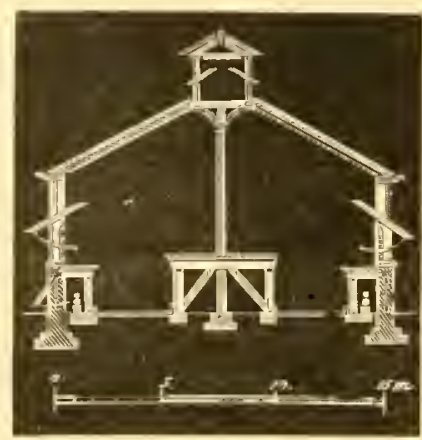

Fig. $3\{$. - Coupe d'une Serre.

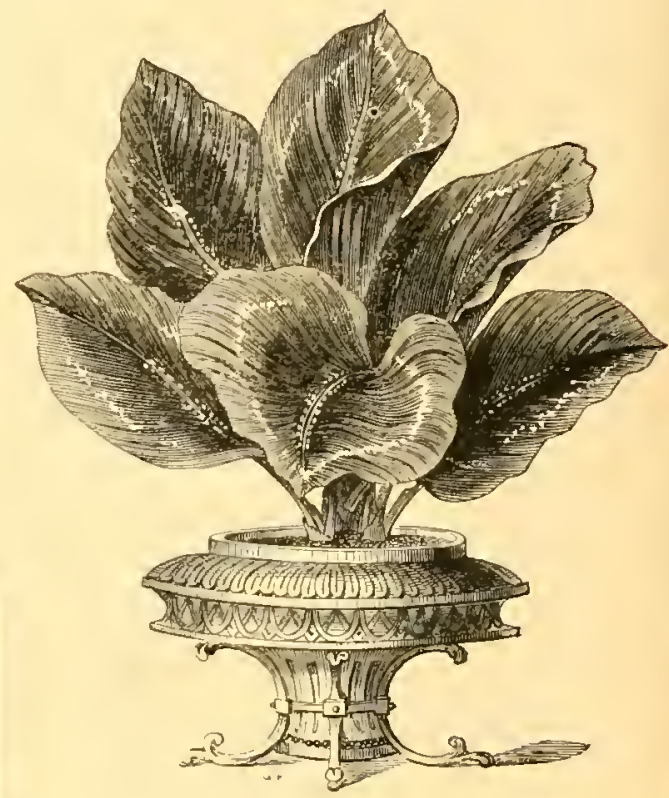

Fig. 314. - Maranta rosea pi:ta.

fasse partie du plan général, soit qu'elle ait été rajoutée après coup. De plus, elle ne peut

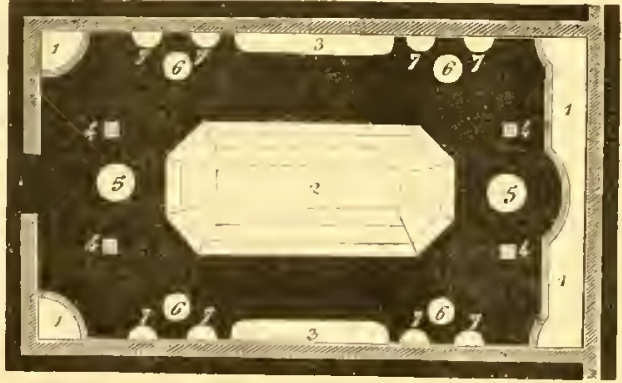

Fig. 3t2. - Plan d'une Serre.

1. Plates-bundes bordées de pierres. -2 . Estrade cemtrale. 3. Etigìres soutenues par des tasseaux. - 4 et 6 . Pièdestaux supportant des rases. - ;. Corbcilles en fil de fer pour pots de fleurs. - .. Paniers ou hottes 'suspendus nu mur.

servir qu'à disposer des plantes en pleine fleur, et non au détail de la culture. Il faut absolument

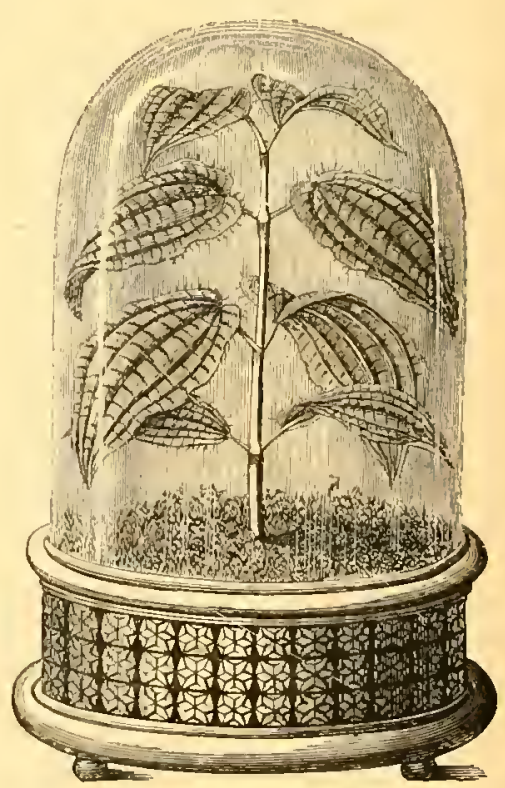

Fig. 346. - Bertolonia guttata. alors une seconde serre, d'utilité pratique, où l'on se procure de quoi orner la première. 
SERES HOLLANDAISES
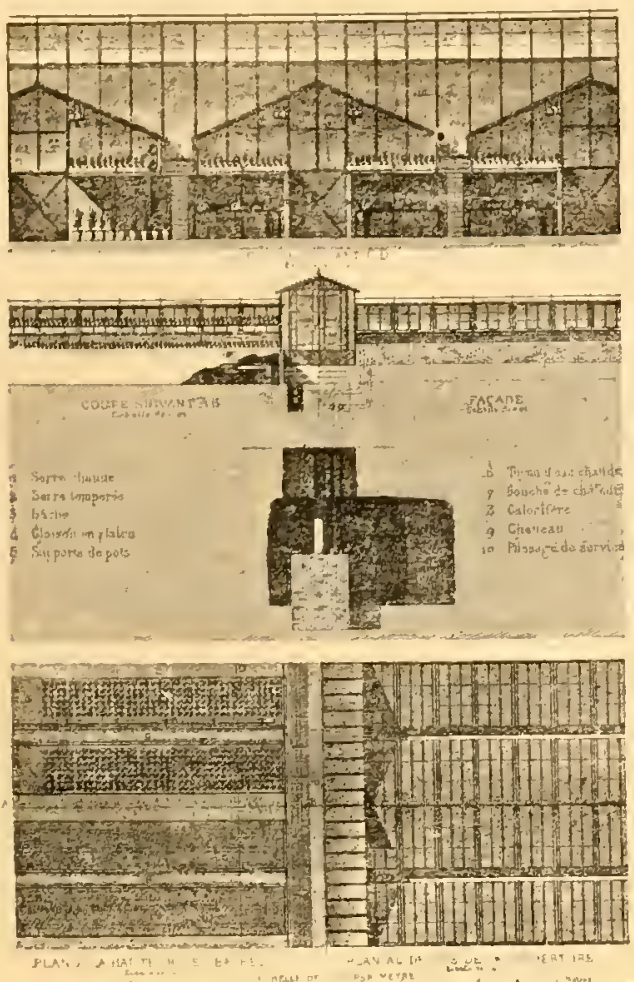
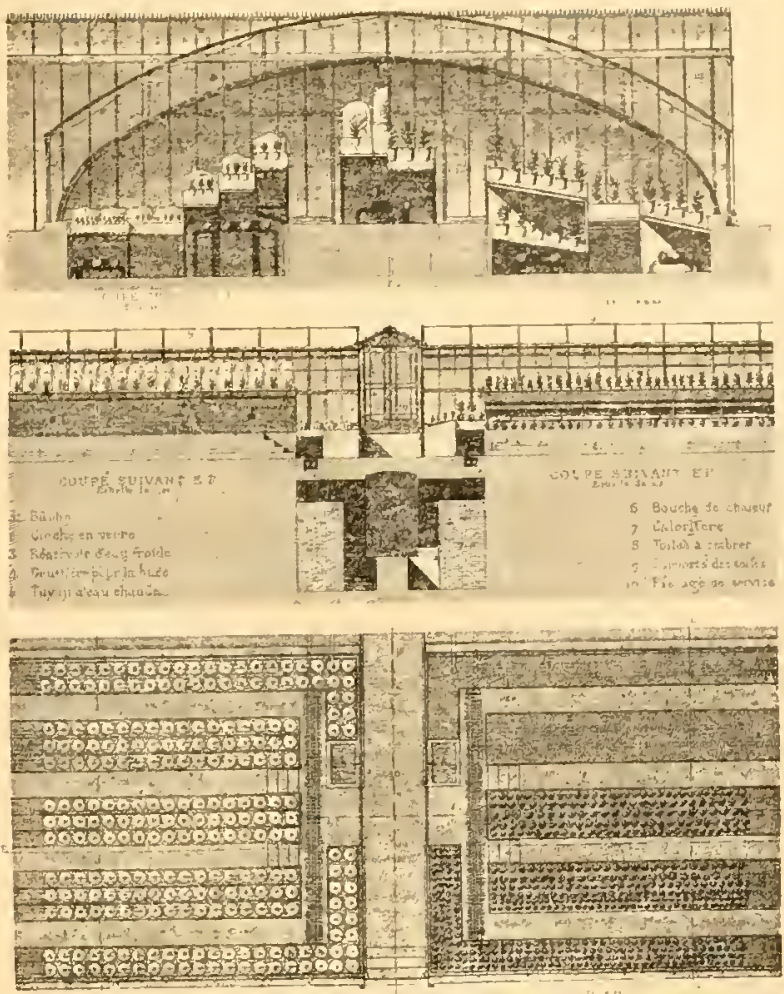

Fig. 347 a 352. - Serres diverses du Fleuriste de la Ville de Paris.
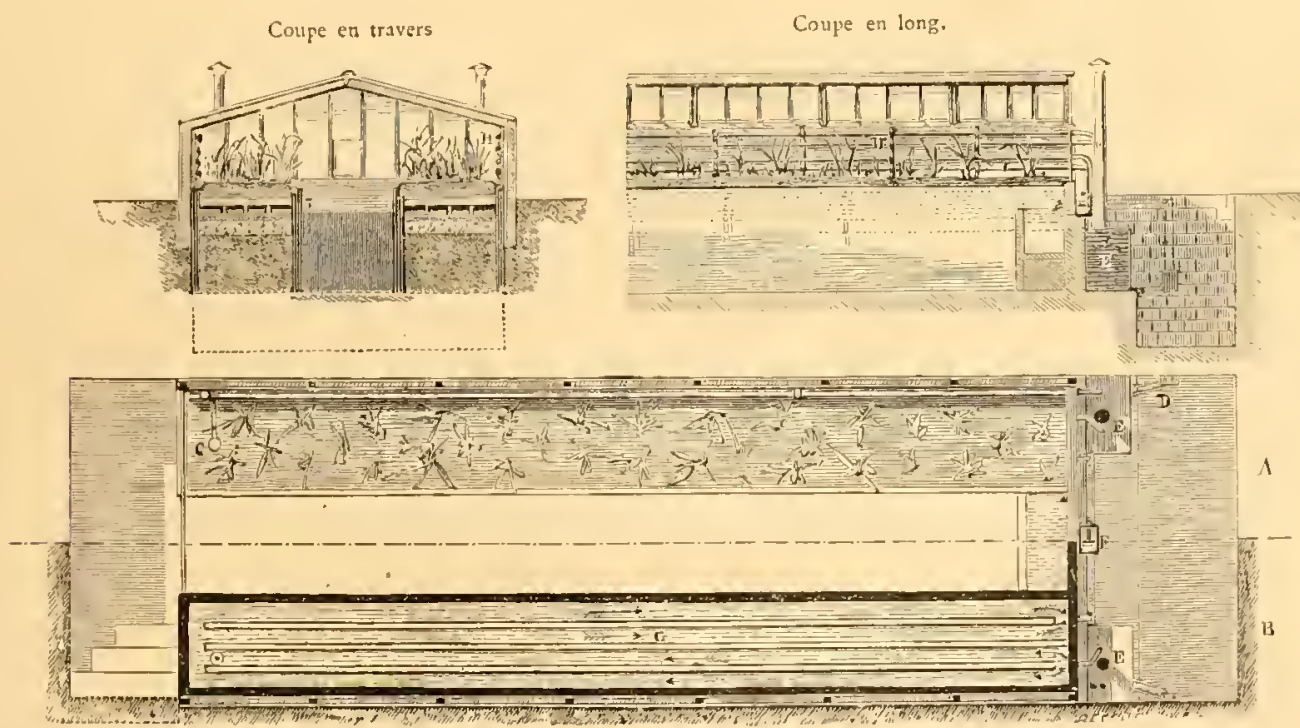

PLA: DE LA SERRE

Fig. 353 à 355. - Appareil úe Chaufiage au Gaz et a l'Eau, - Serre aux Népenthés (Fleuriste de la Ville de Paris).

A Plan au-dessus des Báches. - B. Plan au niveau du vaporisateur. - C, Régulateur thermo-électrique. - D Robinet à gaz communiquant a le calorifire - F. Peut réservotr d'cuu muni u'un flotteur alimentant le calorifére. G. Vaporisateur. - H. Conduits d'eau chaude. 
Les serres en fer léger avec des toits curvilignes ne font un bon effet qu'isolées; elles ne s'adaptent jamais d'unc manière satisfaisante à un bâtiment. Dans une serre d'un style sévère, les statues, les vases, peuvent être

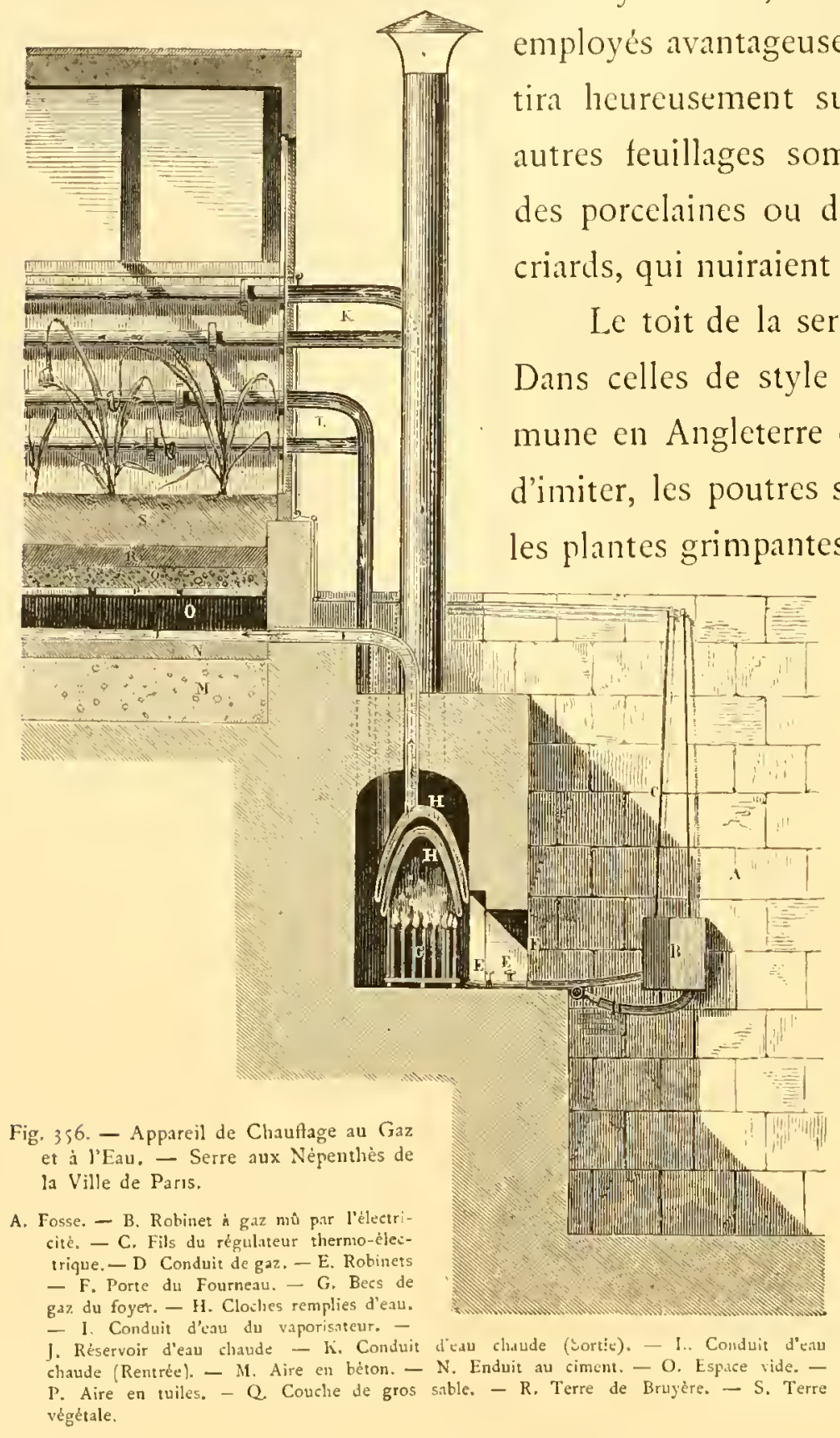
ture, doit être exposée au sud. Il est avantageux pour la croissance et le bon entretien des plantes, que le toit n'ait que la hauteur suffisante pour qu'on puisse circuler aisément dans l'intérieur. Les plantes grimpantes sont un des plus agréables ornements d'une serre, et ne font aucun tort aux autres plantes quand elles sont bien dirigées. On peut les placer dans des caisses ou des pots sur les étagéres, ou leur réserver une plate-bande, si la serre est assez vaste.

En groupant les plantes par espéces sur les gradins, on donnera à l'ensemble une certaine harmonie.

Il ne faut pas, même dans le Nord, négliger les moyens de garantir les plantes de serre d'un soleil trop ardent. On y parvient au moyen de paillassons, de 


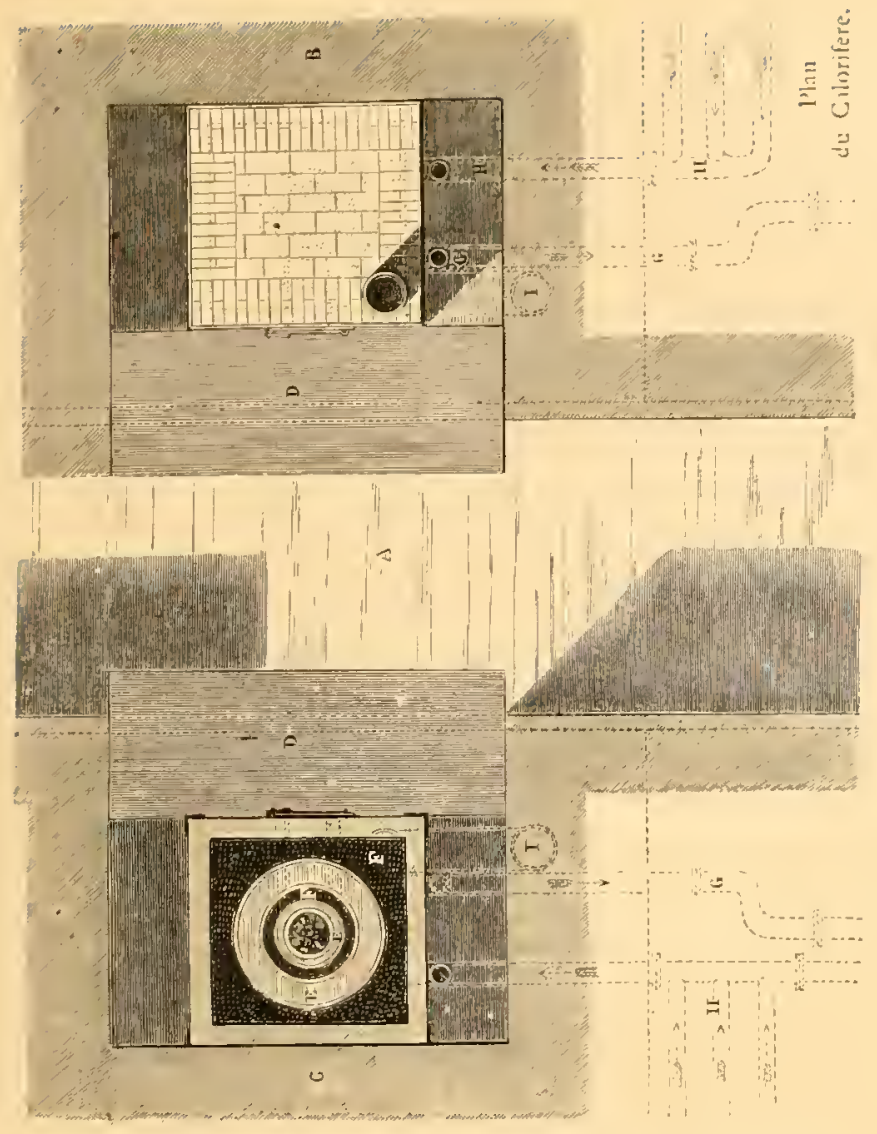

A. Galeric de Service. - B. Plan au-dessus du Fourneau, - C. Plan al milieu de la Chaudière, - D. Cendrier. - E. Chaudière. - F. Passage à fuméc. - G Condui: dFau chaude (Sortie), - H. Conduits d'Eau cladale Renree). - I. Clieminé
Pan gćnćrai.

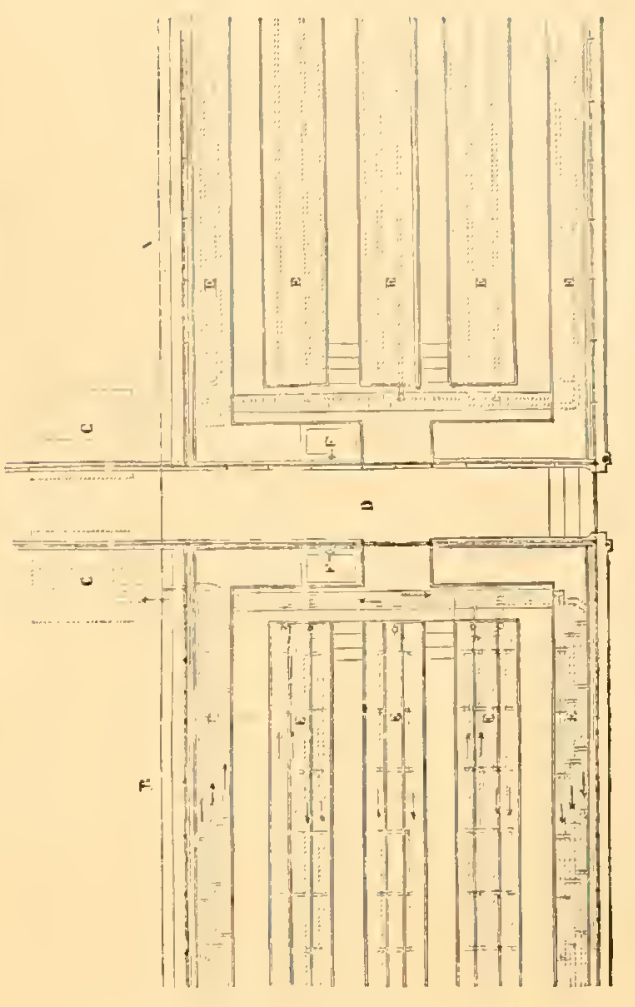

A. Serre à sevrage. - B. Serre à multiplication. C. Emplacement des Caloriféres, - D. Galerie de Service.
- E. Conduits d'Eau chaude, - F. Bassin d'Eau chaude.

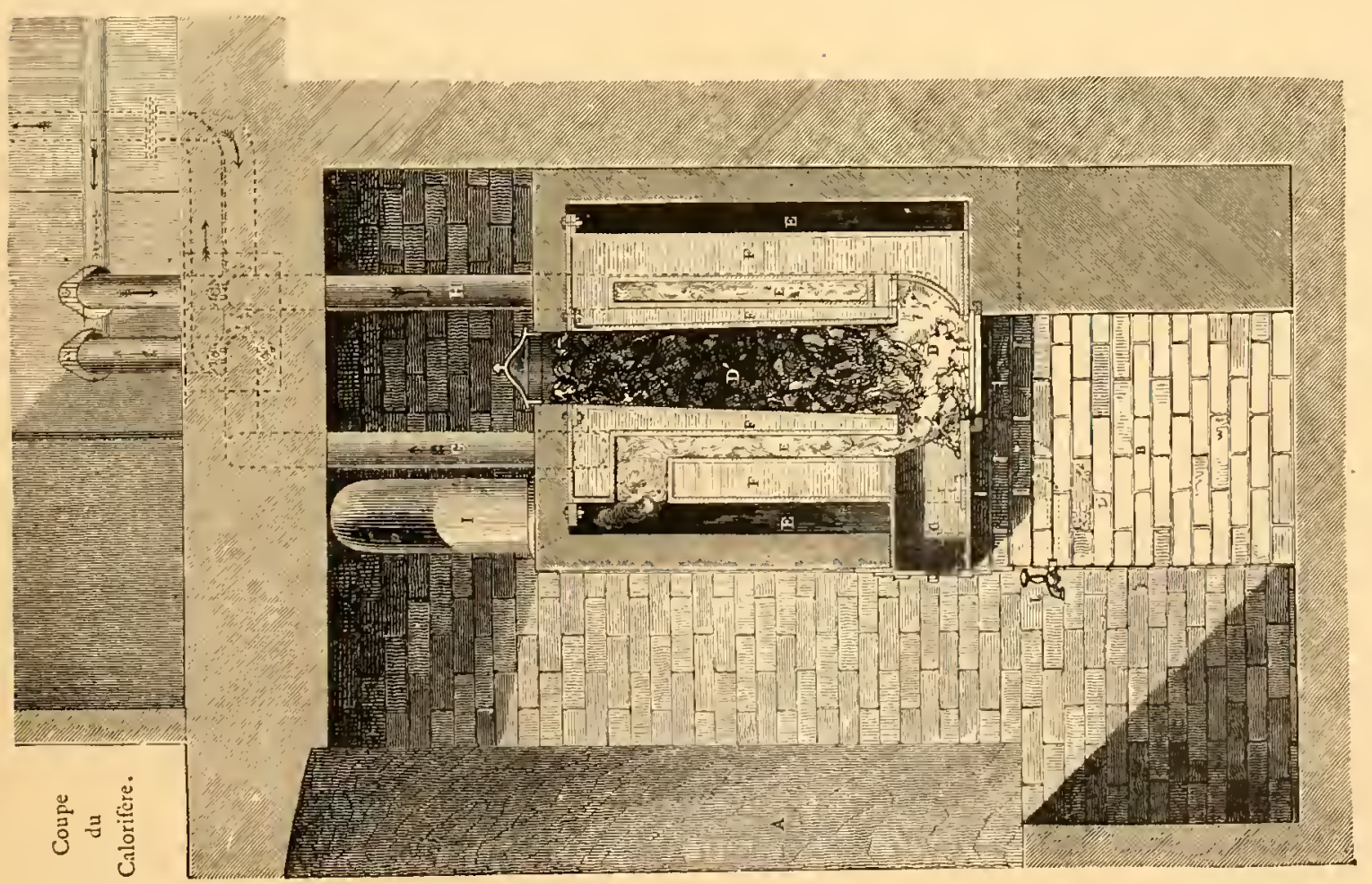

A, Galeric de Scrvice, - B. Cendrier - C. Lintrée du Foger, -- D. Foyer, - E. Passage pour la flamme er la fumée, - F. Eau chaude, G. Conduit d'Eau chaude (Sortie), - H. Conduit d'Eau chaude (Rentre). - I. Cheminćc, - J. Robinet de vidange. 


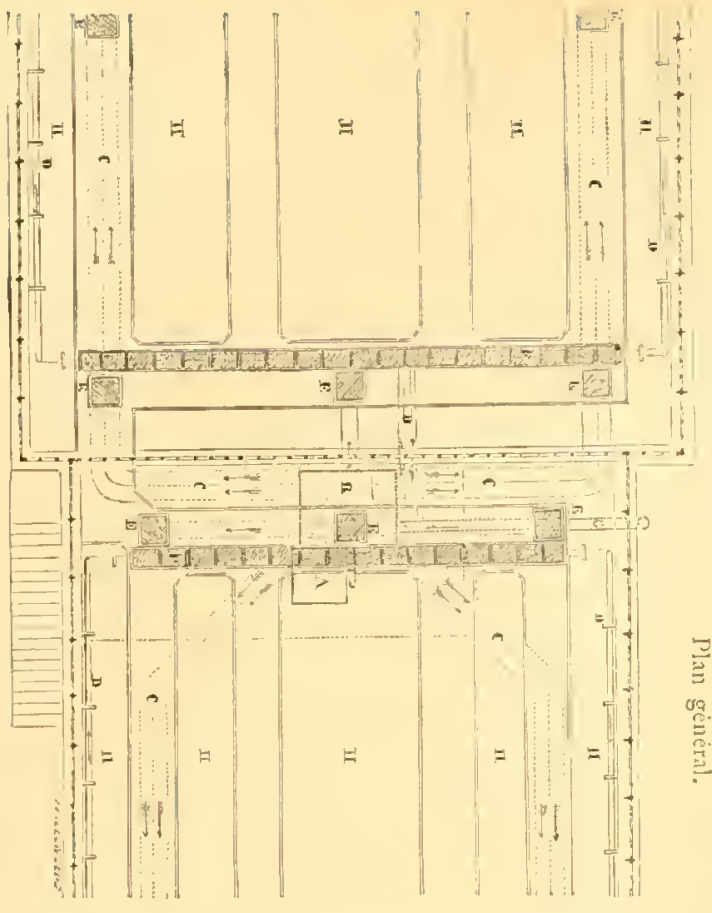

Plan des Caloriferes.

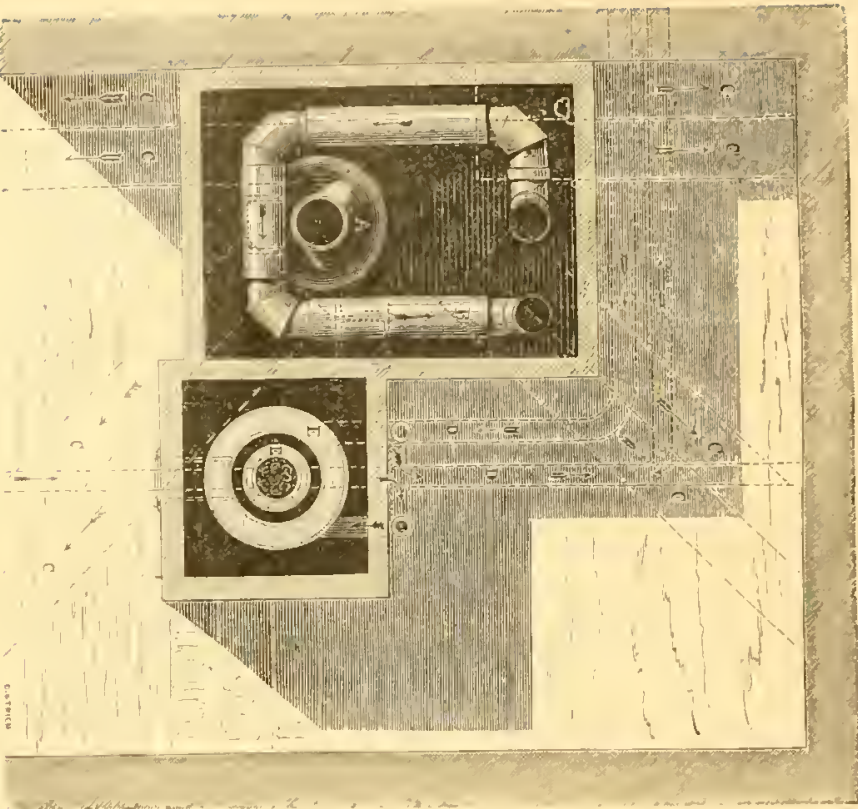

A. Calorifere a eatu - B. Calorifóre a air - C. Conduits d'air chaud F. D. Conduits d'eau chaude. - E. Bouches de chaleur. -chrude. - G. Chemince, - H. Bàches

Serres aux Palmers et aux Camélias (Fleuriste de la Ville de Paris). Coupe sur le Calorifére.

A. Foyer, - B. Serfentin. - C Conduits d'air claud, - D. Valve réghant l'introduction de l'aur claud. - F. Bouche de claaleur. F. Calorifère, - G. Conduits d'eau chaude.

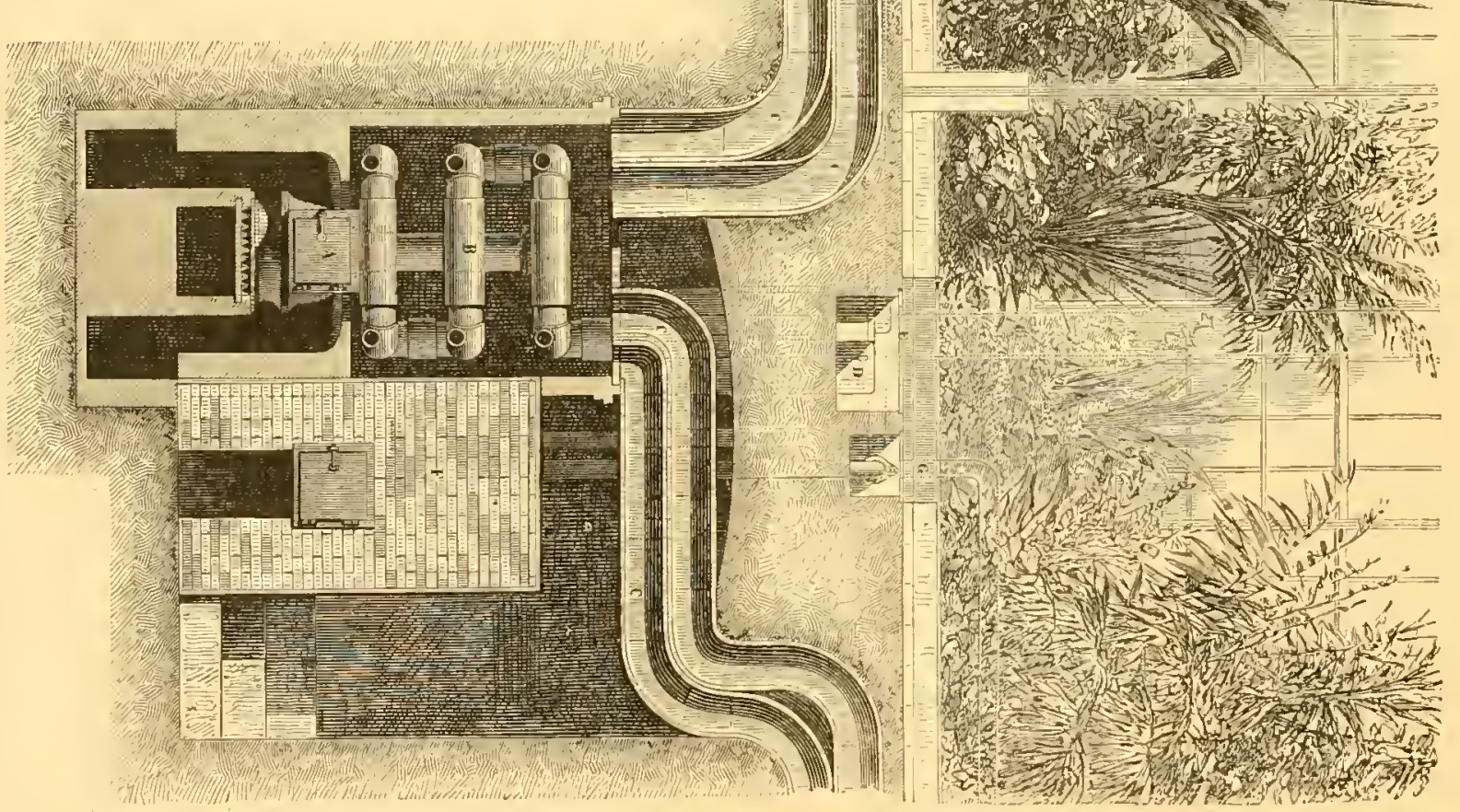

Fig. 360 a 362. - Alpartís de Chauffage à Air chaud (Scrres du Fleuriste de la Ville de Pais). 
persiennes, on de verres dépolis. Les murs doivent étre onnés de treillages pour les plantes grimpantes, ou pour celles qui s'étalent facilement en espaliers, comme les fuchsias. C'est cncore au moyen de l'eau, comme du temps des Romains, qu'on chauffe le mieux une serre. Quel que soit l'appareil cmployé, il est important de pouvoir augmenter la chaleur avec promptitude, car bien des plantes précicuses peuvent être foudroyées par une aggravation de gelie soudaine. C'est ce qui est arrivé dans plus

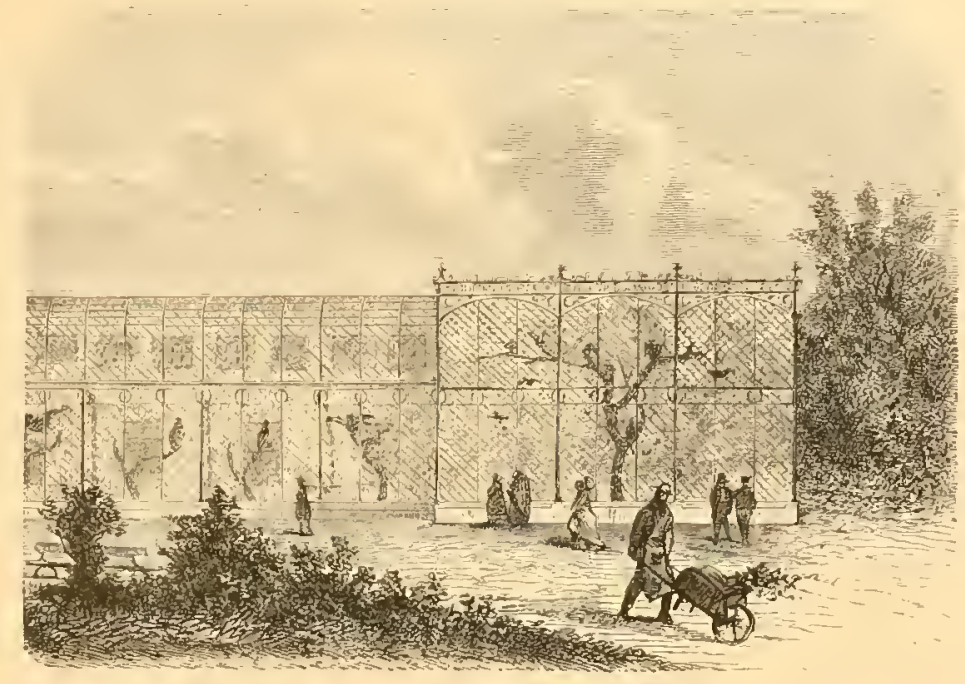

Fig. ;6j. - Grande Volière. - Façade. (Ioyzz p. 24.)

d'une serre importante, lors du grand hiver de 1880 . Le voisinage du potager, le centre d'un parterre de fleurs sont les situations les plus convenables pour une serre isolée de l'habitation. On devra y joindre, en les dissimulant, des abris pour les calorifères, les opérations du rempotage, etc.

Les cultures sous châssis et sur couches, annexes indispensables du potager, sont aussi un auxiliaire précieux pour lil multiplication des plantes d'agrément de pleine terre et de serre tem-

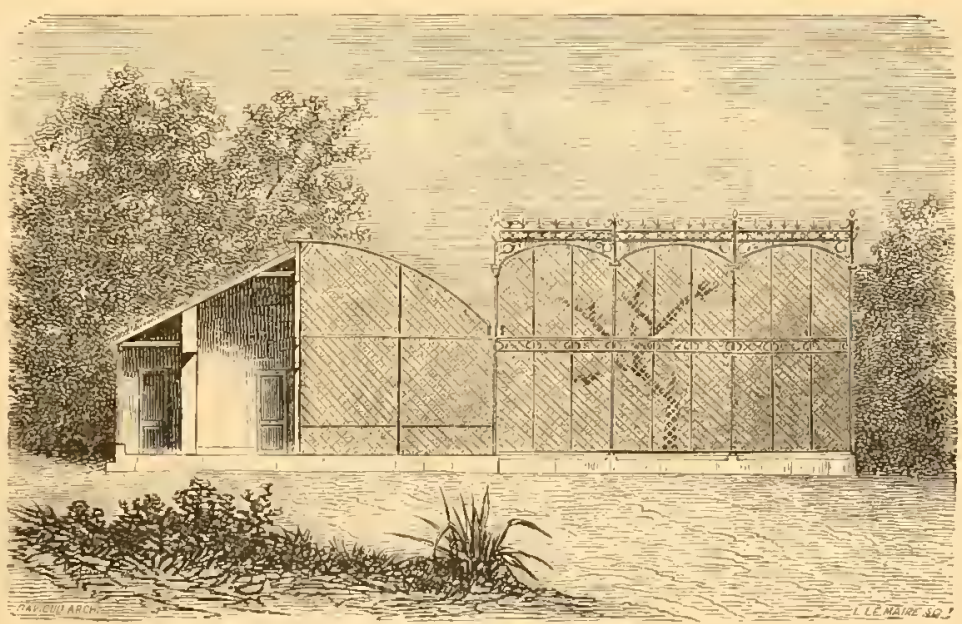

Fig. 364. - Grande Volière. - Coupe. (Voyez p. 244) pérée. Nous donnons ci-joint la coupe extérieure et le plan de l'intérieur d'une petite serre d'agrément (Fig. 34 I ct 342). Ce modéle, et ce que nous renons de dire des serres, ne convient que pour les petites et moyennes propriétés. Pour les serres de grand luxe et de reproduction sur une vaste échelle, on trouvera les meilleurs types au 
Jardin d'Acclimatation et au Fleuriste de la Muette. Nous les arons reproduits ci-dessus (Fig. 347 à 362). On sait aujourd'hui tirer un bien meilleur parti qu'autrefois des plantes de serre d'un caractére ornemental, en les distribuant soit par groupes, soit isolément sur les pelouses pendant la belle saison. Nous donnons seulement quelques beaux spécimens choisis parmi les milliers d'arbustes et de plantes exotiques les mieux appropriés à cet emploi (Fig. 337 à 346).

XXXVIII. - Volières, Ruches, etc. - Nous finirons par quelques observations indispensables sur certains accessoires crdinaires des parcs et jardins.

Les volieres leur donnent beaucoup d'animation. Elles doirent toujours être bien abritées du froid et de l'humidité, ainsi que du trop grand soleil. Une volière élégantc est un excellent motif de construction isolée dans une clairière ou un carrefour, ou bien encore à l'extrémité d'une serre (Fig. 363, 364). Quant aux ruches, c'est dans le potager qu'elles seront le mieux placées, ou dans un coin retiré du parc. Elles doivent être reléguées à quclque distance des allées les plus fréquentées, par considération pour les abeilles, et aussi pour les promeneurs.

Le nombre des places de repos, berceaux, bancs et sièges de bois et de métal, doit être, comme celui des parillons rustiques et autres, proportionné à l'étendue du jardin et du parc. Il est puéril de les multiplier à l'excès dans une petite propriété. Pourtant bien des gens d'esprit, sans parler des autres, ne savent pas se défendre de cette puérilité.

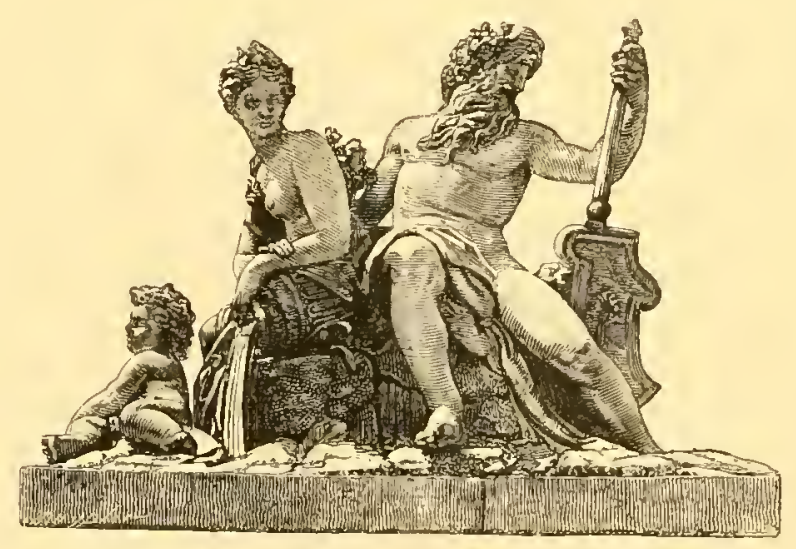




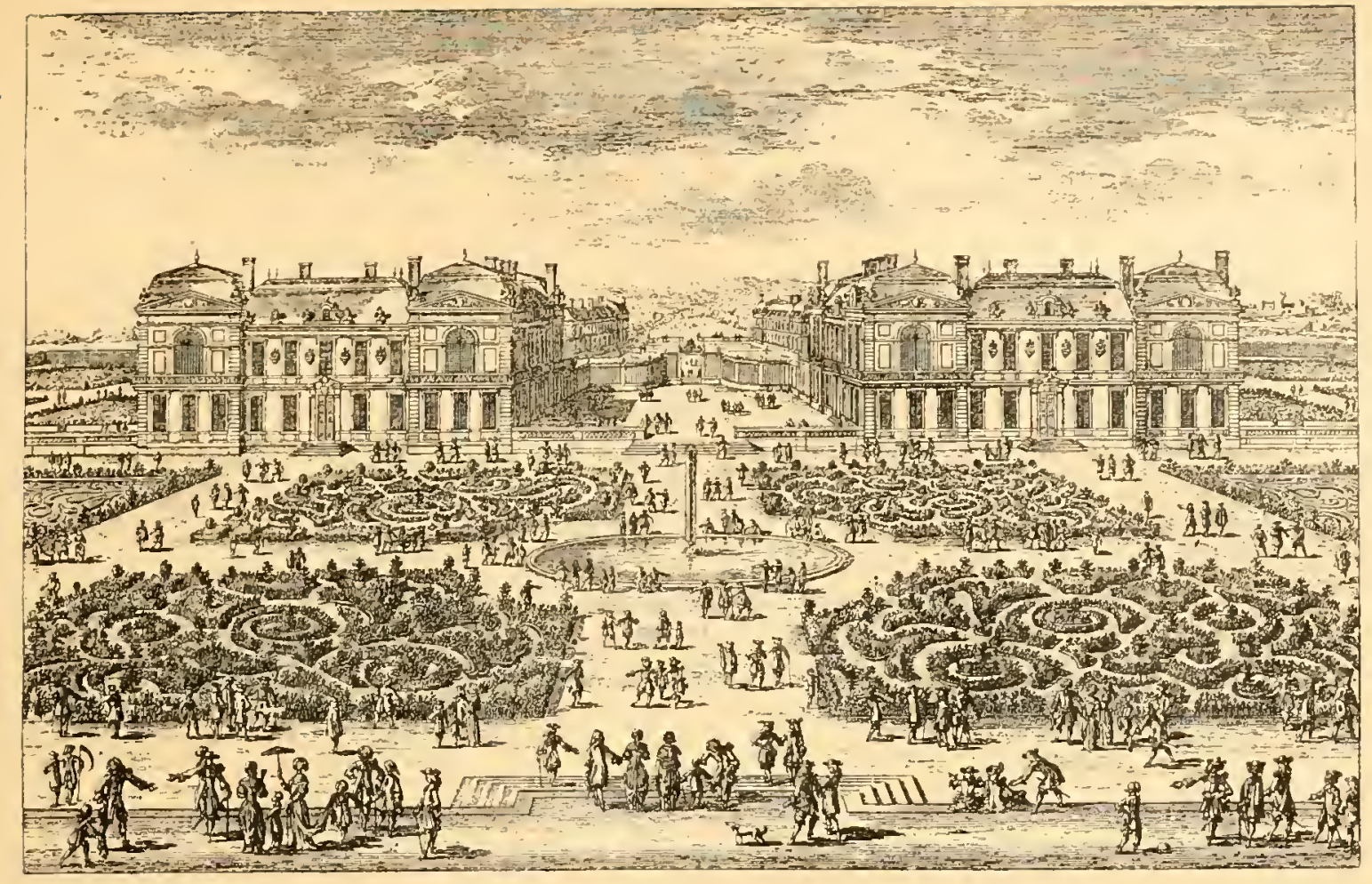

Fig. 366. - Vue des Jardins du Chatcau de Noizi, près Versailles, dessinée et gravée par Pérelle.

\section{CHAPITRE SECOND}

\section{TRACÉ DES JARDINS RÉGULIERS, DITS FRANÇAIS ET DE CEUX DU GENRE MIXTE}

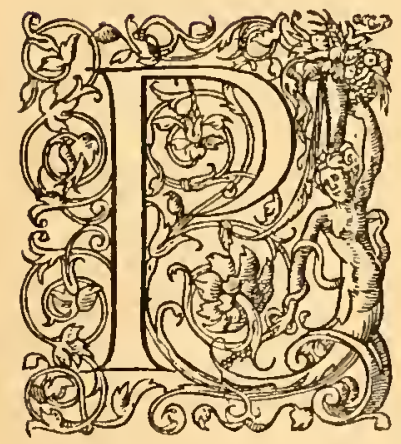

ossibilité des nouvelles Applications totales ou partielles du Système régulier. - Comme on l'a vu dans la partie historique de notre travail, le style régulier, longtemps seul compris, seul pratiqué, fut, dans la seconde moitié du siècle demier, l'objet d'une proscription presque absolue. Comme la plupart des révolutions, celle-ci avait dépassé le but. On est revenu de nos jours à des idées plus éclectiques. Les hommes les plus compétents ont reconnu que, dans certains cas, on pouvait encore faire d'heureuses applications de ce style, soit partiellement aux 
abords d'habitations importantes, soit même dans la totalité du domaine, quand ce

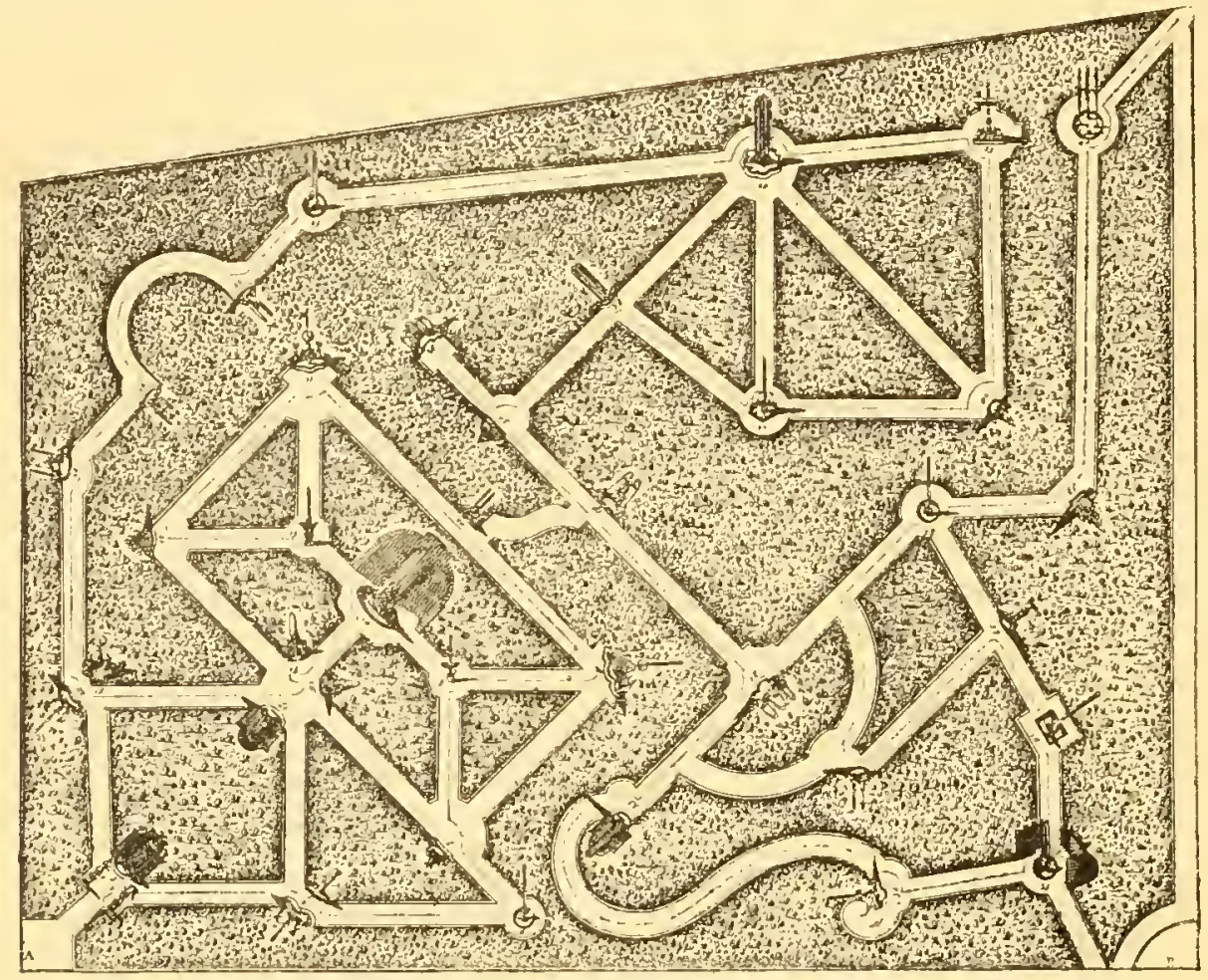

Fig. 368, - Ancien Labyrinthe de Versailles avec les Marbres représentant les Fables de La Fontaine, dessiné et gravé par Pérelle.

systéme paraît mieux en rapport avec la configuration du sol et le caractére général

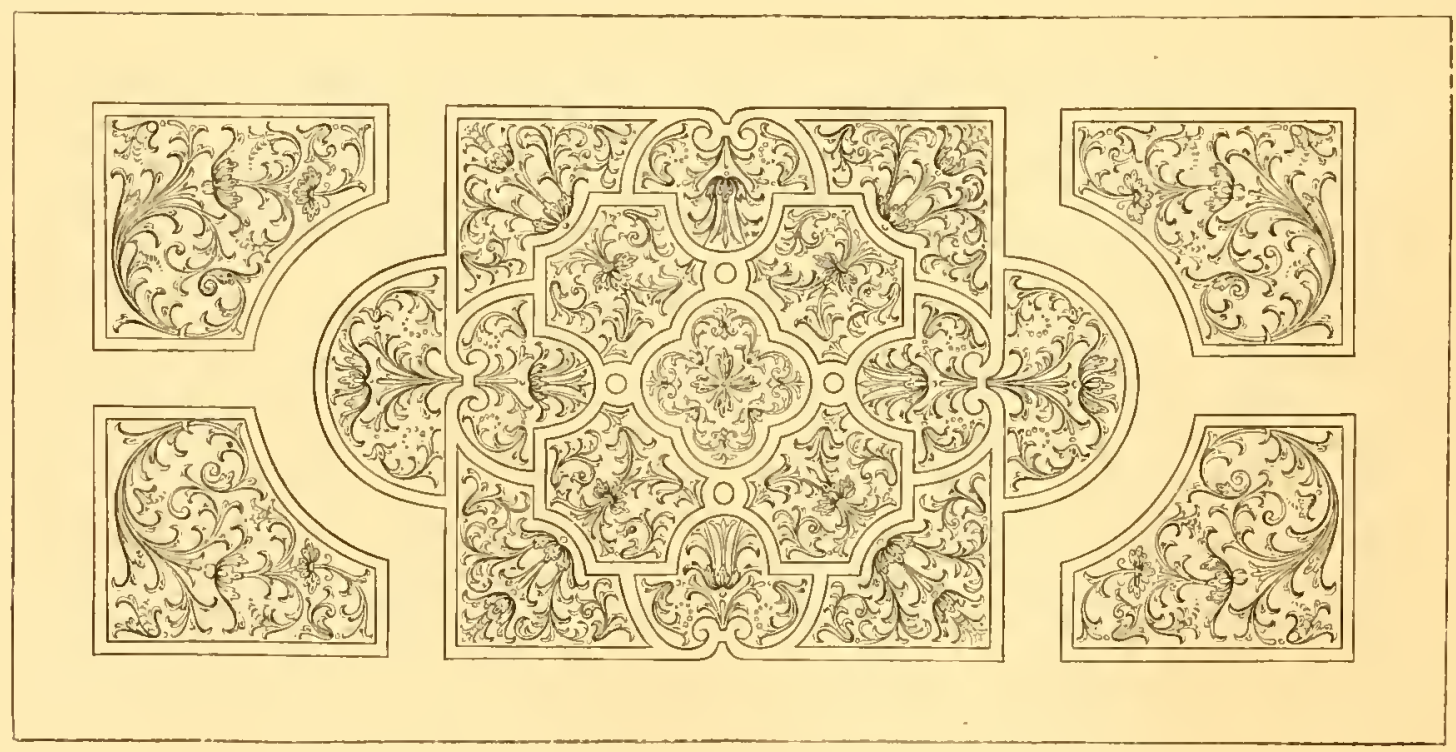

Fig. 369. - Parterre de Saint-Germain, dessinè par Boyceau en 1653.

du pays. Nous croyons done indispensable de donner quelques indications pratiques 
sur le tracé d'un jardin de ce genre. Le style régulier proprement dit subordonne tout a l'habitation, qu'il prolonge pour ainsi dire en plein air par ses " architectures vertes. ” Nous avons dẻjà cité l'un des exemples les plus caractéristiques de cette symctrie inflexible, impitoyable : la fontaine soi-disant rustique de la villa Aldobrandini, dans laquelle la disposition, la forme des moindres rocailles ont èté scrupuleuscment répétées des deux côtés (Fig. 2I 8 ). Autant l'effort humain doit se dissimuler dans le genre paysager, autant il doit saffirmer, s'imposer dans ce genre si different.

Les seules formes de la na-

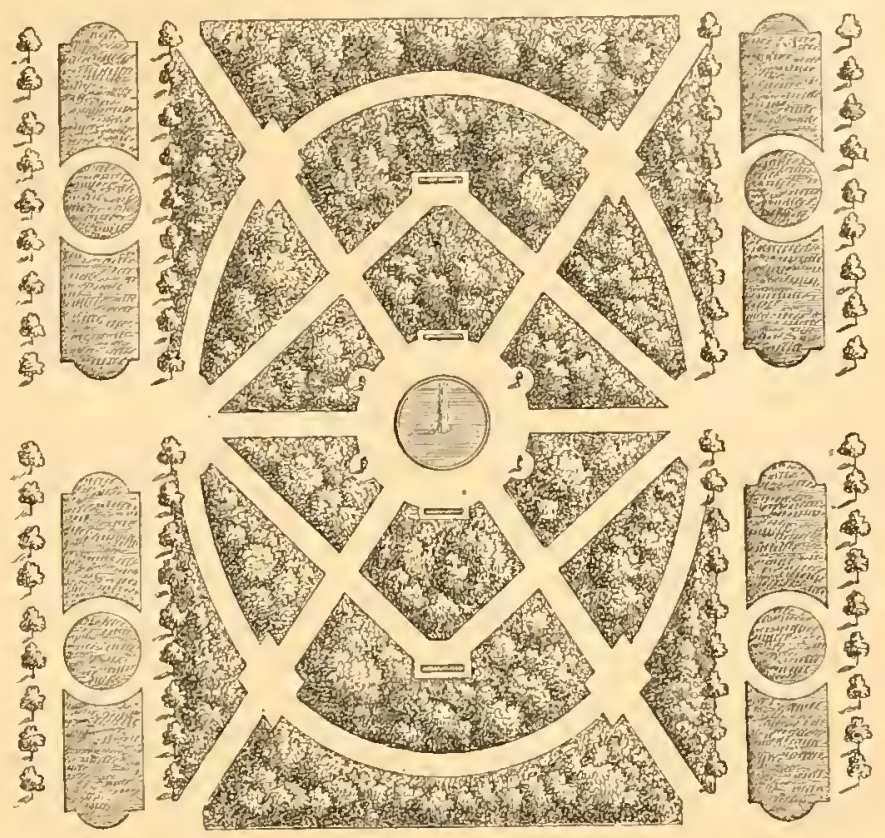
Fig. 37o. - Percẻes régulières dans un Bois de bautc Futaie. ture it rechercher ici, sont celles qui se rapprochent le plus du caractere artificiel, et peurent s'y encadrer avec le moins d'effort.

Hâtons-nous d'ajouter qu'il n'est et ne peut être question ici que d'un retour modéré, mitigé aux principes du genre, et non à ses exagérations, comme les amphitheiatres et les

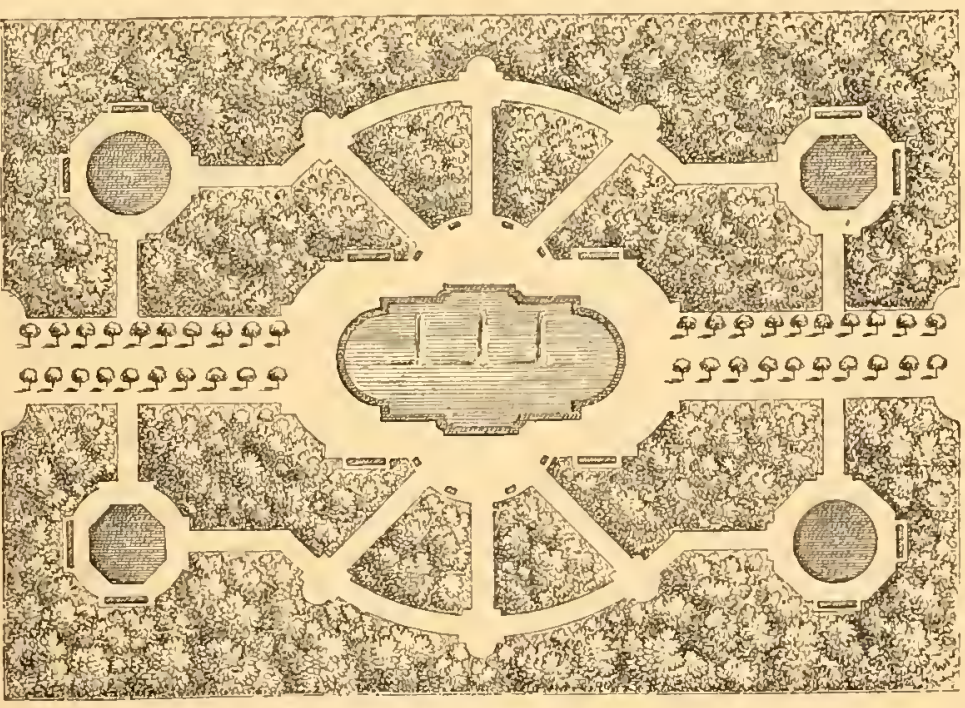

Fig. 371. -- Autre dessin d'Allées. - Bois de haute Futaie. portiques de verdure; les arbres taillés en boules, en sphères, en figures; les parterres à compartiments et à dessins compliqués, faits pour être vus seulement des fenêtres; les boulingrins et mîme les labyrinthes, depuis long- 
temps supprimés dans presque tous les jardins français qui existent cncore (I).
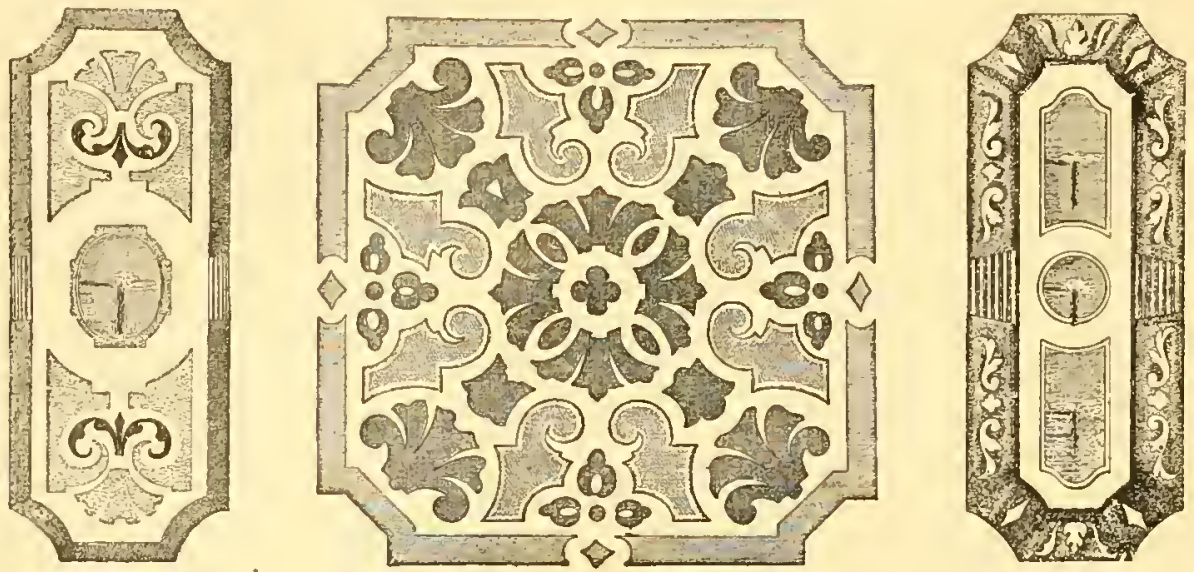

Fig. 372 a 374. - Parterre en Mosaïque figurant un Tapis (srme Siecle).

II. - Règles pour le Choix du Style. - Nous croyons devoir placer

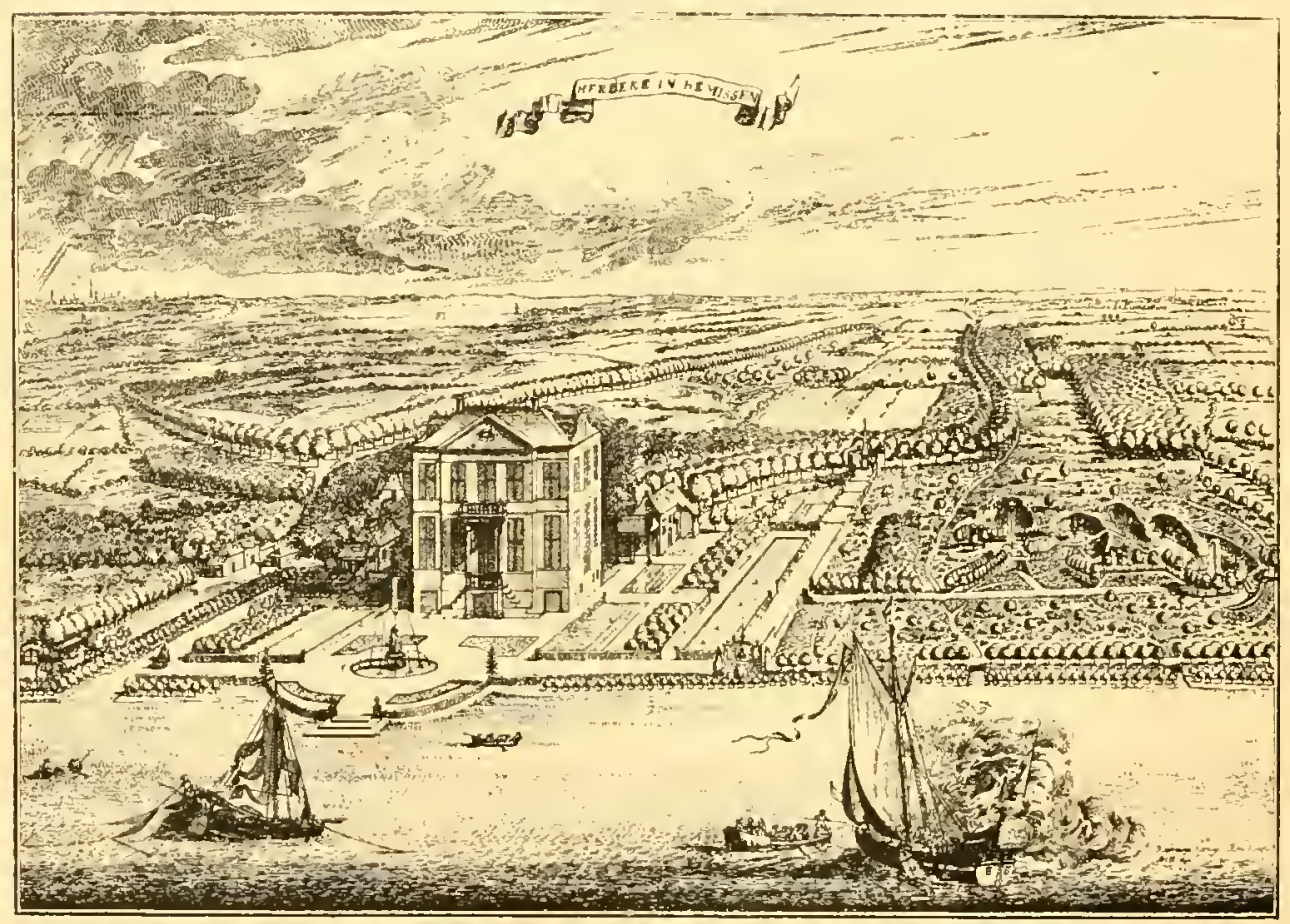

Fig. 375. - Chiteau de Hertehe, frès Anvers, d'aprés Castella (Pretoria Nobilium Brabantice cunobiaque celcbriora), par Jacobi Baronis. (Anterpie, MIncsicvis.)

ici quelques observations préalables sur le "choix du style ì adopter dans la création

(1) Nous joignons à ce chapitre plusieurs beaux spécimens de jardins et pares réguliers qui n'avaient pu trourer place dans notre première partie, comme l'ancien parc de Herbeke, prés d'Anvers (Fig. 375), qui offrait un curieux mélange de fantaisie, d'impréru, avee la symétric; comme aussi l'ancen pare de Triels (Fig. 377). remarquable par la disposition originale de ses avenues latérales en forme d'ellipse allongite, e:c. 
d'un jardin. » Ce style doit, en principe, s'accorder avec celui de l'habitation déja construite ou à construire. Mais si le déreloppement des constructions n'est pas considérable, que le rapentre elles et pose beauUn petit ćdisymétrique, s'accommonage d'un jarque. Il suffit une distance

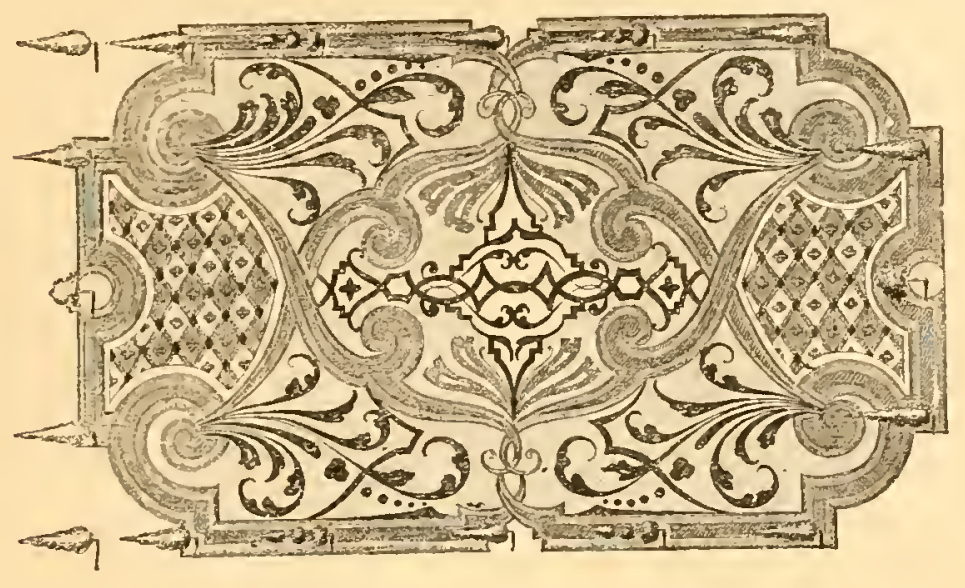

Fig. 376. - Paiterre figurant un Tapis (खrut Siecle).

il est évident port it itablir le jardin s'imcoup moins. fice, de style peut fort bien der du voisidin pittoresde reculer, à convenable les premiers de la façade, groupes d'arbres de haute futaie. C'est ce qu'attestent de nombreuses créations du

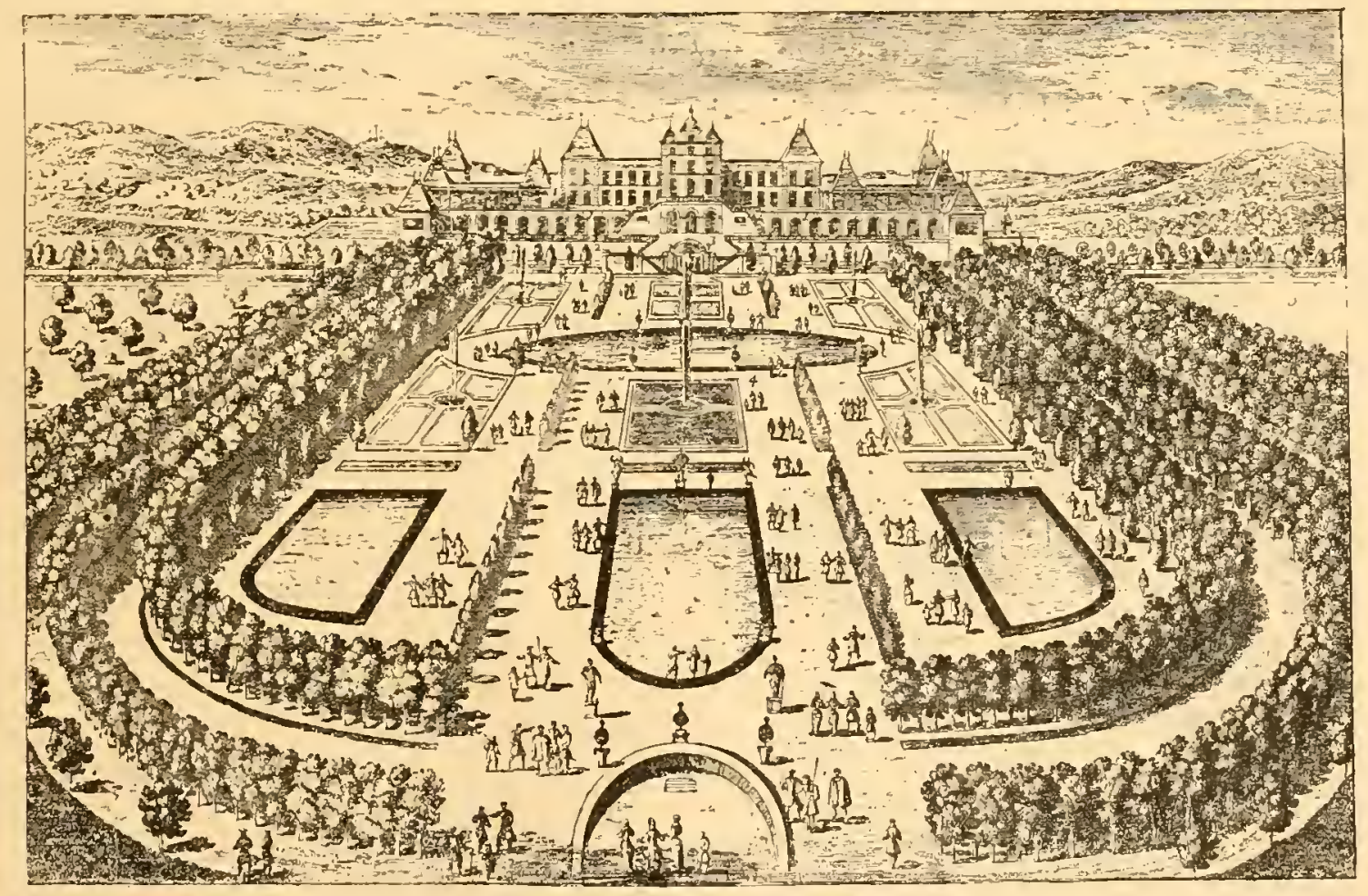

Fig. 377. - Chiteıu de Triels, prés Saint-Marcellin (Isère), dessiné et gravé par Pérelle. (I0ọer p. 248.)

siècle dernier, parmi lesquelles on cite le petit Trianon et le parc de Monceau dans son ancien citat (roir ci-dessus, Fig. 135). Nous terons remarquer, toutefois, que 
l'œuvre de Carmontelle appartenait plutôt au genre mixte. Non seulement le dessin des parterres et l'agencement des eaux devant l'habitation étaient du genre régulicr, mais on en trouvait encore plusieurs réminiscences encadrées dans le pare agreste, notamment les jardins rose, bleu et jamle. C'est l'œuvre d'un novateur timide, qui ne rompt qu'en hésitant arec la tradition classique, et s'efforce d'en retenir quelque chose.

La configuration, le relief du terrain doivent également être pris en séricuse considération pour déterminer le choix du style. Si le terrain était tout à fait plat, il serait assez difficile d'y créer un jardin régulier sans des terrassements conteux, pour obtenir des différences de plans artificiels. Mais unc construction monumentale impose en quelque sorte la régularité, au moins dans la partie du jardin qui est en rapport immédiat avec elle. Cette régularité n'implique pas la symétrie absolue, et se concilic parfaitement avec une certaine élasticité dans l'ordonnance. Nous en avons vu des exemples dans les descriptions des villas romaines, de la Renaissance, et même dans celles de Le Nôtre; à Saint-Cloud, par exemple (Fig. 9j ci-dessus), oú il avait dû surmonter de graves difficultés pour concilier l'application de ses méthodes ordinaires avec les accidents du sol et l'irrégularité des bâtiments.

S'il s'agit d'une habitation considérable et d'un caractère monumental, dominant un terrain accidenté, l'inclinaison du sol facilite, et même peut nécessiter, si elle est très prononcée, la création de terrasses, bien plus commodes pour la promenade et plus faciles à entretenir que des allées en pente rapide. Or, si ecs terrasses sont accompagnées de rampes, d'escaliers, de balustrades, les lignes géométriques doivent être prolongées, complétées par l'ornementation régétale. Le tracé régulier a pour raison, dans ce cas, le relief même du terrain. Done, indépendamment des rapports de style entre l'habitation et le jardin, les tracés réguliers seront heureusement employés au milieu de paysages offrant de puissants reliefs, des profils mouvementés et des horizons étendus. Telle est la situation d'un des plus anciens pares polonais qui subsistent encore, celui du palais de Villanov (1677), ancien domaine de Sobiesli, fièrement campé sur une hauteur qui domine la vallée de la Vistule, non loin de Varsovie (Fig. 378). L'un des exemples modernes les plus curieux d'application du style régulier à la totalité d'un jardin, dans une de ces situations cxceptionnelles, est celui du pare de Monte Carlo prés de Monaco (Fig. 379). On y remarque l'heureux emploi des rochers dans les soubassements des terrasses; ct, dans l'ensemble, une certaine souplesse d'ordonnance, qui, tout en maintenant lidée gènérale de régularité, 
exclut la monotonic. Mais ces retours complets aux dispositions symétriques seront toujours trés rares dans les régions du Nord, parce qu'elles exigent de trop vastes espaces, et que d'ailleurs les raisons qui ont amené le triomphe du style paysager subsistent toujours. (Voir ci-dessus le chapitre du Paysage, pages 9j et suiv.) En revanche, on y trouvera souvent l'occasion d'appliquer le genre mixte dans le voisinage immédiat des habitations monumentales, parfois même à une grande distance, dans la partic la plus en vue de la principale façade. Les parties latérales seront seules dessinées dans le style pittoresque.

On attribue au dessinateur allemand Skell l'nitiative de cette réhabilitation partielle du style régulier. D'autres en avaient eu le pressentiment avant lui, comme on le voit par les anciens plans des parcs de Monceau et de Bagatelle (Fig. I 36 ); mais Skell travailla dans ce genre mixte d'une façon suivic, systématique. Plusieurs artistes ont marché avec succès sur ses traces, notamment Lenné, Siebeck, Nieprascht en Allemagne; Paxton, Nash et Kemp en Angleterre, Thouin et Hardy en France. Le prince Pücliler-Muskau, dessinateur si habile de jardins pittoresques, n'en a pas moins concouru à cette réaction. Il a même été jusqu'à dire que le style régulier était le seul convenable dans les pays oú il a pris naissance; qu'en Grèce, en Italie, la prétention de concentrer les beautés naturelles si multipliées, si intenses, devient téméraire, sinon ridicule. "Dans ces belles contrées méridionales, dit-il, nos plantations pittoresques ne sont, pour ainsi dire, qu'un hors-d'œuvre. C'est comme si, dans un coin d'une belle toile de Claude Lorrain, on voulait ajouter un petit paysage à part. » Malgré cette opinion judicieuse, l'usage «d'ajouter de petits paysages à part» a pénétré partout. L'Égypte, l'Afrique australe, l'Inde, ont aujourd'hui des jardins pittoresques, où l'on est bien forcé de se passer de ces tons doux ct voilés, qui sont l'un des grands charmes des paysages et des jardins paysagers du Nord.

III. - Opérations préparatoires. - Établissement des Perspectives. - Direction des Allees. - Il n'est pas plus possible aujourd'hui qu'autrefois de donner des régles inflexibles pour le tracé total ou partiel d'un jardin régulier; - de prescrire, par exemple, soit une avenue, soit une pelouse inclinée ou une série de terrasses, correspondant à l'axe principal d'un bâtiment. C'est à l'artiste qu'il appartient de juger, d'aprés les ressources dont il dispose, la forme du terrain et cclle de l'habitation, des combinaisons qui pourront le micux faire valoir celle-ci. Toutefois il est toujours indispensable que des perspectives soient ménagécs en 


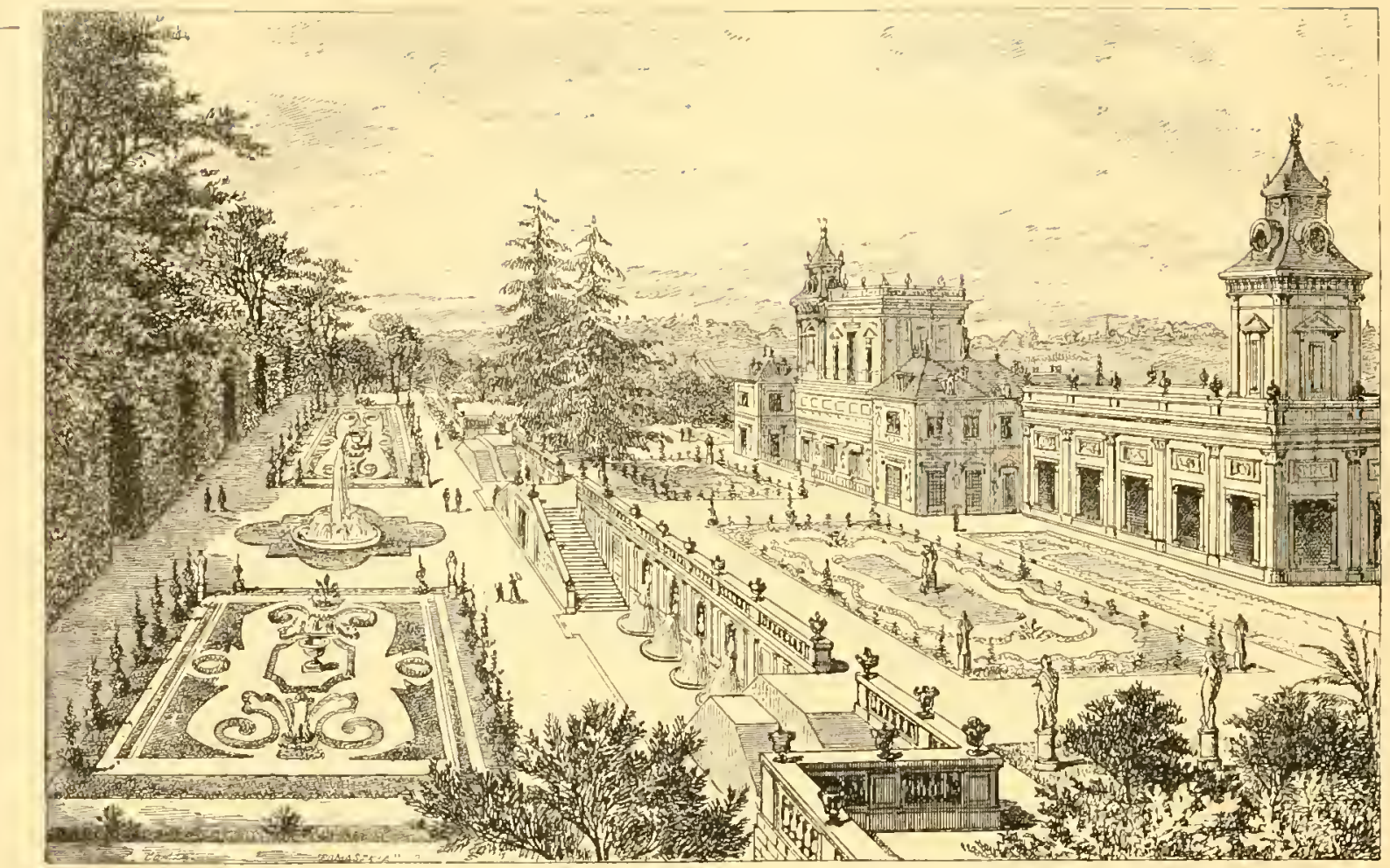

Fig. 37S. - Palais et Ferrasses de Villanov, pres Varsovie. (Vorn p. 2jo.)

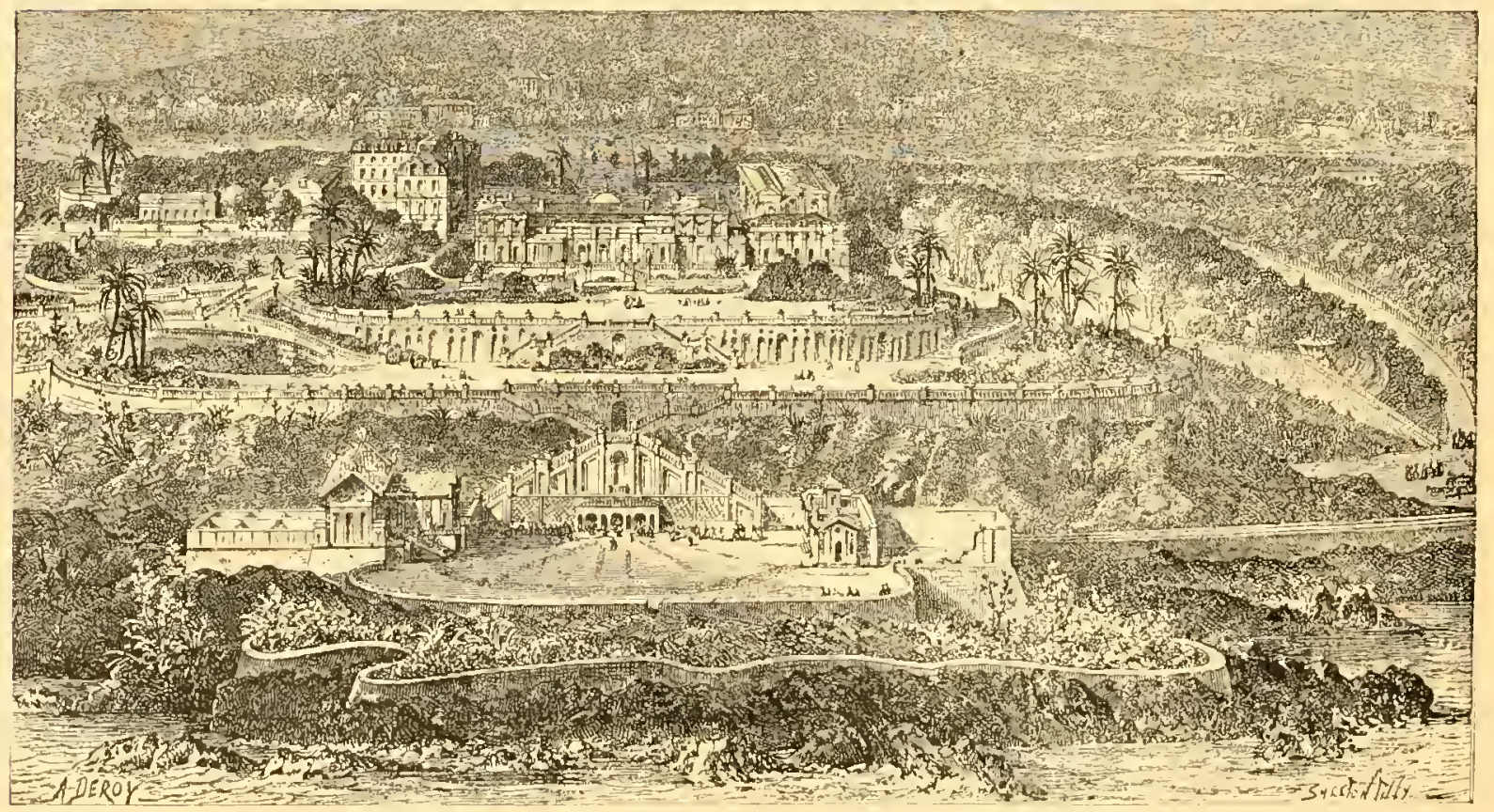


avant (de la façade ou des façades) de l'édifice; qu'un assez vaste espace décourert soit réserví tout autour; ct que du point quil occupe, on puisse dominer les environs.

Une súrie de lignes droites coupées régulièrement ì angles droits, de plates-bandes dans lesquelles la forme géométrique demeure toujours apparente; des escaliers, des murs de souténement, des balustrades, des objets d'art et des bancs réguliérement

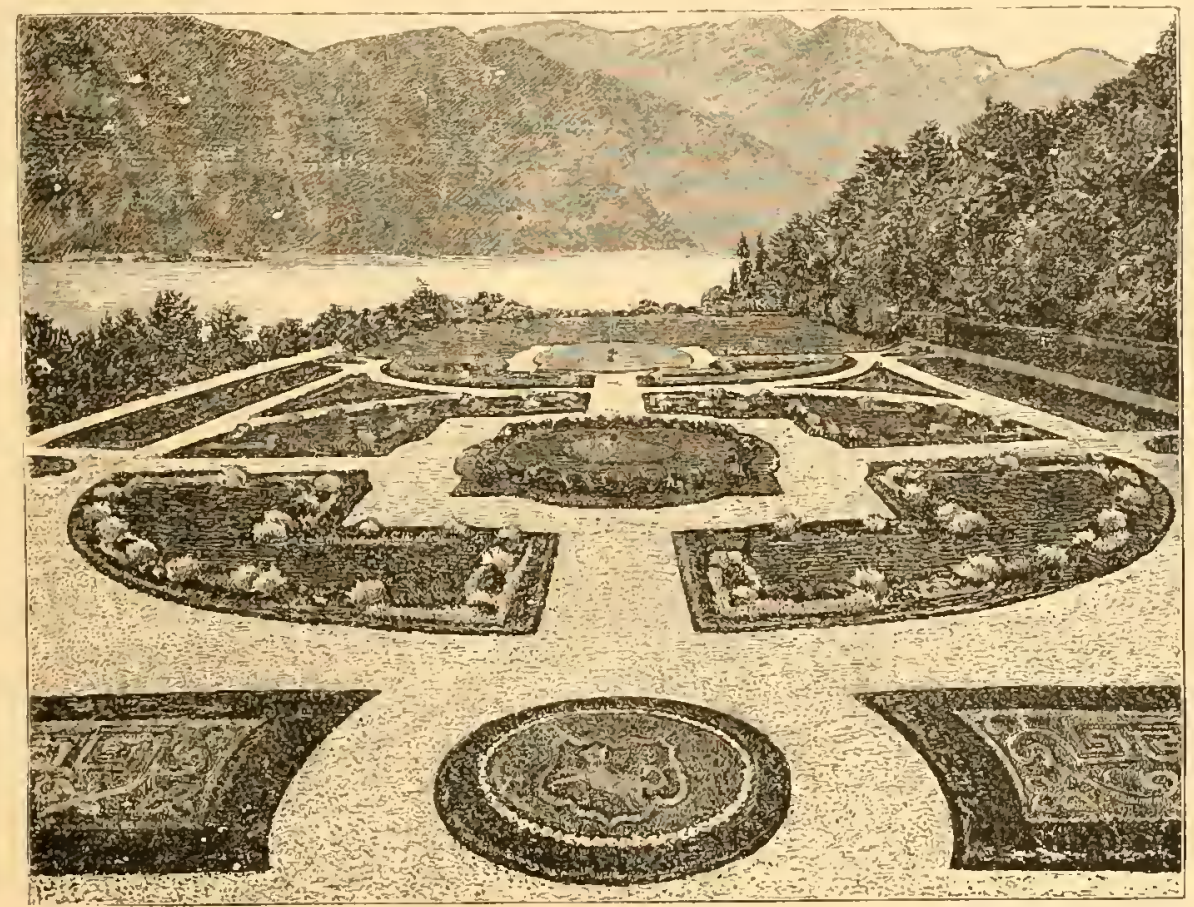

! i

espacés, des arbres alignés, des massifs disposés à intervalles égaux, sont les principaux éléments de ce genre de travail.

Les proportions des terrasses, des parterres, des pelouses, ete., varient en raison de la grandeur du champ d'opérations et de la forme du tracé adopté. Mais l'artiste doit tenir compte de la disposition du terrain et des lois de l'optique (Fig. 3 So). C'est en établissant les perspectives d'aprés les véritables positions qu'un spectateur doit occuper pour embrasser la vue d'un paysage, qu'on arrive à déterminer la juste dimension des arenues, des pelouses principales, la largeur des terrasses, etc., et qu'on évite des retouches coûteuses. Sans cette étude préalable des perspectives sur le terrain, les dessinateurs, comme les architectes, sont exposés à de désagréables 
surprises, en exécutant des plans dans lesquels ils ont négligé de tenir compte des déclivités et des distances relatives.

Il faut employer la même méthode pour fixer la dimension des objets d'art, statues, vases, ctc., qu'on veut placer auprés de l'habitation, dans les carrefours ou aux extrémités des allées.

Dans un jardin ou une fraction de jardin régulier, les eaux peuvent être

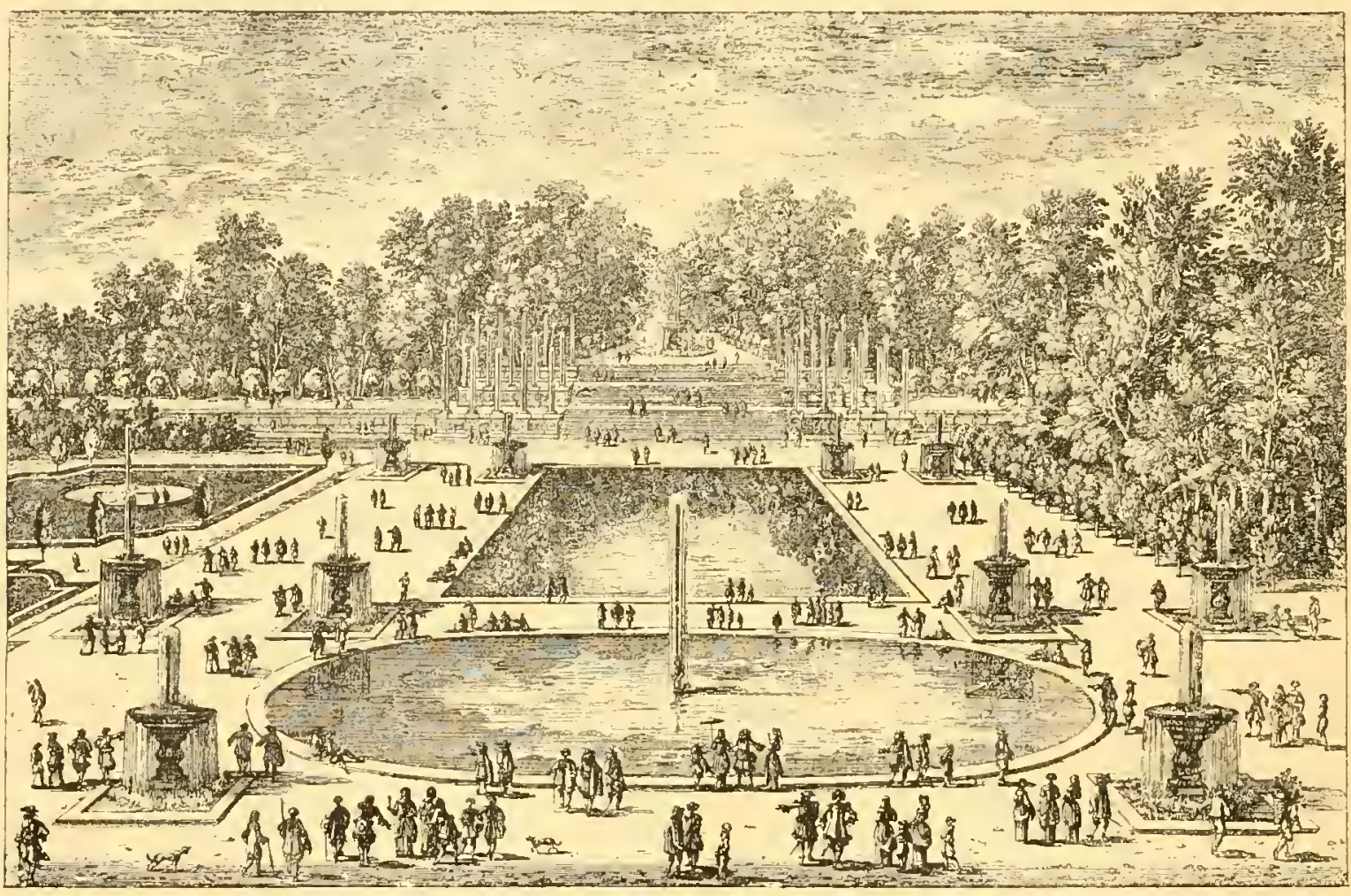

Fig. 38 r. - Les Jardins de Vaux-le-Vicomte, d'aprés l'érelle.

employées, suivant leur abondanee et la forme du terrain, en canaux, en cascades, en bassins (Fig. $3 \delta_{1}, 38_{2}$ ). Pour cet emploi, les artistes pourront toujours s'inspirer utilement des ouvres de la Renaissance italienne et de celles de Le Nôtre.

Le style régulicr ne doit être employé que dans des terrains où les arbres poussent promptement et vigoureusement : il n’admet pas une végétation médiocre, et ne doit pas par conséquent être appliqué sur un sol ingrat. On se souvient encore du triste aspect qu'offrait la majeure partie du bois de Boulogne avant sa transformation.

Les allées dites françaises doivent être droites, ou cn forme d'hémicycle: celles obliques, autrefois trés usitées en Hollande et en Angleterre, sont presque toujours 
d'un effet disgracicux. Nous avons donné ci-dessus un exemple ancien de deux avenues latérales, plantées, venant se rallier en demi-cercle à l'avenue centrale (Fig. 377). Cette disposition, qui naturellement doit influer sur le dessin des parterres qu'elle encadre, est originale et d'un heureux effet.

Dans les jardins réguliers, ce sont principalement les allées qui attirent l'attention

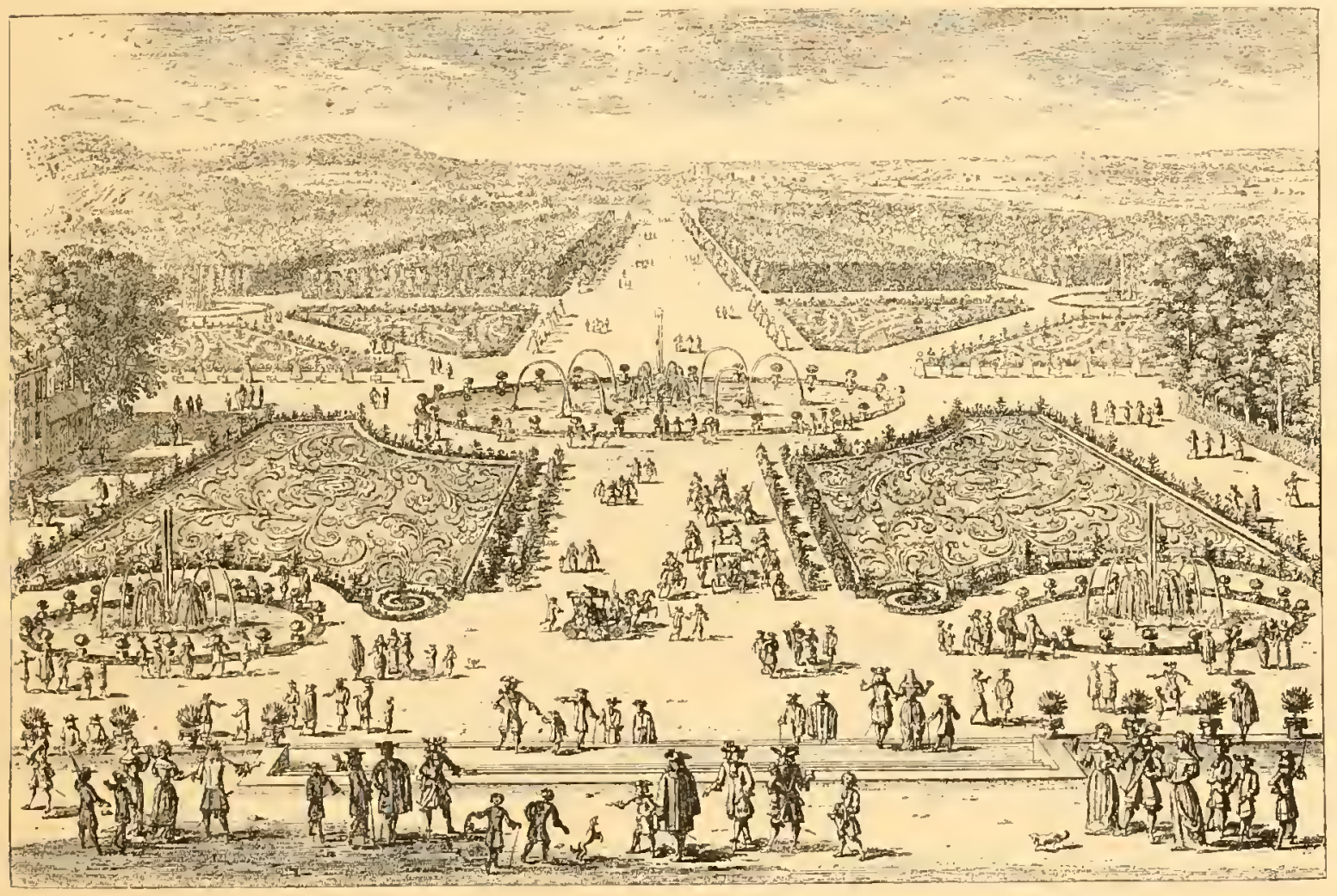

Fig. $382,-$ Avenue et Parterres qui faisaient partie des Jardins de Saint-Germain, d’après Pérelle.

(Fogez P. 254.)

et donnent le caractére. Dans ceux du style paysager, nous avons vu que c'était précisément le contraire.

La largeur atténue l'effet de la longueur; mais cette atténuation peut être à son tour neutralisée par l'emploi des statues, vases et autres ornements, placés aux points d'intersection.

Dans ces compositions, comme dans celles de l'autre style, il faut tenir grand compte de la nature environnante, mais la manière d'en tirer parti n'est pas la même. "Une belle vue doit motiver la création d'une percée, et influer ainsi sur la composition générale, au point d'étre quelquefois le motif principal de la disposition d'un plan. » 
Dans tous les cas, un beau paysage à l'extrémité d'une avenue majestucuse, sera toujours d'un effet grandiose. Il est essentiel alors que la clôture soit placée en contre-bas. Une autre disposition trés heureuse est celle de plusieurs arenues convergeant à une terrasse en forme de rond-point. On en roit un remarquable excmple dans le pare de la Muette (Fig. 383 et 384 ). I.cs allées qui ne donnent pas sur la campagne, doirent aboutir à une statue ou a quelque vase monumental, se

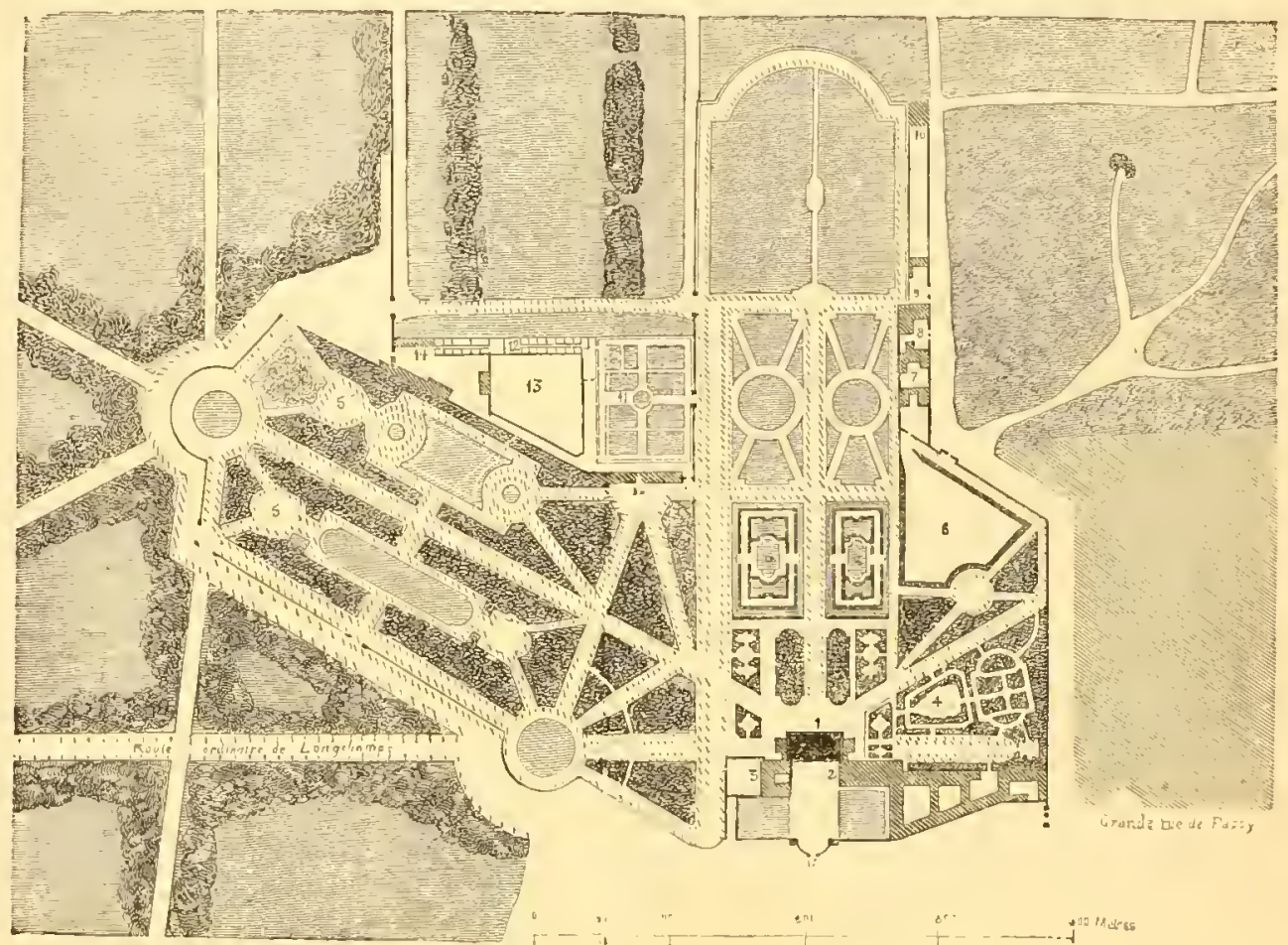

Fig. 383. - Cháteau et Pare de la Muette, a Passy:

1. Clâteau de l. Nuetre. - 2. Aile menue du Château. - 3. Vieux bâtiments. - 4. Jardin de La Reine. - j. Jardin du Roi. - 6. Orangerie d’èté. - \%. Laiterie du Roi, - 8. Pompe. - o. Logement du jardinier. - ro. Tavillon de l'Observatoire, - 11. Jardin potager. - I2. Faisanderie. - 33. Réserve de la Faissnderie. - I4. Logement de l'inspecteur des chasses. - 15. Orangerie d'hicer. -16 . Porte royale.

dẻtachant sur un fond d'arbres ou d'arbustes taillés, ifs, buis ou charmilles. IV. - Plantation. - La régularité des masses de feuillages est une des conditions essentielles du genre. Pour y satisfaire, on compose sourent les plantations aree des arbres de même espéce. Il en résulte une fâcheuse uniformité de coloris; et l'on connaît l'étroite parenté qui unit l'uniformité à l'ennuj. Afun d'obvier à cet inconvénient, nous conseillons de ne planter que le bord des allées et des arenues en arbres de même essence, et d'introduire dans les massifs des espèces variées, de hauteur à peu prés égale. Toutefois, il conviendra d'alterner régulièrement 
ces variantes pour conserver le caractere. Une autre modification aux anciennes méthodes semble en roie de prévaloir, non seulement dans les nouvelles plantations régulières, mais dans l'entretien des anciennes. Au lieu de tailler, comme autrefois,

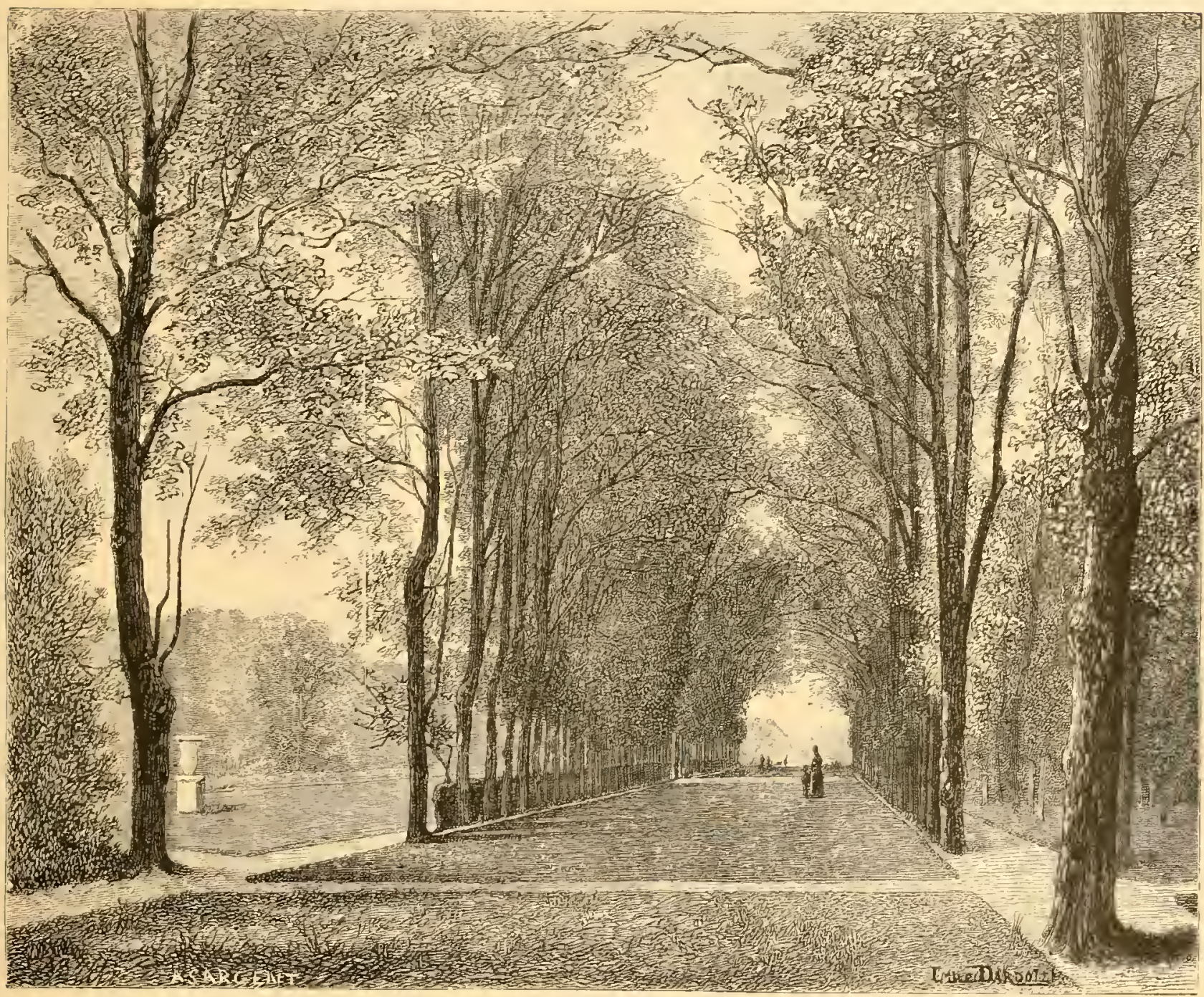

Fig. 384. - Grande Avenue de la .Iuette, it Passy. (Ioyta p. 2;6

les arbres des allées en palissades dans toute ou presque toute leur hauteur, on se borne à retrancher les branches inférieures qui peuvent obstruer la promenade ou gêner la vue. Il est évident, toutefois, que la hauteur de la taille demeure subordonnée aux régles de la perspective. Une arenue de grands arbres dont les cimes forment, cn se rejoignant, une voûte élevée au-dessus d'une allée ou d'un cours d'eau, produit toujours un effet majestueux, qui doit être respecté et soigneusement entretenu (Fig. $3 S_{4}$ ). Une des sections de la rivicre de Charenton au bord de Vincennes 
fournit un autre exemple d'un effet de ce genre (Fig. 2 I ). La Calle de la Reyina dans le parc d'Aranjuez, que Saint-Simon admirait déjà cn 1722, est peut-être aujourd'lui la plus belle avenue de l'Europe. Nous donnons ici le plan et, quelques-unes des anciennes vues de détail les plus intéressantes de cette résidence (Fig. $38 ;$ à 388 ).

Nous reproduisons également la façade de San Ildefonso (la Granja), et le plan

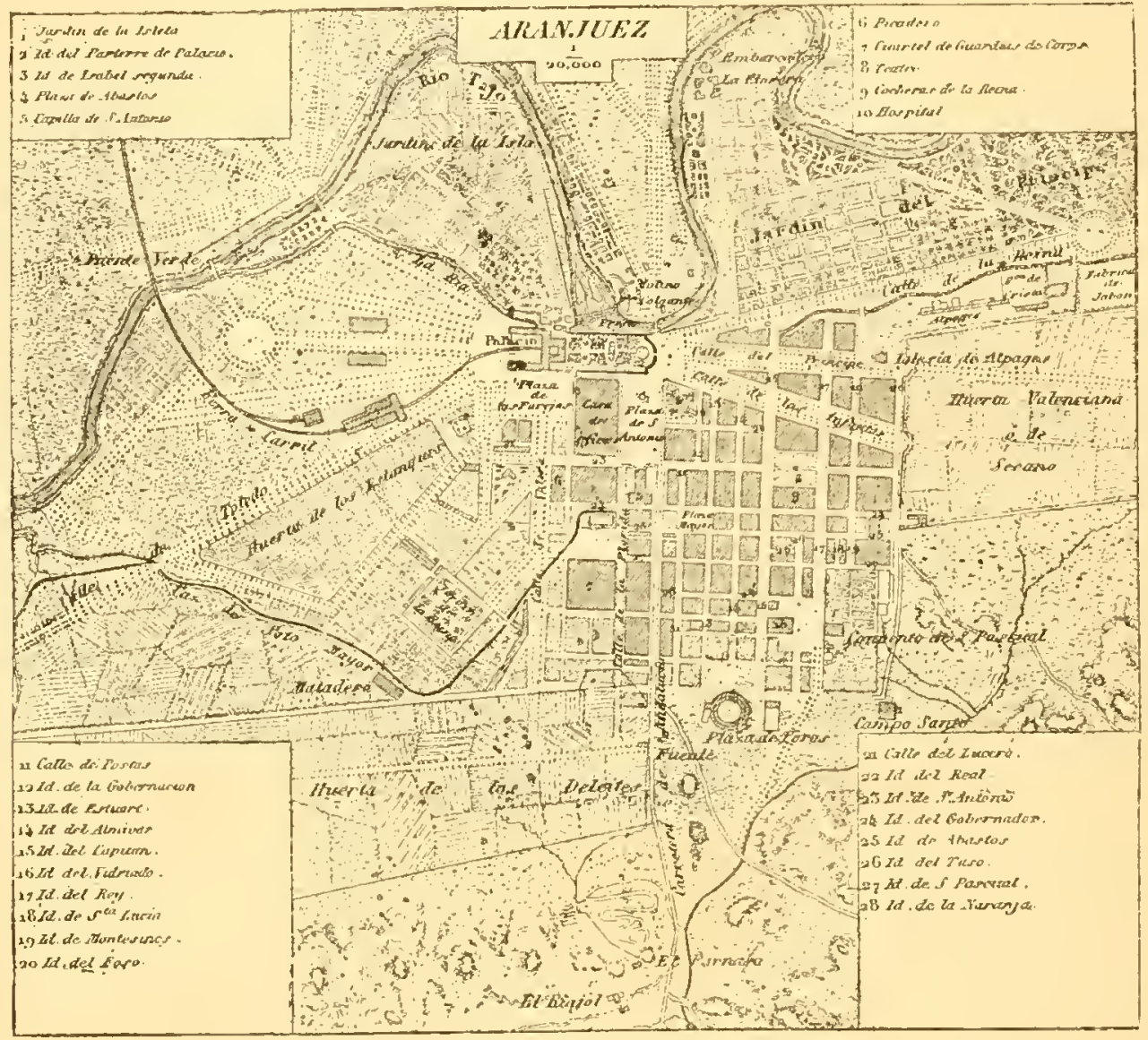

Fig 385. - Plan du Parc d'Aranjuez, d’aprés Guia de Aranjuez, par F. Nard (Madrid, 1851).

du pare, que le même Saint-Simon vit planter, dans un site dont il admirait, en quelque sorte malgré lui, la bidense beauté (Voir ci-dessus, p. 91).

Le tracé de ces jardins avait été fait par Étienne Boutelou et leur décoration par le sculpteur René Carlier (Fig. 389 et 390).

Les allées de gazon, quoique bien passées de mode, sont quelquefois d'un effet agrẻable dans les pares de châteaux antérieurs au xinle siècle. Elles doivent être droites, avec des bordures d'arbustes et de fleurs de la même espéce, ou d'espéces réguliérement alternées, pour former une sorte d'avenue. Les allées de ce genre ne peuvent guére 


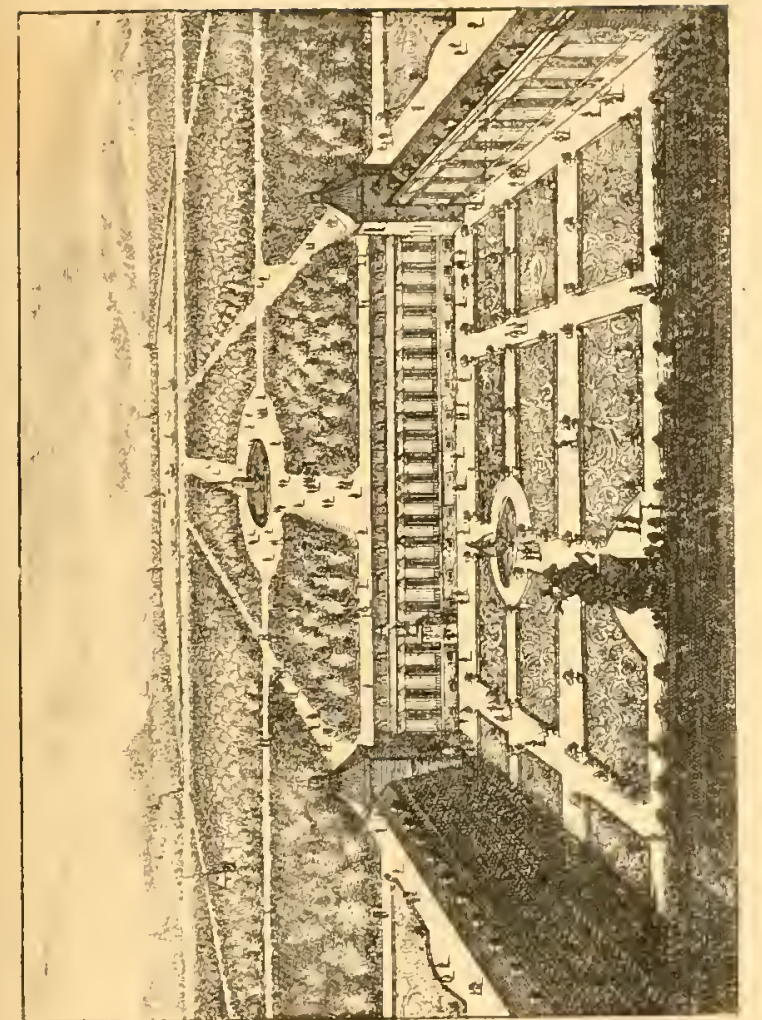

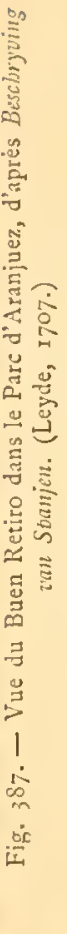

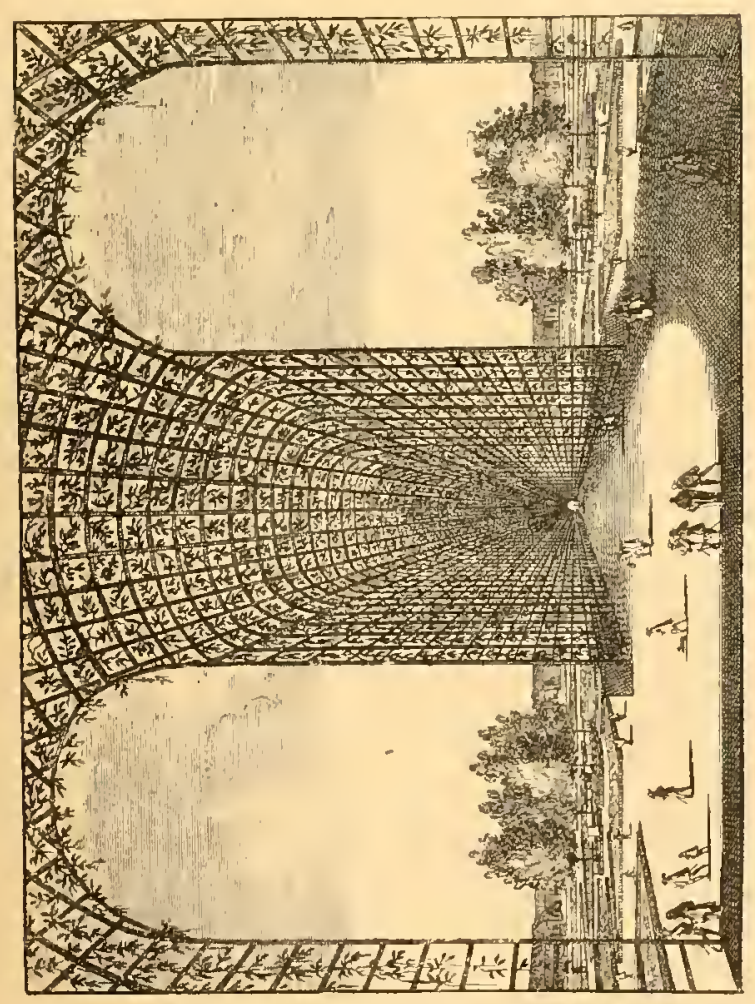




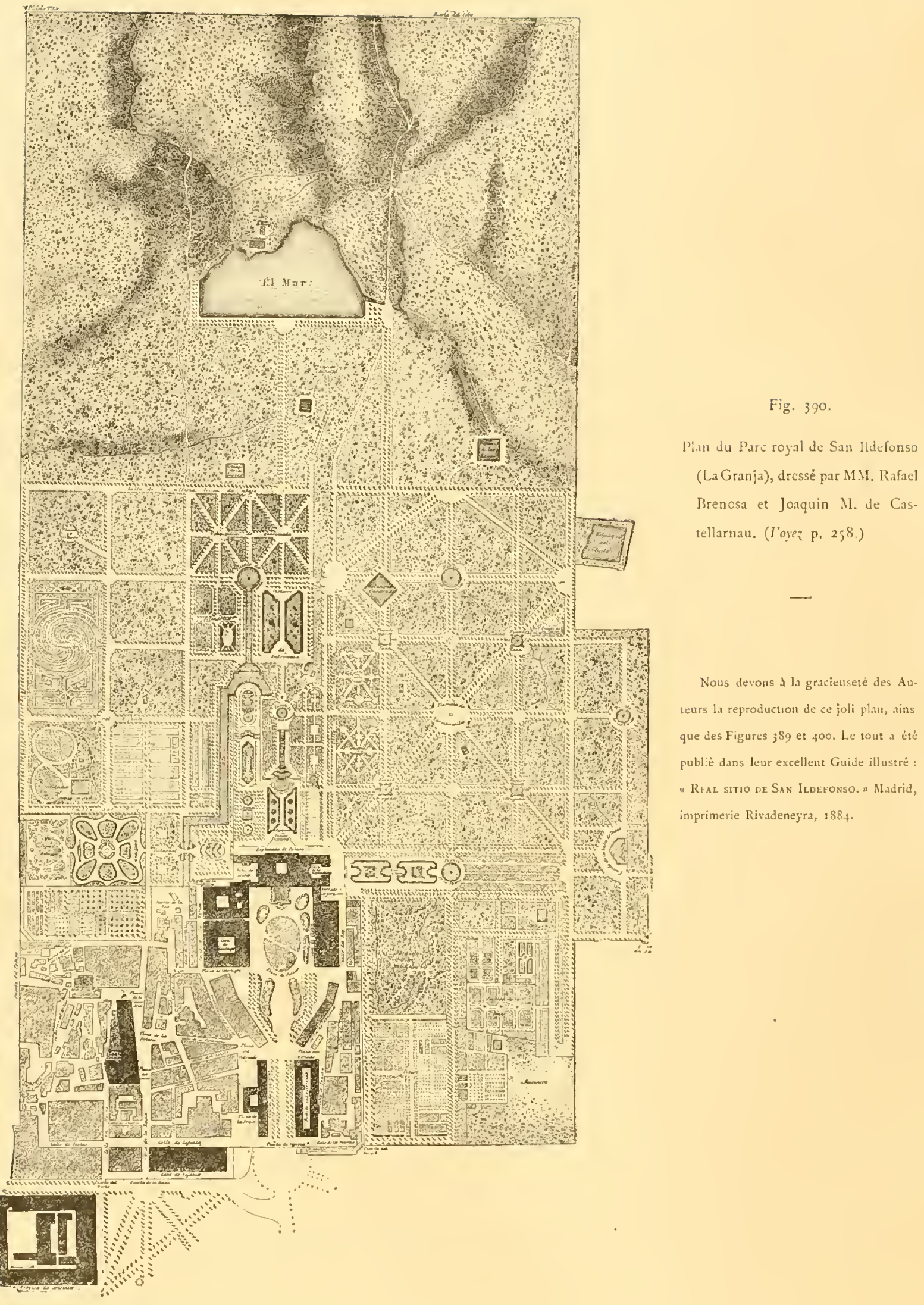




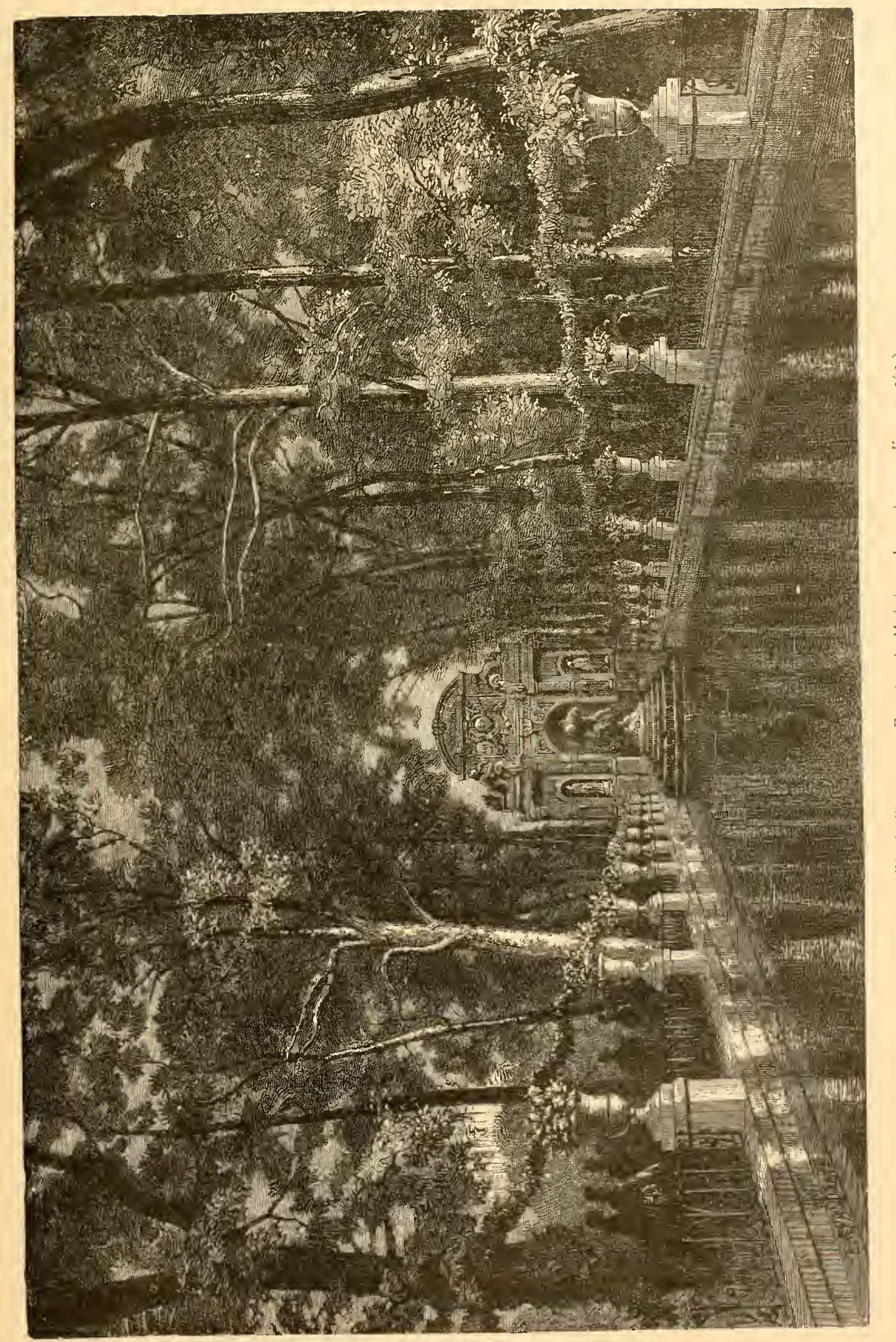


servir à la promenade, à cause de l'humidité. Nous en avons vu cependant quelques-unes dans lesquelles on avait remédié à cet inconvénient, en remplaçant l'herbe par des pervenches.

Dans les ouvres de ce genre, on pourra aussi faire disparaitre ou atténuer la monotonie, en utilisant dans les massifs et les parterres, les nombreuses ressources de l'horticulture moderne, plantes à fleurs, à feuillage, etc. Mais il faut conserver une certaine régularité dans la disposition des corbeilles et des bordures, et dans le place-

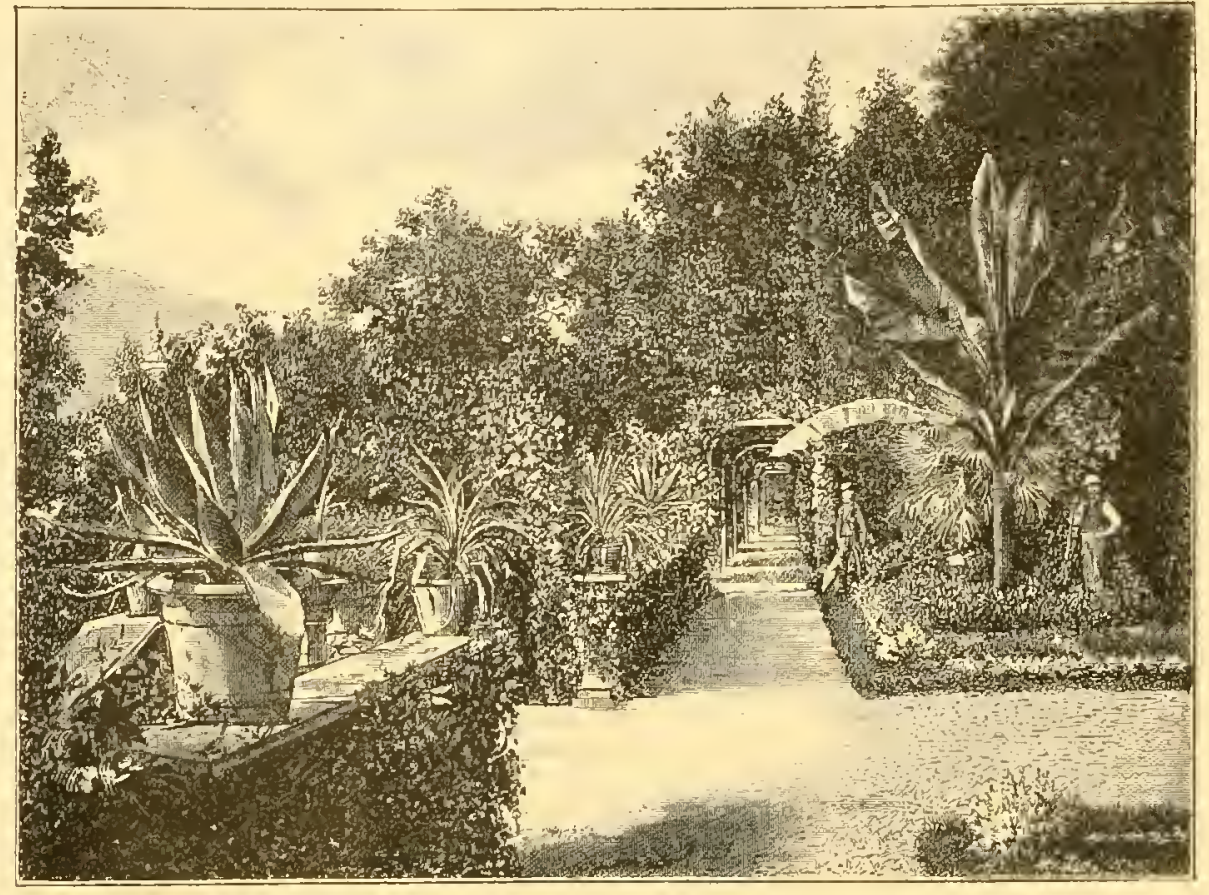

Fig. 392. - Allée taillée dans des Orangers à la villa Carlotta (Lac de Cóme). ment des arbustes exotiques, des plantes de serre ornementales, sur les pelouses, et dans les vases des terrasses et des avenues ( $\mathrm{Fi}-$ gure 392). On peut tirer un cxecllent parti, pour cette doubledestination, des diverses ra-

riètés de palmiers, de cycadées, dracanas, graminées, etc., récemment introduites dans la decoration estivale des promenades publiques et des pares.

On pourra aussi égayer l'aspect des grandes allées, en reliant les arbres par des testons de lierre et autres plantes grimpantes. Ce genre de décoration, renouvelé des Romains, avait été essayé avec succés, pendant le xrrule siècle, dans l'un des plus beaux jardins de Paris, celui de l'hôtel Biron, au faubourg Saint-Germain. Il en a été fait de nos jours une nouvelle application au Luxembourg, dans l'allée de platines qui méne à la fontaine Médicis (Fig. 391 ).

V. - Méthodes de Raccordement. - Il ne se présente guére aujourd'hui d'occasions d'appliquer les préceptes du style régulier à la totalité d'un domaine. Les 
applications partielles de ce style sont au contraire des plus fréquentes. En général, l'importance de cet emploi doit étre proportionnée à celle des bitiments. Nous trouvons un exemple intéressant de cette harmonie de proportions dans le parc du Palais de Cristal (Sydenbam Palace, à Londres), cuvre de Paxton, l'un des plus habiles dessinateurs anglais. Toute la partic centrale est ríguliere; la forme des bassins, des cascades et de leurs encadrements, rigoureusement symétrique (Figure 393), tandis que le fond du parc et les parties latérales sont du genre irrégulier. Un simple rideau de plantations sépare les deux principaux bassins absolument pareils, etd'une rígularité mathématique, d'un grand et d'un petit lac pittoresques, aux contours capricieusement évidés et contournés. La grande difficulté dans ces cuvres mixtes, c'est le raccordement, l'arrangement de la zone limitrophe, dans laquelle doivent s'harmo-

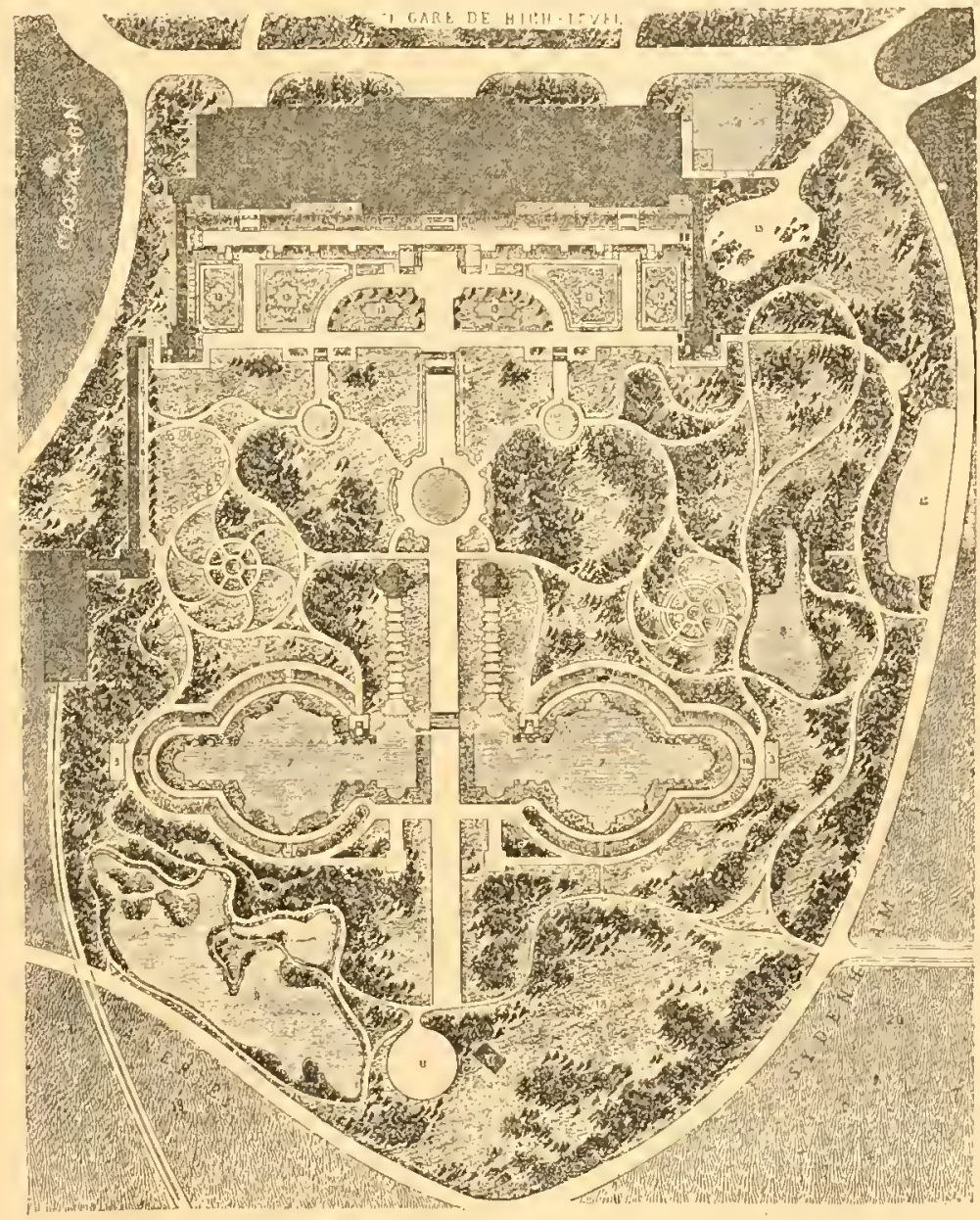

Fig. 393. - Parc de Sydenlam Palace, prés de Londres, exécuté par Paxton.

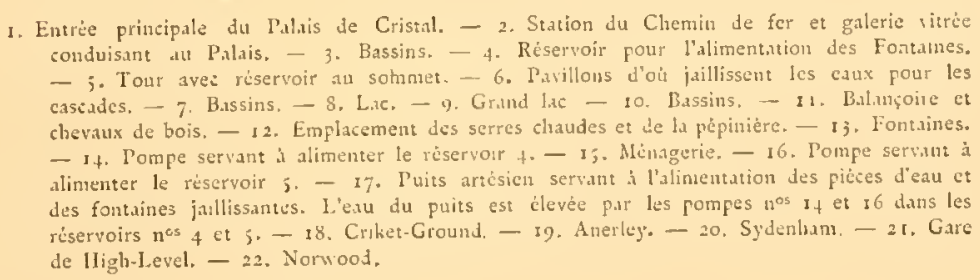

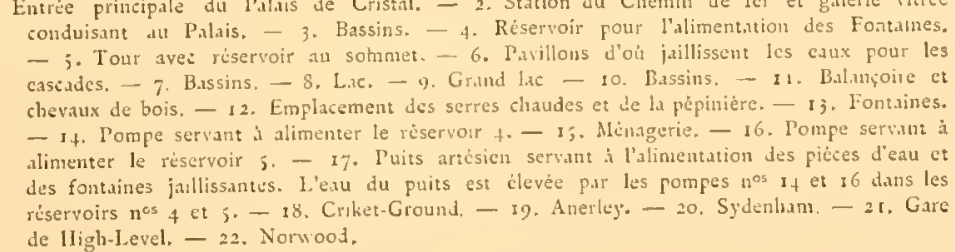
niser et se fondre les deux caractéres. Paxton a tiré habilement parti, pour ce trarail de fusion, du demi-cercle classique. La plupart des cmbranchements ou allées de jonction affectent cette forme au point de bifurcation, et semblent d'abord continuer le tracé régulier. Mais le changement de caractère se révéle insensiblement à mesure qu'on 
s'éloigne de la jonction, par les prolongements des courbes et des inflexions nouvelles, par les vallonnements et la variété de plantation. Ce travail de raccordement est opéré fort habilement (et dans un petit espace, ce qui compliquait encore la difficulté) dans le pare de Sydenham, entre le lac pittoresque, arec îles à l'extrémité sud-ouest (No 9 )

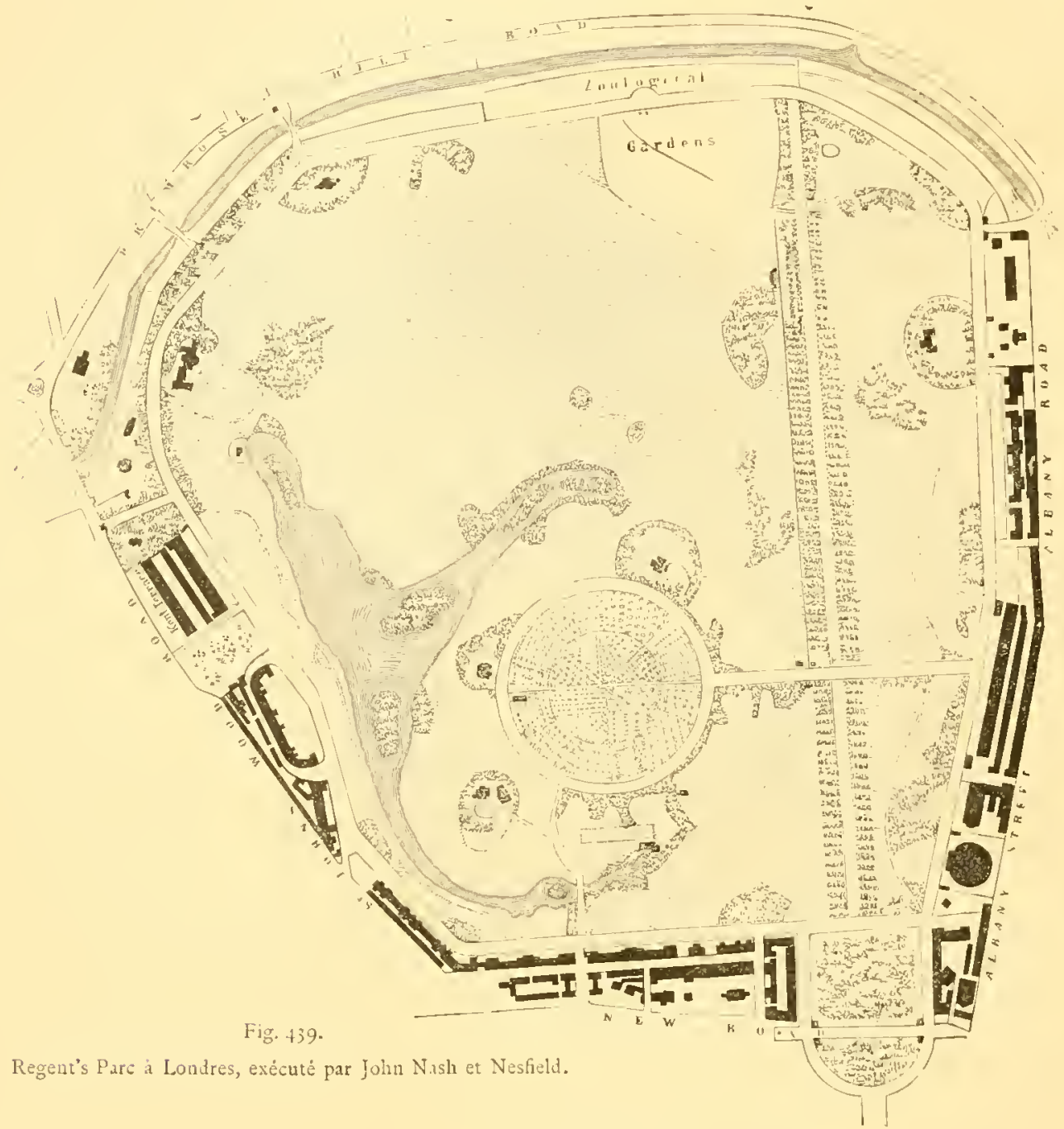

et le grand bassin régulier placé immédiatement au-dessus de ce lac, dont il forme le réservoir supérieur.

A Regent's Park (Fig. 394), l'effet peu gracieux de cette espéce de disque formé par une allée circulaire emmanchée sur une longue avenue droite, a été assez habilement atténué dans un ensemble irrégulier par quelques bordures, et par les contours des massifs adjacents, qui rappellent la forme de l'allée, sans s'y conformer rigoureusement. Cette allée ronde formait, en i $\delta_{12}$, l'encadrement des serres et des 
parterres du Jardin botanique, qui la débordent aujourd'hui. D'autres dispositions de raciordement, dignes d'attention et d'étude, nous sont fournies par le pare de Schwetzingen, un des plus anciens de l'Europe (Fig. 395), et par le jardin Flora

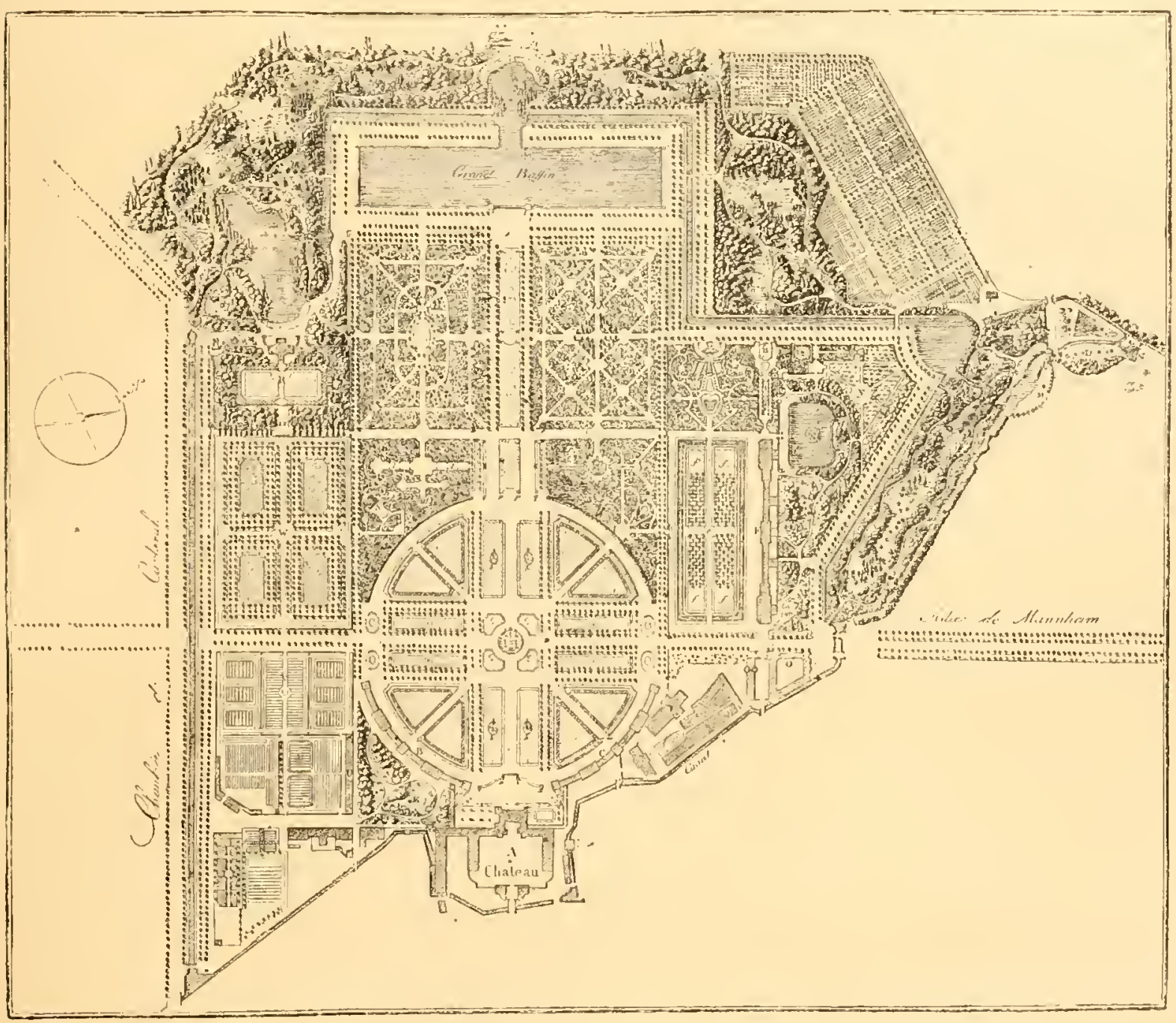

Fig. 39;. - Plan du Parc de Schrvetzingen, prés Heidelberg, d'aprés Zeyher et G. Romer,

à Cologne, ouvre posthume du célèbre dessinateur Lenné, cxécutéc avec quelques modifications par un de ses éléves. Ici la fusion des deux styles offrait d'autant plus d'obstacles, que la part laite au style régulier était plus considérable (Fig. 228). C'est encore, comme on voit, par l'habile emploi des courbes dans les contours des allées d'embranchement, et aussi dans ceux de la piéce d'eau irrégulière, qu'on est arrivé à tormer un ensemble harmonieux des éléments les plus disparates. 
VI. - Places publiques. - " Tout espace employé en plantations sur

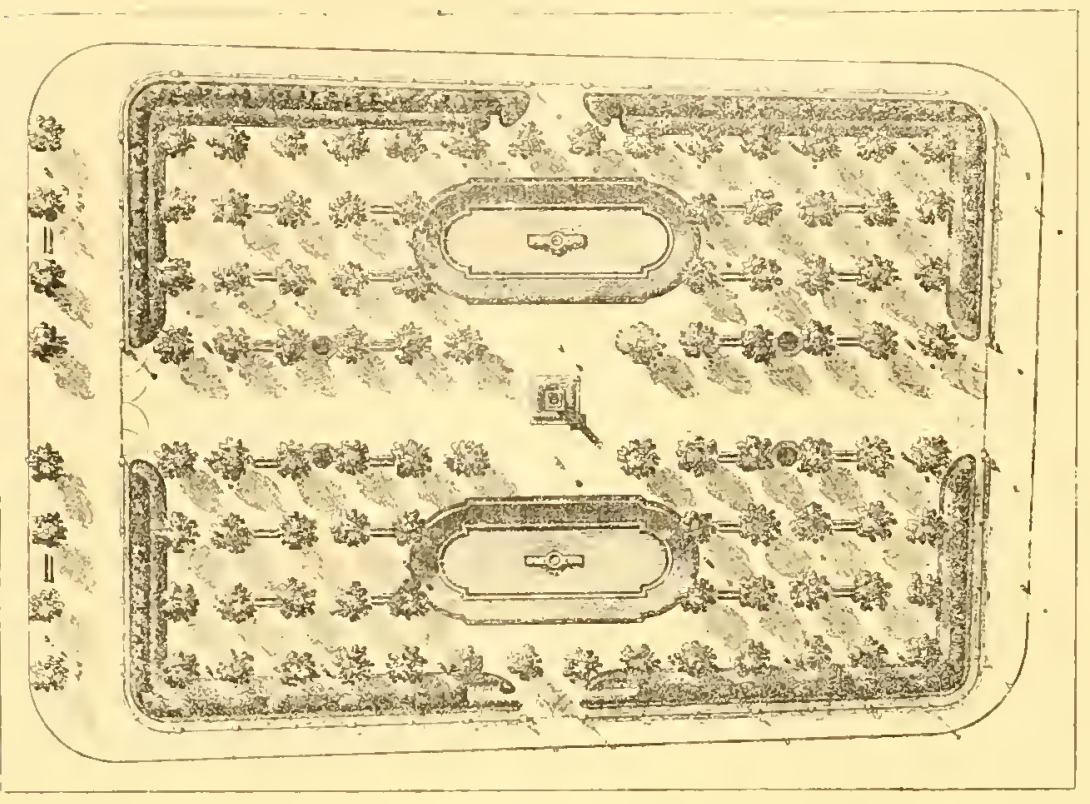

Fig. 396. - Square des Arts et Metiers. des quais, des places, des carrefours et des rues larges dans l'intérieur des villes, si cela se peut, sans nuire a la circulation, est un véritable bienfait pour le peuple (Mayer). " Cette opinion avait déjá été émise, au sicele dernier, par l'horticulteur français Morel. L'alpplication de ce principe philanthropique a été réalisée sur une vaste échelle dans la transformation de

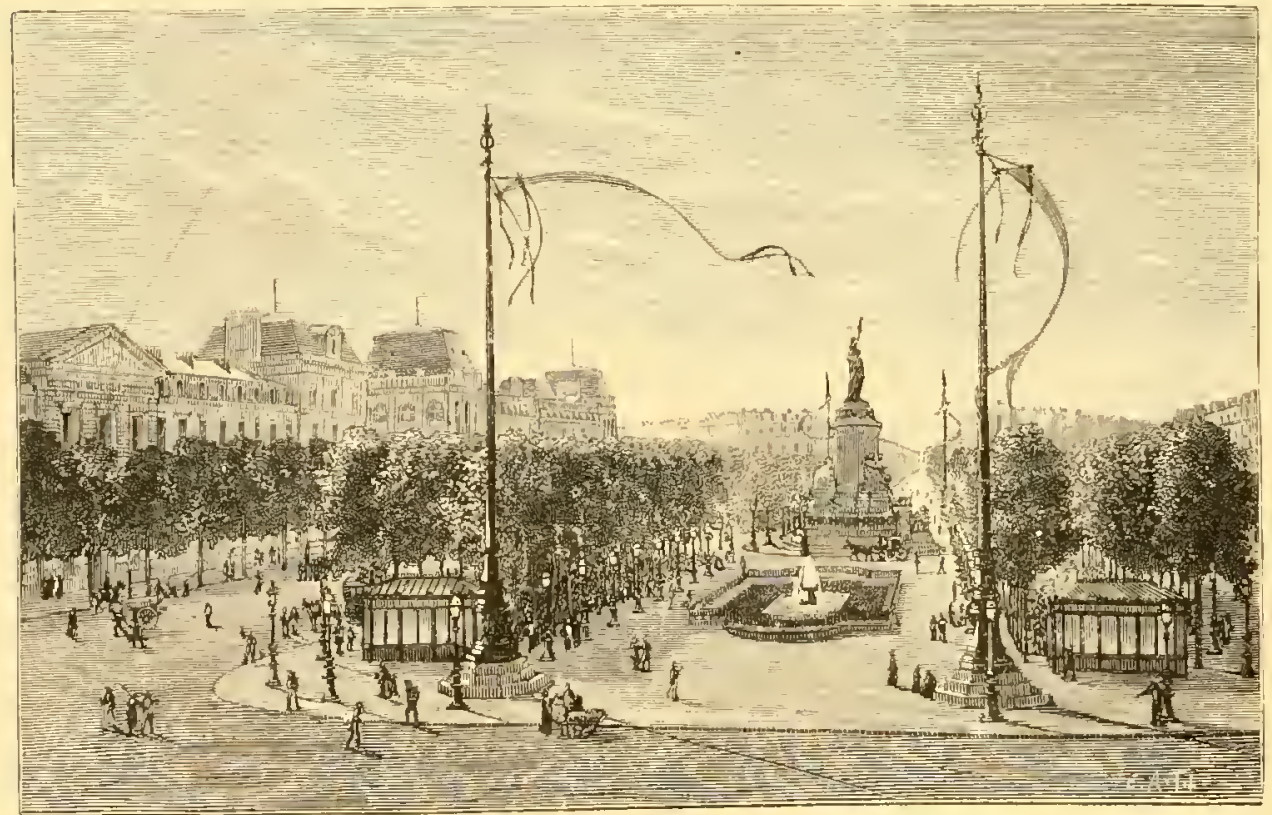

Fig. 397. - Place de la République.

Paris (Voir ci-après, chapitre $r)$.

Suivant les horticulteurs les plus compétents, le style régulier est le plus convenable pour la décoration végétale des places publiques. La forme, le caractére, l'importance des plantations doivent se régler d'aprés ceux des édifices dans lesquels elles sont enclavées, la grandeur et la configuration de l'empla- 
cement, les directions des rues qui viennent y aboutir (Fig. 397). "Il faut autant que possible, dit Mayer, réserver quelques endroits ombragés, avec des bancs d'oú la rue puisse se porter librement sur la statue, la fontaine ou l'édicule quelconque, installés au centre. Si la place est petite, il faut se contenter d'une allée unique, et ne planter que des arbres d'une hauteur médiocre. Si elle est grande, on emploiera des arbres plus hauts. "Mayer conseille, dans ce cas, d'entourer la place entière de grands arbres, en réservant un espace suffisant devant les constructions.

On cite généralement la place Royale (Paris), comme un modéle de l'application du style régulier aux places publiques. Néanmoins elle est moins belle, depuis qu'elle a perdu, sous Louis XVI, son encadrement d'arbres séculaires. Deux autres spécimens tout à fait modernes d'un travail de ce genre, sont le square planté réguliérement, qui sépare le boulevard de Sébastopol du Conservatoire des Arts et Métiers (Fig. 396), et la place de la République (Fig. 397).

Nous reproduisons deux plans de places régulièrement décorées, qui font partie du grand ouvrage de Mayer. Le

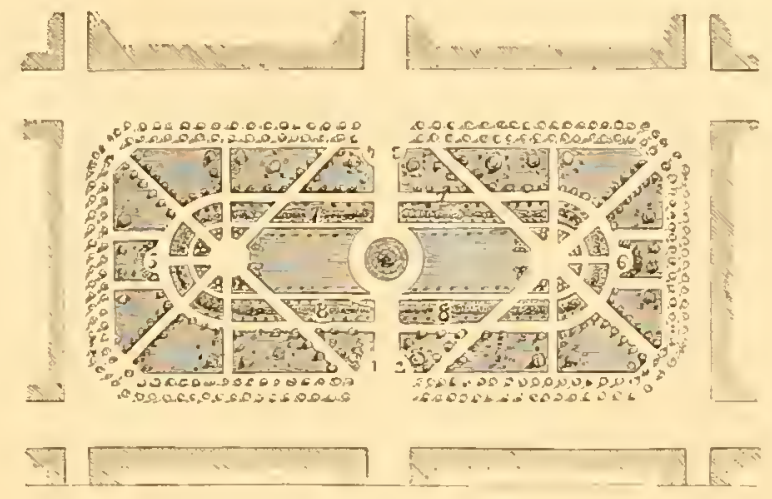
Fig. 398. - Place publique.

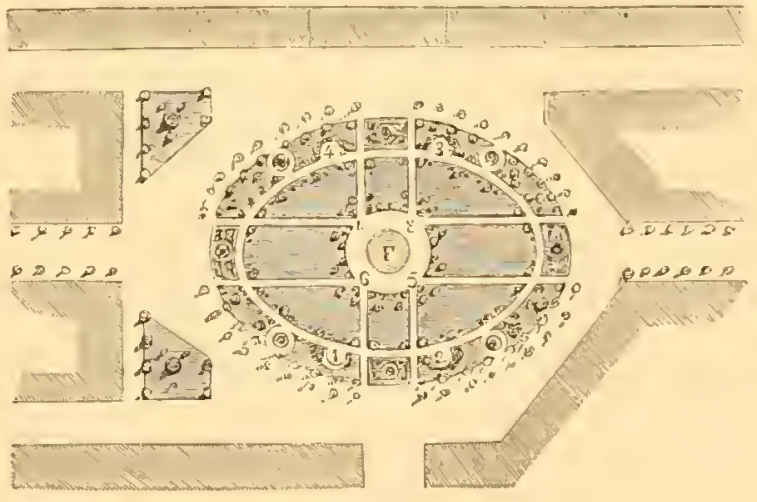

Fig. 399. - Autre Place publique. premier (Fig. 398), arec son agencement d'allées obliques, est dans le goût hollandais et anglais de la fin du Xviri siècle.

Les nos 1 à 6 désignent des bancs; le $n^{\circ} 7$ une plantation d'arbustes toujours verts, alternant avec des plantes à grand teuillage; le $n^{\circ} 8$, un cordon d'arbustes à fleurs.

Le second plan (Fig. 399), se rapproche beaucoup du style de Le Nôtre. L'artiste a fort habilement dissimulé la forme irrégulière de la place.

$F$. est une fontaine monumentale, placée au centre. Les nos I à 8 indiquent les endroits convenables pour placer des bancs. La décoration du pourtour est formée 
d'arbustes à basse tige. En principe, tout espace réservé dans une place publique à des plantations régulières ou non, a droit au titre de square. Mais comme c'est en Angleterre que s'est d'abord établi le plus généralement l'usage de décorcr les places de plantations irréguliéres, le mot square, aujourd'hui naturalisé dans notre langue, correspond plus particulicrement à lidée d'une plantation qui, bien qu'entourée d'édifices, est conçue dans le style paysager, avec vallonnements, allées sinueuses, corbeilles d'arbustes, de plantes à feuillage et de fleurs, disposces capricieusement.

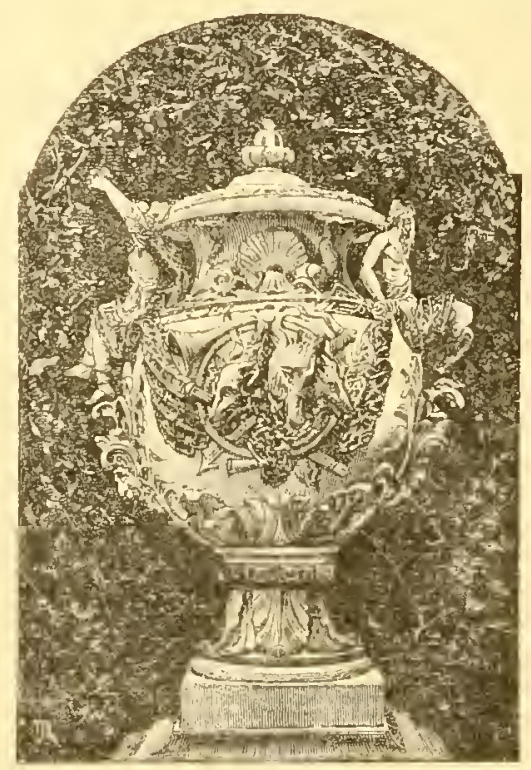

Fig. 400. - Vase d'un des Parterres de San Iidefonso (La Granja). 


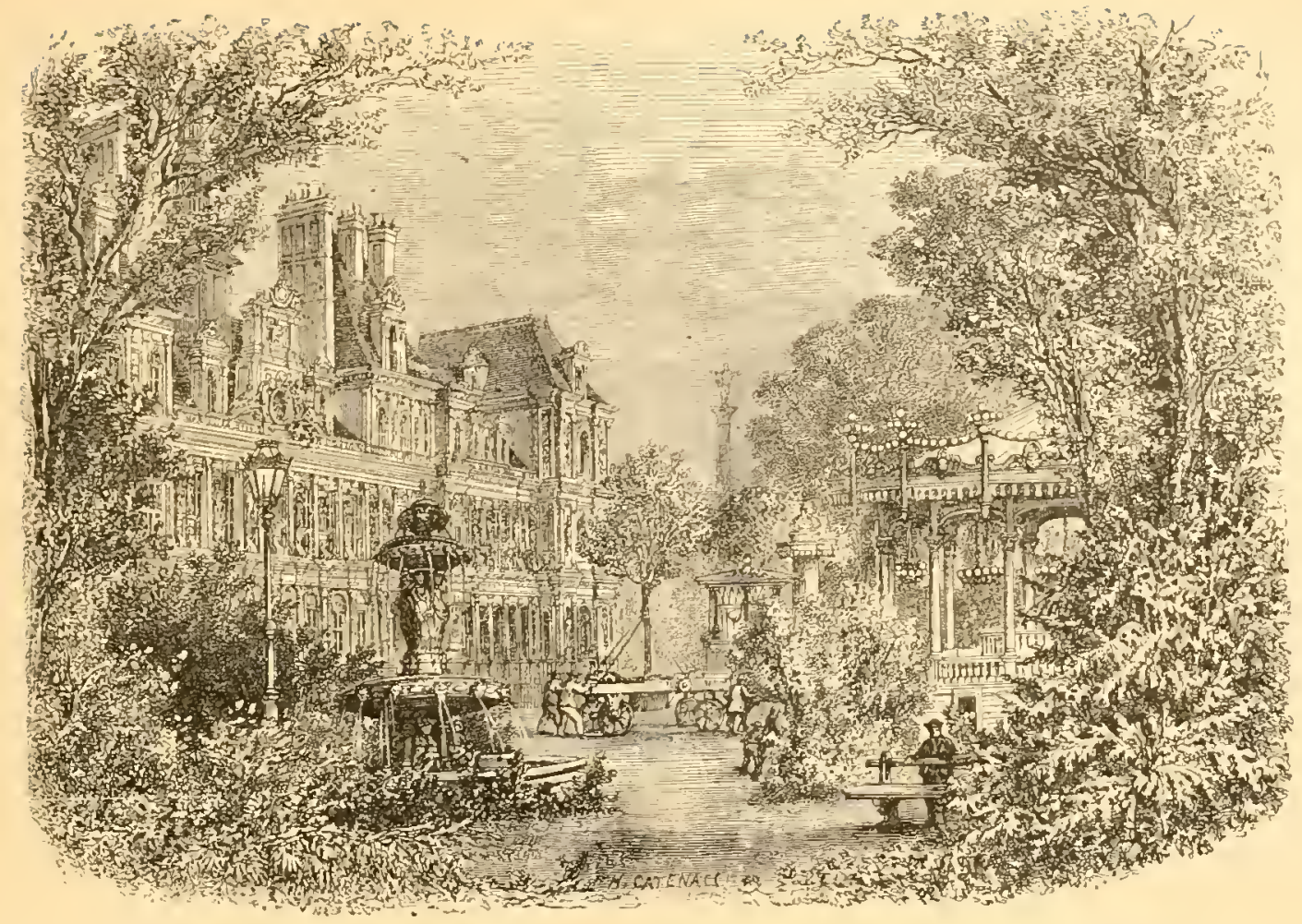

\section{CHAPITRE III}

\section{JARDINS DE VILLES ET D'INSTITUTEURS}

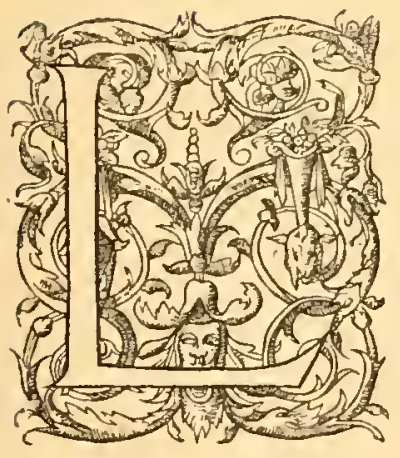

Es priceptes qui suivent concernent spécialement les jardins particuliers de l'intéricur des villes, dont la composition présente d'habitude trois sortes de difficultés: irrégularité de forme, surface trop unie, espace étroitement limité.

Parmi les artistes modernes qui ont le mieux réussi dans ce genre, on doit citer Lenné, Mayer, BarilletDeschamps, Siebeck, Kemp, Nemmann de Dresde. Nous empruntons à un ourrige spécial de ce dernier sur les jardins de rilles, deux plans, dans lesquels les trois difficultés indiquées ci-dessus sont habilement surmontées (Fig. 403, 404).

Dans le premier, le terrain d'opération forme un quadrilatére imparfait, dont la 
plus grande longueur, du côté de l'ouest, est d'environ trente métres. L'entrée n'est ni directement en face de la maison, ni ilu milieu du mur donnant sur la rue. La maison elle-même est placée d'une manière des plus fantaisistes; sa façade principale $\left(n^{\circ} 2\right)$ est parallèle, et non perpendiculaire à la rue. Sur un tel emplacement, on ne pouvait faire qu'un jardin irrégulier.

Un massif d'arbustes à fleurs ( $n^{\circ}$ I) s'étend vis-à-vis de la façade de l'habitation, perpendiculairement it la rue : des arbres fruitiers a haute et a basse tige $\left(n^{\circ} 3\right)$ sont jetés en avant du mur nord-ouest, garni d'espaliers. Du côté de la rue, il y a deux

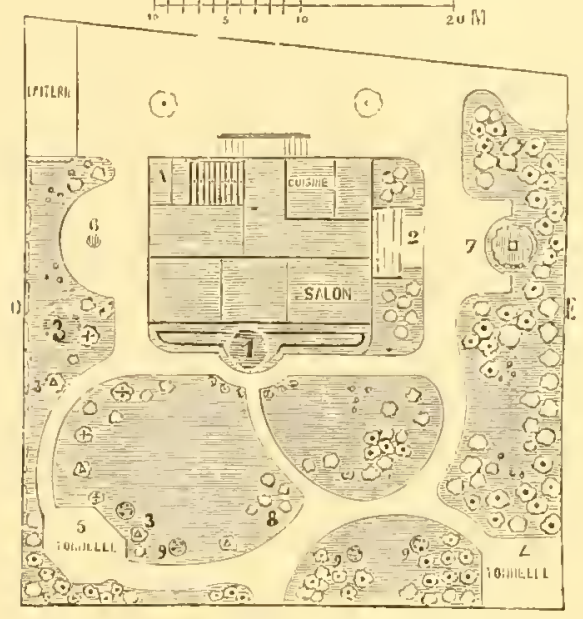

Fig. 403. - Jardin de Ville, par Neumann. tonnelles couvertes de plantes grimpantes, mais leur situation et leur forme n'ont rien de symétrique. L'une touche au mur de clôture et donne sur

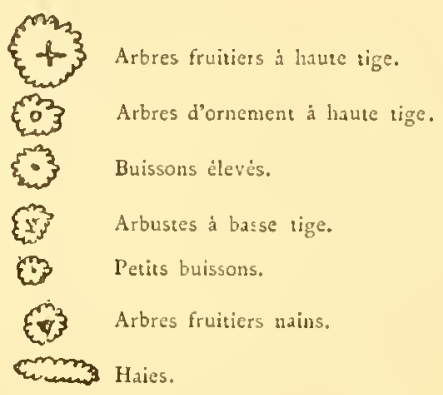

la rue; l'autre, au contraire, a vue sur le jardin.

Ce jardin possède un puits ( $\left.n^{\circ} 6\right)$ et une petite source $\left(n^{\circ} 7\right)$, dont l'émission se fait au moyen d'un mascaron. En arrière de cette source, garnie de fleurs ou de plantes à feuillage, la muraille du côté de l'est est dissimulée par un massif épais d'arbres et d'arbustes toujours verts, choisis parmi les variétés du feuillage le plus dense (ifs, genévriers, cyprès, thuyas, cèdres de Virginic). Cette plantation borde l'allée qui conduit de la porte de la rue á l'entrée principale de la maison, et enveloppe le pavillon de verdure ou tonnelle ( $\left.n^{\circ} 4\right)$ donnant sur la rue. Sur l'autre rebord de cette allée régne une pelouse ornée d'arbustes, de massifs de flcurs et d'arbres fruitiers à basse tige ( $n^{\circ} 3$ ), qui se relient à ceux placés en avant du mur ouest.

L'autre plan (Fig. 404) est un spécimen heureux de la maniére de tirer parti d'une situation assez fréquente dans les villes: celle d'une habitation avec jardin, ì l'extrémité d'un angle formé par la jonction de deux rues, et aboutissant soit ì une place, soit à une grande rue transversale.

Ce plan offre une fusion habile du style régulier, employé dans la partie supéricure autour de l'habitation et dans la scetion finale B; et du style irrégulier dans la 
partie intermédiaire A, fermée par des grillages et disposée pour être vue du dehors.

On pénètre dans la propriété par les deux rues qui la bordent, et ces entrées se font face symétriquement des deux côtés de l'habitation. Le centre de la partic A est garni cxclusivement d'arbustes a basse tige et d'arbres fruitiers nains, pour ne pas intercepter la vue de la maison sur l'extrémité plantée de la partie B. Les $n^{\text {os }}$ I et 2

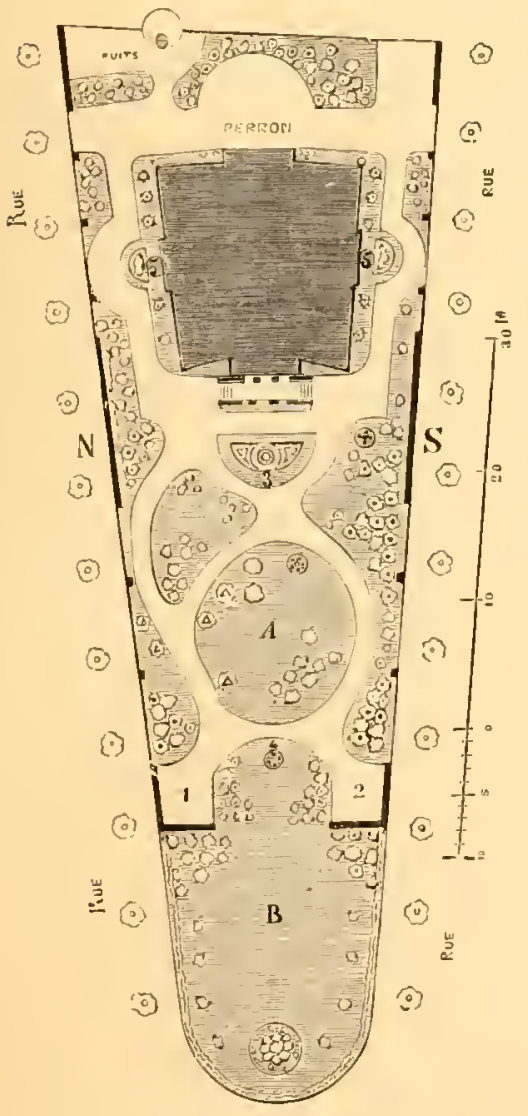

Fig. 4c4. - Jardin de Ville, par Neumann. désignent des berceaux couverts couronnant des éminences placées en regard sur les deux rues latérales.

L'emplacement de ce jardin a quinze métres it peine dans sa plus grande largeur, sur une longueur de plus de cent métres. Mais les dispositions indiquíes seraient également applicables, peut-ître même avec plus d'avantage, si l'écartement des deux rues était plus considérable.

Voici encore un jardin de ville, dessiné par Kemp, d'une distribution assez èlégante (Fi. gure 405).

\section{Le $n^{\circ}$ I est $1 \mathrm{a}$}

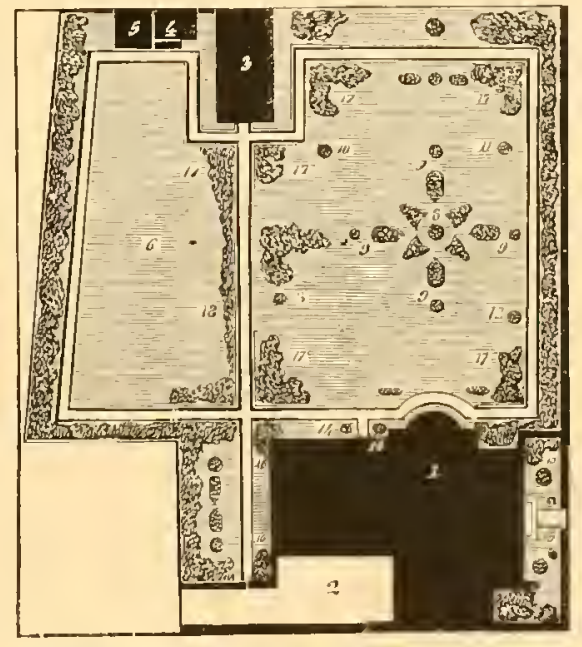

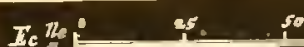

Fig. fo5. - Jardin de Ville, par liemp.

maison, avec entrée principale du côté de l'est, et porte du jardin au nord. Nos 2 , cour; 3,4 , 5, serres et dépendances; 6, potager. Le no 8 , qui fait point de vue de l'habitation, indique un grand vase de fleurs monté sur piédestal, et entouré de massifs de fleurs cultivces. Aux quatre angles de ce décor (no 9), Kemp cmploie, suivant sa trop constante habitude, le Cotoncaster microplyylla, arbuste qui ne nous parait convenable que dans les rocailles. Ce jardin se compose presque exclusivement d'arbres et d'arbustes à feuilles persistantes : houx panachés et autres, disséminés sur la pelouse ( $n^{\circ \mathrm{s}}$ IO, 1 I , I 2 ); ifs pyramidaus ( $\left.n^{\circ} \mathrm{I}_{4}\right)$; massifs de houx ordinaire, aux coins de l'habitation ( $\left.n^{\circ} 16\right)$; longue bordure id., séparant le pota- 
ger du jardin d'agrément ( $n^{\circ}$ I $\delta$ ). L'entrée principale de la maison est ornée de Yuncas $\left(n^{\circ} 1^{5}\right)$. Enfin, les massifs figurés sous le $n^{\circ} 17$ dans tous les angles du jardin, se composent d'arbres et d'arbustes verts, principalement de thododendrons. 'Toutefois, l'atmosphère des grandes villes est nuisible pour ces derniers arbustes:

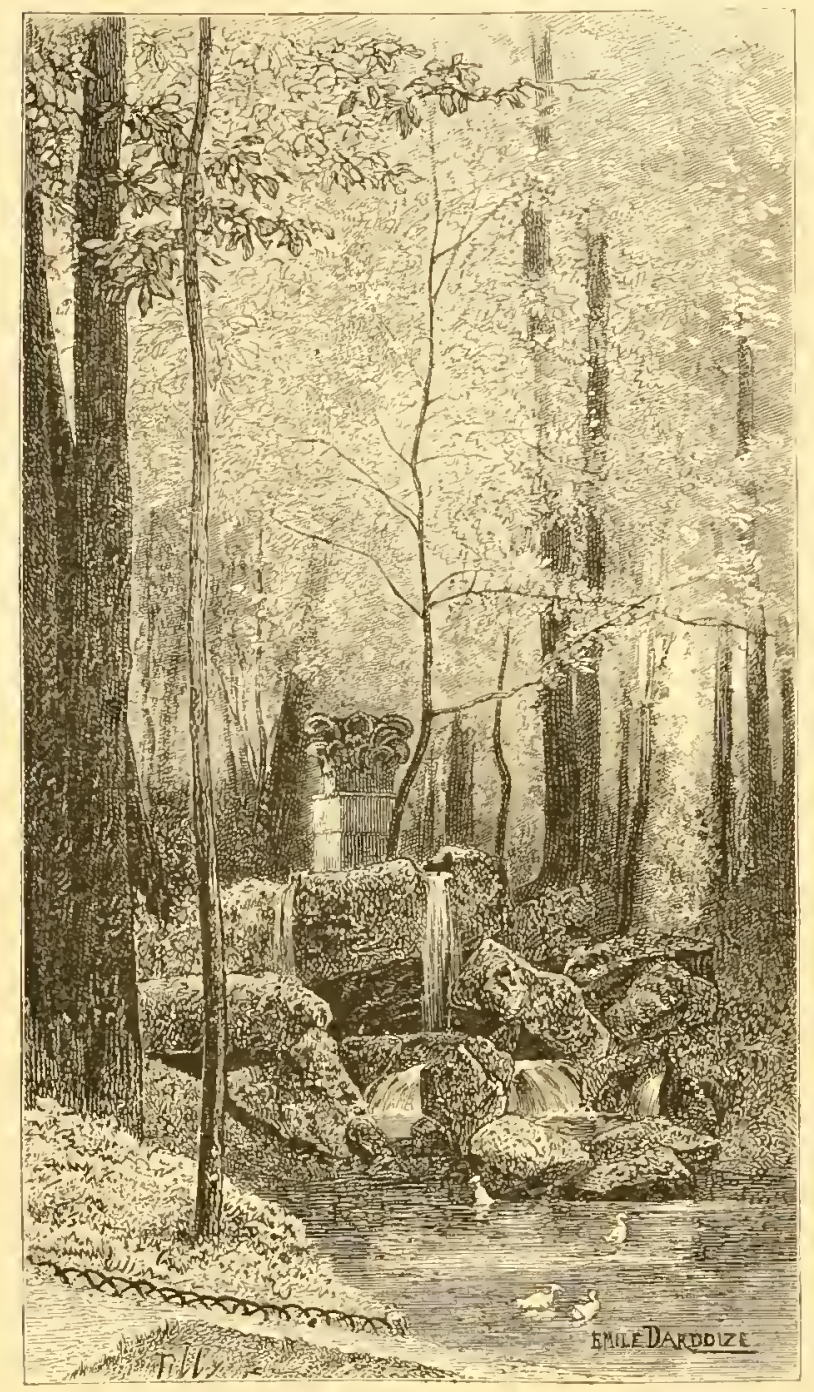

Fig. too - Cascades au Jardın de l'Élssée. les jardiniers des promenades de Paris en savent quelque chose!

De ces exemples, auxquels nous pourrions en joindre beaucoup d'autres, on peut conclure que le style régulier sera souvent employé avee succès dans l'intéricur des villes; que cependant l'applicaion du genre mixte, ou même franchement irrégulicr, peut être autoriscie ou même imposée par la configuration du terrain ou par la situation de la maison. Cus inconvénients de forme ne sont jamais si graves, qu'un homme do goût ne puisse les corriger ou en tirer parti, de même qu'il saura donner de l'igrément ì un petit espace par la variété des massifs d'arbres fruitiers, d'arbustes, de fleurs, de plantes grimpantes et à feuillage.

Nons reproduisons ici (Fig. 406) un des plus gracieux spécimens connus de cascitelles pour jardins de ville, celle du jardin de l'Élysée. Les jardins de ville réclament un grand usage d'arbustes, et, quand l'espace le permet, d'arbres à feuilles persistantes, parec qu'on jouit surtout de ces jardins l'hiver, et que ce genre de régétation cst celui qui dissimule le micux les clôtures.

"Ces arbres, dit M. E. de Goncourt, rous jouent un jardin d'été par un coup de soleil d'hiver. Avee les recherches et les progrès actuels de l'horticulture, il y a it 
faire un jardin de peintre; à se mettre en grand, sous les yeux, une palette de verts, allant des verts noirs aux verts tendres, cn passant par les verts bleuâtres des genévriers, les verts mordorés des cryptomérias, et par toutes les panachures variées des houx, des fusains, des aucubas, qui font l'illusion de fleurs. »

II. - Il y a longtemps déjà que le comte de Lorgues, écrivain distingué ct vraiment philanthrope, a émis le veu «qu'il fût accordé a l'instituteur un jardin; lequel, convenablement organisé, pouvait devenir un auxiliaire sérieux d'éducation ». Il faudrait, pour cela, quau moyen de distributions gratuites de graines et de plantes, ce jardin pût lui fournir le sujet de quelques leçons élémentaires de botanique et d'horticulture; lui permettre de montrer sur place le mode de croissance et les procédés de culture des plantes potagéres ou d'agrément; de faire connaître les meilleures espéces, les variétés nouvelles dignes d'être acclimatées. Bien des fleurs diverses, échelonnées suivant les saisons, peuvent trouver place dans un espace assez restreint. En substituant cette ètude attrayante ì quelques instants de la récréation, l'instituteur pourrait, dans le cours d'une année scolaire, faire connaitre à ses éléves la flore de leur jays, depuis les crocus et les primevères, jusqu'aux chrysanthèmes et aux roses de Noël; leur donner quelques notions de la taille des arbres, des greffes, des boutures. On arriverait ainsi à développer, à utiliser l'amour du jardinage, l'un des plus heureux instincts de l'enfance, ct l'un de ceux qu'on néglige le plus dans l'éducation.

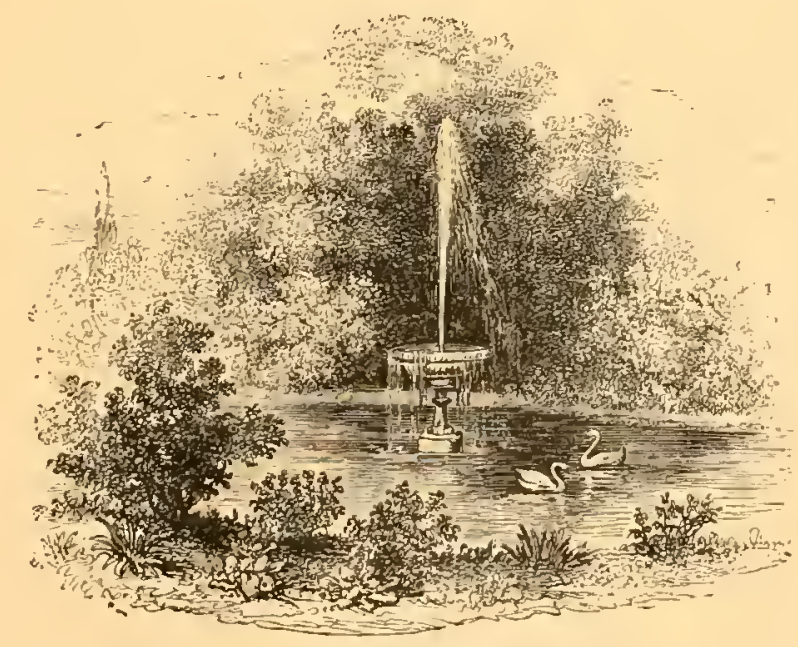




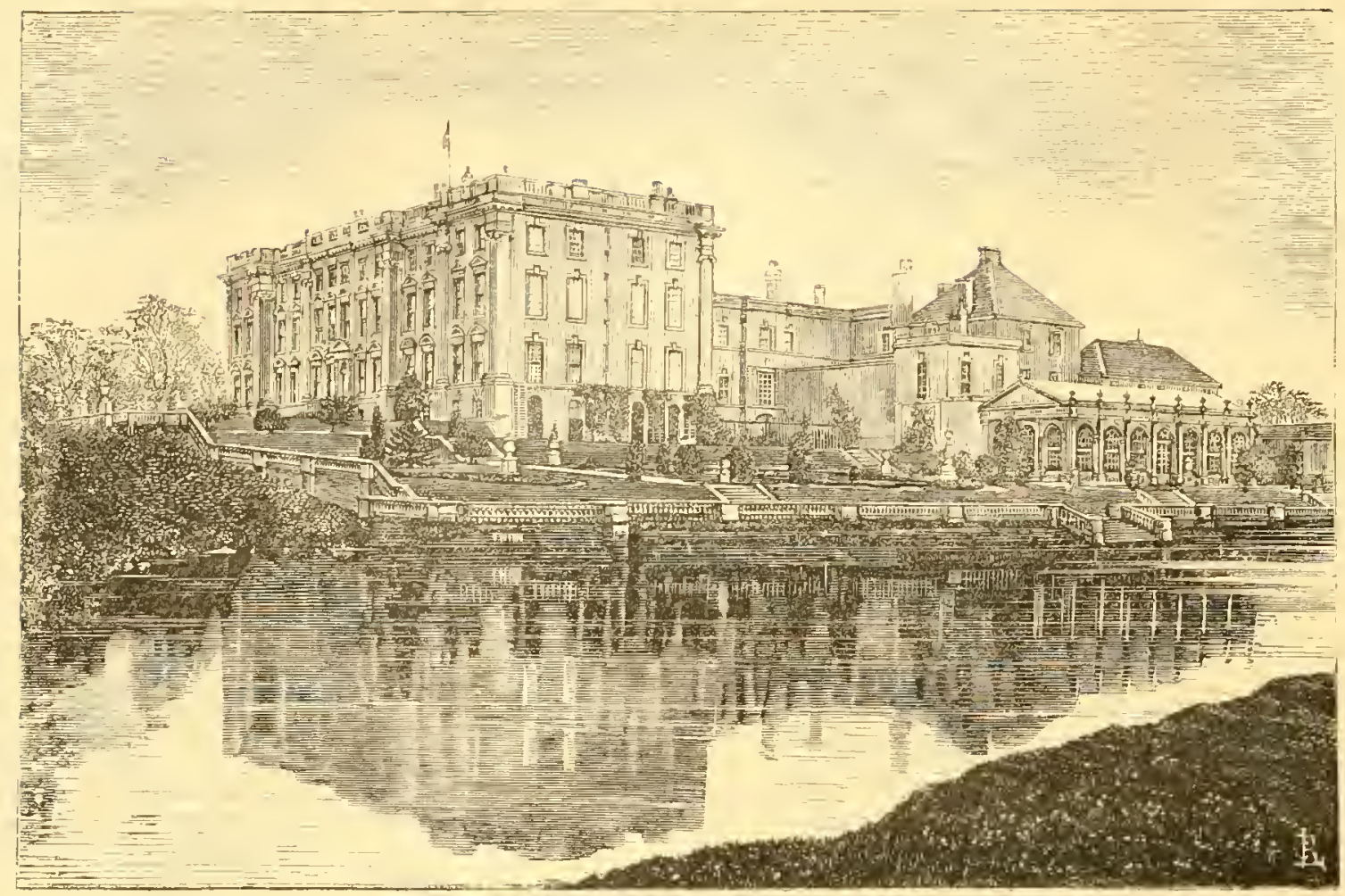

Fig. 408. - Stoncleigh Abbey, anpatenant à Lord Leigh.

\title{
CHAPITRE IV
}

\author{
CREATIONS MODERNES
}

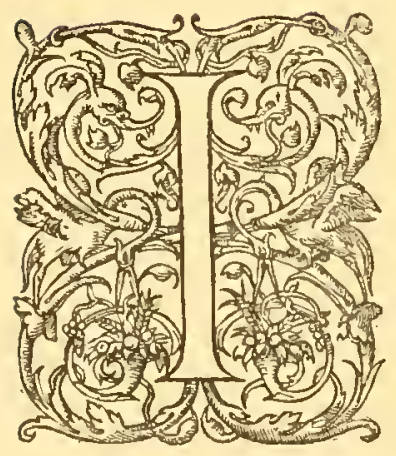

L nous reste ì signaler quelques-unes des plus intéressantes applications des préceptes de l'art, faites réecmment, soit dans les pares et jardins particuliers, soit dans les jardins publics. (Promenades et squares.)

I. - Parcs anglais. - En Angleterre, les pares de l'aristocratic ont été trimsformés, mais non amoindris, dans le courant du siècle dernicr. Hampton-Court, Chiswick, Chatsworth (Fig. III), Stoneleigh Abbey (Fig. fos), Eaton Hall (Fig. 4IO), et bien d'autres, n’ètaient pas moins célébres autrefois comme jardins réguliers. 
Dans le préambule de l'Homme qui rit, Victor Hugo a éroqué les «colossales architectures vertes » du temps de la reine Anne; - Staunton Harold (Leicestershire), "dont le pare géométral en verdure taillée, avait la forme d'un temple ave fronten »; - New-Park (Surrey), " magnifique par son gazon circulaire cntouré d'arbres, et ses forêts à l'extrémité desquelles il y avait une montagne artistement arrondic, surmontic d'un grand chêne qu'on voyait de loin »..., puis encore trois

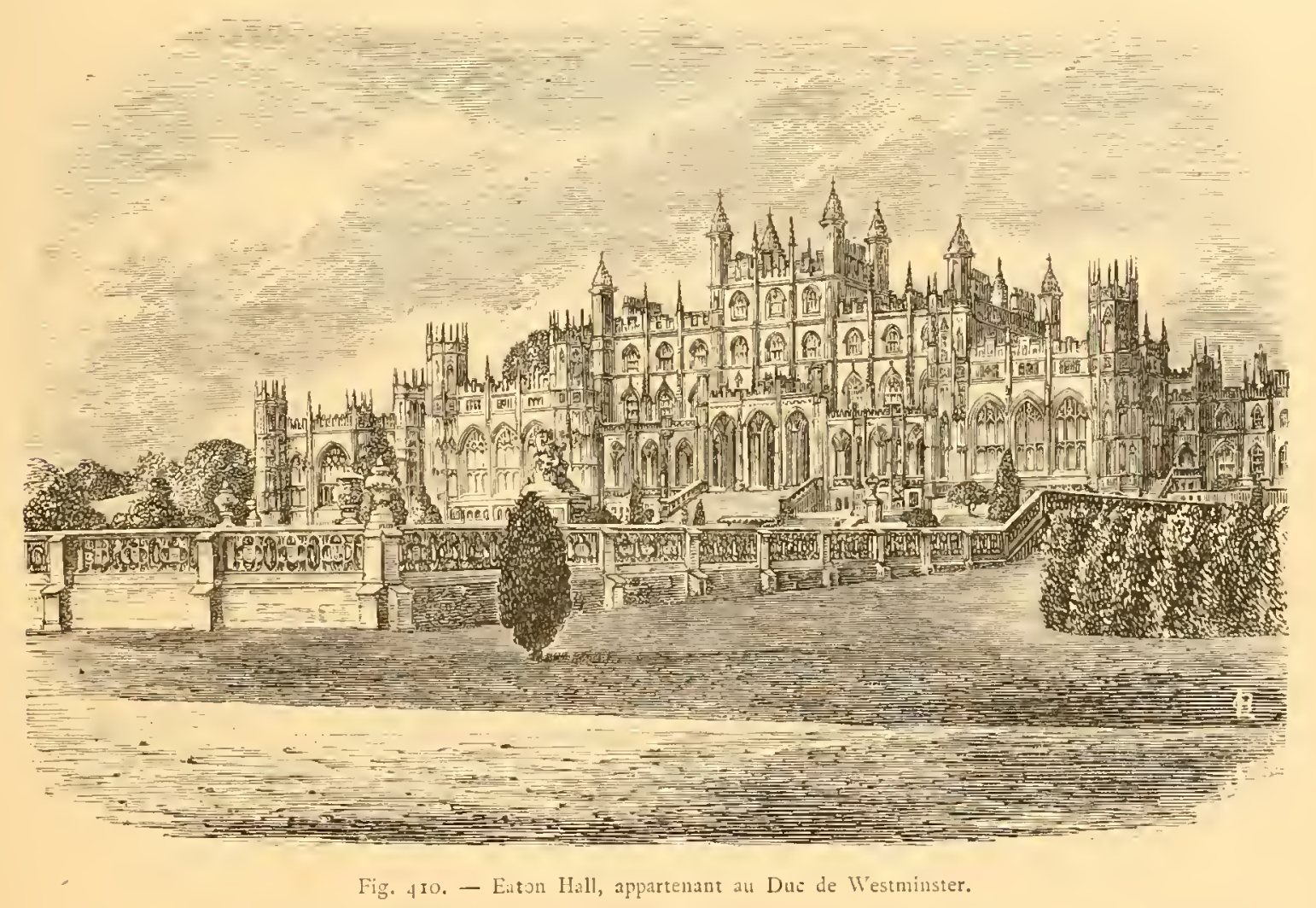

immenses domaines dont il a déjá été question dans la premiére partie de notre travail; Badminton (Fig. I 24); "placé au centre d'une étoile d’où rayonnaient une foule d'avenues»; Wilton, au comte de Pembroke (Fig. IO4), et le plus remarquable de tous peut-être; Stansted, au comte de Scarborough, lord-lieutenant de Durham; Stansted « avec sa double châtellenie, l'une gothique, l'autre moderne ». L'intrusion du style régulier sur un tel emplacement, en dépit des accidents multipliés du terrain, du cours des eaux et de l'irrégularité des bâtiments, est un exemple bien remarquable de la ténacité anglo-saxonne (Fig. 109).

Les propriétés transformées ou créées depuis l'avénement du genre irrégulier, nous offrent des tours de force non moins surprenants, mais d'un genre opposé. Au 
lieu de supprimer ou d'atténuer les mouvements de terrains, les escarpements, on en

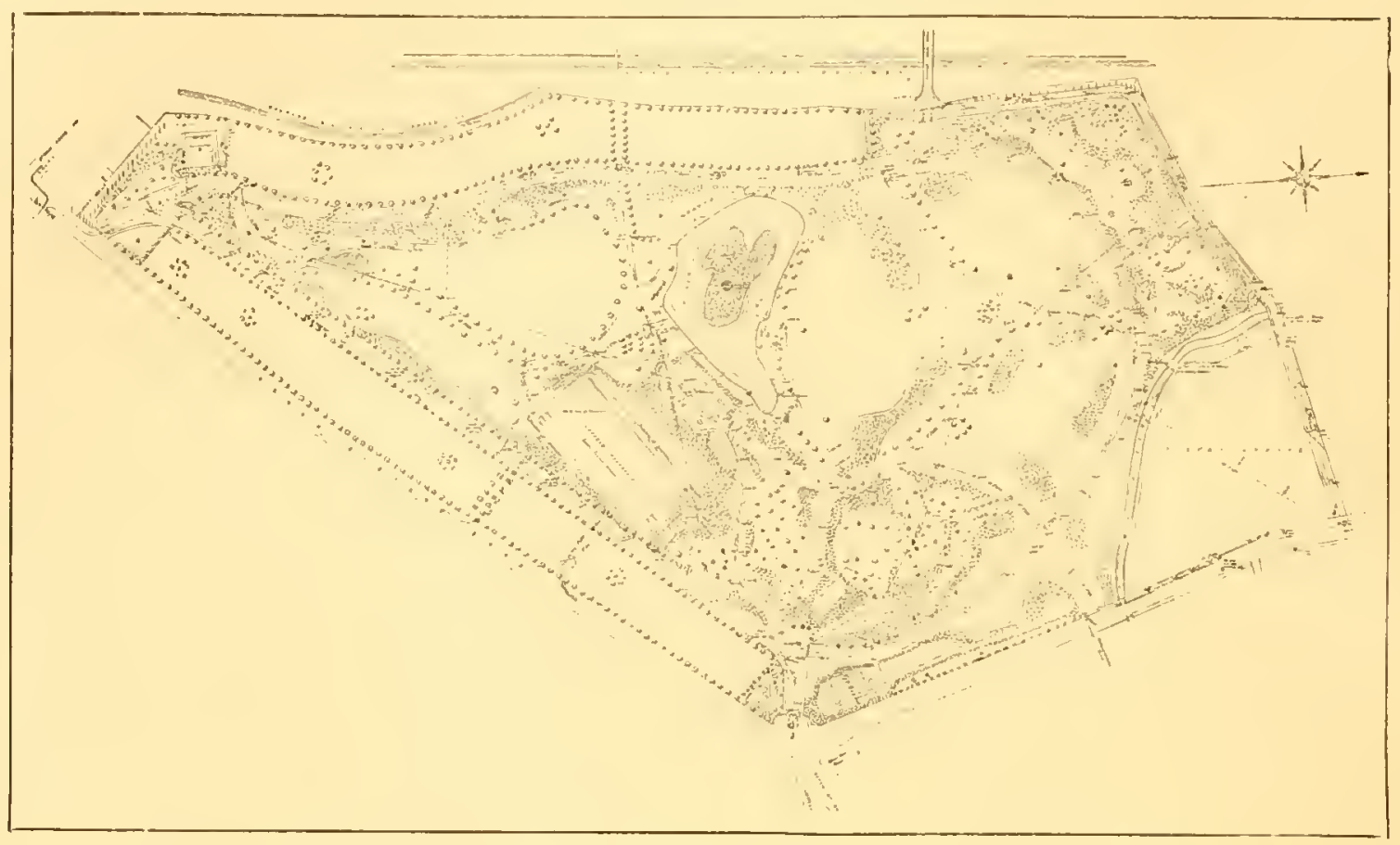

Fig. 411. - Finsbury Park, a Londres. D'apres un Plan du Board of Works de la Ville de Londres.

invente! Les collines artificielles, les rocailles, y sont employées dans de vastes pro-

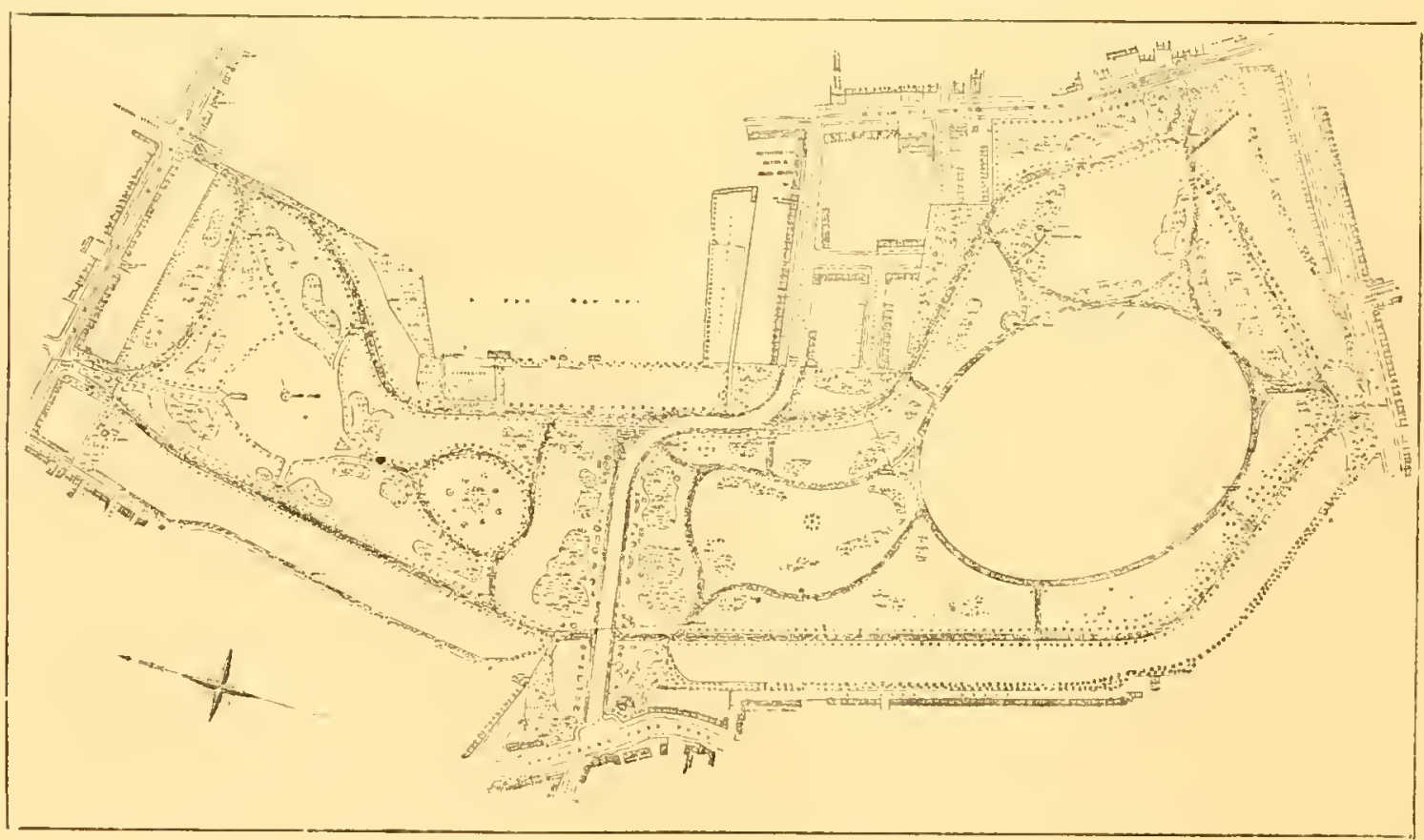

Fig. 412. - Southwark Park, d Londres. D'après un Plan du Board of Works de la Ville de Londres.

portions. Les premiers novateurs prétendaient imiter les scènes naturelles les plus 
grandioses et les plus terribles. Leurs successeurs, plus positifs, ont utilisé les rocailles pour la culture des plantes alpines et des fougères. On cite celles de Regent's Park, de Blenheim (Fig. 200), de Chatsworth. Cette dernière passe pour la plus vaste qui existe : c'est un des chefs-d'curre de Paxton. On voit aussi, dans un grand pare près de Chester, un plan en relief du Mont-Blane et de ses alentours, où les points culminants ont prés de onze mètres de hauteur.

Il n'y a rien de comparable dans d'autres pays à ces grandes rocailles. Chez nous, elles seraient hors de proportion avec l'itendue ordinaire des jardins paysagers.

Parmi les plus beaux pares modernes de Londres, on cite Finsbury Parli (Fig. 4I1), Southwark Park (Fig. 4I2), Victoria Park (Fig. 413), et celui de Birkenhead (Fig. 3OI), prís de Liverpool, exécuté par Kemp, d'après un dessin de Paxton. Presque tout mérite des éloges dans cette composition : l'allée de ceinture, d'un dessin élégant et hardi, les vallonnements, les plantations, réparties avec la sobriété convenable dans un pays humide, les contours gracieux des deux pieces d'eau, qui toutefois se ressemblent un peu trop. 
II. - Pares allemands. - L'Allemagne a produit aussi, depuis un siécle, plusieurs dessinateurs de mérite, notamment Skell, le prince Pückler-Muskau, Lenné, Siebeck et Mayer, auteur d'un grand et bel ouvrage sur les jardins.

Nous arons déjà parlé de Slell, l'un des premiers promoteurs du style mixte. Cependant le jardin anglais qu'il a dessiné à Munich (Fig. 4 I 4, voir page 284), et qui passe pour un de ses meilleurs ouvrages, est absolument irrégulier et ne pouvait être autre chose dans un pareil emplacement. Il occupe une sorte de delta formé

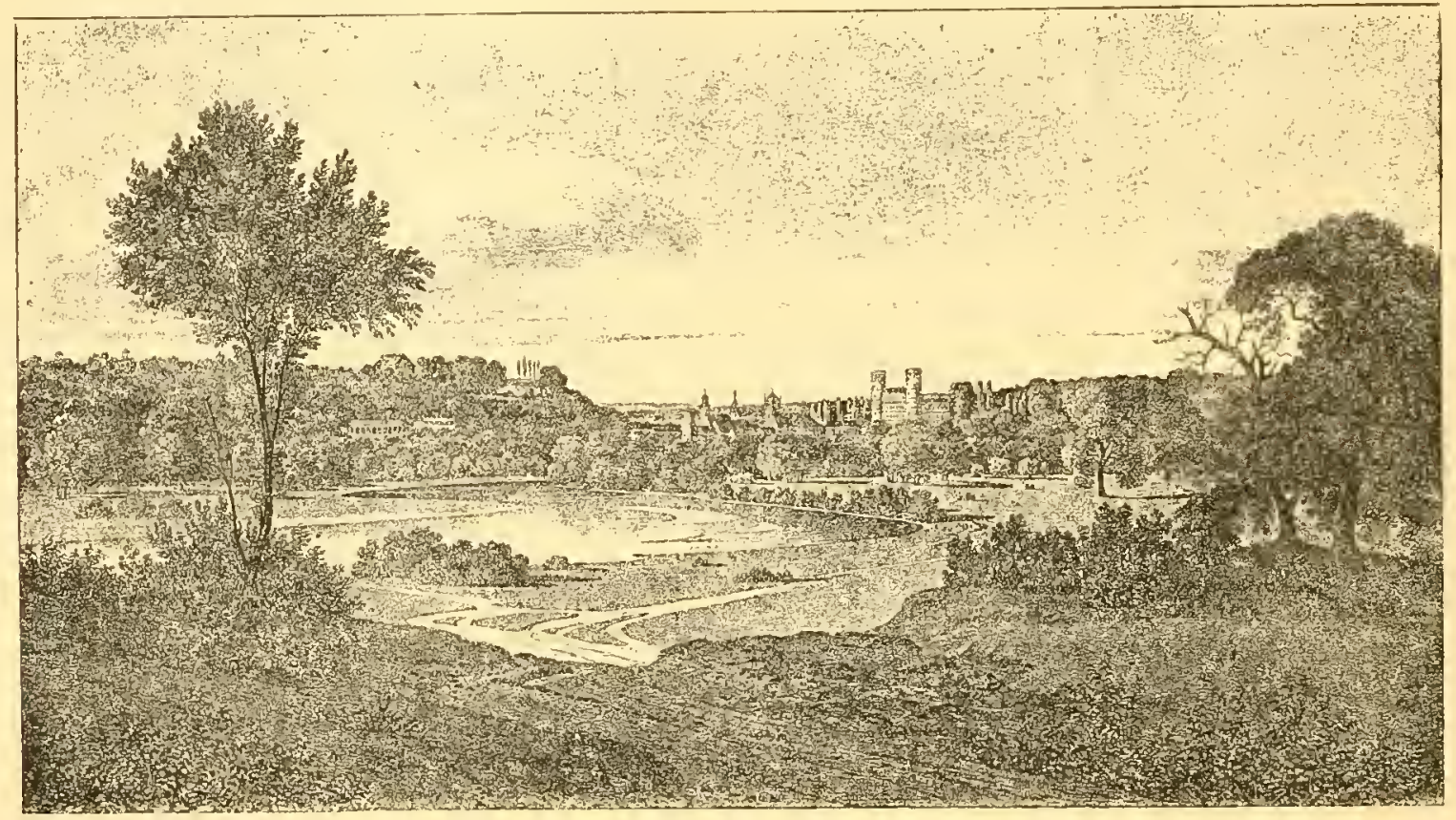

Fig. 415. - Vue du Chateau et du Pare de Muskin.

par l'Isar, beaucoup plus long que large. C'est ce qui explique la multiplicité des allées longitudinales et leur parallélisme, habilement dissimulé par les plantations. Cette ouvre peut encore être utile aujourd'hui aux dessinateurs qui auraient à travailler dans des conditiors analogues.

Le prince Pückler-Muskau est l'un des grands maîtres de l'art des jardins. Son pare de Muskau, en Silésie (Fig. 4Ij et 4I6), qui comprend, outre le château (Fig. 4I5) et ses dépendances, deux villages, une exploitation miniére, ctc., est un modèle achevé de la transformation d'un vaste domaine tout entier en jardin paysager. Pour faciliter aux artistes l'ctude de cette ouvre, le prince a fait reproduire sur une grande cichelle, dans des planches d'une exécution très soignée, non seulement l'aspect définitif des sites principaux et de l'ensemble, mais la situation primitive, les traviux prepara- 
toires, les diverses combinaisons essayées, puis écartées comme défectueuses, etc. Cet atlas peut être utilement consulté, non seulement par les dessinateurs de profession, mais par les propriétaires amateurs. Aprés avoir, sur une étendue de sept à huit myriamètres carrés, détourné des cours d'eau, défriché de vastes landes; transplanté des futaies et des villages entiers, le prince Pückler-Muskau, quoique déjá arancé en âge, se méfiait de son besoin incessant d'activité. Il craignait de se laisser entraîner, comme Titien dans sa vieillesse, à gâter son travail par des retouches incessantes. Il avait done vendu son domaine et en avait racheté un autre en Silésie, qu'il s'orcupait à transformer. C'est lá qu'est mort sur lia bréche, cn quclque sorte, ce créateur infatigable!

Le directeur des pares royaux à Potsdam, M. Jühllke, a rendu compte, dans une brochure publiéc il y a quelques années, d'une exploration des plus beaux pares de l'Allcmagne. Sa relation contient des détails intéressants sur ces grandes propriétés, dont plusieurs avaient été créćes ou remaniẻes par Lenné ct Mayer. On considère en général comme leur chef-d'œuvre le petit parc de Monbijou, prés de Berlin, oủ le caractére de la plantation, mélancolique sans monotonic, s'harmonise à merveille avec le tombeau d'une princesse morte à la fleur de l'âge. On peut citer encore parmi les pares modernes de la Prusse, le Friedrichshain, le Thiergarten, Charlottenburg (Berlin); Babelsberg, près Potsdam, l'île des Paons, Glienicke (Potsdam), décorés de fabriques et de ruines d'un goût douteux, mais remarquables par la plantation. C'était surtout dans cette partic que Lenné excellait.

Depuis Frédéric le Grand, les jardins de Potsdam (Fig. 133) ont grandi, comme la fortunne de la monarchie prussienne! Leur enceinte, plusieurs fois augmentée, conticnt aujourd'hui, comme Versailles, plusieurs châteaux et jardins, et une véritable cohue de fabriques de tous les styles : obélisque égyptien, sphinx gigantesques, bain romain, maison japonaise, mosquée, villa italienne; quelques bonnes statues, davantage de médiocres, et encore plus de mauvaises; un Mansolenm ou cénotaphe dédié à l'Amitié, et qui n'est qu'un pastiche médiocre de la rotonde du pare de Monceaux.

Ce qu'il y a de mieux dans tout cela, c'est le moulin historique, présentement annexé au parc, non par Frédéric lui-même, mais par son successeur, qui l'acquit à l'amiable du même meunier, devenu plus accommodant par suite de mauvaises affaires.

Le pare de Herrenhausen (Hanovre), ceux de Dresde et d'Albrechtsberg (Saxe), 
de Sagan (Fig̣. J49), méritent l'attention des touristes. Mais celui d'Eiggrub, au

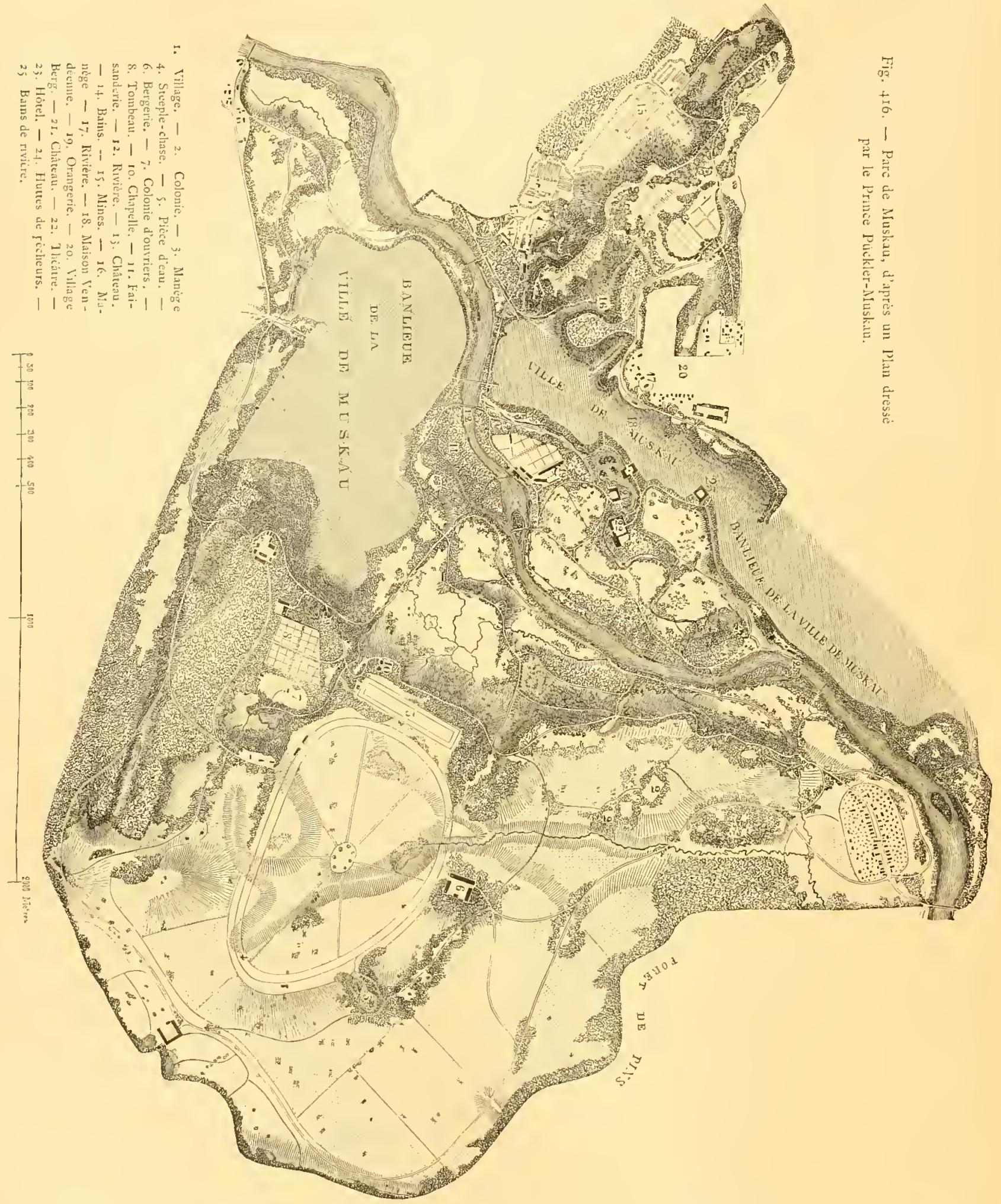

prince de Lichtenstein, situé sur les frontiéres de l'Autriche et de la Moravie, doit 
les arrêter encore plus longtemps. La plus grande partie des terres de ce domaine forme, au confluent de deux rivières, un delta qui se compose de dix îles et de six îlots, reliés aux deux rives et entre eux par cent cinquante ponts de diverses formes. La décoration de ces îles a été remaniée de fond en comble; l'une d'elles, notamment, toute couverte de rosiers, produit un charmant effet. Toutefcis l'artiste moderne a dû respecter les ancicns édicules mythologiques et autres, consacrés à Diane, à scint Hubert, à Apollon, et le pavillon chinois de rigueur. Celui-lí du moins est particulièrement intéressant pour nous autres Français, car on y a réuni

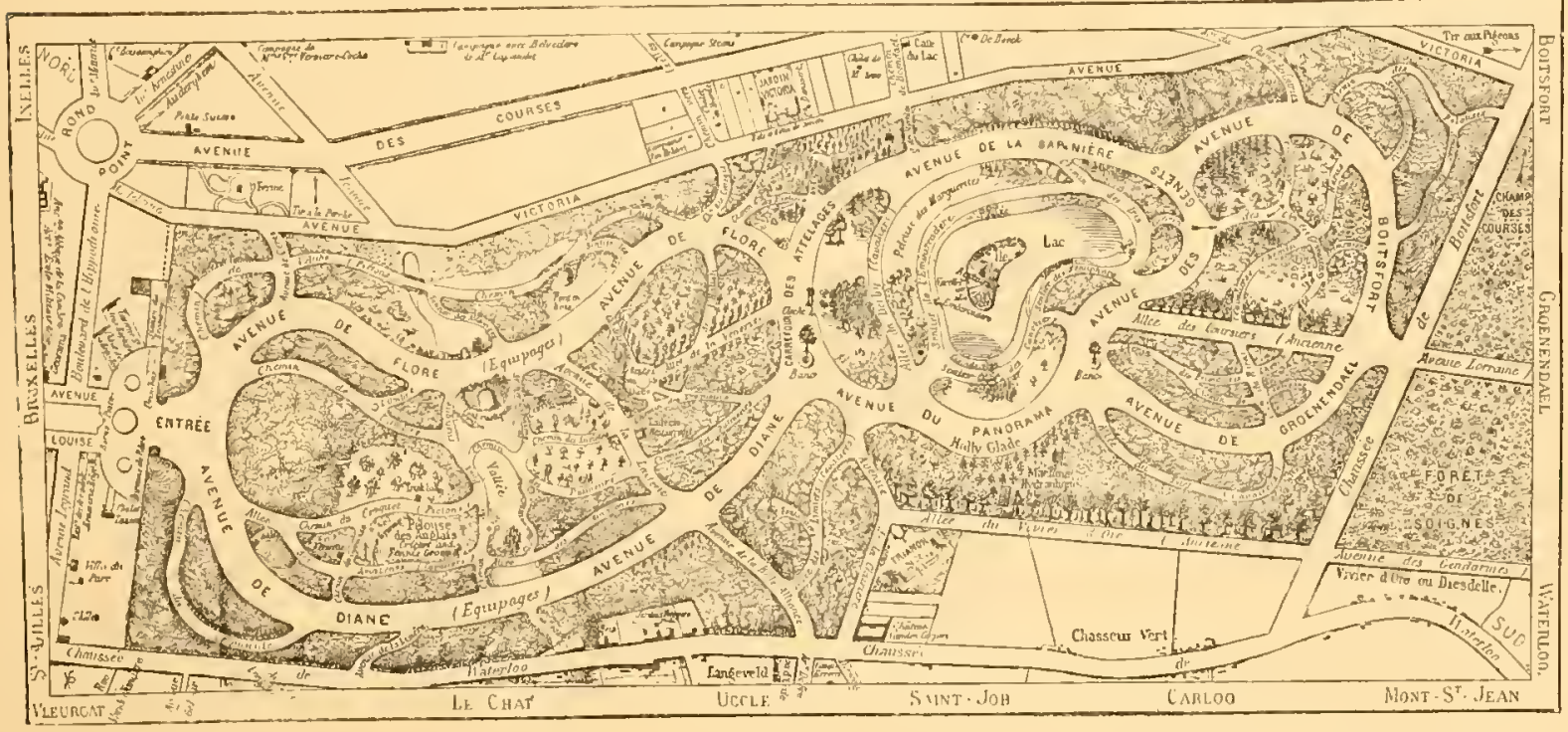

Fig. 417. - Le Bois de La Cambre, à Bruxelles; reproduction d'aprés le Plan en couleur, publié par lia Maison lỉiessling, à Bruxelles.

des tapis et des porcelaines provenant de l'ancien Versailles. De ce pavillon, grâce à la position exceptionnelle du domaine, on jouit de quatre panoramas distincts sur autant de provinces: la Moravie, le Tyrol, l'Autriche et la Bohême.

Nous signalerons encore le pare de Jurjavés, prés d'Agram (Croatie), dont les plans détaillés ont été publiés il y a quelques années. Une inscription constate que les travalux de ec pare, dont la conception première remonte à 1787 , ont été poursuivis avec une honorable persistance, et ont fait vivre, pendant une longue suite d'années, de nombreux travailleurs.

Nous avons déjà cité les parcs autrichiens de Lundenburg et de Laxenburg. Le premier est situé entre Vienne et Brumn, dans la vallée de la Thuya. On y trouve d'admirables spécimens d'arbres et de plantes de tous les pays, même les plus chauds; 
et aussi, par malheur, des bâtisses dont l'importance fait encore mieux ressortir le mauvais goût; par exemple, un gigantesque minaret ture dont l'escalier n'a pas moins de 302 marches, et qui a coûté un million de florins. Quant à Laxenburg (Fig. I34), aujourd'bui relié à Vienne par un embranchement spécial; c'est un ancien pare régulier, remanié dans le genre pittoresque, comme le pare anglais de Kew. Dans tous les deux on a judicieusement respecté plusicurs sections d'avenues et de plantations en quinconces, à cause de la beauté des arbres. Laxenburg est arrosé par le Schwechat Bach, cours d'eau assez considérable. Il y forme une charmante cascade naturelle, et deux lacs, dont le plus grand contient plusicurs îles importantes. Quelquesunes des Fabriques de ce pare offrent un véritable intérêt, parce que tout n'y est pas factice. Par exemple, la Rillerscule, colonne érigée en l'bonneur d'un soi-disant clrevalier, est un beau spécimen original du style gothique allemand du xule siécle. Le tombeau du chevalier est moderne, mais orné de véritables vitraux du xve siécle, et de tableaux de lit même époque. La Franzensburg, forteresse pscudo-gothique, dans une des îles du grand lac, est un muscé de véritables antiquités du moyen âge, etc. (I).

La Belgique aussi renferme bien des pares dignes de lattention des touristes. D'abord ceux du roi: Tervueren, Ciergnon et d'Ardennes, et surtout Laeken, avec ses superbes serres; ensuite les pares des Amervies et de Rieth, au comte de Flandre; celui de Panson, à M. de Sélys-Longchamps; ceux d'Héverlé et d'Enghien, appartenant à la famille d'Aremberg; le parc communal d'Anvers; le pare de Belocil, au prince de Ligne; celui de Chimay, an prince de Chimay.

Le Bois de la Cambre (Fig. 41 7), prés Bruxelles, fait partie de la forêt de Soignes. Cette forêt, qui appartenait à l'Ĺtat, fut mise à la disposition de la Ville, à charge par celle-ci de la convertir en promenade publique. Cette heureuse transformation, opérée par M. Keiligg, a été terminée en 1862 ; le prix des travaux s'est élevé a 5,086,859 fr. 35 c. Le parc a 124 hectares de superficie.

Parmi les plus grands pares d'outre-mer, l'un des plus considérables et des mieux disposés est le Central Parc à New-York (Fig. 418, voir page 284).

(1) On y voit notanment une chapclle, bijou d'architecture gothique, apportée, comne la colonne, de l'mutique abbaye de lilosterneuburg. En franchissant le seuil, on met en mouvement un geólier-mannequin qui agite violemment un trousseau de clefs. Cette surprise, d'un goút équivoque, est pourtant moins désagréable que celle qui existait encore cn I805, dans un autre pare autrichien. En entrant dans un cachot qui faisait partie d'un donjon factice, le visiteur marchait sur un rejsort qui faisait lever et arriver sur lui un squeleate.. Cette agréable mćcanique fut brisće par des soldats fr.uıç.ì 
Nous croyons utile de reproduire plus en détail, comme sujets d'étude, des spécimens de travaux de deux des plus habiles dessinateurs allemands contemporains, MM. Mayer et Siebeck.

La figure ci-jointe, cmpruntée à l'ouvrage de Mayer (Fig. 4i9), est le plan d'un jardin paysager dans un faubourg de grande ville. Le soin qu'on a pris d'intercepter de toutes parts la vue de l'extérieur par des rideaux de plantations, montre bien que ćétait lá une de ces situations difficiles, semblables à celles du square des Batignolles; - dans lesquelles l'artiste, ne pouvant rien emprunter d'agréable à l'aspect de dehors, est forcé de se suffire à lui-même.

L'habitation (A) est perpendiculaire à la rue, et communique avec elle au moyen d'une alléc formant un hémicycle régulier, dont les extrémités aboutissent à deux entrées reliées par unc grille. Le centre de cette grille est le seul point où la maison ait vue sur le dehors. Partout ailleurs les clôtures sont dissimulées par des massifs continus, oú dominent les arbres et arbustes a feuilles persistantes. Deux embranchements, ouverts à gauche sur l'allée d'arrivée, facilitent l'accés des communs (C), séparés de

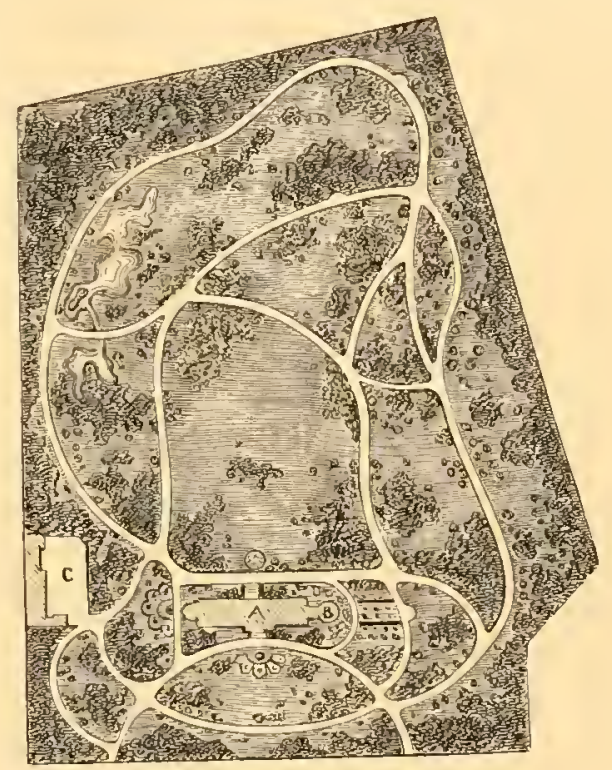

Fig. 4rg. - Jardin paysager. l'habitation par un massif assez épais pour les dissimuler en tout temps. On remarquera aussi l'habile combinaison des allées qui mettent les communs en communication avec les deux côtés de la maison, et facilitent la circulation des voitures. Ces dispositions sont bien conformes aux principes que nous avons précédemment exposés.

La serre (B) tient á l'habitation, et cet ensemble est encadré dans des parterres réguliers, mais non pareils entre eux. Le reste de cette composition appartient franchement au style irrégulier. Nous recommandons, comme modéle, l'agencement de la piçce d'eau, côtoyéc par l'allée de ceinture, et que les artifices de contours font paraître de toutes parts bien plus grande qu'elle n'est. Elle appartient à la catégorie des eaux dormantes, celles dont l'arrangement pittoresque présente le plus de difficulté. Aussi l'artiste n'en a enveloppé que 
la source dans un massif. En aval, il a espacé largement sur les rives des groupes d'aru de l'air. Il faut louer encore le tracé de l'allée de ceinture, circulant à gauche le longd suffisamment pour laisser lées de gazon, parsemées de bustes. Nous regrettons que de M. Siebeck, donné le détail mant jardin paysager. Les trajardins publics de Vienne, gues et notamment en frantribue, dans ces dernicres et l'art des jardins. Personne tré, par des exemples, qu'il dépense, d'obtenir d'excelpace restreint, et en sachant vue sur le dehors, quand

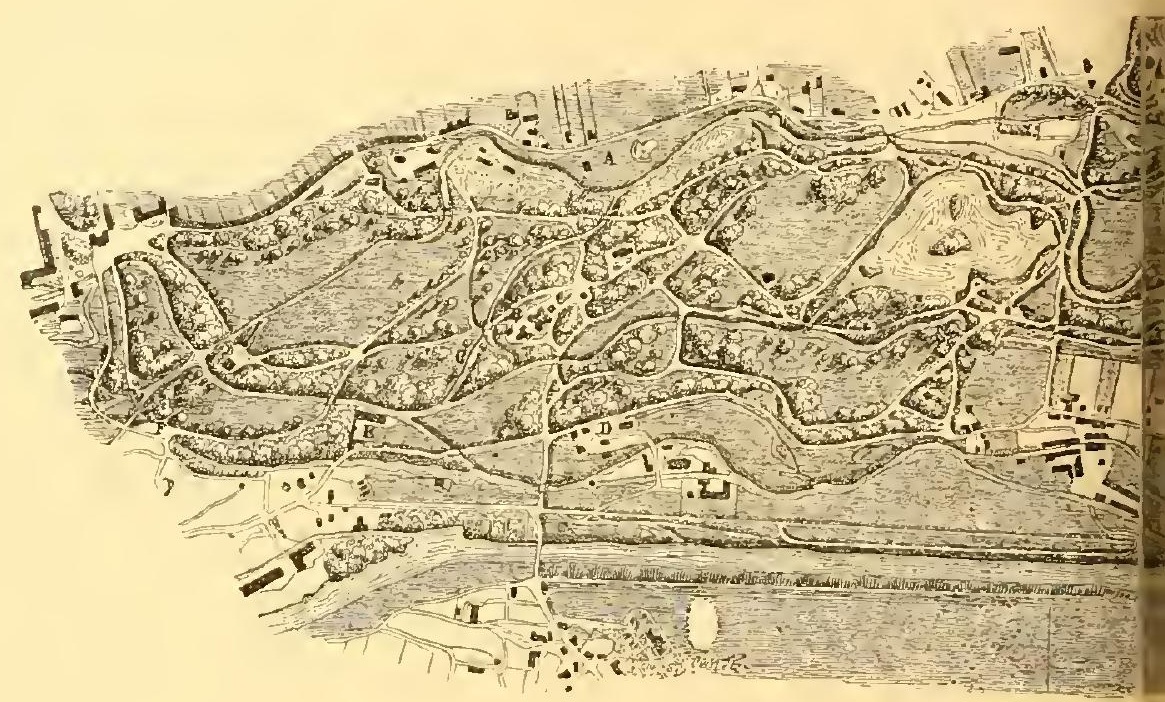
d'agréable. Les plans de Siebeck sont parfaitement appropriés à cette nouvelle phase du jardi xs

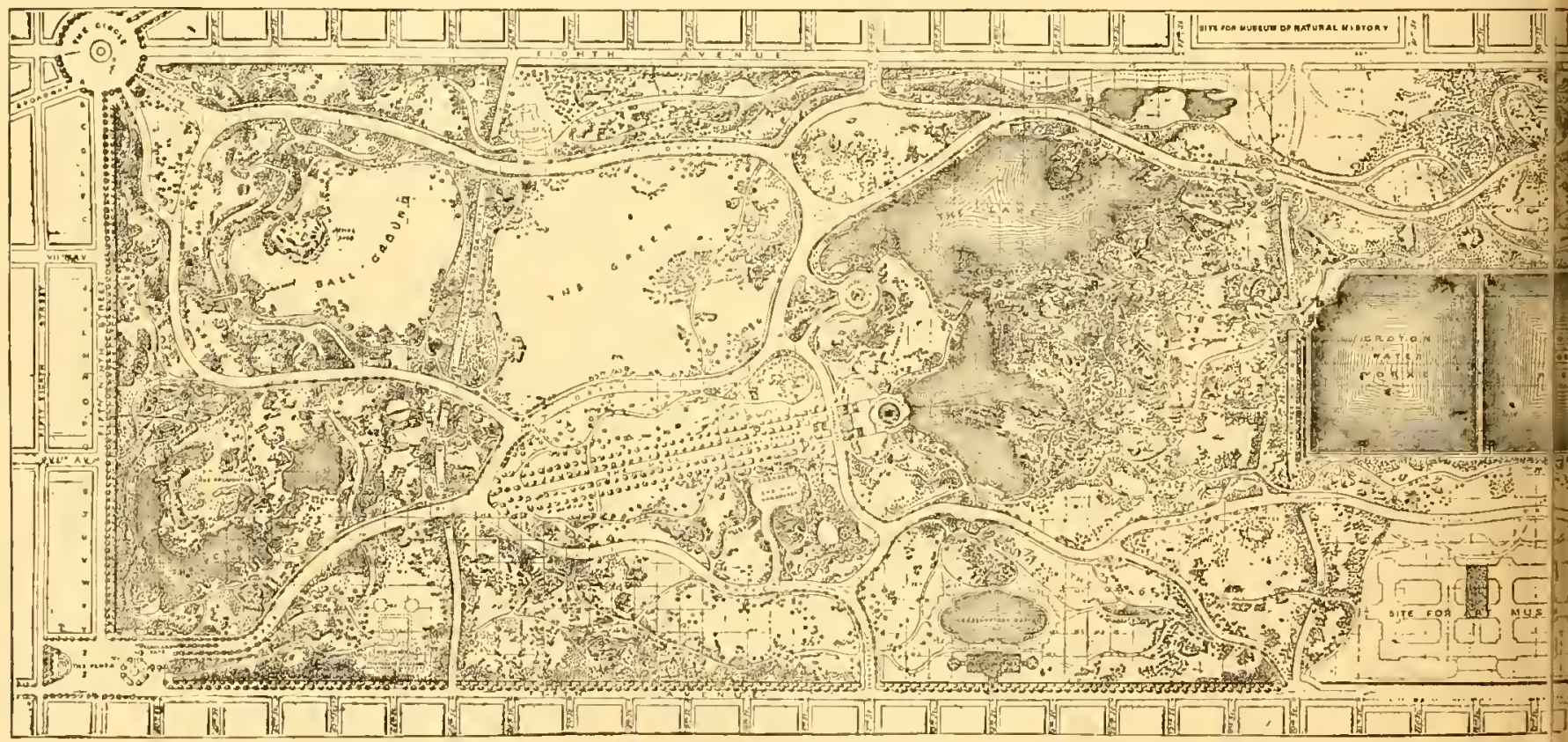

Fig. 4I8. - Le Centr: P.

ceux qui s'enferment dans quelques hectares de terrain; mais l'art triomphe de bien des obsicl explications et les légendes, quatre de ces plans (Fig. 420 a 423), dans lesquels les circonstancello 


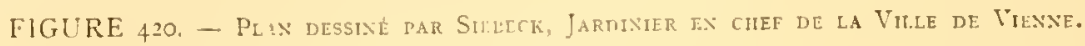

On a, dans ce plan, combiné le double caractère du riant et du grandiose, selon des proportions répondant à l'étendue du site; mais on les a combinés de telle façon, que, non seulement l'un parâ̂t être une des qualités de l'autre, mais que là même oú chacun d'eux devrait être accentué à prot, le passage nécessaire de l'un à l'autre ne forme qu'une insaisissable transition. C'est ce qui a lieu, par exemple, pour l'entrée, où le riant est subordonné au grandiose, et pour la perspective principale, où le riant prédomine, tindis que le grandiose n'est guère mis en relief que par les fleurs et les massifs.

Du dehors on peut, a:1 trarers des sveltes colonnades, aroir rue sur l'entrée imposante, à lazuelle sert de fond la façade de la maison. Des delix cûtis

des bütiments, situés sur les flancs, on a le coup d'ail des parties latérales du jardin minngèes avec diversité.

a. Indique l'habitation, dont les proportions présenteront un caractère imposant. On jouit, par devant, dans son entier effet, du coup d'œil de lentrée, tandis que sur les côtés commencent ì se dessiner de plus libres perspectives. Du côté du jardin se développe, $\mathrm{c}$ n paysages naturels, in perspective principale qui, à une distance éloignte, attire encore le regard par le beau pavillon et ses alentours disposés avec goût.

b. c. Édifices latéraux reliẻs par un péristyle.

d. Pavillon de forme circulaire.

e. Grand pavillon reproduisant, sous un aspect nouveau, les proportions des constructions ci-dessus. Il est situé sur un emplacement décou-

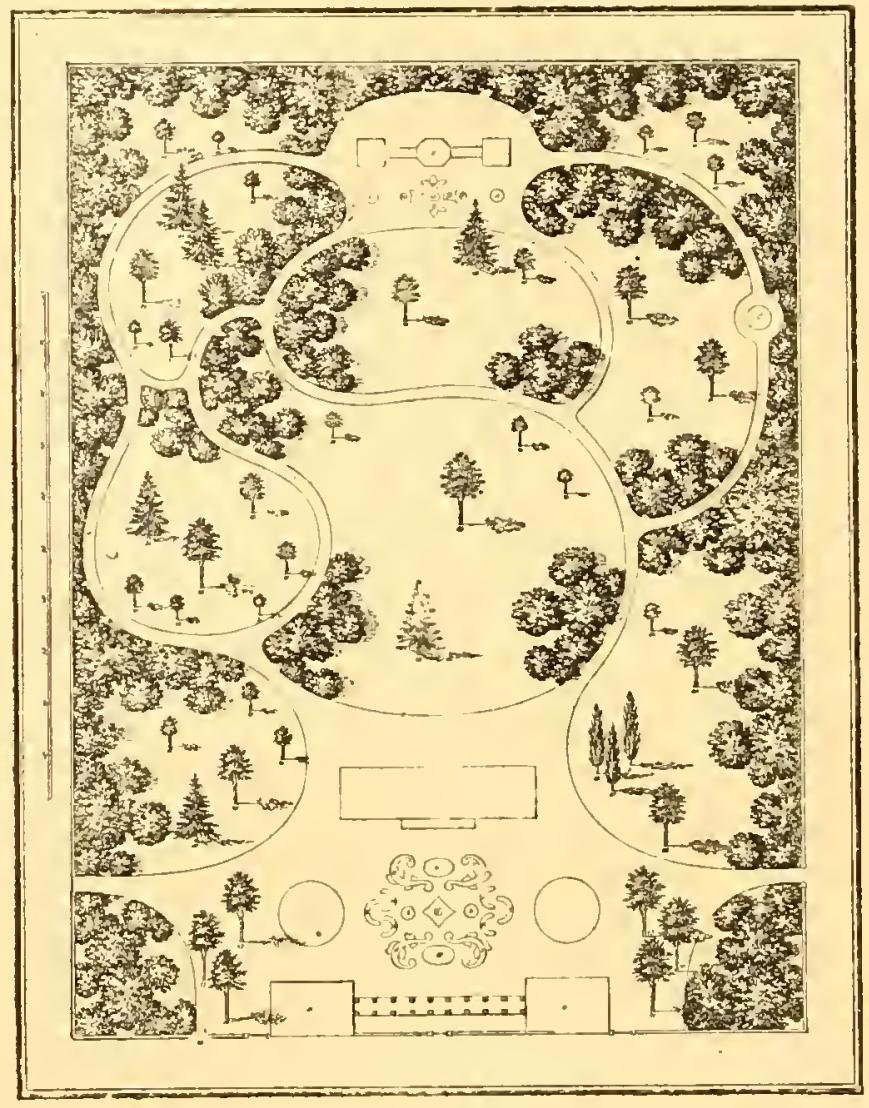
les côtés. Par deviant se présente à la vue le carré de fleurs dans le goût moderne, et la perspective ouverte jusqu'à l'habitation.

f. Banc avec ombrage sur l'emplacement libre derrière le pavillon.

g. Banc à dossier, avec rue sur une petite scène accessoire et détaclıée du reste.

h. On aperçoit de ce banc le devant du pavilion et l'emplacement qui le précède.

$i$. Banc abrité par un fourré de jolis arbustes, et d'où l'on jouit de ln perspective qui se découvre en face.

k. Banc avec une large vue de côté sur une portion considérable du jardin.

1. Banc à dossier ombragé de tous côtés.

$m$. Banc sur un emplacement découvert, ayant de tous côtés une vue peu étendue, mais libre.

$N^{\circ}$ I. Statue de Flore; 2, 3. Carrés de fleurs, I. Jacinthes; II. Erythina Corallodertent par derrière et sur

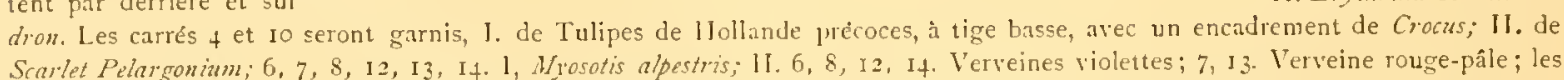
Scaslet Pelargonimn; 6, 7, 8, 12, I3, I4. 1, Wyosotis alpestris; 11. 6, 8, 12, I4. Verveines violettes; 7, 13. Verveine rouge-pale; les

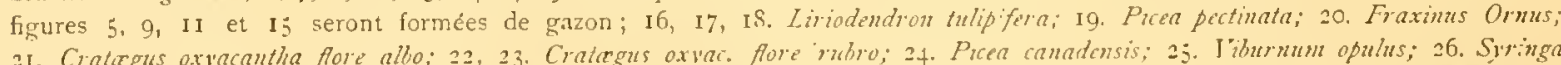

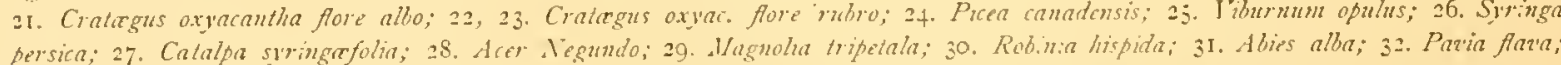

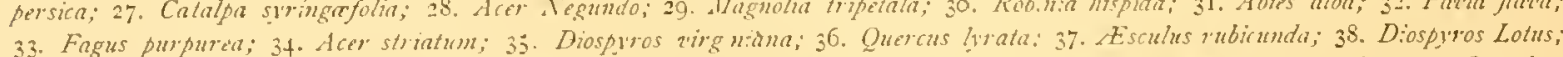
39. Sophora japonica; to. 41. P.cen canadensis; +2. Fobinia hispida; +3 . Broussennetia papyr fera; +4. Wagnolia cordata; +5 . Liriodendron tulipifera; 4 6. Picea pectinuta; 4 . Cratergus oxyacantha fore rubro; +8 a 56 . Carris de fleurs; 57 . Siringa persica; 58 . Salisburia adicutifolia; 59. Robina hisp.da; 60. Ailantus glandulosa; 6r. Onercus coccinea; 62. Catalpa syringafolia; 63. Aralia spinosa; 64. Platanus occidentale; $65,66,67$. Pepulus italica, au trone desquels s'enlaceront des Chèvefeuilles; 68. Gledutschia brachycarpa; 69, 70, 71. Livicdendron tulipifira. 


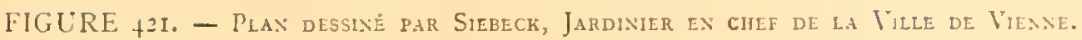

On a supposé cette propriété entourée de beaux horizons de camp̧agnes qui, des deux façades de l'habitation, se relient aux jardins. A cet effet, des grilles ont clé posćes aux deux lignes d'enceinte de devant et de derrière, afin d'ourrir la vue dans toutes les directions. La mise en scène du rond-point d'entréc est disposce dans de grandes proportions, pour s'harmoniser avec le passage extérieur.

a. Indique l'habitation, qui devra ctre construite dans un style simple.

6. Pavillon dans un espace ombragé et isolé. De hauts massifs l'abritent, et la vue n'est libre que par derant, afin de diriger l'attention sur un des points du dehors.

c. Petit pavillon.

d. Habitation du jardinier.

e. Pavillon de forme circulaire. La partie fajsant face a ce pavillon est ménagée de telle sorte que, vue d'ici, la portion restante du jardin à la. quelle elle se relie change complètement d'aspect. De ce point de rue s'ouvre une large perspective jusqu'à la limite no 10.

f. Carré de fleurs où l'on plantera des rosiers à tiges basses, feurissant dans toutes les saisons.

g. Carré de fleurs, I. Jacinthes; 11. Plumbago carulea.

h. Carré de fleurs, 1. Myosotis alpestris; I1. Dianthus chineysis.

$i$ Carre de fleurs, 1. Belles Tulipes pleines; II. Francoa sonchufolia.

k. Banc ombragé, d'où l'on aperçoit la mai. sonnette du jardinier et ses alentours.

1. De ce banc on a sous les yeux la même scène, seulement it une

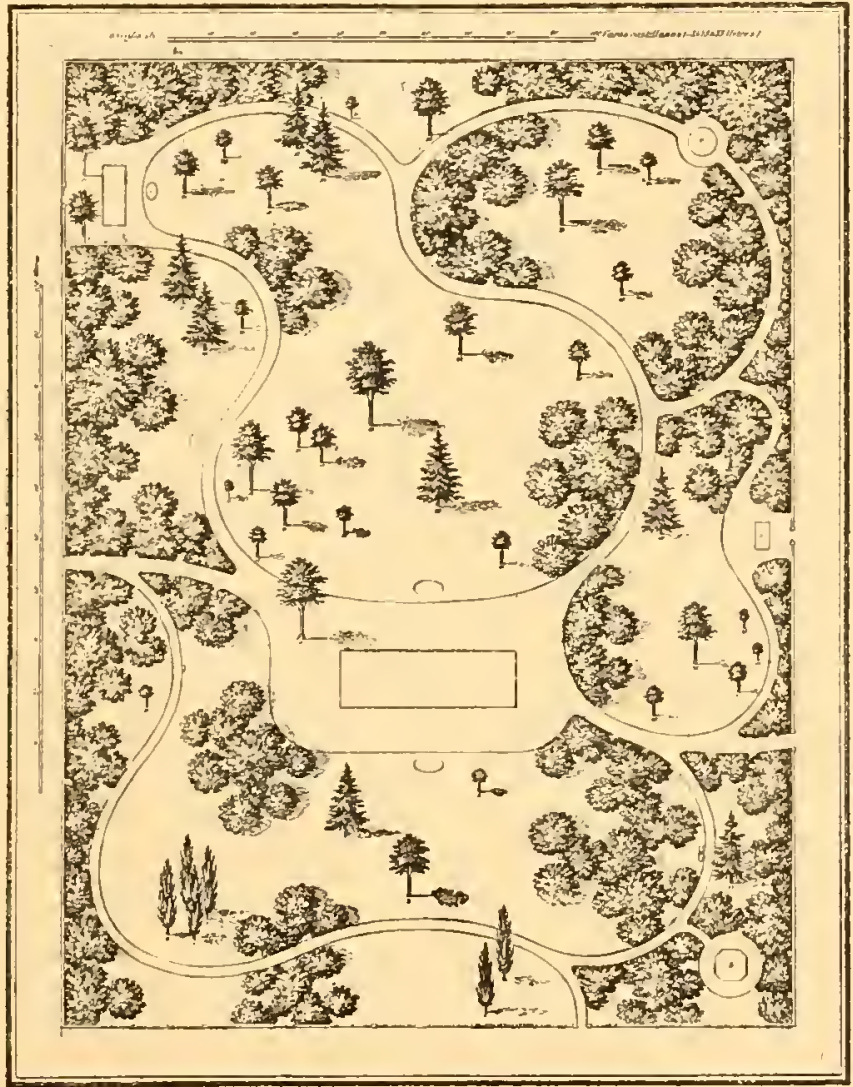
d'un point de vue different.

m. Banc à dossier, avec vue sur la perspective dont le point capital est le pavillon $e$.

n. Ce banc se trouve sur une petite pelouse entourée de massirs sauvacres.

o. Siege ì dossier arec rue de côté sur les alento.rs du devant de la maison.

p. Tauc sous d'è pais omb:ares.

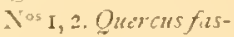
tigiata; 3. Plutanus orientalis, + I'seer pertinata; 5. Cotulpa stringufolian; 6, 7, 8, 9. Popuhes itiz-

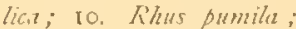
11. Tiliu enropera; 12. Robinia hispidtu; I3. Rusiers a haute tige; If. Acer pseuto-platimus; 15 . Sorbus lavbrida pendula; I6. Amorphiz fruticosa; 17. Elie ignus angustifolins; 18. Craturgus coccineiz; 19 Aluns anevicana; 20. Abie's albu; 21 . Broussonnetir poppyifer $a ; 22$. Liriodendron tulipifera; 23 . Rhus coriarit; 2+. Picen canadensis; 25. Picea peclinata; 26. Magnolia purpurea; 27, 28. EEsculus rubicunda; 29. Acer laciniatum; 30. Cratagus purpurea; 31. Quercus coccinea; 32. Picer balsamea; 33, 34. Abies

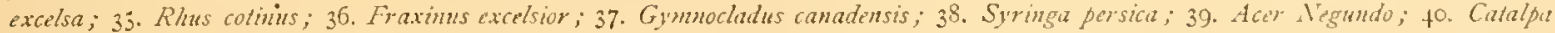

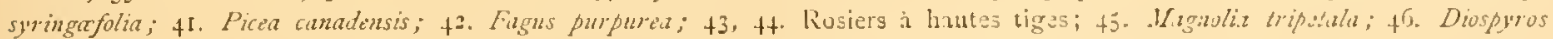
Lotus; 47. Picea canadensis. 


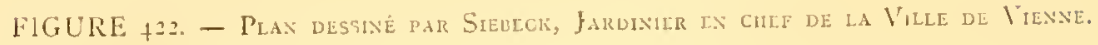

Dans ce plan, l'entrée qui fait face à l'habitation sert exclusivement à l'usage du proprićtaire.

Les grandes portes d'entrée et de sortie sont latérales.

Du dehors, on aperçoit à droite le pavillon $b$, at à gauche l'espace dicouvert avec les ensirons qui l'encadrent.

De l'habitation $a$, on a la rue de l'entrie et du grand carré de fleurs a compartiments. Dans la direction opposce, la perspective s'etend derrière le pavillon e', sur le paysage du dehors.

b. Pavillon de furme ronde d'où l'on aperçoit en troite ligne la voie, et a droite une parlie du jardin. Du côté de ce dernír, on distingue, mar une

échappée entre des mas-

sifs, le paysage qui se relie a l'habitation.

c. Lieu de repos de forme circulaire, onbragé par un sapin et des massils con:igus; on a da la vue sur le dehors it travers l. grille.

d. Autre liev de re. pos, suffisanment ombragé parles truis tilleuls qui s'y trouvent, et offre, au moment de la floraison de ces arbres, une station des plus agréables.

e. Pavillon plus grand, place dans un cn. droit très decouvert, ct faisant ainsi point de vue de diffèrents côtés, en mêms temps quion découvre de ce pavillon une grande partie du jardin et des environs.

f. Carré de fleurs, 1. Tulipes pleines; II. Verveines bleues.

Le carté $g$ sera garni, I. de Jacinthes; 11. d'Eythrinacristag.alli.

Les carrés $h$ et $k$ auront, I. des Wyosotis al-

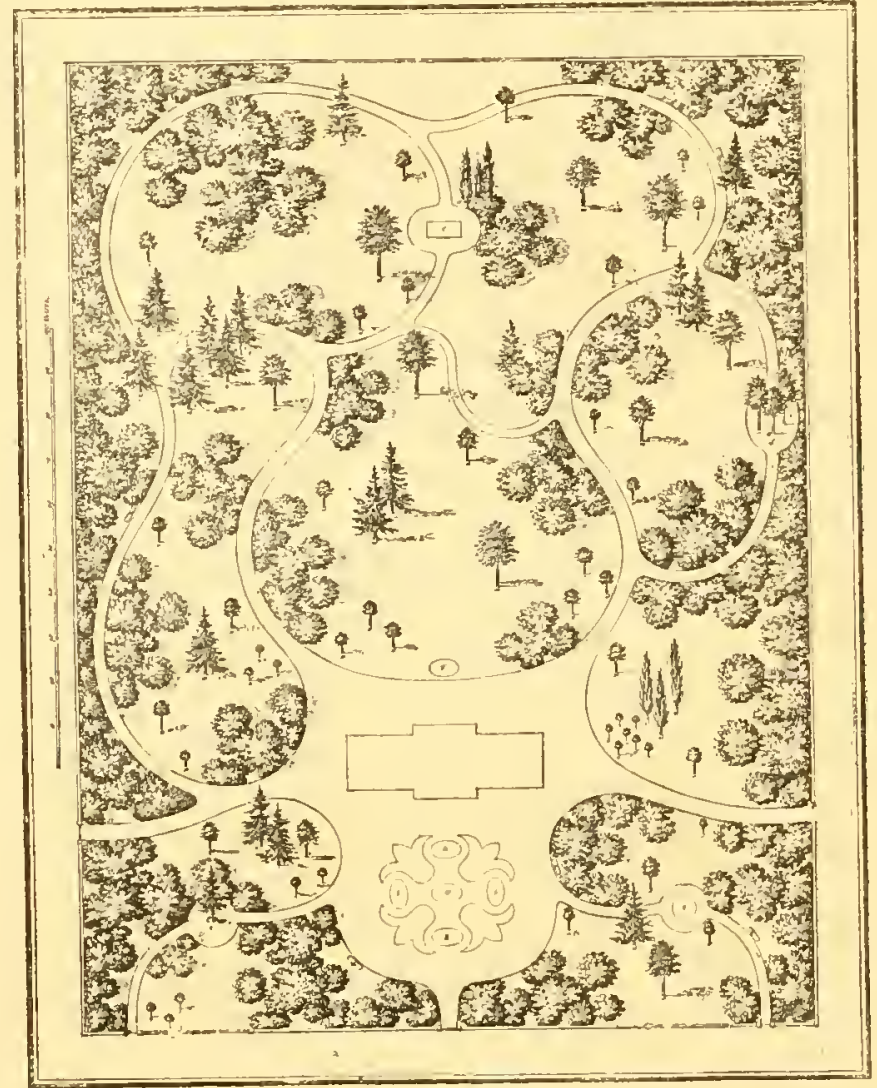
de Christ enlevés du rase.

Les carrés : et / sont garnis comme suit : I Ilepalica trilobu $A$. carruleo pleno; II. Violit tricolor maxima: 11]. Eils de Christ en vase.

m. Banc d'où l'on jouit parfaitcment de la I'ue de l'entree et de celle de l'habitation, tandis que lon pent apercevoir it droite le pavillon $b$.

n. Banc ombraré, arec vue sur le paysage accessoire isolé qui se trouve en face.

o. De ce banc, on aperçoit, entre des bosquets, une partie de l'hnbitation.

I.e banc à dossier $p$ présente une vue de côté du pavillon $e$.

7. Bunc dont l'inorizon découvert parait meublé par les massils qui abritent le pavillon e. Le banc $r$ laisse pareillement aperceroir l'entrée, mais dans une autre direction.

s. Barc à dossier, qui permet de distinguer Ie pavillon $b$, une partie de l'entrée et la voie. lin insignis; III. des Eils

$\mathrm{N}^{\circ} \mathrm{I}_{2}, 3,3,4,5$. Rosiers à hautes tiges; 6. Sorbus nepalensis; 7, S. Picea canademsir, 9. Robinia hispida; 10. Liriodendron

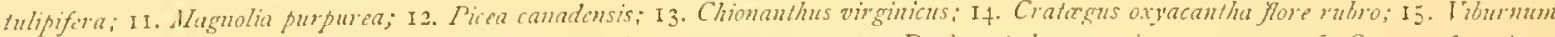
Opulus fore pleno; if. Catalpa syringufoliut: I7, 19, 19, 20, 21, 22, 23. Rosicrs a bautes tiges; 24, 25, 26. Qhercus fast ginta; 27. Cratrgus oxyacunth fore albo; 28. Rosiers à longues tiges; 29. Salisburya atiantifolia; 30, 31, 32 . Rosiers à longues tiges;

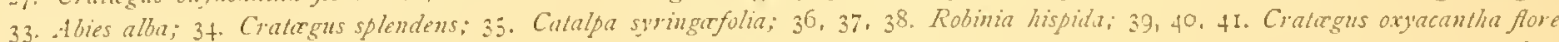

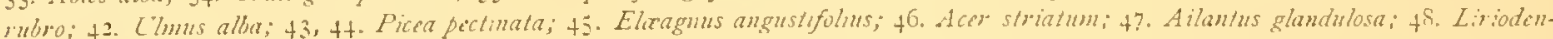
dron tuhpifera; 49 Picea pectinata; 51. Ahies alba; 52, 53, 54. Picea pectinata; 55. Robmia hispuda; 56, 57. Lilas de Marly : 5\$. Acer

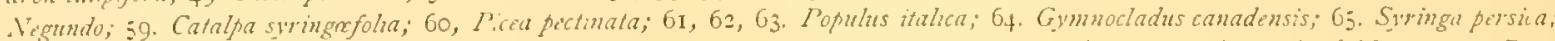
65. Sophora japonica; 67. Abies alba; 68. Cralagus oxyacantha fore albo; 69. Fraxinus excelsior; 70. Rhus juglandifolia; 71, 72 . Picen pect:nala; 73. Platumus occidenlalis; 74. Picea pectinata; 75. Hibiscus syriacus flore pleno; 76. Pavia flava; 77, 78, 79. Tilia europara; 80. Magnolut purpuret. 


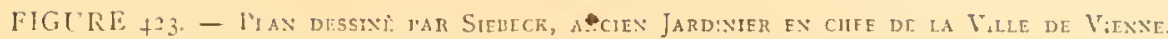

Dans ce travail, l'étendue plus grande du terrain permet une combinaison plus variée d'aspects, et autorise un plus riche emploi de moyens. Le but est le même : joindre l'utile à l'agre̊able. Nous trouvons ici un élément nouveau; une vigne avec une gentille maisonnette de vigneron an sommet. I a pente doucement inclinée de ce coteau et la fraîche verdure des ceps, doivent contribuer it la grâce de l'ensemble.

Du dehors nous apercevons, à travers la grille, la maison d'habitation a, entre des massifs de verdure. Du côté gauche, elle n'est protégée que par quelques arbres isolés contre les rayons du soleil, tandis que d'épais bosquets donnent de l'ombre au côté droit. Du côte du jardin, par-dessus la grande pelouse ornée de massifs, et par-dessus la vigne, la perspective se prolonge jusqu'à la maisonnette du vigneron.

b. Maisonnette du vigneron. On voit de lia I'habitation el sur le côté le grand parillon $c$.

c. Grand pavillon. Des bosquets l'om bragent sur les côtés, et l'on aperçoit par devant la vigne et la maisonnette.

d. Petit pavillon sous des ombrages; les massils qui l'entourent ne s'entrourrent que diun seul côté.

c. Carré de fleurs. 1. Myosotis alpestris; 11. Fola tricolor maxima.

$f$ Carré de fleurs. I. Jacinthes; 11. Hortensias bleus.

g. Carré de fleurs. 1. Tulipes pleines; 1I. Giroflées d'cité; Eils de Christ coniques en vases.

h. Carré de fleurs.

I. Wyosotis scorpioiltes:

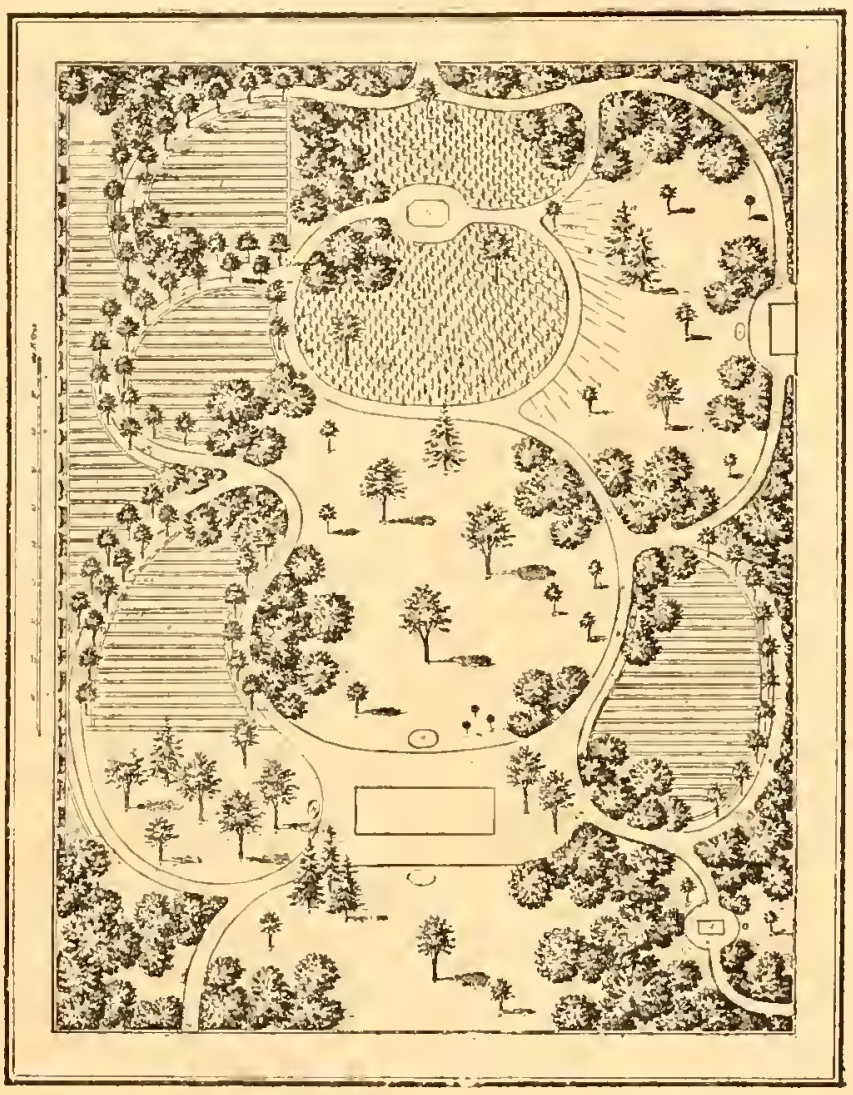
I. Jacinthes; 11. Plumbago corrulea.

$k$. Banc ombragé arec vue sur la vigne.

1. De ce banc à dossier on aperçoit la maisonnette du vigneron.

m. Ce banc ouvre la vue sur la grande pelouse et sur son encadrement varié.

n. Banc à dossier sous des ombrages.

o. Banc ombragé placé a l'entrée.

p. Fispalier de raisins et de pêches. $q, r, s, t, u, z^{\prime}, z^{\prime}$, Carrés de légumes.

$x$. Plates - bandes avec arbres fruitiers, groseillers blancs et rouges, et encadrement de fraisiers.

Nos I. Robinia hisPida; 2. Platanus occidentalis; $3,4,5$. Piceu pectinata; 6. Cratagus oxyacanthu fore allo; 7. P'aria furva; 8. Fughons regitu. 9. Ailanthus glandulosa; 10. Aisculus Hippocastunum; II. Sophora japonica; 12. Abiesalbu; 1 3. Acer striatum; 14, I5, 16. Rosiers a hate lige; 17. Tilia europara; 18. Lirio-

i. Carré de fleurs.

dendron tulipifera; 19. Calalpa syringorfolin; 20. Lobinia hispoda; 21. Eliragnus angustifolins; 22. Acer Nigundo; 23, 24, 25. Craturgus oxyacantha fore vubro; 26. Fuglans cinerea; 27. Chionanthus virginicus; 28. Fagus pupurea; 29. Abies allia; 30. Catalpa syringerfolia; 31. Anygulalus communis; 32. Un Pommier; 33. Un Pêcher; 34. Cerosus pendula semperforens; 33. Rohnia hispida; 36. Sivinga

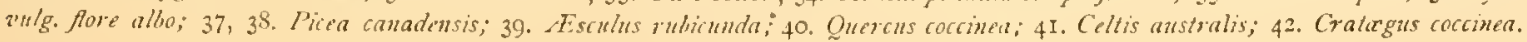


On remarque dans ces plans et dans quelques autres, d'ingénicuses tentatives pour associer, dans une juste mesure, le potager au jardin d'agrément; tendance que nous avons dejjà signalée, dans un des précédents chapitres, che\% Morel et d'autres habiles dessinateurs français. Comme le dit spirituellement M. Naudin, beaucoup d'amateurs, "dans ce siecle d'ćnomic forcée ", sauront gré á l'artiste viennois d'avoir développé ce systéme, montré comment on peut, suivant le précepte d'Horace, marier l'agréable it l'utile. "Pourquoi, aprés tout, n'en serait-il pas ainsi? Un arbre fruitier n'est pas sans beauté, surtout au moment de sa floraison (I), et combien de nos légumes seraient prisés, pour leur feuillage et leurs fleurs, à l'égal de plantes plus recherchées, s'ils étaient rares et venaient de loin! "

Ces plans, ceux du prince Pückler-Muskau, du comte de Choulot, des grands squares parisiens et autres semblables, peuvent donner aux amateurs des indications précicuses, soit pour les dispositions générales, soit pour la plantation.

Mais, comme le leur conseille M. Naudin, « ils ne copieront pas servilement ces plans; ils les modifieront suivant les conditions particulières oú ils seront placés; ils en inventeront même de toutes pièces, en s'inspirant des principes des maîtres, et en s'appropriant leurs procédés. C'est qu'ici, même en s'aidant de l'expérience d'autrui, il faut savoir mettre quelque chose de soi. C'est un tableau à composer d'après des règles générales et strictement formulées, mais qu'il faut faire entrer dans un cadre déterminé d'avance par les conditions d'emplacement, de climat et d'entourage. Qu'on ne s'en plaigne pas! Dans les ceuvres de cette nature, lal jouissance est d'autant plus vive qu'on a pris une plus large part ì leur création. » Ce précepte d'ètude indépendante et intelligente est l'un des plus essentiels. Un calque servile du meilleur plan n'est pas plus une auvre d'art, que l'exécution du plus beau morceau de musique, en tournant la manivelle d'un orgue de Barbarie.

Il y a toujours, dans le tracé comme dans la plantation, des variantes

(1) Quelques-uns même, comme le cognassier, le néfler, offrent un aspect tout al fait ornemental, quand on les dispose avec intclligence. Plus loin, l'éminent horticulteur parle des choux; on sait quel parti sait tirer aujourdhui l'horticulture d'agrément des choux violets et à feuilles fristes et panachées, qui font trés bonme figure à cóté des magnificences exotiques, dans le beau recueil des Plunles à Fuillage coloré (2 vol. avec 120 chromolithographies). - Paris, J. Rothsililu, Éditeur. 
imposées tantôt par l'aspect des alentours, tantôt par le climat, par la nature du sol, l'étendue plus ou moins grande du terrain à employer, la forme différente des constructions, etc. J'ajoute que, même dans des conditions à peu prés identiques, les indications d'arbres, d'arbustes et de plantes ne doivent pas être ponctuellement reproduites, mais utilisces comme renseignements sur la disposition générale des plantations, lcurs formes, les rapprochements ou les oppositions de feuillages. Par excmple, dans les plans de petits parcs de Siebecli, le chévrefeuille est seul indiqué pour garnir les peupliers placés en premier plan. Il ne faut voir là qu'une recommandation générale d'orner de plantes grimpantes les arbres pyramidaux, ou les tiges d'arbres d'une grande hauteur en bonne exposition, qui n'ont de feuillage qu'au sommet. Alors on peut employer à leur décoration non sculement le chévrefeuille, mais tantôt les rosiers Banlis, tantôt les diverses variétés de clématites, les aristoloches, les bignonias, le périploca, la vigne vierge, le lierre, etc. De même, l'association de l'Epicea et de l'Hemlock-Spruce ( $P$. canadensis), répétéc dans la plupart de ces plans, ne doit être imitée que trés librement, comme un heureux type de rapprochement entre des coniféres de nuances et de ports variés, mais également vigoureux et croissant avec la même facilité dans des terrains semblables, comme les cèdres du Liban ct argenté, l'A. pinsapo, l'A. Nordmanniana, l'A. pindrow', le Pimus crcelsa, l'A. Morinda et le Cupressus Lazusoniana. Nous recommandons spécialcment pour les petits parcs l'association de ces deux dernières espéces, d'introduction relativement récente, mais qui ont fait victorieusement leurs preuves sous tous les rapports. Au triple mérite de l'élégance de forme, de la beautć du feuillage et de la rusticité, elles joignent l'avantage, précieux dans les propriétćs d'une étendue médiocre, de n'occuper qu'un espace restreint, à cause de leur forme pyramidale.

Enfin, lc plan ci-joint (Fig. 424) d'un parc de I 40 hectares, emprunté au Guide pratique de M. Siebcek, prouve que cet artiste n'est pas moins habile dans la composition des grandes propriétés, que dans celle des petits parcs et des jardins paysagers de villes et de faubourgs.

L'arrangement de ce domaine offrait de grandes ressources paysagéres, a cause de sa situation dans une région fertile et accidentée, sur les premières pentes des Carpathes, avec de beaux points de vuc sur leurs cimes boisées et leurs contre-forts rocheux, couronnés de ruines féodales. Mais il fallut surmonter bien 
des difficultés, pratiquer de nombreuses éclaircies pour dégager les perspectives dés alentours et les abords de l'habitation, reste d'un couvent bâti au fond d'un

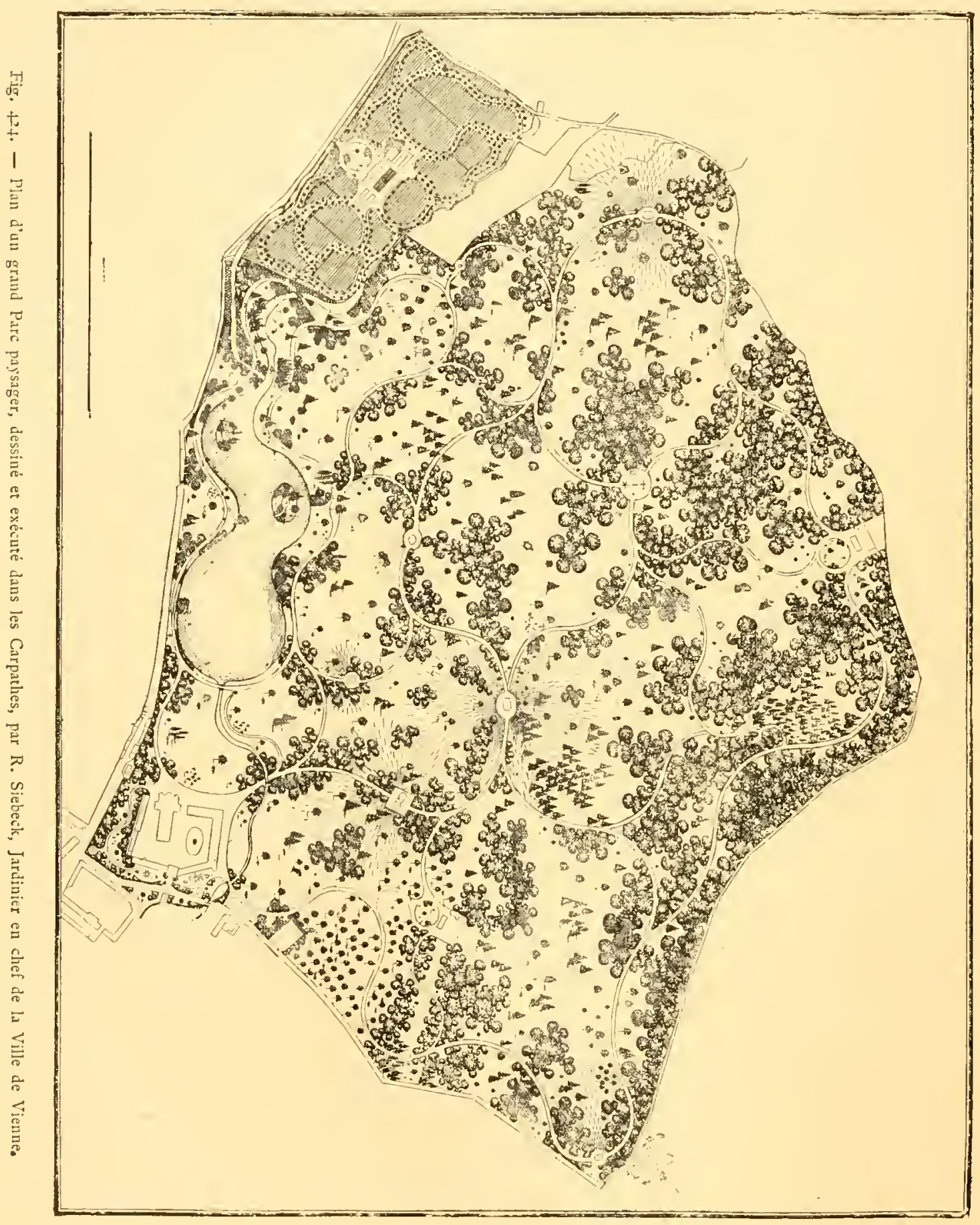

vallon solitaire; - créer un lac en élargissant et creusant le lit d'un ruisseau et drainant des prairies marécageuses, consiruire sur les points culminants des 
bâtiments de différents caractéres; pavillons de repos, chalet, maison de garde, tour gothique, etc. A dire vrai, nous n’amons guére ce gothiqua factice, rapproché d'édifices et de ruines du moyen âge authentiques, non plus que certaines réminis. cences mythologiques, conme un Temple de Thétis an milieu de cette région des moins maritimes, et un Temple des Graces, "composé de forts fils de fer et de rosiers grimpants »... Néanmoins, cette vaste composition offre bien des détails intéressants a étudier. On remarquera que les frais d'établissement du pare (terrassements, gazons et allées), montant al 31,000 florins ( 77,500 fr.), ont été couverts avec le produit des arbres sacrifiés pour dégager les perspectives, et qu'un vaste terrain a été réservé pour l'établissement de pépiniéres d'arbres à fruits, d'arbres et d'arbustes d'agrément, etc., dont le produit pourra, dit-on, couvrir les frais d'entretien du pare et donner même un excédent de bénéfices. Ce systéme économique d'adjonction de pépinières a déjà été appliqué aree succès à Eisgrub et dans d'autres grandes proprictés, dont il assure la conscriation.

III. - Parcs français. - La France, à laquelle il est temps de revenir, nous offre aussi des exemples nombreux de créations modernes d'un grand intérêt. Nous avons reproduit page i6 I (Fig. 196) l'un des meilleurs plans d'un artiste habile, feu Barillet-Deschamps.

Ce plan est celui d'un jardin paysager de deux à quatre hectares, mais dont les dispositions principales pourraient être librement imitées sur une plus grande échelle. A l'extrémité supéricure de la piéce d'eau en forme de rivière, dans plusieurs endroits des rives, et au-dessous du pavillon de l'ilot, le dessinateur a placé des rocailles en bonne cxposition, propres a la culture des fougères. Le gracieux développement de la pelouse centrale autour de l'eau, permet d'y distribuer sans confusion les arbres isolés, les massifs d'arbustes et les corbeilles. On remarquera le raccordement habile du jardin pittoresque avee la disposition réguliére des abords de l'habitation.

Nous donnons aussi le plan du pare breton de M. le marquis De Langle-Beaumanoir, chef-d'œuvre d'un dessinateur des plus habiles, le comte de Choulot, auquel la mort n'a malheureusement pas liassé le temps de terminer son ouvrage sur les jardins (Fig. 425).

Ce pare, d'une superficic de 230 hectares, est entiérement du genre irrégulier, le plus convenable sur un sol aussi accidenté. Le château est assis sur un platcau central, d'oú l'on descend d.uns la vallée profonde oú passe la rivière, par une pente 
rapide, sur laquelle s'éléve une superbe réserve de chênes, forêt druidique, dont l'étendue est de is à i 6 hectares.

Le comte de Choulot a créé ou remanić, avec le même talent, plusicurs autres proprictés importantes, notamment celles de Wartegg en Suisse, et de Chamarande, près Paris. Ce n'était pas trop de tout son art pour faire oublicr, dans ce dernier pare, la destruction des majestucuses futaies plantées par Le Nôtre.

Bien d'autres pares, récemment créés ou remaniés, peuvent offrir aux amateurs d'intéressants sujets d'étude. Leur nomenclature, rien que pour les environs de Paris,

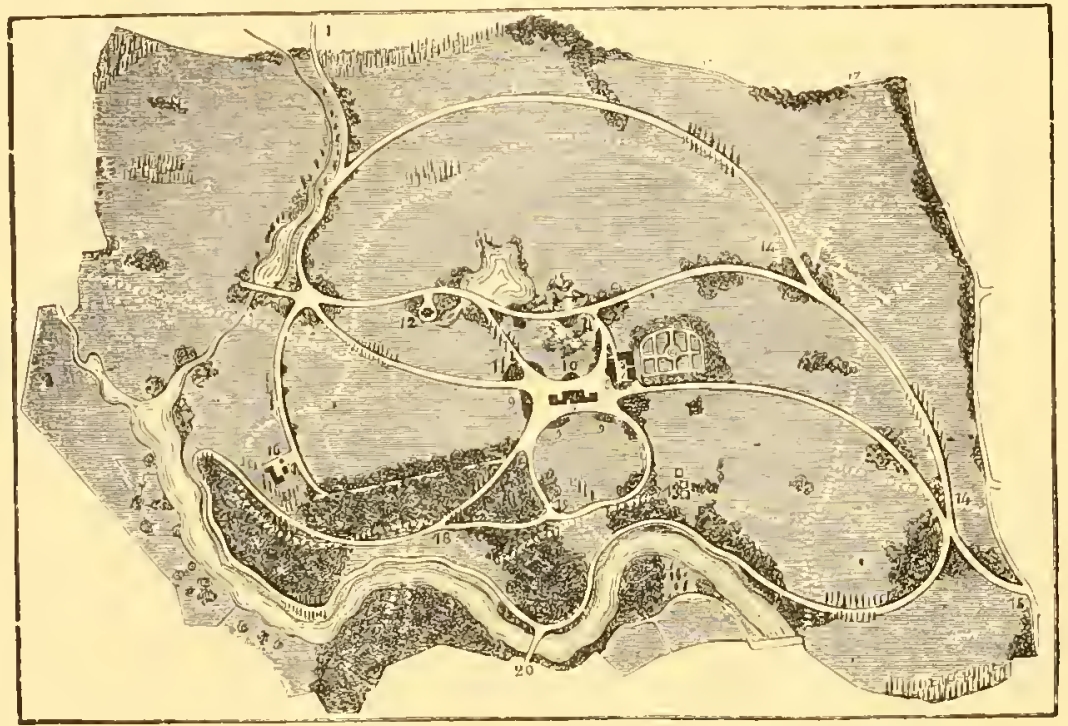

lig. 425. - Pare du Murquis de Langlc-Beaumanoir, exécuté par le Comte de Clioulot. formerait un volume. Toutefois, dans ce genre comme dans tous les autres, les cuvres originales ne sont pas communes. On y trouve presque toujours des réminiscences plus ou moins heurcuses d'Ermenonville, de Morfontaine, du petit Trianon, de Mérérille, de la Malmaison, de Bagatelle.

L'un des plus estimés pour la plantation est l'ancien parc du prince d'Eckmühl, Savigny-sur-Orge, qui bientôt peut-être ne scral plus qu'un sourenir, comme le Raii.ey, Guiscard, Issy, Petit-Bourg, et tant d'autres grandes et belles proprictés.

Le grand pare de Ferricres est dû à l'artiste anglais Paxton. Ce domaine est l'tin des plus mal partagés en fait d'alentours. L'artiste a heurcuscment surmonté ectte difficulté; grâce à l'habile distribution des masses et des groupes de verdure, des caux et des pelouses, ce pare est à lui seul un pays, qui fournit au château de charmants points de vue. Les nombreuses et belles plantations de coniférẹs exotiques ont malheureusement beaucoup souffert à Ferricres, comme dans toute la banlieue de Paris, de l'hiver exceptionnel de is8o.

Le domaine célébre de Dangu, remanié par M. Bühler, présente un exemple trés remarquable d'un jardin français conservé ct encadré dans un pare irrégulier. Nous 
rencontrons encore, dans l'ancien Vexin normand, deux grandes propriétés très dignes de l'attention des artistes; le parc du Chesnay, supérieurement dessiné par son proprictaire, le comte de Pulligny, qui a été aussi l'architecte et le sculpteur de son propre château; - ct, dans la riante vallée d'Andelle, le pare de Radepont, qui satisfait plus largement peut-être qu'aucun autre à toutes les conditions du genre pittoresque.

Nous croyons, comme le prince Pückler-Muskau, que le style régulier, ou tout au moins le style mixte est celui dont l'emploi convient le mieux dans les pares et jardins méridionaux, pour accompagner les édifices ayant un caractire architectural imposant et nettement déterminé.

Toutefois on peut y créer, dans certaines localités plus favorisées et autour d'habitations plus simples, des jardins franchement irréguliers. L'un des plus intéressants de ce genre est celui qu'avait planté le célébre botaniste-amateur, M. Thuret, auprès d'Antibes; e'est aujourd'hui une annexe du Jardin des Plantes de Paris. Il réunit tous les genres d'agrément : beauté du site, disposition grilcieuse des plintations, acclimatation de végétaux exotiques. Cet Éden provençal occupe une superficie denviron quatre hectares, au sommet d'un promontoire situé entre le golfe Juan et celui de Nice, sur lequel s'ouvre lia principale perspective.

Grîce à de copicux arrosements, et à des conditions exceptionnelles d'abri, M. Thuret avait accompli de véritables tours de force d'acclumatation. On trouve lí, en pleine terre, et dans les plus belles conditions de végétation et d'effervescence, une foule de végétaux dont il n'existait encore en France que des spécimens rachitiques dans quelques grandes serres. On y voit des Eucalyptus de la taille de nos plus grands arbres d'Europe. Les palmiers, les datticrs, les bananicrs même, sont lí comme chez eux; le figuier d'Inde y atteint des proportions presque aussi fortes que dans les climats tropicaux. La nombreuse et clégante famille des cistes y flcurit comme les rosiers dans nos jardins du Nord. Nous citerons encore les nombreuses variétés d'acacias d'Australie, entre autres le pubescens, arbuste remarquable par ses énormes grappes de fleurs d'un jaune d'or; plusicurs rares coniféres australiens, notamment l'Actinostrobus pyramidalis, espece naine très élégante; de trés beaux spécimens d'un des arbustes les plus curieux de ce même pays, le Bumlisil, remarquable surtout par la forme étrange de ses énormes graines zébrées de jaune et de noir. 
Ce petit parc, plus digne d'attention que bien des grandes propriétés, est un type accompli des ressources exceptionnelles qu'offre à l'horticulture d'agrément le littoral de la Provence. Des résultats analogues ont íté obtenus à Cannes, dans les environs de Nice, dans ceux de Marseille transformés en oasis par l'aqueduc de Roquefarour. Suivant la judicieuse remarque de Decaisne, "avee de l'eau, il n'est pas de terre stérile dans le Midi ».

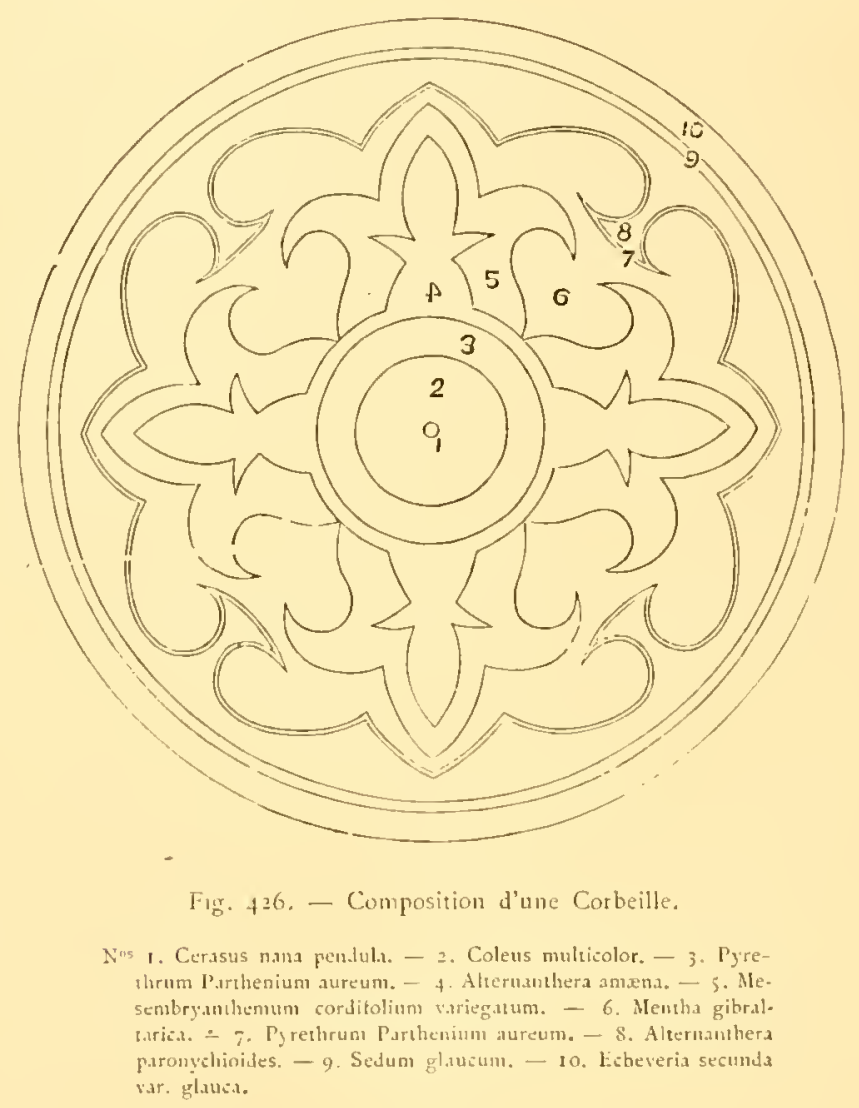




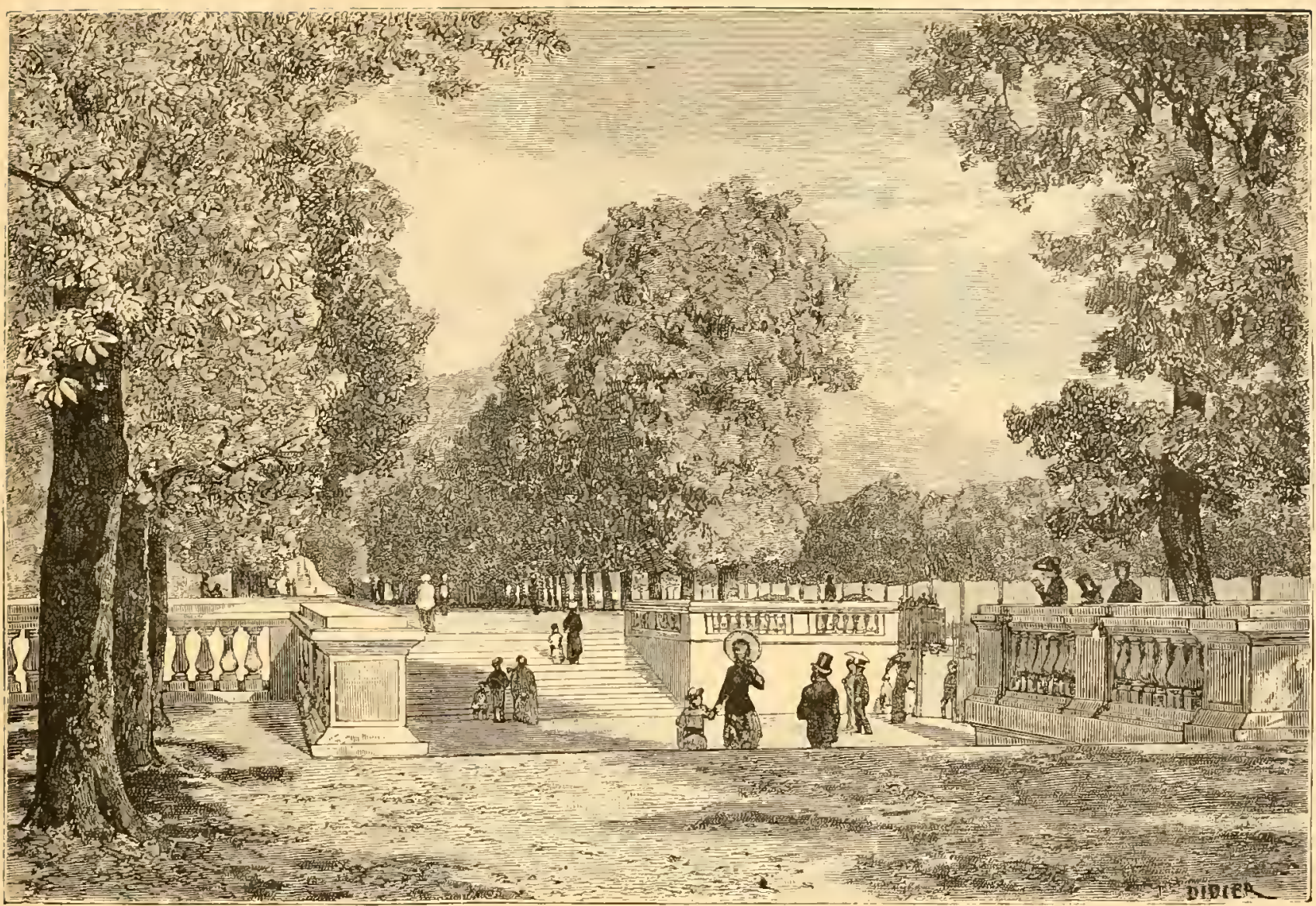

Fig. 427. - Terrasse au Bord de l'Eau daus le Jardin des Tuilerics.

\section{CHAPITRE V}

\section{PROMENADES E'T' SQUARES}

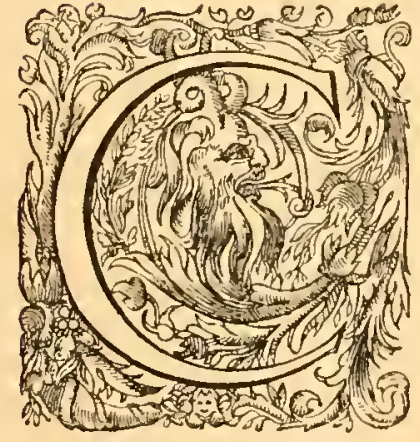

ONSIDERATIONS préliminaires. - Cette branche de l'art des jardins est celle qui a pris de nos jours le développement le plus considérable, principalement en France. Il itait naturel, en effet, que les raffinements et les perfectionnements les plus dispendieux de l'horticulture, désormais moins accessibles aux particulicrs par suite de la division des fortunes, fussent recueillis dans le domaine public. Au train dont vont les choses, il n'y aura plus bientôt d'autres grands parcs que ceux qui appartiennent á loul lc mondc. C'est là un signe des temps nouveaux, et l'un des plus 
caractéristiques. Ce n'est pas qu'on ne puisse faire remonter à une antiquité reculée l'usage des promenades publiques. Ce caractére appartenait ívidemment aux jardins orientaux au milieu desquels s'élevaient les mausolies des souverains, aux bois sacrés plantés autour des temples grees et romains, aux jardins des ciroyens romains opulents, et, plus tard, a ceux des Empereurs (V. premicre partic). En France, il n'existait point, à proprement parler, de promenades publiques arant Louis XIV, saut quelques plantations réguliérement alignces dans l'intéricur ou aux abords des grandes

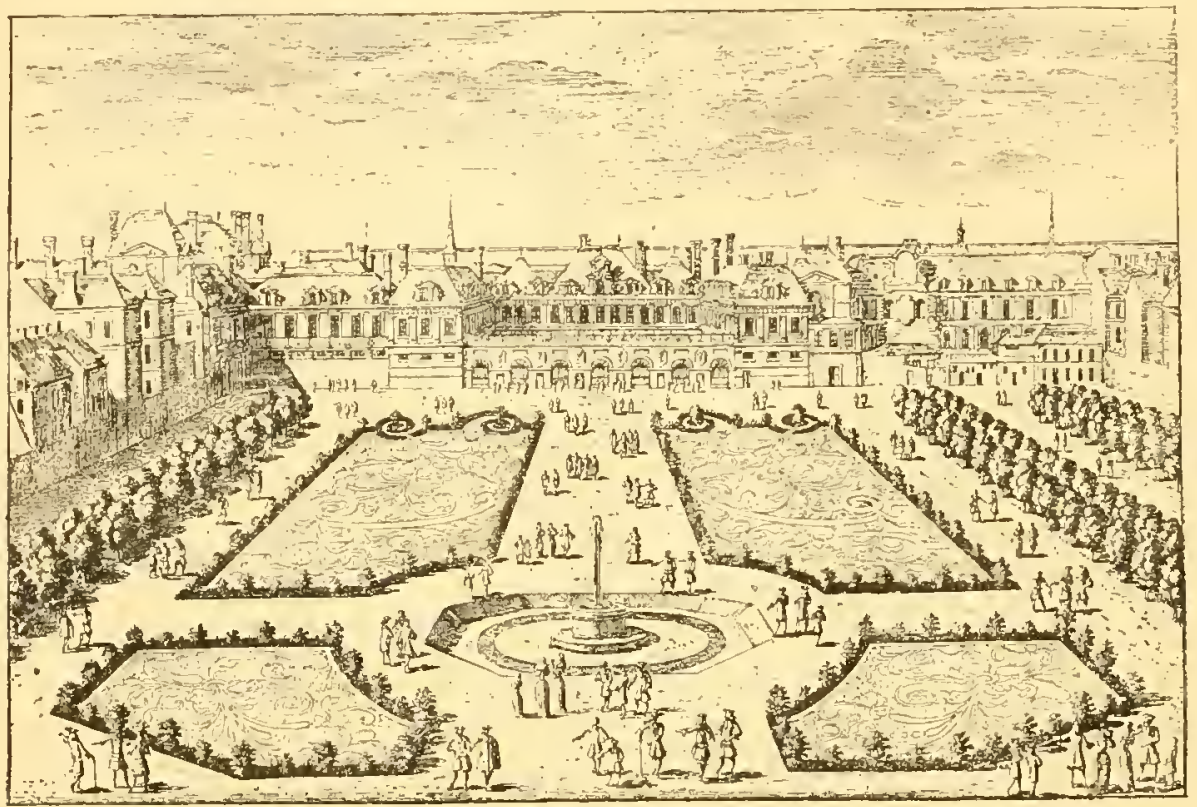

Fig. 429. - Lauzien l’arterre du Palais-Royal, dessinć et gravé par Pirelle.

villes, comme le Palais-Royal (Fig. 429), les tillculs de la place Royale, et le Cours la Reine, planté par Marie de Médicis en I 6 I 6 , et qui ne devint public que quelquesannées plus tard. Le reste de l'emplacement actuel des Champs-Élysées (Grand-Cours), était encore il peine ébauché en I 680. C'est de la seconde moitié du régne de Louis XIV que datent les premiéres promenades publiques vraiment dignes de ce nom, comme celle de Dijon, créce par Le Nôtre. Vers la même époque, autour d'un grand nombre de villes de l'intérieur, à commencer par Paris, les anciens bonlevards de défense, indispensables au temps des guerres privées, furent plantés d'arbres, et ce mot, jadis tout militaire, prit insensiblement l'acception pacifique, seule comprise aujourd'hui. C'est un exemple curieux de l'influence si puissante des mours sur le langage.

Le nombre des promenades s'accrut sensiblement en France pendant le xirne siècle. Ce fut, comme on sait, par des excursions plus ou moins édifiantes it l'abbaye de Longchamps que commença, sous Louis XV', la vogue des ChampsÉlysées (Fig. 430), à peine interrompue pendant les plus mauvais jours de la Révo- 
lution. Cêtte promenade arait été entiérement remaniée, vers i 764, par le surintendant Marigny (Poisson), qui en renouvela les plantations en réservant, à droite et à gauche de la grande allé, les deux Carrốs qui ont subsisté jusqu'i nos jours. C'est également ì ce régne que remontent l'agrandissement, ou plutôt la transformation du Jardin des Plantes par Buffon, ct l'établissement d'un grand nombre de belles promenades dans d'autres villes; comme les allées de Tourny à Bordeaux, le cours

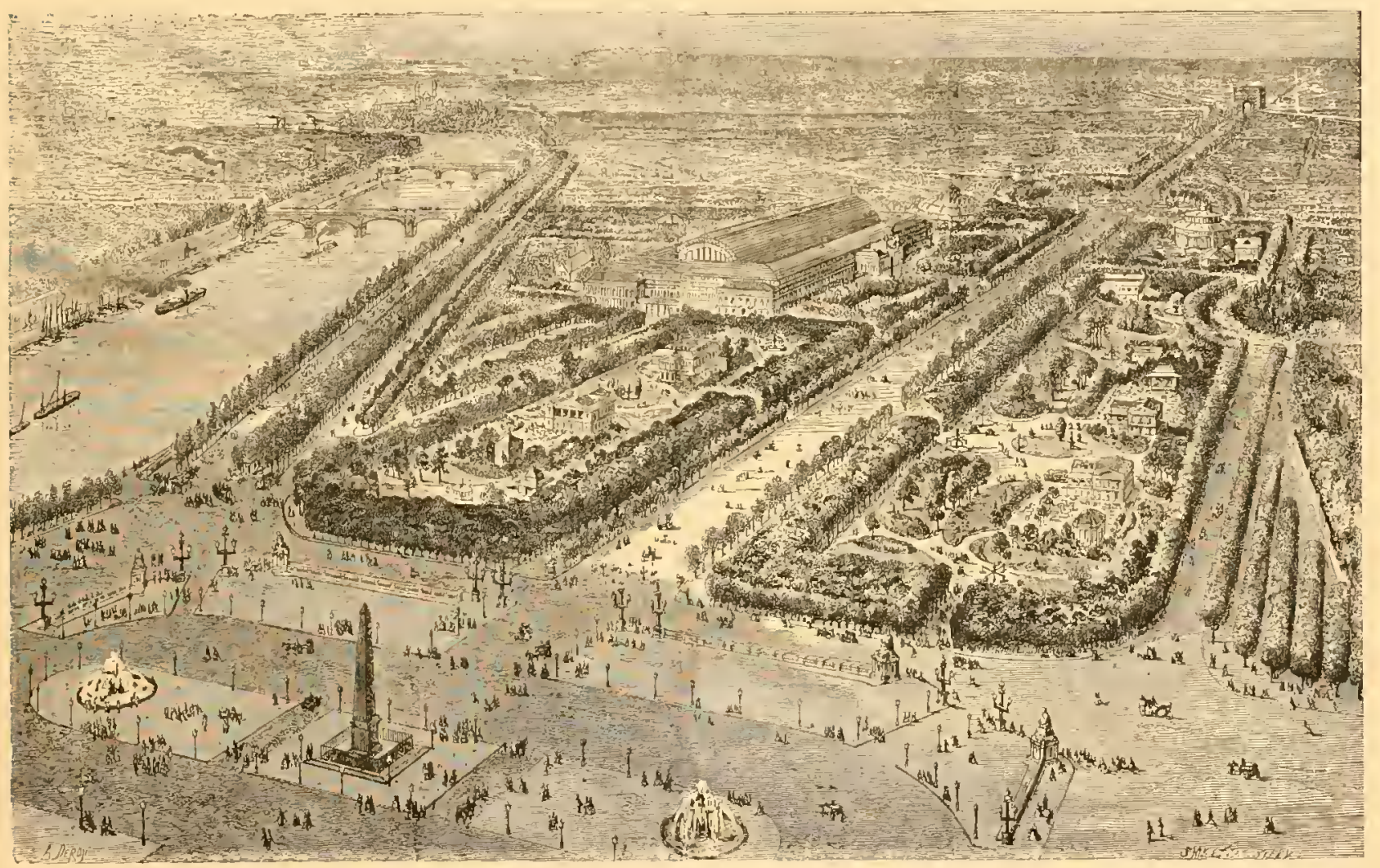

Fig. 430. - Vue i vol d'Oiseau des Champs-Élysées et du Cours-la-Reine.

d'Ajot à Brest, etc., etc. En même temps, on s'habituait peu à peu à considérer aussi comme publics, ou quasi-publics, les jardins des résidences royales, ainsi que ceux des grands seigneurs et des "partisans », où l'on était admis gratuitement ou moyennant une lègère rétribution.

Le style régulier régnait en maître absolu dans les promenades, comme dans les pares. L'importation du systéme anglo-chinois souleval d'abord des oppositions nombreuses. L'Encyclopédie, qui patronnait tant d'autres réformes, repoussait vivement celle-lá. « De tous les arts de goût, disait-elle, c'est peut-être celui-lì qui a le plus perdu de nos jours ( I 760 ). Nous ne savons plus faire des jardins comme ceux des 
Tuileries, des terrasses comme celle de Saint-Germain, des boulingrins, des treillages et des parterres (Fig. 431), comme à Trianon, celui de Saint-Cloud (Fig. 431), des portiques naturels ( $)$ comme ì Marly, des treillages comme à Versailles (Fig. 432) et at Chantilly, ni des parterres d'eau comme ccux de Versailles... Comment décorons-nous aujourd'hui les plus belles situations de notre choix, et dont Le Nôtre aurait su tirer des merveilles? Nous y employons un goût

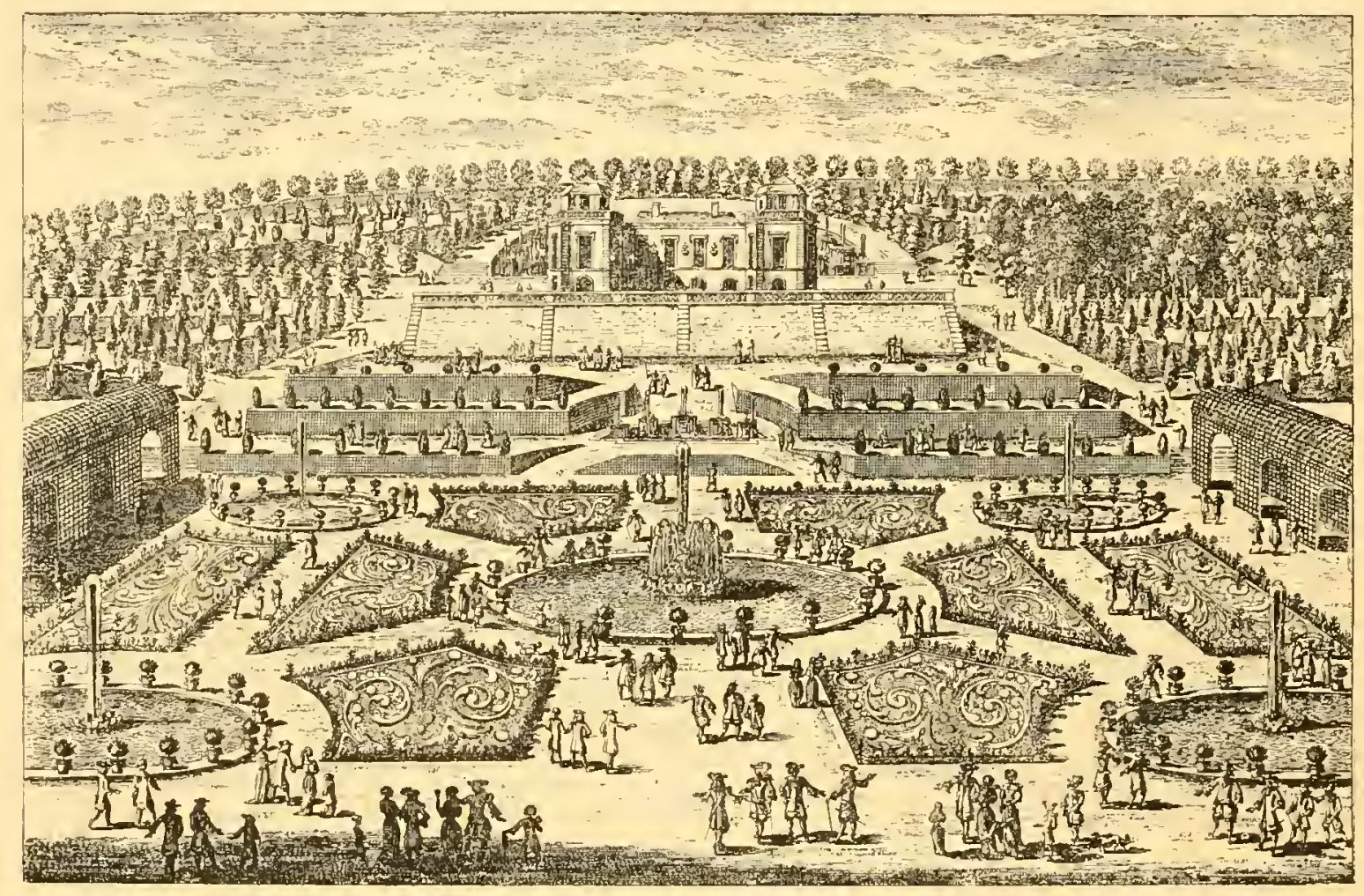

Fio. 431. - Trianon de Saint-Clond (dètruit), d'aprés Pérelle.

ridicule et mesquin. Les grandes allées droites nous paraissent insipides, les palissades froides et uniformes. Nous aimons i pratiquer des allées tortueuses, des parterres contournés, des bosquets découpés en pompons. Les corbeilles de flcurs, fanées au bout de quelques jours, ont pris la place des parterres durables; on voit partout des magots chinois, ctc. »

Jusqu'à la Révolution, il y eut des jardiniers conservateurs fanatiques, tenant le genre irrégulier comme non avenu. Dans le Jardinier-Flenriste, du sieur Liger, dont la derniére édition est de ${ }_{17} 87$, il n'est question que des arbres et arbustes susceptibles de former des areades, des colonnades, et autres tours de force. Voici, par 
exemple, comment il decrivait " une invention moderne, toute des plus curieuses, pour faire des ormes en boule, ne bornant pas la vue dans les endroits oú ils sont plantés. Pour parrenir à cette forme, on les plante la tige haute de quatre à six pieds; et à mesure qu'ils poussent, il faut, tous les ans, tondre les branches, de manière

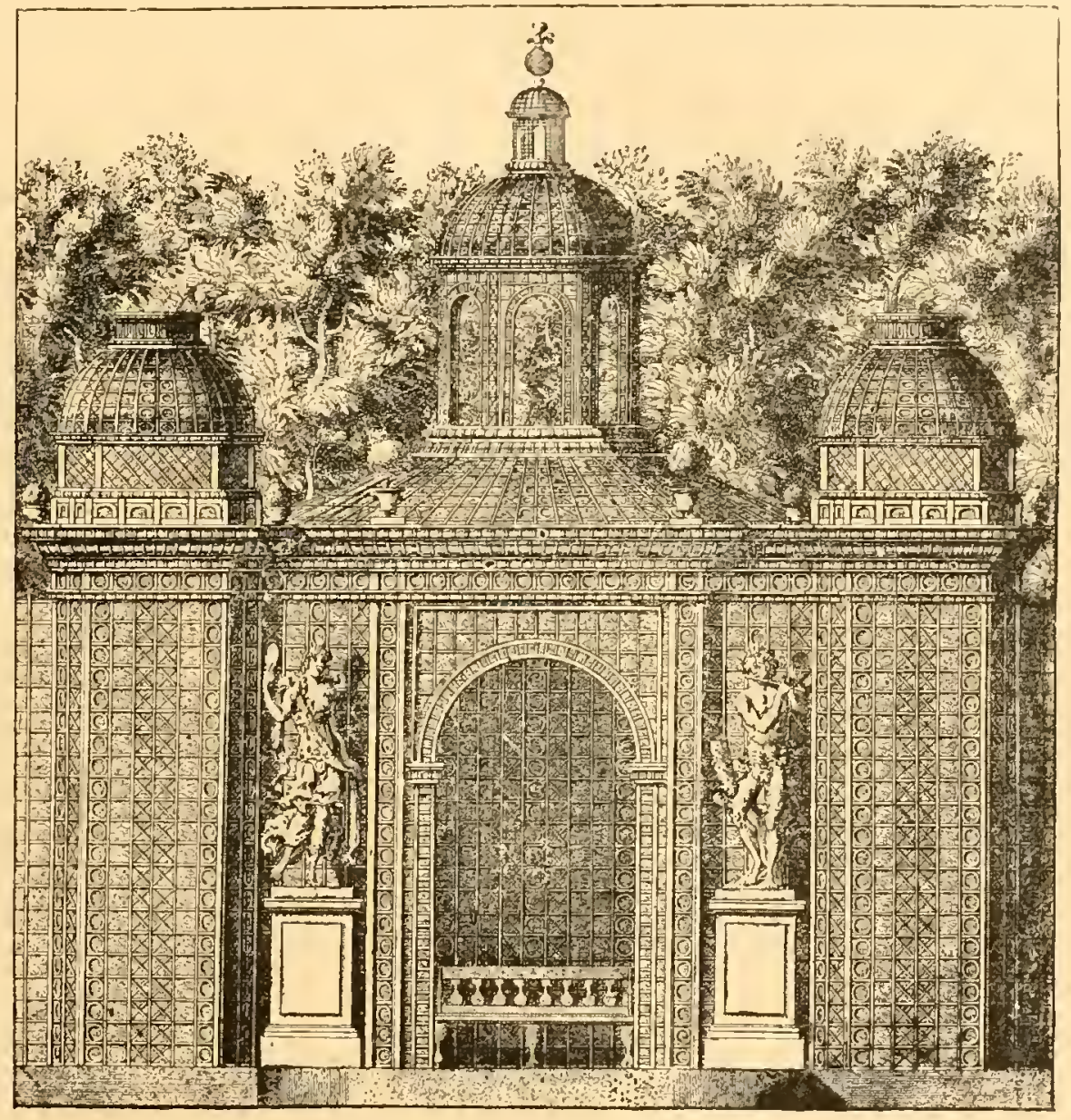

Fig. 432. - Berceau de Treillage au Labyrinthe de Versailles, par Pérelle.

qu'elles forment, à l'extrémité de chaque tige, une boule qui paraisse comme un globe de deux pieds et demi de diametre. Pour donner un plus grand relief à ces ormes, on plante tout autour un petit rond de charmille qui, lorsqu'il est construit artistement, forme une manière de pot sans anse, au milieu duquel l'orme est planté. » L'auteur affectionnait singuliẻrement ce genre de décoration, "fort propre à être employé soit en avenues, soit en quinconces, et chez tous ceux qui ont de quoi. »

Paris était déjá renommé au xvir siècle pour ses jardins publics ou quasi-publics, situés dans les faubourgs et même dans les parties centrales de la ville. Neus arons 
cité celui de des Yveteaux. D'autres étaient célébres par leurs treillages. Ceux du jardin de l'hôtel de Condé avaient un caractére monumental; on voit que « M. le prince le híros », comme l'appelle Saint-Simon, entendait faire grand en toutes choses. Dans d'autres jardins de celte époquc, conformément au précepte d'André Molet, on suppléait it l'insuffisance d'espace au moyen de perspectives peintes. Celle du jardin de Fieubet représentait les ruines d'un palais antique; celle du jardin de Dangeau, une futaie a la cime de laquelle apparaissait un groupe de fioures mythologiques arrivant de l'Olympe en visite (Fig. 433). Les plans des principaux jardins publics et quasi-

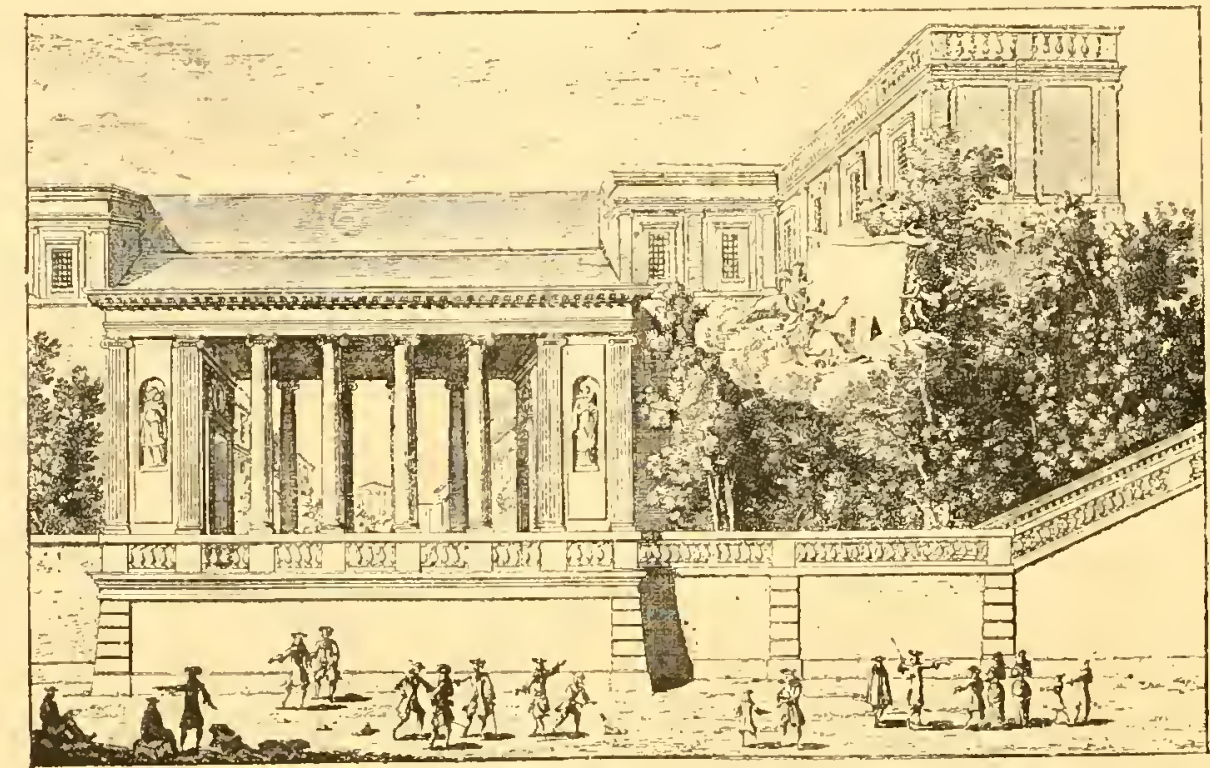

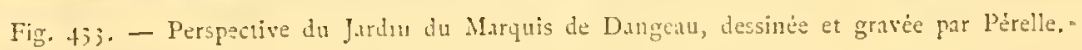

publics de Paris au siecle suivant, se trourent dians la curicuse collection de Le Rouge (I 776 I $\left.7 S_{4}\right)$. Le plus fréquenté était celui du PalaisRoyal, plus vaste et plus beau qu'alujourd'hui, car ses allées de marronniers sćculaires couvraient, en plus, tout l'espace aujourd'hui occupé par les constructions à arcades et la galerie vitrée qui a remplacé les fameuses galeries de bois. L'allée à la mode était celle de gauche, oú, dans l'aprés-midi, la bonne compagnie se réunissait, et revenait le soir à la sortie de l'Opéra. Le jardin de Biron (rue de Varennes) passait pour un type parfait du genre régulicr. On vantait son potager orné, ses tulipes, son « allée des Guirlandes », oủ les arbres étaient reliés par des festons de plantes grimpantes; - disposition toute nouvelle alors, mais en réalité renouvelée de Pline. Celui de Laboëssiére couvrait une grande partie de l'emplacement du quartier actuel de la Madeleine. Il était renommé par son élégant pavillon, du style rococo; pour ses bassins et ses statues, notamment les deux groupes représentant d'un côté Vénus et l'Amour, de l'autre Vénus et l'Hymen (Fig. 435)... L'une des planches les plus 
intéressantes est le théâtre de verdure du jardin de Hanovre (hôtel de Richclieu) (1), avec sa rampe et ses coulisses en charmilles, et ses ifs symétriquement espacés et taillés; le tout scrupulcusement conforme aux méthodes classiques. Les jardins du maréchal étaient aussi régulicrs que ses mours l'étaient peu. - Parmi les jardins du nouveau style, dejia ouverts ou entr'ouverts au public dans l'intérieur de Paris, l'un des plus originaux était celui d'Espagnac, dont nous arons parlé ailleurs.

D'iutres plinches de la collec-

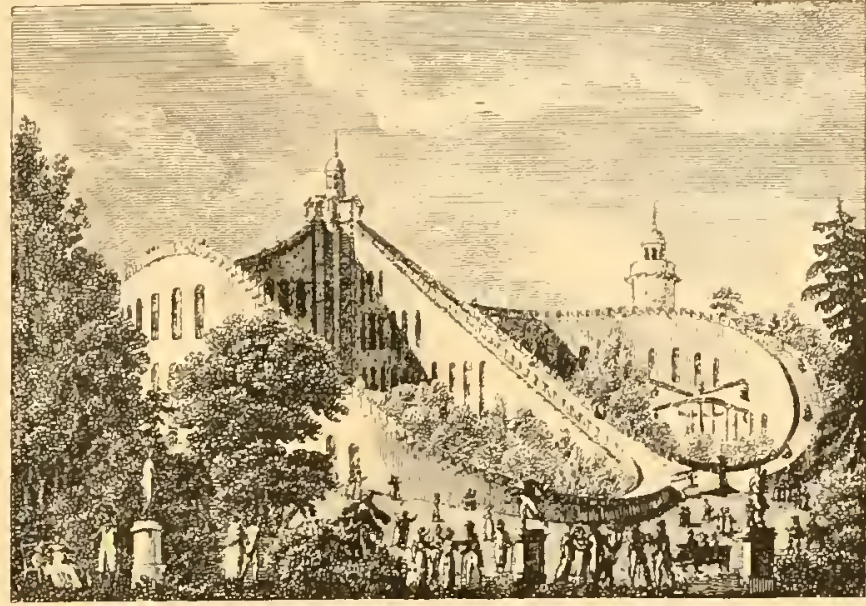

Fig. 434. - Montagnes russes dans le Jardin Beaujon, en 1800. tion Le Rouge nous montrent, dans leur ancien état, le parc de Monceaux ct toutes les Folies qui cn avaient fait faire et vu faire tant d'autres, et qu'allait détruire, trans-

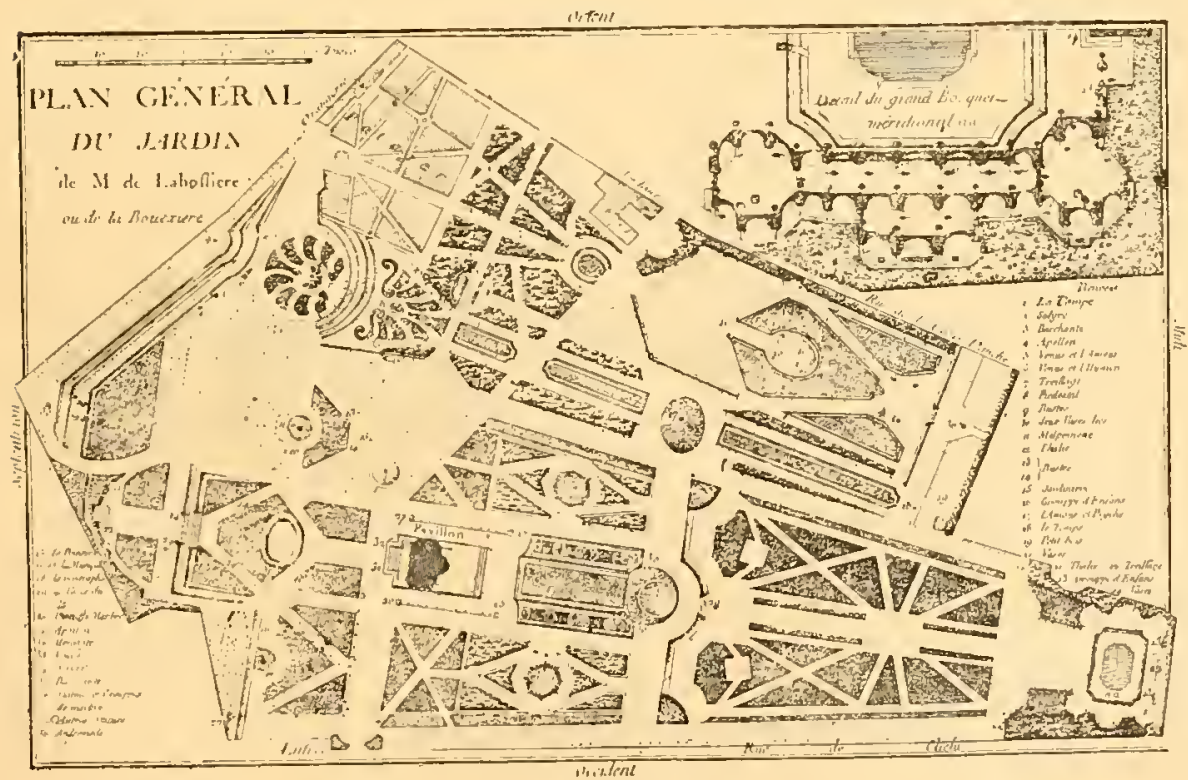

Fig. 435. - l'are de Laboëssière, à Paris.

former ou déformer la Révolution aux environs du Paris de ce tempslà, absorbés dans lc Paris actuel : Folics d'Artois (Bagatelle); Boutin (premier Tivoli); Marbcuf (Idalie); Beaujon; Pajot (Reuilly); Janseen (Porte Maillot). Bagatelle surtout justifiait surabondamment son surnom de Folie. " I.c comte d'Artois, pour donner une fête à la reinc (d'autres disent pour gragner le pari d'ilvoir tout terminé, construction et prantation, dans l'espace d'un mois), fit démolir, rebâtir, arranger et meubler Bagatelle de fond en comble par neuf cents ouvriers

(1) Il n'en reste que le pavillon de ee nom, sur le boulevard, au coin de la rue Louis-le-Grand. 
cmployés jour et nuit; ct, comme le temps manquait pour aller chercher au loin la chaux, le plittre et la pierre de taille, il envoya sur les grands chemins des patrouilles de la garde suisse qui saisissaient, payaient, amenaient sur-le-champ les chariots ainsi chargés. » En mêne temps, un jardinier anglais, Blaikic, ćleve de Kent, remaniait de fond en comble la plus grande partie du pare dans le style á la mode, avee un Tombeal de Plaraon, une Tour du Paldalin, et une grotte, demeure du philosophe obligé. Ainsi fut faite et parfaite, il y a un sicele, cette Folie, qui survićcut à tant de choses séricuses (Fig. I 36, page i 14).

Le jardin du cbovalier Janseen offrait lin essai de compromis entre les deux genres. La majeure partic était plintée régulierement en quinconces, avee des allées torlucuses, mais circulant entre des palissades de charmilles, et dommant accés à des cabinets de verdure ornés de vases ou de statues, parmi lesquelles la Vénus Anadyoméne et l'aulre Vénus n'itaient pas oublices. De plus, tout un coin du pare avait été réservé pour les amatcurs intransigeants de la nature abandonnće à clle-même. Au milieu d'un fourré simulant une forêt vicrge, s'élevait une butte dont le sommet était occupé par des chérres et des boues sous la garde d'une bergère; et le dessous, formant grotte, par un soi-disant crmite. La cabane de la bergére et l'crmitage se trouvaient ainsi fort rapprochés, ct cette disposition, indiquée sur le plan, semblait calculéc pour inspirer aux visitcurs des réflexions folâtres.

Pendant lit Révolution, la plupart de ces beaux jardins particuliers, confisqués et vendus comme propriétés nationales, furent ou détruits, ou transformés en jardins publics par des entrepreneurs de plaisirs, qui se firent une concurrence effrénée d'illuminations, de tours de foree pyrotechniques, d'ascensions en ballon, de jeux et amusements de toute espéce. Telle fut la nouvelle destination du jardin des Biron, des Folies Beaujon (Figr. 434), Boutin (ancien Tịoli), Marbeuf (Iclalic), Laboëssiére (Fig. 435) (nouveau Tivoli), de Monceau, de Bagatelle, de l'Élysée-Bourbon. Nous n'avons pas à raconter ici ces métamorphoses, qui n'avaient rien de commun avec l'art des jardins (I). Nous nous bornerons à rappeler que pendant la première moitié du $\mathrm{x} w \mathrm{x}^{\mathrm{e}}$ siècle, le nombre et l'importance des jardins publics, anciens et nouveaux, cessé-

(1) "Biron eut un instant la vogue, mais ne la garda pas. Son jardin était coupable d'être un jardin français et de n"avoir ni pont, ni torrent, ni bosquet en façon de forêt vierge. "Tous ces avantages se trouvaient réunis dans quarante arpents du jardin Boutin (premier Tivoli). Aussi celui-li fit longtemps les plus belles recettes, et sa direction fut disputéc comme un empire. ( $l$. E. et J. de Goncourt, Hisloire de la Socith Jratsaise sous le Diritoiri, ch. VI.) 


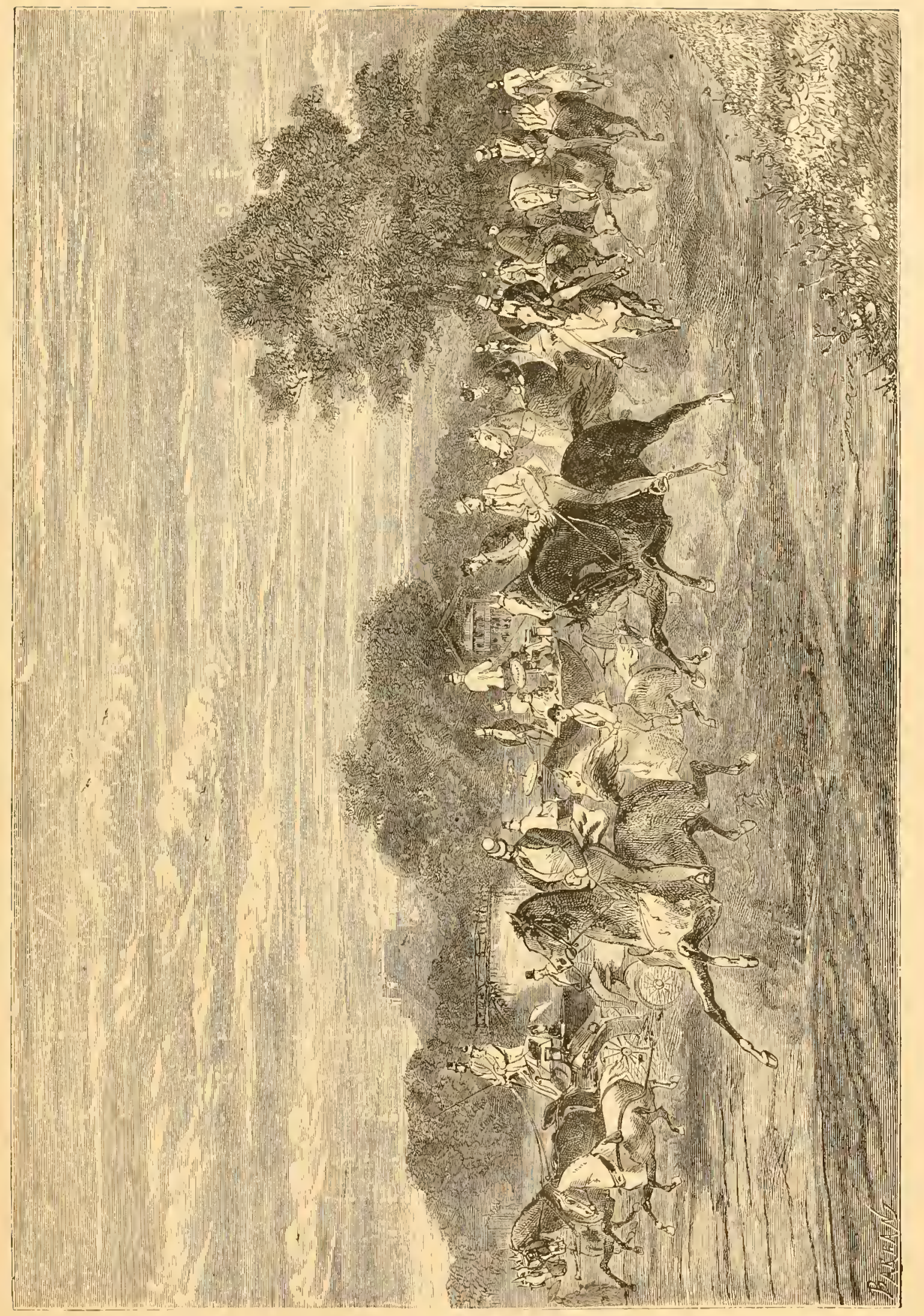


rent peu à peu d'être en rapport avec l'accroissement de la population. A partir de $S_{2}$;, cette disproportion augmenta d'une maniére sensiblement préjudiciable, non seulement à l'agrément, mais à la santé des habitants. On vit en peu d'annćes les constructions nourelles, marée montante sans reflux, envalir successivement l'ancien et le nouveau Tivoli, Marbeuf, Beaujon, une paric des Champs-Élysćes.

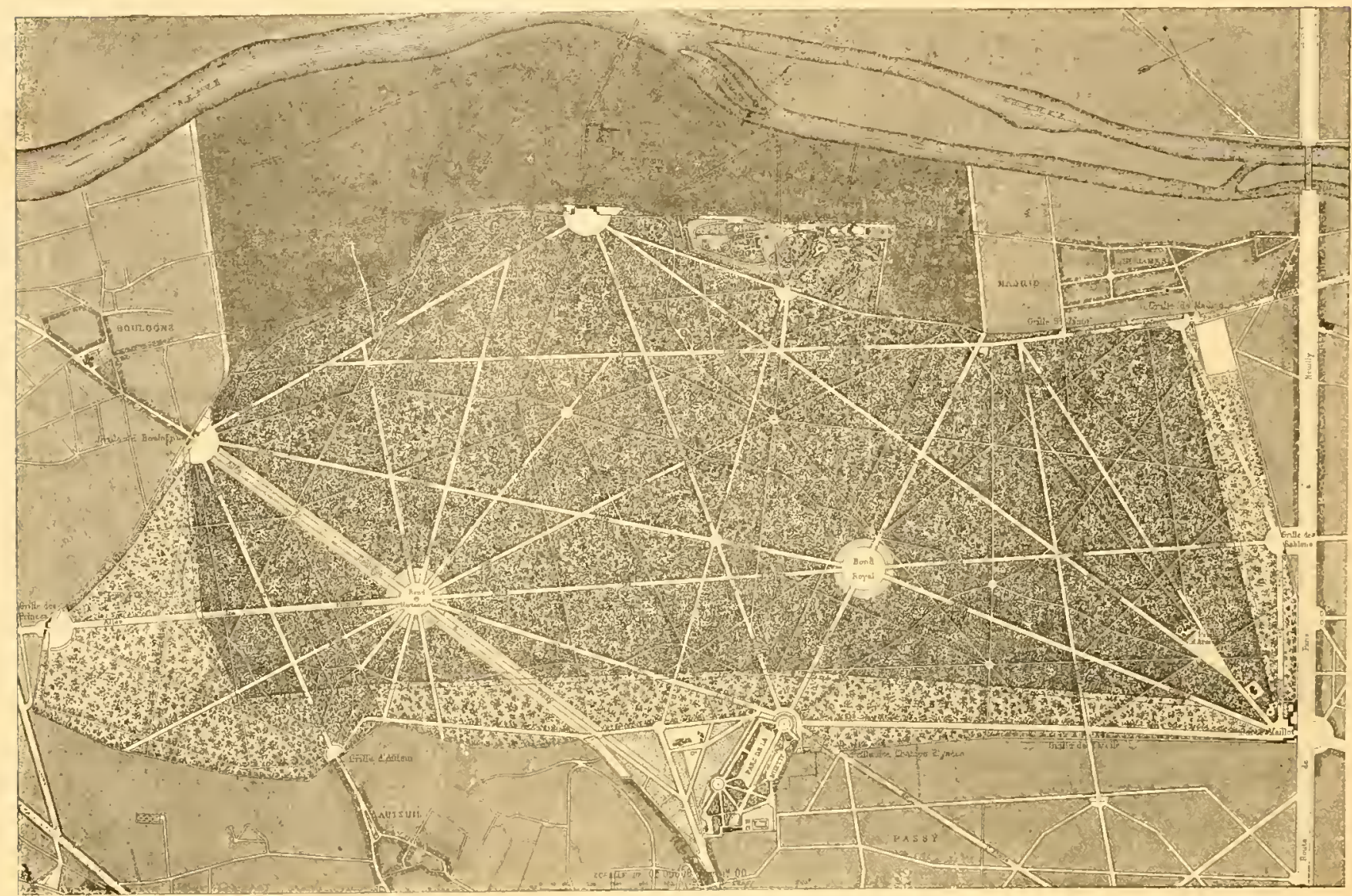

Fig. 437. - Etat nncien du Bois de Boulogne.

Restaient, il est rrai, les bois de Boulogne et de Vincennes; mais ces deux pronenades étaient indignes de Paris, et bien inférienues à celles de Londres (1).

De nos jours, Paris a repris l'avantage, grâce à la transformation de ces deus bois et des Champs-Élysées, à la création des parcs des buttes Chaumont, de Montsouris, à celle des nombreux squares qui ont embelli et assaini la ville.

II. - Promenades modernes de Paris. - Bois de Boulogne.

(1) Th. Gautier écrivait, au retour d'une excursion à Londres (18.0) : "ll serait bien à désirer que l'usage des squares se propageât a Paris, où les maisons tendent à se rapprocher de plus en plus, et d'où la végétation et la verdure funiront par disparaître complètement، » 
(Fig. 436 a 439). - Ce fut, comme on le sait, le pélerinage mondain de Longchamps qui fit la fortune du bois de Boulogne. Aprés aroir été dévasté par la Rérolution et plus cruellement encore par l'invasion étrangère, il était redevenu ì la mode depuis is 30 ,

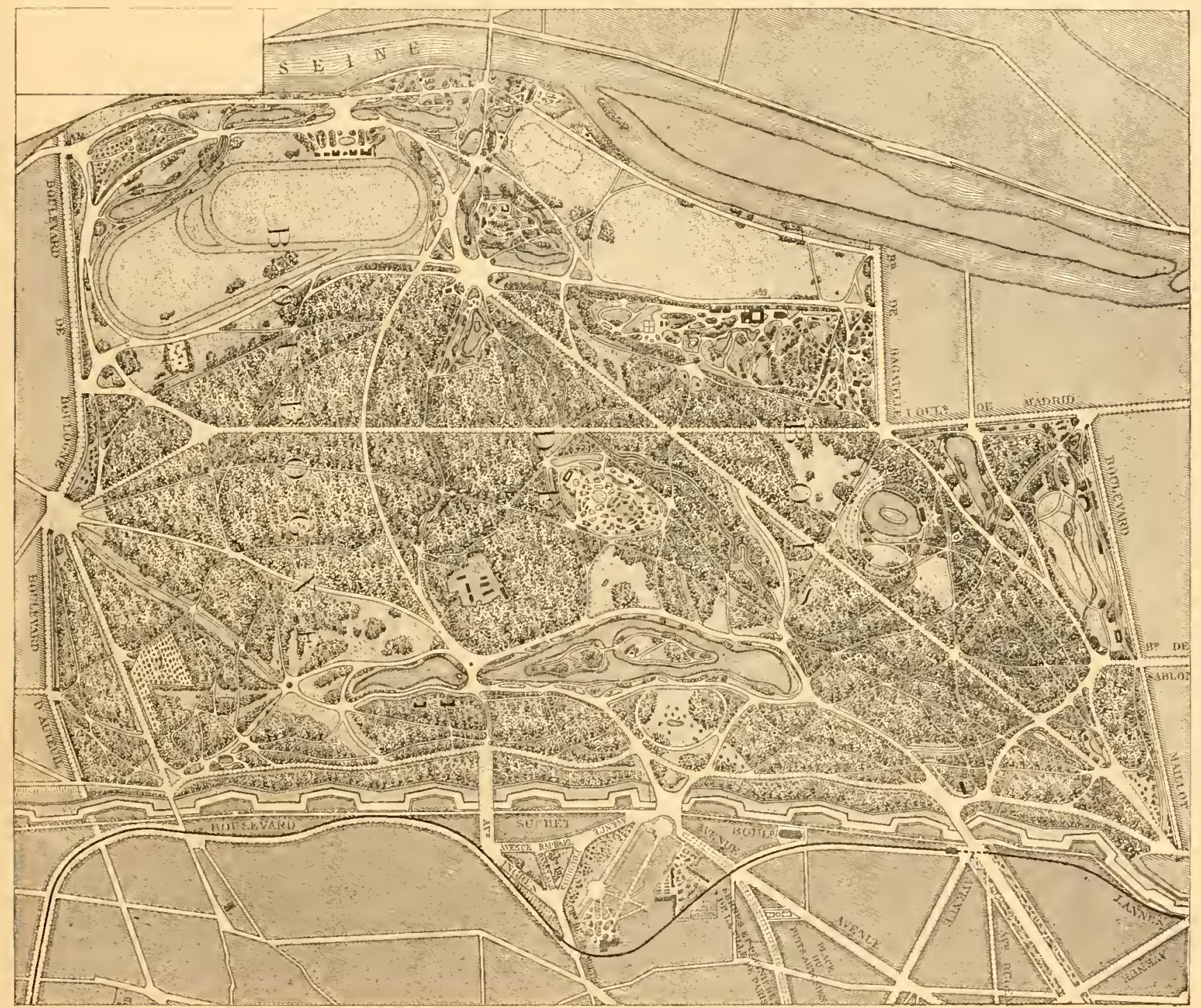

Fig. 438. - Le Bois de Boulogne, état actuel.

mais ne méritait guère cet honneur. Le sol porte des traces visibles du séjour de la mer; il cst composí de sables siliceux mélangés de galets. Sauf dans certaines parties oú le sous-sol argileux se rapproche darantage de la surface, ce terrain ne produisait guère que des arbres médiocres. Dans son ancien état, le bois de Boulogne avait tous les défauts du genre régulier sans ses qualités. Sa métamorphose 
en un vaste jardin paysager dont la superficic a été portie de 676 à 873 hectares, préscntait des difficultés considérables. Nous nous bornerons a signaler ici les renseignements pratiques que fournit ce travail aux artistes et aux amateurs.

D'abord, la comparaison du plan de l'ancien état avee l'état actuel (Fig. 437 et 438 ) leur donnera d'excellentes indications, s'il s'agit d'une entreprise analogue, dans

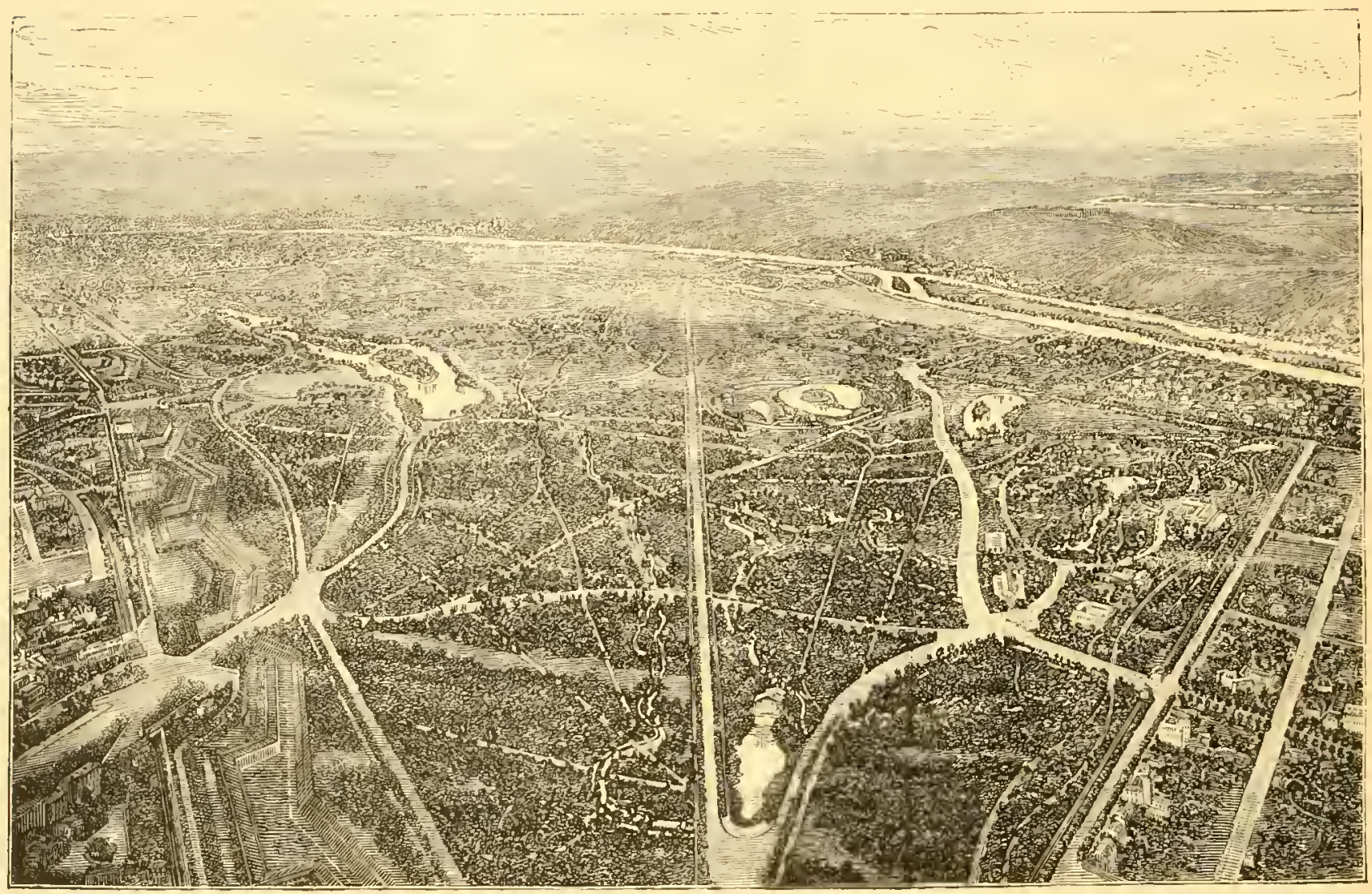

Fig. 439. - The a vol d'Oiseau du Bois de Boulogne. Daprés une Aquarelle de MlM. Hocherciu ct Didjer.

des proportions même beaucoup plus restreintes, c'est-i-dire de la transformation d'un bois ordinaire, sillonné d'allées droites, en jardin paysager. Ils verront comment on est arrivé à faire disparaîte toute trace de l'état antéricur, en fermant, au moyen de plantations d'arbres et d'arbustes forestiers, les allées droites supprimées, en isolant et mettant en rue les quelques beaux arbres perdus dans les fourrés, en rompant les lignes droites des pelouses par des plantations ajoutées sur les lisières; par la distribution de massifs, de groupes d'arbres, variés de port et de feuillage.

Nous retrouvons l'application de l'un des préceptes les plus essentiels de l'art 
des jardins paysagers dans la création de la Butte Mortemart, formée des déblais provenant du creusement des lacs. Bien que cette íminence artificielle n'ait rien d'alpestre, son ascension mérite d'être recommandéc (Toir page ij f, fig. I6 3 ). On y jouit de l'ensemble du bois, et de jolis points de rue sur les hauteurs qui dominent Paris de ce côté.

Pour les nouvelles avenues, on a employé surtout le marronnier, qui réussit facilement dans les plus médiocres terrians. Cet arbre offrait de plus l'avantage local d'être en pleine floraison à l'époque oú le bois de Boulogne est le plus fréquenté. La plantation de chaque à 16 fr. 50 c. Ce prix 11 'il ville de Paris, aguerric a pourrait effrayer bien des des particuliers. Done, il dans ce total figure, pour deux metres de terre végéqui peut être supprimé ou leurs. On pourra aussi se Tutcur (Fig. 440), et n'cmnicux que pour des sujets

L'ailante (Vernis du que le marronnier pour des affectionne également les

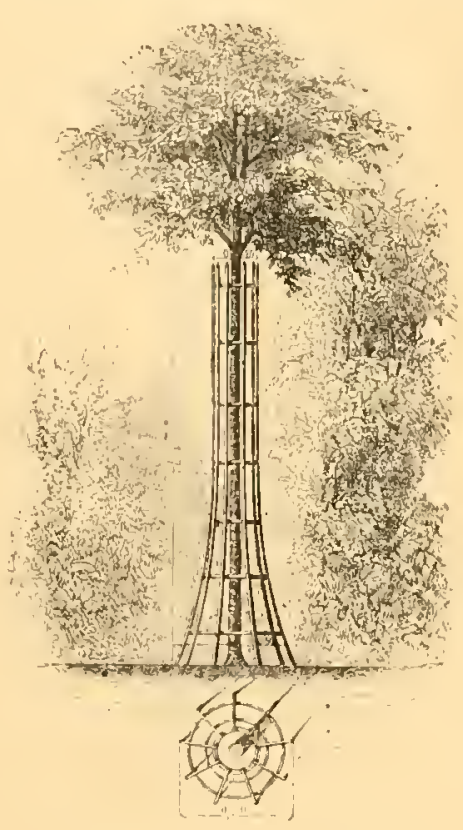

Fig. 440. - Corset Tuteur. tige dejja forte est revenue rien d'exorbitant pour la de tels assauts; mais il villes de province et bien importe de remarquer que chaque arbre, un apport de tale au prix de 5 fr.; apport considérablement réduit aildispenser sourent du Corsetployer cet appareil ingéexceptionnels. Japon) convient alussi bien plantations de ce genre. Il mauvais terrains; ses pousses nouvelles, jaunes et rouges, sont d'un tre's bel effet. Elles ont de plus un avantage encore peu connu; celui de distiller une substance sucrce, qui attire et empoisonne les hannetons.

Dans les plantations foresticres proprement dites, qui ne demandaient pas de soins particuliers, on s'est contenté de défoncer le sol à jo centimétres de profondeur maxima, et d'y planter des tiges de 8 à is centimetres de circonférence, dans la proportion de 54 par are. Sur les points oú l'on tenait à obtenir immédiatement des fourrés, on a ajouté iso touffęs par are. Ces proportions devront également être réduites dans des sols plus riches.

Pour l'exécution des massifs composés d'arbres et d'arbustes de choix, le terrain a été défoncé de so à So centimètres de profondeur, suivant la nature des essences 
cmployies; et fortement bombé, de manicre à donner à l'ensemble de la plantation une forme pyramidale; - cn plaçant au centre les arbres les plus hauts et les plus forts; puis ceux de moyenne grandeur; et enfin les arbustes, étagés aussi parr rang de taille. Ce système est critiqué par quelques artistes modernes, qui prétendent quil donne aux massifs l'aspect de fortifications. C'est pourtant celui qui, dans la pratique, permet le mieux aux arbres et aux aibustes de croitre les uns auprés des autres sans se nuire. Dans ce renouvellement de la plus fréquentée des grandes promenades de Paris, on a scrupuleusement respecté les souvenirs historiques qu'elle renfermait; la croix Catelan (Fig. 245), l'allée dite de la Reine Marguterile; le moulin de Longchamps (Fig. I52), auquel on a restitué sa physionomie d'autrefois; le "Rond des Chênes », près de la mare d'Auteuil.

Le détail des plantations du bois de Boulogne, faites dans des conditions difficiles, est, pour cettc raison même, plus particuliérement instructif. Parmi les arbres forts, plantés d'abord à l'entreprise dans les parties sablonneuses, un tiers de ceux il feuilles caduques et les deux tiers des coniféres avaient péri. Dans les parties basses (terrains d'alluvion), les arbres à feuilles caduques ont seuls réussi. Un beau massif de cedres et de pins laryx, placé dans un endroit des plus apparents, à l'entrée de la route de Passy, dépérissait á cause de la mauvaise nature du sol, composé de sable et d'une argile noire compacte. Cette plantation n'a prospéré que depuis l'époque oú le terrain a subi l'opération du drainage. Ce rapprochement de la sombre verdure et du port rigide des cédres du Liban avee la teinte plus claire et l'attitude ondoyante du pin laryx est d'un joli effet. Toutefois, dans des climats plus froids, il sera prudent de remplacer les laricios par des essences plus rustiques.

Pour la décoration des pieces d'eau, la conduite des ruisseaux, la disposition des gués, des ponts, etc., on pourra s'inspirer de l'arrangement de la mare aux Biches, aujourd'hui permanente, de celles d'Auteuil et d'Armenonville, des méandres du ruisseau de Longchamp. On a peine i comprendre le reproche adressé naguère aux autcurs de cette transtormation "d'avoir retranché a la 'nature quelques-uns de ses charmes! „Qu'avait done de si naturel et de si charmant un bois presque partout chétif, sillonné d'allées droites mąl entretenues?

Avant de quitter le bois de Boulogne, nous devons encore mentionner le Pré-Catelan (Fig. 309), ainsi que le Jardin zoologique d'acclimatation, établissement spécial créé de I858 il $186 \mathrm{I}$, et qui occupe dins la partie nord du bois, entre la porte 
des Sablons et celle de Neuilly, une surface d'environ 20 hectares. Ce jardin (Fig. 441) a été dessinć par Barillet-Deschamps. Sa forme générale, parfaitement appropriée à sa destination, est celle d'un vallon à pentes douces, dont le centre est occupé par un cours d'cau qui, sur plusieurs points de son parcours, s'élargit en bassins et aboutit à un petit lac d'une forme gracieuse (Fig. 2 I 4 ). Toutefois, des constructions multiplices ont enlevé á ce jardin, dans ees derniers temps, beaucoup de son caractére.

Nous n'avons pas à nous occuper ici des établissements zoologiques, ni de l'Aquarium, mais seulement de la plantation et de l'aleclimatation des végétaux. Cut

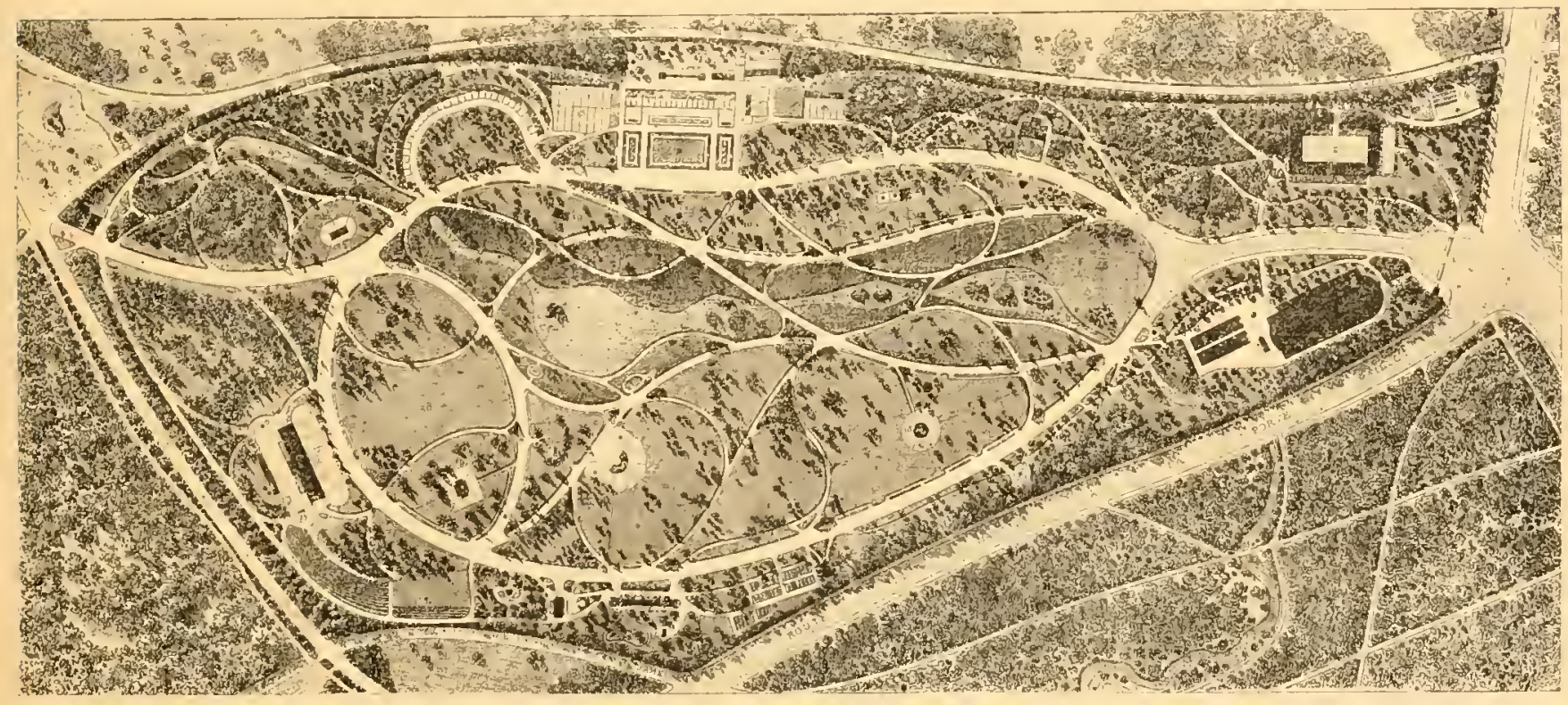

Fig. 4l: - Plan du Jardin d'Acclimatation au Bois de Boulogne.

cmplaccment avait été pris dans la partic la plus ingrate du bois. Aussi, ce n'est qu'ä force de fumures qu'on a obtenu des pelouses et des arbres d'une beauté cxicpionnelle. L' Arborchm conticnt la plupart des arbres et arbustes exotiques, it teuilles ciduques ou persistantes, qui peuvent prospérer sous notre climat. Plusieurs, des plus remulrquables, itaient cncore trús rares, et les expériences faites dans cet Arborclum ont beaucoup contribué à faire connaître leur mérite ornemental, et ì en accréditer l'emploi (I).

(1) Comme le C. Lanusoniana, dont l'introduction en Europe ne renonte qu’i i 8; j. - Ce jurdin contient de plus un terrain d'expíriences consacrí à l'essai des graines et végétaux nouvellement importés. C'est lia aussi qu'on a transplanté la belle collection de vignes qui se trouvait dans l'ancienne pépinière du Luxembotirg (ci-derant enclos ou spaciment des Chartreux), en contre-bas de l'alléc de l'Obscrvatoire; - pépinićre qui formait, depuis 1849 , unc promenade unique en son genre, détruite eil 1866 . - Nous àons parlé précédenument de la serre monumentale du Jardin d'Acelimatation. 


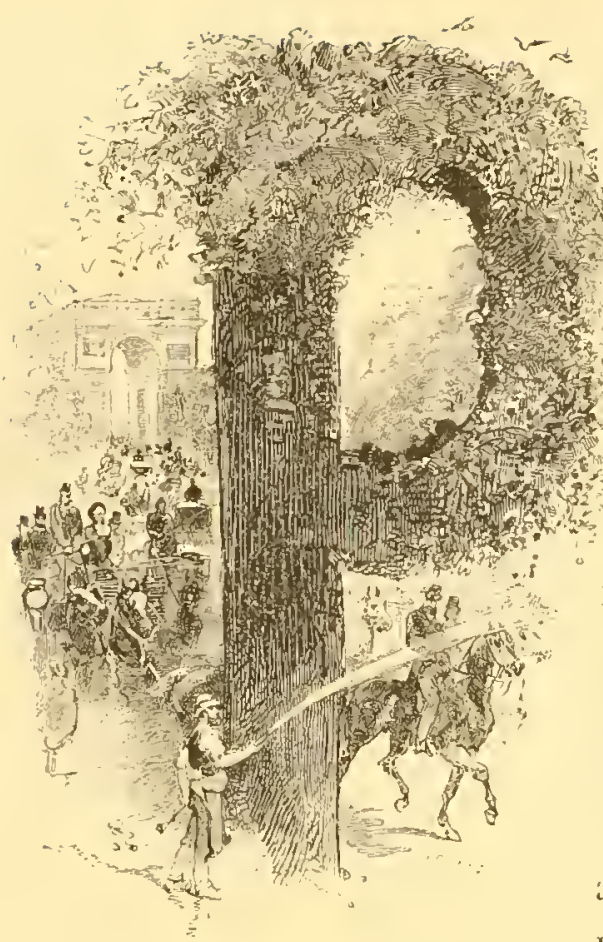

ROMENADES modernes de Paris. Bois de Vincennes, Parcs des ButtesChaumont et Montsouris. - Le bois de Vincennes a subi une métamorphose analogue a celle du bois de Boulogne. Mais il offrait des ressources naturelles qui ont permis de lui conserver un caractère d'ensemble plus forestier. Le terrain y est meilleur, ct les beaux arbres plus nombreux.

Les partics de cette promenade (Fig. 443 à 445) qui méritent particuliérement l'attention des amateurs, sont : a l'est, les Minimes; il l'ouest, le lac de Saint-Mandé, celui de Charenton et ses abords.

D a n s

l'ancien enclos des Minimes, dont une partic a été convertie en lac, on a scrupulcusement conservé (Fig. 201) les beaux arbres isolés, la vieille avenue do tilleuls (Fig. 4t3), l'allce circulaire qui servait de spuciment aux religieux, et que sa forme permettait de raccorder facilement aux nouvelles allées irrégulières. Enfin l'on s'est attaché a imiter le mieux possible la nature, dans l'arrangement de la cascade (Voir ci-dessus, Fig. 217), et de sa décoration végétale. A une autre extrémité, le petit lac de Saint-Mandé occupe unc dépression de terrain oú coulait naguere un égout dont les exhatlaisons écartaient les promeneurs de

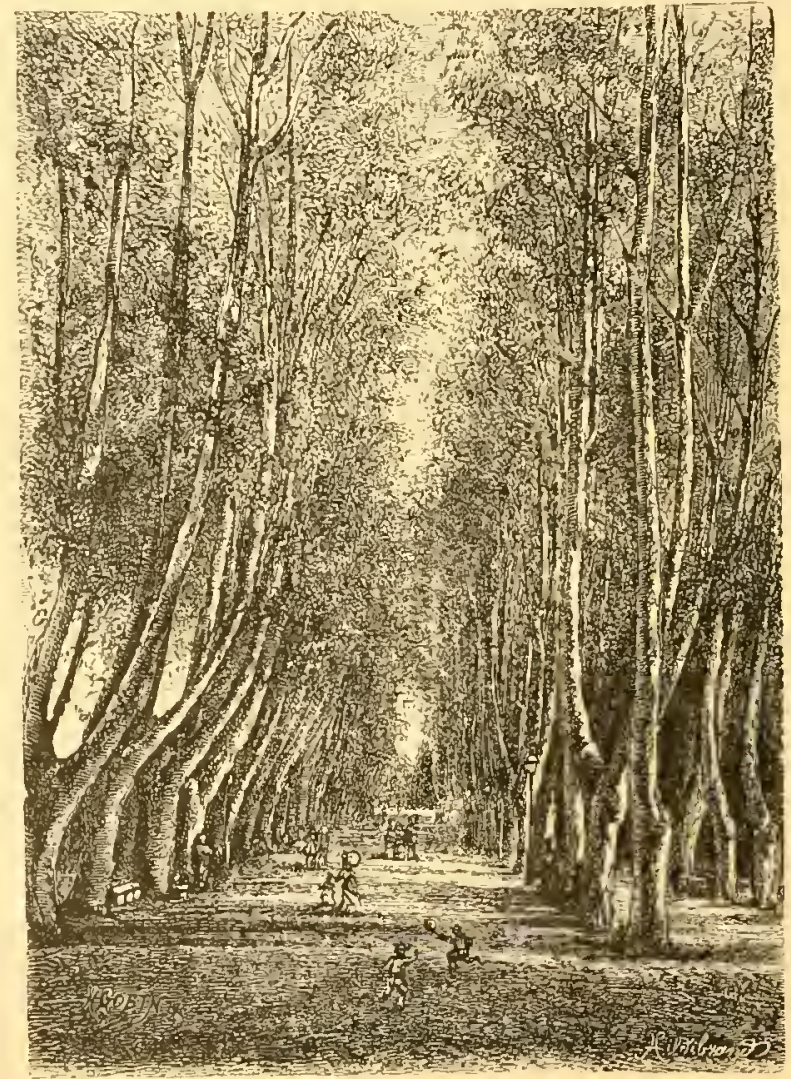

Fig. 413. - Avenue de Tilleuis. cette partie du bois, précisement l'une des plus belles. - L'organisation des terrains nouvellement amnexés, entre Charenton et Saint-Mandé, est une ceuvre 


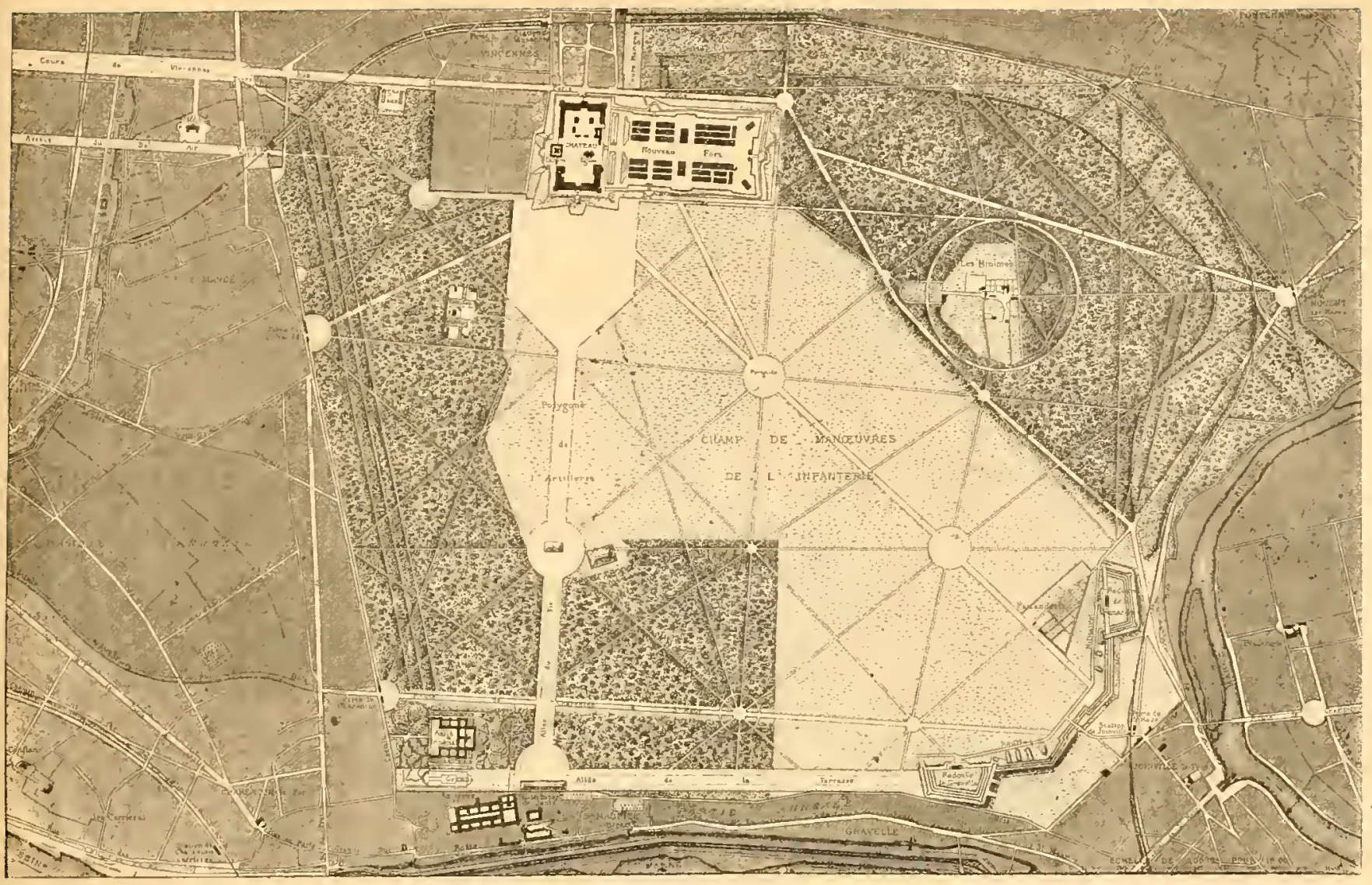

Fig. 4t4. - Bois de Vincenues, - Ftat ancen,

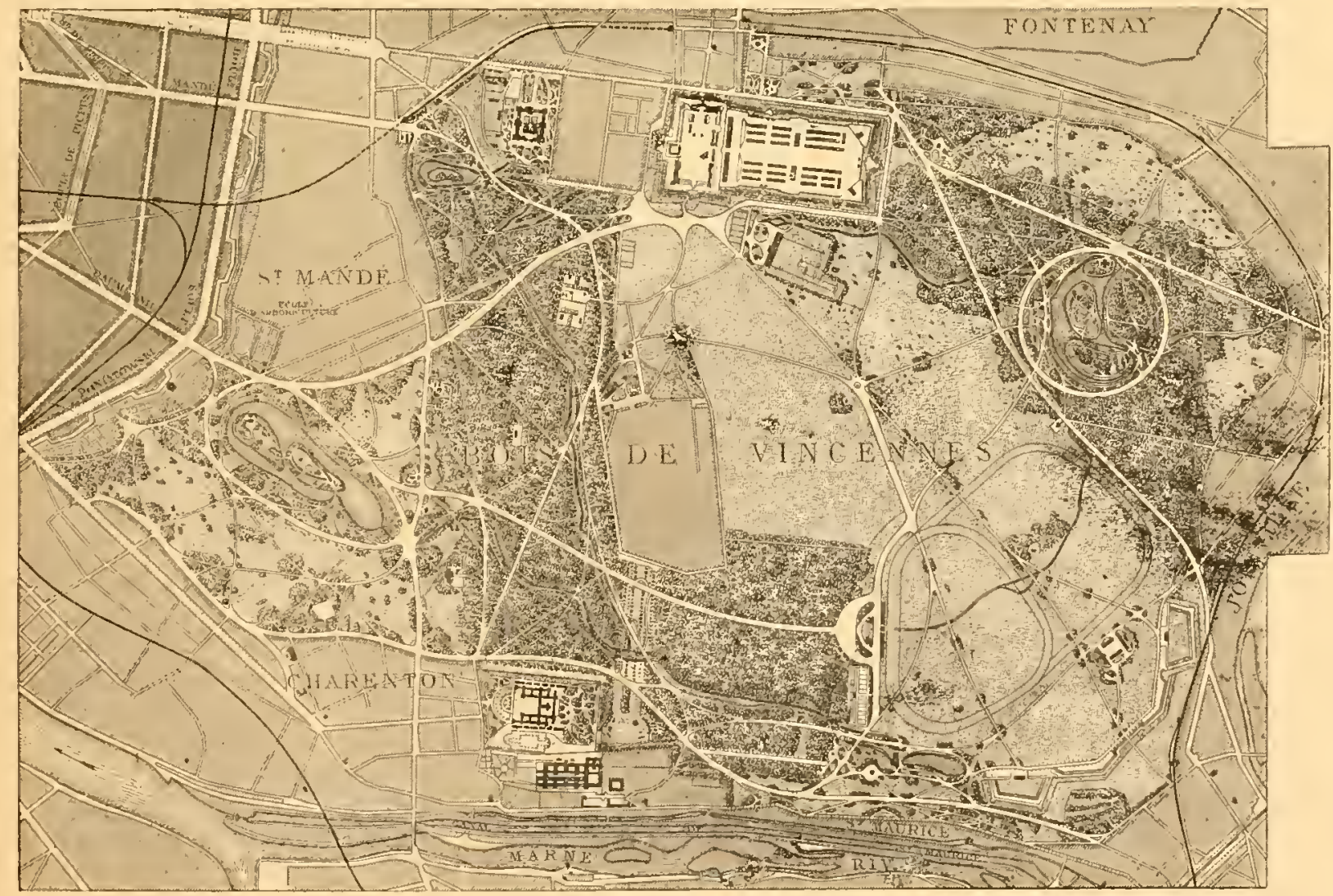

Fig 415. - Bois de Vincennes. - Etat actuel. 
absolument nourelle. Elle forme un jardin paysiger it pirt, soigneusement relic d'ailleurs aux massifs foresticrs. Il comprend le grand lac dit de Charenton, ses deux iles, les pelouses ct les plantations adjacentes. En comparant ees îles avec celles du bois de Boulogne, on voit comment il est possible d'éviter les répétitions, nonobstant certains traits généraux de ressemblance, et l'obtenir des effets differents, par des

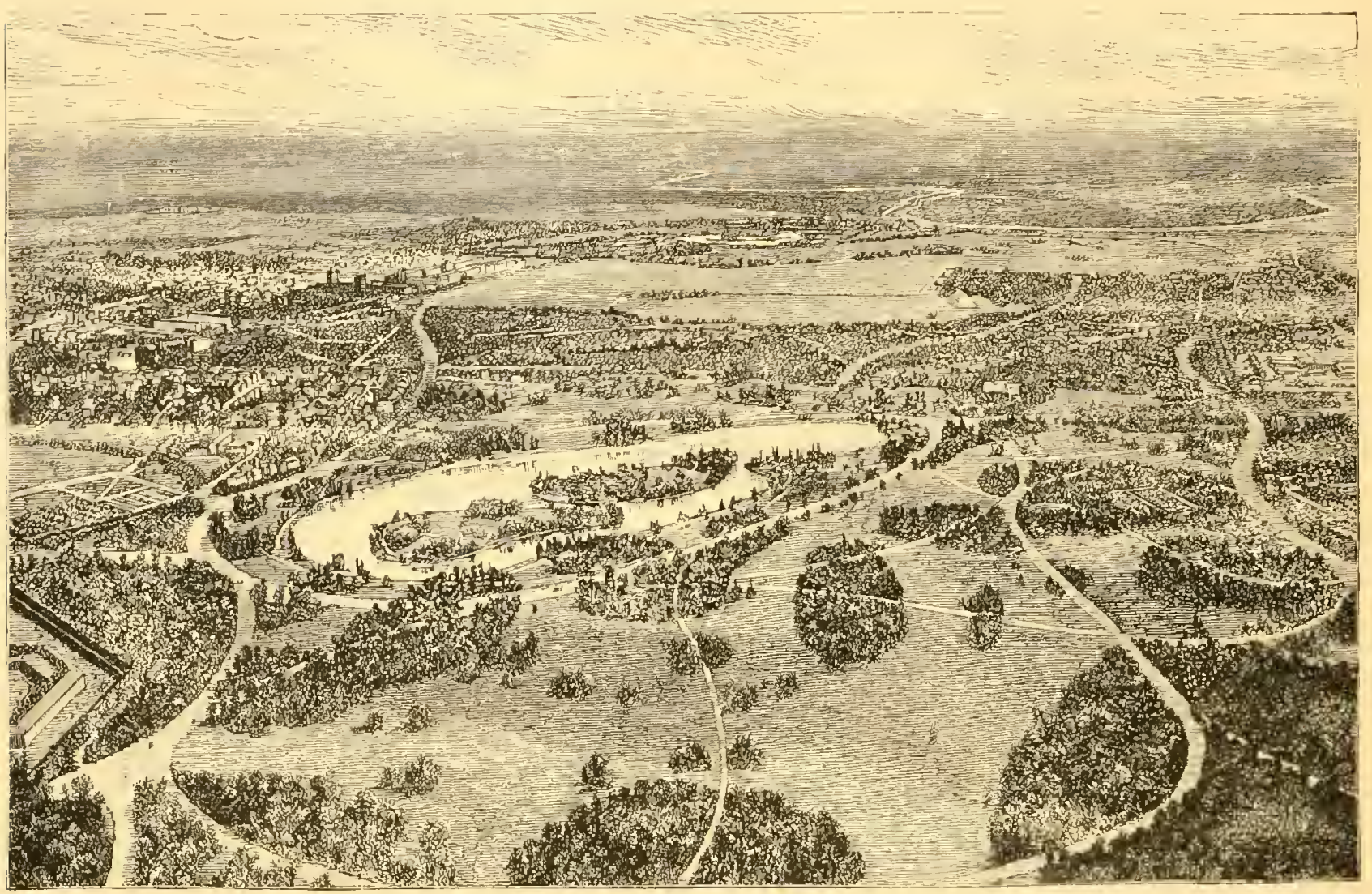

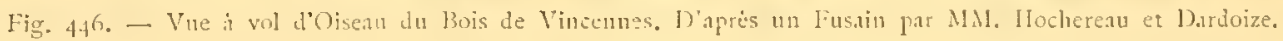

variantes dans lin disposition des édicules, des ponts, dans la forme des bords et la plantation. - Enfin, le bois de Vincennes a aussi sa butte (le plateau de Gravelle); mais la vue dont on y jouit sur Paris et les environs est incomparablement plus belle que celle de la butte Mortemart. Entre les deux grandes promenades parisicnnes, bien des amateurs donnent la préférence à celle de Vineennes, malgré son éloignement des quartiers aristocratiques, et l'énorme solution de continuité résultant du champ de manourres, qui l'a littéralement coupée en deux.

On sait que le parc des Buttes-Chaumont occupe l'emplacement du gibet lígendaire de Montaucon, de sa voirie, et des carrières à plàtre voisines, jadis 
le repaire farori des pires bohémes parisiens. On a eu l'idée d'utiliser la superficie profondément accidentée de ces lieux où tout était repoussant ou sinistre, en y établissant une promenade pittoresque (Fig. 447). Il ne manquait pour cela que de l'eau, de la terre végétale, des plantations et des chemins. Aussi les travaux, entrepris au commencement de 1864 et termines en I869, oni coûté, sur unce étenduc de 23 hectares, 3,4I2,000 francs (chiffres ronds), dont $2,936,000$ francs pour les terrassements et les plantations. La portion du terrain qui a exigé les travaux les plus considérables, est celle où se trouvaient lés carrières

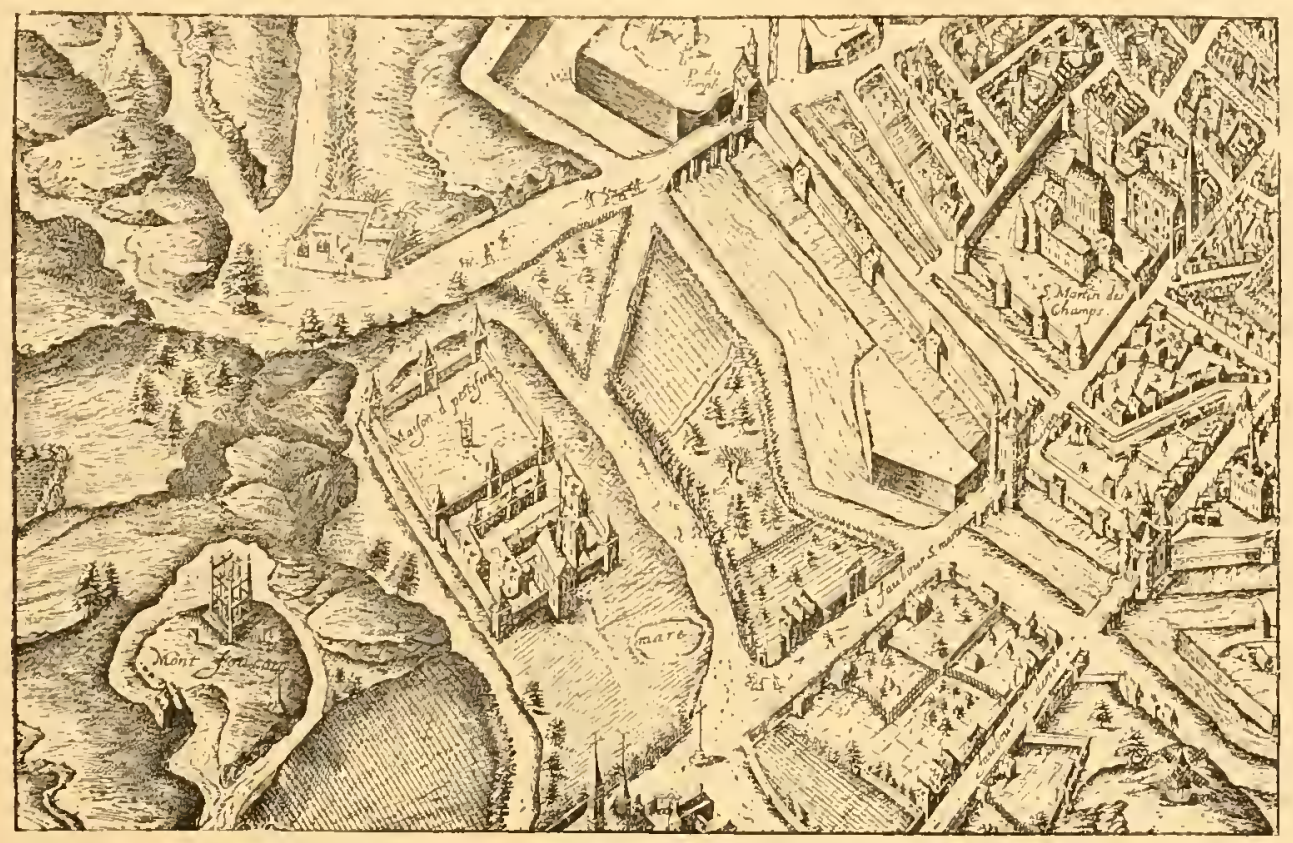

Fig. 447. - Le Gibet de Montfaucon, d'aprés le Plan de Vassalieu (I607).

et la tranchée du chemin de fer de ceinture. La ligne des falaises était heureusement mouvementéc par un grand promontoire, surplombant les terrains inférieurs anciennement exploités. On a détaché ce promontoire de la masse, de manière à en faire un îlot rocheux relié à la partie supérieure du pare par un pont en maçonnerie, et dont la base est baignée par un lac. L'extrémité de cette ile, faisant saillie sur le lac, a été exhausséc et consolidée au moyen d'un revêtement en maçonnerie imitant les rochers de la base, et c'est sur ce point culminant qu'a été ćrigé le Tomple de la Sibylle, dont nous avons parlé ailleurs.

Le lac est alimenté par deux ruisseaux qui parcourent les deux vallons du parc. Ils provicnnent d'une prise d'eau du canal de l'Ourcq, refoulée par une machine spéciale 
dans un réservoir installé sur le boulevard qui domine le parr. L'un des ruisseaux, sortant de la base du mur de sonténement du boulcrard, forme une cascade de 32 mètres d'élévation, qui se précipine dans une vaste grotte ornée de stalactites artificielles : c'est vraiment la reine des cascades purisiennes. Grâce au relief exceptionnel du sol, on a pu faire lá du praysage de montagnes grand comme

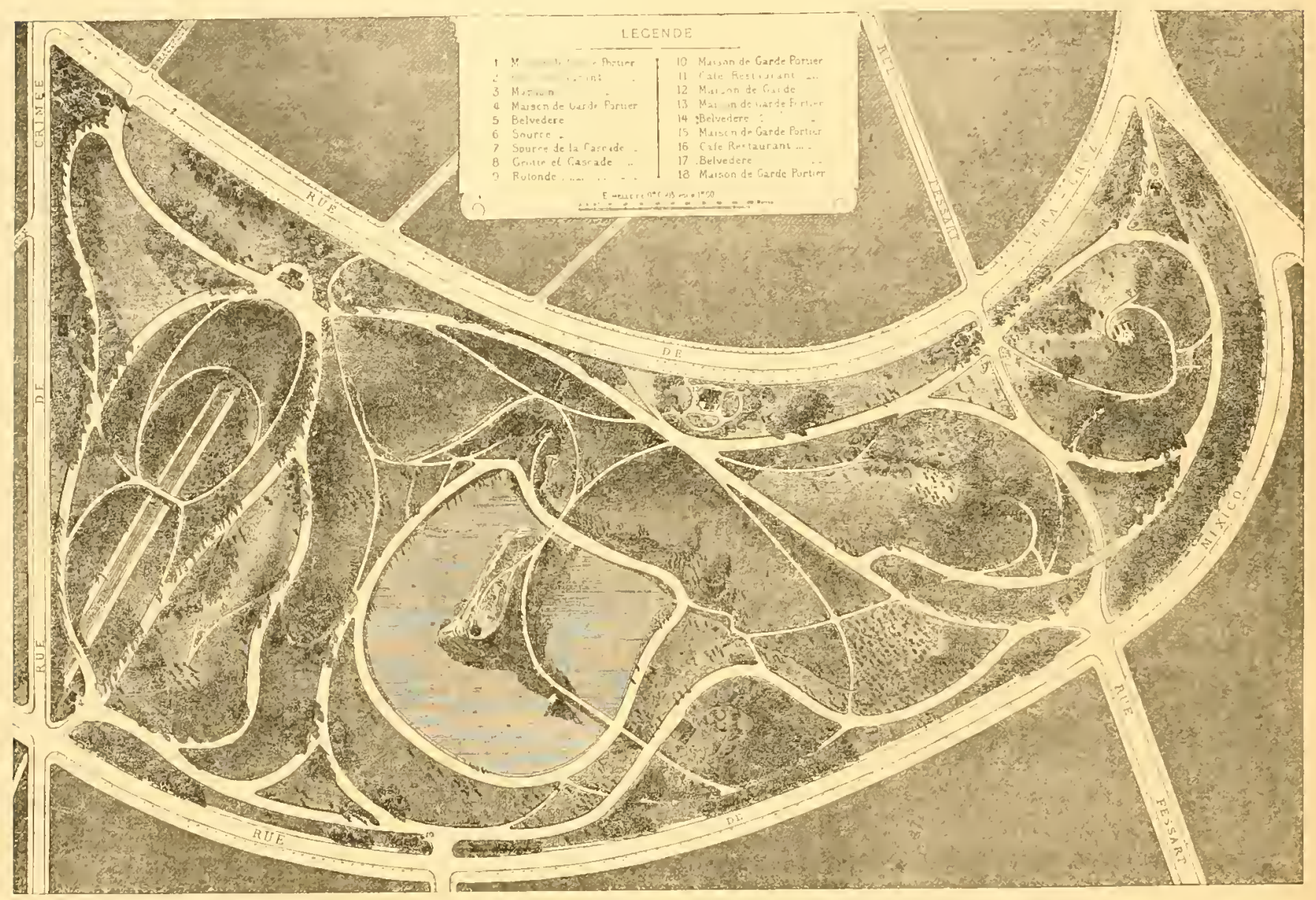

Fig. 4+8. - Pare des Buttes-Chaumont.

nature. Les artistes auront rarement l'occasion d'imiter des créations de ce genre. Mais ec qu'ils peuvent étudier avee profit dans le détail des travaux, c'est leur double caractére d'utilité et d'ornement. Ainsi, le mur d'où jaillit la calscalde, le fond solidement maçonné de la grotte, empếchent l'éboulement des terrains supérieurs. Les talus marneux, presque verticaux et trop peu consistants, ont été tranchés en pentes permettant au sol de se soutenir, de receroir la terre végétale et les plantations. En un mot, il a fallu surmonter des difficultés exceptionnelles, pour assimiler ces terrains à une destination si nouvelle pour eux. 
On ne peut contenter tout le monde; aussi la création de cette promenade souleva des critiques de diverse nature. Les uns auraicnt voulu lí " quelque riche fantaisie, quelques terrasses »; apparemment un pastiche des rillas italicnnes de la Renaissance; absolument déplacé, suivant nous, dans un pareil milieu. D'autres, se plaçant à un point de vue tout opposć, ont qualifié ce travail de " prétenticux »,

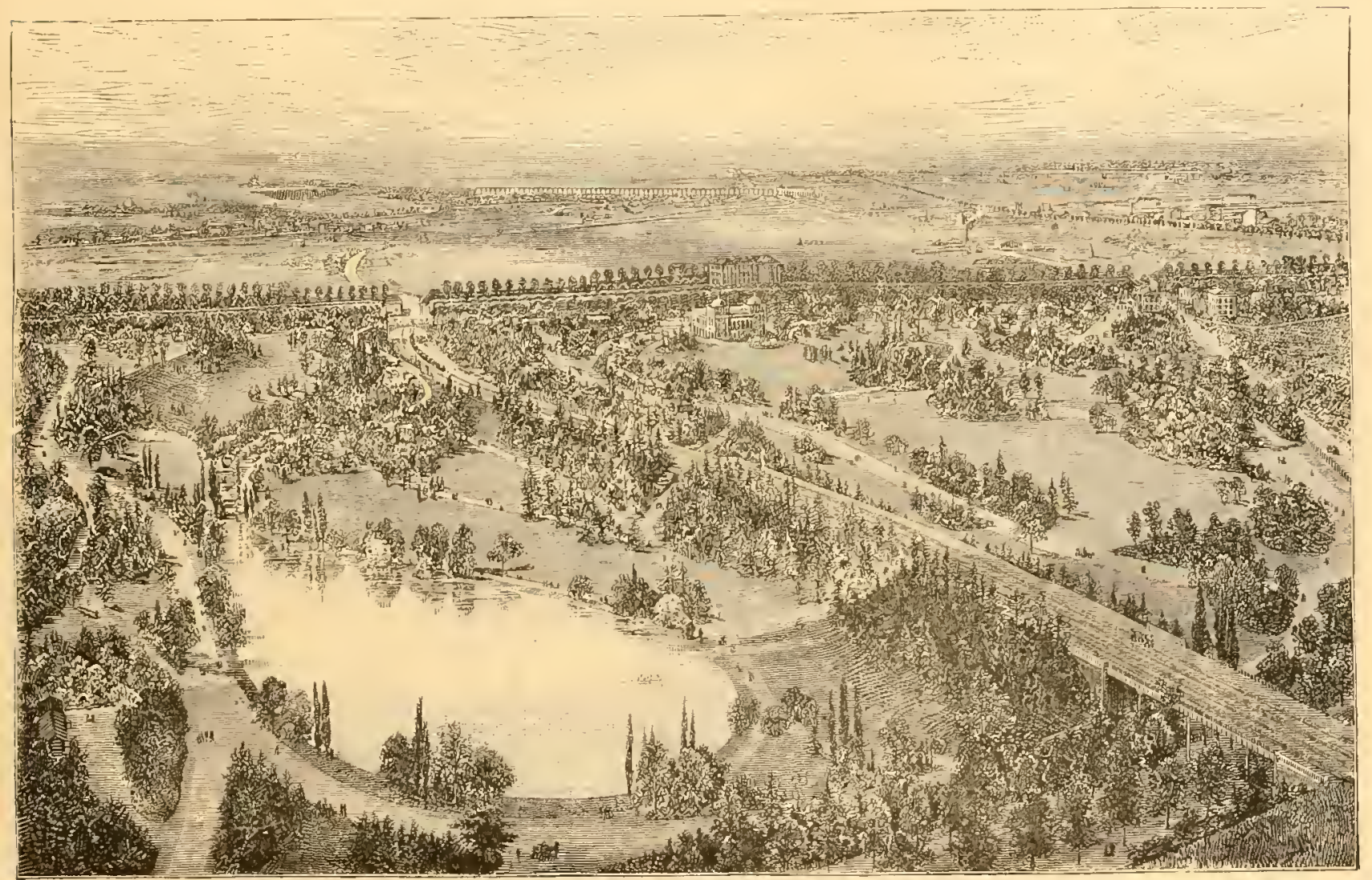

Fig. 449, - Vue à vol d'Oiseau du Pare de Montsouris. D’aprés un Fusain de MM. Hochereau et Dardoize.

se plaignant qu'on eût détruit " laspect primitif, sanvige ct pittoresque de ces lieux. " Eût-il done fallu s’inspirer ici des souvenirs sinistres du passé, críer une de ces promenades du genre ierrible que rêvait Chambers, avec fac-similé du gibet, des campements de bandits dans les carrières, etc.! Au reste, ces critiques remontent à une époque oú les travaux étaient en cours d'exécution ou à peiné finis, et où l'on ne pouvait juger équitablement du mérite de l'ouvre.

La quatrieme grande promenade, dont beaucoup de Parisiens ignorent encore l'existence, est le parc de Montsouris (Fig. 449), le dernier terminé. Ce pare, d'une étendue de i 6 hectares, est situi à l'extrémité méridionale de Paris, sur 
la pente d'un coteau qui domine la vallée de la Biérre. Ce point a été choisi pour obtenir, en sens inverse, une rue de la capitale aussi intéressante que celles dont on jouit des hauteurs en face, mais d'un caracterre tout autre. Cest de Montsouris qu'on peut le mieux apprécier l'immense développement des quartiers de la rive droite, qui y forment le fond du tableau. Ce pare a d'ailleurs été judicieusement

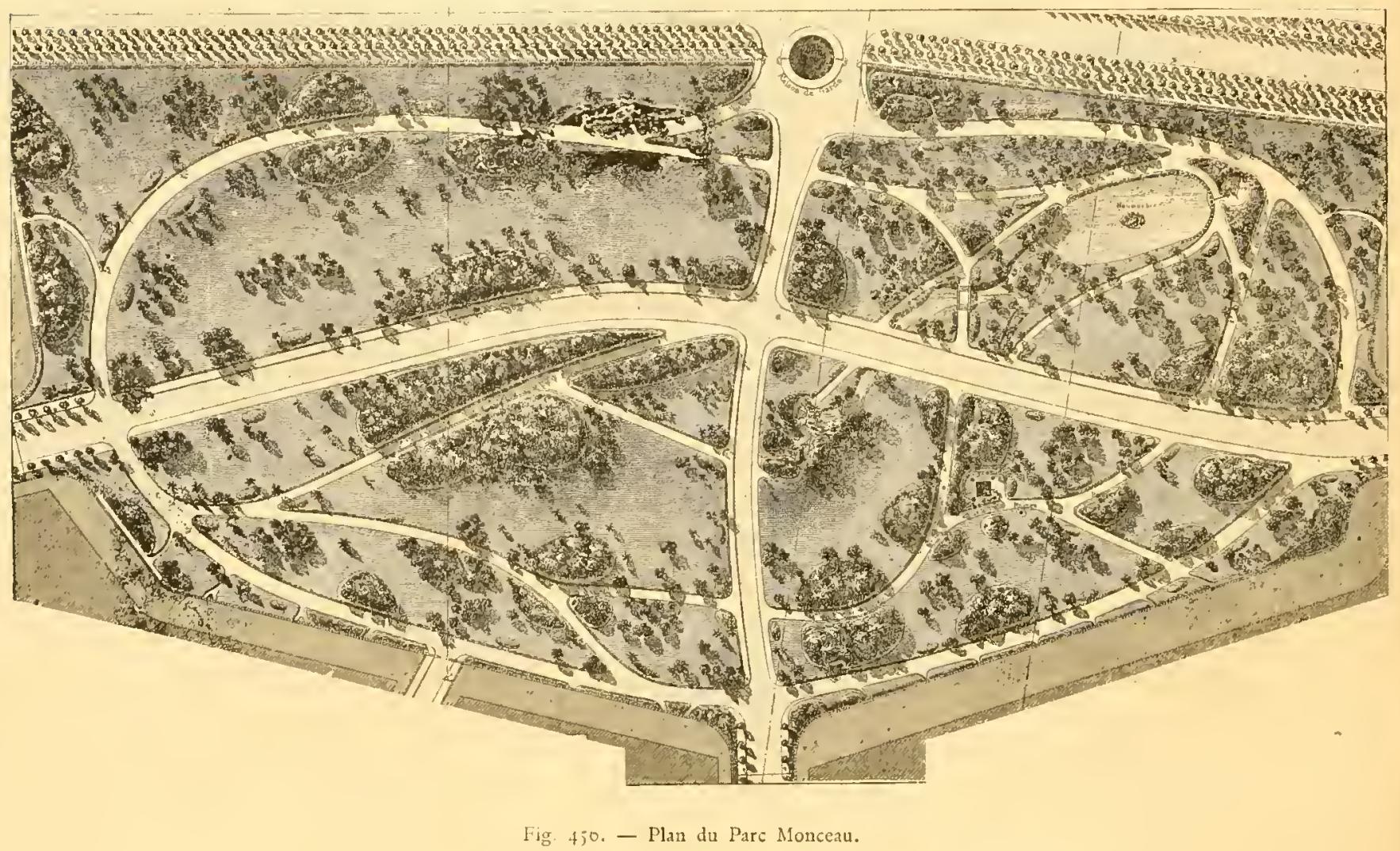

établi sur des terrains coupés par deux chemins de fer, et dont il eût été difficile de tirer parti autrement. C'est un spécimen intéressant du style paysager tempéré.

Bien que diminuć de plus de moitié, Monceau couvre une superficie de $S$ heetares, et mérite encore le nom de parc. Dans le remaniement de la partie conservée, on a ménagé, le plus possible, les anciennes plantations et les ornements de l'œuvre primitive, comme la Nammacbic, qui toutetois perd forcément de son effet, à cause du voisinage des nouvelles clôtures. On al tâché d'approprier cette promenade aux habitudes, aux goûts de son public; par l'arrangement gracicux et confortable de su's abords; la beauté des grilles monumentales placées á l'entrée des grandes voies carrossables; l'élígante disposition des pelouses, qui à clles seules occupent plus de la 
moitié de la superficie du pare, ut sont comme une exposition permanente d'horticulture de luxe, encadréc dans un décor paysager (Fig. 450).

Je remaniement complet de la partic des Champs-Élysées comprise entre la place de la Concorde et le rond-point est trop connu pour que nous nous arrêtions à le décrire. Le détail de cette métamorphose peut fournir des enscignements utiles, même pour l'arrangement de propriétés privées. On remarquera notamment avec quel soin les beaux arbres de l'ancienne plantation ont été conservés et mis à profit pour le raccor-

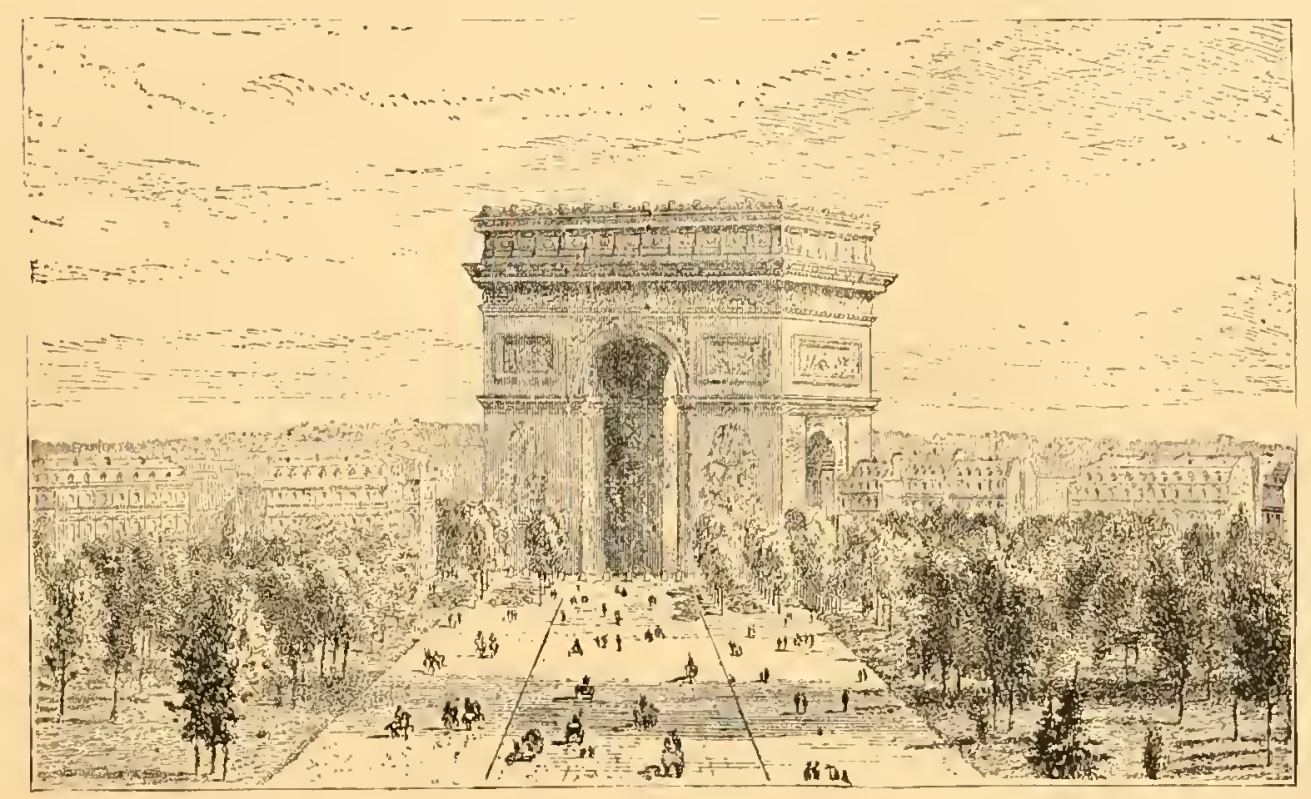

Fig. 45I. - L'Arc-de-Triomplie et l'Avenue du Bois de Boulogne.

dement de l'avenue centrale avee les nouvelles plantations; l'emploi varié des arbres et arbustes à feuilles persistantes pour accompagner les façades des restaurants, cafésconcerts, etc.; pour en cacher les clôtures, et, généralement, tout ce qu'il est bon de dissimuler (Fig. 45 r et 453 ).

On a prétendu que les nouvelles promenades de Paris étaient une imitation, un pastiche des parcs de Londres. C'est la une de ces assertions qu'on répéte de confiance, sans se donner la peine de réfléchir ni de regarder. L'arrangement des pares anglais convient à un climat plus froid et plus humide que le nôtre. Les plantations y sont moins denses, plus elairsemées, les pelouses sont des prairies, oú paissent de nombreux bestiaux. De telles dispositions seraient déja incommodes dans le Nord de la France ct à Paris, et tout à fait impossibles dans le Midi.

Avant de quitter ee sujct, nous devons dire un mot de l'itat actucl des anciens 


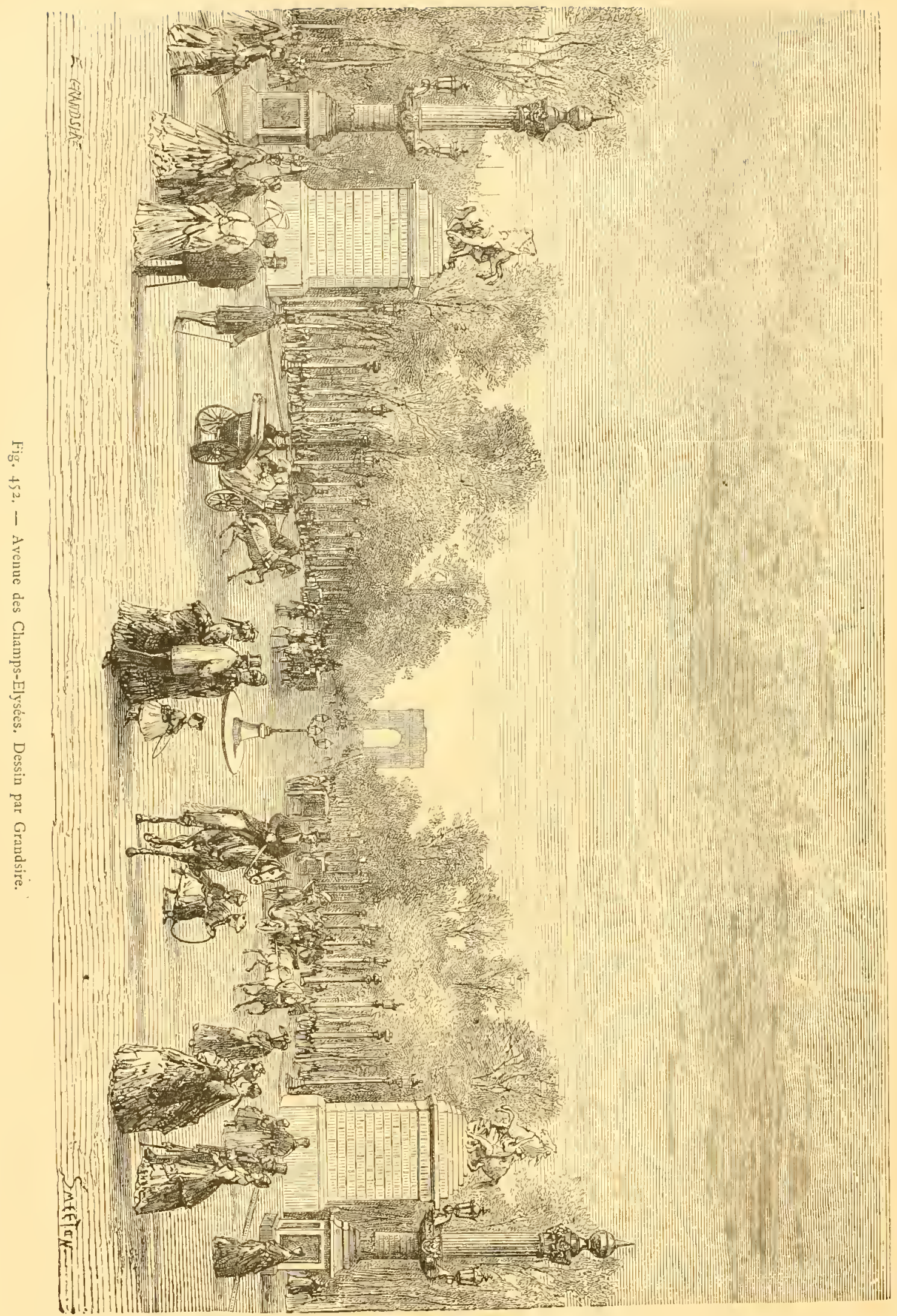




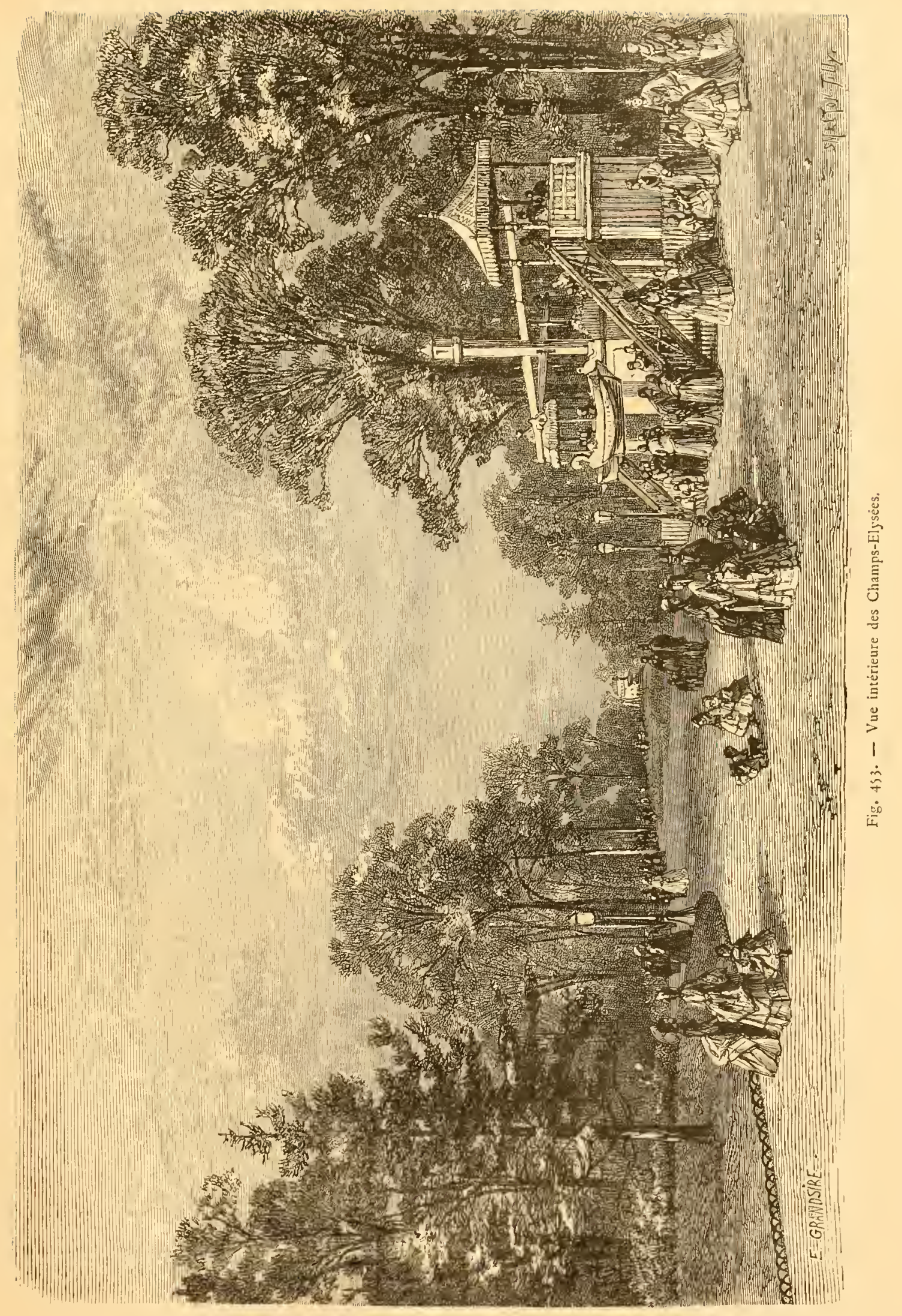


jardins publics, qui, pendant si longtemps, ont suffi, ou étaient censés suffire à une grande partie de la population parisienne; les Tuileries, le Luxembourg, le Jardin des Plantes.

Le premier, dout il a été longuement question, comme de juste, dans la partic

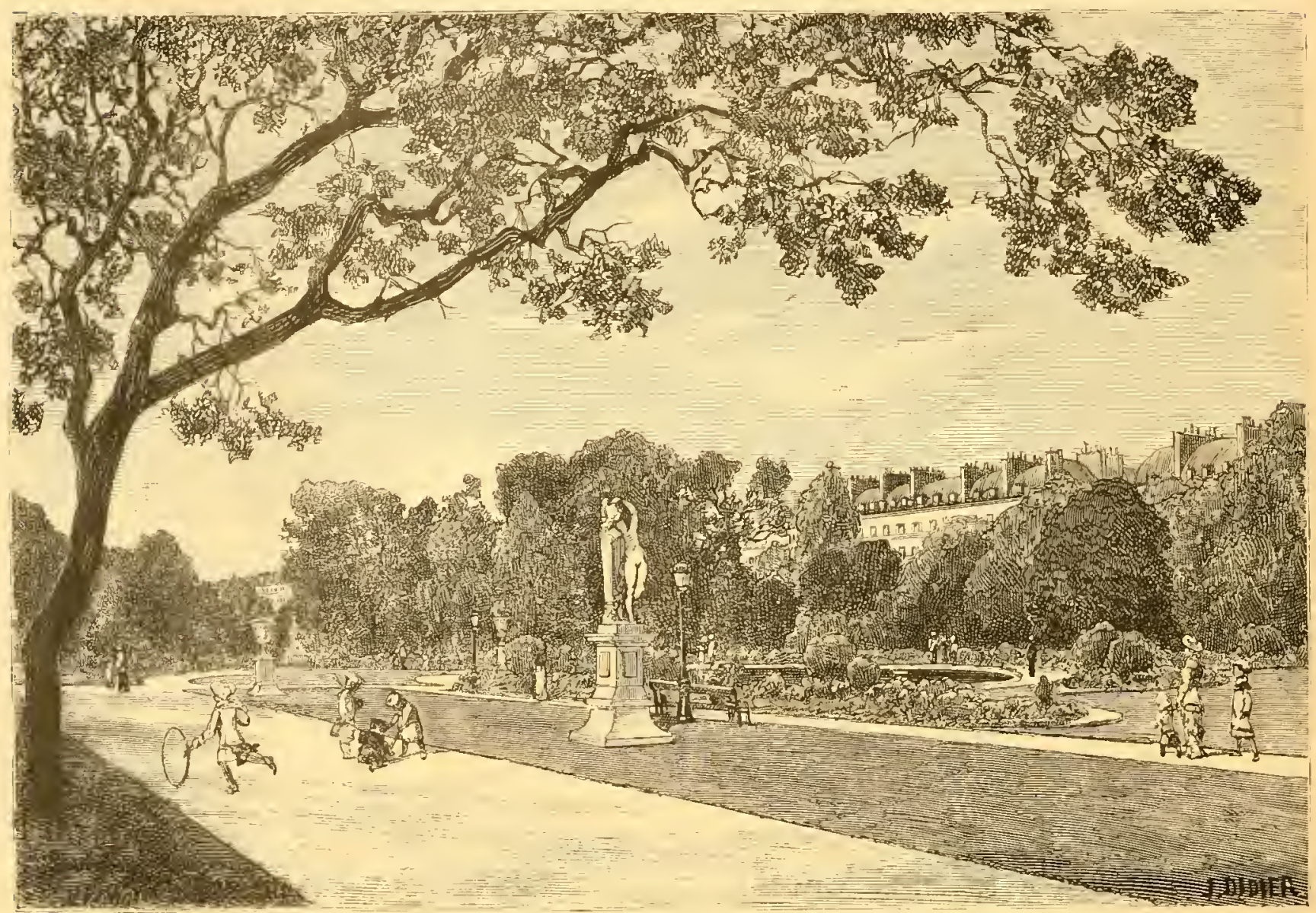

Fiğ 4jt. - Les Tuilerics, - Jardin puysiger; cóté de la Rue des Tuileries.

historique de ce travail, est une majesté déchue, dont les plus beaux jours sont passés. La métamorphose quasi-paysagère de la partie de ce jardin qui touchait au palais a été sévérement et justement blâmće (Fig. 454). C'est lì précisément que le stỵle régulier aurait dû être le plus scrupuleusement maintenu. Ce qu'il y a de mieux dans ce jardin, c'est ec qui subsiste encore de l'ancienne ordonnance.

Le Luxembourg a subi, à une époque plus récente, des changements, et surtout des diminutions, qui ont aussi donné licu à d'améres critiques. Toutefois, nous croyons que le dégagement de la fontaine Médicis, et la décoration de ses abords, 
méritent au moins quelque indulgence. D'uutre part, l'effet facheux du retranchement d'une section de l'allée de l'Observatoire a été tort atténué par la conservation de cette partie me boulesa décoratstyle du jarsimule le ment (Fia 458 ). des Plantes, $\mathrm{t} a \mathrm{nt} \mathrm{d} c$ vue divers, l'attention

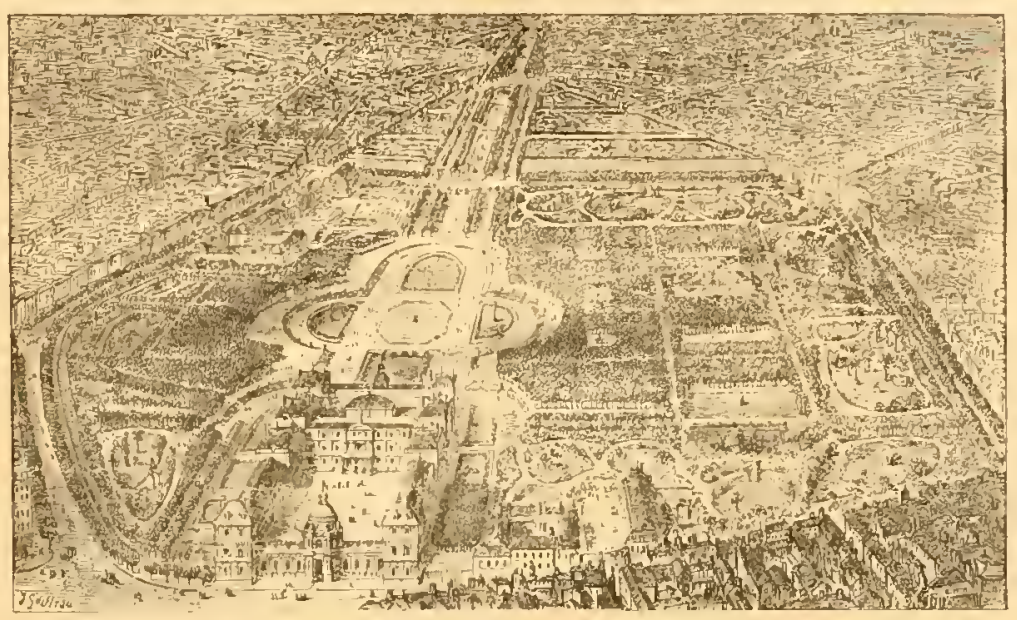

Fir. 15\%. - Vue a rol d'Oiseau du Jardin du Luxembourg. d'allée comvard, et par tion dans le din dont elle prolongegures 455 Le Jardin intéressant $\mathrm{i}$ points de mérite aussi desamateurs de l'Art des jardins par sa butte plantée on labyrinthe darbres verts, it laquelle se rattachent d"intéressants souvenirs, ot par la belle ordonnance,

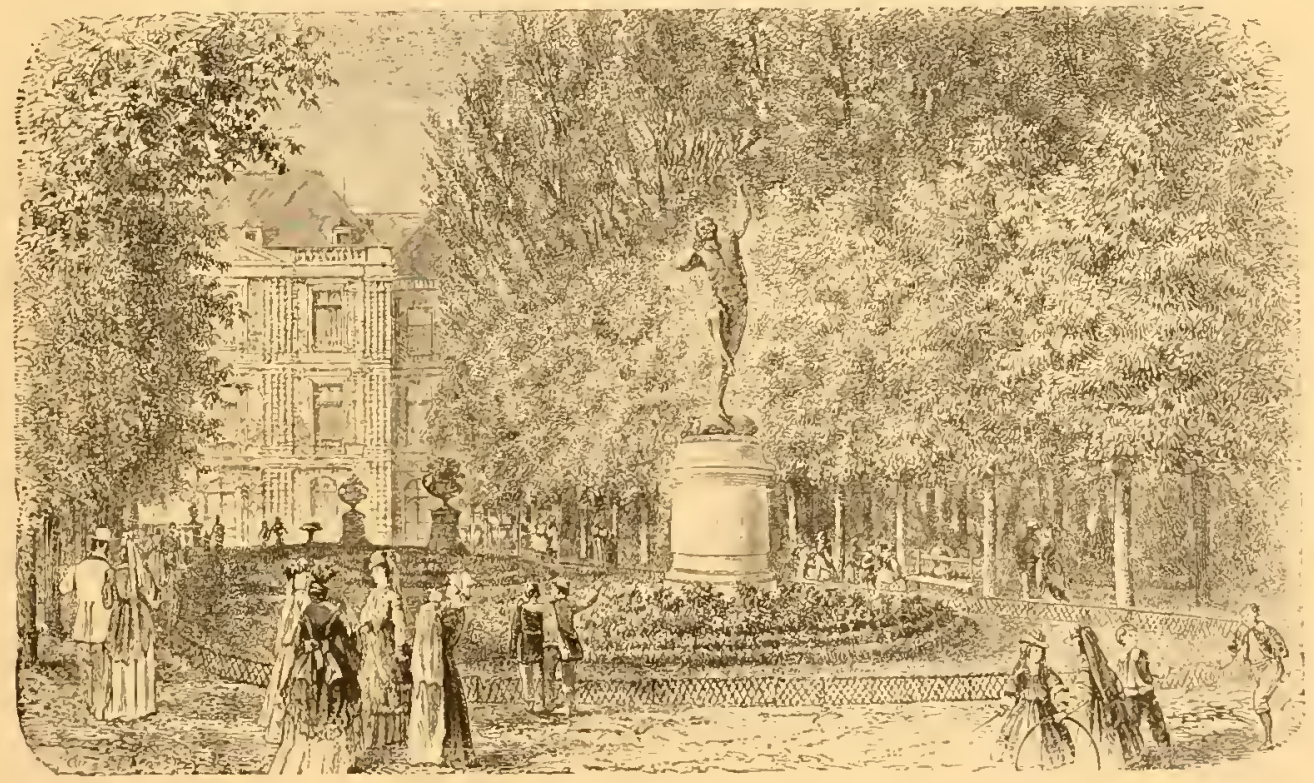

Fig. 456, - Parterre au Jardin du Luxembourg.

respectic dans ses lignes principales, de ses parterres de plantes médicinales et industrielles encadrées dans les avenues. L'effet général de l'enscmble est resté le même; ainsi qu'on peut s'en rendre compte par la gravure ci-jointe, qui le représente tel qu'il était il $y$ a deux siècles (Fi- 
gure 459). La nouvelle scre, teminéc en 188j, est une ceurre remarquable.

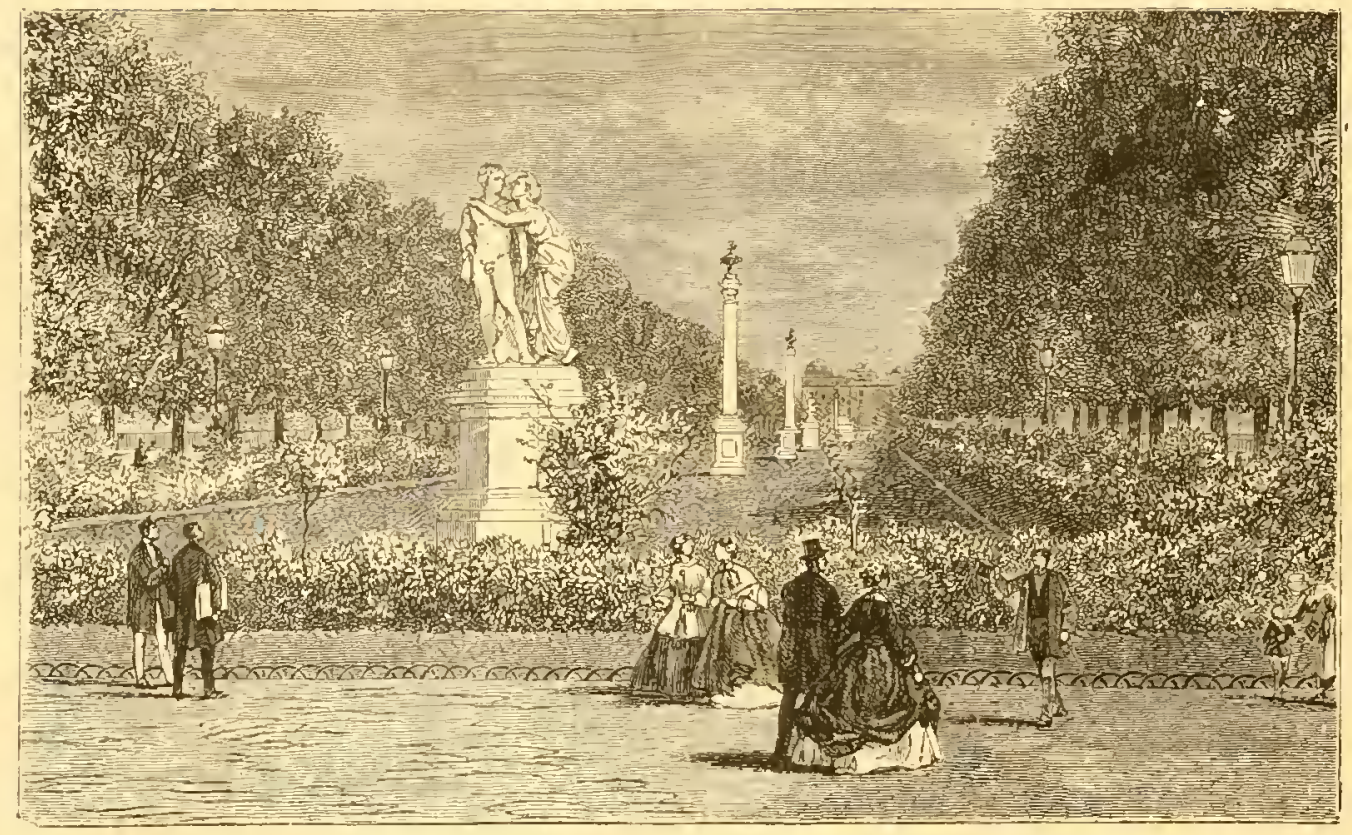

Fig. 457 - Avenue de l'Observatoire.

IV. - Squares parisiens. - Fleuriste, etc. - Indípendamment de ses anciens jardins publics (Tuileries, Luxembourg, Jardin des Plantes), de ses quatre

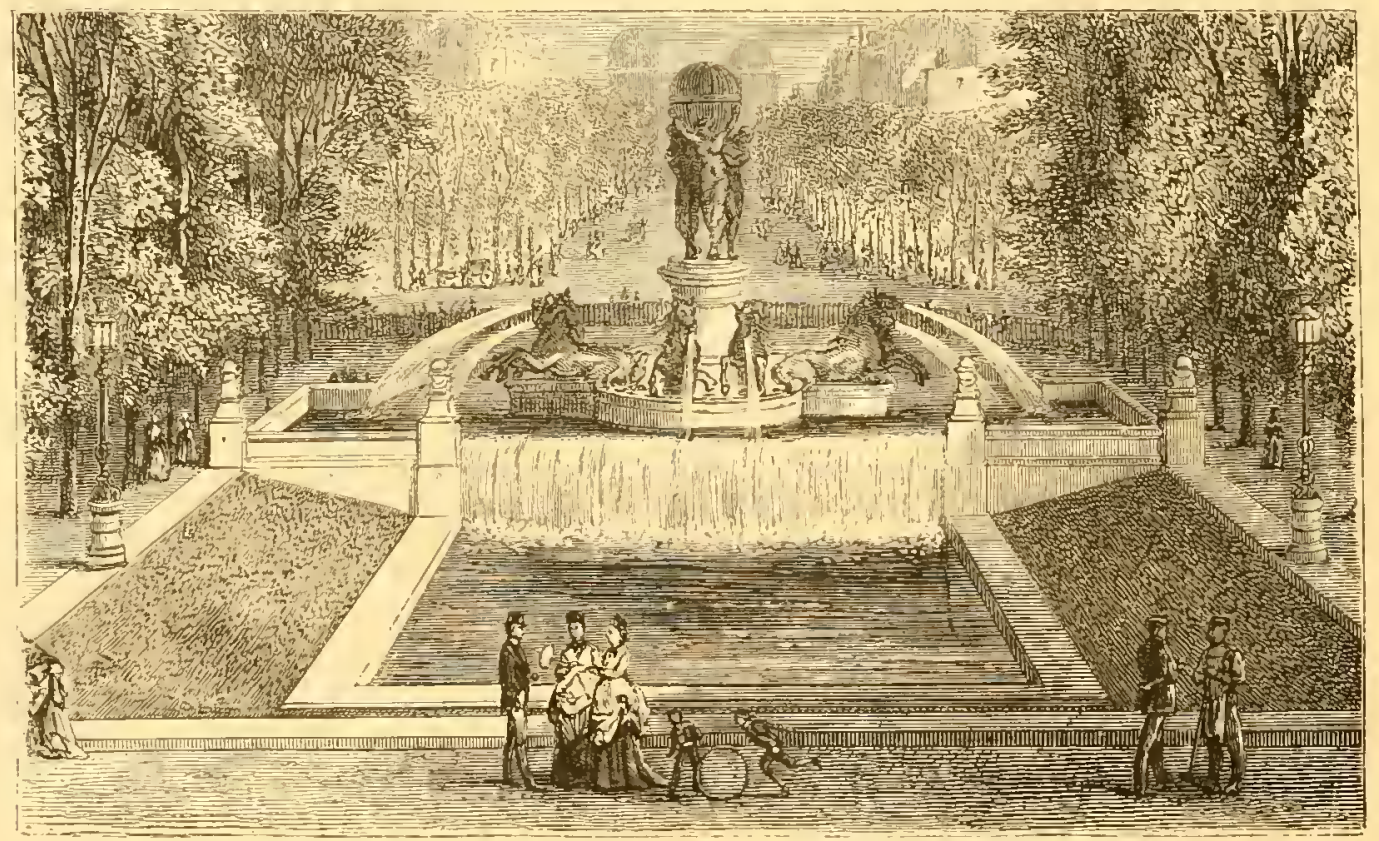

Fig. 458. - Fontaine de l'Avenue de l'Observatoire; les Cinq Parties du Monde, par Carpeaux.

grandes promenades, des Champs-Élysées et du pare Monceau, Paris posséde aujour- 
d'hui un enscmble de soixante-neuf emplacements plus ou moins itendus, couverts de végétaux, et représentant une surface de 728,495 métres carrés; plus de 72 hectares. Ainsi, on a non seulement accompli, mais largement dépassé lés clauses du programme de transformation, qui, outre l'organisation des grandes promenades, comprenait le déreloppement ou la création d'au moins un jardin ou square dans chaque arrondissement de Paris.

En principe, tout espace réservé dans une place ou un carrefour à des plantations entourées d'une cloture, et affecté aux jeux des enfants, à la promenade ou au

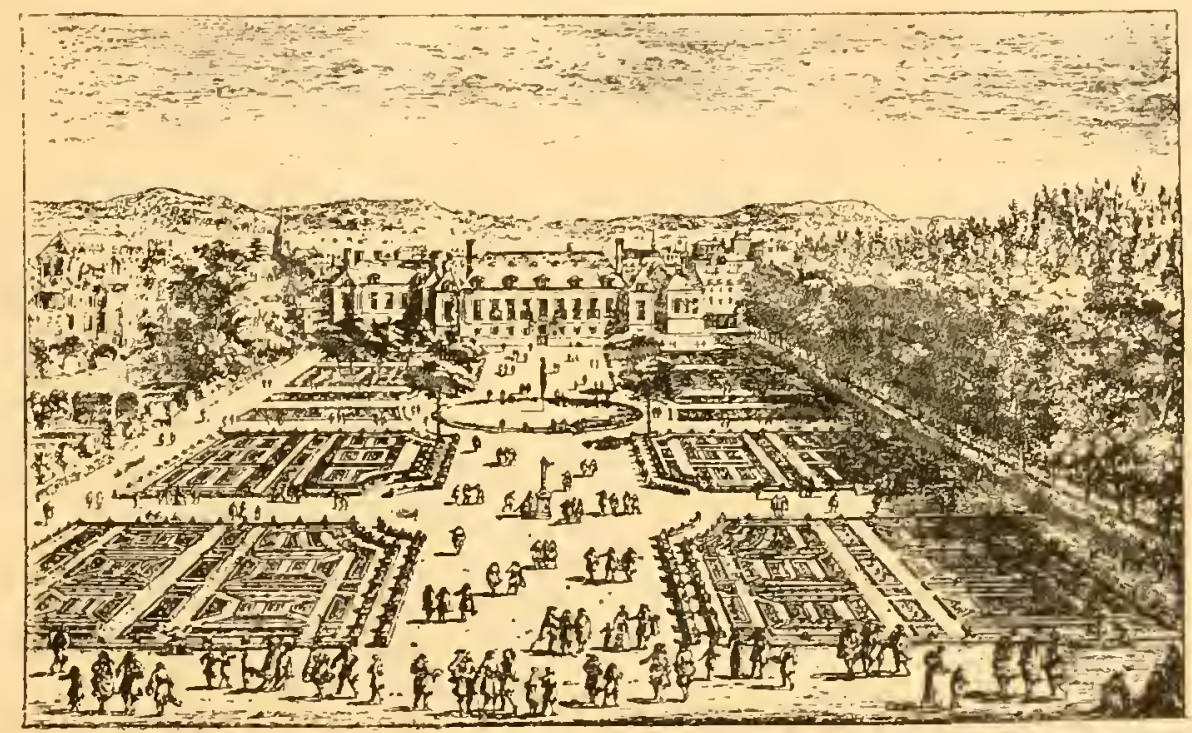

Fig. 459. - Vue du Jardin Royal des Plantes mćditinalcs au Faubourg Saint-Victor. Dessiné et gravé par l'érelle.

délassement des aduites, a droit au titre de square. Mais comme c'est en Angleterre que s'est d'abord ctabli l'usage d'appliquer aussi à ecs petits jardins publics le style irrégulier; - le mot square, aujourd'hui naturalise dans notre langue, éreille plus particulicrement lidic d'une plantation qui, bicn qu'entouréc plus ou moins de constructions, affecte jusqu'à un certain point le style paysager, avec pelouses, vallonnements, allées sinucuses, arbres et arbustes disposés par groupes ou isolés, corbeilles de fleurs ou di: plantes a feuillage.

1] est inutile d'insister sur l'importance hygienique et philanthropique de ces plantations, « aussi nécessaire aux habitudes de la population adulte qu’à la santé des enfants, qu'il faut pouvoir envoyer autant que possible prés de leur domicile, dans un lieu oú ils soient en sûreté, tout en respirant un air sılubre. » Les quartiers les 
plus pauvres, les plus populeux, n'ont pas été les moins favorisés dans cette répartition d'air, de lumiere et de verdure; et ce n'était que justice! De plus, quelques-uns de ecs squares ont une certaine valeur artistique. Le plus digne d'intérêt, sous ce rapport, malgré son peu deitendue ( I hectare 39 ares), est celui des Batignolles, dont nous avons suffisanment parlé ailleurs (Fig. 460). Nous n'ajouterons qu'une remarque sur la plantation de ece square.

La plupart des arbres a feuilles caduques ont ćte choisis dans les essences les plus ordinaires et les plus rustiques (aune, platane, tilleul, írable, faux acacia, sor-

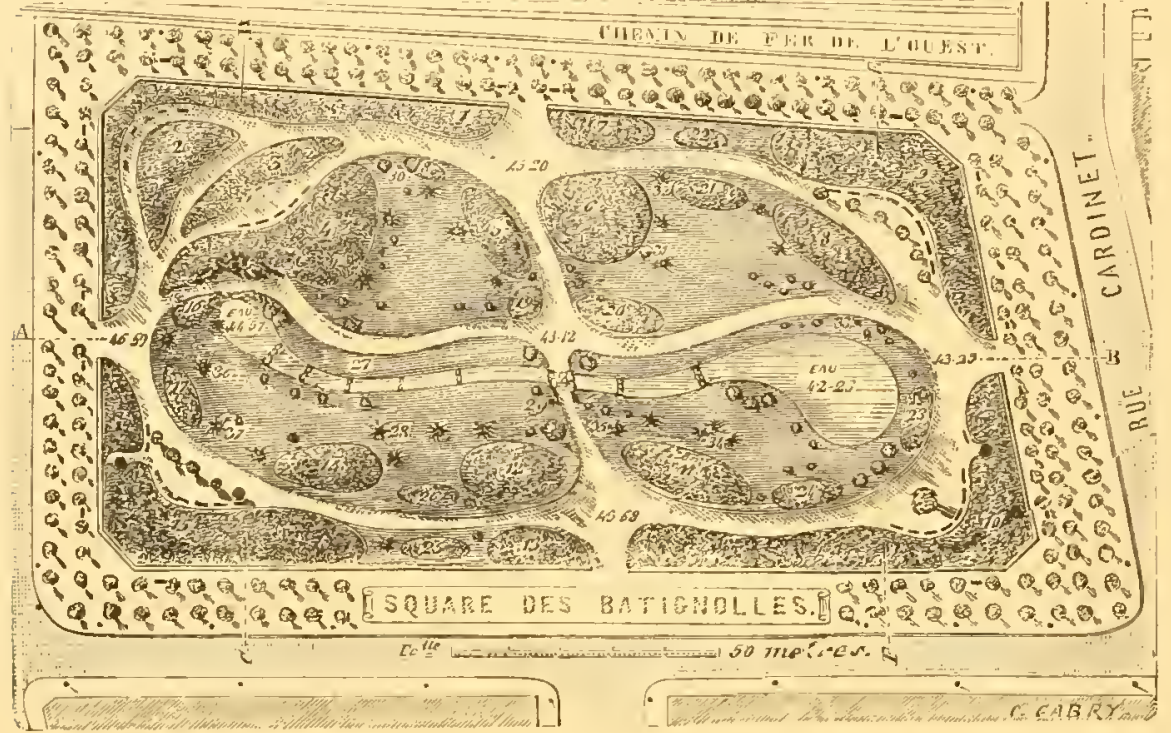

Fig. 460. - Squune des Batignolles. bicr, puulownia, catalpil, etc.). Même observation pour les arbustes (troënes, buis, lauriers, lilas, berberis, spirées, ete.). On a obtenu ainsi un développement plus rapide des effets de feuillage prémédités.

Plusieurs autres squares, sans avoir la même valeur comme composition d'ensemble, méritent aussi d'être consultés pour le détail de la plintation. Nous citcrons entre autres, celui de la tour Saint-Jacques, dont les ombrages accompagnent bien ce beau débris d'architecture gothique, sauvé par une série de hasards providentiels; - ceux de la Chapelle expiatoire, du Temple, Montholon (Fig. $46 \mathrm{I}$ ), cic. (I).

Il a été pourru amplement et dans des conditions des plus économiques, à l'énorme approvisionnement de plantes cxigé par la création, le développement et l'entretien des promenades parisiennes; - au moyen de vastes établissements lorticoles, véritables mamufacturcs de planles. Le plus important est le jardin

(1) Citons aussi le square des Arts-et-.Métiers, du style régulier. L'applization de ce style convicnt particulierement aux places qui sont, comme colle-ci, roisines d'un theître, ct par conséquent susceptibles d'ètre brusquement envahics par l.a ocile il des heures avancies. (Fig. 396.) 
fleuriste de La Muette, oú les diverses serres et leurs annexes, les châssis de conches et les terrains destinés à la culture des plantes de plein air, couvrent une surface totale de plus de dix-huit mille métres (Fig. 358 à ;63). Cet établissement s'est développé, dans l'espace d'un quart de siècle, avec une rapidité féerique. La première année (1855), le Fleuriste n'avait fourni que 600 plantes; en 1864 , le nombre des plantes livrées s'élcra à plus de 870,000 . Bicn que le personnel qui occupait cn moyenne 88 ouvriers avant la guerre de i $870-7$ I, ait été réduit d'un tiers depus

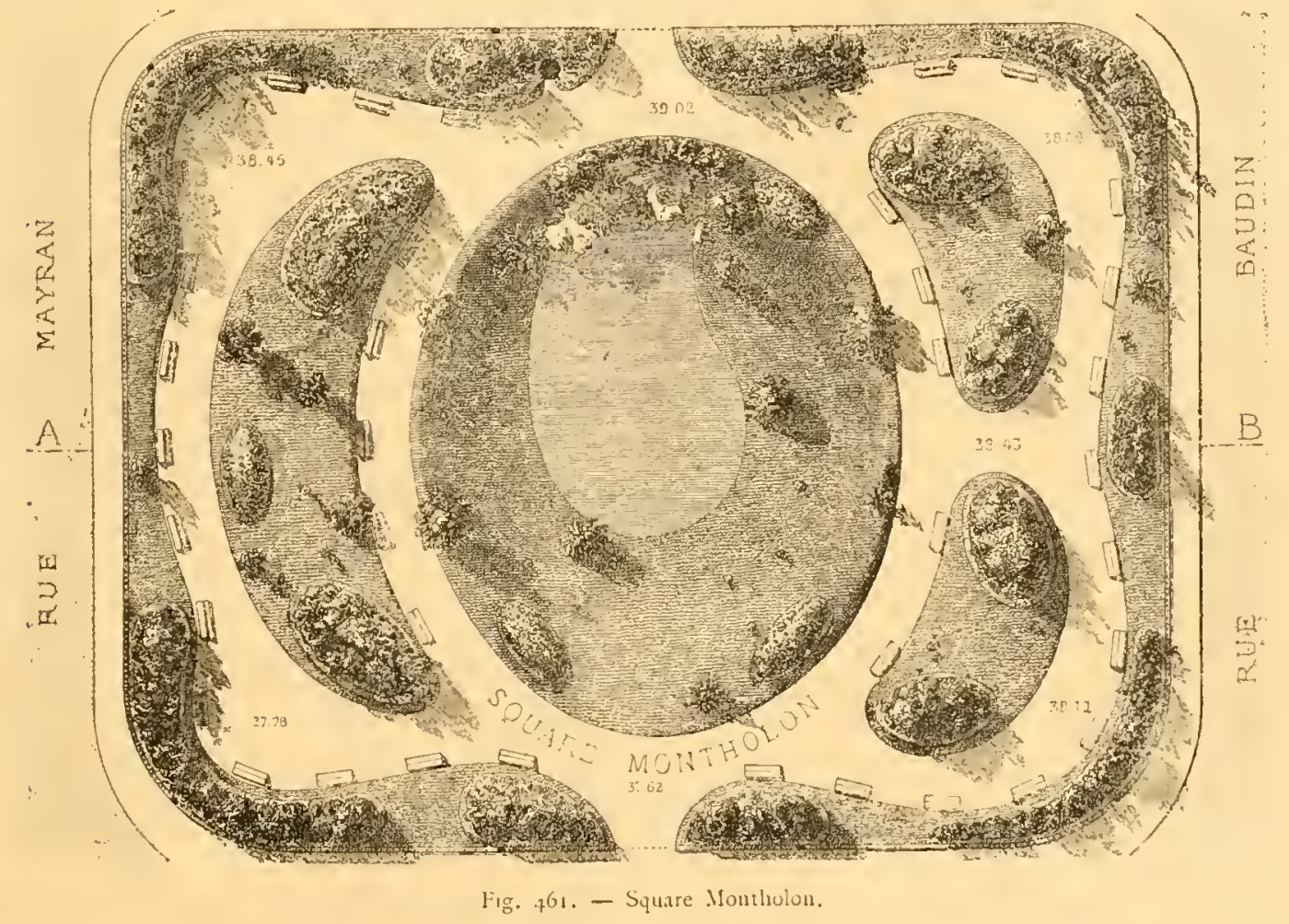

I 872 , il peut produire par an environ trois millions de plantes, qui ne reviennent qu'à o fr. I 3 cent., tandis que la valeur marchande des plantes de choix sorties du Fleuriste dépasse en moyenne o fr. jo cent. Grâce à lui, la Ville de Paris peut orner plus richement ses Promenades, et à moins de frais, que si on était resté tributaire de l'industrie privée. Mais cette "manufacture de plantes», dont la réputation est curopéenne, a un caractére d'utilité plus général. Dans l'état actuel de division des fortunes, rien ne saurait remplacer l'initiative d'un tel établissement. On peut y faire ct on y fait journellement des essais impraticables pour la plupart des particuliers, et d'un grand intérêt pour l'horticulture. C'est ainsi qu'on a pu expérimenter, dans les serres du Fleuriste, la substitution ćconomique du gaz à tout autre combustible. C'est 
là aussi qu'ont eu lieu les premiers essais pratiques les procédés, présentement à liétude, de l'accélération de la croissance des plantes par la continuité du jour,

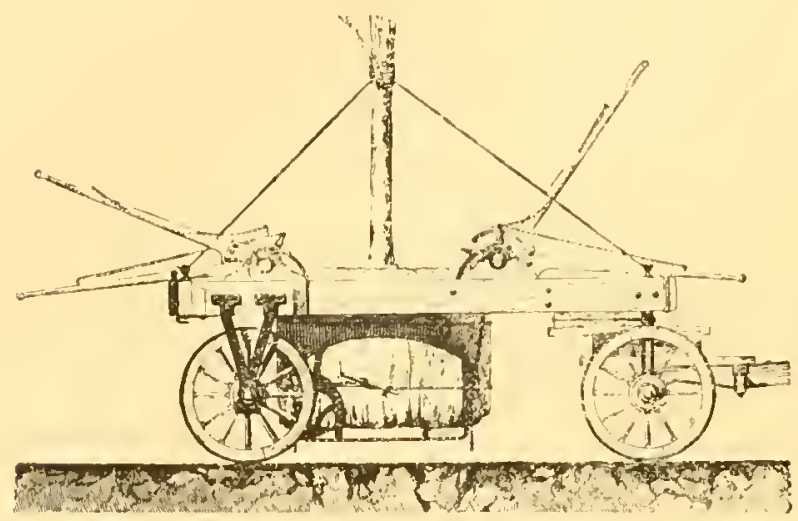

Jïg. 462. - Elévation latérale du Charat à transplanter.

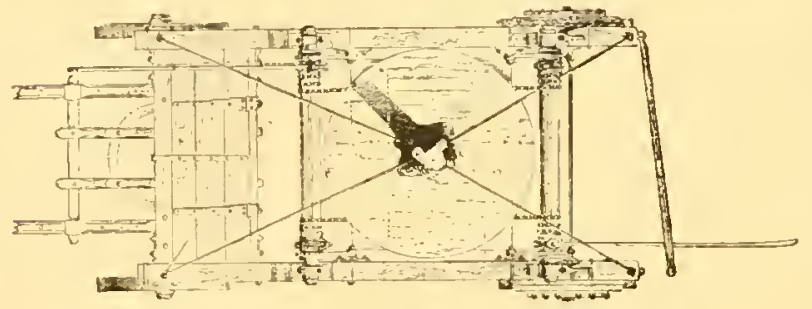

Fig. 463. - Plan du Chariot.

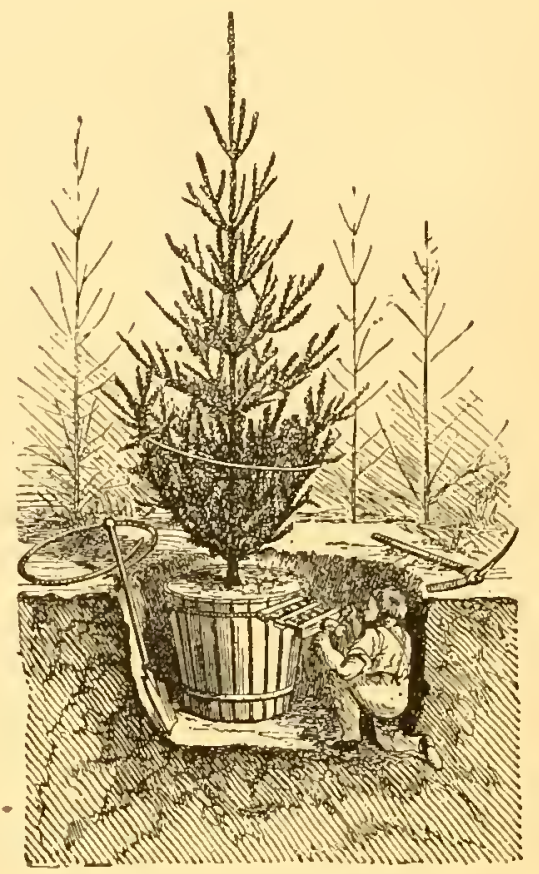

Fig. 465. - Cerilage des Mottes.

obtenue au moyen de la lumiére électrique. Enfin, le Fleuriste a rendu d’incontestables services, en vulgarisant l'emploi dans nos jardins des

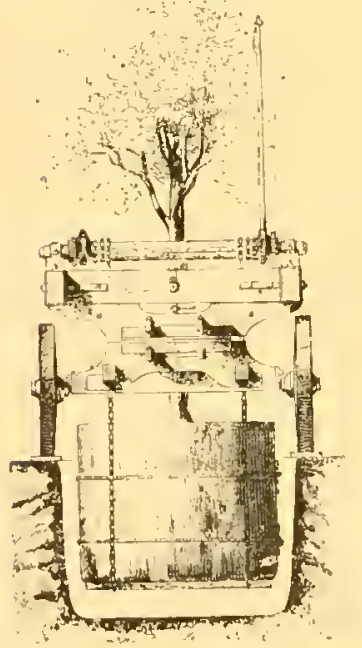

Fig. 464 . Élévation de l'Avant-train. plantes colorées, trés decoratives, et dont un grand nombre étaient cncore à peine connues, ou même tout it fait inconnues en France. On a obtenu ie résultat important ì peu de frais, par des dons de voyageurs, ou des cichanges aree les établissements horticoles itrangers.

Nous donnons ici l'indication des plus belle's de ces plintes, dont plusieurs, ct non des moins remarquables, peuvent être introduites sans grande dépense dans de petites propriètés; ćtant susceptibles d'être conservécs dans des serres

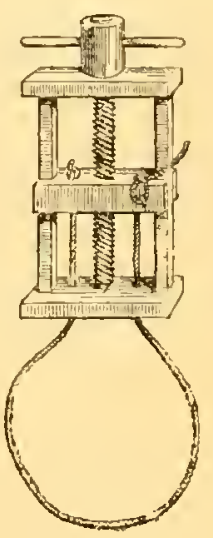

1.ig. 466. - Presse a cercler la Motte.

d'orangerie, et même cultivées en pleine terre dans certaines parties de la France :

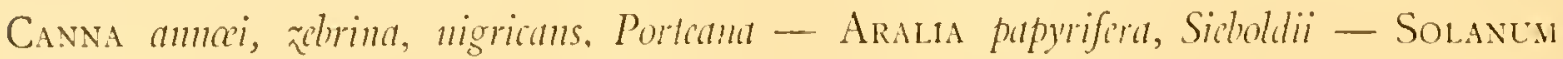


amazonicum, marginatumn, robustum, macranthunn, crinitum, II arsccuiczzii, byporJodium Hibiscus liliflorus (fleurs rouges), Coopirii - Begonias - Mesa rosicca - Ficus,

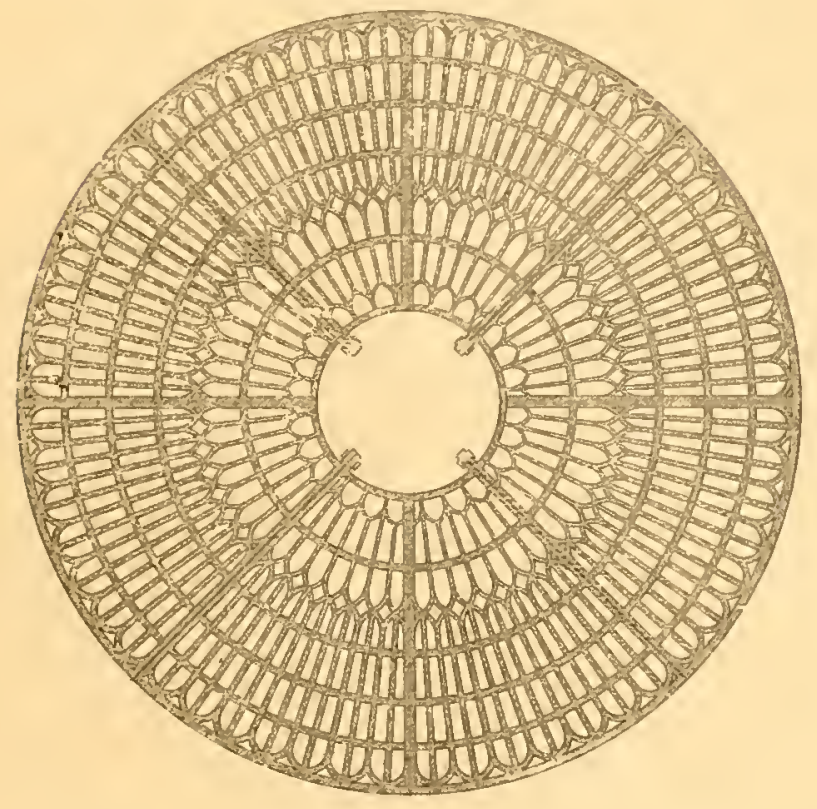

Fig. 467. - Grille en Fonte pour garantir le Pied des Arbres. clastica, Chanvicrii-Coloctsia esculcuta DRAC.ENAS PELARGONiUns, variétés aujourd'hui innombrables WigANDIA Carosanct, robuste et d'ungrind effet

- Montugnea beracleifolia, Ferdinanda cmi-

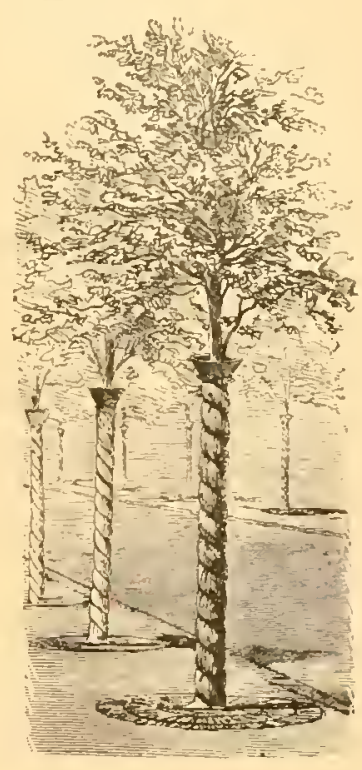

Fig. $470 .-$ Arbre enveloppé d'une Plaque de Moussc.

uchs, Verbena. Arrosées avec de l'engrais liquide, ces trois derniéres plantes peuvent attcindre cinq metres de hauteur (1). Pour la transplantation des gros arbres, on se sert

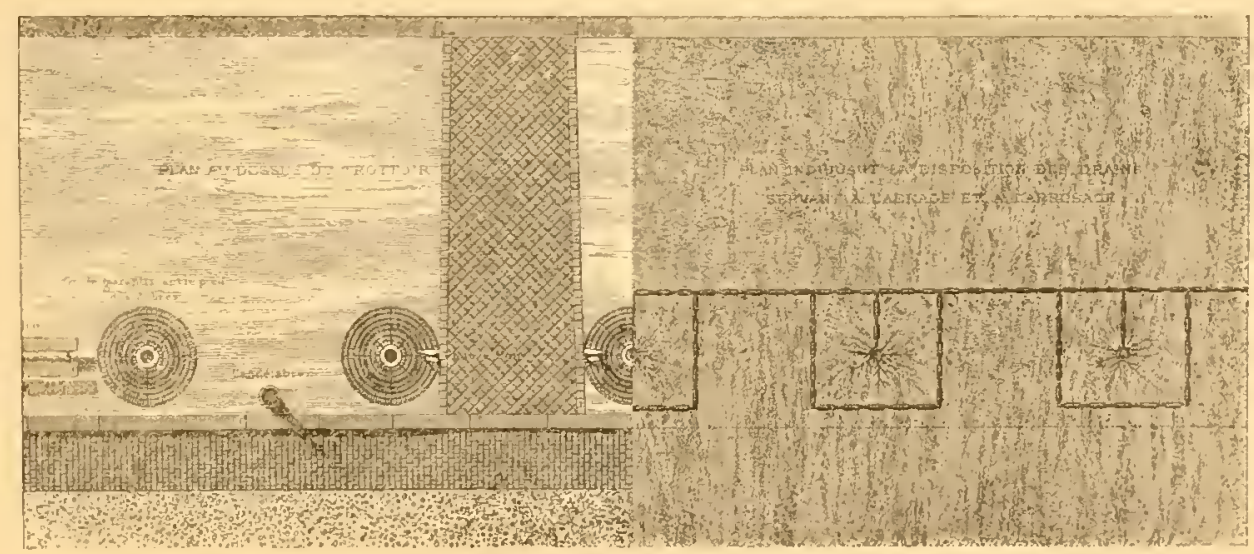

Promenades et vore publiqui de la Vilze de Paris

Fig. 468. - Grilles pour garantir les Pieds des Arbres. Fig. 6 69. - Plan indiquant la distribution des Draius Plan au-dessus des Trottoirs sur la Voie publique. Servant il l'Aérage et il l'Arrosage.

de chariots de diverses dimensions (Fig. 462 in 464 ) : pour les arbres verts et autres d'espéces rares déjil forts, on fait depuis longtemps usage, dans les pépiniéres de la

(1) Nous avons donné préiédemment les figures de la plupart de ces plantes. 
Ville de Paris, d'un procédé aussi simple qu'économique. Il consiste à entourer la

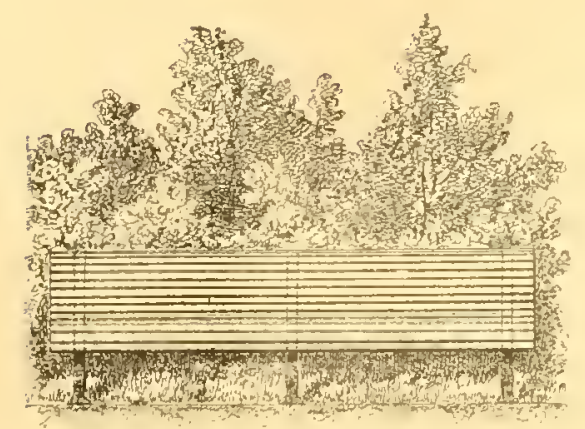

Fig. +7 I. - Banc. motte de l'arbre, comprenant, s'il se peut, toutes ses racines, ou tout au moins les plus importantes, d'une sorte de bac improvisé au moyen de planches légères ou voliges cordecis autour de la motte aree une presse de tonnelier, ensuite cerclées

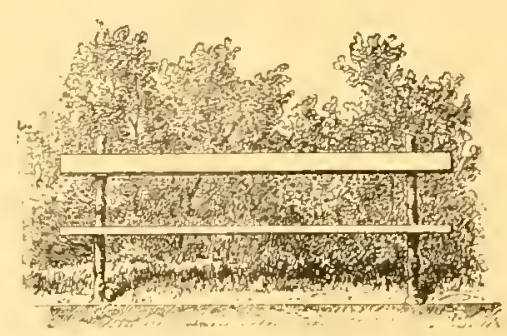

Fir. $472 .-$ Bunc.

et complétées par l'application d'un fond composé de planches scmblables. On a calculé que cet appareil revenait à moins de 2 franes, non compris la main-d'œurre

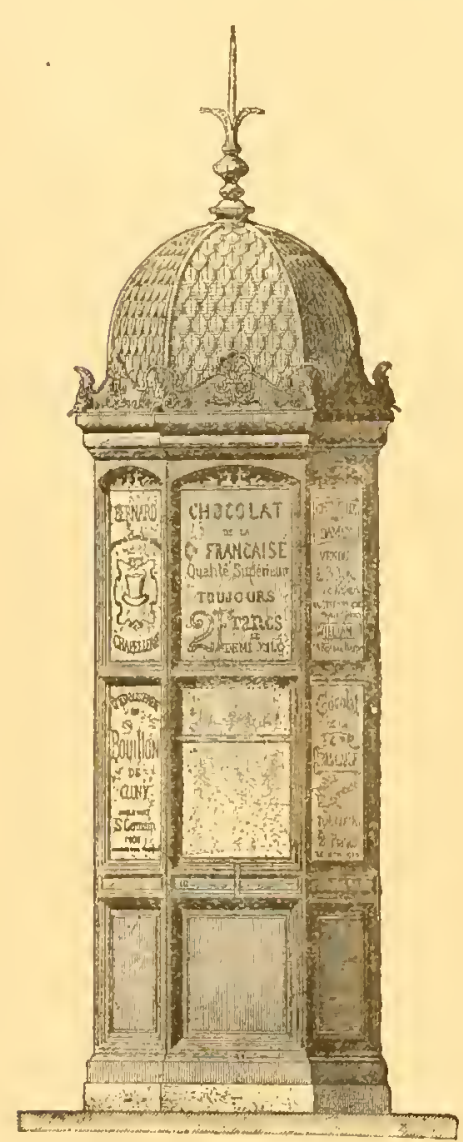

Fig. 473. - Kiosque pour la Vente des Journaux. et I $S$ francs une fois payés pour la presse à cercler la motte, qui peut servir pendant bien des années (Fig. 465 et 466$)$.

Mais, si adroitement que l'on s'y prenne, des arbres tris forts, transplantés, restent stationnaires pendant plusieurs années, et ne ralent jamais, dans la suite, ceux qui ont èté deplacés dans leur joune àge.

Afin d'arriver à un bon árage et à un arrosage facile des plantations sur la roie publique, les pieds des arbres sont garantis par un grillage en fonte (Fig. 467 i 469 ). Trés souvent, la suppression

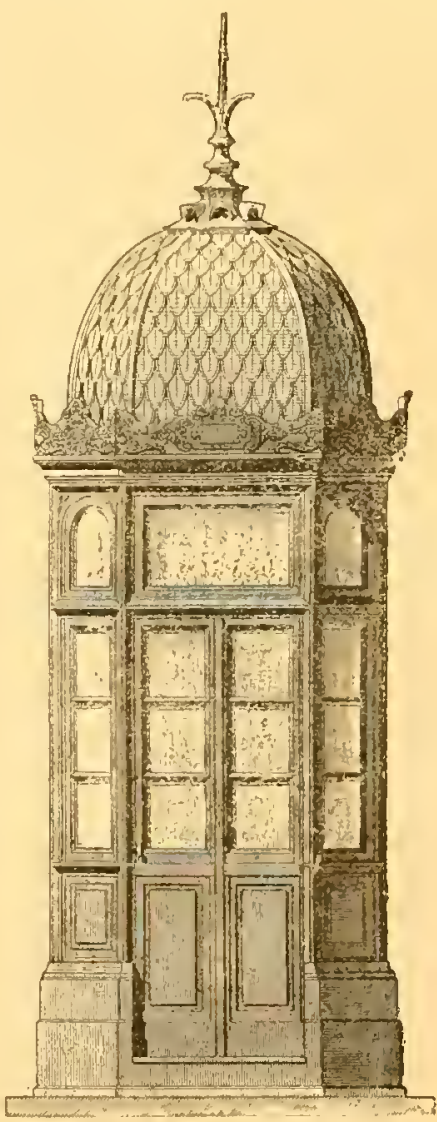

Fig. 471 - - lureau pour les Voitures de I'lace.

d'une partie des racines au moment de la transplantation provoque le dessichement. Pour éviter l'arrêt complet de la séve, il faut envelopper le trone de l'arbre de plaques 
de mousse, maintenues par un fourreau en toile (Fig. 470); tenir cette enveloppe constamment humide, par le godet placé au

Les promenades cemment en Europe, des réminiscences de ne voyons guére France, que pour le parc d'Or, superbe promeplantie on 1856 par fois un Jardin d'accliirrégulier. La partie suprincipalement de codes modéles les plus de plantation.

des publiques. -

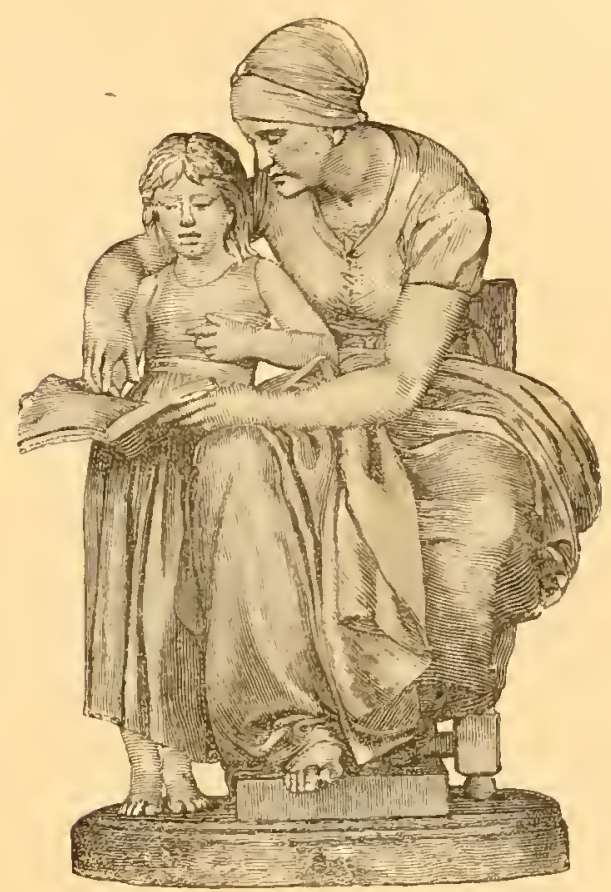

Fig. 475. - L'education maternclle, par Eugene en introduisant de l'eau sommet du tronc. publiques crées rísont presque toutes celles de Paris. Nous d'exception à faire, en lyonnais de la Têtenade de roo hectares, M. Bühler. C'est ì la matation et un pare périeure, composée niféres variés, est un instructifs de ce genre V. - PromenaTurquie, Égypte, Inde, etc. - On sait que dans les villes turques, et notamment a Constantinople, cimetières vent de des publiplusbelles resont «le le petit morts $)$ de celui de bien déTh. Giuun imbois de (C. Filnk-

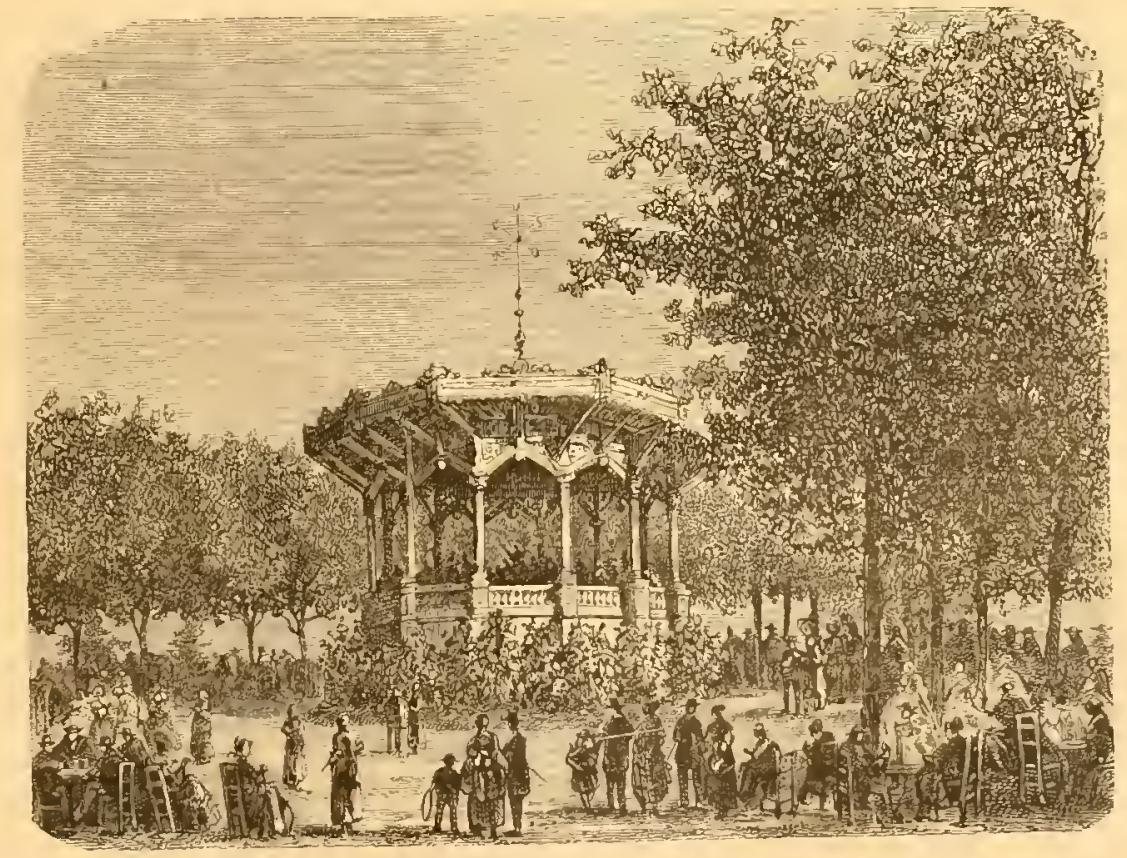

Fig. 476, - Kiosque daus l'ile Dammesnil, nu Bois de Vincennes. ce sont les qui serpromenaques. Les de ce gengrand et champdes Péra, et Scutari, si crit par tier."C'est mense cyprès bris) couterrain vrant un montueux, coupé par de larges allées. On ne se tait pas une idée, dans les pays 
du Nord, du degré de beauté et de développement qu'acquiert cet arbre sous de chaudes latitudes. " C'est surtout dans l'extrême vicillesse que eet heurcux arbre est le plus beau. divise en nerses, semblables des colonnettes ceoree effritic branches s'insiinattenduc, font rieusement diftruirecependant midal. Ses raciagrippent, la des serres de

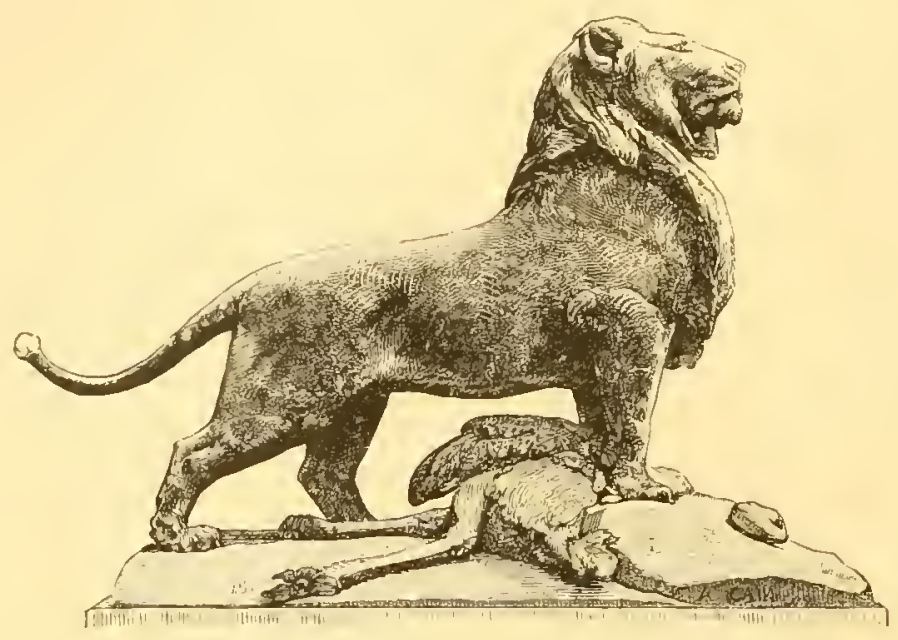

Fig. 47. - I ion en Bronze, par Barye; galerie du Bord de l'Enu, Jardin des Tuileries. " Le trone se vures rugueuaux agrégations gothiques. Son s'argente; ses rent d'une façon des coudes cuformes, sans déle dessin pyranes tortueuses terre, comme vautour posé sur une proie. Sa verdure solide et sombre ne se décolore pas aux âpres feux du soleil, et garde toujours assez de vigueur pour trancher sur le bleu intense du ciel. " (Constantimople, ch. I3.) Ce mode d'appropriation des cimetières

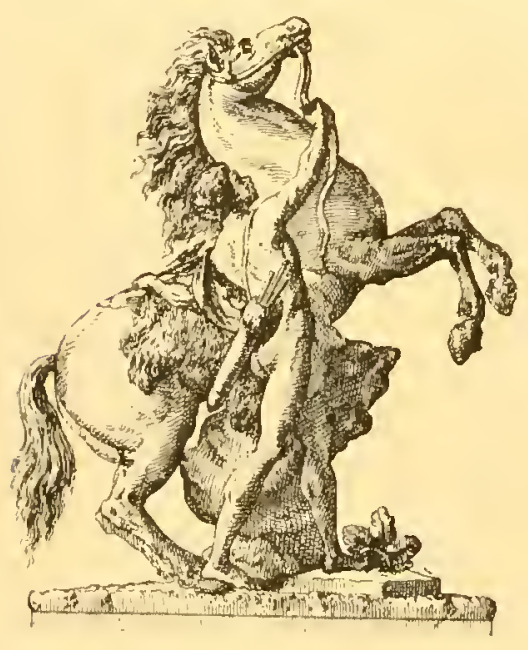
tend aussi ì s'ètablir en Amérique. Nous reproduisons deux spécimens curieux de cimetières américains établis récemment dans ce systeme, ceux de New-York et de

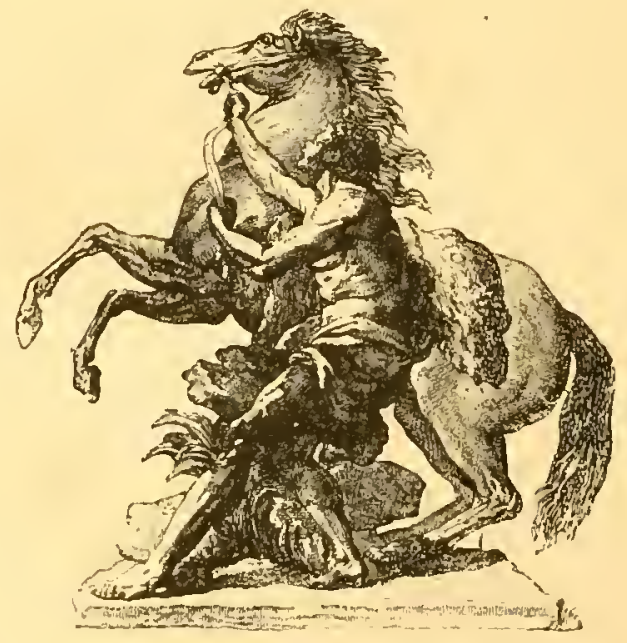

Fig. 478 et 479. - Chevax de Marly, par Coustou, provenant de l'Abreuvoir de l'ancien Chiteau de $11 . u r l y$ - Ces deux Groupes sont placés à l'Entrée de l'Avenue des Champs-Ëlyscées.

Cincinnati (Fig. 483 et 484 ). En Égypte, l'irrigation a produit, depuis quelques années, des merveilles végétales qui rendent vraisemblables les anciens récits. A Alexandrie, sur la betle promenade planté d'acacias et de sycomores qui borde le canal Mahmoudich, s'ouvrent les jardins quasi-publics de Nubar-Pacha, Pastré, Anto- 
niadis, etc. « Ces jardins, dit un voyageur recent, sont courerts de palmicrs (Fig. f $S_{5}$ ),

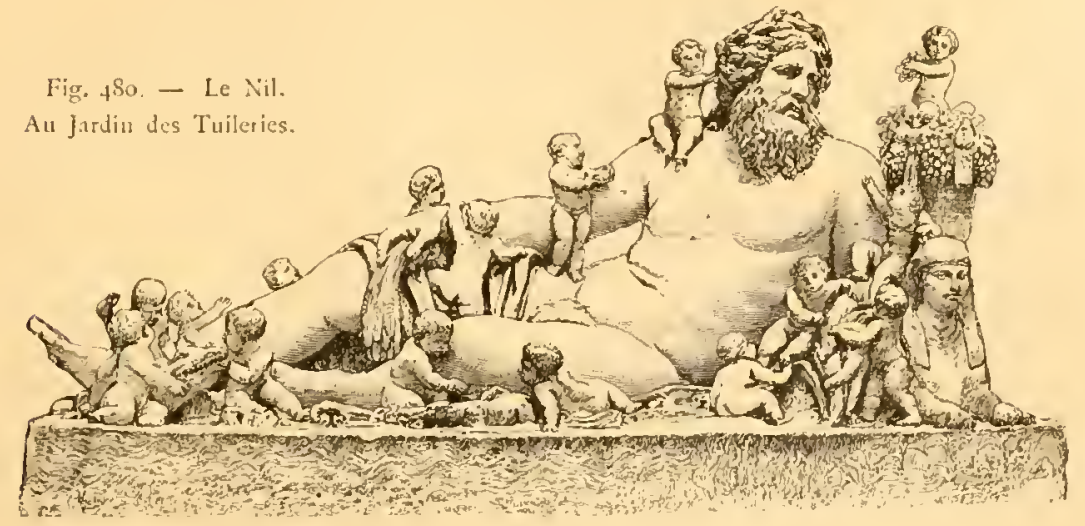

de bananiers, de cactus, d'aloc's, de bambous, de dituras, de mimosas à fleurs jaunes, d'euphorbes rouges, de figuiers bengalais dont les longues tiges, partant du

trone et des branches, viennent s'implanter dans le sol et $y$ tormer de nouveaux arbres... Çá et lí s'élévent des massifs d'arbustes telle-

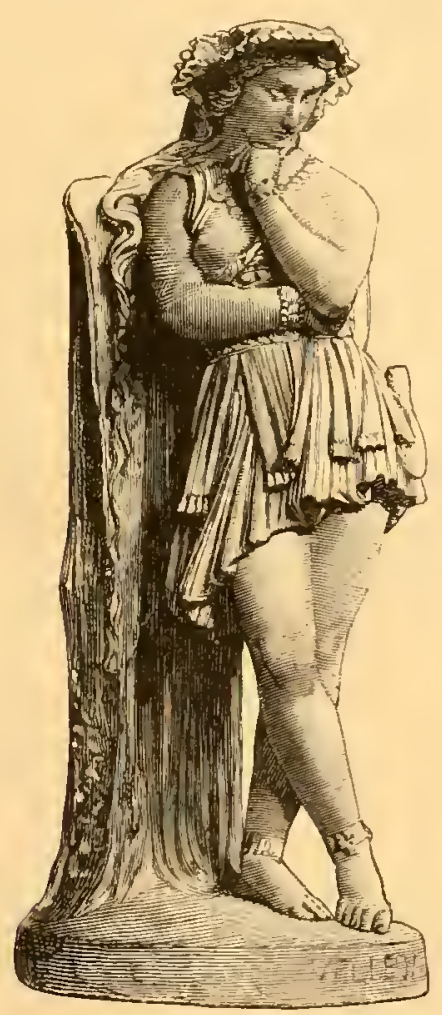

Fig. $4^{81}$. Velleda, par laindron; Jirdin du Luxembourg.

ment ser-

rés que

l'œil a peine à y pinétrer (I)... ». Le même touriste a été fort surpris de voir lá notre herbe d'Oecident élevée en pot et conservée comme une curiositi. Aucune plante n'est en effet plus rare en Égypte, à cause du peu d'épaisseur de la terre, et de lintensité de la chaleur. Les pelouses sont

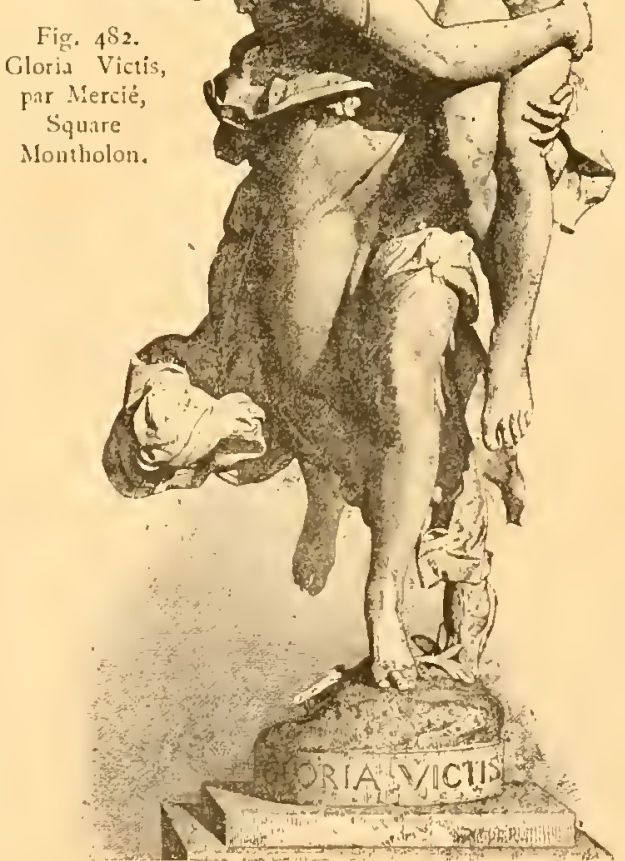
formces d'une espece de plante particuliere au pays, le Zapania nodiffora, verbénacée (1) Charmes, ring mois an Caire et dans la bussi Egrple. 
trouvée à Alexandrie en I 868 par M. Delchevalerie. 11 s'en est servi au Caire pour la transtormation de la place Ezbelich en square à demi parisien, opérée avec le concours de Barillet-Deschamps. Depuis le temps de l'occupation française, cette

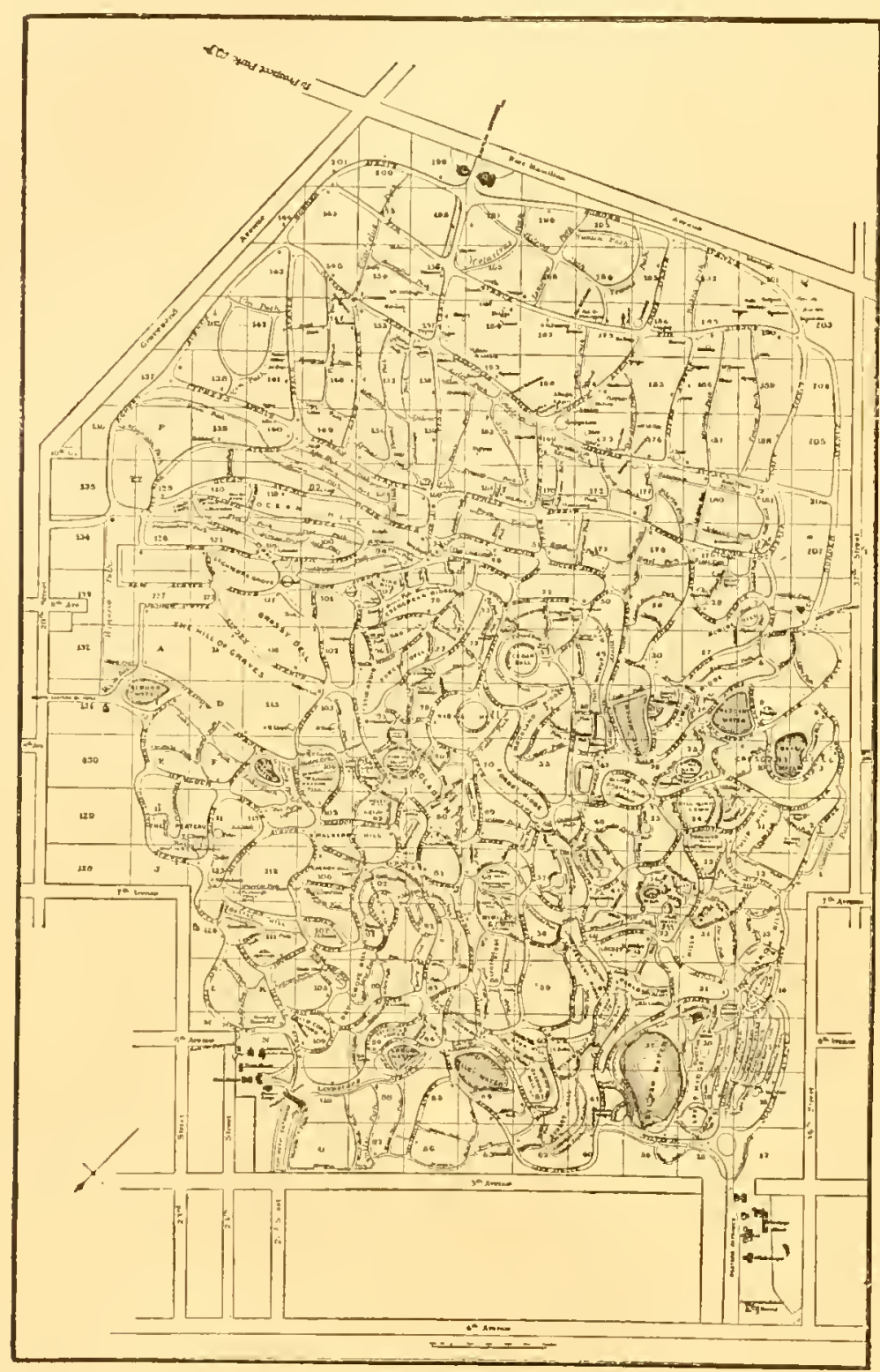

Fig. 483. - Grecn-Wood Cimetiere à New-York. place a subi bien des remaniements. Le tour était primitivement planté de sycomores; le centre, beaucoup plus bas, formait un lac alimenté par l'inondation. Méhémet releva ce milieu, changea le lac en un canal circulaire, mais respecta les arbres. Dans cet état, l'Ezbckich conservait encore une physionomie tout à fait orientale, et c'est ainsi que l'ont représentée un grand paysagiste et un grand poète, Marilhat et Th. Gautier. Celui-ci goûtait peu là métamorphose actuelle. Il regrettait surtout les deux arbres immenses qui figurent au premier plan dans le tableau de Marilhat; " deux mimosas arec un pied monstrueux qu'on aurait cru fait d'une botte de colonnes tordues, et des branches qui étaient elles-mêmes d'énormes trones formant des coudes bizarres, et portant des masses de feuillage à couvrir une forêt. »Il regrettait aussi les maisons arabes qui formaicnt l'encadrement de la place; " avec leurs moucharabichs, leurs étages en surplomb, leurs encorbellements soutenus de poutrelles, et tous les détails caractéristiques que n'avait 
pas encore émondés le progrès. " Aujourd'hui, ces masures que Bonaparte et Kiléber auraient encore reconnues, sont remplacécs par des hôtels et des maisons meublées d'architecture curopéenne; les mimosas et les sycomores, par un pare quasi-parision de huit hectares, avee des variantes de plantations assorties au climat; pare dans lequel les amateurs des Champs-Élysćes et du bois de Boulogne ne se trouvent pas trop - peut-être pals assez - dépaysís! Ce square exporté en Égypte est d'ailleurs dessiné avec goût, et ceux mêmes qui regrettent l'ancienne installation, conviennent que celle-ci sera fort belle quand les nouveaux arbres auront acquis tout leur développement. Quelques-uns, rapportés du centre de l'Afrique par Schweinfurt, font déjà les délices des naturalistes (Charmes, p. 57). Il fallait bien, d'ailleurs, satisfaire le Khédive, qui voulait absolument unc

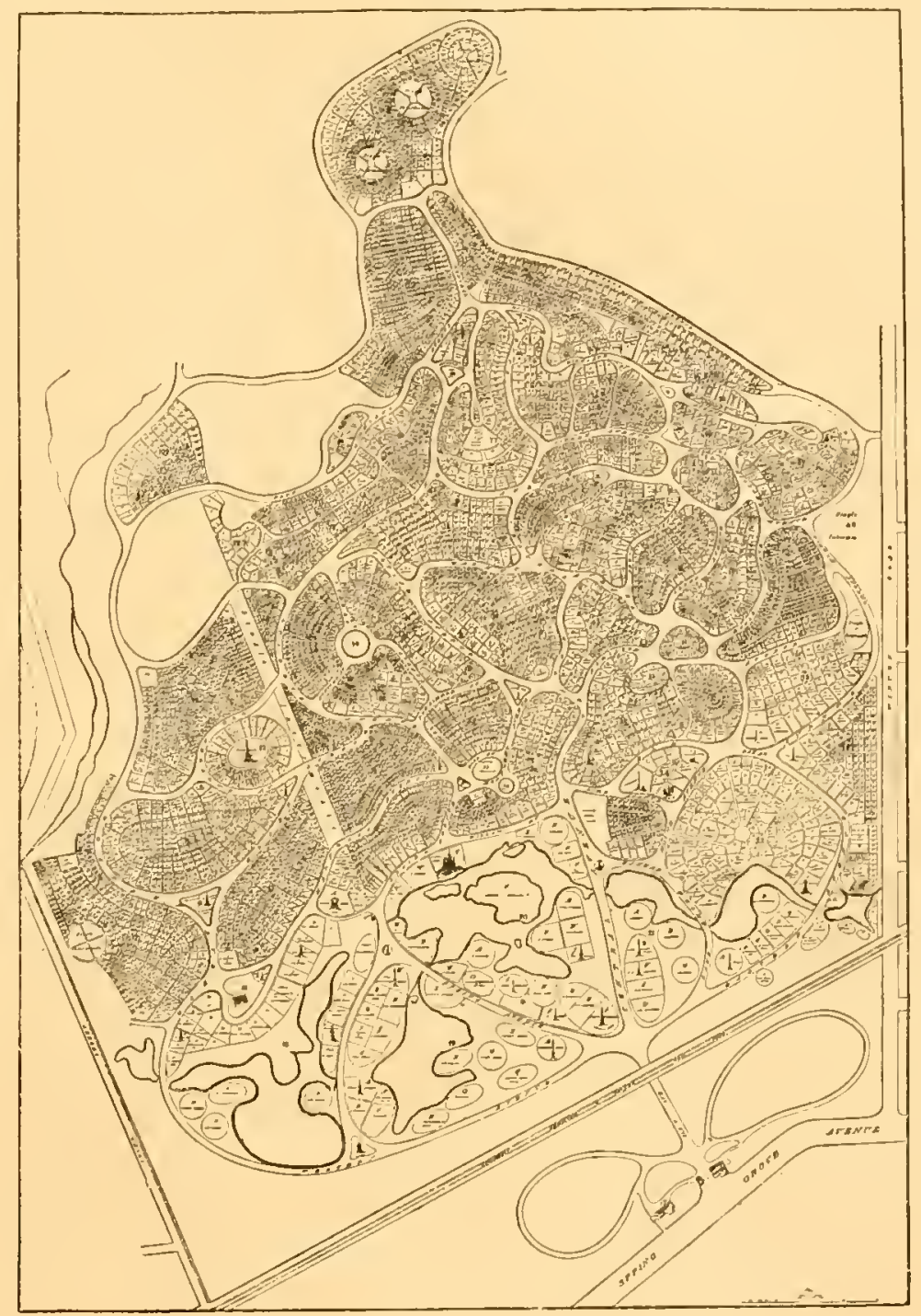

Fig. A S $_{4}$ - Spring Grove Cimetière de Cincinnati. promenade à l'instar des nôtres. Retenir de force les Orientaux dans l'oricntalisme est une idce fort artistique, mais peu pratique.

On déplore également la destruction des belles plantations qui abritaient la ville du côté de l'ouest, où s'étend aujourd'hui le nouveau quarticr Ismailièh, construit a l'européenne. Ces plantations et bien d'autres avaient été faites par Ibrahim, aussi grand arboriculteur que grand guerrier. Le quartier neut est percé de larges rues 
droites et de larges boulevards, disposition fort convenable autour de l'Are de l'Étoile, mais moins bicn approprice au climat égyptien. Pour corriger ce défaut commandé, on a planté lorce acacias leblek is feuillage épais, qui poussent vite et domment beatucoup d'ombre.

Le jardin botanique de Calcutta, et le parc de Barrackpour, château de plaisance

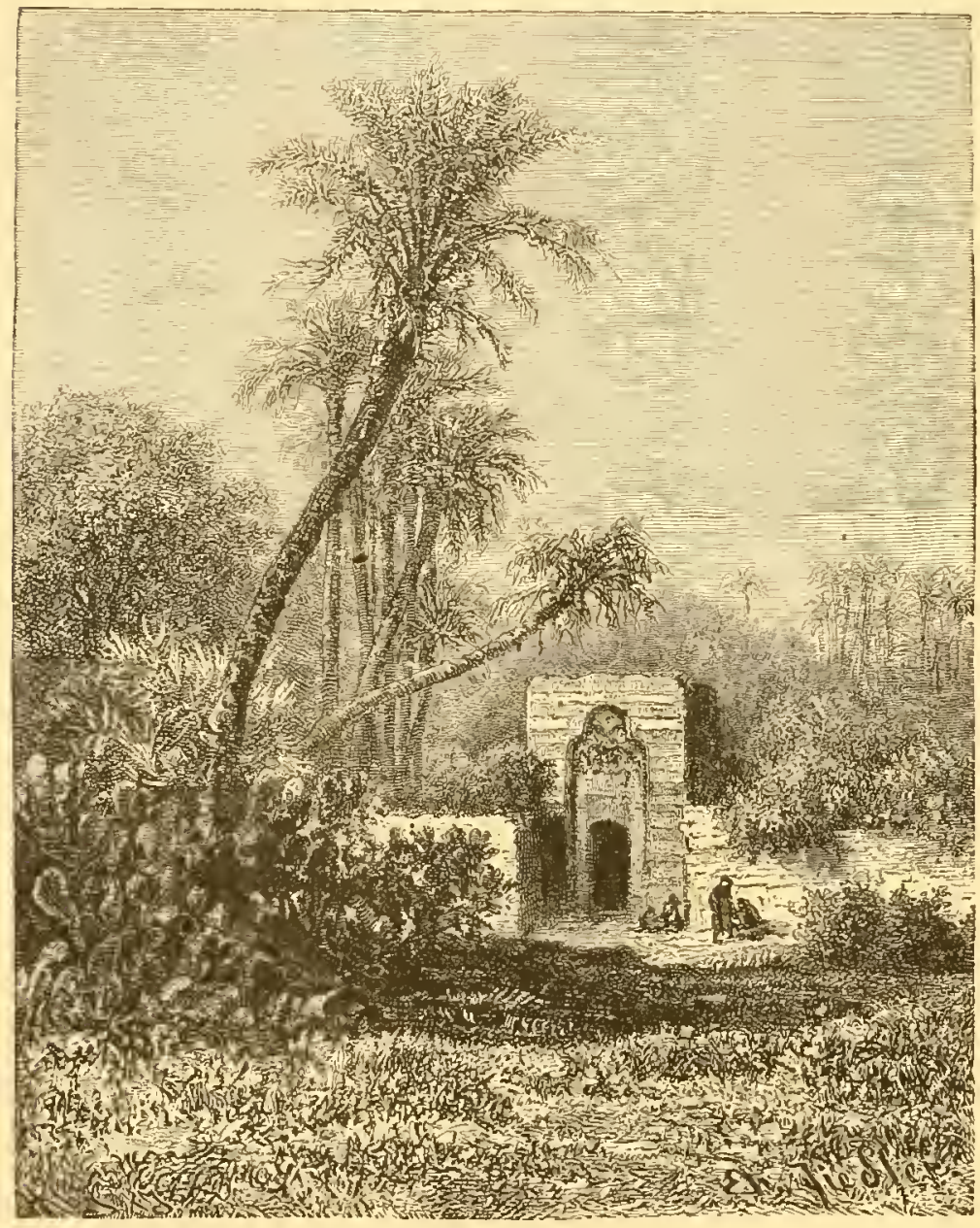

lig. 48 ; - - Jardin igyptien. des vice-rois de l'Inde anglaise, peuvent être considérés comme les plus beaux spécimens des parcs anglo-indiens modernes.

Le Bolanic Garden, qui, suivant l'expression d'un écrivain indigéne, est si grand qu'on n'i pu l'entourer d'un mur de clôture, a été fondé et administré pendant trente ans par le célebre botaniste Wallich, qui y avait formé une magnifique collection de fleurs, d'arbres et d'arbustes, empruntés aux deux Indes, à l'Afrique australe, au Brésil, alux iles du Pacifique et à l'Australic. C'est à la fois un musée végétal et un magnifique jardin paysager. "L'on y voit, dit un voyageur, les belles lianes de l'Amérique du Sud suspendues en guirlandes aux rameaux des plantains gigintesques et du rima de Taïti le muscadier, dont le feuillage de myrte mêle constamment à sa verdure lustrée l'éclat de ses fruits d'or et les teintes délicates de ses fleurs tendres comme celles du pêcher. »

Quant au parc de Barraclipour, il offre encore, après un demi-siècle pendant lequel tant de choses ont changé, le même aspect que du temps de Jacquemont. "A 
force d'argent et de bras, le niveau parfait des plaines où coule le Gange a été assez tourmenté pour animer ce beau pare de quelques mourements de terrain. On y a fait ave goût des montagnes et des vallées, afin d'être obligé d'y bâtir quelques ponts d'un cffet agréable. Sur un gazon toujours vert se dressent, tantôt cn massifs serrés, tantôt cn groupes ou isolés, des manguiers, des pipeuls, des lauriers d'Inde, des banians, des tamarins, des mimosas, des casuarinas, des cocotiers, des dattiers, des borassus et d'admirables gerbes de bambous. Le tour des massifs les plus imposints, et le pied des plus grands arbres, sont garnis d'arbrisscaux à fleurs ou de plantes grimpantes; lauriers-roses, apocynces superbes ou jasmins odorants i larges pétales. Ailleurs ce sont des roses de l'espéce qui s'est répandue si abondamment de ce pays en Europe (Bengale); puis des orangers, des citronniers, des grenadiers de la taille de nos futaies, mais qui ne servent lá

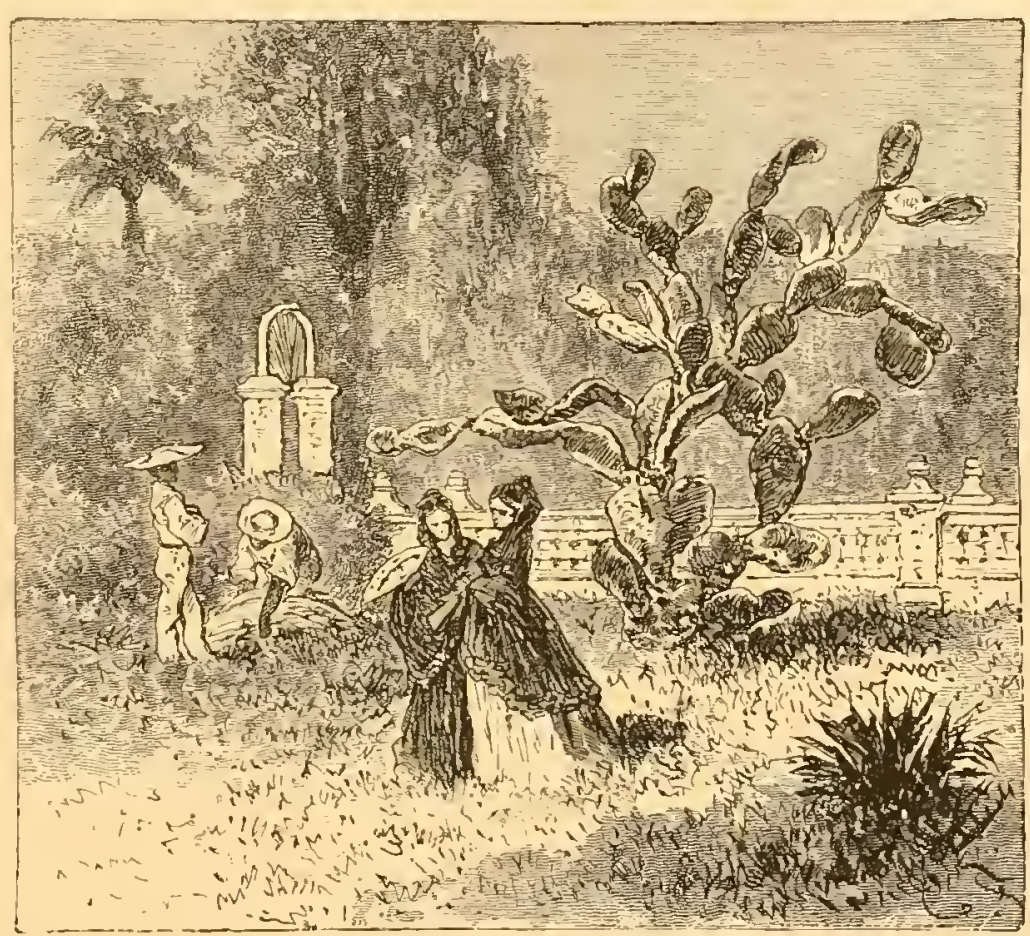

Fig. 486. - Partie d'un Jardiu de Cuba.

que d'ornement. » Suivant un touriste plus récent, "Barraclipoor rappelle Trianon, mais sur une échelle au moins double, avec le ciel ct la végétation des tropiques, des eaux vives et $u n$ grand flcuve pour perspective. „ (De Lanoye, l'Inde contempordine.)

Il faut encore signaler, comme hors ligne, parmi les pares des climats tropicaux, celui du palais de Buitenzorg, résidence ordinaire du gouverneur général des Indes néerlandaises, ì 48 kilométres de Batavia. "Toute lal végétation des zones chaudes ou tompérées du globe est représentée daus ec splendide jardin, depuis les plus luumbles mousses jusqu'aux arbres les plus élevés. Tout ee que les se̊rres les plus riches de l'Europe conticnnent de plus curieux, de plus rare, s'étale ici en plein air. Les plantes 
aquatiques garnissent de vastes piéees d'eau, et toute la surface d'un bassin, sans abri, est couverte par les feuilles rondes, à bords relevés, d'une l'icloria Regit, formant comme autant de plateaux réguliers et brillants, d'un mètre de largeur enriron, entre lesquelles s'épanouissent les fleurs de cet immense nénuphar. » (Devay, Journal d'mu l'oy'tge.)

Enfin, nous citerons, conme trís digne d'intérêt, un nouveau pare brésilien, celui de l'élégante villa impériale de Pútropolis, le Santharimm de Rio-de-Janciro, dont nous reproduisons la vue, publice pour la prenicie fois en France (Fig. 487 ).

Nous pourrions indiquer bien d'alutres jardins publics, récemment créés dans toutes les parties du monde; a Sidney, a Ceylin; jusque dans des villes toutes nourelles, comme Port-Elisabcth (Afrique australe). C'est le port d'embarquement auquel peurent arriver ave le plus de facilité les produits de lintéricur; ce qui lui assure un grand avenir, malgré sa situation sur une étroite plage entre l'Océan et l'horrible désert de Karoo, qui commence aux dernières maisons. L'un des premiers soins des habitants a été de « se créer un délicicux jardin, vraic serre tropicale en plein air, orné d'caux jaillissantes, qui semblent narguer les sables embrasés. » (Dn IVeser an Zambeze.) Nous n'ilvons, en Europe, que des images affiiblies de ces splendeurs végétales, racheties il est vrai par de nombreux inconvénients. Mais éest de nous que les habitants de ces régions trop aimées du soleil ont appris l'usage de leurs richesses. Leurs plus beaux jardins publics, crèés ou remaniés depuis i 860 , sont des dérivations plus ou moins immédiates d'œuvres françaises. Les deux figures ci-jointes donnent quelque idée de ces merveilles cxotiques. L'une a ité prise a Cubar l'autre représente lia célibre Vallie de Yosemiti (Fig. 4 S6 et +88 ).

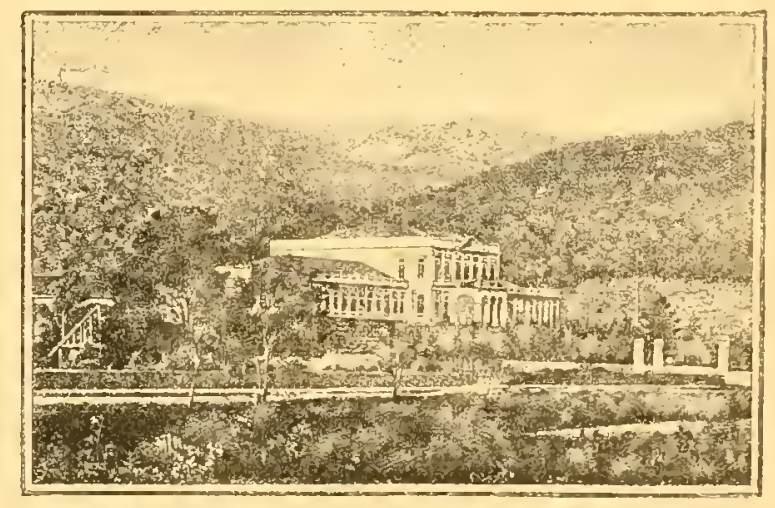

Fig. 487. - Chiteau et Pare imvériax de Pitropolis (Brisil) 
Ainsi qu'on a pu le voir, l'horticulture curopéenne

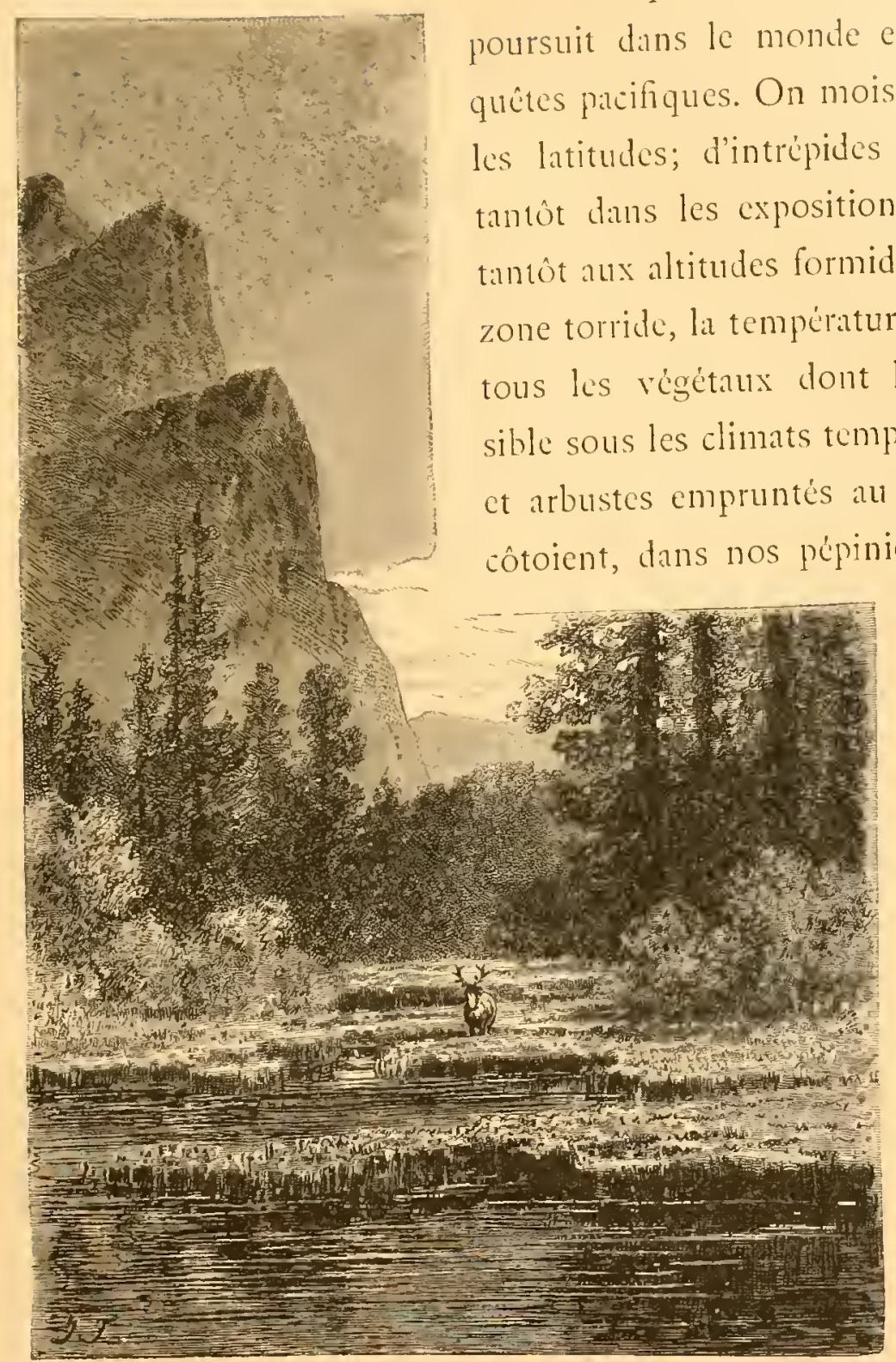

Fig. 4\$3. - Vallée ou Pare naturel de Yosemiti, en Californie.

celles de l'Asie et des deux Amériques. Le dessinateurparsiger a des ressources pour les terrains les plus ingrats. 11 peut même, dans des emplacements trés limités, et sans grande dépense, assigner ì chaque saison sa parure. Il a, pour les premicrs jours de printemps, les arbres ct arbustes clıez lesquels la floraison précéde le tcuillage ou accompagne les premiers bourgeons; arbres de Judice, paulownias, magnolias; les buissons de mahonias, de pommiers du Japon; puis, bientôt aprés, les cytises, les lilas de toute nuance. A ce luxe éphémére de la jeunesse succédent des parfums plus caractérisés, des frondaisons plus vigoureuses. La brillante famille des arbustes de terre de bruyère s'épanouit í son tour, tandis que les feuillages combinés des grands arbres se développent et se colorent, et que les grappes des marronniers, des acacias, puis des catalpas, se détachent en blanc ou en rose sur ces dômes de verdure. Les plus sombres arbres verts participent à ces féeries de la nature; pendant plusieurs semaines leur physionomic sévére est égrivéc par les teintes claires et joyeuses des 
pousses nouvelles. Mais l'automne est vraiment la saison par excellence de nos jardins paysagers. Éclipsée jusque-là par tant de nouvelles venues, fleurs ou plantes à feuillages, la rose "remonte » en septembre, et ressaisit son ancienne et charmante royauté. Bien d'autres fleurs, depuis les dahlias jusqu'aux chrysanthèmes, concourent à la guirlande des derniers beaux jours; et pendant une grande partie de l'année, l'illusion de la végétation tropicale est entretenue dans les plus modestes jardins, même sans le concours des plantes de serre, par les yucats, les cannas, les caladinms et autres végétaux rustiques à grands feuillages. Nais le charme général de nos jardins paysagers pendant l'automne, résulte surtout des teintes si riches et si variées que prennent alors certains arbres indigènes, comme les hêtres, ou exotiques acclimatés, comme le tulipier, le pavia et autres arbres d'Amérique.

Enfin, l'hiver lui-même perd quelque chose de sa physionomie triste et sévére, grâce à l'introduction dans nos pares de ces nombreux coniféres de toute taille et de teintes diverses, depuis ceux qui forment des buissons nains, jusqu’ì ces géants, "gazon des grandes montagnes »; - depuis le vert du Taxus bibernica, sombre comme le destin de sa patric, jusqu'au vert si gai des Cryplomerias, du P. canalensis, du C. Lawsoniana et autres pins, sapins et cyprés étrangers, mais acclimatés et vainqueurs de nos froids les plus rigourcux. La centralisation des conquêtes de l'horticulture nous permet ainsi de reproduire en plein air la verdure iternelle des climats plus chatuds, et les efforts ingénieux de l'art arrachent un sourire à la nature en deuil. Mais, pour faire un digne usage de ces nouvelles ressources, de cette palette végétale aujourd'hui si riche, il faut, aujourd'hui plus que jamais, de véritables artistes!

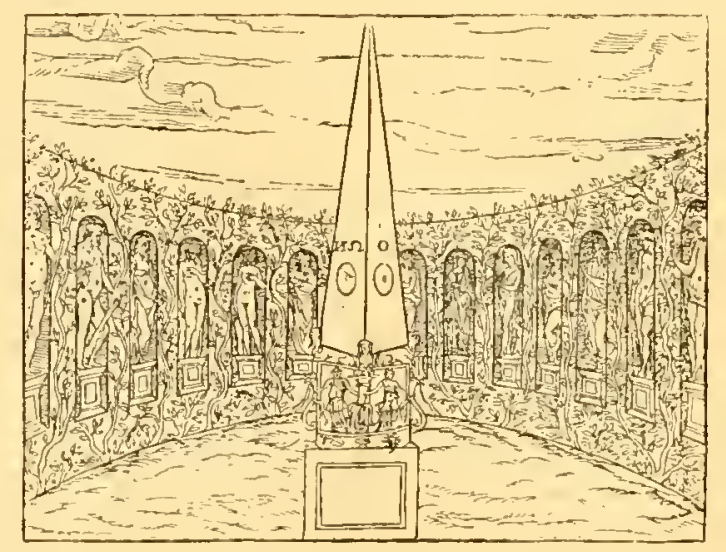

Fig. 489. - Discours du Songe de Poliphile. - Dessin emprunté à l'Édition de motxi, Paris. 


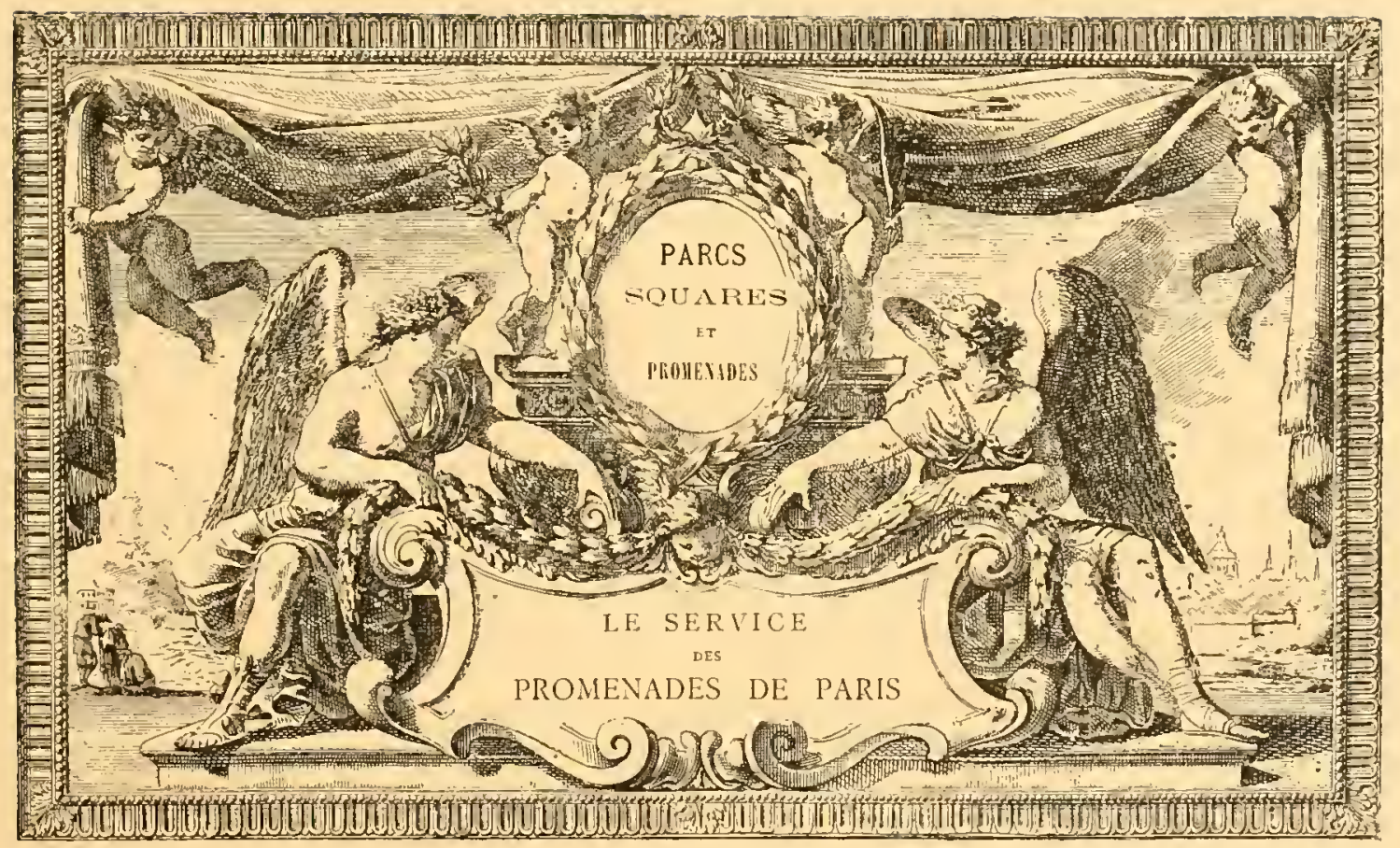





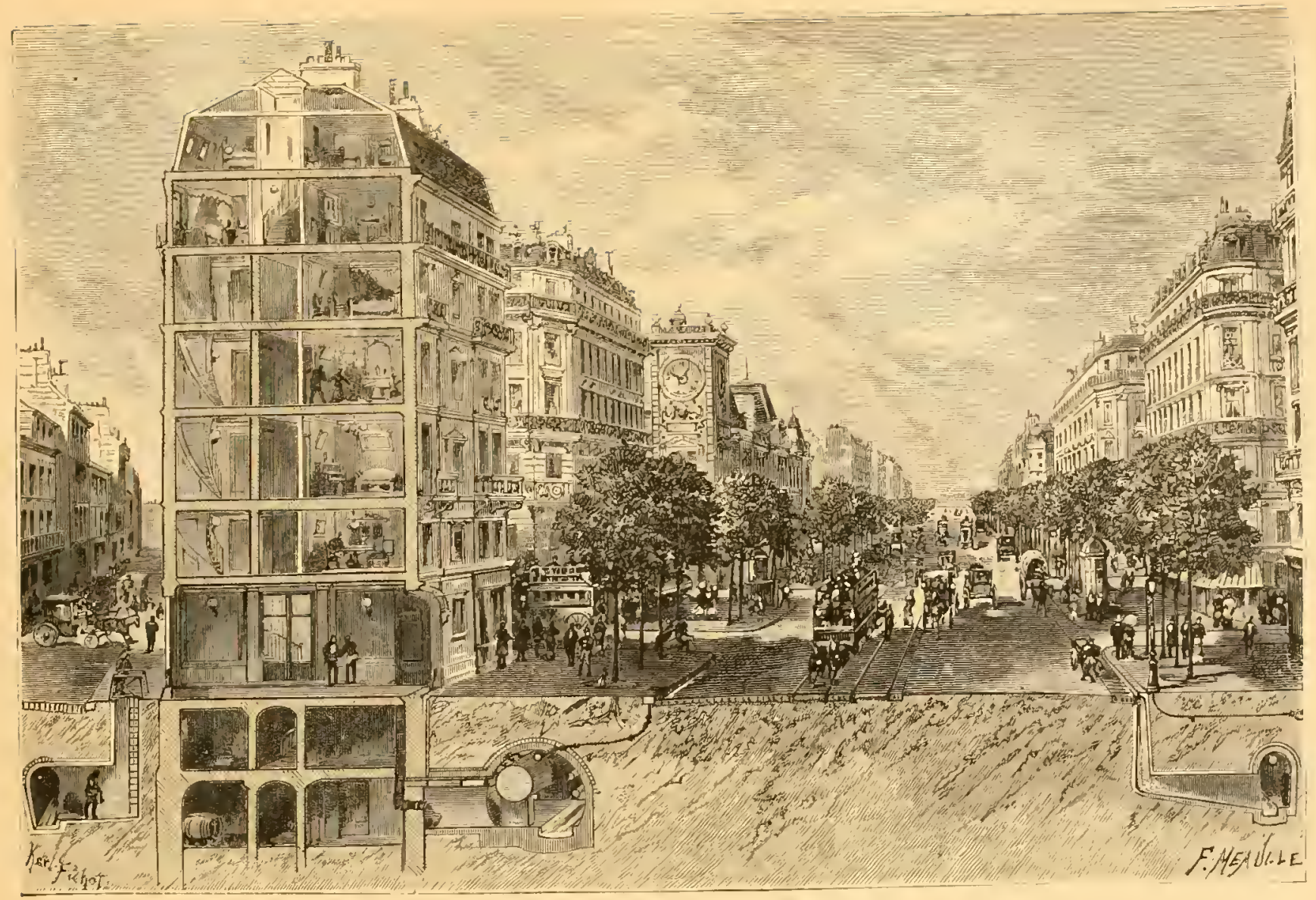

Fig. 49s. - Coupe du Boulevard Saint-Germaiu.

LE SERVICE DES PROMENADES A PARIS

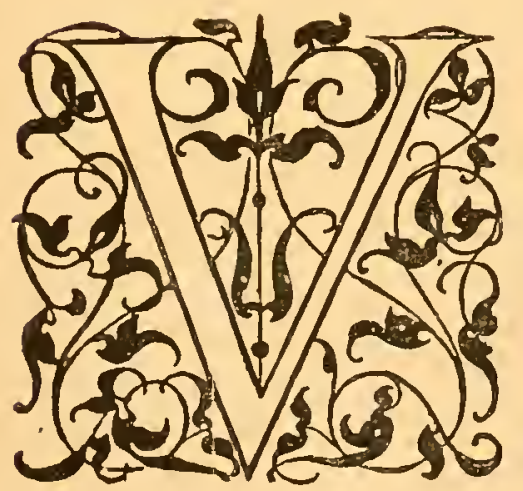

ERS IS4O, le Parisicn n'avilit pour se ricricer qu'un petit nombre de promenades: ${ }^{\circ}$ sur la rive droite de la Seine, le jardin des Tuileries, les ChampsÉlysies, de Palais-Royal et la place Royale, premicre tentative filite par Henri IV pour crier un promenoir populaire; $2^{\circ}$ sur la rive galuche, le jardin du palais du Luxembourg, le Jardin des Plintes, l'Esplanade des Invalides. Nos péres, habitués à leurs rues étroites, ne sentaient nullement le besoin de créer des places; ils n'en réservaient pas même aux abords des monuments 
importants. L'ancien Paris, comprimć pendant sa croissance par des enceintes successives, manquait d'espace, de lumiere et d'air. On avait suecessivement devé jusqu'à cinq étages de hauteur, des maisons qui d'abord n'en avaient qu'un, et celia le long de roies étroites, suffisantes à l'origine, mais qui, à la fin, étaient comme étouffées entre de hautes murailles. On avait installé peu il peu les

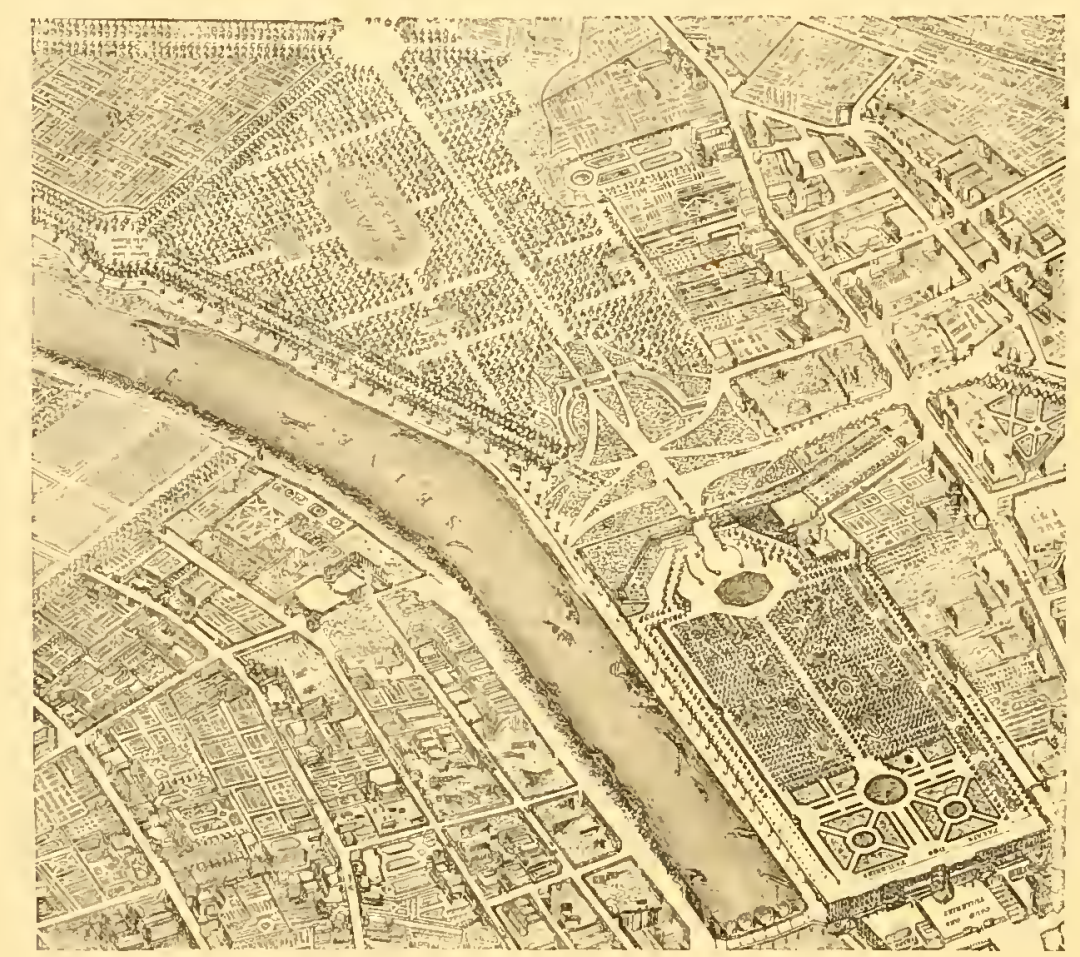

Fig. 493. - Jardin des Tuileries et les Cliamps-[ilysces en 1733.

D'apres le Plaı de Turgot. maisons d'une grande ville en bordure des rues d'un village.

Louis XIV avait tracé quelques grandes et belles arenues sur l'cmplacement des ancicns boulevards et autour de l'hôtel des Invalides, mais ces voies itrient fort mal cntretenues. Les vicux Parisiens doirent se souvenir de ec qu'étaient les arbres des boulevards et des Cliamps-Élysics il y a quarante ans; rien n'était plus piteux que ees débris de l'ouvre du grand siécle. Les arbres ćtaicnt alors traités comme des intrus sur les roics parisicnnes. On ne songeait guére aux jurdins publies à cettc époque, et celui qui cn aurait purlé cût scmblé ridicule. Quelle utopic! des ombriges, des fleurs pour les p.ıssants affairés! des jardins pour les marmots!

En ISjo, quand on commença à menacer de la pioche ce tas de vieilles maisons, on songexit surtout a ouvrir quelques roies indispensables, comme le prolongement de la rue de Rivoli, le dégagement des Halles, etc. Or, précisément sur le parcours de la rue de Rivoli, se trouvait la Tour Saint-Jacques au milicu d'un quarticr infect. Cette tour, que l'on avait songé à démolir en l'an V, et que la Ville arait ahetic en $18 ;$, débris superbe d'une époque artistique, si 
féconde et si originale, arait été isolée en i $85 j$ et restaurce ensuite. L'administration municipale décida, en isj6, que sur l'emplacement du marché provisoire qui environnait la tour, il serait établi un square, c'est-i-dire un jardin public, un jardin à l'usage des Párisiens. Cette création cnchanta le public; ce fut comme une révélation. Le succís fut tel, que d’autres jarlins durent ître organisés coup sur coup : en 1857 , ce fut celui du Temple (F...); en I 858 , la transformation des Champs-Élysées; en 1859 , les squares Sainte-Clotilde, Louvois et des Innocents; en $\mathrm{I} 860$, le pare de Monceau; en 1862 les Jardins des Batignolles, de Montrouge et de Charonne; en I $86_{3}$, ceux des Arts et Mé-

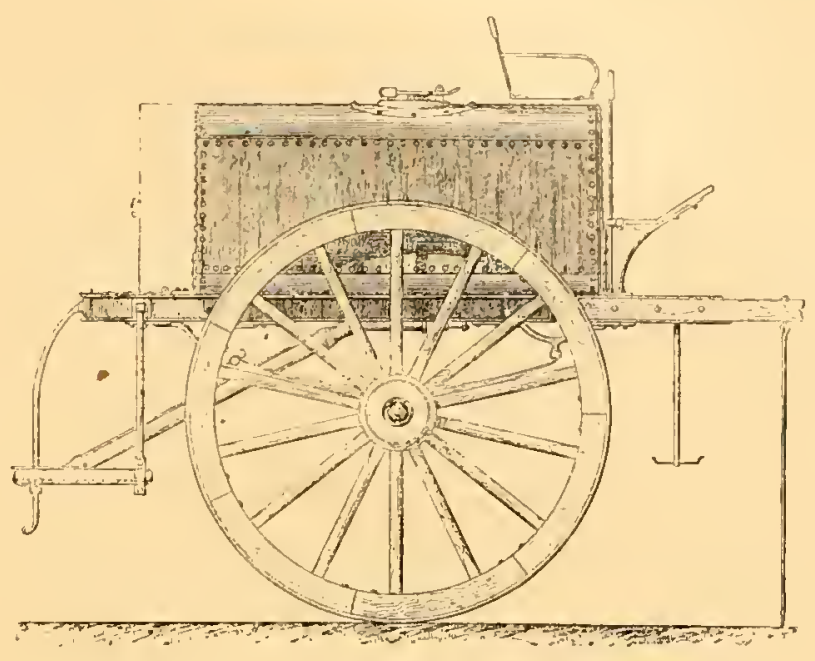

Fïg. 494. - Voiture pour arroser les grandes Voies. tiers et Montholon; en I864-1867, le pare des Buttes-Chamont et le square Laborde, etc.

Dés 1852, le bois de Boulogne avait été cédé par l'État à la Ville de Paris á condition d'opérer en quatre ans son changement è parc paysager.

En is 5 quelques travaux de jurdinage avaient été commencés par l'État dans le Bois de Vincennes, qui faisait alors partic de la dotation de la Couronne. Il était situé à l'opposé du bois de Boulogne, et l'idée vint naturellement d'en faire une promenade pour les habitants de cette partic

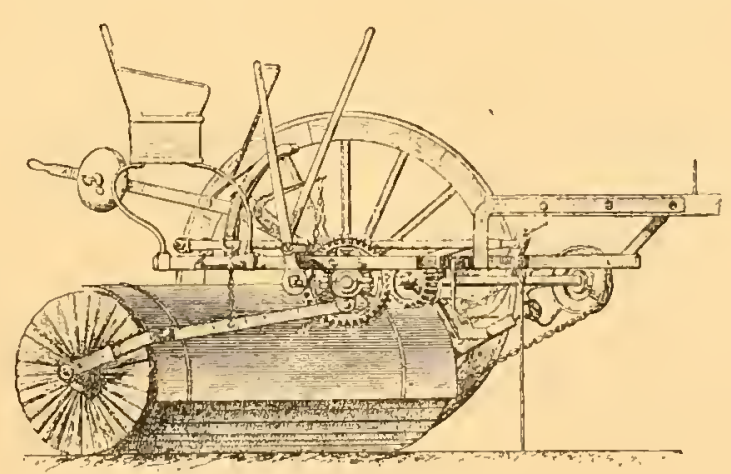

Fig. 49j. - B.layeuse. de Paris. En I860, il fut cédé à la Ville, et c’est à partir de cette époque que cette métamorphose fut sérieusement entreprise.

Le service des promenades avait été organisé à l'occasion des travaux du bois de Boulogne. Les promenades de Paris! c'était à cette époque quelque chose d’idéal qui faisait sourire les gens à courte vue; elles devinrent bientôt une réalité des plus séduisantes. Sous la direction du chef de ce service, la vicille Capitale prit peu í peu un air 
de jeunesse et une grâce qu'elle n'avait jamais eus. Les avenues plantées à demi d'arbres souffreteux et mutilés, furent nettoyées, restaurées, transformées; tout était à faire ou it refaire dans cette partie de la voirie, tout, méme l'échairage! Lorsqu'on songe it

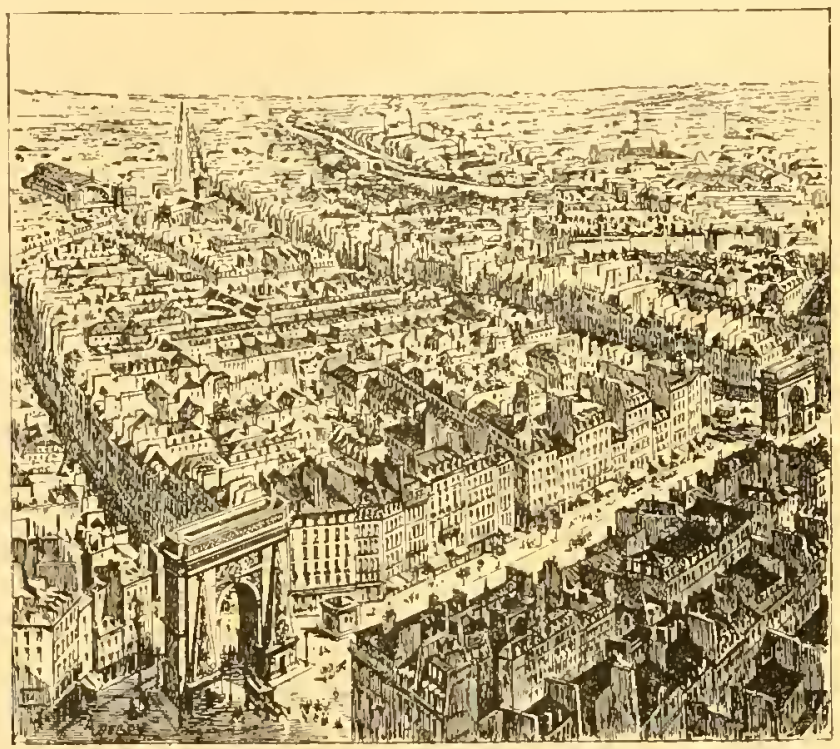

Fig. 4y6. - Vue du Quartier de la Porte Sain'-Denis avant si Transformation.

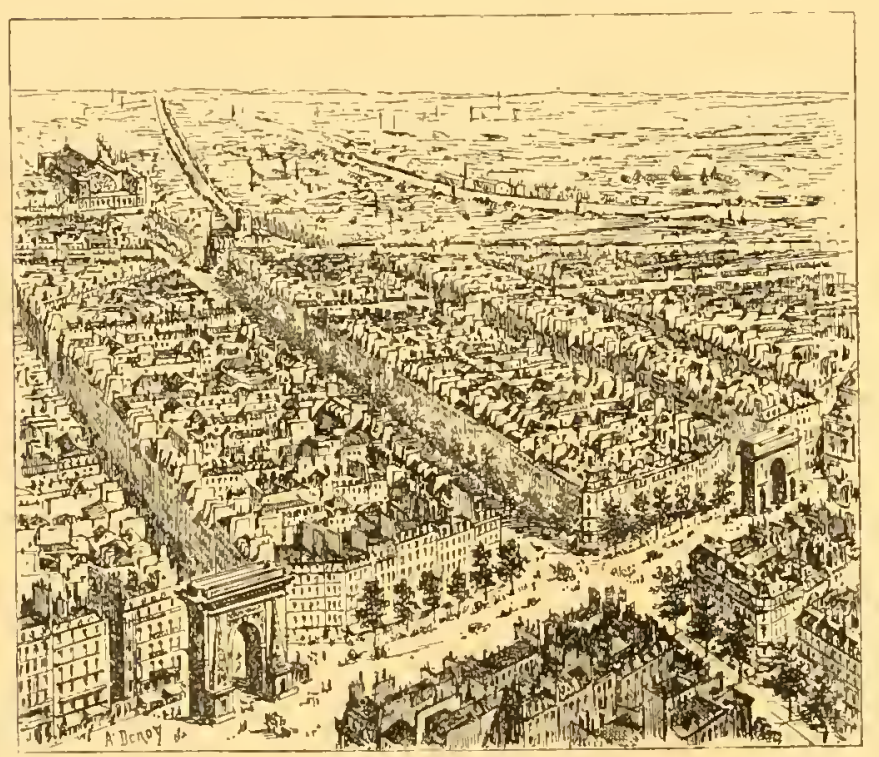

Fig. 497. - Vue du Quartier de la Porte Saint-Denis aprés la Création du Boulevard de Strasbourg. l'uncien citat des boulevards entre la Madeleine et la Bastille et qu'on voit l'état actuel, on croit rêver.

Cette transformation parait maintenant toute simple, mais il a fallu étudier le probléme, le résoudre. Toutes les solutions paraissent faciles quand elles sont faites. Il fallait alors créer, redresser, niveler les clatussées et les trottoirs, placer les arbres, choisir les essences (I), étudier le système de plantation des grands arbres, les faire vivre, les défendre, déterminer l'espacement des candélabres, trouver un meilleur modèle, changer mêne les lanternes, tracer la ligne des feux, placer des bancs, dessiner des liosques, refaire tout, jusqu'au profil des voies. On peut dire, sans exagération alloune, que le service des promenades a complètement renouvelé l'aspect de Paris.

Les squares et les autres jardins de Paris n'ont pas été faits seulement pour

(1) Les prineipales essences comployées sont le platane, le marronnier, le vernis, loome, liacaci., liérabie ct le paulowni.l. 
le plaisir des yeux. Sans doute la question d'art eût suffi à justifier ecs créations, mais les jardins publics dans les villes sont des ceuvres non moins utiles qu'agréables. Quand on pense à cette énorme agglomération parisienne, à ees millions d'habitants cntassés, chugés les uns sur les autres dans des logis ou l'espace est si parcimonicusement mesure; quand on examine les propriétés dont les bitinnents couvrent toute lal surface utilisable de terrains coûtant quelquefois jusqu’a j,ooo francs le mètre, oú les constructeurs laissent i peine des cours suffisantes pour l'acringe et l'éclairage, on doit considerer comme une nécessité la formation de larges voies et de surfaces plantées, assez spacietises, assez rapprochics pour ventiler ces masses de pierres qui semblent percies de couloirs étroits, la largeur des rues étant moindre que la hauteur des maisons.

Autrefois, pour respirer un peu d'air pur et jouir du soleil, il fallait, ou gagner des promenades éloignćes, ou même sortir de Paris; aujourd'hui, les Parisiens ont à leur disposition des jardins répartis à peu près également dans tous les quarticrs de la Ville. Les méres qui vont passer quelques heures sous ces frais ombrages pour y allaiter ou y faire jouer leurs bébics,

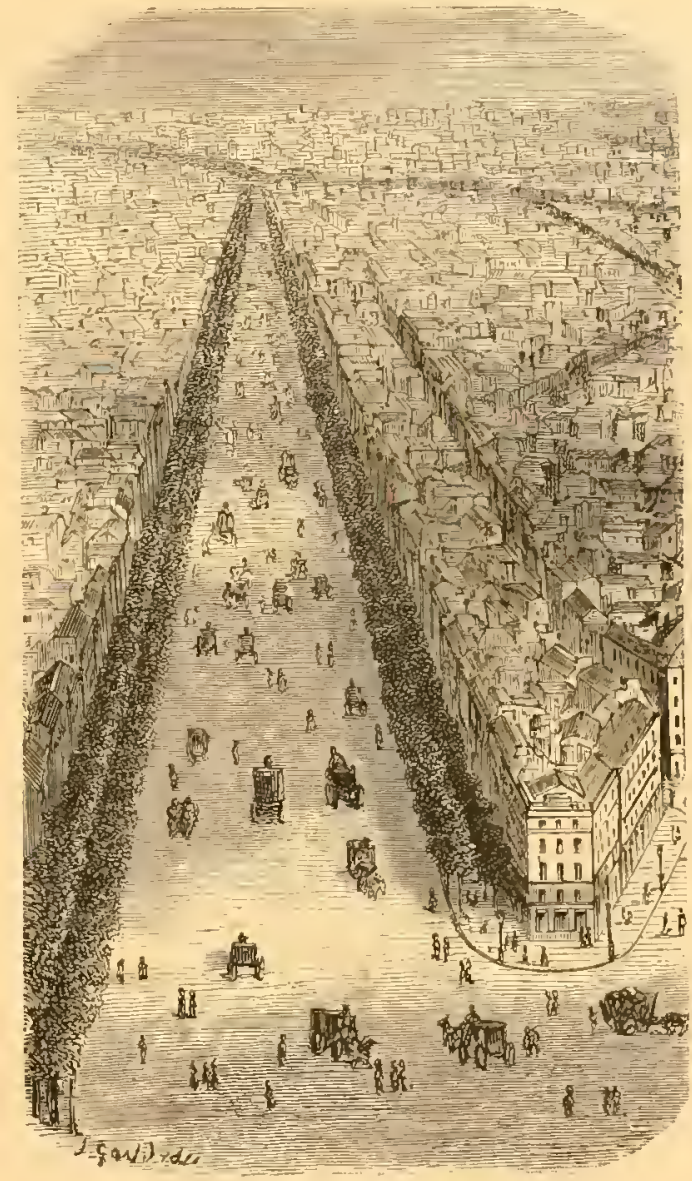

Fig. 498. - Vue du Boulevard Beaumarchais. doivent remercier l'homme intelligent qui a ardemment travaillé à réaliser cette œuvre vraiment démocratique. Combien de charmants petits êtres lui doivent Ja santé ct même la vic! Et les piétons fatigućs qui s'y arrêtent un moment lui doivent aussi une bonne pensée; il est certain que bien des projets violents, des rêves pénibles ont dû s'évanouir, que plus d'un désespéré a dû reprendre courage dans ce milieu reposant.

Les squares sont, en été, de vrais salons de verdure pour la plus grande partie de la population. C'est lít que le soir on se réunit pour jouir un instant de la fraicheur 
de l'air, qu'on se délasse l'esprit et les membres, que l'on oublie un instant les préoccupations de la tâche quotidicnne.

Les grands jardins des $x v 1^{\mathrm{e}}$, $x v 11^{\mathrm{c}}$ et $x \mathrm{v} 111^{\mathrm{e}}$ siècles étaient des promenades particuliéres; un trés petit nombre de privilégiés pouvaient seuls y p'nétrer. Les riches, d'ailleurs, allaient s'installer en dehors de la ville, et, si l'on consulte les plans de Roussel et de

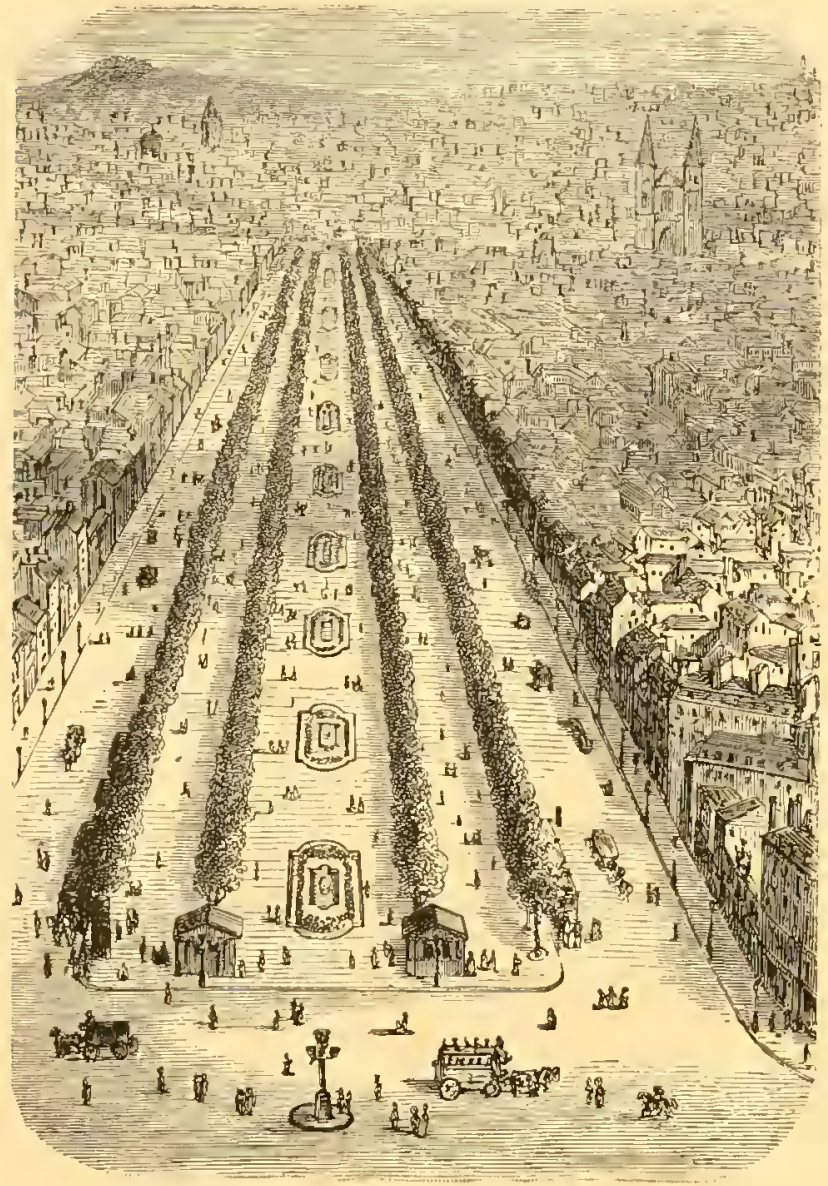

Fig. 499. - Vue du boulevard Richard-Lenoir. Delagrive, on voit que Paris itait entouré de villas qu'encadraient des pares immenses. Chaque localité itait une seigneurie et possédait un château; or, à partir du $\mathrm{xv}^{\mathrm{e}}$ siécle, le luxe des jardins avait été ajouté à celui de l'habitation. Mais les citadins ne jouissaient pas de ce luxe. Il n'y arait pas de propriétés publiques, cela était contraire aux idées du tcmps; peut-être cela cût-il semblé dangereux ou choquant. Depuis, toutes ces jllusions ont disparu. On a pu voir combien les bonnes et belles choses sont encore meilleures, quand l'usage en est rendu accessible i tous.

Grîce au perement de larges roies, à l'installation des Squares, la mortalité a diminué dans la ville; et plus on les multiplicra, plus l'hygiene y gagnera. Outre les modestes jardins de quartiers, on a crée de grandes promenades pour les réunions nombreuses des dimanches et pour les fêtes publiques. Ces beaux jardins ont déterminé l'embellisscment de leurs environs. Le parc Monccau, restauré, et devenu jardin public, a changé complètement la physionomic du quarticr. Il est à remarquer qu'autrefois sur la place de l'Europe, aujourd'hui suppriméc, on avait planté un jardin entouré de grilles, mais accessible sculement à quelques privilégiés. Aprés le pare Monceau qui n'a que changé de régime, on a tracé et construit 
entièrement le pare des Buttes-Chaumont, installé sur l'emplacement d'anciennes carricres dont l'aspect était hideux, puis celui de Montsouris. Ce dernier est daus une situation un peu exentrique, mais il se corrigera bientôt de ce défaut, car on ne sait pas eneore jusqu'oú peut s'étendre la puissance d'agglomération de Parris.

Les esprits timorés s'inquictent de la dépense. L'hygiéne, disent-ils, la santé est un

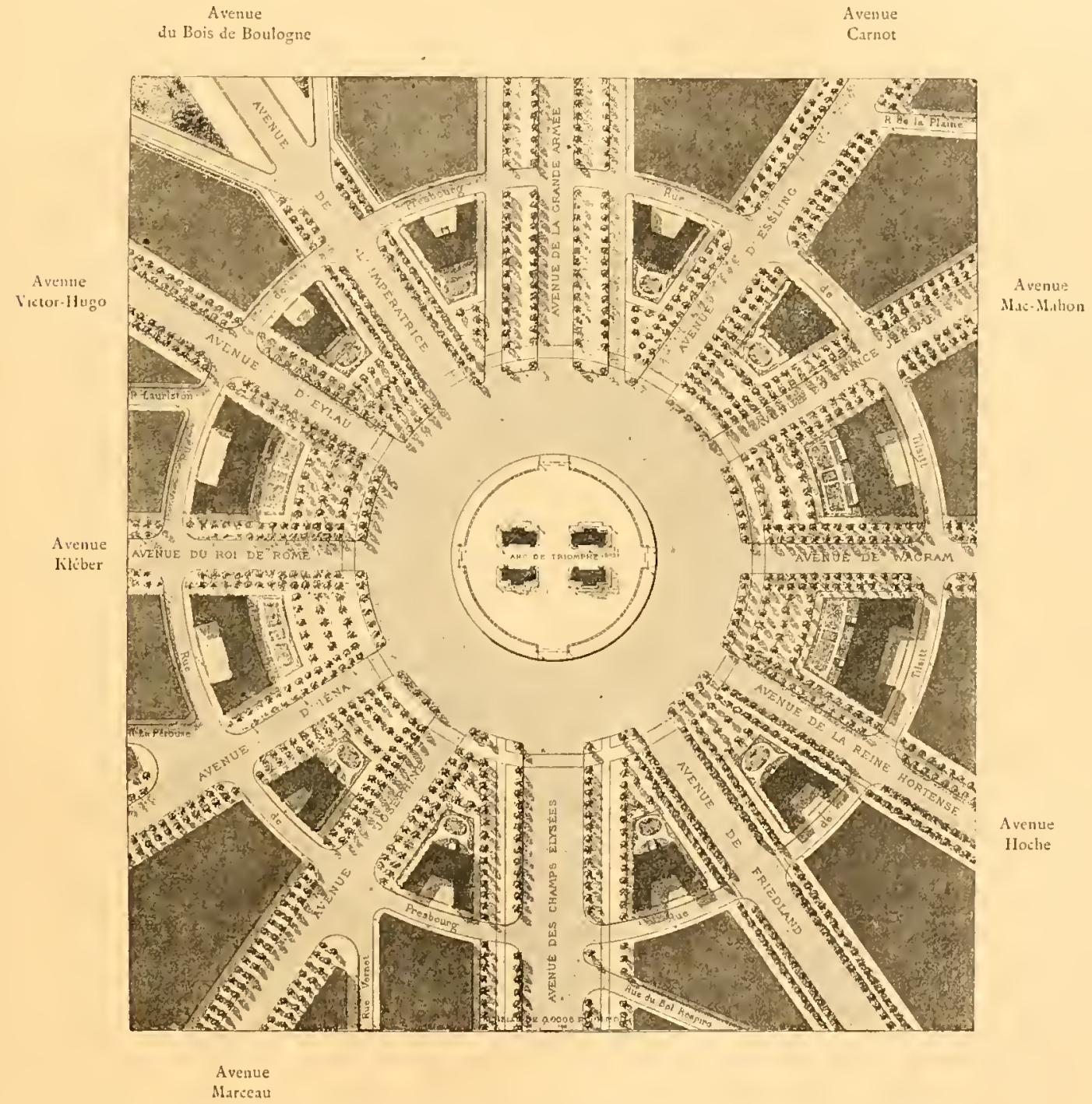

Fig. j00. - Place de l'Are-de-Triomphe (avec la Dénomination nouvelle pour certaines Avenues).

bien, sans doute, mais l'argent aussi est un bien, et il faut l'économiscr. Qu'ils se ras surent! la Ville a fait de beaux jardins et en même temps de bonnes affaires. Les dépenses des Bois de Boulogne et de Vinecnnes, des pares Monceau, des Buttes-Chaumont, de Montsouris, les Champs-Élysces, des squares au nombre de 
vingt-cinq, des places, de l'avenue du Bois-de-Boulogne, cte., ont coûté ensemble trentecing millions de franes environ (1). Cette somme est-clle trop élevéc pour une ville comme Paris? Nous croyons que les Parisiens n'ont rien à regretter, sinon qu'on n'ait pas fait plus en dépensant davantage. En effet, voyons les résultats! Non sculement Paris a eu l'honneur d'inaugurer ces créations ćlégantes et si utiles, que les étrangers se sont empressés d'imiter, mäs ces jardins ont été payés et au delá par ceux qui sont venus de loin pour s'y promener. Il serait curieux, si cela itait possible, de faire le compte de ee que les Champs-Élysées transformés en jardins, les bois de Boulogne et de Vincennes, le Pare Monceau et eclui des Buttes-Chaumont ont rapporté á la Ville en recettes de toute nature.

Mais il faut cneore considerer les plus-values que ces travaux ont fait acquérir aux propriétés voisines. Que valait le métre de terrain alux environs du pare Monceau avant l'ouverture du boulevard Malesherbes, de l'avenue de Messine et l'arrangement du pare Monceau? Environ jo francs; aujourd'hui, ce prix est de 400 franes en moyenne. Les terrains aux environs du bois de Boulogne qui valaient autrefois de I franc so a 6 franes le metre en valent de 100 ì 350 aujourd'hui. Passy et toutes les localités dans les mênes conditions, les quartiers des Buttes-Chaumont, de la Santé, des Batignolles, ont joui d'avantages analogues. Que valent les locations en bordures des grandes voies et sur le périmétre des squares? Assurément plus que dans les rues voisines. La richesse particulicre ítant l'élément de la richesse générale, l'augmentation de valeur des immeubles se traduit en augmentation de recettes dans les caisses municipales.

Indépendamment des plantations de jardins, Paris compte, pour l'ornement des avenues qui atteignent 236,562 mètres de longueur totale, 109,3jo arbres; tout le monde sait quelle animation ces beaux arbres domnent aux anciens et aux nouveaux boulevalds. Cette verdure contribue it embellir la Ville, autant que les maisons nouvelles et les monuments. Disons encore que ces voies magistrales ont été complétées par des bines, des fontaines, des édicules variés. Elles sont plus hospitalieres, et ont aussi grand air que les arenues des pares des anciennes seigneuries. Notons également, que les constructeurs, les capitalistes ont dû élever le

(I) Les bois de Boulogue et de V̈inemmes comprennent une surface de $1,7+7$ hectares. Les pares des ButtesChammont, de Monceau et de Montsouris couvrent sisemble 49 hectares; les Champs-Élysćes et les autres jarlins \$48,c00 mètres environ. 
long de ers belles avenues des maisons mieux étudices, mieux décorées. Ces demeures plus confortables ont exiggé le renouvellement des anciens modéles cmployés dans l'industrie du bâtiment. Ce travail considérable était, sans doute, l'effet de la mode et du progrès, mais il a été énergiquement stimulé par les efforts de la municipalité. Les visiteurs étrangers, frappés de cette transformation, ont emporté le désir d'amćliorer, eux aussi, l'aspect de lcurs villes. L'exemple a été contagieux, et, de proche en proche, un travail immense a été accompli, travail dont le prix serait fabuleux si l'on essayait de l'évaluer.

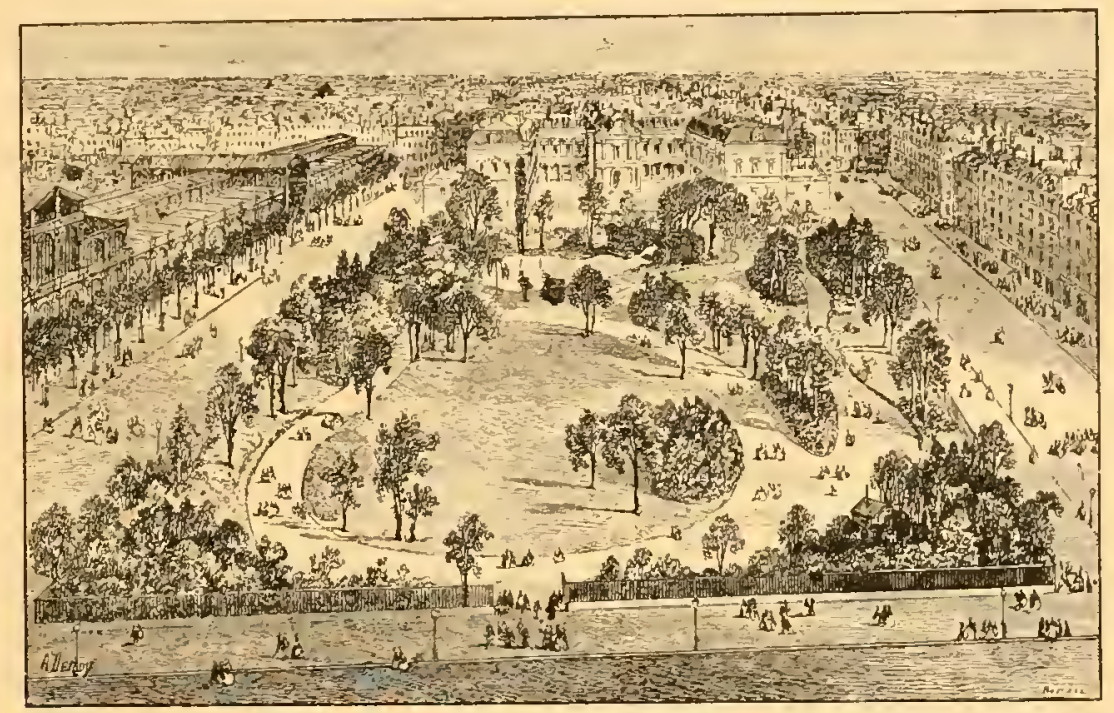

Fig. jor, - Vue à vol d'Oisenu du Square du Temp̧le.

On craignait d'abord que ces plantations élégantes ne fussent parfois dégradées; cette crainte était chimérique. La population apprécie ce bien-être; elle sait que tout cela lui appartient, et l'esprit conservateur se déreloppe rite, quand on a quelque chose à conserver.

Comme nous l'avons dit précédemment, dés le début de l'organisation du scrvice des plantations, on avait críe le jardin horticole et les serres pour la culture des plantes. Grâce au Fleuriste, bien des végétaux qui n'avaient jamais quitté les serres, ont été employés dans les massifs ou dans les parterres. On a perfectionné la transplantation des grands arbres; on a assuré lcur reprise et leur durie au moyen de soins particuliers et du drainage; collectionne un grand nombre d'espéces jusqu'alors inconnues aux jardiniers, des plantes à feuillages varies ou it riche floraison, qui ont permis de donner aux noureaux 
jardins un aspect gracicux et original. Cette acclimatation de plantes nouvelles a exigé beaucoup de persévérance et d'observations délicates. Mais l'effort a complitement réussi, il en est résulté que les richesses horticoles se sont fort accrues, que le goût des beaux végétaux s'est développé, et qu’une industrie un peu délaissée a pris une place importante dans l'art décoratif. A ce point de vue aussi, il y a eu bénéfice.

Elégance, santé, richesse, c'est par ces trois mots que l'on peut résumer l'effort fait par le service des Promenades. Ce progrés ne s'arrêtera plus! Non seulement Paris n'a pas trop entrepris ni mal dépensé, mais il lui reste beacoup à entreprendre et de plus en plus on y verra s'accroître le nombre des jardins. C’est lá, en effet, un correctif indispensable à l'aspect de ces longues rues si monotones et si banales. Il faut bien le dire, nos cités laissent grandement à désirer sous le rapport artistique; de plus, la vie que nous y subissons s'éloigne sensiblement de la nature. Nous devrions vivre au grand air, au milieu de la verdure, mais les habitudes prises nous contraignent a accepter des conditions bien différentes. Il cst done indispensable de ménager dans nos villes des espaces assez vastes pour que nous puissions y retrouver cette douce verdure dont l'aspect est salutaire à l'âme aussi bien qu'aux yeux.

Les travaux de plantation devraient marcher de front dans les villes avec ceux de construction. On a été longtemps à le comprendre, mais aujourd'hui la démonstration en est faite, le tracé d'une ville doit comprendre des jardins publics. Il reste sculement à déterminer la surface à occuper par les maisons et celle à consacrer aux végétaux. Cette verdure est encore plus nécessaire dans les quartiers populeux que dans les autres; pour peu qu'on y réfléchisse, on entrevoit là tout un art à crécr. Les villes se sont déreloppées et s'agrandissent encore un peu au hasard, les intérêts privés ne s'accordant pas souvent avec les intérêts généraux. Mais il devient de plus en plus évident que la création d'une ville est un problème complexe et trés difficile, que sa croissance doit être métliodique et entourée de toutes les précautions que prescrivent la science et l'art. Les jardins des villes n'auront pas l'ampleur des grands pares qui accompagnaient les demeures princières; leurs dimensions seront plus modestes, mais il importe d'en multiplier le nombre, afin de les mettre á la portée de tous les habitants. Ces salons verts et fleuris seront désormais l'annese indispensable de la voirie urbaine, et comme la dépendance des propriétés du voisinage dont leur proximité soutiendra, augmenteral 
la valeur. Quand ces améliorations seront largement réalisées partout, et cela ne tardera guére, les villes auront perdu leur aspect souvent maussade. Ce sera pour elles le commencement d'une ère nourelle, et pour les habitants, un chapitre des plus attrayants de l'art moderne.

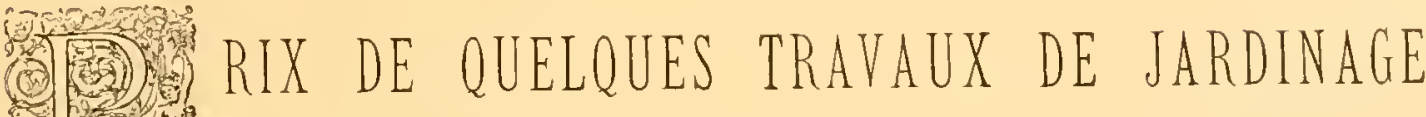

\author{
A PARIS
}

Journécs d'ouvicr $\left\{\begin{array}{c}\text { Chef d'atclier. . l'heure } \\ \text { Compranon .. - } \\ \text { Terrassier ... - } \\ \text { Bûcheron et } \\ \text { charretier . . - }\end{array}\right.$

Cheraux et roitures $\{$ Tombereau. . l'heure Cheral... -

Gravillon, pour allées. . . . le mitre cube

Terre régétale. ..... -

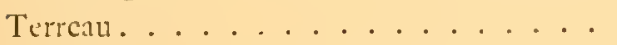

Fumier . . . . . . . . . . .

Perches pour tuteurs, de 2 à 4 mét. la piéce

$\begin{array}{lll}- & 4 a 5 & - \\ - & 5 a 6 & - \\ - & 6 a 7 & -\end{array}$

Tuteurs de $I^{m}, 50$ de hauteur et de $0^{m}, 09$ de circonference ....... . le cent

Tuteurs de $1^{\mathrm{m}} 20$ de hauteur et de $\mathrm{o}^{\mathrm{m}}, 06 \mathrm{de}$ circonférence ....... . le cent

Corsets-tuteurs de $2^{\mathrm{m}}$ go de hauteur, en treillages, composís de dix brins de châtaignier rcliés par sept cerceaux on bois attachés avec du fil de fer; carbonisés et peints à deux couches ....... la pièce

Les mêmes, non carbonisés. . . . -

Corsets-tuteurs en fer, imprimés au minium et pesant if kilogr. .........

Défoncement du sol à cntaille ourerte de $\mathrm{O}^{\mathrm{m}}, 3 \mathrm{O}$ de profondeur, compris brisement des mottes .... . le mètre superficiel
Plus-ralue par on, 10 de profondeur . . . . " $\mathrm{O}_{\mathrm{f}}$ Binage, compris ratissage ct cnfouissement

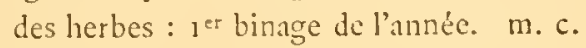
Les autres binages . . . . . . . Labour à la bêche de $0^{m}, 15$ à $\mathrm{O}^{\prime \prime \prime}, 20$ de profondeur, pour pelouses, bordures ou gazons, compris réglement du sol, crile. vement et misc en tas des racincs et pierrailles. . . . . . le mètre carré Labour à la charrue de $\mathrm{o}^{\mathrm{m}}$, is 5 à $\mathrm{o}^{\mathrm{m}}, 20$ de profondeur, compris fourniture du matéricl par l'cntrepreneur..... l'hectare soo "

Le même, le terrain en culturc . . - 60 ”

Hersage arec un cheval, matériel fourni par l'entrepreneur ............... I5 "... Hersage à bras, matériel fourni par l'entre15 " $12 "$ Trous d'arbres carrés ou circulaires dc : $\mathrm{O}^{\mathrm{m}}, 25$ de surf. et $\mathrm{O}^{\mathrm{m}}, 50$ de profr, le trou $" 075$ $\mathrm{O}^{\mathrm{m}}, 65 \quad-\quad \mathrm{O}^{\mathrm{m}}, 6 \mathrm{O} \quad-\quad-\quad \cdots \quad n 23$ $\mathrm{O}^{\mathrm{m}}, 6 \mathrm{~S} \quad \longrightarrow \quad \mathrm{O}^{\mathrm{m}}$, SO $\quad-\quad$ - $\quad$ "3I $1^{\mathrm{m}} "$ - $\quad \mathrm{O}^{\mathrm{m}}, \mathrm{SO} \quad-\quad \ldots \quad \cdots 4^{8}$ Im

$2^{\mathrm{m}}, 25 \quad-\quad \mathrm{J}^{\mathrm{m}}$ ” $\quad$ - $\quad$ - $\quad$ I 35 $4^{\mathrm{m}} " \quad$ - $\quad 3^{\mathrm{m}} "$ - $\quad$ - $\quad 26 q$

Dressement de talus, régicment de forme, $y$ compris une fouille de moins de $\mathrm{o}^{\mathrm{m}}, 20$ d'épaisseur...... le mètre carré Jet i la pellc, charge en brouctte, en tombereau, en rejet daus ja fouille. le métre cube
"02 
Montage à la hotte, an seau, à la corde, par echelle ou parescalier, de déblais de toute nature, par chaque métre de hauteur, le métre cube. . . . . . . . .

Reprise avec piochage de déblais en cavalier......... le mètre cube

Ramassage de pierrailles. . .

Ratissage, y compris le ramassage de pierres. . . . . . le métre carré

Ratissage simple d'allies sablíe on enfouissage de graines. . . . le mètre carré

Régalage de déblais ...........
Pïonnage par conches de $\mathrm{o}^{\mathrm{m}}$, so le m. cube Répandage de sable. . . . . 1) 20 Scmis de pelouse, comprenant le répandage de
3) 25

)IS

3 )

) 002

3005

"os li graine, passage au rateau et roulage. l'h. Roulage aprés semis, arec un cheval a bras d'homme $200 \%$ $5)$ Découpure de bordure en terre ou en gazon....... le métre linénire $60 \%$ Les remblais de terre sont comptés suivant le cube de la tranchée, c'est-à-dire avec unc réduction de $1 / 6$ sur le volume de la trre transportíe. . . . . . . .

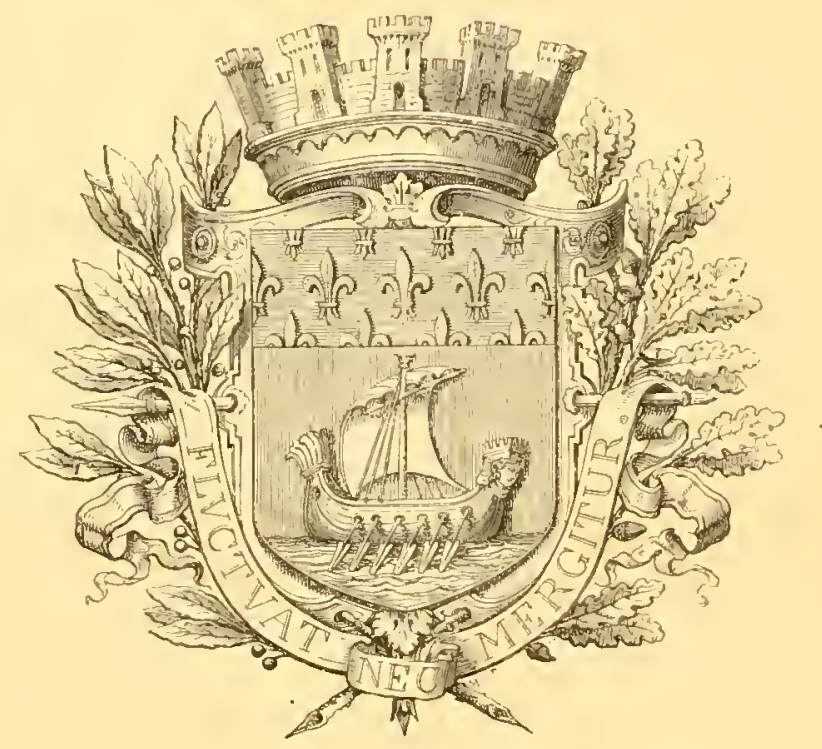




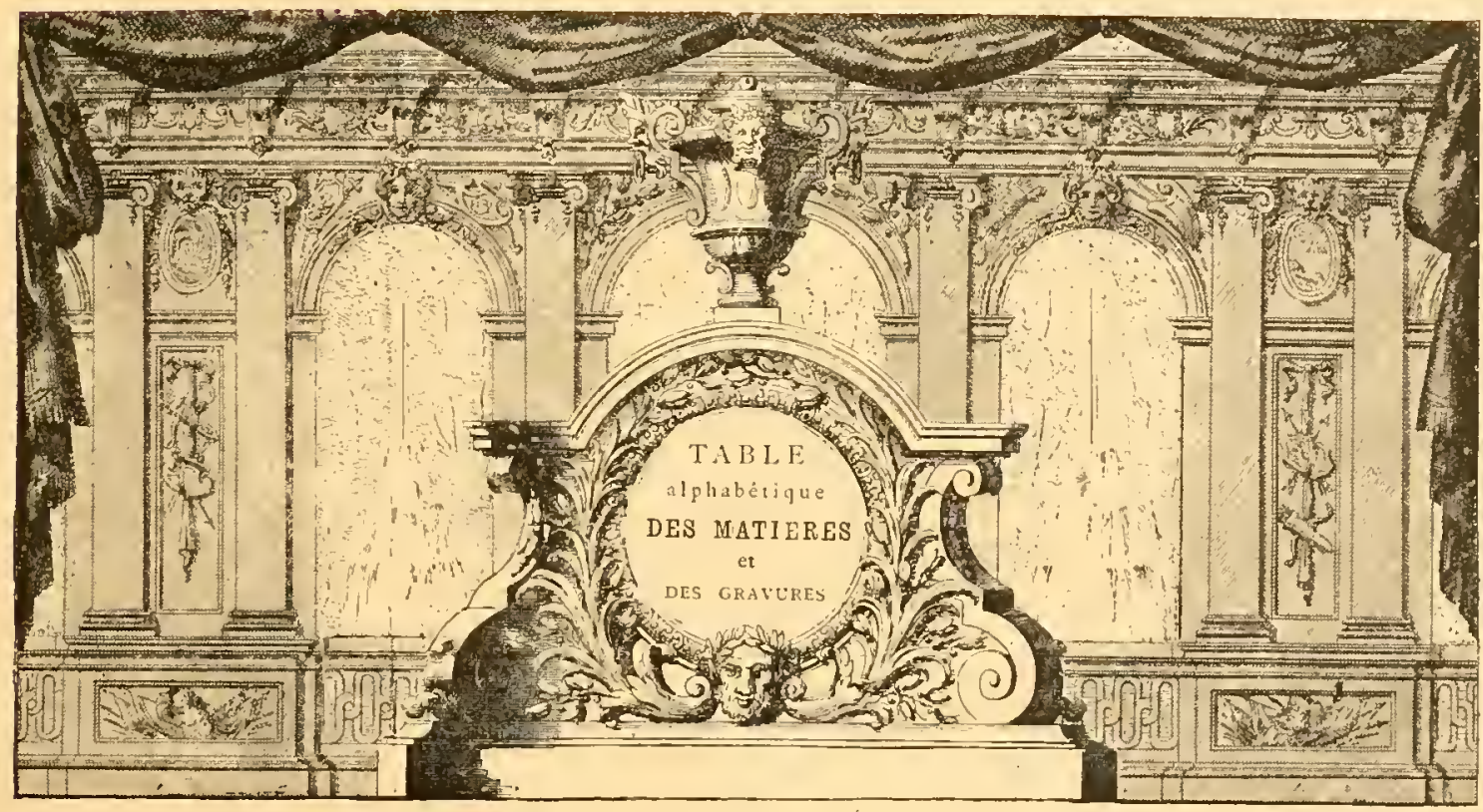




\section{ERRATA ET ADDITIONS}

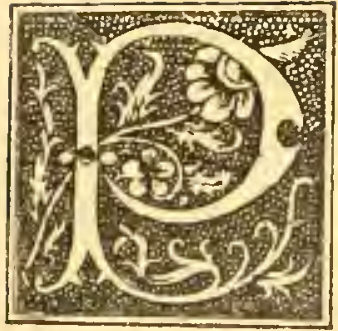

AGE I 4 , note, an lien de : Noshîm, lisez̃ : Nàshîm.

Page 33, au lien de : Fig. 32, lisez : Fig. 33 .

Page 5t, ligne $3 \mathrm{I}$, au lieu de : 1774 , lise : $17+4$.

Page 73 , légende de la Fig. $\$_{3}$, an lien de: $\mathrm{XVI}^{\mathrm{c}}$, lisez: $\mathrm{xVII}^{\mathrm{c}}$.

Page 92, ligne 2 : an lien de: Woodskock, lisez : Woodstock.

Page 92, ligne 6 : an lien de : description, lisez : disposition.

Page 9t, note I : au lim de: de de Pérelle, lisez : de Perelle.

Page 107, ligne 1, an lien de : Iddisson, lise' : Addison.

Page 110 , numéro 26 de la légende, au lie't de: Grotte et silex, lisez: Grotte en silex.

Page İ̈, ligne I2, apris : à feuilles d'if, ajouter : (Taxodium semper virens).

Page I 5 , ligne 30 , an lieu de : iréguliers, lise z : irréguliers.

Pağe I63, légende de la Fig. 200 , au lieu $d c^{*}$ : Bleenheim, lisez : Blenhein.

Page I72, supprime les lignes avant-dernic̀re et dernière, et lisez : dans le paysage javanais (Fig. 232); le pont, d'une structure originale, est egalement en osier.

Page I79, Fig. 227, an lien de : ormosum, lisez : formosum.

Page 150 , Fig. 22S, au lieu de : Jardin La Flora, lisez : Jardin Flora.

P. Igo, Fig. 2 f $^{8}$, légende, au lieu de : Élévation de l'Exèdre, lisez : Exèdre.

Page, 193, Fig. 256, légende, nu liez de : Rocailles au pied, lisez : Soubassement en rocailles.

Page I95, ligne 18, ant licu de : (Fig. 257), lise'z : (Fig. 265).

Pige 200 , au licu de : Mayer, lisez: Mejer.

P.nge 202, légende de la Fig. 275, an licu dit : Fig, lisez: Fig.

Page 204, légende de la Fig. 282, au licu di : Ferdinanda eminens, lisez : Acanthus lusitanicus.

Page 219 , la Figure 303 doit être retournce.

Page 223, ligne 27 : an lien de : deservoirs, lisez : réservoirs.

Page 223, ligne 29, au licu de : reversoir, lisez : réservoir.

Page 224 , les Figures 315 et 316 doivent être retournées.

Page 227, ligne 10 , an lien $d c$ : Nous figurons ici, etc., lisez: Nons donnons ici quelques rues d'entrées des l'romenades de Paris et des grands Parcs des environs.

Page 230, ligne dernière, an lien de : Toutefois, lisez : Nèrnmoins.
Page 235 , ligne 28 , supprimer : des.

Page 262, Fig. 391, ajoutcr la note suinate : Cette allee, taillee dans un bois d'arangers aree palissades fleuries, offre une analogie frappante avec la description du parc de Clagny, par $1]^{\text {me }}$ de Sevigné. (l..p. 82 .)

Page 264 , an lien de : Fig. 439, lisez: Fig. 394.

Page 282, ligne 28, au licu de : Parc, lisez: Park.

Prge $2 s_{3}$, ligne 9, au liew de: de, lisez : du.

Page 286 , lignes I et 4 , remplacer : riant, par : gracieux.

- ligne 2, au lien de : selon, lisez: dans.

- ligne 9, au lieu de : fancs, lisez : côtés.

Page 285 , passim, au lien : d'oeils de Christ, lisez : oils du Clurist (Aster).

Page 289 , legende, lettre $m$, an licu de: C'e banc ouvre la vue, lisez: De ce banc, on a vue.

Page 293, ligne 22, an lieu de : effervescence, lisez : efflorescence.

Page 297, légende de la Fig. 427, au lien de : au, lisez : du.

Page 300, Fig. 43I, légende, ajouter: Ces parterres occupaient une partie de l'avenue actuelle de Breteuil.

Page 302, ligne 8, ajouter: Ces nymphes ou genies apportaient uu portrait laissé en blanc dans la gravure. Peut-être celui de Mercure, qui devait être le dieu favori de Dangeau, joueur et tricheur émérite.

Page 3Ig, ligne avant-dernięre, après: Pré-Catelan, ajoutez : spécimen intéressant de plantations d'arbres et d'arbustes à feuilles persistantes.

Puge 3I6, ligne awant-dernière, au lieu de : assimiler, lisez : approprier.

Fig. 4\$S, p. 339, Vallée d'Iosemiti. Ia meilleure description de ce parc naturel justement célèbre, est celle qui fait partie de la Promenade antony du Monde, de M. le baron de Hübner. On jouit la de plusieurs des plus remarquables sites de notre plantete, grâce ì l'incomparable beauté des eaux, de la végétation, à la forme élegants et grandiose des montagnes qui encadrent et surplombent cet Eden californien. « La nature r'a étć nulle part meilleur architecte et meilleur jardinier", dit M. de Hübner. Parmi les plus beaux sites de cette vallee, il faut signaler la vue de la cascade à trois étages formée par lil Yosemiti, l'une des plus grandes et peut-être la plus belle du globe; Airral Fall, autre chute presqu'aussi pittoresque ; le Lac Wwoir et les Trois Frères, majestueux pics superposés qui se refletent, arec une prodigieuse nettete de contours, dans ces eaux limpides, etc. Une autre merveille presque comparable a celle-la, c'est le parc naturel africain des bords du Zambèze, dans le voisinage des Victoria Falls, où s'étalent toutes les splendeurs de la régétation tropicale. (V. notre transcrintion du royage de Mohr, Du IIeser au Zambize).

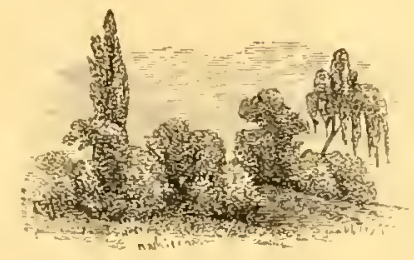




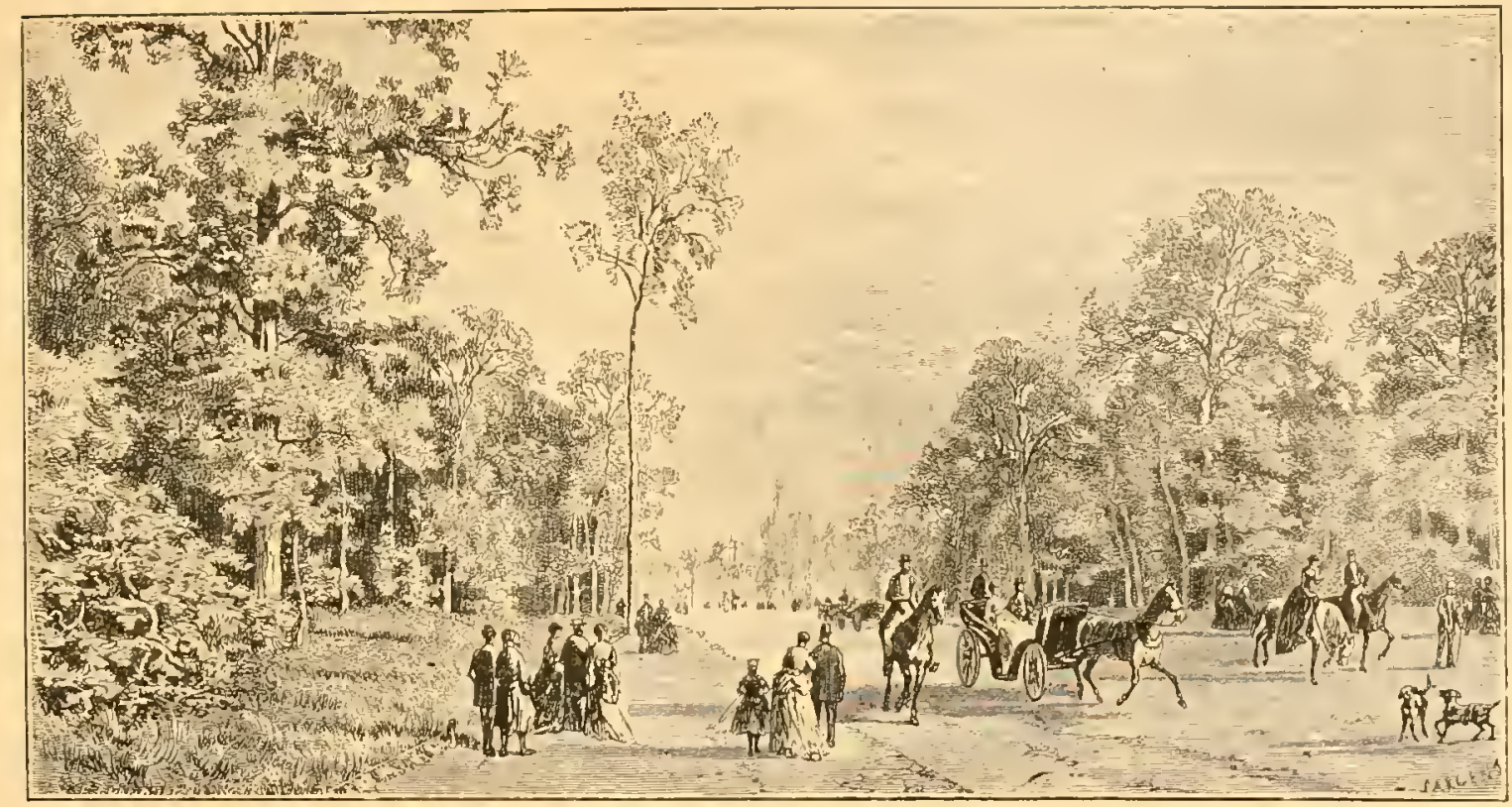

Fig. su7. - Bois de Vincennes, - T'ue de l'Avenue Daumesnil.

\section{TABLE ALPHABÉTIQUE}

\section{DES MATIERES, DES NOMS ET DES FIGURES (I)}

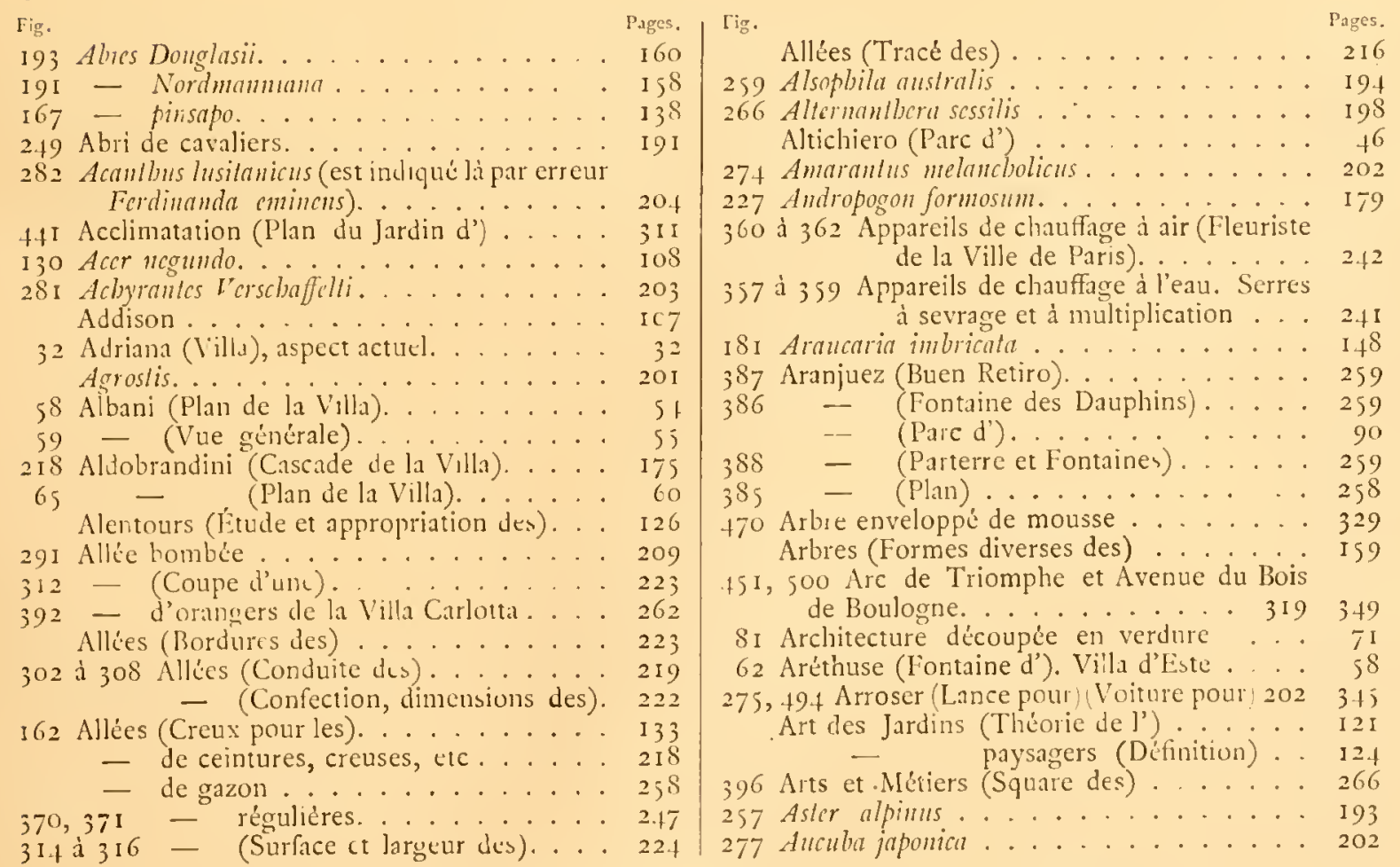

(1) Les chiffres qui présdent les artiiles indiquent lis numieros des iggures; scux qui les suivent désignent les pages du texte. 
Fig.

2 Aula (Restitution d'une)

I64 Avant-projet du Pare de Montsouris .

384 Avenue de la Muette.

507 Arenue Daumesnil .

457 - de lObservatoire

458 - de Tilleuls (Bois de Vincemes).

452 - des Champs-Élysées

451 - du Bois de Boulogne

Ailanthe (Vernis du Japon)

Babylone (Jardins suspendus de)

Bacon (Fr.).

I24 Badminton (Château de)

I 6 Bagatelle (Parc de)

29 Baia (Vue actuelle de)

495 Balayage (Voiture de). .

209 Bamlinsa aurea.

471 et 472 Bancs.

45 Barbaro (Villa)

196 Barillet Deschamps ....... I6I

Barrackpoor (Purc de) ..... 336

230 Barrage sur le ruisseau de Longchamps.

460 Batignolles (Square des)..... I 28

is 7 - V Vue à vol d'oisea

ISo Battersea-Park (Londres).

$4 j+$ Beaujon (Jardin) (Montagnes russes).

267 Begonia rex..........

I:S et I 19 Berghen (Paysage par).

3 +6 Berlolonia gultala.

3 I I Bifurcations.

30I Birkenhead (Parc de), prés Liverpool . .

Biron (Jardin de).

200 Blenheim (Chàteau de).

3. Blois (Château et Jardins de). .

so Boboli (Jardins de), (Fontaine). .

Bois de Boulogne (Corbeilles de l'avenue du).

$\begin{array}{lr}438 & - \\ 437 & - \\ 248 & - \\ 163 & \text { et } 436-\end{array}$

439

4 I 7

444

445

446

Bordures des allées.

Création des Pelouses. .

État actuel .

État ancien.

(Exédre au).

Lac. . . . . . I 34305

Massifs de l'Avenue du.

Vue à vol d'oiseau. . .

Bois de la Cambie, ì Bruxelles. . . . . . .

Bois de Vincennes.

Etat actuel..... 313

État ancicn. ..... 313

Vue à vol d'oiseau. . . 314

et Corbeilles. . . . . . . . . 205

$4+$ Borghèse, Villa. . . . . . . . . . 43

60 - - entrée des Bosquets. . . . 56

49 Borromées (lles) . . . . . . . . . 46

Botanic Garden de Calcutta . . . . . . . 336

499 Boulerard Richard-Lenoir . . . . . $34^{8}$

$49 \mathrm{I}-$ Saint-Germain (Coupe)... 3 $1 \mathrm{I}$

496 et 497 Boulevard de Strasbourg . . . . 346

Boulogne (Bois de) ..... jo6, el suiv.

Boyceau.................. 74

$28 S$ Brassica sinensi. . . . . . . . . 207

Brosses (de)................ $45 \quad 55$

Brown. . . . . . . . . . II If

Buitenzorg (Parc de), a Jaial .... 337

2 Is Buttes-Chamont (Cascide des)..... 173

- $\quad$ (Parc des)..... 314

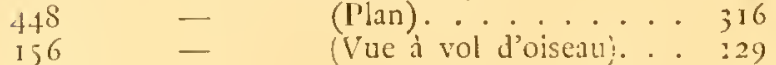

Fig. P.iges.

Cachemire (Jardins de la vallée de). . . . 13

13 - (Vue de)............ I3

173 Caire (Jardin au). .............. 14

338 Colamms Impératrice Marie . . . . . . 235

$3+5$ Calalbea Veilebiana. ......... 238

Calcuta (Botanic Gardens de) . . . 336

Calypso (Grotte de) . . . . . . . . . 4

289 Canna atronigricans. . . . . . . . 207

24 Capitole (Restauration du). . . . . . 25

26 Casa di Sallustio......... 26

2:8 Cascade à la Villa Aldobrandini. . . . . 175

66 - de la Villa Mandragnne. . . . . 61

219 - de Méréville....... 175

2 I5 - des Buttes-Chaumont..... 173

$217-$ du Lac des Minimes ...... 17.1

216 - du Lac supéricur (Bois de Boulogne). I7t

96 - du Parc de Saint-Cloud. . . . . 82

97 - du Parc de Sceanx. . . . . . . 33

220271 Cascade du Parc Monceau . . 176199

406 Cascades du Jardin de l'Elysée. . . . . 272

$26+\quad$ - en face Longchamps . . . . . . 197

268 - (Intérieur des) Bois de Boulogne. :98

3 is Catelan (Entrée du Pré). . . . . . 225

$2+9$ Cavaliers (Abri de).......... :9 I

ISt Cedrus Deodara. . . . . . . . . . IS I

$250+18$ Central Park à New-York. 85 i9 I 28.4

465 Cerclage des Mottes......... 328

Chambers ............ I I3

298 Chamarops excelsa............ 213

152 Champs-Ëysées . . . . . . 219320

t30 - et Cours la Reine (Vue). 299

433 - Vue intérieure. .... 321

Chan-Chang-Yen (Jardin du Puintemps perpétuel) ................... is

9394 Chantilly (Parc, Chiteau et Jardin). $7^{8}$ So

225 Charenton (Gué de la rivićre de). . . I 177

$211-$ (Vue de la riviere de)..... I70

46.t Chariot à transplanter (Élévation de l'avanttrain)................. 328

462 - Élévation latérale ...... 328

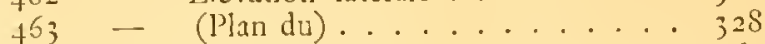

200 Château de Blenheim . ....... 163

107 - de Knebworth ....... 89

S9 ‥ de Meudon ........ . 77

377 - de 'Triels (Dauphiné) . . . . 249

34 - et Jardins de Blois. . . . . . 36

93 - et Jardin de Chantilly ...... So

98 - $S^{\mathrm{S}}$ Jardins de Clagny. ....... $S_{3}$

109 - et Jardins de Durham. ..... 9 I

-S - et Jardins de Fontainebleau . . . 68

67 Chateau et Jardin de Montargis $(1576)$. . . 62

4 Is - et Purc de Musliau ...... 278

${ }_{1} 87$ - et Parcs de Pétropolis, au Brésil. 338

9.4 - et Parterres de Chantilly .... So

I I - et Purterres de Chatsworth . . . 93

I I Chatsworth (Chiteau et Parteries) . . . . 93

201 Chène des Mlinimes (Bois de Vincennes). . 16.4

I72 Chẻne rert (Bois de Vincennes)..... I 43

Chesnay (Parc du)......... 295

48 I et 482 Cheraux, par Coustou..... 332

I 2 Choisy-le-Roi (Labyrinthe de). ...... 94

+25 Choulot (Parc du Narquis de Langle-Baalmanoir)..................293 294

484 Cimetière de Cincinnati (Spring Grove) . 335

483 - Green Wood à New-York . 334

$2 S_{4}$ Cissus discolor ............ 206

$9 \$$ Clagny (Chateau et Jardins de). . . . . $8_{3}$ 
Fig.

Classification ancienne de Jardins.

Clôtures (Dissinulation des).

328 à 332 Clôtures (Modẻles divers de)

337 Cocos australis.

278 Coleus Verschaffolli.

Combinaison des feuillages.

Combinaisons de coniferes.

diverses de plantations.

Composition des Gazons, Pelouses et $\mathrm{He}$ bages

126 d'une Corbeille.

Conclusion

302 à 308 Conduite des Allées.

Conduite des Cours d'eau : lles

22 I 1223 Conduite des Eaux

276 Conduites pour arroser les Pelouses.

Confection, dimensions des Allécs.

Conifères (Combinaisons de)

$8_{3}$ Conrart (Jardin de)

I7 I Contours d'une éminence

126 Corbeille (Composition d'une). 206

Corbeilles de l'Avenue du Bois de Boulogne. des lles du Bois de Boulogne et Bordures.

4.10 Corset tuteur

312 Coupe d'une Allée.

43o Cours-la-Reine et Champs-Élysées (Vue). Créations modernes.

162 Creux pour les Allées

245 Croix Catelan

4\$6 Cuba (Jardin de).

192 Canninglamia sinensis.

I85 Cupressus Lanusoniana.

339 Cycas circinalis.

300 Cyperus papyrus .

$25+$ Cypripedium spectabile

t33 Dangeau (Perspective peinte du jardin de) Dangeau (Perspective peinte is jardin de) Dangu (Pare de) . .

269 Decaisne et Naudin....... 196, et Définition de l'art des Jardins paysagers . . I 24 Delagrive (Plan de)........ $34^{8}$

Delille................ IIs

I9t et I95 Détermination des Perspectives... I61

258 Diantbus monspessulanus . . . . . . 193

343 Dichorisandra mandata.......... 238

263 Dicksonia squarrosa. . . . . . . . . 196

$29+$ Digitalis purpurca. . . . . . . . . . 209

113 Diogène, par N. Poussin. . . . . . 95

Dissimulation des clótures . . . . . . I 28

22 Domaine chinois (Plan d'un). . . . . . 23

Dominiquin (Le). . . . . . . . . 97

$5+5556$ Doria Pamphili (Vilha), avec ses parterres, sa grotte ......... so

Drainage............. I . I36

313 Drain tormant réservoir. . . . . . . . 223

$170-$ (Grand) ............ 140

$169-$ (Petit) ............ Ito

$468+69$ Drains et Grilles (Promenades de Paris).

Ios Drumlanrig (Parc de)...........

Du Cerceau. . . . . . . . . . . .

Dufresny. . . . . . . . . . . .

109 Durham (Chàteau et Jardins). . . . . . .

110 Eaton Hall. . . . . . . . . . .

221222 Eaux (Conduite des) $2 . .$. (Forme à leur donner, Plantations sur les Bords). . . . . . . I $16+$
Fig.

223 Édicules symboliques, etc

Pages.

. $\cdots 17 \quad 350$

476 Éducation maternelle (square Sainte-Clotilde) 331

Effets d'ombre et de lumiére (Etude des). . I 50

Égypte (Jardins de l'ancienne).

Eisgrub (Parc d'), en Autrichc. . . . . 280

I I Elvaston Castle (Parc d"). . . . . . . 92

I7 I Éminence (Contours d'une). . . . . . . I 41

Emploi des Fleurs et Plantes à feuillage en bordures, corbeilles, etc ... 203

- des Plantes Alpines ._. IS6

Encyclopédie (Critique des Jitrdins anghais). 300

317 Entrée du parc Monceaus. . . . . . . 227

$322 \quad-$ du Parc réservé de Saint-Cloud ... 2 225

318 - du Pré Catelan (Bois de Boulogne). 225

319320321 Entrées de Parcs......224 226

323 a 327 - principales (Combinaisons diverses).... 228

Époque des premiers travaux de terrassement. 135

I 22 Eridge Castle. ............ I I :

Ermenonville. ............ I17

I3 I - (E) (Étang du Désert). .... I I09

$137 \quad-\quad$ (Pare d') ...... IIs 178

207 - (Vue du Chatean) .... 166

Essences d'Arbres.......... 346

Este (Villa d').............. 55

$62 \quad-\quad$ Fontaine d'Aréthuse ..... 58

$61 \quad-\quad$ Palaiset Terrasse des Jets d'Eau. 57

$42-$ Vue générile....... $4^{2}$

I 3 I Étang du Désert, Ermenonville. . ..... 109

Étude des effets d'ombre et de lumiére. . . 150

- et appropriation des alentours. . . 126 préliminaire du terrain. . . . . . I I 32

166 Eucalyptus globulus. . . . . . . . . 137

$2+8$ Exèdre au Bois de Boulogne. . . . . . I90

I6I Exhaussement d'un Massif. . . . . . . I I33

Ezbekieh (Place).......... 334

Fabriques, Temples, Édicules. . I 75 , et suiv.

63 Farnése (Terrasses du Jardin! . . . . . 59

125 et I 26 Favorite. . . . . . . . 103104

296 Ferdinanda eminens. . . . . . . . 2 II

Ferriéres (Parc de). . . . . . . . . 294

Feuillages (Combinaison des). . . . . . I I 46

4 I I Finsbury Park à Londres. . . . . . . 276

357 à 359 Fleuriste de la Muette appareils de chauffage à l'eau, serres à sevrage. 327

228 Flora (Jardin à Cologne) . . . . . $180 \quad 265$

78 Fontainebleau (Château et Jardins de). 6; 68

I26 Fontaine de la Favorite. . . . . . . . 104

85 - de Latone, Tapis vert (Versailles). 75

458 - de l'avenue de l'Observatoire (par Carpeaux)......... 324

39 I Fontaine de Nédicis au Luxembourg. . . . 26I

so - du Jardin Boboli ........ 47

Formes diverses des arbres. ...... I59

265 Fougeraie et Jardin foral de Sydnope Hall. 197

Fougitres (Emploi des) . . . . 192, et suiv.

213 Fromhouse aprés la transformation. . . . 17 I

212 - avant la transformation.... I I I

293 Fusain du Japon. . . . . . . . . . 209

Gaillon (Jardins de) .......... 63

$69,7^{2}-$ (Parterre et Labyrinthe) ․ 6365

69,72 - (Portail de).......... 65

246 Garde (Pavillon de), aux Buttes-Chaumont. 189

Gautier (Théophile). . . . 69, 306, 332, 334

Gazon (Allées de). . . . . . . . 258

Gazons, Pelouses et Herbages.... $196 \quad 198$ 
Irig

$4+7$ Gibet de Montfaucon.

3 So Giulia (Parterres de la Villa).

46 Giusti (Jardin du Palais), a Vérone

176 Gloria Victis, groupe du Square Montholon.

389 Granja (Façade du palais de la)

390 - Parc de la)

$400-$ (Vase d'un des parterres de la)

Gréce (lardins de la)

$4^{8}$; Green Wood, cimetière à New-lork

$\$ 67$ Grille pour garantir le pied des arbres

168 et 469 Grilles et drains dans les Promenades.

Grotte de Calypso

56 - de la Villi Pimphili

147 - et Rotonde de l'lle de Reuilly.

$17+$ Groupe de Cédres du Liban

225 Gué de la riviére de Charenton Gués

I 39 Guiscard (Chiteau et Parc de)

283 Gunnera scabra

165 Gynerium argenteum.

Habitation (Rapport des plantations i).

Hanove (Jardir de), de l'Hôtel Richelicu.

I so Hauteur (Maison sur une)

I 27 Heidelberg (Château et Jardins)

273 Heracleum gigantoum.

375 Herbelie, prés Anvers (Château de) . . . Hirschfeld...........99

S I Hooghe (Romain de), Portiques de verdure. Hortensia

8 et 9 Horticulture égyptienne.

$3 S$ Hôtel des Tournelles (ver's 5510 ) I 82 lle des Cédres.

208 - et Lac Saint Mandé (Bois de Vincennes) 224 - et Piéce d'Ean.

23 - (l') d'or, dans le Yang-Tse-lïiang (lieuve bleu)

49 - Borromées.

. . . .

Inde (Jardins de l') .......... 12

Instituteurs (Jardins d') . . . . . . 273

268 Intérieur des Cascades (Bois de Boulogne)

271 - - at Parc Monceau .

Invalides (Esplanade). . . . . . . . $3+3$

Janseen (Jardin) . . . . . . . . . 304

I 73 Jardin au Caire ........... I $4+4$

- d'Acclimatation (Bois de Boulogne) .. 3 IO 3I I

$2 \mathrm{I}+\quad \ldots \quad(\mathrm{Lac} \mathrm{du}) . \ldots . .372$

H. I - - (Plan du).... 3 I I

一 de Biron ............ 302

so - Boboli . . . ...... 47

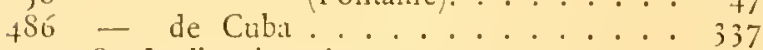

$7+\$ 5$ Jardins égyptiens ...... 7336

to6 Jardin de l'Elysée (Cascades). ..... 272

228 - Flora (à Cologne) ....... ISo

$\mathrm{I}_{2}$ - de Gaillon (Parterre et Labyrinthe).

37 - Gothique (Projet de Meyer)....

- de Hanorre (Hôtel de Richelien). . . 303

$: 2$ - Indien d'Oncleypour. . . . . . I I 1

$2 \mathrm{I}-$ Japonais. ...... 22, et suiv.

19 et $20-$ des Jardins........ 19

16 et 17 - 1 (Yven-Ming-Yven). 17

$+35$

Laboüssicre (Paris)
Fig. 2 Jardin Ludovisi. P'ages.

de Munich, par Skell *.... 49

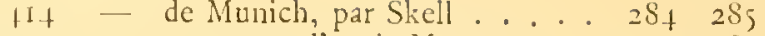

1J9 - paysager, d’aprés Meyer..... 283

$454-$ paysager des Tuileries...... 322

10+ - du Comte de Pembrolie...... 88

des Plantes..............323

459 - - (Vue ancienne). . . 325

335 - potager, paysager et verger réunis...........232

du Printemps perpétuel (ChunChang-Yen)........... Is

Thuret, a Antibes. ...... 295

royal des Tournelles . . . . . 39

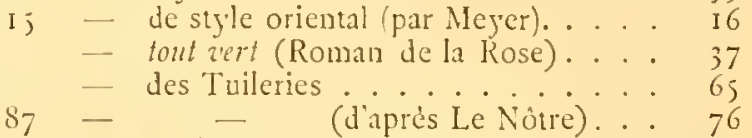

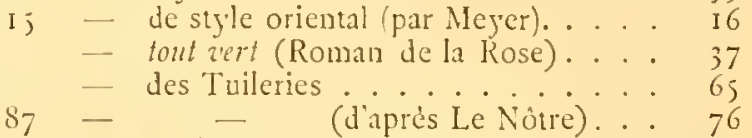

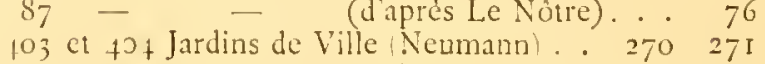

joj - - (Kemp)..... 27 J

Jurdinier flewrisle du Sr Léger. . . . . . 300

Jardins (Classifications anciennes de). . 13 I

- suspendus de Babylone ..... 9

- de la rallée de Cachemire ..... I 3

- chinois et japonais. ...... I7

- de l'ancienne Égypte ... . . 6

- de Fontaineblean ....... 65

français du xvi et du xvII siecles (jusqu’à Le Nôtre) . . . . 62

9

7 I 336 - fruitiers de démonstration et de production (Bois de Vincennes). 233

46 - du palais Giusti (Vérone).... 45 d'instituteurs .

$6 \quad$ - irréguliers. on paysagers (Tricédes) 123

- italiens de la Renaissance ... 42

53 - de la Villa Nédicis ....... 49

-- mexicains.......... 15

- du moyen age........ 36

- orientaux........... 9

$133-$ de Potsdan ......... : I I

$6 . t$ Jardins du Quirinal (xvil siecle). . . . 59

- de René d'Anjou .... 39, et suiv.

- Romains. ............. 25

95 - et parc de Saint-Cloud. ...... S $_{\text {I }}$

de l'hòtel Saint-Paul. . . . . 35

de ville........ . . . . 269

I 28 - du palais de Viürtzbourg .... 106

- de l'Ímen ........... 14

232 Jara (Pont en osier dans un paysage de). . IS 2 Jühllke (Directeur des Parcs de Potsdam). . 279

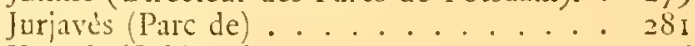

5 Karmak (Sphinx de) ......... 6 Kenp........... I.t2 223224

lient et Chambers .......... Ios

I29 kiew (Parc de) ............ 107 113

Kinsky (Parc à Prague). . . . . . . . . . 179

t75 Kiosque dans l'ile Daumesnil. . . . . . 33 I de l'ile des Roches (Rambouillet). 178

173 et 17. Kiosques pour journaux et fiacres. . 330 Io6 et I07 Kinebworth (Chiteau et Parc de) . S9 135 Laboëssiére (Jardin), Paris ....... 30j I 2 Labyrinthe de Choisy-le-Roi . . . . . . 94 368 - de Versailles........ 246 163 et 436 Lac au Bois de Boulogne. . 13.t 305 2I 1 du Jardin d'Acelimatation..... 172 
Fig.

208 Lac et lle de St-Mandé (Bois de Vincenmes) 216 - supérieur Cascade du Bois de Boulogne) $27)$ Lance pour arroser.

183 Larix curopeca pendula.

299 Lalania borbonica.

$13+$ Laxenbourg (Parc de\} prés de Vienne

Le Nôtre.

$91 \quad$ - jardins français au xvine siécle.

Ior Liancourt (Chateau et Jardins Je).

I7t Liban (Groupe de Cédres du).

I 59 Limite (Plantation de) anrés la transformation .

Igs - (Plantation de) avant la transforma tion finumin

252 Linum flavum...

253 - suffruicosmm .

179 Lions par Barye (Tuilerics)

t79 Loges d'entrée, Maisons de garde

$2+1$ et $2+2$ Loges d'entrée (Plans des).

230 Longchamps (Barrage sur le ruissean)

$26+$ - Cascade en face de).

$152-$ (Moulin de). .......

229 - (Pont rustiquesur le ruisseas de)

I 6 ct I 7 Lormin (Clande) (Paysage par). .

100 Lourois (Château de).

ऽ2 Ludovisi (Jardin).

Lundenburg et Laxenburg (Pares de). $28 \mathrm{I}$

39 I Luxcmbourg (Fontaine de Mídicis) ... .

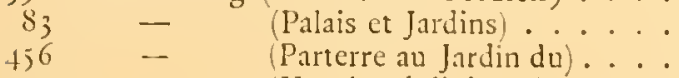

+55 - (Vue à vol d'oiseau)....

2.17 Maison de garde de la porte des Princes.

I5 I Maison dominant un terrain ondulé...

Ijo - sur une hauteur.........

Maisons de garde (Loges d'entrée) . . . . I I

If I Malmaison (La) ............ I I

3+4 Maranta rosca picta. . . . . . . . 238

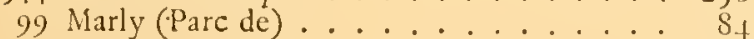

197 Massif d'arbres et d'arbustes. ...... I62

203 - avec arbres à branches retombantes..................... 165

I6I-(Exhaussement d'un)...... I33

Massifs de l'avenue du Bois de Boulogne. . 209

- du Pré Catelan. . . . ...... $21+$

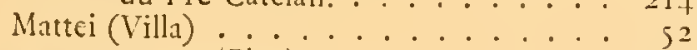

57

$$
\text { (Plan). }
$$

53 Médicis (Jardins de la Villa). ......

219 Méréville (Cascade de).

I38 - (Château et Parc de)..... I I

Sy Meudon (Château de)........ 77

Meyer (G.) . . . . . . . 168200

Michelet. . . .......... 42

Milton.............. IO IO3

217 Minines (Cascade du Lac des)..... I7t

79 Nolet (Parterre par A.). . . . 66 Monceau (ancien Parc de).......

220 - (Cascade du Parc)...... I . . .

317 - (Entrée da Parc) ...... 225

$135-$ (Parc de).......... II

t5o - (Plan du Pare) ........... 31

24 -- (Pyramide et obćlisque du Parc). Is

310 - (Grande Allée) . . . . .

285 Montagna beracleifolia ......... 206

13. Montagnes russes (Jardin Beaujon). . . . \$ jo3

67 Montargis (Chiteau et Jardin de). . . . . 62

379) Monte Carlo (V'ue d'ensemble de).
Pages.

$7 \cdot+$

202

jO

I 2

75

75

86

45

131

25

5

9

8

62

5

2

53

49
75
16

7
7
2
3
+
9

69
16
-6

76
25

8

IS

2 I

6

Fig.

$1+7$ Montfaucon (Gibet de).......... 315

$16+$ Montsouris Arant-projet du Parc de... I I 35

149 - Parc de Tue à vol d'oisenu!. 317

Morel. . . . . . . . . IIt 2;3 a 237

I 12 Morfontaine (Petit Parc de) . . . . I 20

372 a $37 . t$ Mosaiques Parterres figurant un tapis du s.vine siécle.

is 2 Moulin de Longchamps Bois de Boulogne is

Mouvements de terman. . . . . . . . 139

152 Moyen joge (Jardins du . . . . . . . . 36

$3 \dot{S}_{4}$ Muette (Avenue de la)........ 257

383 - Chateau et Parc à Passy). . . 256

Lit Municli (Jardio de) par Skell . . . . 327

297 Musa rosacca.

t 15 Muskau (Chateau et Pare de) . . . . . 278

$+16-$ (Plandu Parc de)...... 250

153 - Vue prise dans le Pare de) aprés

les travaux). . . . . . 127

$15+$ - (Vue prise dans le P'arc de) (avant

lestravaux)......... I 27

33 Néron juune Buste de

ir New-York (Central Park.

83 - Cimetice de Green ivood $28+285$

290 Nicotiana quigandionas.

177 Nil, statue aux Tuileries.

366 Noizi ou Noisy (Jardins de) . . . . . $2+5$

Olivier de Serres......... 6 f

Ondeypour (Jardin indien d') ..... I I

I 2 Opérations préparatoires (pour Jardins régu liers)

26 I Osmunda cimmanomea. .......... 195

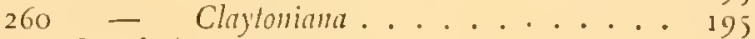

I 20 Ostade van Paysagre. . . . . . . . . 99

¡S9 Palais de la Granja (Façade) . . . . . 259

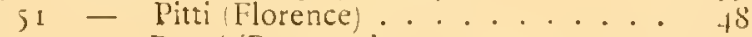

129 - Royal (Parterre du)......... 298

61 - et Terrasse des Jets d'Eau (Villa

d'Este). . . . . . . . 57

$37^{8}-$ et Terrasses de Villanov (l'ologne). . 252

Palissy (Bernard).......... 68

237 Pallavicuni (Temples du Pare de la Villa) . . 184

$5+$ Pamphili (Villa) . . . . 176

$56-$ Grotte de la Villa)....... 50 53

Paradis de la Perse ct de l'Asic-Mineure. . I

Parc d'Altichiero .......... 46

136 - de Bagatelle............. II 4

- de Barrockpoor....... 35\% 337

301 — de Birkenliead ....... 217

48 - de Buitenzorg (Java). Buttes-Chamont (Plan). . . 337

+78 - des Buttes-Channont (Plan)... 316

du Chesnay. . . . . . 78

de Danguy. . . . . . . . 295

10 - d'Elaston Castle. . . . . 294

- d'Ermenonville. . . . . . . . 178

- de Ferricres......... $29+$

— de la Granja. .......... 9 I

129 - de Kew......... 107 I13

25 - du Marquis de Langle-Babmanoir, J79

$13+$ - de Lax Choulot . . * . . . 293294

99 - de Marly. . . . . . . . I I 2

135 - de Monceau ............. 


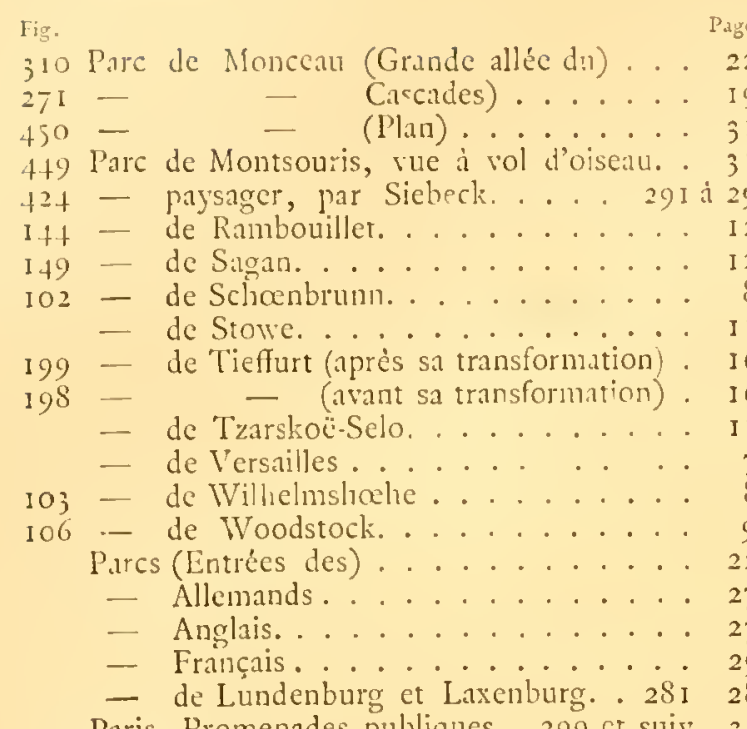

Paris, Promenades publiques. 299 ct suiv., 3 tJ

St Parterre de Boyceau.

79 - par A. Molct.

420 - du Palais-Royal.

360 - de Saint-Germain (1653)

73 So - ciselé (J. de Vriés) . . . 66

372 a $37+376$ Parterres en mosailque figurant uri tapis (Xvme siécle). . 2.4S

$7+$ ì 77 l'arteres des Tuilcries sous Henri IV.

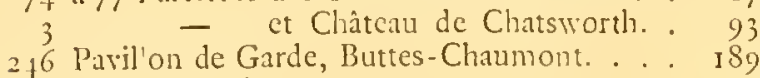

Paysage (Le)............. . 95

I $S$ et IIg Paysage, par Berghem. ..... gS

I1 6 et II7 - par Claude Lormin. . . 97

270 Pelargonimm ronale. . . . . . . I99

Pelouses du Bois de Boulogne (Création des).

$276-$ (Conduites pour arroser les)....

- et Gazons. ......... 196

292 Pente graduéc. . . . . . . . . . 209

Iof Pembroke (Jardin du comte de). . . . . 88

I55 Percíc dans le lois de Vincennes. . . I 128

370 Percées léguliúres dans un bois .... . 247

Punlla............. 205

Perse et Asie-Mineure (Paradis) ..... Io

$19+$ et 195 Prspectives (Détermination des). . I6I

- factices...... 68

$133 \quad$ - printes du jardin de Dangeau . .

+S7 Pútropolis (Chiteau et Pare de), au Brésil.

186 P.cea Morinda............ 153

$22+$ Pićce d'Eau et lle........... I76

SS Piéces d'Eau à Yerailles. . . . . . . 76

202 Pin parasol............. I . . . 65

I90 Pinus cembro. ............ I . . . 57

I6s - cecclsa.............. I 39

S I P.tti (Palais), Florence........ 47

397 Place de la République ....... 266

- Ezbelich . . . . . . . . . 331

398 et 399 Place publique (Mejer) . . . 267

Places publiques ......... 266

s\& Plan de la Villa Albani . . . . . . . 5.1

57 - de la Villa Mattei . $\because . . . .53$

i63 - d'ensemble (Nécessité d'un)... I It

22 - d'un domaine chinois ....... 23

309 -. du Pré Catelan ........ 220 lig. 420 à 423 Plans par Siebeck. .... 286 à 289

2 I et 2.12 Plans de loges d'entrúc..... I 87

Plantation............. $40,3+6350$

159 - de limite (aprés lit transtormation) 131

I5S - - (avant latransformation) I3 i

I75 - variée.............. I46

Plantations (Combinaisons diverses de) . 151 176 a 179 Plantations défectueuses corrigées. I 6 - à l'habitation (Rappont

des)........ If2

$20+$ à 206 - (Spécimens de)... I66

$\begin{array}{lll}\text { Pur les bords des Eaux. } & \text { I } 64 \\ \text { Plantes alpines (Emploi des)..... } & \text { I } 86\end{array}$

3 I Pline (Villa de), Restauration... . 303 I

Poa pralensis, Irivialis, nemoralis . . . . 20I

47 Polyphile (Songe de) . . . . . . . . 45

Pollius Félix (Villa de) ....... . . 28

I Is Polypheme, par N. Poussin ...... 96

Ponceau végétal . . . . . . . . . . . I72

250 Pont du Central-Park à New-York . . . I9I

232 - (en osier) dans un paysage de Java . I\$2

$23 \mathrm{I}$ - du Restaurant de la Porte jaune. . I 2

229 - rustique sur le ruisscau de Longcljamps (Bois de Boulogne) ... I I

256 Pont (Soubassement en rocailles d'un! . . 193

233 à 23 j Ports.................. 1783

Pope ........................... 107

7 I Portail de Gaillon ......... 65

23 I Porte jaune (Pont du Restaurant de la). I 82

2.17 - des Princes (Maison de Garde a la). 189

269 Portrait de Decaisne ........ I 99

$9 \mathrm{I}$ - de Le Nôtre . . . . . . 78

333 Potager de Versailles, par La Quintinic . . 230

$33+$ Potagers (drainage des) .......... 232 - Établissement et déconation des) 231

— et Vergers ........ 229

287 Polbosargyra ........... 207

I 33 Potsdan Jardins de) . . . . . I I 279

I is Poussin (Polyphème par le) . . . 9 96 98

Pratolino ................. 50

309 Pré Catclan (Plan du) ........ 220

(Massif du) ........2 $2 \mathrm{I}_{4}$

366 Presse à cercler la motte ...... 328

Prix de Travaux de jardinage a Paris. . . 353

Promenades publiques, Egypte . . 332 et suiv.

$$
\text { — } \quad \text { de Paris..... } 306 \quad 3+\mathrm{I}
$$$$
\text { - - et Squares. . } 2973063+1
$$

- - Turquic .... 331332

262 Pleris tricolor ............... 196

153, I5 + Pückler-Muskiau (Prince), 124,127 , Puget de la Serre .......... $\quad .698$

Pulligny (Comte de) ........ 295

I 2 I Pyalier, paysage . ........ I . . . . . . .

$2+3$ Pyranide, au Bois de Vincennes... . I $\varepsilon_{7}$

$2+1 \quad$ - et Obélisque du Parc Monceail . 188

64 Quirinal (Jardins du) (xvrne siècle)... 59

Rabelais (Grotte de) à Rambouillet ... . 7 I

Radepont (Parc de) ....... I . I 79

Itt Rambouillet (Parc de) ...... 7 I 120

236 Rapide du petit ravin de Saint-Mandé. . I 83

Rapport des plantations à l'habitation . . . $1+2$

$39+$ Regent's Park, à Londres . . . . . . 26+

Renaissance (Jardins italiens de la)... . 42

t I René (Armoiries du roi) ........ 4 I

40 - (Portrait du roi)....... 40

- d'Anjou (Jardins dc) ..... 39 
Iig

313 Réservoir (Drain formant)...... 223

1.17 Reuilly (Rotonde et Grotte de l'ile de). . 123

286 Ricinus sanguineus .......... 206 Rivoli (Rue de) ......... 3tt

Rocailles (Emploi des)....... I 85 I95

- (Parcs anglais) . . . . . . 277

Roches (Kiosque de l'ile des), Rambouillet. I-s'

Roman de la Rose (Jardin tout vert) ... 37

Rosiers ........... 206

I.17 Rotonde et Grotte de l'lle de Reuilly . . . I 23

Rousseau (J.-J.) ........... I I0

Route des Buttes, figure page . . . . . vil

Rueil (Jardins de) ......... 70

Ruffinella $(\mathrm{La}) \ldots . . . . .61$

1 +5 Ruine dans le Parc de Boc̈iz . . . . . . 120

226 Saccharmm egyptiacum ......... 178

149 Sagan (Parc de) . . . . . . . . 12 .

96 Sant-Cloud (Cascade du Pare de). . . . . $8_{2}$

$322-$ (Entrée du Parc réservé). . . 227

95 Saint-Cloud (Jardin et Parc de)..... 8 ! (Parc de)........ . . 79

Saint-Germain-en-Lay̌ ........ 62

$\begin{array}{ccc}382 & - & \text { (Ancicus Jarduns de) } \\ 70 & - & \text { (Châteat et Jardins) } \\ 369 & - & \text { (Parterre, I } 653 \text { ) . }\end{array}$

36 Saint-Germain-des-Psés (Vue de l'Abbaye).

208 Saint-Mandé (lle et Lac de). . . . . . .

236 - (Rapide du petit Ravin de). .

Saint-Paul (Jairdins de l'Hôtel) ..... 38

Saint-Simon (Némoires de) ..... . 75

Sand (George) . .......56 et suiv.

2 to Saragota ('Temple dans le Pare de). . . I 86

255 Saxifraga longifolia. ......... 192

97 Sceaux (Cascade du Jarc de). ..... 83

- (Parc de)............... 79

I02 Schonbrunn (Parc de)........ \$ . . . . . . .

395 Schwetzingen (Parc de) . . . . . . 265

25 I Sedum opposilifolimm. . . . . . . . . 192

$279-$ Sicbollii........... 203

Sequoia à feuilles d'ıf (Taxodium semperinirens). . . . . . . . . . . I 54

Serbelloni et Sommarıva (Vilias)... . . 46

3 f I Serre (Coupe d'une) . . . . . . . 238

$3+2-$ (Plan d'une) .......... 238

356 -. des Népenthés de la Ville de Paris.Apparcil de chauffige, gaz et eau.

353 à 355 Serre des Népenthés (Fleuriste) (Plan

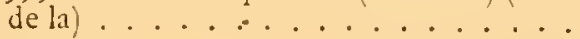

Serres . . . . . . . . . . . 357 i 359 Sures a sevrage et a multiplication.
Appareils de chanfage à l'eau (Fleuriste de la Ville de Paris.

347 à 352 Serres diverses du Fieuriste de ia

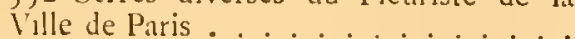

Service des Promenajes de par. . 239

18 Sesto Calende (Lac Majeur) ... $3+5$

$1+$ Siam (Vue d'un jardin a). . . . . . . . I 1 .

239 Sibylle (Temple de la) (Buttes-Chaumont). I 86 Sidoine Apollinaire . . . . . . . 34

424 Siebeck (Parc paysager par) . . . 29i a 293

420 à 423 Siebeck (Plans par). . . . . 286289

295 Sulanum macrantloum. ......... . . 210

Sommariva et Serbelloni (Villas). . . . . ${ }_{16}^{6}$

47 Songe de Poliphile

30 Sorrente (Vue de) .

256 Soubassements en rocalles d'un pont. . . 193

412 Southwark Park, à Londres. . . . . . 276
Fig. P.joes.

5 Sphinx de Karnak.

$t_{4}$ Spring Grove, Cimetiére de Cincinnati. . 335

396 Square des Arts-ct-Métiers . . . $2663+4$

460 - des Batignolles. ...... I 28326

157 - - Vue à vol d'oiseau). I30

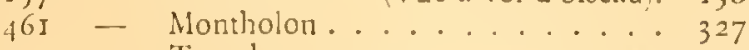

50I - Temple...........345 35 I

- Tour Saint-Jacques. . . . . . 3. 314

Squares et Promenades Considérations pré-

Stace . . . . . . . . . . . . . . . . 28 et suiv.

Stansted (Ch. de Durhans). . . . . . . 275

108 Stonelcigh Abbey ......... 27t

I32 Stowe (Parc de) ........ I:0 I1 2

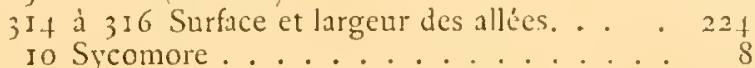

393 Sydenham Palace (Pare de). . . . . 263

265 Sydnope Hall (Fougeraie et Jardin floral de). $\quad 197$

Taine . . . . . . . . I 10

Tallemant des Réaux . . . . . . . t I et suiv.

376 Tapis (Parterre figurant un) (xvir ${ }^{2}$ siécle). . 249

85 - vert; Fontaine de Latone à Versailles. 75

Tasse Le). ............ 100

I89 Taxus baccata Hibcrnica....... . . I56

2 to Temple dans le Parc de Saragota . . . I 86

239 - de la Sibylle (Buttes-Chaumont). . I $\$ 6$

238 - de Vénus à Trianon . . . . I 55

237 Temples du Parc de la Villa Pallavicini . . . IS 4

Terrain (Fude préliminaire du). . . . I I 2

— (Mouvement de)........ I 139

I5 I - ondulé (Maison dominant un) . . I 25

427 Terrasse du bord de l'eau (Tuileries). . . . 297

Terrassements. .................. 135 I 38

63 Terrasses du Jardin Farnése ...... 59

210 Tbalia dealbata .......... 169

3 to Thrinax radiata .......... . 237

Thuret (Jardin) il Antıbes. . . . . . 295

187 Thuýa gigantea. . . . . . . . . . 154

Théorie de l'Art des Jardins. . . . . . . . I2 I

199 Tieffurt (Parc de) après la transformation. . 163

$198-(-)$ avant - I62

Titien (Le). . . . . . . . . . 97

$1+3$ Tombeau de Cook i Méréville. . . . . 120

38 Tournelles (Hòtel des) vers 15 f0. . . . 39

(Jardin royal des).... 39

Tracé des Allées. . . . . . 2 I 6 et suiv.

Tracé des Jardins irrégulers ou paysagers . 123

- _ réguliers et du genremixte 245

432 Treillage au Labyrinthe de Versailles. . . 301

I fo Trianon (Petit). .............. I I 8

238 - (Temple de V'́nus à)..... is;

431 - de Saint-Cloud (détruit).... 300

377 Triols (Château de), Dauphiné. . . . . 249

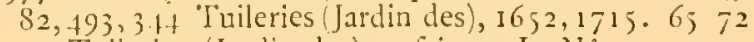

Tuileries (Jardin des), refait par Le Nôtre . 79

454 - (Jardin paysager des). . . 322

76 et 77 Tuileries (Parterres des) sous Henri iv 67

127 - (Terrasse du bord de l'eau) . 297

Tzarskö̈-Selo (Pare de)....... I I 5

Unité de composition . . . . . I 25

488 Vallée ou pare naturel de Yosemiti . . 339

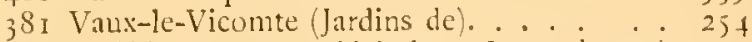

478 Velleda, statue par Maindron Luxembourg) 333

Verger (Fusion du) avec le Jardin d'agrément 2,32

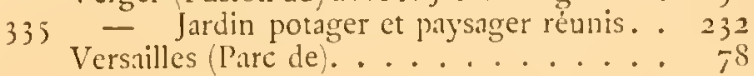


Fig.

$\$ 8$ Versailles (Pićces d'eau à)

230 - (Potager de) par La Uuintunic. 76

432 - Treillage au Labyrinthe de)... 30

90 - a vol d'oiseau.

92 - (Vue du pare de)

4 I 3 Victoria Park .....

32 Villa Adriana (Aspect actuel

- Albani vice générale

65 Villa Aldobrandini(Plan).

+5 - Barbaro.
+1 - Borghise.

392 - Carlotta Allée d'orangers) .....

55 - Doria Pamphili avec ses parterres (Etat actuel).

$$
\text { -- d'Este.. }
$$

$62-$ - Fontained'Aréthuse) (iog. P. 360

$6 \mathrm{I}$ - - Palais et Terrasse des jets d'eau.

42 - Vue génćrale.

66 - Mondragone Ciscade de la .....

-- Pallavicini.

$5+$ - Pamphili.

- - état ancien ........

3 - de Pline Restauration

32 - de Pollius Félix - romane (Intérieur d'une irusturation - de Vopiscus

Villas de Pline le Jeunc.

Sommariva et Serbellomi....

378 Villanov (Palais et Terrasses de), Pulugue . 252

4.t5 Tincennes (Bois de), état actuel..... 313
Fig. P.ges.

Att Vincennes (Bois de), Etat ancien. . . . 313

iss - Percéc dans le Bois $\mathrm{d} t \ldots \ldots$... 128

$2+3 \quad$ - (Pyramide au Bois de)..... I $\delta_{7}$

$160 \quad-\quad$ Vue prise dans le Bois de)... 132

27 et 28 Virilaria (Pompéi). . . . . . . 27

$36 .+$ Volière, Coupe ......... 2.43

363 - Façade............... 243

Volicres, ruches, etc. . . . . . 2 $2+1$

Vopiscus (Villa de)......... . . 28

So Vriès (J. de), Parterre ciselé . . . . . 70 I 56 Vue à vol d'oiseau du Parc des Buttes-

Chaumont.......... 129

453 - intérieure des Champs-Eiysucs... 32 I

2 II - de la Rivicre de Charenton ..... 170

207 - du Chàteau d'Ermenonville.... I 66

459 - (ancienne) du Jardin des Plaıtes. . . 325

I53 et is.t Vue prise dans le Parc de Muslsau. . 127

36 Vue de l'Abbaye Saint-Germain des l'rés. . 37

I60 - prise dans le Bois de Vincennes. . . 132

ISS I'cllinotonia giranter. ......... I I55

ITlately (Sw Thomas)......... 108

280 IV Toandia macropbylla. ......... 203

I03 Wilhelmshohe (Parc de)....... 87

ios WVoodstock (Parc de)......... . 90

I 28 Würtzbourg (Jardins du Palais de . . . 106

23 Yang-T'se-Kiang (l'lle d'Or dans) (le Ficuve

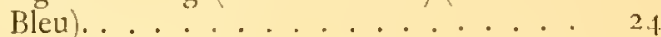

Yémen (Jardins de l') ......... I. . . . .

${ }_{4}$ SS Yosemiti (Vallée ou Pare naturel de) . . 339

272 Yucca flamentosa. ......... 200

16 et 17 Yven-Ming-Yven (Jaidn des Jardins)................. I7

Yveteaux (Nicolas des)......... $7 \mathrm{I}$

Zapania nodiflora. ........... 333

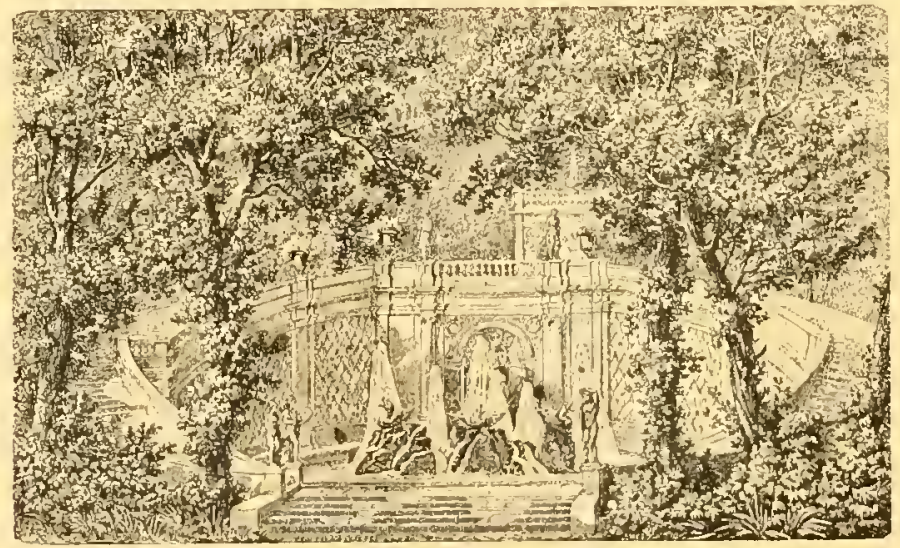

Fig. 508. - Fontaine de la Villa d'Este. 



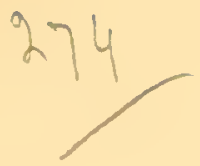


Date Due

14635484 


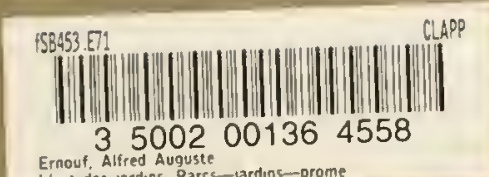




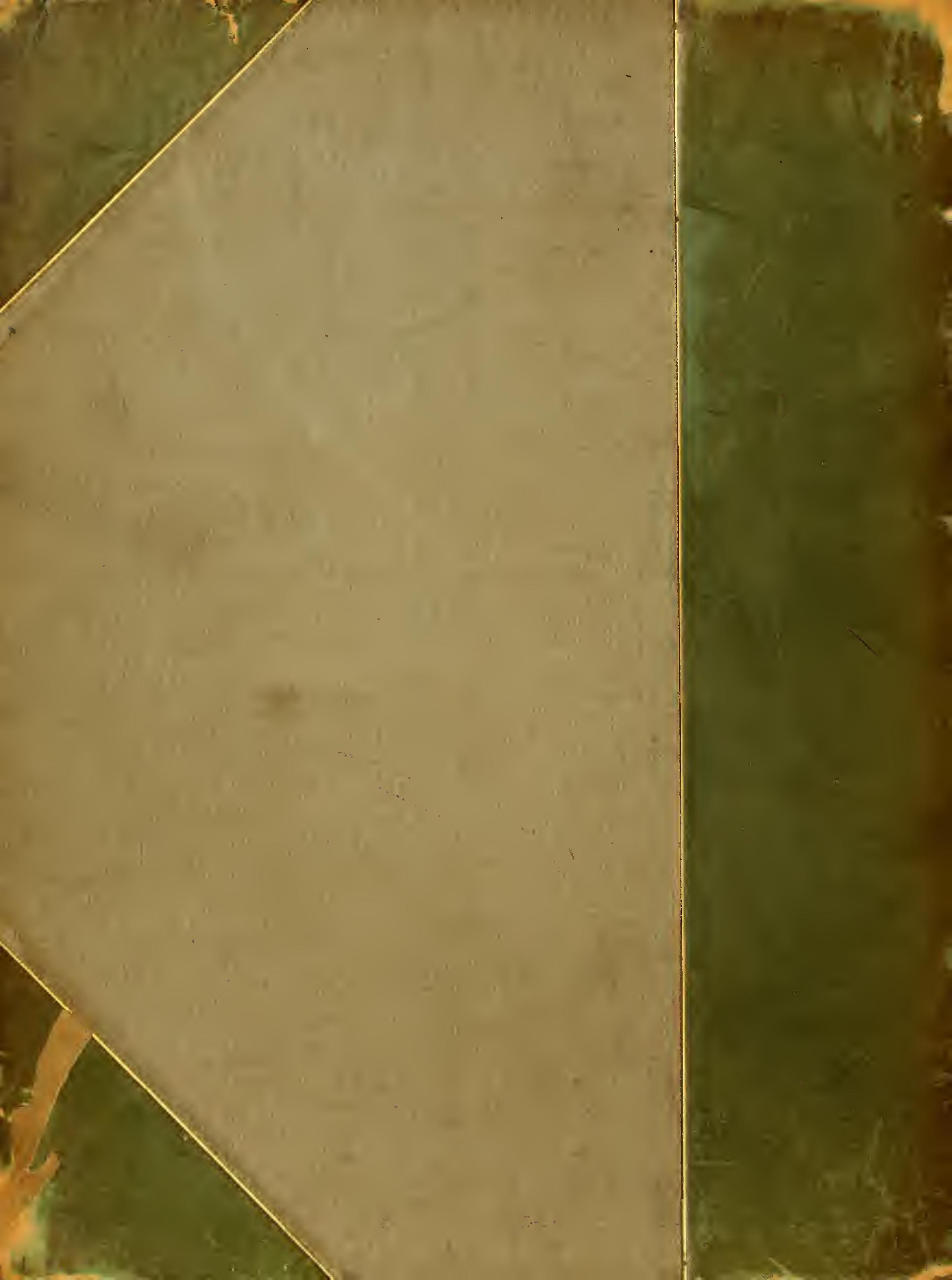

